
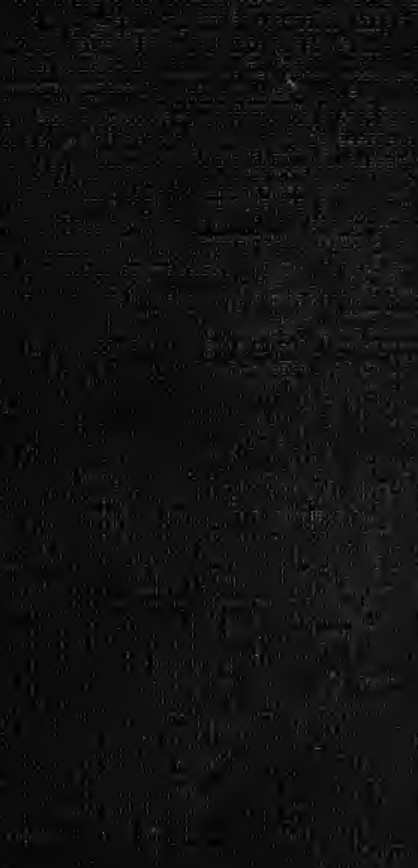
From the collection of the

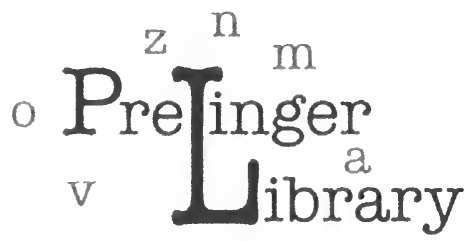

$\mathrm{t}$

$\mathrm{p}$

San Francisco, California

2006 


$$
5^{0} \pi
$$






\section{HEATH SOCIAL RELATIONS SERIES}

Jerome Davis, General Edilor

InTRODUCTION TO SOCIOLOGY. By Jerome Davis, Yale University, and Harry Elmer Barnes, New School for Social Research (with L. L. Bernard, Washington University, Seba Eldridge, University of Kansas, Frank H. Hankins, Smith College, Ellsworth Huntington, Yale University, and Malcolm Willey, University of Minnesota).

READINGS IN SOCIOLOGY. Selected by the Authors of Introduction to Sociology to supplement that volume.

IMMIGRATION AND RACE ATTITUDES. By Emory S. Bogardes, Chairman of the Department of Sociology and Director of the School of Social Welfare, University of Southern California.

INTRODUCTION TO SOCIAL PSYChOlOGY. By Radhakamal Mukerjee, Head of the Department of Economics and Sociology, Lucknow University, and Narendra Nath Sen-Gupta, Head of the Department of Experimental Psychology, Calcutta University.

ECONOMICS AND ETHICS. By John A. Hobson, Formerly Lecturer on Economics, Oxford University.

CRiminology. By Robert H. Gault, Professor of Psychology, Northwestern University, Editor of the Journal of Criminal Law and Criminology.

CONCEPTS OF SOCIOlOGY. By Earle Edward Eubank, Head of the Department of Sociology, University of Cincinnati.

THE Beginnings OF TO-MORROW. By Herbert A. Miller, Lecturer in Social Economy, Bryn Mawr.

immigration and assimilation. By Hannibal Gerald Duncan, Department of Economies, Political Science, and Sociology, University of Colorado.

\section{In Press or in Preparation}

INTRODUCTION TO THE STUDY OF SOCIAL STATISTICS. By ROBERT Morse Woodiury of the Institute of Economics.

COMmunity ORGanization. By E. C. Lindeman, Chairman of the Department of Sociology of the New York School of Social Work and Lecturer for the New York School of Social Research.

mental hygiene. By Frankwood E. Williams.

HISTORY OF SOCIAL THOUGHT. By Harry Elmer BarNes, New School for Social Research, and Howard Becker, Smith College.

THE FAMILY. By Hornell Hart, Professor of Social Ethics, Hartford Theological Seminary.

EDUCATIONAL SOCiOlogy. By Ross L. Finney, Professor of Educational Sociology, University of Minnesota, and Leslie D. Zeleny, State Teachers College, "St. Cloud, Minnesota. 


\section{IMMIGRATION AND ASSIMILATION}

BY

HANNIBAL GERALD DUNCAN, Ph.D.

Department of Economics, Political Science, and Sociology University of Colorado

AUTHOR OF

The Changing Race Relationship in the Border and Northern States, Race and Population

Problems, Backgrounds for Sociology

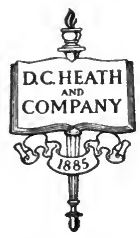

\section{C. HEATH AND COMPANY


COPYRIGHT, 1933, BY

HANNIBAL GERALD DUNCAN

No part of the material covered by this copyright may be reproduced in any form without written permission of the publisher.

$3 \mathrm{H} 3$

PRINTED IN THE UNITED STATES OF AMERICA 


\section{INTRODUCTION}

\section{By Jerome Davis \\ Yale University}

IN an earlier volume in this series, Immigration and Race Attitudes, Emory S. Bogardus attempted to analyze to some degree the causes and consequences of our racial attitudes. Book I of the present volume treats of conditions in other countries that bear on immigration to the United States; Book II is a collection of life histories revealing the processes of assimilation. The immigrant problem is still of momentous significance to America. According to the last census (1930), the foreign-born population of the United States was $14,204,149$. If we include those who were born of foreign or mixed parentage, the number rises to the grand total of $38,727,593$, a number greater than ever before in American history.

The problems which this vast aggregation of human beings present are relative and dynamic. What is the effect of American culture and the organization of American democracy on the immigrant? The analyses which have previously been made usually have dealt only with the rather immediate impact of our culture and the clash of conflicting standards.

This volume is unique in presenting eighty-three life histories of immigrants, the children of immigrants, and the grandchildren of immigrants. While it cannot be assumed that these are typical of the millions of others in America, they do give us a series of clear flashes into the irresistible molding power of our social heritage on a foreign stock.

Professor Duncan thus admirably supplements the work of Thomas and Znaniecki in The Polish Peasant in Europe and America. The impress of any culture in which the individual is immersed leaves its indelible mark. Americanization should be considered not as a process affecting the foreign-born alone but as an interpenetrative process of foreign cultures interacting through a three-generation period. Professor Duncan indicates for the first time the concrete results of assimilation as it actually takes place through three generations. 



\section{PREFACE}

THIs volume had its inception several years ago, while the author was offering courses in immigration and Americanization on the Pacific coast. He had not proceeded far when it became evident that, since the immigrant is a product of biological and cultural processes, an understanding of him depends upon a knowledge of the forces which have shaped him. In brief, one must comprehend the essential conditions of his homeland. Thus the reason for the union of Roman Catholicism and politics among the Irish is revealed in the struggles of the Irish against Protestant England. The tenacious adherence of the Poles to the Roman Catholic religion and the Polish language in America is largely due to the suffering of the Poles under the Russian Orthodox Catholics and German Lutherans. The free-thinking and anti-religious attitudes found among the Czechs are largely explained by their tragic history under the dominance of Austrian Roman Catholics, German Protestants, and Russian Orthodox Catholics. Such factors condition the adjustment of the immigrant to American life.

Book I of this volume deals with backgrounds for immigration. Part I gives a bird's-eye view of the world and serves as an introduction to Book I. Part II deals with the Teutonic group, Part III with the Latin group, Part IV with the Slavic group, and Part V with other racial, national, and cultural groups. These groupings are dictated by convenience. Strictly speaking, there are no Teutonic, Latin, Slavic, or other groups, as the people of the world cannot be divided racially or culturally, politically or economically, religiously or socially. Since all so-called races are mixtures of other racial groups, no well-defined lines may be drawn. Likewise economic, religious, linguistic, and other factors overlap. Many people belong racially to one group and politically, economically, linguistically, religiously, or otherwise culturally to another. For instance, the Bulgarians consider themselves Slavs, and the Rumanians think they are Latins; yet the basic blood among the Bulgarians appears to be Asiatic, and among the Rumanians Slavic. In general, the Basques are culturally French and Spanish, yet biologically related to neither. The Lithuanians and Albanians remain deep puzzles, 
and apparently no one is sure how they should be classified. Biological and cultural lines do not stop at political boundaries.

Book I, therefore, is intended to give a general though brief treatment of the racial, political, economic, religious, educational, and social conditions that bear upon immigration, and so far as possible the number of immigrants received from each racial, national, or cultural group. Since the importance of the countries to us varies with the number of immigrants we have received, a more complete discussion is given of those countries which have sent us the largest numbers of immigrants, especially those countries whose races or cultures differ greatly from ours.

The very nature of Book I precludes a thorough treatment of the topics discussed. An avalanche of dates and details would defeat the purpose of the volume. Since so few studies of immigration have been made that emphasize the importance of backgrounds, the author has not only had to mark out his boundaries, but for the most part clear his own fields. Unexpected difficulty was experienced in trying to harmonize dates, statistics, estimates of population, and other supposedly well-established facts.

Book II of this volume is divided into four parts. Part VI serves as an introduction to Book II and gives a general survey of immigration in the United States. Parts VII, VIII, and IX deal, respectively, with the first, second, and third generations of Americans. Each of these Parts has a chapter in which the main problems of that particular division are discussed, and illustrated with extracts from life history documents. Part VII contains thirty-three life history documents of first generation Americans, or immigrants proper; Part VIII includes thirty life history documents of second generation Americans, or children of immigrants; and Part IX has twenty life history documents of third generation Americans, or grandchildren of immigrants. The eighty-three documents here included in their entirety were selected from a collection of several hundred. They were chosen with two chief purposes in view: (1) to show the main difficulties and changes that immigrants, children of immigrants, and grandchildren of immigrants meet and undergo in adjusting themselves to American life; and (2) to reveal some of the peculiar problems the different racial and cultural groups experience. These life history documents, therefore, are from individuals representing a wide range of backgrounds. Where there are enough differences to justify it, two or more life histories are included from the same 
racial or national group. If a person was born in a foreign country but came here at an early age (before he was old enough to be influenced by the culture of the foreign country - before eight years of age) he is classed as a second generation American, though politically he is of the first generation. It is not claimed that this collection covers all the points of adjustment that the first, second, and third generations of Americans experience, or that all the members of each group meet the same difficulties or make the same adjustments herein revealed. On the whole, these life histories contain a large amount of valuable information. Many of them are as interesting and fascinating as a novel. Others, especially some of the third generation, contain little engrossing information, but are very valuable in showing how completely the persons have become absorbed in American life. The documents are arranged according to first, second, and third generations and also according to racial, national, and cultural groupings.

Several life histories of immigrants - such as An American in the Making, by M. E. Ravage, The Soul of an Immigrant, by C. M. Panunzio, A Far Journey, by A. M. Ribhany, Myself When Young, by Y. B. Mirza, My Mother and I, by E. G. Stern, and $A$ Daughter of Samurai, by E. Sugimoto - have been published in book form, and the five-volume set of The Polish Peasant in Europe and America, by W. I. Thomas and Florian Znaniecki, contains considerable life history material of the Polish group. But no book contains the type of material found in this volume. Nine of the life history documents herein contained (seven in Part VII and two in Part VIII) have previously been published in different journals. The other seventy-four make their first appearance. To the author's knowledge, no life history document of a third generation American has ever been published, and only a very few of the second generation. Thus this volume is unique in being the first to give a comprehensive background for immigration, to offer life histories of grandchildren of immigrants, and to bring together in one book a collection of life histories running through three generations. Therefore it should be of interest to three groups of people: (1) students of problems of immigration, assimilation, and Americanization; (2) people engaged in school work, social work, Americanization, or other activities which bring them in contact with immigrants or the children and grandchildren of immigrants; and (3) the general public.

The author wishes to thank the writers of these different life his- 
tories, many of whom he knows personally, for coöperating in this work; and to express his gratitude to The World's Work, The Outlook, and The Survey for kindly granting him permission to reprint some of these life history documents. Likewise he appreciates the kindness of The Survey of Race Relations for permitting him to use some from their collection. Last, but most of all, he is indebted to his wife, Winnie Leach Duncan, for her valuable assistance in helping prepare this volume. She is truly a co-author of this work.

H. G. DuncaN 


\title{
CONTENTS
}

\author{
BOOK I \\ BACKGROUNDS FOR IMMIGRATION
}

PART I - INTRODUCTION

CHAPTER

I. A Glimpse of the World

PART II - THE TEUTONIC GROUP

II. The United Kingdom . . . . . . . . . . . . 27

III. Germany and Austria . . . . . . . . . . . . . 47

IV. The Scandinavian Countries . . . . . . . . . . 66

V. Holland and Belgium. . . . . . . . . . . . 78

VI. Switzerland and Liechtenstein . . . . . . . . . 93

VII. Lithuania and Latvia . . . . . . . . . . . . . . 101

VIII. British Teutonic Colonies . . . . . . . . . . . 112

PART III - THE LATIN GROUP

IX. France and French Canada . . . . . . . 133

X. SpaIN . . . . . . . . . . . . 152

XI. Pontugal . . . . . . . . . . . . . . . 165

XII. ItALY . . . . . . . . . . . . . . . . 177

XIII. Greece . . . . . . . . . . . . . . 192

XIV. MeXICO . . . . . . . . . . . . . . 202

XV. South and Central America . . . . . . . . . 216

PART IV - THE SLAVIC GROUP

XVI. Rumania .................. . 241

XVII. Russia . . . . . . . . . . . . . . 252

XVIII. Poland . . . . . . . . . . . . . . 279

XIX. Czechoslovakia . . . . . . . . . . . 292

XX. Yugoslavia and Albania . . . . . . . . . 303

XXI. Bulgaria . . . . . . . . . . . . . 320

PART V-OTHER RACIAL, NATIONAL, AND CULTURAL GROUPS

XXII. Finland and Esthonia . . . . . . . . . . 337

XXIII. HungarY . . . . . . . . . . . . . . . 350

XXIV. TURKEY . . . . . . . . . . . . . 367 
CHAPTER

XXV. China.

XXVI. JAPAN

XXVII. European Asiatic Possessions . . . . . . . . . . . 412

XXVIII. Siam, Afghanistan, Persia, and Arabia . . . . . . 439

XXIX. AFrICA . . . . . . . . . . . . . . . 454

\section{BOOK II}

IMMIGRATION AND ASSIMILATION IN THE UNITED STATES

\section{PART VI - INTRODUCTION}

XXX. Immigration to the United States

PART VII - FIRST GENERATION AMERICANS

XXXI. First Generation Americans in Process

XXXII. Life Histories of Teutonic First Generation AMericans . . . . . . . . . . .

XXXiII. Life Histories of Latin First Generation Ameri-

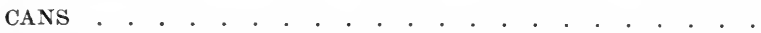

XXXiV. Life Histories of Slavic First Generation AmeriCANS ......................

XXXV. Life Histories of Other Racial, National, and Cultural Groups of First Generation Americans

PART VIII - SECOND GENERATION AMERICANS

XXXVi. Second Generation Americans in Process .

XXXViI. Life Histories of Teutonic Second Generation Americans

XXXViII. Life Histories of Latin Second Generation AmeriCANS .....................

XXXiX. Life Histories of Slavic Second Generation Americans . . . . . . . . . .

XL. Life Histories of Other Racial, National, and Cultural Groups of Second Generation Ameri-

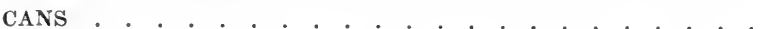

PART IX - THIRD GENERATION AMERICANS

Xli. Third Generation Americans in Process

XliI. Life Histories of Teutonic Third Generation Americans

XliII. Life Histories of Other Racial, National, and Cultural Groups of Third Generation AmeriCANS 


\section{LIST OF MAPS}

PAGE

Racial and Linguistic Map of Europe . . . . . . between 6 and 7

Distribution of Population . . . . . . . . . . . . . . . . 9

Religions of the World . . . . . . . . . . . . . . . . 13

Principal Linguistic Families of Europe and Asia . . . . . . 15

Migrations and Conquests, 150-1066 . . . . . . . . . . . 19

Growth of the British Empire . . . . . . . . . . . . . . 28

Language Boundaries in Slesvig . . . . . . . . . . . 68

Dutch Territory which Belgium Desires . . . . . . . . . . 82

Languages in Switzerland . . . . . . . . . . . . . . . . 94

Ethnography in the Baltic Region. . . . . . . . . . . . . 102

Language Boundaries of Spain . . . . . . . . . . . . . 161

Population Density of Italy . . . . . . . . . . . . . . . 178

Ethnography of Russia . . . . . . . . . . . . . . . . . 254

Ethnography of Russian Turkestan . . . . . . . . . . . . 257

Russian Colonies in Siberia . . . . . . . . . . . . . . . 261

Czechoslovakia . . . . . . . . . . . . . . . . . 293

Minority Groups in Yugoslavia . . . . . . . . . . . . . 304

Hungary . . . . . . . . . . . . . . . . . . . . . 351

Population Density of China . . . . . . . . . . . . . . . 384

Population Density of Korea and Japan . . . . . . . . . . 403

Population Density of India, including Nepal and Bhutan . . 413

Territorial Divisions Affected by the Immigration Laws of the

United States . . . . . . . . . . . . . . . . 496 



\section{BOOK I}

BACKGROUNDS FOR IMMIGRATION 



\section{PART I}

\section{INTRODUCTION}





\section{CHAPTER I}

\section{A GLIMPSE OF THE WORLD}

\section{General World Situation}

Since very early times people have been moving across the face of the earth, ever seeking more satisfactory situations. During early times these were mass movements, but gradually they shifted to what is now known as immigration. For hundreds of years there was little intellectual interest in these movements of people, but during the nineteenth century there developed a realization that immigrants were causing economic, social, religious, political, and other problems. Students then became concerned with the study of the fundamental conditions in foreign lands which caused people to hasten across continents and oceans, but those who essayed to deal with the subject failed to bring to the foreground the differential pressure that operated in shaping the desires of the discontented to emigrate. It is now generally understood that not only the desire of the immigrant to leave his own native land but also many of the problems of adjustment in this country originate in the conditions of his own country. Nor do these problems end with the immigrant; many of them extend to his children, and some of them to his grandchildren.

Before considering the more definite conditions of racial and national groups, it appears advantageous to present a brief view of world conditions and their influence on the movements of people.

1. World Population. The original home of man is still a moot question, but the majority of anthropologists are inclined to the assumption that man originated in central Asia. Whether he originated in one or more places we do not know. Most anthropologists appear to hold to the theory that he had a single origin, and some maintain that he was dark in color. ${ }^{1}$

1 Compare Haddon, A. C.: The Races of Man, p. 153; Buxton, L. H. D.: The Peoples of Asia, p. 83; De Morgan, Jacques: Prehistoric Man, A General Outline of Prehistory, pp. 21-23; The Evolution of Man, edited by G. A. Baitsell, pp. 5-7; Huntington, Ellsworth: The Character of Races, pp. 20-21; Keane, A. H.: Ethnology, p. 236; Wallis, W. D.: An Introduction to Anthropology, p. 40; 
From this feeble beginning man has increased and spread over the world. According to Mulhall there were about 54 million people in the world at the time of the Roman Empire. Balbi placed the world population at 739 millions in 1843. More recent estimates are as follows: Levasseur (1908), 1626 millions; Knibbs (1914), 1649 millions; Stoddard (1914), 1700 millions; East (1916), 1750 millions; Institut International de Statistique (1920), 1791 millions; Institut International d'Agriculture (1921), 1820 millions; Knibbs (1928), 1950 millions; Kuczynski (1930), between 1700 millions and 1950 millions. ${ }^{1}$ According to H. L. Wilkinson ${ }^{2}$ the number of people in the world increased by nearly 170 millions between 1913 and 1928. East thinks that the population of the world is increasing by about 12 million people per year, and Knibbs places the increase at 20 millions. Ross ${ }^{3}$ estimates that the population of the world will be 3800 millions by 1987,7600 millions by 2047 , and 15,200 millions by 2107 ; Pearl ${ }^{4}$ thinks it will be 2026 millions by 2100 ; and Knibbs calculates that it will be 3900 millions by 2033,7800 millions by $2138,15,600$ millions by 2243 . Penck ${ }^{5}$ estimates the potential population of the world at 8000 millions, and Knibbs at between 7800 and 15,600 millions.

Somehow the human family became divided into so-called races. Race, however, is such a flexible term that it defies accurate definition. ${ }^{6}$ While some authors make only four or five chief divisions of the races of mankind, others propose many more, some as many as

Dixon, R. B.: The Racial History of Man, p. 503; Ripley, W. Z.: The Races of Europe, pp. 465-66; Taylor, G.: Environment and Race, p. 33; Read, Carveth: The Origin of Man, p. 19; Osborn, H. F.: “Where Did Man Originate?" Asia, Vol. XXIV, pp. 427 ff.; Gregory, W. K.: "Did Man Originate in Central Asia?" Scientific Monthly, Vol. XXIV, pp. 385-401; Duncan, H. G.: Race and Population Problems, Chap. I, and Backgrounds for Sociology, Chap. IV.

${ }^{1}$ Compare Stoddard, L.: The Rising Tide of Color, pp. 6-7; East, E. M.: Mankind at the Crossroads, pp. 111-13; Knibbs, G. H.: The Shadow of the World's Future; Fawcett, C. B.: "On the Distribution of Population over the Land," Sociological Review, Vol. XVII, pp. 85-104; Gini, C., Nasu, S., Baker, O. E., and Kuczynski, R. R.: Population, p. 290; Baker, O. E., in Problems of the Pacific, edited by J. B. Condliffe, p. 320; Duncan, H. G.: Race and Population Problems, Chap. XIV.

2 The World's Population Problems and a White Australia, p. 2.

3 Standing Room Only? pp. 116-17.

4 The Biology of Population Growth, pp. 172-73.

5 Das Hauptproblem der physischen Anthropogeographie, pp. 242-57.

- See Duncan, H. G.: Race and Population Problems, pp. 48-56. 
Comparative Classification of Immigrant Races or Peoples

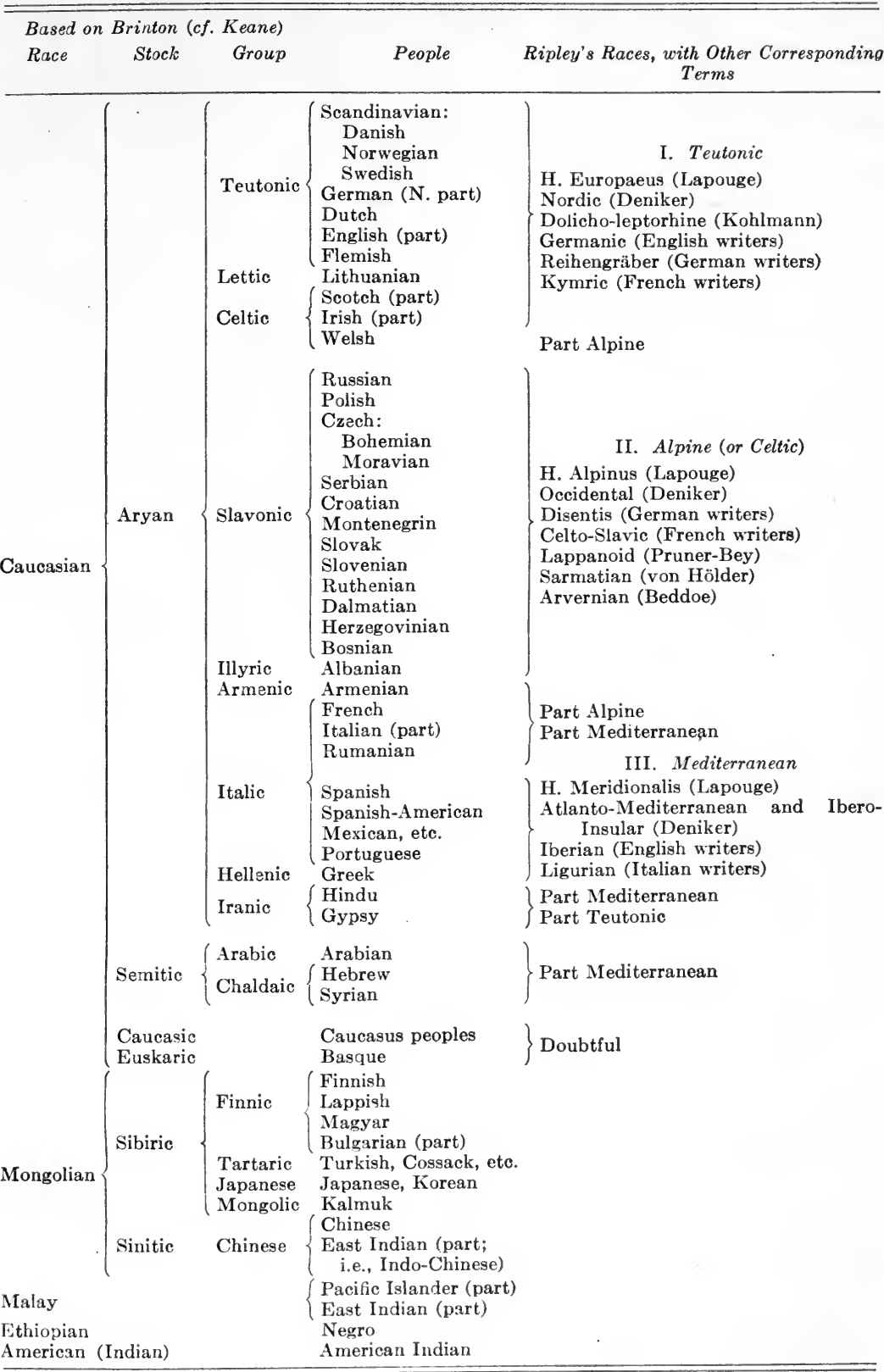


sixty-three. The major classifications ${ }^{1}$ given in the table on page 5 will suffice to show the most outstanding divisions, and the accompanying map the location of the races in Europe.

Using color as a basis, Stoddard and East make the following divisions of the world's population:

\begin{tabular}{lcc}
\multicolumn{3}{c}{ Population OF THE World } \\
World & Stoddard & East \\
& 1700 millions & 1750 millions \\
White & & \\
Yellow & 550 & 710 \\
Brown & 500 & 510 \\
Black & 450 & 420 \\
Red or Unclassified & 150 & 110 \\
& 50 & $\ldots$
\end{tabular}

We have, however, little reliable information either as to the numbers of people who may be classified as belonging to the various racial groups, or as to the increase of the different groups. From the available statistics and estimates, it seems that the European or white group is increasing much more rapidly than the other racial groups.

$$
\text { Population OF THE World }{ }^{2}
$$

\section{Divisions}

Asia (excluding Russia, including

Dutch East Indies)

Europe (excluding Russia)

Russia (including Siberia)

Africa

North and Central America

South America

Australia

Oceania

Total

\section{Population in Millions \\ 1913 \\ 1928}

957.1

353.0

144.0

134.2

133.5

56.5

4.7

3.0

1786.0

1017.0
370.8
153.8
148.2
161.2
79.5
6.3
3.2
1940.0

Percentage

Increase $1913=100$

It is claimed that the yellow, brown, and black peoples have increased very slowly in the last few hundred years. It is estimated that the people of European origin now number approximately 625 millions, having increased some 400 millions since 1800 , while the

1 Dictionary of Races or Peoples, p. 5.

${ }^{2}$ Compare Wilkinson, H. I.: The World's Population Problems and a White Australia, p. 2. 



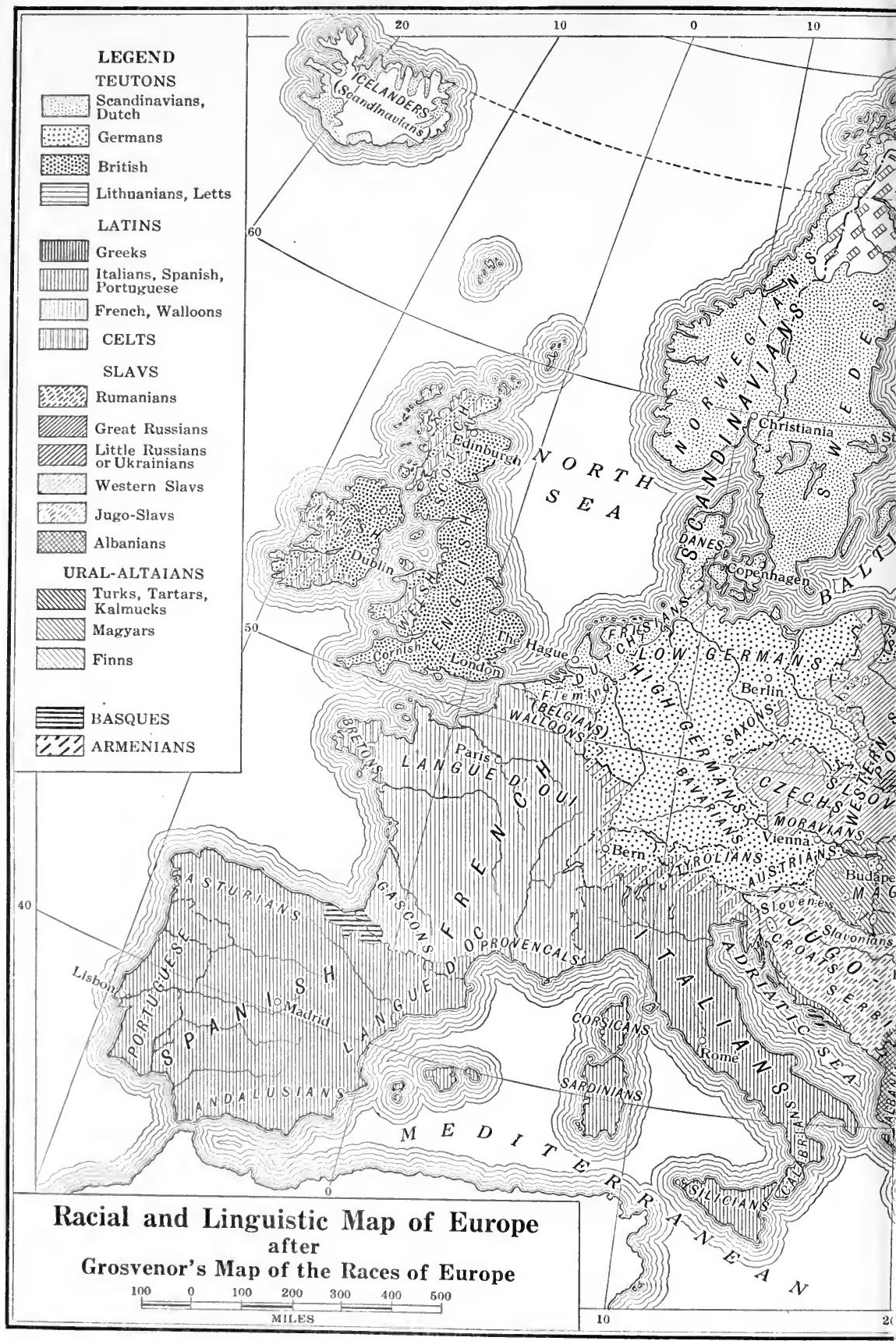




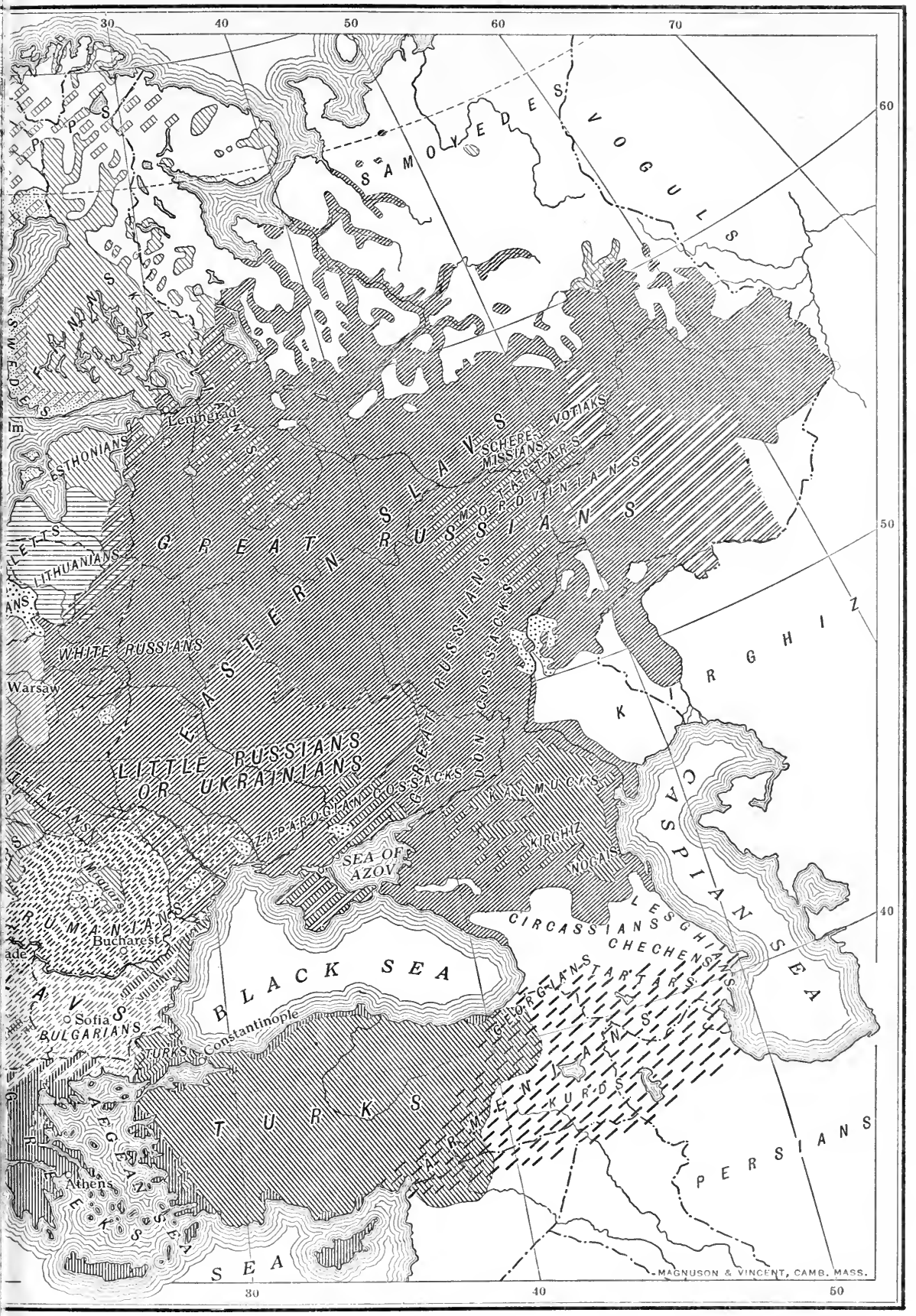



peoples of the rest of the world have probably not increased more than 200 millions or 300 millions. $^{1}$

The white race is found mainly in Europe, the Americas, and Australia; the yellow race chiefly in Asia, especially in China and Japan; and the black race mostly in Africa, the southern part of the United States, and the West Indies. The densest populations are found in India, China, Japan, Europe, and the eastern part of the United States.

Continental Distribution of Population 2

\begin{tabular}{lrrr}
\multicolumn{1}{c}{ Continents } & Population & Square Miles & $\begin{array}{c}\text { Population per } \\
\text { Square Mile }\end{array}$ \\
Asia & $921,000,000$ & $17,206,000$ & 53.5 \\
Europe & $476,000,000$ & $3,872,561$ & 122.9 \\
Africa & $141,000,000$ & $11,622,619$ & 12.2 \\
North America & $136,000,000$ & $8,589,257$ & 15.8 \\
South America & $64,000,000$ & $7,570,015$ & 8.4 \\
Australia & $9,000,000$ & $3,313,613$ & 2.7 \\
Polar Regions & $\ldots \ldots \ldots$ & $5,081,935$ & $\ldots$ \\
$\quad$ Total & $1,747,000,000$ & $57,256,000$ & 30.8
\end{tabular}

But distribution of population according to color and continental densities does not give a complete picture. Three-fourths of mankind are said to dwell in Asia, Europe, and northern Africa. Within these continents are found three great concentrated spots of world population. In the northwestern part of the Old World lies an area of less than 3,000,000 square miles containing some 450,000,000 people; in the Far East a region of 2,000,000 square miles has a population in excess of 450,000,000; and in India an area of 1,000,000 square miles has nearly $300,000,000$ inhabitants. Thus into these three regions are crowded together two-thirds of the world's population on something like one-eighth of the available land.

According to Fawcett ${ }^{3}$ there are three major regions of future world power - eastern North America, southeastern Europe, and parts of Asia between $20^{\circ}$ and $40^{\circ}$ north latitude - and minor areas

${ }^{1}$ Compare East, E. M.: Mankind at the Crossroads; Thompson, W. S.: Danger Spots in World Population; Rossiter, W. S.: "The Adventure of Population Growth," Journal of American Statistical Association, Vol. XVIII, pp. 56174; Reuter, E. B.: Population Problems, Chaps. II, VI; Thompson, W. S.: Population Problems, Chap. XII; Duncan, H. G.: Race and Population Problems, Chap. XIV.

2 Compare Census Report, 1920, Vol. I, p. 13.

3 “Centers of World Power," Sociological Review, Vol. XVII, pp. 91-99. 
in western Siberia, the La Plata region of South America, the southeastern half of the Union of South Africa, and southeastern Australia with parts of Tasmania and New Zealand. From such a forecast, it becomes apparent that the present concentration of population and the future potential areas open to immigration depend upon certain basic conditions. Some areas are and will always be unavailable for the support of large masses of people, while others are capable of supporting dense populations. Generally speaking, the saturation of an area depends upon natural resources with respect to heat, moisture, soil fertility, and minerals, and also upon the amount and skill of labor employed in the production of food and clothing and the extraction of mineral resources. ${ }^{1}$

2. Political Divisions. The surface of the earth is divided among some 60 political powers, varying in size from Monaco, with 7.76 square miles of territory, to the British Empire, with 13,226,749 square miles; and in population from 13,387 in San Marino to $485,473,207$ in the British Empire. The British Empire contains over one-fourth of the population of the world; if China is added, these two powers contain almost one-half of the total population. The British Empire and Russia contain over 47 per cent of the land area in the world. If China, France, the United States, and Brazil are added to the British Empire and Russia, these six nations contain over 76 per cent of the land area and 73 per cent of the population of the world.

The some 60 sovereign states differ in form and in stages of civilization. About 34 are republics and include more than one-half of the population of the earth. The 40 hereditary rulers in 1910 have been reduced to 14 . The World War brought into existence several new republics and at least 13 new constitutions. Republics now girdle the globe.

3. Economic Divisions. Since agriculture is the primary economic foundation of civilization, fertile land is of far more importance than people realize. The problem is further complicated because the white race controls about three-fourths of the land and is determined to hold it for its own advantage. According to Knibbs ${ }^{2}$ the entire

1 See Bowman, I.: "The Concentration of Population and the Distribution of Raw Materials," Proceedings of the Academy of Political Science, Vol. XII, pp. 145-52.

2 "The Menace of Increasing Population," Scientific American, Vol. CXXXIX, pp. $338 \mathrm{ff}$; and The Shadow of the World's Future, Chap. III. 


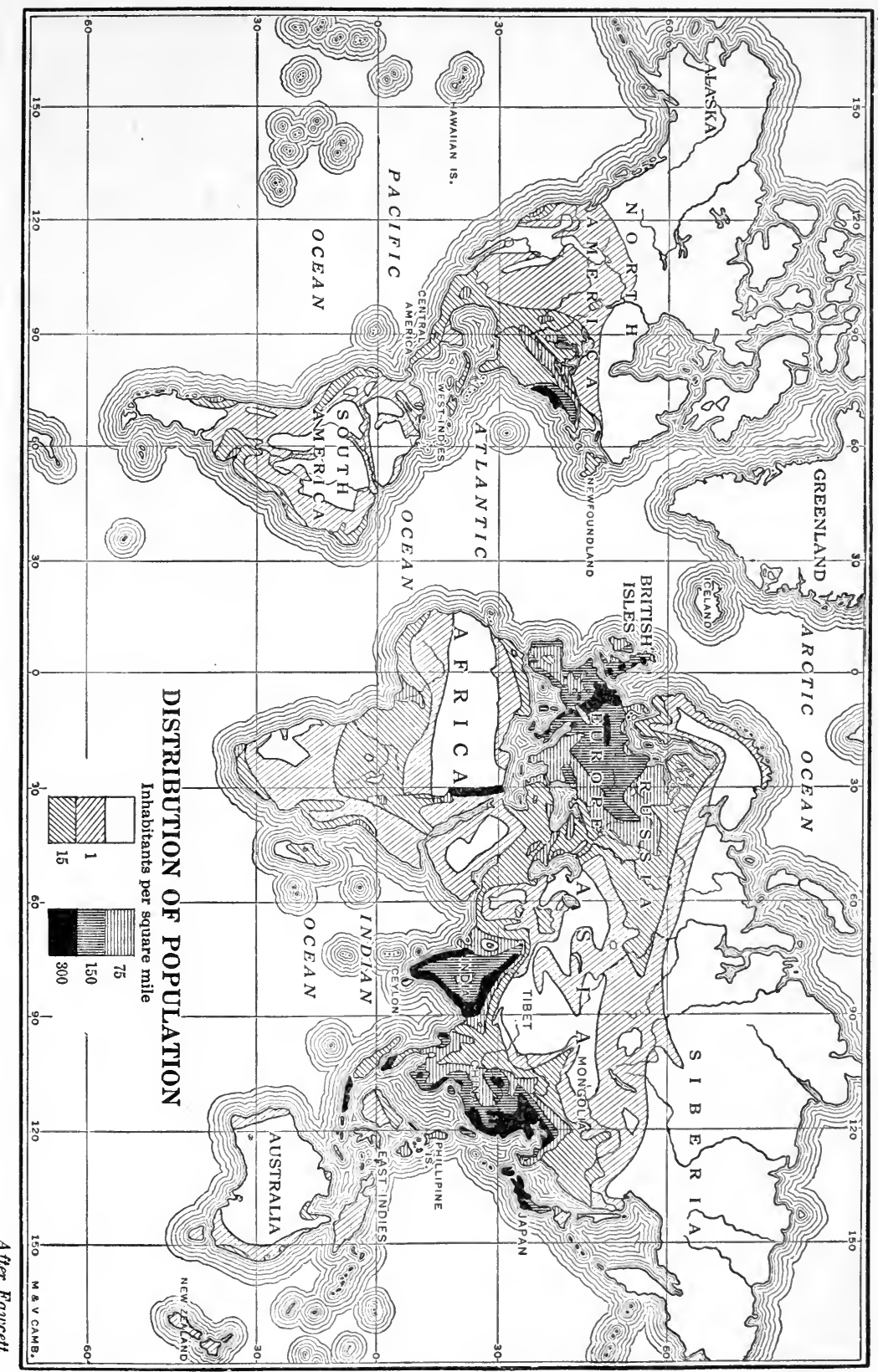


surface of the earth is $\mathbf{1 9 7 . 0 5}$ million square miles, only about onefourth of which is land. Neglecting the polar areas, we find that the actual land surface is only about $\mathbf{5 2 . 5}$ million square miles. Professor Knibbs calculates that only 16.4 million square miles of the land area are productive, 2.8 million square miles being in pasture, 7.5 in forests and shrubs, 1.0 in marshes, and 5.1, or about one-tenth of the whole land surface, in arable land. The proportion of arable land used for cereals and food crops is placed at 76.8 per cent, or about 7.66 per cent of the world's total land area. The utilization of land for the cultivation of these crops varies from country to country, being 43.1 per cent for Czechoslovakia, 34.1 for Denmark, 0.7 for Chile, and 0.1 for Tunis. Likewise there is a divergency in productivity. The world average per acre for wheat is about 14 bushels, but it varies from 51.0 in Denmark to 7.0 in Asian Russia.

Asia contains 52.6 per cent of the world population and 32.6 per cent of the total land area; yet it cultivates only 18 per cent of its land. Europe, the most densely populated continent, has only 7.4 per cent of the land area but 37.4 per cent of the population. It is considered the greatest agricultural region in the world; yet it cultivates only 27 per cent of its land. The Americas contain about 30.95 per cent of the world land area; yet they cultivate only about 12 per cent of their land. Africa has about 22 per cent of the total land area, but is cultivating only 12 per cent of its land. Australia has about 6.6 per cent of the land, but cultivates only about 5 per cent of its area.

Thus the world still has large potential agricultural resources. Agriculture, however, is a complex operation depending not only upon geographical factors and the labor necessary to grow crops, but also upon monetary conditions, transportation facilities, and trade restrictions; consequently all these factors need to be considered in estimating the number of people a region will support.

In 1924 Europe produced 712,824,000 metric tons of coal and lignite; North America, 532,158,000; Asia, 80,059,000; Oceania, 16,224,000; Africa, 13,685,000; South America, 2,050,000. In 1926 the total production of coal was about 1,494,000,000 short tons, and the United States produced 44 per cent of this. Asia has more than 50 per cent of the world's population, but produces only about 7 per cent of the world's coal. The coal resources of the world are estimated to be about 7,397,500,000 metric tons. Of this, North America contains about 67 per cent, Asia 18 per cent, Europe 11 per cent, Oceania 
2 per cent. The deposits in Africa and South America are unimportant. The total world production of iron ore in 1925 was about 144,000,000 long tons. Of this amount the United States produced about 43 per cent, France 24 per cent, and the United Kingdom 7 per cent. The potential iron resources of the world are thought to be around $424,000,000,000$ tons. Of this amount the United States is supposed to have 4,700,000,000 gross tons, and Europe 12,400,000,000 metric tons. The world's production of crude petroleum between 1857 and 1924 amounted to 12,392,541,000 barrels ( 1 barrel $=42$ gallons). Of this amount the United States produced over 60 per cent. Russia and Mexico were our closest competitors, but we produced over twice as much as both of them combined. In 1926 the United States produced $766,000,000$ barrels. The world oil reserve is thought to be over $40,000,000,000$ barrels, of which the United States is supposed to have $8,000,000,000$ barrels. Forest resources of the world cover about $11,700,000$ square miles - an area nearly four times the size of continental United States. About 44 per cent of South America is in forests, 31 per cent of Europe, 27 per cent of North America, 22 per cent of Asia, 15 per cent of Australia, and 11 per cent of Africa.

During the century following 1819, when the first steamship crossed the Atlantic, the total trade of the world increased from $\$ 2$ to $\$ 37$ per capita. In commercial power Great Britain leads, controlling one-half of the gold mined, one-third of the coal and wool, one-fourth of the cotton, one-fifth of the wheat, and one-sixth of the pig iron of the world. France now ranks second in volume of trade. The United States, however, produces 40 per cent of the raw materials, 34 per cent of the manufactured goods, 25 per cent of the food supplies, 70 per cent of the oil, 54 per cent of the copper, 60 per cent of the cotton, 65 per cent of the corn, 46 per cent of the tobacco, and 44 per cent of the coal. The expansion of trade has naturally caused commercial countries to make large foreign investments. In 1914 British capitalists had $\$ 20,000,000,000$ invested abroad; French capitalists had half as much. After the World War the United States became the center of international finance. In 1922 the wealth of the United States reached $\$ 320,804,000,000$ - an amount exceeding that of Great Britain, France, Germany, Italy, and Belgium combined. The United States also became the largest foreign investor. Entirely aside from the war debts, the Department of Commerce estimated that on January 1, 1930, citizens of the United States had between $\$ 13,366,000,000$ and $\$ 15,366,000,000$ invested in 
foreign countries. Foreign investments naturally cause nations to try to dominate the policies of the countries in which they have made investments. The total value of the international trade of the world in 1926 was estimated to be around $\$ 60,427,000,000$. Europe was credited with $\$ 28,951,000,000$ of this, North America with $\$ 11,499,000,000$, Asia (excluding Russia) with $\$ 10,338,000,000$, South America with $\$ 3,515,000,000$, Africa with $\$ 2,631,000,000$, Oceania with $\$ 1,935,000,000$, and Caribbea with $\$ 1,558,000,000$.

The development of national and international trade has led to a shortening of distance by canals and an expansion of railways. In 1926 there were about 700,000 miles of railway in the world. The United States had about 261,800 miles and Europe 242,700. China has an area of about 4,300,000 square miles and a population around $442,000,000$, but only 8212 miles of railways. The Panama Canal shortened the distance from Valparaiso (Chile) to New York by 3747 miles, and from Iquique (Chile) to New York by 5139 miles. The Suez Canal reduced the distance from London to Bombay by 4888 miles. The Kiel Canal saves some 237 miles of troublesome navigation. The Sault Ste. Marie Canal between the Great Lakes is the greatest in the world from the point of view of tonnage. In 1926 about 85,600,000 short tons passed through the Sault Ste. Marie Canal, $31,600,000$ gross tons through the Panama, and 22,700,000 (1923) through the Suez.

4. Religious Conditions. The population of the world is separated into numerous religious groups, customarily divided as shown in the table on page 14 .

The Christian groups are mainly in Europe and North and South America. The Roman Catholics are chiefly in Europe, South America, and North America. In Europe they are principally in the southern part, among the Latins; yet other groups, like the Irish, Poles, and Austrians, are Roman Catholic. The majority of the Protestants are among the Teutonic peoples, and the Eastern or Orthodox Catholies among the Slavs. The Confucianists are chiefly in Asia, among the Chinese; the Hindus among the East Indians; the Buddhists among the Chinese groups. The Mohammedans cover a broad belt from the center of Siberia and Mongolia, across Turkey, Arabia, and the northern half of Africa. The Shintoists are almost wholly in Japan, and the Animists in Africa, Asia, Oceania, and North America. The Jews are scattered over the whole world. Taken as a whole, the nonChristian world constitutes nearly two-thirds of the earth's surface 


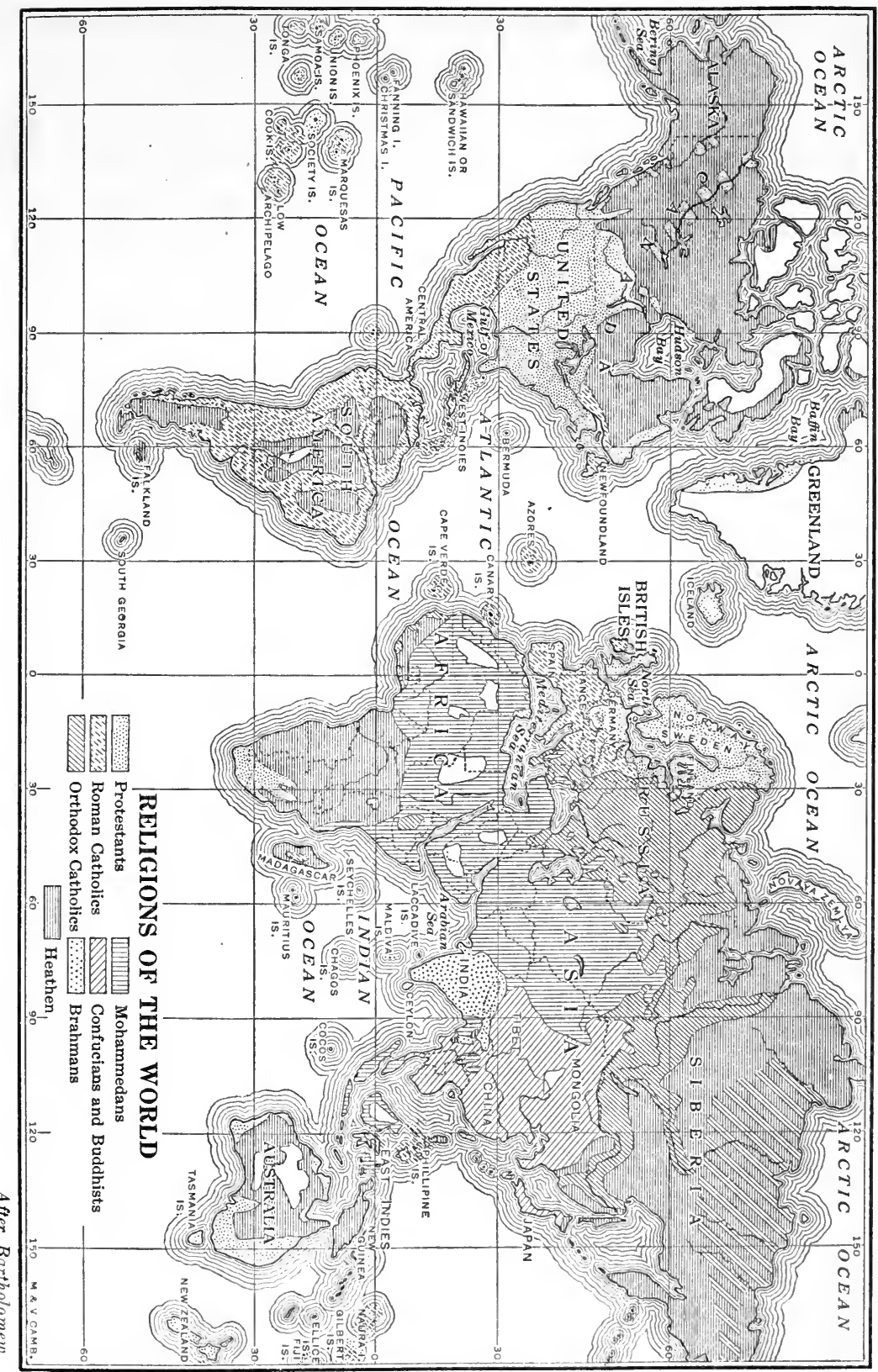


and people, but over this vast area political and commercial ambitions of the Christian world play. The United States, although having a reported church membership of only 46.6 per cent, appears to be the most fervent missionary country. While continental Europe has some two and one-half times as many Protestant communicants as the United States, it supplies only one-sixth as many foreign missionaries and one-twentieth as much money for evangelization.

\section{Religious Membership of the World}

(Figures represent millions:)

\section{SECT}

Christians

Roman Catholies
Orthodox Catholics
Protestants

Total Christians Africa Asia Europe Oceania

$\begin{array}{ccl}\text { North } & \text { South } & \\ \text { America } & \text { America } & \text { Total } \\ 40 & 61 & 331.5 \\ 1 & \ldots . & 144 \\ 75 & .9 & 206.9 \\ 116 & 61.9 & 682.4\end{array}$

Non-Christians

Confucianists, Taoists

Hindus

Mohammedans

Buddhists

Animists

Shintoists

Jews

Miscellaneous

Total Non-

Christians

$\begin{array}{rr}\ldots & 350 \\ \ldots & 230 \\ 44 & 160 \\ \ldots & 150 \\ 90.5 & 45 \\ \ldots & 25 \\ .5 & 1 \\ \ldots & 18\end{array}$

$\begin{array}{rcc}\ldots & \ldots & .6 \\ \ldots & \ldots & .15 \\ 5 & \ldots & .02 \\ \ldots & \ldots & .18 \\ \ldots & .1 & .05 \\ \ldots & \ldots & \ldots . \\ 10 & .03 & 4 \\ 5 & .87 & 25\end{array}$

$\begin{array}{cc}\ldots & 350.6 \\ \ldots & 230.15 \\ \ldots & 209.02 \\ \ldots & 150.18 \\ \ldots & 135.65 \\ \ldots & 25 \\ .1 & 15.63 \\ 2 & 50.87\end{array}$

5. Languages. Linguistic families cannot be definitely determined. Wissler ventures a guess that there are "about two hundred families of languages spoken in the world today." 1 Kroeber ${ }^{2}$ thinks that not over twenty-five of these families exist in Asia and Europe, while Wissler places the number at twenty-one. There are approximately seventy-five linguistic families in each of the Americas. In the world taken as a whole, there are said to be 6760 named tongues and systems of writing, and 2796 "actual" languages.

The most important language group in Asia and Europe, according to the number of speakers, is the Indo-European, also known as Indo-Germanic or Aryan, which comprises the Indic, Slavic, Germanic, Romance or Latin, Persian or Iranic, Armenian, Greek,

\footnotetext{
1 An Introduction to Social Anthropology, p. 85.

${ }^{2}$ Anthropolog! , Chap. V.
} 
Albanian, Baltic or Lithuanian, and Celtic languages. From Europe English, Spanish, French, Russian, and other languages of this group have been carried to other continents. Closely rivaling the Indo-

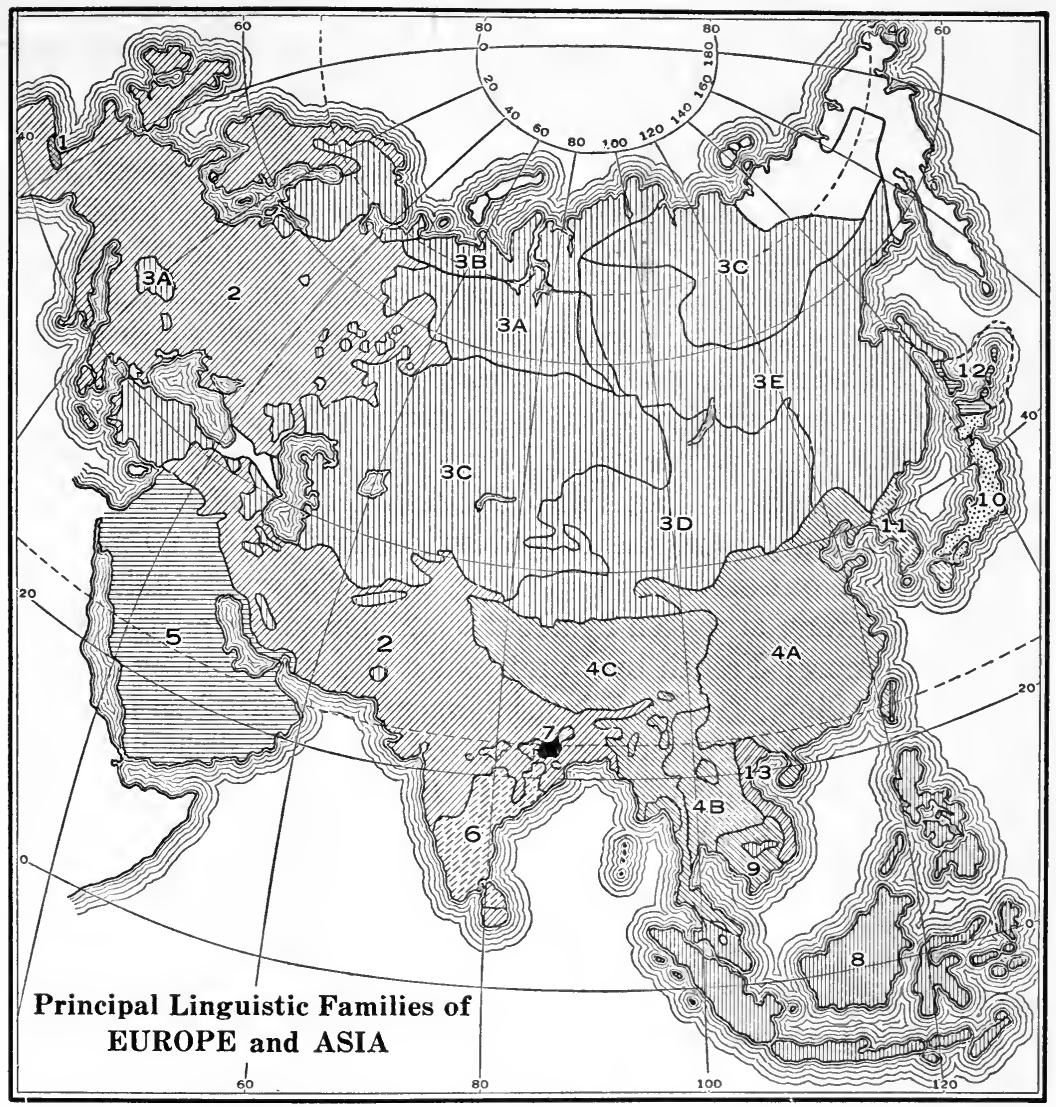

After Kroeber

1. Basque. 2. Indo-European. 3. Ural-Altaic (A. Finno-Urgic; B. Samoyed; C. Turkish; D. Mongol; E. Tungus-Manchu). 4. Sinitic (A. Chinese; B. ShanSiamese; C. Tibeto-Burman). 5. Semitic. 6. Dravidian. 7. Kolarian. 8. Malayo-Polynesian. 9. Mon-Khmer. 10. Japanese. 11. Korean. 12. Ainu. 13. Anamese.

European in number of speakers is the Sinitic group, which includes the Chinese proper with its dialects, the Tibeto-Burman, and the Shan-Siamese branches. The Ural-Altaic group, comprising FinnoUrgic, Turkish, Mongolian, and Tungus-Manchu, rivals the Indo- 
European in the extent of the territory in which it prevails. The Semitic group, of which Arabic is the chief living representative, was once the vehicle of expression for the Babylonians, Assyrians, Phœnicians, Carthaginians, and Hebrews. Arabic, being the orthodox language of the Mohammedans, served to transmit that culture and was closely interrelated with the spread of that religion. Other language families meriting attention are the Dravidian, in southern India, whose speakers number over fifty millions, the Japanese, and the Korean. In northern Africa Hamitic, the language family to which the language of ancient Egypt belonged, has gradually given way to Semitic, as a result of the spread of Mohammedanism. Although Bantu covers the greater part of the territory south of the equator, it does not have a large number of speakers. The locations of these languages are shown on the accompanying map.

Four-fifths of the people speak languages belonging to the Slavic, Romanic, and Germanic divisions. English is the mother tongue of some 160 million people, and is used and understood by 60 millions more. About one-seventh of the people of the world understand English. German is spoken by about 90 millions and understood by 20 millions more; French by 45 millions and understood by 70 millions more. Since the English-speaking people control so much of the land area and are so prominent in commerce, English is fast becoming the language of world communication.

6. Culture Areas. Although political divisions, economic boundaries, religious groupings, and language spread are culture factors which need to be considered in understanding the background for immigrants, there are many other cultural traits, too numerous to mention, which compose a culture area and play an important part in human adjustment.

There are various methods employed in marking off culture areas, none of which is entirely satisfactory, owing to the fact that culture traits overlap and that diffusion and borrowing have to a large extent made the whole world kin. Few, if any, would venture to say what kind of culture pattern the first culture was, since only the indestructible débris of culture survives. The roots of our present cultures are so deeply buried in antiquity that we are able to assign only roughly its origins. It is generally conceded that the first step in its development was the crude chipping of flints. Other discoveries, such as the use of fire, the use of the wheel, and the domestication of animals, followed. 
Usually a distinction is made between Oriental and Occidental cultures, the former generally referring to Asia and the latter to western Europe. Culture differences occur in art, music, customs, forms of recreation, and other traits. The aboriginal culture of the New World contained many distinctive traits of its own, which it stamped indelibly upon the Europeans who came as conquerors. The growing of maize, with all the traits associated with it, certainly was one of the distinct American culture complexes. The use of tobacco was another. On the other hand, the colonists brought over European culture, but this culture rests upon the ruins of the Roman Empire. However, Rome borrowed from Greece, Greece from Crete, Crete from Asia Minor and Egypt, and these two from eastern Asia.

If we wish, we may consider that in a general way Africa, Asia, and Europe (including the Americas and Australia) represent different culture areas. When we examine any of these more in detail, however, we discover numerous differences. Europe, for instance, might be divided into Teutonic, Latin, and Slavic cultural areas. With the Teutonic areas might be included the United States, Canada, Australia, and New Zealand; and with the Latin we might include Central and South America and the West Indies. Certainly there are marked differences between the cultures of the Japanese, Chinese, Indians, and Turks in Asia. Likewise, differences appear between Egyptians, Berbers, Bushmen, Hottentots, Pygmies, and Bantus in Africa.

\section{Population Movements and Distribution}

1. Early Wanderings. As has been indicated, anthropologists and ethnologists have not yet agreed on the original home of man. Likewise the time and direction of his early movements are in question. The subject is as fascinating as it is difficult, and many have attempted to solve these problems. Despite the difficulties and uncertainties, a brief discussion of these early movements is essential for this work, since in these began many of the problems of presentday immigration.

According to Ellsworth Huntington ${ }^{1}$ and J. C. Curry ${ }^{2}$ there were six principal periods of migration. The first period embraced the

1 The Pulse of Asia.

2 "Climate and Migrations," Annual Report of the. Smithsonian Institution, 1929, pp. 423-35. 
centuries which immediately preceded the year 2000 B.c. This constituted a movement of the people inhabiting the steppes of Asia and Europe. At that time the center of civilization was in Egypt, the Aegean, southern Arabia, and Mesopotamia. It was the period when the Canaanites marched out of Arabia, and the Hyksos, bringing with them the horse, crossed the mountains into Persia and Palestine and then moved on into Egypt. The Mediterranean race was probably already around the shores of the sea which bears its name; the Alpines were inhabiting the mountain regions from Pamirs to the western Alps, and Tartar nomads occupied the steppes.

The second period dates between 2000 and 1000 B.c. Sometime between 1600 and 1300 B.c., Aramaean nomads entered Mesopotamia from Arabia, and the Indo-Europeans, who were now an agricultural people, spread into India and Persia, and came into contact with the Syrians. The Hittites went into Asia Minor and the Achaeans into Greece. In the early part of this period the Minoan civilization dominated the Aegean, but it experienced a decline between 1400 and 1350 B.c. The Canaanites established themselves in prosperous settlements in Syria and Palestine, Egypt was reorganized by the Theban dynasties and the "New Empire" founded, and the Assyrians became powerful in Mesopotamia.

The third period includes the time between 1000 and 600 B.c. During this era the Celts (Alpines) moved along the country north of the Italian Alps from the Caspian Sea, the Cimmerians escaped the Scythians by crossing into Asia Minor, the Dorians moved into Greece, the powerful Hittite state disappeared, and the Medes overran Persia. At some time between the second and third periods the Vedic civilization in India was developed by the Aryans. After the third period, civilization developed rapidly in Persia, Asia Minor, Greece, Italy, and India.

The fourth period began shortly after 200 B.c. Nomadic tribes of Asiatics disturbed the steppes, conquered different groups, and moved into new lands; the Turanians overran Persia; and the Germanic tribes moved against Italy and Gaul. After this spree of migration, India, Persia, and Greece declined in civilization, while Italy took on new life and became the center of influence.

The fifth period extends from 250 to 650 A.D. Around 250 A.D. India, Greece, and Italy suffered serious setbacks. Barbarians destroyed the Andhra dynasty in southern India and the Kushan Kingdom in the northern part, and the Goths took Athens. During the 


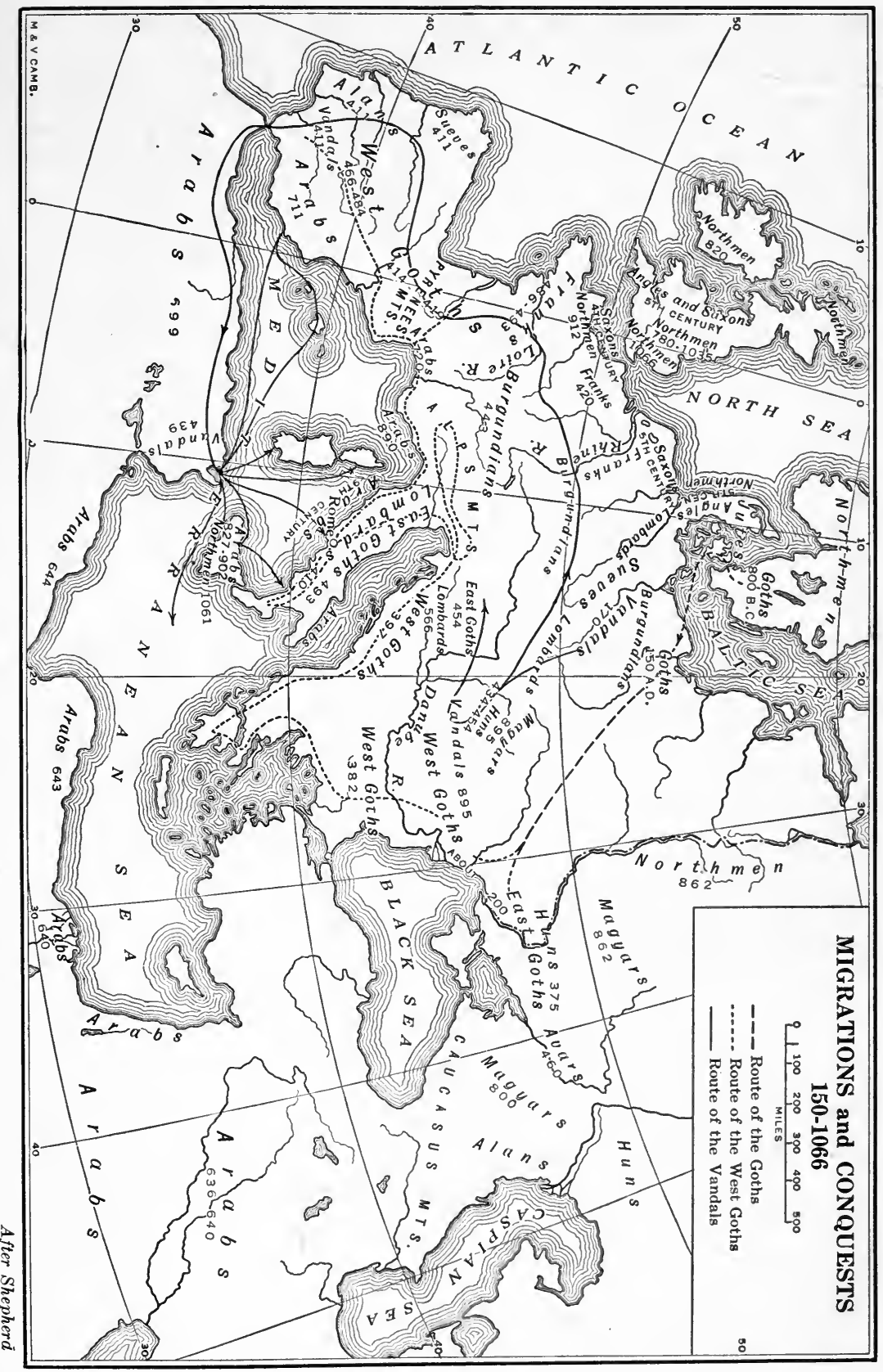


latter part of the third century the Roman Empire was unable to guard its territory against the Franks and Alemanni, who marched through Gaul, and the Saxons, who raided the coasts. About 375 A.D. the Huns swarmed into Europe, displacing the German tribes and driving the Goths below the Danube. The Germans, in turn, overran Gaul, Britain, Spain, and northern Africa, finally conquering the Western Empire. About 640 A.D. Asiatic Mongols destroyed the Hunnish Empire in Europe, and hordes of Huns invaded India, conquering the northern kingdom. The fifth period was the most serious for Europe, and includes the beginning of what is known as the Dark Ages.

The sixth period covers the eleventh, twelfth, and thirteenth centuries, and is characterized by the movements of the restless "wild Magyar horsemen." During the last century of this era, swarms of Mongols moved into Europe and India, working havoc wherever they went. This constitutes the last great movement of people from the steppes. Europe, emerging from the Dark Ages, experiences the Renaissance and moves into the present age.

2. International Migrations. Man has long been a wanderer, but international migrations may be considered (certainly from official statistics) to have begun shortly after the Napoleonic Wars ended. The economic, political, religious, and social conditions resulting from these wars, the far-reaching effects of the Industrial Revolution, and the increased general knowledge of other lands again set man to moving and established the period of what may be termed international migrations. These movements, however, differ from the earlier migrations in three chief particulars. ${ }^{1}$

First, they are individual rather than mass movements. Whereas the early migrations involved whole tribes, like the Huns, Tartars, Vandals, and Norsemen, the later ones are characterized by movement of individuals and single families. These individuals or families may establish their own settlements in the new country, but such foreign communities differ markedly from the settlement of a whole tribe, and the social consequences, as will be indicated later, are different.

Second, attitudes toward these movements have changed. The earlier movements of whole tribes generally meant warfare, bloodshed, and extermination, while the later movements have generally been peaceful. Opposition to the later movements has been char-

${ }^{1}$ Compare Thompson, W. S.: Population Problems, pp. 374-75. 
acterized by legal restrictions. Before the end of the nineteenth century a number of countries prevented or restricted the movements of their people. Japan made leaving the country a capital offense, and Russia prohibited the migration of its peasants even to Siberia. Such restrictions, however, generally broke down, and the great migrations of the nineteenth century took place, increasing from 20,000 to 30,000 migrants per year in Europe at the beginning of the century to between 2,000,000 and 3,000,000 at the end. ${ }^{1} \mathrm{Mi}-$ gration came to be generally encouraged by both the immigrant and the emigrant countries. The immigrant countries, such as the Americas, Australia, and New Zealand, desired to increase their population and expand, while the emigrant countries saw an opportunity for relieving population pressure, establishing colonies, and ridding themselves of certain undesired types. More recently there has been another shift in attitudes, and an effort to restrict or to prevent the incoming of immigrants (or certain types of immigrants) is manifesting itself in most of the immigrant countries, especially the United States, Australia, New Zealand, South Africa, and Canada. On the other hand some countries, like Great Britain and Japan, are encouraging their citizens to emigrate and are aiding. them in so doing.

Third, modern migration may be considered temporary in comparison with the earlier movements. The tribe often moved as a whole and hardly expected to return to the former region, while a large percentage of present-day immigrants expect eventually to return to their native land. There is an annual migration of about 100,000 Polish agricultural laborers into other countries each summer, and at least half of the Bulgarians, Serbs, Chinese, and Italians leave for their native land after a stay in foreign countries.

The number and distribution of people involved in these international migrations can only be conjectured, according to Imre Ferenczi. $^{2}$ The European emigration statistics from 1846 to 1924 show 50 million departures, and the immigration statistics of overseas countries from 1820 to 1924 show $55 \frac{1}{2}$ million arrivals. These statistics, however, do not show the overseas migrations from Asia and other continents, nor the international migrations within the

1 Compare "International Migration and Its Control," by Albert Thomas, in Proceedings of the World Population Conference, 1927, edited by Margaret Sanger, pp. 256-301.

${ }^{2}$ International Migrations, Vol. I, p. 82. 
continents. The British Isles, Germany, Norway, Sweden, France, and Switzerland were the leading emigrant countries up to the decade ending in 1891. From that date until the World War, emigration from these countries decreased, but increased from Italy, Austria-Hungary, Russia, Spain, Poland, and Finland. Of course the United States did not receive the entire migration, but it received a large share as the accompanying table shows.

Percentage Distribution of European Emigrant Citizens by

Countries of Future Residence (1891-1924)

\begin{tabular}{|c|c|c|c|c|c|c|c|c|c|}
\hline Period & $\begin{array}{l}\text { United } \\
\text { States }\end{array}$ & $\begin{array}{c}\text { British } \\
\text { North } \\
\text { America }\end{array}$ & Argentina & Brazil & $\begin{array}{c}\text { Other } \\
\text { American } \\
\text { States }\end{array}$ & Oceania & Africa & Asia or & $\begin{array}{c}\text { Other } \\
\text { Countries } \\
\text { or Destination } \\
\text { Unknown }\end{array}$ \\
\hline $1891-00$ & 54.1 & 3.8 & 7.5 & 11.0 & 12.5 & 2.8 & 6.4 & 0.1 & 1.8 \\
\hline $1901-10$ & 58.4 & 9.2 & 11.6 & 3.6 & 7.3 & 2.2 & 5.6 & 0.1 & 2.0 \\
\hline $1911-14$ & 47.5 & 15.4 & 12.1 & 2.8 & 8.7 & 5.4 & 4.9 & 0.8 & 2.4 \\
\hline 1915-19 & 34.3 & 11.3 & 9.6 & 1.7 & 23.1 & 3.5 & 9.3 & 2.3 & 4.9 \\
\hline $1920-24$ & 42.7 & 15.9 & 11.9 & 3.0 & 8.5 & 6.7 & 5.4 & 1.9 & 4.1 \\
\hline
\end{tabular}

In conclusion we may say that man early began to increase and to wander from his original home. Both early wanderings and international migrations result from the desire of people to improve their condition. Dissatisfaction with the local or national situation, or some element of it, combines with a belief that opportunities for the satisfaction of the unfulfilled wishes are better in the country toward which the movement is directed, and migration takes place. Economic, political, religious, and language situations appear to be the most pertinent causes for dissatisfaction. Because of these, people have forsaken the lands of their birth and transplanted themselves in unknown areas to such a degree that no real classification is possible for the some 1700 million inhabitants of the world. Racial types have migrated and become altered, languages have changed, religions have cut across national boundaries, linguistic lines, and economic planes, and cultural areas have expanded and changed through the process of diffusion and borrowing.

Since the World War there has been a tendency to use race and language as a basis for classification of groups. Pan-Teutonism (Nordic superiority), Pan-Latinism, and Pan-Slavism have been much discussed, but have not yet reached the stage of practical politics. The Irish, Bohemians, Catalans, Flemings, Norwegians, and Lithuanians are now reviving their older languages and using them as rallying points for healthier developments of national consciousness. 
Pan-Islamism is another imperial dream, based upon the ambitions of Moslems to unify and extend their religion and its accompanying culture traits beyond its present bounds. Pan-Americanism and Pan-Europeanism have likewise been advocated, but the terms are misnomers, since the former omits Canada and the latter the British Isles and Russia. A less pretentious effort has been the attempt of the Baltic states to draw together. The League of Nations marks a colossal attempt to bring the world powers together into a kind of political unity. Although it has weathered thirteen years of discord, it largely remains an unfulfilled dream.

In the light of these world conditions it becomes evident that social, political, and economic conditions combine to furnish a difficult background for the immigrant's assimilation into American life. The many problems involved in the reorganization of his attitudes and activities lie rooted in his Old World experiences and the circumstances that combined to force him away from his ancestral moorings. These factors will be discussed more in detail in connection with racial and national groupings in the following chapters.

\section{QUESTIONS, EXERCISES, AND PROBLEMS FOR INVESTIGATION}

1. Account for the lack of interest in earlier movements of people, and for the present trends this interest has taken.

2. Consult the references given and then discuss the rise and spread of the early human group.

3. Give the present estimated world population, the annual increase, and the predicted future limits.

4. What are the difficulties encountered in distinguishing races? Name and locate the most commonly accepted major divisions.

5. Locate the most congested areas of population.

6. Designate the areas capable of supporting larger populations. References. Fawcett, C. B.: "On the Distribution of Population over the Land," Sociological Review, Vol. XVII, pp. 85-104; "Centers of World Power," ibid., Vol. XVIII, pp. 91-99; Duncan, H. G.: Race and Population Problems, Chap. XX; Jones, Clarence, F.: "Agricultural Regions of South America," Economic Geography, Vol. IV, pp. 1-30, 159-86, 267-94; Vol. V, pp. 109-40, 277-307, 390-421; Baker, O. E.: "Agricultural Regions of North America," Economic Geography, Vol. II, pp. 459-93; Vol. III, pp. 50-86, 309-39, 447-65; Vol. IV, pp. 44-73, 399-433; Vol. VII, pp. 109-53; Jonasson, Olof: "Agricultural Regions of Europe," Economic Geography, Vol. I, pp. 277-314; Vol. 
II, pp. 19-48; McFall, R. J.: "Is Food the Limiting Factor in Population Growth?" Yale Review, Vol. XV, pp. 297-316; Valkenburg, S. V.: "Agricultural Regions of Asia," Economic Geography, Vol. VII, pp. 217-37.

7. Mention some ways in which economic factors affect international relationships. Besides the text, see Leith, C. K.: "The Political Control of Mineral Resources," Foreign Affairs, Vol. III, 541-55; Brownlie, David: "Fuel and Power as National Problems," Fortnightly Review, Vol. CXXIV, pp. 484-95; Smith, G. O.: "A World of Power," Economic Geography, Vol. I, pp. 133-42; Van Norman, L. E.: "Problems of American Investments Abroad," Current History, Vol. XXX, pp. 25-30; Jefferson, Mark: "The Civilizing Rails," Economic Geography, Vol. IV, pp. 217-31; "The Future of Power Supply and Public Control," Proceedings of the Academy of Political Science, Vol. XIV.

8. Explain more fully the meaning of an often repeated statement: "Perhaps religion is one of the most entangling of the cultural forces." References. Maycock, A. L.: "The Inquisition," Nineteenth Century, Vol. XCVIII, pp. 265-77, 468-78; Miller, H. A.: Races, Nations and Classes, Chap. V; Shonle, Ruth: "The Christianizing Process among Preliterate Peoples," Journal of Religion, Vol. IV, pp. 261-80; Abel, C. W.: "Conflicting Forces in Papua," Missionary Review of the World, Vol. XLVI, pp. 377-82; "An African Autobiography," Missionary Review of the World, Vol. XLII, pp. 603-08, 683-86, 933-45.

9. Report on Hypes, J. L.: "The Mohammedan Culture Patterns and Social Processes," Publications of the American Sociological Society, Vol. XXV, pp. 29-37.

10. Wherein may it be said that language is the worst frontier in Europe and the most fertile of conflict? References. Guérard, A. L.: "The Battle-Line of Languages in Western Europe," National Geographic Magazine, Vol. XLIII, pp. 145-80; Miller, H. A.: Races, Nations and Classes, Chap. VI. 


\section{PART II}

\section{THE TEUTONIC GROUP}

Professor Ripley used the term Teutonic race to cover the tall, longheaded, fair-haired, blue-eyed people inhabiting the regions around the Baltic and the North Sea. He distinguished this group from another which he called Alpine - the people of medium height, with round heads and brown hair and eyes, inhabiting the regions of Brittany, the highlands of central Europe, the plateau of central France, south Germany, Switzerland, Austria, and Afghanistan. This group, in turn, he differentiated from Sergi's Mediterranean race - the short, long-headed, dark-haired, dark-eyed people inhabiting the area around the Mediterranean Sea.

Long before historic times the so-called Teutonic peoples inhabited the country around the Baltic Sea. They are supposed to exist in their purest type in Scandinavia, but there, as in racial groups elsewhere, there is a considerable mixture of earlier groups. The Teutonic peoples speak Teutonic or Germanic forms of the Aryan language. The term Teutonic is used with a variety of meanings, and may refer to race, language, or general culture.

Taking into consideration racial, linguistic, and general cultural factors, and recognizing that our decision is based on convenience rather than on anthropological or ethnological conviction, we may consider the United Kingdom, Germany, Austria, Sweden, Norway, Denmark, Holland, Belgium, Switzerland, Lithuania, Latvia, and areas settled by people from these countries, such as the United States, Canada, Australia, New Zealand, and South Africa, as Teutonic countries. Inclusion of a country in this group means, not that all the people in that country are Teutonic in race, language, or general culture, but that a majority of them are. Indeed, some of the countries we have listed are sometimes placed with other groups, but the reasons for including them in the Teutonic group will appear under the treatments for the different countries. It is scarcely necessary to add that these countries do not contain all the Teutonic people in the world. 



\section{CHAPTER II}

\section{THE UNITED KINGDOM}

1. General Description. The United Kingdom consists of a group of islands lying off the western coast of Europe. It comprises England, Wales, Scotland, Ireland, the Isle of Man, and the Channel Islands. The people inhabiting these countries present neither biological nor religious unity; yet they have been subjected so long to the same political power, and have for so long a period had the same national language and been otherwise culturally related, that it appears expedient to consider them under the same general head.

The British Empire embraces about one-fourth of the habitable land surface of the globe and over one-fourth of the population. Including the present Irish Free State, the United Kingdom is less than one-hundredth part of the British Empire and contains only about one-tenth of the population; or, to put it another way, it is smaller than New Mexico, and has far less than one-half the population of the United States, or 49,248,728 (1931). England proper, the center of political influence of the Empire, contains 50,874 square miles; it is smaller by a thousand square miles than Alabama, and has a population of over $37,000,000$. Ireland and Scotland are each less than two-thirds the size of England, and the population of each is less than $5,000,000$. Wales boasts of only 7466 square miles and a population of $2,592,014$. The Isle of Man has 227 square miles and 60,284 inhabitants. The Channel Islands contain 75 square miles and 89,867 people.

Because of the modifying influences of the Gulf Stream, the British Isles have a much milder climate than other countries of the same latitude. The rainfall is abundant and amply distributed for crops. The fogs over part of the country are dense; London, especially, is famous for its fogs. The soil of the islands varies in natural fertility; much of it has been cultivated so long without proper care that large amounts of fertilizer are now required. Part of the area, especially Wales, is rich in natural resources.

Concerning the early inhabitants of what now constitutes the United Kingdom we know very little. Archæologists conclude that 


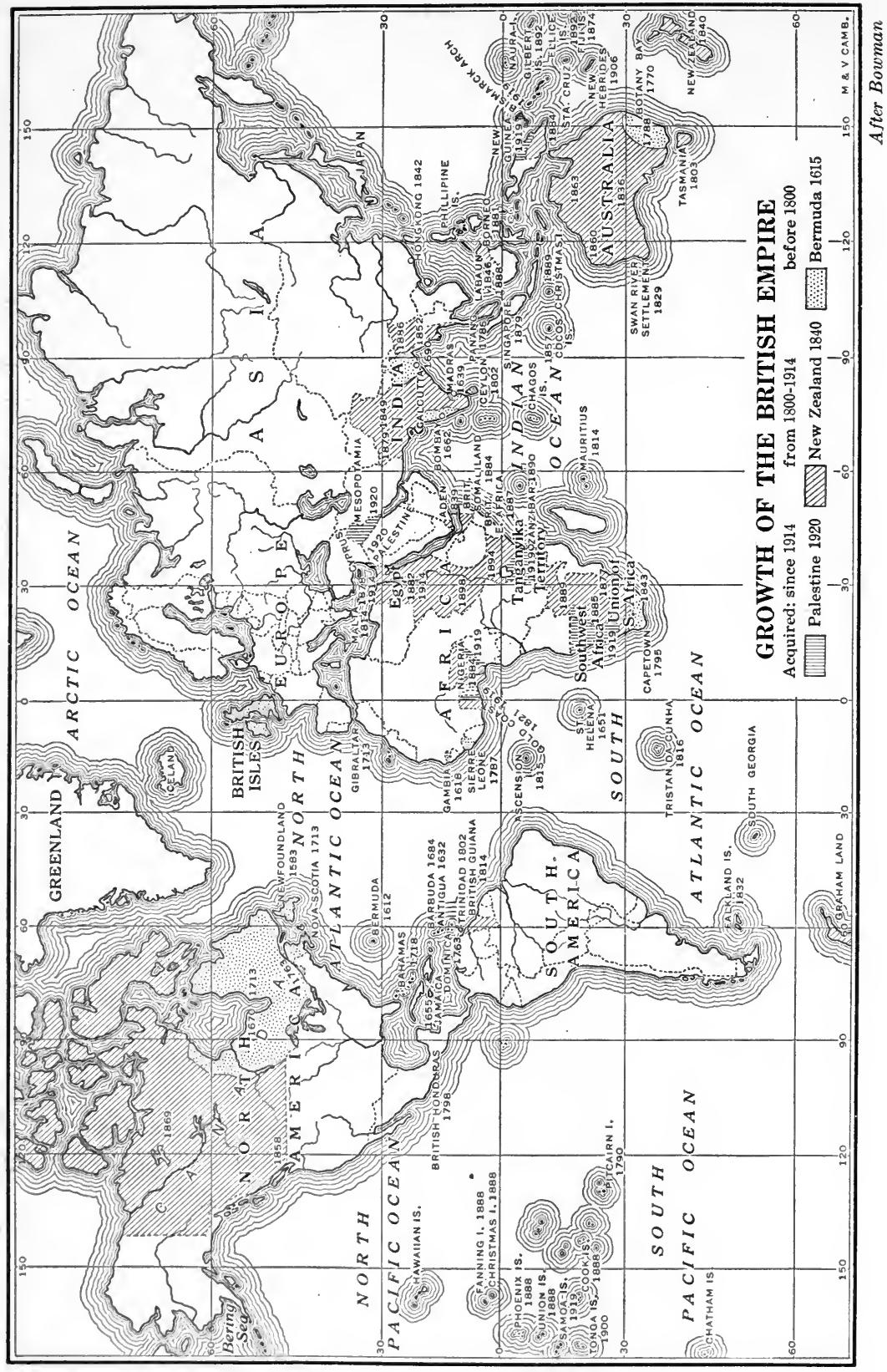


this region was inhabited by Paleolithic and Neolithic peoples before it was separated from the continent and while the Thames and Trent were still tributaries of the Rhine. Our knowledge of these people, however, is vague, and we can visualize their life only from the implements and other relics they have left behind. Their skulls seem to identify them with the Basques, a so-called pre-Aryan group, the modern descendants of whom now occupy a strip of territory along the border of southern France and northern Spain. According to traditions, several Mediterranean groups, principally from Greece, early established themselves in the British Isles. Different Alpine groups, often called Celts, known as Picts, Scots, Gaels, Britons, and Belgae, reached this section during the Bronze Age; much later a new type of invaders began to overrun the islands. These were Teutonic tribes, known as Vikings, Angles, Saxons, Jutes, and Normans. So fast, so numerous, and so long continued were these invasions that many cultural changes, in language, politics, religion, and general social conditions, were wrought. So complete was the biological change that the majority of the population in England and Scotland and parts of Ireland and Wales is now considered Teutonic. Thus, in the British Isles, the long mingling of the tall, long-headed, fair-skinned, blue-eyed, flaxen-haired Teuton, the stocky, round-headed, auburn-haired, hazel-eyed Alpine, the small, long-headed, dark-skinned, dark-haired, and dark-eyed Mediterranean, and the brunette Basque produced the "wonderful mongrel" of the present cosmopolitan population. The amalgamative process, however, is still far from complete, and one can find plenty of evidence of the survival of the earlier groups in Wales, Ireland, the hills of Scotland, and parts of England.

2. Political Development. The early political history of the United Kingdom is that of clans fighting with each other and occasionally uniting to stay the progress of some invading horde. The conquest of northern Gaul by the Romans ( $57-50$ B.c.) established a definite relationship with the Mediterranean and permitted Roman civilization to pass over into Britain, thus giving part of the British Isles an underlying stratum of Latin culture. In 122 Emperor Hadrian had a wall some seventy miles long built, which for about two hundred years marked the northern limit of Roman culture and power and culturally divided the isle. In the lowlands of southern Britain, native tribesmen began to speak Latin, use the material culture of Rome, and consider themselves members of the Roman State. 
North of Hadrian's wall the Picts, Scots, and other aggressive tribes were becoming restless, and early in the fifth century the Teutonic conquest of Gaul cut the island off from Rome. Left thus to themselves, the Romano-British were unable to resist the onslaught of invading hordes. The Jutes from the land we now call Denmark, the Angles from Slesvig-Holstein, and the Saxons from the valleys of the Weser and Elbe rivers came pouring into Britain and "leveled, trampled down, and swept off whatever came in their way, as if they were reaping corn ripe for the harvest." Caring nothing for the churches, towns, or civilization of the Britons, these barbarians burned, sacked, and destroyed the civilization for which they had no appreciation. Latin and Celtic, the prevailing tongues in the rural districts, ceased to be spoken in the conquered districts and Germanic dialects took their place. The same was true of Roman law and forms of government. So fully did Anglo-Saxon language, customs, and behavior patterns dominate that English history is sometimes regarded as dating from the fifth century.

Near the close of the eighth century came a new invasion, that of the Danes or Northmen, from Scandinavia. They overran the country until halted by Alfred (871-901). Emergency lent authority. Alfred organized an army - one part to protect the harvests, and another to meet the enemy - and built sturdy, swift ships to clear the shores of Viking vessels. He also reduced the laws and customs sanctioned by usage to a uniform code and ordered the translation of the most useful books he knew into the unlettered speech of the people. Thus Anglo-Saxon became a literary language.

But England was not yet spared from "the fury of the barbarian"; Danish invasions were renewed in 981. As a result of the "unreadiness" of King Ethelred the Unready, and the friendly feeling for the invaders existing in certain sections, the Norse leader, Swegen, won the day, and the country passed under foreign rule. The eleventh century saw the Norman invasions. Under William I (1035?-1087) all landowners were forced to kneel and swear "to be faithful to the king before all other men." French became the language of the royal court, Latin of the church and law, and Anglo-Saxon of the lower classes. While this foreign rule gave the country prestige, it created a breach between the haughty Norman lords and the Saxon subjects, who continued to speak their native tongue and follow the customs of their ancestors.

Differences between Norman and Englishman gradually decreased 
during the twelfth and thirteenth centuries. Feudalism as a system of government was destroyed, and the church was largely brought under the control of the state; towns and universities were developing, and English was evolving from the old Anglo-Saxon and forging ahead as the generally spoken language. It is not strange then that John, "the most worthless of all English monarchs," should have had the Great Charter, the watchword of English freedom, wrested from him in 1215. Through it the rights of the commoner were guarded as well as those of the noble; the king's authority was carefully circumscribed; the peasant class were not to be dispossessed of their tools; and no one was to be arrested or deprived of his property without trial. With the way thus paved, the artisan, serf, merchant, and freeholder - the ignored nine-tenths of the nation - experienced increasing prosperity. Spurred on by abuse, fired by the radical utterances of the Lollard priests and other reformers, and incensed by the levying of a poll tax, the peasants simultaneously revolted (1381), even in remote districts, but were, on the whole, not immediately successful in bettering their condition.

During the fifteenth century, in civil war Lancastrians and Yorkists battled for the crown. While rival armies vied with each other in plunder and revenge, deprivation and starvation, accompanied by pestilence, took a heavier toll than war. Meanwhile influence and wealth were centering in the hands of a few great families. The Earl of Warwick was obliged to slaughter six oxen daily to provide food for his breakfast table; the Duke of Buckingham entertained some two hundred guests at a time; and the Earl of Berkeley traveled with one hundred fifty retainers dressed in livery. Between these extremes were the citizens of the towns, who, heading toward an industrial age, were impatient of the civil strife and foreign jealousies that interfered with their industry and commerce.

The political history of the English people reached a crisis in the seventeenth century, when the government passed from a monarchial to a republican form - a commonwealth. Although the Puritan régime under Cromwell restored confidence abroad and laid the foundation for a great commercial and colonial empire, it was beset by difficulties at home. When the commonwealth collapsed, a monarchy was reëstablished. The old theory of the divine right of kings, however, was modified by the Whig principle that kings rule by the will of the people and Parliament. Thus was reconfirmed the form of government that is truly a product of English political evolu- 
tion, and the type suited to the country. The legislative body is composed of the House of Lords, made up of peers, and the House of Commons, elected by the direct ballot of men and women who have attained the age of 21 .

From the sixteenth century through the nineteenth, England turned to colonization and planted colonies in America, India, and Africa, and in so doing became involved in a series of wars with rival colonizing countries. These battles were fought on European battle grounds, on the rocky heights above Quebec, in the remote valleys of the Mississippi, and on the plains of India. The American encounters included King William's War, Queen Anne's War, King George's War, and the French and Indian War. The Treaty of Paris (1763) ended the struggle with France. By it England obtained possession of France's colonies in America, secured islands in the West Indies, and gained a foothold in India. English restrictions on colonial trade precipitated the American Revolution. Walpole had remarked in 1763 that "our bells are worn threadbare with ringing for victories," but at the close of the American Revolution England's bells were silent.

The political history of Wales, Scotland, and Ireland is intricately interwoven with that of England and needs little separate treatment. Prior to the fifteenth century they were claimed but hardly ruled. The wild Welsh tribes, who were chiefly a mixture of Mediterranean and Alpine racial groups, resisted successfully the Teutonic invasions and continued to speak Gaelic and to hold to their old customs. Feeling no kinship with England, they resisted English rule, made repeated raids, and retreated into the mountain fastnesses. When their leader Llewellyn was killed in 1282 , they were brought under loose English rule. King Edward I presented his son to the Welsh as their prince and thereby won for the heir to the English throne the title of "Prince of Wales."

The conquering of the Scotch was a more difficult task. The highlanders were racially the same as the Welsh and Irish, but the lowlanders were Teutonic. At first the two groups felt little kinship, but opposition to England welded them into a political unit. In 1290 the Scotch kingdom became a fief of the English king. This arrangement, proving unsatisfactory, soon resulted in war. England was forced to acknowledge the independence of Scotland in 1328. For about three hundred years there was intermittent war between the two nations. Finally (1603), a Scotch king, James VI, became 
James I of England, and the two countries were united under one government.

Ireland was even harder to conquer than Scotland. In fact, it is a question whether Ireland was ever really conquered. By unscrupulous methods the Act of Union was concluded and signed by George III in 1800 , but it was a union of politicians rather than of the people. The people of England and Ireland remained separated and their relations constitute one of the most tragic pages in European history. England, however, had brought Wales, Scotland, and Ireland under one government, under which all have remained, except twenty-six of the thirty-two former provinces of Ireland, which became an independent commonwealth on December 6,1922 .

3. Economic Development. Although the United Kingdom has long been an industrial country, in it agriculture, though it has rapidly declined, remains an important occupation, and various kinds of crops are grown by intensive methods. The percentage of the people engaged in agriculture fell from 34 in 1811 to 28 in 1831 and to 10 in 1861. According to estimates, one-third of the agricultural laborers (including their families a million people) withdrew from the soil permanently between 1871 and 1901. Parts of England and Ireland are chiefly farming areas, but much of Wales and Scotland is too rugged for agriculture. Agriculture has long been blighted by absentee landlordism, which has been more detrimental to Ireland than to other parts of the kingdom. Beginning in the twelfth century, the English used any and all pretexts for invading Ireland, seizing its land and giving it to English landlords who usually continued to reside in England. These landlords took little interest in their tenants beyond exacting as large a rental as possible. It is estimated that in 1847 about one-third of the entire rental of Ireland was being paid to absentee landlords. When the tenants were unable to pay, they were speedily evicted. As a result, a large percentage of the population was continually on the verge of starvation. The potato, which Raleigh introduced into Ireland about 1585, furnished an abundant and easy food for the rapidly increasing population, which rose from $2,845,932$ in 1785 to $8,295,061$ in 1845 . Between one-third and onehalf of the people depended upon the potato for their food, and when this crop failed, as it did in the "Black Year of Forty-Seven," thousands perished and other thousands emigrated to America. During this memorable time the helpless tenants all over Ireland sank into 
despair, and at last died in their cabins or on the roads as they dragged themselves out in search of food. Pestilence, a virulent plague called the "road fever," fell upon the people.

During the latter part of the eighteenth century and the early part of the nineteenth, the enclosure system reached its apex in the United Kingdom. The peasants were deprived of their common, arable, pasture, and wood land, which was fenced for sheep and turned into game reserves. Although a few became agricultural laborers, thousands had to move, and the laborers and shepherds decreased from 965,000 in 1851 to 609,000 in 1901. They were unable to purchase land or to secure employment in the cities. Finally, the discovery that landlords possessed whole villages, dispossessed tenants at will, and turned the land into game wilderness; that the agricultural population was decreasing rapidly; and that thousands of tenants were existing in shacks unfit for human habitation, and laboring long hours for a bare subsistence, started Lloyd George on his reform program in 1890. The large holdings are being divided; tenants are now able to purchase the land they till, and are doing so. Between 1885 and 1910 some 1800 holdings of 300 acres or more were divided, and between December, 1918, and July 31, 1922, 17,511 applicants were provided with small holdings, aggregating 247,000 acres. Less than 3 per cent of the present holdings of England now exceed 300 acres.

The Industrial Revolution was of immense importance in the United Kingdom, and the transition from home-made to machinemade goods brought a great amount of suffering. A series of inventions changed the industrial matrix of the isles; the hand workers were rapidly thrown out of employment and appeared unable to adjust themselves to machine work. Because of a lack of laws and labor unions, women and children manned the factories; men found it difficult to secure employment and existed on the labor of their wives and children. A petition from the weavers made known their extreme distress during this time; they received no more than five shillings per week for a fourteen-hour day; most of them were a year's rent in arrears; their diet consisted of oatmeal and potatoes; they were practically destitute of clothing and asked from the government the means of emigration. From the days of Queen Elizabeth every parish had to provide for those who were unable to find employment. It can readily be understood that the burden of taxpayers grew heavier and heavier. Landlords and parish authorities 
tried to shift as much of the burden as possible by apprenticing children and shipping adult males to America.

With its huge coal and iron deposits, which made the Industrial Revolution possible, and its island base, the United Kingdom was destined to become the leading commercial nation. A mercantile system was developed that made British wares known the world over. Before the end of the nineteenth century London had become the financial center of the world, and English boats were carrying more than half the trade of all seas. Industrial cities grew at a rate ranging from 15 per cent to 25 per cent per decade, and between 1801 and 1901 greater London increased its population from 1,100,000 to $6,500,000$. Thus England especially became a country of industrial cities with millions of industrial workers who "look at a forest of factory chimneys, breathe heavy coal smoke and city dust, hear the endless rumble of industrial machinery. Their England means undersized bodies, disease, poverty, and squalor." 1

Being an industrial and commercial nation, Great Britain suffered greatly as a result of the World War. By 1919 its war debt was more than $\$ 26,000,000,000$. To this might be added $\$ 9,000,000,000$ loaned to its allies. In August, 1931, New York and Paris lent the British government $\$ 400,000,000$. In addition to its huge war debt Great Britain is confronted with an agricultural decline which has been steady for fifty years, increased cost of production, competition with France, which receives cheap coal from Germany, the rapid recovery of German commerce and the expansion of the commerce of the United States, frequent strikes (the coal strike in 1926 alone resulted in a loss of $\$ 275,000,000$ in wages and $\$ 1,500,000,000$ in production), a high natural increase of population amounting to about 207,000 per year, and an army of unemployed of about 2,000,000 people. From the economic point of view the United Kingdom appears to be approaching a crisis; the future is not bright.

No treatment of the economic situation of Great Britain would be complete without a brief reference to the Labor party, which is both political and economic. The Labor Movement had its inception in the Labor Representative Committee of 1900 , received its name in 1906, and adopted its present constitution in 1918. It has for its constituency about five and one-half million organized workers of whom four and one-half millions belong to seventy unions. Affiliated with the unions are the coöperative movements, affecting some

1 Bowman, Isaiah: The New World, p. 34. 
12 million to 15 million individuals. In proportion to population, Great Britain has twice as many of its workers (about 70 per cent of its adult wage earners) organized into unions as does the United States. Ramsay MacDonald has headed two Labor cabinets as prime minister, and, despite his sudden lapse of popularity with that group in 1931, will remain an outstanding figure in the history of the British Labor Movement. ${ }^{1}$

4. Religious Development. The religious history of the countries constituting the United Kingdom is one marred with wars, bloodshed, executions, persecutions, and discriminations. Of the ancient tribal religions, Druidism became the most firmly established. When Christianity - was introduced, many elements of Druidism were incorporated in the new faith, some of which remain today, especially in the rural sections of Ireland. Christianity in the form of Roman Catholicism, however, soon became firmly established, and Irish and Anglo-Saxon monks became famous for their learning and their missionary activities on the continent. After the Reformation, "heresies" began to drift into the British Isles and religious strife began. As a devout Catholic, Henry VIII tried to exterminate Lutheranism and other heresies within his realm, but marriage difficulties caused him to break with the Pope and start the Anglican Church, which soon became the established church of England. Catholics then experienced the same persecution that Lutherans and other Protestant groups had formerly undergone. Henry's daughter, Mary Tudor, tried to turn England back to the Pope and, by killing and persecuting dissenters, to establish the old order. She was followed by her sister, Elizabeth, who made the saying of Mass high treason, punishable by death. Not only Catholics but Puritans, Lutherans, Presbyterians, and all other dissenters from the Anglican Church were punished, driven out, or killed.

In the general religious struggle Scotland, adopting the theology of Calvin as interpreted by John Knox, became staunchly Presbyterian. Accordingly there were long periods of strife between the religious forces of England and Scotland. Ireland remained loyal to the Pope, and because of its loyalty suffered far more than Scotland or Wales. Because Ireland would not yield to English efforts to make it Protestant, its citizens suffered execution, exile, confiscation of estates, and loss of suffrage, paid excessive tithes to support the

1 For an excellent treatment of the British Labor Movement, see Davis, Jerome: Contemporary Social Movements, Book VII. 
English Church, and experienced numerous other kinds of punishments, sufferings, and discriminations. Catholicism flourished and became to the Irish not only a religion but a political party as well. In 1829 the Irish Catholics were emancipated, but continued to suffer many indignities. After the rebellion (1865-68) the Church of England was disestablished in Ireland. Nominal freedom of worship now prevails throughout the United Kingdom and the Irish Free State.

5. Education. As early as 425 we learn that monasteries were being founded in Ireland and that Greek and Latin flourished. In fact, it was said that "if any one knew Greek, it was assumed that he must have come from Ireland." The cathedral school at York in northern England has the distinction of having had as a pupil the famous Alcuin. His importance, however, rests on his work as a teacher in the palace school of Charlemagne, his service as an informal minister of education in the Frankish Kingdom, and the authorship of several texts. At his death in 814, many of the important educational centers of Europe were in control of his former pupils. The Danish invasions, however, greatly hindered educational development.

Prior to Queen Elizabeth's time (1558-1603) education was a function of the church. The church licensed teachers, supervised instruction, and, in short, controlled education. Support for education came either from religious and charitable sources or from private tuition. As religious controversies deepened, school teachers found that their faith was the all-important requisite and that their mission was to teach the accepted religious dogmas. Naturally, when religious houses were confiseated or otherwise hampered by the reformist movement, the administrative groundwork of education was swept away.

Two movements, though not directly connected with the church, deserve notice. The charity school movement, dating from 1699, maintained a system of schools for the lower classes and had as its objective the raising of the intelligence of the masses. A second voluntary movement was the Sunday School, designed to take children off the streets on Sundays and to provide them with religious and secular instruction. These served as the foundation for the voluntary schools which have been such a definite part of the educational system of the English.

In the nineteenth century education came to be regarded as a 
duty of the state. In 1601 the state had recognized a partial responsibility when, in the passage of the poor law, it made the teaching of apprenticed children obligatory and provided for the taxing of all persons to support schools for this purpose. The elementary educational bill of 1871 preserved existing voluntary schools, but made provisions for state-supported schools - board schools. In 1880 elementary education was made compulsory, and eleven years later largely free. At first the voluntary schools were merely assisted from the public treasury, but finally the state assumed the whole responsibility of secular education and brought tax-exempt property under taxation. Since the World War the principle of public control of schools has been steadily strengthened, though many details of the dual organization of voluntary and board schools remain knotty problems. In 1931 there were 11,347 voluntary schools out of a total of 20,747 elementary schools in England and Wales, giving instruction to more than one-third of the children. ${ }^{1}$

Advanced work is given at the universities of Oxford, Cambridge, Durham, London, Manchester, Birmingham, Liverpool, Leeds, Bristol, and Reading, having a combined enrollment in 1930 of 34,951 . Scotland has four universities, Ireland two, and Wales one. In these schools women are generally admitted on the same basis as men.

6. Social Development. We may assume that the different tribes of aborigines inhabiting England, Scotland, Wales, Ireland, and the other isles lived on a low social plane. The different invading hordes introduced new cultural elements which gradually produced higher social planes. With these invasions came wars, conquerors, hatred, prejudices, and a graduation of society from the lowest level to the royal family, which remains the apex of British social life.

The continued efforts of England to force Protestantism on Ireland led to numerous wars which practically depopulated northern Ireland. Part of this land was seized and settled by Protestant Scots who became known as Scotch-Irish. ${ }^{2}$ This treatment increased the hatred of the Irish for the English and also for the Scotch. In 1605 James I seized nearly all of the western section of Ireland and gave it to Protestant nobles. His son, Charles I, seized more Irish land, destroyed the wool trade of Ireland by legislation, and passed a

1 For a discussion of the more recent attempted legislation, see Selby-Bigge, L. A.: "Voluntary Schools," Nineteenth Century, Vol. CX, pp. 8-20.

${ }^{2}$ Professor Commons (Races and Immigrants in America, p. 32) says they "are very little Scotch and much less Irish." 
number of other discriminatory laws. Between 1691 and 1782 Ireland suffered dreadfully under many tyrannous laws that caused the destruction of religious freedom, the prohibition of the exportation of wool, and the annihilation of many minor trades. The peasants founded secret societies and tried to better their conditions by revolting, but failed. After the union with England under George III economic conditions grew even worse. Practically all industry was wiped out by discriminatory laws, the country became bankrupt, and the peasants practically perished. Under such treatment the Irish naturally developed a persecution psychosis, which manifests itself in an extreme loyalty to Ireland and the Catholic Church and a hatred for everything English. So deep-seated is this psychosis that Ireland's autonomous position has not remedied the situation, and the government is now trying to make Gaelic the language of the masses and to restore the Irish culture.

The Welsh, Scotch, and Scotch-Irish retain a certain amount of prejudice against the English, but it is very slight when compared with that of the Irish. Except in the Irish Free State, the people of the United Kingdom realize that their problems are mutual and are willing to solve them together. The general social conditions differ from country to country and from section to section, but the differences are submerged in the similarities.

That conditions in the United Kingdom are far from ideal is shown by the fact that from one to two million people are constantly out of work $(2,726,000$ in October, 1931$)$; that a sum of $£ 53,848,000$ was paid out for unemployment insurance for the year ending March 31, 1929 - five times that for 1921; that 2,140,000 persons in England and Wales, and 138,572 in Scotland, received domiciliary relief under the poor law for June, 1926; and that, according to the general agreement of the officials, several thousands of textile workers are permanently dislocated owing to the shift in manufacturing after the World War. According to press reports, conditions have grown worse since 1926, creating in the United Kingdom a very serious and dangerous situation.

S. K. Ratcliffe ${ }^{1}$ gives us a vivid picture of conditions in England which may be considered typical of not only England but other parts of the kingdom. According to this authority, to have one good meat dinner a week is a high attainment for tens of thousands of British workmen. Tea is the universal drink and bread the main food. Un-

1 Immigrant Backgrounds, edited by H. P. Fairchild, Chap. II. 
doubtedly too much money and time are spent in the saloons, which not only the men and boys, but the women and girls frequent. "The English rural worker," writes Ratcliffe, "is a member of a submerged class, whose forefathers have lived in servitude for ages. He earns a pitifully small wage, is fed on a diet more meager than the worst known in America, and lives in a cottage that may be picturesque but is certainly minute and primitive, while he has been conscious from childhood of his helplessness under the weight of that ancient feudal authority still surviving in the landlord and the parson." He has had some schooling, and he and his wife can vote; nevertheless he remains only one step removed from serfdom. The better class of workers, of course, live better, "but no comparison could be made today between the table of even a well-paid English artisan and that regarded as a decent minimum by the average manual worker in the United States and Canada." 1

The cities and towns largely grew without plans, but the homes of workers, made of dull red brick or grey stone, tend to follow straight lines. They are built back-to-back without thought of ventilation. Frame houses are non-existent, and single dwellings are hardly known. Gas is universally used; electricity is a luxury found only occasionally among the middle class. Bathtubs and running water upstairs are unknown in the majority of working-class homes. Indeed, conditions among the working class of the United Kingdom (the class from which most of our immigrants have come) are hard. ${ }^{2}$ The people are accustomed to doing things on a small scale. They have long remained a submerged group, accustomed to the royal family and a class system.

7. Immigration and Emigration. Despite the fact that some 14,000,000 Britishers emigrated between 1853 and 1920, the population of the United Kingdom is estimated to have increased from 16,300,000 in 1801 to $44,174,601$ in 1921 . The decadal increase in population, however, has been decreasing, and already some writers are classifying England with France - as a dying nation. The population of Scotland and Wales appears to be increasing normally, but that of Ireland has been decreasing since 1841. On that date the twenty-six counties which now compose the Irish Free State had a population of over 6,500,000; in 1926 they had only 2,972,802. Be-

1 Immigrant Backgrounds, edited by H. P. Fairchild, p. 18.

${ }^{2}$ A discussion of English rural life will be found in Terpenning, W. A.: Village and Open-Country Neighborhoods, Chap. VI. 
tween these dates the town population decreased from $1,267,000$ to $1,095,000$ and the rural from $5,281,000$ to $1,878,000$. The chief decrease came between 1845 and 1847, when between 200,000 and 300,000 died and a like number emigrated as a result of the potato famine. In 1851 more than 250,000 Irish emigrated, and 2,390,000 between 1846 and 1861 .

To what extent emigration has affected the population of the United Kingdom we do not know. During the Napoleonic Wars intercontinental emigration, except to Canada, was insignificant. Peace brought unemployment and stimulated emigration. The shift from agriculture to industry during the early part of the nineteenth century and the adoption of a free-trade policy threw many skilled workers out of employment. "High rents and heavy taxation, exorbitant tithes, and grinding leases followed." The number of emigrants jumped from 2081 in 1815 to 103,140 in 1832 , and to 128,344 in 1842. During the period $1815-50$ some $1,829,000$ Irish, 430,000 English, and 110,000 Scotch emigrated. The number of emigrants continued to increase rapidly, being 228,345 in $1873,320,118$ in 1883 , and 469,640 in 1913. Naturally the World War checked the movement, but in 1929 it totaled 263,480.

It seems certain that most of these emigrants during the nineteenth century and early part of the twentieth came to the United States. Ferenczi ${ }^{1}$ thinks the proportion was about three-fifths. It is estimated that in 1790, the time of our first census, about 90 per cent of the people were of British origin. According to estimates, there were $38,727,593$ people known as foreign white stock in the United States in 1930 . Of these, 3,086,522 were Irish, 2,522,261 English, 899,591 Scotch, and 236,667 Welsh. Of the foreign-born whites in the United States in 1930, there were 923,632 from Ireland, 808,672 from England, 354,570 from Scotland, and 60,205 from Wales.

The emigration from the United Kingdom to the British colonies has not been so marked. The movement to Canada rose from 680 in 1815 to 109,680 in 1847 . It dropped to 2469 in 1859 , but rose to 196,278 in 1913 and to 99,717 in 1924 . The movement to other American countries is relatively unimportant. In 1825 only 485 passengers sailed for Australia and New Zealand. Because of state aid, the number to Australia rose to 54,818 in 1853 , and the discovery of gold took 77,526 the next year. A decline culminated in 11,695 in 1871 , but the number rose to 96,800 in 1912 , and to 58,500

${ }^{1}$ International Migrations, Vol. I, p. 101. 
in 1924. For the period 1840-75 908,341 people embarked for Australia and 194,556 for New Zealand, and for the period 1906-24 615,750 for Australia and 168,659 for New Zealand. Emigrants from the United Kingdom have shown little desire to go to South Africa. Between 1821 and 1841 the annual number hardly exceeded 500, and between 1877 and 1924 it reached only 809,476.

Over one-third of the emigrants from the United Kingdom to the United States returned home. Canada compares favorably with the United States, but the number returning from Canada has increased since 1910. About half of those going to other American countries return. Large numbers return from Australia and New Zealand, in some years over a third. From South Africa, about three-fourths return, and in some years more return than enter.

During the seventeenth century Great Britain found colonization to be a good policy. It offered an opportunity to get rid of paupers and criminals, it furnished a refuge for the discontented and venturesome, it gave religious zealots a place to expend their energies, it was profitable to the merchants, and it became a source of national pride. Thus Massachusetts became a haven for the persecuted Puritans, Pennsylvania for the Quakers, Maryland for the Catholics, and Virginia for the Cavaliers. In 1819 Parliament voted $£ 50,000$ to send emigrants to South Africa. From time to time many emigrants were aided in going to other British colonies. Up to 1924 964,299 people were aided in going to Australia. The Empire Settlement Act (1922), an agreement between the United Kingdom and its colonies to aid British citizens to settle in the colonies, apparently has not worked well. During the three years following its passage, an average of 275,000 emigrants went out. A yearly average of 123,000 people went to places within the British Empire, but a total of only 45,000 received state aid.

Economic, religious, political, and social conditions have all been potent factors in emigration from the United Kingdom. Political and religious conditions have gradually decreased in importance, but economic conditions continue to play an important rôle.

In comparing the people of the four chief countries which comprise the United Kingdom, certain general attitudes appear to be manifested, although these vary from class to class within each country. All except a part of the Welsh, a few highland Scotch, and a few Irish, who speak dialects of the ancient Gaelic, use English. All have been accustomed to a compulsory school system, participation 
in government, and other characteristics of civilization found in the United States. Yet their specific backgrounds, and consequently their attitudes, differ. The Welsh emigrant is perhaps a miner and is accustomed to being a member of a low economic and social order. He is perhaps a bit emotional, but on the whole is stable and appreciative of the opportunities in America. Although he has grown up almost in the shadow of London, perchance he will have to learn English in America. This does not thwart his desire for citizenship. In 1920 the Welsh headed the list (72.9 per cent) of naturalized citizens.

A rugged land, vigorous climate, and lack of wealth have developed the hardy Scotchman. The brawny highlander and his thrifty brothers of the lowlands "inherit" from their warring ancestors their loyalty to clan and country, their energy and frugality. In this country the Scotchman is regarded as a stubborn, cold-blooded business man. He is endowed with a strong will power and determination to succeed. In religion he is almost sure to be Presbyterian, whether he comes from Scotland or from the so-called Scotch-Irish group around Ulster, Ireland. The Scotchman is not ashamed of being a British subject, but he dislikes to be mistaken for an Englishman. In emigrating to the United States, he considers that he has come to a country of great opportunities. Considering that he speaks English and has a background of Anglo-Saxon culture, he is somewhat slow in becoming a citizen of the United States.

Ordinarily the Englishman is regarded as somewhat bigoted. $\mathrm{He}$ remembers that the English are the ruling group of the Isles, that his flag is one which all nations respect, that the colonies are only parts of the British Commonwealth of Nations, and that the United States was once a group of rebellious colonies of England. He has a feeling that practically everything in England is superior to what is found in the United States. According to Ratcliffe, "the British are endowed with an almost unlimited self-assurance, a sense of their own rightness, a conviction of their superiority to all 'foreigners,' a complacency which refuses to admit that any portion of the earth can be equal to their own land. And this self-assurance is above all class distinctions." 1 If the English emigrant is a member of the upper group, he is socially obliged to be a member of the Anglican Church, as dissenters continue to be looked down upon. Regardless of what class he comes from, he finds so many things in the United States similar to those he is used to that he does not see any reason 1 Immigrant Backgrounds, edited by H. P. Fairchild, p. 25. 
why he should be considered an immigrant. Yet he discovers many differences. Distances are exceedingly great, and affairs are conducted on a larger scale than in England. As a result of his attitude of superiority, he has been very slow in becoming a citizen of the United States, and for this he has often been severely criticized. Before the United States entered the World War, English immigrants showed unusual interest in naturálization, presumably to escape the British draft law.

The Irishman presents the greatest contrast of the four groups. Because of religious persecutions, absentee landlordism, and government without representation, he may be said to have developed a neurosis. Home conditions have created in the Irishman an almost general pessimism, hatred, and despair, and wherever he goes he generally carries with him a lasting bitterness toward England which he implants in his children and grandchildren. Perhaps because of Pat and Mike jokes, the current belief is that the Irishman is a jovial, good-natured, optimistic type of person, but a closer study seems to show that this is an outward compensation for his inward pessimism. His struggles have taught him how to deal with men. Although we cannot say that the Irish have ruled England, American cities offer a demonstration of their ability. As a ward politician, a labor boss, a policeman, or a salesman, the Irishman shows that he is adept in controlling men. He realizes that in union there is strength, but his loyalty is based on personal considerations, rather than on platforms or principles. He is seldom in a hurry and generally has time for a chat, a smoke, a drink, or an accommodation. Tomorrow can largely take care of itself. He is loyal to the Catholic Church because through long years of suffering it has been the center, not only of his religious life, but of his political and social life as well. He remembers the great country that Ireland once was - a center of university life, intellectual activity, cultural ascendency, and religious zeal. For its decadence, England is blamed. He comes to us as an admirer of the United States. Quickly and eagerly he becomes a citizen. 


\section{QUESTIONS, EXERCISES, AND PROBLEMS FOR INVESTIGATION}

1. What are the distinguishing characteristics of the Teutonic, Alpine, and Mediterranean groups?

2. What racial elements are found in the "wonderful mongrel"?

3. How did Great Britain come to have an underlying stratum of Latin culture?

4. What were the outstanding effects of foreign rule upon the English of the eleventh century?

5. Describe briefly the evolution of the English political system and account for the probable lack of sympathy among the Welsh, Scotch, Irish, and English.

6. Explain: "Catholicism flourished and became to the Irish not only a religion, but a political party as well."

7. How have internal conditions shaped British emigration policies?

8. In what respects do immigrants from Great Britain differ in their general behavior patterns?

9. Make a study of Great Britain's population problem. References. Ross, John: "A Policy of Imperial Migration," Nineteenth Century, Vol. XCVIII, pp. 507-14; Close, Charles: "Population and Migration: A Statistical Study with Special Reference to the English-speaking Peoples," Geography, Vol. XIV, pp. 1-24; Cox, Harold: "The Peopling of the British Empire," Foreign Affairs, Vol. II, pp. 117-29; Jose, Arthur: "Peopling the Empire," Edinburgh Review, Vol. CCL, pp. 242-56; Thompson, Warren: "Britain's Population Problem as Seen by an"American," Economic Journal, Vol. XXXVI, pp. 177-91; and Lindsay, J. A.: "The Races of Ireland," Nineteenth Century, Vol. XCVI, pp. 400-11.

10. What additional information do the following articles give on background conditions in Great Britain? Barbour, John: "Scotland The New Dominion," Edinburgh Review, Vol. CCXLIX, pp. 211-31; Vaughan, H. M.: "The Welsh Language in Life and Education," Edinburgh Review, Vol. CCXLVII, pp. 262-73.

11. Discuss the changes in the economic situation of the United Kingdom. References. Siegfried, André: "The Passing of England's Economic Hegemony," Foreign Affairs, Vol. VI, pp. 525-40; Clark, C. G.: "Statistical Studies of the Present Economic Position of Great Britain," Economic Journal, Vol. XLI, pp. 243-69; Tomlinson, F. L.: "The Allotment Movement in Scotland during the War," International Review of Agricultural Economics, 1925, pp. 73-88; Plunkett, Horace: "Ireland's Economic Outlook," Foreign Affairs, Vol. V, pp. $205-18$. 
12. Report on the religious conditions of the United Kingdom. References. Henderson, G. D.: "Foreign Religious Influences in 17th Century Scotland," Edinburgh Review, Vol. CCXLIX, pp. 342-53; Inge, W. R.: "The Present Condition of the Church of England," Edinburgh Review, Vol. CCXLI, pp. 1-18.

13. Prepare tables or charts showing British emigration by countries - its volume, direction, and periods. References. Ferenczi, Imre: International Migrations, Vol. I; Morehouse, Frances: "The Irish Migration of the Forties," American Historical Review, Vol. XXXIII, pp. 579-92; Stephenson, George M.: A History of American Immigration, Chap. II. 


\section{GERMANY AND AUSTRIA}

1. General Description. The peoples inhabiting the Republic of Germany and the Republic of Austria were at one time a united people, but were separated and kept so by Bourbons, Hapsburgs, and Hohenzollerns. They now desire to be united again, but their union is prevented by the Versailles Treaty and League of Nations. Biologically and culturally they are closely related, speaking the same language and having the same social institutions. It is therefore expedient to treat them together. With these countries should be included the Free City of Danzig, which was a part of Germany until 1920, and the Grand Duchy of Luxemburg, which was a part of the German Customs Union and largely dominated by Germany until the end of the World War.

Germany and Austria are located in the north-central part of Europe. Owing to the fact that the northwestern part of Germany is near large bodies of water, the climate is less severe than would be expected. Harbors on the Baltic Sea, however, are ice-blocked during part of the year. The farther eastward one goes, the lower one finds the temperature during winter. Yet there is a considerable range of climate; when the plains of East Prussia are still covered with snow, the Rhine Valley is in the midst of spring. Since Austria lies south of Germany, it has a warmer climate. Thus the two countries offer a considerable range of climate, and in them a number of different kinds of crops can be grown. The soil, however, is generally poor, but with intense cultivation and the use of large quantities of fertilizer, luxuriant crops are produced, especially in Germany. Most of the land is level, with mountains here and there of enough beauty to attract many tourists.

Germany contains 185,889 square miles of land, or is a little over two-thirds the size of Texas. In 1925 it had a population of $62,348,-$ 782 (estimated at $64,036,000$ in 1929). Austria has an area of 32,369 square miles, a little less than that of Maine, and a population of $6,526,661$ (1923). Both republics date from 1918, Germany resulting from the defeat of the German Empire, and Austria from the separate 
organization of the German-speaking people of the old AustroHungarian Empire. Both countries lost considerable territory as a result of their defeat in the World War. Germany was deprived of its colonies and 27,275 square miles of continental territory with 6,471,581 inhabitants. France, Poland, Denmark, Belgium, and Czechoslovakia now possess lands formerly included within the German Empire. As a result of this transfer of territory, many nonGerman people were united with their own nationalistic groups, but many Germans were forced to live under a foreign flag. This arrangement has perhaps sowed seeds for future wars, especially with Poland, which forcibly annexed territory that voted to remain with Germany. Certainly Germany will not long submit to the Polish corridor which separates its main territory from East Prussia. Danzig, containing 754 square miles and a population of 407,517, 93 per cent of whom speak German, was made a free city, but it is dominated by Poland. The Grand Duchy of Luxemburg, containing 999 square miles of territory and a population of 285,524 , is now in an economic union with Belgium. All told, Germany lost 12.4 per cent of its former area and 12 per cent of its population, 58 per cent of whom spoke German.

The Austria of today is only a shadow of the pre-World War empire of Austria-Hungary, which had 261,259 square miles of territory and a population of $51,000,000$. The Dual Monarchy contained not only the present Austria, with Vienna, one of the most brilliant political, industrial, commercial, financial, and art centers of the world, as its capital, but Hungary, most of Czechoslovakia, Transylvania, Polish Galicia, Slavonia, the Trentino, Herzegovina, Bosnia, and the Banat territories. As a result of this general transfer of territory, formation of new states, and reëstablishment of old ones, many people were returned to their own groups, but many Germanspeaking Austrians were forcibly separated from their language group. Austria was reduced from 116,000 to 32,000 square miles, most of the former Austrian territory going to Czechoslovakia, Yugoslavia, Poland, and Italy. A change in the Burgenland district took some 218,000 people from Hungary and added them to Austria. Disposition of the Klagenfurt basin, inhabited by Austrians and Slovenes, was left to a plebiscite. By virtue of the vote in 1920, it joined Austria.

Austria has made three attempts to unite with Germany. France and some of the small nations oppose such a union. The two countries 
united would give Germany a territory larger by 5094 square miles than the pre-war German Empire, and a population of 70,564,000.

The people composing the German and Austrian republics are classified as Teutonic, but actually they are a mixture of several racial groups. The northern section is inhabited chiefly by the tall, long-headed, light-haired, blue-eyed people commonly known as "Nordic" (according to Professor R. B. Dixon a blend of Caspian and Mediterranean peoples), while the southern part has a heavy Alpine population. Thus the people of southern Austria and Germany are more closely related ethnologically to the people of the northern part of France and Italy than to their own countrymen of the north. Underlying both the Nordic and the Alpine group is an ancient stratum of darker groups, thought by some to be ProtoAustraloid and Proto-Negroid. Pools of Slavs and other racial groups exist here and there, and the prevailing blood in Prussia appears to be Slavic rather than Teutonic.

By no means all of the German-speaking people reside in Germany and Austria. There are about 9,000,000 in the United States, $3,500,000$ in Czechoslovakia, 2,200,000 in Poland, 1,600,000 in Russia, 1,500,000 in France, 900,000 in Rumania, 700,000 in Yugoslavia, 400,000 in Brazil, 270,000 in the other Baltic states, 250,000 in Italy, 250,000 in Hungary, 115,000 in Belgium, 100,000 in Canada, and 100,000 in Argentina. There are also about 2,600,000 Germanspeaking Swiss, and a number of German-speaking people in the former German colonies. ${ }^{1}$

Germany and Austria have few natural boundaries. For centuries their territory has been subjected to invasion, fighting, and the inevitable crossing of the different tribes of Teutons, Slavs, Latins, Huns, Turks, Tartars, and Asiatic mongrels. Meanwhile the German tribes did not always remain at home, but invaded the lands of their neighbors and enemies, sometimes ruling and always mingling their blood with others. This explains why so much Teutonic blood is found in France, Italy, Hungary, Czechoslovakia, Russia, and other neighboring countries.

2. Political Development. As a nation Germany dates from 1871. Under Charlemagne and the Holy Roman Empire, the Germanspeaking people of Europe were brought under the same political power. In 955 Otto I defeated the Hungarians near Augsburg and organized a part of the Bavarian Duchy into a separate district

${ }_{1}$ Compare Bowman, Isaiah: The New World, p. 268. 
known as the Austrian Mark. Rudolf, the first important man of the Hapsburg line, was elected ruler in Germany in 1273. He seized the duchies of Austria and Styria, and with them founded a nucleus for the future extensive and powerful Austrian Empire. The Germanies had fallen apart with the downfall of the Hohenstaufens, and when Charles V was elected emperor in 1519 there were about 300 Germanies. The Holy Roman Empire at this time was composed chiefly of German-speaking people, but there was little feeling of unity among the different groups. Charles tried to unite the German-speaking people, but there were so many free cities and principalities, all hating the Holy Roman Empire and quarreling among themselves, that no bond of union seemed possible beyond a certain similarity of language and customs.

For two centuries prior to 1683 much of the energy of the Germanspeaking peoples was spent fighting the Huns, Turks, and other Asiatic hordes. Many of the Slavic groups sought protection under Teutonic wings, and by the fifteenth century both Bohemia and Hungary were dependencies of Austria. Charles's three successors (1556-1612) witnessed the ever widening gulf between Catholics and Protestants. In 1617 Ferdinand, an ardent Catholic, was crowned king of Protestant Bohemia. This marked the beginning of that gigantic struggle known as the Thirty Years' War. The territory of the Germanic peoples now became the battle ground of the nations, as it had been before, and Spanish, Italian, Dutch, Swedish, Slavic, and Hungarian soldiers ravaged the land. According to records, $13,000,000$ of the $17,000,000$ Germans perished. Of the 500,000 people of the Palatinate, only 43,000 survived. About five-sixths of the German villages were destroyed. Throughout much of the territory, agriculture, industry, commerce, and education were wiped out. It is reported that one could wander for miles without seeing a living creature except ravens and wolves. The weak imperial authority in Germany was destroyed, and national feeling was dead. Hatred of Austria, which had fought against the Germans and which was becoming not only powerful but also a favorite daughter of the Pope, constituted a vague bond of unity.

The Thirty Years' War gave the Hohenzollerns, who previously had been no more conspicuous than many other potentates, an opportunity to establish their leadership. The German-speaking people were now definitely divided between Hapsburgs and Hohenzollerns, and were often fighting between themselves and with the Bourbons. 
While the horrors of the Thirty Years' War were still fresh in the minds of some of the sufferers, the Rhine provinces were overrun by the French. Louis XIV, the "most Christian King," ordered his soldiers to make the German territory along the Rhine one vast desert. They obeyed his command, destroying practically everything that had escaped the Thirty Years' War.

Maria Theresa came to the Austrian throne in 1740, the same year that Frederick the Great became King of Prussia. Frederick, maintaining that he was the rightful heir to the Austrian throne, seized Silesia and held it in defiance of half of Europe. Maria Theresa, however, was not to be outdone; consequently the Seven Years' War broke out in 1756. Austria had become very powerful under the Hapsburgs and had added Styria, Carinthia, Carniola, the Tyrol, Bohemia, Silesia, Moravia, part of Hungary, Croatia, Slavonia, Rumania, Transylvania, Belgium, the Netherlands, Milan, and the Sicilies to its domain. During the Seven Years' War the struggle reached gigantic proportions, involving not only the territories of Austria and Prussia, but France, Poland, Russia, Sweden, England, and even the American colonies. Again the territory of the Germanspeaking peoples became a battle ground. Forty-two years later Napoleon I overran the country, humiliating the Germanies as never before, tearing their states asunder and parceling them out to his favorites. It was during these wars that France annexed AlsaceLorraine, which had long been considered German territory, and before that time part of the Holy Roman Empire.

During a large part of the eighteenth century, then, the Germanies were still disunited. The different German states had so long been pawns of Bourbon, Hapsburg, and Hohenzollern rulers that the desire for a united Germany was continually frustrated, and at times all but dead. In 1834, however, the Zollverein, or customs union, was signed by Prussia, Saxony, Bavaria, and fourteen other states. This led to a more definite national feeling among the Germanies, which became rampant in 1848-49. Efforts to block this desire for unification continued, but the university professors and liberals remained faithful to their convictions. Finally the masses became disgusted with conditions; uprisings of workingmen and peasants became frequent, revolutions followed one another in quick succession, and demands for constitutions and republics became the order of the day. For a time conditions appeared hopeless, but the influence of the Zollverein, the work of Moltke, Roon, and Bismarck in 
building up a strong military machine, wars with Denmark and with Austria, brought a union of all the northern German states. The four southern German states joined the northern states in the FrancoPrussian War of 1870-71. Thus, just 175 years after the accession of a Hohenzollern to the throne of Prussia, and in the Palace of Louis XIV, at Versailles, which for centuries had been the meeting place for the forces that had continually humiliated the Germanies and kept them from uniting, peace was signed and Alsace-Lorraine returned to its original possessors.

This war served to intensify the bitterness between France and Germany, and was one of the links in the causal chain leading to the World War. Vindictive patriotism became rampant, and as a result of this war the different countries of Europe burdened their people more and more with armaments.

Three years before the Franco-Prussian War, Austria and Hungary formed the Dual Monarchy, with the emperor of Austria as king of Hungary. Thus a few Germans in Austria and a few Magyars in Hungary were ruling several Slavic groups which far outnumbered their rulers. Austria-Hungary continually played one Slavic group against another, and so prejudiced them against each other that little effort to unite and revolt was manifested. The Franco-Prussian War caused the peoples of Europe to become more conscious of race and nationalism, and Ireland, Poland, Norway, Finland, and the Balkan states began to strive harder for self-rule. This increased the governmental problems of both Germany and the Dual Monarchy. Some of the people in Slesvig wished to be returned to Denmark; others continued to complain because of the forced annexation of Hanover in 1866, while some of the citizens of Alsace-Lorraine remained loyal to France; but most serious of all was the fact that three and one-fourth million Poles continued to dream of nationalism and refused to be Germanized. As the Slavs and other groups within the Dual Monarchy could not understand each other's language very well, and had religious and other differences, Austro-Hungarian rulers continually magnified and played upon these divergences. It is natural that the Dual Monarchy, with Czechs in Bohemia and Moravia, Poles and Ruthenians in Galicia, Slovaks in western Hungary, Serbs and Croats in Croatia and Slavonia, Slovenes in Carniola and Styria, Italians in Lombardy-Venetia, Rumanians in Bukovina and Transylvania, should wish to suppress nationalism and the desire for self-rule. 
The problem of ruling subject people and the desire to expand in the east tended to bring the rulers of Germany and the Dual Monarchy closer together. But the chief factor was the desire to protect themselves against the powerful alliance of France, Great Britain, and Russia. Better to do this, the Triple Alliance, consisting of Germany, Austria-Hungary, and Italy, was formed. The efforts of Germany and the Dual Monarchy to suppress race and national consciousness in their subject peoples really caused it to grow. When the World War eame, these subject peoples saw their opportunity to strike for freedom, and in so doing brought about the undoing of their masters.

3. Economic Development. The early German tribes lived in a kind of economic communism. Pasture and wood lands and general property belonged to the tribe rather than to individuals. The tribal chiefs generally set the tasks, directing what crops should be planted. After passing through the period of Völkerwanderung, they settled down to more permanent methods of agriculture. Being a prolific people and occupying a region of rather poor soil, the Germans began about seven hundred years ago to wrest gradually from the Slavs the land east of the Elbe Valley, the boundary between Teutons and Slavs. During the twelfth and thirteenth centuries a string of cities - Lübeck, Weimar, Rostock, Stralsund, Greifswald, Stettin, Kolberg, Danzig, Königsberg, Memel, and Riga - was established by German traders on territory conquered by Teutonic knights. Commerce developed rapidly, and danger from pirates was removed by the powerful Hanseatic League.

Germany became a nation too late to secure territory in America for colonization. Since the lands in America were already in the possession of Spain, England, France, and Portugal, Germany's rapidly increasing population was foreed into intensive agriculture. Having an abundance of natural resources, the country developed into a manufacturing and commercial power during the Industrial Revolution. The Industrial Revolution, however, reached Germany much later than some of the other eountries, so that when it began to expand eommereially, it found that other nations had aequired a monopoly of foreign commerce. Furthermore, Germany was handicapped because it had no colonies.

Realizing that his opposition to colonies had been a mistake, Bismarck began, about 1871, to work toward establishing colonies in Africa and elsewhere. These proved to be a drain on the national 
treasury but a source of revenue to the merchants and exporters. In the commercial world Germany started with a decided disadvantage; but it soon became the chief rival of Great Britain. Indeed, its rapid industrial and commercial development, especially its advancement toward India and China by way of the Bagdad Railway, was one of the chief causes of the World War.

More than Germany, Austria remained an agricultural nation. Its energies were largely spent in gaining adjoining territory and exploiting those over which it ruled. Owing to the extent of its territory and the variety of its natural resources, it became an economically well-balanced nation and was uniting with Germany in industrial and commercial expansion.

The World War brought disaster to Germany and the Dual Monarchy. Next to the heavy reparations, the details of which have never been settled, perhaps the hardest blow to Germany was the loss of territory to Poland, which includes the rich Silesian coal field, which accounted for 23 per cent of Germany's coal production, and the rich mineral, forest, and agricultural region around Posen, where onesixth of Germany's potatoes and one-tenth of its grain were produced. The loss of Alsace-Lorraine meant a loss of some 20,000,000 tons of iron ore, 200,000 tons of potash per year, and a prosperous population. The Saar coal mines, which produce about 13,000,000 tons per year, have been forfeited to France for some fifteen years more. In Danzig Germany lost a leading Baltic port. The loss of Slesvig was of strategic rather than of economic importance. Thus, besides losing colonies, ships, and whatever the Allies could seize, Germany lost "from 12 to 15 per cent of her agricultural production, 10 per cent of her manufacturing, and 74 per cent of her iron-ore production." 1

There is now little doubt that Germany will eventually recover much of its economic losses. Geographic fate has placed it in the center of all European problems, but its enemies in war become its customers in peace. Being ringed about with thirteen nations, which contain eighteen cities having a total population of 4,000,000 within a 300 miles wide belt, and having the advantage of the short haul because such desirable markets as Russia, Poland, Czechoslovakia, Switzerland, Austria, Denmark, and the Balkan states are at hand, Germany has a decided commercial advantage, for these countries need German textiles, fertilizers, fuel, and iron and steel goods.

${ }^{1}$ Bowman, Isaiah: The New World, p. 275. 
Most of Germany is a plain. About one-half of its area is under cultivation, one-fourth in pasture, and one-fourth in forest. The richest agricultural region and densest agricultural population are along the Rhine Valley. Along the Baltic coast the soil is sandy, being of fluvio-glacial origin, and in most of the northeast, sandy soil occurs with a deficiency in rainfall. Agriculture, however, is of great importance and, combined with industry, has enabled Germany to support a dense population (population density, about 345 per square mile) and become very powerful. The population is about 65 per cent urban. The large cities, especially the industrial cities, have grown rapidly. Within the forty-year period preceding 1910 the cities of 100,000 or over increased from 4.8 to 21.3 per cent of the total population, and within the thirty-year period following the Franco-Prussian War Berlin doubled its population.

The Allies forced Austria to abolish universal military service and to limit its army to 30,000 men; to surrender all vessels and aircraft and to restrict manufacturing and trading in war materials to a specified limit; to agree to reparations payment; and to deliver live stock to Yugoslavia, Rumania, and Italy.

When Austria was thrown on its own resources, the crown dropped to one fifteen-thousandth of its gold value. Starvation and revolution became imminent, and this country appealed to the League of Nations. An independent bank was created with a loan of $£ 25,000$,000, underwritten by Great Britain, France, Italy, and Czechoslovakia. This brought about better conditions and secured for Austria political and economic independence. Owing to the radical break with the past and the influence of the communists, socialists, city proletariat, and landless peasants, recovery has been slow. Hostilities broke out in July, 1927, and relations between urban and rural populations remained strained for many months.

From the economic point of view the war has left Austria in a sad plight. Between 1880 and 1910 its population increased rapidly, that of several towns from 60 to 120 per cent. The population is now overbalanced on the urban side; Vienna, with 2,000,000 inhabitants, has about one-third of the population of the entire nation. About one-third of the population is engaged in industry, one-third in agriculture, and one-eighth in commerce. About 24 per cent of the land is under cultivation and 38 per cent in forests. The principal source of income is from the forests. Austria imports most of its wheat, corn, barley, rye, and other food products. The loss of its natural 
resources has left its industries in a critical condition. Austria has very little iron and is now importing about 7,000,000 tons of coal per year. Most of its imports come from neighbors, who, in turn, take about one-eighth of its exports. Austria's economic future seems to demand that it become a part of Germany. In March, 1931, these two countries attempted an economic union, but the movement created so much apprehension in France that it was abandoned in September, 1931.

4. Religious Development. The early tribes of Germany and Austria were pagans and worshiped many kinds of gods. The names of some of these gods are preserved in a modified form in the days of our week. Many of the religious beliefs of the Germanic peoples were highly ethical and idealistic. During the spread of Christianity, Roman Catholicism was largely forced upon the Teutonic peoples, but since it was an economic burden and mainly foreign to their cultural traits, the Reformation was almost inevitable. As German territory was a battle ground for political wars, so it was for religious strife. Roman Catholics, Greek Catholics, and Protestants within and without fomented endless trouble. The Peace of Augsburg (1555) was supposed to have settled the religious question in Germany, but it aided rather than abated the Thirty Years' War and the Seven Years' War, because of its inherent weakness. According to it, Germans were to be either Roman Catholics or Lutherans; no provision was made for any other religious group. The princes were supposed to have the power to determine the religion of their subjects, and the people were expected to change religious beliefs every time there was a change of rulers with a different faith.

Perhaps because Austria was near the center of the Roman Catholic stronghold, upon which it could rely for protection from the Mohammedan Turks and Greek Orthodox Russians and other Slavs, it became and remains a strong Roman Catholic unit. After the Reformation Germany, on the other hand, became dominantly Protestant. Thus religious beliefs entered to divide further the Germanspeaking peoples and to hinder their unification.

In the struggle between Italy and the Pope, when he was removed from temporal power, Bismarck refused to participate. The Catholics in Germany became incensed at his attitude, and this led to increased hostilities between church and state, which came to be known as the Kulturkampf. In 1872 Bismarck expelled the Jesuits from Germany and broke off diplomatic relations with the Vatican. 
During the next two years the so-called May laws were passed, requiring future officials of the Catholic Church to be trained in German state. schools and to pass a state examination. The Catholic (Center) party, which had been formed years before, became powerful and continues so today. By 1886 practically all the anti-clerical laws had been repealed and freedom of worship guaranteed. Some of the states under the empire had what might be considered a state church, but freedom of worship was guaranteed, and in some sections even Jewish synagogues were state supported. Today, about 64 per cent of the population of Germany and 3 per cent of the population of Austria are Protestants; 32 per cent of the population of Germany and 94 per cent of the population of Austria are Roman Catholics. Freedom of worship prevails in both countries, but religious prejudice lingers on.

5. Educational Development. The early schools among the German-speaking people were largely developed by Catholic priests. The priests, being the only people who could read, naturally became the advisers to the Teutonic overlords. Since they spoke and taught in Latin, there was a fusion of Roman and Teutonic cultures.

Between 529 A.D., when the pagan schools were suppressed, and the Reformation, the church held a monopoly of education. During this time only those who were to be churchmen and statesmen were educated, while the masses remained in colossal ignorance and manifested practically no interest in education. With the Reformation and the printing press came the demand for a different kind of training - the education of the masses, and that in the vernacular instead of Latin. Luther's views led him to launch an active campaign for free, compulsory schools in which instruction would be given in the vernacular. In 1559 Württemberg organized a complete school system which provided for elementary schools for both sexes, with instruction given in the vernacular, Latin secondary schools, and colleges or universities. These schools were to be under the church, but the church was under the state, and therefore subjected to state regulations. Württemberg's example was soon followed by a number of other German states, including Catholic Bavaria. In 1713 William I became King of Prussia, and in him universal education found a hearty supporter.

William's son, Frederick the Great, was even more progressive in his educational ideas than his father, and through his efforts there resulted better schools, better trained teachers, a centralization 
movement which brought the modern German Gymnasium, and finally the separation of the schools from the churches. In 1808 a Department of Public Instruction was organized as a part of the Interior Department of State, and thus ended church control of schools.

Although Austria remained a Catholic country, the influence of movements in Germany greatly affected it. Maria Theresa worked with untiring energy for the welfare of her people, and laid the basis for school reform. Her son, Joseph II, introduced many reforms and greatly encouraged education. His abolition of 600 monasteries and curtailment of the power of the church brought condemnation down upon him and largely defeated many of his reforms. Although he was too idealistic for the people of his time, he started the movement that led to better schools, which were largely patterned after the German system.

Between 1815 and 1825 the Volksschule was introduced, which supplemented the old religious vernacular schools in Germany. A twoclass school system was thus established - the Volksschule for the masses and the Gymnasium for the leaders. The former educated about 92 per cent and the latter about 8 per cent of the pupils. Because this class system was too rigid, the Realschule was organized as a compromise between the two. Since the World War Germany has tried to reorganize its whole school system on a more democratic basis under the federal government, but so far not much has been accomplished. ${ }^{1}$ Austria has also changed its system, with the definite intention of making it correspond to the system of Germany.

Both Germany and Austria have been famous for their worldrenowned universities. Before the World War it was considered the proper thing, for those who could afford it, to go there to complete their education. As a result, many men in America hold degrees from the universities of Berlin, Göttingen, Halle, Bonn, Jena, Heidelberg, and Vienna.

6. Social Conditions. In early German society the men did the commanding and the women and children did most of the work. The common idea that the German man is too severe on his family is no doubt a social heritage, supplemented by the strenuous life under which the German people have lived.

Among the early German-speaking people four classes of society were recognized: namely, nobility, middle class, peasantry, and

${ }^{1}$ For the new organization, see Educational Yearbook, 1924, pp. 279-327. 
laborer. The Industrial Revolution brought in an unusually large number of industrial workers. Social conditions were greatly influenced, and the three social orders - nobility, burghers, and peasantry - which by this time had become recognized, became mere social classes as the traditional functions of the historical estates became meaningless.

Gradually the Brandenburg-Prussian system was introduced. This reduced the royal masters to hereditary flunkies and graduated society into social groupings from nobility down to landed squires. Burghers and peasants became hereditary classes rather than social groups. They, however, maintained stratification within their own groups. One result of the disorganization following the Napoleonic Wars was the recognition of a labor class.

The workers in these countries came to be favored with advanced socio-economic legislation. The Industrial Revolution brought its problems. Bismarck was a conservative nationalist, but, fearing the socialists, he favored the agricultural and industrial workers by the passage of many socio-economic laws. Workingmen were insured against sickness in 1883 and against accidents in 1884, limitations were placed on female and child labor in 1887, and compulsory old age insurance for workmen became a law in 1889. New kinds of employment were developed and workmen were assisted by having their wages raised by law. Practically all the social laws found in any civilized nation were found in Germany, and in the passing of many of these it has been the leader. Following Germany, Austria enacted many similar laws.

The revolutions ending and following the World War not only sent several hundred royal personages of varying degrees fleeing from Germany and Austria to other countries, but they brought many other changes. Their terrible suffering made the Germans and Austrians realize more than ever before the necessity and dignity of labor. Industry, however, has been disorganized and unemployment has been widespread since the end of the war. In 1926 the average number of unemployed in Austria was 176,000; $\$ 21,800,000$ was paid out in doles for unemployment insurance. The number of unemployed rose to 191,149 in 1929. On March 15, 1927, there were $1,438,000$ unemployed in Germany, and some 2,031,000 persons receiving doles. Wilkinson ${ }^{1}$ says Germany had 3,000,000 unemployed in 1930. In September, 1931, the number of unemployed in Germany

1 The World's Population and a White Australia, p. 22. 
was reported to be $4,195,000$. Before the world-wide depression, Germany seemed to be recovering rapidly, but it is a difficult matter for a small nation to recover when it is forced to pay $£ 100,000,000$ annually as reparations and half as much more as interest on foreign loans.

The World War brought about the abolition of the old rights and privileges of the nobility and the disintegration of the middle class. Consequently there are today roughly but two classes - those who work with their brains and those who work with their brawn - in Germany and Austria. These have not become stratified, but are merely considered as functioning and serving the community in different ways. One does not now completely lose caste by changing from one group to the other. Today German university students may engage in manual labor to defray their expenses, a thing impossible before the war. Residues of the old social groupings, however, still exist and perhaps will for a long time yet. Those born and bred of humble folk still see a gulf between them and the wellto-do and educated. The farmer still has no objection to living under the same roof with his live stock, and still thinks the size of the manure pile in his front yard brings him prestige.

7. Immigration and Emigration. There have been so many shifts in the territorial boundaries of Austria and Germany that it is difficult to trace the population growth and changes of either. According to Thompson ${ }^{1}$ the population of Germany increased 63 per cent, or from $41,000,000$ to $67,000,000$, in the 43 years between the FrancoPrussian and World Wars. He thinks the increase in Austria was about 80 per cent of that of Germany. This was a period of growth and expansion for both countries. Since the World War, however, things have changed. Berlin, which had grown fourteen times larger in area in the last thirty years and increased its population from $1,888,000$ to $4,297,000$, seems not to be growing rapidly at present. Its birth rate has dropped rapidly, and people are shifting from the city into the rural areas and smaller towns. The net loss from this cause was 15,000 for 1930 . Other cities appear to be similarly affected. Not only the cities but the whole nation seems to be changing. Before 1914 the excess of births over deaths averaged around 800,000 per year, but in 1927 this excess amounted to only 402,000. In 1930 there were 27,133 fewer marriages and 20,630 fewer children born than in 1929.

1 Danger Spots in World Population, pp. 241-42. 
Apparently more German-speaking people have come to the United States than any other language group. Not all of them, however, have come from the territory which constitutes the German and Austrian republics. Many have come from Switzerland and other German-speaking areas. In 1920 there were 2,267,128 foreign-born whites in the United States whose mother tongue was German, but only 1,641,482 of these came from Germany. The census reports listed German-speaking immigrants from eight countries besides Germany.

We have no official reports on immigration before 1820 , but we know that German-speaking immigrants became important after Penn founded his colony in Pennsylvania. He had formerly traveled in the Palatinate and witnessed the religious persecutions and economic suffering of the people; consequently he advertised his colony in that country, giving a glowing account of the religious and political freedom and of the economic opportunities. From Germany and Austria came large numbers of the smaller religious groups, such as the Amish, Mennonites, Dunkards, Moravians, and Jews, trying to escape persecution by seeking a haven in the United States. So many came from the Palatinate that in some sections of the United States Palatinate and German became synonymous terms. Other Pennsylvanians later adopted Penn's real estate methods, and shipowners carried on such an extensive advertising campaign that thousands of poor Germans indentured themselves for transportation to the United States.

Records for 1820-1930 show that while Great Britain sent us 4,225,722 immigrants, Ireland 4,578,941, and Italy 4,651,195, Germany sent $5,907,893$. How many of these came from other sections, and how many came unannounced, we do not know. We do know, however, that there is a large colony of Russian Germans in North Dakota, who were driven out of Russia by the Russianization policy. Neither do we know how many German-speaking people came from Austria. Between 1910 and 1913 over 80,000 immigrants came here from Austria per year. Only 7 per cent of these were German, while 36 per cent were Poles, 24 per cent Ruthenians, and 10 per cent Czechs.

From the Napoleonic Wars until 1848, many of the rulers of Germany and Austria were despotic. At the same time liberal thinkers were growing in influence in university circles. They became weary of supporting established churches, being spied upon by governmental 
officials, and otherwise having their liberties curtailed. The powerful Metternich checked progress in Austria and Germany. As a result, many of the intellectual and progressive people, such as physicians, lawyers, teachers, and statesmen, fled to the United States, and constituted one of the greatest contributions, if not the greatest, Europe has made to America. Professor Ross ${ }^{1}$ thinks that the Scotch-Irish have done more to mold our national character than any other group, but it is the author's opinion that this group of educated Germans wielded the greater influence. After the Franco-Prussian War militarism became rampant in Europe, and as a result many stalwart sons of Europe fled to America. In general, it would appear that many factors caused Germans and Austrians to come to the United States. The economic, however, doubtless has been and continues to be the chief factor in their emigration. With their prolific families and ever increasing population, the cry for more land has been almost constant. After the passage of the Homestead law there was a mighty rush of Germans into our Western states. As a result of the scarcity of free land in the United States in recent years and the increasing opportunities in Germany resulting from its industrialization, the number of German immigrants dwindled considerably before the World War.

German emigration is characterized by its size, which at times approached mass movement. Professor H. Grothe ${ }^{2}$ thinks that 9,000,000 Germans emigrated from 1812 to 1912. According to incomplete official statistics for the United States, 22,000 came here in 1817 and practically none in 1818. Another movement took place between 1844 and 1854, the number being 45,655 in 1844, 108,457 in 1847, and 240,427 in 1854. During this period 1,239,900 German emigrants left through the ports of Hamburg and Bremen, 989,283 of them coming to the United States. The year 1881 is another highwater mark; in that year 220,902 German emigrants left. The statistics of the United States show that 2,280,323 Germans came to this country between 1836 and 1870 . For the first two decades of the present century the annual number coming to the United States did not exceed 30,000, except in 1903, when 33,649 came. ${ }^{3}$ In 1923 65,543 came, in 1924 95,627, and in 193056,631 . For the whole

1 The Old World in the New, p. 13.

2 Proceedings of the World Population Conference, 1927, edited by Margaret Sanger, p. 297.

${ }^{3}$ See Ferenczi, Imre: International Migrations, Vol. I, pp. 115-22. 
period from 1820 to 1930 the United States received 5,907,893 German immigrants. In 1920 there were 2,267,128 foreign-born whites in the United States who gave German as their mother tongue; $1,641,482$ of these were from Germany and 201,603 from Austria. Our present law permits 25,957 immigrants from Germany per year, 25,270 less than the two per cent law, and 1413 from Austria, 628 more than the two per cent law.

About 90 per cent of the German emigrants have come to the United States, while only about 1 per cent have gone to Canada. From 1831 to 1924 only 223,376 went to Canada. From 1910 to 1924 12,916 went to Mexico, but between 1911 and 19248602 left; that is, about three-fifths left. Brazil has received more German emigrants than any other South American country, some 174,816 going there from 1828 to 1924 . There was a rush of Germans to Brazil in 1838-70, and in 192421,016 arrived. From 1857 to 1924 100,699 Germans arrived in Argentina and 49,252 departed. The movement from 1871 to the World War was fairly small (generally less than 1500 per year), but in 19239640 arrived and in 19248125 . Only small numbers of German emigrants have been attracted to other countries of the world.

We know little of the Austro-German emigration because the statistics for the Austro-Hungarian Empire included various racial and linguistic groups. In 1923 the overseas emigration from Austria was 15,497, but the next year it dropped to 2650. Most of the Austrian emigrants had departed for the United States, Brazil, and Argentina. Both Germany and Austria have had periods of heavy migrations of seasonal workers across their borders. For each of the years 1907-08 to $1909-10$, between 200,000 and 250,000 seasonal workers (chiefly Poles and Ruthenians) went to Germany.

Perhaps it should be pointed out that the German and Austrian emigrants vary widely - as much as do the economic, political, religious, and social conditions in the countries from which they come. Professor Francke ${ }^{1}$ says: "Racially, there is the greatest difference of temperament between the various ethnical units included in the political unit of what is now the German Republic. The choleric Bavarian, the light-hearted Franconian, the deep, mystically inclined Swabian, the effervescent Rhinelander, the bright and gentle Thuringian, the impassionate, melancholy Silesian, the stubborn, slow-moving Low German, the smart and versatile Prussian - these

1 Immigrant Backgrounds, edited by H. P. Fairchild, p. 42. 
are only a few of the variations which the generic term 'German' embraces." Since racial temperament is a discredited theory today, we may explain these differences, if they really exist, on the basis of the social environment. Certainly the social environment in different parts of Germany and Austria varies widely. Consequently some who emigrate are of the peasant type from the quiet farm life of the Black Forest, Slesvig-Holstein, or other rural sections, where the simple farm communities have not yet been disturbed by the advent of industry, movies, and automobiles. Others are from the Ruhr districts or Saxony, accustomed to highly industrialized conditions, groups of workingmen, tenements, and municipal gardens. Still others come from large cosmopolitan cities like Berlin, Hamburg, and Vienna, where they have long been familiar with the most modern elements of civilization. Still others come from the territory lost by Germany and Austria as a result of the World War or from territory to which they or their parents emigrated. Professor Francke ${ }^{1}$ lists "six essential features of the German immigrant background: high degree of systematic schooling, instinctive thrift and orderliness, sense for aesthetically pleasing home surroundings and recreations, strongly developed pride in national achievements, lack of churchliness, lack of experience in political organization." The German immigrant is literate and shows the effects of life in an intellectual country. "The German," writes Professor Ross, ${ }^{2}$ "is lasting in his sympathies and his antipathies and leisurely in his mental processes. It takes him long to make up his mind and longer to get an idea out of his head." He has been trained in clear thinking, thrift, and orderliness, and is accustomed to wholesome home conditions. He knows something of art, music, the classics, and the sciences. He shows little interest in religion and politics; for these, managed by officials, have given him little opportunity for participation. Most assuredly he will regard a woman as an inferior.

\section{QUESTIONS, EXERCISES, AND PROBLEMS FOR INVESTIGATION}

1. What geographical features have helped determine the destiny of Germany and Austria? What are the reasons for placing them together here?

2. Mention some territorial effects of the World War upon these countries.

1 Immigrant Backgrounds, edited by H. P. Fairchild, p. 51.

2 The Old World in the New, p. 65. 
3. Discuss the statement that "properly speaking, there is no German race from the point of view of physical characteristics." References. Dictionary of Races or Peoples, p. 66; and Wallis, B. C.: "The Peoples of Austria," Geographical Review, Vol. VI, pp. 52-65.

4. Trace the principal events in the development of the republics of Germany and Austria.

5. In what ways was the Dual Monarchy doomed to failure?

6. Of what importance were the Zollverein and Hanseatic League in the commercial development of Germany?

7. What were the chief economic effects of the World War upon Germany and Austria? Besides the text, see Long, R. C.: "Germany's Enrichment," Fortnightly Review, Vol. CXXIV, pp. 367-75; Bergmann, Carl: "Germany and the Young Plan," Foreign Affairs, Vol. VIII, pp. 583-97; Dunlop, R.: "The Future of Austria," Quarterly Review, Vol. CCLVI, pp. 150-58; MaCartney, C. A.: "Austria Since 1928," Slavonic Review, Vol. VII, pp. 288-303; Salter, Arthur: "The Reconstruction of Austria," Foreign Affairs, Vol. II, pp. 630-43; Levainville, Jacques: "The Economic Function of the Rhine," Geographical Review, Vol. XIV, pp. 242-56.

8. Explain more fully the statement that German territory was a battle ground for religious strife.

9. Show the part Germany played in the development of education.

10. How have the World War and economic conditions caused shifts in social classes in Germany?

11. What are the more general characteristics of the Germans who come to us? In what respects do they differ?

12. Show how Germany has striven to avoid overpopulation in parts of its territory. References. Rohr, F. J.: "Home Colonization in Germany," International Review of Agricultural Economics, 1925, pp. 28-72; Brunhes, Jean, and Vallaux, Camille: "German Colonization in Eastern Europe," Geographical Review, Vol. VI, pp. 465-80.

13. Joseph Redlich makes the statement that old Austria has gone forever, and with it the last remnant of old Europe. ("The End of the House of Austria," Foreign Affairs, Vol. VIII, pp. 598-608.) Discuss.

14. Sigmund Münz ("Austria's Relations with Germany and Italy," Foreign Affairs, Vol. I, No. 4, pp. 59-70) makes the statement that Austria is doubtless a costly flask containing within itself extracts of both German and Italian culture. Explain.

15. From the Survey (Graphic edition, February, 1929), Vol. LXI, select and report on the leading articles dealing with social conditions in Germany. 


\section{CHAPTER IV}

\section{THE SCANDINAVIAN COUNTRIES}

1. General Description. The Scandinavian countries - the kingdoms of Sweden, Norway, and Denmark - are here considered to-

gether. Often two of them have been under the same government, and the three have learned to act together as they did during the World War when they agreed not to join either side unless all three unanimously decided on such a course. The three countries are fundamentally rural and closely related biologically and culturally.

Sweden and Norway compose the Scandinavian Peninsula, and are separated from Denmark by two bodies of water, the Skagerrak and the Cattegat. The total land area of the three countries is around 315,265 square miles, and the combined population numbers about $12,562,000$. Sweden is the largest of the group, embracing over one-half of the land area and about one-half of the population $(6,141,671$, census 1930). It occupies the eastern half of the peninsula and is about 965 miles long from north to south; it varies in width from 150 to 225 miles. The coast line of 1375 miles is deeply indented by gulfs and river mouths. It is a country of many mountains and lakes. With the exception of Finland, Sweden has more lakes and rivers than any other country in Europe, nearly one-tenth of its surface being covered with water. About 15 per cent of the country lies north of the Arctic Circle. The remainder, while in the temperate zone, is subject to long, cold winters and short, hot summers, with practically no spring or autumn.

Sweden is commonly divided into three parts. Norrland is the northern section. It is chiefly a land of forests and swampy wilderness, sparsely settled. The few inhabitants live in small communities and engage in lumbering and mining. Svealand, the central part, is a land of lakes, pastures, small, well-tilled fields, and prosperous towns, and is the center of political and inteliectual life. In Götaland, the southern part, one finds the warmest climate, the most fertile lands, and the greatest commercial and industrial activities.

Norway (exclusive of Spitzbergen or Svalbard, with an area of 
about 30,880 square miles and 1503 inhabitants) has 124,964 square miles of land and a population of 2,890,000 (1930). It occupies the western portion of the peninsula and is separated from Sweden by the Kjölen (Keel) Mountains. Although Norway lies due east of Labrador, the Gulf Stream causes its climate to be much milder than that of Sweden.- Norway is more than 11,000 miles long and extends from the Magnetic Pole and Arctic Ocean in the north to the Skagerrak on the south. In breadth it varies from 60 to 275 miles. The west coast is guarded by a series of rocky islands and is deeply indented by fjords. If these fjords and other bodies of water were extended, the coast line of Norway would equal half the distance around the world at the equator.

Some one has said that Norway is a flat country after one gets on top of it. The surface consists of a group of broad mountains, interspersed with level plains and plateaus and dotted with lakes. It has the largest glacier (2000 square miles) in Europe. The area covered by lakes is greater than that at present cultivated. Seventy-five per cent of the area is composed of wild, uninhabitable lands, towering snow-capped peaks, roaring waterfalls, and mile-high banks to the fjords. The valleys are very narrow but fertile.

Denmark, the smallest of the Scandinavian countries, has an area of 16,570 square miles and a population of $3,550,651$ (1930). The Faroe Islands, lying in the Atlantic Ocean, about 300 miles from the Shetlands, with an area of about 540 square miles and a population of 22,835 , are a part of Denmark. Greenland, ${ }^{1}$ Denmark's only colony, has an area of 827,300 square miles and a population of 14,081 Eskimos and 274 Danes. Denmark's area was increased by 1507 square miles and its population by 164,500 as a result of the plebiscite in Slesvig in 1920. Iceland has long been a part of Danish territory. In 1918 it became a sovereign state, but is still united with Denmark through a joint kingship and council. The Kingdom of Iceland has an area of 39,709 square miles and a population of 24,304 (1927).

Denmark is an odd-shaped country, consisting of a peninsula and an archipelago. The peninsula Jutland is joined to the northern part of Germany, and the archipelago lies to the east of Jutland. Denmark's coast line is longer than that of France and is out of pro-

1 In July, 1931, the Norwegian flag was hoisted in eastern Greenland and the Danish government forthwith addressed a complaint against Norway to the World Court. 
portion to its land area. It is said to have one mile of seaboard to every square mile of land. In comparison with Sweden and Norway, there is a complete absence of mountains in Denmark. The highest hill (Himmelbjerget) in Jutland is only 520 feet high.

The inhabitants of the three countries are practically all Teutonic, the purest of the so-called Nordics, but with strata of Mediterranean and Alpine stock, built upon earlier racial groups. In the northern part of Sweden and Norway are a considerable number of Finns and Lapps, who belong to the Mongolian group. The languages of the

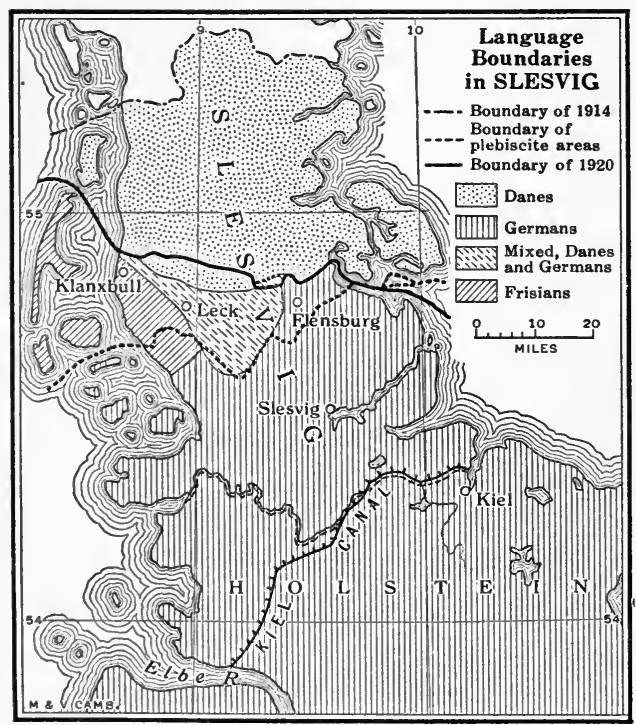

After Bowman three countries are very much alike and are closely akin to German and Dutch. Prior to the nineteenth century, Danish was the written language of the Norwegians. In 1887 Norwego-Danish, a hybrid language consisting of Norwegian sounds and intonations, was recognized for standard reading in secondary schools. Finally it became the language of the church service, the last fortress of Danish tradition. There are, however, three strata of the Norwego-Danish (the "Norwegian" as understood by foreigners) - the upper, middle, and lower class dialects. The Landsmaal, or new national Norwegian, is a common standard literary form for the dialects, and is rooted in the old Norse. It is receiving political sanction, and old Norwegian literature is experiencing a wave of popularity.

2. Political Development. Although there are a few early records of Scandinavia, real knowledge begins with the Viking age, which lasted from 872 to 1319 . The Vikings, being good seamen, good explorers, and good pirates, successfully raided the coast countries of their neighbors and greatly extended their territory. In 876 Gumbjorn reached Greenland, and in 1000 the Vikings, under the leader- 
ship of Leif Ericson, discovered the New World, which they called Vinland. They made two trips to this country, but the hostility of the Indians caused them never to return.

We hear of Danish kings as early as the eighth century, but know little of them. There appear to have been a number of kings who ruled small groups of people, but they were more like mayors than kaisers. The first ruler of importance was Sweyn I of the Forked Beard (985-1014), who for a short time imposed his yoke upon England. With Valdemar I, the Great, began a period of brilliant achievement for the country. Conquests were extended far into Germany and Wendic lands.

From 1319 to 1380 Norway was united to Sweden, during which time (1349-50) the Black Death visited the land, carrying off onethird of the population. Union of the three countries was effected when Margrete of Denmark was chosen regent of Denmark, Norway, and Sweden. Through her influence her great-nephew, Erik of Pomerania, was crowned king of the Scandinavian countries in June, 1397, and thus the Union of Kalmar came into existence. Norway, having no nobility, became a vassal province; Sweden, with an aristocracy backed by vassals, was able to declare its freedom in 1523. Norway continued to be united to Denmark until 1814.

This period in Norwegian history is known as the "long night." Little of importance happened except the establishment of the Lutheran Church in 1537, the substitution of the Danish language for old Norse, and the rise of a dissenter group under a peasant preacher, H. N. Hague. Because of discriminations and wars, the Norwegians developed a bitter hatred toward the Danes, which has caused a national psychosis that is manifesting itself in Norway's effort to make Landsmaal the national language. Norway remembers May 17, 1814, as its independence day, because on that date it freed itself from Denmark and became a constitutional kingdom on a footing of approximate equality with Sweden. Russia, Britain, Austria, and Prussia backed Sweden in enforcing the terms of the Treaty of Kiel. As a result, Swedish troops occupied Norway, which then joined Sweden, but under its own constitution. Norway's merchant marine developed rapidly, and friction arose over the joint administration of consular service in foreign countries. Feelings became intense, but without bloodshed Norway gained its independence from Sweden in 1905 . It was then an independent nation for the first time in 600 years. The throne was offered to the Prince of Sweden, 
and upon his refusal was accepted by Prince Carl of Denmark, who was crowned king in 1906, under the adopted name of Haakon VII. These experiences have left in the Norwegians a mild hatred for both the Danes and the Swedes, which they carry with them to this country.

Under the powerful Gustavus Vasa, Sweden freed itself of the Kalmar Union. The Vasa dynasty lasted for fifty years, and during this time religious differences made Sweden and Poland mortal enemies. The ambitions of Russia soon brought it into conflict with Sweden. Russia wanted Finland and lands controlled by Sweden on the Baltic. In 1611 Gustavus Adolphus, a mere boy of seventeen years, was called to the throne. Under his rule Sweden played an important part in European politics and reached the zenith of its power. By a series of wars Gustavus extended, at the expense of Russia and Poland, the Swedish dominance to the present site of Leningrad. He took a leading part in the Thirty Years' War, but fell before the war was ended. During his reign he strove incessantly to improve the military, commercial, industrial, agricultural, and political conditions of his country. He reorganized the national assembly and divided it into four estates - nobles, clergy, burghers, and peasants - and granted them power of legislation and taxation. He enlarged the University of Uppsala and founded one at Dorpat. After his death, wars with Russia, Poland, Denmark, and other countries continued intermittently. Sometimes the Swedish domain was greatly extended, but at other times it was greatly reduced. In 1807 Sweden lost part of Pomerania, and in 1809 Finland. In 1810 the dominant party (Hats) elected Jean Baptiste Bernadotte, a general under Napoleon, as Crown Prince, with the erroneous idea of conciliating Napoleon. In 1814, however, Sweden joined the allies against Napoleon. After this war its rule was confined to the peninsula, and it was forced from its former exalted rank as one of the great military powers of Europe.

Each of the Scandinavian countries has gradually changed its form of government from one in which rulers were elected to an hereditary constitutional monarchy. Each has two houses, corresponding to our Senate and House of Representatives, and universal suffrage. To be able to vote, however, a man or woman must be 23 years old in Norway, 24 in Sweden, and 25 in Denmark. The three differ slightly in their methods of electing to the two houses and in the names of their political parties. Each, however, has several parties, 
such as conservatives, liberals, socialists, communists, agrarians, laborites, democrats, and independents. Each country has compulsory military service in the form of a militia.

3. Economic Development. Agriculturally the Scandinavian countries present a striking contrast. Almost 75 per cent of the land of Norway is unproductive, 24 per cent is forest and pasture, and 2.2 per cent is arable. About 62 per cent of the land of Sweden is forest and pasture, and 9.1 per cent is arable. Over 70 per cent of the land of Denmark is productive; 4.9 per cent is forest. Thus Norway and Sweden import large quantities of food and Denmark exports large quantities. It is only in the southwestern part of Norway that one finds tracts of arable land as great as 100 square miles. In all three countries a very large percentage of the farms are owned by those who cultivate them. The farms are generally small, about one-fourth being under five acres and over half under twenty-five acres. Mark Twain spoke of a certain man who was able "to fall out of his farm." This very aptly describes many farms in Norway and Sweden. Yet 50 per cent of the people in Sweden and 44 per cent of those in Norway are engaged in farming. From 1900 to 192612,559 new farms were established in Denmark with federal financial assistance.

In proportion to population, Norway has developed the largest shipping interest in the world. The World War, however, caused its merchant marine to drop from fourth to sixth place. Yet about 95 per cent of "Norwegian bottoms carry goods of other nations. Sweden and Denmark also have large merchant marines. All three countries derive considerable benefits from their fisheries. Swedish exports are mainly metals, minerals, wood, pulp, and paper; Norway exports timber, fish, iron ore, and aluminum; Denmark exports food and dairy products. The kroner is the unit of exchange throughout Scandinavia.

Norway and Sweden lead Europe in available water power, whereas Denmark has none. About 44 per cent of the possible 12,000,000 borse power in Norway is within 19 miles of shore. Electrification of rural districts resulting from government control is more general in Norway than elsewhere in the world. Fully 75 per cent of the inhabitants have electric power. In 1928 Sweden was using only about 15 per cent of its potential 15,300,000 horse power. Norway has the advantage of Sweden in that its water power is better concentrated.

4. Religious Development. Christianity was introduced into the 
Scandinavian countries early. From Germany it naturally spread to Denmark. In 995 Olaf Trygveson became ruler of Norway. He had been baptized in England, and through force and bribery evangelized the country. Christianity was introduced into Sweden in 829 , but the old pagan religions were not conquered until the reign of Ingold (1080-1112), when the temple of Uppsala was burned. The Reformation spread rapidly in Scandinavia. Lutheranism became the established religion in Denmark and Norway in 1537, and in Sweden in 1592. Although the Scandinavian countries did not suffer from religious wars as did some of the other European countries, there was serious strife between the pagan and Christian forces in early times, especially in Norway and Sweden, and later between the Catholic and Lutheran powers in all three countries. The accustomed methods of treating dissenters, such as discrimination, exile, decapitation, and burning, were not unknown. Sweden, under Gustavus Adolphus, played a leading part on the side of Protestantism during the Thirty Years' War, and much of the strife between Sweden and Poland was of a religious nature.

Freedom of worship is tolerated in all the Scandinavian countries, but there is only a small percentage of dissenters. Lutheranism is the prevailing creed, but it has apparently become cold and formal. The clergy are recruited more and more from the lower classes, and in many sections attending church is not fashionable.

5. Educational Development. With the adoption of Lutheranism a great need was felt for education in the Scandinavian countries. An increased impulse was added when a knowledge of reading and of the Catechism was made necessary for confirmation in $\mathbf{1 6 8 6 .}$

Realizing that illiteracy is a great handicap, these countries made every effort to wipe it out; today it is almost a thing of the past. School attendance is compulsory between the ages of seven and fourteen. The school systems are well organized and among the most efficient in the world. Boys and girls are taught facts and given vocational training. In establishing folk high schools Denmark and Norway are demonstrating to the world the practicability of teaching future agriculturists. More than 300,000 people have passed through these schools in Denmark; consequently the Danish farmer is not afraid of a new crop, or the community of a new generation. Books and periodicals are in all homes, and the village community hall is not only an educational center but a place for everything wholesome that youth delights in. Sweden has two excellent 
universities, one at Uppsala, having 3208 (1929) students, and the other at Lund, having an enrollment of 2322. The Danish University of Copenhagen has 4700 students, and the Norwegian University of Oslo 3495 students (1929); both are well known in America.

6. Social Conditions. The Scandinavian countries have commissions on social legislation which study social ills and attempt a prescription after a careful diagnosis of the malady. As a result these countries are among the leaders in social legislation. The "health council," founded under a law of 1860 , is probably a distinctly Norwegian institution. In Sweden the sick who are unable to pay private physicians must be treated free of charge. All medical fees are regulated by the state. In 1921 licensed prostitution was abolished and a severe penalty fixed for transmitting a venereal disease. Midwifery is carefully regulated and considered an honorable calling. Norway has less than one fatality per thousand cases from puerperal septicemia, and Sweden 2.58; the United States has eight.

Scandinavia has some advanced ideas in regard to family life, especially in regard to marriage, divorce, and illegitimacy. Norway and Sweden have taken the lead in this. Two weeks before marriage, banns must be published, giving names, ages, occupations, and residences of the parties. A medical examination is necessary, and the customary medical secrecy in regard to venereal diseases does not prevail. The contracting parties must also file a statement as to whether or not they are the parents of any illegitimate children. An illegitimate child bears the name of its father, inherits equally with the legitimate children, and is entitled to its father's support.

Divorce is easily obtained. Before a final decree is given in Norway, however, an officer tries to effect a reconciliation. A division of property must be made and ten months elapse before remarriage is permitted. In Sweden the chief and effectual reason for a divorce is that husband and wife have discovered a mutual unwillingness or inability to go on living together. All the couple are required to do is to report their decision to the proper tribunal and ask for a separation. So long as the application is supported by both, they need not give any reason then or thereafter. What in America is called collusion and made an obstacle to divorce is in Sweden held as prima facie evidence that the relief asked should be granted. The couple are given a year to live apart in order to decide whether or not they wish to be divorced. If they return to each other they violate no law; if they continue apart the divorce is automatically granted at 
the end of the year. In regard to property, children, legal and financial transactions, and other questions, the wife has equal rights with the husband. In case only one party wishes divorce, because of lack of support, drunkenness, vice, or some other reason, much the same procedure is followed as in America.

The people of the Scandinavian countries are democratic and hospitable. Their plane of living is comparatively high, and social distinctions are not rigid. The working people are well protected by different kinds of insurance, and the agricultural population by strong coöperative associations. Danish farmers are the thriftiest and happiest in the world. From Denmark ideas of coöperation spread into Norway and Sweden, and Scandinavian immigrants in the northwest are giving us lessons in sound social economy.

7. Immigration and Emigration. The first Scandinavian settlers in the United States appear to have been a colony of Swedes who settled in Delaware in 1638, and a colony of Norwegian Quakers, who settled near Rochester in 1825. During the decade ending in 1860, some 2000 Danes went to Utah as a result of Mormon missionary activities. During the next decade more than 5000 more came, but only part of them settled in Utah. Groups of Danes, Swedes, and Norwegians came from time to time, but they constituted only a minor element in our immigration until after the Civil War. As late as 1873 they amounted to only 7.7 per cent of our total immigration, but by 1903 Scandinavians ranked third in the number of immigrants coming here. Between 1820 and 1912 the total Scandinavian immigration was around 2,200,000. In 1920 $1,194,933$ of our immigrants and around 3,000,000 of our foreign white stock were Scandinavians. It is claimed that one-fourth of all the Scandinavians in the world live in the United States, and that two-thirds of the Norwegians of the world live in the Dakotas, Minnesota, Wisconsin, and Iowa.

The Scandinavians have come in at the rate of about one Dane to two Norwegians and four Swedes. For the period 1820-1930, 2,346,069 Scandinavians came to the United States. Between 1911 and 1920, 95,074 Swedes, 66,395 Norwegians, and 41,983 Danes came. For the period 1921-30, inclusive, 97,249 Swedes, 68,531 Norwegians, and 32,430 Danes arrived. With the exception of Ireland, Norway has lost a larger proportion of its population to America than any other country. The Scandinavians, being a "land-loving" people, came with their families, and, as some one has said, borrowed 
our great Northwest, pioneered in it, cleared the timber, and plowed the prairie, where they raised grain, cattle, and American citizens. For us they developed the most progressive section of the United States.

The reasons for the coming of the Scandinavians have been many and varied. These countries have not suffered from religious, political, and industrial upheavals as have some other lands. Doubtless the political situation caused some to come, especially from Norway, as a result of its long political subjugation to Denmark and Sweden, and from Slesvig-Holstein after it had become part of Germany and after Bismarck had started his Germanizing process. Between 1867 and 1895, 57,000 people emigrated from North Slesvig, and in 18981000 were expelled by the German authorities. There has been only moderate pressure on small dissenter groups who stood firm in their convictions. Many Lutherans, however, heard of the religious freedom in America and became dissatisfied with religious aristocracy and formalism. In this country many have united with more democratic denominations, others have changed from the episcopal to the congregational form of church government, and many have refused to be affiliated with any church.

Compulsory military service has perhaps caused some to emigrate, but the one important factor has been, and continues to be, the desire for better economic conditions. It is natural that a knowledge of the free and cheap lands in America should spread among a people with small farms and a scarcity of suitable lands and cause the "American fever" to become a contagious disease.

Scandinavians coming to us today bring their families and intend to make this country their home, although an increasing number of individual immigrants are coming. The chances are that they have been farmers and will continue in that occupation. Almost 50 per cent of them in this country own farms, and if we include farm laborers, almost 60 per cent are in agricultural pursuits. They are literate, and many of them are able to speak two or three languages fluently. They respect government and understand participation in political activities. Having been accustomed to wholesome home life, with many visitors, they are easy to approach and are glad to welcome one into their homes. Apparently they adjust themselves easily in the United States as 78 per cent have remained here.

So far Scandinavian emigrants have manifested little inclination to go to any other country than the United States. Since the pas- 
sage of the restrictive laws by the United States, Scandinavia faces the problem of an outlet for its surplus population. According to Dr. Nils Cederblad, ${ }^{1}$ Sweden has about 90,000 more men and 60,000 more women between the ages of 15 and 65 than it would have had if emigration had continued normally. Another problem pointed out by Dr. Helmer Key ${ }^{2}$ is the large surplus of professionally and technically trained people in Sweden. There is nothing for this group to do in Sweden, and so far they have not been able to secure suitable positions in foreign countries.

Although the Scandinavian countries have had their wars with each other and their disputes within recent years, they are now bound by a treaty of friendship and appear to understand that their welfare demands that they act together. Those who come to us, however, often reflect the history of their respective countries. If the immigrant is a Swede, he is almost sure to have a kindly feeling toward Germany, a hatred of Poles and Russians, a sublimated hatred of Danes, Norwegians, and Englishmen, and an utter disregard of South Europeans; if a Norwegian, a hatred of Swedes and Danes; if a Dane, a hatred of Germans, because of the DanoPrussian War and the more recent controversy over Slesvig-Holstein, combined with a kindly feeling because Germany consumes about 60 per cent of Denmark's food exports. According to Professor Ross, ${ }^{3}$ the Danes, though moody, are courteous and pleasure-loving. The Swedes reflect a society accustomed to "aristocracy, refinement, and industrialism," being more polished and melancholic than the Norwegians. The Norwegians reflect a more primitive society, but one which has never been stamped with feudalism. All are literate, progressive, stable, dependable, thrifty, and home-loving.

\section{QUESTIONS, EXERCISES, AND PROBLEMS FOR INVESTIGATION}

1. Compare and contrast the physical features of the Scandinavian countries. Besides the text, see Dennis, A. P.: "Norway, a Land of Stern Reality," National Geographic Magazine, Vol. LVIII, pp. 1-44.

2. W. Z. Ripley (The Races of Europe, p. 205) states that Scandinavia is "the home of the Teutonic race in its maximum purity." Discuss the

1 Proceedings of the World Population Conference, 1927, edited by Margaret Sanger, pp. 276-77.

2 Ibid., pp. 277-79.

3 The Old World in the New, pp. 81-83. 
racial origins and characteristics of this group. References. Ripley, ibid.; Pittard, Eugène: Race and History, Part II, Chap. X.

3. Discuss the Danish influence on the Scandinavian languages and evaluate the significance of Norwegian Landsmaal.

4. Explain how the Norwegians developed a mild hatred for the Danes and Swedes.

5. Make a study of the natural resources of Scandinavia, and from your findings predict the future destiny of Scandinavia. Besides the text, see Barman, T. G.: "Prosperity in Sweden," Fortnightly Review, Vol. CXXVI, pp. 782-93; "Norwegian Studies," reported in the Sociological Review, Vol. XVI, pp. 137-52, 235-50; Brandes, Georg: "Scandinavian Sympathies and Destinies," Foreign Affairs, Vol. I, No. 4, pp. 30-37; Jonasson, Olof: "The Relation between the Distribution of Population and of Cultivated Land in the Scandinavian Countries, Especially in Sweden," Economic Geography, Vol. I, pp. 107-23; "A Map of the Distribution of Population in Sweden; Method of Preparation and General Results," Geographical Review, Vol. XII, pp. 72-83.

6. Account (1) for the apparent lack of religious interest in Scandinavian countries; (2) for their lead in progressive education.

7. Show the relationship between agriculture and education in Denmark. References. Knight, Edgar: Among the Danes; Faber, Harald: "Primary Schools in Rural Denmark," Edinburgh Review, Vol. CCXLVII, pp. 343-52.

8. Give a brief report on the social life of the Scandinavians. Besides the text, see "Denmark," International Review of Agricultural Economics, 1925, pp. 531-40; Galpin, C. J.: "Some Observations of Farm Life in Europe," Publications of the American Sociological Society, Vol. XXI, pp. 223-26; Stacy, W. H.: "Some Agencies for Rural Progress in Europe," ibid., pp. 227-31; Harris, T. L.: "Some Observations on Rural Life in Norway," ibid., pp. 232-35.

9. How does Ross characterize the inhabitants of these three countries? See The Old World in the New, Chap. IV.

10. Report on M. A. Mikkelsen's "The Bishop Hill Colony," Johns Hopkins University Studies, Vol. X, stressing especially the religious background.

11. Outline G. M. Stephenson's "The Background of the Beginnings of Swedish Immigration, 1850-75," American Historical Review, Vol. XXXI, pp. 708-23. 


\section{HOLLAND AND BELGIUM}

1. General Description. Until 1579, and again from 1815 to 1830 , Holland and Belgium were one. Over half of the inhabitants of Belgium are Flemish, a long-headed, blond Teutonic type of the same racial stock as the Hollanders, who speak a language similar to Dutch. Since the two countries were so long historically one, and since the majority of the Belgians are of the same racial stock as the Hollanders, with a similar language and other common cultural traits, they are here considered together. A number of writers regard Belgium as a Latin country, but there seems to be only a slight justification for such a classification.

This area lies in northwestern Europe, across the North Sea from England, and joins Germany and France on the north, east, and south. The northern and larger part, or six of the seventeen provinces of the area long known in European history as the Netherlands or Low Countries, is now the Kingdom of the Netherlands, or Holland, while the southern part (eleven provinces) is Belgium.

Including its inland waters, Holland has an area of 13,208 square miles. As only 12,582 square miles of its territory are land, it is about the size of Los Angeles County, California, or somewhat larger than the state of Maryland. Belgium has an area of 11,754 square miles and is somewhat smaller than Maryland. About 382 square miles of this were gained from Germany as a result of the World War.

Holland's colonial possessions include the Dutch East Indies, with an area of 733,642 square miles and a population of $49,534,618$; Dutch Guiana (Surinam), with an area of 54,291 square miles and a population of 128,822 ; and the Dutch West Indies (Curaçao Islands), with an area of 403 square miles and a population of 56,038 . This gives Holland a grand total of 801,544 square miles of territory and a population of 57,345,516. Continental Holland contains less than one-sixtieth of the total population and less than one-seventh of the total area. Belgium's colonial possessions constitute a compact area of 921,154 miles in central Africa. About 20,500 square miles of this are the mandates of Ruanda and Urundi, which before 
the World War were part of German East Africa. They now form part of the Belgian Congo, which has an estimated population of $8,500,000$, of whom only 17,676 are Belgians. The Ruanda and Urundi mandates have an estimated population of $3,000,000$.

In 1925 Holland had a population of $7,614,419$; in 1926 Belgium had a population of $7,874,601$. Holland's population contained about 100,000 foreigners, almost one-half of whom were Germans. Almost one-half of the people of Holland live in the two provinces of South and North Holland, which lie next to England and from which the name Holland is derived. The density of population for the whole country - 542.9 per square mile - is high, being third among the nations of the world; in the two provinces of South and North Holland it is over 1000 per square mile. Belgium is the most densely populated country in the world, having 686 people per square mile. Both countries contain numerous cities. Amsterdam, the largest city of Holland and the seat of legislative power, has a population of 734,884 , Rotterdam 571,842, and The Hague, the seat of the Court, 416,179. Brussels, the capital and largest city of Belgium, has a population of 815,198 ; Antwerp, the greatest port of continental Europe, has a population of 421,988 . Belgium has a number of other important cities, such as Ghent, Liége, Malines, Bruges, Ostend, Verviers, and Louvain, with populations ranging from 300,000 to 40,000 .

Little is known of the early inhabitants of the Netherlands. In Caesar's time the country was inhabited by tribes of Mediterranean, Alpine, and Nordic stocks. The Frisians were in the north, the Belgae in the south, and Batavians and Caninefates in the center. The two latter groups were Teutonic and spoke Low Dutch. They spread over the country, and with the aid of the Northmen and Saxons changed Holland to a Teutonic country. Today the people of Holland are closely akin to the Germans in language, customs, and habits. An anthropological survey shows a preponderance of the Teutonic type in the north and east, of the Alpine type in Zeeland, and of a mixed type in the provinces of South and North Holland. As has been indicated, anthropologically the Belgians constitute two groups, each of which is composed of earlier racial groups. The Flemish, who constitute over half of the population, are a Teutonic type; while the others are Walloons, a short, broad-headed, brunette, Alpine type, who now speak French. The Flemish inhabit northern Belgium and the Walloons the southern part, but the two types 
shade off into each other to such an extent that language is the main distinguishing factor.

Holland is a continuation of the flat plain of northeastern Europe, which includes parts of Russia, Germany, Poland, and Belgiurn. There are no mountains, hills, rocks, waterfalls, or springs. The average height of the land is 37 feet, and about one-fourth is below sea level. The lowest lands are along the coast, but the most difficult to control are along the Rhine delta. It has been said that Holland is a present of the. Rhine. The land has been made by nature from the mud and silt brought down from the highlands of Germany. The Dutch have a saying, "God made the sea, but man made the land." By the toil of 1500 years the Dutch have won their soil, and the fight is still on. Already 90 lakes have been drained, and all the rivers and the sea diked. The Hollanders intend to create a new province by pumping out the Zuider Zee. Many of their dikes are as high as 60 feet and broad enough for roads and railroads. They are usually planted with various kinds of shrubs which prevent them from reverting to mere shifting sand dunes. The dike commissioner is the most powerful man in Holland. In time of disaster, on his own initiative, he can induct as much help as may be needed. Only the northwestern part of Belgium is included in this low, flat area. The southeastern part is composed of plains, valleys, ridges, and mountains, with rather poor soil.

2. Political Development. Although the name Belgium has come down to us from the time of Caesar, until 1830 the histories of the two countries are, for the most part, interwoven. During the time of Caesar the Romans subjugated all the tribes in the Netherlands except the Batavians of Holland. After the fall of the Romans in the fifth century the country was overrun by various German tribes. Under Charles the Great the country was united and Christianized. But with the break-up of his empire the southern part went to the West Frankish Kingdom, the central part to Lotharingia, and the northern part to the East Frankish Kingdom (Germany). With this came feudalism and the development of duchies and bishoprics, which, because of their distance from the central government, became almost independent. As a result of this situation, there was a strong German influence in the north, a strong French influence in the south, and a fusion of influences among the Flemish of central Netherlands. The cities also became strong and virtually independent of outside authority. 
A marriage alliance in 1369 between the houses of Burgundy and Flanders gave the dukes of Burgundy a foothold in the Netherlands, and they soon had the whole country under their control. A Burgundian-Hapsburg alliance in 1477 caused the Netherlands to pass to Austria. In 1494 Maximilian gave the Netherlands to his son, Philip. At the death of Philip the territory fell to the grandson of Maximilian, Charles V of Austria. Although Charles was a cruel ruler, he was Flemish by birth and favored the Netherlands. Charles's son, Philip II, was a Spaniard who had no Flemish sympathies. When he ascended the Spanish throne, he sought to stamp out Protestantism in the Netherlands. In 1576 the provinces of Holland and Zeeland rebelled, and three years later, with other provinces, formed the Union of Utrecht and declared themselves independent of Spanish rule. Spain, however, refused to recognize their independence until 1648, when Holland showed its naval supremacy.

During the long period of the war the Dutch were reaching out and establishing colonies, developing along commercial and military lines, and eventually coming to be rated as the first nation of Europe. Holland won independence, but Belgium (the Spanish Netherlands as it was called), being Roman Catholic in religion, effected a compromise and remained under the Hapsburgs. Before his death, Philip gave the territory to his daughter, who had married an Austrian, but soon it reverted to the Spanish crown.

As a result of the Treaty of Utrecht (1713), ending the War of the Spanish Succession, Belgium was given to Austria and became known as the Austrian Netherlands. In 1795 the Batavian Republic was established, but eleven years later it was overthrown by Napoleon, who incorporated it in his empire. It was returned to Austria at his fall. The Congress of Vienna (1815) joined Belgium to Holland. Thus the two countries were again united after having been separated for 235 years. Religious, economic, and political differences had become so great during the interim that the union was not a happy one. Holland made the fatal mistake of making Dutch the official language, not a word of which the Walloons understood. Belgium requested that the two countries be separated, but have the same king. To this Holland would not agree, and proceeded further to impose its authority. The year 1830 being one of general political uprising, Belgium declared its independence, but Holland did not recognize it until 1839, when Great Britain, France, Austria, Russia, Prussia, and Holland guaranteed Belgium's independence 
and permanent neutrality. Holland settled down to peace except for minor disputes with its neighbors and difficulties with its colonies. These it has never learned to control. Truly the problem is a great one - that of some $7,000,000$ people trying to control $50,000,000$ colonists.

Under Leopold I (1831-65), Leopold II (1865-1909), and Albert (1909- ), Belgium has made rapid progress. Two events of this period had world significance. Leopold II gained the protectorate, the Belgian Congo, and finally annexed it in 1907. Probably no civilized people has ever treated a preliterate people so cruelly as the Belgians have treated the tribes of the Congo. Finally the civilized

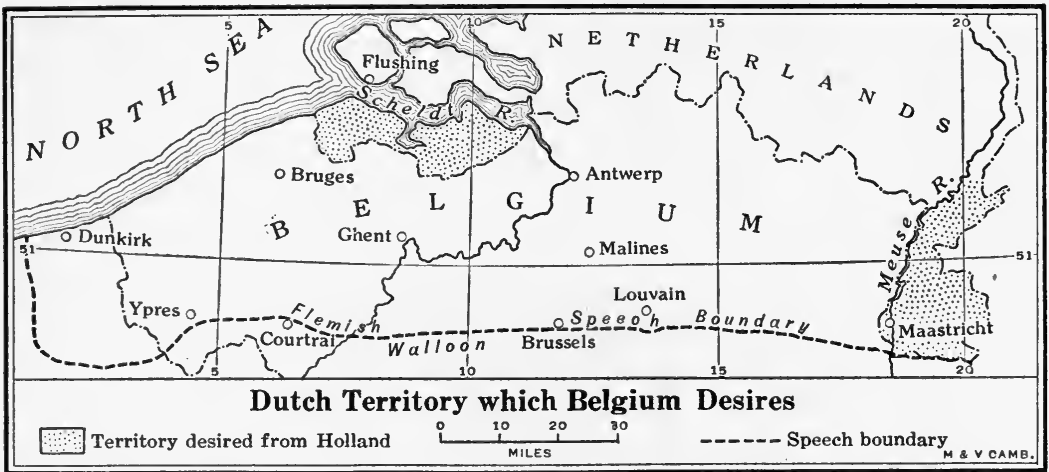

After Bowman, slightly modified

world became so stirred that the Belgians modified their treatment. The second was the violation of Belgium's neutrality by Germany, and the destruction and suffering wrought by the fighting armies on Belgian soil.

Holland has long been engaged in a dispute with Belgium over Dutch Limburg, including the left bank of the lower Scheldt River. Holland retained this in the division of 1839. Because of its military value, its coal deposits, and its importance for water transportation, Belgium is very desirous of possessing it, but Holland is equally determined to retain it. Belgium's chief seaport, Antwerp, is located on this river, 50 miles from its mouth. Since Holland controls the Scheldt River for 40 miles, Belgium claims that Holland strangles its trade in favor of Rotterdam. But Holland refutes this charge by showing that Antwerp has doubled its population within the last 50 years. In 1925 Holland and Belgium agreed that the Scheldt River should be free to all ships except warships during war. 
Both Holland and Belgium are hereditary constitutional monarchies. Each has a Parliament consisting of two houses, and each has several political parties. The Catholic and Socialist parties are in the ascendency in both countries. All citizens of Holland over 25 years of age have the right of suffrage, and compulsory voting is in force. The Representatives of Belgium number 187 and are elected for four years by direct manhood suffrage (21 years of age). The Senate has 154 members elected for eight years. Twenty-seven of them are elected by provincial councils and the others by manhood suffrage. Voting has been compulsory since 1893. In 1894 plural voting up to three, with educational and property qualifications, was put in force, but in 1921 it was changed, and now one man has only one vote. In 1900 proportionate representation was introduced, and in 1919 universal manhood suffrage. Women have communal but not parliamentary suffrage.

3. Economic Development. One would think that Holland, a damp, foggy country with a temperate climate, abundant rainfall, and alluvial deposits, would be a great agricultural country. The making of a farm in Holland, however, is a very slow and difficult process. First the peat is removed and used for fuel. This leaves great holes which fill with water. The law requires those who remove the peat to provide for drainage; consequently small ditches are dug through the land to the lowest point next to a dike. Here a windmill lifts the water over a dike wall into a drainage canal. There are about 100,000 of these windmills working in Holland. These polders or drained inclosures are sometimes 40 feet below sea level, but they are kept dry enough for pastures for cattle and goats by the aid of the windmills. Thus Holland raises cattle in great numbers and produces large quantities of butter and cheese. After the polders have been used for pasture for 20 or 30 years they can be used for farm purposes. Thus the evolution of a farm is not only a slow but an expensive process. Tobacco and flax are grown in restricted areas, but the most important farming is the growing of flower bulbs and seeds and the raising of culinary vegetables. About three-fourths of the land is farmed, but about half of that is in meadows. Nearly 90 per cent of the farms contain less than fifty acres, and 50 per cent less than twelve acres.

In its early development Belgium was almost purely an agricultural country. Today it is one of the most intensively cultivated countries in the world. It is a country of small landed proprietors. One man out of every six is a landowner, and 47 per cent of the land is in tracts 
of less than 100 acres. The land along the North Sea is largely reclaimed marshes and sand dunes. By unremitting labor it is made to produce two crops per year. The Flanders plains are very productive, but the hill country to the southeast has poor soil.

There is a scarcity of iron in Belgium, but plenty of coal and an abundance of certain other metals. Holland, on the other hand, was devoid of coal before 1815, when Limburg joined it. Peat was and is the fuel. In a country with very little coal, no mineral resources, practically no timber, and no water power, one would not expect a large amount of manufacturing. Dutch linens, Leyden woolens, Schiedam liquors, Gouda pipes and vases, however, have long been famous. Leather, sugar, pottery, tiles, and glassware of excellent quality are also produced. Before the Industrial Revolution the Flemings were well known for their laces and other homemade products. During the nineteenth century, Belgium changed from a povertystricken to a highly industrialized country. It now ranks third among the industrial nations of Europe.

For over 300 years Antwerp has been a commercial city and the chief rival of Rotterdam. The Flemings early developed commerce and were the real founders of the mercantile system. Belgium's foreign trade is important, and although most of its goods are now carried in foreign ships, it is rapidly developing a merchant marine. . It depends largely on the Congo and foreign countries for raw materials for its manufactures. Belgium is now reported to rank sixth in foreign trade and eighth in wealth among European nations. Belgium built the first European railroad and is well equipped with arteries of transportation.

Commerce and fishing are exceedingly important industries in Holland. The country is a network of canals and railroads, and its location makes it a thoroughfare for German and Swiss commerce. With their extensive colonial possessions and such rich sections as the Dutch East Indies the Hollanders carry on an extensive commerce. The wealth of Java is brought to the mother country, refined if necessary, and distributed to the other nations, chiefly Germany and England. About 6500 vessels and 18,000 men are engaged in fishing, and the annual returns from this industry amount to about $\$ 3,750,000$ per year. In 1926 exports exceeded imports by $\$ 20,000,000$.

During the World War practically all of Belgium was held by the invading armies. According to estimates, the country was damaged to the extent of $\$ 7,600,000,000$, but within a year of the Armistice 
canals and highways had been repaired, and virtually all its railways were in operation. Ten years after the war the reconstruction of the devastated area was about complete. Belgium is to receive 8 per cent of the German reparations payment, and Germany is to reimburse it, with 5 per cent interest, for all sums above 5,000,000,000 francs borrowed during the war. By private agreement, Germany is to pay Belgium about $\$ 76,800,000$ to compensate for the worthless German mark with which Belgium was flooded during the war.

For many years Luxemburg was a part of the Netherlands. During the French Revolution the French-speaking part became a part of Belgium and the German-speaking part became independent. Belgium now wants it all, and through customs unions and trade agreements has it largely under its control.

4. Religious Development. The Belgians early became Roman Catholics and have largely remained so. During the Reformation many Protestants appeared, but the tyranny and massacres of Philip II and the Duke of Alva almost eliminated them. There are now only about 15,000 Protestants and 4000 Jews in Belgium. The Flemings are conservative Catholics and feel no spiritual kinship with their racial brothers of Holland. The Walloons are liberal Catholics, having been greatly influenced by the liberalism of France. The Walloons are generally anti-clerical in politics, but retain their membership in the Catholic Church. There is an almost continuous struggle between the church party, the liberals, and socialists. The church party has been in the ascendency since 1884 . The majority of the population professing a religion belong to the Catholic Church, but religious freedom is guaranteed. Protestant ministers and rabbis are compensated by the state. The king is required to be a member of the Catholic Church, but an exception was made for Leopold I, who married a Catholic and reared his children in that faith, but steadfastly refused to become a Catholic himself.

The Hollanders had been largely Christianized before the coming of Charlemagne, in whose kingdom they were included. Quite early Holland permitted freedom of worship, and as a result the principles of Protestantism were established long before the coming of Luther. The Ketters appear to have been the first group to have claimed the right to free reading and interpretation of the Bible, and to have demanded separation of church and state. They are thought to be the true fathers of the Anabaptists, English Independents, American Con- 
gregationalists, English-speaking Baptists, and Quakers. The Anabaptists first found toleration in Holland under William the Silent.

With the coming of Charles $\mathrm{V}$ there was a definite change in the religious situation in Holland. He adopted a number of rigid repressive measures against all dissenters from the Catholic Church. In 1550 he issued an edict threatening death "by pit, fire, or sword" to all heretics. If the followers of $\mathrm{Z}$ wingli, Calvin, and Luther did not recant, they were to be burned alive. Recanting, however, was of little value, as the men who abjured their heresy were to lose their heads and the women were to be buried alive. It is estimated that 50,000 perished during the inquisition of Charles, but it did not stamp out Protestantism. As Charles was a product of the Netherlands, there was a kindly feeling between king and subject, and he was inclined to be somewhat lenient with them. He was not a religious fanatic, but he felt that he should take sides, and that the old religion would enable him to rule better his scattered kingdom.

When Charles's son, Philip II, came to the throne in 1556, there was a marked change. Philip was a Spaniard and a Catholic, who was willing to use any measure to maintain the old religion and rid his kingdom of the detested Protestants. During the first month of his rule he put in full force all the edicts of his father. So heartless was he that even devout Catholics protested against his cruelty. Small groups of Protestants began to revolt and to destroy Catholic churches. Philip dispatched the remorseless Duke of Alva to stamp out Protestantism in the Netherlands. The coming of Alva caused thousands to flee from the country. Alva's reign from 1567 to 1573 was truly one of terror. To deal with any one suspected of heresy, he established a court of butchery rather than one of justice, which came to be known as the "Council of Blood." Alva boasted that he had slain 18,000 . Unable to endure persecution any longer, the Protestants revolted and found an admirable leader in William of Orange. With a mere handful of peasants and fishermen, he opposed the most powerful nation on earth. When the long struggle was ended, Spain was bankrupt, and Holland was the greatest maritime power on earth. Persecuted Protestants and Jews flocked to Holland from France, Spain, Portugal, England, and Germany. Some of these Protestants later came to America as Puritans.

Before the Catholic provinces of Limburg, Brabant, and part of Guelderland became a part of Holland in 1815, it was almost purely a Protestant country. It continues to be a predominantly Protestant 
country; about half of the population, including the royal family, are members of the Dutch Reformed Church. The Jews, who number about 35,000 , were granted freedom of worship in 1847 . Holland not only guarantees religious liberty but includes in the state budget allowances for the different religious groups.

5. Educational Development. Before the Protestant era the few schools in the Netherlands were under the Catholic Church. With the passing of Catholicism the Hollanders came to be dominated by Calvinistic ideas of education. Between 1586, when the establishment of schools in the cities was ordered by the Church Synod of The Hague, and 1666 the idea of public elementary education spread over Holland. Most of the schools were supported by taxation but dominated by the church. Several cities, like Amsterdam, required an examination for all teachers. A fair school system seems to have been provided by the middle of the seventeenth century. Since that time the Hollanders have kept pace with the other North European peoples in education, and today illiteracy is practically unknown, only six-tenths of one per cent of the adult population being illiterate. Between the ages of six and thirteen education is compulsory, and is free in both public and denominational schools. Except in the Catholic provinces, practically all children attend the state schools. Holland has several well-known universities - Leyden, Groningen, Amsterdam, and Utrecht, which were founded between 1575 and 1636.

The educational advancement of Belgium has been hampered by two chief factors. The first is the Catholic party, which has fought state control of the schools and sought to keep the schools under the church. Although Belgium reduced its percentage of illiteracy from 30.26 in 1880 to 9.3 in 1920 , it did not have compulsory education, and now only a small percentage of the pupils attend school beyond the minimum requirements of law (13 years). Every commune is required to have a primary school, but in many communes a church school is selected and fulfils this requirement.

The second handicap is two national languages. Although a majority of the people speak Flemish, it was not introduced into the schools until 1883, and was not made a requirement for army officers until 1888. Flemish parents object to their children's studying French, since they seldom hear it unless they go to the southern part of the nation. Likewise, the French-speaking Walloons, whose ancestors spoke a Neo-Latin language, object to their children's 
studying Flemish. Furthermore, a small group of people along the eastern border speak a German dialect somewhat closely related to Rhenish, and the 64,000 people acquired as a result of the World War speak German. Practically all educated Flemings speak French and many speak German, but very few of the Walloons understand Flemish. ${ }^{1}$

The elementary schools of Belgium are very poor. They are free to those who are unable to pay. Religious instruction is required, but children are not required to remain in class while religious instruction is being given. The secondary schools are under state inspection and are much better than the elementary schools. The salaries paid to teachers of both types of schools are very low, and it is evident that Belgium agrees heartily with many other parts of the world in believing that good training and keen intellects are not essential for teachers.

Belgium has a number of agricultural, technical, and normal schools, and four universities. The universities of Liége and Ghent are state institutions, while Brussels and Louvain are independent. Brussels is a liberal school; Louvain is Catholic. Americans contributed some $\$ 2,080,000$ to rebuild and endow the library of Louvain, which was destroyed during the World War.

6. Social Conditions. Holland is not only a land of windmills and dikes; it is also a land of many customs that seem strange to us. Wooden shoes, baggy trousers for the men, and neat caps for the women are still common. There are many variations, however, in customs and language from one province to another. As in Denmark, most people ride bicycles; there are 1,500,000 bicycles and 47,000 motorcycles in Holland.

The Dutch home is the center of social life and is known for its hospitality, neatness, and cleanliness. Because of the fact that every young man is expected to be established in his occupation before marriage, the Dutch marry comparatively late. The unmarried adults outnumber the married almost two to one. Families are usually small, and infant mortality is very low. Birth control has been encouraged by the government for about 50 years.

The people of Holland are reported to be slow, cautious, thorough, thoughtful, honest, hospitable, and neat. They generally dislike drunkenness, rowdiness, and boisterousness, but at Kermis, one of

${ }^{1}$ For a more detailed discussion, see Laurent, Henri: "The Language War in Belgium," Current History, Vol. XXXIV, pp. 834-40. 
their chief holidays, practically all restraints are discarded. St. Nicholas Day, December 5, which corresponds to our Christmas, funerals, christenings, betrothals, and weddings are often great occasions. In some provinces betrothals are apparently of more importance than weddings.

Although Holland has its royal family, social distinctions are not so restricted as in many monarchies. Some groups, however, are distinct from others. Persons engaged in transportation form a closed gild recruited from the inside. There are nearly 100,000 people who live on barges and have no other residences. The barge is regarded as a family possession and is handed down in the same manner as a farm. It resembles a typical Dutch cottage inside and out.

Because of the scarcity of land, the difficulties of making a farm, and the necessity of foodstuffs, the boer or farmer occupies an important place. His farm is tiny, and generally he lives under the same roof with horses, cattle, and other live stock. He is proud of his position and looks upon other occupational groups with more or less disdain.

Like many other countries, Belgium has not yet succeeded in developing a social democracy. The Flemish, with a different racial origin, a different language, and a conservatism in religion, are almost the antithesis of the Walloons. The Flemish used to be manufacturers, but they are now chiefly agricultural people. The Walloons, on the other hand, were the early agriculturists, but have gradually become manufacturers. The Walloons look down on the Flemish and consider them stupid, while the Flemish detest the liberalism and radicalism of the Walloons. For many years there has been a tendency for these two groups to separate rather than unite. The Germans fostered this movement during the World War, offering the Flemish complete independence. To a certain extent this stigmatized the movement, but it is far from dead.

The people are further divided by political and religious ideas which affect their social relationships. In a town one often finds clerical, liberal, and socialist bakeries, stores, banks, and other economic organizations, each catering to its own group. Between these groups there are practically no social relationships.

The social distinctions that exist in some countries between agricultural and industrial, rural and urban, groups are not found in Belgium. Belgium has a larger percentage of people residing in the country and working in the cities than any other country in Europe. 
This helps to decentralize industrial cities and gives people a better appreciation of rural life. The Flemish peasants tend to live isolated on their farms, while the Walloons live in farm villages. Among both groups the women and children do a large amount of work. Their food is coarse, their clothes scanty, and their shoes wooden sabots. On Sundays and fête days they dress in dark clothes and go to Mass. On these days they usually have some hot bacon, fish, or rabbit. Fresh meat is practically unknown. The houses are usually small two-story stone or brick structures. Occasionally there is a chateau or villa which represents the petite noblesse, who live much to themselves because they are now too poor to make a social show.

7. Immigration and Emigration. Much has been written to prove that Holland, rather than England, should be considered our mother country. It is claimed that much was learned from the Dutch by the framers of our constitution, that our ideas of religious freedom originated in Holland, and that our first settlers were mainly Dutch. Holland, especially the city of Leyden, had become the haven for persecuted Protestants and Jews. The English Puritans spent eleven years in Holland before coming to America. They, with the Dutch and dissenters from France, Ireland, Germany, and elsewhere, composed the bulk of the passengers on the Mayflower. About one-third of the colony was composed of boys and girls, most of whom were born in Holland. Those who had fled to Holland had become adjusted to a superior civilization, which included public schools, homes for orphans and the aged, free speech and press, humane courts and prisons. These superior cultural traits were transplanted to America; consequently, in the early years, Plymouth resembled a Dutch far more than an English town.

In 1609 Henry Hudson discovered the river that bears his name, and in 1621 the Dutch established a trading post known as New Amsterdam (New York). The Dutch tried to establish colonies, but few settlers wished to come. When New Amsterdam was captured by the English in 1664, not over a third of the inhabitants were Hollanders. The Dutch possessed the region around New York for about 40 years, yet there were probably not 10,000 Hollanders in all their settlements. A few drifted over and settled in Pennsylvania, but most of the "Pennsylvania Dutch" are German in origin.

During the seventeenth century only a few Dutch settlers came. After the establishment of the Kingdom of the Netherlands (1815) there was much dissatisfaction with the established church. In 1843 
the cattle pest and potato rot swept the country. Economic and religious motives both encouraged the Dutch to come to America. Gradually flourishing settlements grew up around Black Lake, Michigan, and Pella, Iowa. In 1871 only 993 immigrants came from Holland, but eleven years later 9517 came. During the eighties 53,701 more came, and then came a drop followed by an increase the next decade. For the last few years we have been receiving between 2000 and 3000 . The period between 1820 and 1930 saw over 246,609 land in this country. In 1920 there were 136,540 foreign-born whites in the United States whose mother tongue was Dutch; 94.4 per cent of these were from Holland. Our present law permits 3153 immigrants from Holland per year, an increase of 1505 over the two per cent law.

As Belgium usually has more immigrants than emigrants, it has never sent large numbers to the United States. In 192929,162 Belgians emigrated, 24,848 going to European countries and 4314 to non-European. During the same year 55,595 immigrants arrived. Belgians usually go to Holland, Germany, and France, and generally for short periods of time. Most of our immigrants from Belgium are Flemish from the cities and industrial centers rather than Walloons or peasants. Limited economic opportunities and political discriminations by the Walloons have, perhaps, been the chief causes of their leaving Belgium. In 18941709 Belgians came, in 1904 3976, in 1905 5302, in 1907 6396, in 19137405 - the largest number for any one year - in 1925726 , in 1930909 . For the period 1820 to 1930, the total number of immigrants from Belgium was 153,388. In 1920 the Belgians numbered 62,686 of our foreign-born, and 122,686 of our foreign white stock. Belgians are found in every state, and almost half of them have settled in rural areas. They readily become citizens; 49 per cent of those here in 1920 had their final papers. Our two per cent law permitted only 512 Belgian immigrants per year, but our present law raised the number to 1304 .

Very few Dutch or Belgians emigrate to any country other than the United States. After the United States, Canada attracts most of the Dutch, but the numbers are not large. Only 25 landed in 1900, 1524 in 1912, and 1637 in 1924. A few Dutch emigrants have been going to South Africa since 1913, but the largest number for any year was 431 in 1920. A very few Belgian emigrants have gone to Canada, Argentina, and Brazil. The largest number going to Canada in any year was 2072 in 1913; for Argentina it was 383 in 1883, and for Brazil it was 376 in 1862 . Since the restriction laws of the United 
States have been passed, it will be interesting to see where Dutch and Belgian emigrants turn.

\section{QUESTIONS, EXERCISES, AND PROBLEMS FOR INVESTIGATION}

1. (1) Make a comparative statement of the areas and populations of these countries. (2) How do their areas and populations compare with those of their colonies?

2. What may be said of the ethnology of the peoples of the Netherlands and Belgium? Besides the text, see Ripley, W. Z.: The Races of Europe, pp. 157, 293-99.

3. Describe the struggle that Holland has had with the sea. See Gore, J. H.: "Holland's War with the Sea," National Geographic Magazine, Vol. XLIII, pp. 283-326; Van Lonkhuyzen, J. P.: "Land Reclamation and Land Improvement in the Netherlands," International Review of Agricultural Economics, July-Sept., 1925, pp.449-78; and Jansma, K.: "The Drainage of the Zuider Zee," Geographical Review, Vol. XXI, pp. 574-83.

4. Show how different national influences played upon the Netherlanders.

5. Outline the difficulty regarding the Scheldt.

6. Account for the fact that Belgium is highly agricultural as well as industrial.

7. In what respects may religion be said to form a barrier to harmony in Belgium? Trace the rise and development of Protestantism in Holland and show its influence on early colonial life in America.

8. Make a report of the language situation in Belgium. Besides the text, see Laurent, Henri: "The Language War in Belgium," Current History, Vol. XXXIV, pp. 834-40; and Pierard, Louis: "Belgium's Language Question: French vs. Flemish," Foreign Affairs, Vol. VIII, pp. 641-51.

9. Give a picture of the social conditions in Holland and Belgium.

10. What are the characteristics of the immigration from Belgium and Holland?

11. Abstract the article by Marie-Louise De Meeûs, "Brussels a Hundred Years Ago," Nineteenth Century, Vol. CVII, pp. 214-26.

12. How have the geographical positions of these two countries affected their policies? See Theunis, Georges: "Belgium Today," Foreign Affairs, Vol. IV, pp. 264-77; and Clark, G. N.: "The 'Great Netherlands' Idea," Edinburgh Review, Vol. CCXLIII, pp. 240-52. 


\section{CHAPTER VI}

\section{SWITZERLAND AND LIECHTENSTEIN}

1: General Description. Switzerland (German, Schweiz; French, Suisse; Italian, Svizzera) is somewhat larger than Maryland and Delaware combined. It contains 15,976 square miles and had a population of 4,066,400 in 1930. Bounded by Germany, Austria, Italy, and France, Switzerland has no seacoast, but the Rhine, Rhone, Po, and Danube have determined the continental movements of people with their merchandise and their culture., Switzerland, therefore, has been, and through the construction of tunnels continues to be, the Alpine meeting-ground of peoples and the crossway of traffic and culture.

The characteristic physical features of Switzerland are its mountain ranges, enormous glaciers, magnificent lakes, countless waterfalls, and wild, romantic life. The differences of elevation create a varied climate and a wide range of vegetation. The country is ordinarily divided into seven regions, according to elevation. The valleys, having an elevation up to 1700 feet, constitute the first area and have for their main products cereals and grapes. The second area includes the hilly and lower mountain regions, up to 2800 feet. It contains excellent forests of walnut and beautiful meadows, and produces good crops of spelt. The third belt includes the upper mountain region, to 4000 feet. Here are found good crops of barley and oats, excellent pastures and forests. The fourth, or sub-Alpine area, goes up to 5500 feet. No regular crops are grown, but forests of pine and maple are profuse. The fifth area extends up to 6500 feet. It is famous for its Alpine pastures. In the sixth, or upper Alpine region, the vegetation becomes more stunted and the variation of seasons is lost. The seventh area is the region of perpetual snow.

Switzerland is composed of 25 cantons loosely held together. These vary widely in size and population. Two - Geneva and Basel - are primarily city states. Although chiefly an agricultural country, Switzerland has four cities with populations of more than 100,000. In race the people are Nordics, Alpines, and Mediterraneans, with survivals of earlier groups. Nineteen of the cantons speak German, five 
French, and one Italian. According to estimates, 71.4 per cent of the people speak German, 21.7 per cent French, 5.3 per cent Italian, and 1.2 per cent Romansh, a Latin dialect. As there are three national languages, government documents are printed in German, French, and Italian. Many of the people speak two or more languages fluently.

Liechtenstein is a tiny principality shut in by Switzerland and Austria. It has an area of 65 square miles, and in 1930 had a population of 10,213 .

2. Political Development. It is neither race, language, nor religion that binds the 25 Swiss cantons together, but rather their love of free-

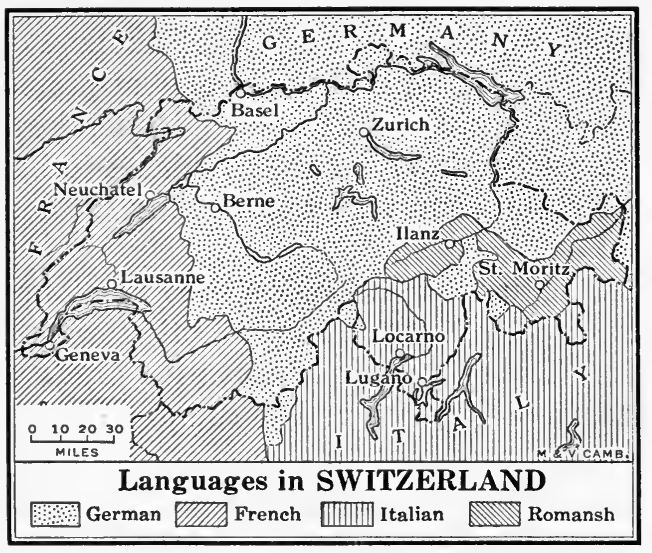

After Bowman dom and their passionate fondness for their mountain country. The secret of their success has ever been their masterful local patriotism and their rustic skill. The two words Swiss Pikeman express this secret. The pikeman fought with a shaft from 15 to 20 feet long, capped with an iron point. Below this lance end was fastened on one side a great ax head, and on the other a hook sharpened like a sickle. These pikes were planted firmly in the ground, row after row, and in one of three ways (by means of lance, ax, or hook) halted the mailed and mounted knights who had successfully plundered much of Europe, and thereby preserved the valleys for the patriotic Swiss. These pikes, in which we see combined the tools used in the five rustic occupations of the Swiss the stake and sickle of the peasant, the crook of the herdsman, the pike of the miner, the ax of the woodsman, and the lance of the primitive hunter - symbolize the union of all groups in defense of their country.

Switzerland is one of the oldest republics and one of the most democratic countries in the world. As a nation, however, it cannot boast of an earlier origin than 1291. Previous to that time it had been occupied by Helvetians, Romans, Alemanni, Burgundians, and Franks. The Swiss, not being enthusiastic over becoming part of Charle- 
magne's empire, refused to become subjects of Charles the Bold and revolted against the Austrian Hapsburgs.

During the interregnum of 1250-72 the seeds of the future republic were sown. In 1291 three cantons - Uri, Schwyz, and Unterwalden - formed a union to resist Austria perpetually. By 1353 five more cantons had become members of the league. Austria attempted to crush the league, but without success. In 1389 a seven-year peace pact was signed between Switzerland and Austria, and by continued renewal remained in effect for about seventy years. At the Convention of $\operatorname{Stanz}(1481)$ the cantons agreed to abandon their local differences in order to résist better any outside power. All groups joined together to resist Austria, and all groups have remained thus united.

In 1798 the short-lived Helvetian Republic was organized, but in 1803 a new confederation was founded by Napoleon. The Congress of Vienna (1815) guaranteed Switzerland's independence and neutrality. In 1848 it adopted a new constitution, modeled after that of the United States, but more democratic and progressive. The Nationalrat corresponds to our House of Representatives, and the Ständerat to our Senate. The Bundesrat is the executive power. It has seven members, and the chairman is the president of the nation. $\mathrm{He}$ is elected for one year only, and cannot succeed himself.

Switzerland has consistently avoided entangling alliances. Although peace-loving, the Swiss maintain an efficient military force of 46,000 men. Service in the national militia is compulsory.

Switzerland remained neutral during the World War; consequently it avoided the problems of debts and boundary disputes. In 1918-19, however, the Austrian province of Vorarlberg, which contains some 140,000 German-speaking people, sought to unite with Switzerland. The Swiss opposed this union because it would raise the problem of war debts, increase the number of Roman Catholics, and augment the German-speaking majority.

In conclusion, it may be said Switzerland has long been the political laboratory of Europe. It has had civil as well as national problems and has tried and rejected more than one solution of them. One interesting experiment was the rotation of the national capital. Each of six cities was to shoulder the responsibilities of the national state government for a fixed period. This arrangement, however, ceased with the fall of Napoleon, whose idea it was, and the national capital was made stationary.

Liechtenstein is a hereditary monarchy. Until 1866 it was a mem- 
ber of the German confederation. From that time until November 7, 1918, when the Diet declared its complete independence, it was practically a dependency of Austria. In 1924 it concluded a treaty with Switzerland which admitted it into the Swiss Customs Union, and Switzerland administers its postal, telegraph, and telephone systems.

3. Economic Development. The natural resources of Switzerland are chiefly of two kinds, water power and timber. The water power is being used in hydro-electric power. Under the comprehensive plan of 1925 , some 1033 miles of the 3753 miles of railways were electrified by 1929 , and about 95 per cent of Swiss towns and villages were served by electricity. Over one-fourth of the land is non-productive, and about one-half of the total area is in forests and pastures. The forest land composes 29 per cent of the productive area. This acreage cannot be reduced. Care of the forests is carefully supervised, and a tree must be planted for every one cut. About 36 per cent of the productive land is used for growing grass, 18 per cent for fruits, and 16 per cent for crops and gardens. Almost one-fourth of the people are wholly engaged in agriculture, and over one-half of the population are supported by agriculture. The system of peasant proprietorship prevails, there being some 212,300 separate farming properties, averaging less than 20 acres each.

Cattle raising and dairying are important occupations, supplying about three-fourths of the total annual production. Swiss cheese has a wide market. Manufacturing, especially of wine, clocks, watches, and other jewelry, laces, silks, and embroideries, is another important occupation. Hand power and primitive methods of production are still common in Switzerland, but these are rapidly being replaced by electricity. Switzerland is known as the "playground of Europe," and every year it is visited by thousands of American and European tourists. Its net income from this source in 1925 was $205,000,000$ francs. The hotels employ about 65,000 people and receive over $\$ 50,000,000$ per year in gross receipts.

Switzerland's chief imports are foods, textiles (chiefly raw and semimanufactured cotton, woolen, and silk goods), and minerals (coal, iron, and chemicals). Its exports are mainly manufactured cotton and silk, clocks, and dairy products. Having no colonies and no seaport, Switzerland is largely at the mercy of powerful neighbors. The Rhine and Rhone are its natural outlets. At the Convention of Mannheim (1868) the Rhine Navigation Treaty gave Switzerland free use of the Rhine from Basel to the North Sea. The World War 
ended this arrangement. Switzerland now has "freedom of access to the sea over all desirable routes," but it has to grant equal rights to other nations across its territory. For some time it has been having trouble with France, because France wishes to construct a canal through Alsace, parallel to the Rhine. The Swiss claim that the proposed French canal and dam would block the Rhine traffic and thus be detrimental to three-fourths of the Swiss population.

4. Religious Development. There are legendary accounts of the introduction of Christianity into Switzerland. It is believed to have come in with Roman culture, rather than through the efforts of missionaries. The Reformation affected Switzerland profoundly through two of the leaders in the movement - Zwingli, who started his work in Zürich, in 1519, and Calvin, who began his in Geneva, in 1536. The usual upheaval between Catholics and Protestants followed, but apparently the strife was less bitter in Switzerland than in most of the surrounding nations. Religious freedom was early granted to all except Jesuits, and Switzerland became a haven for the persecuted. In 1920 there were 2,230,597 (about 57 per cent) Protestants, 1,585,311 (41 per cent) Roman Catholics, and 20,919 (0.5 per cent) Jews. Protestants have a majority in twelve and Catholics in ten of the cantons. Religion has rarely divided the Swiss people. That it is not a dead issue is revealed by the Protestant objection to the acceptance of Vorarlberg into the Confederacy because it is predominantly Catholic.

5. Educational Development. Switzerland has long been a haven for heretics, exiled scholars and scientists, and freethinkers. Despite the fact that some of these exiles used Swiss soil to plot against their enemies, Switzerland has remained an asylum for the persecuted. An excellent system of public schools exists, and the teaching of languages, history, and geography is outstanding. The public schools are free and compulsory for children between the ages of 7 and 14 . The continuation schools are well attended. Illiteracy is almost unknown. Owing to the fact that some cantons are more mountainous than others and public schools more difficult to maintain there, eight receive larger grants from the school fund than the others. Switzerland has seven universities, all of which are patterned after those of Germany, with about 7000 students for a population of $3,886,320$. Some of these universities, especially Zürich and Basel, are well known in America. In 1929-30 about 28 per cent of the matriculated students were foreigners. 
6. Social Conditions. Switzerland is a leader in social legislation. The initiative and referendum had their inception there. Labor legislation dates from 1815, the Grütliverin, a labor organization, from 1838 , and employers' liability from 1875 . Railroads, telegraphs, telephones, and other public utilities are owned by the government. Old age and industrial insurance are nationally operated, and the 48-hour week is in full force. Women and men are supposed to have the same rights, legally and socially. A promise to marry is not binding, and there are no breach of promise suits.

Since Switzerland has a large urban population more or less isolated from the scattered rural groups, it is natural that the cantons should have a colorful and individualistic life. Its excellent school system, high literacy, and liberal laws have given the people a sense of civic and social appreciation which enables them to enjoy life. Singing and dancing are social pastimes, and holidays are much enjoyed. Sunday is not a blue day; instead, it is the merriest day of the week.

Liechtenstein is a mountainous, cattle-raising country. Practically all the people are rural, and social conditions correspond to those of rural Switzerland.

7. Immigration and Emigration. Switzerland loses citizens by emigration, but it also receives comparatively large numbers of immigrants. On the average, it loses from 4000 to 8000 (4608 in 1929) of its citizens per year, most of whom go to the United States. On the other hand, it increased its Italian population from 41,000 to 238,500 between 1800 and 1925. 'The Swiss complain that these Italians congregate in the cities, live in separate colonies in unsanitary surroundings, object to sending their children to school, have an exceedingly high birth rate, furnish an unusually large number of criminals, increase the social and economic problems of the government, and displace Swiss labor, especially in textile mills, hotels, and railroad and construction work.

The Swiss have come to us for a long time in what appear to be small numbers, but which are really large in proportion to population. Very early, like England, Germany, and other countries of Europe, Switzerland shipped a number of criminals and paupers here at public expense. In 1870 there were 75,153 native Swiss in the United States, in 1910 124,848, and in 1920 118,659. From 1820 to 1930, 290,168 Swiss immigrants entered the United States. In 1920, 0.9 per cent of the foreign-born white population from Europe was Swiss, a larger percentage than from France, Rumania, Bulgaria, Spain, 
Portugal, South America, Central America, or Asia. Between 1881 and 1910, 80 per cent of the Swiss emigrants came to the United States, and between 1891 and 1895, 90.7 per cent.

The Swiss come here almost altogether for economic reasons. They usually engage in the same occupations which they followed in their own country. Owing to the advantages of language study which they have had, many of them become teachers of modern languages in high schools and colleges. They bring with them a high plane of living and no national prejudices or psychoses; consequently they assimilate easily.

A few Swiss emigrants have gone to other countries. Brazil, Argentina, and Chile have tried to attract them, but without great success. After the United States, Argentina has received the largest number 37,017 for the period 1857-1924. Some have gone to Canada and a few to Algiers. The numbers going to Brazil and Canada have been increasing since the World War and the passage of the restrictions by the United States. The present law permits 1707 Swiss immigrants to enter, 374 less than the two per cent law.

Most of the emigrants from Liechtenstein have gone to the United States. The quota law grants it 100 immigrants per year, but in 1929 only 35 came, and in 1930 only 9 .

\section{QUESTIONS, EXERCISES, AND PROBLEMS FOR INVESTIGATION}

1. What is meant by "the Alpine meeting-ground of peoples and the crossway of traffic and culture"? Besides the text, see Ripley, W. Z.: The Races of Europe, Chap. XI; and Pittard, Eugène: Race and History, Part II, Chap. V.

2. Discuss the physical characteristics of Switzerland and the significance of its position in Europe and European affairs. In addition to the text, see Gibson, Hugh: "Switzerland's Position in Europe," Foreign Affairs, Vol. IV, pp. 72-84; and Branford, Victor: "Switzerland: An Interpretation," Sociological Review, Vol. XIX, pp. 304-17.

3. Give a brief statement of (1) the relative importance of the three national languages; and (2) the secret strength of unity among the Swiss.

4. In what respects may Switzerland be regarded as the political laboratory of Europe?

5. What is the relationship between Switzerland and Liechtenstein?

6. Account for the effects of the Protestant Reformation upon Switzerland.

7. What factors have doubtless contributed to the efficiency and popularity of Swiss schools? To Swiss leadership in social legislation? 
8. Characterize the Swiss immigration to America. What is its own chief immigration problem?

9. Write a brief historical sketch of Geneva, paying special attention to its place in mothering international organizations. Reference. Branford, Victor: "A Free City and a World in Chains," Sociological Review, Vol. XV, pp. 265-73.

10. Make a chart showing the emigration per decade and also the repatriation. Reference. Ferenczi, Imre: International Migrations, Vol. I. 


\section{CHAPTER VII}

\section{LITHUANIA-AND LATVIA}

1. General Description. On the southeastern shore of the Baltic Sea, on both sides of the Niemen River, between the sea and the Valdai heights, lies the territory of a remarkable, ancient, free people, whose princes during the fourteenth and fifteenth centuries were the mighty rulers of a large section of Europe. Long before the World War, however, this people was an almost forgotten, cowed, and powerless group of peasants, divided between the Russian and German empires. Forty years ago only one-seventh of those on the Russian side could read; nevertheless national ambitions were stirring. In 1918 the Lithuanian nation was resurrected from the state of oblivion in which it was buried at the end of the eighteenth century after the partition of Poland, and emerged a free republic.

Philologists, anthropologists, ethnologists, and historians have long disagreed as to the group to which the Lithuanians belong. They are believed to be the first inhabitants of the region where they live, and to constitute the oldest linguistic racial group in Europe. Some writers classify them with the so-called Litho-Baltic race, which consisted chiefly of Lithuanians, Letts, and the now extinct Bo-russians. Other students think there were a number of tribes, such as Letts, Semigalls, Jmouds, Prussians, and Lithuanians, extending from the region near Doral beyond Königsberg, nearly to Danzig. Biologically they are generally classified as either Teutons or Slavs. Some anthropologists think they form the connecting link between, or are the progenitors of, Teutons and Slavs. Efforts have been made to connect their language with Sanskrit, Greek, Latin, and the Teutonic and Slavonic languages. It appears to be a little closer related to the Slavonic than to any other.

Although the Lithuanians are a mixed group and apparently could be placed with either the Teutons or the Slavs, the Nordic type prevails. Perhaps because of their political connections, our immigration officials have classified them as Russians. Biological and cultural considerations suggest classification with the Teutonic group. Racially the Letts (inhabitants of Latvia) are the same as the Lithuanians, 
and have been placed with them by our immigration officials. Since the two peoples are racially and culturally practically the same and have had a similar history, and since both republics are war-born, they are here considered together.

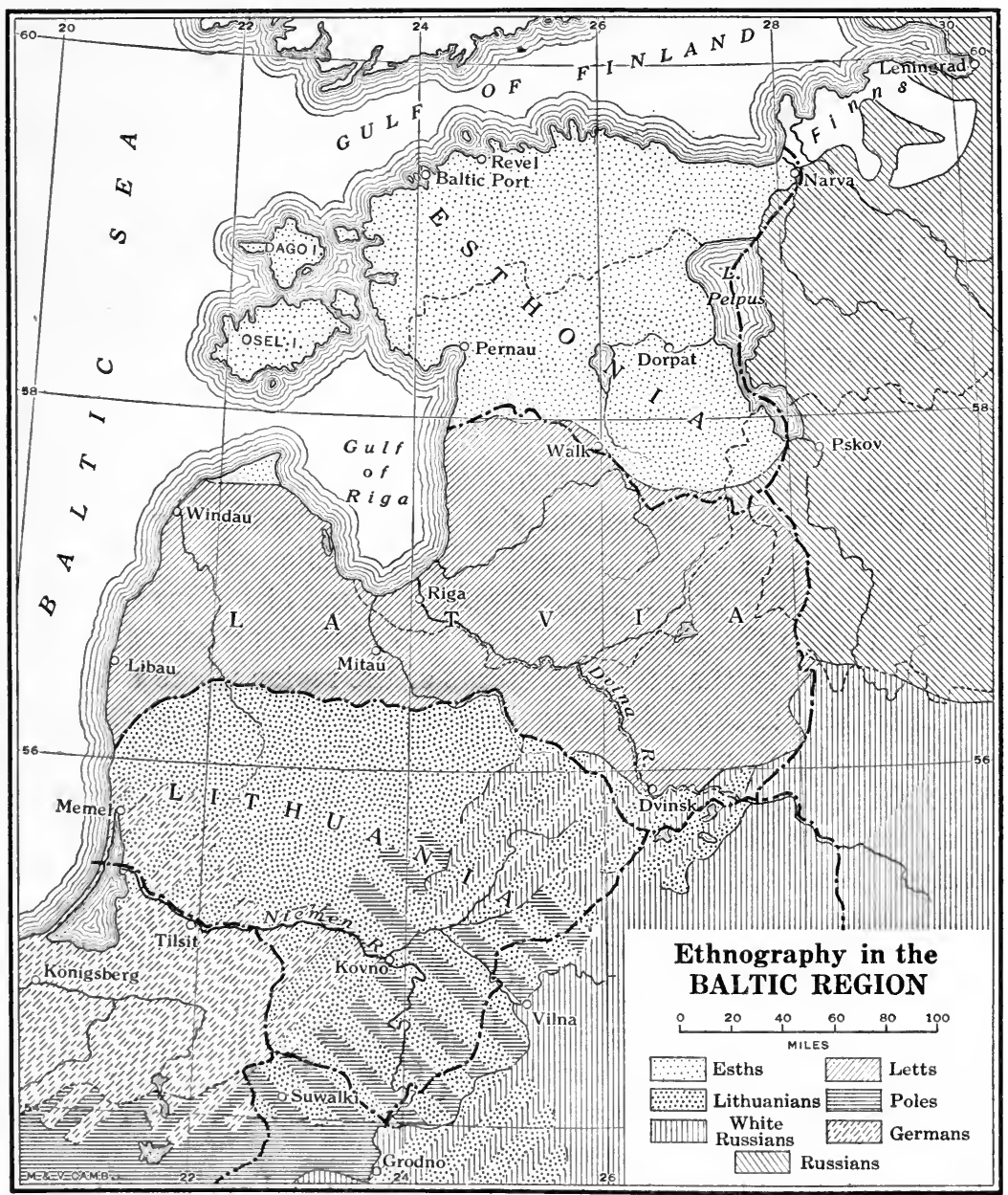

After Bowman, slightly modified

Exclusive of Memel and its territory (1057 square miles) and Vilna (Vilnius) and its territory (5200 square miles), Lithuania has an area of 20,550 square miles or is about half the size of Ohio. In $1923 \mathrm{its}$ population of $2,011,173$ (estimated to be $2,340,000$ in 1930) was di- 
vided as follows: 1,696,158 Lithuanians, 153,332 Jews, 64,015 Poles, 48,392 Russians, 23,973 Germans, 14,318 Letts, and 4656 persons of other racial groups.

The territory of Latvia embraces 25,402 square miles, is a little larger than West Virginia, and has a population of 1,900,045 (1930). Native Letts compose over 80 per cent of the present population. According to the Russian census of 1897, 79 per cent of the people in Courland and 39.3 per cent of those in Livonia were Letts. About 22 per cent of the people live in towns. Riga, the capital, has a population of 337,700 .

2. Political Development. Little was known of the Lithuanians and Letts until about the middle of the twelfth century, when German traders and monks began to acquaint themselves with the people and territory. In 1201 these knights and monks began to overrun the country, to build castles everywhere, and to reduce the inhabitants to serfdom. The Prussians were all but destroyed and the Letts conquered, but the Lithuanians remained free in their forests and marshes. The three groups formed a loose alliance against their enemies, but rival chieftains, bidding for assistance from outside groups, prevented a strong union and almost wrecked the country. After some time Gedimin (1315-39) appeared and extended the Lithuanian domain far into Russian territory. His son Olgerd (1339-77) extended Lithuanian rule across Europe, from the Baltic to the Dnieper and Dniester and the Black Sea. Lithuania was now at the apex of its greatness; it stopped the Tartars, who had often overrun large sections of Europe, broke the power of the German knights, and defeated the Russians at will. Its name was feared and honored throughout a large section of Europe.

In 1386 Grand Duke Jagellon (Jogaila, Jagiello) of Lithuania wedded Queen Hedzwig (Hedvig, Jadwiga) of Poland, and was crowned King Wadyslaw V of Poland, thus uniting the two countries. Soon Poland began to encroach upon Lithuania, thereby causing intermittent struggles. In 1569 the Union of Lublin was perfected, and gradually Lithuania was Polanized by the Polish gentry and clergy. Lithuania, however, continued its own administration, maintaining a separate treasury and army. In 1791 Lithuania became a part of Poland and thus remained until the partition, when Russia took the northern part and Prussia the southern part. Under Russia Lithuania remained a Grand Duchy until the break-up of the Russian Empire during the World War. 
The history of Latvia has been only slightly different from that of Lithuania. Lettish tribes racially akin to the Lithuanians inhabited the present territory from about the tenth century. The country was visited in turn by German traders, missionaries, and crusaders. In 1200 Bishop Albert landed twenty-three shiploads of people, who composed an order known as Brothers of the Sword or Livonian Knights. They were followed by German colonists, who became known as Balts, and whose descendants still remain in the country. Latvia was at different times a part of the Livonian Confederacy, a part of the Grand Duchy of Lithuania, and a part of the Swedish Empire; later it passed under the power of Poland and then of the Russian Empire; finally it became a liberal republic. After 1561 Livonia became a part of Poland, and Courland became a Polish Grand Duchy. Lettland passed under the rule of Sweden in 1629 and of Russia in 1721. In 1621 Livonia was annexed by Sweden, and in 1710 became a part of Russia. With the partition of Poland all the present territory of Latvia became a part of Russia, which retained it until the World War. Throughout this time German culture remained dominant, due to the fact that Teutonic knights and Hanseatic merchants held offices of public trust and were the overlords. Meanwhile the servile Letts were slowly developing a spirit of national consciousness.

The break-up of the Russian Empire gave both the Lithuanians and the Latvians (Letts) an opportunity to strike for their freedom. At first the Lithuanians declared themselves a constitutional monarchy under German protection. Germany promised to support Lithuania in its claim for independence. The Taryba wished a Roman Catholic king and offered the royal crown to William, Duke of Urach, Count of Württemberg. After the German revolution Lithuania declared itself a free democratic republic.

The capital of the new republic of Lithuania was established at Vilna (Vilnius, Wilno), the ancient capital, and its territory was to be that which it anciently possessed. Kovno, however, is regarded as the capital temporarily. The Memel (Klaipeda) territory, formerly part of the German Empire, was made an autonomous unit under the Lithuanian republic. Vilna - the historic Lithuanian capital - and its territory were ceded to Lithuania by the Suvalki agreement, signed October 7, 1920, by Russia, Poland, and other powers. Two days later the lawless Polish General Zeligowski seized the Vilna territory on the pretext that it was a Polish colony, although less than 9 per cent of the population of the territory and a little over 10 per 
cent of the population of Vilna are Poles. The Polish government declared Zeligowski a rebel, but secretly supported him, flouted the authority of the League of Nations, held a sham plebiscite, and "acquired" the Vilna region and held it. The Council of Ambassadors tried to bring about a reconciliation to the disadvantage of Lithuania, but Lithuania persistently, and doubtless justly, refused to be reconciled.

Like the Lithuanians, the Letts had to help bear the first blows of the German army in the World War, and thousands lost their lives fighting for an oppressive government under despised Balt officers. Later the Letts were permitted to form battalions of their own with Lettish officers. This, however, stimulated nationalism. Many Letts had been exiled and were waiting in foreign countries until the time came to strike for freedom for the land of their birth. The opportunity came in 1917, but the country had to be cleared of both Germans and Bolsheviks. In the early part of the war the Letts won the name of being hard fighters and revolutionary thinkers. They sided with the Bolsheviks and remained loyal to them until they were sure that Bolshevism was detrimental to their country. With the onrush of the German army, many Letts fled from their country and scattered over Russia. Those who remained were treated kindly by the Germans and developed a German loyalty.

Latvia contains almost half of the former province of Livonia and all of Courland. It adopted a liberal constitution in 1922. It has a Parliament (Saeima) of 100 members elected for three years by citizens 21 years of age, with proportional representation of some 26 parties. The president is elected by Parliament for a term of three years. He selects a prime minister, who appoints a cabinet which is responsible to Parliament.

The legislative "power of Lithuania is vested in a constitutional assembly of 112 members who are elected directly by universal equal suffrage, with proportional representation. The president is elected by the assembly. The new constitution, proclaimed May 26, 1928, fixed the term of the president at seven years and of parliamentary members at five years; the age of electors was set at 24 , and Vilna was declared the capital of the nation.

3. Economic Development. In ancient times Lithuania was an almost uninhabited land of forests and marshes; today it retains much of its early character. It is unprotected by mountains or hills and has long been a battle ground for Swedes, Poles, Russians, and Germans. 
Perhaps no people have suffered more from wars than those around Vilna and Kovno.

Lithuania's location is now an economic advantage, as international trade from Berlin, Paris, Warsaw, Riga, Dvinsk, and Leningrad passes through its territory. The country is poor in mineral resources but has considerable timber. The Soviets voluntarily gave Lithuania 250,000 acres of timber land, mostly on the Niemen River, for exploitation.

Agriculture has long been the chief occupation, and about 80 per cent of the people are now engaged in tilling the soil. About 48 per cent of the total land area is arable. Before the World War about one-half of the country consisted of estates of 500 acres or more. A reduction of these estates for purely economic reasons was in process before the land law of 1922 was passed. Under the new law the estates are being broken up and parceled out to peasants in lots not exceeding 50 acres. Under this law all private holdings over 197 acres were subject to appropriation, and all over 375 acres were to become the property of the state. The price fixed for the land was the average between 1910 and 1914 . Within three years private holdings increased from 168,000 to 214,000 . Of this number 31 per cent are less than 28 acres, 50 per cent between 20 and 25 acres, and 15 per cent between 50 and 110 acres. The peasants are to pay for this land and equipment in rye, extending over a period of 36 years, and the landlords are to be compensated by 3 per cent treasury certificates maturing in 36 years.

The economic development of Latvia is similar to that of Lithuania. Only about 26 per cent of the land is arable, however. Over half the people are engaged in agriculture, stock raising, and dairying. Flax, rye, barley, oats, and potatoes are the principal crops. The land reform law was passed in 1919 and amended in 1922 and 1924. The estates of nobles and other large landholders were declared to be the property of the state. The owners were permitted to retain their dwellings and about 125 acres of land. By 1926 over 3,463,200 acres had been reallotted, and 95,024 new farms established. There are about 4,399,000 acres of forests; lumber is the chief export. Manufacturing, especially woodworking, match and paper making, distilling, and shipping are important industries. The railroads are state owned, and Riga is an important railroad center. Latvia has a very important position, since most of Russia's trade with the western nations passes through its territory. 
4. Religious Development. Lithuania fought against Christianity for three centuries. It was a strong pagan country in which the fire god was very popular; consequently it long withstood the onslaughts of the Christian swords of the German monk-knights and other missionaries. Compromises between paganism and Christianity were accomplished and followers gained for Christianity, particularly when some of the leaders accepted the new faith. In order to win his wife, Jagellon accepted the Latin form of Christianity, and when he returned to Lithuania he was accompanied by a priest who baptized ,wholesale the people of the last pagan country of Europe. After this union the Polish noblemen, supported by the ever faithful clergy, did everything in their power to denationalize the Lithuanians, to substitute the Polish language for the Lithuanian, and to make the people faithful Roman Catholics.

Under Russian rule the Russian Church did all within its power to Russify the non-Russians, but with little success. No church could be built or repaired, no dilapidated cross by the side of the road replaced. As rapidly as possible Latin churches were condemned as unsafe and Russian churehes erected in their place. Printed matter in Lithuanian was prohibited. The Poles furthered their own cause by persuading the Lithuanians to use the Polish prayer book. As a result the Lithuanians now use many Polish words for theological terms. The Polish insurrection in 1863 caused the Russians to favor the Lithuanians and play them against the Poles. Every effort was made to destroy the Poles and their influence in Lithuania. Churches and monasteries were seized and the use of the Polish language prohibited. Against their will the Uniates in 1874 were officially united with the Orthodox Church. A law was passed, which existed down to 1905, prohibiting any one who belonged to the Orthodox Church from changing his religion. The Edict of Toleration in 1905 permitted the Lithuanians to use their own language in churches, schools, and books. They, however, remained faithful to the Latin Church. At present there is a strong feeling against the Roman Catholic Church officials because of the partiality shown Poland in the Vilna dispute.

During their supremacy the Balt barons imposed the Lutheran faith and ecclesiastical authority upon the Letts. The Russians subsequently tried to convert them to the Greek Orthodox Church by both force and trickery. A questionnaire was sent to the head of each family merely asking if he was German or Russian. No men- 
tion was made of Lettish. Understanding the hatred of the Letts for the German barons, they knew the answers of the unsuspecting peasants. In a short time another and more elaborate document was sent to them reminding them that they had officially declared themselves to be Russians and now they must conform to the rites of the Russian Church. A list of these families was sent to the Lutheran pastors, and they were forbidden under heavy penalties to admit any of these to their churches. Many Lutheran pastors were removed from their churches and severely punished for a violation of this law. Under such treatment the Letts became fervent Protestants. Over three-fourths of the present Latvians are Protestants and about 19 per cent Roman Catholics. On the other hand, about 81 per cent of the Lithuanians are Roman Catholics, 7.3 per cent Jews, 8.8 per cent Protestants, and 2.5 per cent Greek Orthodox. The Lithuanians of the former German Empire are Lutheran and have practically lost their language. Nearly all of them are now studying it or having their children learn it. Both Lithuania and Latvia guarantee freedom of worship to all sects.

5. Social Conditions. Under German, Polish, and Russian landlords the Lithuanians and Letts were made serfs and received little reward for their toil. Alexander I granted the serfs of Livonia freedom in 1819, one year after Esthonia and two years after Courland had done so; but as they were unable to purchase land, they continued to work for their former masters. The government had practically promised them emancipation in $\mathbf{1 8 1 2}$ for their part in the Napoleonic Wars, but it failed to grant it. Finally, in 1861, the Lithuanians were emancipated, but this meant little. The Polish insurrection in 1863, however, caused the Russian officials to deal more liberally with the Lithuanians and to play them against the Poles. But before long the Lithuanians were subjected to a Russification campaign. Under the threat of banishment or heavy fine, they were forbidden to print books or papers in Lithuanian or any Latin letters; to possess books in Lithuanian, unless they had been published before the Russification decree; to speak the language or permit their children to learn it; or to wear their national dress. As a further punishment, their country was made a penal colony for felons for two years. The German Lithuanians had many more liberties than their brothers in Russia, and there and in foreign countries continued to publish books in Lithuanian and to maintain an intelligentsia. 
The Letts began to manifest national feelings in the early part of the nineteenth century. Despite the fact that they were revolutionary, they developed an intelligentsia that conferred with the Russians and secured many advantages for the people. Russia granted autonomy to the Lettish commune in 1866, and immediately a cultural advancement and literary renaissance began. In 1882 the Russians excited the Letts against their Balt masters and encouraged them to use their own language. It was not long, however, before the Russification program was initiated and advancement blighted. Nevertheless, the young Letts continued to imbibe Western ideas, which caused them to react strongly against both Balt landlords and Russian rulers. This brought the revolution of 1905 , which resulted in much bloodshed and the destruction of many palaces of Balt and Russian officials. The Letts thereafter suffered all the oppressive measures inflicted on the people of the other Baltic provinces. Yet so great was the hatred of the Letts for the Balts that they were generally ready to side with the Russian officials. Both groups of rulers treated the Letts as inferiors. The Balts, however, tried to educate the Letts and to train them in scientific agriculture. That they succeeded is shown by the fact that in 1910 only 3.2 per cent of the people were illiterate as against about 50 per cent of the Lithuanians, who were largely dominated by the Poles.

Immediately after gaining their freedom both republics established a system of free and compulsory public elementary and secondary schools. In 1922 Lithuania opened a state university (the University of Kovno) which in 1930 had a faculty of 258 and a student body of 4025. Formerly the University of Dorpat served all the Baltic provinces, but when it became an Esthonian institution the Riga Polytechnic was raised to the rank of a university. The Latvian University now has an enrollment of 8284. Freedom of speech, of communication, of assembly, and of association are guaranteed. Workmen are protected by sickness, accident, and old age insurance. The rights of minorities are fully protected. The governments are trying to regulate economic conditions so that all may have work.

6. Immigration and Emigration. According to the Encycloprdia Britannica, ${ }^{1}$ Latvia lost 40 per cent of its population by emigration in consequence of the German invasion. Hardly 300,000 have returned out of the refugee population of 1915-17. Some 650,000 of the missing perished, and about 10,000 farms were utterly destroyed.

1 Vol. VIII, p. 762. 
In Courland (1915-18) the population diminished to one-third, and over half the farms were either destroyed or vacated. Since the World War there has been a considerable shift of population between Russia and Latvia. In 1920 93,533 persons arrived in Latvia, 87,967 being from Russia, and in 1921 94,881 others came, of whom 91,788 were Russian refugees and other migrants from Russia. During these same years 14,258 departed to Russia, over half of this number being refugees and prisoners of war. In 192188,663 people arrived in Latvia from Russia en route to other countries, and 43,984 en route to Russia. It was long the practice of our Bureau of Immigration to place Lithuanians and Letts together, under the "Slavic division." Consequently we do not know how many of each have come to the United States as immigrants. In 1910 there were 140,963 foreignborn people in the United States who gave Lithuanian or Lettish as their mother tongue. By 1920 this number had increased to 182,227. Of the foreign-born stock by mother tongue, Lithuanians and Letts numbered 207,821 in 1910 and 336,600 in 1920. Almost 50,000 of the 182,227 in the country in 1920 came from Russia, and 3446 from Poland. How many of these were Lithuanians and how many Letts we do not know. According to the Russian figures for 1897, there were 3,094,469 people in Russia whom our Bureau of Immigration classified as Lithuanian and Lettish, and they were almost equal in numbers. We may assume that the two groups were about equal in the number of immigrants. The Prussian census showed 100,000 in that country. How many came in and were classified as German or Russian we do not know.

The Lithuanians and Letts are small in numbers; yet they have been very important in immigration. In 1907 they stood tenth in rank - 6 per 1000 of population - as to rate of immigration. For the twelve-year period ending June 30, 1910, 175,258 Lithuanians and Letts came to the United States. That number was twice as large as the number of Russian immigrants; yet the population of Russia proper was over fifteen times as large as the number of Lithuanians and Letts. Evidently Russian suppression drove them from their native land. For the nine-year period ending in 1929, we received 5403 Lithuanian and 3029 Lettish immigrants. In 1924 we received 2369 from Lithuania and 1473 from Latvia. Between 1924 and 1930 we received 6015 immigrants from Lithuania and 3399 from Latvia. The present law permits 386 immigrants from Lithuania and 236 from Latvia per year. Most of the Lithuanians and Letts have 
settled in Pennsylvania, Illinois, New York, and Massachusetts, where they have engaged in manual labor.

\section{QUESTIONS, EXERCISES, AND PROBLEMS FOR INVESTIGATION}

1. What is meant by the statement: "The Lithuanian nation was resurrected from the state of oblivion"?

2. What are the difficulties encountered in placing the Lithuanians with either the Slavs or the Teutons?

3. Show how Lithuania and Latvia became subjected to alien cultures.

4. Discuss the political effects of the World War upon Lithuania and Latvia.

5. Explain: "Lithuania's location is now an economic advantage."

6. What special rights and privileges have the peasants won in regard to land holdings?

7. Describe the Christianizing process in Lithuania.

8. What were the effects of Russian rule upon the religious life of the Lithuanians?

9. Account for the large number of Lithuanian and Latvian immigrants in the United States.

10. Read and report on one of the following: O'Hare, V.: "Lithuania: The Enigma," Nineteenth Century, Vol. CIV, pp. 63-76; Wilson, W. S.: "The 'Kings' of Latvia," Nineteenth Century, Vol. XCIX, pp. 548-52; Lord, R. H.: "Lithuania and Poland," Foreign Affairs, Vol. I, No. 4, pp. 38-58; and Van Cleef, Eugene: "Some Economic Problems in the Baltic Republics," Geographical Review, Vol. XVII, pp. 434-47. 


\section{CHAPTER VIII}

\section{BRITISH TEUTONIC COLONIES}

The Dominion of Canada, Dominion of Newfoundland, Commonwealth of Australia, Dominion of New Zealand, and Union of South Africa are practically separate nations, but they have remained voluntarily within the British Empire. Great Britain has been able to retain them largely because the loss of the United States taught it that, if it is to keep them it must in a large measure accept the views of its colonies, which naturally drift toward freedom in a distant environment, especially when immigrants of foreign lands become citizens. During the World War each of these countries supported the mother country and made great sacrifices. But after the war each expressed a desire to become self-governing. Each was given a representative in the League of Nations, and Canada established its own diplomatic relations with the United States. Although each nation is practically autonomous, each is linked to the British Empire by a governor-general.

\section{Canada and Newfoundland}

1. General Description. Canada and Newfoundland are in every way, except politically, one country. Although Newfoundland has been a crown colony since 1855, its autonomous government gives it a status equal to that of the other dominions. Canada has long desired to have Newfoundland as part of its territory, but Newfoundland is jealous of its status and has steadfastly refused to submerge itself in Canada. In 1927 the Privy Council awarded Labrador to Newfoundland, a measure which seems to indicate that the two countries are destined to remain separate.

Canada has an area of 3,690,043 square miles, Newfoundland 42,734, and Labrador 120,000. The census of 1931 gave Canada a population of 10,376,786, Newfoundland 271,685 (estimate, 1930), and Labrador 4203 (estimate, 1930). Ottawa, the capital of Canada, has a population of 126,872 , Montreal 818,577, Toronto 681,207, Winnipeg 218,785, Vancouver 246,593, Hamilton 155,547. St. John's, the capital of Newfoundland, has a population of 41,757 (1928). 
It is estimated that there are in Canada 105,000 persons belonging to the aboriginal races, reckoned through the male line of descent. About 3300 of these are Eskimos and the remainder Indians, who are found chiefly in Ontario, British Columbia, Quebec, Manitoba, and Saskatchewan.

Canada, the northern neighbor of the United States, extends from the Atlantic to the Pacific, and from the United States to the North Pole. Excepting the Great Lakes and connecting rivers, there are no natural boundaries between the United States and Canada. The two countries boast of over a hundred years of peace and no guarded boundary. Until the United States passed the Eighteenth Amendment and stationed men along the border to intercept rum-runners, one saw very few officials, and people passed freely between the two countries. The topography of Canada is similar to that of the northern part of the United States. The same mountain ranges, areas of prairies, and level land stretch from one country to the other.

Canada, however, is much colder, most of its area being sub-Arctic. The bulk of its people, cities, manufacturing, and farming are along the southern border, opposite the United States. Newfoundland is an island near the mouth of the St. Lawrence River. It is rugged and has a rigorous climate, largely due to the Labrador current and prevailing winds. Labrador is very cold and is mainly inhabited by Eskimos.

2. Political Development. Newfoundland claims to be the oldest English colony. Nova Scotia (Acadia) and Quebec were early settled and ruled by France, but were gradually lost to England. By the Treaty of Utrecht (1713) Nova Scotia was ceded to England, and in 1763 (as a result of the Seven Years' War) the provinces of Quebec, which contained about 70,000 French, Ontario, New Brunswick, and Prince Edward Island became English territory. The remaining part of what is now Canada was mainly a vaguely known region of the Hudson Bay Company. By 1749 England was making a consistent effort to settle Nova Scotia, which at that time contained all the territory east and north of Maine. In 1767 it contained about 7000 settlers from colonial America, 2000 Irish, 2000. German, 1000 French, and 1000 English. Canada (Quebec) contained about 70,000 French and a few hundred English and Americans.

In 1791 the British Parliament divided Canada into Upper, or English-speaking, Canada and Lower, or French-speaking, Canada, and granted each an elective assembly. As the French Canadians 
knew nothing of representative government, they failed to appreciate this form of political organization. They remained loyal to France, but the French Revolution and the opposition of their priests to liberal ideas created a gulf between them and France; yet it did not draw them any nearer to Britain. The War of 1812 between the United States and Great Britain, however, tended to unite the different elements in the population of Canada, even causing the French Canadians to become hostile to the United States and more tolerant of British rule. Harmony between the English and French provinces, however, did not last long.

By 1837 armed rebellion had broken out in both provinces, and it was strongly advocated that Canada annex itself to the United States. During the Civil War Canada favored the Union, and about 40,000 Canadians enlisted in the Northern armies. England favored the South. This war did much to unite the Canadians, as it revealed to them that the United States was a strong power, and caused them to be afraid of aggression.

On July 1, 1867, the provinces of Quebec, Ontario, Nova Scotia, and New Brunswick united to form the Dominion of Canada. The act provided for the admission of the northwest territory, Newfoundland, Prince Edward Island, and British Columbia. All have availed themselves of the opportunity to join the Dominion except Newfoundland. Canada now consists of nine provinces and certain northwest territories which are under the federal government. The Canadian government, like that of the United States, has a constitution. The Canadian constitution, however, enumerates the duties of the provincial governments, leaving the others to be administered by the federal government; whereas the constitution of the United States enumerates the duties of the federal government and leaves the others to the separate states. The Canadians have become conscious of nationality, but apparently are satisfied with their relationship with Great Britain.

3. Economic Development. Canadian economic development has been similar to that of the United States but has lagged behind it. The chief difference has been due to certain climatic influences. Until 1791 Canada was forced to trade only with England. After it gained the right to trade with other nations, the discriminatory tariffs of the United States were a source of dispute. At times Canada was greatly handicapped and its business men practically bankrupt. In 1854 Canada and the United States concluded reciprocal tariff treaties 
to the advantage of both countries, but to the disadvantage of England. In 1859 Canada erected a tariff barrier against England. This taught England a lesson and it changed its policy of exploitation to one of coöperation with Canada.

Canada is a vast, thinly populated country with an abundance of arable, grazing, and timber lands, and is rich in natural resources. It has about $358,000,000$ acres of arable land, but only about onefifth of it is in crops. The short growing season and mid-season frosts have been detrimental to Canadian agriculture, but gradually plants have been developed which are suited to the climatic conditions. Canada produces about $445,000,000$ bushels of wheat per year, $440,000,000$ bushels of oats, $100,000,000$ bushels of barley, 15,000,000 bushels of rye, and 10,000,000 bushels of corn. It ranks second among the wheat-producing countries of the world, and is one of the leading wheat-exporting countries. Canada has about 340,000 square miles of good timber. The annual cut is around two and one-half billion cubic feet. It produces one-third of the world's total newsprint, and half of the pulp for newsprint production. About 92 per cent of the pulp wood is on the crown lands, and since 1910 this has had to be turned into pulp before shipping. Wood and paper exports to the United States amounted to $\$ 242,000,000$ in 1927 , half the value of the total exports. Newfoundland, also, has a large amount of pulp wood, which is governed by a similar law.

Canada is rich in coal, iron, gold, silver, copper, nickel, lead, and zinc. The coal reserves of Canada rank next after those of the United States and China. It ranks first in the production of asbestos, cobalt, and nickel, and third in the production of gold and silver. In 1929 its mineral products had a value of $\$ 310,850,246$. Newfoundland, also, is rich in timber, iron, copper, and gold, but its mining interests have not been very well developed. About 38 per cent of the people are engaged in fishing; fish exports, chiefly of dried cod, amount to about $\$ 60,000,000$ annually. Canada is extensively engaged in stock raising, fishing, fruit growing, manufacturing, and commerce. It now ranks fifth among the nations of the world in commerce. Trade between the United States and Canada is important, as the United States takes 38 per cent of Canada's total exports, while Canada takes 15 per cent of the exports of the United States. Canada's dairy products amount to $\$ 250,000,000$ a year, meat exports to $\$ 30,000,000$, furs to $\$ 19,000,000$, and tourist trade to $\$ 266,000,000$.

The economic development of Canada has attracted a large in- 
vestment of foreign capital, especially British and American. Many American manufacturers have established sub-plants in Canada, and this alone has called for a vast expenditure of capital. In 1914 the British had $\$ 2,500,000,000$ invested in Canada and the Americans $\$ 700,000,000$. By 1920 the American investments had reached $\$ 1,300,000,000$, and by $1928 \$ 3,470,087,000$, while the British had been reduced to $\$ 2,197,682,000$. Other nations have smaller sums invested $-\$ 236,400,000$ in 1928 .

4. General Social Conditions. The general social conditions among the English-speaking Canadians are similar to those in the United States. In Newfoundland and the maritime provinces, however, there is a more definite patterning after English customs than exists in the central and western portions.

Canadian education is largely in the hands of the different provinces. As each province has its permanent department of education, controlled in details of administration by permanent officials, there is a stronger governmental supervision of education than exists in the United States, where superintendents of education are subject to the vicissitudes of politics. In Quebec there are two distinct systems of education - the Protestant, or English-speaking, and the Catholic, or French-speaking. Education is free and compulsory, generally from 7 to 15 years, in eight of the provinces. In Ontario a pupil may attend school full time up to the age of 16 or part time after 14 up to 18 . In the territories education is not compulsory; in Newfoundland it is free but not compulsory.

There are in Canada 23 major educational institutions and 101 others ranked as theological, professional, or affiliated colleges. Prior to 1914 the more ambitious student regarded Germany as the proper place in which to secure his doctor's degree, and the less ambitious the United States. A problem confronting Canadian higher education is that of making provision for advanced graduate work. Since 1923 the universities of McGill, Toronto, Queens, and Montreal have established complete organizations for graduate studies and research leading to the doctor's degree.

Owing to the large number of Catholic French Canadians and the early dominion of the Church of England, the religious situation in Canada has been complicated. The British, by either persuasion or force, sought to make the French Catholics good British subjects and Church of England members, but without success. The Anglican Church was given liberal land and money grants. The other Prot- 
estant churches strenuously objected to this, and in 1854 church and state were separated. Since that time there has been a gradual working toward harmonious relationships. In 1925 all the Protestant groups except the Baptist entered a formal union known as the United Church of Canada. Three general councils have since been held.

There are four physiographic areas with corresponding cultural divisions in Canada. (1) The central area has always been the center of population expansion. It includes the agricultural land of Quebec and Ontario. Owing to constitutional guarantees of language, separate education, civil law, and religion to the French, and to the topography of the country, Quebec has a relatively static culture pattern. Ontario, on the other hand, was settled by diverse cultural elements and has ample outside contacts. This central area is, therefore, bicultural. (2) The maritime area is marked off by the Appalachian Mountains and is physiographically a continuation of the New England seaboard. Cut off by geographical features and tariff regulations, this area has suffered from isolation that has resulted in loss of status and lack of financial and political power commensurate with that of other sections of the Dominion of Canada. (3) The western plains, known as the Laurentian Shield and consisting of more than half of Canada, are bounded on the west by the Rocky Mountains. This is an area of migration and immigration and solitary farmsteads, three-quarters of the people living in the open country. (4) The Pacific coast region includes British Columbia and the western edge of Alberta; it is extremely mountainous.

5. Immigration and Emigration. Since colonial times there has been a considerable movement of population across the boundary between the United States and Canada. In 1920 there were 400,000 people in Canada who were born in the United States, and 1,117,878 in the United States who were born in Canada. During the Revolutionary War, Loyalists from the United States moved into Canada and Newfoundland. Americans practically settled Upper Canada (Ontario), New Brunswick, Nova Scotia, and Prince Edward Island. In 1812 there was another movement of "late" Loyalists to Canada, but for about 75 years after that period few Americans went to Canada. After the Civil War many Canadians moved to the United States, and by 1890 one-third of the Canadian-born people were said to be living in the United States. Between 1896 and 1914 many Americans went to Canada. In 1925 43,775 Canadian citizens who 
had come to the United States to live returned, in 192756,957 , in 1929 33,798, and in 1930 29,830.

In 1897 Canada began a campaign for immigrants. Advertisements were placed in thousands of papers in the United States, and millions of pamphlets were distributed. In this campaign $\$ 1,936,000$ was spent in the United States alone. The number of Americans going to Canada jumped from 2412 in 1897 to 133,710 in 1912 . Between 1901 and 1921 the number of American immigrants in Canada increased by 246,125, and between 1900 and 1909 Americans took 44 per cent of the Canadian homesteads. In 1916 36,937 Americans moved to Canada, in 1917 61,389, in 1926 18,778, and in 1930 30,727. On the other hand, the number of Canadian-born residents of the United States increased from 493,464 in 1870 to $1,181,255$ in 1900 , and to $1,179,922$ in 1910 . During the last decade, however, the number of English Canadian immigrants has dropped; the number of French Canadian immigrants has dropped for the past two decades. Of the 1,117,878 Canadian immigrants in the United States in 1920, 307,786 were French Canadians. There were also 13,242 immigrants from Newfoundland.

Most of the Canadian immigrants have settled in Massachusetts, Michigan, New York, and California. Maine, Vermont, Michigan, New Hampshire, Massachusetts, Montana, Oregon, Idaho, and North Dakota have the highest percentages of English Canadians, and New Hampshire, Maine, Vermont, Rhode Island, and Massachusetts have the highest percentages of French Canadians. English Canadians compose 35.9 per cent of the foreign-born population in Maine, 24 per cent in Vermont, and 15.3 per cent in New Hampshire, while the French Canadians form 42 per cent of the foreign-born in New Hampshire, 33.1 per cent in Maine, and 31.8 per cent in Vermont. Detroit has 55,216 English Canadians, Boston 40,265, Chicago 23,622, and New York 23,514. Considering the closeness of the two countries, we find that Canadians show a remarkably high percentage of naturalizations. In 192057.9 per cent of the English Canadians and 44.8 per cent of the French Canadians were naturalized. This makes a striking contrast with the Mexican rate of 4.8 per cent.

Canada has had a comparatively heavy immigration from other countries. Between 1903 and 1913 over 2,500,000 immigrants landed in Canada. This was more than the total number of immigrants for the long period from 1869 to 1903 . In 1930 Great Britain sent 81,193, Germany 18,014, Ruthenia 11,332, Poland 6837, Hungary 5787, and 
France 5116. It has been a tremendous task for the small population of Canada to assimilate so many immigrants. The task has been complicated by heavy losses from emigration. In the decade ending in 1910 Canada lost 866,000 by emigration, and for the decade ending in $19201,300,000$ more. The situation was still further complicated by the nature and clannishness of the immigrants. The large number of Ruthenians from Galicia refused to mingle with the Canadians, and the Doukhobors persisted in their refusal to go to war, but insisted on winter pilgrimages in nature's garb. There were more Polish Jews in Montreal than in Jerusalem, old or new, and swarms of Italians in the cities. One-eighth of the population of British Columbia was Oriental - in fact, 1100 of the 1200 East Indians in Canada, 38,000 of the 58,000 Chinese, and all except 1000 of the Japanese were in British Columbia. The situation was helped and hindered by the arrival of 1,100,000 British immigrants between 1897 and 1914 .

Great Britain and its Dominions differ widely in their attitudes toward immigration. The Dominions agree with the policies of the United States and disapprove of the alliance between Great Britain and Japan. They are determined to keep their territory "white," and have passed rigid immigration laws. Canada placed a head tax of $\$ 50$ on Chinese in 1885 and raised it to $\$ 100$ in 1901 and to $\$ 500$ in 1904. This law was abolished in 1923, and now only students and merchants are admitted. In 1907 it concluded a "gentlemen's agreement" with Japan to limit Japanese immigrants. During the same year agitation to restrict Hindu immigrants began. A way out was discovered by falling back upon a clause in the immigration laws which requires immigrants to make a continuous journey from their native land to Canada. East Indians were thus excluded, as no ships came directly from India to Canada. It is interesting that in 1914 a Japanese ship loaded with East Indian immigrants decided to test the law. Canada's first warship was first called into service to expel from one part of the British Empire subjects from another part. Each Asiatic is now required to possess at least $\$ 200$ on landing in Canada.

Canada wants Americans and North Europeans as immigrants. In the Empire Settlement Act of 1922, Canada and Great Britain formulated a plan to aid immigrants from the British Isles, but Canada wants people trained in agriculture and domestic service, and these the British Isles cannot supply. Canadian laws are rapidly becoming more selective. Before 1908 there was no Canadian inspection along the American border, and many Europeans took advantage of this. 
Now many are being turned back. In 1929 a law was passed prohibiting the landing in Canada of any immigrant coming under contract or agreement to perform labor or services of any kind other than farm or house work. The United States denies naturalization to Asiatics; Canada permits it. Of the 23,586 Chinese eligible for citizenship in Canada in 1911, only 2144 had availed themselves of the privilege, and only 1491 of the 6669 Japanese.

\section{Australia and New Zealand}

1. General Description. The continent or island of Australia is in the Pacific Ocean, in the Southern Hemisphere, southeast of Asia. New Zealand is 1200 miles southeast of Australia. The two countries and surrounding islands are often called Australasia, but New Zealand objects to this as the term tends to hide its identity. All of New Zealand and seven-thirteenths of Australia lie within the southern temperate zone. The climate is generally temperate and salubrious. Most of the mountains in Australia resemble a table-land. The highest peak is 7328 feet, and the elevation of the whole continent averages only about 1000 feet above sea level. New Zealand is more mountainous, especially South Island. It has several volcanic peaks, and in certain parts resembles the Alps. The loftiest peak is about 12,000 feet high and is snow-capped. There is considerable snow in the mountain sections of southern Australia during the winter, and heavy snows occur in New Zealand.

Australia is said to be the smallest continent and largest island. It has an area of $2,974,581$ square miles, or is about the size of continental United States, but has only about one-twentieth of the population. New Zealand, which consists of two large islands and a number of smaller ones, contains 103,862 square miles, or is about the size of New York, Pennsylvania, and New Jersey, but has only about one-seventeenth of their population. Thus both countries are very sparsely inhabited. Australia is mandatory for nearly 90,000 square miles (population 70,000) of the former German possessions, and New Zealand is mandatory over the former German Samoa, which has a native population of about 44,000. In 1921 Australia had a population of 5,495,734 (estimate, 1931, excluding aborigines, 6,488,707) and in 1926 New Zealand had 1,407,165 (estimate, 1930, 1,488,595). The bulk of the population of Australia and New Zealand is British, mainly of Teutonic stock. Australia had between 30,000 and 60,000 
aborigines who were not enumerated in the census of 1921, and about 35,000 full-blooded Asiatics, 23,000 of whom were Chinese. New Zealand had 62,781 Maori who were enumerated. Of the larger cities of Australia, Sydney has 1,238,660 (1929) inhabitants, Melbourne 1,018,200, Adelaide 324,898, Brisbane 318,631, Perth 202,888. Of the cities of New Zealand, Auckland has a population of 213,330 (1930), Wellington (capital) 138,510, and Christchurch 126,040.

2. Political Development. It is a disputed question as to who first discovered Australia and New Zealand. The French, Portuguese, and Dutch each claim priority. In 1769 Captain James Cook visited New Zealand and Australia in turn and hoisted the British flag, taking possession of the lands in the name of George III. In August, 1783, Great Britain recognized the independence of the colonies that later became the United States, and realized that it would now be forced to find another land for a penal colony. In 1788, the year before the French Revolution, a settlement of convicts was established in New South Wales, Australia. In 1803 a settlement was established in Tasmania, and a mission in New Zealand in 1814. In both countries the hostility of the aborigines made settlement difficult, but in 1840 a group of tribal chiefs gave New Zealand to the queen of England.

Realizing the need for people other than convicts, the Australian leaders induced settlers, or rather "squatters," to settle there. The free settlers also acted as a British warning to France, which occasionally revived its claims. The squatters, however, composed the chief population of Australia for about fifty years. From 1814 on, English subjects continued to settle in New Zealand, but Britain assumed no responsibility until about 1840, when France tried to encroach by colonization. Great Britain made definite its claim to both countries by right of discovery and settlement. New Zealand was granted responsible government in 1852 and Australia in 1855. By the aid of the home government, each country annexed from time to time the surrounding islands. The discovery of gold in Australia in 1851 and in New Zealand from 1853 to 1864 brought many new settlers and caused Britain to take greater interest in the colonies. The opening of the Suez Canal in 1869 and the laying of a cable in 1872 brought New Zealand and Australia much closer to England and further increased British interest in their development.

Since the Australian settlements could not agree with one another, Victoria was separated from New South Wales in 1851, and Queens- 
land in 1859. A provisional form of government which was organized in 1852 became permanent by 1876 . Union, however, seemed impossible until about 1882 , when the encroachment of other countries, especially France, brought a loosely defined "Monroe Doctrine." The Commonwealth of Australia was proclaimed January 1, 1901. Both Australia and New Zealand have increased their autonomous rule and have now attained the practically free condition of Dominion.

3. Economic Development. Australia and New Zealand are mainly agricultural and stock-raising countries. Over half of Australia is deficient in rainfall, and large areas are desert. H. L. Wilkinson ${ }^{1}$ places the amount of cultivable land at 7.5 per cent of the total area. It has been estimated that 21 per cent of Australia is suitable for close white settlement, 56 per cent for pastoral occupation, and 3 per cent for tropical agriculture; 20 per cent must remain desert. The central part of the continent is a long plateau but a vast desert. The northeast coast of Queensland has over 200 inches of rainfall, while much of southern Australia has less than 5 inches; furthermore, in the southern section the rainfall is in winter. The southeastern section and coastal belt have a sufficiency of well-distributed rains. Large areas are now being irrigated. Artesian wells are of considerable help, but more for watering stock than for irrigation, as much of the water is alkaline. About 80 per cent of the people live in a belt 100 miles wide on the eastern, southern, and southwestern border. At least two-thirds of New Zealand is suitable for agriculture.

Much of the best land in both Australia and New Zealand is held in large estates. There are 1150 holdings in Australia, covering an area of 20,000,000 acres, which contain between 10,000 and 50,000 acres each, and 90 holdings in Australia and 59 in New Zealand which contain over 50,000 acres each. The chief crops in both countries are wheat, oats, barley, maize, hay, potatoes, fruits, and sugar cane. Australia produces about $160,000,000$ bushels of wheat per year and New Zealand 8,000,000. Both countries produce large numbers of sheep, cattle, horses, and swine. Australia has over 106,000,000 sheep and New Zealand 29,000,000. Wheat, wool, frozen meats, and dairy products are the chief exports from both countries. Each year Australia exports about $20,000,000$ frozen rabbits and $\$ 18,000$,000 worth of rabbit skins.

Both Australia and New Zealand have a sufficiency of coal. Gold is mined in both countries, but in diminishing quantities in Australia.

1 The World's Population Problems and a White Australia, p. 334. 
New Zealand imports iron, but Australia has enough for its own use. The amount of forests in Australia is unknown, but the government reserve is said to include $24,500,000$ acres. New Zealand has 3164 miles of railroad and Australia has about 27,000 miles. Owing to the fact that the railroads of Australia are of eight different gages, transportation is considerably handicapped. Both countries are rapidly expanding in manufacturing. The chief difficulty is that there is more money for manufacturing than the market demands, and more land for agricultural purposes than the population requires.

4. General Social Conditions. Four different groups - convicts, free settlers, gold seekers, and assisted settlers - have gone out from Britain to settle Australia. The last three groups also settled New Zealand. From 1788 to about 1837, Britain used Australia as a penal colony. Around 120,000 men and women were sent into the colony to serve sentences ranging from seven years to life. The descendants of these former convicts now form a large percentage of the population of Australia, and there is no indication that they are in any way inferior to the descendants of the free settlers.

The gold rush of 1851 brought many people to Australia, and the discovery of gold in New Zealand in 1853, 1861, and 1864 took many more people there. In 1850 the population of Australia was 404,356, and ten years later it was $1,145,586$. For over 100 years free settlers have been going to Australia and New Zealand, but usually in small numbers. The preference of the British emigrants for the United States and Canada, and the desire to hold Australia and New Zealand against the "Asiatic hordes," early induced the government to pay stipulated amounts toward transportation and settlement. In the Empire Settlement Act of 1922 Great Britain concluded an arrangement with Australia, New Zealand, and other Dominions to aid British settlers within their domains. This arrangement has not worked satisfactorily because the Dominions stipulate the kind of settlers they desire, and decide who may be aided. Australia and New Zealand desire agriculturists and domestic servants, but Great Britain cannot supply these.

Since approximately nine-tenths of the citizens of Australia and New Zealand were born within the British Empire, freedom of religion prevails. In Australia about 45 per cent of the inhabitants belong to the Church of England, 21 per cent to the Roman Catholic Church, and about 12 per cent each to the Methodist and Presbyterian churches. In New Zealand about 41 per cent belong to the 
Church of England, 24 per cent to the Presbyterian Church, and 13 per cent to the Roman Catholic. Educational standards are high. Elementary education is free and compulsory, and secondary education is practically free. Australia has six universities, one in each state capital, and New Zealand has four. The University of New Zealand is an examining body rather than a university as we understand the term.

There are not such great contrasts of immense wealth and extreme poverty in Australia and New Zealand as are found in the United States, and the people are intolerant of aristocratic birth and special privileges. There are, however, two chief groups, capitalists and laborers, more or less mutually antagonistic and unsympathetic. The laborers are well organized and powerful, and maintain a high standard of living. The people are democratic, and have not lost their pioneering spirit. Surrounded by water, isolated, and largely concentrated into compact groups, they have developed a keen sense of unity.

The two countries, especially New Zealand, have led the world in certain advanced social laws. New Zealand claims it was the first country to have a national "secular, compulsory, and free" educational system, to provide non-contributory old-age pensions, to establish state insurance, to adopt universal penny postage, to organize a state department of public health, to enact minimum wage laws for women and children, to establish state maternity homes, to grant women parliamentary suffrage, to establish conciliation and arbitration for industrial disputes, to provide for government grading of butter, cheese, and hemp for export, to operate state coal mines, to build houses and sell them to workmen, and to operate a tourists' department.

5. Immigration and Emigration. It is said that "white Australia" is the only religion of the Australians. The same phobia is equally strong in New Zealand. Regardless of what internal differences may exist, all groups in both countries are united in keeping their countries "white." Both countries are making a supreme effort to attract white settlers. The immigration laws are very rigid and so worded that it is almost impossible for non-Caucasians to enter. The dictation test is used in both countries; that is, the immigrant is required to write 50 words in some specified language. So far the languages have been European. Immigrants from the British Isles and the Dominions are not required to take the test, and it is seldom used 
with Europeans. Asiatics are required to stand it, and it is very seldom that one passes. Chinese are required to read 100 words in the English language and pay $£ 100$ poll tax. From 1911 to 1927, excepting the World War period, Australia had a net average of from 40,000 to 50,000 immigrants per year, and New Zealand from 8000 to 13,000 . Almost 90 per cent of these came from the British Isles. According to the 1921, census there were 5,387,205 British, 13,799 Chinese, 4903 Italians, 3555 Germans, 3257 United States, 2817 Greeks, 2639 Japanese, and smaller numbers of various other nationalities in Australia.

One would hardly expect these two remarkable countries to lose any of their citizens to other nations. Such, however, is the case. Considering their sparse population, the United States has received a large number of immigrants from them. For the decade ending in 1910 , we received 11,975, and for the decade ending in 1920, 12,348. From 1871 to 1930 we received 52,265. In 19212191 came, and in 19301026 . According to the 1920 census there were 11,280 immigrants in the United States from Australia; 10,801 of them were native-born. The largest percentage of these were living in San Francisco and New York. They present no difficult problem of adjustment.

\section{Union of South Africa}

1. General Description. The Union of South Africa occupies the southern part of Africa and is, therefore, mostly in the temperate zone. It embraces four former colonies with a total area of 472,347 square miles. Cape of Good Hope has an area of 276,966 square miles, Transvaal 110,450, Orange Free State 49,647, and Natal 35,284. The population is about $6,928,580$ (estimate, $1930,8,072,800$ ), but the white population was only $1,828,175$ in 1931 . The whites are of European origin and chiefly of Teutonic stock. There were 165,731 (1926) Asiatics and above 5,000,000 colored people, chiefly Bantu. Johannesburg, the largest city, had a population of 288,131 in 1921 ; Cape Town, the seat of the legislature, 207,404; Durham, 146,324; and Pretoria, the seat of the government, 74,052.

Along the coast, especially on the southern and eastern sides, are mountains. The mountain and upland belt along the southern and eastern coasts is about 1000 miles long and 15 miles wide. It has about 40 inches of rainfall per year and is the only well-watered section of the country. Over 65 per cent of South Africa has less 
than 20 inches of rainfall per year, and about 35 per cent has less than 10 inches. In much of the territory which has a fair rainfall, it does not occur during the months when it is needed for growing crops; consequently about 90 per cent of the country requires irrigation for agricultural use. Irrigation, however, is poorly developed. The rainfall varies from year to year, and destructive droughts are frequent.

2. Political Development. It appears that efforts to colonize South Africa resulted from the report of some shipwrecked sailors left there in 1648. When they returned to Holland they gave such a glowing account of the country that the Dutch East India Company decided to plant a colony there. A section was laid out for the Dutch Boers (farmers) in 1652. More settlers came from time to time, and in 1688-89 their number was swelled by about 300 Huguenots. These the Dutch soon absorbed.

Great Britain became interested in South Africa in 1806, during the Napoleonic Wars. It first occupied Cape Colony, and the Congress of Vienna recognized its claim. By 1820 Britishers in rather large numbers were going to South Africa. Then came the discovery of gold and diamonds which led to a mob rush of Europeans. With this went an extension of British rule and the displacement of natives and Boers. The Boers moved farther inland, while the British made treaties with native chiefs and extended English rule over millions of blacks. Many of the Boers continued to "trek" on into central Africa and across to the Atlantic coast, but a large number settled in Transvaal, where they made a determined stand against British aggression. Then came the desperate Boer War of 1899-1902, during which the cruelty of the British aroused the civilized world. The war was very unpopular in England and very expensive. After peace was concluded, however, much of the hatred was replaced by conciliation and coöperation.

In 1910 the Union of South Africa was formed. It is interesting that General Botha, who ten years before had been one of the chief warriors against the British, became the first premier, and his cabinet was composed entirely of Boers. During the World War Botha's army conquered German Southwest Africa and German East Africa. German Southwest Africa became a mandate of the Union by the authority of the League of Nations.

Since the World War there has been a strong movement for separation from Great Britain, because of frequent disagreements over gov- 
ernment policies and the desire of the South Africans for more liberty. Adjustments, however, have been made, and for the time being the cry for separation has been lulled but not stilled. The year 1929 is said to be the most momentous in the history of the South African confederation, as it again brought to the foreground the native question in the national elections. The Nationalist party, largely composed of Boers, obtained a majority in Parliament, over the South African party, representing British interests. South Africa is often referred to as "the flower of British democratic development." The Union is now an autonomous Dominion, like Canada and Australia, and a signee of the League of Nations; it is almost free of British rule.

3. Economic Development. The agricultural possibilities of South Africa do not appear to be very great. One serious difficulty is that much of the land that is high enough to give it a climate suitable for agriculture is too dry. The rivers are generally small, and conditions are not favorable for irrigation. Wells have been drilled in some sections, which furnish water for the flocks but not for irrigation. The coastal strip is the only area suitable for agriculture. In 1926 only 3.1 per cent of the area was in cultivation.

Stock raising is extensively engaged in, especially in the mandate of Southwest Africa. Much of the country is now overstocked. The wool crop in the Union was $285,000,000$ pounds in 1928. Cotton is extensively grown in Natal and Transvaal. The country is rich in gold, diamonds, platinum, and coal. There are over 12,000 miles of railroad, government owned. Coastwise and foreign commerce is developing, and some progress is being made in manufacturing.

4. General Social Conditions. Practically all social questions in South Africa are colored by the racial attitudes. There have been numerous disagreements between the different colonies, especially between the Boer and British elements over the treatment of the natives. The Boers believe that the natives are inferior and that they have Scripture to prove it. They are trying desperately to keep the blacks "in their place," and fear the effects of education and industrialization upon them. The British, on the other hand, while often grossly mistreating the natives, advocate approximate equality. The British program theoretically is "equal rights for all civilized men," while the constitution of the Boer republics of the Orange Free State and Transvaal says that "in church and state there is no equality between blacks and whites." In general the white and black children are separated in schools. 
There has also been considerable trouble with the East Indians. The Indians have long traded with the people along the east coast of Africa, and, being British subjects, feel that they have special rights. In 1808 the British found them to be a great aid in promoting trade. But within the last 50 years large numbers have been brought in to work on the tea and sugar plantations. There are now about 150,000 , and their high birth rate and rapid increase are considered a serious problem by the European element, who insist that South Africa is a "white man's country."

The Asiatic Trade and Land Act of 1919, the refusal of the government to issue trading licenses to Asiatics, and the restrictions placed upon their owning property in Transvaal in the same year aroused keen resentment among the Asiatics, especially the East Indians. In 1925 a bill was proposed to arrange for the segregation of the Indians in certain sections, but adjustments were made without it. The whites will not treat the Indians as white people, and the Indians resent being treated as blacks.

Another serious problem is the one concerned with the poor white laborers. Many of the "treking" Boers have lost the traditions of education, continue to speak sixteenth-century Dutch, and are very backward. Many of them have not been able to adjust themselves to the improved methods of agriculture introduced by the British, and have degenerated into ordinary laborers. They have been joined by a group of poor people of British origin. There are now around half a million of these laborers. They disdain "Kaffir work" and are not able to maintain themselves on the wages they are able to command. The wealthier whites are employing more and more native labor, which is much cheaper and brings better returns. Thus there are three social classes: the wealthier whites, who have a high plane of living, the low whites, and the natives. Between the last two groups may be placed the Asiatics. The low whites are fighting valiantly to maintain a status superior to that of the natives. The wealthier whites will support them on certain issues, such as confinement of the blacks to the low lands and coastal zone of the east, but they will not grant them an increase in wages, the chief essential for a higher plane of living. Between these groups is developing a group of hybrids, which further complicates the whole social situation.

5. Immigration and Emigration. For the five-year period ending in 1926 the increase in the white population of the different states in the Union of South Africa varied from 7.5 per cent in the Orange 
Free State to $\mathbf{1 6 . 0}$ per cent in Natal. Some of these countries take a census of the white populations only. Yet the density ranges from only 2.6 people per square mile in Cape of Good Hope to 5.5 in Transvaal. Apparently the Dutch element is increasing much faster than the British. Although many Europeans go to South Africa, about as many leave as go. In 19276513 Europeans went there and 5433 left. Some years more leave than enter. The social system of "gentlemen farmers" and castes, which restrains whites from engaging in unskilled labor, prevents the immigration of poor Europeans. Many have gone to South Africa and then left. How many of these, or how many people born in South Africa of European stock, have come to the United States we do not know. For the fiscal year ending in 1929, we received 168 immigrants of European stock born in South Africa; 105 of them were of English and Dutch stock.

\section{QUESTIONS, EXERCISES, AND PROBLEMS FOR INVESTIGATION}

1. Explain: "Canada and Newfoundland are in every way, except politically, one country."

2. Read "The Unguarded Boundary," by J. W. Davis, in Geographical Review, Vol. XII, pp. 585-601, and report on the boundary question between the United States and Canada.

3. What forces tended to draw the Canadians together? Apart? Besides the text, see Annals of the American Academy of Political and Social Science, Vol. CVII; Robinson, W. A.: "Canada, Economic Sectionalism in: The Problem of the Maritime Provinces," Journal of Political Economy, Vol. XXXVI, pp. 501-09; Mackintosh, W. A.: "The Laurentian Plateau in Canadian Economic Development," Economic Geography, Vol. II, pp. 537-49.

4. In what respects has Canada been under the economic domination of other countries?

5. What are the principal economic resources of Canada? In addition to the text, see Patton, M. J.: "The Water-Power Resources of Canada," Economic Geography, Vol. II, pp. 168-96; Craig, R. D.: "Forest Resources of Canada," Economic Geography, Vol. II, pp. 394-413; Innis, H. A.: "Economic Conditions in Canada in 1931-2," Economic Journal, Vol. XLII, pp. 1-16.

6. Along what main lines does education in Canada differ from that in the United States? What religious difficulties has. Canada faced?

7. Locate the physiographic regions of Canada and indicate the relationship of population to these. Besides the text see Dawson, C. A.: 
"Population Areas and Physiographic Regions in Canada," American Journal of Sociology, Vol. XXXIII, pp. 43-56.

8. Discuss the Americanization of Canada through immigration from the United States.

9. What countries supply the largest number of immigrants to Canada?

In what respects does immigration restriction in Canada differ from that in the United States?

10. What are some of the current ideas regarding the future of Canada? References. Bell, G.: "Canada's Outlook," Nineteenth Century, Vol. CVII, pp. 189-96; Ewart, J. S.: "Canada, the Empire, and the United States," Foreign Affairs, Vol. VI, pp. 116-27; Stevenson, J. A.: "The Political and Economic Situation in Canada," Edinburgh Review, Vol. CCXLI, pp. 209-29.

11. Make a study of Canada's immigration problem. References. Clark, J. B. M.: "Canada's Immigration Problem," Nineteenth Century, Vol. CIII, pp. 735-46; Annals of the American Academy of Political and Social Science, Vol. CVII.

12. What is the objection to the term Australasia?

13. What groups constitute the population of Australia and New Zealand?

14. Account for Britain's renewed interest in its colonies.

15. What are the economic resources and future possibilities of Australia and New Zealand? Besides the text, see Copland, D. B.: "The Australian Problem," Economic Journal, Vol. XL, pp. 638-49; Taylor, Griffith: "Agricultural Regions of Australia," Economic Geography, Vol. VI, pp. 109-34; Belshaw, Horace: "Dairying Industry in New Zealand," Economic Geography, Vol. III, pp. 281-96; Wadham, S. M.: "Land Utilisation," Annals of the American Academy of Political and Social Science, Vol. CLVIII, pp. 31-39; "The Pastoral Industries," ibid., pp. 40-48; Taylor, Griffith: "Australia as a Field for Settlement," Foreign Affairs, Vol. V, pp. 679-81; Wood, G. L.: "Growth of Population and Immigration Policy," Annals of the American Academy of Political and Social Science, Vol. CLVIII, pp. 9-17.

16. Discuss "The White Australian Policy," Foreign Affairs, Vol. IV, pp. 97111. See also Martin, P. F.: "Australia and Italian Immigration," Fortnightly Review, Vol. CXXIV, pp. 804-11.

17. Discuss the population elements in South Africa, showing the part of each in the racial difficulties that exist.

18. How does immigration compare with emigration? See Wood, G. L.: "Growth of Population and Immigration Policy," Annals of the American Academy of Political and Social Science, Vol. CLVIII, pp. 9-17.

19. Discuss the nature of the social problems caused by immigration. References. Petrie, Charles: "Social Problems in South Africa," Edinburgh Review, Vol. CCXLV, pp. 28-42; Duncan, Patrick: "Race Questions in South Africa," Foreign Affairs, Vol. V, pp. 293-306. 


\section{PART III}

\section{THE LATIN GROUP}

The people of the Latin, Mediterranean, Romance, or Italic group are found chiefly around the Mediterranean Sea. Their early history is lost in antiquity, but they are often connected with the ancient Ligurians. Undoubtedly there is an Illyric basis for some of the people included in this group and an Iberic for others. "The Iberians," wrote Sergi," "gave its name to the great peninsula of the south-west of Europe, Spain with Portugal; the Ligurians under various names occupied various parts of Italy, joining the Iberians through southern France; the Pelasgians occupied the peninsula and islands of Greece, passed into Italy at different periods, and were diffused through Asia Minor under the obscure names of Khatti, Hethei, Chittim, Hittites; finally, the Libyans occupied northern Africa under various names, of which the most glorious was that of Egyptians."

This "Mediterranean or Iberian type," according to Ripley, " everywhere south of the Pyrenees, along the southern coast of France and in southern Italy, including Sicily and Sardinia." In his classification of the races of Europe, Pittard includes an Ibero-Insular race which inhabited principally the Iberian Peninsula, southern Italy, and the islands in the adjoining waters; and a Littoral or Atlanto-Mediterranean race, which inhabited mainly the Mediterranean coast of Italy, France, Spain, and the territory along the Atlantic coast south of the Bay of Biscay. Both of these groups were brunette, having black hair and dark eyes and skin. Over part of the territory, at least, they mingled with each other. ${ }^{3}$ There were early migrations of Teutonic and Slavic people into the areas occupied by these groups, and a mingling of their blood and culture with those of the indigenous people. Today the term is applied to the rather short, brunette, long-headed people inhabiting France, Spain, Italy, Portugal, Greece, and Latin America.

The people of the Latin group are biologically mixed and culturally confused, and it is only in the broadest sense of the term that they can be considered a biological or cultural group. All possess certain traits of Latin culture and all, except the Greeks, speak the so-called Romance tongue.

1 The Mediterranean Race, p. 33.

2 The Races of Europe, pp. 128-29.

${ }^{3}$ Compare Pittard, Eugène: Race and History, pp. 90-91. 
Their cultural traits, however, vary considerably, those of the Greeks being perhaps the most divergent. The Greeks are included in the Latin group because Greece furnished the base for many of the Latin cultural traits, and "the classical Hellenes were distinctly of the Mediterranean racial type, little different from the Phœnicians, the Romans, or the Iberians." 1

${ }^{1}$ Ripley, W. Z.: The Races of Europe, p. 408. 


\section{CHAPTER IX}

\section{FRANCE AND FRENCH CANADA}

It is mainly for convenience that France and French Canada are included in one chapter. The two groups of people were once the same racially and culturally, but they have been separated for several hundred years. Nevertheless the French Canadians largely remain French in race, language, religion, and other culture traits, and represent the old France.

\section{France}

1. General Description. The Republic of France lies in southwestern Europe. The Mediterranean Sea forms part of its southern boundary, and the Atlantic Ocean and English Channel its western. The- western coast line is 866 miles long, and the southern 384 . The abrupt and jagged Pyrenees form a natural barrier between France and Spain, and the Alps between France and Italy and Switzerland. There are practically no natural barriers between France and Germany, Belgium, and Luxemburg.

France has an area of 212,659 square miles, 5605 of which (AlsaceLorraine) were acquired as a result of the World War. It is thus somewhat larger than California but over 53,000 square miles smaller than Texas. Its colonial possessions cover an area of $5,657,804$ square miles. Of this territory, 5,290,268 square miles are in Africa, 325,004 in Asia, 33,166 in America, and 9170 in Oceania. Over some sections France holds protectorates and mandates, but for all practical purposes these may be considered French territory.

According to the census of 1926, France had a population of $40,938,847$. Of its colonial possessions, Africa had a population of $35,380,840$; Asia, 23,124,641; America, 522,398; and Oceania, 79,160 . The grand total was thus $100,045,886$. Paris, the capital and largest city, had a population of 2,871,429. Fifteen other French cities had populations of 100,000 or more, and several more almost reached that number. The foreign population was $2,845,000 .{ }^{1}$ This included 808,000 Italians, 467,000 Spaniards, 460,000 Belgians,

\footnotetext{
1 Compare Bowman, Isaiah: The New World, p. 163.
} 
310,000 Poles, 142,000 Swiss, 91,600 Russians, 84,000 British, 64,600 Germans, 49,500 North Americans, 39,600 Czechoslovakians, and 11,000 South Americans. In 1925 alone, 174,000 Italians settled in France. France has some 240,000 people of Flemish descent, who continue to speak a German dialect; about 1,350,000 Bretons, who speak a Celtic dialect; and 160,000 Basques or Euskarians, who speak a strange agglutinative language of their own. Recent research has connected them with the Hamitic Caucasian Berbers of North Africa rather than with the Mongolians. On the other hand, France contains only a small part of the people in the world who speak French. It is one of the national languages of Belgium, Switzerland, and Canada, and there are numbers of French-speaking people in Italy, the United States, the West Indies, and the French colonial possessions.

Who the first settlers of France were we do not know. Some say they were the Celtiberians, while others think they were the Basques. It is known that the Greeks established settlements around Marseilles and that the Gauls came into the country (perhaps from Asia) early. Between 154 and 51 B.c. the Romans subjugated the country and established settlements. A number of people belonging to the Teutonic tribes of Burgundians, Visigoths, and Franks settled in the country at different times. In the fifth century came Attila, known as the "scourge of God" and "the dread of the world," with his horde of Hun warriors. The Gauls, Romans, Visigoths, Burgundians, Franks, and other tribes combined against him and defeated him at Châlons in 451. In the eighth century came the Moslem Arabs, a fact which perhaps accounts for the Saracenic appearance of some of the peasants of southern France. During the ninth and tenth centuries the Northmen (Scandinavian pirates) raided the coast and river towns, finally making a permanent settlement in the province of Normandy. Perhaps three-fifths of the French belong to the broad-headed Alpine group, but the long-headed brunette Mediterraneans in the south and the long-headed blonds in the north are well represented.

France has several mountain ranges. Mont Blanc $(15,781)$ is the highest peak. There are several peaks in the Pyrenees over 10,000 feet. Brittany is really a mountain range worn down to a tableland, in the center of which is a triangular area of extinct volcanoes. Between the mountain ranges of France are three chief basins and numerous subdivisions. The climate is tempered some by the Mediterranean Sea on the south and the Gulf Stream on the west. The Riviera. 
is a paradise in the winter when northern France has an abundance of snow. There are four important rivers - the Seine, Loire, Garonne, and Rhone - which flow through fertile valleys and furnish arteries for commerce. Waterways cover 7543 miles, 3081 of which are canals. France has a number of good seaports, such as Dunkirk, Calais, Boulogne, Havre, Cherbourg, Bordeaux, and Marseilles. Some of these were greatly enlarged and permanently improved during the war by the United States and other countries. France has a very good railway system which will become state property between 1950 and 1960. Some of the railroads are being electrified.

2. Political Development. After the defeat of the Huns, Clovis, a young Frankish warrior, conquered most of Gaul and established the Merovingian monarchy. Charlemagne (768-814) conquered the Aquitanians, Lombards, and Saxons and brought them under one government. Eventually France, Belgium, Holland, Switzerland, twothirds of Italy, part of Hungary, and northern Spain were brought under his rule. By the Treaty of Verdun (843), his sons divided his kingdom, France constituting the bulk of one of the three parts.

In 1337 the Hundred Years' War broke out between Philip VI of France and Edward III of England. France wished to secure England's wool trade with Flanders, to acquire Aquitaine, which was English territory, and to punish Edward for refusing to surrender the Count of Artois, who had attempted to kill Philip. It is interesting to note that in the early part of this war gunpowder and cannon were first used. The war ended in 1420, and by the terms of peace France practically became a part of England.

Under Louis XI (1461-83), Charles VIII (1483-98), and Francis I (1515-47), France increased its power and prestige. Jealousy of Charles V of Spain, whose territory had grown until it included Spain, Naples, Sicily, Sardinia, Austria, Germany, and the Spanish Americas, caused Francis to wage an unsuccessful war against Charles. Still not satisfied, he allied himself with the Protestant princes of Germany and the Sultan of Turkey and fought another unsuccessful war. This seems to have been the first alliance of Christians and Mohammedans, Catholics and Protestants. Francis excused himself by saying, "When the wolves attack the flock, one has a right to call the dogs to help him." In the midst of this war Francis found time to send out explorers, who discovered the St. Lawrence, Canada, and the Mississippi Valley and claimed them for France. Henry II (1547-59) continued the war with Charles of Spain and succeeded in annexing 
the free German city of Metz and the neighboring cities of Toul and Verdun. This territory France held until the Franco-Prussian War (1871), and regained it in 1918.

The period from 1610 to 1774 (under Louis XIII, XIV, and XV) witnessed the gradual building up of an absolute despotism. The period was also one of frightful bloodshed. During the reign of Louis XIII, the Thirty Years' War broke out, and Catholic France allied itself with Protestant Germany and Sweden against its old enemy, Catholic Austria. By the Treaty of Westphalia (1648), France extended its boundary to the Rhine. Louis XIV wished to rule all Europe and was engaged in almost continuous wars with Holland, England, Austria, Germany, and Spain. He gained nothing, lost Newfoundland, Nova Scotia, and the Hudson Bay territory to England, and left his country bankrupt and starving, without army or navy. Louis XV continued the sport of war, taking part in the War of the Polish Succession, War of the Austrian Succession, and the Seven Years' War (American French and Indian War). He lost to England all the Indian kingdom in Asia, and all the American possessions, except the barren islands off the coast of Newfoundland on which the French dry fish.

Louis XVI (1774-93) came to the throne as an indolent, blameless young man of 20. Having married Marie Antoinette, the daughter of Maria Theresa, he naturally allied France with Austria. He and his chief aids, Turgot and later Necker, wished to introduce necessary reforms, but the power of the nobles was so strong that they were able to bring about the dismissal of these officials. Feudalism had gradually declined and a middle class was forming. By 1484 the citizens and peasants had united into one political party - tiers état which was destined to play an important part in the future development of France. Louis reëstablished parliamentary representation, which his father had abolished, and finally, in 1789, summoned the States General, which had not met since 1614. When the States General was summoned the tiers état (common people), which outnumbered the nobles and clergy combined, requested these two groups to sit with them and not meet separately as before. After five weeks the parish priests joined them. They abandoned the name of States General and formed themselves into a National Assembly. The nobles and higher clergy protested and the king closed their hall. The National Assembly then met in the tennis court of the palace and with solemn oath bound itself to frame a written constitution for the 
government. Seeing the danger of the situation, Necker advised the king to request the nobles and higher clergy to join them. The hall was opened, and for the first time all met as equals. The constitution adopted repudiated the doctrine of the divine right of kings, declared all citizens equal, abolished hereditary titles and privileges, provided for equal inheritance of property rather than inheritance by the oldest son alone, and introduced many other social changes. This was only the beginning of the inevitable revolution which broke out July 14,1789 .

Liberal political ideas had been developing for some time in France. Lafayette and many French soldiers who had served in Washington's army returned home much impressed with the Declaration of Independence. Austria, Germany, and England finally united to restore the king and the old order. But the people had become too liberal to submit. On September 21, 1792, France declared itself a republic, but no new republic had ever lived through such political and religious strife.

Austria, Germany, and England were still at war with France, and foreign soldiers had invaded its territory, when Napoleon began his Italian campaign in 1796 . In two months he had fought and won eighteen battles. Although he made the foreign countries bear the expenses of his army, the financial condition of France caused him (1803) to sell Louisiana, which he had acquired from Spain two years before, to the United States. Napoleon spent nearly twenty years fighting and conquering Europe. He changed France from a weak country in a state of anarchy to the greatest power in the world, but the process left it exhausted.

Between 1792, the date of the establishment of the first French Republic, and 1870, the date of the proclamation of the third French Republic, France alternated not only between a republic and a kingdom, but from extreme autocracy and conservatism to anarchy and radicalism. In 1870 the Franco-Prussian War (1870-71) broke out. This war resulted in the unification of Italy, the unification of Germany, and Germany's acquisition of Alsace and Lorraine from France.

When Austria-Hungary declared war against Serbia in 1914, it was evident that France would not delay in entering the conflict. Germany, Austria-Hungary, and Italy composed the Triple Alliance. France, which was allied with England and Russia, was hostile to Germany because of the Franco-Prussian War. Germany had a rapidly increasing population, while France's population was prac- 
tically at a standstill. Germany was developing rapidly, commercially and industrially; France was handicapped because of a lack of natural resources and wanted the coal and iron fields of the AlsaceLorraine territory. For many years France had been spending much larger sums of money on its army and navy than Germany, and had been extending the period of training for its soldiers.

The heaviest fighting of the war was done on French soil, and for over four years Paris could hear the guns roaring at the front and was subjected to night raids by aeroplanes. A fear psychosis developed, and with it a determination to cripple Germany permanently. ${ }^{1}$ France aimed (1) to make Germany pay for the whole war and place it in economic bondage; (2) to make the Rhine the northern boundary of France. Its allies, however, would not support these extreme demands.

France's fear psychosis has caused it to maintain the largest army, in proportion to population, in the world. From 1922 to 1928 the budget for the army and navy was increased by $4,538,756,665$ francs. Taxation is burdensome. France has only about one-third of the population of the United States and only about 32 per cent of the income; yet its taxpayers pay 52 per cent as much as ours, 20 per cent being absorbed by the federal government against our 11.5 per cent. France has concluded defensive alliances with Poland, Czechoslovakia, Rumania, and Yugoslavia, and apparently refuses to face the inevitable fact that it must be second to Germany. Its population is around 40,900,000 and increasing very slowly while Germany's population is $62,300,000$ and increasing more rapidly. France lost one man out of every 28 during the war, Germany one out of every 35 , and England one out of every 67 . The measurable effects of the war on birth rate will be revealed in a few years. France has been engaged in more, longer, and bloodier wars than any other civilized nation, ${ }^{2}$ and no doubt this is one of the chief causes for emigration and the decline in birth rate.

France adopted a constitution in 1875 and partially changed it in $1879,1884,1885$, and 1889. Legislative power rests in the Chamber

1 For an interesting defense of the French foreign policy, see Cambon, Jules: "The Permanent Bases of French Foreign Policy," Foreign Affairs, Vol. VIII, pp. 173-85.

2 Compare Sorokin, Pitrim: Contemporary Sociological Theories, p. 324; Bodart, G., and Kellogg, V. L.: Losses of Life in Modern Wars and Race Deterioration, pp. 155-56. 
of Deputies and the Senate. The Deputies are elected by direct manhood suffrage every four years. The Senators are elected indirectly for nine years, one-third retiring every three years. The two houses jointly elect a president for seven years. The government is unstable; within sixty years there have been 80 cabinets.

3. Economic Development. France has long been an agricultural country, but at present. less than 48 per cent of the people are engaged in tilling the soil. Eighty years ago 75.6 per cent of the population belonged to the peasantry. In Gers there are some 120,000 acres of uncultivated land and 2500 abandoned farms. Lot, Mayenne and Gers have within the last twenty years lost about one in five of their inhabitants. Thus the small communes are steadily losing, while the great centers are increasing.

France is by no means bountifully endowed by nature. Barren mountains cover nearly one-third of its territory. Brittany is practically sterile, and an almost unproductive plain passes close to Paris. Much of French térritory consists of shifting sand dunes and undrained marshes. Only about one-third of the land is arable, and a large part of that was in the fighting zone during the World War. The chief crops are potatoes, wheat, sugar beets, oats, barley, rye, corn, and grapes. Stock and poultry raising are also extensively engaged in.

The Industrial Revolution affected France shortly after it did England, and as a result France has engaged considerably in manufacturing. Before the World War, it was poor in natural resources, and coal cost about 40 per cent more than in Germany. France has plenty of water power, but it is only partially developed. It now has the rich Saar and other former German coal and iron fields in the AlsaceLorraine territory, and ranks first in Europe in iron production and not far behind the United States in world production. It is also extensively engaged in textile manufacturing.

Although France's coast line is not long, fishing and commerce are important. French colonies, especially those in northern Africa, are rich and furnish raw materials. France is apparently on the road to economic prosperity. Foreigners are going in and manning French factories; exports are much larger than imports; and tourists alone are spending over $\$ 400,000,000$ a year there. Over half of this amount is spent by Americans.

4. Religious Development. In the fourth century the Roman Emperor accepted Christianity, and through his influence the new faith 
was spread into Gaul (France). The bishops and priests were soon busy destroying idols and erecting crosses and crucifixes, and turning Druid temples into Christian churches. The baptism of Clovis and 3000 of his warriors was an event of major importance in the Christianization of the Teutonic tribes. In his zeal for the new faith, Clovis sought to destroy the Visigoths because they were followers of Arius, who denied the doctrine of the Trinity. He succeeded in making those who escaped death good Catholics. Charlemagne used two chief methods to convert people to Christianity. In one day, 4500 of the Saxons who had rebelled against Christianity were executed; other barbarians were attracted by the offer of a new white garment when they received baptism.

Under the preaching of Peter the Hermit and Walter the Penniless in the eleventh century, a multitude of crusaders started for Jerusalem. While many of the crusaders were actuated by unselfish motives and participated in no deeds of violence, others sullied the cause by thievery, vagabondage, and murder along the route. When this element reached Jerusalem it murdered 70,000 Mohammedans and burned the Jews in their synagogues. The Crusades continued until 1270, but the Mohammedans drove the French out of Jerusalem in 1187. During the Crusade period the Pope decided that the Albigenses, a wealthy, industrious group of people inhabiting the county of Toulouse, who refused to believe all the doctrines of the church, were also fit subjects for a crusade. Practically all the inhabitants were massacred and their rich city and country turned into a desert.

During his reign Philip the Fair decided to tax the clergy, who had hitherto been exempt. This resulted in a quarrel between Philip and the Pope. The Pope was murdered and Philip set up a Papacy in France. As the Pope was restrained from leaving France, this period is referred to as the "Babylonian Captivity." French kings and Roman Popes continued to disagree. Finally Francis I made a treaty with the Pope, by which the clergy were to be subject to the Pope in theological matters, but to the king of France in all other things.

Protestantism gained a hearing in France principally through the activity of Calvin. Francis I sent his soldiers to Vaudois to wipe out the chief center of heresy. The murder of 3000 men, women, and children was the result. The period between 1559 and 1573 witnessed terrible massacres of the Protestants (Huguenots) by the Catholics. Queen Catherine, who was ever plotting to exterminate the Protestants, arranged for the massacre on St. Bartholomew's Day, August 
24, 1572. Secretly the Catholics marked all the Protestant houses. At two o'clock on Sunday morning the church bells rang the signal and the massacre began. For three days the struggle went on, and according to records the Seine was choked with dead bodies. Around 20,000 people were massacred in these three days. The Pope was so rejoiced at the news of the massacre that he ordered a thanksgiving and struck a medal to commemorate the act. When he learned the facts in regard to the massacre, however, he wept and condemned it as being a violation of Christian principles.

Henry IV ascended the throne and, finding that he could not rule as a Protestant, became a Catholic to save France. He issued the Edict of Nantes, which granted the Huguenots practically the same rights as Catholics. In 1685 Louis XIV revoked the Edict of Nantes, gave the Protestant ministers fifteen days to leave France, destroyed the Protestant churches, and forbade the Protestants to follow their pastors. The most brutal of the French soldiers were given the job of converting the Protestants. Large numbers of these Protestants succeeded in escaping from France to Holland, Germany, England, and America. About 20,000 settled in Berlin alone. They had been a patriotic, industrious people very much needed in France. They soon established their trades in other countries, and France, no longer enjoying the fruits of their labor, began to decline rapidly in these arts. Louis XIV could agree with the Pope but little better than he could with the Protestants. They quarreled, and Louis established an independent Catholic Church in France. One of the chief trouble makers, not only in France but in all Catholic Europe, was the Jesuit order, founded by Ignatius Loyola. Its members were expelled from France in 1761. The Pope abolished the order in 1773, but restored it in 1814. It was reinstated in France by Charles X, driven out of the schools a little later, and again expelled in 1880 .

The constitution of France, adopted in 1790, guarantees full liberty of worship and civil rights to Catholics, Protestants, and Jews. The Catholic Church had secured possession of about a third of all the land in France. The new republic seized this land (worth about $\$ 400$,$000,000)$ and used it for the welfare of the nation. The state assumed control of the clergy and forced them to take an oath to support the constitution. The Pope resented this and declared that all who took the oath of allegiance would be cut off from communion with the Catholic Church. Many of the religious liberals now became extremists, and under Hébert's influence Sunday and the Christian 
calendar were abolished. Churches were closed and the Goddess of Reason was enthroned in the Cathedral of Notre Dame. In 1801 Napoleon concluded a treaty with the Pope and reëstablished the Catholic Church as the church of France. Later he quarreled with the Pope, because the Papal States continued to trade with England, and took the Pope to France, where he held him as a prisoner as long as he (Napoleon) remained in power. Today France is predominantly Catholic, but the state recognizes no religion.

5. Educational Development. Educational development in France, as in several other European countries, has long been hindered by numerous dialects. The dialect of the north differs from that of the south, and each large division has numerous local dialects. In some cases the peasants of one section can scarcely understand those of another. The situation is further complicated by the Celtic-speaking Britons, German-speaking Flemish, and Iberian-speaking Basques. The educated of all groups understand Parisian French.

The first school system in France seems to have been started by Charlemagne, under the leadership of Alcuin, an Anglo-Saxon monk. The Crusades aided the educational development by introducing new ideas of geography, arts, and general culture. During the reign of Louis XI the New Learning (study of Greek) reached France. About this time the printing press began to be used. The church was evidently afraid that the educational movement would introduce heresy, for it united with the crown in permitting only twelve men to engage in printing.

Louis XII and Francis I both fought in Italy and were impressed with Italian learning, art, and architecture. Louis brought back paintings of Michelangelo and Raphael, and introduced Renaissance architecture. France took on new life, and during Colbert's administration, under Louis XIV, made rapid progress in establishing and improving its schools and libraries. It produced such great men as Racine, Molière, La Fontaine, Descartes, and Pascal. Their ideas had a marked influence on France, but perhaps not so much as those of Montesquieu, Voltaire, and Rousseau, who prepared the way for the revolution which made liberalism possible. In his Italian campaign Napoleon robbed Italy of books, paintings, and other works of art, and sent them back to Paris.

France has an excellent school system which culminates in the University of Paris, founded in the twelfth century. Education has long been compulsory in the primary grades. In 1931 France had 
seventeen universities. The University of Paris, with 27,350 students, was the largest. It also has a number of excellent technical schools.

6. Social Development. According to Caesar, all Gaul was divided into three parts, and the people into three classes: the nobles, who were fighters and disdained work; the priests (Druids), religious teachers, educators, physicians, and judges; and the slaves, who tilled the fields, herded the cattle, and performed other manual labor. The Roman conquest brought with it a Roman organization of society. When the Roman power began to decline, society tended to become stratified into two classes - landlords and slaves. The burden of taxation was so great and regulations of work so rigid that many freemen and property owners sold themselves into slavery. The Franks developed a feudal society. Serfs went with the land but could not be sold apart from the land as could the slaves, the lowest class. A man's property was what he could protect, and small owners had to join with a more powerful neighbor and work for him. By the close of the ninth century France consisted of 29 feudal states or provinces. The rulers of each province were small kings. They had their warriors and slaves and ran affairs as if they were independent rulers, even coining money, engaging in commerce, and declaring war.

Although a few slaves and serfs gained their freedom by participating in the Crusades, the idea became fixed generally that people were born into social classes and could not change from one to another. Philip the Fair incurred the hostility of the nobles by conferring the title of noble on a silversmith. This was a heavy blow to their exclusive social position and to the belief that nobles were born, not made. It opened the way of the unprivileged classes to titles and social position, and at the same time increased the power of the king. Philip did not stop here, but proceeded to free all the serfs who could pay well for the privilege. During the Hundred Years' War the wonderful feat of Joan of Arc, a peasant girl, in leading the hardpressed French army to victory, increased the prestige of the peasants; and the use of gunpowder showed the barons that they could no longer retire behind their walls and be safe. A middle class had also been developing, and when this united with the peasants and formed the tiers état, the nobles and clergy were obliged to recognize their demands.

Although possessing considerable Teutonic blood, the people of France are Latin in culture. They are pictured as a gay, frivolous, 
rollicking, changeable, unsteady people, but this picture is more characteristic of the inhabitants of Paris and southern France than of the inhabitants of the northern part. "It is not easy," writes Professor E. C. Branson, "to get into either the peasant or bourgeois homes of France.... If you get into a French farm home - peasant home, middle-class home, or château - you must be certified by the ambassador of your country, viséed by the minister of agriculture or some other minister of state, and then viséed by the prefect, the subprefect, and the sous-prefect, clear down the line from some almightiness at the top to some little tin god at the bottom. For France is a complicated hierarchy of fonctionnaires, reaching from the minister of state through countless grades to local midgets in the public service. Richelieu made it so four hundred years ago, and so it is today with no essential change anywhere. And France is fonctionnaire France. You are not allowed to forget that fact for a single minute. Without fingering a long line of red tape, you would get into a French farm home at the risk of your feelings or your life."

The Frenchman does not want strangers, officers, or neighbors interfering with his home. "Behind its walls the family lives as it pleases, without let or hindrance. It is their sacred right. How they live is nobody else's business. And not always but commonly the French peasant family pleases to live like pigs in a litter - all for the sake of hoarding money and owning interest-bearing securities." 2

7. Immigration and Emigration. Since the World War, especially, France has had its own immigration problems. Statistics indicate that it has changed from an emigrant to an immigrant country. Within the five-year period 1923-28, resident foreigners, exclusive of seasonal workers, tourists, and natives from colonies employed in mines, factories, and other industries, increased the population of France by almost a million. According to Jean Bourdon, ${ }^{3}$ France is the second immigrant country in the world now, and first in the proportion to numbers of inhabitants. Several reasons may be given for French immigration. (1) The World War wrought devastation to whole villages, fields, and roads, and reduced the man power of the nation. As a result, official commissions were sent to Poland, Italy, Czechoslovakia, and Belgium to secure immigrant help. By 1923

${ }^{1}$ Farm Life Abroad, pp. 268-69.

2 Ibid., p. 274.

${ }^{3}$ Proceedings of the World Population Conference, edited by Margaret Sanger, 1927, p. 295. 
236,365 immigrants were permanently installed in France. (2) When the United States further restricted immigration in 1921 and 1924, the more prolific nations of Europe, notably Russia, Poland, and Italy, found their principal outlet blocked and accepted France as a substitute, although opportunities there were not so great. (3) Persons from Soviet Russia, Fascist Italy, Hungary, and Spain, Jews from Rumania and Poland, and Armenians, finding conditions in their native lands unsatisfactory, have migrated into France to escape persecution.

As a consequence of this influx, France is faced with the necessity of immigration restriction. No serious supervision is exercised at the frontiers, and no method of distributing this population exists. Several villages in the Département du Nord are entirely populated with Poles who have brought not only their families but their priests and schoolmasters as well. Furthermore, the sick and infirm are welcomed, and free medical assistance is rendered to immigrants from Italy, Pcland, Belgium, and Luxemburg.

The French have been coming to the United States ever since it was first discovered. Immigrants, however, have never come in large numbers except during a few years when religious persecution and political revolutions were serious. Groups of French Huguenots settled in South Carolina and Virginia during the religious wars, and a number of the politically oppressed settled along the Atlantic coast. Many of the early French settled in Louisiana and in the Middle West. Only 371 immigrants came from France in 1820, 2843 in 1828, 10,583 in $1846,20,040$ in $1847,20,126$ in $1851,14,798$ in $1873,11,347$ in 1905, and 6387 in 1924. Between 1820 and 1930, inclusive, 582,375 French immigrants came to the United States from France. In 1920 there were 152,890 foreign-born people in the United States from France; of these, 125,589 gave French as their mother tongue. Our immigrants from France are mainly from the educated and adventurous groups. The largest number here, however, are occupied as laborers, servants, and farmers. It is doubtful if France will send many more immigrants to the United States. Its quota for 1930 was 3086 , but it sent only 2812 .

French emigrants have gone to other countries also. Between 1857 and 1924 Argentina received 226,894, and between 1842 and 1924 Brazil received 33,304. The number going to Canada is decreasing, being 2755 in 1912 and 326 in 1924. Between 1900 and 1924, however, Canada received 29,428. From 1916 to 1924 39,896 
French emigrants went to Morocco, but between 1920 and 1924 15,304 left the colony. A few French emigrants go to other countries and to other French colonies, but the numbers have never been large. From 1910 to 1924 the total number of French emigrants amounted to only 199,868 . Nearly that number of Italians entered France to settle in one year.

\section{French Canada}

1. General Description. About a hundred years before the United States gained its independence, somewhat less than 10,000 French settled in Canada, principally in Nova Scotia and Quebec. With practically no further immigration, they increased to 16,417 in 1706 , 69,810 in $1765,679,084$ in 1844 , and over $3,000,000$ at the present time. They show a remarkably rapid rate of increase, having multiplied 300 times in the last 300 years. At one time Quebec gave fathers of 12 living children 100 acres of land, and according to reports it had many gifts to make. A large number of fathers thought they should have 200 acres as they had 24 or more living children. The birth rate remains high, but, contrary to the general rule, it is not accompanied by high infant mortality.

French Canadians perhaps differ more from the French in France than Americans of British descent differ from the British. They have been isolated from France for over 170 years, and there has been very little immigration from France, and very little travel or communication between the two countries. The French Canadians had no part in the Napoleonic Wars, the French Revolution, and other upheavals that have influenced modern France, and have been subject to British influence. They have not changed very much, however, and have held tenaciously to their religion, language, customs, and ideas. When England gained possession of Nova Scotia in 1713, it sought to deport the French and settle the country with Britishers. Some of the French remained, however, and since that time French settlements have been made in different parts of Canada; but Quebec remains the chief center, where about 90 per cent of the people are French Canadians. There are about half a million of them in Montreal. In 192179.2 per cent of the people in Quebec ten years of age and over gave French as their mother tongue, 28.7 in New Brunswick, 12.7 in Prince Edward Island, 9.8 in Nova Scotia, 7.3 in Ontario, 6.5 in Manitoba, 5.7 in Saskatchewan, and 5.7 in British Columbia. 
The language spoken by the French Canadians differs markedly from Parisian French. It consists of an agglomeration of several early French dialects with a preponderance of Norman, contains many forms and expressions extinct in France, and shows the influence of English despite the efforts of the people to keep it pure. Educated French Canadians speak English as well as French, but the uneducated speak very little English. Industry, commerce, and travel have emphasized the importance of knowing English. Very few of the English-speaking people make any effort to learn French. In many places the children of both groups go to school and play together, understanding each other's language but making no attempt to speak it.

The French Canadians are reported to be about nine-tenths pure French. There has been some absorption of Indian blood and there are some settlements of Indian-French crosses. There has been a much greater absorption of British blood than Indian. The number of "Macs" and "Mcs" indicates a considerable intermixture with the Scotch and Irish. The French Canadians and the French language appear to be becoming of less and less importance in Canada.

2. Political and Economic Development. When Quebec came under British rule in 1759 , there were between 60,000 and 70,000 French Canadians. There was no so-called middle class. When a large majority of the upper class withdrew to France, they left a group of peasants under the leadership of the priests. The British established freedom of worship, abolished feudal dues and compulsory tithes, and sought to remove corruption in government. A group of corrupt British and American traders appeared and helped to bring about bad political, economic, and social conditions. Largely to remedy these corrupt conditions and to gain the good will of the priests, the famous "Quebec Act" was passed in 1774. It removed trial by jury and habeas corpus, reëstablished the Roman Catholic Church with tithes, forced the people to recognize the king of England and take an oath of allegiance, and prohibited them from corresponding with foreign ecclesiastical authorities.

During the American Revolution many of the French Canadians sympathized with the Americans, and despite the opposition of the priests, many joined the American army. But the conduct of the American soldiers after they invaded Canada. created a feeling of hostility, and caused the French Canadians to draw closer to England. When the annexation movement developed in 1849, the French 
Canadians were divided on the issue. Those who had been born in the United States greatly favored annexation, and tried to bring about a union, but the priests were afraid they would lose some of their special privileges. Most of the French Canadians now favor continuing as a part of the British Empire. They realize that they compose 28 per cent of the population in Canada but would form only 2 per cent of the combined population of the United States and Canada. They fear, also, that the United States would not continue the special privileges which they possess under Canadian law.

The French Canadians have never been eager to support England in wars. The American War of Independence and War of 1812 tended to unite them with the other Canadians, but the South African War served to widen the gap. They had little enthusiasm in the World War and lagged behind other groups in the number of recruits. By excluding all citizens who had become naturalized since 1902, and by extending the suffrage to adult females who had a male relative in the war, Canada was able to pass the Conscription Act, but draft riots and threats of secession occurred in Quebec.

Although the criminal laws in Quebec are English, the civil laws are French. There is much wrangling over this, and efforts are being made to centralize the government and remove the special privileges of the province of Quebec. The French Canadians, however, have become shrewd politicians, and through appeals to language, religion, and race have been able thus far to thwart such efforts.

Business, even in Quebec, is chiefly in the hands of English-speaking people. The French Canadians remain predominantly farmers. Larger and larger numbers, however, are engaging in lumbering, fishing, and industry.

3. Social Development. Under the dominance of semi-feudal lords, the peasants of the French regions of Canada occupied an inferior political, economic, and social status. They were generally fairly industrious, very religious, and ignorant, but contented under the rule of the seigneurs and priests. Many of the seigneurs, however, were little better off economically than the legally inferior peasants. The priests were socially superior. All religious and educational work and practically all political power were in their hands, and, though weakened some by the British, largely remain so today. Under French rule non-Catholics were not permitted to settle in Quebec and heretics were not tolerated. When the British acquired the country these laws were changed, but the French Canadians remain 
conservative, loyal Catholics. The Catholic Church is not established, but it has special privileges over its own communicants.

Family life is patriarchal among the French Canadians, and one really "marries into" the family. It is remarkable how "in-laws" agree. The male is the ruler of the family, and in Quebec, unless otherwise specified at marriage, the husband has the right to the wife's property and wages. Being conservative Catholics, divorce hardly exists for them.

4. Immigration and Emigration. The French Canadians have long moved over into the United States, especially to such mill towns as Haverhill, Fall River, Lawrence, New Bedford, and Worcester in the New England States, where they compose one-seventh of the population. The five states having the largest percentages of French Canadians are New Hampshire, Maine, Vermont, Rhode Island, and Massachusetts. According to reports there are 1,750,000 people in the United States of French Canadian origin. About three-fourths of these are in the New England States.

They engage mostly in textile work, which pays much better than farm labor in Canada. According to reports, they receive the lowest average wage of the foreign groups; yet investigation shows that their plane of living is higher than that of the Greeks, Italians, Poles, Portuguese, and Armenians. Although 44.8 per cent of the French Canadians in 1920 were naturalized, they are accused of not being interested in becoming citizens. They appear to be slower in changing their allegiance than the English Canadians, but in 1920 they stood 19 on the list of our foreign groups ranked according to percentage of naturalization while Mexico ranked 43. About 63 per cent of those who work in factories speak English, and many of their children cannot read or speak French. They are generally disliked throughout Canada and the New England States, and occupy an inferior social position. Many of the American-born French Canadians are changing their names or moving away from New England in order to escape economic handicaps resulting from race prejudice.

\section{QUESTIONS, EXERCISES, AND PROBLEMS FOR INVESTIGATION}

1. Characterize the Latin group. Wherein does it differ from the Teutonic?

2. What political significance may be attached to the geographical position of France?

3. What diverse elements enter into the early population of France? Give 
a comparative estimate of the different racial groups now living within the French borders.

4. Trace the rise of the tiers état. What is its political and social significance?

5. What may be said for and against France's fear psychosis?

6. What are some of the economic problems of France?

7. Describe the methods of spreading Christianity during the early periods of French history. What were the disastrous results of the banishment of Protestants from France?

8. (1) How was society stratified under the Romans? (2) What changes were wrought by the Franks? (3) How does Branson picture French peasant life?

9. Explain why France has changed from an emigrant to an immigrant country. Why is it probable that we shall not receive many more immigrants from France?

10. Discuss the post-war political situation in France. Reference. Thorp, W. R.: "The Political Bureaucracy of France Since the War," American Political Science Review, Vol. XXII, pp. 301-23.

11. Report on the Alsace-Lorraine question, paying special attention to the economic and political factors. References. Gallois, Lucien: "AlsaceLorraine and Europe," Geographical Review, Vol. VI, pp. 89-115; Callender, Harold: "Alsace-Lorraine Since the War," Foreign Affairs, Vol. V, pp. 427-37.

12. Discuss France's foreign policy. Besides the text, see Cambon, J.: "The Bases of French Foreign Policy," Foreign Affairs, Vol. VIII, pp. 173-85; Newman, E. W. P.: "France's Difficulties in Syria," Nineteenth Century, Vol. CI, pp. 37-47.

13. Compare French immigration problems with those of the United States. References. Lambert, Charles: "French Immigration Problems," Foreign Affairs, Vol. VI, pp. 269-76; Paulian, André and Adrien: "The Problem of Aliens in France," Nineteenth Century, Vol. XCVII, pp. 823-34; Gauld, W. A., and Herbert, Sydney: "France and the Immigration Problems," Geography, Vol. XIV, pp. 111-22; Gautier, E. F.: "French Colonial Policy in Theory and Practice: A Review," Geographical Review, Vol. XXI, pp. 131-41.

14. Report on Blanchard, W. O.: "The Landes, Reclaimed Waste Lands of France," Economic Geography, Vol. II, pp. 249-55.

15. In what respects have the French Canadians remained Latin? What changes have taken place in their culture?

16. Account for the attitude of the French Canadians toward the United States (1) during the Revolutionary War; (2) in recent times. How is this group regarded in the United States and in Canada?

17 Report on one of the following: (1) Belcourt, N. A.: "The French Canadians Outside of Quebec," Annals of the American Academy of Political and Social Science, Vol. CVII, pp. 13-24; (2) Marquis, G. E.: 
"The French Canadians in the Province of Quebec," ibid., Vol. CVII, pp. 7-12; (3) Dexter, R. C.: "French Canadian Patriotism," American Journal of Sociology, Vol. XXVIII, pp. 694-710; (4) Chapter III, "The French Canadians," in Immigrant Backgrounds, edited by H. P. Fairchild.

18. Show how two languages are preventing complete assimilation in Quebec. See Clark, J. B. M.: "French and English in the Province of Quebec," Nineteenth Century, Vol. CII, pp. 327-36. 


\section{CHAPTER $\mathrm{X}$}

\section{SPAIN}

1. General Description. The Republic of Spain includes almost five-sixths of the Iberian Peninsula. France bounds it on the northeast, Portugal on the southwest, and two square miles of British territory on the south; the Atlantic Ocean and the Mediterranean Sea nearly surround the peninsula. The lofty Pyrenees Mountains separate Spain and France, but the boundary between Spain and Portugal is "neither natural nor scientific," consisting for the most part of short rivers, low ridges, and infertile valleys.

Continental Spain embraces an area of 190,050 square miles. Included with this territory in administration are the Balearic Islands (1935 square miles) in the Mediterranean Sea, the Canary Islands (2807 square miles) in the Atlantic Ocean, off the coast of Africa, and the fortified station of Ceuta, containing 5 square miles of territory in Africa, opposite Gibraltar. Spain thus has a total of 194,797 square miles, or is a little over twice the size of Oregon. Spain's colonial possessions are all in Africa, and include Rio de Oro, Spanish Guinea, certain islands, and the protectorate Spanish Morocco - a total of 140,000 square miles, making the grand total 334,797 square miles.

Including the 375,101 inhabitants of the Balearic Islands and the 554,750 of the Canary Islands, Spain had an estimated population of $23,817,000$ in 1930 . Its colonial population was estimated to be 897,000 . Madrid, the capital and largest city, had a population of 883,274 . Other large cities and their populations are Barcelona, 972,946; Valencia, 320,195; Seville, said to be the most Spanish city of Spain, 223,308; Zaragoza, 173,963; Murcia, 158,724; Bilbao, 161,987; and Granada, 117,493:

The Spaniards are a very mixed group. In general they have long heads and dark eyes and skin, and are good representatives of the Mediterranean type. Some writers believe that Crô-magnon man first inhabited Spain. When the Phœenicians arrived in the eleventh century B.c., they found the Basques and Iberians. The Basques are thought to be an offshoot of the Berbers, while the Iberians are 
perhaps descended from the Chaldeans and Assyrians. It is possible that both groups entered Spain by way of Africa. Both continents were probably united at Gibraltar at that time. The Carthaginians came to help the Phœnicians in their struggles with the native tribes, but decided to take the land for themselves. About 650 B.c. the Greeks began to settle in Spain. In 206 B.c. the Romans went to aid the Greeks, who were being ruled by the Carthaginians. Roman rule lasted for six centuries. In 409 A.D. the first successful invasion of the Teutonic Visigoths occurred. They were followed by the Vandals and Suevi. In 711 the Mohammedan Moors, who included in their group Arabs, Persians, Syrians, Copts, Berbers, Carthaginians, and Negroes, crossed over from Africa. The Moslems were followed by the Jews and Gypsies. The bloods of all these peoples have gone to make the modern Spaniard.

Some writers maintain that Europe stops and Africa begins at the Pyrenees. Spain is largely isolated from all countries of Europe except Portugal. The numerous mountain ranges which run in an eastwest direction divide Spain into four sections. In the center is a high plateau which gradually slopes toward the west. The climate, soil, and crops vary widely in the different sections. The rainfall is generally deficient, and in some sections the country is virtually a desert. Spain is moderately rich in a variety of natural resources. Despite its deficiency of large rivers, it has the possibility of great hydroelectric power. Its 10,000 miles of railroads are privately owned, but they are subsidized by the government with a view to nationalization.

2. Political Development. The most outstanding facts of early Spanish history are the six centuries of Roman rule and the stamping of Roman characteristics upon the different racial groups of the Iberian Peninsula. The decline in Roman power enabled the Teutonic groups to establish themselves, but the feudalistic Visigoths were unable to check the hordes of Moors, who within seven years had crossed the Pyrenees. During the eighth century, all of Spain except the territory of a few isolated peoples like the Basques came under Moorish rule.

Moorish Spain began to fall apart in 1030. Small Christian states began to appear in the north and to drive the Moors south. By the end of the thirteenth century Spain consisted of the two important states of Castile and Aragon, and the two smaller states of Navarre and Mohammedan Granada. With the marriage of Queen Isabella of Castile to Ferdinand, heir to the throne of Aragon, in 1469, began the 
real process of unifying the rule of Spain which was completed with the conquest of the Moorish state in 1492.

In 1505 Ferdinand secured rights in Naples, Sicily, and Sardinia, and gradually became a power in Mediterranean affairs. It was during his reign that Columbus discovered America. On the death of Ferdinand (1516), Charles of Austria fell heir to the whole Spanish inheritance; three years later he came into possession of the Hapsburg domain and became Charles V. His realm included Austria, Spain, Holland, Belgium, much of Italy, and most of the Americas. In his twenty-first year he was crowned king of the Holy Roman Empire.

With the passing of Charles $\mathrm{V}$ the Hapsburg rule was divided into two branches. Ferdinand, brother of Charles, became the Austrian Hapsburg ruler under the title of Holy Roman Emperor, and Philip II, son of Charles, ruled Spain, the Spanish Netherlands, the two Sicilies, Milan, and the American colonies. Philip was a bigoted despot who desired to make Spain the greatest country in the world, but his willingness to subordinate everything else to the glory of the Catholic Church led him into endless trouble. The Inquisition was restored, and under the direction of the ferocious Duke of Alva heretics were burned, murdered, and massacred wherever found. Philip lived to see the defeat of the Armada and Spain reduced to a second-rate power. By the end of his reign, Spanish commerce had been swept from the seas, the country had become bankrupt, and part of its possessions - Holland - had embraced Protestantism and become independent.

During the sixteenth, seventeenth, and eighteenth centuries Spain suffered from weak and inefficient rulers, who succeeded in keeping the country at war and in bankruptcy most of the time, despite the great wealth which poured in from the colonies. There were numerous political and religious outbursts, but absolutism and conservatism continued. For the first three quarters of the nineteenth century Spain was torn by civil wars, and it was during this time that it lost all its American colonies except the islands. Long before Charles IV was dethroned, Napoleon was playing politics with Charles's minister Godoy and Prince Ferdinand, leading each to think he was being befriended. In 1807 the French soldiers began marching through Spain toward Portugal. In March, 1808, Godoy fled from Spain to France. A month later the masses rose to drive the hated French from Spanish soil and to restore Prince Ferdinand, whom they considered their 
king, to Spain. In 1812 a Utopian constitution was adopted which reduced the power of the king to a mere shadow, established a onechamber Parliament, manhood suffrage, and equal electoral districts. This did not have the sanction of the people, especially the nobles, and when Ferdinand ascended the throne in 1814, he swept away all the reforms and executed the reformers.

At Ferdinand's death in 1833 war broke out over who should rule, his young daughter or his brother, Don Carlos. The liberals supported Ferdinand's widow, who was serving as regent for her daughter, and in 1834 forced her to grant a constitution, calling for a two-chamber legislative department. Since the legislature was dependent on the Crown, the constitution was an empty form. A revolution in 1836 reëstablished the constitution of 1812 . Revolutions and counter revolutions followed each other in quick succession. In 1856 the military leader, O'Donnell, brought the reigning queen to terms. She soon violated her agreements and affairs became unbearable. A revolution drove her to France; the young queen, though only thirteen years old, was declared of age; and anarchy reigned supreme. Finally a republic was established, in 1873, but fighting between the different factions led to the establishment of a constitutional monarchy with Alfonso XII as king in 1875. He promulgated a liberal constitution in 1876 and did much to bring peace to bleeding Spain. Upon his death in 1885, his wife ruled for his posthumous son, Alfonso XIII. Although a Catholic, she promoted liberty, trial by jury, manhood suffrage, a liberal press, and the adoption of a unified code of laws. She failed, however, to correct the notorious abuses in Cuba and other colonies. In 1895 another insurrection against Spain broke out in Cuba. The United States demanded the recall of General Weyler and the institution of certain reforms. Spain tried to pacify the United States, but commercial interests in the United States favored war. In February, 1898, the battleship Maine was blown up and the United States declared war on Spain. The war was brief. In August peace was restored and Spain lost Porto Rico and adjoining islands, the Philippines, and Guam to the United States, while Cuba became independent. The next year Spain transferred the Caroline and Pelew islands to Germany, retaining nothing of its immense colonial empire but the small possessions in Africa.

The last king, Alfonso XIII, took charge of the government in 1902, and at first it appeared that some advancement was being 
made. That the government was very unstable, however, is shown by the numerous revolutions, the selection of twenty premiers within six years, and the approval of only one budget by Parliament. The military disasters in Morocco in 1921 showed the weakness of Spain and aroused the people. In 1923 a dictatorship was established with Primo de Rivera as leader. The country was under martial law from September, 1923, to May, 1925, and from September, 1926, to January, 1927. Spain had a constitution and a Cortes divided into two houses; men and women householders of 23 had the vote; but apparently nothing was functioning except the dictatorship. The Cortes was disbanded in 1923 and in 1927 replaced by an Advisory Assembly, half the members of which were appointed by the dictator, and the other half by the municipal mayors, who themselves were appointed by the dictator. For several years there had been strong agitation in some provinces, especially Catalonia, to withdraw from Spain, or at least secure local autonomy. On April 14, 1931, Spain suddenly became a republic, but trouble continues, and no one can predict its future.

3. Economic Development. Spain has always been an agricultural country. The Phœenicians and Greeks taught the natives how to cultivate the soil and raise flocks. The Moors introduced many new kinds of vegetables, fruits, and trees, and greatly advanced agriculture by constructing the best irrigation system in Europe. With the expulsion of the Moors, Spain lost an efficient agricultural class and speedily began to decline. Possibilities of wealth in America caused peasants to abandon their farms and seek a fortune in the New World. Gradually most of the agricultural work came to be done by Frenchmen who came for a season and left with their wages. Desolation, misery, and poverty became widespread. In twenty years of Philip's reign the number of farmers and the amount of agricultural products decreased by almost half.

Agriculture remains the basis of Spanish economic life; yet it continues in a very backward state. Some improvement is being made, but in many sections where the Moors had an excellent irrigation system and grew luxuriant crops, the irrigation system has not been kept up, and the country has become practically desolate. Many of the tools now used by the peasants show little improvement over those used in the Roman period. According to estimates, 88.4 per cent of the land can be cultivated. Only a small percentage of this, however, is now irrigated; of the arable land, about one-fourth is 
used for crops and fruits, and one-fourth for grazing. Most of the land is held in small estates; the most valuable land, however, is in large estates. Laws have been passed which provide for the division of the large estates, but practically nothing has been done to accomplish it. The government has attempted to repopulate sections of the country by colonization, but without success. The principal crops are olives, oranges, nuts, grains, onions, grapes, garlic, tomatoes, and pepper.

The Phœnicians and Greeks were good seamen and early began to develop commerce in Spain. The Moors introduced metallurgical works, the manufacture of glass, pottery, and the production of silk with Byzantine designs. Furthermore, the country had an abundant supply of natural resources. It is not surprising, therefore, that Spain became the leading commercial country in Europe. Its goods were in demand throughout the civilized world. With the discovery of America, Spain had another abundant supply of natural resources at its command, and a wonderful opportunity to develop commerce with the natives of its colonial empire; but the expulsion of the Jews and Moors, detrimental trade agreements with other nations, and a usurious tax system to support a corrupt, parasitic group of political and church officials, caused commerce to decline rapidly, and soon Spain was unable to supply the demands even of its colonies. From these early blunders Spain has never recovered. The period of the World War showed marked industrial activity, but internal and external commerce remains in a very backward state. Spain is reported to have had 1035 merchant ships in 1899, and to have bought 67 more from England; now it has only 789 steamships and 95 sailing vessels, not enough to carry its own goods. The manufacture of cotton, woolen, and silk goods is improving, but Spanish factories do not yet supply the home market. Foreign capital is being invested in the country, and the economic future is beginning to look brighter.

Spain has a considerable supply of coal, although it imports some from England and the United States, and an abundance of iron, lead, copper, tin, asphalt, manganese, quicksilver, silver, sulphur, sulphate of soda, salt, and phosphorus. Mining is being better developed; some 160,000 people find employment in this industry. The fishing industry also is important; it affords employment for some 130,000 people.

4. Religious Development. During the first three centuries, Christianity spread rapidly in Spain, and through its organization wielded 
a powerful influence over an otherwise disorganized people. Trajan, fearing that Christianity would weaken his rule, tried to stamp it out by cruel methods, but was unsuccessful. In 306 Constantine granted religious liberty to all Roman citizens, but Theodosius determined to suppress all faiths but Christianity. With the coming of the Moors a new faith, Mohammedism, was added to the religious groups in Spain. There was a small amount of religious friction, but in general Moslems, Christians, and Jews lived in peace. Since the Moors did not interfere with municipal rule, the foundation of Spanish political life, had a superior civilization, and observed higher ethical standards than the Christians, many Christians became Moslems despite the fact that the Moors discouraged this. Intermarriage was taking place freely, and the three religio-racial groups were being amalgamated. Many Christians held high positions in the Moslem army. Not only did Christians become Moslems, but many Jews and Moslems became Christians. But finally a group of fanatical Christians substituted bitter religious antagonism for the former amiable relationship. With the establishment of two noted Spanish institutions - the Inquisition and the Jesuit order - Spain became a religious slaughter-ground and remained such until the death of Philip III in 1621.

At first the hostility was chiefly political against the Moors, and economic against the Jews. The Moors were industrious, thrifty, and prosperous, and the Jews, who were engaging in banking, money lending, and other financial systems, were becoming wealthy. Undoubtedly the Jews practiced usury; for one of the first laws against them limited the rate of interest they could charge to 35 per cent. Each of the religious groups felt itself superior. Seeing the prosperous condition of the non-Christians, the priests began to teach the ignorant Christians that they were the chosen people of God and were called upon to defend His cause by crusading against the "infidel" Jews and Moors. Many of the Moors and Jews had voluntarily become Christians, and thousands of others were forcibly baptized. Jewish and Moorish blood was in the veins of many of the high political and church officials, but this did not cause them to refrain from persecutions and massacres. Conditions gradually became worse, and Pope Sixtus IV established the Inquisition, a horrible politico-ecclesiastical institution which caused Spain to run red with blood for four centuries.

Ferdinand and Isabella saw in the Inquisition an opportunity to 
unite Spain on a religious basis, and also an opportunity to gain much wealth by murdering the Jews and Moors and seizing their property. Under the devout ascetic Torquemada, who was private confessor of the Queen, the fires of the Inquisition burned at full blast, resulting in the burning of 8800 Jews and the use of other punishments, many of which were worse than death, on 96,504 others.

Finally the decree went forth that all Jews - men, women, and children - must leave Spain in four months. They were not permitted to take any gold or silver with them - only such things as they could carry on their backs. At least 160,000 Jews were thus exiled. Every advantage was taken of them as they wandered toward the nearest seaport. Often they were robbed and beaten, and many were murdered on the way. A group finally reached Asia Minor, and a number of their descendants have come to the United States.

After expelling the Jews, the Christians concentrated their efforts on the Moors. They were required to remain at home three days while the orders came directing them where to go to take ship for Africa. As happened in the case of the Jews, Christian officials gained all their property. The law made provision for a small number of the old Christian Moors to remain and teach the Spaniards their methods of irrigation and farming, but they all went together, and as a result many sections where the Moors produced bountiful crops have been deserts since that day. Not less than 500,000 of Spain's best citizens, many of whom had long been Christians, were exiled in 1609-10.

Having massacred and exiled the Jews and Moors, the Catholics next massacred the Protestants, and when Protestants had been crushed they murdered any one who could be accused of heresy. Conditions were made worse by the passing of a law giving the informant one-third of the "heretic's" property. One of the powers behind the Inquisition was the Jesuit order. Through the church, liberty and progress were suppressed, and all Spaniards came to think much alike and to be proud of their enslaved minds.

Roman Catholicism was the national religion of Spain, and the church was supported by the state until the republic was proclaimed in 1931. There are very few non-Catholics in Spain, perhaps 7000 Protestants and 4000 Jews. For some time there has been a movement on foot which is not only anti-Catholic but anti-religious. The new government has disestablished the Catholic Church and guarantees religious freedom. In January, 1932, the Jesuit order was or- 
dered to disband and its property was confiscated for the welfare of the nation.

5. Educational Development. The Greeks and Phœnicians introduced into Spain a knowledge of written characters and the arts of civilization. Under the Romans the people adopted the Latin speech, clothes, and religion. As was their custom, the Romans erected fine buildings, substantial highways and bridges, and public baths. Three grades of schools were established. In sculpture, mosaic, literature, and other arts Spain ultimately surpassed Rome.

With the coming of the Moors the Byzantine culture was introduced, and the fusion of these foreign cultures with the native made Spain the most civilized country of all Europe. At Cordova the Jews took up the study of the sciences and philosophy. Arab scholars joined them in translating the works of ancient Greek scholars and in the study of mathematics, astronomy, botany, medicine, and surgery. Thus, centuries before the time of Erasmus, Moslem universities in Spain were outstanding centers of learning. They also had the best libraries in Europe, and during the twelfth century Spanish-Jewish scholars and physicians were attached to practically all the European courts.

The Inquisition checked Spain's intellectual development, and the Renaissance had less effect in Spain than in other parts of Europe. During the sixteenth century, however, there was a revived interest in literature and art, and Spain reached its Golden Age in these through the leadership of such men as Cervantes, Quevedo, Vega, Calderón, Velasquez, Murillo, Ribera, and Zurbarán.

In 1857 primary education was supposed to have been made compulsory for children between the ages of 6 and 9 years, and free to the poor. A law passed in 1902 granted state aid to elementary schools, and another, passed in 1909, made elementary education compulsory. As the schools were mainly supported by the municipalities, and as neither the poor nor the wealthy were interested in universal education, the laws were never enforced. There was supposed to be one secondary school in each province. Fifty per cent of the girls who received any education were educated in convents. Spain has eleven universities with 31,500 students. Most of the education in Spain has been of the narrow religious type. Illiteracy and ignorance are widespread, but illiteracy is being reduced. In 190166 per cent of the people could neither read nor write; in 1910 the proportion was 59 per cent, and in 192045 per 
cent. The illiteracy rates in the different provinces range from 26 to 82 per cent.

Spain, like a number of other European countries, is handicapped by different dialects. In 1252 Castilian received official sanction and remains the language of literature and of the educated group. The Basques cling to their language, which, as a wit has said, "the devil can't understand or learn." The Catalonians speak a dialect closely related to the language of southern France, the Galicians speak a dialect closely related to Portuguese, and both Castilian and Catalonian have several dialects.

6. Social Development. In early times in Spain there were slaves and free citizens of different classes. Rome granted citizenship to all free Spaniards. With the introduction of Christianity the idea of the liberty and sacredness of the individual spread and resulted in considerably milder treatment of the slaves. The Teutonic tribes grafted feudalism with its social distinctions on to the Roman civilization. Under the Moors many Christians strove to attain to the social position of the Moslem rul-

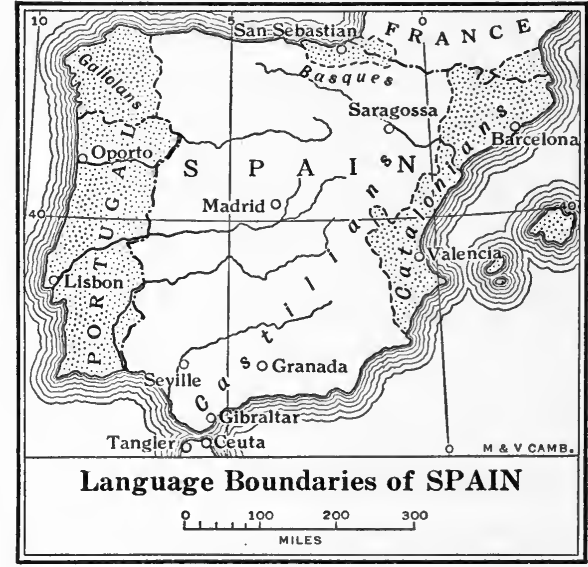

After Agostini, L' Europe ethnique et linguistique ers, and in time became their equals in wealth, luxury, and social position. Gradually special names for Moors and Jews who were forcibly converted to Christianity, for those who were willingly converted, and for Christians ruled by Moors were coined, and social distinctions were made between these groups.

During the thirteenth century the people of the towns grew in wealth, social position, and political power, and began their struggle with the nobility. During the fourteenth century the struggle continued, and finally the people of the towns dismissed the privileged groups (nobles and clergy) from the Cortes. From 1252 to 1479 was an important period in Spanish history. It saw the end of serfdom, an increase in the privileges of the clergy, augmentation of the landed wealth of the nobles through gifts from the kings and through private 
conquests, and advancement of the cause of the middle class in its struggle with the privileged class for equality in taxation and legal matters.

Although Spain was frequently at war, always heavily taxed, and always in poverty, wealth nevertheless flowed into its treasury, without, however, benefiting the masses of people. Special privileges, large grants, and greater privileges made the nobles and clergy more arrogant. Capitalists, nobles, and landed proprietors lived in luxury and opposed labor movements, popular suffrage, liberalism, and reform. Many of the peasants and laborers continue to live in shacks and in dire poverty, but are showing signs of rebellion under the leadership of the socialists and anarchists. Between these two groups stood the Catholic syndicalists in coöperative associations which were working for arbitration and harmony.

The bull fight is still the national pastime of Spain, the first fight of the season occurring on Easter Sunday afternoon and others continuing until early October. Oftentimes the wealthy bull owners and breeders have private rings for testing the mettle of their stock and furnishing amusement for the socially elect. Spain also thrills over state lotteries which take place regularly on the first, eleventh, and twenty-first of each month, with one or two extras, the most important being the Christmas one. The "returns" are anxiously awaited and many fantastic tales are current as to the rise and fall of private fortunes.

Balconies have a prominent place in Spanish life. Instead of finding his Christmas gifts in his stockings, a child finds them in his shoes, which he leaves on the balcony. There is no Santa Claus, but in his place are three kings - Gaspar, Melchior, and Balthazar - who distribute the gifts. If the child finds his cheek blackened in the morning, he thinks he has had a personal visit from Balthazar, the Negro king. The balcony also figures in the romantic life of the young girls and their suitors. The young man follows the girl of his choice to her home, and thereafter each night walks up and down in front of her house. If his attentions are welcomed, she appears on her balcony and talks with him. Since he may not enter her house until he is formally engaged to her, he makes a daily visit to the balcony and plies his courtship. The advent of the modern apartment house and the persistence of this culture pattern have greatly complicated matters for the youth whose lady-love resides on the top floor.

In government the Spaniards have manifested a remarkable in- 
stability. In general they portray the conservatism of an isolated people and the self-satisfaction of a nation with a glamorous past which has refused to admit its present lowered status or to look into the future.

7. Immigration and Emigration. It is not the number of Spanish immigrants into the United States that makes Spain important in a study of this kind, but rather the fact that at one time it owned the larger part of the New World, including Florida, Texas, New Mexico, Arizona, California, and other parts of the southwest, on which were stamped the Spanish language, religion, and other cultural factors. Thus, in understanding conditions in Spain, we are better prepared to understand the Mexicans and other Latin American peoples.

In 192997,465 emigrants left Spain as compared with 50,972 in 1926. Large numbers of immigrants have never come from Spain to the United States. Although the numbers increased rapidly until the percentage laws were passed, only about one-twelfth of our Spanish-speaking immigrants come directly from Spain. Most of them go to the Latin American countries, though part of them later come here. In 1899 we received 385 immigrants from Spain, in 1904 3996, in 19075784 , in 1917 10,232, in 1920 18,821, in 1921 23,818 (the largest number in any one year), in 1922 665, and in 1930 670. Our present law permits 252 immigrants from Spain to come each year, an increase of 121 over the two per cent law. For the ten-year period ending in 1910, we received 27,935 immigrants from Spain, and for the next decade 68,611 . Only 28,958 came for the decade ending in 1930. From 1820 to 1930 we received only 166,865 immigrants from Spain. A large number of our Spanish immigrants return home38,960 for the decade ending in 1920. In 1920556,111 of our foreignborn whites gave Spanish as their mother tongue, but only 48,535 gave Spain as the country of their birth.

Cuba receives large numbers of immigrants from Spain. Between 1902 and 1923 it received 663,478, the maximum number for any one year being 94,294 in 1920. From 1882 to 1923 Argentina received $1,660,637$ immigrants from Spain. The largest number recorded for any one year was 165,662 in 1912 . The largest number going to Brazil in any one year was 41,064 in 1913. According to Brazilian statistics, 530,330 Spaniards arrived between 1882 and 1923. Fairly large numbers of Spaniards go to Mexico, but most of them do not remain there. For the period 1911 to 1924 65,449 entered, but 51,699 , or 79 per cent, left. Fairly large numbers also go to other Span- 
ish American countries, to the Philippines, and to Africa, but many soon return home. Thus large numbers leave Spain annually (189,517 in 1920), but large numbers also return. Between 1882 and 1923 there were 4,262,594 departures and 3,318,343 repatriations. Large numbers go to other European countries as seasonal laborers. In 1925 there were some 500,000 Spaniards working in France.

\section{QUESTIONS, EXERCISES, AND PROBLEMS FOR INVESTIGATION}

1. Describe the geographical location of Spain, noting any physical features that influence it as a world power.

2. What is the racial composition of the Spanish? References. Ripley, W. Z.: The Races of Europe, Chap. X; and Pittard, Eugène: Race and History, pp. 94-114.

3. Prior to the ninth century, what cultural infusions took place in Spain?

4. Trace briefly the events leading up to the establishment of a constitution in 1812; to the fall of Alfonso XIII in 1931.

5. Account for the backward state of Spain's agriculture.

6. What are the prospects for Spain to regain its lost power? Besides the text, see Chesterton, G. K.: "The Future of Spain," Fortnightly Review, Vol. CXXX, pp. 11-20.

7. Summarize the steps in the development of the present religious situation in Spain. Discuss the effects of this development on Spain, and account for anti-religious sentiment.

8. Describe the Golden Age of Spanish educational achievement, and account for the high rate of illiteracy.

9. Show how the different cultures affected social stratification. Account for the widening of the gulf between the wealthier and poorer classes.

10. Abstract one of the following articles: Adams, H. C.: "Barcelona, Pride of the Catalans," National Geographic Magazine, Vol. LV, pp.373-402; Ford, Richard: "Seville, more Spanish than Spain," ibid., pp. 273310; McBride, H. A.: "On the Bypaths of Spain," ibid., pp. 311-72; Crabitès, Pierre: "Spanish Politics of To-Day," Nineteenth Century, Vol. XCIX, pp. 830-36; De Los Rios, Fernando: "The Agrarian Problem in Spain," International Labor Review, Vol. XI, pp. 877-901; De Madariaga, Salvador: "New Life in Spain," Yale Review, Vol. XIX, pp. 67-84; Don Alfonso Merry del Val, "The Spanish Zones in Morocco," Geographical Journal, Vol. LV, pp. 319-49, 409-22.

11. Describe the efforts of the national spirit of the Basques to exert itself. Reference. Davies, A. M.: "Spain and the Basques," Fortnightly Review, Vol. CXV, pp. 37-48.

12. Make charts of Spanish emigration per decade. 


\section{CHAPTER XI}

\section{PORTUGAL}

1. General Description. The Republic of Portugal is situated in southwestern Europe, forming the southwestern part of the Iberian or Pyrenean Peninsula. It is bounded on the west and south by the Atlantic Ocean, and on the north and east by Spain. In shape it resembles a parallelogram; its greatest length from north to south is 362 miles, and its greatest width is about 140 miles.

The area of Portugal, including the Azores (922 square miles), Madeira (314 square miles), and islands in the North Atlantic Ocean, is 35,490 square miles; it is thus a little larger than Maine. Portugal's colonial possessions in Africa include Angola (Portuguese West Africa), 484,800 square miles; Mozambique (Portuguese East Africa), 426,712; Guinea, 13,940; Cape Verde Islands, 1480; and Principe and St. Thomas islands, 360. Its possessions in India include Gôa (1469 square miles), Damão (169 square miles), and Diu (20 square miles). It also owns Timor (7330 square miles) in Malaysia and Macao (4 square miles) in China.

In 1930 Portugal, including the Azores (253,596 inhabitants) and Madeira (210,226 inhabitants), had a population of $6,190,999$. In 1925 Lisbon, the capital and largest city, had a population of 529,524 ; Oporto, the chief seaport, had a population of 215,625 . The population of Portugal's African possessions is 6,603,910, and of its Asiatic possessions 1,179,206. Mozambique, with 25,000 Portuguese out of a population of $3,677,000$, is the only possession that has a considerable Portuguese population.

The Portuguese are a mixture of many groups. The Iberians and Basques are either the descendants of the earliest people or else they have absorbed them. The Carthaginians and Greeks early established trading centers and mingled their blood with that of the natives. Following the Punic Wars, the Romans ruled Portugal for six centuries; their rule seems to have affected the language and civilization far more than any other element. From the fifth century on, there was a series of invasions by the Vandals, Suevi (Swabians), and Alans, each of which dominated the country for short periods. 
Ethnologically the Visigoths and Suevi were of greater importance than the other northern tribes or the Romans, but they too gradually were absorbed in the Lusco-Roman civilization. From 711 until well into the thirteenth century Portugal was ruled by the Moors; consequently a considerable amount of Arab, Berber, and Negro blood was introduced. The Jews came in gradually, and long before their expulsion in 1497, many had become wealthy and intermarried with the Christians. After 1450, Negro slaves were inducted in large numbers, thereby increasing the proportion of Negro blood. The ethnic composition of the present population differs considerably in various parts of Portugal. The peasants in the northern part appear to be closely related to the Galician and Asturian Spaniards. Galician blood appears to predominate in the north, Arabic and Jewish in the central section, and Arabic and Negro in the south. In the Azores Teutonic types are common, but in Madeira there is a definite strain of Negro blood. The Portuguese of the Cape Verde Islands are a mixture of Negro and Portuguese.

The Portuguese are considerably undersized. In the north the men average 5 feet 5 inches; in the south 5 feet 4 inches. They have dark hair, brown eyes, and sallow skin. Their faces tend to be broad and their heads long. A few blonds are found, and about two per cent of the women have light hair. The poor classes are reported to have better physiques than the wealthy.

Portugal is mountainous in character, having several small ranges with some peaks rising to a height of 6000 feet. Some of the valleys are deep and fertile, but most of the country is non-arable. The rainfall is excessive in some sections, but in others so scanty that crops have to be irrigated. The climate is generally temperate, but in some of the valleys it is hot and in some of the highlands cold. Perhaps no small country has such rich flora and presents so great a variety of scenery. Portugal is rich in mineral resources, and has some forests. The only plain of any size is in the north. The coast line is about 500 miles long and has 21 navigable harbors. Portugal also has three rivers, the Douro, Tagus, and Guadiana, which are suitable for water transportation.

2. Political Development. Portugal derived its name from the little seaport of Portus Cale, now a suburb of Oporto. In 1095 it was only an obscure fief under the Kingdom of Leon. Although some writers have maintained that Portugal is identical with ancient Lusitania, it is generally agreed that, throughout the centuries which witnessed 
the overthrow of the power and influence, in turn, of Carthage, Rome, the Visigoths, and the Moors, Portugal remained a part of Spain and showed no sign of national consciousness. Surrounded by Moors and Spaniards, and torn by civil wars, it gradually developed a national consciousness, and within four hundred years became the greatest commercial, colonial, and maritime nation of Europe.

Near the close of the eleventh century the Christian reconquest of Spain from the Moslems brought Crusaders from many parts of Europe, who aided in driving the Moors from northern and central Spain and Portugal. Among these was Henry of Burgundy, who married Theresa, the natural daughter of Alfonso VI, King of Leon, and received Portugal as part of his possessions. Upon the death of his father-in-law he laid claim to the throne of Spain, and out of this struggle developed the movement for the separation of Portugal from Spain. Alfonso Henriques, who assumed the title of King of Portugal in 1140, drove the Moors south of the Tagus and secured for Portugal what was practically the status of an independent nation. He also organized a navy which was the foundation of his country's maritime power. Alfonso's successors continued the struggle for independence, fighting Spaniards and Moors. In 1254 the Moors were subdued, and in 1265 Spain recognized Portugal's independence.

During his reign Prince Henry (1394-1460) attracted to his court the most skilful navigators and geographers of his day and initiated the most marvelous period of discovery the world has ever known. Madeira and the Azores Islands were discovered and colonized. Cape Verde was discovered in 1445, the Cape of Good Hope in 1486, the new route to India around Africa in 1498, and Brazil in 1500 . Portugal claimed all Africa, southern India, and Brazil by right of discovery.

Political corruption at home and in the administration of the colonies grew apace. By 1521 Parliament had ceased to meet regularly. The monarchy grew weak and the church gained more power. The industrious Moors and the Jews, the financial geniuses of the nation, were expelled. Farmers deserted the land to Negro slaves, and the establishment of colonies tended to depopulate the home country. By 1580 Philip of Spain had annexed Portugal and closed Lisbon to Dutch, English, and French commerce. The Dutch seized part of Portugal's colonial possessions. The sixty years of Spanish captivity were marked by numerous insurrections. War between Spain and France enabled the Portuguese to declare their independence in 1640, 
but Spain refused to recognize it. Marriage of the nominal king of Portugal with the sister of Charles VI of England made England the ally of Portugal and caused Spain to recognize Portuguese independence in 1668. The history of Portugal during the following years is one of internal strife, occasioned in part by attempts at political reform.

Portugal joined Great Britain and Spain in a war against Napoleon (1808-13). Napoleon's invasion of Portugal in 1808 sent the royal family to Brazil, and Rio de Janeiro became the capital of the Portuguese Empire. Great Britain drove the French out of Portugal and established a provisional government at Lisbon. In 1815 peace was restored in Europe, but the British prolonged their military occupancy. To this the Portuguese objected, and several rebellions had to be crushed. In 1822 a charter was drawn up providing for a moderate parliamentary form of government. King John VI, entrusting the government of Brazil to his son Dom Pedro, returned to Portugal in 1822. Dom Pedro was Grand Master of the Freemasons of Brazil and an open supporter of the Brazilian party, which desired a liberal constitution and separation from Portugal. Brazil declared its independence and proclaimed Pedro emperor (1822). Upon his father's death Pedro came to the throne of Portugal in 1826, and immediately granted the people a liberal constitution. He appointed his brother Miguel regent in 1827, but Miguel violated his oath to Pedro, assumed absolute power, and retained it until 1834. This is the saddest period in Portugal's history; it was truly a reign of terror. Conditions did not improve much after Miguel's reign, and dissatisfaction increased until 1903, when an insurrection of peasants armed with scythes took place and brought certain changes. The country was supposed to be a constitutional monarchy, but was in reality an oligarchy. In 1908 King Carlos and the Crown Prince were assassinated. King Manoel II ascended the throne, but a revolution drove him to England. Portugal was proclaimed a republic October 5, 1910.

In 1911 Portugal adopted a new constitution. It provides for an Upper Chamber of 71 members elected by municipal councils, and a National Council of 164 members elected by direct vote. Both Chambers elect a president for four years. The president appoints a cabinet, but the cabinet is subject to the Chambers rather than to the president. Illiterates were deprived of the franchise in 1919 Conditions have not improved much under the republic. There have been some 20 revolutions, and more than 40 cabinets have been formed. Lisbon has been bombarded several times, and mutinies in 
the army and navy have been frequent. There are about a dozen parties, each with a narrow program, each struggling against the others.

Traditional friendship for England, fear that Germany would absorb Mozambique, the desire to protect its colonies and fisheries, and its trading interests caused Portugal to enter the World War on the side of the Allies. Its participation was not extensive, but it was active; and as a result, the Kionga Triangle, a portion of Mozambique containing about 400 square miles, which Germany had absorbed, was restored to it, and its colonial possessions were confirmed.

For hundreds of years Portugal has been losing its colonies, and it is in danger of losing those which it now retains. By the Treaty of Tordesillas (1494) Spain and Portugal settled their quarrel over territory, and Portugal was confirmed in its rights to Brazil and its possessions in Africa and India, including Persia and Ceylon. While it was under Spanish rule, the Dutch took part of its possessions, and in the early part of the eighteenth century the Arabs won back part of the territory which Portugal had taken from them. Nevertheless, at the beginning of the nineteenth century Portugal still possessed a larger colonial territory than any other power in Europe except Great Britain and Spain. The European scramble for land in Africa during the middle of the nineteenth century left it with only a small part of its former possessions. For a number of years there has been unrest among its colonists, who blame Portugal for their backward position. Other countries buy most of the products of the Portuguese colonies and foster in them the desire for separation. The Union of South Africa wishes to acquire Mozambique, and Belgium wants the northern part of Angola. Consequently Portugal has been forced to grant its colonies a large degree of self-government and to institute important reforms.

3. Economic Development. Agriculture is the most important occupation in Portugal, 60 per cent of the population being engaged in agricultural pursuits. Yet the production hardly equals the demand, as only about one-fourth of the land is cultivated, and that by primitive methods. About 25 per cent of the land is waste; 37 per cent is cultivated or in pastures; about 6 per cent is in vineyards and the same amount in fruit trees; 26 per cent is in forests. Much of the land is too rugged for cultivation; other sections are too dry; the moorlands are too cold. The common forms of land tenure are peasant proprietorship, tenant farming, and métayage and emphy- 
teusis (ground rent). Crude methods of agriculture still prevail in many sections. Oxen are the motor power for plows and carts, and tools common in the time of the Romans are still used. Men, women, and children labor together in the fields, and women take their places along with the men at the docks and in the quarries. Wages are exceedingly low. As late as 1907, the equivalent of $\$ 1.50$ per week was considered a good wage, and girls considered themselves lucky if they received $\$ 0.75$ per week. In some sections many of the peasants own their small farms, but most of the land is held in large estates, and a majority of the people are tenants and farm hands. Although irrigation is an agricultural prerequisite in some sections, the antiquated Moorish system with practically no improvements is used.

The principal grain crops are wheat, maize, and rye. Almost every section has its vineyards, and wine is the chief export. Most of the deciduous and citrus fruits are grown. Olive oil is manufactured in the south, where the olives grow most profusely. There is some cattle raising, but the chief animal food supply comes from the large herds of swine which are raised in the woods on nuts, and from mountain sheep and goats. About 53,000 men and boys are engaged in the fishing industry. The fishermen form a distinct class and are noted for their strength and seamanship. The majority are employed in tunny and sardine fisheries.

Manufacturing is relatively unimportant. The Methuen Treaty of 1703 with Great Britain prevented the establishment of textile industries; so it has been only for the last 40 years that these industries have made any progress. The chief manufactured articles are laces, embroideries, textiles, pottery, porcelain, cork products, wine, and olive oil. About 45,000 persons are employed in manufacturing.

After Vasco da Gama's voyage to India in 1498, Portugal developed a trade with India, and by twice defeating the Mohammedan fleet, succeeded in holding it. First it had to dispossess the Arabs who early settled along the coast of the Mediterranean and the coast of India. By 1510 Portugal had conquered the people of Mozambique and had established a flourishing colony at Gôa, India, through which it was able to make contacts with other parts of India and with China. Settlements and trade centers were established in India, China, Japan, Africa, and Brazil. Through these Portugal controlled the trade of the East, and Lisbon took precedence over Venice. A decline, however, soon set in, and by the early part of the eighteenth 
century the Arabs had won back much of their former territory. In three years (1737-40) rival European powers and Arab pirates practically swept Portugal's commerce from the seas.

Although Portugal early planted colonies and developed an extensive commerce, its colonies on the whole have never been of much value to it. It has never tried to establish inland settlements or to develop the natives, but has sought rather to hold a fringe on the seacoast. Furthermore, it has failed to foster industries at home to manufacture the raw materials the colonies could furnish, or to establish manufacturing plants within the colonies.

From its African possessions Portugal secures sugar, copper, rice, rubber, tobacco, cotton, cocoanuts, palm oil, cattle, hides, wax, gum, and ivory. From its Asiatic colonies it receives manganese, salt, spices, copra, cocoanuts, fish, coffee, sandalwood, and wax. Most of what it gets is reshipped to England and different parts of Europe without being manufactured, Portugal is fairly rich in natural resources, but it has never had the money to develop them. Salt, gypsum, marble, and lime are exported. Lead, copper, iron, zinc, cobalt, bismuth, antimony, and anthracite are mined to a limited extent. Sulphur and gold are found, and sulphur springs abound.

4. Religious Development. The Portuguese were early converted to Roman Catholicism. During the Crusades they were active, but most of their energy was spent in trying to drive the Moslems out of Portugal. In this they were joined by many foreign crusaders and military orders. To make war on Islam seemed to the Portuguese their natural destiny and duty as Christians. After the Moors had been driven out, they turned on the Jews, another group which refused to accept Christianity. No two groups ever did more to build up the country; the Moors had developed it agriculturally, and the Jews had developed it financially and commercially. But, hoping to secure the throne of Spain by his act, King Emanuel banished the Jews and the unbaptized Moors in 1497 . They were given six months in which to leave the country. Rather than forsake their native land and flourishing businesses, many half-heartedly accepted Christian baptism.

In 1834 the church was deprived of temporal authority, the Jesuits were expelled, the monasteries were dissolved, and monastic property was confiscated. The books from the monasteries were collected and turned into a library of 30,000 volumes in Lisbon. Roman Catholicism, however, remained the state religion until 1910, but other 
creeds had long been tolerated. The founders of the republic were liberals and anticlerical. Religious orders were expelled and their property confiscated, state and church were separated, and the payment of salaries to the clergy by the state ceased.

Despite the toleration for other creeds which has lasted for a long time, and the absolute freedom of worship since 1910, there are very few non-Catholics in Portugal - about 5000 Protestants and 500 Jews. Although Portugal has had a fairly well trained priesthood, many people remain ignorant and superstitious, believing in witches, fairies, enchantments, and sorcery. In fact religion, superstition, and recreation are very closely related in Portugal. Religious festivities and processions are far more popular with the masses than bull fights, the national sport, since the latter cost more than the masses can afford. Church funerals are conducted with much pomp and are popular affairs.

5. Educational Development. The Portuguese are the most illiterate and most backward people in western Europe. Their language is neo-Latin with many Arabic and other foreign words. It is more closely related to Spanish than to any of the other Romance tongues. That the people have great artistic ability is evident from their poetry, music, costumes, and pottery. This ability is part of their Moorish heritage. Portugal has produced some noted poets. Camões, by far the most noted, published his greatest work - Os Lusiadas - in 1572. He is to the Portuguese what Dante is to the Italians and Shakespeare to the English. The Lusiadas relate not only the voyages of da Gama, but also most of Portugal's previous history.

Primary education was provided for by the law of 1844 , which established schools and compelled attendance between the ages of 7 and 15, provided pupils lived within a mile of the school. Practically no attempt was made to enforce the law until 1911. At that time the primary schools were placed in the hands of the local communes, but little has been done since. Often a room or a house is set apart for a school, but no money is provided to pay for teachers, furniture, or books. Many of the peasants oppose education and will not send their children to school. Secondary schools were provided for by the law of 1894, but there is little demand for the educacation they offer. Portugal's oldest university - Coimbra - was founded in the thirteenth century, and a school of commerce was founded in 1759. Portugal has three universities, located at Lis- 
bon, Oporto, and Coimbra. There are few educated people in the country. In 1900 the illiteracy rate was 78.6 per cent; in 1920 it was 71 per cent; most of the adult males who are able to read and sign their names learned to do so during their compulsory military service.

6. Social Development. Portugal early became a country of nobles and peasants. After the period of discovery and the introduction of slavery, the peasants largely abandoned their farms to slave laborers and moved into the cities. In eighty years Lisbon trebled its population. The cities became overcrowded and unsanitary, and plagues often raged. There were many Negroes in the cities as well as in the rural districts. By the middle of the sixteenth century the slaves outnumbered the freemen in Lisbon, and the Algarves was populated almost entirely with Negro slaves. In 1773 a law was passed declaring that all children born to slaves after that date should be free. The law also abolished distinctions between "old" and "new" Christians. New Christians were the descendants of Christianized Jews and Moors. All groups were made eligible for civil, military, and ecclesiastical offices. The republic further showed a tendency toward democracy by abolishing all hereditary titles and privileges.

Writers differ very much in their evaluation of the Portuguese. Some say that "if you take away everything good from a Spaniard, you have a Portuguese." Others consider them a childlike nation, satisfied with little, economical without avarice, pure in morals, generous, sober, and hospitable, and declare they have bred heroes instead of diplomats, and poets instead of capitalists. It is generally agreed, however, that they are sober, good-natured, obliging, and patriotic, but dirty, lazy, and shiftless, the axiom of their life being "never do today what you can put off until tomorrow."

There are not many wealthy people in Portugal, and the few there are live in luxury and idleness, employing many servants. The working people, especially the poorer peasants, live in abject poverty. Their homes are mere hovels, often built of mud, with clay floors, and without windowpanes or doors. Often as many as seven persons live in one room, without furniture except, perhaps, a piece of mattress. They squat on the dirt floor to eat, and each dips his spoon into the common vessel. They live in a hand-to-mouth fashion. Meat is seldom eaten except on feast days or on holidays, but fish is consumed in large quantities. 
The Portuguese have no national costume. However, a great variety of picturesque costumes representing different sections and classes may be seen at a bull fight or religious festival, both of which resemble our county fairs. Sashes, broad-brimmed hats, and coppertipped quarterstaves are worn by men throughout the country; brilliant cotton dresses and gold or silver filigree ornaments are worn by the women, especially on holidays.

The peasants, having no money to pay to see bull fights, satisfy their desires for recreation with church processions, sitting on their doorsteps gossiping with neighbors, smoking cigarettes, and petting the numerous cats. Color prejudice does not seem to enter into their mores.

7. Immigration and Emigration. The Portuguese have long been an emigrating people. Africa, Asia, and South America have felt the Portuguese influence since the fifteenth century. In South America the Portuguese influx has been very large; it is around 30,000 a year at the present time. According to the best available statistics, Portugal lost 1,484,763 people by emigration between 1885 and 1921. About seven-tenths of these went to Brazil. The movement to that country started slowly, being only 120 emigrants in 1837 , but it reached 12 ,918 in 1872, 32,349 in 1891, and 76,701 in 1913. During the World War it decreased to 6817 in 1917, but rose to 31,866 in 1923, dropping to 29,792 in 1929 . Brazil received 1,158,890 Portuguese immigrants between 1837 and 1924 .

Argentina has received a small but continuous stream of Portuguese immigrants. The largest number of immigrants in any one year was 4959 in 1912. Argentina received 38,196 between 1857 and 1924. A few Portuguese emigrants go to other Latin American countries; a few - never over 2500 per year - go to Africa; small numbers go to other European countries. The return movement also is not very marked.

Except for a few fishermen and seamen, it was not until the middle of the nineteenth century that the Portuguese turned to North America in large numbers. The number of immigrants from Portugal to the United States was less than 1000 per year until 1872 and less than 3000 until 1892. In 18942196 were admitted, in 1900 4234, in 1902 5307, in 1903 9317, in 1912 10,230, in 1913 14,171, in 192119,195 (the largest number in one year), and in 1925619 . The total number received between 1820 and 1930 was 252,715 . In 1920 there were 105,895 foreign-born people in the United States who gave 
Portuguese as their mother tongue, but only 66,726 , or 63 per cent, came from Portugal. Our present law permits only 440 immigrants per year from Portugal, 63 less than the two per cent law.

Most of the Portuguese immigrants into continental United States have come from the Azores, Hawaii, the Cape Verde Islands, and the northern part of Portugal. Those from the Cape Verde Islands are very dark, being a mixture of Negro and Portuguese blood. Those of the Azores show traces of a Flemish infusion. In Hawaii the Portuguese are low in the social scale. The Portuguese have settled mainly in three regions - California, New England (chiefly in Massachusetts, Rhode Island, and Connecticut), and New York and New Jersey. It seems that the early Portuguese settlers in California were from Hawaii, while the settlement in New England originated when some Portuguese emigrants on their way to Hawaii were shipwrecked off the coast of Massachusetts and settled in that state. Those in the northeast engage chiefly in textile work and fishing, and those in California in fishing, dairying, and grape growing.

Undoubtedly some have come to escape military service and revolutions; most of them, however, have come because of economic reasons. Most of them have been laborers and peasants. Of the 130,000 who came here between 1820 and 1910, 95 per cent were laborers and 70 per cent were illiterate. Differing from other southern and eastern Europeans, the Portuguese usually bring their families. Very few, however, manifest an interest in citizenship.

\section{QUESTIONS, EXERCISES, AND PROBLEMS FOR INVESTIGATION}

1. What racial mixture predominates in Portugal? References. Dictionary of Races or Peoples; Pittard, Eugène: Race and History, pp. 112-14; Ripley, W. Z.: The Races of Europe, pp. 273-76.

2. What geographical contrasts does Portugal present?

3. Show how Portugal developed national consciousness.

4. Describe (1) the expansion of Portugal and the steps by which it established its prestige; (2) its decline as a world power.

5. What use does Portugal make of its land? What are its chief industries?

6. In what ways has it developed its natural resources? In what ways has it failed? Besides the text, see Bowman, I.: The New World, Chap. VII; and Blanchard, W. O. and Elizabeth: "The Grape Industry of Spain and Portugal," Economic Geography, Vol. II, pp. 182-202.

7. Account for the tendency of the Roman Catholics in Portugal to persecute other religious groups. 
8. In what respects are the Portuguese said to be the most backward of civilized European peoples?

9. To what countries do the Portuguese emigrate?

10. What reasons were chiefly responsible for the emigration of Portuguese? From what area do most of our Portuguese immigrants come?

11. How do the Portuguese fit into American life?

12. Luis Araquistain makes the statement that bureaucracy, civil and military, is the cancer eating into the entrails of the nation. ("Dictatorship in Portugal," Foreign Affairs, Vol. VII, pp. 40-53.) Discuss.

13. Read Two Portuguese Communities in New England, by D. R. Taft, Columbia University Press, 1923, and show to what extent the foreign element has become Americanized. 


\section{CHAPTER XII}

\section{ITALY}

1. General Description. The boot-shaped peninsula known as Italy is situated in southern Europe. It is 760 miles long and juts out into the Mediterranean Sea for about 600 miles, almost dividing the sea into two parts. It is, generally speaking, about 100 miles wide, and nowhere over 150 miles. The Alps Mountains on the north form a natural boundary between Italy and its neighbors - France, Switzerland, Austria, and Yugoslavia. The eastern shore of Italy is washed by the Adriatic Sea, and the western by the Tyrrhenian and Ligurian seas. There are numerous bays and gulfs but few good harbors on the eastern coast. The Apennines cross the northern part of the peninsula obliquely, but then run nearly parallel with the coast the remainder of its length. There are several lofty peaks and volcanic mountains, such as Mt. Etna and Mt. Vesuvius. The rivers are mostly mountain torrents, and the Po and Tiber have more historical than commercial importance.

Italy proper includes the peninsula and numerous islands - Sicily, Sardinia, Elba, and about seventy others - a territory of 119,744 square miles, or an area a little less than that of New Mexico. Of this, 9084 square miles were gained as a result of the World War. Italy's colonial possessions consist of the Dodecanese and other islands of Asia Minor, and African possessions including Eritrea, Somaliland, and Libya, an area of 871,416 square miles. Thus Italy has a grand total of 991,160 square miles.

In 1931 Italy had a population of $42,118,835$. Its colonial territory had a population of $2,157,416$ (partly estimated). In 1931 Rome, the capital and largest city, had a population of $1,003,881$, and in 1930 Naples had 980,338. Italy had 19 cities with populations ranging from 110,401 to 973,299 , and 39 cities with populations between 50,000 and 100,000 .

In 1928 the Italian governmental statistical bureau estimated that nearly 10,000,000 Italians were living under foreign flags. On the other hand, there are many non-Italians living within pre-war Italian geographical borders; some 85,000 French, 12,000 Spanish, 29,000 
Greeks, 10,000 Germans, 81,000 Albanians, 43,000 Slavs, and 12,000 Spanish. The former Austro-Hungarian territory annexed by Italy after the World War contained 326,715 Slovenes, 215,345 Germans, and 141,663 Croats. These three nationalities alone totaled over a third of the population. The majority of the people in Italy's colonial

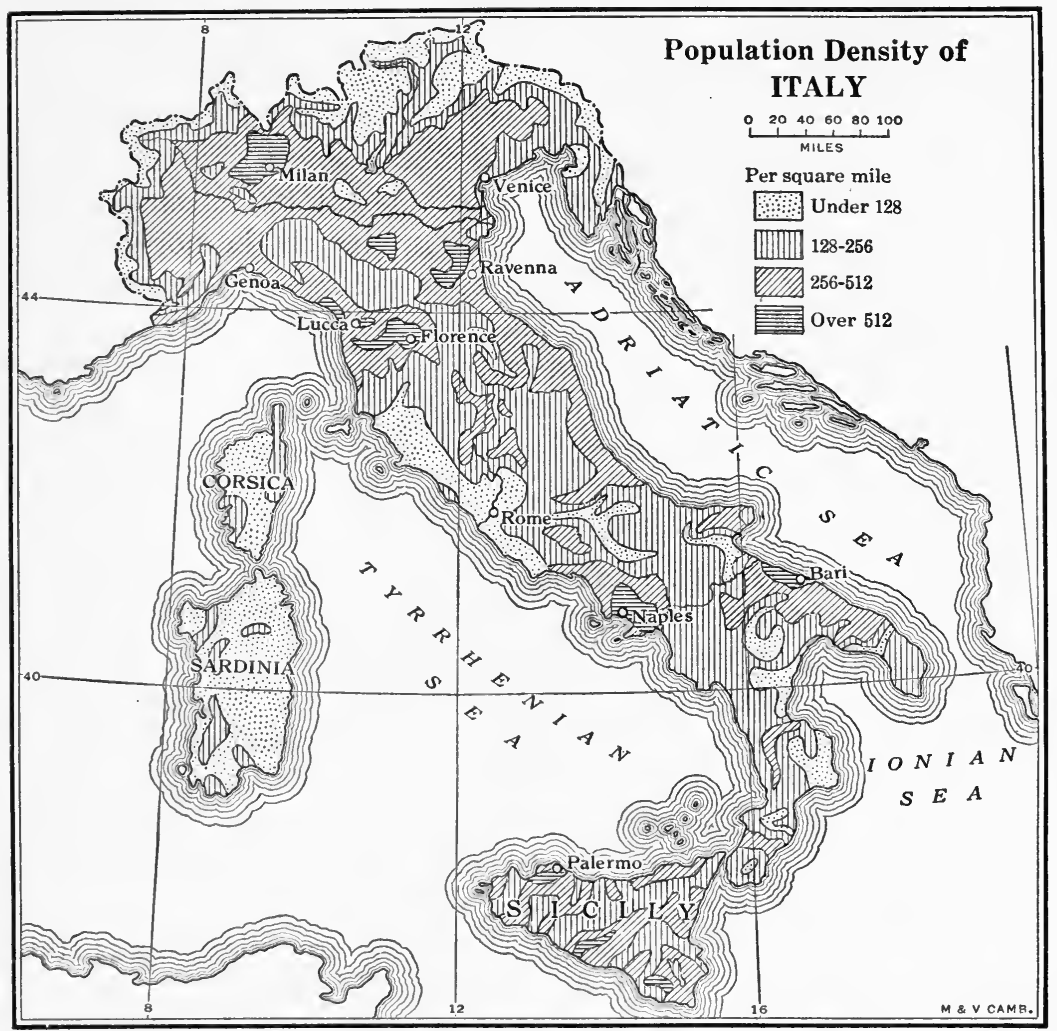

After Bowman

possessions are non-Italians. The Dodecanese and Aegean islands are practically populated by Greeks; Libya has only 9402 Italians in a population of 750,000 ; Eritrea has 3900 Italians in a population of 405,681; Tientsin has 60 Italians in a population of 5000, mostly Chinese; and Somaliland has a population of 900,000 with almost no Italians.

The Italians, perhaps, constitute the most mixed nation in Europe. Italy has been subject to invasion since before 1000 B.c. Etruscans, 
Ligurians, Venetians, Lombards, Siculi, Greeks, Carthaginians, Romans, Goths, Saracens, Normans, Germans, French, Spaniards, and Slavs have all contributed something to the polyglot Italian people. Even now there are two groups so distinct that our Bureau of Immigration divides them into northern and southern. The Italians of the north are of the Alpine group. In general they have broad heads, are blonds, and have the general appearance of the people of northern France and southern Germany. The southern Italians are a longheaded, short, brunette people of the Mediterranean type. They are supposed to be descended from the ancient Ligurians, whom Sergi traces to the Hamitic stock of northern Africa, and are thus akin to the Iberians of Spain and the Berbers of northern Africa. There is a large mixture of Greek blood in the southern Italians, and considerable Moorish blood in the Sicilians.

Italy has the distinction of having within its realm two territories over which it has no control. - One is the Roman See, which contains the Vatican, the Lateran, and the Villa of Castel Gandolfo (area 108.7 acres, population 632). The second, the Republic of San Marino, has an area of 38 square miles and a population of 13,387 (1929). Situated in the heart of Italy, it claims to have been founded in the fourth century, and to be the oldest state in Europe. Agriculture and stock raising are practically the only occupations.

2. Political Development. Politically Italy has had a checkered career. The Italians appear always to have been more interested in personalities than in political issues and to have manifested little interest in affairs outside their immediate community. Italy early reached its Golden Age. Then, for thousands of years, it was composed of many city states, with different dialects, customs, and forms of government, mutually hostile and showing little desire to coöperate even when their very existence was threatened. Occasionally there appeared a military genius who ruled over a large area, but his territory usually fell apart rapidly after his death. That Italy was able to develop such political leaders as Scipio, Caesar, Trajan, Cavour, and Garibaldi is remarkable.

Although only nobles (patricians) voted, Rome had a republic in 500 B.c., and by 450 B.c. its laws had been reduced to writing, and the people were permitted to share in making them. The century between 146 and 49 B.c. was one of revolutions. It was followed by a century of peace. In 157 A.D. the Mediterranean Sea was a Roman lake, but the century following 180 A.D. was marked by revolutions 
and struggles between liberal government and Oriental despotism. The Visigoths conquered Rome in 410 and the Vandals in 455, but before 476 Rome had again become a great power and ruled over the peoples surrounding the Mediterranean Sea, England, Europe as far as the Rhine and Danube, and parts of Asia and Africa. The Ostrogoths were in power from 488 to 553, and the Lombards from 568 to 774. The wars from 535 to 553 brought about such fearful conditions that not one-tenth of Rome's 250,000 population was left, and for forty days the city was completely deserted. By the sixth century the people had largely forgotten the language of Caesar, Cicero, and Virgil and a Greek dialect was in common use. Charlemagne (768814), the first of the Frankish emperors, built up a powerful kingdom of which Italy was a part. By the Treaty of Mersen (870), which ended the quarreling of his grandsons, Charlemagne's empire was divided into three parts, of which Italy was one. The next 200 years were a period of invasion. The Mohammedans had made conquests in Asia and Africa, and now established themselves in Sicily and even threatened Rome. The Slavs and Hungarians overran the northern sections, and the Scandinavian pirates plundered and burned many of the coast towns.

From the twelfth century through the fourteenth, Italy was divided into three sections - the Papal States cutting across the center of the peninsula, the Kingdom of Naples in the south, and the northern territory, ruled chiefly by Austria. There were many city states, each of which had some territory, an army, and commerce. The rulers were for the most part usurpers and defended their territory mainly by the aid of foreign soldiers.

When Charles VIII ascended the throne in France in 1483, he decided to enforce his claims to the Kingdom of Naples. His march through the peninsula revealed the fact that the Italians had no national feeling and that Italy was an easy prey for foreign rulers. From that time until the latter half of the nineteenth century the Italians were ruled by foreigners, mainly Austrians and Spaniards.

In 1820 Italy was what Metternich termed "a geographic expression." In the south was the Kingdom of the Two Sicilies, ruled by a Spanish Bourbon; in the center, the Papal States; in the north, the different city states, which were Austrian territory or ruled by the Austrian family. Napoleon I overran Italy and introduced some reforms, but the Congress of Vienna reëstablished the old order. The people, however, having tasted of liberty, were in a ferment 
under the old abuses. The Carbonari, a secret organization which aimed at individual freedom, constitutional government, and a united Italy, grew in power. The Neapolitans compelled their king to give them a constitution, and other sections were in revolution. This aroused Metternich, who invited Prussia, Russia, France, and England to help Austria crush such radicalism. Austria marched into Italy and succeeded in crushing the revolution. At about this time Mazzini, who desired to teach republican principles to the young men so that they could govern themselves, founded the Young Italy movement. Another group centered hope of reform and unity in a liberal Pope. As Pope Pius IX had just ascended the Papal throne, they turned to him, but what seemed to him the excesses of the liberals caused him to become a reactionary. The revolution in Germany and Austria in 1848, and the flight of Metternich, gave the Italian city states their opportunity. One by one they took up arms and threw off the Austrian yoke. It was evident that the Pope favored Austria; he fled the country, his temporal power was abolished, and Rome was declared a republic.

Austria soon recovered from the revolution, marched through Italy, and reëstablished the old order. In the meantime Victor Emmanuel II succeeded his father as ruler of Piedmont. With Count Cavour as Minister, he succeeded in building a modern state. Napoleon III, wishing to maintain his popularity with the French, plotted with Cavour to make war on Austria and free the Italians. Victor Emmanuel found an excuse to go to war with Austria in 1859. Napoleon immediately joined him, but within a short time Europe was surprised to find that Napoleon had concluded peace with Austria, left Venetia in Austrian hands, and limited the size of Piedmont. Napoleon feared the unification of Italy, but he was powerless to stop it. Tuscany, Modena, and Parma voted to join Piedmont. Under the generalship of Garibaldi, southern Italy and Sicily were united with northern Italy. Only Venetia and the Papal Kingdom remained out of the union in 1861. By sending French soldiers to Rome, Napoleon was able to check the union, but the leadership of Victor Emmanuel, the diplomacy of Cavour, and the generalship of Garibaldi were too strong for him. After the War of 1866 Austria ceded Venetia to Italy, and the Franco-Prussian War caused Napoleon to withdraw his soldiers from Rome; all Italy was united by 1870. Thus, within the brief space of eleven years, eight formerly distinct states were united in a federal government as one nation. 
After the unification, Italy began to make itself a modern nation. Industry was reorganized, the navy improved, and the army modeled after that of Germany. Desiring colonial possessions, in 1870 it purchased a part of Assab in Africa. In 1889 it sent an army to Abyssinia to establish a protectorate, but was so badly defeated that it had to content itself with a strip of unprofitable land along the Red Sea. In a war with Turkey in 1911, Italy acquired Tripoli (Italian Libya) and the Dodecanese and other islands off the coast of Asia Minor. Italian colonial possessions, however, have proved to be of very little assistance to the mother country.

When the World War broke out, Italy severed an alliance with Germany and Austria-Hungary to which it had been a party since 1882 , observed neutrality until 1915 , and then secretly made a bargain with the Allies. It agreed to make war on all the enemies of the Allies, but fought Austria-Hungary a year before it declared war on Germany, and never marched against Turkey. Italy suffered heavy losses in the war and came out much poorer than it was in the beginning. Having failed to gain as much territory as it had hoped to do, it disregarded the Allies and proceeded to seize as much territory as it dared. After threats of war, Yugoslavia unwillingly permitted it to retain Fiume, which it had occupied. The Allies had to force Italy to remain behind a line in southwestern Anatolia, and in 1926 it violated its treaty with Yugoslavia and practically established a protectorate over Albania. All the territory Italy has gained since 1911 contains large numbers of non-Italians, and its extreme methods of Italianization, which include suppressing all foreign languages and changing the names of the towns and even families, have aroused deep resentment.

Before the World War there was much dissatisfaction with the government in Italy. The Socialists wished certain reforms, the liberals desired a republic, and the Catholic party were eager to restore the temporal power of the Pope. In 1919 and 1920 strikes became common and some of the factories were seized by revolutionary workers. Repeated efforts were made to establish a communistic republic, and fully one-third of Italy was "red." Under Mussolini, Fascism arose, a reaction set in, and today Italy is ruled by one of the most autocratic governments in the civilized world. Italy is supposed to be a constitutional monarchy, ruled by a king with the assistance of a constitution and two houses. The suffrage requirements have been changed; in 1928 the right to vote was restricted 
to males over 21 years of age who own property, to civil officers, to Catholic and other recognized clergy, and to married males between 18 and 21 who have sons. Under Fascism Mussolini has increased his power until he dominates the government of all Italy. His aggressiveness makes Italy one of the danger spots of Europe.

3. Economic Development. Italy has always been an agricultural and stock-raising country. About 10 per cent of the area is barren rock, and 13 per cent is unproductive. The numerous swamps are being drained under the government's reclamation plan, and the people are being taught how to improve the poor soil. There are three systems of cultivation in Italy: peasant proprietorship, which is most common in Piedmont and Liguria; partnership, which exists in Tuscany; and tenancy, which is common everywhere. From 60 to 70 per cent of the people are engaged in agriculture, but the methods employed are antiquated, especially in the south. The ox-plow and crude hand tools are in general use, but improved farm machinery is found in places, especially in the north. In the valley of the Po, where the population is densest, intensive methods produce good crops. The chief crops are wheat, oats, beans, potatoes, and semitropical fruits. Stock raising and dairying are also important occupations.

Italy suffers greatly from deforestation. The French and other invading armies destroyed such large amounts of timber that only 16 per cent of Italy's area is in forest. This not only causes a shortage in the lumber and fuel supply, but it creates a shortage in chestnuts, one of the sources of food, and causes the rivers, during rains, to become mountain torrents which injure the low lands below.

Many of the early Italian cities engaged in extensive commerce, and some of them remain commercial cities. Italy's merchant marine had 1396 steamships and 2692 sailing vessels in 1929. About 30,000 boats and 110,000 men are engaged in fishing.

For many years Italy has been trying to develop industry, but it has no petroleum and practically no coal for power. It has, however, plenty of undeveloped water power. A strenuous effort is now being made to utilize latent resources; thus, experiments with volcanic ashes for fertilizer have been tried. Italy has a fine climate and plenty of cheap labor, but mineral resources and raw materials for manufacturing are practically non-existent. Industrial establishments employ about 4,000,000 men and commercial concerns about 
$1,600,000$. Italy has an increasingly unfavorable balance of trade. On the whole, its economic future is not bright.

4. Religious Development. The early tribes of Italy had an elaborate set of gods and rites, closely related to those of the Greeks. There was an infiltration of Oriental ideas, and as a result the emperor was deified and connected with the "Invincible Sun," whose birth was during the winter solstice, December 25. Many pagan superstitions were retained by converts to Christianity, and many of the pagan holidays became saint days and festivals.

The western branch of the Christian Church had its center in Rome and came to play a very important part in Italian affairs. At times the Pope ruled over large areas, but at other times his territory was reduced to the small district known as the Papal States. With the exception of short periods, the Papacy was able to maintain its temporal power until the final unification of Italy, when a wave of patriotism finally swept away the temporal power. This Pope Pius IX resented very keenly. His domain was restricted to the Vatican, the Lateran, and Villa of Castel Gandolfo. The government guaranteed him and his successors a yearly indemnity of 3,225,000 lira (about $\$ 622,425$ ) with which to maintain his court. This he refused to accept. He persisted in referring to himself as a prisoner, and forbade Catholics to vote or hold office under the federal government. His behavior aroused the hostility of many patriotic Italians who have continued to refuse to have any part in church affairs. In 1930 Mussolini and the Pope concluded an arrangement whereby the Vatican greatly extended its influence in Italy. In the early part of 1931, however, the Pope and Mussolini had an open break. Riots between Catholics and Fascists became common, but the trouble was quieted.

Italy remains almost completely a Catholic country, as there are only about 123,253 Protestants and 34,324 Jews there. Yet it is the least Catholic of the Catholic countries of Europe. According to the Annuario Statistico Italiano, there were a million people in Italy in 1915 who openly professed no religion. According to both Catholic and Protestant estimates, between 60 and 75 per cent of the Italians in the United States maintain no connection with the church.

5. Educational Development. Perhaps every high school graduate has read of the part Italy has played in the development of law, road building, literature, Christianity, the Renaissance, art, music, universities, and science. He also has some knowledge of Cacsar, Cicero, 
Virgil, Pliny, Trajan, Scipio, Columbus, Polo, Mazzini, Cavour, Garibaldi, Dante, Machiavelli, Michelangelo, Raphael, Marconi, Caruso, and other great men whom Italy has produced. Perhaps he contrasts them with the Italian immigrants in this country. Indeed, Italy is a land of contrast. Paradoxical as it may seem, the home of the oldest European university is one of the most illiterate countries in Europe.

About 2000 B.c. the lake dwellers, who built their homes on piles, introduced a remarkable early civilization into Italy. Before the Christian era, the Romans held many Greeks as hostages and slaves. Some of these, as Polybius, were well educated and introduced Greek culture into Italy. Roman conquests spread Roman culture, which continued to influence the barbarian tribes long after the fall of Rome. In 1200 the University of Bologna was founded, and during the thirteenth century and the early part of the fourteenth, nine other universities were established in Italy. In the sixteenth century, the age of Leonardo da Vinci, Michelangelo, and Raphael, Italy was the art center of the world. But today it is considered a backward nation in some respects.

Although Italy now has one of the most ideally unified systems of education found in Europe, it long followed the German method of permitting each city and section to manage its own school system. As a result, until recently, many towns had no schools. The peasants did not believe that education would help grow crops; the people were not willing to pay increased taxes for schools; the nobles did not wish their children to attend school with the children of peasants; and above all, the poorly trained priests opposed schools because experience had taught them that they lost control over the people as they became educated. Conditions have been changing rapidly in Italy for the last twenty years. Elementary education was made free and compulsory up to 9 years of age in 1877 , but the law remained inoperative until 1904, when every community was required to have at least one school. A radical reform in Italian education was made in 1923. The elementary school course now covers eight years. There are some six different types of secondary schools, designed to meet the needs of pupils who wish to complete their education, enter certain professions, or take advanced training. Universities have been reorganized and ten recognized as Royal universities.

Italy is making an effort to wipe out illiteracy. In 187173 per cent of the inhabitants were illiterate, in 188167 per cent, and in 
190156 per cent. At the last-named date the smallest amount of illiteracy was found in Piedmont (17.7 per cent), while Calabria in the southern part had 78.7 per cent. Illiteracy in the north varied from 11 to 25 per cent, in the central part from 25 to 50 per cent, and in the southern part, Sicily, and Sardinia, from 50 to 78.7 per cent. In 1921 only 27 per cent of the people were illiterate. Existing side by side with Italy's 7,000,000 illiterates are thousands of well-educated people who speak French, Spanish, German, and English fluently, and discuss intelligently the latest productions in art, music, scientific research, and philosophical theories. Many of these, however, have been exiled by Mussolini.

6. Social Development. Social conditions in Italy vary widely. Even villages in sight of one another differ markedly in dialects, customs, morality, and general behavior patterns. ${ }^{1}$ Throughout Italy one encounters vivid contrasts - intelligence, education, and refinement in the midst of gross ignorance and uncouth behavior; rationalism and free thinking in close association with superstition and emotionalism; numerous priests and churches in the face of great religious indifference; luxury and wealth in the same neighborhood with want and abject poverty; high ethical and moral codes or violent immorality; modern science and century-old customs; at least twenty-five universities but many poor elementary schools.

There appears to be a marked difference between the Italians. in the north and those in south Italy. The former are in general much wealthier, better educated, more refined, alert, and willing to cooperate, and have better organizing ability. The latter are extremely individualistic, but shrewd, temperate, generous, and hospitable.

Throughout Italy there are two main social groups or castes. The first group is known as the Aristocrazia (Aristocrats). There are really two classes within the aristocracy. The first class consists of the nobles, or landed gentry, who have inherited estates and titles from their ancestors. The second class might be termed a middle class; it consists of government officials, professional people, wealthy business men, and others who move in "good" society. The nobles of the north are the wealthier and more aggressive. Those of central Italy, like those of the north, live on their farms, but have less wealth and are less aggressive. Those in southern Italy live away from the land, mostly in Rome, and set strict taskmasters over the peasants

${ }^{1}$ A description of an Italian village community will be found in Terpenning, W. A.: Village and Open Country Neighborhoods, Chap. IX. 
to wring out of them as much as possible. There are large numbers of the second class of aristocracy in the north and central parts of Italy, but practically none in the southern region.

The Contadini (peasants and day laborers) compose the second main social group or caste. They are at their worst in southern Italy, where they are little more than slaves. Working from daylight until dark, receiving very low wages, dressed in rags, and sleeping in mere hovels, often shared by donkeys, pigs, and poultry, they eke out an existence as best they may. Neither the peasants nor their landlords live on the farms. There are no solitary farmhouses, but the peasants live in little farm villages, clustered around the top of some hill or mountain, and go out to the farms to work, to pasture their herds or flocks, or to gather fuel, sometimes miles away. Their houses are dirty, unsanitary, weather-worn stone or stucco structures, generally of one room, with few or no windows. The furniture is generally scarce and crude, the floors consist of dirt or dirty flagstones, and the walls are smoked black. Toilet facilities are generally lacking. The peasants' food consists mainly of black bread, made from rye or chestnut flour, and such vegetables as they can grow, accompanied by light wine. Meat is a luxury for holidays. During the winter months one and often two meals per day are eliminated. Their clothes are usually nondescript and home-made, but distinct in that each reveals the village of nativity. Children, pigs, and chickens mingle indiscriminately in the houses and "streets." The grown-ups mingle on the plaza or in the cafe if the village is large enough to have one. Here they live their simple lives, knowing and caring little about the outside world.

There is no intermarrying or social intercourse between the two social groups. An aristocrat would by no means do any manual labor or associate with one who did. He looks after his estate or belongs to the army or navy, or a professional or business group.

Family life in Italy tends to be patriarchal. The oldest male is the man of the house and all others are expected to obey him. The birth of a child is hailed with great joy and its baptism means a feast. Daughters are closely guarded and are married within their own social group. The dowry system prevails and the daughters have little to say about their marriage or rather purchase. There is no divorce. Group standards are strict and offenses are usually settled individually.

The peasants have always borne the burden of taxation. Somehow 
Italy has long succeeded in wringing a larger percentage of taxes from its people than most other countries. Luxuries are exempt but necessities are taxed. Thus the riding horses and works of art of the wealthy are exempt while the peasants' donkeys and other necessities are taxed. Between the state and the church they are forced into extreme poverty. That they remain cheerful and light-hearted, and can call out joyfully to their neighbors and whistle on the way to their fields, is indeed remarkable. Conditions have changed considerably during the last few years, but out of just such a background came many of our Italian immigrants.

7. Immigration and Emigration. Large numbers of Italians are living out of Italy. According to Professor A. Niceforo, ${ }^{1}$ the population of Italy numbered about 7,000,000 at the time of Augustus, $11,500,000$ in the sixteenth century, $16,500,000$ in the eighteenth century, $18,000,000$ in 1800 , and $40,000,000$ in 1925 . In the fiftyyear period from 1872 to 1921 Italy lost $15,000,000$ of its citizens by emigration.

The United States has been the goal of Italian immigration. Italians began to come in small numbers very early. Only 30 came in 1820,3 in 1832, and 1699 the next year. This number was not reached again until 1870, when 2893 arrived. In 1907 we received 294,061 , and in 1914296,414 , the largest number in any single year. Between 1820 and 1930 4,651,195 Italian immigrants were admitted to the United States. This number was surpassed by Germany only. At first the Italians, especially those from the north, preferred to go to South American countries, but by 1890 the United States was receiving more than all of South America. Between 1891 and 1900 Italy was our leading source of immigrants. For the twelve-year period ending in 1910, the southern Italians headed the list with $1,911,933$, while the northern Italians came ninth with 372,668 , a total of $2,284,601$ for the twelve-year period. During the exodus some Italian towns lost around 20 per cent of their population. Amalfi decreased from 10,000 in 1890 to 3000 in 1914. It is reported that the mayor of one of the towns said to the visiting premier: "I welcome you in the name of 8000 inhabitants - of whom 3000 have just left for America, and the other 5000 are at home preparing to go." Between 1911 and 1920 1,109,524 Italian immigrants came to the United States, and for the period 1921 to 1930 455,315. In 1920

1 Proceedings of the World Population Conference, 1927, edited by Margaret Sanger, pp. 59-70. 
$1,624,998$ of our foreign-born white population gave Italian as their mother tongue. Over 98 per cent of these were from Italy.

The literacy test and the quota laws have greatly reduced the number of Italians coming to the United States. For example, the two per cent law permitted only 3845 Italian immigrants to enter, whereas 296,414 came in 1914 . The present law permits 5802 to enter. The Italians in both Italy and America keenly resented these laws, tending to take the restrictions as a personal affront. On the other hand, the United States resented Italy's insistence that an Italian and his American-born children, regardless of his naturalization, were Italian citizens, and that it had the right to arrest them, if found in Italy, and place them in the army or in prison. The recent treaty between Italy and the United States removes this cause for friction.

Large numbers of Italians have also gone to Brazil and Argentina. From 1857 to 1875209,000 arrived in Argentina. Smaller numbers went to other Latin American countries and to Africa. The movement to countries on the continent has also been large. For example, in 1913559,566 left for overseas and 313,032 for European countries. Large numbers have gone to France, Switzerland, and Germany. The return movement to Italy is also large, especially from South American, African, and European countries. From 1857 to 1875 three-fifths of the Italian immigrants to Argentina returned to Italy. Taking Italy as a whole, 62.8 per cent of its emigrants for the period from 1902 to 1924 returned home; for the period from 1921 to 1924 , 35.9 per cent returned. In 1930 213,545 Italians emigrated to European countries and 53,873 to North and South America. During the same year 136,199 repatriated. In 1930 there were 170,000 foreigners in Italy.

The United States, Australia, New Zealand, and Canada are restricting the number of Italian immigrants that may enter. This has raised the question: Where can the Italians go? They have always shunned Italy's colonial possessions and for the last decade have been moving over into France so rapidly that it appears that part of France may become part of Italy. Population experts seem to be agreed that Italy is a badly overpopulated country; yet Mussolini thinks that Italy should have a population of $60,000,000$ and is doing what he can to bring this about. He advocates large families, opposes birth control, and has restricted Italian emigration. Instead of relieving the population pressure by an overseas emigration of 559,566 , 
as in 1913 , and a continental emigration of 271,089 , as in 1924 , the restriction reduced it to 70,794 overseas and 79,772 continental in 1928. It rose, however, to more than 260,000 in 1930 . Italy's unemployment problem is acute, the number of unemployed being 408,748 in December, 1929, and 707,486 in March, 1931. The future of Italy's population problem one dares not predict.

\section{QUESTIONS, EXERCISES, AND PROBLEMS FOR INVESTIGATION}

1. Give a brief description of the geographical features of Italy, showing their probable effects upon its growth as a nation.

2. Elaborate on the statement that the Italians are probably the most mixed nation of people of Europe. Besides the text, see Marinelli, Olinto: "The Regions of Mixed Populations in Northern Italy," Geographical Review, Vol. VII, pp. 129-48; Ripley, W. Z.: The Races of Europe, Chap. X; and Pittard, Eugène: Race and History, pp. 135-44.

3. Why has it been said that Italy has been more interested in personalities than political issues? Trace the steps by which unification was finally achieved.

4. Explain what Metternich meant when he described Italy as a geographical expression.

5. Make a more detailed report of Mussolini's place in the political affairs of Italy. Besides the text, see Bolitho, William: Italy Under Mussolini; Salvemini, Gaetano: The Fascist Dictatorship in Italy; Schneider, H. W., and Clough, S. B.: Making Fascists; and Gentile, G.: "The Philosophic Basis of Fascism," Foreign Affairs, Vol. VI, pp. 290-304.

6. Describe the conditions of the agricultural peasants, showing in what ways they are objects of discrimination.

7. Show how Italy is commercially and industrially handicapped.

8. Give a brief account of the loss of authority and the decrease in territory of the Roman Catholic Church in Italy. Besides the text, see Toschi, Umberto: "The Vatican City State: From the Standpoint of Political Geography," Geographical Review, Vol. XXI, pp. 529-38.

9. How do the rates of illiteracy differ among the various sections? What light does this throw on the difference in attitudes we have toward northern and southern Italians?

10. What vivid contrasts does Italy present?

11. Give a brief statement of the number of Italians coming to the United States at different intervals. In what ways have we sought to limit this number? 
12. What difficulties will Italy evidently have in carrying out Mussolini's ideas regarding emigration? Besides the text, see Schanzer, Carlo: "Italian Colonial Policy in Northern Africa," Foreign Affairs, Vol. II, pp. $446-56$.

13. How does Bruno Roselli (Immigrant Backgrounds, edited by H. P. Fairchild, Chap. VIII) characterize the background of the Italian immigrant? 


\section{CHAPTER XIII}

\section{GREECE}

1. General Description. The Republic of Greece, or Hellas as the Greeks call it, occupies the southern portion of the Balkan Peninsula in southeastern Europe. Joined to Albania, Yugoslavia, Bulgaria, and Turkey, it juts out into the Mediterranean Sea, with the Aegean on the east and the Ionian on the west. It is a very mountainous country with small plains and deep basins. The seacoast is rugged, and has numerous inlets, bays, and islands - "a naked land with all the bones showing."

The present area of Greece is 49,022 square miles; it is thus about the size of New York State. As a result of the Balkan Wars, a territory of 20,617 square miles, consisting of Macedonia, Epirus, and the Aegean Islands, was added to what is called old Greece $(25,223$ square miles), and by the Lausanne Treaty (1923) 3182 more. The population in 1920 was $5,447,077$ and in $19296,204,468$. Only $2,800,164$ people, or about half the population, lived in old Greece in 1920. Athens, the capital and largest city, has a population of 452,919.

There are between 12 and 15 million Greeks living in that part of the world, mostly in Turkey, Bulgaria, Rumania, and the other Balkan countries. There are some 100,000 , who form 99 per cent of the population, in the Dodecanese; 300,000 in Cyprus, or 97 per cent of the population; and 470,000 in the United States. Many of the ancient Greeks, such as Herodotus, Archimedes, and Aristotle, as well as many modern Greeks have lived outside of Hellas proper. Throughout history this fact has frequently been an excuse for Greek wars. The ancient Greeks were scattered over the Greek Peninsula, Ionian Islands, Archipelago, Cyprus, Crete, the coast of Asia Minor, the shores of the Black Sea and Bosporus, and the borders of Italy, Sicily, and northern Africa. The modern Greeks are scattered over a much wider territory.

Anthropologically the ancient inhabitants of Greece appear to have belonged to the Pelasgian tribes of the Mediterranean group of the Aryan branch of the human race. For the most part the groups 
which developed into the ancient Greeks had long heads and were brunettes. Achaeans and Dorians, a blond group, came in from the north and fused their blood and culture with that of the aborigines. Greece was flooded with early and late invaders - Goths, Lombards, Venetians, Germans, French, Ottomans, Vlachs, Albanians - many of whom remained. These invasions brought about changes which in some places are still marked. In the tenth century Porphyrogenetus wrote: "All Greece has become Slav"; in the thirteenth century Valenciennes declared that the Greeks had become French; and in the nineteenth century Fallmerayer asserted that the Greeks had "hardly a drop of true Greek blood in their veins." Some modern writers still claim that the modern Greeks are chiefly Slavs, owing to the heavy Slav migrations during the eighth century. Indeed, stocky Greeks with broad heads, broad faces, and blond characteristics are found. But, considering racial origins, language similarities, and culture spread, it seems best to include Greece with the Latin group.

2. Political Development. Although the authentic history of Greece does not begin until about 776 B.C., the Greeks claim a continuous history of 3000 or 4000 years. The barbaric Greeks (Achæans) appear to have come in from the north and destroyed the Aegean civilization about 2000 B.c. Another horde of Greeks (Dorians) came in about 1000 B.c. and supplanted the civilization of the Peloponnesus with their own. About 700 B.c. the different groups of Greeks began to be ruled by tyrants, especially from 600 to 500 B.c. Under such strong tyrants as Solon, Draco, Pisistratus, and Clisthenes, there was a development toward a democracy, with constitutions and many social laws. Solon granted all free men equal rights in court, and the privilege of being tried by a jury. The fifth century B.c. is spoken of as the Golden Age of Greece. It was the age of Pericles, Socrates, Plato, Aristotle, and other noted men familiar to students of history. In 336 B.c. Alexander the Great became king of Macedon, and in his brief reign of thirteen years united the Greek city states, conquered Persia, Phœnicia, Palestine, Egypt, and practically the rest of the known world.

In 46 в.c. Greece was completely conquered by Rome, and became a Roman province, but instead of becoming Romanized, it Hellenized the Romans. In 395 A.D. Greece became a part of the Byzantine Empire, which was already saturated with Greek ideas and was to be the center of civilization for 1000 years. During this long period Greece 
was a buffer state protecting southern Europe against the Eastern hordes.

Greece was conquered by the Turks in 1456, and then began the Dark Ages of Hellenic culture. For almost four centuries the Greeks were subjected to severe oppression and persecution. It was a period of misrule, burdensome taxation, atrocities, massacres, and the conscription of children to be brought up as Mohammedan soldiers. Bands of Greeks, known as Klephts, maintained an existence of semiindependence by hiding in the mountains, and lived by raiding Turkish territory. Greek religious leaders were specially favored by the Turks and used their offices to proselyte Slavs and Rumanians into the Greek Church and make them Greeks. They also united with the Turks in making the lives of these other Christian groups almost unbearable.

Gradually the Turks became more severe with the Greeks, and in 1821 Archbishop Germanos of Patras raised the Christian banner and the Greeks flocked to arms. At Tripolitza 12,000 Turks were massacred in cold blood. The Turks answered massacre with massacre; 23,000 Greeks in the island of Chios were slain, and 47,000 sold into slavery. In 1827 Russia, France, and England intervened and defeated the Turks. Greece was made independent, but received only one-third of the territory it claimed and one-fifth of the Greek people. As Greece had no royal family, the great powers forced the Greeks to accept Otho, a Bavarian boy of 17, as king. Otho ruled as a German and crushed many revolutions with the aid of foreign soldiers, thereby wounding Greek pride. In 1843 he was forced to sign a constitution providing for two houses. Members of the Chamber were elected, but the Senate was largely under the control of the crown.

During the Crimean War Greece thought it an opportune time to seize Turkish territory, but France and England would not permit it to do so. In 1862 another revolution drove the king from the throne. After much hawking of the crown among minor princes of Europe, George of Denmark accepted the kingship and ruled until 1913. With the accession of King George (1863) real progress and constitutional reform began. In 1864 the Senate was abolished and a new and more democratic constitution was adopted. Disregarding the advice of foreign diplomats, Greece went to war with Turkey in 1897 over Crete. The "Thirty Days' War" ended disastrously for Greece. It not only lost part of its territory, but it had to pay an indemnity of 
$\$ 20,000,000$. Crete became autonomous, but remained under the suzerainty of the Sultan. Greece took part in both the Balkan Wars and gained 18,000 square miles of territory and 1,800,000 people. After much hesitation, it entered the World War, but did very little. However, it gained considerable territory, but afterwards lost much of it in a war with Turkey.

Since the World War, political upheavals and changes of premiers have been rapid. As a result of the struggle between King Constantine and Venizelos, the king was exiled. Constantine's son, King George II, was forced to quit the country in 1923, and in 1925 Greece proclaimed itself a republic. While docile to outside control, the Greeks are extremely individualistic. It is commonly believed that their extreme individualism disinclines them to personal or organized control, and that consequently they cannot.adapt themselves to a democracy.

3. Economic Development. From very early times Greece has been an agricultural country. So important was agriculture that the early kings tilled the soil, and today almost 70 per cent of the people are engaged in agriculture. The country, however, is largely rock and grit, one-third being rock and wholly unproductive, and only one-fifth arable. The chief crops are currants, raisins, olives, tobacco, cotton, cereals, figs, and other fruits. Stock raising, especially of goats and cattle, is important. Since the rainy season is from September to May, agriculture involves protecting the soil from the torrential rains during the winter and irrigating the crops during the summer. Farming is backward and mostly done by hand and with small oxen. Greece has never been an industrial country. It has only about 2200 factories, employing some 36,000 workers. Spinning and weaving are the most important industries.

Owing to the fact that Greece is dotted with bodies of water, most villages being less than 20 miles from the sea, the early Greeks turned to navigation. The activities of the pirates and the influence of the fairs, which were held mainly to exchange goods, brought about the development of commerce. To facilitate trade the Greeks almost encircled the Black, Adriatic, and Mediterranean seas with colonies, and soon surpassed the Phœnicians. In 1930 the Greek merchant marine consisted of 547 steamers and 718 sailing vessels.

Greece formerly had valuable forests, but the area in forests has been reduced by probably one-half in the last thirty years. It is moderately rich in iron, chromite, iron pyrite, magnesite, zinc, 
lignite, and salt. In 1929 it had 1567 miles of railroad, 825 miles of which were state operated, but very few highways - 8611 miles in all.

There are other potential resources. The Greeks have incomes from wealth invested in other countries. The remittances of Greek emigrants have been as high as 40 million dollars a year, and the increasing number of tourists puts large amounts of foreign money into circulation. The ill effects of rapid political changes and constitutional upheavals have militated against foreign credit, which Greece needs badly to remedy the effects of wars. Furthermore, taxes are too heavy for a country of its size. They affect incomes, profits of companies, transfer of real property, inheritance, cultivated lands, net profits on agricultural enterprises, crops, licenses, insurance premiums, exemption from military service, education, patents and trade marks, signs in foreign languages, and other matters. In brief, Greece taxes both production and consumption.

4. Religious Development. The early Greeks had elaborate systems of rites and an interesting mythology. Later they developed philosophical systems that represent the highest achievement of pagan thought.

The Greeks were among the first Gentiles to accept Christianity. Paul organized churches among them, and the New Testament was written in Greek. The Greek fathers were important as leaders of thought, administrators of churches, and formulators of church doctrines. They did much to harmonize Greek philosophy with Christian teaching. By the close of the fourth century, Christianity had superseded paganism in Greece. It spread over Europe, and eventually two centers of Christian influence developed. Constantinople became the center of the Greek form while Rome was the center of the Latin form. Different beliefs and practices developed which led to many controversies, and in 1054 the Roman Pope and the Greek Patriarch excommunicated each other and each other's followers. The Greek Church has no pope or papal supremacy, infallibility, doctrine of immaculate conception, or purgatory. Baptism is threefold immersion; communion consisting of wine and leavened bread is granted all baptized persons; ikons (pictures) are extensively used, but graven images, except the cross, are strictly forbidden; instrumental music is not permitted, and only men do the singing. The clergy marry, but the bishops and monks must be celibate.

The struggle with the Moslems has caused the Greeks to feel that 
membership in the national or Greek Church, called also the Greek Orthodox or Eastern Orthodox Church, is evidence of patriotism. The Greek is born into his religion, and church connection with him is like citizenship in the United States; to change churches is virtually to change or to lose his nationality. Any Greek who changes his church is regarded as a traitor or renegade; thus missionary and reform movements have met with little success in Greece.

In the United States the Greek Church is often confused with the Greek Catholic Church. The latter is a wholly different denomination, comprising no Greeks but groups of Slavs, Rumanians, and others who keep the Eastern Orthodox rites and customs, but are under the Pope. This church is often called Uniate, meaning one with Rome. The Greek Church is the church not only of the Greeks, but of the Russians, Serbians, Rumanians, Montenegrins, and Bulgarians. The various national churches have the same doctrines, practices, and liturgy. The languages, however, differ. Each is independent and self-governing, administered by a Holy Synod composed of bishops, the president of which is called a metropolitan or patriarch. Thus the church in Greece is governed by a Synod of bishops with the Archbishop of Athens as president. There are four patriarchates of the Eastern Orthodox Church - Constantinople, Antioch, Jerusalem, and Alexandria. That of Constantinople is called ecumenical. It is the highest authority in the Eastern Orthodox Church, corresponding to the Papacy in the Roman Catholic Church.

5. Educational Development. There were two prehistoric civilizations in Greece - the Mycenæan and the Achæan. Upon the Mycenæan the Greeks, with hints and borrowings from abroad, built their renowned culture. About 776 в.c. writing began, and by 650 B.c. the Greeks were using the alphabet, which they had borrowed from the Phœnicians, very freely. Most of their information, even the poems of Homer and Hesiod, which had long been repeated orally, was now reduced to writing.

Two types of education developed. Sparta stressed athletics, while Athens stressed intellectual pursuits. Socrates, Plato, Aristotle, Archimedes, Euclid, Pytheas, and Callimachus were famous teachers to whom our civilization is still indebted. Thus education has played a prominent part in Greek culture. Even during its Dark Ages the monasteries remained educational centers and kept the torch of civilization burning. 
Greece now has a fair system of public schools which has been developing since 1834. The primary and grammar schools and the gymnasia are free, and attendance is compulsory for children between the ages of 5 and 12. Education at the University of Athens is free to Greeks regardless of where they dwell. It is now open to women on the same basis as men.

Greek education is handicapped as a result of the fact that there are two dialects - the high Greek (Ellenika) and the low Greek (Roumaika). The former is the written language and the language of the schools, and the latter is the spoken language. High Greek differs from ancient Greek about as much as Italian from Latin, or English from Anglo-Saxon. The uneducated cannot understand the high Greek, while the educated understand both. Instruction of the peasants, then, is practically in a foreign language.

6. Social Development. The Greeks have gone through the same social development as other southeastern European peoples - the relationship between masters and slaves, nobles and serfs, landlords and peasants; the absorption of large numbers of foreign stock; and the subjection to foreign rulers. They are courteous, polite, hospitable, but at the same time excitable, quick-tempered, and passionate. They are reported to be very individualistic and at the same time very autocratic. It is said that a Greek would fight for a national or political cause but never for a political institution. They have shrewd business ability, but are somewhat vain, egotistical, restless, volatile, and superficial, spending much of their time haggling over bargains. Greeks are severely criticized for their dishonesty, which usually expresses itself in lying rather than in actual theft. This is explained first as being due to their keen desire to please, and secondly as a trait developed during the Turkish rule, when facts and acts had to be concealed.

In general, Greeks are fond of politics, music, noise, show, gambling, and dancing; they spend much of their time in coffee-houses discussing the glorious past of Greece rather than striving to produce a glorious present or future. The fondness of the Greeks for news is revealed by the fact that although Athens has a population of only about 450,000, it has more daily papers than New York City. The chief item of interest is politics. Greeks are praised for their temperance but condemned for their immorality. The current idea is that every young man must sow his wild oats. The women, however, are usually well protected; but the wretched dowry system, which 
virtually means the buying of a husband for the girl, "saps all romance out of the marital relations." Usually the men of a family delay marriage until dowries are provided for their sisters and husbands secured. Then they search for a wife with a large dowry.

The average Greek does not work much or eat much. Holidays, especially "name days," are very important. Every saint has his day, and persons named after him must keep his name day. As a result, on popular saint days, industry and business practically stop. The peasants and laborers usually live in one-room houses with dirt floors. Their food is coarse, consisting chiefly of vegetables and black bread. Many of them never have butter, milk, or eggs; meat is a luxury to be had only three times a year.

7. Immigration and Emigration. Greece has within its own confines a serious problem of assimilation. It has had to receive and absorb into its national life some 26 per cent of its former population, of whom two-thirds were totally destitute. This influx of population was the result of the exchange agreements between Greece and Turkey in 1922-24. The text of the treaty provided for the "compulsory exchange of Turkish nationals of the Greek Orthodox religion established in Turkish territory, and of Greek nationals of the Moslem religion established in Greek territory." When Serbia, Bulgaria, and Greece felt strong enough to throw off Turkish rule in the Balkan Peninsula and free a subject population joined to them by ties of sentiment and religion, they almost completely drove the Turks out of Europe. In order to free some 1,500,000 Greeks in Asia Minor, Greece undertook a campaign in their behalf, which resulted disastrously for it. As a result, some 800,000 Greeks fled into the mainland and islands of Greece, and about 200,000 more trekked into western Thrace and Macedonia. Later arrivals from Gonstantinople and Bulgaria swelled the number to about 1,500,000. By expelling Turks, Greece could make room for part of this sudden influx of people and Turkey could gain inhabitants for abandoned lands and houses. The result was that Greece became frightfully congested with a destitute population, while parts of Turkey were underpopulated. That Greece was able to handle the problem as well as it did is a marvel. By 1930 the 145,000 farmers with their families, totaling 561,190 individuals, and some 30,000 of the other 105,000 families had been provided with homes. In 1926, at a cost of $\$ 25,000,000$, an American engineering corporation began to reclaim the marshes of the Vardar River near Salonica. This will pre- 
pare around 326,000 acres for cultivation and enable some 25,000 of the refugees to settle in that section.

Thirty-five years ago there were very few Greeks in the United States. Formerly they migrated to Bulgaria, Rumania, Turkey, Russia, and England. By 1891 a change had taken place, and they began to come here in larger and larger numbers. In 1907 the number reached 46,283 , the largest number in any single year. Of this number, 36,404 were from Greece, 7060 from European Turkey, and 1353 from Turkey in Asia. For the twelve-year period ending in $1910,216,962{ }^{1}$ Greeks were admitted to the United States, 79.6 per cent being from Greece proper. The rate for 1907 was about 7 per 1000 of population for all Greeks, and 14 per 1000 for Greece, the highest rate for any country. In the two decades ending in 1930, 235,285 Greeks came to this country; the total number from 1820 to 1930 was $421,489 .^{2}$ Our present law permits 307 per year, 207 above the two per cent law. A few Greeks go to Canada (about 1053 in 1907), Australia (2028 in 1924), Brazil, and Cuba. The statistics of the United States indicate that about 46 per cent return to Greece. From 1908 to 1923 366,454 entered and 168,847 left. Very few Greeks bring their families, an indication that they do not intend to remain.

There have been two outstanding reasons why Greeks have turned to the United States. The economic was and is the primary one. Greece is a poor country and in its present state of economic development cannot support an ever increasing population. Crop failure is serious and causes many to leave their native land; the failure of the currant crop in 1891 caused our first swell of Greek immigrants. Up to 1908 , Christians were exempted from the Turkish army by paying a tax each year. After that date it was not possible thus to escape; consequently many Greeks fled secretly and without passports.

There is a saying that "when Greek meets Greek he opens a restaurant." Indeed, it is in the restaurant, candy kitchen, fruit store, florist's shop, ice-cream parlor, and shoe-shine parlor that Americans

1 Dictionary of Races or Peoples.

2 Annual Report of the Commissioner General of Immigration, 1930.

It is evident that there is a conflict between these two government reports, for when we combine these two sets of figures, we find that the number of Greek immigrants for the period 1898-1930 exceeded the number for the period 1820-1930 - an impossibility. 
are most likely to come in contact with Greeks. Few know, however, that some of our largest tobacco and candy manufacturers are Greeks. As Greeks generally do not like hard work, they do not seek work as laborers in our large industries.

\section{QUESTIONS, EXERCISES, AND PROBLEMS FOR INVESTIGATION}

1. Characterize the physical features of Greece, showing their probable effects upon the life and institutions of the inhabitants.

2. What have been the political effects of a large Greek population outside Greece?

3. In what respects are the Greeks a mixed race? What justification is there for including the Greeks with the Latins? See Ripley, W. Z.: The Races of Europe, Chap. XV; Pittard, Eugène: Race and History, pp. 295-99; and Dictionary of Races or Peoples.

4. What were the effects of the Roman conquest? Of the Turkish invasion?

5. In what respects are the Greeks said not to be suited to the workings of a democracy?

6. What are the chief occupations and resources of the people of Greece?

7. Characterize the Greek Church. How does it differ from the Greek Catholic Church?

8. Account for the early educational development of Greece. Contrast Spartan and Athenian educational systems. What is the present language handicap?

9. Give some of the peculiar customs of the Greeks. How are the Greeks generally characterized?

10. Why do Greek emigrants leave their native country? To what countries do they go? About what per cent repatriate?

11. What is Greece's great problem of assimilation?

12. Report on Armstrong, H. F.: "The Unredeemed Isles of Greece," Foreign Affairs, Vol. IV, pp. 154-57; and Howland, C. P.: "Greece and the Greeks," ibid., pp. 454-64.

13. Discuss the Greek refugee problem. References. Howland, C. P.: "Greece and Her Refugees," Foreign Affairs, Vol. IV, pp. 613-23; Blanchard, R.: "The Exchange of Populations Between Greece and Turkey," Geographical Review, Vol. XV, pp. 449-56.

14. Outline the more recent migrations, in the Balkans. Reference. Pallis, A. A.: "Racial Migrations in the Balkans during the Years 1912-24," Geographical Journal, Vol. LXVI, pp. 315-31.

15. Give a résumé of "The Greeks," Chap. V, in Immigrant Backgrounds, edited by H. P. Fairchild.

16. Make a statistical report on Greek emigration and repatriation. 


\section{CHAPTER XIV}

\section{MEXICO}

1. General Description. Our southern neighbor, the Republic of Mexico, has an area of 767,198 square miles, including numerous small islands. The 1600-mile boundary between Mexico and the United States is political; it is neither natural nor economic, and only partially racial and cultural. The Rio Grande forms part of the boundary, but at times it is mostly a dry river. For 3883 miles the Pacific Ocean bounds Mexico on the west. The Gulf of Mexico and the Caribbean Sea form its eastern boundary and Central America its southern.

Mexico's population of $16,404,030$ (1930) is a mixture of racial groups. Before the coming of the Spaniards, there were a number of Indian tribes in Mexico, chief of which were the Aztecs, Mayas, and Yaquis. The Aztecs and Mayas possessed civilizations in a number of respects equal if not superior to that of the conquering Spaniards. The Indians, being chiefly of Mongolian origin, though differing among themselves, possessed some of the Asiatic characteristics, such as long, straight black hair on their heads but little on their faces or bodies, round heads, and drooped eyes. To this mixture were added the Spaniards and a number of Negro slaves. Since the Spanish conquest there have been additions from most of the racial and national groups of the world. There has always been some color prejudice, but amalgamation has taken place freely. Different names early came into use to distinguish the different mixtures. Mestizo, however, is the general term now used to cover all crosses between Spaniards and Indians, Mulatto for crosses between Spaniards and Negroes, and Zambo for crosses between Negroes and Indians. In most classifications Mestizo covers all types of mixtures. Of the population in 1930, 9,040,590 were classified as Mestizos, $4,620,880$ as Indians, $2,444,466$ as whites, and 158,000 as foreigners. Most of the Mestizos are so predominantly Indian that they might be thus classified. In 1930 Mexico City, the capital and largest city, and also the flower of European civilization in Mexico, had a population of 968,443. In 1921 there were 12,063 Spanish, 2382 Americans, 
1652 French, 1223 Germans, 803 Cubans, 610 English, and 6322 persons of other nationalities in the capital city. Other large cities are Guadalajara, with a population of 150,000 ; Pueblo, 110,000; Monterey, 85,000; San Luis Potosi, 85,000; Tampico, 80,000; and Vera Cruz, 48,633.

Mexico has three principal mountain ranges which are mainly extensions of our western ranges. The Sierra Madre range runs near the western coast. It is the most important and has three peaks of extinct volcanoes between 17,343 and 18,209 feet. Another range, which is an extension of the Rocky Mountains, extends along the eastern border nearly to Vera Cruz. The narrow 760-mile peninsula of Lower California, which is almost separated from the rest of Mexico by the Gulf of California, is practically a mountain range. Apart from the two peninsulas of Bajo California and Yucatan, Mexico is a cornucopia-shaped plateau rising from the narrow coastal plains. It is broadest and lowest in the north, narrowing gradually and growing higher toward the south until it attains an altitude of some seven or eight thousand feet. The region extending from the American border to the 23rd parallel of latitude is predominantly desert and is known as the Mesa del Norte. Below is the Mesa Central, the region of greatest agricultural productivity and densest population. But even here it is only in the valleys between high mountains and in small pockets where water gathers that land can be used satisfactorily for agricultural purposes. Along the coast where rainfall is plentiful, heat, bacteria, disease, vermin, and the general unsuitableness of the damp, hot lands for human habitation have checked primitive agriculture, the only kind this country has ever known. In short, latitude, soil, altitude, and precipitation are nowhere correlated in a satisfactory combination.

2. Political Development. The Indians had their own forms of government before the coming of the Spaniards. Some of them still retain in a measure their own form of rule. Practically every Mexican régime has had difficulty in trying to pacify the different Indian groups. The Mayas of Yucatan are analogous to Britain's Ireland or the Slav population of the former Austro-Hungarian Empire. They loathe the white man and hate the Mexican government. Yucatan is practically autonomous, but wishes to break away completely and form a government of its own or effect a union with Guatemala. The Aztecs continue to cherish the glorious days of Montezuma, and to dream of their revival. Díaz penalized their 
customs, festivals, and money, and the church abolished certain feasts and holidays because these kept alive their militant desire for the old empire. The Zapotecas, Nahuas, and Yaquis have a similar group loyalty and are continually demanding concessions.

The Spanish conquerors came to Mexico, as they did to other parts of the Americas, to acquire wealth and to take the country for Spain and the Roman Catholic Church. Cortez set the example, and every viceroy who followed hoped to gain fabulous wealth and to grant absurd favors to his friends. At first it was very easy to massacre the Indians, appropriate their wealth, and gather surface gold and silver. Later, when they found that in order to gain riches they had to work the mines and till the soil, the conquerors proceeded to enslave the Indians. The native population was "given in trust" "to be made use of" for two generations. Slavery was forbidden, but this encomienda system prevailed through nearly a century of independence. Every form of politico-religious corruption existed.

Theoretically the Pope owned the land which the King of Spain held as a fief. Under certain concessions the king divided the land among his friends, but politically Mexico was ruled by autocratic Spain. Weary of autocratic, corrupt, and inefficient Spanish government, Mexico declared its independence in 1810, and in 1821 was recognized as an independent country.

The political history of Mexico represents a long series of crimes in which thousands of people have lost their property, their homes, and their lives. Since Mexico achieved independence it has had over 800 revolutions. Not all of these have been national, but several have involved the whole country, and each has been great enough to upset the political equilibrium.

At first Mexico was a limited independent monarchy under Agustin I (Iturbide). In 1823 it was proclaimed a republic. The next year a republican constitution was adopted and General Victoria became president. The constitution was closely modeled on that of the United States. It declared, however, that Roman Catholicism should forever be the state church. In 1827, when a plot was discovered to reëstablish Spanish rule, the Spaniards were expelled.

The Mexican government continued to have internal troubles. The territory which now composes most of our state of Texas was being settled chiefly by Americans who persisted in retaining their Negro slaves in defiance of Mexico's laws. Finally, Texas declared its independence and became a separate country in 1836. It wished 
to become a part of the United States, but our government did not desire to offend Mexico and Spain; furthermore, it was engaged in a dispute with England over the Oregon territory. Consequently the union was not effected until 1845. The annexation angered the Mexicans, and they invaded Texas and killed some Americans. War with the United States followed, and as a result Mexico lost all the territory now included in the southwestern part of the United States.

Struggles between royalists and republicans, conservatives and liberals, clerical and anti-clerical groups continued. With the aid of Santa Anna, who seemed to desire only to be a great warrior, the liberals gained power in 1833. They confiscated church properties, promoted lay education, and liberalized the university. In 1839 Juárez, leader of the liberals, promoted further democratic reforms. A new constitution, which stressed at length the rights of the people against the dominance of the church, was adopted in 1857. Juárez became president in 1858 and continued the struggle for liberty. The financial condition of the country caused him to suspend payment on foreign loans for two years. To this England, Spain, and Napoleon III objected. Napoleon invaded Mexico and set up an empire under Maximilian. The United States was engaged in the Civil War, but when the war was over it protested against Napoleon's acts, invoking the Monroe Doctrine, and as a result Napoleon withdrew his troops, leaving Maximilian to be shot.

Under the new republic unsettled conditions continued, but under the long rule of Porfirio Díaz there were mostly peace and prosperity. Revolutions are common in Mexico and political upheavals frequent. Between 1913 and 1920 it had seven presidents. The president of Mexico is elected for a term of six years, but it sometimes takes six presidents to fill out one term. The somewhat idealistic constitution has been changed several times, particularly in 1857, 1917, and 1924. It is about as socialistic as Russia's, since both have grown out of similar economic and social conditions. It is far too idealistic for the mass of Mexicans, but is doubtless beneficial as it furnishes them an ideal toward which to work.

3. Economic Development. Estimates place the potential cultivable land at from 5 to 25 per cent of the total. Cultivation of the soil is possible only after strenuous human labor, and owing to the primitive methods employed the fertility of the soil has been largely depleted. In the production of wheat, corn, barley, rice, tobacco, and live stock Mexico ranks exceedingly low. Although the entire working 
community is engaged almost exclusively in producing food, the large mass of the Mexican people continue to be underfed. Imported food has to be paid for out of national capital resources, many of which either are not income-bearing or else are controlled by foreigners.

The Spanish conquerors were chiefly interested in mineral and other forms of natural wealth, but gradually turned to agriculture, in which the natives were already engaged. The Aztecs had already laid out their land, giving a portion to the king, hierarchy, and nobles, and setting aside communal lands for the villagers, which could neither be sold nor alienated. At first the Spaniards respected these ejidos lands; but by the twentieth century most of them had been appropriated and the natives reduced to peonage. Generally speaking, the hacienda, or feudal estate, became the chief agricultural unit of Mexico. For four centuries - from the time of the Spanish conquest to the fall of Diaz - the caste system grew more pronounced and the conditions of the rural proletariat worse.

With the exception of the Juárez interlude, until the Obregon administration little effort had been made to solve the agrarian problem. The revolutions since 1910 have been largely the warfare of serfdom against capitalism for industrial freedom. Until 1920 the bulk of the land was in the hands of a few Mexicans and foreigners and the churches. Foreigners possessed 62,600,000 acres. In 1923 a new land law was passed, which guarantees each Mexican citizen 18 years of age, who does not possess land, a plot of ground for agricultural purposes, upon the payment of $\$ 25$ in gold. The amount to each is limited to 25 hectares (61 $\frac{3}{4}$ acres) if the land can be irrigated, and to 100 hectares if it is pasture land. By the end of 1930 15,228,964 acres had been distributed according to the agrarian laws. In 1926 the National Farm Credits Bank with a capital of 50,000,000 pesos was established to aid small farmers with loans. The land cannot be mortgaged or sold, or even held by the cultivator unless he works it.

Mexico is rich in mineral resources. At present it is producing about 5 per cent of the world's gold and one-third of its silver. It has an abundance of low-grade coal, and produces large quantities of lead, copper, arsenic, graphite, mercury, pig iron, steel, and petroleum. Stock raising is important, and about one-third of the land is in pasture. Forests cover about one-tenth of the area. In 1927 Mexico had 16,714 miles of railroad, most of which was under federal control. Mexico is not a manufacturing country. Most of its exports consist of minerals and oil. Neither is it a great importing country, since 
about three-fourths of the population live on such a low plane that practically all their wants are supplied by their own efforts. In 1928 2660 vessels, 10 tons or over, entered Mexican ports. It had a merchant marine of 56 vessels in 1929 . Foreign as well as domestic trade is greatly handicapped because of the almost complete absence of credit and commercial paper, which necessitates the shipment of boxes of gold into distant sections, and the payment of excessively high rates of insurance because of revolutions, bandits, and highwaymen. Another handicap to the economic development is political corruption and general dishonesty.

In 1910 the cry was raised, "Mexico for the Mexicans." The Mexicans had grown tired of seeing the natural wealth of their country going into the pockets of foreigners and the coffers of the church. In 1917 a new constitution was adopted, Article 27 of which brought Mexico into a controversy with foreign governments, especially the United States. Americans, English, Germans, French, and persons of other nationalities went into Mexico and, taking advantage of the weak political situation and general ignorance, obtained concessions through graft and other methods, became very wealthy, and appealed to their respective governments to support them in their claims. The Mexicans, on the other hand, claimed that natural resources, especially subsoil products, belong to the nation and should be used for the welfare of the people of that nation. According to the Mexican argument, only Mexicans had the right to develop mineral fuel, but foreigners might be permitted to do so. The petroleum law, which became effective December 31, 1926, required those who had acquired titles previous to 1917 to have these titles confirmed and exchanged for fifty-year concessions before the law became effective. Several companies refused to comply with the law and the government canceled drilling permits. A lengthy and heated controversy followed between the United States and Mexico, centering around the interpretation of Article 27. The United States held that the law was retroactive, while Mexico held that it was not. In 1928 the objectionable fifty-year confirmatory concession clause was removed and a more liberal interpretation was given to the law. In 1927 the Alien Land Law, which prohibits foreigners from owning land in Mexico, was put into effect. Those who owned land before 1917 may retain it until death, and corporations may retain it for ten years. Thus, after over four hundred years, the people of Mexico are determined to build a nation and use their natural resources for 
their own benefit. Because of foreign investors, it will be very difficult for Mexico to manage its own affairs. According to official estimates in 1925, $\$ 2,881,114,576$ was invested in agriculture, petroleum, railways, mines, manufacturing, light and power. Of this amount Americans have invested $\$ 1,325,000,000$. The investments of Americans amount to 57.8 per cent of the total value of investments in oil, those of the English to 33.4 per cent, those of Mexicans to 1 per cent.

4. Religious Development. Mexico was conquered by the sword and cross, and church and state worked together to despoil the natives. The church in Mexico has generally sanctioned the wishes of a few wealthy people, and as a result there have been four hundred years of religious corruption. Practically all the early priests were Spanish and a part of the tyrannical aristocracy. Yet the priests did something toward educating the people and mitigating the cruelty of conquest. Gradually the church secured large tracts of land, became very wealthy, and continually interfered with the affairs of the nation. That the church was very narrow in its outlook is shown by the fact that it secured the passing of a law excluding even the grandchildren of heretics and liberals from Mexico.

The constitution of 1857 disestablished the Church of Rome in Mexico. It was forbidden to interfere with the political life of the nation, its lands and revenues were to be confiscated, all priests were to be disfranchised and not permitted to inherit property, foreign priests were not to be permitted to function in the churches, and primary education was to be wholly under the state. The church had collected large sums of money for missions. These were seized to feed the starving people. There is always a wide gap between Utopian laws and the mores of the people, and as a result little effort was made to enforce these drastic church laws. The corruption continued, and finally the Pope excommunicated a number of priests and their churches. The old abuses, however, continue; the most noticeable are those regarding marriages, deaths, and births. Compliance with religious rites makes it expensive to be born, to marry, or to die in Mexico. As a result, many poor people live together without a marriage ceremony. For the last couple of decades civil marriage has been increasing rapidly, but many pious Mexican ladies consider it only half marriage.

Another interesting thing in regard to the church in Mexico is the number of pagan customs and ceremonials which have sur- 
vived. We find the eating of maize-cake, the Aztec fire-worship, and other forms of nature worship.

In 1917 the constitution of 1857 was strengthened, and the fight between church and state for political control became more militant. In 1926 President Calles proceeded to enforce the constitution which he had sworn to uphold, and all religious property became the property of the state. A storm of indignation swept over the Catholics. But the government remained firm and most of the churches and religious schools remain closed. Most of the Mexicans are at least nominal Catholics, but a majority are apparently willing to stand by their constitution. The educated look on the church as something for women and peons, while many of the radicals consider it something to be annihilated. In 1929 a compromise between church and state was effected and many churches were reopened. The churches are considered national property and are under federal control. Priests must register under the laws of the nation. Religious instruction is prohibited in schools but permitted in churches.

Various interpretations have been placed upon the real significance of the conflict between church and state. It seems that the crux of the conflict is whether or not the Mexican clergy will accept the régime resulting from the social revolution. Behind this question is the fact that the Mexican Church has been identified with foreign intervention and the conservative interests of state. It is hoped that the Mexican Church will identify itself with the aspirations of the common people, become more democratic, and thereby cause the hostility between state and church gradually to fade away.

5. Educational Development. Despite the fact that the University of Mexico was established in 1553, 83 years before Harvard, and is still one of the leading universities of Latin America, illiteracy is widespread and the people are generally ignorant and superstitious.

Although education has legally been under federal control since 1857 and is free and compulsory from 6 to 16, it has been dominated by the church and ignorance prevails. In 1921 over 62 per cent of the people were illiterate; rarely could a peon be found who could read. In 1926 only 35 per cent of the children of school age were in school. About 20 per cent of the population consists of Indian tribes, mostly uncivilized. It has been difficult for Mexico to maintain its schools. In sections the population is sparse and scattered. The salaries of teachers are small and, owing to the revolutions and unstable government, uncertain. There are a number of normal, vocational, and 
scientific schools, and in 1921 there were 2000 voluntary teachers helping to stamp out adult illiteracy. Training in sanitation and health has been woefully neglected although badly needed. English is being accorded an important place in the school curricula, and the aim is to teach all the children to speak English.

6. Social Development. Mexican polite society, which represents a blend of aristocratic ideas and French bureaucratic conceptions, has the appearance of a cultured and refined aristocracy, living in seclusion from and disdaining the lower order of society, which lives as did its ancestors a thousand years ago. Refined manners, beautiful flowers, and colorful costumes, stately marble palaces and public buildings, give Mexico the appearance of a highly civilized country. But underneath is a large mass of half-starved people struggling to wrest a living from a niggardly soil with primitive tools, "afraid of God, hacendado, and the policeman." Natural resources have gone to create this show, instead of being spent to bring water to parched fields and build roads to inaccessible hamlets.

In 1910, when this bureaucratic civilization was celebrating its centenary, it was deemed expedient to exclude the rural population from the capital while the visitors admired Mexico's progress. These wide divergences have been created and maintained through the attitudes that separate the two groups. The fact that a former president showed courage enough to "raise tomatoes and garbanzos instead of race horses and concessions" has created no little comment.

Midway between the hacendado, or land baron, and the hacienda peon, or serf, is found the small independent cultivator. In addition to these three classes there are the Mestizos, who secure their living by doing odd jobs in the cities, and the common soldiers, who move about with their wives and children, a blanket and a cooking vessel for each family, and live on the streets behind a cloth where they cook, eat, sleep, and beget and bear children, depending on the pigs for scavengers. The nation retains many of the social ideas brought over from Spain. But today Mexicans have a deepseated contempt for the Spanish, an indifferent respect for the British, and a terrible fear of the Americans. To a certain extent the upper classes imitate the French, but it is with the Germans that they associate freely and amalgamate.

Mexicans have a number of social customs which differ markedly from those of Americans. We may draw the following composite 
picture. Mexican women of the better classes have very little freedom. They rarely travel even in their own country. If they appear on the street they must have an escort, a woman servant or a male relative. The majority wear the rebozo or head shawl when out of the house. The women have great respect for the wisdom of their husbands, and usually spend their lives trying to make their husbands and children happy. Family ties are very strong, and often five or six families, consisting of married sons and daughters with their husbands or wives and children, live together. Children are treated kindly and are early taught to avoid crying, loud laughing, or any unnecessary noise or rudeness. Birthdays are not celebrated, but the dia de santo (day of the saint after which each child is named) takes the place of our birthday celebration.

The behavior of young people is very much restricted, and sweethearts never go out together. A young man seldom enters the home of his sweetheart; when he does, the couple are always in the presence of some older person. The courtship is usually conducted by means of letters written by the evangelista (letter writer), a man who sits on the sidewalk with a board across his knees and pen in hand.

The higher classes tend to be very exclusive, a fact which is manifested by barred windows, guarded doors, and the use of closed carriages. Only the most intimate friends ever visit. The morning promenade, which often includes Mass at the church, an afternoon drive, and perhaps the theatre at night are the chief sources of recreation out of doors. Ladies, especially those of the upper class, do not go to market, but have a man servant to do this.

Most Mexican women do not like American cook stoves, but prefer the little clay stove so characteristic of the Mexican quarters in the cities of the southwest. Most of their foods pass between the metale and mano, two stones for beating foods. Street venders are common, but Mexicans know nothing of our modern methods of advertising. Business and social intercourse are handicapped because many persons do not use a calendar. Everything is dated from the cholera, the plague, the advent of the French, or the coming of the Americans. A man will say he is eleven years old, meaning that he was eleven when the Americans came, and insinuating that he has merely existed since. Another confusing custom is that of assuming the name of some important man in Mexico.

In Mexico friends shake hands each time they meet, and remove their hats when passing each other. The back seat of a carriage and 
the right end of a sofa are places of honor. Changing residence requires that cards be sent announcing the fact and "muy a su orden" (at your orders); otherwise visiting ceases. Ladies seldom attend funerals, but visit the family or send letters of regrets. Mourning is worn even for companions. Feast days, baptisms, births, and deaths are important. New Year's Day is very important, but no presents are sent at Christmas. Graves and coffins are often rented for from one to seven years, at the end of which time the bones are taken up and thrown into the charnel house. Although polo is popular, athletics are not engaged in to any great extent. Bull and cock fighting are popular sports.

The position of native women varies. In general the Indian women of the rural districts enjoy greater equality with men than do their white or Mestiza sisters; for the men do not have before them the examples of arrogant superiority and infidelity so deeply ingrained in the culture pattern of the pre-conquest days. Although the family relations law of 1923 removed a great number of legal discriminations against women, it failed to elevate women to a very high status. At present, according to Gruening, ${ }_{1}^{1}$ woman "represents one of the conspicuous wastes of the Mexican heritage; for the considerable contribution she could make to Mexico's social, economic, and spiritual progress is still unutilized - obliterated by the shroud of persistent custom."

7. Immigration and Emigration. Mexico is another country affected by both immigration and emigration. ${ }^{2}$ For the period 1911 to 1915 Mexico received 53,205 immigrants from the United States, 18,326 from Spain, 15,218 from China, 12,546 from the British Isles, and smaller numbers from other countries, a total of 121,888. For the period 1916 to 1920 the United States and British North America sent 31,295 , Spain 17,080, the British Isles 5299, China 5199, Japan 2255. The total for all countries was 77,693. During the period 1921 to 1924 , inclusive, 75,137 people from the United States went to Mexico, 24,116 from Spain, 11,367 from the British Isles, 6140 from Central America, 5734 from Germany, 5172 from Italy, 4046 from China, 1984 from Japan, 1816 from Brazil; total number, 155,244.

For the period 1911 to 1915 Mexico sent 82,007 people to the United States and 5344 to Cuba. Between 1916 and 1920 it sent

1 Mexico and Its Heritage, p. 631.

2 Compare Ferenczi, Imre: International Migrations, Vol. I, pp. 271-73, 502-04. 
136,997 to the United States and 3104 to Cuba. In the period from 1921 to 1924 203,413 went from Mexico to the United States and 1659 to Cuba.

In dealing with immigration from Mexico to the United States we face several different problems. There is the question as to who should be considered as Mexican. It has been the custom of the Bureau of Immigration not to include as Mexicans natives of Mexico who are either of Negro or of Indian descent. For our purpose, we may include as Mexicans the rather round-headed, black-haired and eyed, dark-skinned people from Mexico who are mainly Yaquis and other Indians with a thin veneer of Spanish civilization. These compose the bulk of our immigrants from Mexico, and no one is able to tell how much Indian, Negro, Spanish, or other blood these individuals contain. On the other hand, there are some Spaniards, Syrians, English, Germans, who come in under the generic title of Mexican. Thus our statistics are largely guesswork. We should consider also that most of our southwest at one time was claimed by Spain and later belonged to Mexico. This included California, Arizona, Nevada, Utah, most of Texas and New Mexico, and parts of Colorado and Wyoming. Within this territory live the descendants of many Spanish and Mexican families who settled there before it became a part of the United States. Roughly, these old settlers may be grouped under two classes. The wealthy and educated group usually disclaim any connection with Mexico and prefer to be called Spanish Americans. The others know little or no English, and many of them are not aware that they are American citizens. In almost every respect they are similar to the Mexican immigrant.

No statistics of incoming Mexicans were kept before 1908, and until recently no record was kept of non-immigrant aliens. According to our records, 5682 Mexican immigrants were admitted in 1908, 15,591 in $1909,23,238$ in $1912,52,361$ in $1920,63,768$ in 1923 , and 89,336 in 1924 . In 1931 the records show that 2627 Mexican immigrants were admitted and that 14,406 departed. Large numbers of Mexicans do not bother with legal formalities, expense of head tax, visé, or examination, but simply walk across the border and are welcomed by their countrymen here as "wet backs" (Rio Grande waders). According to estimates, over 100,000 crossed the border "informally" during the first half of 1920. There are perhaps over a million people in the United States who may be classed as Mexicans. Practically all of these live in the southwest. 
Although widespread indifference regarding Mexican immigration now prevails, sooner or later the immigrant peon may create a serious problem and cause trouble with Mexico. From the Mexican point of view the Mexican immigrant, although worse off in the United States than other ethnic groups, is better off than he was in his native land. Mexico also gains when its emigrants return, because, in the course of their residence in the United States, many of them receive the rudiments of an education in industrial life, learn new techniques, and embrace higher standards of living. Dr. Gamio would encourage temporary residence in the United States. He would permit American employers to contract for labor in Mexico, but require them to furnish return transportation to the border. Likewise, he would remove illiteracy restrictions and obviate the payment of the head tax and visé fee. Such changes Dr. Gamio thinks would ultimately benefit both countries.

The United States, however, is not able to use as much Mexican labor as Mexico would gladly furnish. Unlike certain European countries, the United States does not require large numbers of outside laborers, owing to the use of improved machinery and to its supply of transient and colored laborers. The demand for Mexican labor is chiefly in the truck-farming regions of California and Texas. Although the Mexicans may not be as desirable as other ethnic groups, they are cheap and available. Ignorant and accustomed to abject poverty, they will live under conditions unbearable to other groups.

But there is another side to the cheapness of Mexican labor. As some one has said, the peon is comparatively unassimilable except in assimilating American charity. In this he is adept. In 1925 Mexicans, numbering only 10 per cent of the population of Los Angeles County, furnished 44 per cent of the charity tuberculosis patients and 57 per cent of the venereal clinic cases. More than 50 per cent of the budget of the Bureau of Catholic Charities of the City Maternity Service was expended in caring for them.

\section{QUESTIONS, EXERCISES, AND PROBLEMS FOR INVESTIGATION}

1. Of what significance is the boundary between the United States and Mexico?

2. Discuss the racial mixtures predominating in Mexico. Besides the text, see Pittard, Eugène: Race and History, Part V. 
3. What were the effects of Spain's occupancy on Mexico? Besides the text, see Gamio, Manuel: "The Sequence of Cultures in Mexico," American Anthropologist, Vol. XXVI, pp. 307-22.

4. What is the agricultural situation in Mexico? What are its chief commercial handicaps? What is the situation in regard to ownership of land? Give some estimate of the importance of the mineral wealth of Mexico. Besides the text, see Spence, Lewis: "Mexico," Nineteenth Century, Vol. XCVII, pp. 118-31; Davis, J. S.: "Economic Factors in Mexico," Economic Review, sup. Vol. XV, pp. 40-44; Gruening, Ernest: "The Land Question in Mexico" and discussions, Economic Review, sup. Vol. XX, pp. 49-72; and Schneider, Franz, Jr.: "The Financial Future of Mexico," Foreign Affairs, Vol. VII, pp. 83-95.

5. Discuss the efforts made by the Mexicans to preserve and utilize their natural resources for their own benefit. Besides the text, see Rippy, J. F.: Latin America in World Politics, pp. 260-64.

6. Explain: "Mexico was conquered by the sword and cross, and the church and state worked together to despoil the natives." Besides the text, see Lippmann, Walter: "Church and State in Mexico: The American Mediation," Foreign Affairs, Vol. VIII, pp. 186-207.

7. Describe the different social groups in Mexico.

8. Show how many of the Mexican customs differ from ours.

9. Present arguments, based upon factual evidence, to show (1) why the United States should restrict Mexican immigration; (2) why it should not. , 


\section{SOUTH AND CENTRAL AMERICA}

1. General Description. South of the United States is an area of over 8,000,000 square miles, generally known as Latin America. Mexico is included in this area, but it received treatment in a separate chapter because of the large number of immigrants which it sends us, in contrast to the other Latin American countries. British Honduras, the Canal Zone, Porto Rico, and the British, Dutch, and French Guianas hardly come within the scope of our discussion since they are foreign possessions. However, they have many racial, economic, and cultural factors common to the other countries. On the other hand, Panama, Nicaragua, Cuba, Santo Domingo (Dominican Republic), and Haiti, though Latin American, can scarcely be included since they are virtually protectorates of the United States. Spanish is the official language of all the republics except Brazil (Portuguese) and Haiti (French).

Included in our study are Central America, with an area of over 182,600 square miles; South America, with 7,181,000; and the West Indies, with 71,654. Central America includes Nicaragua, with 49,000 square miles; Guatemala, 42,353; Honduras, 46,322; Costa Rica, 23,000; British Honduras, 8598; and Salvador, 13,173. South America includes Brazil, with an area of $3,285,319$ square miles; Argentina, 1,153,418; Peru, 533,916; Bolivia, 506,467; Colombia, 482,400; Venezuela, 396,976; Chile, 281,820; Paraguay, 147,000; Ecuador, 118,627; Uruguay, 72,153; and Panama, 33,667. British Guiana has 89,480 square miles; Dutch Guiana, 54,291; and French Guiana, 32,000. Cuba has 41,634; Santo Domingo, 19,325; and Haiti, 10,204.

The population of Latin America exclusive of Mexico is some 100,000,000. Brazil has 40,272,650; Argentina, 10,904,022; Colombia, 7,967,788; Peru, 5,500,000; Chile, 4,364,395; Venezuela, 3,026,878; Bolivia, 2,952,139; Ecuador, 2,000,000; Uruguay, 1,850,120; Paraguay, 791,469; Panama, 467,459; British Guiana, 297,691; Dutch Guiana, 142,896; and French Guiana, 44,202. Of the Central American countries, Guatemala has a population of $2,454,000$; Salvador, 
1,688,129; Honduras, 773,408; Nicaragua, 638,119; Costa Rica, 471,524; and British Honduras, 45,313. Of the West Indies, Cuba has 3,413,216; Haiti, 2,300,200; and Santo Domingo, 1,022,485. Buenos Aires has a population of 2,225,000. It is the second largest Latin city in the world, closely following Paris, and the third largest city of the New World. Other important cities of Latin America are Montevideo (Uruguay), 458,784; Santiago, 620,000, and Valparaiso (Chile), 225,242; Havana, 562,968; and Lima (Peru), 250,000.

Anthropologically the population of Latin America does not differ materially from that in some sections of the United States, the chief difference being in the ratios of the racial groups and the degree of mixture. According to estimates, there are around 30,000,000 whites, 25,000,000 Indians and Negroes, and 45,000,000 Mestizos, Zambos, and Mulattoes. The whites are chiefly Spanish and Portuguese and their descendants. The populations of Uruguay, Argentina, Chile, and Costa Rica are chiefly white, while those of Paraguay, Bolivia, Peru, Ecuador, Salvador, and Guatemala are mainly Indian. Uruguay and Argentina drove out most of the colored peoples and absorbed the remainder. In the southern part of Chile there is a diminishing group of Araucanian Indians, who to a small extent have amalgamated, forming the "roto" or Mestizo group. The few Negroes in Costa Rica occupy the lowlands, and the Indians have been mostly absorbed. Paraguay is almost completely an Indian country; in Bolivia the whites form less than 20 per cent of the population. In several of the republics the Indians have never been numbered, and in parts of Bolivia and Brazil they are reported to be head-hunters and cannibals.

Negroes seem to have been brought into the West Indies by the Spanish to replace the native Indians whom they enslaved to work in mines and on plantations. In Haiti the population is said to be composed of 90 per cent full-blood Negroes, the other 10 per cent being Mulattoes and immigrant whites. Since the driving out of the French, it has been the policy of the Haitians to keep Haiti for the Haitians. According to census figures, the black and mixed population of Cuba dropped from 43.8 per cent in 1775 to 27.7 in 1919 . There is also a large infusion of Negro blood in Brazil. According to various estimates there were in 1583 three Negroes to five whites; in 1830, three Negroes to two whites; in 1872, one Negro to two whites; in 1890, one Negro to three whites; and in 1920, one Negro to four whites. Although these figures do not take into account Mes- 
tizos, the proportion of Negro blood seems to be decreasing. In Colombia the Negroes and Zambos constitute from 30 to 35 per cent of the population. In Venezuela the white population constitutes only 10 per cent, Mestizos 70 per cent, and Indians, Negroes, and resident foreigners 20 per cent. On account of color prejudice, no effort was made in the last census to probe into racial origins. In general the Negro has replaced the Indian in the regions of the tropical plantations, but on the west coast of the continent, in the forests and highlands, the Indian predominates over both whites and Negroes. In the temperate regions of Latin America, the white type preponderates, owing chiefly to an increasing white immigration.

All the Central American countries are traversed by mountains and dotted with plains, valleys, and lowlands. The climate is very hot in the lowlands, but on the central plain of Costa Rica, which is 4000 feet above sea level, and in the mountain sections of the other countries a temperate climate prevails. Nicaragua and Guatemala have many volcanic peaks, and earthquakes are frequent in Salvador. Guatemala, Honduras, Nicaragua, and Costa Rica are bordered by both the Pacific and the Caribbean.

Many of the countries of South America are very mountainous. This is especially true of Panama, Colombia, Ecuador, Peru, Bolivia, Chile, and the western borders of Argentina, as they are traversed by the Andes. All these countries except part of Chile lie in the torrid zone and the lowlands are very hot and generally unhealthful. Panama is a mountainous isthmus, less than 100 miles broad. Colombia, Peru, and Bolivia are cut into three parts by the Andes. The strips on the west coast are low and almost desert. The central parts are mountainous, with high plateaus and a temperate climate. The eastern sections extend into the Amazon basin and are very hot. Ecuador and Peru have several peaks above 19,000 feet, and Bolivia has three over 21,000 feet. The bulk of the people live in the highlands. Bolivia has a plateau over 500 miles long and over two miles high. Bogota has an elevation of 8600 feet. Practically all of Chile is mountainous, and at least one-third is uninhabitable. This narrow country extends along the coast for 2700 miles. On the east are the Andes and on the west a high range. Between these two, for 1000 miles, is a lifeless desert. In the south it is cold. The bulk of the people live in the central part. On the average, Chile experiences two earthquakes per day.

Only the western border of Argentina is mountainous; the remain- 
der consists of rolling plains. Most of Argentina is in the temperate zone; it has the most varied climate in South America. Uruguay is the only South American republic completely in the temperate zone. Its climate is very mild, and the rains are generous throughout the year. Its surface is rolling, and except for a few hills in the northwest the land is arable. Paraguay consists chiefly of plains. Onethird of its area is in the torrid zone. The climate is very hot, but is considered healthful. Brazil has several mountain ranges, but its center consists of the Amazon Valley. Practically all the people live in the table-lands in the southern part and along the coast, in or near the temperate zone. Venezuela has mountains in the north and south, while the center contains the Orinoco Valley. The lowlands are very hot and unhealthful. The three Guianas have a cultivable fringe along the coast, and swamps and savannahs near the center, followed by table-lands and mountains. Despite the heat, the climate is said to be salubrious. Cuba is the largest island of the West Indies group. It has some mountains, one peak reaching 8320 feet. Santo Domingo and Haiti comprise the next largest island of the West Indies group. Their climate is considered healthful. All the South American countries except Panama, Ecuador, and Uruguay border Brazil. Uruguay is the best-watered country in the world, and Brazil has the greatest river system. The Kaieteur Falls in British Guiana are five times as high as Niagara.

2. Political Development. Spanish and Portuguese discoverers took possession of, settled, and left a definite imprint upon Latin America. During the sixteenth century explorers from these countries were busy searching for riches, destroying the Indian civilizations, and planting colonies. The Indian civilizations varied from pure savagery to a highly developed sedentary life. In Mexico, Guatemala, and Salvador was the great Aztec-Toltec-Maya civilization, and in Colombia, Ecuador, Peru, and Bolivia was the famous Inca Empire. These groups were well organized and presented a formidable barrier to Latin aggression. Gradually, however, settlements and towns grew up, where austere Castilians, wealthy Moorish Andalusians, fiery Estremadurans, energetic Basques, and meditative Portuguese spread and fused their civilizations among the Indians.

After about 300 years of Spanish rule the colonies began to tire of the Spanish hierarchy, the corruption of the courts, the sale of offices, the tyranny of officials, economic limitations, unequal privileges, the denial of political rights, and excessive taxation. Being influenced by 
the writings of Montesquieu and Rousseau, and the examples of Switzerland, France, and the United States, they wished for more freedom. At first they were loyal to the king, and apparently desired autonomy under Spanish suzerainty, but the overthrow of Spain by Napoleon and the placing of his brother on the throne caused them to strike for complete freedom. Miranda, who had fought for the liberation of France in the French Revolution, and with a legion of Spanish soldiers for the freedom of the United States, returned to South America and began the movement for liberating the colonies in 1798. On July 5, 1811, Venezuela led the other colonies by declaring its independence. The remaining colonies followed suit rapidly, and by 1826 the last of the Spanish force was withdrawn.

All the newborn republics drafted constitutions and patterned their governments largely after those of the United States, France, and England. However, they began their independent careers with very little training, and the mass of people were given political institutions for which they were not prepared. As a result, the constitutions have existed mainly on paper. As the gap between theory and practice has been wide, there has always existed a strong tendency toward a centralized government. Even today Latin Americans know very little of representative government as we understand the term. After gaining their freedom they went through the usual stages of anarchy and dictatorship, with numerous rebellions and frequent changes in constitutions. Some countries are developing stable governments, but others are still under dictators or in a state of anarchy.

In trying to justify our high-handed methods of dealing with Colombia and Panama, Roosevelt pointed out that between May, 1850, and July, 1902, there had been 53 revolutions or attempted revolutions in Panama. If we were to count revolutions and attempted revolutions, we should find that Panama and Colombia have been comparatively peaceful countries, as some of the republics can easily double, if not triple, their records. In Chile there were four different governments during one month in 1931. Dr. Ayala, who was inaugurated in 1924, was the first president of Paraguay to serve four years without a rebellion. For 80 years Uruguay was engaged in rebellions, and 1907 was the first year to see no rebels in arms.

Bolivia had three constitutions and 70 presidents within 100 years. Between 1825 and 1898 it had 60 revolutions and a series of international wars. Six presidents were assassinated, and several others died in exile. Argentina was under the Junta in 1810, the Trium- 
virate in 1813, and the Directory in 1819. Between 1811 and 1819 it had a new constitution every two years. Peru had three constitutions in 10 years. The average life of a cabinet in Chile has been three months. Up to 1908 Colombia had engaged in 27 civil wars, in which it lost 80,000 men and spent $37,000,000$ pesos. In 1922 São Paulo tried to secede from Brazil, and in 1925 Honduras was placed under martial law. Nicaragua has been in a state of revolution for a number of years, and Chile has been under a dictator and is now a socialist state. Chile has been one of the most militaristic and aggressive nations of the world. It was largely settled by Basques, and is proud of its navy and army, which are organized on the Prussian plan. Brazil, on the other hand, is peaceful. Its non-militaristic attitude is perhaps largely due to the fact that it quietly passed to an independent empire under Pedro I (1822) and then again quietly developed into a republic under Pedro II (1889), avoiding the unpleasant experience of having to fight for its independence.

There has been an almost continuous quarreling over boundaries among the Central and South American republics. Even now some of the boundaries have never been surveyed or staked, and hardly explored or mapped. Bolivia actually comprises only about twothirds of the territory it claims, and Paraguay little more than half. If Ecuador were to lose all the territory Peru claims, it would be reduced by more than two-thirds. Peru and Bolivia are still threatening Chile over boundaries. Uruguay, which was first known as Banda Oriental, was carved out of the La Plata territory, and came into being in 1828 when a territorial dispute between Brazil and Argentina ended in a compromise. Likewise Ecuador came into existence in 1830 as the result of a territorial dispute between Colombia and Peru.

Besides numerous revolutions and boundary disputes, South America has had two important wars. During the half century of dictatorship when the elder and the younger Lopez ruled it, Paraguay developed a powerful army. In 1865 the younger Lopez became involved in war with Uruguay, Brazil, and Argentina. The war lasted five years, and out of Paraguay's population of $1,337,437$ less than 28,746 able-bodied men were left, and only 192,333 women and children. Regiments of boys between the ages of 12 and 16 years engaged in the slaughter. The country was laid waste and 60 years afterwards had not recovered from the effects of the devastation. The other war is known as "the War of the Pacific." Chile fought 
Bolivia and Peru, and took valuable nitrate fields from both countries. It also seized Bolivia's only seaport. Treaties were signed in 1883 and 1884, but animosity has never subsided and threats of war have never ceased. Some adjustments have been made. TacnaArica long remained one of the chief danger spots of South America. After a break that lasted over 17 years, Secretary Kellogg finally succeeded in getting Peru and Chile to resume diplomatic relations in 1928. In June, 1929, a treaty was signed ordering a survey of Tacna-Arica to be made, and some months later the line was completed and mapped. Thus has been established one more South American boundary.

The Latin Americas show considerable variations in their political procedure. In most of the countries a president is elected for four years, but it is for five in Peru, six in Argentina, Chile and Cuba, and Santo Domingo, and seven in Venezuela. In some a president is never eligible for reëlection, and a few require a period of years to elapse before reëlection. Some have no vice president, but make definite provision as to who shall act in case of a vacancy. Most of the republics have two houses, but a few have only one. There is a definite tendency to link the executive and legislative departments by means of the cabinet. Suffrage is universal for males 21 years of age in most of the republics and under certain conditions for males of 18. Brazil, however, restricts suffrage to literates. The ballot is often influenced by guns, coercion, and bribery, and the struggle is usually one of personalities rather than political issues.

The political relationship between the United States and the Central and South American republics makes an interesting study. Naturally the United States, being a republic some 20 years of age when the struggle began in Latin American countries, looked upon itself as a model and lent moral support to their efforts. As it was having difficulty in negotiating the purchase of Florida from Spain at that time, it could not openly embrace their cause until the negotiations were completed, in 1819. When England tried to seize Buenos Aires in 1807 and 1808, the United States was too young and weak to be of much service; but when France blockaded Buenos Aires in 1838 and joined Great Britain in another blockade in 1845, the United States backed Dictator Rosas when he invoked the Monroe Doctrine and refused to recognize the blockades. The outcome of the Civil War in the United States defeated the attempt of Napoleon III to establish a protectorate over Ecuador. In 1895 a boundary dispute 
arose between Venezuela and Great Britain. Great Britain was not inclined to submit it to arbitration, but a message from President Cleveland left it with the alternative of submitting to arbitration or fighting the United States. In 1900 Castro became dictator of Venezuela and the United States had a trying time as long as he ruled. $\mathrm{He}$ did not hesitate to have foreign representatives murdered or to seize and plunder foreign ships, and refused to meet the financial obligations of his nation to European powers. In the upheaval that followed the attempt of foreign countries to collect their debts Roosevelt was inclined to interpret the Monroe Doctrine as giving a foreign power the right to use force to collect debts from an American nation. But Argentina's secretary of foreign relations, L. M. Drago, interpreted the Monroe Doctrine as denying the right of any European power to use force against an American country to collect debts, thus making the United States the accountant and banker for all American republics.

Most of the above procedure was pleasing to the Latin American republics, but there were other incidents which were not so satisfying. In 1831 the governor of the Falkland Islands, which were claimed by both Argentina and England, seized two sealing vessels from the United States for violations of the fishing rights. Captain Duncan of the United States forces dispersed the islanders. President Cleveland answered Argentina's demands for damages by calling the islanders "a piratical colony," maintained that Argentina's claim was "wholly groundless," and argued that the island originally belonged to England. In 1895 he decided in favor of Brazil in a dispute between Argentina and Brazil. These two cases, coupled with Drago's interpretation of the Monroe Doctrine in the Venezuela troubles, have tended to prejudice the people of Argentina against the United States.

In 1891, in a drunken brawl which occurred between United States soldiers of the ship Baltimore and Chileans in Valparaiso, one United States soldier was killed and some others wounded. For this the United States demanded an indemnity of $\$ 75,000$, which Chile preferred to pay rather than go to war. About the same time the Chileans became convinced that the United States was supporting the president, Balmaceda, whom they were deposing. Thus the people of Chile tended to develop a hostile attitude toward the United States, which was accentuated by what they interpreted as partiality to Peru and Bolivia in their dispute with Chile. 
Latin Americans have watched very carefully the expansion policies of the United States. The acquisition of Louisiana in 1813, Florida in 1819, Texas in 1845, Mexican provinces in 1848 and 1853, and Alaska in 1867; the annexation of Hawaii in 1899, Porto Rico in 1898 , the Philippine Islands in 1899 , and Guam in 1899 ; the establishment of a virtual protectorate over Cuba in 1898; the annexation of Tutuila (Samoa) in 1899; the general supervision over Panama established in 1903; the supervision of the finances of Santo Domingo undertaken in 1907, and the military administration of that island undertaken in 1916; the establishment of a virtual protectorate over Nicaragua in 1913, and the granting by Nicaragua of canal rights and a naval base in 1916; the supervision of the finances of Haiti undertaken in 1916; and the purchase of the Virgin Islands in 1917 these have aroused the fears of Latin Americans against the "imperialistic Yankee."

The Wilsonian phrase, "Catch Villa dead or alive"; the arbitrary method used by Secretary Hughes in settling the boundary dispute between Panama and Costa Rica; and our habit of sending soldiers into Mexico, Panama, Nicaragua, Cuba, Haiti, and Santo Domingo at will have added fuel to the flame. Roosevelt's arbitrary methods in the Colombia-Panama case did more, perhaps, to alienate the friendship of South America than all the others. The United States had offered Colombia $\$ 10,000,000$ and an annual payment of $\$ 250,000$ for the privilege of building the Panama Canal. The French company that had started work on the canal had twice exhausted its finances, and was anxious to dispose of it, but Colombia refused to ratify the treaty in 1903; it had already been ratified by the United States. A short time afterwards (November 3,1903 ) a rebellion broke out in Panama, and the leaders declared Panama independent. The next day Roosevelt ordered United States sailors to occupy the railroad, and thus prevented Colombian soldiers from crushing the rebellion. The United States broke the "diplomatic speed limit," for on November 6 it was transacting business with a new state. Within two weeks after the rebellion began, the French engineer and Secretary Hay signed a treaty granting the United States just what it wanted. Although Panama had elected to remain a part of New Granada with Colombia, it had seceded in 1841 and again in 1857. It would appear that the rebellion in 1903 was deliberately fomented by the French engineer and certain officials of the United States and Panama. A large number of the people of the United States demurred at this 
"big stick" policy, and Latin Americans stood aghast. Colombia protested vigorously against such treatment by a friendly nation, but the work was completed. Roosevelt's phrase, "I took the Isthmus," reverberated throughout Latin America, and "the Colossus of the North" became an object of fear and hate.

Our relations with Haiti afford another interesting example of our arbitrary methods. In 1915 the President of Haiti put to death 200 political prisoners, and as a result of this act was savagely killed by an infuriated mob of relatives and friends of the murdered prisoners. Immediately we intervened, and ever since have maintained control of that country through about one hundred Americans and a brigade of marines. All important administrative offices are manned by Americans or Haitians who are mere figureheads. In 1928 United States army trucks were used to convey voters to the elections which were to decide whether or not the powers of the president should be increased. They were, by a vote of 170,000 against 3000 . But this is not all. Officers of the United States served closing orders to a social club two of whose members had criticized the president. Furthermore, we are creating a new land system. We have forced native squatters on the land to forfeit their rights unless they can show a written title, regardless of how many decades this land has been in possession of their families. American firms have thus been able to secure concessions.

When the United States declared war on Germany and called on the Latin American republics to follow suit, practically all diplomatically declined. Many of their leaders, however, desired an explanation of "Wilson's sudden change of front," and wondered why he should assume "the moral leadership of the world." The spirit of the opposition has shown itself in Panama's request to the League of Nations for an interpretation of the Monroe Doctrine, and the protest of Santo Domingo's citizens against the United States before the Pan-American Conference. Through our oil interests an adjustment was made with Colombia in 1922. Doubtless it would have been accomplished before, but Roosevelt's friends were not willing to admit that he had made a "mistake" and our oil speculators did not know that they had an opportunity to acquire valuable oil concessions in Colombia. But now Latin Americans protest against our "dollar diplomacy," and look with disfavor upon the Monroe Doctrine because to them it supports "Yankee aggression."

3. Economic Development. The early settlers in Latin America 
were primarily interested in its mineral resources, especially gold and silver, and in trade with the Indians. The Portuguese in Brazil and the Spaniards in the La Plata region, however, soon turned to stock raising. The economic development of the new territory became more and more handicapped by Spanish laws, excessive taxes, restrictions on commerce, and regulations that prevented ships from sailing around southern Chile. Spanish officials did not realize the economic possibilities of Latin America, but today its wealth is farfamed. In the mountain sections there is an abundant supply of most of the minerals. The La Plata area is the chief grazing region of the world. The Amazon and Orinoco valleys and the Gran Choco contain the world's greatest virgin forests.

As Latin America is not the manufacturer but the producer of raw materials, it is economically tied to Europe and the United States. Although Argentina has been and remains a great stockraising country, it is rapidly turning to agriculture and manufacturing. With only 14 per cent of its arable land under cultivation, it is the world's greatest exporter of corn and linseed, and the second largest exporter of wheat. It is now producing large quantities of cotton, coffee, sugar, wine, and bird seed. Large numbers of cattle, sheep, horses, goats, and hogs are raised, and quantities of gold, silver, copper, and oil are produced. As is the case everywhere else in Latin American countries, the land is owned principally by the whites and held in large estates. Argentina has 237,768,000 acres of public land open to settlers. The large landowners have long opposed homesteading plans, but officials encourage people to settle on the land. Uruguay, the smallest state in South America, is eight times the size of Massachusetts; yet it has a population of only $1,042,686$, of whom 181,222 are immigrants. Considering its area, Uruguay is the leading cattle and sheep country in the world. It has about $8 \frac{1}{2}$ million head of cattle and $41 \frac{1}{2}$ million sheep. Over 95 per cent of its exports are cattle and sheep products. About $41 \frac{1}{2}$ million acres are in pasture and over two million in agriculture. Paraguay is primarily a stock-raising and timber country. About one-half of Brazil is in virgin forest. Very little of the country has been brought under cultivation; yet Brazil furnishes four-fifths of the world's coffee supply, ranks fourth in the output of sugar, and produces large quantities of cotton. The growing of rubber is becoming important as the wild rubber supply is threatened with exhaustion. Brazil has great mineral resources, but they are little 
developed. It exports cocoa, tobacco, herbs, hides, leather, meat, manganese, monazite, gold, and diamonds.

The highlands of Bolivia produce sheep, llamas, millet, barley, and potatoes; while the lowlands grow oranges, bananas, cocoa, coffee, sugar cane, and rice. Five-sixths of Bolivia's exports are mineral products, chiefly tin, silver, gold, copper, bismuth, lead, antimony, tungsten, and oil. Much of Chile is desert, but through irrigation it is becoming a great fruit country. Most of the country is mountainous, but its people are the most industrious of the Latin Americans, and produce large quantities of potatoes, beans, peas, cereals, and grapes. Grazing is extensively engaged in. Prior to the World War Chile produced 95 per cent of the world's supply of nitrate, but for the past few years synthetic nitrates have caused a decrease in this industry. It is now the world's second largest producer of copper, and it also has large deposits of iron, gold, silver, and coal. The west coast of Peru is desert, and as the efficient irrigation system of the Indians was not maintained, it is largely unproductive. On the east side of the Andes large quantities of wild rubber, sugar, and cotton are produced. Peru produces between 70 and 80 per cent of the world's supply of vanadium, and ranks fourth in the production of silver and ninth in the production of oil. It has 12,700,000 sheep, 1,580,000 alpacas, and 500,000 llamas. Ecuador is known to be rich in mineral resources, but they are little developed. Most of the land is covered with forests, and wild rubber abounds. Ecuador produced about 15 per cent of the world's supply of cocoa in 1916, but owing to plant disease the crop is decreasing. Its chief exports are Panama hats, copper, ivory nuts, and hides.

Much of Colombia is in forests, and it exports large quantities of mahogany, cedar, and dyewoods. It possesses the greatest emerald mines in the world, supplies half of the world's platinum, and possesses large deposits of gold, silver, copper, lead, salt, iron, and coal. It also exports coffee, cattle, cocoa, bananas, ivory nuts, tobacco, and wheat. Its rich oil fields are now being developed. Venezuela is largely a cattle and agricultural country. Its chief exports are cotton products, coffee, cocoa, and gold. It is rich in oil and minerals which are beginning to be developed. It is also beginning to engage in manufacturing, especially of textiles. About five-eighths of Panama is unoccupied and only a small part of the remainder is properly cultivated. Its chief exports are bananas, cocoanuts, gum, and hides. The Guianas produce some rubber, sugar, gold, and dia- 
monds. Their undeveloped state is a reflection upon the countries which own them.

Guatemala is rich in minerals, but undeveloped. Stock raising is extensively engaged in. It produces some timber, gum, bananas, coffee, and sugar. Honduras is mainly engaged in agriculture and cattle raising. It is rich in minerals and timber, but undeveloped. It exports bananas, cocoanuts, coffee, sugar, cattle, and hides. Salvador is a one-crop country - coffee. It has rich deposits of minerals and extensive forests, but they are yet to be developed. Besides coffee it exports small quantities of sugar, tobacco, rice, hides, balsam, and henequen. Nicaragua is chiefly engaged in agriculture and grazing, although it has valuable forests and some gold. It exports bananas, sugar, coffee, lumber, and hides. Costa Rica grows bananas and coffee. It has extensive forests and grazing lands. It also has mineral deposits, and some gold is mined.

Perhaps the greatest immediate need of Latin America is better means of transportation and communication. Practically all the railroads are centered around Buenos Aires and Rio de Janeiro. Uruguay has a network of 1729 miles, over nine-tenths of which are British owned. Argentina has about 24,000 miles, one-fourth being state owned. Brazil has about 20,000 miles, about one-half being owned by the nation. Most of Chile's 6000 miles are state owned. It is connected with Argentina, Bolivia, and Peru, with one road to each. It is two days' journey from Santiago to Buenos Aires, but for months the road is not open because of snow. Bolivia has about 1500 miles of railroad. The other countries have practically no railroad facilities; consequently different sections of the same republic are almost completely without means of communication. The highlands and lowlands of Bolivia are so isolated that it takes less time for a person in the lowlands to go to New York City than to his own capital. Peru is famous because it has the highest standard gage railroad (reaching 17,000 feet) in the world; yet it is easier for a person in Lima to go to Moscow, Russia, than to Iquitos in his own country. Perhaps the quickest way for a person in Lima to go to Iquitos would be to take a steamer for England or France, and then travel back to Brazil and up the Amazon. Owing to lack of transportation facilities, three men out of four in Bolivia are at least partially engaged in transportation. In many sections of South America some as large as Pennsylvania, the only means of transportation are the burro, the canoe, and the Indian runner. From Barranquilla on 
the coast to Bogota, the capital of Colombia, was formerly a journey of from eight to ten days, but now it is an aeroplane journey of five hours. Colombia, however, does not avail itself of the opportunity to develop a government monopoly of mail service, and a person is at liberty to get his letters transported and delivered in whatever way he chooses.

The Amazon, Orinoco, and La Plata, with their tributaries, are three wonderful waterways. There are also many harbors in Latin America. Even Bolivia has 10,000 miles of navigable rivers. Yet little has been done to improve harbors or rivers, or to construct canals. The Panama Canal is of great economic advantage to western Central and South America. Owing to the eastward extension of South America, the Panama Canal makes Valparaiso nearly a thousand miles nearer than Buenos Aires to New York.

Economically South America is developing rapidly, but mainly through concessions to foreign capitalists. Americans have $\$ 400,000$,000 invested in Brazil and $\$ 450,000,000$ in Argentina. In each of these countries the British have invested about four times as much. Between 1912 and 1927 American investments in Uruguay increased from $\$ 5,000,000$ to $\$ 77,000,000$. Americans have over $\$ 507,000,000$ invested in Chile, $\$ 220,000,000$ in Colombia, $\$ 250,000,000$ in Peru, $\$ 1,505,000,000$ in Cuba, and large amounts in the other Latin American countries. Almost every day some concession is being sold to American, British, or other foreign investors.

4. Religious Development. Early settlers in the United States were familiar with the idea of religious freedom, but we must admit that usually they were willing to extend it only to persons who shared their own beliefs. The Spaniards introduced into Latin America absolutism in government supported by intolerance in religion. The early colonists were fanatically religious and wished to take the country for the Catholic Church. Their experience with the Mohammedans in Spain had made them very dogmatic and fervent, but it had so changed their religion that it was the Moorish type of Christianity of northern Africa, rather than that of western Europe, that was introduced into the Latin American colonies. It suffered still other changes in the Americas owing to the drifting in of pagan practices from the Indian religions. From the political and commercial point of view the church soon became so wealthy and powerful that practically all questions were submitted to it.

The Roman Catholic was the established church in all the Latin 
American colonies, and practically all the early constitutions connected church and state. Sometimes a liberal leader would arise, like Rivadavia in Argentina (1826-27), who suppressed convents, seized church property, built liberal schools, and promulgated a constitution founded on Rousseau's Social Contract; Mosquera of Colombia (1845-49, 1861-67), who separated state and church, abolished tithes, exiled bishops, confiscated the property of convents, and established a national church; or Francia of Paraguay (1811-40), who disregarded the authority of the Pope and made himself head of a national church.

There' has been a definite movement on the part of Latin American republics to separate church and state, but in some, such as Costa Rica, Santo Domingo, Haiti, Paraguay, Peru, Venezuela, and Bolivia, the Roman Catholic is declared to be the national church. The president of Argentina is required to be a member of the Roman Catholic Church. The leaders in Argentina think their arrangement a good one, since the bishops are patriotic citizens who support the state school system rather than establish church schools. All the republics guarantee religious freedom and tolerate other faiths. Peru, Ecuador, and Bolivia were the last to remove penalties against Protestants. Ecuador made civil marriages obligatory in 1902 and placed the church under the state in 1904, at the same time declaring that church property was state property. In 1927 it passed a law prohibiting any foreign clergyman of any faith from entering the country. In 1880 Bolivia permitted no other faith than the Roman Catholic, but in 1906 it recognized others. Chile is considered the most definitely Catholic of the republics, but it separated state and church in 1925.

The fight for religious freedom in Central and South America has been similar to that in Mexico. The men of the upper class consider the church as something for women, children, and peons. European Catholics often express surprise at the condition existing within the church in Latin America. There are very few Protestants in Latin America. Even Brazil, with its heavy immigration from northern Europe, has only about 100,000 Protestants.

5. Educational Development. Spanish settlers, on their arrival, found two Indian empires well organized and in a comparatively high state of civilization. These people were not easily driven off, as were many of the wandering groups in the United States. Many of the Spaniards took Indian wives, and a fusion of culture began to take place. A hybrid race with a hybrid culture resulted in 
many sections. Throughout the area the Spanish culture has been modified and enriched by contact with Indian and other cultures. Spanish is the language of the government and the schools, but it has tended to become dialectic. In Colombia it is spoken in its purest form among the aristocrats, who are conservative, provincial, and little influenced by foreigners. In Argentina and Uruguay Spanish culture has been considerably modified by the influx of immigrants, and Argentine Spanish differs more in pronunciation from Castilian than that of any other republic. Chile is considered the most Latin republic. In many sections of Latin America Indian dialects prevail. The mass of people in Paraguay speak Guarani, and millions of people in Bolivia and Peru speak only Aymara and Qúechūa. Spanish culture in Cuba is giving way to American. English is even threatening to supersede Spanish as the common language. Haiti has a mixture of African, Spanish, and French culture, the last two having been largely extinguished. French is the literary language, but French Creole is the language of the street. Portuguese is the official language of Brazil, but it has suffered some modification.

At first schools in Latin America were under the church, and much of the teaching was of the dogmatic, fanatical religious type. There has been a long struggle for freedom in education in Latin America, and even now much of it smacks of Medievalism and Orientalism. Yet many of the early priests were well trained, and the Spanish had universities long before any were established in the United States. From the high percentages of illiteracy which prevail, one would surmise that the universities have not influenced the masses of people to a noticeable degree.

All the Latin American countries make education free, and all except Brazil and Colombia make it compulsory for the elementary grades. In Brazil it is compulsory in some states but not for the nation. Colombia has recently secured the services of a group of German experts to introduce the latest methods from that country. It is generally rated the cultural leader of Latin America. That the law is not enforced is evident from the school attendance records and rates of illiteracy. In Costa Rica, where school attendance is considered excellent, the illiteracy rate is 23.6 per cent. Paraguay has a law providing for free and compulsory education, but 60 per cent of the people are illiterate. Lima, Peru, is one of the oldest cities in the Western Hemisphere, and the University of San Marcos was established there by Charles V in 1551. Peru has free schools, 
and attendance is compulsory for children between the ages of 7 and 14; yet 80 per cent of the people are illiterate, and in 1928 less than 5 per cent of the children of school age were in attendance. The University of Cordoba was founded in 1613; yet there is a high rate (ranging from 30.8 to 67.4 per cent) of illiteracy in Argentina. Illiterate immigrants are responsible in part for the high illiteracy rate. Ecuador and Nebraska have about the same population; yet in 1915 Ecuador spent $\$ 600,000$ for education, while Nebraska spent $\$ 10,000,000$.

In many respects Uruguay is the most advanced country in Latin America, and many of its social laws are far superior to any found in the United States. Both Uruguay and Argentina are modern states, while Paraguay and Bolivia are considered to be among the most backward countries in the world. Bolivia's contact with the outside world began in 1913, but was not very definite until 1920 . Until recently the whites have opposed education and reform for the Indians or Mestizos. There were in 1926 about 1600 schools in Bolivia, and illiteracy was reduced from 84 per cent in 1900 to 60 per cent in 1925.

6. Social Conditions. The social conditions of Central and South America are very much like those of Mexico. Although certain changes have been wrought in the new country - such as the introduction of afternoon tea and horse racing from England, and other customs from France - in a broad sense, the social pattern remains Iberian.

The Latin American countries abolished slavery long before the United States, and are reported to have no color prejudice. While it is true that color has not become socially stratified to the extent that it is in the United States, throughout Latin America there are two main social classes, more or less based on color. Although Mestizos, Zambos, Indians, and Negroes occasionally become socially, politically, religiously, or economically important, it is the so-called whites who constitute the ruling caste or oligarchical class. They are the politicians, the professional people, the landowners. The Creoles disdain any activity that has the semblance of manual labor. A white man cannot carry his grip to the station or a small package from the store without danger of losing prestige, and women call their servants for such tasks as putting on their shoes or opening the door. Professors are reported to have difficulty in teaching courses in engineering and science because the students have no peons to do 
their work and object to performing laboratory experiments or assembling machinery. Ross ${ }^{1}$ relates the case of a station agent in Argentina who permitted two trains to collide because the switchman was ill and there were no peons near to pull the switch.

City life has a peculiar attraction for the Latin Americans. Buenos Aires has been dubbed "a pretentious city in a pastoral republic" and "a plaster Paris." In the size and design of their buildings and in their general beauty, the larger cities far surpass those of the United States. Some of the smaller cities, however, have an abundance of cobblestone and grass-grown streets. Nevertheless, the cities are the centers of social life and all Creoles desire to reside therein. The ranchman prefers to entrust his acres to some Mestizo overseer while he resides in the city and enjoys the social life.

The peons, Mestizos, Zambos, Negroes, rotos, pongos, inquilinos, cholos, and others compose the lower class, and on many of the large estates they are held in virtual serfdom and slavery. They have practically no social standing and on some of the ranches are treated like cattle. In general, the whites oppose education or any reforms that will benefit the peons, for fear that they will become unmanageable.

The influx of immigrants and contacts with the outside world are beginning to break down the two-class system. In Uruguay, Argentina, Chile, and elsewhere a powerful middle class, composed of immigrants, the children of immigrants, and Mestizos, is dethroning the white aristocrats and establishing a new order. The class struggle in many places is becoming serious, as socialistic theories are giving away to communistic doctrine accompanied with riots and bombings.

As in Mexico, the family is of the patriarchal type. Relatives are important and friends are seldom invited into the home. Ladies do not appear on the street without an escort. Sweethearts do not speak to each other until the case is serious enough for the young man to be invited to the home by the parents. Even after betrothal the lovers meet only in the presence of some older person. In Lima, Peru, which was settled by Moorish Andalusians, the women wear a manto over their heads and part of their faces, and are as cloistered as those of North Africa or nineteenth-century Turkey. In Uruguay, Argentina, and Chile the women have more liberties, but everywhere there is a forced chastity among the women of upper classes, while their husbands are generally promiscuous, and often polygamous.

From the American standpoint, the illegitimacy rates are every1 South of Panama, p. 208. 
where high. In 1919 about one-fourth of the entire population of Cuba was of illegitimate birth. About 95 out of every 100 marriages among colored persons were consensual and 13 out of every 100 white marriages. This is largely due to the fact that the church charged so much for weddings that the poor people could not afford to pay for the ceremony. Some writers claim that the Protestant missionaries have done considerable harm by teaching the people that they are sinning and insisting that they have a marriage ceremony performed. A few years ago a group of Protestant Latin American women protested against this teaching of the missionaries. They argued that the couples saw no harm in their custom of omitting the ceremony, and that so long as the marriage ceremony was not performed the woman was on an equal plane with the man, and was free to leave him if he mistreated her or her children; whereas a religious marriage ceremony binds the wife to the husband, who then forces her to become his slave and beast of burden. A change, however, is taking place, for civil marriages are coming into vogue, and with them the possibility of divorce. In fact, Latin America is in a social ferment, and no one can divine the future. While some South Americans dream of a supercivilization, based upon the intermingling of divergent races and cultures, others are inclined to be more skeptical.

7. Immigration and Emigration. The Latin American republics are considered immigrant countries. Although foreigners do not constitute over 5 per cent of the population in some of the more backward republics, immigrants and the children of immigrants form 85 per cent of the population of Argentina. Bolivia has very few immigrants. Recently some Germans and other foreigners have been going into Paraguay. Between 1861 and 1872 some 58,000 Chinese entered Peru, but Peru and Ecuador have recently restricted immigrants from China and Japan. West Indian Negroes who retain their British citizenship form about one-tenth of the population of Panama. Chile has old colonies of Germans, and recently there has been an influx of Spaniards. In 1920 115,763 foreigners were in residence; of these, 24,775 were Spaniards, 11,535 Italians, 8551 Germans, 6924 French, and 6899 English. The net immigration for 1927 was 819 . Immigrants into Venezuela have been mostly West Indian Negroes, but recently Europeans and Americans have been rushing in because of developments in the oil industry.

Uruguay, Brazil, and Argentina are the destinations of most of the immigrants. Uruguay has thousands of Spaniards, Italians, Ger- 
mans, French, English, Brazilians, and Argentineans. The Spaniards and Italians each number over 10,000. The net immigration, however, was only 6865 for 1927 . Most of the immigrants to Brazil settle in the states of São Paulo, Parana, Santa Catharina, and Rio Grande do Sul. The southern section is almost wholly European. In the 100 years ending in 1922, Brazil had grown from 4 to 30 millions. At least 3,200,000 immigrants landed in Brazil between 1820 and 1912. Of these, 1,300,000 were Italians, 900,000 Portuguese, 400,000 Spaniards, and 116,000 Germans. In 1924 over 96,000 aliens were admitted to Brazil, of whom 22,168 were Germans, 23,267 Portuguese, and 13,844 Italians. Although arrangements have been completed between the governments of Japan and Brazil for the settlement of Japanese immigrants, large numbers of Japanese have not emigrated there. The net immigration of Japanese was only 9625 in 1927.

Brazil has always favored immigration. In 1823 a colony of Germans settled in the southern part. Each family was given 200 acres of land and full rights of citizenship. The colony has grown until it now comprises an area over 8000 square miles and has a 90 per cent German population. They have largely retained their language and German customs. In 1914 Brazil passed a law enabling a person to be a citizen of Brazil and at the same time retain citizenship in the country of his birth. It has also offered many other inducements to immigrants. During the World War, however, it became afraid of separative tendencies in the southern area, and most of the time between 1922 and 1927 São Paulo and certain other sections were in open rebellion or under martial law.

Argentina is now reported to have more than two million Italians, one million Spaniards, and hundreds of thousands of other foreigners. Buenos Aires alone has 1,000,000 foreign-born. Between 1857 and 1909 some 3,500,000 Europeans landed in Buenos Aires. According to estimates there were 2,200,000 foreigners in Argentina in 1909 and $2,378,217$ in 1914. These were mostly Italians, Spaniards, French, Russians, Syrians, Austrians, Germans, and Swiss. In 1908 255,000 immigrants landed in Argentina, in 1923 232,501, and in 1927 161,518. ${ }^{1}$ Argentina desires to locate its immigrants on the land, but about a million have settled in Buenos Aires, where some complaint has been raised about their "cluttering up" the city. The constitu-

1 Wilkinson, H. L.: The World's Population Problems and a White Australia, p. 95, gives the immigrants as 139,894 and the recorded emigrants as 39,259. 
tion and government of Argentina are favorable to immigration. The immigrant hotels entertain immigrants free for five days after landing; then the government transports them free of charge to any part of the republic in which they wish to settle.

Since Latin America is itself an important immigrant country, one would not suppose that it would be of much importance as a source of immigration to the United States. Such is not the case. In the preceding chapter it was shown that increasingly large numbers of Mexicans are entering the United States, while many Europeans and Americans are going into Mexico. The same thing is happening in the other Latin American republics. We do not know the racial distribution of the immigrants in the United States from Central and South America and the West Indies. The Bureau of Immigration usually recorded only Creoles and Mestizos as Spanish Americans. Indians, Negroes, Europeans, and the children of Europeans were recorded under their respective headings. According to our statistics, 588,292 immigrants arrived in the United States during the period 1820 to 1920 from the West Indies, Central America, and South America. Ferenczi, ${ }^{1}$ however, gives 1,034,986 as the recorded emigrants entering the United States from South America during the same period. From these countries we received 28,829 immigrants in 1924 and 10,145 in 1930 . In 1920 there were 20,929 immigrants in the United States from Central and South America, but only 11,491 gave Spanish as their mother tongue, while 2603 gave Italian, 2284 English and Celtic, and 1430 Portuguese. At the same time there were 26,369 from the West Indies, 13,125 of whom gave Spanish as their mother tongue, 11,364 English and Celtic, and 371 French.

Since approximately two-thirds of the foreign-born in the United States from the West Indies are Negroes, we are placed in the inconsistent position of barring certain colored groups and admitting others, even darker in color. Furthermore, these come to us not as the bearers of an ancient civilization, but as the descendants of slaves captured and brought in from Africa. Speaking several languages, notably English, Spanish, French, and Dutch, coming from a background of high illiteracy and illegitimacy, having little conception of the social disparity of whites and blacks, and being shunned by the native Negroes, the West Indian Negroes find assimilation a difficult process.

${ }^{1}$ International Migrations, Vol. I, p. 178. 
Latin America is important in the study of immigrant backgrounds in another way. Many immigrants into Latin America remain there some years, absorbing part of the culture; but later, finding that conditions are not to their liking, they emigrate to the United States. This process has been accentuated by the quota laws of the United States, since Latin Americans were not on the percentage basis. According to the census reports, 55,630 immigrants came into the United States in the decade ending in 1920 who gave Central or South America as the country of last permanent residence, but only 17.76 per cent of these were Spanish Americans. Thus Latin America as well as Canada has become an "underground railway."

\section{QUESTIONS, EXERCISES, AND PROBLEMS FOR INVESTIGATION}

1. Give their approximate relative sizes and locate the different population groups in South and Central America. Besides the text, see Foerster, R. F.: "The Racial Problems Involved in Immigration from Latin America and the West Indies to the United States," United States Department of Labor, 1925; Bernard, L. L. and J. S.: "The Negro in Relation to Other Races in Latin America," Annals of the American Academy of Political and Social Science, Vol. CXL, pp. 306-18; Schurz, W. L.: "The Distribution of Population in the Amazon Valley," Geographical Review, Vol. XV, pp. 206-25.

2. What are the peculiar geographic advantages and disadvantages of the South and Central American countries?

3. What is the underlying stratum of South and Central American culture?

4. How would you account for the political instability of the Latin American countries? See Calderon, F. G.: "Dictatorship and Democracy in Latin America," Foreign Affairs, Vol. III, pp. 459-77; Calderon, F. G.: "Latin America, Europe, and the United States," ibid., Vol. VII, pp. $185-97$.

5. Show how the various foreign countries have tried to gain advantages in South and Central America, and in some detail describe our own efforts to exercise our authority. Besides the text, see series of articles in Annals of the American Academy of Political and Social Science, Vols. CXXXVIII, CLVI; Wilson, A.: "Oil Legislation in South America," Foreign Affairs, Vol. VIII, pp. 108-19; Haring, C. H.: "The Two Americas," Foreign Affairs, Vol. V, pp. 364-78; Buell, R. L.: "The Intervention Policy of the United States," Annals of the American Academy of Political and Social Science, Vol. CXXXVIII, pp. 69-73; Rippy, J. F.: Latin America in World Politics; Fletcher, H. P.: "Quo Vadis, Haiti?" Forcign Affairs, Vol. VIII, pp. 533-48; Scroggs, 
W. O.: "The American Investment in Latin America," Foreign Affairs, Vol. X, pp. 502-04.

6. What are the major economic assets and the more important industries of the different Latin American countries? How are these countries tied economically to the United States and to Europe? Besides the text, see Economic Geography, Vols. I, V; Morris, Ray: "Economic Changes in South America," Yale Review, Vol. XIX, pp. 45-60; Klein, Julius: "Economic Rivalries in Latin America," Foreign Affairs, Vol. III, pp. 236-43; McBride, G. M.: "The Agrarian Problem in Chile," Geographical Review, Vol. XX, pp. 574-86.

7. What special inducements does Argentina have to offer foreign settlers? What is its attitude toward immigrants?

8. Account for (1) the strong hold Catholicism has in South America; and (2) the high rates of illiteracy and illegitimacy.

9. How does the emigration of foreigners from South and Central America affect us? Compare the attitude of Latin Americans toward the colored race with the dominant attitude in the United States.

10. Summarize Pezet, A. W.: "The Latin Americans," Chap. XI of Immigrant Backgrounds, edited by H. P. Fairchild. 


\section{PART IV}

\section{THE SLAVIC GROUP}

Since there are approximately $156,700,000$ Slavs in Europe, they constitute its most important racial group. Their early home appears to have been in the middle territory between the Baltic and Black seas, near the Carpathian Mountains, along the Bug, Dnieper, Dniester, Dvina, Pripet, and Vistula rivers. For a long time they occupied principally the part of Europe that lies east of the Elbe River.

The Slavs are classified as belonging to the so-called Indo-European group. Most writers classify them as Alpine, some as Nordic. A few writers think they are closely related to the Teutons. They are generally of stocky build; their heads are round, and they have eyes and hair of varying shades.

The Slavs have always been in such a disorganized state that they have never shown a united front to their enemies. Many of them have long been part of other nations, and those that have been independent have usually had as sovereigns persons belonging to other racial groups. The rulers of both the subject and the independent groups have usually stressed differences in language and religion, and have thus kept the various Slavic groups isolated from one another. The Roman Catholic Slavs use the Latin alphabet, while the Eastern Orthodox (Greek) use the Cyrillic, a modified or mutilated form of the Greek alphabet. Many of the Slavs are Uniates (Greek Catholics). They are under the Pope, but retain all the Orthodox rites, use the old Slavonic language in their ritual, and have a married clergy. Through religion the Orthodox have been greatly influenced by Byzantine culture, while the Roman Catholics have been subjected to Latin culture.

Besides the two alphabets, there are numerous dialects, but the variations in language are not nearly so marked as they are among the Teutonic and Latin groups. The Slavs have not spread so far from their point of origin, been separated by broad oceans, or come into contact with so many divergent cultural groups as have the Latin and Teutonic groups. But despite their compactness and slight variations in culture, they have neither developed nor maintained the sentiment of racial solidarity. Instead each group has stressed its own dialect, language, literature, and religion. As a result of the World War, many of the Slavs rid themselves of their former rulers and became independent, but there is little indication that the feeling of unity is stronger now than formerly, or that Pan-Slavism will become a reality. 
The number of Slavonic nations has long been a subject of discussion and dispute among philologists. Excluding those which have become extinct, we find that the number varies from seven to ten. Following a political grouping, we may say there are seven. These are made up of the descendants of numerous former tribal groups, differing from one another in general appearance, language, and other cultural traits.

The three most difficult groups to classify are the Rumanians, Bulgarians, and Albanians. The Rumanians think that they are Latins, are trying to become more so, and are now often popularly so classified. Yet it is inconceivable that a few Latin soldiers or colonists in a country for 168 years could change a people biologically or culturally. Although the Bulgarians believe themselves to be Slavs and are thus generally classified, anthropologists and ethnologists seem agreed that they are mainly "Slavonized Finns." It is difficult to include the Albanians with the Slavs or any other group. They have long presented a problem. Deniker calls them "a separate Adriatic or Dinaric race," and Ripley thinks them "indigenous to their country." They are perhaps descendants of the Illyro-Pelasgians who have been influenced biologically and culturally by both Slavs and Latins. No one seems to know how to classify them, but they appear to fit with the Slavs better than with any other groups. The Rumanians form a connecting link between Latins and Slavs. Likewise the Bulgarians may be considered as a connecting link between Slavs and Asiatics. For convenience the Albanians are placed with the Yugoslavs. 


\section{CHAPTER XVI}

\section{RUMANIA}

1. General Description. The Kingdom of Rumania, situated in eastern Europe, borders the Black Sea and has for its neighbors Russia, Poland, Czechoslovakia, Hungary, Yugoslavia, and Bulgaria. Rumania occupies 122,282 square miles, and is somewhat less than half the size of Texas. It includes Old Rumania (the two ancient provinces of Wallachia and Moldavia, the Dobruja, and other territory acquired before the World War), which has an area of 53,489 square miles; Transylvania, 22,312 square miles; Bessarabia, 17,146 square miles; east Banat, 11,009 square miles; Crisana, 8038 square miles; Maramuresh, 6258 square miles; and Bukovina, 4030 square miles. Bessarabia and Bukovina were once a part of Moldavia.

The population of Rumania numbers $17,393,149$ (preliminary census of $1930,18,000,000)$. Old Rumania has 7,904,104; Transylvania, 2,678,367; Bessarabia, 2,344,800; the Banat, 1,582,133; Crisana, 1,316,981; Maramuresh, 766,666; and Bukovina, 800,098. Bucharest, the capital and largest city, had a population of 630,000 in 1930 . There are about $16,000,000$ people in southeastern Europe who claim to be the so-called Rumanian race, but only about $13,000,000$ live in the present Kingdom of Rumania. There are about 274,000 Rumanians in Yugoslavia, 600,000 in Ukraine (Russia), and 500,000 in Macedonia, and about 1,500,000 Vlachs or Kutzo-Vlachs in Greece, Albania, Yugoslavia, and Bulgaria who claim to be Rumanians. On the other hand, there are over 4,000,000 non-Rumanians living in Rumania. Over 1,100,000 of these are Ukrainians, 1,500,000 Magyars, 750,000 Jews, and 400,000 Germans. Most of the non-Rumanians reside in what is now the center of Rumania and along the borders. There are about 1,000,000 Magyars, known as Szeklers, living in the central part of the kingdom entirely surrounded by Rumanian peasants. The Dobruja has about 250,000 Bulgarians, Bukovina about 300,000 Ruthenians and 170,000 Germans; Bessarabia about 900,000 Ukrainians and 300,000 Jews. Rumanians form an absolute majority only in a circle surrounding the central part. In Transylvania and the Banat there are about 1,500,000 non- 
Rumanians. Thus the new Rumanian boundary forces millions of people to live under an alien government. In places the new boundary cuts across not only ethnological lines but commercial lines as well. For instance, in the Banat the line cuts across the rivers and irrigation ditches, and in Transylvania a row of Magyar cities that are tied to Hungary commercially must submit to Rumanian rule.

The Rumanians are another ethnological and cultural puzzle. Their language is partially a corrupt form of Latin that is closely related to Italian and other Romance tongues. Yet two-fifths of the words are Slavic, and many others are of non-Latin origin. Not over one-fifth of the words show Latin origin. In common with Bulgarian and Albanian, in Rumanian the article is attached to the end of the noun, a practice which seems to indicate a common origin for all three languages, perhaps the speech of the Dacians. The civilization is chiefly Slavic, although there are some Roman residues. Biologically there is no clear type. In general the Rumanians resemble the Slavs. Those in the western section appear to be Alpine, while those of the eastern section show a Mediterranean survival. These considerations and the fact that the Rumanians for the most part belong to the eastern form of Christianity, and until a few years ago used the Cyrillic alphabet, have led a number of writers to consider not only the inhabitants but even their language as Slavic, and perhaps caused our Bureau of Immigration to place them with the Slavs.

The country consists of fertile plains interspersed with mountains, rivers, and valleys. The Carpathians extend from the north to the center of the country, from which the so-called Transylvanian Alps extend due west for about 200 miles; the Danube forms the southeastern boundary for a like distance. The country is rich in mineral resources; it also has valuable forests and great possibilities for hydroelectric power.

2. Political Development. The early inhabitants of the region now known as Rumania appear to have been Dacians or Getae, one of the Thracian tribes. During the time of Julius Caesar the Romans came into conflict with these people who often raided the Roman territory south of the Danube (Bulgaria) and came to be known as the "most warlike of men." Trajan led an army against them, overran the country, and made it a Roman province in 106. The Romans held the territory for 168 years, and during this time Italian, French, and Spanish colonists numbering 240,000 settled therein. In 247 the 
first invasion of Goths, which was followed by five more, occurred. The Romans were unable to stop the Goths and in 274 withdrew their garrisons, taking with them all the colonists who cared to leave. About 330 the Roman Emperor Constantine reoccupied the country, but soon withdrew, taking with him many colonists.

From 274 until about 1250 Rumania was invaded and ruled by hordes of barbarians. The Goths (Gepidae) ruled intermittently for about 1000 years. The Huns appeared in 375, but withdrew in 453 . The Lombards came for a short period, and the Avars ruled for about 80 years. During the first Bulgarian Empire (893-1018) Rumania was ruled most of the time by Bulgaria. About this time the Petchenegs and later the Kumani, barbaric Mongol tribes, appeared as disturbing elements. In the twelfth century the Wallachs (Vlachs), who were probably descendants of the Daco-Roman colonists, appeared, and in 1240 the Mongol Tartars overran the country. During most of this time there was a steady infiltration of Slavic peoples, and the amalgamation of the different peoples proceeded steadily, giving rise to the hybrids called Rumanians.

In 1290 Negrou or Rudolph the Black, a descendant of the DacoRomans, came out of the Carpathians and established himself as ruler of Wallachia. About the same time the Daco-Roman colony in Transylvania moved to Moldavia. These two provinces form the cornerstone of modern Rumania. For about a century the two provinces struggled for their rights against the Hungarians and the Poles. Between 1386 and 1418 Prince Mircea ruled Wallachia and became a national hero. During this time a new menace appeared. The Turks crossed the Danube about 1391 and began to overrun the country. The Rumanians had aided the Serbs against the Turks some 30 years before at Adrianople, and at Kassovo in 1389. Mircea was captured by the Turks but later released, and Wallachia was made a Turkish province. Five years later Mircea allied himself with Hungary and marched against the Sultan, whom he captured. For a short period the Turkish menace was checked, but soon Mohammed I formed a Turkish suzerainty. About the same time Moldavia came under the rule of the Poles. By the sixteenth century both provinces were under the suzerainty of the Sultan. For 47 years (1457-1504) Steven the Great, perhaps the greatest man in Rumanian history, had defended his country against the Turks and their Tartar allies, against Hungarians, and against Poles. He called on his Christian neighbors to help him keep back the Turks, but in- 
stead they tried to seize his country. He fought thirty-six battles and lost only two. At his death there was no one to keep back the Turkish hordes.

When Turkish oppression became unbearable, John the Cruel (1572-74) of Moldavia started a rebellion, but was killed. A few years later Prince Michael the Brave (1593-1601) took advantage of the Turko-German war, freed his country from Turkish rule, and brought Moldavia, the Banat, and other sections of Rumania under one government. Within the brief period of eight years a powerful kingdom had been built and had fallen apart. It set a goal, the union of all the Rumanian people, toward which they never ceased to work. After Michael's death the Greeks, who had long been prominent because of their religious connections, became politicians and joined the Turks in suppressing the Rumanians. The cry was raised, "Rumania for the Rumanians." The Sultan showed his contempt for Rumanian patriotism by appointing an Italian prince as ruler of Moldavia in 1619. Gradually independence all but disappeared. Then Basil (Vasile) Lupu (1633-54) of Moldavia and Bassarab (1634-53) of Wallachia, who were borne into office on a wave of popular feeling against the Greeks, began secret negotiations with Russia for an alliance against Turkey, but nothing happened until 1711 . The Russian campaign against the Turks failed, and the Sultan determined to have no more natives on the throne of the two provinces. Consequently the principalities entered the saddest period of their history - the Phanariot Epoch (1716-1822), when Greek rule and government became organized robbery. In 106 years Wallachia had 35 rulers and Moldavia 33, each of whom squeezed the people to the limit and then retired.

The situation in the provinces seemed hopeless, particularly because the so-called protection of their Christian brothers had proved but a scheme to advance Greek interests. In 1736 Russia made another unsuccessful attempt to unite the two provinces. In 1768 Catherine II of Russia went to war with the Sultan. The Rumanians aided the Russians, but the Russians treated them so harshly that a strong anti-Russian party developed. The Rumanians learned that Christian Russians were as hard taskmasters as Mohammedan Turks. By bribing the high Turkish and Russian officials, Austria managed to annex the northern part of Moldavia (Bukovina) in 1774. Finally brigands became the dread of both Turks and Russians, but they gave Russia an excuse for strengthening its hold on the provinces. 
By 1812 (Treaty of Bucharest) it had annexed the delta of the Danube, a part of Moldavia, and renamed it Bessarabia.

The most determined struggle for freedom began in 1821. It resulted in civil wars but ended the Greek rule and restored the native rulers. The chief problem for the Rumanians now was to protect themselves from their Christian protectors. In 1828 Russian soldiers invaded the country for the sixth time, as Russia and Turkey were again at war. The Peace of Adrianople the next year left the provinces under the suzerainty of the Sultan, but Russian soldiers were stationed throughout the territory and were the real rulers. By 1848 a revolution had broken out, but this time it was against the Russians instead of the Turks and Greeks. In 1853 Russian soldiers invaded the provinces for the eighth time as a result of another RussoTurkish war. Austria, France, and England all joined in this, the Crimean War. At its close, part of the territory which Russia had annexed in 1812 was restored to Moldavia, and a European protectorate was substituted for the Russian one, which was assumed in 1774. The powers, however, could not agree on the union of the Rumanian provinces. Finally it was decided that they should be separate, but have a central committee to devise common laws. The Rumanians immediately solved the diplomatic puzzle by both electing the same prince, Colonel Alexander Couza (1859), and thus effected a union. In 1866 Couza was forced to abdicate, and Prince Charles, a Hohenzollern related to the house of Bonaparte, came to the throne. He was a soldier and a liberal, and his wife was well educated; both worked diligently to advance the interest of their adopted country. Determined to throw off the yoke of Turkey, Charles allied himself with Russia and followed Russia into war with Turkey. In 1877 Rumania declared its complete independence. Its fears of Russia were completely justified. Russia caused the Rumanians to bear the brunt and burden of the war, and forcibly exchanged Dobruja, a less valuable country with a very mixed population, for Bessarabia. On March 26, 1881, however, Rumania became an independent kingdom and Charles became King Carol I. In order to protect itself against Russia, it became a party to the Triple Alliance of Germany, Austria-Hungary, and Italy.

In 1913 Rumania joined the other Balkan states against Bulgaria and gained more of the Dobrujan territory from Bulgaria. In 1916, after being served an ultimatum by France, Rumania abandoned the Triple Alliance and joined the Allies in the World War. Assistance 
had been promised by the Allies, but before it arrived Von Mackensen's army had crushed Rumania and forced on it a humiliating treaty which King Ferdinand refused to sign and which was never ratified. The Central Powers demobilized Rumania's army, took possession of its available resources, and left it prostrate for the time being. Consequently it developed a deep-seated hatred for the Central Powers. After some time the Allied armies reached Rumania, and Rumanian troops again took up their arms. As a result of the World War, it more than doubled its territory and population, gaining 68,793 square miles and a population of $9,489,045$. Its key position, the methods it used in acquiring some of the territory, the dissatisfaction of Russia over the loss of Bessarabia, and the disgruntled non-Rumanians within its borders will perhaps lead $\dot{R} u-$ mania into future wars.

The present government of Rumania is a liberal constitutional monarchy. A new constitution was adopted in 1923, replacing those that had been in force in the different sections of the newly acquired territory. It provides for two houses: a Senate composed of exofficio and indirectly elected members, and a Chamber of Deputies elected by "universal, equal, direct, compulsory, and secret suffrage, on the basis of the representation of minorities." It provides for centralization and contains a sweeping bill of rights; monopolies and special franchises are forbidden. The railroads, means of navigation, mineral and other subsoil products are nationalized. Foreign mining and oil companies are given ten years in which to transfer 55 per cent of their stocks to the government. Military service is compulsory, and a strong army and small navy are maintained.

3. Economic Development. Rumania is primarily an agricultural country. About 82 per cent of the people are rural, and about fourfifths are engaged in agriculture and stock raising. The soil is very fertile, and under ordinary conditions the peasants are prosperous. Wheat, oats, barley, and maize are the principal crops. So great is the production of cereals that Rumania is considered the granary of Europe.

In Rumania, as in other countries, it has been a long road from slavery and serfdom to independent peasantry. The country early faced the question of land reform. Foreign rulers reduced the inhabitants to serfs, and for centuries they were tied to the estates of Turkish, Greek, Russian, Polish, and Magyar noblemen, or to the estates of their own countrymen who favored the ruling powers. In 
either case, they were systematically robbed and suppressed. In 1864 feudalism was abolished and the first land reform inaugurated. The vast estates held by monasteries were confiscated, and some 4,000,000 acres were distributed among 400,000 peasants. As each received only between $7 \frac{1}{2}$ and 15 acres, it was impossible for them to gain a livelihood from their holdings. In 1889 a large number of estates, comprising about one-third of the total area of the country, were divided among the peasants, and in 19123755 more estates were divided and sold to them. At this time there were about one million landowners with less than 25 acres apiece. Just before the World War about 40 per cent of the land was owned by peasants possessing less than 25 acres each. Exclusive of government lands, 4071 landlords owned all the rest. The law of 1917 required all large cultivable estates to be divided. In 1921 this law was extended to all the newly acquired territory. There was a sliding scale clause inserted, however, so that the larger a man's estate the more land he could retain. The maximum was set at 200 acres and the minimum at 40 . This has caused a serious problem in some of the new territory, since most of the landlords are non-Rumanians.

Rumania has about 18,750,000 acres in valuable forest lands, and the lumber industry is the source of a large revenue. Fisheries are also important. It is rich in mineral resources, especially petroleum, coal, lignite, iron, and salt. Normally exports are much larger than imports; hence the general impression is that Rumania is a prosperous country.

4. Religious Development. Christianity was introduced into Rumania by the Roman conquerors, and by 360 the country was considered a part of Christendom. Apparently the hordes of people who overran the country following that date did not accept the new faith, as the ruling Kumani had to be converted in 1240. Although the Rumanians think they are Roman in blood and culture, they early accepted the Byzantine form of Christianity and strongly resisted the efforts of the Popes and Hungarian kings to bring them under the Papacy. While under the Sultan the Greeks used their religion and Turkish political power to crush the Rumanians. About 1840 the Jews began coming into Rumania from Russia, Poland, and Galicia. As the Jews were more thrifty than the Rumanians, economic jealousy changed to religious persecution, and the Jews suffered from all the refined methods of cruelty which the Greeks and Turks had practiced against the Rumanians. Jews were not permitted to be 
citizens, to own land, to engage in handicrafts or trades. They had to rent lands at exorbitant rentals, and were allowed no educational or other advantages. The persecutions became so notorious that the Congress of Berlin forced Rumania to agree to grant religious liberty. Rumania ignored its promise. At the Conference of Paris the question was again raised, and once more Rumania promised religious freedom. The prejudice against the Jews is so strong, however, that it is doubtful whether they will ever enjoy equal rights with Christians. The Orthodox clergy are paid by the state, and the other clergy subventioned. The Jews were given $\$ 60,000$ in 1928 , the first money they had ever received from the government.

According to the census of 1918 , the religious groups in Rumania are as follows: Orthodox, 9,695,714; Roman Catholics, 1,483,929; Greek Catholics, 1,456,147; Protestants, 1,334,970; Jews, 834,344; Mohammedans, 44,087; Armenians, 17,596. Freedom of worship was guaranteed in 1866, but only Christians may become citizens. Old religious prejudices are strong, and where religion is tied to nationalism or race a difficult problem is created.

5. Educational Development. At first Rumanian was the speech of peasants, while Slavic was the language of the litterati. Gradually, as patriotism developed, Rumanian began to be substituted for Slavic in literature and among the upper classes, but it continued to be written with Cyrillic characters. As national consciousness further developed and the mythical kinship with the Latins acquired a stronger hold on the popular imagination, efforts were made to remove all non-Slavic words, and finally the Latin alphabet was substituted for the Cyrillic.

The first literary production seems to have been Neagoe's (Bessarab) philosophical writings in the sixteenth century, but as few people at that time could read, they made little impression. About 1640 the printing press was introduced, making possible the publication of books in the Rumanian language. Up to 1850 there were practically no schools in Rumania, but Couza established many educational institutions. The most prominent figure in Rumania's literary history was the wife of King Carol I. Under the pseudonym of "Carmen Sylva," she wrote poems and stories, published collections of Rumanian folklore, and greatly encouraged education and nationalism. The number of schools has increased rapidly, but they are mainly primary. There are several colleges, but no outstanding universities. Many students go to Italy and France for advanced 
training. Instruction is free and compulsory "where there are schools," but in many districts there are no schools. The illiteracy rate in 1912 was 60.7 per cent of all people over seven years of age. It is perhaps higher now, since Rumania has gained a large number of illiterate peasants from Russia and Austria-Hungary.

6. Social Development. Apparently the early inhabitants of what is now Rumania lived in a democratic society under their own chiefs. Invasions brought changes. Some of the invaders mingled freely with the natives, but others drove them into the mountains or subjected them to a harsh rule. In general, two chief social groups developed - masters and slaves, or nobles and serfs. After Couza had freed the serfs, nobles (boyards) and peasants formed the two social classes. The nobles usually belonged to the foreign ruling group or were natives who favored the foreign rule and had no sympathy for the peasants. Since the clergy were mostly Greek and joined the nobles in oppression, they may be classed with them socially. The Greek rule under the Turks was systematic robbery; under the Russians the nobles had no duties and the peasants no privileges. Even some of their own native princes, as Michel, were so oppressive that many of the peasants sold their children and themselves into slavery.

It was not until about the middle of the seventeenth century that the Rumanians had any written laws. To ill-treat a serf was no offense, but to harbor one who had fled from his master was a serious crime. On the other hand, a noble or his children could not be empaled, hanged, sent to the galleys, or forced to work in the salt mines. The most liberal laws were promulgated by Prince Charles. He encouraged compulsory education and signed a constitution guaranteeing freedom of the press, of speech, and of conscience.

The Rumanians appear to have many reasons for their prejudices. Because of its key position, Rumania has been a pawn in the hands of Turkish, Russian, French, English, and German politicians. Along with prejudices against outside rule, there developed religious prejudices between the eastern and western religious groups, between Rumanian and Greek churchmen, and between Christians and Moslems. Because of its situation, Rumania feels isolated from the Latin nations, and because of its belief in Latin superiority, it feels superior to neighboring nations.

7. Immigration and Emigration. According to the 1920 census there were 102,823 whites in the United States who were born in Rumania; 62,336 gave Rumanian as their mother tongue, and of 
these, 51,682 were born in Rumania. The Rumanians are late comers and have a low rate of immigration. In 1907 the rate was only 2 per 1000 of the population, and for the twelve-year period ending in 1910 only 82,704 came to this country. Less than 400 came in 1900, but the number increased to 11,425 in 1906 and to 25,817 in 1921. Between 1820 and 1930 153,074 Rumanians entered the United States, and 67,646 in the decade ending in 1930. A few Rumanians emigrate to Canada, Cuba, Brazil, Argentina, and Palestine. Repatriation statistics indicate that 34 per cent remain in the United States. Most of our Rumanian immigrants have come from Austria-Hungary. Only 300 of the 11,425 who came in 1906 were from Rumania proper. Just before the World War about 99 per cent came from Transylvania. Apparently it was Magyar suppression rather than conditions in Rumania proper which caused them to come. Most of these have been illiterate peasants who came without their families. They are mostly unskilled laborers who work in the steel mills and coal fields. Cleveland, Dayton, and Pittsburgh are their chief centers. They seem inclined to become citizens and adapt themselves to this country. Only 295 Rumanian immigrants may enter the United States under the present law, 308 less than under the two per cent law.

\section{QUESTIONS, EXERCISES, AND PROBLEMS FOR INVESTIGATION}

1. Of what does modern Rumania consist?

2. Outside of their native country, where are Rumanians chiefly found?

3. Explain: "The Rumanians are another ethnological and cultural puzzle."

4. Upon what do they base their claim to being Latin?

5. What other invasions occurred?

6. To what countries has Rumania been subject?

7. What rulers played an especially important part in the political development of Rumania?

8. Describe briefly Rumania's part in the Balkan Wars and the World War.

9. What are its economic assets?

10. What efforts is it making toward agrarian reform?

11. Mention some important educational problems.

12. Account for the high rate of illiteracy.

13. Into what groups do the Rumanians divide?

14. Explain the psychic isolation of Rumania.

15. What have been the apparent reasons for Rumanian emigration?

16. What type of citizen does the Rumanian make? 
17. Explain in greater detail why the Rumanians are so diversely classified. References. Dictionary of Races or Peoples; Ripley, W. Z.: The Races of Europe, Chap. XV; Pittard, Eugène: Race and History, pp. 280-83.

18. What is the Rumanian minority problem? How does this affect Rumania's relationships with neighboring countries? Reference. Bowman, I.: The New World, Chap. XVI.

19. Give a résumé of the political conditions in Rumania. Reference. Woods, H. C.: "Rumania - Yesterday and To-Day," Fortnightly Review, Vol. CXXIV, pp. 80-89, and "The New Régime in Roumania," ibid., Vol. CXXVI, pp. 378-87.

20. Abstract Hanbury, Dorothy: "The New Roumania," Nineteenth Century, Vol. CI, pp. 653-60.

21. Point out the economic resources of Rumania. References. Armstrong, H. F.: "The New Balkans," Foreign Affairs, Vol. III, pp. 293-312, especially pages 299-306; "The New Rumanian State: Regions and Resources," Geographical Review, Vol. XIII, pp. 377-97.

22. What group or groups are most unsatisfactorily located in Rumania? References. Bowman, I.: The New World, Chap. XVI; and Ferenczi, Imre: International Migrations, Vol. I.

23. Make a study of post-war Rumanian emigration. Reference. Ferenczi, Imre: $O p$. cit. 


\section{CHAPTER XVII}

\section{RUSSIA - UNION OF SOVIET SOCIALIST REPUBLICS}

1. General Description. Although the World War caused Russia to lose Bessarabia, Esthonia, Finland, Kars, Latvia, Lithuania, and Poland - a territory containing 260,493 square miles, with a population of about 24,689,600 - the Union of Soviet Socialist Republics still has an area of $8,144,228$ square miles and a population of $147,-$ 013,609 (estimated as 161,006,200 in 1931). The Soviet Union consists of seven constituent republics - Russia proper, White Russia, the Ukraine,Transcaucasia, Turkmenistan, Uzbekistan, Tajikistan eleven autonomous republics, and fourteen autonomous areas. The Russian Socialist Federal Soviet Republic (Russia proper) had an area of 7,626,717 square miles and an estimated population of 110,932,000 in 1931 . Moscow, the capital and largest city, had a population of 2,025,947 in 1926 .

Some one has said that "Russia is not a state, but a world." In area it is second to the British Empire. It contains about one-sixth of the land area of the world and stretches across two continents, a distance of almost 7000 miles. Russia is more than three times the size of Europe, and Asiatic Russia is three times as large as European Russia. Russia has an advantage over the British Empire in that its area is a united whole, but it has a serious disadvantage in the fact that most of its coast is ice-locked for a large part of the year. Russia's motley family includes some 130 tongues, 64 racial or tribal divisions, and 169 smaller ethnic groups, varying from a very high to a very low level of civilization, without manners, customs, or traditions to bind them together. Indeed, Russia has no unity unless it be "unity in immensity" or monotonous landscape.

Russia consists of a great plain with no large or important mountain range. This Great Northern Plain, the largest in the world, extends from the Danube and Niemen rivers on the west to the Yenisei on the east, several thousand miles away, and from the Black Sea and Hindu Kush Mountains on the south to the White Sea and the Arctic Ocean on the north. The Ural Mountains traverse the northern portion of this great plain, running north and south. 
There are no mountains to impede the march of armies from east to west, or to force a heavy rainfall from the ocean winds. Neither are there any mountains to check the advance of the Arctic winds from the north, or the hot, dry winds from the Asiatic deserts.

Narrowing from a broad base near the Altory Mountains to a point in Galicia is a wedge of very fertile soil. To the south of it, near the Caspian Sea, is the region of the salt plains, which is almost useless for cultivation. Both the salt plains and the "black-soil" region are almost treeless, and are commonly known as the steppes. On the north is the great forest region, centering around Moscow and eastern Siberia. The northern part contains a large amount of marsh land. Most of the northern part of the great plain is useless for cultivation.

European Russia is about two-thirds the size of the United States and includes about 60 per cent of Europe. About five-sixths of the population of Russia live in European Russia. This is the homeland of the Russian Slavs. The Russian Slavs include the Great Russians, Ukrainians, White Russians, and other Slavs. The Great Russians are the most numerous, numbering between 60 and 80 millions according to different estimates. They inhabit the Central Provinces, centering around Moscow and the district east of it, but many, perhaps 7 millions, live out of this area, chiefly in Siberia, Caucasia, and Central Asia. They claim to be the purest Slavs, from whom the others have sprung, and to speak the purest of the Slav languages. Although there has been considerable absorption of Finnish blood, they boast that they have not been contaminated by southern blood. They are proud that their ancestors were the Muscovites who removed the Tartar yoke from Russia, and that they have produced Tolstoy, Dostoievski, Turgenev, and Vereshchagin.

The Ukrainians inhabit the area north of the Black Sea and Rumania, adjoining the Great Russians and White Russians on the south. There are perhaps between 30 and 40 million Ukrainians in Europe, centered chiefly around the city of Kiev. Since the Russians and Austrians tried to disguise the Ukrainians, we find them called Little Russian in Russia and Ruthenian in Austria. (They are also called Malo-Russian, Yugo-Russian, Red Russian, Russniak, Russive, Galician, and Cherkasi.) Many Ukrainians live in Galicia and Bukovina. Roughly speaking, they inhabit the fertile blackearth area between the Dniester and Dnieper rivers. This is the most productive cereal region of all Europe; it also has rich deposits 
of coal and iron. Like the Great Russians, the Ukrainians claim that they are the pure Slavs, but they show distinct traces of the absorption of Greek and Tartar blood. They are much darker than the Great Russians, a large majority of them having brown hair and

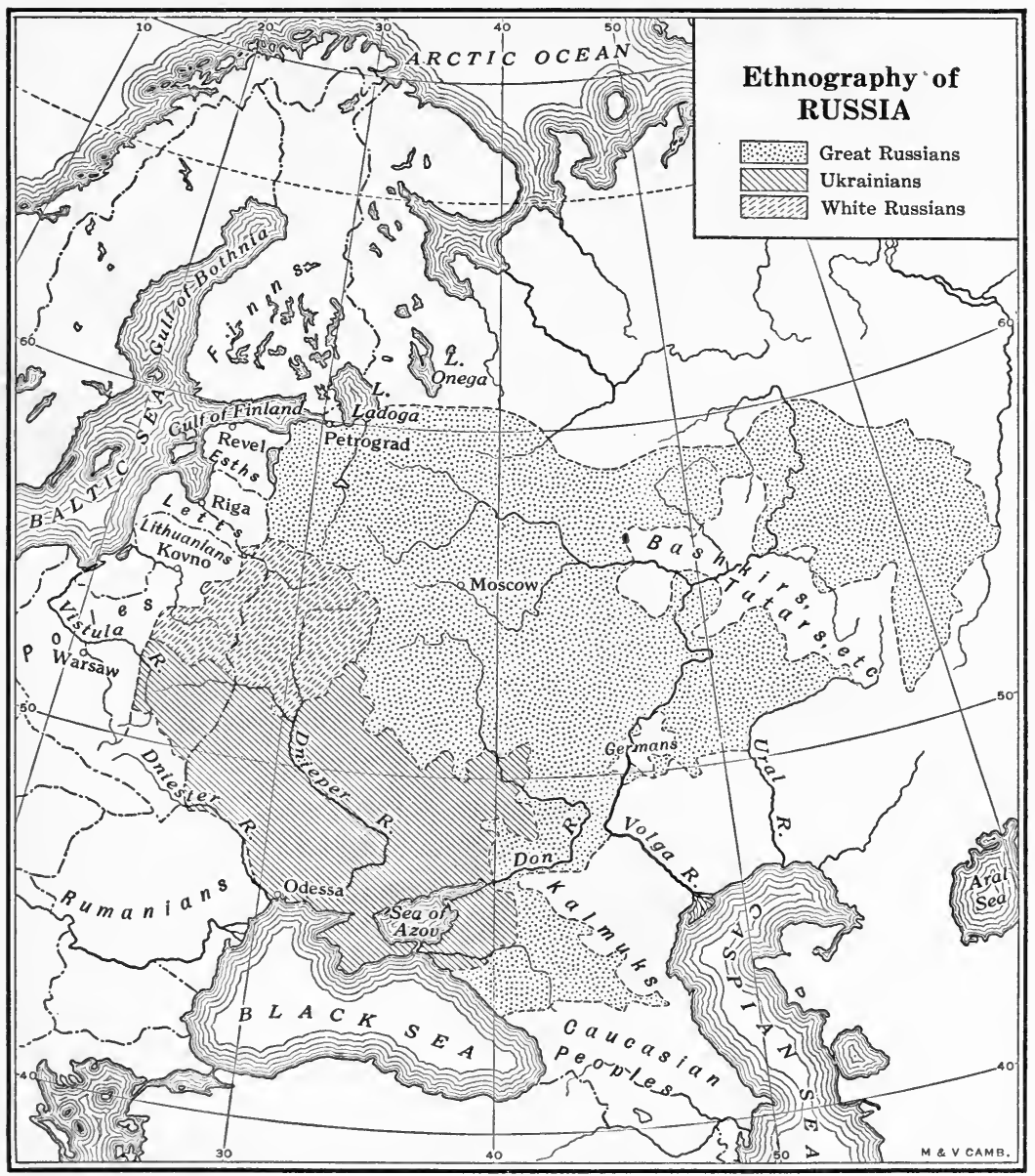

After Bowman

dark eyes. They are also taller, have a better physique, and are more militant than the Great Russians.

The White Russians number between five and six millions. They inhabit the six former Minsk provinces bordering Poland and Lithuania, and constitute 82.2 per cent of the $4,983,884$ people composing 
the White Russian Soviet Socialist Republic. They have amalgamated considerably with the Poles and Lithuanians; yet they are not so dark as the Poles, and exhibit more Nordic characteristics than any other Russian group. They appear to have acquired the name White Russians not from their fair complexions, but from the white, broad-belted overcoats which the men and women wear. On the whole, they are short and stoutly built, with finer features than the other Russian Slavs. White Russia was within the Jewish pale, and about 10.6 per cent of the population is Jewish, against 5.4 per cent in the Ukraine.

Besides the three chief Russian groups discussed, there are in Russia other Slavs, such as Poles, Czechs, Slovaks, and Rumanians, and non-Slavic groups, such as Finns, Lapps, Germans, Magyars, Greeks, and Tartars.

The Russian territory in Asia includes Siberia, Transcaucasia, and Central Asia, and contains over one-third of the area of Asia, but less than one-fiftieth of the population. Siberia occupies a broad belt across the northern part of Asia. It contains over 5,600,000 square miles of territory and a population of approximately $17,000,-$ 000 people, about 20 per cent being "native" stock. Siberia includes almost a third of Asia, but less than one ninety-fifth of its population. The narrow land bridge between the Caspian and Black seas is generally known as Transcaucasia. With the exception of the Kula Valley and other small scattered areas the land is generally rough and mountainous. It has an area of 71,255 square miles, which is 0.8 per cent of the whole Soviet territory. In 1922 it consisted of three republics - Armenia, Georgia, and Azerbaijan. Central Asia is a term used to cover a number of political divisions which have shifted their boundaries and names rapidly during the last two decades. The area is bounded by the eastern and northern shores of the Caspian Sea, European Russia, Siberia, Afghanistan, and Persia.

The people inhabiting Siberia are a mixture of Slavs, Semites, and various Turko-Tartar, Finno-Ugrian, and Mongol tribes. Apparently various Asiatic tribes, including Magyars, Finns, and Lapps spread over large areas of Siberia, European Russia, and certain other parts of Europe at an early date. The expansion of the Slavs pushed the Magyars, Esthonians, Finns, and Lapps into their present location. Many of the Asiatic peoples were absorbed by the Slavs, but pools of them remain in European Russia. Between the sixteenth and the eighteenth century the Slavs pushed over the Ural Mountains into 
Siberia, where they now number nearly $9,000,000$. The western provinces of Siberia are about 90 per cent Slavic. It is claimed there are 59 different racial groups in Siberia. The aborigines, being of Mongolic origin, differ racially and culturally from the Slavs.

The inhabitants of Transcaucasia are a mixture of all the racial groups that have crossed and lingered on this land bridge between the two seas and continents. The country is a Babel not only of languages but also of races. It is reported to have 34 nationality groups, 5 main racial groups with some 40 subdivisions, and over 70 languages and dialects. The three main groups of people are the Armenians ( 24 per cent), Georgians (34 per cent), and Turko-Tartars (23 per cent). The Armenians trace their descent from Haig, the grandson of Joseph. Although very much mixed racially, they have the general characteristics of southern Alpines. They have a remarkably short, high head, flattened in the rear, dark hair, dark eyes, and other brunette chàracteristics. Their so-called Jewish nose connects them with the ancient Hittites. Their early language was doubtless non-Indo-European, but now it is akin to Persian, Hindi, and Gypsy, and more European than that of the Magyars, Finns, or Basques. The Soviet Socialist Republic of Armenia contains a population of 876,557 (1926), of which about 86 per cent is Armenian. According to estimates, there are between 3,000,000 and 5,000,000 Armenians in Transcaucasia, India, Africa, America, and other parts of the world.

The Georgians constitute 68 per cent of the people in the Georgian Soviet Socialist Republic, which had a population of 2,660,936 in 1926. They trace their descent back to Noah. Originally they were a broad-headed Caucasian people, but now they are a mixture of Caucasian and Mongolian elements. There are several divisions of them, but the Grusians are generally known as the Georgians. They are a tall, broad-headed people, and usually have dark eyes and hair. The women are famed for their beauty and were long prized as slaves and members of Turkish harems. The Azerbaijans belong to the Tartar group, which migrated to this region early. They differ widely from the Armenians and Georgians; in race, language, and religion they are practically the same as the Turks. There are perhaps 3,000,000 Azerbaijans, mostly in Russia and Persia. Most of the 2,313,172 people constituting the Azerbaijan Soviet Socialist Republic are Azerbaijans.

Central Asia is another mixed racial area, but with the exception 
of the Tajiks (Persians) in the southeast, and scattered groups of Russians, the country is inhabited by Tartar groups, generally known as Kirghiz, Turkomans, Uzbergs, Kara Kalpaks, and Sarts. Studies of this region show that there are 42 nationality groups in this area.

2. Political Development. How a few scattered Slavonic tribes, centered around what is now Moscow in the Great Northern Plain, grew into the great Russian Bear, containing about one-sixth of the land area and one-twelfth of the population of the world, makes fascinating history. We know very little of early man in Russia. The

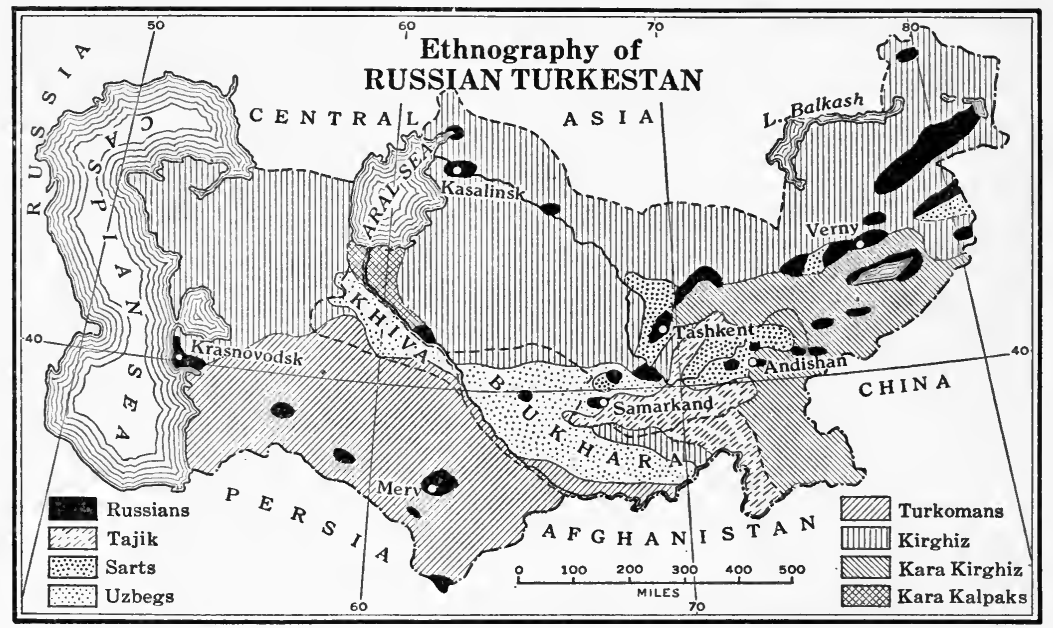

After Atlas of Asiatic Russia, 1914 (in Russian)

region around the Black Sea was very fertile, and two early civilizations apparently developed there: the Cimmerian-Thracian between the tenth and the eighth century B.C., and the Scytho-Iranian between the eighth and the third century B.c. This region was perhaps the granary of the early Mediterranean world and the center of western civilization. Although the civilization was eastern, the Greek influence was undoubtedly strong. The failure of the Greeks to Hellenize the population was perhaps due to the strong cross currents from the east.

By the ninth century there were three main centers of cultural life in European Russia: (1) Kiev in the southwest; (2) Novgorod in the northwest; and (3) Tmutarakan in the southeast. These three centers were politically, economically, and culturally independent of each other. The Kiev state reached its zenith between the ninth 
and the eleventh century, but lost most of its trade, became impoverished, and was captured in 1169 by Andrey Bogolyubski, Prince of Suzdal, who declared himself Grand Duke of all the Russians. Between 1280 and 1462 the Moscow Principality played an important rôle, but no one really ruled. In fact, the only bond of union was the dependence of the Russian Church on the Byzantine Patriarchate. For some two centuries before the rise of Ivan III (1462-1505), ruler of Moscow, who united the numerous principalities and freed his people from foreign dominance, the Russians paid tribute to the Mongol Empire. Being so long dominated by the Mongols, their whole political life had an Asiatic rather than a European coloring.

It remained for Peter the Great, who is called the father of modern Russia, to Europeanize Russia and make it one of the great nations of Europe. As a volunteer soldier he visited the leading European countries and studied military tactics, ship building, industry, and commerce. He sent large numbers of engineers, soldiers, artisans, and others to Russia to instruct his subjects. After his return he introduced reforms, extended his domain in Asia, around the Black Sea, and supplanted the powerful Sweden as the controller of the Baltic. When he died in 1725 , Russia was compact, efficiently organized, well administered, and westernized. Catherine II (176296) continued many of his policies. She successfully fought the Turks and Poles, established an outlet on the Black Sea, extended Russia's boundaries into the very center of Europe, and dominated the three partitions of Poland. As Peter had made Russia a western nation, so Catherine made it a great power.

Alexander I ascended the throne in 1801. The training in humanitarian philosophy that Catherine gave him, and the tyranny of his father, the Emperor Paul (1796-1801), caused him to sympathize with his subjects. He did not accomplish much, however, and what he did was largely undone by his brother, Nicholas I (1825-55). It was left to Nicholas's son, Alexander II (1855-81), to institute three reforms that stand out in Russian history. He emancipated the serfs, established provincial assemblies to enable the people to participate in local government, and remodeled the legal and judicial systems. The Polish insurrection of 1863, however, checked his liberalism. Reversion to autocratic government caused the Nihilists, Socialists, and Terrorists to initiate a reign of terror, with the result that Alexander once more adopted a liberal policy. On the very day he signed a decree embodying his new policy, he was assassinated. 
Alexander III (1881-94) came to the throne with a firm belief in the autocratic policies of his grandfather, Nicholas I, and undertook the difficult task of rectifying the liberal policies of his father, Alexander II. He disliked western civilization and believed that the hope of Russia lay in autocracy, the Eastern Orthodox Church, and Slavic nationalism. He decreased the privileges of the peasants, opposed secular education, and revoked the liberties granted to non-Russians. Bessarabia, Caucasia, Courland, Esthonia, Finland, Lithuania, Livonia, and Poland had all been brought under the wing of Russia, and now the Tsar began the impossible task of forcibly Russifying the various racial and religious groups. He became a leader in the Pan-Slavic movement, which had a twofold object: to make the language and institutions uniform throughout Russia, and to extend Russian influence eastward through Asia and southward through the Balkans. The rapid rise of Germany and its reactions to Pan-Slavism changed his traditional attitude of friendliness to one of hostility. To oppose Germany, the most autocratic ruler of all Europe aligned himself with France, which was then a very democratic country.

Nicholas II came to the throne in 1894 with a determination to carry out the policies of his father, but his defeat in the RussoJapanese War in 1904-05 ended his attempts to extend Russia to the Japanese and Yellow seas and checked his autocracy. General dissatisfaction resulted in strikes, revolutions, and terrorism. Red Sunday, January 22, 1905, was truly a day of bloodshed. Nicholas weakened. A Duma (legislature with two houses) was granted to Russia and a constitution with women's suffrage to Finland. Other reforms were introduced, but in less than two years a reactionary movement set in, which led to a repeal of most of the liberal laws. Conditions gradually grew worse until the World War. Then came the overthrow of Russian autocracy and the establishment of the Soviet Republic.

Until the sixteenth century Siberia was a wild and almost unknown land, inhabited mostly by savage nomads, who made it dangerous to travel in the country. During the sixteenth, seventeenth, and eighteenth centuries Russia, chiefly through the explorations of Yermak and Bering and the encouragement of Peter the Great, was busy discovering this land and making settlements. Since 1860 all Siberia has remained Russian territory. After the revolution, however, Siberia declared its independence. The eastern section was immediately seized by Japan and held for some time, but subsequently it 
entered the Russian Republic, where it remains as one of the autonomous Soviet Socialist Republics.

Russia began its encroachments on Transcaucasia in 1722. Taking a large area around the Sea of Azov between 1762 and 1796, it continued to encroach on Persia and Turkey until, in 1881, it practically reached the present Transcaucasian boundary. Most of the present province of Transcaucasia had been incorporated in the Russian Empire by 1864. In 1917-18 the Armenians, Georgians, and Tartars of Azerbaijan declared their independence and established a federated republic. However, they could not agree among themselves or defend their territory against the aggression of Turkey in 1918. After the Brest-Litovsk Treaty, Azerbaijan favored Turkey, Armenia Russia, and Georgia Germany. National aspirations and racial and religious difficulties further complicated the situation. It appears that Great Britain, France, and Italy had agreed in 1919 to divide the better parts of southern Russia among themselves. Great Britain wanted the oil fields around Baku; France the fertile Ukraine with its rich deposits of coal; and Italy the coal fields south of the Black Sea. Poor, unprofitable, troublesome Armenia was to become a mandate of the United States. While the League of Nations was trying to find a solution to all the various religious, racial, and boundary troubles and at the same time divide the rich oil fields and coal and manganese mines among the nations that desired them, the Russians appeared and solved the problem. All the territory voluntarily became a part of Russia.

Central Asia has long been a source of contention between Russia and Great Britain. Russia desired an outlet to the Indian Ocean. Great Britain, on the other hand, was determined to thwart Russia's attempts to secure a southern outlet, and to prevent it from possessing territory contiguous to India. So far Great Britain has been able to block Russian advances, but no one knows what will happen in the future.

The Union of Soviet Socialist Republics is a free socialist society of all working people of Russia. All laboring people, except the employers of labor for profit, over eighteen years of age have the right of suffrage. The clergy and others "who do no socially useful work," manufacturers, and farmers who employ labor for profit are not permitted to vote. The District Soviet Congresses choose delegates to the Soviet Congress of the Republic on the basis of one delegate to every 125,000 inhabitants of the provincial Soviets, and one to every 


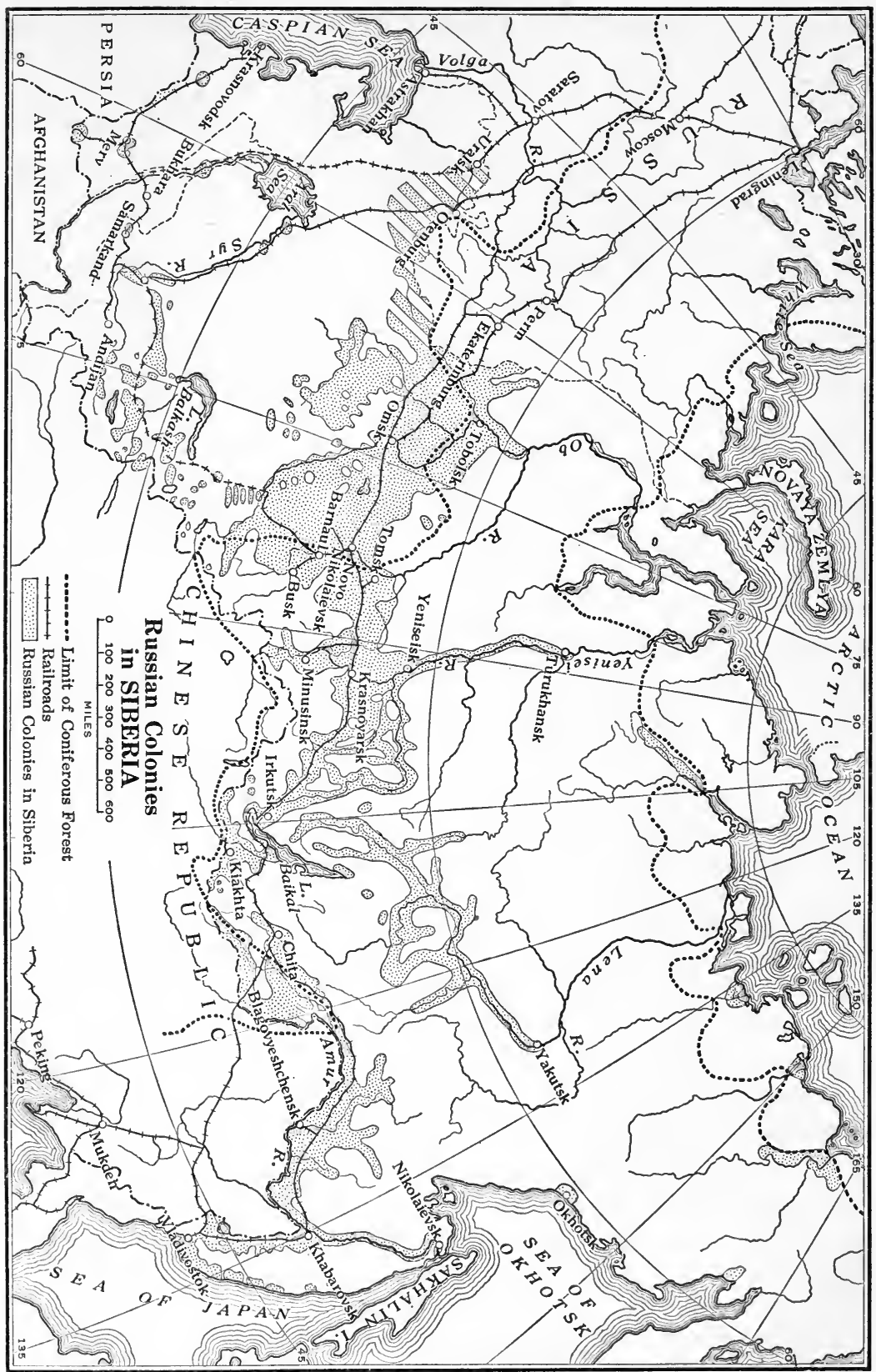


25,000 voters of the city Soviets. There are two houses: members of the Federal Council are chosen on the basis of population by the Federal Congress of Soviets, and members of the Council of Nationalities are chosen by each constituent autonomous republic and by each autonomous area, regardless of population. Each house names nine members to a standing committee, and jointly they name nine more. These 27 members constitute the supreme authority of the Republic. All laws must be published in the six languages current in the Union. Land and natural resources are held in trust by the Union. Every one may have land to till, which he holds by perpetual leases. All public utilities belong to the Republic. Concessions may be secured by companies or individuals, but ultimate ownership belongs to the Union.

3. Economic Development. The early Russians appear to have been traders rather than agriculturists. There was little cultivation of the soil before the eleventh century, when the Tartars overran the country, disrupting the political, economic, and social conditions, and causing the Slavs to begin tilling the plains of the Upper Volga. Gradually agriculture became the most important occupation of Russia. For a long time the bulk of the land remained in large estates; "down to one hundred years ago nine-tenths of it was in the hands of the few." 1 These estates were cultivated by the serfs. Serfdom was finally abolished by Alexander II in 1866. The serfs were to receive land, but the amount they received was only about $6 \frac{1}{2}$ acres per family. The peasants increased rapidly but the land did not, and the government did practically nothing for them; consequently famines were common, thousands dying of starvation as in 1891-92. It should be remembered that only a small part of Russia is good agricultural land; only about 8 per cent of the total area of European and Asiatic Russia was under cultivation in 1926. The Ukraine is the best farming area in Europe, but in most of it only about 50 per cent of the land is cultivated. Most of White Russia is swamps and marsh land unsuited for cultivation. The northern part of European Russia is too cold for cultivation, and the eastern part is subject to dry hot winds and droughts. The forest lands of the U. S. S. R. are estimated at 2,040,330,000 acres, $1,984,547,500$ being in the R. S. F. S. R.

Siberia is spoken of as the land of latent resources. It is a land of peasants and of great agricultural possibilities. In 1917 there were

1 Bowman, Isaiah: The New World, p. 456. 
$2,000,000$ farmsteads of which 81 per cent belonged to the peasants, 15 per cent to "natives," and 4 per cent to Cossacks. There are great possibilities in wheat growing, and it is estimated that Siberia could grow a surplus of 2,000,000,000 bushels if it used American methods. Under present conditions it is one of the greatest graingrowing regions in the world. Although it raises cattle, horses, and goats, it largely ignores hog raising. The government has been instructing the peasants in the care of dairy products, and hundreds of tons of butter are being shipped to Europe weekly.

The rich forests of Siberia furnish an excellent range for fur-bearing animals, and Siberia is the greatest fur-producing area in the world. Of great importance also are its mineral resources. Although no one knows the extent of Siberia's mineral wealth, it is believed to be large. Part of the Ural Mountains are very rich in minerals, such as iron, platinum, gold, sapphire, topaz, emerald, garnet, and amethyst. Transcaucasia has great economic value because of its rich oil fields, especially around Baku, the manganese deposits of Georgia, the coal deposits along the southern shore of the Black Sea, and its key commercial position. Cotton is now being grown in increasing quantities, silk production is good, and many kinds of subtropical fruits are grown. Tiflis is the capital and chief city, and Baku and Batum are the chief ports.

Central Asia is practically all semi-arid, and has great stretches of deserts. The remains of ancient cities, however, show that it was once a much better watered region and had a heavy population. Two large rivers cross western Turkestan and offer very good opportunities for irrigation. The natives lead a half-civilized nomadic life. The Russians are rapidly colonizing all the well-watered fertile areas of Central Asia, where they engage in agriculture and stock raising. Many of the Tartar groups, especially the Uzbegs and Turkomans, have adopted a sedentary life and are engaging in agriculture, especially cotton growing. Over 900,000 acres in Turkestan, Khiva, and Bokhara are now cultivated in cotton. The economic possibilities of the whole area are limited.

A new economic era in Russia began when the Communists seized control in 1917. The country was agriculturally undeveloped and economically and politically in chaos. The population had for many years been increasing faster than the means for providing ordinary necessities and employment. The Tsarist government had forced the peasant producers to increase their output and even sell grain needed 
for home consumption in order to meet its foreign obligations. In other words, the agricultural population was forced to bear the burden of the national government. Upon this inheritance the Soviet Union had to build its program. It undertook to transform the capitalist system with its anarchy of production and distribution into a socialistic system of unified plan and control; and to transform society from a hierarchy of classes into a classless order of "collective men."

According to Bruce Hopper, ${ }^{1}$ there have been three periods in this development. The first period, that of military communism, saw the destruction of traditional private property and personal rights. The state monopolized large industries, transportation, foreign trade, banking, insurance, and large agricultural estates for the purpose of organizing industry as a single state factory. By 1919 industrial enterprises were being operated by the state on a non-commercial basis and workers were receiving wages in the form of "payok," a card entitling them to food and goods in proportion to the labor credited to them. By 1920 private property had been abolished and money had ceased to be a medium of exchange. Peasants tended to limit production to their own needs, thereby causing the towns to fear starvation. A peasants' strike and famine in 1921 ushered in a second period, that of the new economic policy. Certain restrictions on private capital were removed and money was again made the medium of exchange. This policy was in reality a compromise between the ideological abolition of capitalism and the necessity of using the initiative engendered by private capital to increase production. As a result the private enterprises in 1926-27 controlled 17.2 per cent of the total production in industry, 98.1 per cent in agriculture, 3.3 per cent in wholesale trade, and 35.3 per cent in retail trade. Production had been greatly increased by the new economic policy, but private capital had become a great obstruction to the government's plans.

In 1927 the socialistic offensive, or third period, opened. It attempted to stay redevelopment of capitalism by compelling more collectivism, and to tighten control over all economic life. Foremost was the problem of creating an exportable surplus to pay for imported equipment. In 1925 alone, 10,000 Fordsons were imported. In May, 1929, the tentative five-year plan, in operation since October 1, 1928, was adopted. This plan provided for an increase of 133 per

1 "The Soviet Touchstone: Industrialization," Foreign Affairs, Vol. VIII, pp. 379-98. 
cent in the industrial output, and of 55 per cent in the agricultural. It also envisaged the development of the largest hydro-electric plant in Europe, at a cost of $\$ 115,000,000$; of the Turkestan-Siberian railway (950 miles), at a cost of $\$ 100,000,000$; and of the Volga-Don Canal, at a cost of $\$ 85,000,000$.

There is dissatisfaction among the 125 million peasants, but armed rebellion is virtually impossible, and those who do not like the government's policy may starve. Prices are fixed by the government, which manipulates them so as to increase and decrease the production of certain crops. Political, social, and tax pressures force the peasant to sell to the state although he could receive much higher prices elsewhere. On the other hand, he must pay current prices for industrial retail commodities. Since there is no land tax in our sense of the word, the peasant pays a tax on his estimated production. It is a class tax in that it exempts the very poor peasant, and mulcts the nepmen (private traders) and kulaks (private farm owners). In 192735 per cent of the peasants were exempt from the agricultural tax. The middle peasants, constituting 53 per cent of the total households, paid 39 per cent of the tax, and the kulaks, numbering 12 per cent of households, paid the rest -61 per cent. The belief that taxation is unjustified oppression is so deep-seated that in 1929 a special law had to be passed to restrain the peasants from so subdividing their holdings as to escape taxation entirely.

Since the World War, agricultural conditions seem to be improving. Over 1,080,000,000 acres were taken from the landlords by the peasants during the Revolution, and 48,000,000 acres more were taken from the richest peasants. In 1922 it was reported that 50 per cent of the farms contained 14.5 acres, and 45 per cent from 14.5 to 25.7 acres. Between 96 and 99 per cent of European Russia has passed into the hands of peasants, and about 85 per cent of the people are engaged in agriculture. In 1929 there were about 27,000,000 homesteads, and in 193021.5 per cent of all peasant holdings were joined to the collective farms of the Soviet Union. Agricultural schools are now being established. Thoroughbred stock are being imported in large numbers, and agricultural machinery is being used. The country is now advancing industrially, hydro-electric power is being developed, foreign capital is being invested, and economic conditions will perhaps be much better in the future than they have been in the past. One wonders, however, if the Soviet régime is not neglecting the present too much. 
4. Religious Development. The early Russians were pagans with a variety of vague and indefinite religious ideas. One of their leaders, Vladimir, began his reign as a pagan, but was willing to adopt another religion. He rejected Judaism because the Jews were scattered over the world "for their sins"; Mohammedanism because of its prohibition of the use of wines; and Roman Catholicism because the supreme power rests with the Pope. He accepted the Greek or Byzantine type of Christianity (988), and caused it to be the faith of his domain. In accepting Christianity Russia isolated itself from the Mohammedan and pagan East and allied itself with the West. In accepting the Greek type, however, it perpetuated many Oriental ideas, and imbibed the bitter prejudices against the Roman Catholics.

Like most of the European nations, Russia was long torn by religious strife. Thousands of pagans were murdered because they refused to accept Christianity. No one is able to picture the suffering of the Jews. Massacres, murder, and almost every form of punishment were heaped upon them. Neither did the Roman Catholics, Uniates, or Protestants escape. Under Alexander III Roman Catholics, Uniates, and Protestants were ruthlessly "converted." Dissenter churches could not be built or repaired without permission, which was impossible to secure. Roman Catholic Poles were excluded from government posts and their language placed under ban. The Jews refused to be converted and fared worse than any of the other groups. In 1890 the Jews in the interior were forced to migrate to the western provinces, and were prohibited from owning or leasing land. Free rein was given to anti-Semitism among the peasants and townspeople. Secretly and sometimes openly pogroms, in which thousands of helpless Jews were massacred, were encouraged.

The Russians of Siberia belong mostly to the Orthodox Church, but the aborigines are either pagan or else adhere to other religious faiths. In Transcaucasia members of different Christian sects, Mohammedans, Jews, and persons belonging to other religious groups meet and mingle. The Armenians boast of a Christian church as old as that of Rome. Their religion appears to be a mixture of Roman and Greek theology and practices, with survivals from Iranian paganism. The building of their churches with a hole in the middle of the roof, in order to permit the sun to shine down in the center, may be a survival from the worship of the ancient Iranian sun god. They have been fanatical religionists, and with them, as with the Poles, Irish, and Greeks, religion has taken the form of nationalism. 
The Armenians claim to have once been a powerful independent nation. They came under the Turks during the thirteenth and fourteenth centuries. The Turks began massacring the Armenians in the thirteenth century. In 1894-95 between 100,000 and 200,000 were massacred, and between 1914 and 1918 some 800,000 more. Most people in the United States think that the Turks massacred the Armenians because of religious differences, but it would seem that the disloyalty of the Armenians to the Turkish government and their unreliable business methods caused the massacres rather than a difference in religion. Even though the Georgians adopted a form of Greek Christianity during the sixth century, they seem never to have been massacred because of their religion, despite the fact that their country was overrun and ruled by Turkey before it was proclaimed a Russian province in 1802. Part of the Georgians continued to live in Turkey. The Azerbaijans are mostly Moslems in religion. Practically all the Tartar elements of Central Asia are Mohammedans, and live according to Moslem customs. Since the Bokharans are very strict Moslems, a man seldom sees the face of a woman.

Religion under the Soviet has attracted a great deal of comment both favorable and unfavorable. Lenin, as early as 1905, expressed his belief that all religion is evil. In 1918 a law was passed making religion a private matter, placing church property under political authority, and forbidding religious rites and ceremonies. A number of people, not less than 20, could obtain the use of church property on condition that it be used only for religious purposes, kept in good repair, and that all meetings were always to be open to Soviet officials. This was the beginning of the persecution of the Russian Orthodox Church and its members. It was based on the assumption that religion is the nursery of counter revolution and that all ministers encourage it. Tombs were opened and the relics turned over to museums. All memorial tablets belonging to and perpetuating the memory of members of the imperial family were ordered destroyed. In 1922673 monasteries were closed, and the monks who remained to till the soil were placed under special supervision. In the famine of 1921 the Soviet saw a further excuse for confiscation. The churches were ordered stripped of their valuables and the proceeds were placed in the hands of the state committee for the relief of the famine sufferers. All these things caused the believers to protest so vigorously that the Soviet finally had to stop the pillage. In 1929 citizens were granted the right to profess any creed, but only anti-religious propa- 
ganda was sanctioned. Prior to April, 1921, persecution had been chiefly against the Russian Orthodox Church, but after that date all other churches suffered the same fate.

The Soviet attitude toward the church and its followers has been variously explained. One claim is that such a policy is necessary to break the hold of the church, in order to liberate the masses from the bondage of ignorance and superstition, and to make productive and available wealth that is now withheld from circulation. Critics, analyzing the situation, see in it a compensatory emotional reaction, in which the power long held by the church is now turned against it. Some predict that it is but a part of the general plan to convert the independent farmers into state farm laborers. By banishing religion, the Soviet leaders hope to take from the masses their last form of organization, and by severe punishment they hope to deprive them of the comforts of their religion. Then, broken financially and spiritually, they will be passive to any measure the Soviet may find necessary to impose.

5. Educational Development. Russia's early educational system was molded in a Byzantine pattern. Peter the Great, having become acquainted with the western world, wished to Europeanize Russia. He built St. Petersburg (Leningrad) to connect his country with the West, and moved the seat of government there from Moscow. He made the eleven Russian universities outstanding institutions of learning and research, equipped with the best possible libraries, laboratories, and clinics. Observatories and meteorological and seismological institutes were established; paleontological, zoölogical, anthropological, and ethnological museums were built; and an Asiatic museum with a rare collection of Oriental manuscripts was founded. One would expect such a liberal-minded ruler to try to elevate the masses, but he actually strengthened serfdom. P Peter's successor, Catherine the Great, posed as an advocate of higher learning. She invited European scholars to her court and sought to make the western world believe that Russia was "cultured," but she did nothing for the masses.

Very few of the other rulers of Russia showed much enthusiasm for public education, and as a result Russia was considered the most illiterate country in Europe before the World War. Practically all the Tartars of Siberia are illiterate and live on a low culture plane. Since the Slavs are mostly in pioneering communities and come from one of the most illiterate nations of Europe, the illiteracy rate among 
them is very high. All the cities and most of the towns have schools, but many of the people, especially the non-Slavs, live in isolated village communities and tribal groups which have no schools. Tomsk, the educational center of Siberia, has a very good university with some 2000 students.

The Armenians are about the only large group of people in Transcaucasia who have manifested a considerable interest in education. They have a school attached to almost every church. Their schools have been aided considerably by Americans, and many Armenians have received training in Roberts College, Constantinople. The Georgians rank next to the Armenians in educational interest. Until recently some of the Tartar groups of Siberia and Transcaucasia have not had a written language. Although Bokhara has some Moslem colleges and is spoken of as the educational center of the territory, illiteracy prevails throughout Central Asia. The knowledge of the Tartar element, who claim to be literate, rarely goes beyond the ability to read a few verses of the Koran.

The Soviets are endeavoring to stamp out illiteracy. In 1927-28 137 universities were reported as against 124 in 1926-27. About 50,000 schools for adult illiterates have been running for the last three years, and about 2,700,000 persons each year have been taught to read and write. In 1930 there were about 125,000 schools for "social upbringing," 4400 for giving vocational instruction, and 12,600 for educating pre-school children. Beginning in the summer of 1931, a continuous school year was instituted in many of the schools. In 1928-29 \$500,000,000 was spent for public schools, $\$ 75,000,000$ more than the year before. Experts in education differ regarding the Soviet schools. To some they are outstanding models in educational theory and practice; to others they are instruments for the distribution of communistic propaganda and the indoctrination of pupils.

6. Social Conditions. In the early history of Russia social distinctions seem to have been based on prowess. The period between the middle of the fifteenth century and the second decade of the seventeenth is marked by the disappearance of Tartar power, the ascendency of the boyer military class, the consolidation of large estates, and the appearance of serfdom. Although household servants had long been regarded as chattels, peasants were supposed to be able to move about at will until the sixteenth century. Many of them, however, had become attached to the land. They had become 
heavily indebted to the landowners and the state, and easily slipped into serfdom. When the census was completed in 1628 they had been inscribed, and were thereafter compelled to remain where they were found.

Peter the Great made many changes in Russia. Under penalty of heavy fines, his subjects were forced to substitute German and French clothes for the traditional Russian garb. Peter had the chief potentates assembled so that he might clip off their beards and mustaches. Those who persisted in wearing beards had to pay a heavy tax. He prohibited the Oriental semi-seclusion of women, and made the use of tobacco mandatory. Yet he did not relieve the burdens of the serfs. Catherine extended serfdom to the ends of her domain and gave 800,000 partially free peasants on the state lands to her favorites. Peter and Catherine, however, introduced numerous reforms, and Alexander II continued this process by improving the laws, removing some of the restrictions on the press, establishing more schools, and building railroads. Instead of strengthening serfdom as his predecessors had done, by a series of edicts he liberated the serfs. The emancipation of the serfs, however, was nominal. Whereas the serf had previously been tied to his landlord, he was now tied to the village council and was a "serf of the state."

The peasant believed then, as always, that the land he tended was his. Emancipation was supposed to bring him a piece of land with his freedom, but the distribution of land was largely in the hands of the former masters, who were interested in creating a class of almost landless peasants, who would clamor for employment and thus reduce wages. About 720,000 personal servants received nothing but their freedom; about 640,000 took one-fourth of their allotments without paying anything; others bought their freedom by paying a high price for the first acre of their allotment. As landlords were in no case to lose more than two-thirds of their lands, the peasants received very little. The peasants now had to pay taxes and work at very low wages, and soon many found themselves in a far worse economic condition than serfdom. The peasant population increased rapidly (from around $50,000,000$ in 1860 to $86,000,000$ in 1910), but there was no increase in land. Conditions grew worse, especially during lean years. Discontent became widespread, riots were more frequent, and large numbers of peasant laborers wandered far and wide, working long hours for a few dollars to pay taxes and help support their families. 
Over 80 per cent of Russia's population live in villages. The Russian farmers live in groups that number anywhere from less than 100 to 10,000 , and go out, sometimes long distances, 15 miles or more, to till their fields. The villages consist of rows of houses on each side of a road which serves as a drain and becomes almost impassable during rainy weather. The wooden church with its belfry and five cupolas has long been a characteristic of the village. There is also a "Narodni Dom," or social center, where celebrations are held, weekly movies shown, if the village can afford entertainment, and evening classes conducted. In the north the houses are made of wood; in the south of sun-dried brick. In both sections the gables rather than the front face the road, and entrance is through a gate. In the north the houses and barns are built together or joining, but in the south they are usually separate. Here and there is a house with a tiled roof, usually painted green. It indicates high social status, and a girl is considered fortunate if she can marry into a house of this type. Many houses have dirt floors.

Describing the home life of the peasant, Professor Jerome Davis says: "The little wooden huts with thatched roofs usually contain but one room and a shed. The one room combines kitchen, dining, living and bedrooms, besides being used for a calf-pen, pig-sty, or horse-stall in cold weather. In summer, when the children sleep outside, the doors and windows are open, and the entire family spends the day in the fields, perhaps the one room is adequate. In winter, when all sleep in the one room and the windows and doors are tightly closed, conditions are not so satisfactory, but even then the huge oven on which part of the family sleeps must cause some change of air in the loosely built hut. ${ }^{1}$

During the farming season the peasant arises and works until about nine o'clock. He then eats his breakfast, which consists for the most part of bread and tea. In the south the bread is white, but in the north it is dark, white bread being eaten only on special occasions. About three o'clock the main meal of the day is served. It is composed of several kinds of soups served in a large bowl, out of which all members of the family eat by dipping in their large wooden spoons. Bread, potatoes, and sometimes meat are a part of this meal. At the end of the meal, tea is served to the men in glasses and to the women in cups. The Saturday night bath - or, rather, broil - is almost a sacred necessity. During this broil another member of the family

1 The Russian Immigrant, p. 201. 
beats the bather's back with twigs. As the Russian abhors still water, the water is usually poured while one is bathing.

Prior to the World War there were officially five classes of Russians - nobles, clergy, merchants, burghers, and peasants or moujiks (mughik). These, however, could be reduced to three - nobles, intelligentsia, and peasants. The nobles were the people of rank and property. They were the landlords in the days of serfdom. The intelligentsia were the educated people, many of whom were exiled to Siberia. Since the World War and Revolution, the nobility and intelligentsia have practically disappeared, and Russia has become a land of peasants.

Major W. Evans-Gordon, writing in 1903, gives us a vivid picture of Russian life. The agricultural laborer had to obtain written permission before he could migrate to a neighboring town; once secured, it had to be renewed each year. It was an offense to possess any book except those sanctioned by the government. If a person wished to deliver a lecture on any subject, he was obliged to submit the full text to the Lord-Lieutenant; and everything published in a newspaper had to be approved by the government censor. If one wished to entertain friends in his home he had to secure permission from the police. "Moreover, one hundred and sixty-five saints' days and holidays are recognized by the State, and on these occasions no orthodox Russian may work." 1 Writing of the conditions of Russia, M. J. Rudwin says: "The misfortunes of Russia are darker and deeper, her shrieks of agony are louder and longer, than those of any other country. Her literature is sadder and gloomier than that of any land. . . . If the joys of Russia are bitterly ignored in her literature, it is because in truth they cannot be said to exist: the humorous details in Russian literature often hide a most tragical background, which all of a sudden breaks through. Russian literature is indeed a faithful reflex of the life and character of the land and the people." ${ }^{2}$

Writing of the conditions of the Russians and Ruthenians (Ukrainians), Jerome Davis makes this significant statement: "The Russian and the Ruthenian come from a dark background of misery, poverty, and ignorance. They come from a land but yesterday under the heel of a despot. Education was stifled, the peasants were compelled to live under an oppressive burden of taxation which made poverty almost inevitable and starvation frequent. They were forced into

1 The Alien Immigrant, pp. 50-51, 129-30.

2 Slavonic Nations of Yesterday and Today, edited by M. S. Stanoyevich, p. 71. 
the maelstrom of wars to become cannon fodder over issues about which they cared little, or not at all. It was thus in the recent World War. Russia mobilized sixteen million men; they were snatched from their homes, to which, during three years of war, they often never returned. They served at a wage of twenty-five cents a month instead of thirty-three dollars which our soldiers received in France. They ate out of a common dishpan, seven soldiers dipping their wooden spoons into the same bowl for their noonday meal. There was little or no welfare work done for them; they died like flies. At home their wives struggled alone with the land, accepting without a murmur whatever came of sickness and death; frequently they were entirely without word from their husbands, who might be alive or dead for all they knew. Yet in this war they were treated better than in any of the former wars by which Russia has been afflicted. From such a black background have these Ruthenians and Russians come to us. They have been the victims of religious intolerance, class inequality, economic slavery, political despotism, and compulsory ignorance. A fair chance at the good things of life has been denied them." 1

As in economic, political, and religious affairs, the Soviet has also brought about changes in the social life of the Russians. The church controversy has affected the social life, because under the present laws, written and unwritten, church members cannot collect money for the indigent, establish children's, women's, or literary societies, erect libraries, arrange excursions, or found hospitals lest they shackle the young with religious beliefs. As a result of the antagonism against the church, family life is said to have suffered. The Soviet has sought to destroy the family as a religious union, but the masses still regard church marriage as the only correct union. It is difficult for the orthodox peasant to be born, married, and buried without the services of his church. In the light of these conditions even the "Union of the Godless," the communist organ for religious oppression, had to invent some substitute ceremonies. Such former important days as Easter and Christmas are now used for anti-religious festivities. Thus Russia is now a land of contradictions, adjustments, and maladjustments, fighting for political, religious, economic, and social equilibrium.

Social conditions in Siberia differ widely. Among the Slavic element of western Siberia they are similar to those in European Russia.

1 Russians and Ruthenians in America, pp. 19-20. 
In other parts of Siberia there is a meeting of the Occident and Orient, of Russian and Tartar tribes, of settled agriculturists and nomadic herdsmen and hunters. The Russian sections of the cities are fairly clean and modern, but the other sections have all the filth, scents, and squalor of an Oriental city. In Transcaucasia the cities and homes reveal both Occidental and Oriental influences. Men rule and women are considered their inferiors. Formerly the Circassians often reared girls for the harems and disposed of them for a profit without any feeling of disgrace on the part of their fathers. With all the racial, religious, political, and social differences in Transcaucasia, prejudices, hatreds, and strife abound. In Central Asia various types of society are found, but in general it is that of the Tartar Moslem, colored by nomadism. Practically all the Tartars are Mohammedans. The Bokharans are very strict and do not permit the face of a woman to be seen. In Turkestan the houses are built in two parts, one part for each sex, and men and women do not mingle in cooking or eating. The women seldom venture on the streets, or even beyond the mud walls which surround their houses. The men shave their heads, but do not cut their beards, and wear white turbans and loose flowing gowns. Some cities are walled. The cities and homes are unspeakably filthy, and the people conform to many customs characteristic of a people on a very low plane of civilization.

7. Immigration and Emigration. Fourteen immigrants from the Russian Empire were admitted to the United States in 1820 , and less than 200 in any year until 1846, when 248 were admitted. It was 20 years before this number was again reached, and it was not until 1872 that the number reached 1000 . The number increased to 81,511 in 1892 , and to 291,040 in 1913 (the largest number for any one year). For the decade ending in 1900, 505,290 immigrant aliens were admitted into the United States from Russia, 1,597,306 for the decade ending in 1910, 921,201 for the decade ending in 1920, and 61,742 for the decade ending in 1930 . From 1820 to 1930 a total of $3,341,991$ were admitted. These, like other immigration statistics; doubtless do not represent the true figures. Russia's law did not recognize the right of citizens to emigrate. Evidently large numbers slipped out, and it is possible that many immigrants reported themselves as coming from another country or belonging to another group. Prior to 1899 immigrants from Poland were recorded separately by our Bureau of Immigration. How many of the people reported from Russia were Jews, Poles, Finns, Lithuanians, Letts, Rumanians, we 
do not know. Between 1910 and 1919 1,106,998 people entered the United States who gave Russia as the country of their last permanent residence. Of this number 386,330 were Hebrews, 338,997 Poles, and only 147,281 Russians. According to the 1920 census, 1,400,489 of our foreign-born white population gave Russia as the country of their birth, but only 361,843 gave Russian as their mother tongue. Of this number, 12,117 were from Austria and 8781 from Poland. It is probable that some of these were Hebrews rather than Russians. According to the same census, there were 55,672 Ruthenians in the United States. Of this number, 43,534 were from Poland and 7452 from Austria. It is evident that many people of Russian stock came from Russia's neighbors. Only about one-tenth of the Ruthenians live in the territory formerly belonging to Austria-Hungary; yet in 190575 per cent of our Ruthenians came from Austria, 22 per cent from Hungary, and less than 200 from Russia. Some Austrian provinces lost 15 per cent of their population by emigration in one decade.

In 1880 both Kansas and the Dakota territory reported large numbers of Russians. Since about 92 per cent of the Russians were peasants, it is possible that most of them engaged in agricultural pursuits. A change, however, soon took place, and the Russians turned to our industrial centers, settling mainly in New York, Pennsylvania, Illinois, Massachusetts, and New Jersey. Apparently the chief cause of the emigration from Russia has been economic, but political conditions also have played an important part. During the Revolution a large number of the intelligentsia escaped to the United States. About 65 per cent of the Russian immigrants have been males, and only about 40 per cent have become naturalized. Our present law permits 2784 Russians to come here each year as immigrants, 536 more than the two per cent law. Russian immigrants composed 19.4 per cent of our immigrants from Europe for the decade ending in 1910.

Perhaps four-fifths of the Russian overseas emigrants went to the United States, but Brazil, Canada, and Argentina have also received considerable numbers. In 189029,226 went to Brazil and in 1891 10,051. In 1913 Canada received 17,433, and in 1912 Argentina received 15,274. Russia granted its citizens short-dated passports for seasonal emigration. The number of these was 71,428 in 1898,283 ,536 in $1902,493,260$ in $1906,636,826$ in 1910 , and 849,792 in 1913.

Doubtless the greatest volunteer population movement in all history occurred in Russia in 1908, when in the first ten months of that 
year approximately 720,000 people left European Russia for Siberia. After the building of the Trans-Siberian railway, the longest railroad in the world (over 6800 miles), the population of Siberia doubled in 15 years, while that of the maritime provinces tripled; that of Vladivostok increased from 30,000 to 120,000. Between 1907 and 1913 the Russians were moving into Siberia at the rate of from one-fourth to three-fourths of a million per year. The government fostered homesteading in Siberia to help solve the acute agrarian problem and better enable it to hold Siberia. An effort was made to keep the Manchese, Koreans, Chinese, and Japanese out by rapid settlement with Russians, but thousands moved in. The present Russian government is making soil surveys and trying to locate Russian settlers advantageously. Most of the people have settled in what is known as the black soil belt along the Trans-Siberian railway, and in the valleys of the Ob, Yenisei, Lena, and Amur rivers. This movement differs from the movement to the United States in that those who came here were mainly of the so-called "aliens" from the western border, while those who went to Siberia were mainly of Slavic stock from central European Russia. Perhaps not over 4 per cent of those who came here and gave Russia as the country of their last permanent residence were Russians in the strict sense.

Since Siberia and Russian Central Asia are vast, sparsely settled countries, it is probable that Russian emigrants would not go to the United States in large numbers if there were no restrictive laws. Baievsky ${ }^{1}$ estimates that southern Siberia (proper) can accommodate $4,000,000$ farmer families, or about $20,000,000$ in addition to its present population of $15,000,000$. Additional immigrants are needed for manufacturing. Southern Siberia can well take care of from 40,000,000 to $50,000,000$.

With the exception of Armenians, emigrants to the United States from Siberia, Transcaucasia, and Central Asia appear not to be important. If any other groups have come they have been included under Russia, Turkey, or other countries. Doubtless a number of convicts and exiles from Siberia have fled to the United States, and since the Revolution a number of the intelligentsia have thus escaped. Most of the Armenian immigrants have come here within the last three or four decades. According to records, "Martin the Armenian" was a member of the Jamestown colony in 1619, but the stream of

1 "Siberia - The Storehouse of the Future," Economic Geography, Vol. III, pp. 167-92. 
Armenians did not really begin to flow until after the massacres in 1894. Only 2644 came in 1907 , and 26,498 in the twelve-year period ending in 1910. In 1920 there were 37,647 foreign-born people in the United States who gave Armenian as their mother tongue. Since the World War and Armenian union with Russia, very few Armenians have come to the United States - only 89 for the six-year period ending in 1930. The disagreements between the Armenians and Turks, and the resultant massacres, seem to have been the chief causes for the Armenian emigration. The Armenians have settled mostly in California and Massachusetts. Around Fresno, California, they are extensively engaged in growing raisins, fruits, and truck.

\section{QUESTIONS, EXERCISES, AND PROBLEMS FOR INVESTIGATION}

1. Of what does the Soviet Union consist?

2. Characterize Russia's "motley family," and describe Russia's population problem. Besides the text, see Ripley, W. Z.: The Races of Europe, Chap. XIII; Pittard, Eugène: Race and History, Part II, Chap. XI; Dictionary of Races or People; Semenov-Tian-Shansky, B.: "Russia: Territory and Population: A Perspective on the Census of 1926," Geographical Review, Vol. XVIII; Baievsky, Boris: "Siberia - The Storehouse of the Future," Economic Geography, Vol. III, pp. 167-92.

3. Show the geographic and political importance of Siberia. Of Transcaucasia. Of Central Asia.

4. What cultures penetrated into Russia? Which made a more lasting impression? Where were the main centers of cultural life in European Russia during the ninth century?

5. Explain the working of the Soviet Republics.

6. What have been some of the major economic problems of the Soviet? Discuss the periods of economic development under the Soviet. What are some of the points of dissatisfaction with the new economic policy?

7. Explain the significance of Russia's adaptation of the Greek type of Christianity. Describe the religious practices of the Siberians. To what religious groups do the people of Central Asia chiefly belong?

Outline the rôle of the church under the Soviet Union.

8. Account for the Byzantine pattern in education and show how the Soviets are trying to stamp out illiteracy.

9. Show how the serfs gradually lost their political rights.

10. Describe a typical Russian village. Into what social classes were the people divided prior to the World War?

11. Show how social conditions vary in different parts of the Soviet. 
12. Give a résumé of Ruhl, Arthur: "Russians and Baltic Peoples," Chap. XIV, in Immigrant Backgrounds, edited by H. P. Fairchild.

13. Abstract Wang, Ching-Chung: "The Dispute between Russia and China," Nineteenth Century, Vol. CVII, pp. 167-78.

14. Discuss the economic situation in the Soviet Union. References. Earle, F. M.: "Mechanization of Agriculture in U.S.S. R.," Economic Geography, Vol. VII, pp. 296-307; Harper, S. N.: "The Soviet FiveYear Plan," Proceedings of the Academy of Political Science, Vol. XIV, pp. 83-96; Goudkoff, P. P.: "Economic Geography of the Coal Resources of Asiatic Russia," Geographical Review, Vol. XIII, pp. 283-93; "Russia's New Economic Divisions," Foreign Affairs, Vol. IV, pp. 331-33; Hopper, Bruce C.: "The Soviet Touchstone: Industrialization," Foreign Affairs, Vol. VIII, pp. 379-98; Liubimov, N.: "The Soviets and Foreign Concessions," Foreign Affairs, Vol. IX, pp. 95105; Hopper, Bruce C.: "Soviet Economy in a New Phase," Foreign Affairs, Vol. X, pp. 453-64.

15. According to J. A. Mackenzie, what is the present crisis in Russia? ("The New Crisis in Russia," Nineteenth Century, Vol. CV, pp. 74756. See also Chernov, V.: "Russia's Two Parties," Foreign Affairs, Vol. IX, pp. 79-94.)

16. Trace the expansion of Russia across Asia, showing its important footholds. Reference. Gibbons, H. A.: The New Map of Asia, Chap. XV.

17. Trace the development of the anti-religious sentiment in Russia. Reference. Ganfman, M. I.: "Religious Persecution in Russia," Fortnightly Review, Vol. CXXVII, pp. 441-63.

18. Describe the Russian peasant, noting especially the change that has taken place in his status. References. Chamberlin, W. H.: "The Russian Peasant Sphinx," Foreign Affairs, Vol. VII, pp. 477-87, and "Daughters of the Russian Revolution," Yale Review, Vol. XVIII, pp. 732-48; Calverton, V. F.: "Sociological Aesthetics of the Bolsheviki," American Journal of Sociology, Vol. XXXV, pp. 383-92; Zenzinov, Vladimir: "The Bolsheviks and the Peasant," Foreign Affairs, Vol. IV, pp. 134-45; Wilcox, E. H.: "Who Has a Good Time in Russia?" Nineteenth Century, Vol. CIV, pp. 184-94.

19. Discuss the environmental conditions surrounding communist leaders. Reference. Davis, Jerome: "A Study of One Hundred and Sixty-Three Outstanding Communistic Leaders," Publications of the American Sociological Society, Vol. XXIV, pp. 42-55.

20. Make a statistical study of Russian emigration. (See Ferenczi, Imre: International Migrations, Vol. I.) 


\section{CHAPTER XVIII}

\section{POLAND}

1. General Description. Poland is another war-born republic. It is a little larger than Montana, having an area of 149,140 square miles. Of its present territory, 43,804 square miles formerly belonged to Russia, 30,481 to Austria, and 17,789 to Germany. The "plebiscite" in Silesia and eastern Prussia and the seizure of the Vilna area from Lithuania added considerably more territory. Some boundaries are yet undetermined. Official estimate in 1929 placed the population of Poland at $30,840,247$. In 1922 its population of $27,372,447$ contained 3,789,000 Ukrainians, 2,126,000 Jews, 1,559,000 White Ruthenians (Russians), and 1,033,000 Germans. Thus, only 69.2 per cent of the population was Polish, and in some districts less than 10 per cent. Warsaw, the capital, had a population of $1,086,305$ in 1929. Poland has 40 cities with a population of 25,000 or more. A little over 24 per cent of the people live in cities. Population density is 182 people per square mile. In population Poland is the sixth nation of Europe.

The Poles compose the western division of the Slavs. It is not known how long they have inhabited their present area. The Phœnicians followed the Vistula River and found people inhabiting that region, but it is not certain that these were the ancestors of the present Poles. Our earliest knowledge is of some eight loosely connected warlike tribes inhabiting the territory west and east of the Vistula River, between the Baltic Sea and Carpathian Mountains. This location early brought them into contact with both eastern and western civilization, and subjected them to invasions of Lithuanians, Germans, Hungarians, Tartars, and other Asiatic mongrels. Many of these people were absorbed by the Poles, who are consequently a very mixed group. Anthropologists think there are at least four distinct groups among them.

Except for a small outlet to the Baltic Sea, Poland is surrounded by six neighbors - Latvia, Lithuania, Russia, Rumania, Germany, and Czechoslovakia - with whom it may quarrel. Barring the Tatra range of the Carpathians, which reaches an elevation of 8000 feet, 
the country is an almost unbroken plain, across which three glaciers have moved. The climate is temperate, with abundant rainfall and heavy snows. The soil is generally poor.

2. Political Development. The early Poles lived in tribes ruled by chiefs, and with the exception of a few serfs, all were supposed to have been equal. The pressure of the better organized German tribes brought the Poles into a loose federation, but the organization was too weak to withstand the attacks of the Teutons, and gradually the Poles passed under the sway of the Holy Roman Empire. For some time, however, two pagan dynasties, known as Piasts and Popiels, ruled. Historically Poland may be said to have been born when Mieszko I (960-92) laid the foundation for its future greatness. His baptism and marriage to the daughter of the Bohemian king removed the excuse for invasions by Germans, and caused Poland to become a "treasure-house of Latin civilization." His son, Boleslaw (Boleslaus) I (992-1025), continued his policies by enlarging Poland's territory through the incorporation of neighboring Slavic tribes, and by establishing its political and ecclesiastical independence of Germany. After his death, however, wars with neighboring countries followed in quick succession and caused Poland to suffer serious territorial losses. Germany took Lusatia, Bohemia, and Moravia; Hungary acquired Slovakia, Kilo, and eastern Galicia; and Denmark gained Pomerania. Mieszko II was followed by Kazimir I (Casimir the Restorer, 1040-58), who united all the territories inhabited by pure Poles. The centralization of state and church authorities and the exploitation of the people by the feudal lords and clergy, however, caused a great deal of dissatisfaction. The masses revolted, demolished and burned the churches, monasteries, and cities, murdered many priests and monks, and returned to paganism.

Boleslaw III (1102-39) divided Poland among four of his sons. This led to civil wars and ultimately to the passing of Poland as a nation. A group of autonomous units was formed with only language, religion, and common traditions to remind them of kinship. Tartar hordes invaded the country and thereby united the Poles, but the land was laid waste so completely that Polish landlords settled their domains with German colonists, and German knights who had been expelled from Hungary were invited to settle in the country in order that they might conquer the heathen Prussians. Later the Pope attempted to expel the knights, but the order refused to leave and remained as masters of Prussia. The knights and colonists intro- 
duced the German form of local self-government in different parts of Poland and thus complicated the political situation.

The thirteenth century marks the passing of the first Dark Ages of Poland. The period from 1306 to 1586 was one of such growing power, influence, and prosperity that the sixteenth century is spoken of as Poland's Golden Age. With the aid of the Hungarians, Wladyslaw I united Great and Little Poland and was crowned king in 1320. Through the marriage of his sons and daughters, he effected skilful foreign alliances. His son Kazimir III (1333-70) fought with the German knights but left them in possession of Pomerania, which shut Poland off from the Baltic until the territory was retaken in the fifteenth century. He ceded the western part of Silesia - "the pearl of the Polish crown" - to Bohemia. However, he attached Ruthenia to Poland and brought about such a strong union that it is said that he "had found a Poland of wood and left it of stone." At his death it was a rich and influential country, allied with the powerful Hungary, and a basis had been laid for a union with Lithuania through the marriage of Jadwiga (Hedwig), daughter of King Louis of Hungary, to the Grand Duke Jagiello (Jagello) of Lithuania. After the World War the Czechs claimed Silesia on these grounds.

During this period of greatness, nations flocked to Poland for protection and alliance. Its sphere of protection included Livonia, the Russian territory almost to Moscow, the region around the Black Sea, Moldavia, Moravia, Bohemia, Prussia, Brandenburg, and Pomerania - the bulk of the land of central Europe - and made it the most powerful country of all Europe. Within these countries lived many ethnic groups, such as Slavs, Lithuanians, Germans, Jews, Tartars, and Armenians, each being autonomous but under the protection of the Polish government.

This Golden Age was followed by a period of rapid decay, culminating in the three partitions. It was a period marked by entangling alliances, political bargaining and bribery, and religious reaction and intolerance which crushed out most of the intellectual life of the nation. Poland began to lose territory. Anarchy spread rapidly. The corruption of officials gave the great powers an opportunity to conquer and divide the country on the ground that the Poles were incapable of ruling themselves. Russia and Prussia shared in the three partitions which took place in 1772, 1793, and 1795. Austria shared in the first and last.

At the first dismemberment Poland lost more than a fourth of its 
territory and over a third of its population. It tried to reorganize its government to prevent a further dismemberment, but certain powerful nobles plotted with Russia and Prussia, stirred up further strife, and brought about the second partition. Kosciuszko, a hero of the American Revolution, was created general-in-chief of the army and tried to save the remainder of Poland, but his efforts failed and Poland disappeared as an independent nation in 1795 .

Soon after the partitions, the three nations made efforts to absorb the Poles into their respective nationalities. At first Austria was very autocratic in dealing with the Poles, while Russia and Prussia were very liberal, but soon each reversed its position. The Poles were forbidden to use their own language, and forced to go to the German and Russian schools. To go to the German schools meant to become Germanized and Lutheranized; to go to Russian schools meant to become Russianized and Eastern Orthodox in religion. Germany adopted a method of scattering the Poles by buying part of their land and settling Germans in the territory. All Polish schools were suppressed; the Catechism had to be learned in German; German names were substituted for Polish cities and villages. Germany, however, soon saw its mistake, changed its policy, and became very liberal toward the Poles. But the Poles were not satisfied, and in 1906-07 over 100,000 school children struck for eight months against the Germanizing of their religious instruction. At first the Poles had the sympathy of a large element of the liberal-minded Germans, but they caused so much disturbance that even the radicals lost patience with them. Although Germany did use certain repressive measures, it developed agriculture and commerce among them, afforded them good economic opportunities, and offered them excellent schools, even if in another language.

Austria, being Roman Catholic in religion, did not try to change the religion of the Poles. But it reduced their rich country to a state of poverty, and at first forced the people to use German in the schools. Later it lightened the burdens of the peasants through a reduction of taxes and hours of labor, but nothing appeared to satisfy the Poles.

Russia began by being liberal in its treatment of the Poles, and under Paul I a plan was adopted to give them autonomous government under the protection of Russia. Continued disharmonies between Russians and Poles, however, caused Russia to become more and more repressive. The government of the territory was taken 
over completely by Russians, the use of the Polish language was forbidden, and most of the universities were closed.

Catherine the Great is reported to have hanged priests, noblemen, little children, and dogs on the same gallows in order to teach the Poles not to resist Russia. They rebelled in 1831 and brought a rule of the sword upon themselves. Those who dared to use the Polish language or wear their national costume were severely whipped. Children as young as seven years of age were taken to form the "enfants de troupe" in the Russian army. The Poles rebelled again in 1863, but this only resulted in "orgies, floggings, massacres, torture; wild Cossacks shooting and sabring in the streets; a vast crowd, men and women and children, kneeling in the snow before the palace and praying to God for Poland, till the last of them was mowed down by the cannon or crushed to death under the horses' hoofs, and the snow was scarlet . . . and the waters of the Vistula were foul with corpses." 1

Polish history is certainly one of bloodshed. How much of it has been due to Poland's aggressive determination cannot be stated. Immediately after the partitions secret treasonable societies were organized and secret conferences were established with headquarters shifting from Cracow to Leipzig, Venice, Constantinople, and finally Paris. Thousands of Polish soldiers served in the French army, believing themselves to be helping to restore Polish independence. In the World War German and Austrian Poles were forced to fight Russian Poles, and their country became a vast bloody battlefield. As a result of the struggle, Poland was reborn and its independence established after 125 years.

Poland is governed by a constitution and a two-chamber legislative body. The president is elected by Parliament for a term of seven years. Universal suffrage and a system of proportional representation are in force. The political aspiration of the Poles is revealed by the fact that in the election in 1928 there were 2000 candidates, representing 34 parties, for 444 seats in the Diet (Sejm). In affairs of state they display instability. The overthrow of the government in 1926 by Pilsudski, the seizure of Lithuanian territory by Zeligowski, the occupation of East Galicia, the acquisition of territory by fraudulent "plebiscites," the encroachment on the Free City of Danzig, Poland's disregard of the authority of the League of Nations, its continued persecution of the Jews, and its

1 Slavonic Nations of Yesterday and Today, edited by M. S. Stanoyevich, p. 215. 
frequent quarrels with its neighbors - all these lead the thoughtful observer to the conclusion that Poland is still a storm center. It has the support of France and as a result "violates treaties, offends laws of international usage, and is protected in everything she does." 1 Nitti shows that, despite all the trickery of Poland, Upper Silesia voted to join Germany. But the powers permitted Poland to take it, thus making the Treaty of Versailles a "scrap of paper."

3. Economic Development. About 48.6 per cent of Poland's area is in arable land, 24.1 per cent in forests, and 16.9 per cent in pastures. Poland is, therefore, an agricultural and stock-raising country. Some 65 per cent of the people are engaged in tilling the soil. Like most other countries it has had to struggle with the problem of large estates. In the fifteenth century townspeople and peasantry were excluded from owning landed estates and were required to dispose of their lands as speedily as convenient. Under the Land Reform Act of 1920 about 1,000,000 acres were taken over by the government for redistribution. According to estimates 15 per cent of the people who till the soil owned no land in 1920. From 1919 to 1927 about 3,335,512 acres were parceled out. In parts of Poland agriculture is very poorly developed, but in others, especially the section formerly belonging to Germany, it is highly developed. The chief crops are potatoes, rye, oats, barley, and wheat. In 1924 Poland produced about one-fourth of the world's potato crop.

Poland has long engaged in manufacturing and commerce. The Vistula River is a good waterway, but Poland has been handicapped by being shut off from the Baltic, as a result of losing Prussia to the German knights and later to Germany, and by being shut off from the Black Sea, through the loss of Bessarabia to the Turks. Some of Poland's cities, as Lodz, are highly industrialized. The country is now rich in forests, coal, oil, salt, iron, zinc, and lead, and thousands of people are engaged in the development of these resources. In Galicia Poland acquired rich oil fields; in Upper Silesia it obtained enough coal to mine 50 million tons per year for 300 years, practically all the zinc mines, which produce 18 per cent of the world's zinc, most of the iron industry, with 22 of the 36 blast furnaces, and the railways. Acquisition of the southeastern section of Upper Silesia in 1922 brought another rich coal field, which is producing over 30 million tons per year. The textile industry centers in Lwow (Lem${ }^{1}$ Nitti, F.: The Wreck of Europe, p. 183. 
berg), which has around 900,000 spindles. Thus the economic future of Poland is bright.

4. Religious Development. The early Polish tribes were pagan. In order to win a wife, Miezko I received baptism and introduced Christianity among the Poles. German monks and knights aided in the Christianizing process, but most of the religious teachers came from Bohemia. After the accession of Kazimir I, the unification of church and state permitted the clergy and nobles to oppress the peasants. They revolted and returned to paganism. The Prussians were the most obstinate in their paganism, and the German knights were called in to crush and convert them. The clergy became wealthy and powerful. They secured large tracts of land upon which the serfs were forced to labor, held their land tax free, and, until Pope Innocent III in 1215 insisted on celibacy of the priesthood, produced large families. When Kazimir III became king, he tried by diverse means to turn his Galician subjects from the Eastern Orthodox Church to the Roman Catholic, but had little success.

The Reformation spread rapidly over Poland, and although rather short-lived, it aided Poland in becoming the most liberal and most advanced nation of Europe. Sects of various kinds sprang up and found a substantial following. Many Catholics were in sympathy with Protestant ideas and spread them from their churches. The Protestant element soon became strong enough to demand absolute toleration and equality for all sects except the anti-Trinitarians (Arians who were finally banished in 1658). Liberals and persecuted Protestants flocked to Poland, "the most liberal republic of all Europe." Soon a reaction set in and liberals and Protestants were again persecuted, and finally lost their freedom. In 1717 the Diet prohibited the building or repairing of Protestant (dissident) churches in Poland, and in 1736 Protestants were forbidden to hold any public office and to hold public meetings. In 1767 Russia, supported by England, Denmark, Prussia, and Sweden, forced the Poles to restore equal rights to dissidents.

After the partitions, Catholicism became the chief means of resisting assimilation into other groups. In fact, Roman Catholicism and nationalism came to be so much the same thing among the Poles that Protestants and Jews practically lost all feeling of nationalism. They were hated and persecuted not so much because they were Protestants and Jews as because they were non-Catholics, and therefore non-Polish. Wherever the Catholic Poles have gone, they have 
made their church a symbol of nationalism and continued to rally around it.

Although the new constitution guarantees freedom of religion, Poland remains largely Roman Catholic, and Jews and Protestants continue to be discriminated against. Roman Catholics number 63.9 per cent of the population, Greek Catholics (Uniates) 11.2, Jews 10.5, Eastern Orthodox 10.5, and Protestants 3.7.

5. Educational Development. Poland early became famous as an educational center. The University of Cracow (Alma Mater of Copernicus) was founded in 1364, and is the second oldest university in central Europe. Persecution of liberals by the religious forces brought about the intellectual decadence of Poland. After the partitions, the Poles sank lower and lower in the intellectual scale until they became an illiterate mass of religious fanatics. Their conquerors closed most of their schools on the ground that they were fostering Polish patriotism, teaching disloyalty to the ruling nations, and preventing assimilation; and largely because they feared nonCatholic ideas, the priests encouraged the people to keep their children away from other schools. This resulted in illiteracy and ignorance.

Since Poland has regained its freedom, it has been making a strong effort to eradicate illiteracy. All education is free, and school attendance is compulsory for all elementary school children between the ages of 7 and 14. Minorities are permitted to have their own language schools, but the Polish language must be taught in all nonPolish elementary schools, and Polish history must be taught in the secondary schools. Religious instruction is compulsory in all elementary schools. The different religious bodies are responsible for the instruction of their respective communicants, and their clergymen are compensated by the school authorities. This education, however, is always subject to the supervision of the state. Poland has six universities and two polytechnic institutes. The University of Warsaw has about 10,000 students.

6. Social Conditions. Polish tribal society consisted of a few serfs and a mass of free citizens. Gradually a caste system of knights, clergy, and peasants developed. The German colonists introduced autonomous municipal government where they settled, and as a result another class, the burgesses, composed of merchants, developed and gradually broke down the old three-class system. The Jews came to compose a society of their own, though they might be classed 
with the burgesses. They monopolized trade and made usurious loans to the peasants. When the parliamentary form of government was established, it came to be so dominated by the nobility that they considered that they alone constituted the nation. For a time there were clear social distinctions between clergy and nobility, but after peasants were prohibited from becoming clergymen, the clergy and nobles united in oppressing the peasants.

The nobility and clergy did no manual labor, but spent their time in social activities, politics, intellectual pursuits, and in oppressing the peasants. The Jews dwelt mostly in the towns and cities and constituted the bulk of the mercantile class. The peasants spent their time tilling the soil to eke out a bare existence. From the beginning the peasants had few liberties, and gradually lost most of those, especially during the period from 1374 to 1569 . At first two sons had the right to leave their district, but this small number was reduced to one and then none. Thus the peasants came to be tied to the soil. If a peasant could escape his master for a year he was free, but this law was changed, and fugitive peasants could be captured at any time. The work a peasant was obliged to do for his master left little time for anything else. Finally, he lost his last legal rights and had no court to which he could appeal to gain justice. He had to grind his corn at the master's mill, buy from his store, sell at his market, work at his bidding, and even be killed if he so ordered. All this was the master's business, and his alone. In 1794 Kosciuszko ruled that peasants were free to leave their masters if they paid their taxes and debts. This brought back to them certain rights and led to greater liberties.

The modern peasant class, from whom we have received most of our 4,000,000 Poles, led a very simple life. Many of them owned small strips of land, averaging seven acres, despite the fact that according to estimates thirteen acres was the smallest amount on which a peasant could support his family. Occasionally he could work for a few days on a large estate, but wages were very small, and church holidays so numerous, averaging from 100 to 200 per year, that only about five months remained for making his living.

The nobles and clergy oppressed the peasants and led them to believe their horrible condition was caused by the Jews. As a result the peasants added spice to their monotonous life by engaging in pogroms, in which thousands of helpless Jews were murdered.

The peasants' food consists chiefly of such vegetables as they can 
grow in their own gardens or fields; meat is rare and a delicacy to be enjoyed only in winter, when a pig is killed, or on special festival occasions and holidays. The peasants' clothes are chiefly homemade. Shoes and hats are not worn a large part of the time. Church fairs, weddings, christenings, village dances, and neighborhood visiting are the principal forms of recreation. Houses usually have one story, and are made of stone, logs, or plank, daubed with mud and whitewashed. The roofs are either thatched or made of mud, and covered with moss. The interior generally has two parts separated by an open hall. On one side the family - often more than one family cook, eat, sleep, and live. The other shelters the live stock and poultry of the farm.

Industrialism, urbanization, German, Austrian, and Russian rule, and the World War have wrought havoc with class distinctions and changed the Poles' outlook on life. There is a residue of sentimentality for people of noble birth, corresponding to our Mayflowerism, but distinctions today, as in America, are based chiefly on wealth. Under the new republic all citizens are supposed to have the same political, religious, industrial, educational, and social rights. Social distinctions, however, are difficult to regulate.

7. Immigration and Emigration. Polish emigration has been closely linked with Polish history. After each war, insurrection, and partition, a larger number of people emigrated. How many have left their native land, permanently or temporarily, we do not know. In 1929 the total emigration was 243,442, and in 1930 218,387. Poles began to come to the United States early, and three were outstanding in the American Revolution. Not over 5 per year came before 1831, and less than 100 per year thereafter until 1851. In 18733338 came; in 189240,536 . For the period 1899-1919 Polish immigrants were included with those from Austria-Hungary, Germany, and Russia, according to the country from which they came. According to the best statistics we have, 138,033 came in 1907 and 174,365 in 1913 . In 1921 95,089 came, in 1924 28,806, and in 1930 9231. In 1920 Poles ranked fourth in number among our immigrants, with 1,139,978. Between 1921 and 1930227,734 came. Wilkinson ${ }^{1}$ estimates that there are 3,000,000 Poles in North America at the present time. Our present law permits 6524 immigrants from Poland each year, 542 more than the two per cent law.

How many of the people given in the statistics are Poles we do not 1 The World's Population Problems and a White Australia, p. 26. 
know. About 1885 Russia prohibited all emigration except that of Poles and Jews, and it is probable that a number of Russians, Germans, Lithuanians, and others came as Poles. On the other hand, doubtless many Poles from Germany and Austria came as Germans and Austrians. In 1920 there were 1,077,392 people in the United States who gave Polish as their mother tongue. According to the same census, only 922,812 of the $1,139,978$ of our foreign-born white population giving Poland as the land of their birth gave Polish as their mother tongue; 114,362 gave Hebrew, 43,534 Ruthenian, and 38,179 German. On the other hand, 43,618 Poles came from Austria, 27,853 from Germany, and 72,065 from Russia.

Polish emigrants also go to other countries, especially to Canada, Argentina, Brazil, and Palestine. In 1910 Canada received 2177 immigrants from Poland and around 10,000 in 1912 and in 1913. For the fiscal year ending March, 1929, 8515 immigrants of Polish origin arrived, and for the year ending March, 1930, 6837. Argentina received 2407 in 1921 and 9938 in 1923 . The number going to Palestine from 1922 to 1924 ranged from 2252 to 5702. Undoubtedly these were Jews. Apparently the emigration from Poland had shifted from the United States. Ferenczi ${ }^{1}$ says: "In 1921 about four-fifths of the Polish emigrants went to the States, but in 1924 only one-fifth. In the latter year Argentina and Palestine received more than the United States. Brazil and Canada each received about one-tenth." According to the statistics of the United States, about 40 per cent of the Polish immigrants return to Poland. In some years large numbers go back; for example, 46,727 in 1908, 42,207 in 1921, and 31,004 in 1922.

There has also been a considerable movement of Polish people into other European countries. These are mostly seasonal laborers, who formerly went to Germany, but now go to France. The number is given as 254,895 in $1908,377,674$ in $1913,26,846$ in $1920,72,020$ in 1923, and 52,082 in 1924. Dr. Leon Wernic ${ }^{2}$ estimates that after the World War, over half a million Poles went to France in addition to those who went to Germany and America.

The Poles who have come to the United States have settled mostly in our large industrial cities, where they have maintained the highest birth and infant mortality rates of any of our immigrant groups.

1 International Migrations, Vol. I, p. 127.

2 Proceedings of the World Population Conference, 1927, edited by Margaret Sanger, p. 301. 
According to the 1920 census, Poles ranked first in the number of foreign-born in Chicago, Buffalo, Cleveland; second in Milwaukee and Detroit; third in Baltimore, Jersey City, and Pittsburgh; fourth in Newark; and fifth in New York and Philadelphia. The Poles who have come to us have been for the most part ignorant and illiterate peasants. They have been so accustomed to primary group contacts and subjection to other nations that they have become introverts and tend to view everything subjectively. They bring with them a baffled wish, an inferiority complex, and a mild state of psychosis. They have three outstanding characteristics.

First, they are extreme nationalists. They came to America for one chief purpose, and that was to help restore Poland. They had little intention of remaining in America permanently or of becoming citizens. They wished to better their economic status, and to do so were willing to exist on a very low plane, quite often lower than the one to which they were habituated in Poland. America, therefore, was the recruiting ground for Poland's battles. The Polish American Society - "the Fourth Division of Poland" - tried to shield them from the contaminating influence of Americanization and to send them home with unspoiled loyalty. That some 60 per cent remained here permanently, and that some 28 per cent became citizens, is under the circumstances remarkable, and shows that part of them have at least partially adjusted themselves to American life.

Second, they are Roman Catholics and remain so. America dechurches many immigrants, but the Poles and Irish remain faithful to the Catholic Church, which has long been the symbol for their patriotism and remains so in America.

Third, they speak Polish and teach it to their children. They lost their country, but their religion and language came to have imponderable values, and to give up either would be to give up their patriotism.

Now that Poland has regained its freedom, no one can predict the attitude the Polish immigrants of the future will bring with them. Instead of talking of the glories that were once Poland's, they are looking for another Golden Age. That they are still persecuting the Jews is shown by the fact that about 95 per cent of our present immigrants from Poland are Jews. 


\section{QUESTIONS, EXERCISES, AND PROBLEMS FOR INVESTIGATION}

1. Explain: "Poland is another war-born republic," and "Geographically her present position is not enviable." See "The Polish Corridor," Fortnightly Review, Vol. CXXIV, pp. 155-73; Harley, J. H.: "Poland and the Peace," Fortnightly Review, Vol. CXIV, pp. 104-12.

2. Make a study of the ethnic history of Poland. Besides the text, see Dictionary of Races or Peoples; Pittard, Eugène: Race and History, pp. 221-62, passim; Ripley, W. Z.: The Races of Europe, Chap. XIII, passim; Bowman, I.: The New World, Chap. XX; Romer, E.: "The Population of Poland according to the Census of 1921," Geographical Review, Vol. XIII, pp. 398-412; Znaniecki, F.: "The Poles," Chap. XIII in Immigrant Backgrounds, edited by H. P. Fairchild.

3. Compare the treatment of the Poles by the various countries after the divisions of Poland.

4. Account for the degree to which Poland's agriculture and industry have developed. See Arctowski, H.: "Agriculture and Landownership in Poland," Geographical Review, Vol. XI, pp. 161-71; Romer, E.: "Poland: The Land and the State," ibid., Vol. IV, pp. 6-25; Chmielewski, Z., and Wilczewski, W.: "Agricultural Co-operation in Poland," International Review of Agricultural Economics, 1925, pp. 499517.

5. (1) Describe the struggle between paganism and Christianity. (2) What did the Protestant Revolution mean to Poland? (3) Account for the rise of Catholicism and its symbolism of nationalism. See Fox, Paul: "The Reformation in Poland: Some Social and Economic Aspects," Johns Hopkins University Studies in Historical and Political Science, Vol. XLII, No. 4.

6. Describe the social background from which most of our Polish immigrants come.

7. Why have the Poles emigrated? Characterize the Polish immigrant.

8. What changes are likely to take place in Polish immigrant attitudes, and how will these affect adjustment to American life? 


\section{CHAPTER XIX}

\section{CZECHOSLOVAKIA}

1. General Description. Czechoslovakia is another war-born republic. It consists of the ancient Bohemian Kingdom (Bohemia, Moravia, and a part of Silesia, which formerly belonged to Austria), the upper part of the former Hungarian Empire, known as Slovakia, and Carpathian Russinia, or the western part of the Teschen (Decim) district. The latter is an autonomous part of the republic.

Lying in central Europe, Czechoslovakia may be viewed as a Slavic peninsula projecting far into the Teutonic world. It embraces a strip of territory about 600 miles long and from 50 to 125 miles broad, bordered by Germany, Austria, Hungary, Rumania, and Poland.

Czechoslovakia contains 54,207 square miles, is a little larger than Arkansas, and in 1930 had a population of 14,726,158. Praha (Prague), the capital and largest city, had a population of 848,081 . According to the 1921 census, only about $6,000,000$ of the population were Czechs (Bohemians and Moravians) and about 2,000,000 were Slovaks. The remainder of the population was divided as follows: Germans, 3,123,568; Magyars (Hungarians), 745,431; Ruthenians, 461,849; Jews, 180,855; Poles, 75,853; all others, 25,871. Thus, around 35 per cent of the people were neither Czechs nor Slovaks. Only about 10 per cent of the national boundary follows the outer settlement of the Czechoslovakian people. As Nitti ${ }^{1}$ points out, Czechoslovakia was created largely to injure the Germans and Magyars. It is a nation with nearly five million people who are neither Czechs nor Slovaks. Separating nearly half a million Ruthenians and over three million Germans (including whole towns like Pilsen and Karlsbad) from their countrymen is not likely to keep peace in Europe.

It would appear that the Czechs were in their present location around 500 B.c., but we have no proof of their existence in this region until the sixth century. The earliest inhabitants seem to have resembled the Mediterraneans, while the Czechs are Alpines with Nordic affinities. Since the Czechs have long been largely surrounded by

1 The Wreck of Europe, p. 190. 
a Teutonic ethnic sea, amalgamation has been considerable, and the modern Czech resembles the German more than the Russian Slav. Likewise the Slovaks have amalgamated with the Rumanians and Magyars.

With the exception of the Danube Valley, the country is generally mountainous. The soil is very fertile and the country is rich in natural resources. The nation is landlocked and has no outlet to the sea, which is about 200 miles away. Within it, however, is a

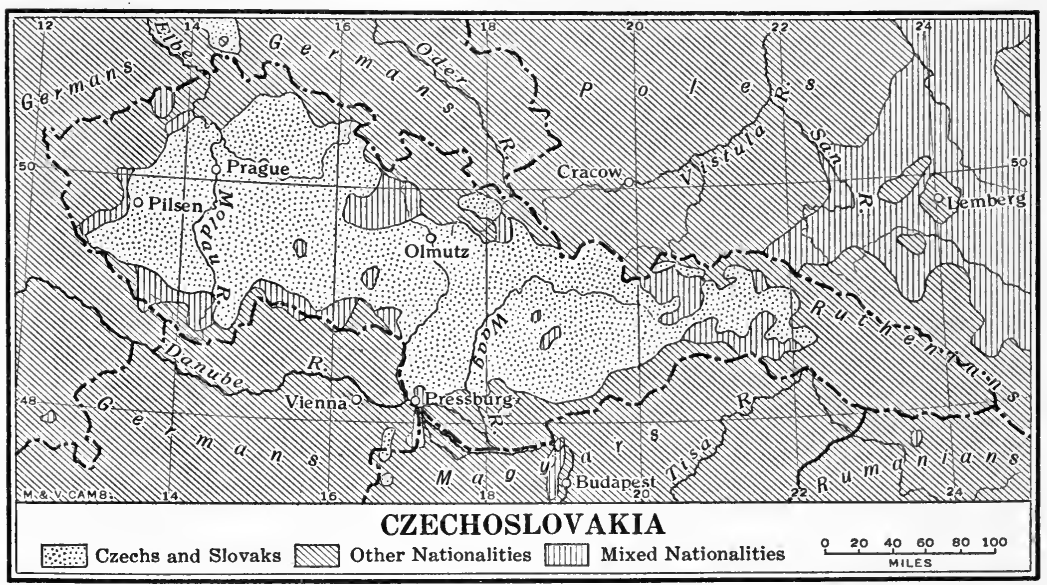

After Bowman

mass of railroads connecting it with the outside world, and the Danube and Elbe furnish water transportation.

2. Political Development. From earliest times the Czechs have been noted for their love of freedom. Under tribal society they elected their chiefis by a representative assembly. During the sixth and seventh centuries Bohemia was a free nation of pastoral and agricultural people with a patriarchal organization. After kingship became hereditary, accession to the throne had to be ratified by the National Diet. In 630 the Czechs began a struggle against the German tribes which lasted for several hundred years. In the ninth century Bohemia became a part of the great but short-lived Moravian Empire. By 1068 Bohemia was acknowledged a kingdom, and the next four centuries are its Golden Age.

Under King Ottakar II (1253-78), it became one of the most powerful nations in Europe. Its territory extended from Saxony to the Adriatic. Ottakar, however, was overthrown and his kingdom 
divided. In 1306 the Premyslide line died out, and between 1310 and 1437 Bohemia was ruled by the house of Luxemburg. In 1526 a Hapsburg ascended the throne, and Bohemia became practically a hereditary province under Austria. In 1618 the Thirty Years' War broke out in Bohemia, and at the battle of White Mountain (1620) the Czechs lost their semblance of independence and became a part of the Austrian Empire, where they remained until 1918, when they secured independence and established a republic.

After the Thirty Years' War the Czechs were exhausted. For some 150 years, determined effort was made by the Austrians to stamp out the Czech language, Protestantism, and patriotism. About 1848, a revival of the Czech language began. Kollar published a collection of old Czech poems, and Palacky published a historical treatise on the Czechs. These men published their works in Czech, though it had become the language of peasants, and only a few people could read it. Austria became more liberal in its treatment of the Czechs; street signs could be printed in Czech and German, and Czech schools could be established. The language revival became so strong that persons able to speak both languages refused to speak German, and parents who spoke only German had their children speak Czech. German was the language of Prague, but about 30 years before the World War, it had been largely supplanted by Czech. Language had become a symbol of nationalism, and it was unpatriotic to speak German.

In 1862 the Sokol was started in Prague. Outwardly it was a gymnastic society to keep the people physically fit; inwardly it was a secret organization to throw off the Austrian yoke. At the beginning of the World War over 300,000 men were members of the organization. The World War offered them an opportunity; whole regiments surrendered to the Russians, Italians, and other Allies without firing a shot, and then organized independent regiments under those nations and fought against the Austrians.

There are approximately 3,000,000 Slovaks in the world, about $2,000,000$ of whom inhabit the less fertile section of the region which they call Slovensko, along the southern slopes of the Carpathians. Some 75,000 more live in the adjacent territory, Moravia, and about 17,000 in Croatia-Slavonia, which is now a part of Yugoslavia. Until the World War they had never tasted real freedom. The Moravian Empire, of which they were a part, was conquered by the Hungarians. In 973 they became a part of Poland, but were soon 
back under Hungary. In 1848-49 they established their independence while Austria was fighting Hungary, but were given back to Hungary when peace was restored.

Unlike many of the other oppressed groups of Europe, the Slovaks cannot point to a glorious past. Ruled by Poles, Magyars, and Czechs, overrun by Avars, Tartars, and other groups, harried by the Hussite Wars, they have experienced many difficulties. Under Hungarian rule they continued to speak German and Czech and attend the University of Prague. In 1848 the Magyars tried to separate them from the Czechs by substituting Slovak for Czech in the schools and churches. Finding that this stimulated nationalism, the Magyars abolished the Slovak language in 1868 and substituted Magyar, a language which thousands were unable to understand. All Slovak and Czech literature was under ban. The right of assembly, freedom of speech, and freedom of worship did not exist. Despite this treatment, the Slovaks kept the spark of Slavic consciousness alive. The Magyars changed their attitude considerably during the last few years before the World War, and as a result the two peoples were beginning to develop harmonious relationships. After the war, the Slovaks were undecided whether to join the new Hungarian state or unite with the Czechs.

The Czechoslovakian legislature has two houses: the Chamber of Deputies, composed of 300 members elected for six years, and the Senate, made up of 150 members elected for eight years. Jointly they elect the president for a seven-year term. Universal suffrage with proportional representation, freedom of speech, freedom of religion, and compulsory education are in force. Some writers think that the Czechs and the Slovaks will not long hold together as one nation, and that the Slovaks are already tired of Czech dominance. The two dominant groups, however, do differ considerably. The Slovaks are far behind the Czechs in economic, educational, and political development. Most of the Slovaks are peasants, while many of the Czechs are industrial workers, owing to the rapid progress of industry in Bohemia during the nineteenth century. About 40 per cent of the Slovaks are illiterate, as compared with about 2 per cent of the Czechs and 5 per cent of the Germans. The Slovaks are very religious and very conservative, while the Czechs are liberal, freethinkers, and almost anti-religious. The lay of the land, the sterile soil, and the poor road connection between the Czech and Slovak territories direct the Slovaks toward Hungary, but ethnically they 
are related to the Czechs. Thus the two groups are conducting an interesting experiment.

3. Economic Development. Czechoslovakia is one of the richest agricultural countries of Europe. However, it has long been cursed with large estates. At one time 33 noblemen held one-sixth of all the land in Bohemia, and at another 5 families owned 6 per cent. Before the new republic began the sequestration of land to be expropriated, 74.6 per cent of the farms contained not over $7 \frac{1}{2}$ acres, onethird of the peasants' holdings ranged from 14 to 17 acres, and thousands owned less than 3 acres. Under the new law, all estates of over 475 acres under cultivation and all of 350 acres not under cultivation are to be expropriated. The state has taken over 10,750,000 acres. Of the 1,500,000 new farms in 1927, 40 per cent contained less than 5 acres, 30 per cent between 5 and 12 acres, and 25 per cent between 12 and 50 acres. The chief crops are oats, rye, barley, wheat, potatoes, sugar beets, flax, and hemp. The raising of sheep, cattle, horses, and poultry is extensively engaged in. Large amounts of foodstuffs are exported, and the net surplus of food is larger than that of any other European country.

Czechoslovakia is rich in natural resources. Forests cover 32 per cent of the land, and are scientifically managed. Coal, iron, graphite, lead, copper, silver, gold, and garnets are found in large quantities. Czechoslovakia shared with Germany the industrial development during the nineteenth century, and today it is one of the chief manufacturing countries of Europe. The union of the Czechs and Slovaks is advantageous to both groups, since the Slovaks are able to exchange with the Czechs raw materials for manufactured goods. One of the chief problems now is to secure suitable transportation facilities between the two parts of the country.

Czechoslovakia's location in central Europe is both a disadvantage and an advantage. Not having an outlet to the sea is a disadvantage. This is partially overcome by guarantees of transit to the ocean. It has the right to export and import goods over German rivers free of duties. It also has the right to use the Danube, the Elbe, and canals joining the Elbe, and is allowed reasonable use of the ports of Danzig, Fiume, Trieste, Hamburg, and Stettin. On the other hand, Czechoslovakia's location gives it easy access to the other nations of central Europe, since many of the chief railroads cross Czechoslovakian territory. Slovakia is rich in agriculture. Before the war Bohemia, Moravia, and Austrian Silesia, although composing only 
about one-fourth of Austria, produced 90 per cent of its sugar beets, 59 per cent of its barley, 48 per cent of its rye, 35 per cent of its wheat, and 32 per cent of its potatoes. Bohemia produced 80 per cent of its hops and 75 per cent of its fruit. Czechoslovakia received almost four-fifths of Austria-Hungary's industries, 90 per cent of its coal, and 60 per cent of its iron ore. Economically Czechoslovakia is in a coveted position.

4. Religious Development. The Czechs were early converted to Christianity by Saint Methodius and other missionaries, and played an important rôle in the Holy Roman Empire. Under the influence of Huss, the Hussite (Protestant) faith spread rapidly over Bohemia and Moravia. Huss, a Catholic priest who preached against the corruption of the church, was burned at the stake in 1415, and his ashes were thrown into the Rhine by authority of church and state. The manner of his death caused Huss to be regarded as a national hero, and led to the Hussite Wars. After these wars the Czechs enjoyed semi-independence for about 200 years. By the beginning of the seventeenth century about 90 per cent of the Czechs were Protestant.

During the Thirty Years' War Comenius, one of the most outstanding educators the world has ever known, a Moravian and a bishop in the Hussite Church, was exiled, as were other noted Czechs. At the battle of White Mountain (1620) Catholicism triumphed over Protestantism, and ruthless persecution began. Most of the Czech nobility were either killed or exiled, and their property was given to others. Some 36,000 families, of which 185 belonged to the nobility, emigrated. Between three-fourths and four-fifths of the land changed hands. All Protestant teachers and ministers were banished in 1621, and in 1627 an imperial order permitted no non-Catholic to live in the country. This order continued in force until 1781 . Huss's disciples organized the Bohemian or Moravian Brethren, which played such an important part in the religious development of central Europe. Persecution drove many of these to Georgia and other places in America. It is said that contact with these people led to the conversion of John and Charles Wesley.

Before the Act of Toleration (1781), many Czechs sought liberty in other countries, while others feigned Catholicism in order to retain their property and escape discriminations to which nonCatholics were subjected. After the Act of Toleration, a Reformed Church came into existence, but as it represented state sanction, it 
was never popular and secured as members only about 3 per cent of the people. Because of persecutions by the Roman Catholic Austrians, German Lutherans, and Eastern Orthodox Russians, the Czechs in both Europe and America organized free-thinking societies and developed great antipathy toward religion.

The Slovaks are mostly Roman Catholics, but they have been fortunate in having a number of Protestants and persons of other faiths among them, so that religion or anti-religion has never become a symbol of nationalism. The Ruthenians in Czechoslovakia are largely Uniates (Greek Catholics). They are under the Pope, but use the Slavic liturgy and the Eastern Orthodox ceremonial, and have a married clergy.

In 1914, according to Austrian statistics, about 96 per cent of the Czechs were Roman Catholics. The census of 1930 gave 10,833,423 Roman Catholies, 1,109,229 Protestants, 853,717 without confession, 585,406 Greek Catholics, 793,092 National Czechoslovakian Church, 356,768 Jews, 145,583 Russian Orthodox, and 55,426 of other faiths. Before the war there was no definite effort on the part of the Catholics to withdraw from Rome; but since, the cry in both America and Czechoslovakia has been, "Away from Rome!" Consequently in 1920 the Reformed clergy withdrew from the jurisdiction of the Pope and formed the Czechoslovakian Church. In 1928 an understanding was reached between the Vatican and the National Church.

5. Education. The University of Prague was the earliest and most outstanding of the central European universities, and with the aid of such men as Huss and Comenius, the Czechs became culturally the most advanced people of central Europe. Under Austrian Catholic suppression the Jesuits burned thousands of valuable books and manuscripts, and exiled teachers and thinkers. The Czechs' love of knowledge, however, was not killed. After being permitted to have their own schools, they brought about a revival in literature. Although they had to support their own schools where they were in a minority, they willingly did so, and taught their children to destroy Austria with brains. As a result the Czechs are one of the most literate peoples of all Europe.

The Slovaks have been held back far more than the Czechs. At first they were permitted to use Czech and to go to Czech schools; then Slovak was substituted, and finally Hungarian. Before the war there were about 200 schools in the territory of present Slovakia, but not one was allowed to use Slovak. Students were not permitted 
to converse or read books in Slovak or Czech. During the first year of the republic, 27,000 schools were established for Slovak children, and a corresponding number of higher schools. Instruction is compulsory for children between the ages of 6 and 14. Libraries are being opened in every community. In 1918 a Czech university was established at Brno; in 1919 a Slovakian university at Bratislava; and in 1921 a free university for Ukrainians. Every effort is being made to educate the people, and they have the privilege of using their own language.

6. Social Conditions. Owing to the fact that the Czechs and Slovaks have been subject to different nations, there has been some difference in their social development. Both started as tribes with tribal social distinctions, but the Czechs early became the cultural leaders of Europe. Prague was the social and educational center of Europe, but Austrian suppression destroyed the Czech intelligentsia and reduced them to mere peasants, subject to German nobles who considered them as inferiors. To a certain extent the Czechs amalgamated with the Teutons in their midst, and this cultural fusion gave them a distinct advantage over other Slavic groups. The Czechs never forgot their former greatness, and after 1848 they began to develop the attitude that, though peasants, they were in no sense inferior to their masters. On the other hand, the Slovaks, having always been subject to others, had practically no intelligentsia. They were simply peasants in the power of Magyar nobles, and resisted with less determination the flaunted superiority of the Magyars.

The peasants live in farm villages and go out to the fields to work. They know every one in the community, but their social vision seldom extends beyond their immediate confines. They are very fond of music and dancing, which are their chief means of recreation. Like those of other Slavic peasants, their houses are of the two-room variety - one room for the peasant family and the other for the live stock. The food of the peasants consists chiefly of vegetables, potatoes, rye bread, soups with garlic, and meat on holidays. The floors are usually of dirt.

The Russinians are culturally the most backward group in Czechoslovakia. They came over the Carpathian Mountains from Russia and have long lived in Sub-Carpathian Russia, which is now an autonomous part of Czechoslovakia. As they mingled very little with their Hungarian masters, they were able to retain their spoken language, religion, and general culture. They belong to the Greek 
Catholic Church, use the Cyrillic alphabet, and speak a dialect closely related to Russian. Miller ${ }^{1}$ estimates that there are about 500,000 of these people and that 20 per cent are in the United States. According to the same authority, their culture is very primitive, they have no literature, and they became nationally conscious for the first time after the World War. In a plebiscite among these people in the United States, they voted to become an autonomous part of Czechoslovakia.

7. Immigration and Emigration. Czechs began coming to the United States in the seventeenth century, but in small numbers. The banishment of Protestant teachers and ministers in 1621, and of Protestant laymen two years later, together with an imperial order in 1627 prohibiting non-Catholics from inhabiting the territory controlled by Roman Catholic Austria, caused large numbers of Czechs to flee their native land. How many found their way to America is not known. It is known that colonies of Moravians settled in Bethlehem, Pennsylvania, where they founded the Moravian Seminary in 1742; and in Salem, North Carolina, where they established Salem College in 1771. It is known that before they moved to Salem they settled at Moravian Falls, being among the first settlers in this region - a fact which indicates their early immigration.

In 1840 there was a failure of the potato crop, and large numbers left for America. The discovery of gold in California and the vigorous activities of steamship companies caused many to seek America. In 1854 a colony was founded in St. Louis. In 1867 the newly granted right to emigrate and Austria's disastrous war with Prussia gave a fresh impetus to emigration. Many Czechs settled in the northwest where land was within their limited means. Wisconsin canvassed for immigrants, offering cheap land, religious freedom, free schools and universities, equality before the law, suffrage, and other inducements which appealed to the liberty-loving Czechs. A large number became farmers, establishing colonies even as far south as Texas. Between 1850 and 1868, 57,726 people came from Austria, and according to estimates, at least 43,643 of these were Bohemians.

The Slovak movement to the United States started later than the Czech, but increased until it reached greater proportions. For the period 1809-1910 the Slovaks stood eighth in the number of immigrants, whereas the Czechs stood eighteenth. For the same period, 377,527 Slovaks came, against 100,189 Czechs, although the Slovaks

1 Immigrant Backgrounds, edited by H. P. Fairchild, pp. 148-49. 
are less than a third as numerous as the Czechs. The Slovaks have settled in our industrial centers to a larger extent than have the Czechs. In 1920 there were 362,436 foreign-born whites in the United States who were born in Czechoslovakia - 190,808 Czechs and 133,179 Slovaks. At the same time there were 234,564 who gave Czech as their mother tongue and 274,948 who gave Slovak. In 1921 40,884 Czechoslovakians came to the United States, but only 102,194 for the period 1921-1930. Our present law permits 2874 Czechoslovakian immigrants to enter each year, 199 less than the two per cent law.

The Czech movement to the United States reached its height between 1850 and 1890; before the World War between 25,000 and 30,000 Slovaks were coming here per year. The number of emigrants from Czechoslovakia has declined considerably since 1922-23, when it reached alarming proportions. The Czechoslovakian government objects to the emigration of its citizens.

Our early Czech immigrants were a mixture of educated people, peasants, agricultural and domestic laborers. Many of the latter group had very limited opportunities under Austrian imperialism. Those who have been coming to us in recent years are better trained, as is revealed by the fact they have the lowest percentage in illiteracy and highest percentage in skilled labor of all our immigrant groups. The Slovaks, coming from a very different environment, have had a high percentage of illiteracy, and have often been considered stupid and unprogressive.

Reaction to Austrian suppression is revealed in the behavior of the Czechs in this country. Until the World War they maintained their Sokols and their free-thought societies and fraternities, which, while claiming to exclude religion, were often so anti-religious as to "make a religion of their antipathy to religion." Even the Roman Catholics shared this strong feeling of nationalism; yet Catholics and freethinkers were so opposed to each other that they would seldom enter each other's buildings. Miller ${ }^{1}$ points out that the feeling was so strong that freethinkers and socialists would not go to hear any one who spoke in a church or building connected with a church, and that their papers would not print advertisements for churches. But within a short time after the United States declared war on AustriaHungary, all the Czechs - freethinkers, socialists, Protestants, Roman Catholics - were working together for the independence of their native land.

1 Races, Nations and Classes, p. 50. 


\section{QUESTIONS, EXERCISES, AND PROBLEMS FOR INVESTIGATION}

1. Why is Czechoslovakia called a Slavic peninsula?

2. What grounds has Nitti for saying that Czechoslovakia was created largely to injure the Germans and Magyars?

3. What is the ethnic composition of the Czechoslovakians? Reference. Ripley, W. Z.: The Races of Europe, pp. $345 \mathrm{ff}$.

4. Under what powers have the Czechoslovakians lived? How did Austria attempt to obliterate the patriotism of these people? How did the Czechs react?

5. Trace the growth and development of Czechoslovakian independence. References. Montgomery-Cuninghame, T.: "The Making of CzechoSlovakia," Nineteenth Century, Vol. CV, pp. 317-26; Kerner, R. F.: "The Winning of Czechoslovak Independence," Foreign Affairs, Vol. VII, pp. 308-16; Graham, M. W.: New Governments of Central Europe, Chap. XII; Hrdlička, Aleš: "Bohemia and the Czechs," National Geographic Magazine, Vol. XXXI, pp. 163-80, paying special attention to the growing spirit of independence; Broz, Aleš: "Minority Rights in the Czechoslovak State," Foreign Affairs, Vol. VI, pp. 158-60; Wallis, B. C.: "The Slavs of Northern Hungary," Geographical Review, Vol. VI, pp. 268-81.

6. Describe the agricultural situation of Czechoslovakia. What are the industrial resources? Besides the text, see Moscheles, Julie: "Natural Regions of Czechoslovakia," Geographical Review, Vol. XIV, pp. 55175; Engle, B. C.: "Sugar Production of Czechoslovakia," Economic Geography, Vol. II, pp. 213-29.

7. Account for the antipathy of the Czechs toward religion. Compare the religious attitudes of the Czechs and Slovaks. In what respects do the Slovaks and Czechs differ in educational achievement and social development? Besides the text, see the contribution of $\mathrm{H}$. A. Miller in Immigrant Backgrounds, edited by H. P. Fairchild, pp. 143-50.

8. Account for the early emigration of the Czechs. Where have they gone? Compare the immigration of the Czechs and Slovaks to the United States.

9. Make a study of international migrations to and from Czechoslovakia. Reference. Ferenczi, Imre: International Migrations, Vol. I. 


\section{CHAPTER XX}

\section{YUGOSLAVIA AND ALBANIA}

Yugoslavia and Albania have enough in common to be considered in the same chapter. Geographically, the two countries lie in southeastern Europe and join each other. Racially, they are related, both having a substratum of the same racial groups, and both having been influenced by invasions and amalgamations of similar racial groups. Historically, they have both been subject to the same powers. Culturally and religiously, they have many similar traits.

\section{The Kingdom of Yugoslavia}

1. General Description. The Kingdom of the Serbs, Croats, and Slovenes, now called the Kingdom of Yugoslavia or Jugoslavia (South Slavs), is situated in the southern part of Europe, bordering on the Adriatic Sea, and has Italy, Austria, Hungary, Rumania, Bulgaria, Greece, and Albania as neighbors. It has a territory of 96,134 square miles, and is thus a little smaller than the state of Oregon. In 1931 it had a population of 13,930,918. Belgrade, the capital and largest city, had a population of 241,542. Yugoslavia is composed of the two former kingdoms of Serbia and Montenegro, the Austro-Hungarian provinees of Bosnia-Herzegovina, Dalmatia, Croatia, Slavonia, Slovenia (consisting of parts of Istria, Styria, Carniola, and Carinthia), and Voivodina (made up of portions of the Banat, Baranja, and Backa). Serbs, Croats, and Slovenes form about 83 per cent of the population. A little over 84 per cent are Slavonic. Besides these closely related Slavic-speaking people, there are 513,420 Germans, 472,409 Magyars, 446,740 Albanians, 229,398 Rumanians, and 12,825 Italians.

Yugoslavia is primarily a mountainous country with numerous peaks from 7000 to 9000 feet high. Above one-fourth of the area, however, is covered by the Great Pannonian Plain. It has black alluvial soil and is one of the most productive regions of Europe. Even in the mountain sections there are fertile valleys and high basins which have resulted from the drying up of lakes. The mountainous "Karstland" region, with practically no soil, includes most of Herze- 
govina and Dalmatia, and a large part of western Bosnia, Croatia, Slavonia, and Montenegro. The valleys (poljea) constitute the only fertile areas of this region. Yugoslavia has a number of large lakes and rivers. The climate varies widely. In parts of Dalmatia it is warm and sunny, while in the northern section the changes are sudden and severe.

The Slavs of Yugoslavia differ so much from the other Slavs that Deniker called them Adriatic. They have so amalgamated with

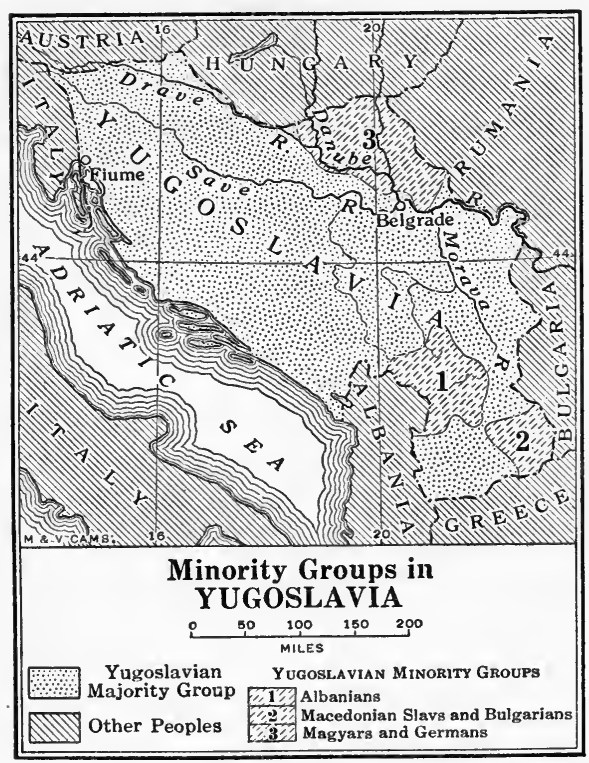

After Bowman, slighty modified

the old Illyric population, the more recent representatives of the Mediterraneans, the Teutonic peoples, and the Turks, that no one type prevails. In general they, are a round-headed brunette type, but not very dark. In Herzegovina are found some of the tallest people in Europe. They average 5 feet 9 inches and have very broad heads (average cephalic index of 87). From this section the population type shades off in all directions, according to the degree of mixture with the surrounding peoples.

2. Political Development. The Serbs are the largest of the three most numerous Slav tribes that settled in southern Europe. They apparently migrated from the Carpathian region in the period between the second and the sixth century. During the first few centuries after their migration to the southern regions, they lived a practically free political life under their own tribal chiefs (zupans), though nominally under the Greek Emperor of Constantinople. About 917 the Serbians were conquered by Bulgaria and were ruled by it until 1018, when both countries came under the rule of the Greeks. In the twelfth century a strong Serbian monarchy was established under Stephen Nemanya. For two centuries this kingdom, which reached its Golden Age under Dusan (Dushan, 133155), dominated the whole peninsula except Salonika, extending from 
the Aegean Sea to the Danube and from Thrace to the Adriatic. Under Dusan, Belgrade, which had been a part of Hungary, was annexed. Bosnia, which had enjoyed many years of freedom but had come under the rule of Hungary, was incorporated in his kingdom in 1350. Herzegovina, which in the early days had been part of Serbia but was joined to Bosnia in 1325, also came under his power. And during his reign the Bulgarians joined the Serbians in a Synod and elected an independent Serbian Patriarch.

Under Dusan's son, Uros (Uroh) V, the Serbian Empire began to decline. Belgrade again became part of Hungary; Bosnia and Herzegovina broke away; and within ten years after the death of Uros, his son was a fugitive and his empire had been largely dismembered. The Turks steadily advanced, and at the battle of Kossovo (1389) the Serbian Kingdom fell. It was not until 1459, however, that Serbia completely ceased to exist as a state. Except for a brief period in the eighteenth century, when Austria occupied the northern part of Serbia, the Serbs remained completely subjugated until 1804. In 1804 there was a revolt and terrible massacre, but Serbia obtained more liberty. After fighting for nine years, it obtained its freedom, but the Treaty of Bucharest, ending the TurkoRussian war, left Serbia under the Turks. In 1815 another uprising occurred, and Serbia was permitted to choose a hereditary prince.

At first the Turks treated their Slavic subjects justly, but soon they became very oppressive. Thousands of noble families fled. Part went into the mountains of Montenegro, part into Bosnia, which had not yet come under Turkey, and part into the Theiss River section of Hungary, where they lived practically free under their own princes. At least 100,000 went to Russia, and 37,000 followed Arsenuis into Old Serbia, then under Austria. Those who remained lost hope and submitted to the Turkish suppressions. They had to send their quota of youths for the Turkish Janissaries, and all males from their seventh birthday had to pay a poll tax. When Russia and Turkey went to war, the Serbs flocked to the Russian and Austrian armies; the Serb whom the Turkish official met thereafter was a different individual. Patriotism had been aroused. Between 1804 and 1860 there was a continued struggle for freedom. This period included many massacres and saw the rise of Black George, the national hero of Serbia. Gradually Serbia gained more liberties, and finally independence in 1882. Serbia played an important part in the two Balkan wars, increased its territory by 15,241 square miles, 
- almost doubling it - and added 1,250,000 to its population. Out of the World War came the freedom of the South Slavs.

Many Slavs settled in Montenegro during the early migrations, and many Serbs during the Turkish rule of Serbia. Many of the present inhabitants of Montenegro claim to be descendants of the noble Serbian families which fled from Ottoman rule. Before the coming of the Slavs Montenegro was a part of Illyria and contained a number of Roman cities. In the seventh century it formed part of the Serbian confederation under the Greek Emperor Heraclius to fight the Avars. In the twelfth century, under Nemanya, it voluntarily became a part of Serbia and remained such until the battle of Kassovo. As the Turks were never able to defeat Montenegro, it remained independent. They seized part of its territory, but the Montenegrin ruler Ivan, with a handful of men, withstood a Turkish army of 70,000. When sorely pressed he offered his people the alternative of choosing another prince who would make peace with the Turks or of following him. They swore to follow him, and from that act it came to be a custom that any man who showed himself to be a coward was dressed in women's clothes, had a spindle placed in his hands, and was driven out of the country. After the World War the Montenegrins joined the Serbs and other Slavs in forming Yugoslavia.

Under Samo (627-58) the Slovenes constituted part of the CzechoSlovene Kingdom. In 748 they voluntarily submitted to the hegemony of the Franks. When Charlemagne's empire was divided, the Slovenes were divided between Friuli and Bavaria, and thus were exposed to German culture and methods of colonization. During the fourteenth century they came under the Hapsburgs, where they remained until 1918. Voluntarily they entered the Kingdom of Yugoslavia.

The Croats early established themselves in what came to be known as Croatia-Slavonia. After successive periods of dominance by both the Eastern and the Western Empire, Croatia-Slavonia virtually became independent in 925 under their chief, King Tomislav. In 1102 Croatia became an autonomous province under Hungary. In 1526 Slavonia, which was a separate monarchy, and a part of Croatia came under the rule of the Sultan, while the rest of Croatia became subject to Austria. In 1687 the two provinces came under the Hapsburgs, where they remained - except during 1809-14, when they formed part of Napoleon's Illyrian Provinces - until 1918, when they 
gained their freedom and joined the other Slavs in forming Yugoslavia.

Dalmatia was settled by Slavs during the seventh and eighth centuries. The older Italian population was driven to the coast towns, and the Slavs remained mainly in the interior. Between the tenth century and 1718, the Italians maintained themselves in certain coast towns, but the hinterland was ruled successively by Croats, Magyars, Serbs, Bosnians, and Turks. In 1718 it came under the rule of Venice, where it remained until the overthrow of the Venetian Republic by Napoleon in 1797, when it was transferred to Austria. Between 1805 and 1809 Dalmatia formed part of Napoleon's Illyrian Provinces, but after his defeat in 1814, it returned to Austria, where it remained until it became part of Yugoslavia in 1918.

The region now known as Voivodina was settled by migrating Slavs during the sixth and seventh centuries. After the defeat of Serbia by the Turks in 1389, many Serbian refugees fled to this region. The Magyars granted them autonomous rule. Hungary, however, became a part of the Ottoman Empire in 1547, and by the Treaty of Karlowitz (1699) became a part of the Austro-Hungarian Empire. Voivodina remained part of Hungary until 1918, when it became a part of Yugoslavia.

Following the World War the South Slavs (except Albania and Bulgaria) formed the constitutional and parliamentary monarchy of Yugoslavia. The constitution guarantees equality of the Roman Catholic, Orthodox, and Moslem religions, and the use of both the Latin and the Cyrillic alphabet. It provides for a single legislative chamber (Skuptchina) of 315 members elected for four years. The government has been unstable, and there have been assassinations, murders, and threats (especially by Croatia) of withdrawal from the union. During a debate of the Skuptchina in 1929, a Montenegrin leader shot down some of the Croatian leaders. Since that time the Croatians have manifested great dissatisfaction with the government, and remained obstinate and bitter. On January 6, 1929, King Alexander dissolved the Skuptchina, suspended the constitution, and declared himself sole source of power. Until September, 1931, he ruled as an autocrat, dissolving the Croatian peasant party and other parties. In September, 1931, he ended his dictatorship and returned much of his power to the people. The Croatians, however, are still dissatisfied with their political condition.

From the political point of view, the Yugoslavs have perhaps as 
much cause for deep-seated prejudice as any other people of Europe. They have been the pawns in the intrigues of practically all the large nations of Europe. The commercial and political rivalry of the larger nations brought deception, trickery, bribery, and intrigues which caused untold misery among the South Slavs, and naturally caused a suppressive psychosis to develop. These things did not stop with the World War, but have continued because of the difficulties with Greece and the seizure of Yugoslavia's territory by Italy. The South Slavs detest the Germans, Austrians, and Magyars with an undying hate. The troubles with Bulgaria, Greece, and Italy cause them to be hostile toward most of their neighbors.

Racially and linguistically the Yugoslavs are closely related, but it is doubtful if the feeling of Slavic kinship is strong enough among them to keep them united in the future as difficulties with other nations have done since the World War.

3. Economic Development. Yugoslavia is primarily an agricultural country, about 85 per cent of the people being engaged in tilling the soil. Over 45 per cent of the kingdom is used for agriculture, and 80 per cent of this is devoted to growing cereals. In Serbia and Montenegro the farms are small, averaging about 20 acres each. In Croatia, Slovenia, Voivodina, Bosnia, and Herzegovina they are larger. In pre-war days there were a number of large estates, especially in the former Austro-Hungarian provinces, but these have been divided among 350,000 peasants. The landless peasants who volunteered for service during the war obtained land free; others were to pay for it in ten years. Farming methods are primitive. Before the large estates were broken up, modern farm machinery was used on a number of them, but now the farms are so small that modern machinery has largely been abandoned. Corn, wheat, tobacco, and sugar are the chief crops. Stock raising and forestry are also important occupations.

Yugoslavia has coal and iron mines, and some lead and copper. The coal is mostly of poor quality, being the brown variety. Slavonia and Dalmatia are mountainous and have noted resorts. Slovenia has important coal deposits and engages in manufacturing. Croatia and Slavonia have well-developed lumber industries and some coal. The country has been industrially retarded because of poor railroad facilities and seaports, but these are being improved. Susak is the only Adriatic port, but Yugoslavia also has a free zone in Salonika, Greece. The chief exports are grain, cattle, prunes, and 
lumber, and the chief imports are agricultural and animal products, machinery, and chemicals.

4. Religious Development. The Yugoslavs early came into contact with both the Eastern and the Western branch of Christendom, and became vital and warring factions of these faiths. Bogomilism and Mohammedanism were introduced and became disturbing factors. Among the Yugloslavs, as with most other peoples of Europe, religion has been so intertwined with politics that it has led to murders, assassinations, massacres, and wars. King Stephen ordered that Roman Catholics should be sent to work in the deepest mines or banished, and any Latin priest found proselytizing was to be sentenced to death. Priests were often bayoneted without cause, and Moslems were given their choice of being baptized or being shot. After the break-up of Stephen's empire, the rulers of Serbia and Bosnia tried to save their tottering thrones by placing them under the protection of the Papacy, but religious prejudice was so strong that the masses declared they preferred to be Moslems rather than Roman Catholics.

The religious population is as follows: Serbian Orthodox (State Church), 5,602,227; Roman Catholic, 4,700,134; Moslem, 1,363,210; Protestant, 235,169; Jewish (chiefly Spanish Jews), 72,946; Uniate, 41,597; other creeds and no creed, 19,652. The prevailing religion in Serbia, Montenegro, and Bosnia-Herzegovina is Orthodox; and in Croatia-Slavonia, Dalmatia, Slovenia, and Voivodina Roman Catholic. Moslems are found in all provinces, but chiefly in Serbia and Bosnia-Herzegovina. Protestants are found chiefly in Voivodina. The situation is especially complicated by the use of two alphabets and two calendars, which serve as a constant reminder of religious differences and keep alive old hatreds. Religion appears to be the fundamental obstacle to unity in Yugoslavia. The religious condition in Yugoslavia is reflected among our immigrants from that country. Many are freethinkers, and according to estimates, 70 per cent of the Croats and 50 per cent of the Slovenians do not attend church in the United States.

5. Educational Development. The illiteracy rate for Yugoslavia is high, ranging from 20 to 86 per cent. In 1921 only 48.5 per cent of the school population could read or write. The illiteracy rates for the different provinces were as follows: Slovenia, 86 per cent; Voivodina, 77.8 per cent; Croatia-Slavonia, 67 per cent; Dalmatia, 50.5 per cent; Serbia, 34 per cent; Montenegro, 33 per cent; Bosnia-Herzegovina, 20.6 per cent. Perhaps the better showing of Bosnia-Herzegovina is 
due to the fact that in 1232 and 1322 Bogomil kings were elected who established schools. The Slovenians, on the other hand, have no written language and have had to study in a foreign tongue.

Such high percentages of illiteracy make the task of education difficult. The peasants are ignorant, superstitious, and provincial; yet there are many young people from peasant homes in the universities. Education is now free and nominally compulsory. The school system differs from ours in that the primary school course requires only four years while the secondary school course is divided into two parts of four years each. The requirements for teachers are high. Primary teachers must be at least graduates of normal schools, and teachers in secondary schools must have a university diploma. There is very little coeducation. There are three universities, besides technical, agricultural, and industrial schools. Belgrade, with over 8000 students is the largest university.

6. Social Development. Yugoslavia early developed two social classes, lords and serfs, and in some provinces this social distinction continued down to the World War. Feudal rights and serfdom were abolished in Croatia-Slavonia, Slovenia, and Voivodina in 1848, but the land that the peasants received was so small and so poor that they were unable to secure a living from its cultivation, and had to continue working for landlords. In Bosnia-Herzegovina the serfs were technically given the right to secure their freedom in 1912, but the terms imposed made it practically impossible for them to do so. In Dalmatia feudal rights and serfdom existed until the World War.

Under Turkish rule the Slavic noblemen were so oppressed that the provinces tended to become lands of peasants. In some sections Turkish noblemen were substituted for Slavic noblemen. Furthermore, certain Slavs became Moslem noblemen and aided in making the life of the peasant hard. The Turkish noblemen in BosniaHerzegovina were especially favored by Austria-Hungary, and this tended to make the Slavs bitter.

The South Slavs are famous for the $z a d r u g a,{ }^{1}$ a type of family life in which several related families live either in the same house or in the same village. The patriarchal type of family life prevails; when a young man marries, he brings his bride into the household.

${ }^{1}$ For a description of this type of family life, see Sorokin, P. A., Zimmerman, C. C., and Galpin, C. J.: A Systematic Source Book in Rural Sociology, Vol. II, pp. 57-67. 
If the house becomes too small an annex is built. Sometimes as many as 80 people have been known to dwell in one household. The peasants generally marry early and have large families. The Serbian lad who is not deeply in love at sixteen is considered a fool. $\mathrm{He}$ places woman on a pedestal until marriage; then she becomes his drudge and beast of burden.

Racially and linguistically the South Slavs are considered as being closely related. The Bosnians (named from the river Bosna) are mainly Serbians and Croats. It was in their capital, Serajevo, that the Austrian Crown Prince was assassinated on June 28, 1914, and thus precipitated the World War. The Herzegovinans (Helvats) are also Serbs and Croats, and were ruled by Austria. In fact Herzegovina was a part of Bosnia, which was lopped off by Austria and named after Archduke Herzog. The Croats closely resemble their kinsmen, the Serbs. Before the World War about 98 per cent of the inhabitants of Bosnia and Herzegovina were Serbs and Croats, but in religion they were divided. About 42 per cent were Eastern Orthodox and called themselves Serbs, 28 per cent were Roman Catholics and called themselves Helvats, and 20 per cent were Mohammedans and called themselves Turks. In general the Croats, Slavonians, and Dalmatians are Greek Catholics or Uniates; they use the Slavic liturgy and Cyrillic Slavic (Glagolithic) alphabet in their churches. The Slovenes (Wends) are found in Carinthia, Carniola, and Styria. They number about 1,350,000, and are closely akin to the Croats and Slavonians, but have so freely amalgamated with the Germans, Italians, and Magyars that noticeable culture differences appear. They are Roman Catholics and use the Latin alphabet. They were treated very leniently by Austria and manifested little racial consciousness. The Slavonians are closely related to the Croats. They have long been subjected to the Magyars, for whom they retain deep-seated hatred. The Dalmatians live along the Adriatic. They are often called Pagani or Pagans because they were the last of the South Slavs to accept Christianity, but are generally known as Morlachs, (Mavro-Vlachs, Black-Vlachs). They have never known independent existence, yet the country is often referred to as the cradle of Slavic civilization, because of the number of remarkable people it has produced.

7. Immigration and Emigration. Before the World War our Bureau of Immigration listed immigrants from the territories that now form Yugoslavia as Bulgarians, under the general classification of 
Bulgaria, Serbia, and Montenegro, or as Germans, Austrians, or Hungarians, since much of the territory of Yugoslavia then belonged to Germany and Austria-Hungary. Furthermore, the people tended to classify themselves according to religion. For example, a Bosnian, if asked his race, would probably reply Serbian if he belonged to the Eastern Orthodox or Greek Church, Croatian or Latin if he belonged to the Roman Catholic Church, or Turk, if he were a Mohammedan.

Until 1880 there were practically no immigrants in the United States from Yugoslavia, but the number grew rapidly. As early as the seventeenth century, however, a number of Yugoslavian missionaries arrived, most of them going to Mexico. Many Dalmatians went to California during the gold rush. The Dalmatians have long been expert seamen and fishermen, and a number went to California by the Strait of Magellan. There are several Yugoslavian agricultural and fishing colonies on the Pacific Coast, some of which were established early. The Louisiana fishing industry is largely controlled by the South Slavs. Kraintown, Minnesota, was established by a group of Yugoslavs from the province of Krain. Most of the Yugoslavs have settled in industrial states like Illinois, Pennsylvania, New York, and Ohio. Cleveland is the chief Yugoslav center, there being some 10,000 Yugoslavs in that city.

It is estimated that there are 400,000 foreign-born Yugoslavs in the United States, and about 200,000 native-born of Yugoslavic parentage. According to the census for 1920, there were 169,437 foreign-born whites in the United States who gave Yugoslavia as the country of their birth. Of this number, 60,204 were Croatians, 46,388 Slovenians, 27,954 Serbians, 13,815 Slovaks, 7787 Germans, 4191 Montenegrins, 2678 Magyars, 1765 Dalmatians, and 4655 others. In 1920 there were 102,744 foreign-born whites who gave Slovenian as their mother tongue, and 125,844 who gave Serbo-Croatian. In 1921 23,536 Yugoslav immigrants entered the United States, but the number dropped to 6047 the next year. The total for the decade ending in 1930 was 49,064 . Our present law permits 845 Yugoslavians to come per year, 174 more than the two per cent law. Many have returned home since the World War; 13,034 in 1920 alone, and 38,306 for the decade ending in 1930.

According to Yugoslavian statistics, 5988 Yugaslavs left their native land in 1920 for overseas, 12,965 in 1921, 6086 in 1922, and 17,238 in 1924 . Until 1922 practically all came to the United States, 
but in 1923 Brazil and Argentina received almost half, and in 1924 the United States received only one-eighth, while Brazil welcomed more than one-third, Argentina over one-fifth, and Australia and Canada one-tenth each.

Undoubtedly most of the Yugoslavs have departed from their native land for economic reasons, and to escape persecution. As Miller ${ }^{1}$ says: "Our Serbians came from Bosnia and Herzegovina where they had been under the government of Austria-Hungary. They are all Greek Orthodox." In the United States the Yugoslavs are considered industrious and loyal citizens. In 1920 they ranked first among the groups having first papers, but thirty-third among those naturalized. Over 400 from Cleveland alone served in the United States Army during the World War.

\section{Albania}

1. General Description. The Kingdom of Albania is located in southeastern Europe, on the Adriatic Sea. Yugoslavia and Greece are its neighbors, and Italy is only 45 miles across the Adriatic. Less is known of Albania than of any other European country. It is often referred to as a "mysterious country," a "land of miracles," a country "darker than dark Africa"; yet it is generally agreed that the country is occupied by the oldest people in the Balkans. The territory of Albania is estimated at 10,630 square miles, and is a little larger than Vermont or New Hampshire. In 1930 it had an estimated population of $1,003,068$. Tirana, the capital and largest city, had a population of 30,806 , and Scutari, the next largest city, 29,209. There are perhaps between 1,500,000 and 2,000,000 Albanians in Europe. According to estimates, between 200,000 and 250,000 live in Greece, between 90,000 and 200,000 in southern Italy, and a smaller number in Yugoslavia.

The origin of the mysterious people who, since the fifteenth century, have been called Albanians is a puzzle. They are a very mixed group and possess such varied characteristics that it is difficult to place them with any racial group. Apparently they are the descendants of that ancient group of tribes, known as Illyrians, which occupied the territory south of the Danube. Certain characteristics connect them with the Mediterranean group, while others relate them to the Alpine. They are among the tallest people in Europe, and at the same

${ }^{1}$ Immigrant Backgrounds, edited by H. P. Fairchild, p. 141. 
time have the broadest heads. Those in the north resemble the Slavs, while those in the south have more the appearance of Greeks. In general their hair and eyes are dark. Light hair is exceptional, but blue and grey eyes are frequent. There are two chief tribes or groups - the Ghegs (Gegs) and the Toshks (Tosks). The Ghegs inhabit the northern part while the Toshks live south of the Semeni River. The Ghegs are fairer, taller, and more warlike than the Toshks. The Albanians were long subjected to Greek, Roman, Slavic, and Ottoman influences. Apparently they could be classed with the Latins, but evidence favors the Slavs.

The country is very mountainous, and the people call themselves Skipetari (Shkyiperi), or mountaineers. There are a number of lakes and rivers, which flow through deep-cut ravines into the Adriatic. The climate varies according to altitude. In the higher mountains the winters are very cold, but in the lowlands snow rarely falls, and the winters are short and mild. Along the coast is an area of marshy lowlands where malaria is prevalent.

2. Political Development. The Albanians have long been known as warriors, and a people difficult to govern. They were soldiers of Pyrrhus and Alexander the Great, and proved to be the most formidable opponents encountered by the Romans and Turks. History shows, however, that Albania was invaded and partially ruled by Greeks, Gauls, Romans, Goths, Slavs, Normans, Venetians, and Turks. In the seventh century B.c. the Greeks pushed the Albanians into the interior. The Romans built a road across their country into Macedonia, and a few walled cities along the coast, but failed to conquer the inhabitants. During the fourteenth century the Ottoman invasion began, but under their national hero, Scanderbeg, the Albanians withstood the Turkish forces for over 20 years. After his death they succumbed to the Turkish conquest, which was completed in the sixteenth century. For some 500 years they were ruled, nominally at least, by the Mohammedans. There were frequent revolutions, and during the First Balkan War (1912) the Albanians gained their independence.

As the Albanians have never had a definite boundary line, and as the Turks have never recognized the existence of Albania, the powers proposed various boundaries in 1913. In 1915 the Allies attempted to divide the territory into four parts. The central part was to be a self-governing Mohammedan state; the southern part was to be given to Italy, the northern part to Yugoslavia, and the southeastern 
part to Greece. Since Albania is only a few miles across the Adriatic, Italy has long tried to dominate the country. In 1917 Italy declared itself protector of Albania, but was forced to withdraw and content itself with part of Valona and the island of Sasseno. Albania's independence was assured by the Great Powers in 1920, and in 1926 its boundaries were established. Its agreement with Italy in 1926 for mutual support almost precipitated another war in Europe. As a result of the First Balkan War, Serbia hoped to gain access to the Adriatic by absorbing Albania, but was blocked by Austria-Hungary. In 1913 the timorous Prince of Weid (German) became king of the warlike Albanians. He was glad to flee the country at the outbreak of the war in 1914. Serbia joined the Second Balkan War for the purpose of expansion, but again was blocked. Its dream of a Yugoslav state which would include Montenegro, Dalmatia, and Albania was partially realized after the World War. As a result of a revolution in 1924, Albania proclaimed itself a republic. In 1928 the constitution was changed and the president became king. A new civil code, patterned after the Swiss, French, and Italian codes, was adopted in 1929, and heads of families were ordered to assume surnames. Tribal loyalties are still strong, however, and hinder the development of national feeling.

3. Economic Development. Albania is mainly an agricultural and sheep- and cattle-raising country. Most of the land is too mountainous for extensive agriculture, but the central region contains two large fertile plains - Kavaja and Muzakia - separated by snowcapped Mount Tomor. The southern part has a number of small plains and valleys suitable for agriculture. Agriculture, however, is in a very backward state. Most of the land belongs to a small group of Begs and Pashas, who received it as fiefs from the Sultan. It is leased to the peasants in perpetual leases. Since the peasant has to give a third of his crop to the landlord, he grows no more than enough for his own meager needs. In Albania and some of the other Balkan states, stock raising has been interrupted by the shifting and establishing of national boundaries. Much of the former common pasture land is now in different nations.

Albania has an abundance of forests, but it has no railroads and only one highway. Consequently lumber has not yet become a source of wealth. The country is thought to be very rich in mineral resources, but these have not been developed. Until recently it had neither banks nor a monetary system; many kinds of foreign 
coins circulated in the country. It now has one bank, which has the exclusive right to issue currency. There is practically no industry. Eighty-seven per cent of the people live in the country - a country tied together only by trails, over which cargoes are transported on the backs of animals. Albania's chief exports are wool, skins, dairy products, olive oil, and tobacco. Manufactured goods constitute the chief imports, which are much larger than exports. Most of its trade is with Italy, Greece, Yugoslavia, and the United States.

4. Religious Development. The Albanians have long been subjected to three religious forces: the Greek or Eastern Church, the Roman Catholic Church, and the Mohammedans. The Ghegs are mainly Mohammedans and Roman Catholics, while the Toshks are chiefly Eastern Orthodox and Mohammedans. The Ghegs use the Latin alphabet, while the Toshks use the Greek. According to the religious census of 1921 , the Mohammedans numbered 584,675, or 66 per cent of the population; Eastern Orthodox 158,215, or 21 per cent; and Roman Catholics 88,987, or 12 per cent. The Albanians are not bigoted in their religious beliefs. Miller ${ }^{1}$ states that "during the Peace Conference three hundred Albanians in Pittsburgh telegraphed their representative in Washington that if it would have any influence for the freedom of their country on the Peace Conference in Paris they would become Christians."

5. Educational Development. Remains of the early Illyrian, Cyclopean-Pelasgian, Greek, and Roman cultures, covered with the dust of nearly 30 centuries, have been discovered in Albania. They show that the civilization of the country at an early date ranked favorably with that of neighboring regions. Until 168 A.D. education was mainly in the hands of the Greeks. Little is known of it, however, because of an almost complete absence of Albanian literature. It appears that after the downfall of Rome, Albania entered a period of deterioration, from which it has never recovered.

Albanian educational development has been greatly handicapped by the fact that two dialects and two alphabets are in use. Furthermore, the Turks exiled every Albanian who tried to establish a school in which the Albanian language would be used, and made it a crime to possess a book in the Albanian language. Albania's language is different from the languages of its neighbors, and remains a philological problem. It is believed to be of Illyric origin. At least 10

1 Races, Nations and Classes, p. 55. 
per cent of the words are of undisputed Illyrian origin, and the remainder are disputed Illyrian-Pelasgian, ancient Greek and Latin, with a mixture of Slavic, Italian, Teutonic, and Turkish. Many of the words are much like the ancient Greek, and some writers think that the Greeks derived the names for many of their gods and much of their mythology from the Albanians.

The Albanians have never had a school system, and very few schools have ever existed. A number of schools were established about 1908, but the revolutions of 1910 caused them to be closed. The Albanians in the United States, most of whom learned to read and write their language here, have been the chief supporters of schools in their native land. Since gaining its freedom, Albania has been establishing schools and trying to force attendance. There were 530 public schools with 955 teachers and 30,766 pupils in the school year 1927-28. There were also 54 private schools with 122 teachers and 2892 pupils. At present Albania is said to be the most illiterate and backward country of Europe.

6. Social Conditions. In general the Albanians live the simple life of pastoral people. Every household produces practically everything it uses. Family life is mostly patriarchal. The blood feud and revenge are almost sacred institutions, and the blood tie is exceedingly strong. Not less strong is the brotherhood of choice. Young people wishing to become brothers bind themselves by solemn promise in the presence of their families, and each drinks a few drops of blood from the opened veins of the other. Tribal feuds, especially between Toshks and Ghegs, are common. The Catholic Mirdites allow no Mohammedan in their community. The Albanians are great warriors, and weapons are constant companions. They are brave, loyal to their tribe, reliable, hospitable, and chivalrous. It is claimed that a woman can travel where she pleases without fear of molestation, since "only a coward would harm a woman." 1 Monogamy, even among the Mohammedans, is the existing form of marriage. Talk, music, and dancing are the chief forms of recreation.

7. Immigration and Emigration. Colonies of Albanians early established themselves in other countries, notably Greece, Italy, and Yugoslavia, where they have largely maintained their language, customs, and traditions over hundreds of years. Some of the most

1 This protection is doubtless due to the bessa, or mountaineer code, which protects the holder absolutely. All women, men accompanied by women, and generally those incapable of protecting themselves come under this safeguard. 
noted men of Italy, Greece, Yugoslavia, and Turkey have been Albanians. As, until recently, no separate entry was made for Albanian immigrants, we know very little about the number admitted to the United States. Furthermore, many probably said they were Greeks because they belonged to the Eastern or Greek Church, while others called themselves Turks because they were Moslems. In 1920 there were 5515 foreign-born whites in the United States who gave Albanian as their mother tongue; of these, 5086 gave Albania as the land of their birth. Between 1924 and 19301663 Albanians came to the United States as immigrants. Our present law permits 100 Albanians to enter each year as immigrants, the same number as could enter under the two per cent law.

\section{QUESTIONS, EXERCISES, AND PROBLEMS FOR INVESTIGATION}

1. Trace briefly the ethnic origin of the inhabitants of Yugoslavia. Besides the text, see Bowman, I.: The New World, Chap. XV; Milojević, B. Ž.: "The Kingdom of the Serbs, Croats, and Slovenes; Administrative Divisions in Relation to Natural Regions," Geographical Review, Vol. XV, pp. 70-83; "The New Kingdom of Jugoslavia: Maps and Note," Foreign Affairs, Vol. VIII, pp. 297-300.

2. Geographically speaking, what dangers encircle Yugoslavia?

3. Discuss the disharmonic relationships existing in Yugoslavia.

4. What are the economic assets of the republic? Besides the text, see Atwood, W. G.: "Yugoslavia's Resources and Beauty," Current History, Vol. XIII, pp. 278-86.

5. Describe the religious mixtures in Yugoslavia and indicate how they affect racial relationships. Account for the high rate of illiteracy in Yugoslavia.

6. Under what foreign powers have the Serbs lived? Explain more in detail the statement that the Yugoslavs "have been the pawns in the intrigues of practically all of the large nations of Europe."

7. Abstract one of the following: Pavitchich, A. T.: "Early Yugoslav Civilization," Yugoslav Review, Vol. II, pp. 2-7; Chater, Melville: "Dalmatian Days," National Geographic Magazine, Vol. LIII, pp. 4790; Armstrong, H. F.: "Italy, Jugoslavia and Lilliputia," Foreign Affairs, Vol. VI, pp. 191-202.

8. Make a study of the present political conditions in Yugoslavia. Besides the text, see Armstrong, H.F.: "The Royal Dictatorship in Jugoslavia," Foreign Affairs, Vol. VII, pp. 600-15, and "Jugoslavia Today," ibid., Vol. I, No. 4, pp. 82-104; Heathcote, Dudley: "The 
Problem of Croatia," Fortnightly Review, Vol. CXVI, pp. 385-92; Montgomery-Campbell, M.: "The Psychology of Italian and YugoSlav," Nineteenth Century, Vol. LXXXVI, pp. 889-98.

9. Discuss the difficulties in making a satisfactory study of Yugoslav immigration. To what countries do they go? Where do they settle in the United States? What immigrant heritages in particular does H. A. Miller point out as coming from Yugoslavia? See Immigrant Backgrounds, edited by H. P. Fairchild, Chap. X.

10. Distinguish the different groups in Albania, and report on the Albanians as a racial and cultural group. In addition to the text, see Dictionary of Races or Peoples; Ripley, W. Z.: The Races of Europe; Pittard, Eugène: Race and History, pp. 284-94.

11. What facts in the religious history of Albania would lead the Albanians of Pittsburgh to be so willing to change their religion, if so doing would have any influence on the independence of their country?

12. Characterize Albanian social life, and show the difficulties in education.

13. Abstract one of the following: Stirling, W. F.: "Albania," Nineteenth Century, Vol. XCIX, pp. 495-501; Nowack, E.: "A Contribution to the Geography of Albania," Geographical Review, Vol. XI, pp. 50340; Miller, W.: "Albania and Her Protectress," Foreign Affairs, Vol. V, pp. 438-45. 


\section{CHAPTER XXI}

\section{BULGARIA}

1. General Description. The Kingdom of Bulgaria is located in southeastern Europe, on the Black Sea. Rumania, Yugoslavia, Greece, and Turkey are its neighbors. Its territory contains 39,814 square miles, and is about the size of Kentucky. In 1927 it had a population of 5,596,800. Sofia, the capital and largest city, had a population of 213,002 . About 85 per cent of the people of Bulgaria are of Bulgarian origin. About 70,000 Bulgarians were transferred to Yugoslavia as a result of the World War, and a smaller number to Greece. Before the World War considerable numbers were living in Turkey, Russia, and other parts of Europe.

The Bulgarians are a strange mixture and very difficult to classify. Biologically and culturally they represent fusions of early groups, whose history is not well known. It appears that an ancient ThracoIllyrian group was overrun by Slavic tribes between the third and the sixth century. The Bulgars, a Ural-Altaic group akin to the Tartars, Huns, Avars, and Finns, appeared in the latter part of the seventh century, and overran the more civilized Slavs. The Bulgarians gave their name, political organization, and slight Mongolic appearance to the Slavs, but lost their language and most of their customs. Apparently another influx of Slavs followed. Later, groups of Turks, Tartars, Circassians, and Gypsies came into the country and continued to exist as more or less isolated pools. To a great extent, however, amalgamation has taken place, and as a result very few of the present inhabitants claim to be pure Bulgarians. High cheek bones and narrow eyes are about the only Asiatic features retained. Nevertheless some authorities classify the Bulgarians as Mongolic, but the Bulgarians believe that they are Slavs and are generally so classed. Ripley ${ }^{1}$ says that they " are merely Slavonized Finns." Although most of the Bulgarians have broad heads, long heads are rather frequent, especially in the eastern part. This fact seems to point to a pre-Mongolic invasion. About two-thirds of the present Bulgarians are brunettes, but blue eyes and light hair are

\section{The Races of Europe, p. 405.}


common. In general the Bulgarians are large-boned and stockily built. Biologically and culturally they appear to be more closely related to the Slavs than to any other group, and because of these factors are here placed with the Slavs.

2. Political Development. Bulgaria was early settled by wild Thracian and Illyrian peoples with a loose form of tribal government. Philip II of Macedon appears to have been the first ruler to unite the people of what is now Bulgaria and Macedonia under one government. During the Second Punic War, Roman soldiers invaded the country and brought it under the Roman Empire in 29 B.c. Although a large number of the people spoke Latin, and it was said in the fourth century that the people were half Roman and half barbarian, the Roman occupation made no deep impression on the country, as it did on Rumania. Groups of Goths and Huns also overran the country without materially affecting it. But in 679 the Bulgarians crossed over the Danube and left a lasting impression. The Bulgarians and Slavs, being the antithesis of each other, brought together two widely different racial groups, languages, and civilizations. The Bulgarians were nomadic warriors with a central authority; the Slavs were settled farmers and keepers of cattle, living peacefully under a loosely connected tribal administration. At the end of two and a half centuries, the amalgamation of the two groups was practically complete. In the ninth century the Bulgarians north and south of the Danube were united under the leadership of Krum (Crum) (802-15). They defeated the Avars, captured Sofia from the Greeks, and established an autocratic monarchy, extending from Adrianople to the Carpathians. During the reign of Boris (852-84), Bulgaria was converted to Christianity and came under the influence of the Greeks.

Under Simeon (893-927) the first Bulgarian Empire was established, and Bulgaria reached its Golden Age in political power, territorial expansion, and literary excellence. Simeon had been educated in Constantinople, but returned to his native country and took the title of Tsar fully five centuries before Russia employed the term for its rulers. Being a great warrior, he extended the boundary from the Black Sea to the Adriatic, from the Slavic kingdoms of the Carpathians to Thessaly. At no other time has Bulgaria included so much territory or been so powerful. His son Peter proved too weak to maintain his father's kingdom. Allying themselves with the Russians, the Greeks took advantage of Peter's inability. The Russians 
appeared in 967 , the date which marks the beginning of Russia's meddling in Bulgarian affairs, but were repulsed. Boris II and Samuel after him also proved themselves too weak to maintain the former prestige of Bulgaria. The Greeks continued to war with the Bulgarians. Serbia, which had been brought under Bulgarian rule, gained its independence.

Between 1018 and 1186 Bulgaria was ruled by Greece. It was during this period that the Albanians first gained prominence, and that the Kumani, a wild gypsy tribe, speaking a language akin to Turkish, appeared and joined their kinsmen, the Petchenegs, adding another disturbing factor to Bulgaria's difficulties. In the first few years under Greek rule there were a number of insurrections, but the Bulgarians lost courage and during the last sixty years general quietness prevailed.

The second Bulgarian Empire existed from 1186 to 1398 . In 1186 two men of noble lineage, Peter and John Asên, of Trnovo, the ancient capital of Bulgaria, went to the Greek authorities and requested commissions in the army and a grant of land. John received a slap on the cheek from the highest court official. He returned home and started an insurrection which led to the independence of Bulgaria. Under Asên II the Bulgarian domain reached the Black, Aegean, and Adriatic seas. After his death Bulgaria came under the rule of Turkey, where it remained until 1878.

For almost five centuries Bulgaria had no history. Politically it was under the Turks and religiously under the Greek Byzantine Patriarch. There were a few insurrections in the early period of Turkish rule, but these were crushed with great severity. To escape persecution many Bulgarians became Mohammedans and said they were Turks, while others claimed to be Greeks. The Bulgarian language disappeared from churches and schools, and Greek took its place.

During the eighteenth century Father Paisii, a historian and monk of Mount Athos, wrote his history of Bulgarian tsars and saints. It is a panegyric of Bulgarian history. He reminded the Bulgarians that their country was the first Slavic land to become Christian, to have a Christian church and a Christian school, to have an alphabet, produce writers, and develop a system of education, and also the first to have saints. He assailed the Greeks for destroying the Slavic literature and language and trying to Hellenize the people. He pleaded with the Bulgarians not to forget their beautiful language 
and not to be ashamed to call themselves Bulgarians. The effect of the book was almost magical. The Bulgarians awoke to national consciousness, and there was a revival of everything Bulgarian.

In 1876 an insurrection took place, and the Turks butchered 12,000 unarmed Bulgarian Christians. This aroused the European nations and an investigation was undertaken. Disgusted at the delay, Russia declared war on Turkey. Rumania joined Russia, and the Bulgarians did all in their power to aid the Russians. Turkey was defeated and the San Stefano Treaty was signed. Serbia, Rumania, and Montenegro were to be absolutely free. A free Bulgarian state which included most of Macedonia and a large part of the Aegean coast was to be established. Russia was to have Dobruja to exchange with Rumania for Bessarabia. This raised a storm in England, and the government, conniving with Austria, dispatched a fleet to Constantinople to drive out the Russians. Tsar Alexander II was forced to submit the whole matter to the Congress of Berlin. After a long and stormy session it was decided that Rumania, Serbia, and Montenegro should be absolutely free and that Bulgaria (without Eastern Roumelia and Macedonia) should be a principality under the suzerainty of the Sultan. Bosnia and Herzegovina were left subject to Turkey, but certain reforms were to be administered by Austria. Thus, because of England's economic jealousy of Russia, thousands of Balkan people who had fought and gained their independence were left under Turkish rule. The treaty caused Tsar Alexander to lose favor in the eyes of his own people, and almost embroiled him in war with his ally, Rumania; it also caused the Bulgarians to develop an intense hatred of England and Austria-Hungary.

About seven years after the Treaty of Berlin, the Bulgarians of Eastern Roumelia, who had never acquiesced to the treaty, effected a bloodless revolution and joined Bulgaria. Although this was against the treaty, none of the powers objected except Serbia, which declared war to its own detriment. In 1908 Bulgaria and Austria both disregarded the Treaty of Berlin. Bulgaria declared its independence of Turkey, and Austria annexed the two Turkish provinces, Bosnia and Herzegovina.

After the Ottoman revolution in 1909, the Young Turks began a movement to Ottomanize all races within the domain of Turkey. This Bulgaria, Greece, Serbia, and Montenegro resented. Laying aside their petty quarrels, they bound themselves together in a common cause against Turkey. During the summer of 1912, while 
Turkey was in an exhausted state after its war with Italy, and also harassed by mutinous outbreaks in Albania, rumors were again spread that the Turks were massacring the Christians in Macedonia. The Balkan states and Turkey mobilized their troops. The powers behind the Berlin Treaty informed the Balkan states that there was to be no "modification of the territorial status quo in European Turkey." Montenegro immediately declared war on Turkey and called on its allies for assistance. The fiercest of the Balkan wars was now on, and Turkey was the loser. A peace conference was arranged in London, but Turkey would not concede the demands of the victors. In the meantime the Young Turks effected a coup d'état and set up a cabinet with the motto "No surrender"; and the war was on again. By the next spring the Turks were again on their knees. Serbia and Bulgaria had agreed to a division of the spoils, but Austria-Hungary, Italy, and Germany forced Serbia to relinquish the highly desired Adriatic port of Durozzo, and Montenegro to withdraw from Scutari. Strong protests came from Russia, and the World War was narrowly averted. Serbia was now unable to expand to the south as had been planned, and requested a new division of the spoils, which Bulgaria refused. Serbia declared war on Bulgaria; Montenegro, Greece, Rumania, and Turkey joined Serbia. The "July War" ended disastrously for Bulgaria. A peace conference met in Bucharest, and, ignoring Turkey, all the Balkan states signed the treaty. Bulgaria was left alone to settle with Turkey. Rather than have a third Balkan war, it permitted Turkey to retain the territory around Adrianople, though it cut Bulgaria off from the newly acquired Aegean coast.

As a result of these two Balkan wars, Turkey lost 54,900 square miles of territory. The creation of an independent Albania took away 11,000 square miles. Greece received 17,000 square miles; Serbia 15,200; Bulgaria, 9600, and Montenegro 2100. Although Bulgaria bore the brunt of the wars, it did not receive what it expected; it was, however, the second largest Balkan state. Fully 200,000 soldiers had laid down their lives, and some $\$ 1,500,000,000$ had been expended on the war. At the close of the second war the Bulgarians hated Serbs and Greeks more than Turks.

But for the fact that an Austrian Prince was on the Bulgarian throne, and that the hatreds resulting from the Second Balkan War were intense, Bulgaria perhaps would not have joined the Central Powers in the World War, thereby allying itself with Austria-Hungary 
and Turkey, two of its former enemies. The Bulgarian soldiers fought bravely, but not whole-heartedly. They had been in disputes with Russia, but they remembered Russia as their deliverer and did not like to fight against it. Trusting the United States, France, and England, Bulgaria made an unconditional surrender. Its Aegean Sea front and Thrace were torn from it for Greece, and a strip of territory, Tsaribrod (Caribrod), with some 21,000 Bulgarians and practically no Serbs, Strumitsa (Strumica) with 25,000 people mostly Bulgarians, Bosilegrad, with 22,000 Bulgarians and no Serbs, and Timok Valley were given to Serbia, on the ground that their possession by Bulgaria would be dangerous for the railroad between Salonika and Nish. The country was also left bankrupt.

3. Economic Development. Bulgaria is traversed by two mountain ranges, running in an east-west direction, with broad fertile valleys between. The climate is generally temperate, but changes are sudden, and the winters, especially in the northern part, are very cold and the summers hot. Fertile valleys and a scarcity of undeveloped mineral resources cause Bulgaria to be primarily an agricultural country. Two-thirds of the people are in this occupation. It is a land of peasant proprietors. With the exception of some rather large tracts of land owned by monasteries, there are no large estates. Some of the Turkish noblemen had large estates, but these were seized and divided among the peasants. The holdings are small, however, averaging eighteen acres, and smaller holdings of from one to six acres are common. The agricultural lands are held in fee, while the pasture and wood lands are held by the communes in perpetuity. Agriculture is in a very backward state. Fertilizers, rotation of crops, and modern farm machinery are hardly known. The government, however, has established a number of agricultural schools, and farming conditions are improving.

About 30 per cent of the land of Bulgaria is in woods, but most of this is mere brush, owing to devastation of the forests by the Turks to prevent them from being used as hiding-places by Bulgarian refugees and bands of outlaws. As a result there is very little timber, and lumber is not a great source of income.

There are several kinds of minerals in Bulgaria, but the coal mines are the only ones developed. Industry is little developed. In 1922 there were only 1540 manufacturing establishments. In 1927 167,000 people were employed in manufacturing. The railroads are state owned and perhaps are in the best condition of any in the Balkans. 
Bulgaria early became a commercial country and hoped to do so again, but the Allies shut it off from the Aegean Sea by giving Greece a narrow strip of Bulgarian territory, in some places not over ten miles wide. They promised Bulgaria an outlet to the Aegean, but so far the offers made have been unacceptable. Tobacco, maize, wheat, barley, hides, petroleum, and attar of roses are its chief exports; the chief imports are textiles, metals, and machinery.

4. Religious Development. The early inhabitants of Bulgaria were nature worshipers, and elements of this religion still exist in remote sections. Before the coming of the Bulgarians, Christianity had been introduced among the Slavs. The Bulgarians burned their dead and sacrificed the wives and slaves at the husband's death. The Slavs sometimes cremated the dead, but did not kill the wives at the husband's death.

During the ninth century two Greek brothers, Constantine (Cyril) and Methodius became "Apostles of the Slavs." They composed the Slavonic (Cyrillic) alphabet, which is so widely used among Slavic peoples, and translated religious literature into Bulgarian. The Bulgarian language of their day survives in the Orthodox Church and is known as Old Slavonic. Tsar Boris, seeing that Bulgaria was becoming isolated, accepted Christianity (864) but, being more interested in politics than theology, hesitated between the Greek and the Roman Church. After negotiating with both, he decided that it would be to Bulgaria's advantage to unite with the Greek Church (869). The Roman Catholic Church officials immediately withdrew from Bulgaria. Pagan uprisings, for the purpose of substituting a pagan ruler for Boris, were common and difficult to suppress.

In the early part of the tenth century there arose a religious sect, founded by a priest named Bogomil, which became troublesome to the southeastern rulers. The Bogomils rejected the sacraments and rituals, considered ikon-worship idolatry, abhorred the cross, rejected all the Bible except the Gospels, Epistles, and Apocalypse, and gave a psychological interpretation to the virgin birth and all the miracles. They opposed war - in fact the killing of anything but snakes - and recognized neither civil nor spiritual authority in government and churches.

It is apparent that such teaching would be disturbing to the hierarchal systems of the Greek and Roman churches. The Bogomils were frightfully persecuted, but continued to increase until they were an important element in the population of southeastern Europe. 
While Bulgaria was subject to the Greeks (1018-86) the Greek Church was naturally influential. But during the second Empire Tsar Kalojan, for political purposes, brought Bulgaria again under the Papacy. This, however, had little real influence upon the dogmas or ritual of the Bulgarian Church. Kalojan's successor, Asên, threw off the yoke of the Papacy and declared the Church of Trnovo independent of both Rome and Constantinople. He reformed the national church but permitted his subjects to worship as they pleased.

At first the Turks did not interfere with the Christians, but later they persecuted them. As the Bulgarians were politically under the Turks and spiritually under the Greeks, the two ruling groups united in suppressing them. The Greeks tried to destroy all Bulgarian books, manuscripts, even the language itself, and substituted their own language. The Greek Church became a political machine. Church offices were freely bought and sold; barbers suddenly became bishops, and bakers priests. The Turks also engaged in systematic suppression. Bulgarians were not permitted to build churches or buy church bells, and many churches became mosques. Bulgarian Christians over 14 years of age were required to pay a poll tax, and a tax was placed on their cattle and other possessions. Two groups of Bulgarians escaped most of these discriminations. One group placed their swords at the disposal of the Sultan, and for some time escaped taxation and other burdens. Another group became Mussulmans (Pomaks) and were well paid for their hypocrisy by being given possession of large estates on which Christian serfs had to give a certain amount of free labor. Weary of these conditions, the Bulgarians made efforts again to have a free church. This they accomplished in 1870 . The first national church was established' by Simeon, the second by Asên II, the third by the Bulgarian people. About three-fourths of the people belong to the national church. There are also some 650,000 Mohammedans, 70,000 Greeks, 40,000 Jews, 15,000 Armenians, and 6000 Protestants in Bulgaria. All clergy are paid by the state and full freedom of worship is guaranteed.

5. Educational Development. Of all the Balkan countries, Bulgaria is said to have made the greatest educational progress in the shortest length of time. ${ }^{1}$ In the first half of the nineteenth century Bulgarian education began to assume national importance, and in 1835 the first school was established. In 1856 the Bulgarians were promised their

1 Compare Monroe, W. S.: Bulgaria and Her People; Russell, W. F.: Schools of Bulgaria; Educational Yearbook, 1924, edited by I. L. Kandel. 
own language in church and school, but were disappointed. Finally, after ten years (1860-70) of struggling, spiritual independence was won from the Patriarch at Constantinople and the way paved for educational advancement.

The Bulgarian Exarchy, formally recognized by Turkey in 1871, served unofficially as the ministry of education. Although created to look after religious interests, its efforts were principally directed toward providing better educational facilities in the various Bulgarian communities. The School Sobors of the Bulgarian parishes, however, were exceedingly critical of the reforms and policies of the Exarchy.

Elementary education is free and compulsory for children between the ages of 7 and 14. Special attention is given to the teaching of Bulgarian and old Slavonic. Commercial and vocational training is provided in secondary schools and in separate institutions. Sofia, the state university, had a faculty of 346 and an enrolment of 4508 in 1924; the free university, which is private, had 1500 students. Bulgaria has been conspicuous among the Balkan states for its attention to matters of hygiene and sanitation among school children, and for its summer colonies for weak and undeveloped children. Another outstanding feature of its educational program is the insistence of Tsankoff upon academic freedom for teachers and stability in tenure of office. "In all modern democracies," he says, "the professor today plays one of the most beneficent and salubrious rôles in the destinies of his country." 1

6. Social Development. The union of the Bulgarians and the Slavs at first produced hatreds and jealousies, but during the next two and a half centuries, as the two cultures fused, the people came to show more cohesion, virility, and ambition than the other Slavs. As a result the Bulgarians early became a civilized nation. Under the Turks and Greeks they appeared to atrophy. Many became ashamed to admit that they were Bulgarians, but with the revival of nationalism, Bulgaria, remembering its Golden Age, assumed an attitude of superiority, and attributed its backwardness to suppression by its neighbors.

Bulgaria, because of its situation, holds the key to the Balkans, and perhaps because of this it has suffered more from the scheming of larger nations than any other Balkan state. Turkish rule, the Balkan wars, the World War, and numerous intrigues of the large nations have made the Bulgarians suspicious. They appear to be peace-

1 Compare Educational Yearbook, 1924, p. 57. 
loving, but the conditions under which they have lived have developed in them hatreds, prejudices, and a readiness for warfare.

Present-day family life in Bulgaria, shows traces of the zadruga, in that several married brothers with their families are often found living in the same house. The zadruga was an early kinship organization in which relationship was traced through the males. Whether the tendency of brothers and their families to live together is a survival of the zadruga pattern, or whether it is an economic necessity, cannot be stated.

Like many other European countries, Bulgaria has its peasant village communities. The peasants live in these village communities or on the outskirts of the cities, and go out to cultivate their crops. Meetings around the village well or at the inn or store, and the folkdance offer opportunities for social intercourse.

7. Immigration and Emigration. Bulgaria was late in sending immigrants to the United States. Yet America, chiefly through Roberts College of Constantinople, has played an important part in Bulgarian thinking, and until the end of the World War Bulgaria had great respect for the United States. But the unjust treatment which it received at the end of the World War caused it to lose respect for the Allied nations, and especially the United States, since in us it had placed its hope.

As Bulgarian immigrants were formerly grouped with those from Serbia and Montenegro in our immigration reports, and often confused with Turks, Greeks, and other Balkan peoples, we do not know how many have been admitted to the United States. A great deal of confusion has existed regarding the number of Bulgarians from Macedonia and other non-Bulgarian territories. In fact, many of the people of Macedonia have slight idea of what they are, as the area has been "conquered and reconquered, ravaged and raped back and forth, nationalized and denationalized so often that even the Last Judgment will find it difficult to settle once for all the question of its racial identity." 1

Apparently the rate of Bulgarian immigration has been low, but higher than the rate for Bohemia and Russia proper. In 1910 there were in the United States 18,341 people who gave Bulgarian as their mother tongue, and 12,853 in 1920. According to estimates, some 80 per cent of the Bulgarians in this country are from Macedonia, and 95 per cent are of Slavic stock. Yet, according to the 1920 census,

1 Keyserling, Count Hermann: Europe, p. 321. 
9462 of the 12,853 foreign-born whites who gave Bulgarian as their mother tongue were from Bulgaria, and only 2651 from Greece. For the decade ending in 1900 we received only 160 immigrants from Bulgaria, 39,280 for the next decade, 22,533 for the next, and 2945 for the next - a total of 64,918 for the four decades ending in 1930. As only 12.1 per cent (rank 40) of our Bulgarian immigrants were naturalized in 1920, it would appear that they do not come here to make this country their home; yet Bulgarians ranked second among the nationalities having their first papers. According to estimates, about 90 per cent of the men come alone. About 70 per cent of those that come worked on farms at home, but here enter industries, mainly in Ohio, Michigan, Illinois, and Pennsylvania. Statistics regarding illiteracy are conflicting. According to some authorities, about 78 per cent were illiterate, but about 20 per cent had some knowledge of English.

Evidently the chief reason for the Bulgarians' leaving their native land is economic. Being an agricultural country with small holdings and a dearth of factories, Bulgaria affords very limited opportunities. Another factor is the high taxes; it takes from one-fourth to one-third of a farmer's yearly income to pay the national taxes. The World War rendered conditions much worse. Bulgaria not only lost much of its land and many of its citizens, but it had to care for many refugees, give up its demands for access to the Aegean Sea, deliver to Greece, Rumania, and Serbia 70,000 head of live stock as restitution, agree to contribute to the liquidation of the pre-war external debt of Turkey, and pay $\$ 4,825,000$ for the army of occupation, and $550,000,000$ gold francs (reduced in 1930 to 37 yearly payments of $11,500,000$ gold francs per year) for reparations. Its economic survival appears difficult. Emigration seems to be the only alternative for many of its citizens.

\section{QUESTIONS, EXERCISES, AND PROBLEMS FOR INVESTIGATION}

1. Explain: "The Bulgarians are a strange mixture and very difficult to classify." Besides the text, see Dictionary of Races or Peoples; Ripley, W. Z.: The Races of Europe, passim; Pittard, Eugène, Race and History, pp. 288-92.

2. What cultures swept over Bulgaria? Which apparently had the least effect? 
3. Show how Bulgaria has been sacrificed to the individual interests of other nations. In what ways did it exhibit a national consciousness?

4. Account for the emphasis the Bulgarian government has placed on agriculture. What are Bulgaria's prospects for becoming an industrial country?

5. Characterize the Bogomils, and explain why the Greek and the Roman Church opposed them.

6. Trace the difficulties growing out of the conflict between the Greek and the Roman Church. How did these affect Bulgarian education?

7. Describe Bulgarian peasant life. Besides the text, see Petroff, Louis: "Peasant Primary Groups in Bulgaria," Sociology and Social Research, Vol. XIII, pp. 557-65.

8. What are Bulgaria's own immigration problems? What are the chief causes for emigration from Bulgaria? Compare Bulgarian immigration to the United States with that from other foreign countries.

9. Contrast Bulgaria's post-war situation in the Balkans with its pre-war one. References. Armstrong, H. F.: "The New Balkans," Foreign Affairs, Vol. III, pp. 293-312; Polyzoides, A.: "The Balkans as an Element of European Peace," Proceedings of the Academy of Political Science, Vol. XII, pp. 287-98; Pears, E.: "Bulgaria's Past and Present History," Contemporary Review, Vol. CXIV, pp. 484-88.

10. What are the forces underlying Bulgaria's aspirations to the Aegean? See Armstrong, H. F.: "Bulgaria and the Aegean," Foreign Affairs, Vol. V, pp. 148-51.

11. What has been Bulgaria's particular problem in regard to population exchanges and other migration problems? Reference. Atkinson, Meredith: "Bulgaria and the Refugee Crisis," Nineteenth Century, Vol. XCIX, pp. 195-202.

12. Abstract Bogory, N. de: "A Simple Folk with a Heart," Outlook, Vol. CXXXV, pp. 536-39. 



\section{PART V}

\section{OTHER RACIAL, NATIONAL, AND CULTURAL GROUPS}

The areas included in this section total approximately $28,560,180$ square miles, and their populations total approximately 1,068,225,000. Within them are found every race and every variety of culture, so mixed that no significant classification is possible. Consequently political divisions will be largely followed.

Within them are found several million Europeans who belong to the so-called Aryan race, but they have been dealt with under the Teutonic, Latin, and Slavic divisions. There are also other Aryan groups, such as Persians, Afghans, and Hindus, which are treated under the national divisions. The Mongolian is numerically the largest group or division discussed in this section, but the Semitic, Malay, and Negro groups are important. Although a large part of Asia is now in the barred zone, and none of the people we shall consider, except the Finns, Magyars, Esthonians, Chinese, Japanese, Jews, and Syrians, are of much importance from the point of view of numbers in the United States, all are important from the standpoint of indirect influence and as a possible source of future immigrants.

The Mongolian group is ordinarily divided into two main branches Sibiric and Sinitic. The Sibiric includes the Finnic (Finns, Lapps, Esthonians, Magyars, and Bulgarians), Tartaric (Turks, Cossacks, etc.), Japanese (Japanese and Koreans), and Mongolic (Kalmuks). The Sinitic embraces the Chinese, Tibetans, and some East Indians, especially the Indo-Chinese. The Semitic group is composed of the Arabic (Arabs) and the Chaldaic (Hebrews and Syrians). The Malay group includes certain East Indians and Pacific Islanders. Most of the people in Africa and adjacent islands are placed in the Negro (Ethiopian) group.

The Mongolians are characterized by a yellow skin, short or round head, rather flat face, and the "Mongolian eye." Apparently this group arose in central Asia and spread in several directions. Part went far into Europe. If we agree with some ethnologists, we may include in the Mongolian division not only the Eskimos of the Arctic regions and the Indians of the New World, but also the entire Malay group. Huxley includes in it the Polynesians and Indonesians, groups which some think represent an early Caucasian elc- 
ment in the Pacific. Estimates vary widely as to the number of people in the world who should be classified as Mongolians. Perhaps between 600 million and 900 million could be so classified. The Sibiric branch of the Mongolian division reveals considerable biological amalgamation and cultural fusion. The Finns, Esths, and Magyars have largely become Europeanized; yet they retain their Ural-Altaic (Turanian) speech, which is agglutinative in contrast with that of the Sinitic branch, which is monosyllabic.

The Semitic division is usually associated with the Hamitic, because the two are thought to have been closely related biologically and culturally, though they now differ considerably, especially in language. The Semitic division includes the Arabians (Arabs, Bedouins, etc.), the Chaldeans (Assyrians, Babylonians, Israelites, Aramians, Syrians, etc.), and the Abyssinian branches. Hamitic is the term applied to the Libyans (Berbers, Riffs, etc.), Egyptians (Copts and Fellaheens), and East Africans (Gallas, Somalis, etc.).

The Semitic-Hamitic stock has an inflected language like that of the Aryans and is classified as Caucasian. Many of them, however, especially the Hamites, are easily mistaken for Negroes. Some of the Berbers of North Africa, on the other hand, are very fair and are probably Nordics. The Semites are thought to be indigenous to southwestern Asia, and the Hamites to northern Africa. However, the Abyssinians, a division of the Semites, are found in Africa, and some ethnologists claim that the Hamites came from the Euphrates region.

The Semitic-Hamitic division, numbering some 50 million people, covers about one-third of Africa and a considerable area in southwestern Asia. In Africa are found the Copts and Fellaheens of Egypt, Berbers and Riffs of Morocco, Zouaves and Kabyles of Algeria, the Senagas of Senegal, and the Abyssinians and "Ethiopians" of East Africa. Since the territories of many of these people border on the lands of the Negroes, amalgamation has taken place to a considerable extent. Sergi thinks that the Hamites originally peopled southern Italy and other areas along the north shore of the Mediterranean Sea. The Arabs, Syrians, and Hebrews are well-known groups of the Semitic branch. Many of these people, especially the Hebrews, have wandered far from their original home, and largely become Europeans in blood and language. Excepting the Hebrews and Christianized Syrians and Abyssinians, practically all of these people are Moslems.

Blumenbach made the Malay group one of his five grand divisions of mankind. It is the smallest of the large groups, including only 35 millions. These people largely inhabit the Malay Archipelago and Peninsula, Madagascar, part of Indo-China, and certain islands of the Pacific and Indian oceans. Physically the Malays are closest to the Mongolians and are often included with them. The Malays have a brown color which often approaches the Chinese yellow. Many have distinct "Mongolian eyes," and their general facial and head appearance is similar to that of the Mongolians. In language and culture, however, they differ markedly from the Mongolians. They 
speak the so-called Polynesian tongue, and have the tropical culture found among backward peoples of hot climates.

The Negro division of mankind is generally characterized by black color and woolly hair. There is a variety of opinions among ethnologists as to who should be classed as Negroes. All seem to be willing to include the peoples inhabiting the central and western third of Africa as Negroes. This includes the Sudanese, from whom most of our American Negroes came.

A few ethnologists exclude the Bantus because such subdivisions as the Zulus are a reddish-brown and never sooty black like "true" Negroes. Others would place the Bushmen and Hottentots of South Africa in a special division, because they appear to be as much Mongolian as Negro. Still others would reject the so-called Oceanic Negroes of Malaysia, the Papuans of New Guinea, and the Australian black fellows who do not have kinky hair. Almost all exclude the Dravidians and Veddahs of India.

Excluding the Veddahs and Dravidians, most authorities classify some 150 million people as Negroes. It is generally thought that they evolved in Africa. Keane, however, maintains that they spread from a now submerged continent. The state of civilization among these people, especially among the aborigines of Australia, the Negritos of Malaysia, and the Negrillos of Africa, is very low. 



\section{CHAPTER XXII}

\section{FINLAND AND ESTHONIA}

1. General Description. The Republic of Finland and the Republic of Esthonia border on the Gulf of Finland in northwestern Europe. Finland is between Russia, Norway, and Sweden, while Esthonia is bounded by Russia, Latvia, the Gulf of Riga, the Baltic Sea, and the Gulf of Finland. Finland contains the former Grand Duchy of Russia, and Esthonia comprises the former Russian province of Esthonia (Estland), the western part of Pskow (Pskoff), and the northern part of Livonia (Livland). Both republics were at one period a part of Sweden, at another a part of Russia; and both gained their independence as a result of the World War.

Finland is the most northern nation in the world. About onethird of its territory lies within the Arctic Circle. Esthonia is south of Finland, across the Gulf of Finland. The area of Finland is 149,641 square miles; it is thus about the size of the New England states, New York, New Jersey, and West Virginia. The area of Esthonia (including about 90 islands) is 18,353 square miles; it is about the size of New Hampshire and Vermont. In 1920 Finland had a population of 3,366,507 (estimated to be 3,582,406 in 1927), and in 1929 Esthonia had a population of $1,116,474$. Helsingfors, the capital and largest city of Finland, had a population of 234,096 in 1927, and Tallinn (Reval), the capital and largest city of Esthonia, had a population of 150,000 in 1930. About 50 per cent of the people of Finland live in towns, and the population density ranges from one person per square mile in the north to 93 along the edge of the Gulf of Finland. Esthonia has a population density of 60 persons per square mile. In $19202,754,228$ of the population of Finland spoke Finnish, 340,963 Swedish, 4806 Russian, 2378 German, and 1603 Lapponic. In the old province of Esthonia there are about 30 Esths to one German, and in the former Province of Livonia Germans constitute only about one-fifteenth of the population. In 1929 the population consisted of 87.7 per cent Esthonians, 1.7 per cent Germans (Balts), and 10.6 per cent Russians and other nationalities.

As Finland is a glaciated rocky country, the soil is generally poor. 
About three-fourths of the land area is in forests, and about onethird of this is peat marshes and bogs. Lakes cover over 11 per cent of the surface of the country. Esthonia is generally low, with some fairly sharp ridges running from north to south. It is a moraine plain formed during the Glacial Epoch. The soil in the south is relatively fertile, but in the north there are large areas of oil shale, a combustible rock. Marshes and rivers are numerous, covering about $22 \frac{1}{2}$ per cent of the total area. Nearly 900 square miles, or 5 per cent of the total area, is occupied by lakes. Owing to the influence of the Gulf Stream, the climate is less severe than in Finland, and less so than one would judge from its location.

The Finns (Suomi) and Esthonians (Esths) belong to the group of people known as the Urgo-Finns, a branch of the Ural-Altaic (Mongolian) group of the human race. The Finns and Esthonians are closely related to the Lapps, Magyars, and Old Bulgarians, and more distantly related to the Turks, Tartars, Kalmuks, Koreans, Japanese, and other branches of the Sibiric group of the Mongolian division of the human family. Most probably the Finns and Esthonians migrated from Asia at an early date and were pressed into their present locations by the advancing Slavic tribes. The Finnish tribes appear to have migrated from the other side of the Baltic between the fourth and seventh centuries. One group seems to have migrated from Livonia or Esthonia by the island of Oesell, while another went by the Karelian Isthmus. A large group of people living in Karelia, Archangel, and Olonetz are Finnish biologically, but have been so Russianized that they have largely lost their identity. The Soviets, however, have granted them autonomy.

Inhabiting the northern part of Finland and.adjoining areas in Sweden and Russia are some 38,000 people, Lapps, who are closely related to the Finns. They have amalgamated with Finns, Swedes, and Russians to such an extent that no shade of hair, eyes, or complexion may be considered typical; yet they appear more Asiatic than the Finns. They are the most round-headed people in Europe, and are very short, averaging about 4 feet 7 inches in height. They inhabit the frozen waste of the tundra, and depend mainly on reindeer for food.

In general the Finns and Esthonians are short, have round heads, fairly flat faces, high cheek bones, Mongoloid eyes, thin beards, dark hair, and often dark complexions. In common with other members of the Sibiric group of the Mongolic division, they speak an agglu- 
tinative language. Both the Finns and the Esthonians have amalgamated with Swedes, Russians, and Germans to such an extent that many of them are very fair, with blue eyes and light hair. The long subjection of Finland and Esthonia to Sweden and Russia, and the influence of German Balts in Esthonia, caused the people to assimilate a considerable part of the culture of these nations. Sweden especially influenced Finland, and Germany Esthonia. Both peoples are mainly Lutheran in religion and have a number of other Teutonic culture residues. Our Bureau of Immigration used to include the Finns with the Teutonic division, and some writers think Finland should be classified as a Teutonic nation. There seems to be only slight justification, however, for such a classification.

2. Political Development. The Esths are known to have occupied their present site since the early part of the fifth century. They first appeared in history as a warlike tribe which terrorized Baltic commerce. Several Danish kings tried to subdue them without much success. Canute VI invaded their country in 1194-96, but failed to conquer them. Beginning in the thirteenth century, the Danes and Christian crusaders began a desperate conquest of their territory. Finally the Esths were conquered and many forced to become slaves. The German knights established themselves in the south, and Waldemar IV sold his territory to these knights or Balts, as they were later known. The Esths were reduced to a state of serfdom, in which they remained for some 600 years. In "the great rebellion" (1343), they made a masterful effort to regain their freedom, but failed. This did not kill their patriotism, but made them stubborn and resentful. In 1521 the nobles and town authorities voluntarily placed the territory under the protection of Sweden. The actual rule of Sweden, however, was from 1629 to 1710 .

Before migrating to their present home, the Finns came in contact with the Teutonic people and learned something of their civilization. In 1157, 1219-45, and 1249 Sweden undertook three expeditions to Finland and gradually conquered the country. This precipitated a dispute between Russia and Sweden over the boundary line in Karelia. The settlement of this dispute in 1323 determined for the first time the Finnish boundary, and united most of the Finns under one rule. Sweden began to develop the Finns; they were divided into four estates (nobility, clergy, burghers, and peasants), with full civil rights. Under Tsar John III (1568-92) there was another long war between Russia and Sweden. At the Peace of Teusina (1595) Sweden 
received Esthonia and a strip of territory to the north of Finland. At the Peace of Stolbova (1617) Sweden added two more Russian provinces to its territory. It then controlled practically all the Finns and Esths. The period of Swedish rule is the only bright spot in Esthonian history, and is referred to as "the good Swedish times." During this period the University of Tartu (Dorpat) was founded, the authority of the Balt landlords was curbed, and rents and other fees were determined.

The Thirty-Years' War caused great suffering in Finland and Esthonia, but the bravery of the Finns made them famous in Europe for the first time. During the Great Northern War, which broke out in 1700, Finland suffered dreadfully under eight years of Russian rule. At the Peace of Nystad (1721), Charles XII of Sweden ceded to Peter the Great, of Russia, Esthonia and part of Finland. Sweden's inability to ward off the seizure of Finland by Russia caused the Finns to become dissatisfied with Swedish rule. During the reign of Gustave III, the writings of Porthan (died 1804), a professor in the University of Turku, helped to awaken national consciousness among them. At the end of the war of 1808-09 Sweden was forced to cede to Russia the remainder of Finland, which had been a part of Sweden for 600 years.

The Russians ruled Finland and Esthonia for about 200 years. During this period the Esths had to struggle against both Balts and Russians. The Balts regained many of the privileges revoked by Sweden, and again made the life of the serfs almost unendurable. In 1804-05 the Esth and Lett serfs were technically offered opportunities to secure their freedom and land. This was not satisfactory to the Balts; consequently they made a proposition in 1811, which was accepted by Alexander in 1817, to free the serfs without land. Without land, the serfs were forced to continue working for their former masters. In 1861 they were granted the right to buy their own land, and thereafter began to derive some benefit from their labor. In 1869 , the fiftieth anniversary of their "freedom," the Esths were permitted to hold a song festival. This greatly strengthened their racial consciousness and made them more determined not to lose their identity. Seven of these song festivals were held before the Esths gained their freedom.

Under Russia, Finland became a Grand Duchy. Tsar Alexander I and his successor swore to uphold the Finnish constitution of 1772 and the Act of Union and Safety of 1789. In 1811 Alexander vol- 
untarily reunited Viborg, which Russia had taken from Sweden, and Finland. The results of outside meddling in Finnish affairs, however, soon became evident. Helsingfors (Helsinki) was proclaimed the capital instead of Turku (Abo). This act caused a keener feeling of nationalism to develop, and soon the expression of Arvidsson, "We are not Swedes; we don't want to be Russians; let us then be Finns," became the rallying cry.

During the reign of the autocratic Nicholas I (1825-55) true national feelings were born among the Finns. Snellman and Runeberg aided Finnish nationalism by collecting folk-sayings and causing the Finnish language to become the language of the intellectual group rather than that of peasants and day laborers only. Racial consciousness developed to such a degree that the Finns refused to speak Swedish or Russian. Under Alexander II a more liberal Finnish policy was pursued. The Diet, which had long been the chief governmental organ of the Finns, was assembled again after an interval of 54 years. Finnish was made the official language along with Swedish, a separate Finnish currency was established, and an elementary school system was organized. Up to the time of Alexander III the Finns had much freedom under Russian rule. They had their own Diet, representing the four estates, Senate, public debt, budget, laws, courts, flag, army, navy, schools, university, post and railways, and customs. They paid the Tsar, whose title was Grand Duke of Finland, 250,000 marks per year.

Upon the accession of Alexander III (1881-94) a Russification policy was inaugurated. Russian had been substituted for German in Esthonia in 1867, but as the officials were Balts, they made no effort to enforce the law. The Balts oppressed the Esths, but they made no efforts to Germanize them. Under the Russification policy officials of both the government and the Eastern Orthodox Church worked together. The Balts were affected as well as the Esths, since both groups were Lutherans and neither spoke Russian. Russian was made compulsory in schools and churches, and Orthodox churches were substituted for Lutheran. Various other suppressive measures were inaugurated. The Esths rebelled in 1905, but were put down with such cruelty that their cause seemed hopeless.

In Finland the Russian officials worked to destroy the Finnish constitution and to absorb Finland into Russia. Many newspapers were suppressed and others were suspended, Russian was made the language of the higher courts, laws were published in Russian, and 
spies were posted throughout the country. The chief struggle came over the attempts to conscript Finnish soldiers into the Russian army. The Finns adopted a policy of passive resistance. After three attempts at conscription the policy was abandoned, and the Finns were fined ten million marks per year. Within five years the Russians had made the peace-loving Finns a stubborn and rebellious people.

Liberal political ideas drifted in from Russia, and Finns and liberal Russians began to smuggle in arms and to institute a reign of terror by bombing and by killing Russian officials. Strikes, burglaries, and struggles between socialists and other political groups became common. These conditions, coupled with the reverses which Russia suffered in the Russo-Japanese War and the general dissatisfaction throughout the Russian domain, caused the Tsar to adopt a more liberal policy, and most of the constitutional rights of the Finns were restored.

In 1908 began the second period of Russification. The constitutional rights of the Finns were again violated; the Finnish assembly was dissolved; Russian troops were stationed in Finland; Finnish officials were removed, and Russians substituted; Russian was again made the official language of the courts; and another attempt was made to conscript Finnish soldiers into the Russian army. Furthermore, patriotic Finnish statesmen were imprisoned in St. Petersburg or exiled to Siberia instead of to a foreign country as formerly. Censorship and spying became the order of the day. Finland apparently had never desired independence and would have been content with merely its constitutional rights, but by the autumn of 1914 definite plans for complete independence began to take shape. At first it turned to Sweden, but the timidity of Sweden caused it to turn to Germany. Two thousand patriotic young Finns were smuggled into Germany to be trained in military tactics. After their initial training they were to return home to form the nucleus of a Finnish army of independence. Finland planned to revolt and to join Germany, when that country made an expected attack on St. Petersburg. However, these plans miscarried.

The Russian revolution offered both Finland and Esthonia an unexpected opportunity to strike for freedom. Both, however, experienced many difficulties before independence was completely won. Esthonia was overrun and pillaged, twice by German soldiers and twice by Bolsheviks. The party for complete independence in Fin- 
land was strong, and the first move was to establish a republic. But loyalty to Germany caused a limited monarchy to be set up, and Prince Karl of Hesse, brother-in-law of the Kaiser, was chosen king. The White Finns, with the aid of the Germans, defeated the Red party and drove out the. Bolsheviks. Then came the revolution in Germany, which caused Finland to establish a republic.

Finland patterned its government after that of the United States to the extent of adopting our electoral college. The president is chosen for a term of six years by a body of 300, who in turn are chosen by proportional representation by direct vote. Citizens of 24 years of age have the right of suffrage. The legislative chamber consists of 200 members elected directly on a proportional basis. State power in Esthonia is vested in the State Assembly (Riigikogu), which is composed of 100 members chosen for a term of three years by proportional representation and by equal, direct, universal suffrage. The State Head and the ministers form the government. They are chosen and confirmed by the State Assembly, and have no power beyond that which the assembly delegates to them. There is no presidency as we think of the office, but the State Head acts as chairman, without veto power.

3. Economic Development. The early Esths and Finns were hunters, fishermen, and herders. In the thirteenth century the crusaders and German knights, under the pretext of spreading Christianity, overran Esthonia and enslaved the people. For almost 600 years the Esths existed without land or rights. In 1875 the nobility, mostly Balts, owned 97 per cent of the land. The Balts, however, were interested in scientific farming. In 1918 the large estates and church lands, totaling $5,798,475$ acres, were declared to be the property of the state, but the former owners were to be compensated at a reasonable rate. These estates have been divided into small farms for the peasants. Out of these estates 10,000 homesteads and 39,997 farms had been created by 1928 . The law of 1925 allows the peasants to have the land in freehold or to purchase it from the state. The limit of the new farms is 185 acres, but the average farm is 54 acres. The government is helping the people to buy machinery and is training them in the latest methods of agriculture. About 23.5 per cent of the total land area is under cultivation, 36.9 per cent in grass and meadows, and 21.5 per cent in forests. The chief crops are rye, barley, oats, potatoes, and vegetables. Although the soil is generally poor, much food is exported. 
While about 60.4 per cent of Esthonia is under cultivation or in pasture, only about 8.5 per cent of the land area of Finland is thus used. Yet about 65 per cent of the people of Finland are engaged in agriculture and cattle raising, most of them being poorly paid agricultural laborers. The land purchase act of 1918-19 offers every farmer tenant an opportunity to purchase land, and is causing an increased interest in agriculture. The number of farms cultivated by owners increased from 110,000 in 1901 to 182,000 in 1920 . The farms are small, however, 78 per cent containing between 12.5 and 25 acres. Sometimes the crops fail, as they did in 1867 and 1869, and famine results. Only potatoes, hardy grains, root crops, and hay can be grown on a large scale, but these do not supply the home market. There are hundreds of coöperative dairies, and dairy products constitute one of its chief exports.

Lumbering is the chief industry in Finland. The state owns about 25 million acres of forests, most of which are productive. The net revenue from the forests was over 136 million marks in 1926. The forests are so scientifically managed that the annual growth is larger than the cut. It is estimated that the annual cut can be increased 50 per cent under improved methods of forestation. Only about onefifth of Esthonia is covered with forests, but it received a concession of 2,700,000 acres of timber lands from Russia. Lumbering, therefore, is an important industry in Esthonia.

Finland has a little workable iron, but almost no other minerals of economic importance. There are about 2000 square miles of shale rock deposits in Esthonia which form a good substitute for coal, and from which gasoline and oil are extracted. The peat beds are sufficient for several hundred years. Phosphorite, gypsum, naphtha, and "tervismuda" also exist.

Since both countries are maritime, fishing and commerce are important. Esthonia's location especially favors it for commerce, and Tallinn (Reval) possesses a fine harbor which is usually open all winter. Wood manufacturing, especially of matches and paper, textile manufacturing, and stock raising are other important occupations. Timber, paper, and pulp constitute about 87 per cent of the exports of Finland, and foodstuffs constitute about one-third of the imports. The chief imports of Esthonia are cotton, machinery, and metals, and the chief exports are dairy products, paper, potatoes, flax, and timber.

4. Religious Development. Several unsuccessful attempts were made 
to Christianize the early pagan Esths. Canute VI forced many of them to be baptized, but after his departure they returned to their old gods. Under the influence of the Balts, however, they became Lutherans, and have remained such. The Orthodox Church tried to stamp out Lutheranism when Esthonia became part of Russia, but failed. Today about 78.6 per cent of the people are Lutherans, and 19 per cent Orthodox. The remainder are mostly Roman Catholics and Jews. The new government recognizes no state church, and freedom of worship in any language is guaranteed.

The early Finns possessed very vague religious concepts. Their gods were dark in color and possessed wings and tails. They came out in the twilight to watch what the Russian gods were doing. At first the Finns resisted Christianity, but gradually they came to accept a mixture of Christianity and heathenism which still exists in some of the remote areas. Under the influence of Sweden the Finns became Roman Catholics, and remained so for four centuries. When Sweden became Protestant, Lutheranism was introduced into Finland, and because it employed the vernacular and manifested an interest in education, exerted a unifying influence. The church became so interested in education that it refused to publish marriage banns for any who could not read and repeat the Catechism. The Lutheran Church is the state church, and all but about two per cent of the population are of that faith. Freedom of worship is guaranteed.

5. Educational Development. The Finns and Esths owe much of their cultural achievement to the Teutonic peoples. Before the Finns separated from the Esths, they came in contact with Teutonic and Slavic peoples, and to a certain extent a fusion of cultures resulted. Later, both peoples were parts of Sweden, and their school systems followed the lines of development of the Swedish schools. As Finland was under Sweden longer, its educational system is more advanced than that of Esthonia. In 1640 the University of Turku (Abo) was opened. In 1874 the adult educational movement, which practically wiped out illiteracy, was started. Despite the suppressive efforts of Russia, Finland maintained an illiteracy rate of less than one per cent. An excellent public school system is in force and education is free and compulsory through the elementary grades. The three universities have some 4500 students. It is indeed remarkable that such a poorly endowed and economically handicapped country can maintain an excellent public school system, three universities, 
350 newspapers and periodicals, numerous learned societies, and a high level of intellectual life.

The Finnish schools have been somewhat handicapped because of the language situation. Before the development of Finnish, Swedish was the language of schools and polite society. In 1835 Professor Lönnrot published Kalevala, a collection of Finnish folk-songs, and thus inaugurated a Finnish revival. Gradually Finnish came to share equal honors with Swedish even in the University. When Finland became a part of Russia, more and more time had to be given to the study of the Russian language. As a result a large amount of time in the elementary schools had to be given to the study of languages. In the high schools students were required to study five or six languages. Today the National University and government are bilingual.

Educationally the Esths have had much the same experience as the Finns, and next to the Finns have remained the most literate of the peoples included in the former Russian Empire. Under the Russification policy their beloved University of Tartu was converted into a Russian high school, and within some 20 years illiteracy arose from under two per cent to over five. Education is now free and compulsory in the primary grades, and the law provides for the education of foreigners in their own language. The University of Tartu now has about 5000 students. The present illiteracy rate is about three per cent.

6. Social Conditions. The early Finns and Esths lived in a tribal society with the ordinary social distinctions. After Sweden had conquered the country the people were divided into four estates nobility, clergy, burghers, and peasants - which created and tended to perpetuate social distinctions. There were also social distinctions due to the different racial elements. Since Sweden was the conqueror, the Swedes naturally assumed an attitude of superiority, but in Finland they feared the Finns because the latter were in the majority. After the Finnish "revival" the Finns came to feel themselves superior, but they had already absorbed much of the Swedish culture. When Russia conquered Finland, the Finns compared themselves with the Russians and came to regard all Russians as stupid peasants. Suppression by the Russians caused the Finns to develop a strong hatred for the Russian leaders.

The general social conditions in Finland are similar to those in Sweden Both countries are outstanding in social legislation. Fin- 
land was the first country to grant suffrage to women. All males and females 24 years of age may vote, and women are eligible to the Diet.

The Esths were long under the dominance of the Balts, and it is remarkable how a people held for some 600 years in slavery and serfdom could maintain themselves and advance so rapidly as have the Esthonians. Theirs, however, was more an economic than an intellectual handicap until they were suppressed by the Russians. As the Balts were an intellectual and progressive people, the Esths benefited by association with them. But a Balt would not think of inviting an Esth to dine with him. Suppression by the Russians tended to bring both groups closer together.

Esthonia has a large number of modern social laws, including an eight-hour day, restrictions on the work of women and children, prohibition of night work, public insurance for workmen, government ownership of railways and telegraphs, and almost universal coöperative industries.

7. Immigration and Emigration. Since the United States has regarded Esthonians as Russians or Finns, we do not know how many have come to this country. It is probable that many did come, since most Russian immigrants came from regions near the Baltic and were non-Slavic people. We received 765 immigrants from Esthonia in 1924, and 1576 for the period 1924-30. The present law permits 116 immigrants from Esthonia per year, 9 less than the two per cent law.

Finnish immigrants to the United States began coming to us early, and increased very rapidly. Between 1893 and 1905 Finland lost 128,600 citizens by emigration, practically all of them to the United States. For the period 1899-1910 151,774 Finns were admitted to the United States as immigrants. For this period Finnish immigration from Russia was the largest of any racial group ruled by Russia except Jews. The yearly average was 12,348 , a rate of 1 to 191 . Suppression by Russia was perhaps the chief cause, but economic conditions played an important part also. In 1920 there were 149,824 people in the United States who gave Finland as their native country; 133,567 gave Finnish as their mother tongue, and of these, 130,808 were from Finland. In 1905 we received 17,012 immigrants from Finland, but our present law permits only 569 per year, 98 more than the two per cent law. Practically all Finnish emigrants have gone to the United States. In 1905 only 37 went to other countries. Our restrictive laws will doubtless cause them to seek other countries. 
The Finns that come to us are generally Lutherans, literate, able to speak two or more languages, hardy, industrious, and thrifty. Amalgamation has taken place to such an extent that many of them appear to be pure Nordics; yet suppression has made them conscious of their race and proud of their Finnish speech and heritage. In 1920 they ranked 21 among the nationalities in naturalization; this rate was perhaps largely due to their comparative isolation in the lumbering industry in the United States. The. Finns have settled mainly in the West and North, chiefly in Michigan, Minnesota, Massachusetts, and New York. Wherever the Finns have gone they have carried with them some of their Old World customs, especially the inevitable bathhouse in which they steam themselves by dashing water on hot rocks, and at the same time have others whip them with switches.

\section{QUESTIONS, EXERCISES, AND PROBLEMS FOR INVESTIGATION}

1. What groups are placed under this general heading? Why?

2. Characterize the (1) Mongolic division; (2) the Semitic; (3) the Malay; (4) the Negro.

3. What has been the historical relationship between Finland and Esthonia?

4. Give the physical characteristics of Finland and Esthonia. How does their location affect their economic and political conditions? Besides the text, see Nordenskiold, E.: "Finland: The Land and the People," Geographical Review, Vol. VII, pp. 361-79.

5. Give a brief discussion of the ethnological history of the Finns and Esths. In what respects do the Lapps differ from the Finns and Esthonians? On what grounds has Finland been classed as Teutonic? See Pittard, Eugène: Race and History, Part II; Ripley, W. Z.: The Races of Europe, Chap. XIII; Dictionary of Races or Peoples.

6. What cultural forces long played upon these countries?

7. Describe the peculiar political situations in which Finland and Esthonia find themselves. References. Lyon, F. H.: "Baltic Alliances: Finland at the Cross-Roads," Fortnightly Review, Vol. CXV, pp. 30111; Polsom-Newman, E. W.: "The New Finland," ibid., Vol. CXXIV, pp. 774-83; Lord Ernle: "Tales of Estonia," Nineteenth Century, Vol. XCVI, pp. 343-54; Ruhl, A.: New Masters of the Baltic, Chap. VI.

8. What were the effects of the Russian rule on these countries? Of what economic advantage was the dominance of the Balts to Esthonia? 
What were its disadvantages? What were the results of the Swedish dominance on these countries?

9. What are the chief industries of these two countries? Compare their agricultural conditions. How is agriculture being aided in Esthonia? See van Cleef, E.: "Some Economic Problems in the Baltic Republics," Geographical Review, Vol. XVII, pp. 434-47.

10. Show how Christianity gained a foothold. In what ways did it become modified?

11. What forces greatly aided education? In what ways has education been handicapped?

12. In what respects are these countries socially outstanding?

13. To what countries do most of the Finns and Esthonians emigrate? Why is it difficult to study the immigration of these peoples into the United States? 


\section{CHAPTER XXIII}

\section{HUNGARY}

1. General Description. The Kingdom of Hungary is a small landlocked nation in central Europe, surrounded by Austria, Czechoslovakia, Rumania, and Yugoslavia, no one of which is directly related to it biologically or linguistically. Its territory is mostly a plain or valley, much of which is hardly above sea level, surrounded by mountains. Two medium-sized rivers flow through the country, but they afford neither water power nor good routes for commerce. It has few forests and few minerals. The soil is very fertile, however, and well adapted to agriculture.

Hungary possesses 35,875 square miles of land and has a population of $8,683,740$ (1930). In 1914 it had 125,609 square miles of land and a population of $25,000,000$. This, however, was less than one-third of its size under Louis the Great (1342-82), when it included the territory between the North, Black, and Adriatic seas. As a result of the World War Hungary lost 67.3 per cent of its land and 58.4 per cent of its population. Rumania received 39,452 square miles of this territory, or 36.2 per cent of the total area of Hungary, and 5,240,000 inhabitants, or 28.7 per cent of Hungarian population. Of this number, $2,820,000$, or 53.8 per cent, were Rumanians, and $1,670,000$ were Magyars, who formed 16.7 per cent of the total Magyar population of Hungary. Czechoslovakia received 24,326 square miles of land, or 22.3 per cent of Hungary's territory, and 3,570,000 jnhabitants, or 19.5 per cent of the Hungarian population. On this territory were $1,700,000$ Slovaks, who formed 47.7 per cent of the population, and 1,070,000 Magyars, who formed 10.8 per cent of the total Magyar population of Hungary. Yugoslavia received 8120 square miles, or 7.4 per cent of the total area of Hungary, and 1,520,000 inhabitants, or 8.3 per cent of the Hungarian population. On this territory were 460,000 Magyars, who formed 4.6 per cent of the total Magyar population of Hungary; 380,000 Serbs, who formed 24.9 per cent of the population of the territory, and 150,000 Croats and Wends, who formed 10 per cent of the population of the territory. Austria received 1554 square miles of land, or 1.4 per cent of the total 


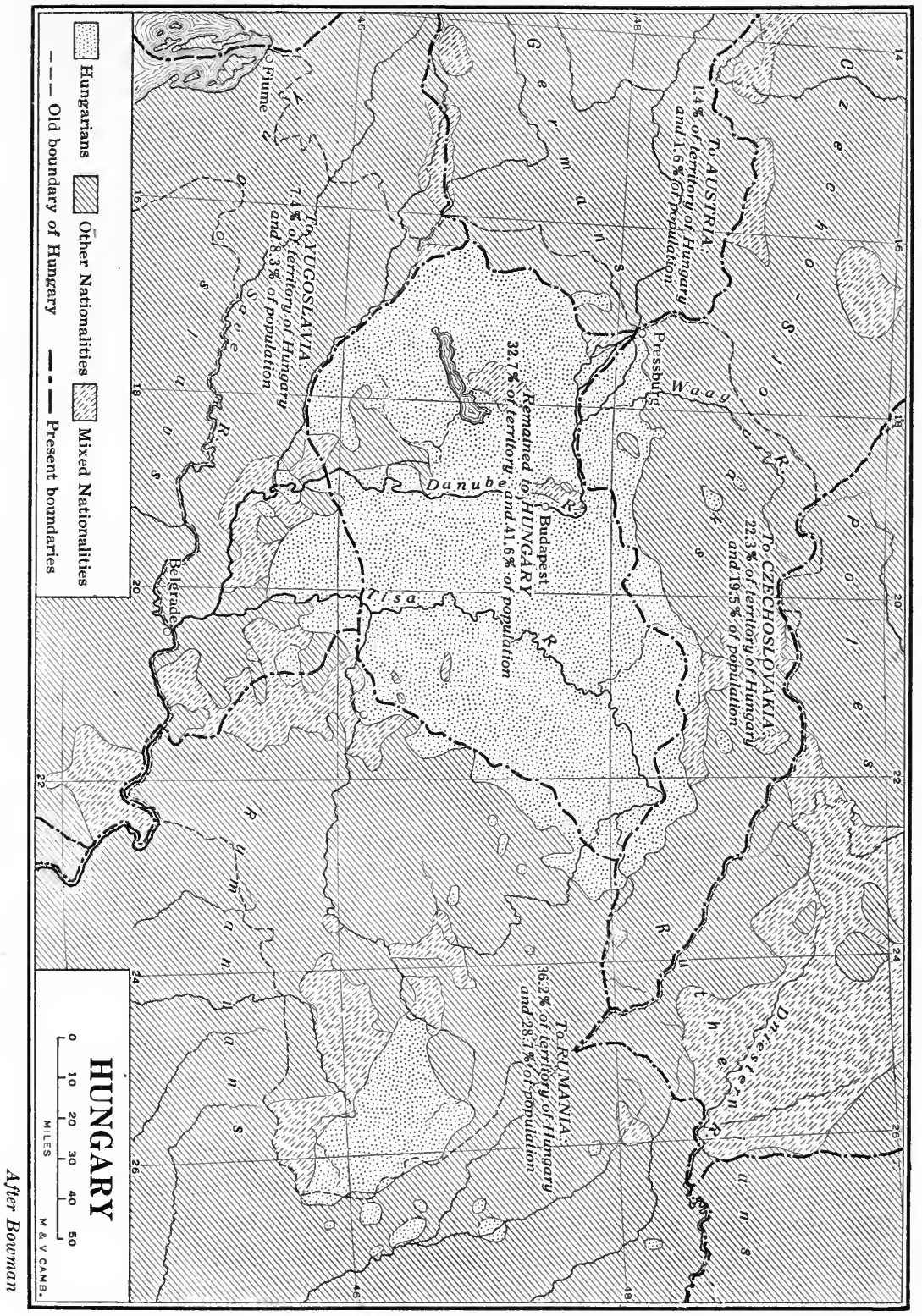


area of Hungary, and 290,000 inhabitants, or 1.6 per cent of Hungary's population. On this territory were 30,000 Magyars, who formed 0.3 per cent of Hungary's total Magyar population, and 220,000 Germans, who formed 73.9 per cent of the inhabitants of the territory. Whereas before the World War less than half of Hungary's population was Magyar, now about 90 per cent is Magyar. At the same time it has some 800,000 non-Magyars, 7 per cent of whom are Germans. On the other hand, only 67.5 per cent of the Magyars in Europe now dwell in Hungarian territory. Although some boundaries are not yet determined, Hungary is objecting seriously to the action of the Peace Conference. It sees no reason why territory, especially districts in which Magyars compose more than half the population, should be recklessly snatched from it without regard for its future welfare or for the wishes of the inhabitants of the territory. It believes itself to be under no moral obligation to refrain from seizing such territories at the first opportunity. Magyars everywhere are clamoring for union, and even some of the Ruthenians are dissatisfied with Czechoslovakian rule and wish to return to Hungary.

Concerning the origin of the people now known as Magyars, we have many fanciful and pseudo-scientific theories, but little real knowledge. They are classified as Urgo-Finnic under the Mongolian race. As such they are closely akin to the Finns, Esths, Turks, Tartars, Avars, and Huns. Their language is related to Finnish, while their customs show Turkish affinities. The Magyars apparently originated in central or northern China, wandered across Turkestan, through the Uralo-Caspian gap, over the Ukrainian steppe, and finally entered their present location from the north during the latter part of the ninth century. There seems to have been a large number of them, and it is probable that the horde was augmented by Khazars, a Judizied Turkish tribe, by remnants of Avars, another Turkish group, and by Slavs. Apparently they followed the Huns and Avars into Europe and became a plain and agricultural people. Some writers, however, make them a part of the great Hun group which, under Attila, became the "Scourge of God" to Europe during the early part of the fifth century. During the period between 300 and 900 , fragments of many different groups migrated into Hungary. These the Magyars conquered between 884 and 895. The Magyars have always absorbed the different people who have gone among them; consequently there is now no pure Magyar type. Although the Magyars show their Oriental kinship in their features and cus- 
toms, the traces are so slight that the Magyars can hardly be distinguished from their neighbors. Their language and their racial consciousness are the chief isolating factors.

2. Political Development. According to authentic history the Magyars, a million strong, migrated with their flocks and herds from southeastern Russia into Hungary in 896. Hungary's political history may be divided into four parts: the first lasts to the Tartar invasion (896 to 1244), the second to the Turkish invasion (1526), the third to the World War, and the fourth to the present time. Arpád led the Magyars into Hungary and established the first dynasty, which lasted for three centuries. He possessed remarkable qualities of Oriental statesmanship and was able to mold the heterogeneous mass into a compact group. After his death in 907 the Magyar horsemen became the terror of Europe, ravaging large parts of Russia, Germany, and Italy. Otho I, King of Germany and later the founder of the Holy Roman Empire, proclaimed them "the enemies of God and man."

Under the Duke of Geyza (Geiza, Géza), Christianity was introduced among the Hungarians. The Duke's son, St. Stephen I (9971038), became the first Christian king of Hungary. He was crowned with the sanction of Pope Sylvester II, who conferred upon him the title of "Apostolic King" and sent him the famous crown which has ever since been used at the coronation of Hungarian kings. This crown has played an important part in the political history of the nation. It is not regarded as a symbol of the king's power, but rather as a symbol of the power of the whole nation, voluntarily bestowed upon the king.

Stephen proved to be a wise ruler who laid a solid foundation for the Hungarian Kingdom. However, he was followed by weak kings who did little except crush the pagan rebellions and secure Hungary's independence from Germany. Ladislaus (1077-95) was perhaps the most noteworthy king of Ārpád's line. He ended the German menace and added Croatia to his realm. The next Hungarian ruler of any importance was Béla III (1173-96), who cleared Hungary of Greek influence, took back the territory which Greece had seized, reconquered Dalmatia from Venice, which one of his predecessors (Coloman, 1095-1116) had annexed to Hungary, and so policed his nation that he drove out the thieves and robbers. Andrew II (120535) was forced to sign a constitution known as the Golden Bull, the Magna Carta of Hungary (1222), which future kings had to swear, 
both orally and in writing, to defend. It granted the people the right to resist any intrusion of a king without being charged with treason.

Béla IV (1235-70) tried to restore law, order, and peace. Hoping to strengthen himself against foes within and without his kingdom, he permitted the Kuns (Cumans), who had been driven west by the Mongols, to enter on the promise that they would become Christians and settle down. They were slow to keep their promise, and their lawlessness brought general complaint. Hungary was now entering its second important period. On came the Mongol hordes, through Russia, Poland, and Moldavia into Hungary, leaving devastation in their wake. The king called frantically at home and from abroad for help to stay the Mongol tide, but even the nobles did little to aid him. Hungary was overrun and devastated. Pestilence and famine appeared to complete the carnage, and little was left except dead bodies and bleaching bones. Cannibalism became widespread. Upon the death of their ruler the Mongols suddenly disappeared. Béla set about rebuilding his nation. He gathered together a small army and proceeded to punish the treacherous Duke Frederick of Austria, to whom he had entrusted his wife, children, and royal treasures while fighting the Mongols. Frederick was slain in battle, and Austria was left without a ruler. The Bohemians (Czechs) then tried to conquer Austria, but neither Hungary nor Germany wished a strong Slavic state thrust in between them. They united, and by the side of 10,000 German soldiers marched 40,000 Kun warriors. Bohemia was defeated, but Hungary failed to secure its share of the spoils.

Another line of weak kings brought chaos to Hungary. Many nobles became petty kings and great thieves. Strife and corruption of every kind existed. Finally Louis the Great (1342-82) ascended the throne, and under him Hungary reached the zenith of its power and expanse. It was during his reign, however, that the Turks and Hungarians began their long period of warfare. So long as Louis lived the Turks were unable to make any progress, but after his death danger threatened from all sides. The vassals of Moldavia and Wallachia declared their independence, and Serbia and Poland planned attacks. Had it not been for the rise of an obscure knight, John Hunyadi, the greatest warrior Hungary ever produced, the Hungarians would have come under the rule of the Turks long before they did. Hunyadi's son, Matthias (1458-90), proved to be one of 
Hungary's greatest kings. He was a lover of justice and a great warrior. He defeated the German knights, captured Vienna, organized the Black Troops, the second standing army in Europe, and reformed the laws.

Weak kings brought on national decline. Territorial losses followed in rapid succession, crusaders pillaged the country, and the county system led to the development of some 50 autonomous political and military units. The nobles were so busy oppressing the peasants and robbing each other that they failed to heed the frantic calls of the kings against the Turks. Unwilling to endure the suppression any longer, the peasants revolted and murdered nobles wherever found; 50,000 people were killed within a short time. There was no army, no navy, and no order. Finally the king, Louis II, decided to march alone against the Turks; but by the time he met the Turks at Mohács (1526), he had a poorly equipped army of 25,000. The Magyars were badly defeated, the king was killed, and there was little resistance to the onrush of the Turks, who swept over two-thirds of the country, killing some 200,000 within a short time.

Realizing that they could not cope with the Turks single-handed, the Magyars looked for outside aid and elected as king the Hapsburg Ferdinand, brother of Charles $\mathrm{V}$, the most powerful monarch in Europe. The expected help of Charles did not materialize, and the Turks, not wishing to see Hapsburg power extended, did all they could to keep Hungary in turmoil. At the end of thirty years of fighting, Hungary was divided into three parts. The Turks drove a wedge through the center and seized the fertile Alföld; Transylvania remained semi-independent under a native prince and the suzerainty of the Sultan; and the western realm was held by the Hapsburg rulers. Transylvania proved the salvation of Hungary, for it became the haven of persecuted peoples. It might be mentioned here that there are now some 1,500,000 Magyars, known as Szeklers, in Transylvania, permanently separated from Hungary by the Peace Conference.

It soon became evident that the Hapsburgs were not interested in advancing the welfare of Hungary. King Maximilian (1564-76) made little effort to conceal his desire to destroy Hungary and annex it to Austria. Rudolph (1576-1608) openly violated Hungary's constitutional rights. He had sworn to live in Hungary, but for twentyfive years he did not even visit the country. By a coup d'état in 1600 
Transylvania was brought under his autocratic rule. In 1673 Hungary became an Austrian province.

In 1672 began a rebellion of Magyars against the Austrian Germans. After several years it became well organized under Tökölyí, whom the Turks recognized as king of Hungary. The Turks joined the Magyars and marched against Vienna, but were defeated. The rebellion was finally put down, but it aroused the Austrians and finally led to the expulsion of the Turks from Hungary. By 1683 Leopold had gained control of the Alföld; but the claims of the Magyars to the fertile Alföld of which the Turks had deprived their ancestors were totally disregarded, and the land was settled mostly by Germans but also by Serbians, Czechs, Slovaks, Croatians, Poles, Ruthenians, Bulgarians, and Rumanians. Some 36,000 families of Serbians were settled in the southern part of Hungary. Before the Turkish invasion 80 per cent of the population of Hungary was Magyar, but by 1787 only 39 per cent. The Viennese government favored the colonists with tax reductions and many other privileges not extended to Magyars, and in 1848 plotted with the Croatians, Serbs, and Wallachs in bringing about the massacre of thousands of helpless Magyars, the destruction of many towns and villages, and the great rebellion of 1848 in which Széchenyi, Kossuth, and Deák became national heroes and world figures. As a result, the Austrians and Russians crushed Hungary and instituted such a reign of terror that Europe rose against the inhuman butchery. It was on the basis of these colonies that some of the new states laid claim to Hungary's territory after the World War.

Joseph I (1705-11) conquered the rebel bands and ended the rebellion which had continued intermittently since 1672 . His successor, Charles III (1711-40), established the Pragmatic Sanction of 1722, by which Austria and Hungary were made separate and independent countries having the same Hapsburg ruler. The reforms of Joseph were continued by his daughter, Maria Theresa (1740-80). Her accession to the throne was approved by a number of European rulers who were ready to attack her on all sides and divide her kingdom. She called on the Magyars and they responded 80,000 strong. She showed her appreciation by remitting to Hungary the strip of land which her father had reconquered from the Turks, and gave the Magyars the city of Fiume for a seaport.

Maria Theresa's son, Joseph II (1780-90), brought about many reforms, but he failed to understand his people. He insulted them by 
refusing to be crowned with St. Stephen's crown, and aroused deep resentment by removing the crown to Vienna. He wished to execute the reform rather than let the Diet do it. Furthermore, he tried to Germanize the people and make German the official language. Joseph's brother, Leopold II, had the welfare of the people at heart also, but he used a different method. Instead of disregarding their constitution and trying to do everything for them arbitrarily, he let them do things for themselves. His fine work ended with his death in 1792. Francis I, his son, was exactly the opposite of his father, and soon Hungary was in turmoil. He sought to stamp out every liberal idea. Yet the Magyars remained loyal to him during the Napoleonic War in the face of the many liberal offers of Napoleon. Before he died, he changed many of his policies, but it was too late; the revolution of 1848 was already under way and did not cease until the conclusion of the Ausgleich in 1867, whereby the Dual Monarchy came into being.

The Dual Monarchy existed until the era of the World War. The relationship between the two countries was very formal and never satisfactory to Hungary. The same ruler was Emperor of Austria and King of Hungary. The two countries had a common army and navy, system of weights and measures, tariff, and ministers for finance, foreign affairs, and war, and a commission for joint affairs. On the other hand, each country had its own Parliament, ministry, and administration, and governed its internal affairs without interference from the other. Both were supposed to be equal in every sense, but German continued to be the language of military and foreign service, and at no time did the Magyars number 33 per cent of those in common service, while the war and foreign service offices always remained in Vienna.

In October 1918 the Dual Monarchy collapsed and the close relationship between Austria and Hungary which had existed since 1526 was ended. Conducted under national colors and with Count Michael Karolyi, a member of one of the old aristocratic families, as one of the leaders, the revolution was regarded as a movement away from aristocracy toward freedom. A short-lived republic with Karolyi as president was established, but the country soon entered upon a period of Bolshevism under the leadership of Béla Kun. The Bolsheviks eame into eonfliet with the Rumanians, who proceeded to oceupy Hungary. When they withdrew they took practically everything movable that had any value. In 1919 Admiral Horthy reor- 
ganized the remnant of the army and succeeded in establishing order. Hungary is overwhelmingly monarchical in sentiment. The Allies made it pass a law dethroning the Hapsburgs, but this only made them more popular. In 1920 it declared itself a monarchy, but it has no king. There are three claimants to the throne, but Archduke Otto, born in 1912, son of Emperor-King Charles, will perhaps become king in opportune time. Hungary is merely biding its time, refusing to accept the fate the Allies imposed upon it. It has no navy and no air force, and is permitted to have an army of only 35,000 men. It is surrounded by nations alien in race and language. Being a defeated power, it received no recognition at the Peace Conference, and remains the most dissatisfied country in Europe. At the Treaty of Trianon its deputies "were clad in mourning, and many were weeping. At the close they all rose and sang the national hymn." 1

Hungary has two houses - the Upper or Old House of Magnates (Nobles), and the Lower House. Members of the Lower House are elected by a restricted suffrage. Men who are literate and over 24 years of age, and women over 30 years of age who earn their own living, have three children, have a diploma from an institution of higher learning, or are the wives of graduates of secondary schools or colleges, have the right of franchise.

3. Economic Development. The Magyars have long been an agricultural people. When they first settled in Europe they occupied the fertile Alföld (low lands). The Magyars have always manifested a passion for owning land, and either by gifts from the kings, seizure, or purchase, the magnates and nobles came to own practically all the land. Under such conditions the serfs and peasants were helpless. They paid the taxes and did practically all the work, but had no political rights.

For a number of years the Jews have been entering Hungary in larger and larger numbers. Being superior to the Magyars in business methods, they have monopolized banking and, through banking, industry. There is little doubt that the Jews often became wealthy at the expense of the laboring Magyars. The nobles, however, could and did live largely independent of the Jews. After the World War, anti-Jewish sentiment became strong and resulted in restrictive legislation. Jews are forbidden to own more than one house, and to own or lease landed property. Foreign Jews who have come into the ${ }^{1}$ Nitti, F.: The Wreck of Europe, p. 168. 
country since 1914 are ejected, and others are forbidden to enter. They are not permitted to hold positions in any of the schools, edit papers, hold civil or military offices, manage theaters, hold a government contract, or have Gentile servants, and only 5 per cent may enter the universities. It would probably be a mistake to think the present anti-Jewish sentiment is wholly due to economic causes. Some of it may be attributed to the fact that the Magyars transferred their religious animosity toward the "infidel" Turk to the incoming Jews, and some to the part the Jews played in the Bolshevik régime.

The economic condition of the Magyars gradually improved until the World War. Hungary had drained its swamps and become one of the greatest grain-growing countries of the world. At the same time it had been developing industrially and building up commercial centers. It was economically a well-balanced country. But as a result of the World War it lost 92 of its 139 cities, 84.5 per cent of its forest land, all its gold, silver, copper, and salt mines, 83.7 per cent of its iron, 28.8 per cent of its lignite, 41.1 per cent of its industries, and 48.9 of its manufacturing plants. Although it is slowly improving in textile manufacturing, many manufacturing plants remain idle because it has lost the sources of its raw material. The production of wool has decreased 75 per cent; of cattle, 31 per cent; of horses, 40 per cent; of hogs, 44 per cent; and of hemp, 15 per cent. Over 25 per cent of the glass works, 42 per cent of the spindles, and 84 per cent of the looms are in ceded territory. Besides these losses, it suffered from the Bolsheviks and the Rumanian occupation. The Rumanians ended their occupation by taking 40,950 railway coaches, 1151 locomotives, 4000 telephone installations of the Budapest exchange, all the live stock, grains, and feed possible, and even by removing the telephones and typewriters from the government and school offices, and the scientific apparatus from the school laboratories.

About 60 per cent of Hungary's land is now under the plow, and 23 per cent in pastures and forests. Some 65 per cent of the population till the soil. Approximately 82 per cent of the arable land is farmed by proprietors, and 18 per cent by tenants. Even though Hungary has a land distribution law, its farms are fairly large. According to estimates, there are 331,882 holdings under 11.5 acres, 176,930 between 11.5 and 115 acres, 9264 between 115 and 1150 acres, and 1458 over 1150 acres. Over 18,600,000 acres remain to be divided. Wheat, maize, sugar beets, and potatoes are the principal 
crops. Despite all its losses, a pre-war account, a war debt, and an indemnity bill, Hungary is slowly struggling to its feet.

4. Religious Development. Christianity appears to have been first introduced into Hungary through a former pagan chief, Geyza, father of St. Stephen I, who invited many missionaries to come into the country between 972 and 995 . Many of the Magyars, however, refused to accept the new faith; consequently strong pagan rebellions occurred under Andrew I, Béla I, and even under Ladislaus in 1095. Hungary was among the very last countries in Europe to accept Christianity, yet the earliest of the Finno-Tartaric tribes of Europe to do so. Hungary was directly in the line of march of the crusaders, many of whom were fanatics, marauders, and thieving vagabonds. King Coloman received the condemnation of the Pope and neighboring rulers because he would not tolerate the lawlessness of the crusaders. He drove them out of his country, and also refused them permission to pass through, except those of Godfrey de Bouillon, from whom he required a rigorous security for good behavior. That crusaders were unpopular in Hungary may be judged by the fact that all robber bands and revolutionists became known as crusaders. Béla III, however, favored the crusaders and furnished them supplies, and in 1216 Andrew II set out with a large army to the Holy Land.

The Magyars, not being devoted to the Papacy, secured the enactment of a law which rendered the Hungarian Church free from the interference of the Pope. Lutheranism found a ready response in Hungary, especially among the German element. Even Queen Mary, wife of Louis II, and her German courtiers became enthusiastic Lutherans. The Catholic clergy led a reaction against Lutheranism and secured the passing of a law (1523) directed especially against the queen, declaring Lutherans foes to the "Holy Virgin Mary, the patroness of Hungary." The offenders were to be punished with death and their property confiscated. In 1525 another law was passed, declaring that Lutherans were to suffer death by fire wherever found. Soon the stakes and flames gave mute evidence of what was happening throughout Hungary. Nevertheless, owing to the general rottenness of both church and state, the Reformation spread rapidly over Hungary. ' Lutheranism prepared the way for Calvinism, which seemed to suit the Magyars better than the doctrines of Luther. It spread so rapidly that soon it became known as the "Hungarian faith," and Debreczen became known as "Calvinist Rome." Lu- 
theranism became a recognized religion in Transylvania in 1545 and in Hungary in 1550; Calvinism was recognized in Transylvania in 1562, and in Hungary in 1564. The German element remained Lutheran while the Magyar became Calvinist.

In 1606 a general law was passed granting Protestants equal rights with Catholics. This aroused the Catholics and launched the antiReformation movements. Many returned to the Catholic fold, but the mass of people remained Protestant. The Protestants had never actually received equal rights, and under the powerful Jesuit organization began to lose ground. The Hapsburg rulers made a determined effort to make Hungary Roman Catholic; yet throughout the seventeenth century less than one-seventh of the people were of that faith. Leopold I swore he would make Hungary Catholic; consequently he made religious persecutions the order of the day in Hungary. During this same long period the struggle with the Turks continued, or Christianity against Mohammedanism. The Protestants, however, found the Turks to be more tolerant than the Catholics. Luther had condemned the Turks for not drinking wine; while other Protestant leaders taught that a contract with a Turk was not binding, and that it was no sin to kill the "infidel Turk." Yet the Protestants found that the Catholics were about as hard task masters as the Turks. Instead of uniting to drive the Turks out of Hungary, the Christian sects spent their energies in killing one another. The guarantees of religious freedom which the Protestants had received were almost constantly violated. Occasionally a rebellion would break out, and then the Viennese government would reaffirm the religious guarantees. These, however, were soon forgotten; and again Protestant churches were seized and given to the Catholics (as the Cathedral at Kassa), defiled, or torn down, and Protestant ministers were set adrift, exiled, or sent to the galleys. Under Leopold thousands of Protestants were sold as slaves, and no Protestant was safe anywhere at any time.

During the struggle with the Hapsburgs, Transylvania remained the one "free" spot in eastern Europe. Being under the suzerainty of the Sultan, the Hapsburg Catholics could not control it, and religious toleration was the rule. It became the center of Calvinistic activities. By 1691 four religious faiths - Catholicism, Calvinism, Lutheranism, and Unitarianism - were recognized. Gradually the people in Transylvania and Hungary proper came to be taxed by the state through the church. As a result every one had to belong 
to one of the recognized religious groups, and it was difficult for a new sect to gain recognition.

There is supposed to be complete religious toleration in Hungary today. There are numerous sects, but Roman Catholics compose the majority of the population. The Hungarians have never been slavishly devoted to any one creed, and their religion has never been entangled with nationalism; consequently they have not developed the religious psychosis that is so manifest in Ireland and Poland.

5. Educational Development. Hungary was fortunate in having several kings who were interested in education. During the period of the Ārpáds it absorbed western culture and kept pace with many of the countries of western Europe. King Coloman was so interested in scholarly pursuits that he became known as the "bookish" or learned king. He objected to fanaticism and superstition and suppressed the persecution of witches "because no witches existed." Béla III was also very much interested in spreading higher learning. The court of Louis the Great was one of the most distinguished in all Europe, and many kings sent their children to it to be trained. These rulers greatly influenced the cultural life of the nobles. Nothing was done for the serfs or peasants, but they assimilated some of the culture of their masters.

With the Protestant Reformation there developed a greater interest in education. Apparently the Protestant schools, especially the Calvinistic, were much better than the others. The Viennese law of 1867 prohibited Catholic children from attending Protestant schools; yet a majority of the students in many Protestant schools were Catholics. The Calvinistic schools also stressed the use of the Magyar language. Up to 1825, when Stephen Széchenyi made his first speech before the Diet and used the Magyar language, Latin was the only language of the Diet, while German was the social language. The Magyar language had formerly been considered the language of serfs and peasants, but with the development of patriotism, a reaction against Latin and German set in and a definite trend toward Magyar appeared. Széchenyi was also instrumental in establishing the Hungarian Academy of Science to counteract the use of the German language.

For about forty-five years previous to the World War, education was practically compulsory. This applied chiefly to Magyars, however; the subject races were not compelled to send their children to school, but if they chose to do so they had to select a Magyar 
school. About three months after the outbreak of the World War, the subject nationalities were permitted to use their mother tongues. Education is.now compulsory for children from 6 to 12 years of age. The lower school term covers four years, while the middle school occupies eight. Hungary has a number of universities and industrial schools. It has no outstanding universities, however, and attracts practically no non-Magyar students. It had 2,414,491 illiterates in 1910 and $1,888,536$ in 1920 , or a rate of 15.4 per cent. Since the population within this period decreased by about $14,000,000$ it appears that illiteracy was higher among the Magyars than among the subject peoples.

6. Social Development. The early Magyars lived under a tribal chieftain. There were many Slavs and other racial groups in Hungary, and in time these and weak Magyars became serfs. By the thirteenth century there was a fairly clear distinction of titles and distribution of the nobility. The nobles received their titles and estates from the king because they had borne arms in defense of the country. Many other racial groups besides Magyars, however, were included among the nobility. Gradually a distinction between the magnates or great nobles and the gentry or small nobles grew up; also more and more people became serfs. The gentry were far more numerous than the magnates and were inferior to them in prestige, but felt equal socially, and superior politically. The nobles constituted the government; for until the sixteenth century all nobles, mounted on horseback and clad in armour, were supposed to meet out on the plains in a general assembly to elect their officers. The serfs and peasants had practically neither political nor social rights, but paid the taxes and bore the other economic burdens of the country. In 1514 the serfs rebelled and proceeded to murder the nobles and burn their castles. For this the peasants were tied to the soil. Gradually they gained back the little liberty they had lost.

As cities began to grow up, a new group developed which belonged to neither of the old groups. Burghers or traders, mostly Jews and Germans, began to establish stores and commercial enterprises in the towns. This tended to break down the old social stratification, based on titles, and make wealth the basis of social distinctions. Present-day Hungarian society, as in other modern countries, is based chiefly on a money classification.

The Magyars appear to have had little racial and religious prejudice 
until taught by the Austrian Catholics. The Turks encouraged rebellions against the Hapsburgs, but also plotted with the Hapsburgs and caused the Tartar hordes to overrun Transylvania and take away thousands of Magyars and sell them into slavery. At the same time Austria was doing all it could to destroy nationalism, but this only increased the Magyar hatred for Austria. Many of the patriotic Magyar nobles were executed or exiled, and Magyar children were sold to the Turks as slaves. Colonies of Germans and Slavs were settled in different parts of the country and given liberties not granted to Magyars. After the Magyars had freed their country from the Turks, the Hapsburgs plotted with the South Slavs and caused massacres in which thousands of helpless Magyars lost their lives. As a result, intense hatreds developed.

Transylvania, which was settled by Magyars, Szeklers (a branch of the Magyars), Saxons, and Wallachs (Rumanians), often aided the Magyars in their struggles against the Austrians. In the decade beginning in 1672 and often thereafter, the Transylvania border became the chief region of conflict, and witnessed all the coarser methods of cruelty. "To cut tobacco on the enemy's bare back," writes Arminius Vámbéry, " "or to cut strips from his quivering skin, to drive thorns or iron spikes under the finger-nails, to bury him in the ground up to his head and then fire at him, to skin him alive, to put a stake through him, - in a word, to perpetrate tortures at which humanity shudders, these were the every-day courtesies exchanged between the two belligerents."

The Gypsies have played an important part in the social life of the Magyars. Gypsy music is popular, and their superstitions are widespread. In 1928, however, the government ordered the Gypsies to settle down, speak Magyar, pay taxes, and abandon their ancestral customs. They were granted suffrage and the right to own property. Foreign Gypsies were ordered to leave the country. The Gypsies, however, are not hated as are the Jews. The riots between Jews and Magyars have been frequent since the World War, and the liberties of the Jews are very much restricted today.

The Magyars are individualistic and cling to their customs and costumes; yet they are very sociable and much given to talk and play. The husband is autocratic and overbearing with his wife and children; yet their family life appears peaceful and satisfying. Some writers think the Magyars very immoral because about one-tenth of

1 The Story of Hungary, p. 357. 
the births are reported illegitimate. Illegitimacy, however, was advocated by Maria Theresa to increase the population, and was sanctioned under Joseph II.

7. Immigration and Emigration. It is elaimed that a Magyar viewed the land of North America long before Columbus. Certainly the Magyars began to come to this country early, and played a much more important part in our Revolutionary and Civil Wars than their apparently small numbers would indicate. Their attainments as army officers, physicians, and business men indicate that we received some excellent citizens from Hungary. The bulk of our Magyar immigrants, however, came after the Civil War, mostly in response to calls for industrial laborers. For the twelve-year period ending in 1910, 338,151 Magyars were admitted as immigrants. In 1907 the Magyars ranked eighth in percentage of immigrants, there being 7 per 1000 of population. In 1920 there were 268,112 foreign-born people in the United States who gave Magyar as their mother tongue, and 518,750 native whites of Magyar stock. We admitted 60,071 Magyars, the largest number in any one year, in 1907, and 44,538 in 1914. For the decade ending in 1930, we received 30,680. Between 1908 and 1913, 585,344 were admitted. Our present law permits 869 Magyars to enter each year as immigrants, 396 more than the two per cent law. In 1910 there were 160.8 Magyar men to every 100 Magyar women in this country. For the period 1910-14 8.7 per cent of the Magyars admitted were illiterate. Since the World War a large pereentage of our immigrants from Hungary have been from the educated and professional classes. In 1920 Magyars ranked 26 among the racial groups who were naturalized and 4 among those having their first papers. Between 1921 and 1923 Hungarian overseas emigration was almost exclusively to the United States, but in 1924 almost two-thirds of the emigrants went to Canada. Most of the continental emigrants went to Rumania and Germany. Almost 60 per cent returned home.

The Magyars have come here mostly to engage in industry, and have generally settled in urban communities. Many later drift into agriculture and thus satisfy their thirst for land ownership. Others establish restaurants or tailoring and other shops. They are very industrious and tend to overwork. In 1919 the money orders sent to Hungary averaged $\$ 109$ per person. 


\section{QUESTIONS, EXERCISES, AND PROBLEMS FOR INVESTIGATION}

1. What is the significance of Hungary's geographical location?

2. Discuss the significance of Hungary's losses at the close of the World War. What dissatisfaction is it expressing? Besides the text, see Temperley, Harold: "How the Hungarian Frontiers Were Drawn," Foreign Affairs, Vol. VI, pp. 432-47; Salter, Arthur: "The Reconstruction of Hungary," ibid., Vol. V, pp. 91-102; Bethlen, Stephen: "Hungary in the New Europe," ibid., Vol. III, pp. 445-58; Maxwell, Francis: "The Treatment of Hungarian Minorities," Fortnightly Review, Vol. CXVI, pp. 104-18; Jászi, Oscar: "Dismembered Hungary and Peace in Central Europe," Foreign Affairs, Vol. II, pp. 270-81.

3. Give a brief description of the ethnological composition of the Magyars.

In addition to the text, see Dictionary of Races or Peoples; Pittard, Eugène: Race and History, pp. 270-77; Ripley, W. Z.: The Races of Europe; Chap. XV; Wallis, B. C.: "The Peoples of Hungary," Geographical Review, Vol. IV, pp. 465-81, and "Central Hungary: Magyars and Germans," ibid., Vol. VI, pp. 421-35; Remenyi, Joseph: "The Hungarians" in Immigrant Backgrounds, edited by H. P. Fairchild, Chap. VI.

4. Trace the efforts of the Magyars to free themselves of foreign rule.

5. What were the inherent weaknesses in the Dual Monarchy? What are Hungary's national aspirations?

6. Of what commercial importance are the Jews to Hungary? Account for the rise of anti-Jewish sentiment. What have been its results?

7. What are some of the economic problems confronting the Magyars? References. Armstrong, H. F.: "Hungary's Access to the Sea," Foreign Affairs, Vol. V, pp. 675-78; Bowman, I.: The New World, Chap. XIII, and "Wheat Currency in Hungary," Economic Review, Vol. VII, pp. 433-34; Ecker, L. L.: "Obstacles to Hungarian Reconstruction," Foreign Affairs, Vol. X, pp. 505-09.

8. Trace the tardy development of Christianity in Hungary; the rise of Lutheranism; religious persecution in Hungary. What significant position did Transylvania hold?

9. Why have the Magyars developed no religious psychosis?

10. How were early culture contacts brought about? What forces have largely been responsible for the development of the educational system in Hungary?

11. What social classes developed in Hungary? Describe them. What position do the Gypsies now hold?

12. Why have most of the Magyar emigrants come to this country? What types are now coming? To what other countries do they emigrate? 


\section{CHAPTER XXIV}

\section{TURKEY}

1. General Description. The Republic of Turkey is located in western Asia and eastern Europe. Some of its boundaries are yet undetermined, but its area is approximately 282,627 square miles, being a little larger than that of Texas. Most of Turkey - 273,808 square miles - is in Asia; European Turkey includes only 8819 square miles. According to the census of 1927 , the population was $13,660,275$. Constantinople (Istanbul), the largest city and former capital, had a population of 673,029 ; Angora (Ankara), the new capital, has 74,789 inhabitants.

The present Turkey or Anatolia is largely a plain which begins with mountains in the east and southeast and slopes gradually to the northwest. The land bordering the Black, Mediterranean, Aegean, and Marmora seas, the Bosporus, and the Dardanelles is generally level and low. The outer fringe, especially along the Black Sea, has a sufficient rainfall, but it gradually decreases, and the interior of Anatolia is practically a desert.

. Since Turkey is at the junction of three continents and borders so many bodies of water, its territory has been crossed and recrossed by trade routes, wandering peoples, and contending armies from earliest times. We do not know who the earliest inhabitants were, but Babylonians, Syrians, Persians, Medes, Hebrews, and other historic groups once spread over it or inhabited certain parts of it. From about 330 to 1453 Constantinople was the capital of the Eastern Roman Empire and the center of Byzantine or Greek influence.

While the Byzantine Empire was reveling in all its greatness, two forces were stirring which eventually would unite and sweep away Byzantium's ancient glory, and form the powerful Turkish Empire. One was a religion suited to a wandering, fighting, simple cultured people, and the other was a warrior horde suited to that faith. Arabia furnished the prophet Mohammed, who supplied the new faith, and inner Asia the people. The first of the people were the Seljuks, often called "Ghuzz," members of the Turanian family of 
Mongolians, who left their home in inner Asia and moved west, overrunning Syria, Arabia, Palestine, and the territory near Constantinople. The Seljuk Turks were followed by the Ottoman Turks, another Turanian group that had been thrust out of inner Asia by the Mongol hordes. The two groups came together near the Euphrates, and after considerable strife the Ottomans gained the ascendeney and began to absorb gradually the Seljuks. By about 1000 A.D. the majority of these people had aecepted the Mohammedan faith, which gave them a new incentive for conquest. They eaptured Anatolia from the Byzantines during the eleventh century, and in 1453 Constantinople fell into their hands, where it has since remained.

The Turks began as a mixed Mongolian group, and in their migration westward absorbed more and more alien blood. After they had adopted the Moslem faith and established themselves in western Asia and eastern Europe, they practiced certain customs which continued to introduce alien blood into the Turkish group. Harems were filled with the fairest of Christian girls, and many Turks had nonTurkish mothers. The blood tax, which required that the best of the Christian boys between the ages of 10 and 12 be taken and reared as Turkish soldiers (Janissaries), also introduced more alien blood. Furthermore, many Armenians, Greeks, Syrians, Arabs, Slavs, and others turned Mohammedan to escape the blood tax or to receive special advantages.

Fundamentally, the Turks belong to the Turanian, Ural-Altaic, or Finno-Tartaric group of the Sibiric branch of the Mongolian family, and are thus related to the Magyars, Finns, Lapps, Japanese, and Koreans. They are now, however, akin to these groups linguistically rather than physically. Their language remains agglutinative like that of these peoples, and is not inflected like that of the Armenians, Syrians, Arabs, Hebrews, Slavs, and other neighboring groups. Physically they have largely become European, resembling very much the brunette type of south Europe. Their culture has also been greatly influenced by Europeans and Near Eastern peoples. They seem to prefer to be known as Arabo-Persian in culture instead of Turkish.

At present the Turkish elements of Turkey live mainly in the partial highlands and mountain-rim of Anatolia, and in Constantinople. The semi-nomadic Kurds, the largest non-Turkish element of Antolia, occupy the headwater area of the Tigris and Euphrates rivers. The Armenians live in the elevated valleys around Lake Van. 
From there they have spread southwest to the Cicilian plains, near the Gulf of Alexandretta, and north into the Transcaucasus valleys. The Arabs occupy the oasis and fertile sections in the desert interior of Arabia and the desert-border near and within Syria and Palestine. The Syrians live in a fertile strip bordering the Mediterranean. Owing to the Syrian Desert in the east and the Lebanon Mountains in the south, they are largely isolated from the other peoples.

2. Political Development. Turkish political development is little more than a narrative of wars, bloodshed, and conquest, much of which has been discussed in connection with the European peoples.

The Ottoman Turks apparently derived their name from Osman I, who declared his independence of the Seljukan Sultan and began a program of expansion, conquering Brusa in 1326, the year of his death. His son Orchan (1326-59) drove most of the Greeks out of Asia Minor and established the Turks in Europe. He seems to have created the Janissaries. This had a tremendous effect on both the Turks and their Christian enemies. It deprived the Christians of soldiers, created a strong Turkish army, caused many Christians not to wish to fight the Turks for fear of killing their own sons or brothers, introduced new blood among the Turks, and caused many Christians to turn Mohammedan to save their children; but it made the Christians very bitter against the Turks. On the other hand, some parents apparently regarded it as a privilege since their children would receive a better education and enjoy advantages impossible in their own station in life.

In 1367 Murad I (1359-89) moved the Turkish capital from Brusa to Adrianople, thus announcing to the Christians that the Turks had come to Europe to stay. By his efforts Bulgaria, Serbia, and Bosnia were made Turkish tributary provinces. His son, Bayezid I (13891403), continued the warfare with the Christians, and assumed the title of Sultan. In the midst of his glory, Timur (Tamerlane) the Tartar, of the family of Genghiz Khan, came from the east and defeated him decisively at Angora in 1402. Bayezid lost his life, Timur turned east to attack China, but died on the way, and Bayezid's three sons began a civil war over the crown. This offered the Christians a golden opportunity to conquer the Turks and drive-them out of Europe; instead, they took sides in the civil war and finally, through the aid of the Greeks, allowed Mohammed I (1413-21) to become ruler. He did little fighting, but reorganized his army, so that when his son, Murad II (1421-51), succeeded him, the 
Christian armies were easily defeated and the Turkish rule greatly strengthened south of the Danube.

The Turks had long wished to capture Constantinople, but had not succeeded. Mohammed II (1451-81), realizing that the Byzantines had not recovered from the struggle by which they freed themselves from the Latins in 1261, and that they were then engaged in serious religious quarrels among themselves, decided that he was strong enough to avenge the defeat of his father, and laid siege to the city on April 6, 1453. The ruler of the city could only raise an army of less than 9000 out of 35,000 men of military age. The religious dissensions continued, and the monks told the people that if the Turks did enter, the Arm of God would strike them down and send them back to Asia. On May 29 the Turks took the city while many of the inhabitants stood watching for some great miracle to deliver them from the "infidels." For ten days the massacres, robbing, and destruction continued, and perhaps stopped then only because Mohammed realized that a heavy non-Moslem population was needed to carry on trade and to keep his new capital in a flourishing condition. Consequently he permitted the different religious groups largely to rule themselves, and induced groups of Greeks, Rumanians, and Slavs to settle in the city.

Mohammed's son, Bayezid II (1481-1512), made few boundary changes, but his grandson, Selim I (1512-20), brought Syria and Egypt under Turkish rule. Selim was a dissolute ruler who dethroned his father and executed so many of his relatives that he practically exterminated the generation. However, he gave his son, Solyman I, "The Magnificent" (1520-66), an excellent education. Within one year Solyman took Belgrade, which had withstood many Turkish onslaughts. Then Rhodes and later Bagdad fell into his hands. At Mohács he defeated the Magyars (1526), and half of Hungary came under Turkish rule, where it remained for about 140 years. Venice, also, was conquered and made a tributary state. Solyman made an alliance with Francis I of France and a treaty with Austria, which he regarded seriously; but the French and Austrians regarded them lightly, since the Pope had ruled that a contract made with a nonbeliever was not binding. Solyman, however, failed to conquer Vienna and Malta, and died a disgruntled old man.

Beginning with Selim II, "The Sot," a drunkard with unspeakable vices, a line of weaklings ruled over Turkey. Moslem power was on the wane. Under the power of the Kuprullu as Grand Viziers during 
the reign of Mohammed IV (1648-87), vigor was renewed, and Turkey reached its greatest expanse. But the second defeat at the gates of Vienna in 1683 spelled disaster for Turkey, and from that date until 1919 Turkey lost territory and prestige.

Had it not been for the jealousy of the European powers, especially England and Russia, Turkey would have passed out of Europe, if not off the map, a hundred years or more ago. But they could use Turkey as a threat, and were willing to hold up the arms of "the sick man of Europe" when there was an advantage in so doing. The Turks soon learned Europe's political game, and often saved their country by playing nation against nation. European rulers circulated propaganda that they were protecting the Christian people from the "infidel" Turk, but there is little evidence that they had any abiding interest in the subject peoples either religiously or racially. There is plenty of evidence that the Turkish rulers were generally ethically superior to the Christian European rulers. There is also evidence that many of the massacres of Christian people by the Moslem Turks were instigated by the Christian people to stir up trouble within and without Turkey for the sake of gaining commercial advantages. That the different peoples subjected to Moslem rule were not loyal to Turkey, and were usually eager to strike for their freedom, is undeniable. However, they had to meet the opposition and jealousies of the Christian powers as well as fight the Turks.

In 1876 the Turks demanded government reform. Sultan Abdul Hamid II, who had just come to the throne, was forced to grant a constitution and establish a parliament. On paper, Turkey became a liberal, semi-democratic monarchy, but the Sultan was reluctant to make the reforms a reality. His long reign was marked by wars and internal strife. In 1908 a revolution broke out which overthrew the ruling party and forced the Sultan to enforce the reforms. There was great rejoicing throughout Turkey, not only among the Turks, but also among the Armenians, Greeks, Albanians, and others. Old religious and racial hatreds appeared to vanish, and all groups started to work together. The old régime tried to regain control, but the Sultan was imprisoned and Mohammed V, a helpless puppet in the hands of the Young Turks, enthroned.

The Young Turks planned to build an immense empire, including such distant peoples as the Magyars, the Finns, and the Arabs of north Africa. These people were to have autonomous government under the Great Turkish Empire. The movement, however, was doomed 
to failure. Its leaders, lacking in experience, sought through schools, the press, and forensic ability to revive the worship of Attila, Khan, and other notorious leaders for whom the non-Moslems had no special liking. They wished to improve economic conditions, but, instead of remaining true to their early declarations, began to persecute the Armenians and Greeks, who constituted the bulk of the tradespeople and shopkeepers. In 1909 the Adana Massacre occurred, in which over 30,000 Christians were killed. The Christian element then understood that the new régime was no better than the old.

There can be little doubt that the chief interest of the European powers in Turkey was commercial. Jealousy, however, had prevented them from agreeing with one another. Having learned lessons in coöperation in the World War in 1915 and 1916, they were able to agree on spheres of influence in Turkey after the war. Great Britain was to have partial control over Mesopotamia and Palestine; Russia, northern Armenia; France, southern Armenia, Syria, and the Adana region; and Italy, Adalia and the Dodecanese. In 1917 the Russian claims faded, and later the three republics of Armenia, Georgia, and Azerbaijan appeared. Before this time, various harbor rights and navigation concessions had been wrung from Turkey, but there had not been much coöperative action. In 1911 Italy had seized Libya (Tripoli). In the war which followed, it gained possession of the Dodecanese Islands, which are inhabited by Greeks. The non-Turks had also gained special privileges; thus, non-Moslems could secure passports from their own consuls, be tried in non-Moslem courts, and be exempt from search and certain taxes. At the beginning of the World War Turkey abolished these special privileges (capitulations), but the powers refused to accept its action until forced to do so at the signing of the Lausanne Treaty.

In 1918, when the military power of Turkey collapsed, the Allies speedily occupied Constantinople and soon were threatening to dismember Turkey. The Treaty of Sèvres (1920) was signed by Turkey, but before it was ratified the Nationalistic party, which had been organized the year before by the present president, Mustapha Kemal Pasha Ghazi, was strong enough to defeat it. The treaty imposed such severe terms that Turkey would have been completely dismembered and helpless; consequently the Turks decided to fight rather than submit. Adrianople, Brusa, and all of the interior of Anatolia readily joined the movement. The Turks defeated the French and then drove the Greeks from Smyrna. At the same time 
the Kurds harassed the British in guerrilla warfare along the border of Kurdistan. Soon the powers, realizing the hopelessness of the situation, were willing to negotiate with the new government for peace. The Treaty of Lausanne was signed July 24, 1923. By it Turkey regained practically the same boundary in Europe which it had in 1914, and a large amount of territory in Asia of which the Treaty of Sèvres would have deprived it. It assumed 40 per cent of the war debt, and the lost territory was held responsible for the remainder. The lands along the Dardanelles, the Bosporus, between Turkey and Bulgaria and Greece, and certain islands form a demilitarized zone.

Turkey made drastic changes in its constitution in 1924. It is now a republic with a president elected for four years. The National Assembly, which has legislative power, is composed of 315 Deputies elected for four years. The executive power is entrusted to a cabinet that is responsible to the Assembly. A Council of State is composed of members appointed by the president. In 1926 the National Assembly adopted a new code of laws. The criminal code was taken from Italy, the commercial code from Germany, and the civil code from Switzerland. In August, 1929, a new penal code, modeled after that of Germany, was put into effect. The civil code abolished slavery and polygamy, and guarantees complete religious freedom. All persons are now considered as citizens of the state. In March, 1929, the Law of Maintenance was abrogated and dictatorship was supposed to end. Yet many people favored its continuance as a means of effecting further reforms.

3. Economic Development. Turkey is mainly an agricultural country, with some very fertile soil, but much of its land is either too dry or too rough for good crops. Only about 20 per cent of the total area is under cultivation. The Anatolian plateau has many mountains in the eastern and southern parts. Some sections are desert, and large areas are semi-desert with scattered arable tracts. The western portion has arable areas and good pastures, and a strip on the Black Sea has a good rainfall. The central part (Lycaonia) has less than eight inches of rainfall per year. Large areas could be irrigated. Before the World War the Germans had reclaimed about 100,000 acres in Konia by utilizing the water of the Isaurian Lakes in the Taurus Mountains for irrigation. European Turkey is fertile and well watered. The slopes and valleys of Smyrna and Adana are rich and well suited for agriculture. The interior of Arabia is a 
desert, and very little can be irrigated. In general, agricultural methods are backward. The flint-tipped crooked stick, drawn by water buffaloes, still constitutes the prevailing type of plow. In many areas deep plowing is unknown. A rapid change is now taking place with the introduction of western methods and the establishment of agricultural schools. In 1925 Turkey had 600 Fordson tractors and 150 of larger makes. There are four different systems of land tenure: the miri, or crown lands, rented by the crown for a fixed fee; the vacouf, or pious foundation lands, formerly set aside for the maintenance of church and state; the mulikaneh, or land formerly given to feudal lords for protection; and mülk, or freehold property, portions of which have been purchased by peasants.

The chief crops are tobacco, figs, cotton, cereals, fruits, opium, silk, and wool. Turkey is a stock-raising country. In 1928 it had almost 13,000,000 sheep, 12,000,000 goats, 5,000,000 cattle, 1,000,000 mules, 500,000 horses, and 500,000 buffaloes.

Turkey has about $20,765,000$ acres in forests, of which some 88 per cent belong to the state. Its fisheries also are important. The mineral resources are regarded as important, but they are not developed. They consist of considerable zinc, chrome ore, antimony, copper, manganese, borax, asphalt, emery, and meerschaum, and some gold, silver, coal, lignite, salt, and petroleum.

As the Turks have never been a commercial people, most of their trade has been conducted by Greeks, Jews, Armenians, English, Germans, Italians, and French. Turkey lost much valuable territory in wars, and piled up large war debts. Prior to the World War its debt was around $\$ 716,000,000$. Of this amount, 60 per cent was due France, 20 per cent Germany, and 15 per cent Great Britain. The administration of the debt was in the hands of a group of men representing France, Great Britain, Germany, Austria-Hungary, Holland, Italy, and Turkey. The powers of "this group were so great that they could even levy taxes, and Turkey was greatly handicapped by it. When the World War ended, it appeared impossible to collect an indemnity from Turkey.

Turkey is greatly in need of railroads, highways, and irrigation, but it does not have the money to develop them, and foreign countries are not inclined to lend it money at present. Prior to the World War, Germany promoted the development of Turkey through the irrigation projects and the building of the Bagdad railroad, but these activities resulted in international jealousies and were one of the main 
causes of the World War. Through the Bagdad railroad Germany could secure copper from the Taurus Mountains in Armenia, and tobacco, cotton, wool, and fruits from Kurdistan and Mesopotamia. The railroad also enabled it to extend its trade with India and China. German exports to Turkey grew rapidly, increasing from 6 per cent in 1887 to 21 per cent in 1910, and Austrian from 13 to 21 per cent. During the same time, the British exports dropped from 60 to 35 per cent, and French from 18 to 11 per cent.. Germany also obtained important railroads and other concessions around the port of Alexandretta, which would better enable it to tap the resources of the Mediterranean and Far East. Great Britain and France were willing to wage war if it would stop Germany's commercial expansions.

4. Religious Development. In 570 A.D. Mohammed, the founder of the religion which bears his name, was born in Arabia. He was a wanderer and a trader, who came into contact with both Jews and Christians. His religion is a mixture of Hebrew and Christian doctrines suited to Arabian conditions. It includes the belief in one God, Allah, good and evil spirits, prophecy, revelation, hell, heaven, resurrection, and a judgment day. Many of the Old Testament characters are regarded as prophets, but Mohammed is the last and greatest. "There is no God but Allah, and Mohammed is his prophet" is the slogan of Islam. Prayer, almsgiving, fasting, and a pilgrimage to Mecca are the duties of all Moslems. Gambling and drinking are prohibited, but polygamy is permitted. The Koran, the Mohammedan Bible, contains the revelations to Mohammed, and is like the Old Testament.

About 1000 A.D. the majority of the Turks were Mohammedans, and now practically all are. The Mohammedans soon divided into numerous sects and perhaps at no one time since have they ever been united or accepted any one man as head of the church. The cruel and blood-thirsty Selim I was the first to attach to himself the title of Kalif or Caliph (head of the church and defender of the faith), but several of the Moslem groups never accepted him. The Turkish Kalif seems never to have been recognized in Libya, Morocco, or the Egyptian Sudan.

While the Mohammedans were moving into Europe and conquering territory belonging to the Byzantine Empire, the Christians were divided into several sects, but mainly into two large hostile camps the Greek Church, centered in Constantinople, and the Latin Church, centered in Rome. The Greeks despised the "non-yeast-using" 
Romans, whom they regarded as being "cubbish barbarians," and as possessing a doubtful form of Christianity; but they had treated the Romans with a certain respect and had aided them in their former efforts to capture the Holy Land from the "infidel Turks." During the Fourth Crusade (1202-04), friction between the two groups became so acute that the Latins turned against the Greeks and conquered Constantinople, which became the scene of massacres and pillage. In cold blood, thousands of unresisting people were slain. Whole libraries were burned, and the priceless Greek art was wantonly destroyed. Many of the "Soldiers of the Cross" forgot their mission to Jerusalem and made off with as much wealth as they could carry. Such was the Christian example to the Mohammedans.

The Western World has heard much of Moslem massacres of Christians. For commercial and political reasons propaganda has been spread against the Turks. Apparently there have been two chief reasons for the massacres. First, there was within the Turkish Empire a minority group of people who happened to be Christians; these were arrogant in their religious views and disloyal to the Turkish government. Second, there were small groups of people, who happened to be Christians, who monopolized the trade and commerce of Turkey. Thus the political and economic situations appear to have been the real cause of the massacres rather than a difference in religion.

Under the republic, religious conditions in Turkey have been profoundly modified. The Sultan and Kalif are rulers of the past. Prayers, pilgrimages, almsgiving, and fasting are now optional. The sermons in the mosques may now be in the Turkish language, but the prayers, in general, remain in Arabic. Turkey is still a Mohammedan country, but freedom of worship is guaranteed. In 1928 the clause guaranteeing Islam as the state religion was abolished, and efforts are being made to alter details of the form of worship. Organ music is urged as a substitute for vocal music; worshipers are encouraged to sit for prayer and to wear their shoes in the mosques. As a result Mohammedanism is not only disestablished, but criticized and discouraged in its present form.

5. Educational Development. The location of Turkey resulted in the introduction of many cultures, such as the Babylonian, Arabian, Syrian, Byzantine, Egyptian, Hebrew, and Mongolian. But this fusion of cultures has never greatly affected the masses of Turkish people or led to conspicuous intellectual activity. Turkey, however, 
has had a small number of well-trained, broad-minded leaders and rulers at different times. It is also true that in the early Middle Ages, Arab. philosophers and scientists, through translations and commentaries, preserved for us much of the ancient Greek learning.

Turkey has long had a system of schools, and attendance for children between the ages of 7 and 16 has been compulsory since 1913 . Teachers, however, have been poorly trained, salaries have been low, and equipment has been inadequate. Furthermore, the Koran, which has been greatly stressed, has had a conservative influence.

Turkey now has a very good system of education, beginning with the elementary schools and culminating in the University of Constantinople. The Mohammedan schools have been taken over by the state, and new schools have been established; attendance is more strictly enforced, and the curricula have been broadened so that only one hour per week is now given to religious instruction, and that in the elementary grades. There are various Christian schools, chiefly American and French, which are compelled to maintain the Turkish standard. The new law requires schools to be established for minority groups in their own language, where there is a sufficient number. Turkey has many obstacles to overcome in its educational program. About 85 per cent of the people are illiterate and uninterested in education. Furthermore, about 1,500,000 Kurds have not abandoned their semi-nomadic life. The difficult language has been simplified and Roman letters have been substituted.

6. Social Conditions. Social conditions under the old régime in Turkey were complicated. On the political side there were gradations from Sultan to slaves. It must be remembered, however, that the title $k u l$ (slave) was used for every one belonging to the ruling house, whether grand vizier or gardener. From the religious standpoint there were various sects with their differing organizations. Added to these were the economic and military groups. Furthermore, the Turks were influenced by the cultures of surrounding nations and peoples. Consequently social stratifications, prejudices, and culture conflicts abound to such a degree that no definite culture pattern can be said to have prevailed among the mass of people.

Without doubt social conditions, on the whole, have been bad, and many of the Turkish rulers have been despicable characters. Bayezid I, by killing his brother, set a dangerous precedent which became a recognized principle frequently resorted to. But under the republic social conditions are being changed rapidly, although the 
country had been undergoing reforms for some twenty years. The first and most spectacular was the "hat law" of 1925, which dispensed with the fez. A less noticed but much more important reform was the adoption of the Swiss code in place of the Islamic family law. Prior to 1916 the family was under authority of Sheihul-Islam, the judicial head of the Islamic religion. Naturally the family code was very conservative, but when, in 1916, the Islamic courts were placed under the Ministry of Justice, women gained more rights in their marriage contracts. These provisions were abrogated in 1919, and the Swiss code was passed in 1926. Fortunately for Turkish women, feminine emancipation has not become a class or party struggle. Western opinions to the contrary, Turkish women have not been the object of discrimination in wages, and have been privileged to attend the University of Istanbul since 1916. On the whole, Turkish women have profited more than men by the reforms; yet, owing to the fact that some 90 per cent live under the drudgery resulting from poorly developed agriculture, they are not able to enjoy their social and educational freedom to the fullest extent.

Another important change has been the adoption of the Latin alphabet. Some ten years before the Balkan disaster, the Turks had been purifying and Turkicizing the language and literature. Poets, prose writers, and linguists as well were struggling to rid the language of Arabic and Persian artificiality. These changes, however, met with stern disapproval. It was claimed that the adoption of a new alphabet would destroy Turkish unity and deprive future generations of their cultural heritage. But by 1928 Turkish unity was practically gone, and the introduction of the Latin alphabet met little opposition.

In short, the best European customs are being imitated. The most progressive codes of law found in Europe, the Gregorian calendar, the 24-hour day, and the metric system have been adopted; the language has been simplified; secular marriage has been made obligatory; and families have assumed surnames. Education is being extended, the Moslem religion liberalized, and freedom of faith guaranteed. Women are shedding their veils, attending the university, and exercising the right of divorce. Men are casting aside the fez for European hats. Harems, polygamy, and slavery are conditions of the past, for now all citizens are technically free and equal.

7. Immigration and Emigration. Because of the great amount of propaganda that has been spread against the Turks, and our lack of contact with representatives of that nation, there is widespread and 
deep-seated prejudice against the Turks in the United States. ${ }^{1}$ The United States has never received many Turkish-speaking people from Turkey. For the twelve-year period ending in 1910, only 12,954 came. Most of these were from European Turkey, the ratio being about five to one; but now Asiatic Turkey appears to be furnishing the largest number.

Between 1893 and 1925, inclusive, 324,761 immigrants came from Turkey, but most of these appear to have been non-Turkish. In 1920 there were 16,298 foreign-born whites in the United States who gave Turkey as the country of their birth, but at the same time only 6627 (5326 from Turkey in Asia and 416 from Turkey in Europe) gave Turkish as their mother tongue. A number of the immigrants from Turkey are Moslems and otherwise Turkish, but speak Syrian, Arabic, or other non-Turkish languages. Most of our Turkish immigrants have gone to Massachusetts, New York, and Pennsylvania, where they have generally engaged in day labor. In 1914 we received 2558 Turkish immigrants, up to that time the largest number in any one year. For the decade ending in 1930, we received 33,735 immigrants from Turkey (14,659 from European Turkey and 19,076 from Asiatic Turkey), but we do not know how many of these are Turks in the strict sense. Our present law permits 226 to enter, 126 more than the two per cent law.

Argentina and Brazil have received considerable numbers of immigrants from Turkey. For the decade ending in 1900 Argentina received 11,583; for the next decade 66,558; and for the next decade 59,272 . Brazil has received smaller numbers. The numbers varied from 1000 to 1500 between 1904 and 1907, but reached 10,886 in 1913. Since the World War the number has been very small. Brazil received 4829 in 1923. Repatriations from the United States run from one-ninth to one-third, and for Argentina from one-third to one-half.

\section{QUESTIONS, EXERCISES, AND PROBLEMS FOR INVESTIGATION}

1. In what respects does Turkey have a peculiar location? See Merriam, G. P.: "The Regional Geography of Anatolia," Economic Geography, Vol. II, pp. 86-107.

2. To what ethnological and cultural forces has Turkey been subjected?

${ }^{1}$ Compare Bogardus, E. S.: Immigration and Race Attitudes. See Index, "Turks." 
See Dictionary of Races or Peoples; Pittard, Eugène: Race and History, pp. 317-26; Ripley, W. Z.: The Races of Europe, pp. 368-419, passim.

3 . Of what political and social significance were the Janissaries?

4. Briefly trace the unification of Turkey from the siege of Constantinople, placing special emphasis on the movements of the Young Turks. See Chirgwin, A. M.: "A New Turkey," Nineteenth Century, Vol. XCIX, pp. 356-63.

5. In what ways did Turkey prove a bone of contention among the Allies? See Pallis, A. A.: "The New Turkey," Nineteenth Century, Vol. CIV, pp. 618-28; and Edib, Halidé: "Dictatorship and Reforms in Turkey," Yale Review, Vol. XIX, pp. 27-44.

6. What are the agricultural prospects of Turkey? What are its most important natural resources?

7. Give a brief account of the rise of Mohammedanism. What religious changes have recently taken place? Besides the text, see Hurgronje, Snouck: "Islam and Turkish Nationalism," Foreign Affairs, Vol. III, pp. 61-77; Chirol, V.: "The Downfall of the Khalifate," ibid., Vol. II, pp. 571-82.

8. What are the chief difficulties in the way of establishing better schools?

9. Upon what were secial classes in Turkey based? What social changes are taking place?

10. Analyze the prejudice against the Turks.

11. Why have we received so few Turkish-speaking people? Where do Turkish emigrants go?

12. Abstract Wood, M. M.: "Latinizing the Turkish Alphabet: A Study in the Introduction of a Cultural Change," American Journal of Sociology, Vol. XXXV, pp. 194-203. 


\section{CHAPTER XXV}

\section{CHINA}

1. General Description. China, the largest country in Asia, is about one-third larger than continental United States. On its north and west is Russia; the Sino-Russian border constitutes the longest international boundary in the world. On its southwest is the populous country of India. To the east are Japan and the Pacific Ocean.

China has an area of $4,277,170$ square miles. China proper contains 1,532,420 square miles; Mongolia, 1,367,600; Sinkiang (Eastern Turkestan), 550,340; Tibet, 463,200; and Manchuria, 363,610. The population of China has never been exactly ascertained. In 1923 it was estimated to be $441,094,953$. China proper had 411,491,940; Mongolia, 2,000,000; Sinkiang, 2,519,579; Tibet, 3,000,000; and Manchuria, 22,083,434. The resident foreigners (1926) numbered 346,683. Of this number, 235,339 were Japanese, 74,089 Russians, 14,670 British, and 9401 Americans. In 1926 the Chinese Post Office Department placed the estimated population of China, including the outer territories, at 485,508,838 and in 1929 the Chinese Maritime Customs, at 438,933,373. Shanghai, the largest city of China, has a population of 1,539,000; Hankow, 1,500,000; Peking (old capital, renamed Peiping in 1928), 1,297,719; Nanking (new capital), 584,000.

The people known as Chinese belong to the Sinitic branch of the Mongolic division of the human race. The general physical characteristics are a yellowish skin, flat face, high cheek bones, slanting eyes, and straight black hair. The origin of the Chinese and the cause or causes of their peculiar characteristics are shrouded in obscurity. Various sections of Asia have been put forth as their original home, and reasons have been advanced for their physical characteristics, but so far anthropologists have not been able to substantiate their theories. It would appear that they arose somewhere in central or western Asia, and that the main bulk migrated eastward, pushing the aborigines before but not destroying them, as the presence of the Lolos, Shans, and Miao-tse seem to prove. In their literature, the Chinese have never assumed that their forefathers of some 5000 
or 6000 years ago were located in any definite place, but they do consider that the valley of the Wei Ho River, around Si-an-fu, is the cradle of their race. Here, they imagine, lived Fu-hsi, the first emperor of their history ( 2852 B.c.). ${ }^{1}$

In general physical characteristics the Chinese differ among themselves. In China proper, three types are generally recognized. The members of the northern group are taller, less brachycephalic, and lighter-skinned than those of the other groups. Some consider this group to be Manchu-Korean in origin, with a probable proto-Aryan admixture. The members of the southern group are dark-skinned, short, partly brachycephalic, partly mesocephalic, with suggestions of a Malay admixture. The central group is about midway between the other two. Deniker thinks that they preserve best the original Chinese type. The people in Manchuria, Mongolia, Sinkiang, and Tibet differ slightly from the Chinese proper. Some are lighter and some darker, showing mixtures of Caucasian, Tartar, Malay, and other bloods.

In China there are between 2,000,000 and 5,000,000 people known as Mongols, natives of Mongolia. Linguistically they are more closely related to the Japanese, and even to the Finns, Magyars, and Turks, than to the Chinese. They extend west as far as the Turko-Tartaric groups of Russian Central Asia, and eastward nearly to Peking. Through the Manchu dynasty they were long the rulers of China. At different times they established their rule over different parts of India. During the thirteenth century, led by the descendants of Genghiz Khan, they invaded Europe as far west as Germany. The Kalmuks of southeastern Russia appear to be the chief representatives of these people in Europe.

On the whole, China is a mountainous country. The whole country is shut off from the rest of the world. The different bodies of water on the east and south, the high mountains in the south and north, and the deserts and arid plains on the west and north combine to make isolation pronounced. China proper, lying in the southeast, forms a third of the country. This part is well isolated from the outlying territory. The only artificial boundary is the comparatively short one between China and Tonkin. The land along the coast tends to be level, interspersed with mountains, hills, and river basins,

${ }^{1}$ For a critical evaluation of this theory see Maspero, Henri: "The Origins of the Chinese Civilizations," Annual Report of the Smithsonian Institution, 1927, pp. $433-52$. 
but becomes more and more mountainous toward the western border. Manchuria, on the extreme northeast, has some high mountains, but also considerable level land and plains. Mongolia, on the north, within whose boundary is the great Desert of Gobi, is largely barren plains, between high mountains. Sinkiang, lying between Mongolia and Tibet, is a land of mountains and plains, most of which are arid. Tibet, west of China proper, is a high country. The central plateau, which is 16,000 feet above sea level, is surrounded by snow-capped mountains.

China proper is a well-watered country having large rivers in the west which flow eastward to the ocean. The Yangtze divides the country almost into halves, and has often been the boundary between the northern and southern factions. The Hwang-ho (Yellow River) rises in Tibet and flows through the famous fertile loess. This river is also called China's Sorrow, because it often floods the country, destroying the crops, drowning thousands, and bringing widespread famine and plague. In one flood over a million lives were lost. In the flood of 1898 some 200 square miles were covered with silt and sand to a depth between 2 and 10 feet. The Sikiang flows through south China, and the Pehho (Paiho) waters northern China. These four rivers drain about four-fifths of the country.

About two-thirds of the people of China live in the narrow coastal belt and the plains and alluvial river basins which stretch inward for more than 300 miles. In the basin of the Yangtze live almost twice as many people as are in the United States. It is the most densely populated river basin in the world. China proper has a density of 174 people per square mile, but in the province of Kiangsu it averages 897. There are farming areas in Chihli where the density reaches 2600, and in Shantung where it reaches 3000 . Mongolia, on the other hand, has only two inhabitants per square mile.

2. Political Development. Before it became a republic on February 12 , 1912, China was one of the oldest empires in the world. Its history dates back to the Mythical Five Rulers, beginning in 2852 B.c. Until the end of the Shan or Yin dynasty. (1766-1122 B.c.), China consisted of several independent countries inhabited by savage people. During the Chou dynasty (1122-249 в.c.) these independent countries became a group of federated states which owed a loose allegiance to the emperor, but continued to be ruled by their feudal lords. It was during this period that China tried to isolate and protect itself from its barbaric and warlike northern neighbors by build- 
ing most of the Great Wall, a structure over 1500 miles long and 20 feet high and wide. Watch towers about 50 feet high were built every few hundred feet.

A civil war at the end of the Han dynasty divided China into three parts. Disunion continued until the beginning of the T'ang dynasty. During this period (618-907) the empire was extended west to the

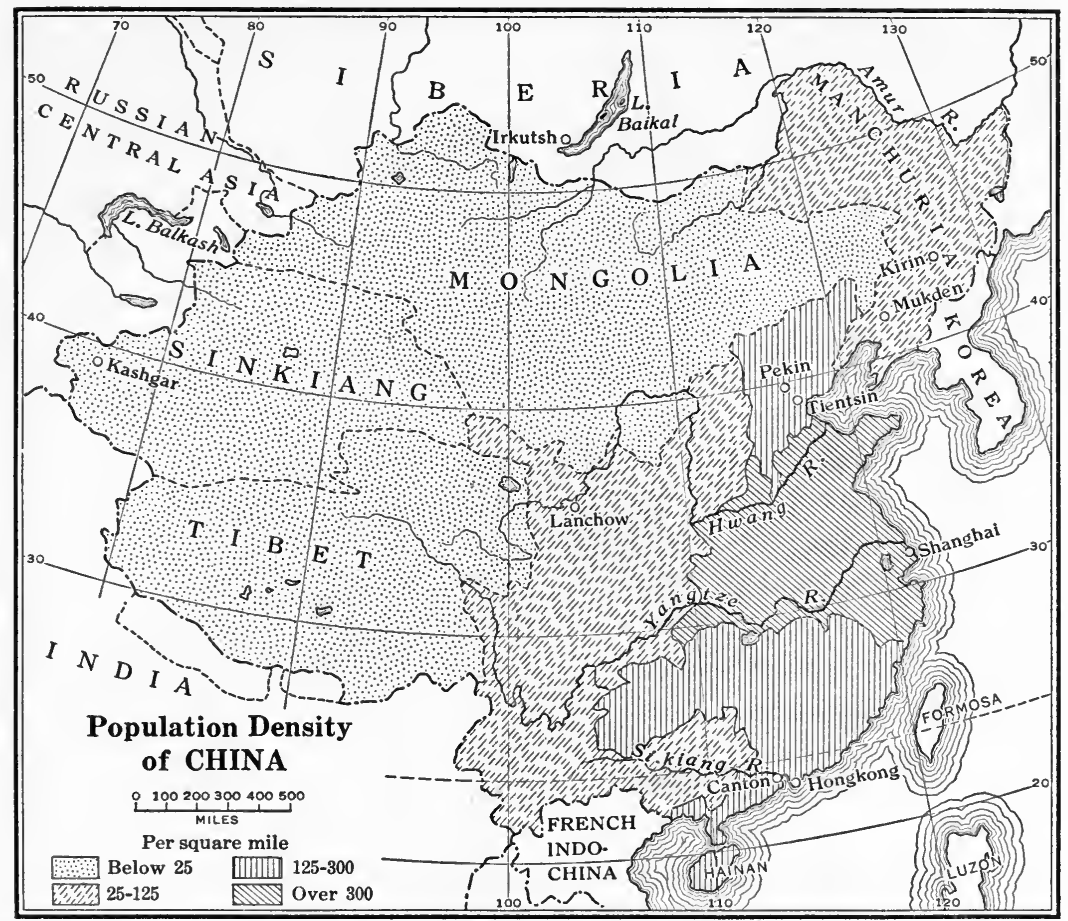

After Bowman

Caspian Sea and south to Annam. A period of disorder, known as the Five Dynasties (907-960), followed the T'ang dynasty. The civil wars enabled the Tartar tribes to come in, and the Kin (Chin) tribe held the north until defeated by a kindred tribe, the Mongols, in 1213, under the great chieftain Genghiz Khan. It is interesting to note that Ogatai, the son of Khan, overran central Europe as far west as Hungary and Poland, and Khan's grandson, Kublai Khan, completed the conquest of China and established the Yüan dynasty (1280-1368). Although the Mongols did not succeed in taking Japan, they conquered Korea, Annam, and Burma, extending their empire 
from the Yellow to the Black Sea, and from Indo-China and the Himalayas to northern Mongolia.

The Chinese finally succeeded in driving out the Mongols and established the Ming, a Chinese dynasty (1368-1644). The government resumed much of the old form, reëstablishing a recognized form of civil service, and assuming the general characteristics which it retained until the revolution in 1911. The Tartars again invaded the country in 1644, and established the Tsing or Manchus dynasty, which lasted until 1911. Since the line was of a different culture, there was considerable friction for a period, but gradually the Chinese became reconciled. There were not many changes in customs, as the conquerors quickly adapted themselves to the ways of the Chinese. It is claimed, however, that the plaited queue was forced upon the Chinese during this dynasty.

There has long been a limited amount of contact between China and the outside world, but little official intercourse until modern times. Diplomatic intercourse, in the European sense, the Chinese could not understand, as the emperor, the Son of Heaven, had no equal, and those who approached him could do so only as vassals. When the Dutch sent two envoys to the Chinese emperor in 1655 , they had to prostrate themselves before his throne and strike their heads on the earth nine times, indicating their inferiority, before they would be received. The European nations wished to make commercial agreements, but the Chinese considered commerce degrading, and no high official would condescend to negotiate trade agreements with barbarians, a term used synonymously with foreigner until 1860 .

As early as 300 A.D. a colony of Arabs, Indians, and Persians had established themselves in Canton. By the ninth century they were trading in three other cities, and by the thirteenth century in two more. The Portuguese reached Canton in 1517 and quickly acquired a monopoly of the trade. Soon all ports were closed, but by 1537 the Portuguese were permitted to establish factories and trade at Macao. For centuries this was the only place of trade and residence for Europeans. In the seventeenth century, vessels of the British East India Company appeared in Chinese waters, and by the eighteenth century practically all China's foreign trade was in the hands of this company. By imperial edict in 1757, all foreign trade had to pass through Canton.

Until the nineteenth century the Chinese preserved their semiisolation, but forces were working that no Chinese Great Wall could 
withstand. China's first serious trouble with a western nation was with the British Empire. Realizing that the use of opium was detrimental to its people, in 1796 China made the opium trade illegal, but no serious effort was made to enforce the law until 1837. In 1839 the Chinese government seized several thousand chests of opium and informed Great Britain that the trade would have to stop. But Britain would not have a trade stopped that amounted to between $\$ 5,000,000$ and $\$ 8,000,000$ per year, and made war on China. Before the British, with their modern war equipment, the Chinese were helpless, and the struggle ended in 1842 . China was forced to pay $\$ 21,000,000$, open five ports to foreign trade and resident British consuls, and give British officials legal jurisdiction over British subjects. This was the first time the Chinese had humiliated themselves to enter into a commercial treaty with a foreign nation. America and France, two years later, were successful in negotiating treaties similar to those of the British. China disregarded the treaties, and in 1857 the British and French fleets took Canton. The next year the Chinese were suing for peace. Russia, the United States, Great Britain, and France signed the treaty of peace. China again refused to consider the treaty binding, but two years later it was glad to submit to opening a number of ports and paying heavy indemnities.

Discovering the weakness of the Chinese military system and the susceptibility of the officials to graft, the European nations began to obtain concessions. Between 1894 and 1898 the struggle for concessions reached its apex. By 1899 China had practically no rights. Foreign governments had secured concessions in practically all the large cities, where they constructed modern quarters like those in their home countries. Here they had their own post offices, courts, and offices, levied their own taxes, and managed affairs as in their own countries. The United States did not secure any concessions, and, being handicapped, advocated the "Open Door" policy. Had it not been for this doctrine of the "Open Door" and the jealousy of the different European powers and Japan, China would perhaps have been divided like Africa.

Seeing their country mutilated and dominated by foreigners, the Chinese organized a secret anti-foreign society in 1895. Its purpose was to drive out all the foreigners with their hated religion, and to restore the old order. This Boxer Rebellion, as it is called, broke out in 1899, when foreigners were murdered wherever found. Protest 
from the foreign governments brought no results. Finally Japan, Russia, France, Germany, Great Britain, and the United States put down the rebellion. Jealousies prevented them from putting down the rebellion more quickly, and jealousies prevented them from agreeing upon the terms of peace. Finally they concluded that China must pay an indemnity of $\$ 337,500,000$.

Since that time China has had endless trouble with Japan and Russia. In 1894-95 China and Japan were at war. By the Treaty of Shimonoseki (1895) China ceded Port Arthur, Formosa, the Pescadores Islands, and the Liao-tung Peninsula to Japan, and agreed to pay an indemnity and recognize the independence of Korea. Russia connived with France and Germany and compelled Japan to surrender Port Arthur and the Liao-tung Peninsula, and to withdraw completely from the mainland. Russia thereupon began encroachments upon China, especially on Korea, which eventually led to the RussoJapanese War in 1904. Russia was forced to recognize Japan's interest in Korea and to transfer its concessions and leases to Japan.

As a result of the World War Japan gained Shantung and Kiaochow for an "indefinite period." This incensed China, as some 40,000,000 Chinese became Japanese subjects. Furthermore, Shantung is a very rich province and is regarded as "The Cradle of Chinese Civilization." In 1915 Japan presented its famous "Twenty-one Demands" in China. This act aroused China and the civilized world and caused Japan to lose prestige in China, Europe, and the United States, for the demands practically made China a vassal of the Japanese Empire. A Chinese boycott of Japanese goods and the disapproval of the western powers caused Japan to change its attitude. In 1919 the United States insisted that Japan withdraw from Shantung. At a conference in Washington in 1922, special attention was given to the Chinese question, and several treaties were drawn up. The United States, Great Britain, Belgium, France, Italy, and Japan signed an agreement guaranteeing the protection of China. A separate compact was signed by China and Japan in which they agreed "to settle amicably and in accordance with their common interest outstanding questions relative to Shantung." Great Britain offered to surrender its lease of Wei-hai-wei, but delayed doing so because of the change in political conditions in China.

Strained relations between China and Japan reached a crisis early in 1932, when Japanese forces moved on Shanghai, in defiance of protests from the leading countries of the world and the repeated 
objections of the League of Nations. Although strong notes of protest were addressed to the Japanese government by these countries, and half-hearted excuses and promises rendered, no satisfactory settlement has yet been reached (March, 1932). Anti-Japanese sentiment was engendered and augmented by two incidents: the bombarding of the International Settlement in Shanghai, by the Japanese, and the establishment of an independent government in Manchuria under the supervision of Japan. Although Japan denies violating its former agreement on the ground that Manchuria has had no territorial integrity since the Chinese revolution in 1911, and places the blame for the Shanghai affair on the Chinese boycott of Japanese goods, international sympathy has been on the side of the Chinese.

The present Sino-Japanese trouble is but a last link in a chain of trouble with foreign powers. Some years ago Dr. Sun endeavored to create a national consciousness that would unite the Chinese against foreign encroachments. As a result Students' Unions, numbering over 700,000 members, were organized, and some 2000 newspapers, of which 800 were dailies, undertook to develop Chinese solidarity against foreign aggressions.

The Revolution, begun in 1911, continued with intervals of peace until 1928, when a Nationalist government was organized. In 1928 General Chiang Kaishek assumed the presidency, and immediately the foreign minister demanded relinquishment of extraterritorial rights. The jealousy of military leaders and Bolshevist propaganda have been chiefly responsible for keeping China in a state of civil war. In 1932 it was under a Committee government, representing the Nationalist party.

3. Economic Development. Since the early part of the Chou dynasty (1122-249 B.c.), China has been an agricultural country, and before contact with the outside world was a self-sufficing nation. Over 80 per cent of the people are farmers; yet only about one-fourth of China's arable land is cultivated. Actually only about $176,000,000$ acres out of a possible 706,000,000 are tilled, or about 0.38 acre per person, compared with 3.4 acres per person in the United States. The question arises: Why does a country with so much idle land have so many famines? Several answers might be given; but the chief one is that China lacks machinery and capital to cultivate marginal lands. Practically all work in China is done by hand; beasts of burden are little used on farms, and hardly seen in most of the cities. In the southern part, a kind of buffalo is hitched to a crude plow and 
used to stir the mud in the rice fields. The camel is extensively used on the caravan routes of Mongolia, and the yak and sheep are used as pack animals in Tibet. But almost everywhere the coolie is the beast of burden. Even though severely handicapped by a lack of adequate transportation facilities, the Chinese have been averse to employing more modern methods. It is the opinion of authorities that agricultural conditions would be greatly benefited if the surplus agricultural population could be attracted to industrial centers.

The three food crops, rice, wheat, and sorghum-millet, occupy 69 per cent of the cultivated land. Rice is grown on 28 per cent, wheat on 21 per cent, millet on 20 per cent, cotton on 2 per cent, and other crops on the remaining 29 per cent. Little beef, mutton, milk, or butter is eaten. Rice and millet are the staple foods, although wheat is used in certain sections. Pork, chicken, and fish are consumed in large quantities.

Although Chinese agriculture is primitive, it is adapted to intensive cultivation. The land is made to yield two or more crops per year; yet the fertility has been maintained for thousands of years. Some of the methods of fertilizing the soil are highly perfected. The refuse and sewage of the cities are utilized, and the fertile dirt from the roadways and canals is collected and scattered on the farm plots. But the agricultural system does not maintain the great bulk of Chinese above the poverty line. According to estimates, over 80 per cent of the people of the northern farm villages and over 50 per cent of those of the southern farm villages have an income below the poverty line, $\$ 15$ per year per capita. ${ }^{1}$

The Industrial Revolution began in 1890 when the first modern spinning plant was established. Five years later, foreigners were granted the right to operate mills in China. The silk industry has flourished in China for some 4000 years. It is now producing about 27 per cent of the world's supply. Cotton textiles are the greatest modern industry. The domestic demand is enormous, power is cheap, and labor is plentiful, with no restrictions placed upon it. Flour milling is the second modern industry. It was started with Russian capital. China is also noted for its poultry. Its $350,000,000$ hens produce about 26,250,000,000 eggs per year. Fishing is important. The chief crops of China are rice, millet, tea, wheat, barley, corn, and beans.

1 See Sarvis, G. W.: "The Standard of Living in China and Its Meaning," Sociology and Social Research, Vol. IX, pp. 187-95. 
China has peculiar advantages for developing industrially. It is a country of almost unlimited natural resources, especially those necessary for industrial purposes. Its coal and iron reserves are among the largest in the world. Coal is found in all the 18 provinces of China proper. A famous geologist estimates that there is enough coal in one province to supply the world for several centuries. There are also large supplies of oil and tungsten. China is the world's greatest source of antimony. Copper, tin, lead, silver, gold, murchey, and bismuth are found. Manchuria has rich deposits of coal, lead, iron, gold, silver, and asbestos, and about 28,500,000 acres in forests. Sinkiang produces large quantities of jade. With all these resources, in addition to an enormous supply of cheap labor, a domestic demand for manufactured articles, and navigable rivers and canals, China is potentially a great manufacturing nation.

On the other hand, China has peculiar disadvantages. It is organized on the family system, which is associated with the gild. There is no government control of industry. The currency and system of weights and measures are woefully inadequate. Pony carts, wheelbarrows, and human carrriers are employed for the transportation of raw materials. Transit taxes are heavy. Scientific education has been neglected. Industrial workers and merchants occupy the lowest place in the social scale. China has only about 10,000 miles of railway, and that was constructed and chiefly used by foreign powers. It has also greatly handicapped itself by granting foreign concessions. However, as soon as it can stabilize its government, it will probably progress rapidly. Great Britain has over $\$ 1,250$,000,000 invested in China; Japan has $\$ 1,250,000,000$, and the United States $\$ 250,000,000$. Other countries have invested large amounts, and all will invest large amounts when the country becomes more stable. Although foreign investments are not always advisable, under present conditions they seem a good thing for China. ${ }^{1}$

4. Religious Development. The early Chinese worshiped nature and showed such a profound respect for their ancestors that many writers speak of them as ancestor-worshipers. If ancestor-worship can be classified as a religion, it is the oldest and most widespread cult in China today. No religious duty is more faithfully or universally performed. In many sections, when a person dies, the people dress in white, the emblem for mourning, and with noisy hired mourn-

1 See Blakeslee, G. H.: "The Foreign Stake in China," Foreign Affairs, Vol. X, pp. 81-91. 
ers and a coolie bearing special foods for the departed; proceed to the grave. The dead person's name is engraved on an ancestral block; prayers are.addressed to his spirit each morning; and at stated times the oldest son places food and red paper money on the grave. It is easy to understand how this would influence social conditions. Indeed, the dead rather than the living have ruled China, and graves occupy more land than cities.

Confucianism is the most widespread religion of China. Confucius (550-478 B.c.) was a collector of the wisdom of the past rather than a person who claimed to have received divine revelation as did most other founders of religions. The basis of his teaching was the duty of man to man. He showed no interest in heaven, hell, a future life, ceremonies, or ritual, but propounded precepts similar to some of those of the Old Testament. His cardinal principle was: "Do not to others what you would not wish them to do to you."

Taoism is based on the philosophy of Lao-tzse (about 570 B.c.), which seeks a solution to the puzzle of existence. At first it was purely philosophical, but about 1800 it borrowed ritualistic ideas from Buddhism and became a religion. It is now very difficult to distinguish between Taoism and Buddhism.

Buddhism was imported from India about 67 A.D. The mingling of the mythologies and philosophies of the Chinese with the Mahayana system of Buddhism formed a blend which is little understood by the Chinese masses. Buddhistic temples are found throughout China, but many are in decay. Many of the priests are poorly trained, and many of the monks are beggars. There has been very little rivalry among these three religions in China, and many Chinese are at the same time communicants of all three religions.

In Tibet, Mongolia, parts of Manchuria, and northern China proper is found a peculiar form of Buddhism known as Lamaism. It has developed an extreme ritualistic cult with a very complicated hierarchy of spiritual potentates. The prayer wheels and prayer flags are of much interest to foreigners. Prayers are printed on cloth or paper and hung up or carried around on a wheel. The city of Lhassa, Tibet, is a sacred city where the Grand Lama, who is both a god and ruler of the country, lives. All worship him, and his palace is sacred. Many pilgrims from all parts of Asia journey to the holy city. Until Great Britain overran the country in 1903 and forced Tibet to open the border to trade, only Chinese were permitted to enter the country. This form of religion has a strong hold on the Tibetans and is a great 
handicap to their advancement. One or more of the boys in every household become a priest or lama, and almost a fifth of the people are engaged in religious work.

Mohammedanism is said to have been introduced into China by the uncle of Mohammed in 628. The first mosque was built in Canton. There are now between 15,000,000 and 20,000,000 Moslems in China. Part of these are the descendants of 4000 Arabs sent to crush a rebellion in 755 .

Christianity was introduced into China by the Roman Catholics about three centuries ago. There are now about 2,000,000 Chinese Roman Catholics. The Russian Orthodox Church began missionary efforts in China in 1685 and now has about 20,000 adherents. Protestant missions started in 1807 and now have about 618,000 followers. Attached to the Protestant missions are 27 colleges, 256 high schools, and 581 elementary schools. For the last three decades the hostility toward missionaries has increased in China, as the Chinese believe many of the missionaries are working with commercial interests to the detriment of their country. In 1914 Confucianism became a state religion, but other faiths are permitted.

5. Educational Development. China remains a riddle. Although it was highly civilized when nine-tenths of the world was hardly removed from savagery, it is now 60 per cent illiterate and extremely backward. It was among the first to discover and use paper, printing, and gunpowder; to domesticate plants and animals; and to construct such stupendous works as the Great Wall and Great Canal. Nature did not force it to take to the seas or to compete with aggressive foreign nations, except as a defender of its status quo.

During the Chou dynasty (1122-249 B.c.), Chinese culture took the form which it has retained. From China this culture spread to Korea, Japan, and other contiguous lands. Emperor Shih Huang Ti, during the Tsin dynasty (249-06 B.c.), tried to destroy the classical literature and start a new régime, but failed. During the T'ang dynasty (618-907 A.D.) there was great activity in invention, art, and literature. Apparently printing was discovered during this dynasty.

For thousands of years China has had a small literary class. Examinations were conducted to award degrees which were prerequisite for government positions. Only a small group could afford to go to school. Those who went did so solely to obtain government positions. If they failed, they could find little to do without losing prestige. 
The training they received was mostly committing to memory the writing of Confucius, which did little to fit them to be leaders of the people.

In 1905 the old system of education was abolished and a new system adopted, patterned after that of the West and Japan. At present there are 10 government universities, 35 Protestant colleges, a number of Catholic colleges, and several private universities. During the last few years middle and elementary schools have been increased. There are several thousand Chinese students in foreign countries. This movement was stimulated in 1908 when Roosevelt refunded the Boxer indemnity to China to be used in educating Chinese youths in American universities. Girls are now taking a great deal of interest in education in China. Under the old régime it was not considered worth while to send girls to school, since they could not hold government positions.

In China there are numerous dialects which are scarcely understood outside the regions in which they are spoken. Another difficulty is that the language, being idiographic, requires the memorization of thousands of characters. J. Y. C. Yen, a graduate of Yale (1918), took 1300 of the most common Chinese characters and made four cheap textbooks. He selected a corps of teachers, and by 1928 they had taught between 4,000,000 and 5,000,000 farmers and laborers to read, and had delivered to them a certificate of "literate citizen."

6. Social Conditions. In the traditional sense, four classes are distinguished in the Chinese social system: namely, the literary, the agricultural, the artisan, and the trading classes. The coolies are hardly a social class, but rather beasts of burden. Under the Manchu dynasty, China had an imperial family. A few people held hereditary titles, the most noted being Duke Yen, the lineal descendant of Confucius and the possessor of the longest genealogy in the world. The aristocracy was composed of the government officials, who, roughly speaking, composed the literary class. Though the legal emoluments of officials were small, custom permitted them to receive many kinds of contributions and to practice many forms of graft and corruption. As a rule, an official retired a wealthy man. Usually he invested in land and built a castle in his native district among his relatives. His descendants generally followed him in office, acquired great influence, became a kind of caste, and wielded great political and social influence. 
The bulk of the people in China are small farmers, but they are greatly respected as a class because they produce food. The artisans, not being food producers, are not so highly regarded. Neither is the soldier, because, on the one hand, he does not produce food, and, on the other, he destroys life. Traders have generally been condemned, because they were working for monetary gain without being producers. The literary-official group avow that they are working for the welfare of others, but are generally open to graft. It is interesting to note that the returned students have not been received by the old literary classes. Consequently they have been forced into business and education.

The whole social system centers in the family. Confucius taught respect for elders, and filial piety is so stressed that the control of the parent over the child is almost complete throughout life. All are expected to marry young and rear sons to care for the graves of their ancestors. The longer the line of ancestors, the more honorable is the family. There is little courting. Marriage is arranged by the parents or professional matchmakers, and often the couple have never seen each other until the day of marriage. After marriage the bride is taken to live with the groom's parents, and in reality to serve her mother-in-law. Very little attention is given to the girl until she becomes the mother of a boy. As she grows older and her sons marry, she acquires more prestige. Her life then becomes easier as she has daughters-in-law to perform the household duties. The more sons a man has, the more prestige he has. He has very little interest in girls; if asked how many children he has, he enumerates his sons, and often does not mention his daughters. Polygamy is common and popular - with the men because it brings added prestige, and with the women because it means more hands to assist in the household tasks.

The Chinese dress in simple and comfortable garments with the idea of minimizing sex. Clothes vary with seasons more than they do in America; the Chinese put on clothes to keep them warm rather than build fires. In fact, the weather is usually distinguished by the number of coats one wears rather than by a thermometer. They speak of one-coat, two-coat, and three-coat weather. No one wears shoes in the house, but there is no objection to keeping the head covered. The Chinese are very polite, but do not shake hands with friends. They welcome them by shaking their own hands. There is no kissing, but much prostrating on the ground and bowing. The 
Tibetans greet people by sticking out their tongues. A coffin is the most appreciated present in China. The Chinese calendar is different from ours; there are few holidays and feast days. New Year's day is the most important, and its celebration lasts about two weeks. Age is counted from New Year's day rather than from the natal day. If a child is born a few days before New Year's, he begins his second year at New Year's.

Many of the wealthy live in mansions behind high walls, but the mass of people live in one-story affairs made of mud, reeds, or bamboo, with tiled or thatched roofs. Furniture hardly exists, but many things are stored in the house. As most of the houses have no chimney, the smoke finds its way out through a hole in the roof. Oil lamps are now coming into use. The food of the poorer people is simple, consisting mainly of rice in the south and millet in the north. Chips of meat and fish, such as may be eaten with chopsticks, are served. Tea is the chief drink. Throughout most of China proper, milk and butter are hardly known. The common word for milk is lai, which refers to the human product.

Chinese social life is now at the crossroads. The favorite phrase of the young Nationalists is "Ta Tao," which is equivalent to "Down with the old cultural pattern!" The old clan is looked upon as an instrument of oppression, and the old village life as stupid and backward. While there is disagreement as to the phases of Chinese culture that should be rejected if the country is to become a modern state, the democracy of China promises to be an oligarchy of the intellectuals.

7. Immigration and Emigration. The Chinese have never been an emigrating people: Out of a population of over $400,000,000$ in 1922 , only $8,180,000$ were living abroad. Practically all of these were living in countries near China. In 1878 the official barrier to immigration in Manchuria was removed, and since then a steady stream has flowed into that country, which, although one-fourth as large as China proper, contains only about 6 per cent of the entire population. Since the Japanese have not been able to induce their surplus population to go to Manchuria, on account of the lower plane of living that prevails there, they are encouraging Chinese settlements. In 1922 Formosa had 2,258,650 Chinese; Java, 1,825,700; Siam, 1,500,000; and the East Indies, 1,023,500. In the Americas, there were 61,639 in the United States, 45,000 in Peru, 90,000 in Cuba, 20,000 in Brazil, 12,000 in Canada, and 3000 in Mexico. 
Hawaii had 23,507; South Africa, 5000; Europe, 1760; Australia, 35,000; the Philippine Islands, 55,212. ${ }^{1}$

The first Chinese to come to the United States appear to have been two men and a woman who landed in San Francisco in 1848. In 1853 only 42 Chinese came, but the next year the number reached 13,100 . This number was not reached again until 1870 , when it rose to 15,740 . For two years it dropped to about half that number and then jumped to 20,292 . In 1876 it reached 22,781 , but then declined rapidly until 1882 , when it increased to 39,579 , the largest number for any one year. All told, about 377,245 Chinese have been admitted. In the last 30 years 71,790 have been admitted.

The restriction of Chinese immigration to the United States began in 1880, when a treaty between China and the United States permitted a reasonable limitation of Chinese laborers. In 1882 immigration of Chinese laborers was prohibited for ten years. This agreement was renewed in 1892 for another decade. In 1902 China refused to renew it, and the United States made it a permanent law. In 1917 China was included in the barred zone. Most of the Chinese coming to the United States now are students. Chinese are not permitted to become naturalized, and ordinary immigrants are not permitted to enter. The number of Chinese in the United States is steadily decreasing. Most of them live in California, New York, and Oregon. About three-sevenths are in California, and over one-half in California, Oregon, and Washington. The Chinese usually settle in cities and engage in a number of occupations, though we usually think of them in connection with laundries and chop suey restaurants. Curiously, no Chinese ever heard of chop suey, unless from America, or made a collar stiff until he came to America.

\section{QUESTIONS, EXERCISES, AND PROBLEMS FOR INVESTIGATION}

1. Give a brief statement of the racial origins, size, and distribution of the population of China. In addition to the text, see Cressey, G. B.: "The New Map of China," Geographical Review, Vol. XX, pp. 65256; Dictionary of Races or Peoples; Pittard, Eugène: Race and History, pp. 395-403; Willcox, W. F.: "The Population of China in 1910," Journal of the American Statistical Association, Vol. XXIII,

1 See Bland, J. O. P.: "China's Southern Secessionists," Current History, Vol. XXXV, pp. 235-39. 
pp. 18-30; Roxby, P. M.: "The Distribution of Population in China: Economic and Political Significance," Geographical Review, Vol. XV, pp. 1-24; Chen, Chang-Heng: "Changes in the Growth of China's Population in the Last 182 Years," Chinese Economic Journal, Vol. I, pp. 59-69; Bowman, I.: The New World, Chap. XXXI; Bland, J. O. P.: "Racial Equality in China," Edinburgh Review, Vol. CCXLIX, pp. 274-88.

2. Briefly describe the geographical features of China.

3. Discuss (1) China's policy of aloofness from intercourse with the outside world; (2) its difficulties over commercial treaties with other nations.

4. Account for the fact that China has not been able to establish a strong national government. Besides the text, see Elliston, H. B.: "China in the World Family," Foreign Affairs, Vol. VII, pp. 616-27; Leveson, W. E.: "China and the Powers," Fortnightly Review, Vol. CXXVI, pp. 298-303; Spykman, N. J.: "The Social Background of Asiatic Nationalism," American Journal of Sociology, Vol. XXXII, pp. 396411; Bowman, I.: The New World, p. 586.

5. Summarize the economic situation in China, naming the chief handicaps. Besides the text, see Pollard, R. T.: "The Economic Background of China's Nationalist Movement," American Political Science Review, Vol. XXI, pp. 853-57; Machray, Robert: "Prospect in China," Fortnightly Review, Vol. CXXVII, pp. 9-13; James, H. P.: "Industrial China," Economic Geography, Vol. V, pp. 1-21; La Fleur, A., and Foscue, E. J.: "Agricultural Production in China," ibid., Vol. III, pp. 297-308; Baker, O. E.: "Agriculture and the Future of China," Foreign Affairs, Vol. VI, pp. 483-97; Gray, G. D.: "Contemporary China," Nineteenth Century, Vol. CV, pp. 650-58.

6. Why are the Chinese sometimes called ancestor-worshipers? Compare the leading religions of China. See also Yard, J. M.: "Christianity in the Chinese Laboratory: Will It Stand the Test?" Journal of Religion, Vol. VIII, pp. 524-38.

7. What part has the literary class played in Chinese history?

8. Along what lines is China developing educationally? Why is advancement difficult?

9. Explain the significance of the family. See Tzu, Lien Chao: "Some New Factors that Affect the Old Values of the Chinese Family," International Journal of Ethics, Vol. XXXVIII, pp. 341-50; Hahn, C. C.: "Psycho-Social Effects of the Chinese Family System," Sociology and Social Research, Vol. XII, pp. 455-60; Liu, C.: "Chinese versus American Ideals Concerning the Family," ibid., Vol. X, pp. 243-48; Headland, I. T.: Home Life in China; Williams, E. T.: China Yesterday and Today, Chaps. II-V:

10. Describe the different Chinese customs mentioned in the text. See also 
Liu, C.: "Contrasts Between Chinese and American Social Codes," Sociology and Social Research, Vol. X, pp. 41-45.

11. Name and characterize the different classes in the social system of China, and compare these with Western civilization. Besides the text, see Bridges, J. H.: "A Comparison of Chinese and Western Civilization," Sociological Review, Vol. XIX, pp. 89-105; Price, M. T.: "Culture Contact in China," Social Forces, Vol. VII, pp. 270-78; Cressey, P. F.: "Influence of the Literary Examination System on the Development of Chinese Civilization," American Journal of Sociology, Vol. XXXV, pp. 250-62; Hummel, A. W.: "What Chinese Historians are Doing in Their Own History," American Historical Review, Vol. XXXIV, pp. 715-24; Lung, C. F.: "A Chinese Student and Western Culture," Sociology and Social Research, Vol. XVI, pp. 23-38; Liu, J.: "The Social Relationships of the Villagers in China," ibid., Vol. XIV, pp. 462-68.

12. Where have Chinese emigrants gone? Why have we sought to restrict Chinese immigration? Besides the text, see Stephenson, G. M.: A History of American Immigration, Chap. XX; Garis, R. L.: Immigration Restriction, Chap. IX; Mallory, W. H.: "The Northward Migration of the Chinese," Foreign Affairs, Vol. VII, pp. 72-82; Bland, J. O. P.: "China's Southern Secessionists," Current History, Vol. XXXV, pp. 235-39; Ferenczi, Imre: International Migrations, Vol. I. 


\section{CHAPTER XXVI}

\section{JAPAN}

1. General Description. The islands which constitute the Empire of Japan lie in the North Pacific Ocean, off the coast of China and Siberia. The Japanese in ancient times called their country Yamato, but after 670 they began using the Chinese name Jih-pen (Sun origin), which was corrupted to Nihon or Nippon, and finally to the English form Japan. Japan has an area of 261,567 square miles; it is almost as large as Texas. Japan proper has an area of 148,756 square miles; Korea (Chosen), 84,738; Formosa (Taiwan), 13,944; Sakhalin (Karafuto), 13,253; mandate isles in the Pacific, 928; Pescadores (Hokoto), 47. According to the census of 1930, Japan had a population of 91,337,635; Japan proper had 64,450,005; Korea, 21,058,305; Formosa, 4,594,161; Sakhalin, 221,243 (1927); Kwantung (territory in Manchuria leased from China), 883,778 (1927); and the mandate territory (Marshall, Caroline, and other South Sea islands), 58,816 (1927). In 1928 there were 717,529 Japanese residing abroad, and 35,254 foreigners residing in Japan.

The Japanese and Koreans belong to the Sibiric branch of the Mongolian race. In appearance the Japanese are less Mongolian than the Chinese; their skins are not so yellow, eyes so oblique, and noses so small. The Japanese are more stockily built than the Chinese, but their hair is truly Mongolian. Their language is agglutinative, whereas that of the Chinese is monosyllabic. The general cultures of the two peoples are similar. Although classified as Mongolian, the Japanese are of mixed origin. The Ainos, who live principally in Yezo and the Kurile Islands, are thought to be Caucasians, and there is evidence of a Caucasian substratum through other parts of Japan. There-is also evidence of a Malay mixture, especially in the southern part of the islands. It appears that the Ainos were the aborigines of Japan. Then a Malayan people spread over the country, only to be absorbed later by the Mongolian conquerors. There is evidence of a very close relationship between the cultures of early Japan and the Philippines.

Japan proper consists of four large islands and several hundred 399 
smaller ones. These are of volcanic origin and very mountainous. The islands are generally narrow, and few places are far from the mountains or far from the ocean. They have long been subject to earthquakes. In some sections there are as many as 500 a year. In the earthquake of September 1, 1923, the casualties amounted to 246,540. The earthquake of March 9, 1927, resulted in a casualty list of 5715. There are a number of volcanoes, but most of them are extinct or inactive. In 1924 a submarine volcano was discovered. Mt. Fujiyama is a beautiful snow-capped inactive volcanic mountain, which the Japanese have long held sacred. Both Korea and Formosa contain important mountains.

The islands composing Japan skirt the eastern Asiatic coast for some 3000 miles. They have a wide range of climate. The extreme north is sub-Arctic and the extreme south tropical. Sakhalin, the Kurile Islands, Yezo, and the northern part of Honshu are cold in winter, with much snow and ice. The main part of the country has a temperate climate. The rainfall varies, being heavy in the south and lighter in the north, but in most sections it is sufficient for crops. The rivers are short and swift, with many beautiful waterfalls, suitable for the development of hydro-electric power. The falls of Nikko have an unbroken plunge of 350 feet.

2. Political Development. The Japanese date their history from 660 B.c., when the first Emperor (Mikado or Tenno) ascended the throne. His predecessors were a group of tribal chieftains. With him began a line of rulers which continues today, the longest dynasty in the world. Sujin, the tenth emperor, stands out among the early rulers. He sent an expedition into Korea, the first into any foreign country, promoted agriculture, levied taxes on the proceeds of the chase and on the handiwork of women, and substituted clay images for the live persons and animals formerly buried with the deceased husband, father, and master.

During the Gempei era (1159-99) military feudalism became firmly established in Japan. This was followed by the Hojo Tyranny (11991333), when the government sank to its lowest depths. Knowledge of Japan was first brought to Europe in 1295 by Marco Polo, who heard of a country called Chipangu (Japan) while traveling in China. In 1542 the Portuguese visited Japan. They were the first Europeans to go to Japan, and were followed by a group of Jesuit missionaries. The ruler, Hideyoshi, became alarmed at the ambitions and methods of the whites and ordered the missionaries out of the country in 1587. 
Between 1624 and 1638 all foreigners were banished from Japan. No one was permitted to enter, and no Japanese was allowed to leave. This period lasted until 1853 and is known as the "Great Sleep" or "Great Peace." During this period many countries, especially Portugal, France, Great Britain, Russia, and the United States, made repeated attempts to establish friendly relations with Japan, whose only contact with the outside world was with a small colony of Dutch, who lived practically imprisoned on a small island, Deshima, close to Nagasaki. Only one Dutch ship per year was permitted to visit it. In 1853 Commodore Perry, backed by the United States navy, forced Japan to open its doors, and the next year a treaty was concluded between the United States and Japan. Apparently this was Japan's first international treaty. It was followed by treaties with Great Britain, Holland, and Russia. In 1858 a commercial treaty was concluded between the United States and Japan. It, too, was followed by treaties between Japan and Great Britain, Holland, Russia, France, and other countries. In 1868 a complete change in political, economic, educational, and social conditions began in Japan, and about 50 years later it was a world power on an equal footing with other nations.

Then treaties began to cause trouble. Beginning in 1336 the Shogun or Prince (hereditary chief official, for a long time a member of the Tokugawa family) practically ruled the country, while the Mikado was a mere puppet. Because the Shogun had signed treaties with foreign countries, the feudal princes (daimyos), who had long been jealous of the Shogun, accused him of a double crime - usurping the authority of the Mikado, by signing treaties without consulting him, and permitting barbarians to land on the sacred soil of Japan. In 1860 the Shogun sent an embassy, numbering about 70 persons, to the United States, where different cities tried to surpass each other in welcoming the Japanese. At the same time the daimyos were organizing against the Shogun and demanding that the barbarians be expelled. In 1861 they attacked the British Legation, and the next year the Richardson affair occurred, in which four British subjects, one a lady, were set upon and one killed. The British bombarded the fort of Kagoshima and brought the daimyos to terms. In 1864 the daimyo of Chōshū opened fire on foreign vessels passing through the strait. The British, French, Dutch, and Americans, however, demolished the forts and levied an indemnity of $\$ 3,000,000$ on Japan. 
These affairs convinced the Japanese that they were no match for the "barbarians" of the West and would be unable to defend themselves. The antagonism of the daimyos against the Shogun increased. They advocated learning all they could from the barbarians and encouraged Japan to try to excel them in their own arts. The Shogun was unsuccessful during the revolt of 1867-68; consequently the Mikado came into full authority. The chief and lesser daimyos voluntarily surrendered to him their feudal possessions, rights, and honors as an act of patriotism. In 1871 the prefectures were substituted for the feudal jurisdictions, and the former daimyos became government officials with good salaries. Change followed change in rapid succession. Fighting, which had been the privilege of a few, was now made the duty of all, and Japan started to build a strong army and navy. Railroads and telegraph lines were built, and many other changes inaugurated. In 1889 the government was reorganized on European models and a constitution was adopted. Although the Mikado has great authority, the Imperial Diet, consisting of two chambers - the House of Peers and the House of Representatives is gradually gaining in power. Universal suffrage for males 25 years of age became a law in 1925, and the first trial by jury took place October 1, 1928.

Japan began its policy of expansion in 1875 when it secured the Kurile Islands from Russia and relinquished Sakhalin. In 1876 it took over permanently the Ryukyu Islands. In accordance with the treaty of Shimonoseki in 1895, China ceded Formosa and the Pescadores to Japan. By the treaty of Portsmouth, New Hampshire (1905), Russia ceded to Japan part of Sakhalin. Japan occupied the rest of Sakhalin as well for some time, but finally released it in 1926 . Russia also ceded its lease of Port Arthur. In 1910 Japan annexed Korea. In 1915 its lease of the southern part of the Liaotung Peninsula, including Port Arthur and Dalny, was extended to 99 years. By secret agreement with Great Britain, Japan secured a claim to the Caroline, Marshall, and other German islands in the South Seas. It also decided to occupy for an "indefinite period" Shantung and Kiao-Chow. There has been considerable opposition on the part of the western nations to Japan's policy of expansion, especially its interest in China, but most of them have not been in a position to raise legitimate objections. In 1902 Great Britain and Japan made a defensive alliance, and Japan is familiar with British intrigues in Egypt, India, and other countries. In 1910 Roosevelt recognized 
Japan's special interest in China, and in 1917 the Lansing-Ishii agreement confirmed it. The United States could not do otherwise, since it was trying to justify its conduct in Cuba, Haiti, San Domingo, Panama, and Nicaragua under the Monroe Doctrine cloak. In 1916 Russia and Japan signed agreements in regard to spheres of influ-

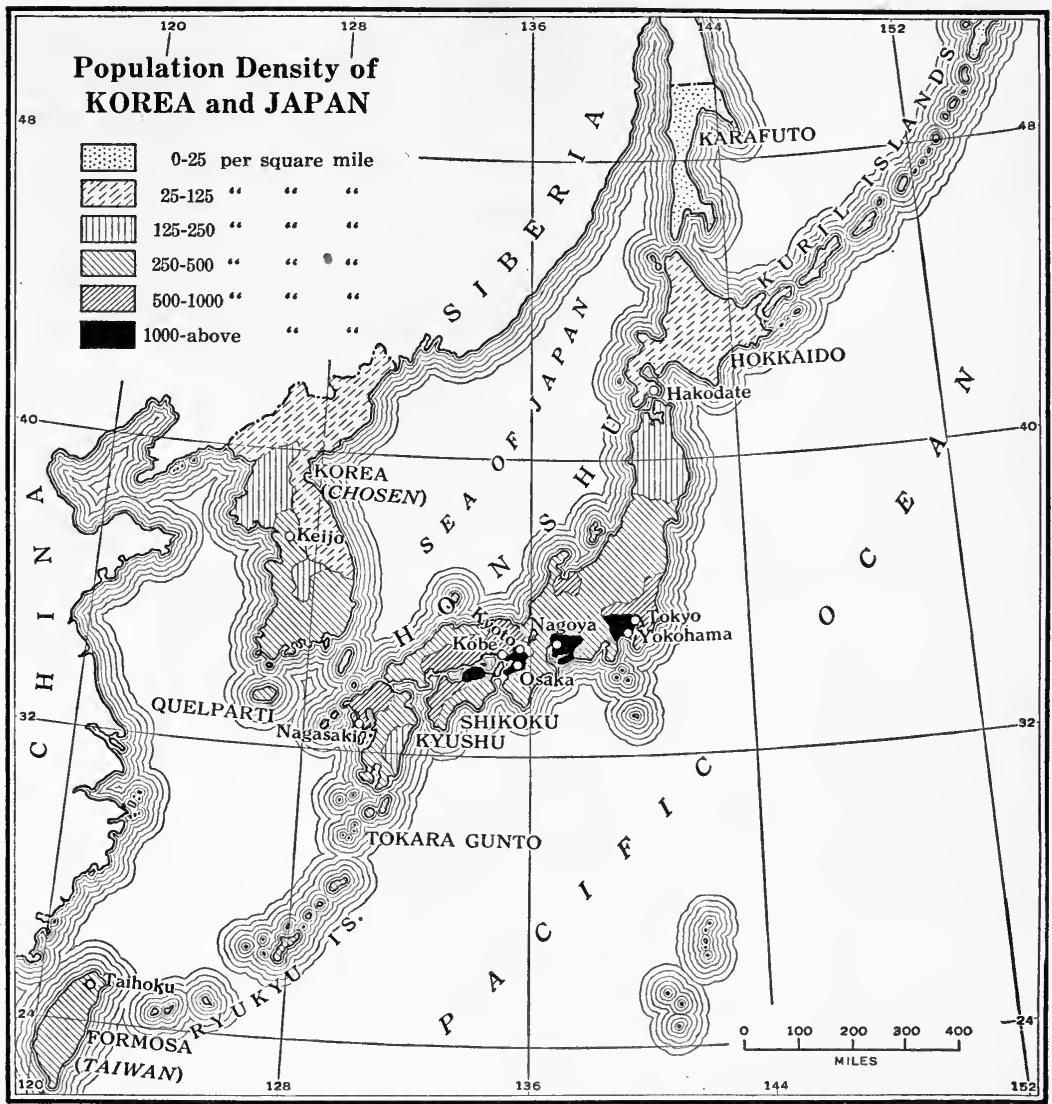

After Bowman

ence in China. At present (March, 1932), China and Japan are in conflict over Manchuria, and the western nations and League of Nations seem unable to bring about a peaceful settlement.

Japan has had difficulty in administering Korea. It has largely subdued and tamed the head-hunters of Formosa, but the Koreans, though cowed, have never become submissive. Korea is an older 
kingdom than Japan and at one time included considerable territory, but it has had a long line of weak rulers and has been a bone of contention among China, Japan, and Russia for years. Japan promised Korea independence after the defeat of China, but instead, after several intrigues, annexed it. It has made many improvements in Korea, which was long a hermit and backward nation, but the Koreans cannot forget their ancient glory, the intrigues of Japan, the murder of their queen, and the flight of their emperor. At present they appear sullen and lifeless, but Japan realizes that the volcano may erupt at any time. Recent nationalistic disturbances, however, have resulted in increased measures of home rule for Korea.

3. Economic Development. During its hermit period Japan learned to be a self-sufficing nation. As there was no opportunity for expansion, it became crowded and reached the stage where its population was practically stationary. After it opened its doors to the world, commerce developed rapidly, it began to expand, and its population began to increase. It is now a crowded nation. The average population density is 375 persons per square mile, but Honshu, the largest island, has a density of 731.9, Shikoku 432.8, and Kyushu 483.5. These four islands have an area of 137,000 square miles, and are about the size of Montana; they have to support about 60,000,000 people. During the last decade the land under cultivation increased but 5 per cent and the area planted in rice but 4 per cent, while the population increased 12 per cent.

Japan has much mountainous and stony land. Only about onesixth of the land, or an area of 15,000,000 acres (about one-third of Kansas), is under cultivation. It is claimed that about one-fourth more of the land could be brought under cultivation. About 70 per cent of the Japanese farmers cultivate areas less than $2 \frac{1}{2}$ acres. The average is one-half acre per inhabitant. Considerably more than half of the land under cultivation is used in growing rice. In many sections the land is made to produce two or more crops per year. The southern and coastal regions have a favorable climate for crops, and here the majority of the people live. Formosa and Korea have good agricultural lands, and since they have become part of Japan, agriculture is flourishing there. Most of the people in Japan are engaged in agriculture and silk raising. Fishing and manufacturing are also important. Nearly 1,000,000 people are employed in the former, and about 2,000,000 in the latter. From 1909 to 1925 the number of factory workers increased 97 per cent. 
The southern islands produce rice, cotton, tobacco, sweet potatoes, sugar, and oranges. The central section adds tea, millet, wheat, and silk raising to these. The northern section grows wheat, millet, barley, and beans. In parts of Korea and Kwantung stock is raised. The principal foods are rice, millet, barley, and beans. Tenants pay 57 per cent of the rice as rental, and 44 per cent of other crops. Taxes take 16 per cent of the total yield of farms, and incomes are taxed from 20 to 30 per cent.

With the exception of copper, Japan is not rich in mineral resources. It has considerable coal, however, and some petroleum. The Caroline Islands are rich in phosphorus. Korea is thought to be rich in minerals, but the resources are poorly developed. Korea and Formosa have extensive forests, and about 70 per cent of Sakhalin is covered with primeval forests. Formosa is well known because of the camphor tree, which is carefully protected. It is now the world's chief supply of camphor. Commerce and manufacturing in Japan are developing rapidly. Silk constitutes about 40 per cent of its total exports, and the United States buys 96 per cent of that. Cotton goods are the next largest export -24 per cent of the total exports in 1926.

4. Religious Development. Japan is a land of many religious sects. The oldest and most widespread religion is Shintoism. It is a Japanese system which developed in prehistoric times, and is really patriotism exalted to a religious cult. It has no sacred books, dogmas, philosophy, metaphysics, or code of ethics. The forces of nature, family ancestors, and emperors are deified. Essentially it is a religion of gratitude and love, which stresses following one's natural impulses, respecting one's ancestors, and obeying the laws of the state.

During the Asuka period (550-708), Buddhism and Confucianism were introduced into Japan. About 1542 the Portuguese arrived, introducing firearms, tobacco, and Christianity. The Jesuit missionaries were tireless workers, and by 1582 there were about 150,000 native Roman Catholics. Nobunaga, who was a friend of Christianity and an enemy of Buddhism, sent an embassy to the Pope in 1584. He was followed by Hideyoshi, who became disgusted with the foreigners, especially the fanatical Jesuits who were attacking Buddhist priests and destroying their temples, and issued an edict in 1587 giving the Christian priests 20 days in which to leave the country. In 1614 another edict declared that members of all religious orders, either European or native, should be expelled from 
the country. Churches were destroyed, and all native adherents were to be forced to renounce the faith. In 1622 the "Great Martyrdom" occurred in Nagasaki, which had become a "Christian city." From that time until Japan was closed, Christians were tortured to death by revolting methods.

When Japan opened its doors to the world, other religions were permitted to enter. The chief faiths, however, are still Shintoism and Buddhism. Neither has state support, and there is absolute religious freedom. There are thirteen seets of Shintoism, twelve of Buddhism, and twelve of Christianity. The Japanese manifest very little interest in Christianity, and less than one-fifth of one per cent profess this faith.

5. Educational Development. Japan's literary history began about 284 A.D. A Korean acquainted with the Chinese elassics was appointed tutor to the emperor's son. He was followed by a Chinese, and thus the Chinese classies were introduced. Although the beginning of art dates from the period when clay images were substituted for living persons and animals at funerals, painting, based on Chinese art, was not introduced until the latter part of the sixth century.

Emperor Tenchi (662-71) established the first sehool in Japan, and Emperor Mommu (697-708) established the first university. During the eighth century there was a considerable migration from China to Japan, and the Chinese language and school system were largely taken over. The first textbooks in Japan were published in Chinese idiographs. During the hermit period Japan made little progress along educational lines, but since it has established contacts with other nations it has made wonderful advancement. In 1871 a delegation was sent to Europe and America to study sehool systems. The following year a modern system, including eompulsory education, was put into operation. An added impetus to education was given in 1883 when the United States returned to Japan its share of the indemnity of the "Sakuroda affair," to be used for educational purposes.

The elementary sehools in Japan are managed by the municipalities, rather than by the federal government, but the federal government controls the high schools and has five imperial universities. There are thirty-two other colleges in Japan with university rank. Since there are so many inducements to attend higher educational institutions, one being the shortening of the period of army service, entrance is chiefly determined by competitive examinations. English 
is the language of commerce and is a required subject in secondary schools. The education of girls has not been developed to the same extent as the education of boys, but a few girls are now being admitted to the imperial universities. Japan has also established schools for both the Japanese and the natives in Formosa and Korea.

6. Social Development. There are many cultural residues in Japan, such as the customs of building light, flimsy houses, of wearing the kimono, of permitting nude mixed bathing, and of recognizing prostitution, which would indicate a southern origin for the Japanese. On the basis of these culture traits, a number of writers contend that the Japanese migrated to their present location from a warmer climate, and some think that they are chiefly Malay in blood.

Until the beginning of the modern period, the social development of Japan was similar to that of China. At times there was considerable intercourse between the two countries, and many Chinese customs and institutions were adopted, with modifications, by the Japanese.

The Japanese early developed a fivefold caste system. (1) The Kugĕ were the aristocrats of the emperor's court. (2) The Daimyos were the feudal lords who constituted the aristocrats of the Shogun's court. These two groups seldom intermarried. (3) The Samurai were the military caste. Their appointments were hereditary, and they were not permitted to intermarry with a lower caste. (4) The Heimin, the commoners, were divided into three main castes farmers, artisans, and traders. (5) The Eta (Yeta) group, "outlaws" or "untouchables," were segregated and forced to live with and marry within their own group. Since Japan has become modernized, it has tried to stop the use of the word Eta, and to stamp out the discrimination against this group.

The contact with Western civilization brought many social changes, and Japan is still in a transition period, in many respects Western, in others Oriental. In 1871 the "outcasts," who had been regarded as animals, were registered as human beings. In making the swift change from feudalism to modern society, the nobility were rehabilitated and a peerage was established in 1884 with five orders - prince, marquis, count, viscount, and baron. Peasants were freed from servile dues and required to pay a land tax like other free people. The people are free, but legal and recognized social distinctions obtain.

Differing from those of most of Asia, Japanese cities and homes are 
clean and neat, and disagreeable odors are absent. Owing to the frequency of earthquakes, the houses usually have one story and are built of wood. The Chinese make their streets crooked, with many sudden turns, because they wish to retard the spirits, which they believe move in straight lines. The Japanese, on the other hand, generally have their streets straight and houses set in straight lines. The houses are so constructed that the two ends may be opened during the day. Rooms are separated by sliding partitions which, when folded back during the day, make the house one large room. The floors are covered with clean mats six feet by three feet. Rooms are measured by the number of mats it takes to cover the floor. There are few chimneys, windows, and doors, and no basements or attics. The furniture is meager, as there are no bedsteads, chairs, or tables. Shoes and hats are not worn in the house. The general means of transportation is still the jinrikisha drawn by coolies, but Japan is widening its streets and making room for the increasing number of street cars and automobiles.

Since Japan is nearly 50 per cent agricultural, women do a large share of the farming. In positions such as teaching, clerical work, and employment in silk mills, a woman is handicapped by prejudice and lack of education. Since the family is the unit, woman owns no property before her marriage and only technically afterwards, as her husband is legally entitled to her possessions. Marriage carries with it no religious obligation and can be terminated at will by the contracting parties. The birth of an illegitimate child does not penalize the mother. If the child is a boy, the father is only too glad to claim it and rear it in his home with his legitimate children, or the woman's parents will willingly assume care of it. Before 1875 parents could sell their girls into houses of prostitution; and after that date they could pledge them for three years in exchange for a loan made by the brothel keeper. However, public opinion against this system is forming.

There are three obediences for woman - to parents as a maid; to husband as a wife; and to eldest son as a mother. With the opposite sex she has little contact; before her marriage she serves her father and brothers in the capacity of servant and afterwards renders the same service to her husband, plus child bearing. Although she dresses artistically, she makes no effort to employ sex appeal. A class of women entertainers serve in this capacity. The wife lives in the house with her parents-in-law and spends more time with the servants than with her husband. On the whole, she is a submissive, 
self-sacrificing, artistically dressed person, but not a companion to her husband in our sense of the term. Woman's suffrage has received the support of the press, and other western ideas have been welcomed, but the Japanese woman's position is still bound by taboo. That she should receive equal social and educational advantages with men is not considered at all. Her place is still in the background, even though certain rights for her are advocated.

Social conditions in Korea differ to some extent from those of both Japan and China. The towns are generally very dirty, and some of them are surrounded by walls. The social classes can usually be distinguished by the clothes which their members wear on the streets. All men wear long hair, but unmarried men have to wear theirs in a certain way and generally are not highly respected. Men wear mourning hats for three years after the death of a relative. Women of the upper classes seldom appear in public, and when they do, their faces are veiled. Men consider themselves very superior to women. The husband or father does not eat at the same table with his wife and children, but has a separate table.

7. Immigration and Emigration. The early history of Japanese immigration is not very clear or important. From 1636 to 1866, the Japanese government made emigration a capital offense. According to accounts in the California papers, there was a colony of Japanese in that state as early as 1869 . They had been brought there in a silk-raising venture and were very favorably received. According to records, there were only 55 Japanese in the United States in 1870, but 218 had entered between 1861 and 1870. In 1880 there were only 148 enumerated, but 2039 in 1890 . The Chinese exclusion law of 1882 caused a scarcity of Oriental laborers on the Pacific coast, and Japanese laborers were induced to come to this country. The number, however, grew slowly at first. Until 1898 it did not exceed 2000 per year. It reached 12,628 in 1900, 20,041 in 1903 , and 30,824 in 1907 , the largest number for any one year. Since that time there has been a gradual decrease. For the twelveyear period ending in 1910, 148,729 Japanese were admitted. Between 1920 and 1930 33,462 Japanese entered the United States, and between 1860 and 1930 275,643. In 1920 there were 111,010 Japanese in the United States. Many Japanese have gone to the Hawaiian Islands. For the twelve-year period ending in 1910, 77,777 went to Hawaii, 32,273 to California, 25,912 to Washington, and 4485 to Oregon. Many of those who go to Hawaii later come to the United 
States. Between 1902 and 1907 some 32,855 are reported to have sailed from Honolulu for the United States.

Most of the Japanese have settled in California. Seven-elevenths are in California, and nine-elevenths in California and Washington. East of the Rocky Mountain states, no state except New York, which has 2686, has as many as 1000 Japanese in its population.

Japan is having difficulty in finding an outlet for its rapidly increasing population. From 1878 to 1925 it increased from $34,338,000$ to $59,736,000$, or 74 per cent. At first Japan was reluctant to permit its citizens to emigrate, but the crowded conditions, limited opportunities, heavy taxes, and family and social systems with police surveillance caused many to leave. About 13,000 per year now emigrate beyond the near-by Japanese territories. There is room in northern Japan, Manchuria, and Mongolia for expansion, but the Japanese are not inclined to go there, doubtless because the standard of living is too low and their racial and class pride too high. Brazil welcomes Japanese immigrants and about 50,000 have settled there, mostly in São Paulo, and about 11,000 have gone to Peru. But the Japanese are more inclined to go to the United States, Canada, Australia, and South Africa, and these countries make it known that they are not desired. Owing to effective propaganda, conditions became acute in California in 1906. In 1907 Japan and the United States entered into an agreement to restrict Japanese immigration. Japan was not to issue passports to either unskilled or skilled laborers bound for the United States. Although it has been accused of violating this agreement, there is no evidence to substantiate the charges. Japan even went so far, in its policy of conciliating the United States, as voluntarily to restrict the issuing of passports to Hawaii and countries contiguous to the United States.

The immigration question between the United States and Japan is a delicate one. Japan naturally resents discriminations against its citizens. The western states, especially California, have passed much discriminating legislation, which has hurt the pride of the Japanese. Joseph Huo, who was picked up shipwrecked, became not only the first Japanese immigrant but a naturalized citizen of the United States. Despite this fact, the Supreme Court in 1922 declared that Japanese (Orientals) were ineligible for naturalization. And in 1923 the Supreme Court sustained California in its anti-alien land laws. Japan was seriously offended in 1917 when it was placed in the barred zone and all immigration of Japanese to the United States was prohibited. 


\section{QUESTIONS, EXERCISES, AND PROBLEMS FOR INVESTIGATION}

1. Characterize the Japanese and compare them with the Chinese. Besides the text, see Dictionary of Races or Peoples; Pittard, Eugène: Race and History, Part III, Chap. X; Matsumoto, H.: "Notes on the Stone Age People of Japan," American Anthropologist,Vol. XXIII, pp. 50-76.

2. What are the chief geographical advantages and disadvantages of Japan?

3. Trace the leading events in the commercialization of Japan, and describe the internal complications during this period.

4. Describe Japan's policy of expansion. With what countries has it come in conflict?

5. Discuss the economic situation of Japan, paying special attention to its agricultural possibilities and the pressure of its population. Besides the text, see Nasu, S.: "Agriculture and the Japanese National Economy," Foreign Affairs, Vol. VIII, pp. 658-64; Orchard, J. E.: "The Pressure of Population in Japan," Geographical Review, Vol. XVIII, pp. 374-401; Kennedy, M. D.: "Industrial Revolution in Japan," Fortnightly Review, Vol. CXXVI, pp. 636-47; King-Hall, S.: "The Political Future of Japan," ibid., Vol. CXVI, pp. 532-46; Orchard, D. J.: "Agrarian Problems of Modern Japan," Journal of Political Economy, Vol. XXXVII, pp. 129-49, 285-311; Thompson, W. S.: Danger Spots in World Population, Chap. II.

6. Explain the nature of Shintoism. What hold have other religions gained? Account for the fact that the Japanese have manifested little interest in Christianity.

7. What affect have Chinese and Western cultures had upon Japan? In addition to the text, see Redman, H. V.: "Feminism in the Far East," Fortnightly Review, Vol. CXXVII, pp. 345-54; Kennedy, M. D.: "Some Forces Behind the Woman's Movement in Japan," Nineteenth Century, Vol. CIV, pp. 161-75.

8. Why do some writers claim a Malay origin for the Japanese?

9. In what respects does Japan differ from other Asiatic countries? Mention some of the educational and social changes which have been introduced.

10. Where have Japanese emigrants mostly gone? How were the early Japanese immigrants to the United States received? What efforts have been made to debar Japanese immigrants? In addition to the text, see Buell, R. L.: "Against the Yellow Peril," Foreign Affairs, Vol. II, pp. 295-309; Piesse, E. L.: "Japan and Australia," ibid., Vol. IV, pp. 475-88; Hayden, R.: "Japan's New Policy in Korea and Formosa," ibid., Vol. II, pp. 474-87; Adams, Romanzo: "Some Statistics on the Japanese in Hawaii," ibid., Vol. II, pp. 310-18. 


\section{CHAPTER XXVII}

\section{EUROPEAN ASIATIC POSSESSIONS}

Excluding Asiatic Russia, which has been considered with European Russia, we find that a large part of Asia is possessed or controlled by European nations. Great Britain, France, Holland, and Portugal have jurisdiction over an area of approximately $3,124,221$ square miles, with a population of about 409,000,000.

\section{British Asia}

Great Britain has succeeded in hoisting its flag over most of the strategic positions in southern Asia. Its strictly Asiatic possessions extend as far east as Wei-hai-wei (China) and include an area of $2,035,376$ square miles with a population of $335,209,901$. The islands of British Oceania contain 28,365 square miles and have a population of 430,357 . If the Oceanic islands are added to British Asia, Great Britain controls in that part of the world an area of 2,063,741 square miles, with a population of $335,640,258$.

\section{A. India}

1. General Description. The largest of the British Asiatic possessions is India. It contains $1,879,332$ square miles and has a population of $324,774,980$. The Kingdoms of Nepal and Bhutan are included with India, since their foreign affairs are so regulated by Britain through India as to render them only semi-independent. Nepal has an area of about 54,000 square miles with a population of $5,639,000$, and Bhutan has an area of 20,000 square miles with a population of 250,000 . Thus India is over fifteen times as large as the British Isles and has a population almost seven times as large. In comparison with the United States, India has an area over half as large and a population over three times as large. There are only two cities - Calcutta $(1,327,547)$ and Bombay $(1,176,000)$ - with populations over a million. Delhi, the capital, has a population of 304,420 . Only about 10 per cent of the population of India is urban, and three-fourths of the people live in villages of less than 2000 population. Parts of southern and northeastern India have an average of 512 inhabitants per square mile, while in northwest India the 
density is less than 26. Over four-fifths of the population depend upon the soil, and two-thirds live in one-quarter of the area.

India is almost surrounded by the Indian Ocean, and is practically shut off from the rest of Asia by the lofty Himalaya and Hindu Kush Mountains. Yet at different times the country has been invaded by different peoples, such as the Aryans, Arabs, Afghans, Persians, and

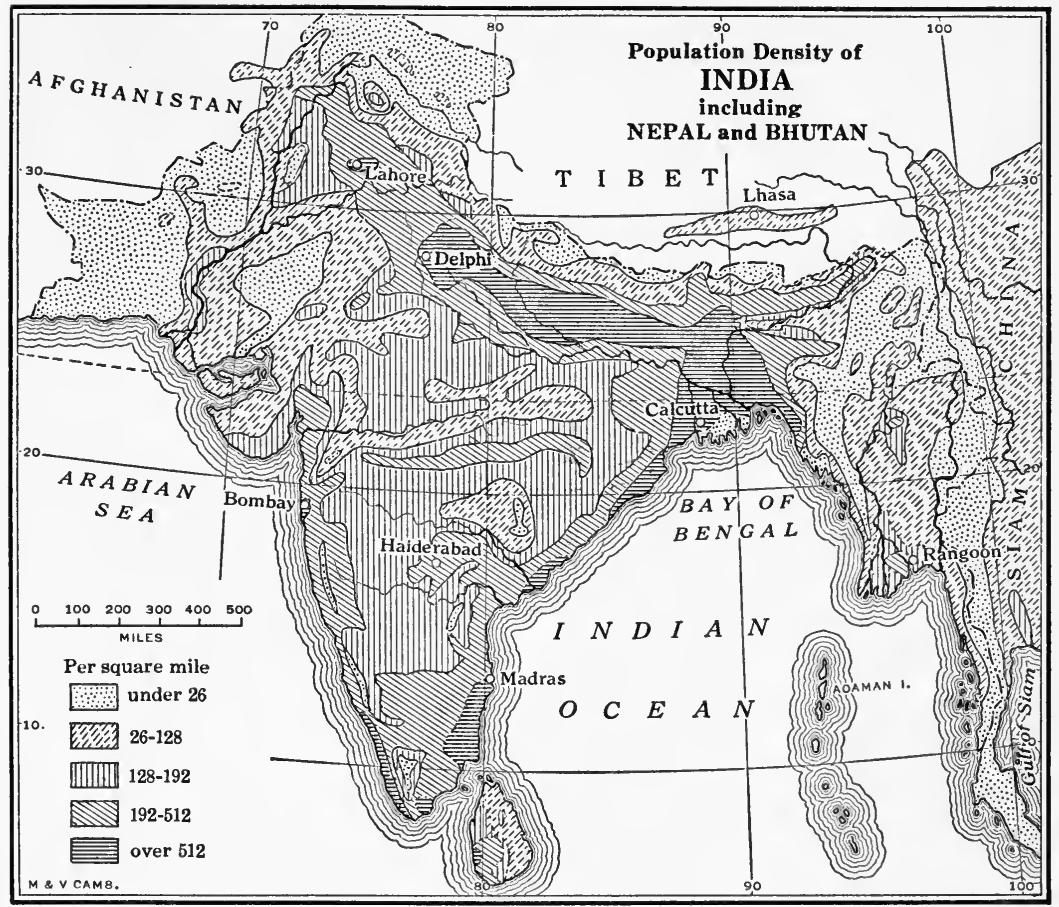

After Bartholomew, Advanced Atlas of Physical and Political Geography, 1924

Mongols. As India has been very successful in absorbing these alien groups, the population is very mixed. Nevertheless, there are several semi-distinct groups, such as the Indo-Aryans, Dravidians, TurkoIranians, Marathas, and crosses and mixtures of all these. The Indo-Aryan group, represented by such subdivisions as the Rajputs, Kashmirs, and Jats, largely inhabit the Indus Valley region of northwest India. They are tall, have long heads, light complexions, and European features. The Aryo-Dravidians inhabit the upper Ganges, while the Mongolo-Dravidians live in the lower Ganges and Brahmaputra valleys, Assam, Bengal, and Orissa. The well-known Bengali 
show traces of Aryan blood. With the exception of the Marathas, who show a mixture of Dravidian blood, the whole of southern India (Deccan) is inhabited by people of Dravidian stock. They are very dark and have faint traces of negroid blood. According to estimates, there are about $54,000,000$ Dravidians, some $11,000,000$ of whom belong to the wild tribes of the interior and may represent the aborigines of India. There are about 155,000,000 Aryans in the region of Hindustan proper, including some 20,000,000 Brahmans and Rajputs, who are said to be of "pure" Aryan blood. There are about 60,000,000 Moslems, mainly the descendants of Arab, Afghan, Persian, and Mongol invaders.

2. Political Development. Including the some 700 feudatory states and the nine large British provinces, the governmental units of India are of almost every age, size, and form. In size the feudatory, or allied, states range from Hyderabad, with an area of 82,698 square miles and a population of $12,471,770$, to Sandur, with an area of 161 square miles and a population of 11,700. In form of government they range from absolute despotism to almost pure democracy.

Great Britain began its encroachments on India through the East India Company in 1600. This company, which included ruffians, freebooters, and pirates, soon displaced the Portuguese and Dutch traders, and entered upon a long struggle with the French. In 1760, during the Seven Years' War, Britain acquired the Asiatic possessions of France, leaving it the small territories it yet retains. Opposition developed to the East India Company, culminating in the Sepoy Mutiny in 1857, and resulted in the transfer of the rights of the East India Company to Great Britain in 1858. Since that time there have been changes, but British reforms come slowly.

It is difficult to understand the unrest of India apart from its setting, since it is so intricately connected with Indian history, philosophy, religion, and economic conditions. Of the $316,000,000$ people whose religion is known, 68 per cent are Hindus and 22 per cent Mohammedans. The Moslem regards himself as the descendant and heir of the Moguls and other Indian overlords, and cannot endure the idea of being subject to a Hindu in governmental positions. The Hindus are divided into four large castes, the largest of which is regarded as intellectually and morally unfit to function in Hindu society. Thus the greater bulk of Indian society is unfitted by centuries of racial and social isolation to coöperate fully in a democratic government. 
The outstanding movement in India for the past ten years has been the non-coöperative movement. The political phase involves a boycott of foreign goods which compete with native industries, the wearing of khaddar or homespun as a patriotic duty, and a refusal to pay taxes to the British government. The leader of the movement is Gandhi, who has been proclaimed Mahatma, meaning Great Soul. He is not a political leader, but primarily and essentially a moral and religious leader. There is another anti-British party, which differs from the Gandhi group in that it is divorced from the masses and wants the power transferred to high-caste Hindus. One other movement should be noted - communism. Although unintelligible to Indian thought, it has made strides among the urban proletariat whose pay and living conditions are miserably low.

Home rule, therefore, is fraught with many problems, their nature depending upon the point of view. The English point of view is that an all-India assembly and Provincial councils are not safe trustees of public interests, since so many factions obtain in India, so many deepseated racial and cultural conflicts exist, and so few people have or are able to exercise the franchise. It appears, however, that until recently Britain has done little to develop India into a self-governing country.

The Act of 1919 conferred on the people of India certain powers and gave them certain opportunities designed to prepare them for eventual self-government. A diarchy (government by two authorities) was introduced in the local governments. Each of the major provinces, excluding Burma, was given two executives, a governor appointed by the crown or viceroy, and ministers chosen from elected members of the legislative council, of whom only 20 per cent could be British. The governors retain power over "reserved questions" and the ministers deal only with "transferred questions." Many Indians feel that the transferred questions are of little importance and that progress toward self-government is unduly blocked by British authorities.

Through the exercise of the franchise a legislature has come into existence, consisting of two chambers and the Governor-General. The upper chamber, the Council of State, consists of 60 members, of whom not more than 20 can be officials. The lower house, or Legislative Assembly, consists of 140 members, of whom 100 are elected. The Governor-General, with the specific consent of the King and Parliament, may enact measures contrary to the wish of council or assembly. The foreign department is directly under his authority. 
In Great Britain the government of India is administered by a Secretary of State for India, assisted by a council of from 8 to 12 members, of whom at least half must have lived in India. Notwithstanding the concessions granted to natives of India, the governmental machinery is still run by British officials.

3. Economic Development. When Britain took over India, there were practically no docks, harbors, canals, roads, railways, or banking facilities. Yet India was doing considerable manufacturing and enjoying a good trade. In the first eight years of its existence, the East India Company paid its stockholders 117 per cent, and shares of stock increased to five times their par value. In 1787 the city of Dacca alone exported muslins valued at $\$ 1,500,000$ to England, but by 1817 its exports had ceased. In 1823 Indian silks and silk and cotton mixtures were excluded from the British markets by a duty of 67 per cent. Shortly thereafter, cotton fabrics, which had been a staple export from India, were actually being imported. There can be little doubt that Britain's desire to protect its own manufactures strangled India's industries and forced it to rely upon agriculture.

Today between 80 and 90 per cent of the people in India are engaged in agriculture, which has long been a gamble. The rainfall throughout most of India is seasonal, over 90 per cent falling during the southwest monsoon. Within large areas the rainfall varies considerably from year to year, resulting in famines when it is light. Wheat and cotton are the most remunerative crops, and these are partially dependent upon irrigation. There are now some 40,000,000 acres of irrigated land in India, and two great projects are being undertaken - the Sukkur being the largest irrigation scheme in the world. Only in Assam, Lower Burma, and eastern Bengal is the rainfall sufficient for raising crops without irrigation. Added to the limited rainfall is the limitation of agricultural expansion set by mountains and climatic conditions. Agriculture is very primitive. One person is required to cultivate 2.6 acres, against 17.3 acres in England. The average family has from two to four acres for cultivation, and little or no ambition to wring from that plot more than enough to keep them alive. Hindu philosophy does not envision high standards of living; instead, it favors indigence and emaciation. It is from this lethargy that Gandhi wishes to arouse India. In the spinning wheel he sees a cure for idleness, an opportunity to inculcate thrift, and a way to dignify labor. He has faith that India ultimately will be a self-respecting nation, able to avoid starvation, 
to prevent epidemic disease, and to cope successfully with an ever increasing birth rate. But lack of ambition is not the only handicap. India's reverence for the sacred cow spares the lives of $25,000,000$ superfluous cows and thereby robs it of some $\$ 585,000,000$ yearly, or more than four times its land revenue.

Added to the tariff wall and agricultural handicaps is the fact that Britain has kept a large army and host of functionaries stationed in India at India's expense, and proceeds to take out of India at least $\$ 150,000,000$ each year without any returns. In 1928-29 the British Army in India cost India $\$ 212,779,040$. This, coupled with poor management, has reduced India to such a poverty-stricken condition that nine-tenths of the people connected with agriculture are living in squalor, and the average Indian seldom if ever has enough to eat. Population has increased, rents have gone up, and taxes are high. The average wage of the Indian was four cents per day in 1850, three cents in 1882, one and one-half eents in 1900, and from four to eight cents in 1925 .

India's minerals include coal, iron, manganese, wolfram, mica, copper, silver, gold, precious stones, and petroleum. The range is wide, but deposits are not extensive. Some 254,000 people are engaged in mining. In 1927 India had nearly 6000 incorporated joint stock companies, mostly textile, and 1,456,000 factory workers. About 2,000,000 people are employed in operating hand looms.

4. Religious Development. In India are found all variations of religious creeds and beliefs, ranging from crude animism to refined agnosticism. The Hindus, who constitute the largest religious group, number 216,734,586 persons; the Moslems, the next largest group, $68,735,233$; the Buddhists, 11,591,268; the Animists, 9,774,661; and the Christians, $4,754,079$. There are numerous other sects, most of them being Hindu heresies. For hundreds of years there have been bitter antagonisms among the religious groups, especially between Hindus and Moslems. The Hindus introduced purdah and child marriage to protect their female children from the Moslems, and hate the Moslems because the latter eat the sacred cows and accept outcasts into their faith. Britain has promoted these religious hatreds, but now the Hindus and Moslems are fraternizing and uniting against Britain, and fighting Christianity because it represents Britain.

5. Educational Development. In 1929 there were 223,796 "recognized" schools, with 11,547,497 pupils, and 34,222 "unrecognized" 
schools, with 618,342 pupils. There are eight universities. Great Britain has been ruling all India since 1858; yet only about 7 per cent of the total population are literate, and only about 2 per cent of the females. Only about 2,500,000 have any knowledge of English. Missionaries were the first teachers to give instruction in English to the natives. There are three serious defects in the British system of education for India: (1) it trains for government service; (2) instruction is superficial and of little benefit to persons unable to obtain government positions; (3) the native languages and cultures are ignored. According to reports, there are 264 native languages, some of which are very crude while others are rich in literature. The numerous dialects of northern India are akin to Sanskrit. Over 50 languages are spoken in Assam and Bengal. Hindi, spoken by about $82,000,000$ people, comes nearest to being a national language, as it was adopted by the Mogul Court in the sixteenth century. Both Moslems and Hindus can speak it with dialectic effect, but it is often written with several sets of characters, which add to the confusion. The variety of languages is a serious handicap to India's educational development.

6. Social Conditions. Added to the racial, political, economic, religious, and language confusion of India is the caste system. According to estimates, there are some 3000 castes and an unknown number of subdivisions. Among the Brahmans there are some 60 leading castes, and thousands of lesser castes, with an unknown number of subcastes and subdivisions. No one seems to know when the caste system appeared in India. Neither do we know its origin. Some explain it on the basis of racial migration, others on political authority, and still others on occupations. We do know that certain castes are confined to certain occupations or professions. The Rig-veda makes no mention of caste, and it is probable that the differentiation of the Hindus into Brahmans (priests), Kshtriyas (warriors), Vaishas (husbandmen), and Sudras (slaves) was not known when it was compiled.

The caste system kills ambition, since one is born into a caste and cannot climb out without becoming an outcast. It prevents intercourse with foreigners and other castes, coöperative enterprises, and political unity. The Rajputs and Jats belong to the Indo-Aryan group. The Rajputs boast of a princely origin, and are priests and warriors. They own land, but would not think of engaging in agriculture, while the Jats are hard-working husbandmen. The Hindu- 
stani, Brahmans, and Chamars belong to the Aryo-Dravidians, but Chamars are a caste of tanners and leather-workers, and are not permitted to come within 24 feet of a Brahman. The Brahman caste includes only about 5 per cent of the population, but it is the highest caste and very powerful. The most pitiful group in all India is that of the "outcasts" or "untouchables." If a Brahman were to be touched by an outcast, he would be defiled. The outcasts have to live in certain isolated areas. They may draw water from their own wells only, and must observe many other restrictions in order that they may not come in contact with caste people. If one goes to school, he is placed on a veranda outside the regular school rooms. Regardless of how intelligent a boy may be, there is no escape from this social slavery. The outcasts engage in the most degrading work. Many of them have no homes, but wrap up in a blanket and sleep on the ground wherever night overtakes them.

Added to the numerous Indian castes is the British caste. The British establish clubs, such as the Yacht Club and Byculla Club of Bombay, where no Indian, except a servant, regardless of his station in life, is permitted to enter. This is very humiliating to the sensitive Hindus. The British mingle with them to rule, but then withdraw to their own clubs to enjoy their own social life.

Another situation in India which caused social degradation to a large group of people was the custom of child marriages. According to the 1921 census, there were 597 Hindu widows under a year old, 11,892 under 5 years of age, 85,037 under 10 years, and 330,000 under 15 years. Between 1901 and 1921 the number of Hindu widows under 5 years of age decreased by 3804 , the number under 10 years increased by 3000 , and the number under 15 years increased by 9000 . The Hindus introduced child marriage as a protection for the female children against the Moslems, but the Hindu religion and custom condemn these female children who lose their husbands to perpetual widowhood and social servitude, and their condition is often worse than death. A law was enacted by the Legislative Assembly in 1929 making the minimum age for marriage for girls 14 years.

In brief, in India the fifth century is trying to live in familiar and harmonious relationship with the twentieth. As a result there are all grades of culture, from savagery to high urban civilization; all kinds of human social aggregations, from the very primitive family, group, and clan to the magnificent urban life; all types of dwellings, from mere hovels to luxurious homes; all types of marriages, from 
polygamy to strict monogamy; all types of social distinction, from the untouchable or outcast to the native or British noble; and all kinds of sanitation, from filth to modern sanitation.

7. Immigration and Emigration. India has had a steady emigration of agricultural laborers for over 100 years, yet much of the country, especially the villages along the alluvial plains of the north and the low-lying parts of the south, continues to be badly congested. By reclaiming large areas of semi-desert land, it has made room for over 10,000,000 and can supply ample room for $6,000,000$ more. Furthermore, Burma and Assam have each taken more than 1,000,000 recruited laborers for their rice fields and tea gardens. Ceylon and Malaya have likewise drawn large numbers of permanent residents some $1,750,000$, to say nothing of the seasonal laborers. The present irrigation projects in India promise to relieve population pressure in some of the congested areas. It is expected that the Sukkur Barrage in the Sind and the Sutlej Valley irrigation in the Punjab will treble the cotton acreage, add between two and three million acres to the wheat-producing area, and stimulate sugar-cane production in the Sind.

To save the sugar plantations of Natal, Mauritius, and the West Indies, which were owned by leading merchant families of England, the indenture system, operated by professional recruiters, was inaugurated about 1834. As a result of this system many indentured Indians were brought into British Guiana, Trinidad, South Africa, and the Fiji Islands. This type of Indian emigration caused numerous difficulties. The recruiting degenerated into kidnaping and other fraudulent practices. Owing to the small ratio of women to men in the foreign area, these practices were extended to the Indian women. Race friction developed in some of the regions where the Indians went, and the stigma of indenture brought on discriminations. Tropical diseases also took a heavy toll and made successful emigration difficult.

The future of Indian emigration is difficult to predict. Several nations have legislated against Indians. The political friction between India and Britain threatens to make Indian movements to English colonies, and even to Ceylon, serious. There is some room in Mesopotamia, but differences in religion and general culture promise friction. The most satisfactory solution is the Amazon Valley of South America, but the Japanese threaten to monopolize that.

There have been but few Indian immigrants in the United States. 
For the twelve-year period ending in 1910 only 5786 were admitted. In 1908 only 1710 were admitted, and 700 of these were from Canada. In 1920 there were only 4901 East Indians in the United States. Most of these were in California and Washington. In 1917 India was included in the barred zone, and all Indian immigrants were prohibited from coming to this country. It is probable that some are entering the United States by way of the British possessions in the West Indies. A number, however, come as students and visitors. For the decade ending in 19301177 people entered this country from India.

\section{B. British Arabia}

The territory known as British Arabia includes Iraq, Palestine, Transjordan, and Aden, and several islands such as Perim, Sokotra, and Kuria Muria, a total area of about 164,000 square miles with a population of $3,914,464$. The domination of this territory gives Britain strategic control over Arabia and surrounding waters.

1. Iraq (Mesopotamia). General Description. The Kingdom of Iraq is a British mandate. It has an area of 143,240 square miles and a population of $2,849,282$. Bagdad, the capital, has a population of 145,000; Basra, the chief port, 50,000; and Mosul, located on the site of ancient Nineveh, 60,000. The population is mostly Arab in blood and language. About 17 per cent are Kurds. There are many other racial groups, such as Turks, Jews, Persians, and Syrians. The country is practically a desert.

Political Development. Iraq, or Mesopotamia, as it was known in classical days, passed under Turkish rule during the early Mohammedan conquest, where it nominally remained until the World War. Iraq declared its independence during the war and later became a limited monarchy. In 1921 Prince Feisal, brother of the King (Emir) of Transjordan, was chosen king. The country is supposed to be independent, and Britain was to withdraw when Iraq became a member of the League of Nations in 1932. It is probable, however, that Britain may manage to hold it. Britain has invested heavily in oil and built large oil refineries and docks. The country flanks Britain's land route to India, and if released might become a member of the Arab confederacy and a menace to British interests. Britain has encroached until it has secured possession of the chief resources; it has built railroads, and controls transportation on the rivers.

Economic Development. Iraq embraces practically all the famous 
Tigris-Euphrates Valley. The country is mostly an alluvial plain with rolling hills around Mosul and limestone mountains near Kurdistan. As the rainfall is very light, coming mostly during the winter months, irrigation is necessary for most crops. The soil is generally very fertile, and when irrigated produces abundant crops. The climate is subtropical, but with great variations. About four-fifths of the people are nomads and wander around with their flocks. Most of them, however, remain in or near the Tigris-Euphrates and Shatt al Arab valleys, where they have water for their flocks.

It is estimated that the Tigris-Euphrates rivers could irrigate $7,000,000$ acres in the winter and 3,000,000 in the summer. Even if the old system, which was used during the glorious days of Babylon and Nineveh, were to be restored, a dense population could be supported. The cotton acreage alone could be increased from the present 1300 acres to 200,000 . Iraq is now producing about 40 per cent of the world's supply of dates, and quantities of tobacco,. silk, wool, hides, wheat, rice, and barley. Oil, however, is the chief interest.

General Social Conditions. The inhabitants of Iraq are mainly Moslems (about 1,494,015 are Shiites and 1,146,685 Sunnites); 87,488 are Jews, 78,792 Christians, and 42,302 members of other sects. They live largely according to their creeds. A large number are herdsmen who do not recognize international boundaries, property rights, political or religious authority. The other elements of the population live chiefly in the few cities or in the river valleys. The country is very unhealthful, and the people know or care little about sanitation. Illiteracy is widespread, and the plane of living very low.

2. Palestine. General Description. Palestine (Flstin) is divided into a western and an eastern section, the latter being known as Transjordan. Palestine, as the western division is generally called, has a territory variously estimated at from 9000 to 10,000 square miles and is about the size of Vermont. In 1931 the population of $1,035,154$ was composed of some 759,952 Moslems, 175,006 Jews, 90,607 Christians, and 9,589 others. Jerusalem, the capital, had a population of 90,407 . Since Britain was experienced in dealing with unruly peoples, and since Palestine lies close to the Suez Canal and other British interests, Palestine became a mandate of Great Britain.

Political Development. Palestine, the original home of the Hebrew and Christian religions, was conquered by the Moslems in 636, reconquered by the crusaders in 1229, again taken by the Moslems in 1244 , and captured by Turks in 1517, under whom it remained 
until 1917. Out of these political changes developed two national groups, each claiming priority over the other. The Arabs cannot understand why the Jews should now claim land they lost over 800 years ago, and point to the fact that they have equal right to claim Spain, which they likewise lost. They also are unable to see why the Jews should hold a monopoly of descent from Abraham, as they too count themselves descendants of Abraham through the line of Ishmael. The real Arab movement began some 40 years ago and led to the securing of 80 seats for Arab provinces in the first Turkish Parliament. During the years $1915-18$ the Arabs, who formed nearly 88 per cent of the population, were given assurance, as they interpreted the negotiations, that they would be given the authority and privilege of establishing "governments and national administrations deriving their authority from the initiative and free choice of the indigenous populations." These promises are now the bone of contention between the Arabs and the British, and similar promises made to the Jews are the source of Britain's present troubles with that people.

Zionism was initiated some 35 years ago by Theodor Herzl. The British favored it, and Uganda was offered as a homeland for the Jews, but rejected. In 1917 the celebrated Balfour Declaration favoring the establishment of Palestine as the Jewish homeland was promulgated. Although, a year later, the covenant of the League of Nations did not mention the Balfour Declaration, it embodied the essential provisions of that document. And thus "the neatest piece of war propaganda which the British ever evolved" promises two different groups the same national home. This duplicity is further carried out in the phrase "Palestine for the Palestinians," used by British officials in placating the aspirations of both groups.

When the Arabs became aware of the true significance of the mandate, their apathy turned to hatred. Consequently they refused in 1920,1922 , and 1923 to coöperate or accept certain rights of representation tendered to them, believing that these were merely an "official eyewash." On the other hand, the Jews, who the Arabs think have been granted greater privileges, are not pleased with their treatment by Britain. The mandate requires the British government to make unoccupied state lands available for Jewish settlement, but the vacant area is much smaller than was expected, and must be bought in the open market. Jewish holy days have been disregarded; the Jewish language, one of the three national languages, has been given scant respect; the Jewish National Council, the elected representative body 
of the Jews in Palestine, has been denied the privilege of imposing taxes for religious, educational, and social purposes; and the country was closed to Jewish immigrants in 1930.

Economic Development. For the most part Palestine has been an agricultural country. It has no mineral resources, and up to recent years has done little manufacturing. The plateau of Judea has an elevation from 2500 to 3000 feet, and most of it has a rainfall sufficient for agriculture. Here the cities of Jerusalem, Bethlehem, and Hebron are located. There is a well-watered, fertile coastal plain about 100 miles long and 15 miles broad on the west. In the east are the Ghor, the long barren region of the Jordan, and the Dead Sea - a body of water 1200 feet below sea level. The scarf between the Jordan plateau and the Ghor is a wild, barren country, inhabited by nomads who often raid the settled inhabitants.

Much of the arable land still remains vacant. The Jews have opened up large tracts of malaria-ridden swamps, one project consisting of 12,000 acres; have developed over 120 agricultural communities; and have organized banks and coöperative organizations. During the past 10 years more than $£ 10,000,000$ has been contributed to the Jewish Palestine program. The Jews have capital, enterprise, efficiency, and a capacity for sustained and organized effort, qualities lacking in the native Arab population. They are, however, an urban, commercial people, and for hundreds of years have manifested little interest in agriculture. So far their farm colonies have not been a financial success, but the initial expense has been too great to expect immediate returns. Industries are being established, and the Jordan is being harnessed to furnish hydro-electric power. In 1928 there were some 3505 commercial establishments, mostly small, employing 18,000 people.

Social Conditions. Because of its connection with the Hebrew and Christian religions, Palestine has long been known as the Holy Land. The Arabs have so long been in the majority that they have developed a superiority complex regarding the Jews, who, prior to the World War, traded mildly and lived carefully lest they offend their Arab neighbors. The newer type of Jews, mostly from Russia, Poland, and Czechoslovakia, come not by the toleration of the Arab and by his permission, but through their own rights. Rejoicing in their freedom, they regard the Arab as an obstacle to their regeneration as a nation. As a result, two superiority complexes are in conflict in a setting bristling with vague promises and diplomatic maneuvers. 
The Jews have been going back to Palestine since the sixteenth century, but the main movement has taken place during the last 60 years. The pogroms in Europe, especially in Poland, caused the Zionist movement to be launched, which greatly stimulated the movement to Palestine. Since the British mandate was established, this movement has been more rapid. The course of the Jewish immigration, excluding residents, has been as follows: 8346 from the Armistice to 1920, 8517 in 1921, 7844 in 1922, 7421 in 1923, 12,856 in 1924, and 29,124 to October, 1925 - a grand total of 74,108 . It is thought that some 110,643 Jews entered between 1917 and 1930 . The net immigration between 1922 and 1930 is placed at 63,066. Official estimates gave the Jewish population as 162,000 in June, 1930. The Jewish population was showing a decrease before the ban on immigration in 1930. For instance, in 19272713 Jews were admitted and 5071 left; in 19291194 arrived and 2746 left. The Arabs are said to have increased by about 80,000 .

There are almost $16,000,000$ Jews in the world. About 4,000,000 of these are in Russia, 2,000,000 in Poland, and 1,000,000 in former Hungary. There are colonies scattered throughout the world, especially in the cities. New York, with 1,750,000, has more Jews than any other city in the world. Everywhere the Jews have been hated because of their business methods, social customs, aggressiveness, and religion; consequently they have long been discriminated against. To a degree they have lived apart; yet they have amalgamated and acculturated with the peoples among whom they have drifted until they have no definite racial or cultural characteristics. They have become black in Africa, yellow in China, and very fair in northwestern Europe. The movement of the Jews back to Palestine is introducing a wide mixture of ethnic and cultural elements which is causing complex social conditions. Freedom of worship is guaranteed, and English, Hebrew, and Arabic are national languages in Palestine. Schools and museums have been established, but conditions are far from ideal.

3. Transjordan. This is an Arab state administered by Britain through its mandate over Palestine. In 1923 plans were adopted to make it a principality like Iraq, over which British rule should continue. In 1928 the High Commissioner for Iraq accepted a like responsibility for Transjordan, and the new Legislative Council met for the first time in 1929. Since the boundaries are undetermined, we do not know the exact area of the country, but the population is 
estimated at 260,000. The western border runs along the Jordan and Dead Sea valleys. Transjordan is largely a desert country, hemmed in by deserts on almost all sides. The rolling country on the west has good pastures, and some wheat and barley are grown. Most of the population consists of nomads. About 220,000 of the population are Moslems, 10,000 Circassians, and 10,000 Christians. Religious prejudices are strong, and hostile outbreaks frequent. The civilization is in a very backward state.

4. Aden. With Perim, Sokotra, Kuria Muria, and other islands, Aden guards the entrance to the Red Sea. Aden proper contains 75 square miles. Aden, Perim (5 square miles), and Sokotra (1382 square miles) have a total population of 68,000 . Aden is the principal port for the Arabian Peninsula, Abyssinia, Somaliland, and Eritrea. The chief exports are salt, coffee, gum, hides, and cotton goods. Manufacturing consists chiefly of cigarettes and salt. The Bahrein Islands, off the Arabian coast, guard the Persian Gulf. Perhaps Oman should be included with British Arabia, since it is subsidized by India and an Indian or British political agent is maintained there. The population of Aden and the other territory is mostly Moslem, and lives on a low cultural plane.

\section{Other British Asiatic Possessions}

1. Ceylon. This island, off the coast of south India, has an area of 25,332 square miles. It is about the size of West Virginia, and has a population of $5,442,000$. It was taken from the Dutch during the Napoleonic Wars and became a British colony early in the nineteenth century. The population consists mostly of Sinhalese and Tamils, who invaded the island from India and practically exterminated the aborigines. More than 500,000 Tamils, recent migrants from India, are employed on the tea estates. Until the World War Britain had little difficulty in ruling Ceylon, but in June, 1915, serious riots broke out at Kandy and spread to other towns. Martial law was proclaimed in five provinces, and Britain may expect trouble in the future. Ceylon is one of the richest of the British possessions. About one-fifth of the land is tilled, and one-sixteenth is in pasture. The chief products are rubber, cocoanuts, tea, cinnamon, and cereals. In 1926 65 plumbago mines were being worked. Over half of the people are Buddhists and one-fifth Moslems.

The Maldive Islands are about 400 miles west of Ceylon. They 
have a population of about 70,000 , mostly Moslems. The chief products are cocoanuts, millet, palm nuts, and fruits.

2. Straits Settlement. These include Singapore, Penang, Wellesley, Malacca, and Pangkor islands, a total of 1600 square miles, with a population of $1,095,635$. In 1867 these were detached from India and put directly under the crown. Singapore was the scene of serious riots in 1915. About 1000 Indian soldiers mutinied and then escaped to the jungles, only to be hunted down by Dyak head-hunters under British direction. Singapore, the capital, is an important center of trade, and very profitable to Britain. The population has increased rapidly, largely by immigration, and now numbers about 500,000. In 1916 the profits to Great Britain from the Straits Settlement amounted to $\$ 3,500,000$. Although Chinese compose about half of the population, there are many Japanese, Malays, Africans, Europeans, and Americans in the colony. In 1929 there were 293,167 immigrants from China and 114,252 from India. Tin, rubber, and pepper are the main exports. The British are now building a great naval base at Singapore, and expect to make it a Gibraltar of the East.

3. Federated Malay States. These possessions lie in the Malay Peninsula, in the southern part of Asia. In 1896 the four Sultanates of Perak, Selangor, Negri Sembilan, and Pahang were combined to form the Federated Malay States under British protection. The total area is 27,506 square miles, and the population is $1,660,919$. About one-fourth of the population is Chinese, one-fourth Malay, one-fourth Europeans, and the remainder natives of India and Eurasians. The Malay States are rich in tin and gold. In 1916 the net revenue amounted to $\$ 11,000,000$. The chief products are tin, gold, rice, cocoanuts, rubber, tapioca, pepper, camphor, and nepah palms. Over 1,231,000 acres are in rubber.

4. Unfederated Malay States. These consist of Johore, Kedah, Perlis, Kelantan, and Trengganu, an area of 23,355 square miles having a population estimated at 1,459,950. In 1909 Siam transferred its rights to the last four of the above states to Great Britain, and in 1914 Britain obtained a protectorate over Johore. Each of the states is ruled by a native sultan, and over all is a British adviser. Johore is inhabited mostly by Chinese, and the other states mainly by Moslem Malays. Rubber is the chief export.

5. British Borneo. This includes North Borneo, Brunei, and Sarawak. These three states lie in northwestern Borneo, an island south- 
west of the Philippine Islands. The total area is 75,606 square miles, and the population numbers about 883,000 . Brunei has been a British protectorate since 1888, and has been administered by a British resident since 1906. At one time it included practically all of North Borneo, but British encroachments reduced it to its present area. Sarawak is the country of the White Raja. In 1842 Sir James Brooke secured a concession from the Sultan of Brunei, and added to it in 1861, 1885, and 1890. He created an independent state and conferred upon himself the title of "Raja," which continues to be handed down. To protect his country he placed it under Great Britain. The chief exports from Borneo are petroleum, gold, rubber, sago, pepper, oils, and nuts. In 1930 there were some 60,000 Chinese immigrants in British North Borneo.

6. British China. This includes Hong Kong and Wei-hai-wei. Hong Kong is an island in the Canton River, 60 miles below Canton. Including the Kowloon territory on the mainland, Hong Kong has an area of 391 square miles and a population of $1,143,000$, about 18,150 of whom are non-Chinese. After the disgraceful opium war in 1841, Great Britain wrung this concession from China, and has since worked to increase its possessions and strengthen its hold. Its efforts to gain adjoining territories were checked by the strikes and boycotts of the Chinese in 1925, 1926, and 1927. Hong Kong has great strategic value as a naval and commercial base. It is one of the greatest trans-shipping ports in the world.

7. British Oceania. This area contains 28,365 square miles and has a population of 439,428 . There are about 250 islands in the Fiji group, inhabited mostly by Fijians and Indians. They produce tropical fruits, hemp, and domestic animals. The Tonga Islands (Friendly Islands) export mostly live stock and copra. The Gilbert and Ellice islands produce large quantities of phosphate. The Soloman Islands produce tropical fruits. The New Hebrides are under the joint administration of Great Britain and France. British Oceania is composed of groups of scattered islands which lie northeast of Australia. The inhabitants are probably of the same racial stock as those who at one time inhabited Australia, New Zealand, and numerous islands in that part of the world. They are often spoken of as Malaysians, but more specifically as Indonesians, Melanesians, and Polynesians. They live on a very low cultural plane.

So far we have received few immigrants from any British Asiatic possessions other than India, or from British Oceania. In 1920 there 
were 1508 Jews from Palestine in this country, 1183 people from Palestine who gave Syrian or Arabic as their mother tongue, and 451 not specified. From 1924 to 1930 8,916 people entered the United States from Palestine, Persia, and Syria. The present quota limits for the Arabian Peninsula, Iraq, Oman, and Palestine and Transjordan are 100 each. Part of British Asia is within the Asiatic barred zone, but other parts are not, and these may become a more important source of immigration.

\section{French Asia}

France is another European nation which has extended its power far over the world. In Asia it controls 325,004 square miles with a population of $23,124,641$, and in Oceania, which for convenience is included with Asia, it controls an area of 9170 square miles with a population of 79,160 .

\section{A. French Indo-China}

1. General Description. Lying south of China, alorg the South China Sea, is French Indo-China, an area of about 265,004 square miles having a population of around 19,124,641. It includes CochinChina, Annam, Cambodia, Tonkin, Laos, and Kwangchow (leased territory from China). Hanoi (Tonkin), the capital of Indo-China, has a population of 115,000 , and Saigon (Cochin-China), the chief port, 108,566. Like the Chinese, the Indo-Chinese belong to the Sinitic branch of the Mongolian family. In some places there is a considerable mixture of Malay blood. There are about 25,770 Europeans in Indo-China, 8444 living in Saigon.

2. Political Development. France began its encroachments in IndoChina in 1787, when it assisted Gia Long to recover his crown in that country. France received trade rights, and had the Tourané Peninsula and the island of Bulo-Condo receded to it. It showed little interest in this territory until about 1858, when a Spanish bishop was killed by the natives and Spain began an investigation. France occupied Tourané in 1858, Saigon in 1859, and Bien-hoa in 1861, and made Cambodia a protectorate in 1863. In 1884 Annam, on the Chinese Sea, and Tonkin, on the Gulf of Tonkin, became French protectorates. Then France began to move inland, robbing Siam of its territory. Laos was made a protectorate in 1893.

The whole area is governed by a Governor-General, and each protectorate, except Cochin-China, which is a French colony with 
a governor of its own, has a resident-superior and a host of smaller officials. Annam, Cambodia, and Tonkin have native hereditary kings, but they have no real authority and very little prestige. France rules with an iron hand, and, as a consequence, has experienced endless trouble. It is doubtful if it will ever be able to pacify the natives. The Annamese and Tonkinese are demanding self-government, and the Laosese refuse to coöperate with the French officials. The Indo-Chinese resent being exploited by the French, and, as a result, sedition, banishment, and revolutions are becoming more common. During the World War France brought Indo-Chinese soldiers to Europe to fight for it, and sent French soldiers to IndoChina to prevent revolution there. France has liberalized its policy, but the natives are not satisfied.

3. Economic Development. Indo-China may be divided into three economic units. The hinterland of Saigon includes the lower Mekong Valley, one of the greatest rice-producing regions in the world. Over $2,000,000$ tons of rice are produced yearly, and Saigon is one of the greatest rice ports in the world. Various kinds of tropical and semitropical fruits and vegetables are grown, and cattle raising and fishing are important occupations. The second economic unit includes the hinterland around Haifong. Agriculture, mining, and manufacturing are the chief occupations of this area. Hanoi has become one of the great railroad centers of Asia, and much of the commerce of southern China flows through Hanoi and Haifong. The third unit includes central Annam, with Tourané as the chief port. This is mainly an agricultural area and produces tea, sugar, cinnamon, cotton, rice, and other tropical and semi-tropical products. Parts of Laos and Tonkin are mountainous and have mines of tin, lead, coal, limestone, salt, and other products. The teakwood forests of Laos are valuable.

4. Social Conditions. France has built railroads and highways in Indo-China, and exploited the natives. Until recently it has done little to educate them or raise their standards. France has ruled Tonkin since 1884; yet in 1930 there were only 13 native primary schools with 5770 pupils for a population of $6,850,453$. In 1917 the University of Indo-China was opened at Hanoi, and in 1918 a European university also was opened there. Although there are some savage tribes in the remote districts, the people of Indo-China, especially the Annamese, are highly civilized and intelligent. The general religious and social conditions are similar to those in China 
and India. Few immigrants have come to the United States from Indo-China, and those who have come have been classed as Indians. This area was included in the barred zone in 1917. It is, however, an immigrant country itself, having over 370,000 Chinese immigrants in 1931.

\section{B. French India}

France's five footholds in India have a total area of 196 square miles, with a population of about 290,460. Mahé lies north of Calicut, on the Malabar coast, and is the only French possession in the western part of India. Karikal, Pondicherry, and Yanaon are enclaves of Madras on the Gulf of Bengal. North of Calcutta, in the Ganges delta, is the island town of Chanderagor. Karikal and Pondicherry each have a small hinterland with a railroad, while the other three are trading posts.

The French India Company established a trading post at Pondicherry in 1674, and the others later. During the early part of the eighteenth century there was bitter strife between the French and British trading companies, and each was backed by its government. France took over the rights of the French company and had its possessions confirmed by the Congress of Vienna. The administration of the possessions centers in Pondicherry. The people are represented at Paris by one Senator and one Deputy. The natives are considered as French and are treated much better than those of Indo-China, or their brothers under Britain. They are very loyal to France, and protest against any plan to transfer them to Britain. In race and culture they are similar to the inhabitants of British India.

\section{French Syria}

1. General Description. The French mandate Syria is estimated to have an area of about 60,000 square miles and a population of $3,000,000$. Beirut, the administrative capital, has a population of 134,655. The Syrians appear to belong to the Semitic branch of the Caucasian group. They seem to be a remnant of the Phœnicians who entered Syria about 2500 B.c. and amalgamated with the Armenian Israelites, who arrived about 150 B.C., and with the Arabs of a later period. There is also a mixture of Egyptian, Greek, Roman, Turkish, and other blood. Most of the Syrians now speak Arabic.

2. Political Development. Syria once belonged to the Roman Empire, but was conquered by the Saracens in 634, and by Selim I 
of Turkey in 1516. It remained a Turkish province until the end of the World War. In July, 1919, the first general Syrian congress was held at Damascus. At that time the representatives stated that the Syrians wanted neither mandate nor foreign interference. They desired to create a greater Syria, including Palestine and the territory between the Mediterranean Sea and the Syrian Desert. Britain had promised them their freedom during the World War and supplied them with gold. They thought that they were fighting for their independence, and are dissatisfied with their position as a French mandate.

The so-called Arab renaissance began about 1904, when the people commenced to reflect on their past glory and to plan to be free under their own officers, with Arabic as their national language. Wilson's statements were pleasing to them, but shortly after they declared their independence and elected a king, France's army appeared and drove him away, captured Damascus, and levied a heavy fine on the city. There has been chronic disorder in Syria since 1920, and a general uprising took place in 1925. France has broken up the country into small units, promoted racial, religious, and political hatreds, and defeated the move for union and independence. Syria has been so difficult to govern, and such a drain on French finance, that a change of officers and methods has been adopted, but this has not pacified the Syrians. Even Christians have joined the Moslems in opposing France. Nothing but an independent greater Syria will satisfy them.

3. Economic Development. Beginning at the Mediterranean Sea and extending eastward, Syria may be divided into four belts. There is a range of mountains and plateaus along the coast, followed by a long, dry valley. Then a highland belt is followed by a semiarid plateau. Most of Syria is deficient in rainfall, and only about 6000 square miles, or 10 per cent of the land, is efficiently cropped. Practically all the settled population, the cities, and the agricultural lands are along the narrow coastal belt. The main products are wheat, tobacco, fruits, wine, silk, cotton, and olives. The agricultural area could be greatly extended by irrigation. The mineral resources are generally considered to be unimportant, but they have not been sufficiently exploited.

4. Social Conditions. Although Syria is separated from Anatolia by the Taurus Mountains, and from Iraq by the Syrian Desert, it has long been a land subjected to migrations, wars, and conquests. 
As a result there is a conglomeration of races and religions. About two-thirds of the people are Moslems, about 500,000 Christians, and about 100,000 Druses. There are 29 sects. The different religious groups tend to dwell in separate areas, and many of them have an intense hatred for each other. Almost three-fourths of the country is inhabited by nomadic pastoral people, and it is common for the nomads to raid the settled areas. The Druses, a warlike people in the Lebanon Mountains, frequently raid the Maronites, a settled agricultural people; and the Ansarieh, a half agricultural and half pastoral people, along the mountain slopes of the Gulf of Alexandretta, frequently raid the outlying territory. The Bedouin tribes of the desert recognize no international boundaries, drive their flocks wherever they can find pastures, and take anything they desire. Under such conditions it is difficult to educate and raise the standards of a people, especially when a country has few railroads or highways and is so deficient in natural resources that there is little incentive for foreigners to develop it. Yet in 1929 Syria had 610 public and 1441 subsidized private elementary schools, with a total of 145,516 pupils. In 1874 the Syrian Protestant College was founded at Beirut. It now has about 1200 students, and shares American educational honors in the Levant with Roberts College in Constantinople. Although uneducated, the Syrian is intelligent and refined. His language is rich in pious phrases, proverbs, and wise sayings. He has a courtesy and a grace of manner that have elicited praise from numerous travelers. He is devoted to his family and local community; nationalism means little to him.

5. Immigration and Emigration. Syrian immigrants have been coming to the United States for many years. Most of those who have come have been Christians, and undoubtedly missionaries have fostered Syrian immigration. Since the United States has confused Assyrians (a religious group of people along the borders of Persia, Turkey, and Russia) with Syrians and included Syrians with Turks, it is difficult to determine how many have come here as immigrants. According to reports, 56,909 Syrian immigrants came to the United States for the twelve-year period ending in 1910. As 32.1 per cent were females, it would seem that a large number of immigrants brought their families and expected to remain permanently. In 1920 there were 51,900 people in the United States born in Syria. At the same time there were 57,557 who gave Syrian or Arabic as their mother tongue; 50,727 of these were from Syria. Most of the Syrians 
have settled in New York, Massachusetts, Pennsylvania, Ohio, and North Carolina. The present law permits 123 Syrian immigrants to come here each year.

\section{Dutch Asia}

1. General Description. Holland's possessions in Asia are known as the Dutch East Indies, Malay Archipelago, or Malaysia. They constitute the most important island group of colonies in the world, and are situated south of the Asiatic mainland and the Philippines and north of Australia, in the torrid zone. They extend from New Guinea to the Strait of Malacca. Their area is about 733,642 square miles, and their population around $61,000,000$. The total area of the islands is over 58 times the size of the mother country. Either Sumatra, the Molucca Islands, or the Dutch part of Borneo is larger than the entire Philippines. Java has about one-fifteenth of the total area of the islands and about three-fourths of the population. It is the most densely populated country in the world, having 821 people per square mile. Batavia, the capital of Java, had a population of 437,000 in 1930, an increase of 72 per cent in the last decade.

The natives of the Dutch East Indies belong to what the older ethnologists (following Blumenbach) called the Malay, Malaysian, or Brown race; but according to later ethnologists, these people form a part of the Mongolian group. The Mongoloid eyes and other physical features would indicate Mongolian origin. If the inhabitants are Mongolian, certainly they are the most divergent of all the divisions. There is little in language and other cultural factors to indicate a Mongolian origin. Our immigration officials classify them as a division of the Mongolian group. There is some Negro blood scattered through the islands, as is shown by the Negritos of the Philippines and the Papuans of New Guinea. There are now about 995,000 Orientals, chiefly Chinese and Arabs, in the islands, and some 210,000 Europeans.

2. Political Development. In 1602 the Dutch East India Company began its conquest of the islands, and by 1642 it had established trading stations in Borneo, Java, Sumatra, and other islands, and thereupon laid claim to them. When this company dissolved in 1798, Holland took over the possessions and for a long time governed them in a very autocratic manner. The colonies are ruled by a GovernorGeneral appointed by the Queen of Holland. For administrative purposes the islands are divided into two groups. Java and Madura 
constitute a crown colony, while the other islands are outposts or outer possessions. Scattered through the islands is a hierarchy of Dutch officials, who are responsible to the Governor-General. The crown colony has a complete system of European courts, but the outposts have a mixture of Dutch and native rule. The Dutch fill the higher administrative posts, while the native tribal chiefs, sultans, and rajas rule according to native customs in smaller matters. The sultans, rajas, and chiefs form a bureaucracy of Dutch and native officials. In some islands, where the native rulers control the territory, the Dutch authority is nominal. Holland has experienced considerable difficulty in ruling its colonies. Only Java and Madura have been pacified. The Achinese of Sumatra were in rebellion between 1902 and 1909, and besides the men, over a thousand women and children were killed by the Dutch in the spring of 1904 . Bloody wars also raged in Borneo, Celebes, and Sumatra between 1905 and 1907. The colonial policy aroused the liberal members of the Dutch Parliament, and in 1909 the queen promised reforms. In May, 1918, the Volksraad came into being. This is considered the first step in making the colonies an autonomous unit.

After the Napoleonic Wars, Great Britain continued its former policy of robbing Holland of its colonies, but the Convention of London in 1814 (confirmed by the Congress of Vienna), guaranteed Holland its East Indian possessions. The fear of losing its colonies has colored the whole foreign policy of Holland, and has deterred the manifestation of anti-British sentiment in Holland many times. Holland favored the Boers in the South African War and Germany in the World War, but dared not lend them aid. Part of its possessions lie along the British passage to India, and there is danger that England may consider them in its way.

3. Economic Development. The East Indies lie in the tropics, and supply many articles which Holland needs for home consumption and for foreign trade. The soil is very fertile, and large quantities of rice, sugar, coffee, tea, cocoa, spice, indigo, tobacco, cinchona, rubber, and other tropical products are produced. About 99 per cent of the world's supply of quinine (cinchona) comes from Java. It is the most intensively cultivated tropical land mass in the world. The islands also have valuable timber resources, and are rich in tin, coal, and petroleum. Large plantations of rubber trees are being cultivated, and foreign capital is being invested, thereby bringing prosperity. 
4. Social Conditions. Although there are some Buddhists, Christians, and Animists, the majority of the people are Moslems and follow the Mohammedan customs. Mohammedanism, however, is not evinced by mosques, but rather by the number of people who maintain a certain prestige by wearing the cap which shows that they have made the pilgrimage.

Until about 20 years ago, when a system of schools was established, little was done to improve the natives, most of whom are agricultural laborers. Public and private schools are now being established rapidly, but only one person out of every 500 in Java can read, and in many sections of the outposts even primary education hardly. exists. There are European, Dutch-Chinese, Dutch-Vernacular, Désa (very elementary schools for natives), and Mulo (inter-racial) schools. There are about 24 secondary schools.

The variety of schools reflects social and racial distinctions. The Dutch officials stand at the top of the social ladder. When on duty the native sultans carry golden umbrellas to indicate their superior rank, and the provincial governors indicate their rank by carrying green umbrellas with gold edges. Most of the natives live in a very low state of civilization. As the country is very hot, little clothing is needed. In fact, the children in the remote areas wear no clothing, and the men and women wear none above the waist. It was not until 1914 that forced labor was abolished. Very few people from the East Indies have found their way to the United States. In 1917 this area was placed in the barred zone.

\section{Pontuguese Asia}

Portugal possesses only some rather insignificant footholds in Asia. On the west coast of India are the provinces of Gôa and Damão. Gôa is on the Malabar coast, and Damão is on the coast about 100 miles north of Bombay. Diu is a small island in the Arabian Sea, about 140 miles west of Damão. The aggregate area of these three possessions is 1638 square miles, and the total population 548,472. Portugal also owns the eastern part of the island of Pulo, called Ambing. This territory has an area of 7330 square miles and a population of 451,604 . In China, Portugal possesses the tiny island of Macao, near the mouth of the Canton River. Its area is 4 square miles, and its population 151,175. All Portuguese Asia thus has an area of 8972 square miles and a population of 1,151,251. Other than a few Portuguese officers and traders, there are practically no 
Europeans in these possessions. The natives are racially of the same stock as those of the neighboring larger areas; i.e., Indians, Malays, and Chinese. The general religious, educational, and social conditions are also similar to those of the larger groups of people near by. The possessions are of commercial importance but of no advantage to the mother country. Very few immigrants have ever been received from these possessions, and they are now in the barred zone.

\section{QUESTIONS, EXERCISES, AND PROBLEMS FOR INVESTIGATION}

1. Locate the British, French, Dutch, and Portuguese possessions in Asia, and show their specific advantages and disadvantages to the mother countries. In addition to the text, see Gibbons, H. A.: The New Map of Asia, Chaps. IV and VII; Valkenberg, S. Van: "Java: The Economic Geography of a Tropical Island," Geographical Review, Vol. XV, pp. 563-83; Bowman, I.: The New World, pp. 208-09.

2. Point out the racial groupings and population problems found in India. In addition to the text, see Pittard, Eugène: Race and History, pp. 387-94; Andrews, C. F.: "India's Emigration Problem," Foreign Affairs, Vol. VIII, pp. 430-41; Thompson, W. S.: Danger Spots in World Population, Chaps. VII-VIII.

3. Discuss the English policy in India and its effects upon the people.

4. What part is Gandhi playing in the Indian demand for reform?

5. Explain the forces underlying the 1930-31 crises in India. References. Shirras, G. F.: "India in Convalesence," Foreign Affairs, Vol. IV, pp. 648-60; Andrews, C. F.: "Gandhi and Indian Reform," Yale Review, Vol. XIX, pp. 491-507; Coatman, J.: "The Present Situation in India," Nineteenth Century, Vol. CVII, pp. 741-53; Kirk, William: "Will India Follow Gandhi?" Sociology and Social Research, Vol. XIV, pp. 342-57; Rice, Stanley: "Communism in India," Nineteenth Century, Vol. CII, pp. 38-47.

6. What is the agricultural and industrial situation in India? Has England added to the financial burden? How does Hindu philosophy affect the standards of living? Besides the text, see Blackett, Basil: "The Economics of Indian Unrest," Foreign Affairs, Vol. VIII, pp. 41-51; O'Brien, Aubrey: "The Welfare of the Indian Agriculturist," Nineteenth Century, Vol. CIV, pp. 322-31; Moreland, W. H.: "The Indian Peasant and His Future," Edinburgh Review, Vol. CCXLVIII, pp. 262-75; Strickland, C. F.: "The Indian Village and Indian Unrest," Foreign Affairs, Vol. X, pp. 70-80.

7. What religious sects are found in India? How are they divided? United?

8. Mention the major difficulties in establishing an educational system in India. What has Britain done toward (1) educating the masses; 
(2) public health? Besides the text, see Ali, A. Y.: "Education in India," Nineteenth Century, Vol. CIV, pp. 745-56; Coatman, J.: India in 1926-27; Williams, G. B.: "Public Health in India," Nineteenth Century, Vol. CIII, pp. 190-200.

9. Explain briefly the caste system. What is the sociological significance of this system? Of child marriages? Of the status of woman? Besides the text see Sorabji, C.: "Women in India," Fortnightly Review, Vol. CXV, pp. 661-73; O’Dwyer, M. F.: "Mother India - Swaraj and Social Reform," ibid., Vol. CXXIII, pp. 171-82.

10. What has been the history of Iraq? How has Britain sought to develop it? What are its agricultural possibilities? Picture the social conditions. In addition to the text, see Slater, S. H.: "Iraq," Nineteenth Century, Vol. XCIX, pp. 479-94.

11. Trace briefly the political history of Palestine, and give the points of view of both Arabs and Jews in the controversy. Besides the text, see Tweedy, Owen: "The Palestine Conundrum," Fortnightly Review, Vol. CXXVII, pp. 318-28, and "The Palestine Liability," ibid., Vol. CXXIX, 639-49; Page, Kirby: "Conflict in Palestine," ibid., Vol. CXXVI, pp. 733-39; Polson-Newman, E. W.: "The Palestine Muddle," ibid., Vol. CXXIX, pp. 362-73; Cohen, Israel: "The Tragedy of Palestine," Nineteenth Century, Vol. CVII, pp. 808-14, and "The Palestine Question," Fortnightly Review, Vol. CXV, pp. 381-93; Nevinson, H. W.: "Arabs and Jews in Palestine," Foreign Affairs, Vol. VIII, pp. 225-36; Frankfurter, Felix: "The Palestine Situation Restated," ibid., Vol. IX, pp. 409-34.

12. Comment on Lord Raglan's article, "Transjordania - and the Mandate Farce," Nineteenth Century, Vol. XCV, pp. 833-42.

13. From the point of view of immigration to the United States, of what importance is British Asia? Of what importance in relieving population pressure of other countries?

14. How were France's footholds in India acquired? What has been our attitude toward immigrants from this section?

15. What are some of the difficulties that France faces in Syria? See PolsonNewman, E. W.: "France's Difficulties in Syria," Nineteenth Century, Vol. CI, pp. 37-47.

16. To what racial groups do the Syrians belong? Trace the political development of Syria. What are the religious and social conditions?

17. Account for the fact that many Syrians have come to the United States.

18. Locate Holland's possessions in Asia. Discuss the difficulties Holland has experienced with these colonies.

19. Where are the Portuguese footholds in Asia? Show how the importance of Portuguese possessions has declined.

20. Secure or construct a map of Asia, and on it locate the possessions of each of the European nations discussed in this chapter. 


\section{CHAPTER XXVIII}

\section{SIAM, AFGHANISTAN, PERSIA, AND ARABIA}

\section{SIAM}

1. General Description. The Kingdom of Siam is located in southern Asia between British Burma and French Indo-China. From a one-time large empire, Siam has been reduced by British and French conquests to its present area of only 200,148 square miles. It has a population of 11,506,207 (1929 census). Bangkok, the capital, which had a population of 745,640 in 1923 , is the only large city. It is clean and modern. The Siamese, who constitute the majority of the population, belong to the Indo-Chinese group of the Sinitic branch of the Mongolian family. There are many Chinese in Siam, and intermarriage has taken place freely.

2. Political Development. Siam has the distinction of being the only country in the eastern peninsulas of southern Asia that has maintained its independence, and one of the few ancient Asiatic kingdoms that have remained free. Being caught in a vise between two aggressive nations - Great Britain and France - it has found it difficult to preserve its freedom against their unscrupulous imperialism. Using various excuses, the foreign nations secured capitulations, and the French especially, and the British to a certain extent, enrolled several hundred thousand Chinese and other Asiatics under their protection without any apparent justification. In 1904 France took 7800 square miles of Siam's territory and in 1907 about 7000 more. In 1909 Great Britain took about 15,000 square miles. France practiced intrigues and refused to abide by its treaties with Siam, fully expecting to annex all of its territory, but Britain objected. Since the two countries could not agree on a division, and since neither would permit the other to annex Siam, they agreed that it should remain independent as a buffer state between them.

3. Economic Development. The topography of Siam is generally rolling, and much of the country has to be irrigated. The Royal Irrigation Department has opened up large tracts of land north of Bangkok by constructing a canal connecting the Bangpakong and 
Menam rivers. The bulk of the population live around Bangkok and in the Mekong Valley. It is claimed that about half of the population live in boats on the water. Agriculture and stock raising are the principal occupations. The Siamese are content to see traders and manufacturers of foreign extraction in their country, but their agriculture they reserve for themselves. Rice is the main crop as well as the national food. Opium and vegetables are also produced. Elephants, horses, cattle, and water buffaloes are raised and used as draft animals. The white elephants are regarded as sacred, since the natives believe that white elephants contain the souls of emperors. Siam possesses good forests, especially of teakwood, which constitutes one of the chief objects of export. Mineral resources are varied and extensive, especially tin, tungsten, coal, wolfram, iron, zinc, antimony, and manganese. With the exception of tin, mining is not well developed. Commerce has grown rapidly, especially since the development of a system of railroads. Practically all commerce passes through Bangkok. In 1899 Great Britain had about 80 per cent of Siam's commerce, but within two years Germany had superseded it. The war destroyed Germany's commerce, and now the United States has a good share of Siam's trade.

4. Social Conditions. In general, the culture of Siam is similar to that of southern China. The women do most of the work and trading. The people seem to dislike white teeth, and theirs are kept dark by almost constant chewing of betel nuts. Buddhism is the prevailing religion, but the people remain very superstitious. The king, who is an Oxford graduate, is the only independent Buddhistic ruler. Only about 11 per cent of the people are literate. Schools are developing rapidly, however, having quadrupled in the last 20 years. Elementary education is now free and compulsory. There is a good national university at Bangkok. Polygamy exists in the upper class, but the first wife retains a preëminent position. Divorce may be obtained for gross cruelty. Slavery was abolished in 1905, but forced labor is still found in the interior. Disposal of the dead is by cremation, the body being embalmed, sealed in a jar, kept in the house for several months, and finally cremated with Buddhistic rites. At the final ceremony the remains are carried out amid great rejoicing, accompanied by elaborate theatrical performances and fireworks, in order to cheer the soul of the departed. The great festival of the year is on the anniversary of the birth of Buddha. Twice each year the water-drinking ceremony (Teu Nam) is observed, on which 
occasion the royal family and state officials present themselves to the king and drink water from a golden jar. Early in May occurs the ceremony associated with rice planting, which testifies to the importance of rice. Fish and rice, the staple foods, are served on the floor and are eaten with the fingers by those squatted around. The more wealthy, however, use knives, forks, and spoons. The native dress of both men and women consists of the panung, a cloth wound around the waist so that it hangs down and covers the thighs. Formerly it was homespun, but now it is machine-made.

Although a number of Siamese students have attended American universities, not many immigrants have found their way to our shores. Those who have come have generally been considered as Chinese. In 1917 Siam was included in the barred zone. Siam is itself still confronted with an immigration problem. From 1918 to 1926 643,000 immigrants arrived from China. In 1929-30 73,651 deck passengers from China arrived in Bangkok and 54,661 departed. According to estimates, there were 2,000,000 Chinese in Siam in 1930 .

\section{Afghanistan}

1. General Description. The Kingdom of Afghanistan, famed as "the land of rocks and stones, and sanguinary feuds," is tucked away in inner Asia, and serves as a buffer state between Great Britain and Russia. Its area is estimated at 245,000 square miles, and the population at 6,330,500. Kabul, the capital and largest city, has an estimated population of 150,000 .

About a third of the people are Afghans or Pathans, a branch of the Iranic group, with Caucasian physical characteristics. In language (Pashto) they are related to the Persians and northern Hindus. There are large numbers of Hindus and Tajiks (Persians), and smaller numbers of Mongolic, Turko-Tartaric, Aryan, and other racial groups in the country.

2. Political Development. Little is known of Afghanistan before the. eighteenth century. Great Britain has had considerable trouble with the Afghans, notably the costly wars of $1839,1842,1878$, and 1880, which were mainly due to the activities of unscrupulous French merchants, who smuggled in arms and encouraged the wild border tribes to raid British territory. Great Britain did not pay much attention to the Afghans until 1875, when Russia was advancing in Turkestan, and later built its "secret" railroad from Merv to the border of 
Afghanistan, a distance of about 200 miles. Since foreigners were not permitted to ride on this railroad, and since it served no towns, and was used only to transport soldiers and war equipment, Great Britain regarded it as an encroachment toward India. The AngloRussian conference in 1907 agreed that Afghanistan should remain free. Great Britain had granted the Amir (a title replaced by that of King in 1926) a liberal subsidy and had used Afghanistan as a shield for India for about 80 years; it wished to continue to block Russia's advance south.

In 1919 the Amir of Afghanistan was assassinated, and the new Amir immediately attacked India. By using frightful methods, the British soon forced him to sue for peace. In 1921 Great Britain recognized the complete independence of Afghanistan, stopped all subsidies, and prohibited the Amir from receiving arms through India. The same year Russia granted him a subsidy of $\$ 500,000$ per year. Turkey then made an offensive and defensive alliance with Afghanistan and Russia. Realizing the seriousness of this situation, Great Britain negotiated another treaty with the Amir, permitting him to receive arms through India.

Afghanistan is a monarchy, and the king signs all laws. It long remained the largest closed country in the world. To enter it a foreigner had to secure a permit from the ruler, and then he was furnished with a military escort which accompanied him everywhere he went. The country is now becoming more interested in the outside world. In $1928 \mathrm{King}$ Amanullah and his wife made a tour through Europe. On his return he introduced many reforms, but these were too advanced for the people, and a revolution broke out. His uncle, Nadir Khan, finally conquered the rebels and became king.

3. Economic Development. Afghanistan is an inaccessible elevated land, the general elevation being over 4000 feet. Towering above the capital, on the northeast, are the Hindu Kush Mountains, which reach an elevation of over 25,000 feet. The country has three river basins. The Helmund runs southwest through the middle of the country, and the Kabul and Oxus flow through the northeast portion. There are many fertile valleys and plains, and an abundance of water for irrigation. Two harvests a year are gathered - one of rice, maize, millet, and dal, and the other of wheat and barley. Fruits of the temperate zone grow in profuse abundance. Madder, castoroil, and asafœtida plants grow over wide areas.

Afghanistan is famous for its fat-tailed sheep, which furnish the 
natives with some of the chief necessities of life. The sheep are used as pack animals, the fat-tails are a substitute for butter, and the wool is the chief export. The country is fairly rich in copper, and deposits of several other minerals have been discovered. Afghanistan has no railroads, but plans have been made to build two which will cross the country and connect it with the outside world. Camels, ponies, sheep, and men are the means of transportation. Long trains of camels are a frequent sight on the seven important trade routes. Goods going to India have to be carried on the backs of sheep or men through the famous Khyber Pass.

4. Social Conditions. The Afghans are mainly unruly fanatical Moslems of the orthodox Sunni (Sunnite) sect, who hold strictly to the old traditions and ecclesiastical law. When the king and queen visited Europe in 1928 a storm of protest arose because the queen appeared unveiled.

Conditions are gradually improving. Education is free and compulsory for children between the ages of 6 and 11, and free to those over 11 who desire it. Children who live in the remote areas are taken to the urban districts, where they are housed, clothed, fed, and educated at the expense of the state. There are two small colleges in the country. Although the masses live in huts made of sundried brick, the king has a beautiful palace, with offices equipped with American roll-top desks, typewriters, and fountain pens. European games, such as golf, polo, and cricket, are enjoyed by the upper class, who live much like Europeans and Americans. The general culture of the masses, however, is similar to that of other Islamic countries. So far we have had no recorded immigrants from Afghanistan. Our present law permits 100 per year to come as immigrants.

\section{Persia}

1. General Description. Lying north of the Arabian Sea and the Persian Gulf, and extending north to the Caspian Sea, is the Kingdom of Persia, one of the oldest monarchies in the world, and one which has played an important part in world civilization. Persia is now a very small country in comparison with its ancient greatness, but it still has an area of 628,000 square miles, and is over one-fifth as large as the United States. Its population is estimated to be $10,000,000$. Tehrān, the capital, has an estimated population of 250,000; Tabrīz, 200,000; Isfahān, 100,000; and Meshed, 80,000. 
As Persia has a water and land frontage on the south and opens into the great Russian steppe on the north, it has often been overrun by migrating hordes and invading armies, and has long been crossed by trade routes. As a result, its population contains elements from several ethnic groups. The Persians (Tajiks) apparently migrated south from around the Caspian Sea, and now mainly inhabit the eastern part of Persia between the Persian Gulf and the Caspian Sea. They are a mixed Caucasian group, speaking an Iranic branch of the Aryan tongue, closely akin to Hindi. In the west are the Kurds, Arabs, and Armenians. The Kurds seem to be a mixture of Semitic and Mongolic stocks, but their language is a dialect of Persian. The Arabs and Armenians are Caucasian Semites. There are also Arabs along the Persian Gulf, Turks in the northeast, and a negroid element along the southern border.

2. Political Development. Prior to 546 B.c. there was a group of Iranian tribes, known as Persians, dwelling along the north shore of the Persian Gulf. One tribal group, known as Anshan, dwelling in the mountains of Elam, composed a small kingdom. They were ruled by a certain Cyrus, but were subject to their strong kinsmen to the north, the Medes. Cyrus succeeded in uniting the other Persian tribes, rebelled against the Medes, conquered them, and became their ruler. Fearing this new warrior, the rulers of the strong states of Lydia, Babylon (Chaldea), Egypt, and Sparta formed a powerful union against Cyrus. But within five years his power had swept through Asia Minor to the Mediterranean. He then turned east and defeated Belshazzar of the Chaldeans, scaled Nebuchadnezzar's walls around Babylon, and conquered the city. Some ten years later (528 в.c.) he fell in battle, and his son, Cambyses, took charge of the army, conquering Egypt in 525 B.c., and rounded out the Persian Empire, which then embraced all Asia Minor, including Mesopotamia, Afghanistan, Egypt, and part of eastern Europe. Thus in 25 years Persia had become the greatest power in Asia, if not in the world, and reached its Golden Age. Cyrus and Cambyses conquered, but it was left to Darius and Xerxes to organize and rule. Darius organized, ruled, and fought, but was defeated by the Greeks, and Xerxes was sadly defeated by Leonidas in the famous battle of Thermopylæ.

Between the tenth and the eighteenth century Persia was subject to many vicissitudes. It was overrun by hordes of Tartars, Arabs, and Turks. During the nineteenth century it was ruled by the cor- 
rupt Kajar dynasty, which was Turkish in origin. The founder of this dynasty, Agha Mohammed, set a standard for cruelty by selling 20,000 women and children into slavery, and by ordering 70,000 eyes of the inhabitants of Kerman to be brought to him on a platter. During the seventeenth and eighteenth centuries, Russia continued its encroachments on Persia. England became alarmed at Russia's movements toward the Mediterranean and India, and by a series of encroachments blocked Russia. About 1900 Germany and Turkey agreed to build the Bagdad railroad, which would have given Germany and Austria an outlet toward the Orient through the Persian Gulf. The British immediately secured a clandestine agreement with the Sheikh of Koweit and blocked this outlet. Fearing that the Germans and Russians might come to an agreement, England reached an understanding with Russia in 1907. According to this arrangement Russia took about two-fifths of Persia, across the north, as its sphere of influence, and Great Britain took about one-fourth, mostly desert, in the southeast. The rest of Persia was to be neutral or independent territory. Britain had now blocked both Russia and Germany.

The World War was supposed to have been fought for the rights of small nations; yet Britain and Russia did not respect the neutrality of Persia. For three years Russia occupied northern Persia and Britain occupied the southern part without consulting Persia, and even after the armistice Britain sent its armies across Persia as if it were British territory. Many battles were fought on Persian ground, in which many Persians lost their lives. Cities and farm areas were devastated, and economic resources destroyed. In 1915 Persia proposed to join the Allies, but was ignored. It was the only independent country of Asia which was not invited to the Peace Conference. Despite this fact, it formally presented its claims to the Peace Conference, demanding the restoration of all territory of which it had been robbed, denouncing the Anglo-Russian agreement, and asking for modification of all treaties which infringed upon its rights, the withdrawal of all foreign soldiers, and the privilege of governing itself like any other free nation.

In 1919 Great Britain continued its policy by the Anglo-Persian "agreement," which practically made Persia British territory. But the Persians would not submit to it, and in 1921 it was denounced. Riza-Khan, who rose from the rank of common soldier, overthrew the old line of corrupt rulers, with the assistance of the Kemal of Turkey, and established a new line in 1925. He repudiated all ca- 
pitulations, reorganized his army, rid himself of foreign meddlers, crushed numerous rebellions, and served notice to the world that the Persians were going to rule their own country. He has introduced a number of reforms, but since his people are largely a conservative Moslem group, he hardly dares move so rapidly as the Kemal.

3. Economic Development. Persia is mostly a plateau surrounded by mountains which reach their greatest elevation in the north and west. The table-land has an elevation ranging from 2000 to 6000 feet, much of which is barren and sandy, crossed here and there by ridges or hills. In the north central part, extending in a northwest and southeast direction, is a vast desert some 800 miles long and between 100 and 200 miles wide. It is thought to be the bed of an inland dried-up sea. The air is so dry in places that the water for irrigation is brought through underground channels. Many of the streams completely dry up during the summer. In much of the area the rainfall is less than five inches per year. There is sufficient rainfall around the Caspian Sea and in some of the mountain areas. Most of the people live around the Caspian Sea and in the irrigated areas in the northwest. Much of the soil is fertile, but requires irrigation, which is not well developed. Agriculture, however, is the principal occupation. The chief crops are wheat, rice, barley, fruits, tobacco, tea, silk, sugar, opium, and cotton. Grazing is important, and considerable wool is produced.

Persia has practically no railroads - only some short lines along the borders. It has only two highways, and these were built in the northern part by the Russians. Many caravan routes, however, cross the country, and long lines of elephants are much in evidence. Persia is now in the midst of a railroad and highway building campaign. Foreign contractors are constructing a railroad across the country from the Persian Gulf to the Caspian Sea. Persia slopes toward the north, the bulk of the population live in the north, and most of its foreign trade has passed through Tabrīz into Russia. In 1912 foreign trade amounted to $\$ 70,000,000$. Russia received 57 per cent of this, and Great Britain one-half of the remainder. Lack of transportation facilities has naturally tied Persia to Russia, which sometimes takes three-fourths of Persia's exports. When Russia declares an embargo on Persian goods as it did in 1926, Persia suffers severely. Its chief exports are petroleum, cotton, rugs, fruits, opium, and rice, and because of the poor transportation facilities, these compete disadvantageously with those from other countries. 
The chief industries in Persia are the making of the famous rugs which are woven on hand looms, the working of the turquoise mines in Nīshāpūr, and the manufacture of certain famous brands of wine. The country has some good forests, is rich in oil, and contains valuable coal and iron deposits. Oil is the chief asset of Persia, but Great Britain has control of at least 500,000 square miles of the oil fields. The country has long suffered from a vicious tax system and corrupt financial conditions. In 1922 Dr. A. C. Millspaugh, of the United States, became Administrator-General of Finance. Within three years he converted a heavy deficit into a small surplus, reduced the debt, and accumulated enough cash in the treasury to pay all of Persia's funded debt. Within four years the expenditures for public works had increased from $\$ 100,000$ to $\$ 2,500,000$. For education it had increased from $\$ 700,000$ to $\$ 1,500,000$, and for public health from $\$ 120,000$ to $\$ 275,000$. In 1927 Dr. Millspaugh refused a new contract because of the curtailment of his power, and opposition on the part of some of the grafting wealthy landowners and politicians.

4. Religious Development. The early religious condition of the Persians is of considerable interest because it was the ancient Persians who developed two remarkable cults - Zoroastrianism and Mithraism - which have greatly influenced Christianity and Mohammedanism, and to a lesser extent Judaism and some other religions. Zoroaster (Zarathushtra), the remarkable Iranian prophet, was born about 660 B.c. He seems to have preached an ethical monotheism with a dualistic concept. According to the Yasna (xxx: 3-4) there were two primal spirits who were twins - Ahura Mazdah (God of Wisdom) and Angra Mainyu or Ahriman (Evil Spirit) - but they could not agree. Thus arose the Persian dualism which has so profoundly influenced philosophical speculations. Ahura Mazdah was accompanied by six archangels personified into "Good Thought," "Perfect Righteousness," "Wished-for Wisdom," "Dominion," "Welfare," and "Immortality," and a number of lesser angels. Ahriman, likewise, was accompanied by a host of spirits. Zoroaster taught that there was a heaven in the sky, a hell in the earth, and a judgment day. Many miraculous things are supposed to have happened at Zoroaster's birth; he began preaching when about 30 years of age. The Vesta (Zendavesta) is the bible of the Zoroastrians. At one time Zoroastrianism was a very strong cult, but its adherents, generally known as Parsîs, have declined until there are perhaps not 
over 10,000 in Persia. Most of them migrated to India where their descendants still live.

Mithraism is another Persian cult that at one time had a large following and greatly influenced religious thinking. Mithra was an old Aryan sun-god. Since Zoroaster was not able to abolish his worship, he made Mithra an angel. However, it became a separate cult, taking on the Persian dualistic concept and the chief features of Zoroastrian eschatology. At one time Mithraism threatened to supersede Christianity in Europe.

About 8,500,000 of the people in Persia now belong to the Shiite sect of Mohammedanism and about 850,000 to the Sunnites. There are also some 10,000 Parsîs, 40,000 Jews, 50,000 Armenians, and 30,000 Nestorians.

5. Educational Development. Until recently education was very backward in Persia. All who could afford it hired private tutors, and those who could not sent their children to street schools, maktab. The schools taught little but the reading of the Koran, and something of Persian and Arabic literature. It is surprising that a people who produced such remarkable religions, profound philosophy, and classic literature as the early Persians should become so backward. Improvement along educational lines, however, is being made. Schools are now being organized more on the European model, and opened to girls. The government bears all expenses of the public schools, and gives grants to private and foreign schools. About 2000 students have been sent by the government to study in Europe, and about 100 are to have like opportunities each year. Fifteen French professors have recently been imported. In 1930 there was a school attendance of 127,000 (18,700 girls).

6. Social Conditions. The general social conditions in Persia are very similar to those in adjoining countries. The same types of filthy cities with narrow streets, offensive bazaars, mud huts, veiled women, and beggars are found. Although the people live in scattered communities, separated by vast tracts of uncultivated land, they are bound together by a common culture and the subtle brotherhood of Islam. H. G. Hart ${ }^{1}$ characterizes the Persian as one who prefers a conciliatory lie to a strife-causing truth; shirks responsibility, yet does his duty to his family; drives a hard bargain, but is hospitable to a degree unknown in Europe; is vain and pompous, yet a lively and agreeable companion.

1 "Sidelights on Persian Society," Nineteenth Century, Vol. CIV, p. 119. 
Persian women, by custom, have been hidden from the sight of all men save the nearest relatives. Women are not regarded as being wholly responsible; consequently when a Persian wife goes astray, the husband is despised for not making the bolts and bars of the andaroon stronger. There are some districts, however, where Moslem women are not veiled; while their Armenian neighbor women wear a triangular piece of white cloth tied around the chin and mouth, said by some authorities to signify silence, an important code of group behavior.

Persian society is divided into definite classes. The upper class, ayán, consists of government officials (actual and aspirant), who are busily engaged in killing time. The middle class is small. Since professions are for the most part not represented, it consists chiefly of merchants. They use religion as a cloak for their fraudulent dealings, and most of them secure the title of Hajji, which is conferred on those who make the pilgrimage to the holy cities of Medina and Mecca. The third class consists of the villagers, handicraftsmen, and laborers. The typical laborer's home in central Persia is a two-room structure made of mud and having no windows. Niches in the mud walls hold the water pipe, cash box, and other objects. The mud floor is partly covered with strips of thick felt. The heating system (kursi) includes the brazier, in which is burned brushwood or dried dung, and a framework of wood over which a thickly padded quilt large enough to hang down on the sides is placed. Under this canopy the group sit on mattresses, arranging themselves so as to keep their heads cool. They sit, eat, and sleep on the floor, thus dispensing with bulky furniture. Shoes are kicked off upon entering the houses. Bread is the staple diet, and occasionally an extra, consisting of sour curds, a little meat, grapes, or melons in season, is served.

Very few Persian immigrants have come to the United States, but a number of people of other races have come from Persia. In 1920 there were 817 foreign-born whites in the United States from Persia who gave Persian as their mother tongue. Our present immigration law permits 100 immigrants to come from Persia each year.

\section{IV.. Arabia}

1. General Description. Arabia occupies the peninsula in southwestern Asia between the Red Sea and the Persian Gulf. According to estimates, Arabia has an area of $1,200,000$ square miles, is over 
half as large as the United States west of the Mississippi River, and had a population of $7,000,000$. Nearly one-half of the country is a barren desert, but about two-thirds of it has fertile soil, and part of it could be irrigated. The interior is a table-land, with high mountains to the east shading off through vast steppes to the purely desert country. The area known as the Empty Quarter, a broad tract in southeastern Arabia, has never been explored by white men. A ridge about 20 miles broad and 400 miles long, known as Jebel Tuwaik, extends north and south across Arabia. Along the western border is a scarf about 400 to 600 feet high. This slopes off into the interior, where there is little rainfall and little irrigable soil.

The Arabs are supposed to be fairly pure Semites. That is, they belong to the Semitic branch of the Caucasian group, and are thus related to the Hebrews and Bedouins. Especially on the western border, a mixture of Arabs and freed African slaves is found. No stigma is attached to being a freed African slave if the person is a Moslem.

2. Political and Economic Development. Out of Arabia are supposed to have come the ancestors of the Babylonians, Hebrews, and Phœnicians. Today the population consists predominantly of nomads. In the northern part, where the rainfall is heaviest, they have adopted a sedentary life, but over most of the country they remain completely nomadic. They are divided into tribal organizations, with many feuds, especially between the north and south, and with a general hostility toward strangers. The country has long been considered Turkish territory, and the people have been content to let the outside world believe this so long as Turkey did not disturb them. Their political affiliation has always been weak, and the Turkish rule but a shadow. The rulers of the small states along the southern coast have tacitly recognized British protection since 1885 . In 1909 a treaty with Turkey recognized the British sphere of influence over most of Arabia.

Arabia is divided into five small political divisions. The Kingdom of Hejaz borders the Red Sea. It is about 170 miles long and 150 miles broad, and has an area of about 112,500 square miles and a population of 900,000. Hejaz was created in 1916, when Hussein Ibn Ali, the Grand Shereef of Mecca, surrendered his allegiance to the Sultan of Turkey and joined the Allies in the World War. Hejaz is important because it borders the Red Sea, which is a British thoroughfare, and contains two holy cities - Mecca, with a population of about 80,000, and Medina, with about 100,000. Considerable 
revenue is derived from the pilgrim trade, and some hides, gum, and wool are exported.

The Kingdom of Nejd lies east of Hejaz, including all of the central Arabian desert. Nejd has an area of about 170,000 square miles and a population estimated at 2,000,000. In March, 1924, Hussein, King of Hejaz, had himself proclaimed Caliph of Islam. To this Ibn Saud, King of Nejd, objected, and made war on Hussein. As a result Ibn Saud was proclaimed King of Hejaz and Sultan of Nejd on January 11, 1926, and thus the two countries were brought under the same head.

The Sultanate of Oman is in southeastern Arabia. Very close relations exist between India and Oman; a British consul and a British political agent reside at Muscat. The area is estimated at 82,000 square miles and its population at 500,000. The Imamate of Yemen occupies the southwestern part of Arabia, bordering on the Red Sea. It contains an area estimated at 75,000 square miles and a population of possibly 2,500,000. The Sultanate of Koweit extends along the Persian Gulf. It has an area of about 1950 square miles and a population of 50,000 to which an indeterminate number of Bedouins may be added. Koweit, the capital, has an estimated population of 25,000. This city is one of the most important on the Persian Gulf, and was to have been the eastern terminus of the Bagdad railway.

3. Religious and Social Conditions. Since Arabia contains the two holy cities, Mecca and Medina, it is important as a Moslem religious center. The rulers of Mecca are the arrogant Koraichites, who guard the Kabba, a cloth-covered cubical structure which contains the Black Stone, the sacred well of Zem-Zem, and the "Three hundred and sixty idols." The Black Stone is supposed to have fallen from heaven. At first it was white, but gradually became black by absorbing the sins of the many pilgrims who have kissed it. Mecca is supposed to be the birthplace of Mohammed, while Medina contains his tomb. Between 100,000 and 130,000 (150,000 in 1930) Moslems make the pilgrimage to these holy cities annually. It is the source of a considerable revenue. About 50 per cent of these pilgrims come from the Dutch East Indies, and about 20 per cent from India. Arabia has been the center of considerable religious strife among the different Moslem sects. The Wahabs of Nejd are fanatical Moslem zealots, and oppose the liberalism of other Moslems, especially those of Turkey.

Since Arabia is a desert with occasional oases and fertile valleys, 
most of the people have no settled abode. Even Mecca is in the midst of a barren country, and its streets are usually ankle-deep with dust. There are practically no schools, and civilization is on a very low plane. Wealth is measured by the size of the flocks or the number of date palms. The settled people generally live in mud huts, eat sitting on dirt floors, and sleep on the roofs. The people wear their hats in the houses but remove their shoes. The women go barefooted, but cover their faces. Water is carried about in skins and sold to those who wish it. Ice is an unknown luxury. The people use bread for plates and then eat the plates. Although Oman is the most advanced area of the country, its plane of living is low. The people in general, and the Wahabs especially, are hostile to strangers and manifest little interest in the outside world. Very few immigrants from Arabia have come to the United States. Our present law permits 100 to come each year as immigrants.

\section{QUESTIONS, EXERCISES, AND PROBLEMS FOR INVESTIGATION}

1. Locate Siam, explain what special distinction it claims, and account for its territorial losses. Besides the text, see Gibbons, H. A.: The New Map of Asia, Chap. V.

2. Read and report on the following: "Progress in Siam," Edinburgh Review, Vol. CCXLVIII, pp. 88-107; "Siam in the Modern World," Foreign Affairs, Vol. IX, pp. 657-64.

3. Relate some of the social customs of Siam.

4. Explain the political significance of the geographic location of Afghanistan.

5. Explain: "It [Afghanistan] long remained the largest closed country in the world." In addition to the text, see MacMunn, George: "Afghanistan and the Outer World," Nineteenth Century, Vol. CIII, pp. 344-53; Potocki, Joseph: "Afghanistan Looks Abroad," Foreign Affairs, Vol. VII, pp. 110-17; Young, George: "The Near East Goes West," Yale Review, Vol. XVIII, pp. 718-31; Comyn-Platt, T.: "Afghanistan and the Soviet," Nineteenth Century, Vol. CV, pp. 297-305.

6. Describe some of the social customs of Afghanistan.

7. How has Persia's position affected it culturally and ethnologically? In addition to the text, see Coleridge, Guy: "Great Britain and the Persian Gulf," Nineteenth Century, Vol. C, pp. 828-36; "AngloPersian Relations," Edinburgh Review, Vol. CCL, pp. 195-209.

8. Trace the important steps in the development of Persia, paying particular attention to its treatment during and following the World 
War, and its financial reorganization. In addition to the text, see Turlington, Edgar: "The Financial Independence of Persia," Foreign Affairs, Vol. VI, pp. 658-67.

9. Discuss the agricultural and industrial conditions of Persia.

10. Why are the early religious conditions of Persia of considerable interest? What religions originated there? Summarize the chief points in each.

11. Characterize Persian social groupings. Besides the text, see Hart, H. G.: "Sidelights on Persian Society," Nineteenth Century, Vol. CIV, pp. 118-29.

12. Locate Arabia. To what race do the Arabs belong? In addition to the text, see Hogarth, D. G.: “The Arab World Today," Foreign Affairs, Vol. IV, pp. 406-14.

13. Show how politics and religion have become entangled in Arabia. See Musil, A.: "Religion and Politics in Arabia," Foreign Affairs, Vol. VI, pp. 675-81; Sirdar Ikbal Ali Shah: "A Journey to Mecca," Fortnighlly Review, Vol. CXXX, pp. 70-78.

14. Describe the social conditions of Arabia. 


\section{CHAPTER XXIX}

\section{AFRICA}

1. General Description. The continent of Africa has an area of $11,622,619$ square miles. It has few high or long mountain ranges; consequently much of it is a barren desert of sand and rock, and a large part is too dry for dense forests or good crops. The shore line is generally smooth, with few harbors. The lowlands along the coast are in narrow strips, while the interior is mostly a broad plateau. This causes the rivers to descend by rapids and falls which prevent navigation. About two-thirds of the continent lies almost completely in the torrid zone; the climate and the prevalence of tropical diseases are a serious handicap to advancement.

Africa has long been considered the home of the Negro race and now contains the bulk of the black peoples. With the Bantus they number about $120,000,000$, or some four-fifths of the total black population of the world. The total population of Africa is about 130,000,000, of whom 4,000,000 are Europeans. The so-called Negro race is a very mixed group, and ethnologists differ widely in regard to who should be classified as Negroes. Inhabiting northern and northeastern Africa, almost one-third of the continent, is a group of people known as Hamites and Semites. They include the Arabs, who belong to the Semitic branch, and the Berbers and Riffs, who belong to the Hamitic branch. They are generally dark, and not always easily distinguishable from Negroes, but they belong to the Caucasian group. There are about 7,000,000 Berbers in Morocco and Algeria, and 500,000 in Tunis and Tripoli. Some of these people have blue eyes, and occasionally a pure blond is found. Many ethnologists apply the term Negro to the inhabitants of the central and western third of Africa, excluding the Bantus, who occupy practically all of Africa south of the equator. The Bantus, including the Zulus and Kaffirs, are of a reddish-brown color and never sooty black. The Hottentots and Bushmen are an ethnological puzzle, as they appear to be mainly Asiatics. All seem to agree that the Sudanese, who inhabit a broad belt in central and western Africa generally known as the Sudan, are Negroes. This group, however, is very mixed, some 
being large and others, like the dwarf Negrillos, small. It was from this region that most of the Negroes of the New World came. Our Immigration Bureau makes no clear distinction, but includes under "African (black)" all persons whose appearance indicates an admixture of Negro blood regardless of the part of the world from which they come.

2. Political and Economic Development. In early times northern Africa, especially Egypt and Carthage, played an important part in Mediterranean affairs, and pirates from the decaying Barbary States long raided commerce along the Barbary coast. In the early part of the sixteenth century Portugal began the process of partitioning Africa which reached a feverish height during the nineteenth century. As a result of that process, only two small independent countries remain. The remainder of the continent is divided among six European powers.

\section{A. Independent Countries}

Ethiopia. The Empire of Ethiopia (Abyssinia), one of the two independent countries of Africa, has an estimated area of 350,000 square miles and an estimated population of 10,000,000. Many ethnologists maintain that the Abyssinians are a mixed group of HamitoSemitic people with no Negro blood. The royal family claim to be directly descended from King Solomon and the Queen of Sheba.

A considerable part of the country is an elevated plateau with sufficient rainfall for agricultural purposes. Lake Tsana, which is 6000 feet above sea level and covers 1100 square miles, affords a valuable water supply for irrigation, not only for Ethiopia but for adjoining countries. There are a number of high volcanic peaks, separated by deep valleys, some of which contain high waterfalls suitable for the development of hydro-electric power. Part of the lowland is hot and arid, but irrigation is possible. Economically, the country is poorly developed, and the land is subject to the control of the church or throne. Agriculture is in a very backward state, transportation facilities are poor, irrigation possibilities are not utilized, mines are not developed, and water power is not employed. The main occupations are farming and grazing. The country is rich in coal, oil, and potash, but little use is made of these. Some ivory, beeswax, hides, coffee, gum, cotton, sugar cane, tobacco, and fruits are produced and exported.

Owing to its fear of European aggression, especially from its neigh- 
bors, Great Britain and Italy, Ethiopia consistently avoids an international debt. Swamps and deserts largely isolate it from the other powers and help it to withstand their attempts at aggrandizement. During the World War, Ethiopia was the only neutral African territory. In 1923 it became a member of the League of Nations, hoping thereby to be better able to maintain its independence. The church is said to be the most corrupt of Christian churches. It retains the cult of spirits and magical practices and dominates other institutions. About one-fourth of the male population consists of priests, monks, and deacons; over one-third of the land is under church control; and education is largely in its hands.

Liberia. The Republic of Liberia, the other independent country of Africa, has an estimated area of 45,000 square miles. The population is variously estimated from 700,000 to 2,500,000. Between 12,000 and 20,000 of the inhabitants are descendants of American freedmen. Liberia was established in 1816 by the American Colonization Society, as a home for free American Negroes. In 1847 it became a free and independent republic. Its constitution and government are modeled after those of the United States.

Liberia is on the west coast between British and French territories. It has not been able to withstand their aggression, and has lost part of its interior territory. The United States has become its financial adviser and practical protector. Liberia was the second nation to pay its war debt to the United States. Membership in the League of Nations will perhaps help it in maintaining its integrity. The country is covered with tropical forests. The chief exports are rubber, oil, coffee, ivory, raffia, and ginger. The Firestone Rubber Company, of Akron, Ohio, has leased 1,000,000 acres of land from the Liberian government for the cultivation of domestic rubber.

\section{B. French Possessions}

French Africa. France controls an area of 4,775,640 square miles in Africa, and a population of $35,380,840$. Practically all of northwestern Africa is under French control. France has also a small area at the mouth of the Red Sea, known as French Somaliland, and the large island, Madagascar, off the coast of southeastern Africa. The area in Africa under French control is much larger than continental United States, and over 22 times the size of continental France. Indeed, the great size of the French African possessions, 
the large desert areas, the uninhabited regions, and the lack of roads and waterways make their political and economic development very difficult.

Algeria has an area of 847,552 square miles and a population of $5,522,604$. Three-fourths of the inhabitants are Berbers. There are about 873,000 Europeans, 690,000 of whom are French. The coastal strip along the Mediterranean Sea is practically a desert. Running parallel with this is the Tell, a mountainous region from 50 to 100 miles broad. It contains fertile valleys of great agricultural importance. In this area most of the people live. Although colonization has been slow, the country has prospered under French rule. Great improvement has been made in irrigation, railways, highways, and education. The chief products are cereals, olives, tobacco, and wines. Cotton and silk are being produced in increasing quantities. Livestock exports amount to about $\$ 250,000,000$ per year. Mineral resources are not well developed, but quantities of iron, zinc, phosphate, petroleum, lead, copper, and coal are produced. The country is rich in forests, especially cork, oak, and pine. It is prosperous and pays its own way. Provisions are being made to grant concessions of land to French colonists and others. From 1830 to 1856 Europeans grew by immigration from 600 to 169,000 .

Tunis, which borders Algeria on the east, has an area of 50,000 square miles and a population of 2,159,758. The inhabitants are mostly Berbers and Arabs. According to the census of 1926, there were 1,932,184 Arabs, 89,216 Italians, 71,020 French, and 54,243 Jews. Using the raids of the natives on Algeria as an excuse, France occupied this region in 1881. By barter it supported Britain's claim to Cyprus, and Britain supported France's claim to Tunis. The country has about the same agricultural possibilities and produces practically the same kind of products as Algeria. It is prosperous and meets its financial obligations.

Morocco and Tangier lie west of Algeria. France has a protectorate over Morocco, and is the chief authority in the supposedly international Tangier. Morocco has an area of 223,000 square miles and a population of $4,229,146$. The natives are mainly Arabs and Berbers. In 1926 the European population numbered 106,000, twothirds of whom were French. Tangier has an area of about 200 square miles and a population of 80,000 (11,700 Europeans and 12,000 Jews). Tangier is little more than a seaport and health resort. Its importance is due to its location on the Strait of Gibraltar. The French 
and Spanish Moroccos and Tangier were anciently a part of the great Sherifian Empire, and it was from these and adjoining territories that the Berbers and Arabs (Moors) came, who overran and conquered Spain and Portugal. For several hundred years it has been a storm center for Christianity and Mohammedanism.

The bifurcation of the mountains west of Algeria gives Morocco the Riff and Atlas ranges. Among these ranges are fertile valleys, and between them is a plateau suitable for agriculture and European residence. The country is poorly developed, and part of it has hardly been explored. The people, especially the Riff tribes, are difficult to control. The country is rich in phosphates and has other mineral wealth and forest resources, but these have not been developed.

French West Africa has a territory of $1,844,400$ square miles, joined to about 1,500,000 square miles of the Sahara Desert. The estimated population of 13,541,611 consists mostly of Arabs, Berbers, and Negroes, with 16,000 Europeans. About one-half the Negroes are Mohammedans. Their religion constitutes a rare combination of Mohammedanism and Negro superstition. Dakar, in Senegal, is one of the most important commercial cities in West Africa. Joined to this territory are 20,200 square miles of the former German Togoland, Germany's only self-supporting African colony. Excepting Togoland, French West Africa is poorly developed. Different parts are suitable for forests, pastures, cereals, fruits, cotton, tobacco, ground nuts, and sugar cane. The chief exports are palm nuts and oil, fruits, rubber, cotton, cocoa, and lumber. The Europeans are anxious to develop cotton growing but better means of communication must be had first. It is thought that French West Africa will probably develop into a second Brazil.

French Equatorial Africa, including the French port of the former German Cameroon, has an area of 1,148,538 square miles and a population of $5,027,707$. There are about 4502 Europeans, and the rest are Negroes, mainly Bantus. There are about 30,000 square miles of tropical forests, rich in rubber. The chief products are rubber, palm oil, tobacco, coffee, and ivory. Minerals are known to exist but are not developed.

French Somaliland, Madagascar and adjoining islands, and Reunion conclude France's African possessions. Somaliland has 5790 square miles and a population of 85,778 (1928 estimate). The inhabitants are nomadic tribesmen. Its importance is due to its location at the mouth of the Red Sea. Madagascar has an area of 228,707 square 
miles and a population of $3,621,342$, of whom 18,040 are French. Agriculture and stock raising are the chief occupations. The main products are rice, manioc, vanilla, coffee, corn, tobacco, cloves, cocoa, sugar, gum, beeswax, resin, raffia, cabinet and tanning woods, graphite, and gold. Reunion is an island 420 miles east of Madagascar. It contains 970 square miles and a population of 186,637 , of whom 180,694 are French. It has belonged to France since 1643.

\section{British Possessions}

British Africa. Great Britain's African possessions embrace an area of 4,707,121 square miles and a population of $61,493,895$. They are smaller in area than the French possessions but their population is almost double that of the territories possessed by France. Britain and France control approximately 84 per cent of the territory and 70 per cent of the population of Africa. Most of France's possessions are in the northwest, most of Great Britain's in the southeast. Since the Union of South Africa claims to be a "white man's country," and was settled chiefly by the British and the Dutch, it was discussed in Chapter VIII.

Egypt, over which Great Britain still exercises control, was an important country in the early history of the world. Its area is estimated to be 347,840 square miles; the population, according to the 1927 census, was $14,186,898$. Cairo, the capital, has a population of 1,064,567, and Alexandria, the next largest city, has 573,063. Egypt is wholly dependent upon the Nile for irrigation to produce crops. Only 13,600 square miles of the country are cultivated, and threefourths of this is in the delta triangle at the mouth of the Nile. Only 80,000 of the population live outside the delta triangle. Excepting this delta triangle and a narrow strip along the banks of the Nile, the country is a barren desert. The water supply is becoming inadequate for the population, and during low seasons the Nile cannot supply the demands. A large dam at Assouan (Aswân) stores a large amount of the flood waters to be used as needed, and another dam is planned, but it will of necessity be built in the Anglo-Egyptian Sudan. This would make Egypt more dependent on Britain, and probably rob the Sudan of part of its water supply. Egypt has long been and doubtless will remain an agricultural country, with little manufacturing or other interests. How to secure water to extend the farming area for the rapidly increasing population is one of the most momentous questions Egypt has to face. 
Egypt is a country with 60 centuries of history. In 1517 it came under Turkish rule, and in 1875 Britain began its encroachments, which resulted in annexation in 1914 as a war measure. Great Britain has had so much trouble in Egypt that since the World War it has adopted the policy of granting Egypt more self-government. In 1922 it "abolished" its protectorate over Egypt, but because of the Suez Canal and its desire to control Egypt's cotton crop, Britain is determined not to permit Egypt's independence to become complete. Egypt retains its king, but he must rule in accordance with British interests. There have been many serious disturbances under British rule, and only a truce prevails at present. Britain continues to maintain its soldiers in Cairo and Alexandria. Egypt wants complete freedom from British rule, a protectorate over the Anglo-Egyptian Sudan, and neutralization of the Suez Canal.

British South Africa has an area of 731,714 square miles and a population of $3,140,256$. Southern and Northern Rhodesia have an area of 438,294 square miles and a population of $2,366,632$, about 44,600 of whom are Europeans. Southern Rhodesia was fully annexed to the British Empire in 1922; Northern Rhodesia is a crown colony. Southern Rhodesia is mostly an elevated plateau suitable for European settlers. Northern Rhodesia is mainly a thinly forested high plateau. Southern Rhodesia produces large crops of maize and tobacco, and fair crops of fruit and cotton. Dairy farming is important. It also has quantities of coal, gold, and asbestos. The Victor Falls are one of the greatest spectacles of Africa. Much of Northern Rhodesia is suitable for grazing and agriculture, but it is undeveloped and produces little for export except lead. Basutoland has an area of 11,716 square miles and a population (1921) of 498,781, of whom 1603 are Europeans. It is a well-watered elevated plateau with a fine climate that is well suited to European settlers. Stock raising is the most important occupation, but farming is extensively engaged in, and some mining is done. Wool and cereals are the chief exports. Bechuanaland and Swaziland, the other two countries of British South Africa, are undeveloped. Bechuanaland has an area of 275,000 square miles and a population of 152,083 . Cattle raising is the most important occupation. Some gold is being mined. Swaziland has 6704 square miles and a population of 122,760 . It produces small quantities of tobacco, corn, sweet potatoes, live stock, and gold.

British West Africa has an area of 493,473 square miles and a population of $24,166,526$. Only 7267 are Europeans. This area includes 
Nigeria, the Gold Coast, Sierra Leone, Gambia, and the British part of the former German territories of Togoland and Cameroon. The region is rich in natural resources. Nigeria is the sixth country in the world in the production of tin, and possesses great deposits of iron and lead. The Gold Coast produces large quantities of gold, diamonds, and manganese. Both countries produce rubber, cocoa, palm oil, nuts, ivory, live stock, drugs, tobacco, and ostrich feathers for export. Cameroon has very rich soil and great agricultural possibilities, but it is yet undeveloped. At present the chief products are vanilla, ginger, cloves, pepper, ivory, and palm oil. Peanuts form 95 per cent of the exports of Gambia. The Gold Coast and Sierra Leone have very valuable forests. Rubber, cocoa, kola nuts, palm nuts, and oil are among their chief exports.

British East Africa has an area of 798,894 square miles and a population of $13,151,731$. The Europeans number about 20,000. Kenya is one of the most important areas of East Africa. It is a tract of land covering over 245,000 square miles, which extends across the equator, but, being at an elevation of 4000 feet, has a remarkable climate. It has vast rolling plains, dotted with lakes, and a climate very much like southern California. Cotton and rubber can be grown easily, and two crops of vegetables a year. Experts claim that enough cotton can be grown in Kenya to make British mills independent of American producers. The lowlands, thronged with wild game and occupied by roving natives, are largely unexplored.

Tanganyika, formerly German East Africa, was taken by the British in 1918. It has an area of 366,632 square miles and a population of 4,825,061, of whom 5808 are Europeans. It has immense forest wealth and great agricultural and grazing possibilities. The western part has an abundance of big game, and a game reserve is being established there. The exports are mainly cotton, sisal, coffee, ground nuts, and hides.

Uganda, Nyassaland, Zanzibar, and Somaliland are the other parts of British East Africa. Uganda has an area of 94,204 square miles and a population of 3,410,857 (1929), of whom 1995 are Europeans. Cotton is the chief crop. Foreign trade is increasing rapidly. Nyassaland has 47,949 square miles and a population of $1,359,998$, with about 1700 Europeans. It produces quantities of cotton, coffee, tea, tobacco, and live stock. Zanzibar is an island 23 miles off the coast. It has an area of 1020 square miles and a population of 216,790. The bulk of the world's supply of cloves comes from this island. 
The copra industry is also important. The city of Zanzibar (population 35,000) contains one of the finest ports in Africa. Somaliland has an area of 68,000 square miles and a population of 347,000 . Its chief importance is due to its location on the Gulf of Aden near the mouth of the Red Sea.

The Anglo-Egyptian Sudan and a number of islands, among which is St. Helena, conclude Britain's African possessions. The Sudan has an area of 1,008,100 square miles and a population of 5,605,848. The country is largely desert, but is crossed by both the White and the Blue Nile. Large dams are being constructed to store the water for irrigation purposes. In the near future it is expected that 100,000 bales of good Egyptian cotton will be produced yearly. The Sudan is the chief source of the world's supply of gum arabic. The country is prosperous under British rule, foreign capital is flowing in, manufacturing is being established, and a great commercial development is taking place.

\section{Portuguese Possessions}

Portuguese Africa. By 1510 Portugal had overcome the Arabs on the east coast and laid claim to practically all of Africa. Of all its once extensive claims, it retains but 927,292 square miles of territory with a population of $7,736,700$. Its colonies are widely scattered and only of minor importance in their present backward state of development.

Angola (Portuguese West Africa) is the largest of Portugal's possessions. It has an area of 484,800 square miles and a population of 2,481,956, of whom 90 are Portuguese. It produces small amounts of rubber, coffee, sugar, ivory, nuts, tobacco, cotton, fish, cattle, petroleum, asphalt, and diamonds. There are large deposits of malachite, and deposits of iron, copper, gold, and salt have been found. Mozambique (Portuguese East Africa) has 426,712 square miles and a population of 3,479,042 natives and 49,746 Europeans. Over 400 square miles of this territory were acquired in 1919, as Portugal's share of German East Africa. Mozambique contains the important lower basin of the Zambezi, and has vast natural resources practically untouched. The chief products are cocoanuts, sugar, and beeswax. Portuguese Guinea has an area of 13,940 square miles and a population of 770,791 . Its chief exports are oils, beeswax, ivory, and hides. The area of the Cape Verde Islands is 1480 square miles, and the population is 150,160 , of whom about 5000 are Europeans. 
The chief products are coffee, hides, millet, and medicinal products. These islands, fourteen in number, are located in the North Atlantic Ocean. St. Thomas and Principe Islands have an area of 360 square miles and a population of 63,845 , about 1500 of whom are Europeans. These islands are about 125 miles off the coast between Angola and Guinea. They are hilly, and the soil is volcanic, but the vegetation is rich. The chief products are coffee, cocoa, rubber, and cinchona.

The Portuguese colonies have been badly administered and are poorly developed. For several years the revolutionary spirit has been strong. The colonies blame Portugal for their backward condition and it has been in danger of losing them. The settlement of the World War strengthened its hold, but the Belgian Congo would like to have Angola, and the Union of South Africa would like to acquire Mozambique. Portugal is now granting more autonomy in government and showing greater interest in the economic development. The colonies could furnish food and other products which Portugal lacks, if they were properly administered and if better transportation were furnished.

\section{E. Belgian Possessions}

Belgian Africa. Belgium has the advantage of having all its African possessions in one area of 900,654 square miles plus 20,500 square miles of former German East Africa. The Bantu population numbers about $8,300,000$ and the white population 25,679 , of whom 17,676 are Belgians and 544 Americans. African Belgium is about 85 times the size of European Belgium. The Congo came under Belgium in 1885 and was annexed in 1907. The Urundi and Ruanda (formerly German East Africa) mandates were secured in 1921, but not formally accepted till 1924. The Katanga region of southeastern Congo, and Ruanda and Urundi are mainly high plateaus suitable for European colonization. There is one area of about 25,000 square miles which is around 6000 feet above sea level. The rainfall is about 40 inches, the soil is fertile, and native agriculture is well developed. Cotton growing and cattle raising are increasing rapidly: There are 17,000 miles of road and 2548 miles of railroad. There are thousands of miles of navigable rivers. The copper reserves are among the largest in the world. Rubber, palm nuts and oil, copal, coffee, and cacao are the leading exports. Ivory is abundant, rich mines of gold, diamonds, and tin are worked, and deposits of coal, iron, and cobalt are known to exist. 


\section{F. Italian Possessions}

Italian Africa. Italy's African possessions contain an area of 871,416 square miles and a population of $2,052,893$. Its territory is in three main divisions: Libya (Tripolitania and Cyrenaica) on the Mediterranean Sea; Somaliland, on the Indian Ocean; and Eritrea, on the Red Sea. The population of Libya is about 40 per cent Negroes, 30 per cent Arabs, 23 per cent Jews, and 7 per cent Europeans. Tripoli, the capital, has a population of $55,243(11,651$ Italians). Tripolitania has an estimated area of 350,000 square miles and a population of 570,700, including 20,716 Europeans $(18,093$ Italians). Cyrenaica contains an area of 230,000 square miles and a population of 229,700, of whom 9719 are Europeans (9402 Italians). Part of Libya is desert, and most of it is barren. The chief occupations are cattle raising, sponge fishing, and the growing of date palms, olives, almonds, figs, grapes, and cereals. Eritrea has an area of 45,435 square miles and a population of 405,681 (3900 Italians). The lowlands are very hot and the uplands are cool. The soil is very poor and crops have to be assisted by irrigation. Italy attempted to colonize the upper region, but had to abandon the project. Agriculture and stock raising are the chief occupations. A little gold is mined, and petroleum exists but is undeveloped. Palm nuts are the chief article of export. So far the country has been of no economic advantage. Somaliland has an estimated area of 254,000 square miles and a population of about 1,000,000. Agriculture and stock raising are the main occupations. At present this country is of no economic value.

Italy began its colonial venture in 1870 by buying the port Assab in the southern part of Eritrea. The territory of Eritrea became an Italian colony in 1890. Italy annexed Tripoli in 1912. As a result of the World War, it gained a small amount of invaluable land from the former German colonies. Its African colonial area is of very little value. Much of it is desert and a low country which affords no outlet for Italy's surplus population.

\section{G. Spanish Possessions}

Spanish Africa.' Spain's African possessions contain about 140,000 square miles and a population of 980,000. Its scattered small holdings are along the west coast, and consist of Spanish Morocco (protecto- 
rate), Rio de Oro, Adrar, Guinea, Ifni, Canary, Fernando Po, and other islands. Some of the territory, especially Fernando Po, contains very fertile soil, and some is heavily forested. The territory is in a very backward state and is of no commercial value. The provinces have long been a drain on Spanish finances, and because of the turbulent conditions in Morocco a large army has to be maintained. Only Spanish pride causes the retention of these possessions.

3. General Social Conditions. Africa is a land that has long presented a complexity of social conditions. The inhabitants are in various stages of civilization. Generally speaking, the natives north of the Sahara share on equal terms, except politically, in the common cultural and economic development of the country. South of the desert, with the exception of some tribes, the natives have reached a tolerably advanced civilization, while in South Africa they are mainly a hired labor class and, apart from certain native territories, possess little land of their own. Herskovits ${ }^{1}$ has divided the continent into nine culture areas, beginning with the most southern extremity and extending northward. (1) The Hottentots, in the extreme south, live in portable huts, built of poles with mats thrown over them. Cattle, which are used for food, clothing, carrying purposes, and presents for one's future father-in-law, are the distinguishing culture trait. (2) The Bushmen, who live north of the Hottentots, are distinguished by their extreme poverty. Being chiefly nomadic hunters, they have no domesticated animals, save the dog, and carry on no agriculture. They seek shelter in rock caves and from there raid the Hottentot and Bantu herds. Their paintings, depicting the scenes in their lives and executed on the walls of their caves, are remarkable. As Ratzel says of these natives, "[They] are much smaller than the other children of men; they live in high rocks; they have no settled place of abode; their home is wherever they kill game; they eat it all up and go on." (3) To the east and extending along the eastern coast is the East African cattle area, where the culture is basically agricultural with cattle superimposed upon it. Cattle are not held sacred, but are almost worshiped economically. Unless a man has cattle, even though he may have land, hoes, and trinkets, and possess special aptitudes, he has no prestige. The complex is so strong among the Banyankole that chiefs are appointed to rule over cattle rather than people. Among the Zulus the position

1 "A Preliminary Consideration of the Culture Areas of Africa," American Anthropologist, Vol. XXVI, pp. 50-63. 
of the child in the family and in the community is definitely determined by the number of cattle his mother received. The central unit is the kraal, where cattle are kept. The land is usually held by the chief in trust for the people. There is a strong legalistic bias shown in all dealings between individuals. (4) The Congo area, comprising the area drained by the Congo River, differs markedly from adjoining areas. Here are found a closely knit system of markets and an entire absence of cattle. Agriculture is more advanced, and the number of domesticated animals much larger. The iron hoe is generally the unit of value, although bark cloth and the cowrie shell are sometimes substituted. Land is generally owned en bloc, and the village is the political unit. As in the East African cattle area, the ruler and queen mother maintain separate courts. Property passes from father to son, and sometimes includes growing trees. (5) To the east, jutting out into the Indian Ocean, is the East Horn area, which represents a blend of cultures, chiefly dominated by Islam. (6) The Eastern Sudan is a marginal area. Since the country is desert and the religion Mohammedan, the social organization is necessarily adapted to geographical conditions and Islamic influences. The head of the group is the sheikh, who controls the movements of the people as they move to and fro over the desert seeking food for their animals. Here the camel plays an important rôle. The milk is used for sustenance, and the animal for transportation and dowry payments. (7) In the Western Sudan, one finds a conflict between the Negro influence of the south and the Mohammedan of the north. Although the Mohammedan religion has been largely accepted, the intense political organization scarcely gave way before the invaders.

The two remaining areas to the north are the (8) Desert and (9) Egypt. The former is occupied chiefly by the nomadic Berbers, who follow camel and horse raising. The latter constitutes a specialty. Egypt was once one of the leading civilized nations from which much of European civilization was derived. It is a country resplendent in archeological remains which testify to its former cultural ascendency. In its glory it succored other nations, but now it lies impoverished amid its ruins. Roughly speaking, there are four social classes: (1) the fellaheens, or peasants; (2) the Bedouins, or nomadic Arabs of the desert; (3) the Nubia Nubians, or Berberins, a mixed group of Negroes and Arabs; and (4) the foreigners. Proximity to Europeans has caused a great modification in the native costume, which, although on the same design, lent itself to elaborateness or simplicity, as the 
case might be, to suit the economic position of the wearer. Two articles, the red cloth fez or tarboosh of the men and the veil of the women, used to cover the face except the eyes, are most successfully resisting innovation. Coffee is taken at all hours, and tobacco is generally smoked with little intermission by the men and many women, especially the rich. There are numerous festival occasions connected with the Moslem religion. The inundation of the Nile has given rise to a series of observances. A crier in each district of Cairo goes his daily rounds, announcing in quaint chant the rise, and at the greatest height concludes his employment by presenting each house with fruits and dry lumps of Nile mud.

It is upon these native culture areas that a white civilization has been superimposed. When the importance of Africa was realized, the leading European nations rushed in with not very much appreciation of native culture. The United States, not being able to circumvent the meaning of the Monroe Doctrine, had to be content with missionary endeavors. The general result has been a conflict of commercial and political interests and of native and foreign cultures. What the result will be, no one can tell. Certain practices have been abolished. The English abolished slave trading in Nigeria in 1917 and freed 250,000 slaves in Sierra Leone in 1927.

Ethiopia, however, still recognizes domestic slavery, but slave trading is punishable by death. It is usually pointed out that the suppression of head hunting, slavery, and the like represents a great advance, but it must be remembered that the introduction of alcohol, firearms, and new diseases, and the breaking down of controls by a sudden thrust of a new culture are often far more detrimental to a preliterate people than their tribal customs.

Especially in South Africa, race and other related problems have become acute. There are three main non-European groups: (1) the natives; (2) the "colored," or the mixed races, and a small colony of Malays near Cape Town; (3) the Asiatics, for the most part British Indians, who came over to trade or are descendants of persons brought over to work on the tea plantations. The 1921 census gave 4,699,433 natives, 545,548 "colored," and 163,896 Asiatics not including adjacent territories. The nature of this population mixture is such as to create many racial problems. The white man has come to stay and has brought his civilization with him, which, he fears, the natives will monopolize and thereby prevent his further expansion. The conflict of the two planes of civilizations has produced a detrib- 
alized group, numbering some 500,000. These, in seeking the white man's industries, have become alienated from their tribes and despised by the poorer whites, whom they have tended to displace. In the northern provinces and the Cape the "colored" people are circumscribed by a color line, which is strictly enforced. Although denied the rights of skilled workers, they are generally placed with the Europeans. Sentiment became so strong that Asiatics were forbidden to enter in 1913 and are now prohibited from inter-provincial migration. The educated Indian is proving a special menace to the white settlers. Added to these diverse frictions are the jealousies and strifes among the Europeans who are keenly interested in commercial gain. Evans Lewin ${ }^{1}$ goes so far as to say that Africa occupies the key position in the industrial life of European civilization.

Mohammedanism made a special appeal to the natives and spread rapidly over northern and eastern Africa. Today these regions remain largely Moslem, while the central and western areas are largely pagan. Believers are divided as follows: Moslems, 44,000,000; Protestants, 3,000,000; Orthodox, 3,000,000; Roman Catholics, $2,000,000$; and Jews, 500,000. Over much of the country there is a considerable mixture of sects, and in some sections the church has a strong hold upon the people. The American and European religious groups have done considerable missionary work in Africa, but much of it is of controversial value.

The Europeans have established universities, colleges, and elementary schools in many places in Africa, but these are mainly for the European element. In many places natives are not permitted to attend European churches or schools. As a result illiteracy is widespread, and the masses are densely ignorant and superstitious. In Ethiopia education is for the clergy alone. Although Egypt boasts of several universities, one of which dates from 972 and had 9749 students in 1914, 92 per cent of the people in Egypt are illiterate. The fellaheens, peasant farmers, who constitute 62 per cent of the population, are very ignorant, live on a low plane, and are in extreme poverty.

The Europeans have always discriminated against the natives of Africa. The French are perhaps least and the English most guilty in this discrimination. Especially in the Union of South Africa, Southern Rhodesia, Basutoland, and Kenya, laws have been passed which segregate the natives and Indians in the low, unhealthful sections

1 "Africa in the Twentieth Century," Yale Review, Vol. XVII, pp. 78-91. 
and reserve the high, healthful regions for Europeans. The Indians and Negroes oppose land segregation and suffrage discriminations, but to no avail. In Basutoland the native males have to pay a poll tax of 1 pound 5 shillings per year. This amount is doubled for the second wife and tripled for the third. Many other discriminations in tariffs, wages, and other matters increase the prejudice of the blacks against the whites and further complicate the social conditions.

4. Immigration and Emigration. It is not the number of Negroes, Egyptians, Arabs, Berbers, or Europeans received that makes Africa important in a study of this kind. So far we have not received many non-Europeans directly from Africa. Some are coming, however, and it is quite possible that the numbers will increase rapidly as education brings discontent. Besides, immigration and racial conditions present an interesting comparison with those in the United States. Again, by studying conditions in Africa we are better prepared to understand the cultural residues which the Negroes took to other countries and now are transmitting to the United States.

Negro immigration into this country is increasing rapidly. According to the census, 32,504 Negro immigrants were admitted for the decade ending in 1910, and 66,471 for the decade ending in 1920, an increase of 33,967 . In 1924 we received 12,243, a number larger than that of any previous year. Before 1901 only 13.7 per cent of foreign-born Negroes came to the United States in contrast with 41.7 per cent of foreign-born whites, but for the period 1915-19 the percentage of foreign-born Negroes was 28.4 and the foreign-born whites 55. The Negro immigrants began to come in increasing numbers around 1880. Between 1830 and 1897 about 12,000 people came per decade from the West Indies; for the decade ending in 1910, 100,960 came, for the decade ending in 1920,120,860, and for the decade ending $1930,41,675$. Since the West Indies have a very heavy percentage of Negroes, we may assume that they are the chief source of our Negro immigrants. If Porto Rico and the Virgin Islands were not parts of the United States, the number would be much larger. For the decade ending in 1920, 8832 Portuguese Negroes were admitted into the United States as immigrants. These came mainly from the Cape Verde Islands, and a few from the Azores. Thus the two chief sources of our present Negro immigrants are the West Indies and the Cape Verde Islands. Increasing numbers, however, are coming from Central and South America and Africa.

The three main destinations of the Negro immigrant are New York, 
Florida, and Massachusetts. As about 91,000 Negro immigrants came between 1900 and 1920, but only 50,000 foreign-born Negroes enumerated in 1920 came after 1900, it would appear that many are "birds of passage."

The Negro immigrant greatly complicates the situation in the United States. Many come from places like Haiti and Santo Domingo, where Negroes are in the ascendency and color prejudice is not strong. Numbers come from Jamaica, and, by retaining their British citizenship, have the support of the British Empire in case of race riots or other disturbances. Racial problems generally increase as an element in the population increases which has obvious physical difference. The Negro immigrants not only retain their color and other marked physical differences, but present language and other cultural differences. Those coming from Haiti speak French; those from Santo Domingo, Cuba, South and Central American countries speak Spanish; and those from the Cape Verde Islands, Azores, and Brazil speak Portuguese. Thus Negro immigration into the United States presents a complicated situation.

\section{QUESTIONS, EXERCISES, AND PROBLEMS FOR INVESTIGATION}

1. What are some of the physical handicaps of Africa? Advantages? In addition to text, see Renner, G. T.: "The Geographic Regions of the Sudan," Economic Geography, Vol. II, pp. 256-73; Buell, R. L.: "The Destiny of East Africa," Foreign Affairs, Vol. VI, pp. 408-26; Gemmill, P. F.: "Egypt Is the Nile," Economic Geography, Vol. IV, pp. 295-312.

2. What racial groups predominate in Africa? Besides text, see Dictionary of Races or Peoples; Pittard, Eugène: Race and History, Part IV; Johnston, H. H.: "Race Problems in the New Africa," Foreign Affairs, Vol. II, pp. 598-612; Speight, W. L.: "Indians in South Africa," Nineteenth Century, Vol. CVII, pp. 197-204.

3. Give the major divisions of Africa and the countries controlling these. What countries are independent? In as far as possible, show how each foreign power gained control in Africa. From the point of view of the welfare of the natives, how successful has each rule been?

4. Taking each of the larger possessions or protectorates, show of what advantage each is to the mother country.

5. Discuss some of the recent political developments in Africa. References. Evans, P. V. E.: "Nationalism in South Africa," Nineteenth Century, Vol. CII, pp. 642-51; Worsfold, W. B.: "The French Effort in North 
Africa," ibid. Vol. CIII, pp. 310-21; Hofmeyr, J. H.: "South Africa after the Elections," Foreign Affairs, Vol. VIII, pp. 130-34; Amos, M. S.: "England and Egypt," Nineteenth Century, Vol. CV, pp. 306-16; Lewin, Evans: "German and Italian Interests in Africa," Foreign Affairs, Vol. V, pp. 472-81.

6. Give the background for, and show what is being done toward, the economic development of Africa. Besides the text, see Walton, L. A.: "Liberia's New Industrial Development," Current History, Vol. XXX, pp. 108-14; Renner, G. T.: "The Geographical Regions of the Sudan," Economic Geography, Vol. II, pp. 256-73; "Geographic Regions of Sierra Leone," ibid., Vol. VII, pp. 40-49; "Economic Adjustments in Liberia," ibid., Vol. VII, pp. 189-201; Baker, W. H.: "Trade Communications in Tropical Africa," ibid., Vol. I, pp. 315-36.

7. Describe briefly each of Herskovits's culture areas of Africa. See Herskovits, M. J.: "A Preliminary Consideration of the Culture Areas of Africa," American Anthropologist, Vol. XXVI, pp. 50-63.

8. Abstract Lugard, F. D.: "Education in Tropical Africa," Edinburgh Review, Vol. CCXLII, pp. 1-19.

9. Discuss the various angles of the native question in Africa. References. Hall, Daniel: "The Native Question in Kenya," Nineteenth Century, Vol. CVII, pp. 70-80; Buell, R. L.: "The Struggle in Africa," Foreign Affairs, Vol. VI, pp. 22-40; Marquard, L.: "The Native Question in South Africa," Nineteenth Century, Vol. CIV, 19-33; Duncan, Patrick: "Race Questions in South Africa," Foreign Affairs, Vol. V, pp. 293-306; Lewin, Evans: "The Black Cloud in Africa," ibid., Vol. IV, pp. 637-47; Clarke, W. E. C.: "The Native Problem in South Africa," Edinburgh Review, Vol. CCXLIV, pp. 32-48; Lugard, F. D.: "The White Man's Task in Tropical Africa," Foreign Affairs, Vol. V, pp. 57-68.

10. Of what interest is Africa to the student of immigration? What are the sources of our present Negro immigration? How does "the Negro immigration complicate the situation in the United States"? 



\section{BOOK II \\ IMMIGRATION AND ASSIMILATION IN THE UNITED STATES}





\section{PART VI}

\section{INTRODUCTION}





\section{CHAPTER XXX}

\section{IMMIGRATION TO THE UNITED STATES}

In Book I we have pointed out some of the more important geographical, racial, political, economic, religious, educational, and social factors that have influenced movements of population. Having these factors in mind, we are now prepared to take up the study of immigration to the United States and the problems it creates.

Emigration and immigration are the result of two conditions. On the one hand, certain political, economic, religious, or social causes force individuals and groups to consider leaving their native lands; on the other hand, certain conditions in other countries afford them the hope that by emigrating they may satisfy desires unrealized in their native countries. Often it is difficult for an emigrant to decide which of these conditions influenced him more. Certainly his cultural background assists in the formulation of his personal motives.

Prior to 1850, emigration from Europe to the United States was determined mainly by oppressive political, economic, and religious conditions. After the French Revolution the individual was to some extent free, and could migrate if he desired to do so. The Industrial Revolution brought with it a new economic era in which machines displaced many workers. Bad harvests, especially in Ireland and in Germany, created a serious situation, which could be relieved only by importation of food or by deportation of inhabitants. As a result, compulsory or encouraged emigration was resorted to. Also, struggles between Catholics and Protestants, hatred of the Jews, and in recent times anti-religious movements, have forced not only individuals but units of people to migrate.

\section{History of Immigration to the United States}

Fairchild ${ }^{1}$ divides the history of immigration to the United States into five periods, but it appears expedient for our purpose to divide it into three chief periods.

1. From the Founding of Jamestown to 1820. The founding of a colony in Jamestown, Virginia, in 1607 provided a nucleus for the

\section{Immigration, pp. 26-122.}


colonial development of the United States. This settlement was followed by others, such as that of the Pilgrims in Plymouth, Massachusetts, in 1620; that of the Dutch in Manhattan (New Amsterdam) in 1823; and that of the Swedes in Delaware in 1638. In 1681 William Penn was granted the territory of Pennsylvania for settlement, and by 1682 some 6000 Swedes, Dutch, Germans, and English were in this territory. Between 1684 and 1713 the Wars of the Grand Alliance and of the Spanish Succession caused a great exodus from the Palatinate (Germany), and in the first half of the eighteenth century intolerable economic, political, and religious conditions in the United Kingdom sent the Scotch-Irish here in large numbers. According to Professor Fairchild, 4200 Scotch-Irish left for America in 1718, and 12,000 annually after the famine in 1740. At least 150,000 came to America within the fifty years preceding the Revolution. "They were by far the largest contribution of any foreign race to the people of America during the eighteenth century, and constituted a strong element in the army at the time of the Revolution." 1 Professor Ross says, "More than any other stock has this tough, gritty breed, so lacking in poetry and sensibility, molded our national character." 2

It was exceedingly difficult for many of the early colonists to get to America. Ferenczi ${ }^{3}$ tells us that many Germans exhausted their meager funds in Holland, and had to beg their way home. A group of about 13,000 Palatines, who arrived in London practically destitute, aroused the sympathy of Queen Anne, who had food and shelter provided for them, and sent them on to the United States, at a cost of $£ 135,000$ to the British government. ${ }^{4}$ According to F. Kapp, ${ }^{5}$ the food on a ship in 1731 became so scarce that the passengers ate rats and mice, paying 18 pence for a rat and 6 pence for a mouse. Only 48 of the 156 passengers reached America, the others having died of starvation.

Despite the difficulties of migration, our population had a rapid natural increase. Less than 80,000 colonists had grown into 1,000,000 by 1741.6 "It is estimated," writes S. P. Orth, "that between

1 Immigration, p. 37.

2 The Old World in the New, p. 13.

${ }^{3}$ International Migrations, Vol. I, p. 116.

${ }^{4}$ See Fairchild, H. P.: Immigration, p. 35.

5 Immigration and the Commissioners of Emigration of the State of New York, p. 21.

6 See Hall, P. F.: Immigration, p. $4 . \quad 7$ Our Foreigners, p. 32. 
1790 and 1820 only 250,000 immigrants came to America, and of these the great majority came after the War of 1812 . The white population of the United States in 1820 was $7,862,166$. Ten years later it had risen to $10,537,378$. This astounding increase was almost wholly due to the fecundity of the native stock." Although an Armenian was a member of the early Jamestown settlement, and the Jews had a synagogue in Manhattan in 1691, most of the early settlers were of Teutonic stock. According to statistics, the English composed 82.1 per cent of our population in 1790 , the Scotch 7.0 per cent, the Germans 5.6 per cent, the Dutch 2.5 per cent, the Irish 1.9 per cent, the French 0.6 per cent, and all others 0.3 per cent. ${ }^{1}$ "It is the distinctive fact regarding colonial migration," writes Commons, " "that it was Teutonic in blood and Protestant in religion."

2. The Period of Expansion - 1820 to 1882. The year 1820 is significant in the history of immigration, for in that year the first federal law in regard to immigration was passed, and the first official statistics of the numbers of immigrants were collected. Since our history as a separate nation does not begin until 1783, Professor $\mathrm{R}$. Mayo-Smith ${ }^{3}$ and others have chosen to regard all whites coming here before that date as colonists, and all entering after that date as immigrants. ${ }^{4}$ As there were no official statistics of immigration before 1820 , estimates vary from 250,000 for the period 1776 to 1820 , to 345,000 for the period 1784 to 1810 , to 250,000 for the period 1790 to 1820 . Before 1820 immigration did not attract very much attention; immigrants who wished to come were expected to do so. In general, immigrants were encouraged to come and often aided in so doing.

The period from 1820 to 1882 was one of great industrial activity and national expansion. The completion of the Erie Canal, the extension of the first railroads, the increase in manufacturing, and the flow of population into the West are significant events of this period. The demands for labor were imperative, and immigrants responded to the demands. In 1825 the number of immigrants arriving was 10,000. Around 60,000 came during the fifteen months ending December 31,1832 , and 104,565 in the year 1842 .

This influx brought with it many serious social problems, such as

1 Compare Orth, S. P.: Our Foreigners, p. 29.

2 Races and Immigrants in America, p. 27.

3 Emigration and Immigration.

${ }^{4}$ For a distinction between colonists and immigrants, see the author's Backgrounds for Sociology, p. 227. 
pauperism, begging, prostitution, and intemperance. Horrible conditions on boats, in labor camps, and in towns are recorded. The reported practice in England and Germany of sending over shiploads of paupers and criminals brought vehement protests from people in the United States. Active opposition to immigration began to develop, and eventuated in the rise of the native American party and the anti-Catholic riots of 1844. The Irish were coming in large numbers at this time, and bore the brunt of the attack, but some criticism was directed toward the Germans also. The Germans, however, were not so poor as the Irish, they tended to settle on the land, and they were Protestants. The failure of the potato crop in Ireland increased the influx of Irish and helped to swell the total number of immigrants until it reached 427,833 in 1854. By this time the Know Nothing party had become powerful, and several states passed antiimmigration laws. Perhaps these laws had some effect, but it was largely as a result of the industrial depression of 1857 and the Civil War that the number of immigrants dwindled, reaching a minimum in 1862 , when only 72,183 came, the smallest number in twenty years. The thinning of the population during the Civil War and the Homestead Act of 1862 increased the opportunities for immigrants in the United States. Also, the attitude of the older settlers toward newcomers was more friendly for a time. Steamships were supplanting sailing vessels, and in 187396.8 per cent of the immigrants arrived on steamships. Consequently the time of voyage was shortened and steerage conditions alleviated.

With the return of prosperity after the Civil War, the number of immigrants arriving increased very rapidly, reaching 459,803 in 1873 . The Irish and Germans dominated this period. In 1851 272,240 immigrants came from the United Kingdom (chiefly Irish), and in 1854 215,000 came from Germany. In 1854 immigrants from the United Kingdom constituted 87.7 per cent of the total number for the year, and in 1873 they constituted 68.8 per cent. After this date Scandinavians came in larger numbers; they composed 7.7 per cent of the total number of immigrants in 1873 and 13.4 per cent in 1882 . The great influx of Irish caused old prejudices to revive and to increase. The people in New Hampshire would not permit the Irish to cross over from Massachusetts, and the Molly Maguires proved to be a serious problem in the coal regions of Pennsylvania. In dealing with the English, the Irish had developed a hostile attitude toward any one who reported the lawless activities of another. Con- 
sequently it was difficult to bring the lawless Molly Maguires to justice. Finally they were apprehended, nineteen were hanged, a large number were imprisoned, and the organization was destroyed. This organization greatly increased the prejudice against the Irish.

The Chinese were attracted to the Pacific coast during the California gold rush in 1848, and by 1852 numbered around 25,000. At first they were welcome. They were industrious, peaceful, and sober, and, manifesting a servile attitude, did not arouse prejudice. They became workers on vegetable and fruit farms, domestic servants, and unskilled laborers, especially in railway construction. But the influx of laborers from the East, after the railroad to the Pacific coast was completed, and the depression in California caused a hostile attitude toward the Chinese to develop. "The Chinaman," writes Eairchild," "became the scapegoat for all the ills that afflicted the youthful community, from whatever cause they really rose, and in time an anti-Chinese declaration came to be essential for the success of any political party or candidate."

3. The Modern Period - 1882 to 1931. Considering it as a whole, this period is characterized by an increasing number of immigrants and an increasing number of restrictive laws. The year 1882 is one of the most significant in the history of American immigration. In that year: (1) the first comprehensive immigration law was passed by the federal government; (2) the first Chinese exclusion law was enacted; (3) the number of immigrants - 788,992 - reached a peak not surpassed until 1903; and (4) the change from the so-called old to the new immigration became marked. The old immigration includes the immigrants from the countries in northwestern Europe, while the new immigration includes those from southern and eastern Europe. The old immigration is characterized as Teutonic, while the new is Latin and Slavic. The table on page 482 indicates the percentage change.

The change from the old to the new immigration is usually claimed to be significant for the following reasons:

(1) Teutonic blood and culture predominate in the old immigration, and Latin and Slavic in the new. In general, the Teutons are more vigorous and more progressive than the Latins and Slavs. They are also larger and more stalwart than the Latins. Furthermore, the Teutons are culturally ascendent at present, but this has not always been true and may not remain so.

1 Immigration, p. 100. 
Percentage Distribution of Immigrants by Countries of Origin

\begin{tabular}{c|c|c|c|c|c|c|c}
\hline \hline Period & $\begin{array}{c}\text { Northern } \\
\text { and } \\
\text { Western } \\
\text { Europe }\end{array}$ & $\begin{array}{c}\text { Southern } \\
\text { and } \\
\text { Eastern } \\
\text { Europe }\end{array}$ & Asia & $\begin{array}{c}\text { Canada } \\
\text { and New- } \\
\text { foundland }\end{array}$ & Mexico & $\begin{array}{c}\text { West } \\
\text { Indies }\end{array}$ & $\begin{array}{c}\text { Other } \\
\text { Countries }\end{array}$ \\
\hline $1820-1830$ & 68.0 & 2.2 & $\ldots$ & 1.6 & 3.2 & 2.6 & 22.4 \\
$1831-1840$ & 81.8 & 1.0 & $\ldots$ & 2.2 & 1.1 & 2.1 & 11.8 \\
$1841-1850$ & 93.0 & 0.3 & $\ldots$ & 2.4 & 0.2 & 0.8 & 3.3 \\
$1851-1860$ & 93.6 & 0.8 & 1.6 & 2.3 & 0.1 & 0.4 & 1.2 \\
$1861-1870$ & 87.8 & 1.4 & 2.8 & 6.6 & 0.1 & 0.4 & 0.9 \\
$1871-1880$ & 73.6 & 7.2 & 4.4 & 13.6 & 0.2 & 0.5 & 0.5 \\
$1881-1890$ & 72.0 & 18.3 & 1.3 & 7.5 & $\ldots$ & 0.6 & 0.3 \\
$1891-1900$ & 44.6 & 51.9 & 1.9 & 0.1 & $\ldots .6$ & 0.9 & 0.6 \\
$1901-1910$ & 21.7 & 70.8 & 2.8 & 2.0 & 0.6 & 1.2 & 0.9 \\
$1911-1920$ & 17.4 & 58.9 & 3.4 & 12.9 & 3.8 & 2.2 & 1.4 \\
$1921-1930$ & 31.3 & 29.0 & 2.4 & 22.5 & 11.2 & 1.8 & 1.8 \\
\hline \hline
\end{tabular}

(2) Forgetting the large numbers of paupers and criminals shipped into the colonies, some persons claim that the bulk of our Teutonic immigrants were from the middle and upper classes, while the majority of the new immigrants are from the lower class. Ambition and dissatisfaction, however, are the chief causes of immigration, and neither of these factors is an exclusive characteristic of either the higher or the lower class. It appears to be true that a larger number of the old than of the new immigrants come with their families, expecting to settle here permanently. A number of factors, however, may be responsible for this characteristic.

(3) A very high percentage of the old immigrants are literate and maintain a high plane of living, while the reverse is true of the new. Factors over which the immigrants have no control may be responsible for this divergence also.

(4) Excepting most of the Irish and part of the French, the old immigrants were Protestant, while most of the new immigrants are Roman Catholic or Eastern Orthodox. The only significance that can be attached to this fact is that at present the Protestant countries are, on the whole, culturally ascendent.

\section{Number and Distribution of Immigrants}

Perhaps it is well to point out that immigration to the United States, unless restricted by laws, has been determined by conditions here as well as by conditions in the immigrants' native lands. Pros- 
perity in the United States attracted immigrants, but in periods of depression fewer entered, and many returned to their native countries. Such has been the case throughout the history of our immigration.

1. Number of Immigrants. How many immigrants came to the United States before 1820 - the first year in which federal statistics were kept - we do not know. According to estimates, there were $3,929,214$ people in this country in 1790 and 250,000 immigrants had been added by 1820 . During that year 8385 immigrants were admitted - 6024 from the United Kingdom and 968 from Germany. Following a commercial depression in England, there was an increase in the number of immigrants in 1827-28. In 183122,633 immigrants arrived, in 1842104,565 , in 1850369,980 , and in 1854427,833 . The panic of 1854 and the Civil War a few years later caused a marked decline in the number of immigrants, but this was followed by a rapid increase, for 387,203 were admitted in 1870 . In 1903857,046 immigrants were admitted, in 1905 1,026,499, in $19061,100,735$, in 1907 1,285,349, in $19131,197,892$, and in 1914 1,218,480. According to our census reports, $37,762,012$ immigrants came to this country for the period 1820 to 1930 . For the five years ending in 1925, 103,803 aliens were debarred from entering the United States, and for the next five years 85,504. Between 1921 and 1925 28,427 aliens were deported; and for the period 1926-30 63,730. . The following table gives the number of immigrants to the United States by decades, from 1820 to 1920 , and the percentage of the decadal to the total immigration.

Immigration to the United States, 1820-1920

$\begin{array}{ccc}\text { Period } & \begin{array}{c}\text { Number of } \\ \text { Immigrants }\end{array} & \begin{array}{c}\text { Percentage of } \\ \text { Total Immigration }\end{array} \\ 1820-1830 & 151,824 & .45 \\ 1831-1840 & 599,125 & 1.78 \\ 1841-1850 & 1,713,251 & 5.09 \\ 1851-1860 & 2,598,214 & 7.72 \\ 1861-1870 & 2,314,824 & 6.88 \\ 1871-1880 & 2,812,191 & 8.36 \\ 1881-1890 & 5,246,613 & 15.59 \\ 1891-1900 & 3,687,564 & 10.96 \\ 1901-1910 & 8,795,386 & 26.13 \\ 1911-1920 & 5,735,811 & 17.06\end{array}$

According to this table, $33,654,803$ immigrants entered the United States during the period 1820-1920; 43 per cent came after 1901, 
and 70 per cent after 1881. For the decade ending in 1930, 4,107,209 more immigrants were admitted. Since no record was kept of departures of immigrants in our early history, we do not know how many returned to their native lands. The following table gives the admissions, departures, and net gain by years from 1908 to 1930 .

\begin{tabular}{lrcr}
\multicolumn{2}{c}{ Admissions, } & Departures, AND Net Gains, $1908-1930$ \\
Year & $\begin{array}{c}\text { Immigrants } \\
\text { Admitted }\end{array}$ & $\begin{array}{c}\text { Immigrants } \\
\text { Departed }\end{array}$ & Net Gain \\
1908 & 782,870 & 395,073 & 387,797 \\
1909 & 751,786 & 225,802 & 525,984 \\
1910 & $1,041,570$ & 202,436 & 839,134 \\
1911 & 878,587 & 295,666 & 582,921 \\
1912 & 838,172 & 333,262 & 504,910 \\
1913 & $1,197,892$ & 308,190 & 889,702 \\
1914 & $1,218,480$ & 303,338 & 915,142 \\
1915 & 326,700 & 204,074 & 122,626 \\
1916 & 298,826 & 129,765 & 169,061 \\
1917 & 295,403 & 66,277 & 229,126 \\
1918 & 110,618 & 94,585 & 16,033 \\
1919 & 141,132 & 123,522 & 17,610 \\
1920 & 430,001 & 288,315 & 141,686 \\
1921 & 805,228 & 247,718 & 557,510 \\
1922 & 309,556 & 198,712 & 110,844 \\
1923 & 522,919 & 81,450 & 441,469 \\
1924 & 706,896 & 76,789 & 630,107 \\
1925 & 294,314 & 92,728 & 201,586 \\
1926 & 304,488 & 76,992 & 227,496 \\
1927 & 335,175 & 73,366 & 261,809 \\
1928 & 307,255 & 77,457 & 229,798 \\
1929 & 279,678 & 69,203 & 210,475 \\
1930 & 241,700 & 50,661 & 191,039
\end{tabular}

According to the Monthly Labor Review (January, 1924), from 1908 to 192335.2 per cent of our immigrants emigrated. The Chinese led; 30 per cent more left than entered in that period. Other groups showed the following percentages of emigrants in relation to immigrants: Montenegrins, Bulgarians, Serbians, 89 per cent; Turks, 86 per cent; Koreans, 73 per cent; Rumanians, 66 per cent; Magyars, 66 per cent; southern Italians, 60 per cent; Slovaks, 57 per cent; Russians, 52 per cent. Other groups showed less than 50 per cent. In comparing the United States with other countries, we find that from 1857 to 1924 Argentina had a net immigration of 53.2 per cent, and from 1908 to 192462.3 per cent. Argentina had the largest 
number of immigrants in proportion to population. Australia retained 30 per cent of its immigrants from 1906 to 1924. For most of the decades Canada stands above the United States, and Brazil always remains low in the number of immigrants retained.

2. Distribution of Immigrants. When Europeans began settling what is now the United States, those from the United Kingdom scattered themselves along the Atlantic seaboard, gradually pushing into the interior. The Dutch settled in New York and Pennsylvania, the Germans in Pennsylvania and New York, the French Huguenots in the Carolinas and Georgia, the French in Louisiana and the northern Mississippi Valley, the Swedes in Delaware, and the Spanish in Florida and the southwest. Late comers tended to scatter more, but the bulk of the Germans and Scandinavians settled in the middle west and northwest, and the bulk of the French Canadians in New England; the Irish and Jews tended to remain in New York and Boston.

The old immigrants were inclined to take up their abode in rural areas, for when most of them came there was plenty of free or cheap land. The late comers among the old immigrants and a large portion of the new immigrants have settled in our cities. As a result, practically all our larger cities have their foreign quarters, such as "Little Italy," "The Ghetto," "Chinatown." Some of our cities contain what are virtually large foreign cities within them. Chicago is said to have more Czechs than any other city except Prague and Vienna, New York more Irish and Jews than any other city in the world, and more Italians than any other city except Naples. In our cities having a population of over 250,000 in 1920, we find that Germans ranked first in numbers among the foreign-born in Pittsburgh, Cincinnati, St. Louis, and Milwaukee; Russians in New York, Philadelphia, Baltimore, and Washington; Italians in Jersey City, Newark, New Orleans, and San Francisco; Poles in Chicago, Cleveland, and Buffalo; Irish in Boston; Canadians in Detroit; Swedes in Minneapolis; and Mexicans in Los Angeles. Germans ranked second in Baltimore, Buffalo, Chicago, New Orleans, and San Francisco; Russians in Cincinnati, Newark, and St. Louis; Poles in Detroit, Milwaukee, and Pittsburgh; Irish in Jersey City, Philadelphia, and Washington; Hungarians in Cleveland; Canadians in Boston and Los Angeles; and Norwegians in Minneapolis.

Twenty-three per cent of the 1,285,349 immigrants coming to the United States in 1907 went to the North Central states, 6 per cent 
to the Western states, and 4.5 per cent to the Southern states. In 1910, more than 25 per cent of the population of the Atlantic states and 20 per cent of that of the Pacific states were foreign-born. In the same year 84.8 per cent of the foreign-born population lived in the North, 9.7 per cent in the West, and 5.4 per cent in the South. The region north and east of a line drawn from Baltimore to Cairo, Illinois, and then to Minneapolis, is the area in which most of our immigrants have settled. The following table reveals the geographic distribution of the foreign-born whites in the United States in 1920:

Distribution of Foreign-Born Whites in the United States, 1920

\begin{tabular}{|c|c|c|}
\hline Geographic Division & Number & $\begin{array}{c}\text { Percentage of } \\
\text { Total Population }\end{array}$ \\
\hline Middle Atlantic States. . . . . . . & $4,912,575$ & 22.1 \\
\hline East North Central States.... . & $3,223,279$ & 15.0 \\
\hline New England States. . . . . . . . . & $1,870,654$ & 25.3 \\
\hline West North Central States.... & $1,371,961$ & 10.9 \\
\hline Pacific States............ & $1,033,868$ & 18.6 \\
\hline West South Central States..... & 459,333 & 4.5 \\
\hline Mountain States........... & 453,225 & 13.6 \\
\hline South Atlantic States......... & 315,920 & 2.3 \\
\hline East South Central States..... & 71,939 & 0.8 \\
\hline
\end{tabular}

From the previous discussion it is evident that for several decades our immigrants have tended more and more to settle in cities and industrial areas. Dr. Edmund deS. Brunner ${ }^{1}$ found that in 1920 only one-fourth of our foreign-born population lived in rural districts, and only about one-half of these were farmers. Ranked according to numbers, the settlers in rural districts were Germans, Swedes, Norwegians, Canadians, Russians, Austrians, English, Danes, Italians, Poles, Irish, Dutch, Finns, Swiss, and Mexicans. Although a large percentage of our immigrants were farmers in their native lands, three-fourths of them settled in cities in this country. For this they are often censured, but it is well for us to remember that it is impossible for most of our immigrants to settle on the land in this country. To purchase and equip a farm is far beyond their financial ability. Furthermore, if immigrants manifested a keen desire to purchase land, it is possible that they would be legally prohibited from doing so, as are the Asiatics in California. The distribution of immigrants remains an important problem.

\section{Immigrant Farmers and Their Children, Chapter I.}




\section{Effects of Immigration}

Immigrant countries are inclined to view their problems subjectively, and forget that there is a triple effect in movements of people - the effect upon the emigrant country, the effect upon the immigrant country, and the effect upon the immigrants. "On the debit side," writes Luigi Villari, " "we must remember that while the emigrant leaves his home in good health - if he is ill he is refused admittance - he often returns maimed by industrial accidents, which are appallingly frequent in the United States, or ruined in health by living in unsanitary factories and slums; tuberculosis, alcoholism, and syphilis are among the very visible exports from America to Italy. The fact that so many emigrants return home to die contributes to give American cities credit for a low death-rate. Moreover the returned immigrant is seldom a better citizen than he was before he left home. He never comes into contact with the America of high ideals, which certainly does exist, but finds himself associated with low-class contractors, Irish political bosses, shady financial agents of German-Jewish extraction, who for him constitute America. He learns little in America beyond a certain smattering of appalling slang and a bumptious manner, while he loses many of his best qualities. There is hardly a case of any improvement in agriculture or of the setting up of any industry in Italy due to returned emigrants. The existence of a mass of Italians residing in foreign cities does tend to some extent to the spread of Italiantà abroad, but the emigrants exercise very little political influence, as so few of them belong to the educated classes. In many cases they are a handicap to their Government, constituting as it were hostages in the hands of foreign Governments in the case of international conflicts. They also tend to increase Italy's trade to some extent, but as the immense majority of them belongs to the poorer classes they do not buy imported goods in large quantities, and where extensive Italian communities grow up local industries tend to arise and provide them with imitation Italian goods."

So far Americans have given very little attention to the effects of migration upon the emigrant countries, and, until recent years, to the effects upon the immigrants. From the following discussion, and from the life history documents of immigrants, it is hoped that the reader will acquire a better understanding of some of these problems.

1 "The Problem of Emigration," Edinburgh Review, CCXLII, pp. 297-98. 
1. Economic Effects. Around 80 per cent of our immigrants have come here at ages between 14 and 45 years, and about 65 per cent have been males. That means that a large number of males come here in their most productive years. Since we do not know what the economic conditions here would have been without these immigrants, it is impossible to say what effect they have had. It appears that, at times at least, there has been great need for a supply of cheap labor, and that immigrants supplied that need. Doubtless some of our railroads could not have been completed so rapidly, or our industries built, enlarged, and maintained, had it not been for the supply of immigrant labor.

Immigrants are accused of working for low wages, of taking jobs away from Americans, of living in tenements and shacks, of having a very low standard of living, and of saving money to send to their relatives in foreign lands. In considering such questions, we have to rely more upon logic and reasoning than upon statistical analyses. Statistics, however, show that immigrants generally receive smaller wages than Americans, and that wages vary considerably among the different racial and national groups. It is well to remember that immigrants have come to this country to better their condition; many are poor, and must work for the wages offered or look for other jobs. In most cases immigrants are working for Americans, and Americans set the wages they receive. No one doubts that immigrants would gladly accept higher wages. If they peacefully work for the wages offered, they are blamed for their docility; and if they organize and strike for higher wages, they are accused of being ruled by foreign agitators and radicals. Equally problematic is the charge that immigrants take jobs away from Americans. When immigrants dispossess Americans, it seems reasonable to conclude that the Americans have secured better positions, that the immigrants have been more efficient, or that immigrant labor has been more profitable to the employer. For the most part, immigrants are engaged in work that Americans refuse to do.

Bad housing conditions are not confined to immigrants, but are frequently found among the poor whites of old American stock and Negroes. Furthermore, Americans own the tenements and shacks which they rent to the immigrants, and city fathers permit such buildings to stand and be rented. With Frances Kellor ${ }^{1}$ we may ask: "Does the immigrant really desire to live in inferior homes and eat

${ }^{1}$ Immigration and the Future, p. 155. 
less food, and dress more poorly, and have fewer comforts and luxuries than his native born neighbors?" There is very little evidence that he does. His requests for improvements are ignored, and if he attempts to move into a better neighborhood he often meets with threats, bombings, and beatings. It is inconsistent to accuse immigrants of lowering our standard of living and at the same time admit that our standard has been rising.

Condemnation of the immigrant for sending money back to his native country appears to be based on a false economic theory. A large part of this money goes to pay for his passage to America, or for that of a relative or friend, or to help his people in the old country. The money flowing into the old country enables the people to buy more goods from us or from nations which buy from us. This in turn enables our producers to operate more fully and to pay higher wages. Thus both countries are benefited economically. Moreover, the immigrant gives value received for his wage, and should be free to send it back to his country if he so pleases.

2. Biological Effects. Most of the biological arguments against immigration are based on the discredited theory of Nordic superiority. Since there are no pure races, and since we have no means of accurately testing inherent racial abilities, this theory has been discarded by our outstanding authorities. Since it is widespread and frequently met, however, it is desirable to discuss briefly some of the arguments.

P. F. Hall, ${ }^{1}$ Robert Hunter, ${ }^{2}$ S. G. Fisher, ${ }^{3}$ and other authorities apparently accept the theory of General F. A. Walker that immigrants supplant the native stock. Walker believed, since fewer children were being born among the native stock than among immigrants, that the native stock refrained from bearing children because they did not wish their children to compete with immigrants. Such a theory seems to be erroneous for the following reasons. (1) The falling birth rate is a cultural factor, largely depending upon the plane of living of the group. (2) The people who limit their birth rate are not the groups who compete with immigrants. The poor whites of native stock continue to have large families, and they are the people who compete with immigrants. (3) The birth rate has fallen

1 Immigration, p. 107.

2 "Immigration the Annihilator of our Native Stock," Commons, Vol. IX.

3 "Has Immigration Increased the Population?" Popular Science Monthly, Vol. XLVIII. 
in areas of the United States not yet affected by immigration. (4) The birth rate has been dropping in those countries from which our immigrants have come, and in some of those countries more rapidly than in the United States.

Many psychological tests have been given in attempts to compare the mental abilities of the different racial groups. Unfortunately many of the testers and makers of tests found what appears to have existed in their own thinking before the tests were given. They seem to have forgotten that they were endeavoring to test a natural endowment by artificial means and under artificial conditions. As a result they have tested cultural attainment rather than innate ability. Even with this defect the more scientific of the tests, such as those that were conducted by Dr. Bertha M. Boody ${ }^{1}$ and Dr. Edmund deS. Brunner, ${ }^{2}$ do not produce evidence of any racial inferiority. $^{3}$

Another argument is that most of our immigrants for some decades have been inferior representatives of their racial and national groups. The exponents of this theory assume that our colonists and early immigrants were superior representatives of superior races. They forget that many criminals, paupers, malcontents, and ne'er-do-wells were shipped over, and that many of the colonists and early immigrants belonged to the Celtic (Alpine) and Mediterranean groups rather than to the Nordic. Furthermore, Professor A. M. CarrSaunders ${ }^{4}$ and others have become convinced that it is the ambitious who emigrate. The economically superior have little need to emigrate, and the inferior have neither the money nor the ambition to do so.

Some writers fear that the amalgamation of the different racial stocks, especially if they are very divergent, will cause racial degeneracy. This theory also lacks scientific proof. As there are no pure races, all so-called races are the result of amalgamation. Furthermore, the cross breeding of animals and studies of racial crosses have not proved that a crossing of stocks is detrimental. In fact, biologically it seems to be beneficial. ${ }^{5}$

1 A Psychological Study of Immigrant Children at Ellis Island, pp. 151-52.

2 Immigrant Farmers and Their Children, pp. 73-74.

${ }^{3}$ For a fuller discussion of this subject see the author's Race and Population Problems, Chapter V.

4 The Population Problem, pp. 297-304.

${ }^{5}$ For a fuller treatment of this subject see the author's Race and Population Problems, Chap. XI. 
On the other hand, we must recognize the color prejudice in the United States. The Negro or the Asiatic wears his "racial uniform" and is treated differently. Biologically, there appear to be no harmful results from the amalgamations of racial or national groups, but the social consequences often make them undesirable.

3. Political Effects. Immigrants frequently manifest considerable interest in international questions which involve their native countries. It is claimed that the independence of some of the war-born republics was declared in the United States before it was announced in Europe. Immigrant groups often collect and spend money to spread favorable propaganda in their own country and in the United States. They also manifest much interest in policies of the United States that affect their native countries, and sometimes attempt to secure legislation favorable to their homelands. This does not mean that they are not loyal to their adopted country. Most of them are, and would stand loyally by the United States if an open break should occur between their native land and their adopted country.

Quite often immigrants are blamed for our corruption in politics, but it appears that immigrants usually do not become enthusiasts over our political platforms. Most immigrant newspapers give more space to political conditions in the old countries than to those of America. Many immigrants never voted in their old country and are not interested in doing so here. If an immigrant receives $\$ 58$ for voting in place of twenty-five dead men in New York in one day, and if another is paid $\$ 2$ to vote in Philadelphia less than twenty-four hours after he lands in this country, surely Americans are responsible. Sometimes it takes an immigrant to correct a bad political condition, as Mayor Cermak, the Czech mayor of Chicago, tried to do.

4. Social Effects. Our immigrants are accused of being responsible for many of our crimes, social ills, and problems. It has not been proved that crime has increased, or that immigrants disproportionately increase crime. From the studies which have been made, it appears that immigrants are more likely to be arrested than nativeborn whites. According to the report of the Commission of Immigration and other studies, there appears to be no disproportionate amount of crime among our foreign-born. Immigrants are supposed to lead in certain types of crimes - Italians in murder and assaults, Irish in drunkenness and petty crimes, Poles in wife-beating, French, French Canadians, Russians, Poles, and Jews in sexual misdemeanors, and Germans, Greeks, and Russians in violations of city ordinances. 
A report for Massachusetts shows that although Italians constituted only 3 per cent of the population of that state in 1920, they formed 62 per cent of the persons committed to the state prison for murder and manslaughter. On the other hand, Dr. Antonio Stella ${ }^{1}$ shows that the United States has a much higher rate of crime than Italy, and that in the twelve states with the smallest percentage of Italians the homicide rate is almost four times as high as in the twelve states with the highest percentage of Italian population.

Statistics show that immigrants greatly increase our army of paupers. For example, on January 1, 1923, the white foreign-born composed 32.6 per cent of the total white paupers enumerated in almshouses, while in 1920 the white foreign-born composed only $\mathbf{1 4 . 5}$ per cent of our total population. A part of this is undoubtedly due to our economic system. Immigrants engage in dangerous occupations. As a result the bread winner is often killed or injured, and the family thrown on charity. On the other hand, part of the pauperism is due to the characteristics of some racial and national groups. Complaints were recorded early against the lack of thrift and prevalence of pauperism among the Irish, and that complaint continues today. "A decade ago," writes Professor Ross, ${ }^{2}$ "the Irish were found to be relatively thrice as numerous in our almshouses as other non-native elements ... nor do their children provide much better for the future. In Boston, those of Irish parentage produced two and onehalf times their quota of paupers. In both first and second generations the frugal and fore-looking Germans there have less than a tenth of the pauperism of the Irish." Rarely does an Asiatic ask for charity.

Despite the fact that the literacy test has been in force since 1917, the number of illiterate immigrants in our population increased from $1,650,361$ in 1910 to $1,763,740$ in 1920 , or from 12.7 to 13.1 per cent. For 1930, however, there was a decrease to $1,304,000$, or 9.9 per cent. The rates have been well over 50 per cent for some of the groups included in the new immigration, such as the Ruthenians, Syrians, southern Italians, and Portuguese, but less than one per cent for the Scandinavians. Another complicating factor is the large number of immigrants who are unable to speak English.

Religious, political, and racial prejudices among our immigrants complicate our social problems and prevent harmony and coöpera-

1 Some Aspects of Italian Immigration to the United States, pp. 78-84.

2 The Old World in the New, p. 29. 
tion. Many of these are products of peculiar situations in Europe. They are acquired there, transmitted to this country, and being deepseated, continue to function in a new environment." "The Pole," writes Emily G. Balch, " "wastes no love on the Russian, nor the Ruthenian on the Pole, and a person who acts in ignorance of these facts, a missionary for instance, or a political boss, or a trade union organizer, may find himself in the position of a host who should innocently invite a Fenian from Cork County to hobnob with an Ulster Orangeman on the ground that both were Irish."

Another phase of immigration that should be discussed briefly is the fusion of cultures. It has been largely neglected and little understood. It is peculiar in that it presents problems which bring ultimate benefits. Since races, nations, and classes generally consider their own cultures superior, they usually object to the introduction of an alien culture or elements of an alien culture. The prejudice against an alien culture presents an immediate problem, but a careful consideration of the history of races and nations shows that those racial groups and nations that have been so situated as to come in contact with alien cultures have been the ones to make the greatest advancement. ${ }^{3} \quad$ R. B. Dixon ${ }^{4}$ points out that between two and three thousand years after certain groups had come together and begun to amalgamate and fuse their cultures, an outburst of great intellectual and industrial activity resulted. It appears that the coming of many immigrants causes the breakdown of customs and traditions which bind a group and make it static, and that out of this wreckage arises a higher culture. We are unable to predict the future of the United States or what part our immigrants will play. So far it seems that the greatest advancement in the United States has been made in those areas in which immigrants representing a wide variety of cultures have settled.

\section{Restrictive Legislation}

As soon as the colonists developed a national consciousness, they expressed apprehension of an influx of foreigners. As early as 1751 Benjamin Franklin ${ }^{5}$ was writing: "Why should the Palatine boors

1 Compare Miller, H. A.: Races, Nations and Classes, especially pp. 43-44, 50.

2 Our Slavic Fellow Citizens, pp. 8-9.

${ }^{3}$ For a fuller discussion of this subject, see the author's Race and Population Problems, Chaps. VIII, IX, X.

4 The Racial History of Man, pp. 510-17, and The Building of Cultures.

${ }^{5}$ Works of Benjamin Franklin, edited by John Bigelow, Vol. II, p. 233. 
be suffered to swarm into our settlements and, herding together, establish their language and manners to the exclusion of ours? Why should Pennsylvania, founded by England, become a colony of aliens, who will shortly be so numerous as to Germanize us instead of our Anglifying them?" Some thirty years later Thomas Jefferson ${ }^{1}$ was deploring the fact that foreigners "will infuse into it [our legislation] their spirit, warp and bias its directions, and render it a heterogeneous, incoherent, distracted mass." In 1834 and 1837 there were antiforeign riots in New York, Boston, and Cincinnati, and in 1848 Jesse Chickering, in his Immigration in the United States wrote a flaming treatise on the necessity of transmitting our institutions unimpaired to our children. "Know-nothingism," tinged with anti-Catholic prejudice, was largely an anti-immigration movement that fanned the fires of prejudice against foreigners during the fifties. Edward E. Hale, ${ }^{2}$ however, took a different view. The Irish, he said, being an inferior race, were sinking to the bottom "and the consequence is that we are, all of us, the higher lifted because they are here."

In brief, our whole attitude toward immigration has been one of conflicting practices and theories. So long as we had a sparsely settled country and a scarcity of labor, we were generously hospitable. As a consequence, the United States became a haven for the poor and oppressed of other lands. Our fears for the future of American civilization were partly calmed by the passage of restrictive measures debarring certain undesirable aliens, and by our childish faith in the "melting pot theory" that environment would fuse all aliens of dif'ferent languages, customs, and habits. Many of our foreign-born, however, refused to give up their religion, their language, and other elements of their native culture; others, though willing to be Americanized, found themselves psychologically unable to make the change in a short period; while still others found the American groups unwilling to accept them under any conditions. To many people, particularly the eugenists, the most disturbing element in the melting pot theory has been the amalgamation of racial types.

There are two divergent and impracticable views of immigration control: unrestricted admission and absolute exclusion. On the one hand, the United States would become the dumping ground for the social refuse of other countries; and, on the other hand, it would suffer culturally. Between these extremes is the per centum limita-

1 The Writings of Thomas Jefferson, edited by Paul L. Ford, Vol. II, p. 190.

${ }^{2}$ Letters on Irish Immigration, pp. $54 \mathrm{ff}$. 
tion, which is devoid of logic. It represents a fear psychosis lest we admit too many. But it does not take into consideration how many can be assimilated, the special type of economic development needed, or the personal worth of the individual. At best it gives a method for reducing numbers, and the base may be shifted at any time. On the whole, our methods of restriction seem to indicate that we accept the theory of Nordic superiority; that we use physical characteristics as a criterion for judging races; and that we believe that Protestants are likely to make better citizens than persons of other religious views, that an illiterate man is incapable of becoming a good citizen, and that only the inferior representatives of racial groups desire to emigrate.

Although opposition to immigration had been developing since colonial times, no general restrictive law was passed by the United States until 1882. In 1820 a law was passed requiring a record to be kept of the immigrants entering this country, and in 1861 another law insured greater comfort to steerage passengers coming to this country. In 1876 the Supreme Court held that immigration was a subject for federal legislation, thereby overruling the claim of the individual states that they had the right to regulate immigration within their own borders. The law of 1875 prohibited the importation of women into the United States for immoral purposes and the landing of criminals other than political offenders. The law of 1882 excluded idiots, lunatics, and other persons likely to become public charges. In this same year immigration was placed under the Secretary of the Treasury, a head tax of 50 cents was levied on each immigrant, and Chinese were excluded by an agreement with China.

In 1891 the office of Superintendent of Immigration was created to take charge of all immigration work. The laws of this year excluded polygamists, persons afflicted with loathsome diseases, paupers, and persons whose passage was paid by labor agents. Promising employment, posting sailings, advertising fares, and encouraging immigration were considered illegal. Transportation companies were compelled to take back to their own countries, free of charge, any aliens who were refused admittance. Immigrants from Mexico and Canada had been on the exemption list since 1885, but were now made subject to the same laws as other aliens.

In 1903 the Department of Labor and Commerce was created, and the Secretary of Labor and Commerce was placed in charge of all immigration matters. All existing immigration laws were to be 
codified. The head tax, which was raised to one dollar in 1893, was increased to two dollars. Epileptics, anarchists, professional beggars, persons attempting to bring in women for immoral purposes, persons deported within one year as contract laborers, and persons who had been insane within five years previous, or who had had two or more attaeks of insanity, were placed on the exclusion list.

In 1907 the United States Immigration Commission was ereated, its purpose being to investigate and publish recommendations for immigration legislation. The head tax was raised to four dollars, greater air space was required for steerage passengers, and the President was given the power to refuse admittance to immigrants whose presence would have an adverse effect on labor. By the "Gentlemen's Agreement" Japan ceased issuing passports to Japanese laborers bound for the United States. As a result of the findings of the Immigration Commission a stringent law to prevent the importation of women and girls for immoral purposes was passed in 1910, and also a law requiring the expulsion of such people if brought in.

In 1917 the famous literary test bill became a law. It had been vetoed by Cleveland in 1897, Taft in 1913, Wilson in 1915, and again

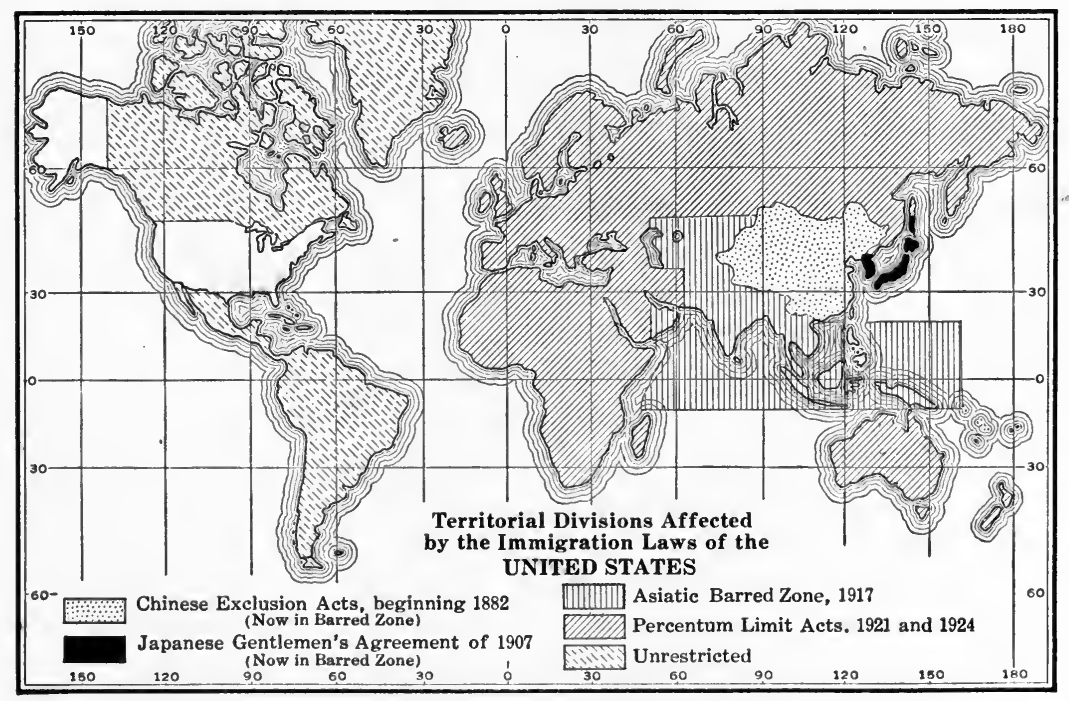

by Wilson in 1917, but secured the necessary two-thirds vote to make it a law. It requires aliens over 16 years of age to be able to read and write in some language or dialect. Exceptions, however, are 
made for persons seeking to escape religious persecution, and for near relatives of admissible aliens. The head tax was raised to eight dollars. This was also the year of the so-called Barred Zone Act, or latitude and longitude plan, which excludes practically all Asiatics not already excluded by the Chinese Exclusion Law $(1882,1902)$ and Gentlemen's Agreement with Japan (1907).

In May, 1921, the first of the quota or percentage laws was passed. Being sponsored by the American Legion and American Federation of Labor, it became a law over Wilson's veto. It was enacted as a temporary law to extend to June 30,1922 , but before it expired it was extended for two more years. It limited the number of immigrants who could enter this country from Europe, Australia, Africa, New Zealand, Asiatic Turkey, Persia, and certain islands of the Atlantic and Pacific oceans to 3 per cent of the number of foreign-born of such nationalities residing here when the 1910 census was taken. Not over 20 per cent of the yearly quota of any nationality could enter in any one month. Government officials, students, tourists, visitors, and aliens under 18 years of age whose parents were citizens of the United States were exempt from the quota regulations.

This law accomplished two things. (1) It reduced the total number of immigrants coming to this country. Between 1910 and 1914 we received an average of 1,034,940 immigrants per year. Only 356,995 could come in under the quota law. However, only 46.4 per cent of the number of immigrants permitted the northern and western European countries came to this country in the year 1921-22. Germany filled only 28 per cent of its quota, and the United Kingdom only 55.2 per cent of its allotment. (2) It favored and stimulated the immigration of Protestant northwestern Europeans and excluded most of the Catholic southern and eastern Europeans. In 1922-23 the northwestern European countries filled only about one-half of their quotas, but the next year 90 per cent. Immigrants from northwestern European countries increased from 20.8 per cent of the whole in 1913-14 to 55.7 per cent in $1923-24$, or nearly 140,000 ; and southeastern Europeans decreased from 75.6 per cent of the whole to 27.2 per cent, or by 728,561, for the same date. For instance, 296,414 Italians came in 1914, but Italy's quota under the new system was 42,057 ; 122,657 Poles came in 1914, but Poland's quota. was 25,827; 45,881 Greeks were admitted in 1914 , but only 3294 could come in 1922. Each year an increasing number of immigrants were admitted from non-quota countries - Canada and Latin America - and out- 
side the quota. For example, 46 per cent more aliens were admitted outside the quota than under it, or a total of 879,302 , for the year ending June 30, 1924. In 192873,154 persons were admitted from Canada, and 59,016 from Mexico. Perhaps several thousand others "walked" across.

In May, 1924, another percentage law was passed. This law preserves the basic principles of the law of 1917 , and changes the quota basis from the three per cent of each nationality in this country in 1910 to two per cent of each nationality here when the 1890 census was taken. Under the three per cent law 357,803 immigrants were admitted in 1924, while under the two per cent law of 1924 only 164,667 could enter. The immigration of northwestern Europeans was further favored. The old immigration was entitled to 56.33 per cent under the 1921 law and to 84.11 per cent under the law of 1924 . The 1924 law abrogated the Gentlemen's Agreement with Japan by placing Japan in the barred zone and thus preventing all "Orientals" from entering as immigrants. The law permits the wives, parents, if over 55 years of age, and children, if under 18 years of age, of citizens of the United States to enter unrestricted by quota regulations. It also provides for a preliminary examination of prospective immigrants before they depart from their native countries, thus practically assuring their admittance here. It makes 100 the basic number of immigrants that may enter from any country whose citizens are admissible. That is, if two per cent of the Greeks who came here in 1890 numbered less than 100 , up to 100 Greeks were permitted to enter.

With the law of 1924 was passed another law, providing that after July 1, 1927, the number of persons of each nationality permitted to enter must be in the same ratio that the number of persons of that nationality here in 1920 was to $150,000 .{ }^{1}$ The percentages were to be computed on the population according to the 1890 census for three years, and thereafter on the population according to the 1920 census. The minimum quota remained at 100. On March 3, 1927, it was voted to delay this law until April 1, 1928. It was later delayed another year, or until April 1, 1929, when it became a law.

Whereas 7.5.4 per cent of our people are of northwestern European stock, the national origins law gives them 83.7 per cent of the quota.

${ }^{1}$ Compare Senate Documents, Miscellaneous, 70th Congress, 2d Session, Document No. 259, pp. 4-5. 
The accompanying table gives the quota basis for the most important immigrant countries. ${ }^{1}$

Quota Basis for Most Important Immigrant Countries

\begin{tabular}{|c|c|c|c|c|}
\hline Country & $\begin{array}{l}\text { Total Con- } \\
\text { tribution to } \\
1920 \text { Popu- } \\
\text { lation of the } \\
\text { United States }\end{array}$ & $\begin{array}{l}\text { Ycarly Quota } \\
\text { 1922-1924 }\end{array}$ & $\begin{array}{c}\text { Yearly Quota } \\
1924-1929\end{array}$ & $\begin{array}{c}\text { Yearly Quoto } \\
\text { (1931-1932) } \\
\text { National } \\
\text { Origin }\end{array}$ \\
\hline $\begin{array}{l}\text { Great Britain and North- } \\
\text { ern Ireland } \ldots \ldots \ldots \ldots \ldots\end{array}$ & $39,216,333$ & $77,342^{*}$ & 34,007 & 65,721 \\
\hline Germany............ & $15,488,615$ & 67,607 & 51,227 & 25,957 \\
\hline Irish Free State......... & $10,653,334$ & $17,784 \dagger$ & 28,567 & 17,853 \\
\hline Poland............... & $3,892,796$ & 30,977 & 5,982 & 6,524 \\
\hline Italy................... & $3,462,271$ & 42,057 & 3,845 & 5,802 \\
\hline Sweden .............. & $1,977,234$ & 20,042 & 9,561 & 3,314 \\
\hline Netherlands........... & $1,881,359$ & 3,607 & 1,648 & 3,153 \\
\hline France.............. & $1,841,689$ & 5,729 & 3,954 & 3,086 \\
\hline Czechoslovakia......... & $1,715,128$ & 14,357 & 3,073 & 2,874 \\
\hline Russia............... & $1,660,954$ & 24,405 & 2,248 & 2,701 \\
\hline Norway.............. & $1,418,592$ & 12,202 & 6,453 & 2,377 \\
\hline Switzerland . . . . . . . . & $1,018,706$ & 3,752 & 2,081 & 1,707 \\
\hline Austria.............. & 843,051 & 7,342 & 785 & 1,413 \\
\hline Belgium . . . . . . . . . . & 778,328 & 1,563 & 512 & 1,304 \\
\hline Denmark.............. & 704,783 & 5,619 & 2,789 & 1,181 \\
\hline Hungary. ............. & 518,750 & 5,747 & 473 & 869 \\
\hline Yugoslavia............. & 504,203 & 6,426 & 671 & 845 \\
\hline Finland .............. & 339,436 & 3,921 & 471 & 569 \\
\hline Portugal.............. & 262,804 & 2,465 & 503 & 440 \\
\hline Lithuania.............. & 230,445 & 2,629 & 344 & 386 \\
\hline Greece.............. & 182,936 & 3,063 & 100 & 307 \\
\hline Rumania............... & 175,697 & 7,419 & 603 & 295 \\
\hline Spain................ & 150,258 & 912 & 131 & 252 \\
\hline Latvia. . . . . . . . . . & 140,777 & 1,540 & 142 & 236 \\
\hline Turkey .............. & 134,756 & 2,654 & 100 & 226 \\
\hline Esthonia............. & 69,013 & 1,348 & 124 & 116 \\
\hline Other quota countries..... & 244,310 & $\ldots \ldots$ & $\ldots \ldots$ & $\ldots \ldots$ \\
\hline Non-quota countries...... & $5,314,357$ & $\ldots \ldots$ & $\ldots \ldots$ & $\ldots \ldots$ \\
\hline
\end{tabular}

* Includes Irish Free State.

$\dagger$ Admitted from Ireland.

Since the minimum quota remains at 100, Albania, Bulgaria, Danzig, Iceland, Liechtenstein, Luxemburg, Monaco, and San Marino

${ }^{1}$ Because the law states that no country shall have less than a quota of 100 , it is necessary to add 3714 , and 4000 for "other quota countries." 
are permitted to send 100 immigrants per year. Australia, New Zealand, the Union of South Africa, the independent African states and the different territories of Africa, and the different Asiatic states and territories not in the barred zone are also each permitted 100 immigrants per year. The nations and territorial areas in the barred zone are permitted 100 immigrants per year, but these are to be of races eligible for citizenship and not Asiatics.

\section{Racial Attitudes ${ }^{1}$}

Immigrants bring with them sets of attitudes which are the results of their reactions to their environments. On reaching the United States and coming into contact with native Americans, they encounter new sets of attitudes which often are strange and puzzling. If these attitudes are directed toward another race, they are spoken of as racial attitudes. Some of these attitudes are relatively fixed, while others are comparatively fluid.

1. Origin of Race Attitudes. Although it is not always possible to discover the origin of race attitudes, we may say they are the result of primary and secondary contacts. We judge members of our own group as individuals, but unfortunately we consider one individual of another group as typical of the whole group or race. If our first experience with a member of another racial group is unpleasant, then we are almost sure to develop an aversion to his racial group. On the other hand, if the first experience is pleasant, a friendly feeling for the race develops. The younger we are when we have these experiences, or the more vivid they are, the more deep-seated the antipathy or friendliness becomes.

Although racial attitudes derived from secondary experience lack the vividness of primary contacts, they are likely to be deep-seated and lasting. In our homes and among our companions we hear derogatory comments on certain racial groups; in the newspapers we read of the crimes of foreigners; in the movies we have flashed before our eyes the unfavorable behavior of individuals belonging to certain races; and from the politicians we hear stereotyped catch phrases which are uncomplimentary to certain immigrant groups. As a result, we develop antipathies and hostile attitudes toward races about which we know very little. So many adverse reports concerning the Turks have been circulated in this country that

1 This section largely follows Immigration and Race Attitudes, by E. S. Bogardus. 
prejudice toward them is strong and widespread; yet most persons cherishing this antipathy have never seen a Turk. Newspaper accounts of the activities of Mexican bandits and motion-picture portrayals of Mexicans have made many visitors to southern California afraid to travel in Mexico or even go through the Mexican districts of Los Angeles. Politicians have ridden into office on anti-Japanese and anti-Negro campaigns, and commercial concerns have capitalized racial prejudice. Most people do not investigate the origin of their racial antipathies, and thus remain the victims of cunning political and commercial propaganda.

On the other hand, kind treatment from a Japanese is almost sure to cause a child to develop a friendly feeling toward Japanese. Familiarity with the wonderful deeds of a race causes us to admire them, and knowledge of the suffering of other peoples under oppression arouses our sympathy; both lead us to develop a friendly feeling. Immigrants are like Americans in these matters. Many of them have learned about the United States while in their own country and have developed a friendly attitude, but experiences here often result in counter attitudes. ${ }^{1}$

2. Variations in Racial Attitudes. In general, people are greatly infiuenced by their local environment. The attitudes of persons who live in Maine toward the Japanese and the Mexicans are markedly different from those of Californians toward these groups, and the attitudes of New Englanders toward the French Canadians differ from those of Southerners toward these peoples. With respect to some racial groups attitudes are fairly uniform throughout the United States, such as hostility toward the Turks and friendliness toward the Scotch. In general, however, there are regional and local differences. Racial feelings are generally less pronounced in rural districts than in urban areas. Wide variations, however, often exist within the limits of a large city.

Bogardus's study shows that racial attitudes vary with age, sex, occupation, and religion. Children have no definite racial attitudes, but usually acquire them early from their parents and companions. Adolescents have much stronger racial feelings than older people. Apparently experience sobers judgments, and reason rather than emotion tends to function. Men differ from women in their racial attitudes. If competition threatens, their behavior is similar, but in

1 For a fuller treatment of this section and interesting case material, see Bogardus, E. S.: Immigration and Race Attitudes, Chaps. I-VII. 
general the reactions of women are stronger than those of men. Although less willing to marry immigrants, women show more friendliness toward some races, such as the Chinese and Mexicans. Racial attitudes often reveal the effects of occupations. The American workman develops an antipathy toward any immigrant group that threatens his status and manifests marked cultural differences. The racial attitudes of professional and business people vary according to the nature of the relationship and the type of immigrants with whom they come in contact. Teachers and social workers manifest far more racial friendliness than the general public. During three years of residence in southern California, the author came in contact with many teachers and social workers in Los Angeles and its environs, and found only one teacher hostile to the Japanese. This is remarkable when one realizes the great amount of anti-Asiatic propaganda that has been spread in that area and the resultant bitterness. Bogardus found that religion does not play the part in racial antipathy that is generally attributed to it. Protestants were more friendly toward Irish Catholics than Americans in general. Protestants and Catholics, however, were less friendly toward Turks and Japanese, as religious groups, than Americans in general. Apparently, religion plays a dominant part in racial antipathy when it is entangled with other cultural factors. ${ }^{1}$

3. Change and Adjustment of Race Attitudes. Doctor Bogardus ${ }^{2}$ lists "seven types of static attitude situations: (1) that due to an overwhelming fear and hatred of a dominant race; (2) that due to a consuming disgust for 'low' types of culture traits; (3) that due to a sense of dynamic loyalty to one's own race and to an overmastering superiority complex; (4) that due to an absence of knowledge; (5) that due to general knowledge about equally favorable and unfavorable; (6) that due to a brotherhood-of-man cosmopolitanism and idealism; and (7) that due to a rationalized philosophy of judging all races on a basis of personal worth rather than of racial heredity."

Racial attitudes do not always remain static, however; they may be augmented or reversed. Racial hatred may be augmented by a war, propaganda, migration to a new region or area, unpleasant personal experiences, and the like. On the other hand, racial antipathy may be changed into racial friendliness by broad training, knowledge

1 For a fuller discussion of this part of the subject and case material, see Bogardus, E. S.: Immigration and Race Attitudes, Chaps. XII-XVI.

${ }_{2}$ Immigration and Race Attitudes, pp. 148-49. 
of the background of a people, contact with the better class of an immigrant group, or in some other way. Augmentations are likely to be more rapid than reversals, since augmentations are more emotional and reversals more intellectual. The discussions and life history documents in the remaining chapters will reveal how some of these forces operate. ${ }^{1}$

\section{QUESTIONS, EXERCISES, AND PROBLEMS FOR INVESTIGATION}

1. How does Book I prepare one to understand Book II? With what is Book II to deal?

2. What two conditions combine to cause emigration and immigration?

3. What groups of people came in largest numbers in the period between the settlement of Jamestown and 1820? Why did they come? What were some of the difficulties they experienced in getting here?

4. Characterize the different periods of immigration.

5. Why is 1882 one of the most important dates in the history of American immigration?

6. Distinguish between the old and the new immigration. Why was this change thought to be significant?

7. Disregarding the effects of our laws, how do you account for our periods of heavy immigration and emigration?

8. Trace the flow of immigrants into this country. How does our net gain of immigrants compare with the number admitted? In this respect, how do we compare with Argentina, Brazil, and Australia? Which of our immigrant groups leads in emigration? How do you explain this?

9. How do you explain the distribution of immigrants in this country? What immigrant groups locate in urban areas; in rural areas?

10. Evaluate Luigi Villari's statement concerning Italian emigration.

11. Evaluate the probable biological, economic, political, and social effects of immigration.

12. Trace the early opposition to immigration. What were the chief restrictive laws up to 1917? Beginning with 1917, trace the restrictive laws. Evaluate the quota laws. Besides the text, see Garis, Roy L.: Immigration Restriction; Part III, "The Immigration Policy of the United States," Proceedings of the Academy of Political Science, Vol. X; Ward, R. DeC.: "Our New Immigration Policy," Foreign Affairs, Vol. III, pp. 99-110.

13. How do race attitudes originate? In what ways do they vary? Point out

1 For a fuller discussion of some of the phases of this section and case material, see Bogardus, E. S.: Immigration and Race Attitudes, Chaps. VIII-XI, XVII-XX. 
the chief changes and adjustments of race attitudes. Besides the text, see Bogardus, E. S.: Immigration and Race Attitudes, passim.

14. Abstract Part II of the Annals of the American Academy of Political and Social Science, Vol. CXLIII.

15. Read Maxson, C. H.: Citizenship, Chaps. III, VII, VIII, XIV, and make a report to class.

16. Discuss the part public lands have played in determining our immigration policies. References. Young, D., and Weaver, W. W.: "The Public Lands and Immigration," Annals of the American Academy of Political and Social Science, Vol. CXLII, pp. 151-57; Hibbard, B. H.: A History of the Public Land Policies.

17. Abstract Speek, Peter A.: "The Meaning of Nationality and Americanization," American Journal of Sociology, Vol. XXXII, pp. 237-49.

18. Develop the topic "American Immigration as a Fertile Field for Social Research," listing the most promising research projects. References. Hansen, M. L.: "The History of American Immigration as a Field for Research," American Historical Review, Vol. XXXII, pp. 500-18; Duncan, H. G.: "A Study in the Process of Assimilation," Publications of the American Sociological Society, Vol. XXIII, pp. 184-87; Thomas, W. I., and Znaniecki, F.: The Polish Peasant in Europe and America, Vols. I-V; Villari, Luigi: "The Problem of Emigration," Edinburgh Review, Vol. CCXLII, pp. 291-307. 


\section{PART VII}

FIRST GENERATION AMERICANS 



\section{CHAPTER - XXXI}

\section{FIRST GENERATION AMERICANS IN PROCESS}

\section{Causes of Immigration}

The causes of immigration are many and varied. For our purpose, however, they may be discussed under two main heads.

1. Dissatisfaction with Conditions in Native Land. A person who is satisfied with conditions in his home country has little or no reason for taking up his abode in a foreign land. On the other hand, such factors as primogeniture and other traditional methods of land holding, the uncertainty of economic prosperity, revolutions, pogroms, and massacres may result in intolerable conditions for certain groups or individuals. Dissatisfaction in modern times is frequently an individual matter, and often develops into grievances, some of which may be more imaginary than real. In no two countries are conditions the same, nor do all individuals react alike to the same conditions; yet all human beings become more or less dissatisfied with certain general conditions when these act unfavorably on them.

(a) Economic. An analysis of several hundred life histories and a study of the inflow of immigrants during periods of prosperity in the United States and periods of economic depression in foreign countries have convinced the author that economic conditions constitute the most important factor in immigration. The majority of our immigrants are in the prime of life, unmarried, and in good health. Desirous of bettering their condition, they have left poor sections where wages are low and gone to a country where economic possibilities are greater. For example, the interior of Asia Minor is the poorest region of Turkey, and it was from this area that most of our immigrants from Turkey came. Even in 1920 coal miners received from 45 to 75 cents per day of eleven hours. ${ }^{1}$ Mr. M. E. Ravage ${ }^{2}$ shows how the return of a native son who has apparently made a fortune in America gives the whole town the "American fever" and induces many to leave for America.

1 Compare Gordon, L. J.: "Immigration from Turkey," Sociology and Research, Vol. XV, pp. 153-66.

2 An American in the Making, pp. 8-9, 12-14, 27-28. 
The life histories which we shall examine record varying degrees of dissatisfaction with economic conditions in their native lands on the part of immigrants to the United States. "Friends of mine," writes a Mexican, "who had been in the United States came back with glowing stories of how easy it was to earn money there and that working conditions were so much better. This evidence of earning money fast interested me and I decided to go too and earn enough money to return and start a store."

(b) Political. Revolutions, diplomatic exchange of territory without regard for the wishes of the inhabitants, compulsory military service, wars - all these are factors which produce miserable conditions and drive thousands of desirable citizens from their native lands. A consideration of the conditions that drove to this country the Slavs from the former Austro-Hungarian Empire, the Poles from Russian Poland, the Armenians and Greeks from Turkey, and the Mexicans from their country during the frequent revolutions there gives us an insight into the importance of political factors in immigration.

Many strips of territory in Europe have frequently been shifted from one nation to another as a result of wars or diplomatic agreements. The territories and towns have been renamed, the official language has been changed, and the inhabitants have been expected to transfer their allegiance according to the whims of rulers and diplomats. A number of our immigrants do not know the country or town of their birth. "The place where I was born," writes a Rumanian, "was the cause of constant arguments between Austria and Rumania. Sometimes it belonged to Austria and sometimes to Rumania. I don't know who had the place when I was born." A Southern Slav says: "I do not know the name of the town in which I was born. Several countries had the territory in succession and they changed the name of the town so many times, I don't know what they call it now."

Undoubtedly, the subject people have been the ones to suffer most and the ones to wish to escape. Between 1900 and 1924 only 5 per cent of the people coming to us from Turkey were Turks, while 27 per cent were Greeks, 25 per cent Syrians, and 18 per cent Armenians. About one-tenth of the Ruthenians live in the former Austro-Hungarian Empire, but in 190575 per cent of our Ruthenian immigrants were from Austria, 28 per cent from Hungary, and less than 200 from Russia. In 1906 only 300 of the 11,000 Rumanians who came to us were from Rumania proper. About 80 per cent of 
the Bulgarians here in 1920 were from Macedonia. Between 1910 and 1913 over 80,000 immigrants per year came here from Austria; but only 7 per cent were Germans, while 36 per cent were Poles, 24 per cent Ruthenians, and 10 per cent Czechs.

Many of the people from disputed territories and conquered areas who have fled to America have worked diligently in this country for the overthrow of despised rulers and usurpers, and for the freedom and independence of their kindred in Europe and elsewhere. This has been the case particularly among the Poles, Czechs, Bohemians, Greeks, and Koreans. A Korean girl writes: "My father is a Methodist minister. I came to America to learn how to help get my country away from Japan. I want to learn all about laws, because I will have to know everything I can to beat Japan. Japanese so mean. Korea is forty-three centuries old. Her customs come down all that time. Korea is the best country. Koreans don't want to live anywhere else. They want to stay in Korea and drive out Japan. I learn all I can here, then I go home to help my country drive out Japan."

(c) Religious. In the lives of families coming to us from the Old Country, religion generally plays an important part. Indifferent Americans little realize the grip and pervasiveness of the newcomer's religion. It is part of his personality, something almost as dear as life itself. In countries where religious wars were frequent and persecutions and discriminations almost constant, religion functioned not only as religion but as a political party as well. Persecution by Protestant England converted the Irish into a Roman Catholic political party. Suppression by the Eastern Orthodox Russians and Lutheran Germans made the indifferent Poles staunch Roman Catholics. Greeks and Armenians remained loyal Christians because of the Mohammedan Turks. On the other hand, persecution from Eastern Orthodox Russians, Roman Catholic Austrians, and Lutheran Germans changed many Czechs into freethinkers and socialists. When one reads of the horrors of religious wars in Europe, of the Turkish, Armenian, Greek, and Slav massacres, and of the Russian-Polish pogroms inflicted upon the Jews, he cannot but admire the efforts of these suppressed peoples to escape to a country where religious prejudice is a less important factor in social, political, and economic relationships than it is in their native lands.

(d) Social. In the Old World, generally speaking, inherited privileges and class groupings, rather than individual worth, condition 
one's success in life. The fact that "self-made men" in America have become millionaires and attained high social standing tends to establish unfavorable comparisons between their home countries and America in the minds of prospective immigrants. To break former bonds and to begin life anew are the dreams of many young ambitious immigrants. "I belong to a second group," writes a Porto Rican, "one that needed only money to belong to the top. My relations are still landowners, but circumstances, failures, and the death of my father placed us in a precarious condition. In Porto Rico, as in other countries of the world, America spells opportunity, but a different kind of opportunity is what lures the Porto Ricans to this country. It is not religious and political freedom, nor is it the desire to become millionaires. The opportunity that we seek is a chance for selfimprovement in education and social status."

The fact that an immigrant may go to school here and work his way through a university without loss of social status was a revelation to Ravage as it has been to many an immigrant before and since. Recently a German immigrant said to the author: "I am here working and paying my way in the university. Why, in Germany none of the students would speak to me. Here, it makes no difference. In fact, I believe that one who is working and paying his way is more respected."

2. Reports concerning America. In diverse ways reports concerning America reach the people in foreign countries. Broadly, these may be classified under the headings: general information, letters, and reports of travelers.

(a) General Information. In the early history of our country special reports, designed to stimulate immigration, were prepared and distributed in foreign countries. Many of the school books of foreign countries contain information regarding the history, geography, and national heroes of America. "I heard," writes an Oriental girl, "of America the first time when I was in the 4th grade of the primary school from the teacher, and later studied it in the world geography. I learnt by heart the names of the capitals and large cities like Washington, and New York, and Chicago, etc. I also read the stories of the great Washington and Lincoln and Franklin in the text books of the primary school, and I admired them in my little hero worship mind; but about the country or its ideals, I did not hear much and it was quite vague to me."

(b) Letters. Letters have long been a means of making and main- 
taining social contacts. Across the Atlantic and the Pacific they have carried many a story of America, and have instigated many an emigration. They are brought by the illiterate to the synagogue to be read, perused again and again by relatives and friends of the addressee, and printed in the local papers. Containing specific information and an invitation to visit America, they are concrete and tangible. "We knew about America," relates a Scotch lady, "but did not think of coming here until a man from our town who had come to California for his health wrote back home. His letter was printed in the town paper and we read it." Another "became excited about his [her uncle's] good luck and pleased over the money he used to send back to us. My father then began to plan his American trip mainly because of the letters my uncle wrote him, and because he hoped to make more money and have a easier life. It seemed that all things were possible in America."

(c) Reports of Travelers. Living in ports or other places where former emigrants return for a visit, the residents have opportunities of hearing directly of this country. The return of one emigrant, as Ravage points out, is enough to give a whole town the "American fever." American travelers and missionaries also spread much information about America. "I became acquainted with a number of American missionaries," writes an immigrant, "and I heard many interesting stories about America. Then of course it was my greatest ambition to come."

It should be remembered that not all persons who acquire information concerning America are equally impressionable. The young, especially the child and the adolescent, are prone to weave myth and romance into the facts; the oppressed grasp at the opportunity for freedom; the prospective student reacts to educational possibilities; the satisfied oppose any suggestion of emigrating to America. Much of the information is exaggerated, glowing, and colorful. One immigrant said: "I had heard of America since I was a small boy five or six years of age. Then I thought of it as a supernatural country, a fairy land." Another expected to see the "streets in the cities lined with churches like the temple streets in Japan, and every person in America a Christian." Another reports that there was a popular belief widely current that "among the middle and lower classes every one has money, that money is easy to get, and all that one has to do is to come here and live happily ever after." Information that came to a schoolboy left him with the impression that America was a 
"Country of Utopia, Country of Freedom, Country of Christianity, Country of Equality."

It should also be remembered that not all the impressions of America found among foreigners are favorable. To a Russian immigrant America was a "Lodz magnified a hundred fold, and the chimneys were in my imagination perhaps fifty stories high, breathing oceans of smoke. The factories and mills were not crowded into one section of the city but covered all of God's earth - no dream of a glimpse of the sky in that country. I thought with deep compassion for all those machine men and women. If not for the war, I believe I would never have ventured into the United States."

"After my father's death," writes a Japanese girl, "my brother returned from America. This introduced a new and exciting element into our home. He wore a strange dress with tight sleeves and his black stockings suggested kitchen people. He talked rather loud and I was a little disappointed. I had a vague feeling of dislike for America strengthened by stories told by old servants about red-faced barbarians. It was said that animals were eaten whole by these strange people. It was told that the cheap red blankets imported at that time were dyed with the blood of stolen infants."

In their ignorance of America little villagers in lands known as heathen to us discourage those who aspire to come to America on the ground that it is a "savage country." This "capitalist's hell" is also regarded as a "big octopus that sucks blood out of you, and leaves you a bloodless, unthinking machine, an automat, a 'robot,' a 'la capec.'" Therefore, there are forces which both encourage and discourage those who would brave the unknown. Entering into many decisions, however, is the fact that "I would have gladly gone then to Africa or to the North Pole, just a desire to go and see things."

\section{First Impressions and Discoveries}

Regardless of how illiterate or how well educated one may be, seeing and experiencing a thing is entirely different from hearing or reading about it. So it is with the immigrant: his impressions of America are generally utterly different from his ideas of it before his arrival. He has perhaps seen pictures of beauty spots and heard of the Statue of Liberty and of Ellis Island. He probably views the Statue of Liberty with thanksgiving, but Ellis Island, the scene of 
many tragic experiences, awaits him. ${ }^{1}$ Although conditions at Ellis Island have improved remarkably during the last twenty-five years, still, according to a recent immigrant: "Immigrants arriving at Ellis Island are crowded in pens by day and at night sleep on iron shelves."

1. Culture Comparisons. The immigrant immediately begins to notice differences when he leaves Ellis Island or any other immigrant station. Fortunate indeed is an immigrant if some relative or friend meets him. "My brother," writes a Rumanian, "met me and took me to his house in the Rumanian quarter. That street car ride was a revelation to me, with all the noise and.bustle, and the tall buildings. Even a year in Paris did not prepare me for the sights I saw in New York. I was rather surprised by the actions of my countrymen as we walked through our district. At home we were used to mingling freely, and no one was a stranger. A locked door was unheard of. In New York not one countryman looked our way, or seemed to care anything about us."

A young German, who has been in this country less than a year, writes: "The first things I saw different in the United States was when I landed in Boston; high buildings, many more automobiles, and better streets. In this country the people drink rootbeer and in Germany we drink what we like. The young people in this country, I think, do not have so good manners. I saw fellows sitting in the movies with their feet on the seats in front, and they can meet some lady on the street and never lift their hats. On Sundays the towns are like death. Germany has four years of public school and eight years of high school, but here it is the reverse. The boys and girls never go to the same high school in Germany. Here many more people go to college. I wonder what all of them are going to do when they graduate. In Germany no working men go to work in cars, not even a Ford; but here many laborers have cars, and even students. In Germany there are about twenty political parties, but here only two. There you cannot write in the papers against the government or president, but here they seem to say what they please. There is not so much killing in Germany by gangsters and bootleggers, but they fight with the Communists."

If the immigrant comes from Asia, he is astounded at the difference in culture. "After I landed," writes a Japanese, "I was surprised

1 For a good description of the treatment which immigrants received at Ellis Island thirty years ago, see Brandenburg, B.: Imported Americans, Chap. XVIII. 
to see prosperous material civilization and the great buildings of commercial and religious works. At the same time I wondered to see an American gentleman tying a woman's shoe-string; a man take off his hat when he saluted a woman, while a woman never took off her hat when receiving polite salutation from a man; and a man put on his overcoat by himself, while a woman was helped by a man when she puts on her light overcoat." Another Japanese writes: ${ }^{1}$ "My experiences in San Francisco were strange and puzzling, but delightful in their novelty - the astonishing little room at the Plaza Hotel which we had no sooner entered than it began to rise upward, finally depositing us in rooms where we had a view as vast as from a mountain top; the smooth, white bathtub which could be filled with hot water without fuel or delay; the locked doors everywhere, for in Japan we never had a lock; and then the bigness of everything, streets, buildings, trees, people!" In much the same vein a Chinese writes: ${ }^{2}$ "Their men and women live together like animals without any marriage or faithfulness ... and even were shameless enough to walk arm in arm in daylight."

The attitude of the Oriental is further shown by the following extract: ${ }^{3}$ "I shall never forget my first experience in seeing kissing between man and woman. I was on the trip across the continent when I came from Japan. A seat near me was occupied by a young lady, very prettily dressed and gentle, almost timid, in manner. She was a young married woman, returning from her first visit to her parents. One morning I noticed that she was dressed with unusual care, and it was evident that she was nearing the end of her journey. When the train had barely come to a stand, in rushed a young man who threw his arms around that modest, sweet girl and kissed her several times. And she did not mind it but blushed and laughed, and they went off together. I cannot express my feelings - but I could not help recalling what my mother said to me just before I started for America: 'I have heard, my daughter, that it is the custom for foreign people to lick each other as dogs do." "

2. Disappointments. Many immigrants come to America with the expectation of receiving a hearty welcome, but unless they have relatives or friends to meet them, they are almost sure to be sadly disappointed. Not understanding English, they are likely to mistake "greenhorn," "Dago," "Wop," "Hunkey," and "Chink" for friendly

1 Asia, Vol. XXIV, p. 642.

2 Independent, Vol. LV, p. 419.

Asia, Vol. XXIV, p. 660. 
greetings. "I felt race consciousness," writes a Japanese, "when I was going down — Street in the third day of my American life. A group of young shipyard workers were coming up the opposite sidewalk and poured upon us, for I was with one of my friends, the words, 'Hey, yellow!' 'Jap, Jap.' I did not know what they meant until my friend explained it to me. I tried to forget it by thinking that they were ignorant, uneducated workers. But things similar to this happened many times since." Often they meet "friends" who cheat them out of their money or otherwise take advantage of them. No doubt a Korean lady had experienced some such treatment when she wrote: "I always thought that Americans were Christians. I don't understand. People here are not real Christians."

If the immigrant is met by relatives or friends, the shock resulting from cultural differences is lessened, but often his disappointment is increased. Perhaps he sees his relatives, friends, or countrymen in a new light; they are wearing American clothes, living in a crowded foreign quarter, in stuffy, dirty tenements, and engaging in occupations thought degrading in their own country. He experiences many differences and disappointments. He too must change his clothes to meet the mythical American standard, even if his new clothes do suggest persons of a lower social status. He too must seek work and perhaps engage in labor or an occupation which he considers degrading. Sooner or later he will come into contact with Americans and receive more disappointments. Dark mines, rapidly moving machines in factories, cursing bosses, exploiters, shyster lawyers, vote-buying politicians, bootleggers, quack doctors, panderers, and degraded American women await him. A Filipino, who had heard much about the freedom and opportunities in America, writes: "Last summer I had a hard time in getting a job. Some of the employment agencies down town would not give me any job because I am an Oriental. In a large restaurant in —-, the manager said to me when I applied for work, 'I am sorry, you are dark.' . . . One time I went to a barber shop. The barber was sitting and had nothing to do. He said he had no time to cut my hair. The next day I went to him again and he said he would not cut my hair. In another place, when I stepped into the barber shop, the barber asked me in a coarse tone, 'Are you Jap?' This kind of treatment is hard for me to comprehend."

Disappointed with conditions in America, the immigrant begins to contrast conditions here with those in his native land, magnifying his unpleasant experiences here and forgetting his hardships in his 
own country. Homesickness overtakes him; he longs for his native village. At this stage many immigrants would return home, but a number of factors prevent their doing so. First, many do not have the money to return. A number state that they would have attempted to walk back, had there not been an ocean to cross. Second, many have left to make their fortune or accomplish some other purpose in America, and they cannot return because that would be admitting their failure.

Professor Panunzio writes: ${ }^{1}$ "The reader will understand that on the day I left Louis and the camp my feelings were far from joyous. Here I was, all alone, the only real companion I had in America forever gone. I was far away from Boston and farther than ever from my dream of returning home. By evening I reached the depot at Stacyville, and sitting down upon the station platform I put my face in my hands and began to meditate upon all that had transpired from the time I left home years before to the present. Whenever I think of that scene, there comes to my mind the picture of the Prodigal Son. But in that parable there was no ocean, no foreign country, and it was comparatively easy for the son to return to his father. If some of these difficulties had been considered in the story, I am sure it would hold a very deep significance for foreign boys in this country. I have no doubt that many of them at times are filled with deep yearnings to return to their father's houses, but the distance is too great, the ocean is too big, and they cannot go."

3. Disorganization. The many disappointments and heartaches of the immigrant naturally fill him with bitterness and lead to an indifference. Mental and social conflicts continue. He is away from his native village with all its traditions, customs, and other social restraints, and he does not understand the new culture. Partially breaking away from the old social background, but not yet really participating in the new; witnessing the fading away of old traditions, but not yet appreciating new ones; and drifting away from old associates, but coming in contact only with marginal men composing shifting groups, the immigrant becomes more and more disorganized. The type of person he has met has perhaps led him to feel that in America no one cares for any one else, and all that any one wants is money. He may fall into crime, or he may withdraw as far as possible from Americans and live unto himself.

Speaking of the experiences his parents met in America, Lewisohn

1 The Soul of an Immigrant, p. 103. 
says: ${ }^{1}$ "'They were left in a state of solitariness which would have broken stronger and better-balanced natures. The strain of wild eccentricity in my father's character sharpened, my mother's brooding melancholy deepened from year to year. When after nearly fifteen years in Queenshaven a breach was made in that inhuman wall, my father was hopelessly 'queer' as a social being; my mother whose sweet and gracious presence atoned with people for his rasping ways - has become morbid and morbidly suspicious of this belated kindness."

- Ravage, writing of his experiences at the University of Missouri, says: ${ }^{2}$ "I tried very hard to make myself agreeable to my fellowstudents. But I failed miserably. In the first two months I had, and lost, a half-dozen room-mates. . . . I spent many sleepless nights trying to figure out the thing. It wounded my self-esteem to find my society so offensive to everybody. . . . All the same I did not leave them alone. I did the very opposite. How, in the first place, was I to avoid them? I was a lonely, deserted rock surrounded and buffeted by a vast ocean. Wherever I turned I must face them. If I wanted a job, I must work for and with them. The class-rooms, the library, the boarding-houses, the very streets swarmed and echoed with them. I had no choice but to walk with them, talk with them, and trade with them. Nay, my case was far worse than poor Shylock's: I must even eat with them and - at brief intervals - sleep with them."

\section{Aсcommodation}

Since disorganization is an unsatisfactory condition, the otherwise normal immigrant seeks to escape it by personal adjustment. He is in America and must remain for a while at least. Many things he does not like, but he is unable to change them. Consciously or unconsciously, he becomes indifferent to them. But his indifference is productive of change. He begins to distinguish between the lower and the higher types of Americans, to see America in a different light, to discover that all Americans are not bad, and that some are interested in him and are willing to treat him kindly. Thinking over the whole situation, he begins to understand himself better in relation to American life and to reorganize himself on a different basis. Perhaps he continues to hold to some old-country customs and ideas, remains indifferent to some of those in America, accommodates him-
1 Up Stream, p. 59.
2 An American in the Making, pp. 206-208. 
self to others, and takes over other behavior patterns. An East Indian reveals this process of accommodation when he says: "At first I was really shocked by the freedom of the women. I have now grown accustomed to the practice of men and women going along the street together. If I were to return to India, I believe I would carry out this practice over there. I have several American neighbors now with whom I am on good terms." A Mexican writes: "When I first came I thought I was fooled about its being a better country to live in than Mexico. I do believe it a fine country to live in. I like it all right here now." In regard to her experiences, Etsu Inagaki Sugimoto ${ }^{1}$ says: "I saw many other things that mystified and shocked me. The thin waists made of lawn and dainty lace were to me most indelicate. . . Indeed, after years of residence in this country, which is now my well-loved home, I have so changed that I can look back with surprised amusement at my first impressions! . . . Now I can watch the ladies in evening dress with pleasure."

\section{Naturalization}

Naturalization is a formal, legal procedure, giving the alien the right to participate politically in the affairs of his adopted country and to receive its protection. It does not mean that the immigrant is assimilated, as many people seem to think, but it does mean that, for some reason or reasons, he is willing to transfer his chief political loyalty. Even this is a very difficult matter for many immigrants; some can never bring themselves to the point where they are able to go through this process.

Even when immigrants reach the stage where they are willing to shift their political loyalties, they may find that our laws prohibit or hinder them from doing so. Asiatics from the barred zone are ineligible for citizenship; yet other peoples from Asia, Europe, and Africa who are fundamentally as Asiatic and Oriental as many people in the barred zone are eligible for citizenship. The immigration law of July 1 , 1929 , raised the naturalization fees from $\$ 5$ to $\$ 20$, a considerable sum for many immigrants. The difficulty of securing witnesses and the necessity of answering many questions discourage others. Panunzio ${ }^{2}$ gives us an insight into some of the psychic and legal obstacles to naturalization. The following extract ${ }^{3}$ reveals the disorganized

1 Asia, Vol. XXIV, p. 642. $\quad 2$ The Soul of an Immigrant, Chap. XII.

3 Razovsky, Cecilia: "Americanizing Husbands: Shall We Naturalize Only Wife Deserters?" Survey, Vol. LIV, pp. 515-16. 
state of another immigrant resulting from the naturalization laws. "I appeal to you to tell me what to do. In 1921 I took out first papers and now I started to go to school, but the teacher rejected me, saying that since my wife and children are in the old country I cannot get papers for the feet are in Europe and the head in America, so I cannot become a citizen. He said that I must first bring my wife and children to America. So I left the school and I returned the steamship tickets which I sent my wife two years ago, for there is nothing else to be done. It is very hard, sins will keep one out of heaven and here a husband is torn apart from his wife and children. What is there to be said about this? Nothing remains but to hang a stone about one's neck and jump in the river, for this is not life but torture. I want to get citizenship papers and am told that I must bring my wife to America. How can I bring her over when the steamship company notified her that since her husband is not a citizen she cannot go to America. I have tried every means but nothing helps. So I feel like a fool. All I did do was to return the prepaid steamship tickets. I am in America 13 years. The papers say that you cannot bring your family here unless you are a citizen. I want to become one but am not allowed to do so. I am not the only one - there are many others who are in the same predicament and all of them have returned their prepaid steamship tickets, for it is impossible to get naturalization papers when the family is not here. My wife and two sons, one 17 and one 14, would be a help to America. Please explain the situation to me as I am losing my head. It seems impossible to refuse me citizenship because my wife is not here and to refuse to let my wife come here, because I am not a citizen. It is unreasonable and I cannot understand it. Please explain the matter to me and advise me what to do."

\section{Assimilation}

According to P. K. Hitti, ${ }^{1}$ Americanization " is invisible and subtle, if it is to be real and enduring. . . . Donning American clothes and eating American food does not constitute Americanization." It "means divesting one's self of a certain deep rooted patrimony of ideas, sentiments, traditions and interests, and an acceptance of, and participation in, a certain new spiritual inheritance. Such a thing cannot be accomplished completely in one generation. Even the second generation among immigrants cannot be fully assimilated." 2

$$
1 \text { The Syrians in America, p. } 99 . \quad 2 \text { Ibid. }
$$


Assimilation is fundamentally a culture process, which implies the acceptance of the ideas, attitudes, customs, and traditions of the new group. It is rarely, if ever a completed process, as people assimilate only on points. On different points the person isolates, accommodates, and assimilates himself. On what points the immigrant will isolate, accommodate, and assimilate himself depends on many factors, but mainly on his own nature, his cultural background, and conditions which he experiences in America. Some people are unable to surrender their deep-seated loyalties and accept the attitudes of America. Others become assimilated into their American group, but, realizing that they are to return to their native country, develop also their associations with their own people. A Korean writes: "The friendships I have cultivated among the students on this campus for the last two years have been very precious and some of them are my real personal friends whom I talk to as though they were my race. On the other hand, I feel just the opposite when I come in contact with my own Korean student friends. I cannot seem to find anything in common with them and I cannot feel free with them as I am with the American students. Until last year, I did not speak my language for ten years and consequently I forgot nearly everything I knew. I did not even have any desire to see my own people. But last year the people of the Korean Mission did not have any organist and they asked me to come and play for them. I considered it very seriously at that time whether I cared to mingle with them. Finally I thought to myself this would be a stepping stone to my life's work since I am planning to go back to Korea to work among my people after I finish my education. Thus, I am attending the Mission every Sunday afternoon and my language is gradually returning to me so that I can understand most all of it, but I cannot speak it very much."

Orientals coming to this country at an early age are placed in a situation that presents many problems for them and for their parents. They apparently become Americanized, then disorganized, and then partially at least, un-Americanized. A Japanese writes: "I spent two years in Oakland High School where I heard enough of Americanization and assimilation. I often overheard the people say that Orientals are absolutely impossible to be assimilated or Americanized, hence they are undesirable immigrants. I was inexpressibly discouraged to hear that sort of criticism and naturally my eagerness was to be assimilated and Americanized just as much as the second generation of Japanese in America. Consequently, I was particularly con- 
scientious about every single movement of American boys and girls. 'What was the result?' you may ask. I was rather disappointed because of the fact that Americanization no doubt involves getting acquainted with the best American traditions and current standards and striving for the improvement of those qualities of traditions and standards. To me, foreign born, Americanization means to give up my sincere loyalties to my country for another set of loyalties. To abandon the idea of loyalties to my country for another involves delicate mental and social readjustments."

The following extract reveals how a young Japanese, who came here as a student, views some of the difficulties of Japanese assimilation: "Social attitudes toward different races prevent their Americanization. For instance, high school students are often chagrined because their parents cannot speak English well. They do not like to say that they are descendants of Japanese. They say, 'What can Japan do for the world, a little poor country? I would willingly fight against Japan if an American Japanese War were to break out. Japan is an uncivilized country. Japan is a militaristic country.' They [second generation] are very proud of being American citizens. This, their notion of Japan, I think, comes from bias education in the public schools where Japan and Japanese are interpreted ill. But when they want to get an occupation after they graduate from high school, they want to get acquainted with Japanese, because they cannot find any job among Americans, and are obliged to get it among Japanese business society. Here they begin to think of the difference between Japanese and Americans. As to the college boys, I could say that in the first two years they hate Japan and Japanese, but in the last two years they begin to think of their future, and regret that they have not learned Japanese language. And they begin to recognize that the field where they find their living is nowhere but in the limit of the Japanese group. In a word, when they were innocent, they were well Americanized, but according to their growth they are prevented from being Americanized by the social conditions."

Americanization is often such a subtle process that many immigrants do not realize how completely they have become assimilated until they face certain problems which sometimes cause disorganization, such as a return to their former situation. Ravage did not realize how much of a Missourian he was until he returned to East Side New York. After spending some time in Italy, Panunzio "felt like 
kissing the ground" when he returned to America. "Three years ago," writes a Japanese, "I went back to Japan for six months. I saw the high spots, but everything looked queer to me. On the other hand I looked queer to them. Folks told me I looked different, walked different, and dressed different. My grandparents told me I spoke Japanese like a Korean - a very doubtful compliment." Even Jacob A. Riis ${ }^{1}$ had to return to Denmark to discover that he was an American. "It was," he says, "when I went back to see my mother once more and, wondering about the country of my childhood's memories, had come to the City of Elsinore. There I fell ill of a fever and lay many weeks in the house of a friend upon the shore of the beautiful Oeresund. One day when the fever had left me they rolled my bed into a room overlooking the sea. The sunlight danced upon the waves, and the distant mountains of Sweden were blue against the horizon. Ships passed under full sail up and down the great waterway of the nations. But the sunshine and the peaceful day bore no message to me. I lay moodily picking at the coverlet, sick and discouraged and sore - I hardly knew why myself. Until all at once there sailed past, close inshore, a ship flying at the top the flag of freedom, blown out on the breeze till every star in it shone bright and clear. That moment I knew. Gone were illness, discouragement, and gloom! Forgotten weakness and suffering, the cautions of doctor and nurse. I sat up in bed and shouted, laughed and cried by turns, waving my handkerchief to the flag out there. They thought I had lost my head, but I told them no, thank God! I had found it, and my heart too, at last. I knew then that it was my flag; that my children's home was mine, indeed; that I also had become an American in truth. And I thanked God, and, like unto the man sick of the palsy, arose from my bed and went home, healed."

\section{QUESTIONS, EXERCISES, AND PROBLEMS FOR INVESTIGATION}

1. What are the main causes of immigration?

2. Why should we consider the individual's reason for his emigration?

3. Discuss economic conditions in the home country as a cause for emigration. Supplement this part of the text by concrete examples from Book I.

4. What is the significance of the fact that our immigrants have been young men, unmarried, and in good health?

1 The Making of An American, pp. 442-43. 
5. How have political conditions in the home country affected immigration to the United States? From Book I select illustrations.

6. What are some of the things that happen when territorial exchanges take place?

7. Cite specific instances of peoples whose language or religion has been modified or changed by political transfers.

8. What does the emigration of subject peoples seem to prove?

9. Give examples to justify the statement that many people from disputed territories and conquered areas have worked diligently for the freedom and independence of their kindred in other countries.

10. Why do most Europeans apparently take their religion more seriously than most Americans do theirs? Mention several groups that came to America to escape religious persecution.

11. Give several concrete instances showing that inherited privileges, rather than individual worth, condition success in part of the Old World.

12. Enumerate the ways through which reports concerning America reach the prospective emigrant.

13. Illustrate by example how grossly exaggerated some of these reports have been. Contrast the favorableness and unfavorableness of these reports.

14. Elaborate: "It should be remembered that not all persons who acquire information concerning America are equally impressionable."

15. Give illustrations showing how the immigrant reacts to his first impressions on reaching the United States. Account for the differences in first impressions.

16. What are some of our culture elements which puzzle and mystify Orientals?

17. In what ways are immigrants disappointed in America? Why do they not return home?

18. Analyze the period of disorganization through which many immigrants pass. Besides the text, see Krueger, E. T., and Reckless, W. C.: Social Psychology, Chap. XIII, Park, R. E., and Miller, H. A.: Old World Traits Transplanted, Chap. IV.

19. What happens while the immigrant is accommodating himself to American life? In addition to the text, see Duncan, H. G.: Backgrounds for Sociology, Chap. XXX; Dawson, C. A., and Gettys, W. E.: An Introduction to Sociology, Chap. XI.

20. Define naturalization. What is the attitude of most immigrants toward naturalization?

21. Make a detailed study of the naturalization acts of various immigrant countries regarding the naturalization of Orientals.

22. Give illustrations showing some of the legal difficulties immigrants experience in trying to become naturalized.

23. How does assimilation differ from naturalization? See Duncan, H. G.: 
Backgrounds for Sociology, Chap. XXX; Dawson, C. A., and Gettys, W. E.: An Introduction to Sociology, Chap. XII, XIII; Park, R. E., and Burgess, E. W.: Introduction to the Science of Sociology, Chap. XI.

24. Why do some immigrants assimilate more quickly than others? Show why some assimilate and later become unassimilated. In what respects does the Oriental find assimilation difficult?

25. "Americanization is often such a subtle process that many immigrants do not realize how completely they have become assimilated until they face certain problems which sometimes cause disorganization." Explain by giving concrete examples.

26. Report on "Religion's Entangled Alliances" and "Anti-Semitism" in Miller, H. A.: Races, Nations and Classes, Chaps. V, IX.

27. Report on immigrant types. See Park, R. E., and Miller, H. A.: Old World Traits Transplanted, Chap. V.

28. Report on Lee Chew, "The Biography of a Chinaman," Independent, Vol. LV, pp. 417-23.

29. Report on one of the following books: Panunzio, C. M.: The Soul of an Immigrant; Ravage, M. E.: An American in the Making; Sugimoto, E. I.: A Daughter of the Samurai; Antin, Mary: The Promised Land; Riis, J. A.: The Making of an American; Steiner, E. A.: Against the Current; Rihbany, A. M.: A Far Journey; Cahan, A.: The Rise of David Levinsky; Cohen, Rose: Out of the Shadow; Hasanovitz, E.: One of Them; Mirza, Y. B.: Myself When Young. 


\section{CHAPTER XXXII}

\section{LIFE HISTORIES OF TEUTONIC FIRST GENERATION AMERICANS}

I. "Why Am I an American?" 1

Answers from a Few of the Thirteen Million Foreign-Born Citizens of the United States

Nine of us were crowding close and leaning over the edge of a scrubbed and scarred writing table in the clean office of a little hotel in South Dakota. For two weeks the war in Europe had been raging; and the Big Fellow who traveled out of Minneapolis for a farm machinery house had just spread before us the first war map any of us had seen.

Rudolph was the first to trace out upon the map the lines of contact of the armies - he had read the war news with eager interest, and he remembered something of the look of Germany as he left it twenty years ago. Earlier in the evening, white-haired, tolerant Mrs. Haggerty, who keeps the cosmopolitan little hotel, had warned us not to talk war when Rudolph showed up; but we couldn't keep the Big Fellow's map under cover even to save the feelings of spectacled, thin, and excitable Rudolph.

So we explored Europe with hesitating fingers, looked up statistics of population printed on the other side of the map, compared the war strength of France, Germany, Austria, England, and Russia as the papers had reported it - and talked! Rudolph, of course, became a sputtering fountain of speech.

Before the war map. had come upon the table, another drummer from Minneapolis had started a game of Norwegian whist - one of those games that by reason of frequent penalties may last all evening. He was a Scandinavian, clearly - a rugged, simple-spoken man. Rudolph had been his partner; opposed to them were an IrishFrench drummer and a Swede who was interested in a string of grain elevators along the branch railroad at the end of which lies the little town where Mrs. Haggerty runs the Commercial Hotel.

1 By John M. Oskison in World's Work, Vol. XXIX, pp. 209-13. 
We explored the map eagerly - for a few minutes. Then, to our surprise I think, we sat back, baffled to find anything more of interest. All except the Scandinavian; he was trying to locate on the map Tromsö - not that he had any idea Tromsö was in the theatre of war, but because he still had relatives living there. That was his own word, "still." Later he explained.

Presently, we were talking wheat - that morning, Chicago was paying $\$ 1.24$, and the farmers who hauled to the local elevators were getting $\$ 1.03$. Then somebody asked for the right time, and the Big Fellow drew out a thin gold watch he had recently bought from a Jewish dealer in Minneapolis. The Jew was his good friend, and had made a special price and given a special guarantee; only two days before it had been regulated. Oh, yes, the Big Fellow and the Jew belonged to some commercial organization in Minneapolis, half fraternal in character, which held picnic outings once a year - the Big Fellow told us about a fat man's foot race he had won last spring.

We weren't vitally interested in the war. Rummel, the Norwegian, sensed this fact and blurted out a question:

"How many of us were born in this country?" Three of us raised our hands; neither Mrs. Haggerty nor the Big Fellow were among the three.

"Six out of nine born in other countries - but we're all Americans, no?" As he took off his spectacles and folded them into their case, the Scandinavian drummer looked around at us. Five foreign-born Americans assured him that he had guessed right.

"I wonder why all of us are here in America, so interested in the price of wheat that we don't really care about that war over the water - unless it's Rudolph, eh?" The man from Tromsö looked round on us with something of the manner of a college professor in a small lecture room.

"No, no! I am a Cherman once, but no longer; yet still can I talk about de war and de unfairness of de Roosians coming to fight mit France against Chermany. To me it makes no deeference, really, for I am so long an American I am not touched in here!" And Rudolph tapped his chest with a nervous forefinger. It never came out just what business Rudolph was in, but he lived at the hotel as a permanent guest.

"Well, Karsten," said the Big Fellow, turning to the Scandinavian, "I know why I am an American citizen and not a Bohemian."

"You a Bohemian!" It was surprising; the Big Fellow's name on 
the register was as American as Jones; and he himself might have posed for a picture of the typical American drummer.

"Yes, born in Prague," affirmed the Big Fellow. "I was only five when my father brought me over to Chicago. My father got sick of fighting and heavy taxes and religious rows. We Bohemians over there never liked Austria - and we were only one of the many little peoples that have hated the Empire. My father has told me about the old religious wars our people fought. He got sick of it all, and he brought his family to Chicago; I remember we came to a house in Chicago where a friend of my father's lived, and there was a carpet on the floor and they had an organ over in the corner of the parlor. The old people talked and talked - this was indeed America and what would my father do?

"Well, my father worked in a brewery. I got in with a bunch of Bohemian kids that sold newspapers; we soon forgot where we lived even, so busy were we finding out how to be Americans. We lived in the streets, and the old people shook their heads - so different from Prague! But what could they do? Nothing! We were afraid only of the cops; we did go to school when we had to, but we got our education in the streets.

\section{WHAT AN AMERICAN CAN DO}

"A friend of mine got a job at Rockford, in the factory where they made reapers and plows and such things. I went over from Chicago, too, and we lived in a boarding house with a lot of other hands in the factory.

"I got interested in making machinery, and they let me work in nearly every department - sure, glad to have me find out all I could; maybe I'd turn out to be a salesman. Say, that was when I first woke up to what an American could do. He could do anything he felt like doing, go as far as he wanted to in finding out things. I had a turn for machinery, and I bit in.

"Well, I've handled machinery ever since - been doing all right!" Before we went to bed we heard a great deal more about the Big Fellow, his family in Minneapolis, his friends, and the increase of property values in the street where his Minneapolis home is already shaded in summer by ten-year-old maple trees.

Of course our group didn't immediately dissolve into an experience meeting; what is told here, about the Big Fellow and the others, came out during the talk of that evening and a second evening during which 
we held together. Rudolph, the German, and Rummel, the Scandinavian, were in manner and vocabulary strikingly contrasted: one was excitable and fragmentary, the other precise and almost scholarly. Over in the "old country," Rudolph would probably have been a workman, a member of the Social-Democratic Party, and a delirious patriot in this time of national struggle. It seemed plain that Rummel had come from an educated family, the scholar elass. Yet here there was no recognition of the difference. Rudolph interrupted whomever and whenever he pleased; and Rummel smiled with the rest of us at the German-born's dogmatic statements.

When Rudolph had delivered himself of his intense anti-"Roosian" feelings, he began to give us a picture of the Germany he left twenty years ago.

He told us that he was a native of a little town (the name doesn't matter) near Potsdam. His father had fought in 1870, had been wounded, was a gunsmith, and kept a repair shop. One of his brothers, on reaching the age of twenty, had gone off to serve in the army. There had grown up a spirit of militarism; in his little town the army officers strutted along the sidewalks as if they were the Kaiser - even the women had to step aside into the street to let them pass.

At the age of nineteen, Rudolph took ship at Hamburg and sailed for New York. For a time, he worked in the big city, putting in order the weapons with which a certain pawnbroker kept his window stocked. For a long time it did not occur to Rudolph that he could follow any other trade than that which he had learned from his father. Then he came into a group of young Germans in New York who were writers and proof-readers on one of the German papers. They said the manager of the paper wanted another proof-reader; they tested Rudolph, and found that his schooling had been good enough; they coached him in the technique of the business and sent him to apply for the job.

"Sure, I right away got a chob!" said Rudolph, smiling foxily at the memory. He will never get over the feeling that he "put it over" on the newspaper that time, though he did, as a matter of fact, meet with entire satisfaction the demands of his new position. He couldn't have made any such leap forward in Germany. Not the true Spirit of '48, which sent Schurz and his fellow intellectuals to this eountry, had moved Rudolph; and yet some feebler, less clear flame of protest against military dominance and the rigid limitations imposed by overpopulation and caste traditions burned within him. 


\section{THE THREAT OF POVERTY IN NORWAY}

Where Rummel came from in Norway the shadow of the soldier was not over the young man's life, but the threat of poverty was. And to a Scandinavian poverty is terrible. People were crowding, crowding; on the farms the new labor-saving machinery was coming to supplant the hand worker; many of Rummel's friends were leaving the farms, some resorting to the cities to find employment on the docks, in the warehouses, or in the factories, but more of them crossing to America.

"Our country was getting too full," Rummel explained. "Not yet had we begun to build our factories for which we make great electric power from our waterfalls. Not so many of our people are coming over to America now." He came in 1885, at the full tide of Scandinavian immigration.

Rummel's daughter is a student at the University of Minnesota; he told us that he had made a trip East last summer, with his wife and daughter. They had stopped for three weeks at a hotel at Gloucester, Mass., to find out what the seaside, as his friends had talked about it, really was like. We understood that they had been rather uneasy; Rummel was positive that it was sinful to waste money as many of the summer visitors to the coast hotels of New England do. Rummel is evidently scattering his investments in the territory over which he travels, for I heard him in serious conversation with Mrs. Haggerty concerning a lot just a few doors down the street from the Commercial Hotel. He sees growth of opportunity in the America he knows; and his one definite interest in the old country is to bring from Tromsö the remaining members of his family.

"They stay over there still," said Rummel, "but I think I will bring them to America as soon as this war is over." He went off to bed at ten o'clock - and we had an impression that he was always in bed by a quarter past ten; then he would get up early, and go round to call on Stavig and his other Scandinavian storekeeper friends before the tide of the day's business began to flow over their counters and distract them from Rummel's careful display of his samples.

\section{FROM IRELAND TO SOUTH DAKOTA}

Later in the evening, Mrs. Haggerty traced back for us the record of her life in America. Twenty-one years she had been in this little Dakota town; before that she had kept a hotel at Cripple Creek, Colo. 
She became a hotelkeeper directly after the close of the Civil War, for her husband was killed in the War with two of her brothers. They were all Irish, and had come to America in 1855 (she was 12 years old then), when there was so much trouble in Ireland "you know, the famine and rebellion an' all!" She married Haggerty in New York, when she was 18, and they moved to Maine. Haggerty soon afterward enlisted to fight for the North. After the War, Mrs. Haggerty went West with her one surviving brother who had been too young to go to war.

"I guess we'll never have another war like that," said Mrs. Haggerty. It cost her much in the blood of her own kin, but she counts the price none too high to pay for a united America. Living with Mrs. Haggerty is a niece, a pretty and plump young woman who has seen something of the world as a "cowgirl" in a Wild West show. Both women bear themselves as important cogs in the machinery of life of the little town; and they are just that. In Ireland -

"Dear me!" said Mrs. Haggerty frankly, "I was nothing but a poor little shape of a thing with one dress to my back and hungry most of the time. Before I married Haggerty I worked in a family in New York that was very good to me; they used to say:

"'Nora,' they'd say, 'you must get married to a nice man and maybe go out West and take up a farm of your own.' Sure, I didn't believe what they said about the West then; but here I am, a healthy old woman of more than seventy, and I guess I could pay my debts." She owns the lot down the street that the shrewd Rummel wants to buy, besides the Commercial Hotel. She is saturated with the climbing, forward-reaching spirit of the town and of the prosperous wheatgrowers who make it a trading place of surprising importance.

Before we went to bed, the Swede told us that he had come to the Northwest believing it was to become the "new Sweden" that Gustavus Adolphus once dreamed about and tried to establish on the Delaware River. It wasn't just money and material success that drew him, though American dollars are more easily gained than Swedish rigsdalers.

\section{A GREEK WHO MADE GOOD IN OKLAHOMA}

Just before I went to college, there came into the little town in the Indian Territory where I was staying a Greek. He rented a narrow room on the main street and opened a candy and fruit store. There he sat waiting for customers and reading a Greek newspaper; 
he could hardly talk to those who came to buy, for his English was fragmentary and twisted. We regarded him as a curiosity.

Five years later, I struck that town after spending a year in New York; and one of the first men I met was Gianopolus. He had grown fat and self-confident; his stock of English was ample to carry on a lively conversation. He gave me the gossip of the town, told me what my old friends were doing, and insisted that I should go in and drink an ice cream soda at his new fountain. He told me that he was buying the frame building in which his business (now expanded to include a restaurant) was housed. My brother Richard came in from the ranch to meet me, and when he met the Greek he stopped to shake hands and ask:

"Well, Gin, how goes it?" Gianopolus laughed and slapped my brother on the back as he replied:

"Well, Deeck, fine as seelk!" Then, after a few more words, "I say, you don' want to lease me that hay land yet?"

This fall I saw Gianopolus again - in the back parlor of one of the banks of that Oklahoman town talking oil leases. He had given up his fruit store and restaurant, had passed through a period of speculating in Indian land, and had joined the army of cool gamblers who dealt in oil leases. Long before he had become an American citizen; and when I spoke about New York and his fellow Greeks there (a subject that had interested him intensely the first time I talked New York with him) he was not responsive. Gianopolus had married an Oklahoman girl; he would soon be rich enough to buy an automobile - unless this war knocked the bottom out of the oil can!

Somebody has said that the American dollar is the honey-pot that draws the "swarms of European flies" over the water to us. I asked Gianopolus if that was what brought him over from Greece.

"Well, what you think!" he challenged. "You bet I make more money here in one year than I make over there in all my life!" And his children will spend it. They will sit in the schools with the children of parents from Kansas, from Ohio, from Missouri, and with the dark-skinned mixed-blood children whose mothers and fathers let in the whites upon the Indian reservations and welcomed them into their families. 


\section{AN OPPORTUNITY TO DEVELOP ONE'S IDEAS}

Away from New York, and away from those industrial camps where the foreigners are apt to go first and live in colonies, you can get your truest answers to the question, Why am I an American?

"Why am I an American?" Visser, from a little town in Holland called Purmerend, repeated the question I was asking of a good many foreign-born Americans. He had dropped in to recall to me the tour of Holland we had made seven years ago - the time he returned to visit his family after working three years in Louisville in a big plant for the manufacture of machinery.

"Things are not in a groove in America," said Visser. "If you have got an idea good in your work, then you can always find here some one who will help you to work it out, and then you make a business for yourself. In Holland, they want to know have you gone through the technical schools and who are your family before anybody will take up your idea.

"Let me see, I been in America now ten years; now I am twentynine years old; I speak good English; and I have a little shop of my own out there in Louisville. My good idea is in that shop, and I am making money. But also I am having a good time out there. You remember I told you about the time I went to work in that shop right away when I come from Holland. I didn't know any English. But my brother-in-law was working there, and he told me when the boss came around and spoke to me, I was to say 'I'm pleased to meet you!' So that morning all the time as I worked I kept saying that over in English, 'I'm pleased to meet you!'

"One of the fellows working close by me heard me saying this over to myself. He was a Hollander, and he asked me why I kept repeating it; and I explained what my brother-in-law said.

"'Oh, you got that wrong!' he said. 'What you must say to the boss is this: 'I don't want to meet you!'

“'Oh, thank you,' I said. Then I began to say to myself so I would not forget, 'I don't want to meet you!'

"Well, the boss came around after awhile, and stopped to speak to me. I bowed to him and said loud, 'I don't want to meet you!' Then all the fellows laughed, and the boss laughed too. I didn't know why, and I was so ashamed!

"Well, in my own shop I have had that same trick played on another green Hollander - ain't that funny !" 
"It's American," I suggested.

"Yes; ain't it so!" Visser cried; and his smile was a delight to watch.

In New York, more than anywhere else in America, the dollar is the honey-pot that draws the flies from Europe.

"I came from Germany to better myself," said an uptown grocer whose two brothers and four cousins are fighting for the Kaiser. He was one of a big family that lived on a farm. "There was no chance for me over there, so I came away before I was taken for the two years in the army; I have been in New York ever since." $\mathrm{He}$ is an American, but his sympathies are with Germany, and he was anxious that I should understand Germany's side of the war.

\section{WHAT A GERMAN WAITER SAID}

Said a German-born waiter who plods quietly back and forth between the bar, the kitchen, and the round tables of one of New York's old restaurants:

"No, I had no chance over in Germany; over there you must do just what the old people tell you. I didn't want to follow the trade of my father. He was a carpenter, and I didn't want to be for a long time an apprentice and then work at that trade I didn't like. So I came away, before I had to go to serve in the army.

"Here I do very well. My daughter she is the oldest of my children, and she has finished with the high school and gone to work. Well, did she have to do what the old folks say? No; the first job she got was for three dollars a week. There she stayed only eight months, then she heard of another job with a woman that makes hats on Fifth Avenue. There she gets six dollars a week; and some day she will make hats in a shop of her own!"

There was no tinge of cynicism in that middle-aged waiter's last remark as he retreated to the kitchen:

"America is better, even if here I am only a flunkey!"

Benedetto, who is in charge of a combined shoe shining, repairing, hat cleaning, and clothes making and repairing store on upper Broadway, has just become an American citizen, though his brother-in-law and two of his brother-in-law's brothers have been in New York for periods ranging from sixteen to eleven years. They own the store which Benedetto runs, and two others farther downtown.

"Oh, I like 'm all right," said Benedetto, referring to America as he has seen it in New York. "It's gooda place for me and my child'rn. My boy he'sa fourteen years old now." 
"Does he help you in the shop?"

"No! He go to school; oh, he carry things for me after school, and in summer time when he don't go to school he help shine de shoes."

"Will he stay in the shop when he gets through school?"

"No! He go to work then for Nicolo Marini." No need to ask, in New York, about Marini (though that is not the real name). He is one of the big real estate speculators and builders, a man who began his American experiences in the crowded Italian quarter and who now lives in a huge Americanized stone palace. Probably the Benedetto clan in New York have money invested in the enterprises of Nicolo Marini.

"Will Italy go to war, too?" Benedetto shrugs his shoulders.

"Too much taxes already!" He couldn't enlarge upon that point, but if you are curious you may hunt down the statistics. One authority says that nearly half of what the Italian produces is taken for taxes; and another says that 84 per cent of what is taken is spent upon the national debt, the army and navy, and for administration. Less than 3 per cent is spent for education, and in a country where the suffrage is given only to those who can read and write more than six million men of voting age are unable to meet the test. Compulsory education is a law not enforced in Italy.

When the tax-gatherer is keeping your family poor, when at any time between the ages of 21 and 40 you may be called to serve in the army, when so many of your relatives and neighbors have gone to America to work for unheard-of wages, and when you see some of those who have become Americans return with the swagger and assurance of monied tourists, you are apt to do what 300,000 other Italians are doing every year. You'll contrive to get money enough to bring you and your family to America. You and your fellow Italians will distribute yourselves over the country -3 of every 4 in the region north and east of Washington, one of every 6 in the Middle West, one of every 14 in the far West; many will go into the South.

That's what will happen, too, if you live in any of the other countries where tax burdens are heavy, where the army sits on your neck, where you are born into a caste, where the country's "culture" is kept on a shelf a little too high for you to reach.

So out of the many motives which drive the foreign-born into the congregation of American citizens, we can separate three outstanding ones: 
America means equality of citizenship - every man has a vote.

America means schools for the kids, and a way open for their advancement to better work and a higher social position.

Most of all, America means relief from the burdens of taxes and militarism, and an opportunity to make more money and live better.

\section{ENGLish}

\section{A Handful of English Soil Is Kissed Again and Again}

I was born in a little village in the English midlands. The quiet drowsiness of our village was as charming as the lovely background of green meadows, purling brooks, and lacy willows at their edge. The houses which marked the winding village street were of grey stone with an occasional brick dwelling, and were for the most part thatched with glistening straw which faded into a soft, deep brown after a season or two. The new thatch covered the old one, and sometimes a house bore sixteen or eighteen successive thatchings. Under the wide eaves the swallows and martens built their mud houses in the spring. The icicles hung long and glittering in the winter time and could be reached by a daring hand from an upstairs bedroom window.

Not a single new house had been built in our village in more than one hundred years, and since my departure nineteen years ago only one new villa has been added. The charm of the old church, built in 1300 , its graveyard with the quaint epitaphs and verses in stone, the rectory with its laurel driveways and ivy-covered walls, the little old grey schoolhouse where my father and mother were taught before me, the village square with the Jubilee oak in the center of the greensward, all hold a sweetness and haunting loveliness with which memory gilds our remembrances.

My ambition in life was to become a school teacher. It was the only occupation in the rural district for ambitious young womanhood, the only other alternative being domestic service. As a student teacher, I began apprenticeship at fourteen years of age. While at Oxford taking special work at a model school, I was very happy, and the lectures were all a part of a delightful holiday. Even the stern disapproval of my father, who was a Free Methodist, failed to deprive me entirely of the charm of my first theater party, a presentation of "Julius Caesar" by the Benson players. The rigidity of the student's training failed to shake my ambition, and my father, who did not approve of women in public life, left me alone - at least 
did not interfere much when he found my whole life set toward this goal.

It was continually pointed out that I was a very fortunate girl. Was I not allowed to earn my way and not go to service and take my money home as my other girl friends were compelled to do? At eighteen I was "passing rich on forty pounds a year." Every penny was taken home, but I was given a little better clothing than I had worn before. But this good fortune was not for long. One day after my father had been ill again, I was called to a family council and told the astounding news that we were going to America to live in California. An uncle and aunt had offered to help pay our way, hoping father would benefit by the change. I heard the news in dismay. How could I go? I had made a success of my work and was planning for further study and higher promotion. It came as the sounding of doom to me. I wept. Might I be left in England?

I could not move my parents. Every one said of course I must go. The family might need my help in the new land. There were seven of us, I being the eldest. The family had raised me; I owed a duty to them. Needless to say, I went. After the keen disappointment had passed, I heard things which were being said of America. We were told this was a rich land, a land of opportunity. I began to take a morbid interest in our impending departure. My father was a leader of the liberal party and secretary for the labor union. Our departure was an occasion to be long remembered and is talked about yet. At a farewell mass meeting, a purse of gold was presented to father, and the whole population turned out to bid us farewell as we boarded the train which was to take us on the first lap of our journey.

On the boat we mingled for the first time in our lives with strangers, an experience I shall never forget. The larger number of the passengers were emigrants as we were, planning to make a successful change in life. All spoke hopefully of the new land, but nowhere did I find the enthusiasm I had expected to find. We had a cabin to ourselves, just four walls between us and the rest of the crowd. My mother, my sisters, and I slept on hard bunks, while my father and brothers occupied quarters near the engines, an arrangement which made father ill. We ate at long tables with a motley crowd who dressed shabbily as though they cared for nothing. We met miners, weavers, and skilled craftsmen of many types, all bringing to the new land health and skill. The contribution was large; for they were mostly Nordics. On that voyage we were served our first portion of Ameri- 
can ice cream and found it delicious. On reaching New York we lay at anchor fourteen hours and saw our first "Sunday paper." The comic section was a mystery to us; we saw nothing to laugh about it was meaningless.

At Ellis Island we were vaccinated, and when I tell you father was one of the leaders in the anti-vaccination law, you will understand what he must have endured when he submitted to it. We were huddled with foreigners of all colors and races. In England we knew no race prejudice, only French, and that was a hold-over which is bred in the very blood of an Englishman. The colored races gave me no reaction save a curiosity, but my baby sister, on seeing her first Negro, declared she saw Satan. We were cordially treated by the officials and were shown every courtesy. The head of the examining board patted my sister's curls and said: "Too bad we don't have more of your kind coming in." We felt a welcome, a sense of friendship. Father offered a tip to the customs man, who grandly refused it. We were bewildered. Refuse a tip - who ever heard of such a thing?

New York remains in my memory as a blur of cobblestone streets, rushing street cars, and people madly going by as if late for some important engagement. Other impressions remain of a dirty rooming house. The sight of people eating on the street distressed me. What were they eating? It was my first initiation to chewing gum. Prunes were delicious, but we noticed no one else touched them. With only three meals, we were hungry most of the time, but mother bought fruit and crackers. We were glad to be taken on the Proteus, a dirty and slow boat to New Orleans. Oh, the newness, the vastness, and wonder of the country as we looked from our car window as we sped toward California! Desert wastes, green fields, and flashing fireflies all mingle with my memory of that journey. At one station we bought some oranges, and never again will fruit seem so wonderful. Our uncle was waiting at the depot, and although he had never seen us before, he knew us immediately. He said afterwards it was our clothes, but I am sure we did not feel conspicuous. Out on the big dairy ranch was heaven indeed. Mother cried on Aunt Rose's shoulder; both wept, for they had not seen each other for thirty years.

We had a wonderful time. Strawberries were ripe, and our two cousins took us to the fields where they were. After some weeks of happiness, I decided to go to work. I was told I could not teach here, 
being an alien. To my utter dismay, I found that the thing I had fought against (domestic service) in my home land was thrust upon me. I must learn to keep house. Well! I spent two months as help to a society woman who paid me $\$ 12$ a month and offered me a dress she had cast off, as part payment. I accepted but did not wear the dress. The hardest blow came when I was sent to the kitchen to eat my supper alone after setting my place at the dining table. I had heard that snobbishness was unheard of here, but that night I wept myself to sleep. I was not happy. I scorched dresses, for I had never ironed in my life. I could not cook; mother had said it was too expensive to teach me. I worked twelve hours a day seven days a week, very poorly I guess, although I tried very hard.

A wealthy woman, a friend of my aunt, was my Angel of Mercy. She took me to her home near by, smoothed out the hurts by her kindness, and then found me a position as tutor to the children of a clergyman from Kentucky. Their ways were almost English, and I was at home. Negro servants were kept, and happiness was in that home for all. The neighbors were all kind to me, and on Sundays I went to a new little California house on the hills where my father had built a four-room cottage.

Then came homesickness with the arrival of my trunk. On opening it, I found the last thing I packed on that June morning ages ago when I left England. The morning had been wet and I had walked in the dear old meadow for the last time. On my return, I removed my walking boots, wrapped them hurriedly in paper, and thrust them into my trunk. Here they were, and on the soles of them was a handful of earth, the soil of my beloved homeland. I kissed it again and again, while my mother laughed at me with wet eyes. However, that passed, and as time went on I became less homesick. Then one day I met my husband. He was a young Englishman, and before I had been here two years we were married. It has been seventeen years since that time and we have two splendid boys. The oldest plans to be a Rhodes scholar. Strange to us, he has the American complex for England. One day he told me very proudly: "Mother, you used to be English, didn't you? Well, we beat the English up in the Revolutionary War." He is American and even resents any allusion to our former English citizenship.

My education is beginning once more. I spent two years in junior college during my baby's kindergarten and first grade. My husband, 
an oil engineer, approves and hopes some day to take up his beloved art in night school again. Recently I was given honorary membership in a Chamber of Commerce for my civic work, chiefly the securing of a kindergarten for the Mexicans in our district. For the past year I have taught classes in citizenship to foreigners in a district hitherto unorganized, and have assisted in organizing a small library for this work. I have not consciously become an American; the spirit was always there. I believe the English people have the American spirit when they can get beyond the narrow environs of the homeland. My husband has also been active and is a member of one of the most American of lodges, that of the Masons.

My mother and father have altered greatly. During my work in summer school, they are keeping house for me. Although I have never gained honors, I want to become a more useful citizen and I believe my experience as an immigrant is of major importance in leading the alien to know America as a spiritual thing.

\section{EnGLish}

\section{Loving America Better Than England, But Incompletely Assimilated}

I think perhaps an Englishman coming to this country feels less like an immigrant than any other nationality; he can more easily adapt himself to the new life.

I was born in Hoylake, England, coming to this country when young, from a home with every comfort. My sister and I attended a private school. My father was very well fixed financially. Through some unfortunate circumstances his business failed. We were forced to do without many of the luxuries we had been used to. Due to economic conditions of the country, my father came to America in 1910. He sent for us two years later.

It is exceptionally hard for a foreigner coming here to obtain work. Though well educated, my father had to do work in stores at whatever seemed to be available. Without friends one is very much alone, and it seems as if everything is obtained through "pull." At least I have since found it that way in working places. I have been able to get a position when others have been turned away, just because some influential person has sent me. My father's desire was to preach; that desire was gained after a short time.

I think it is the tourist that gives the impression of great wealth in America. He seems to have plenty of money when coming over to 
foreign countries. America is represented as being a place of opportunity and wealth.

My mother's great difficulty was the money - she knew nothing about American currency. The slang and peculiar expressions also puzzled her greatly. In restaurants they would often charge us more than we really owed, on account of mother's ignorance in regard to the value of the money.

One entering America is struck with the immensity of things and the hustle and bustle in the streets. Every one seemed in a hurry. During meals, people would come into a café and just gobble up their food. It seemed as if there was not a moment to live. A very amusing thing was seeing nearly every one's mouth moving. Mother said that surely they could not be eating all the time. We thought it so amusing, for everywhere we went they all were doing it. Mother finally inquired and found it to be gum. One very noticeable thing is the discourtesy of the American people. I have never been able to get over the lack of manners. It may seem a small thing to them, but life is made much more pleasant if some of the finer things are not ignored. Riding home every day on the street car, I have had Negro and Mexican men offer me their seat, while a dozen white men remained seated. I should think they would be ashamed.

It is very hard for parents to become accustomed to the freedom of the people as a whole, and especially to that of young girls who are allowed to go out with boys when only in grammar school. They go to public dances and theatres, staying out late at night. The American attitude toward Sunday is astonishing. Even I, who have been raised here, cannot understand the lack of thought about a God. While I feel that they carry the "Sunday business" a little to extreme in the old country, it swings over to the other extreme in this country.

I have become quite used to the "freedom" of young people in their discussion of love and affairs, their frank manner of speech. There is no sense in being prudish, but I feel that they go to extremes and come to the point of ' being disgusting at times. I am sure that the "freedom" of and "independence" of America bring the younger generation into conflict with their parents. It is much easier for my sister and me to become used to the life here than for our parents to break away from the life which they had been living for many years.

I owe a great deal to my home here, for my father is a great reader, and through our discussions I learn more than I do out of text books. Speaking of home, it has been brought quite forcibly to 
me that many of the young people here do not have what could be called homes. They seem to think of them as places to eat, sleep, and get clothes. Their interests seem to be outside of the home. This state of affairs is due, I believe, to the freedom given them. One does not, or at least did not, find it so in England at the time when I was there.

America is surely the place of opportunity. It does not give away its wealth, but one can obtain one's ambitions if willing to work, and work hard. I am very interested now to know what I shall think of the life in England, for I plan to go back. Not to stay though. I love America too much to want to remain over there.

\section{SсотCH}

\section{Not in Scotland But Still at Home}

My life began on the 8th of January, 1884, in a small town situated on the shores of the lonely Moray Firth in the north of Scotland. I was the third member of a family of six - all girls. My father and mother had been married at the ages of 23 and 21, respectively, and were in fairly comfortable circumstances. My mother's people had engaged in farming, and my father's people for several generations had been engaged in rope making, sail making, and in supplying the fishing boats with materials and equipment they needed to pursue the fishing industry which was the mainstay of the town.

Until I reached the age of nine I attended a private school. Then suddenly all of us were landed in a public school, where for the first year I suffered tortures. Children who were to pursue academic work transferred from the elementary school to the upper grade department at the age of 11 years, and those who were not to continue school beyond the required age limit took up those things which would be of help in later life; e.g., fisher boys were taught cooking and such simple sewing as might be necessary while they were at sea. Children in Scotland had to make up their minds rather early as to what career they wished to take up. Very often the element of choice did not enter in at all. That was true in my case.

I had always had a hankering for nursing, and all the cut fingers and repulsive-looking sores were brought to me for dressing. As this attitude of mine with regard to a nursing career could not be maintained against the pressure of both parents, I submitted with 
a bad grace and took up teaching. I often dwell with mixed feelings on the four years that followed. At that period I came under the personal supervision of the principal, a brilliant scholar and an excellent teacher - a man who took the last ounce out of himself and every one else.

There is no doubt in my mind at all as to what my feelings with regard to those first six months were; they were just hell. I had to be at school at eight in the morning and had classes until five. Supper was over by six, and so intent was I on being a success that immediately after supper I retired to an attic room away from all the other members of the family, and nobody saw me any more that night. It was not the most comfortable of places; for there was no heating system except a large lamp, and in winter I used to wear a coat, and wrap rugs around me in order to keep comfortable. Saturday afternoon and evening were the only times I took for relaxation. Sundays we went to four services, but the minister was so long-winded and uninteresting that I could give all the sermon period to a consideration of problems in English. Sometimes, if it were possible, I smuggled a book into church under cover of its being a hymn book and had an enjoyable hour.

This association with the school principal for four years made a deep impression on me. I learned to appreciate thoroughness as I had never known it; I learned to put the best effort into whatever I attempted, and never to give up. I acquired confidence to speak my mind frankly, and detest hypocrisy and lying just as he did. To the influence of this teacher and my father, I owe whatever high ideals I may have and the desire to live up to these. After teaching in a neighborhood town, I came back to the old school and spent four harmonious years teaching there. Then came a change.

My sister wrote to say she and her husband intended to go to Canada. I already had a sister there - in Vancouver, B. C., married to the son of two old friends who had emigrated twenty years before. It was a distinct shock when she suggested that I accompany them, but I ultimately made up my mind to do so, on condition that my father and mother would come out the following year. We reached Vancouver in September. My first two years in Canada were not happy ones. My brother-in-law found difficulty in getting work went idle for about a year. I got a position in school at a salary not very much in advance of what $I$ had been getting in Scotland. There seemed to be a lack of thoroughness in the educational system. There 
was a constant shifting of population such as I had not been accustomed to. The spelling was vile and the grammar atrocious. People seemed to me to have a singular elasticity of conscience with regard to truth and honesty. There was a lack of stability. In fact everything was all wrong. Nothing was like anything I had been accustomed to. Even the houses were gimcrack affairs made of wood. I couldn't do any reform work. People just laughed and told me I'd get accustomed to conditions. Children seemed to me to be rude and lacking in good manners. Teachers seemed lacking in respect to principals. My associations during my stay in Canada were for the most part with Scotch and Irish people. I knew very few Canadians. What few I got to know well I liked, and the feeling was mutual I believe. I taught in that school for a year and a half, and on leaving to be married I was presented with a silver cocoa set which surprised me tremendously; and while I value it very much, I cherish much more the short note which accompanied it.

After being two years in Canada, I married a Scotchman who had spent twenty years in Canada. We had many interests in common and the union after thirteen years is a very happy one, with two children - the girl resembling her father's people both in looks and disposition, and the boy my father. About seven years ago my husband received a letter from his brother in California, inviting him to become a partner in a flourishing business there. I have never once regretted the move, and have never felt homesick, although I was an absolute stranger. It was truly like coming home. I have never experienced such kindness, and strange as it may seem, my friends are not Scotch and Irish people, but Americans.

I decided to take up teaching again, as my children were of school age and the board of trustees were willing to give me a position. That was the only thing I ever asked - a start. I became principal of two different schools, and finally was elected district superintendent. There was a little protest over this election, but it made me very happy when my staunch American friends sprang to my defense. The remark was made that no alien should be at the head of schools. My reply was that I had never felt an alien, had never been treated like an alien, and had never felt anything but at home. One thing rather surprised me. The Ku Klux Klan had been trying to get control in the school board. Due to my open fight against their candidate, I naturally thought my appointment would not be pleasing to that body, but the man I helped to defeat later spoke publicly in my 
behalf. Truly this amazed me, and while I have no connection with the Klan, and no sympathy with this organization, I number quite a few of them among my friends. Fortunately, our schools were taken over by the city of Los Angeles and I was spared the heavy duties, retaining the principalship of my own building.

There are two things here to which I have never become reconciled - one is the amount of politics that enters school business, and the other is the attitude of university students, almost disrespect, to professors. One finds talking during lectures, coming in late continually and leaving early, handing in assignments late or not at all, and not the least of the offenses - cheating at examinations. These things at first shocked me immeasurably, and even yet I get jarred to the point of checking people. In Scotland there wasn't the changing of positions that there is here. People got a principalship and occasionally made a move, but there was no such thing as conspiring to get a person out of a position, and it would be a still more impossible thing now with a centralized authority in each county taking the place of the old school boards. I consider the political situation in the schools a very serious one. It means so often that positions of trust are given to people utterly incompetent. I personally have known two district superintendents in this state who were no more able to run a school system than a sixth-grade child. The county office knew it, but still hunted jobs for them. I think the county superintendent who does such a thing is criminally negligent. However, these situations seem to exist all over; but where the schools are concerned, I think it is playing with fire.

I retain very pleasant memories of Scotland. My father and mother died during the war, within nine months of each other, and that was a shock. The tie is not so strong now. I have still two sisters there. The husband of one is principal of a school; the husband of the other has a studio. Another sister died at the age of fourteen and a half. Some day I want to take the children back to show them over all the old ground where their father and I spent our childhood days. It would be a joy for me to see once more an August sunset on the Moray Firth, but with so many of the old friends gone I could not hope to have a great deal of pleasure from the visit. I never was any happier in Scotland than I have been here. The climate suits me. I have splendid health, many good friends, congenial work, and a happy home. I am and ought to be contented and happy. I get as big a thrill out of seeing the Stars and Stripes 
float out on the breeze as I ever did out of seeing the Union Jack, and that may be accounted for by the fact that I was always more Scotch than British, and the Union Jack seemed to me more English than Scotch. I never pretended to get on with English people. It jars me to hear old-country people run down the United States. I am on the defense immediately. Some of the happiest years of my life have been spent in the land of my adoption, and I am proud and happy to be an American and to know that my children are also little Americans.

\section{German Russian \\ A Prisoner in Russia, A Dirty Russian in Germany, A Lady in America}

My father and mother were children of farmers without much education but with a desire to give us more. For this reason our lot was much harder. I was born in the Russian town of Ekaterinoslaw, where my father had a flour mill with some partners he did not much like. He therefore planned to go to Siberia to my grandfather's and work on my mother's farm. With the help of grandfather he built a house only for the first winter. In the summer we had a better house built, and there we lived for a while. Not liking this very well, father wanted to go back to the mill business, and with the family, including my youngest brother and sister, who were born in Siberia, left the country. It was a hard journey. It always happened that we had to travel in the winter time. We children all were little and most of us helpless.

Cold as it was, my mother had to find a way of getting us to the depot, which was far distant, without our taking colds. Very soon, being accustomed to the weather in Siberia, she found it. All of us were warmly and tightly packed in a wagon that was filled with plenty of blankets and covered on top, with only a little space for air and light. In this way we arrived at the depot, glad to get out of the wagon. On the train it was much better, and we children, being always so many, had many kinds of fun. My youngest sister, only a few weeks old, made all the music we wanted. By and by we reached the little village.

Only Russians lived there, with the exception of our relatives. No schools were to be found. Father, wanting us to have a good education, gathered all our relatives together and collected money for a school building, where the German children could go to school. 
We had our teacher, who was well educated; therefore, we got a real good education at a Russian village and surprised the Russian peasants.

Father was not home often as he was traveling on business, buying grain to be ground at our mill. As this was the only mill in a great area, trade was flourishing. Our partner, whom we had again, was a Russian citizen and we were German, but we got along very well. Not long could we enjoy this business and this home. In 1914, when the World War broke out, father, being a German, had to go into Russian captivity, far away from home to the city of Krasneger on the shores of the Volga, and that in a stormy winter.

My mother, troubled with all this, was lying in bed sick. Father took his farewell standing at one side of the bed and we eight children around it. Not very much was said, but our hearts were all full of care for our dear father. What would they do to him? Nobody knew for sure, but every one felt it was going to be very hard to bear. Then it was winter again, and father with other Germans went on and on with Russian Guards till the Russians got tired and put them all in jail. These jails were the worst things on earth at that time.

Forty men were crowded into one small room, where no beds, benches, nor a single seat was to be found. These poor human beings were shut up so as to be of no use, and they wanted death. No sanitary facilities were there, and nothing in the shape of a wash basin. They had no windows to open, and the odor became offensive. One of the worst things was the vermin; everything was covered with lice and nobody could sleep, even though tired and weak, ready for death. The prisoners got water and bread to eat. They went down and down in weight; and all this only because they were German. If the German Kaiser ever had good citizens, he had them in these suffering people, who were treated worse than animals.

After a long travel through many of these jails, they came to the river called the Russian mother river. Snow and ice covered it, and they had to walk more than 40 versts farther through storms and with bodies that already had lost all strength. Half-dead, they arrived at Krasneger. If good comrades had not carried my father, he would have seen nobody besides death at a frozen river in the snow storm. But where everything is at end, God helps. Prayer did much at that time, and we did not lose our father, but father lost his health for all his life. Not very long after father left, the Russians would not allow the women and children to stay home either. Till this time, only 
the German men were sent into captivity, but now the rest of the family. How terrible it was - the things the German people had to suffer, during the war, in Russia.

They would not let us go to see father all together; no, that was too good to be true. We all had to be divided and sent to a different place, and father and mother also. The whole family was going to be torn up. That money is power we all know, and this time we were most glad to have this power. Before the tiding to leave our house too got to us, my mother went to many places and spent that money to get a license permitting us all to go together to our father. Glad that money could do that much for us, we left our mill in the hands of our partner, and went on the journey to where he was kept prisoner.

Our interest in the mill was now almost gone. For in the hands of a Russian citizen we lost it very soon, but it helped a little at the time we were in captivity. Our journey was better than father's, for we could go on the train. Even though it was only a train for cattle, we were glad to get it. It was in winter. Cold and without any fireplace, we were freezing in these wagon cars. We had a hard time to get food because the Bolsheviks would not allow us to buy.

My mother"was suffering worse than words can tell, but she was very brave and always happy, to keep us from getting too sad. We traveled and traveled and at last got to the river. We did not have to walk across this river like father, for the river was not frozen. At the end of this long and hard journey, we arrived in Krasneger, where my father was kept.

Father had changed much and gotten so thin that we did not know him. He took us with him; we were glad to be together again. Here in this place, we were a little more comfortable than on the journey. The German state had one committee there, which kept us from perishing with hunger and cold. We ourselves, getting in a very difficult way some money from our partner kept at our mill, were pretty well off. We rented a big enough house, where we could live somewhat better than the rest of the Germans, and we could buy some food besides what we got at the community kitchen. We children grew happy, not wanting more.

The Russians would throw stones at the German children and we could not go to school either; none of all the Germans that were there. My father, always wanting us to go to good schools, realized the situation, and at last got the idea of having a home teacher come 
into our home and teach. We were not allowed to talk German on the street at all. If we did, we were put in jail right away. Many Germans died here from all the suffering, and we saw and went through this all. After four years, kept in captivity, we tried to flee from there. This could be done only in winter time, because we had to cross the river. In this fourth winter, when the river was covered with ice, we loaded all our household goods on a big wagon, sat on top and, choosing a dark night so that no Russian guards could see us, crossed the river without breaking into it. At one place we almost broke in, but saw that the ice was bending down slowly just in time to avoid this dangerous place.

If we had broken in we would all have left earth at once and all her troubles. It was my mother's thought, and we all said, that this would be best. When we came out of the guarded district, we got a train, and then had another journey back to where father's parents lived. When we arrived there, it was hard for us to live with our grandparents, because we were many, and they were rather discontented to have such a crowd of people in their home. My father tried to get the mill back, but there was nothing left of it. Our partner sold it to a Jewish man and we did not get much money for it. We now were poor and helpless. What now to do? No home and no home country. We thought about going to Germany. Nothing else could be done, and again we packed our things and went on.

This time was the hardest. The Bolsheviks hated us with all their might. They treated us badly; but somehow we got through. If I were to stop to tell the things we went through, I never could finish. After one month we arrived in Germany. We had left everything in Russia, and came only with the clothes we had on, and a few things, which we saved and got through.

We had one uncle with his family in Germany and there we went to that country. They too were discontented when we came, and we tried hard to get away from there very quickly. We had to stay for a while until we got enough money to rent a house. The Germans now called us dirty Russians after all the suffering we had in Russia for keeping up our German citizenship in Russia. These Germans were not reared in a very fine way or they would not have done it. Even so we had much help from the Germans, for we could go to school without paying any money, which was very fine for us, as the schools are very expensive in Germany. We did not stay very long here either. When this part of Germany became Poland, we 
again had to go deeper into the central part of Germany. Therefore, we left and went to Berlin. They sent us to many different places, wherever the city council would permit us to settle. Each time we had to go back to Berlin. At last, tired of spending so much money on us, they found out where we had relatives and sent us there. We lived in soldiers' huts and were helped by the state. Being fourteen and a girl, I could no longer go to school. For boys it was different. When I left school, I felt as if I were losing my fortune and my future as I had always wanted to be a teacher and had nearly ruined my eyes studying toward this end. No matter what else I had to do, I never wanted to leave school, but I had to now.

I secured a job as sales girl and liked it very much, but not for long. I begged mother to let me learn to sew and did this for three months; then my eyes gave out and I grew thin and pale. Even though I was not well, I did not want to stay at home without work; so I went to do housework. Not long could I stand this, and again had to go home to get well. My parents could not support me or get along without my help; therefore I again went to work in a store. Had it not been for getting money from the government, we never would have come through; the Germans did very much for us, but not enough by far. My father at length heard of a colony that was settled by Russian fugitives and there he went, leaving my oldest brother and me in our places. I learned for the first time what it was to be without a mother. I tried nursing, but my father did not want me to do this and wrote a letter in which I found the sentence, "Come home and stay here." This was the gladdest day for a long time. As quickly as I could, I started back to my dear mother, but when I got there I could hardly breathe the close air or see through the darkness. After I got used to the darkness, I could see my mother looking worse than ever. We looked at each other, and then I fell into her arms and we both cried for gladness to be together and for sadness for our poor lives. Now I was home again, but how poor was this home. I missed all the comforts of the hospital, the warm room and good food. Only mother's sunshine made life bearable. here. The place could not be made cheerful.

After being at home fourteen days, the Red Cross Committee would not allow me to stay longer as I had been self-supporting before I came. Finally I secured work at the Red Cross rooms, but I was not settled for long. I could not help my parents; neither could 
I work up to something for myself. Then came the turning point in my life. Once when I was at Hamburg a preacher from California lectured, telling wondrous things about America. Everybody went crazy over America after hearing these things, and my parents too. Afterwards when I was not pleased with things at all, my father said, "Go to America." But how was this to be done? Not long after I conceived the idea of getting over to America, the same preacher wrote that he might help a girl to come over. All the girls got busy and had their pictures taken; and I, the youngest and smallest of the crowd, was selected. It was God.

Meanwhile, I fell in love. Once father allowed the oldest of us children to visit a family whom he knew. Here I, a seventeen-yearold girl, learned to love one of the boys of the family, who in turn loved me. We were both very young, but loved very much. But we could not see each other often. Once he got a chance to come over to see us. He stayed at our house one night and day; we were glad to see each other. Not long after this my ticket came. Now I did not want to leave my friend. I could not ask my father to permit me to stay at home, for I was never satisfied. There was nothing to do but get my visé and go. At Munich I saw my friend and, thinking it was the last time, we felt much more unhappy than at the first time. We tried to be cheerful. My father, who was with me, noticed now that we loved each other. When I left he was very angry, and so was my mother. It was a rainy and dark day when I told my friend good-bye, and in our hearts it was dark to part. It was my hardest day; seeing my friend so few times, and being loved and loving made everything harder still. The train ran into the depot. The last parting kiss was given, the last squeeze of his hand, and on I sailed to an unknown world, where new friends were waiting for me.

When the shores of Germany disappeared, my courage went with them. I got my guitar and played home songs. I had my eighteenth birthday on board. Not letting myself go, I tried to be happy, even though I was alone. I traveled over a month. I arrived in Los Angeles, the minister who sent the ticket for me received me, and after three days I started to work at a place I work now, doing housework. I like my place very much and am satisfied with it, till I can do something that I like more. I am homesick once in a while but try to be happy always and sing most of the time at my work.

Some day I hope to get my friend out here or go back to Germany when my parents don't need my help any more. I do not want to 
stay here when nobody comes and when my parents can support themselves.

This is my thought, but I may have to do much differently; for I cannot see what is going to come. I will be happy and gay as much as possible and do as much good as I can, and that makes me happy too, even when I get lonesome and homesick. My proverb is: "Always happy, always gay, sunshine never goes away; be as cheerful as can be, try it hard, it goes you'll see."

\section{Dane}

\section{Why and How I Became an American ${ }^{1}$}

It was out on wind-swept, treeless, heather-covered Jutland that I was born. I loved that country; but - perhaps it was the whisperings of sea-roving, Viking ancestors - I always had a longing for getting out, out in the world. I often thought of lands and people that enjoyed milder climates and more favorable conditions. The place that I wanted to see more than all others, was sunshiny, jolly Italy.

But I stayed in Denmark. My twenty-third birthday found me holding a clerical position in Copenhagen - a good enough position, somewhat above the average. I might have got on and worked my way up; but at the time, my position did not look to me as holding any possibility of future independence.

In the years of which I speak - the 'eighties and early 'nineties there were imposed upon the people of Scandinavia, especially of Denmark, certain political restrictions which, to the free-spirited, made life seem unbearable. Then there were all the old conventions of caste, the old social hindrances that almost irresistibly held down a man of humble parentage. These political and social conditions were largely responsible for the big emigration from Denmark during the 'eighties and early 'nineties. It should be added, however, that since then these conditions have entirely changed.

In our school-books, we Danes read about Washington, Franklin, Lincoln, Grant - names from out a new world, names that lighted up the Western Hemisphere. From articles in newspapers, but more particularly from tales brought back by returned emigrants, our minds were fed with the idea of America as the great and rich country where opportunity awaited all.

1 By E. V. Eskesen in World's Work, Vol. XLI, pp. 380-81. 
Three brothers and a sister had gone to America, and were writing me, urging that I follow. And so it came that, at the age of twentythree, I decided to emigrate to the United States. Like the majority of Danish emigrants, I did not regard the migration as a permanent thing: I was simply going to America, for an unknown number of years, for the purpose of making money, and then returning to my home - to Denmark - to live and die. I was interested in music, art, literature, particularly in literature, in poetry. In Denmark, though I was only a clerk and had only a clerk's income, I could hear good music and find among my associates men who could talk with intelligence and sympathy of art and literature. In America, I knew it would "be different: I had heard so much about American materialism and the hunt for the almighty dollar, that I feared that if I stayed permanently in America, my better belongings should be submerged in the maelstrom of materialism.

After settling my affairs and paying for my equipment, there was very little left of the money which I had been able to raise; so I decided that inasmuch as I had to start from the bottom when I got to America, I might just as well begin with the beginning - I bought a steerage ticket.

I went by way of Great Britain, sailing from Glasgow on an old steamer that took eighteen days to cross the Atlantic. But the trip was joyous enough. There were a few Danes, and many Scotch and Irish, the latter coming aboard when the ship touched at Londonderry. The good company and the long trip combined to make my small treasure dwindle away: I had only one dollar left when finally we came in sight of America. It was an afternoon in April, 1891. I remember distinctly the eagerness with which we all had been gazing shoreward to see the first gleam of the promised land. When the shore and green hills appeared on the horizon, seemingly gliding up out of the ocean toward us, I remember how I isolated myself from the rest of the company, and with eyes fixed on the new land, thought of the future before me and dreamed the dreams of youth and ambition.

It was late evening when we came in through the Narrows and anchored off Tompkinsville for the night. It was unusually warm for the season - just like a beautiful, clear summer night. Some one brought out a concertina; the rest of us lay around on the deck, listening to the music. Close to us, from the hillsides of Staten Island, shone myriads of lights. In front of us were Manhattan and Brooklyn 
joined by the web-like span of the Brooklyn Bridge, all, everything wrapped in light - oceans of light all around us. Indeed, this was fairyland!

The next morning we landed at Castle Garden. I was worried about that single dollar in my pocket, for the rules at that time required that an immigrant have at least ten dollars. So I made an arrangement with a fellow voyager who was a little better financed than I was; he showed the necessary ten dollars to the inspector, was duly passed, and, once outside the fence, slipped the ten dollars between the pickets of the fence to me on the inside. I, too, was duly passed.

Outside the gate I found my younger brother waiting for me. He had been working in a terra cotta factory. So after looking around for a couple of days we secured work as pressers in an architectural terra cotta plant located in Long Island City. It was hard and unusual work for me, my surroundings rough, ugly, depressing.

The first years of an immigrant's life are always the hardest. These years leave their marks and are never forgotten. For the man who has to fight his way up from the bottom, it is work, work, work hard, grinding work. But it is not this that leaves its mark - it is the fact that he is made to feel that he is an outsider, a Pariah. My early years in America were before the great influx of immigration from South and East Europe. The word "greenhorn" was then very much in use and was applied to any one who was not born here. It carried with it a stigma and was meant to hurt.

For me, as for other ambitious immigrants, the first years in America were bare of leisure or recreation. After the hard, manual labor of the day, I went to evening schools to study English, bookkeeping, stenography, and many other things which I found necessary in order to advance myself. It was sometimes two schools in one evening. I had to put aside all those things that represent the finer ideals of life, music, art, literature. I had expected that I would have to give up for a time my writing and poetry; but I had not expected to find my life stripped so absolutely bare of even a reference to these things - the talk around the shop and outside was mostly about baseball and prizefights - so different from what I had been accustomed to in Denmark.

After about four years of manual labor and study, I found in my selected trade the opportunity for success. The idea of making useful and beautiful things out of clay appealed to me as a happy combina- 
tion of industry and art, of getting perhaps satisfactorily close to art. I took hold of this thing and stuck to it. The old desires of my boyhood, to rove and adventure, came to me, but I repressed them even though I sometimes felt that in doing so I was bridling part of my better self. I did not, like many of my countrymen, Jacob A. Riis for instance, strike out into the uncertain, wandering from place to place, depending on chance jobs between communing with nature. So my experience as an immigrant is commonplace.

Since business success has brought me freedom from the steady grind, the old longing for adventure occasionally awakens. How carefully now I nurse it to life! And so, in my spare time, I have roamed all over the United States and the continent of Europe. I have been to Italy, that land of my boyhood dreams, and though I found it as sunshiny and jolly as I expected, yet if I were to be born again and had the choice of my birthplace, my choice would lie between two countries - the United States and Denmark.

\section{Hollander}

\section{America Makes Two Big Hits with a Hollander}

I was born in Amsterdam, but early in my boyhood I was sent to school in Rotterdam. I attended school there until I was nineteen years old, only paying occasional visits to my home. I acquired what would be considered in this country a good grammar and high school education.

My family was very well to do, and my father, being a very prominent man, secured me a job in The Hague. It was an office position, and to me did not seem to offer much chance for advancement. I worked here for a short time and then came to the conclusion that I should like to be a naval officer. In Holland a person with a fair education can become a naval officer by serving two years' apprenticeship on a merchant ship. I had just completed my first year, and was very interested in my work and exceedingly anxious to some day captain a ship. But there occurred at this time an incident which changed my whole life. In Holland every able-bodied man is numbered. If his number is drawn, and drawings are held at frequent intervals, he must begin serving his six years, either in the army or navy. Two years' straight service in the beginning, and then sixweek periods every few months, until the six years have been served. My number was drawn just as I was most enthusiastic about my work. 
I felt as if my entire life was ruined, and that I had suddenly been deprived of my freedom.

For some time rumors and tales of America had come to my ears, and with the army service staring me in the face, and being young and adventurous, it did not take me long to decide to migrate to America. I did not come steerage, but bought a third class passage.

The first thing which awed and impressed me when I arrived in New York was the massiveness of all things which I saw. The buildings seemed to scrape the heavens, and all other things seemed equally as immense in comparison to what I had known at home.

I spent the first week in America seeing New York and spending all my money. When I was broke I decided it was time to look for work. Owing to the fact that I had learned to read and speak English in school, I was not handicapped by the language as many immigrants are. I soon secured a job as waiter on a coastwise boat. I will never forget the first group I served. I took their orders and put the orders into the kitchen. Although I could read and speak the English language, I did not know one English dish from another. Consequently, when the dishes were ready to serve, I did not know which one belonged to which person. The people had no little fun over this and made quite a joke out of it at my expense. The good-heartedness of these American people with my stupidity scored the first big hit for America with me. By the end of the first month, I was acquainted with most of the American dishes, and being in port I decided to quit my job and find work on land.

I had not been idle more than a day or two when I got a job as bellhop in a moderate-sized hotel. I worked at this until an opening occurred in the dining room, and then I became a waiter again. I worked at this for a considerable length of time, and then being restless, I decided to come out West. It was not hard to leave the East because I had never become attached to any colony, as I did not, and do not now, believe in colonies. I wanted to become a thorough American and I thought the best way to do this was to mingle with Americans.

I might have come West sooner if I had understood that I could travel from one section of this vast country to another without considerable red tape, passports, etc., so common in European countries. I also did not know for some time that I could as easily find a job in the West as I could in the East.

Whatever made me stop in M-, California, I do not know. 
I secured a job there as waiter in the best hotel in the city, and stayed with it until I had worked myself into the position of head waiter. For some time, in connection with my waiter's jobs, I had been acquiring a slight knowledge of cooking, so that when the hotel needed an assistant chef I made known my desire for the job. The reason I desired this change was purely from a financial standpoint. I worked in this town until I had become head cook, and then I decided to move farther south. I had no trouble in securing work.

I had not been there very long when I met an American girl, with whom I fell in love. Although she had the American woman's independence, which is not found among the women in Holland, I desired very much to make her my wife. We were married a year and a half after I arrived; this was America's second big hit with me.

I soon acquired a job as head chef in a large hotel, and was in this line of work for some years. About five years ago I became interested in the massage business and found it paid well. Feeling I had a trade through which I could begin an independent business, I began to look around for opportunities. In my search I came across a man giving sand massages in Ocean Park, and I learned from him it was a very profitable business. At the end of three years, I find it furnishes a very modest income. I have a nice home now, a wonderful wife, and three fine children. I own my own home and am very happy.

When I try to visualize what my life would have been in my native land, I cannot conceive of ever securing the happiness that I have attained here. Through my folks I might have achieved financial success, but never the feeling of personal freedom I now possess. I am also very thankful I came to this country because of my children. I am glad they can call a country their own, where every person has a chance to succeed according to his or her own individual merit. Yet in regard to freedom, the economic freedom of the United States has made more of an impression upon me than the political freedom. Excepting the compulsory military service, the political freedom of the United States does not seem to me to be greater than in Holland. My vote does not seem to bring me any more freedom or say in the government here than it did in Holland. I have adopted America as my country, and I hope America has adopted me. I want my children to be true Americans, and marry American men. There is only one way in which I want my children to differ from the general run of 
Americans. That is, I want them to be deeper individual thinkers than I believe the average American is. I believe most Americans leave the deep thinking to a few leaders and are also governed by mob psychology.

\section{BELGIAN}

\section{Prohibition Ruined This Country for My Dad}

I was born in Belgium a few miles from the French boundary. My father followed in the footsteps of his father and became a cigar maker. He was fired by no ambition to rise in the economic world, but to work constantly until death to support his family - myself and three other children. As his folks were laborers, he was forced into their class and there had to remain. Living under these static conditions, it is little wonder that he listened eagerly to the tales of travelers as they told stories of fortune to the group gathered in the saloon. There he heard that a person could pick up gold along the gutters of the street and that the government saw to it that every one in America was well taken care of. My father, being just a day laborer, built air castles out of the myths brought to Belgium by adventurers who had been to the land of golden opportunity.

Leaving his family in Belgium, he came to America in 1912. He was met in Boston by his brother, who immediately told him that he had made a mistake in eoming over; but, being a good fighter, he laughed and proceeded to find a job. Eighteen months later he sent for the family. While we were on the way across, he lost his job and was forced to seek another in a different city. During this period of job-hunting, his own country people looked good to him. He went to them for information and on more than one occasion found assistance out of his difficulties.

This trait of mutual helpfulness seems to be characteristic of the Belgian people in America. They cluster together and help one another in all things. To the Belgian club my father goes daily to sit and chat, and perhaps play a game of cards. He and the members of his club are very much opposed to the way things are run here; they much prefer the Belgian method of administration. As they see it, the working man continually stays in the gutter and plugs along the best he can, ever fearful that he will lose his job. Prohibition just about finished my father's desire to stay here. I have often heard him say, "What a shame to take the working man's beer, his last source of pleasure, from him!" Without this beverage, life is just 
one working day after another to his club members, and I agree with them too.

But there is another side to the effects of the Belgian clannishness. Mingling with and depending upon the members of his group, he has, in the atmosphere of the old country, isolated himself from the English-speaking people. Living only a short distance from the factory and having no interests outside his group, he doesn't brush elbows with native Americans and doesn't feel comfortable in their presence. Although he comprehends English, he doesn't speak it, and furthermore doesn't want to learn it.

The case was different with us children. Certainly it was a hard proposition for us to become accustomed to the culture and general behavior patterns, different types of people, and a new language; but being young and active, it wasn't long before we picked up the language and fell into the habits of our classmates and playmates. I really can't tell my reactions, because we were led along in sheep fashion and did just about as we were told.

One thing Americans seem never to understand - how we can hold on to our culture and at the same time accept new ideas. They simply do not understand us. The Belgian people do not show affection. As far back as I can remember, I never saw my dad kiss my mother; not that he doesn't love her, but just because it isn't the custom. My mother never kisses us children when we leave to go on a trip for a few days or weeks, but she does shake hands with us. This is one thing I found strange when I first saw it done in American families. My dad is not at home to meet me when I come home from school. Some American boys would be offended, but not I. I know it isn't because he doesn't care for me, but just because it is a habit. I know he thinks more of me than anything in the world by stories that drift back to me from other people. My father's whole life is in his family, the only thing that is keeping him in this country.

Although my dad does not shower affection upon me, and often embarrasses me with his frankness, especially when I am serving as interpreter, I think more of him than any one else. It is true that he is just a common laborer, but what is that to be ashamed of? If he has not had money to give me or been able to exercise political pull in my behalf, he has given me physical health and has thereby enabled me maintain myself in school through my athletic ability and to crash into fraternity and other social circles. Right here I cannot refrain from saying that if I were to express what I feel 
deepest about the United States and its people, I would say they rank money too highly.

I am in favor of intermarriage, but I draw the line on color. The Belgians have a tendency to marry within their own national group. I believe that two people of entirely different environments and blood produce a hybrid which is a very good, high-class human being, and an improvement upon the races from which it came.

\section{QUESTIONS}

1. Of what special interest to students of assimilation is the first document?

2. Reread each life history in this chapter and outline the reasons for emigration. In each case seek (1) the background conditions causing the immigrant to become dissatisfied with his native country; (2) the hopes and ambitions that drew him to America.

3. Judging from these documents, what do you think has been the chief reason for the emigration of Teutons?

4. What similarities are there in the first impressions? Account for the differences.

5. Why was the comic section of the Sunday paper meaningless to the English teacher (number 2)? Cite other instances of bewilderment on the part of newly arrived immigrants.

6. Give specific incidents showing the advantages and disadvantages of having relatives or friends to relieve the jar of harsh adjustment.

7. Why did the English teacher (number 2) feel so much at home with the family from Kentucky? The Scotch girl (number 4), in the United States?

8. Account for the Belgian cigar maker's (number 8) idealization of his native country.

9. In which cases do you note (1) a lowering of status; (2) a raising of status? How would the experiences of the English girl (number 3) probably have differed had her family been of the lower class?

10. In what respects did the type of personality cause easy adjustment in the case of the Hollander (number 7)?

11. In what ways did the German-Russian girl's (number 6) philosophy of life make her adjustment less difficult?

12. Account for Rummel's (number 1) wide investments, and his idea that it is sinful to waste money at summer resorts. Enumerate other points on which immigrants have not been able to accommodate.

13. What was the psychological effect of the arrival of the English girl's (number 2) trunk? What would the effect have been had it arrived later or even earlier? 
14. Evaluate: "America is better, even if here I am only a flunkey!" (number 1)

15. How did being an alien affect the Scotch girl's work (number 4)?

16. Select and compare the statements regarding each individual's assimilation. Do the English, on the whole, find assimilation easy or difficult? Why?

17. What are the various attitudes toward the mother countries? 


\section{CHAPTER XXXIII}

\section{LIFE HISTORIES OF LATIN FIRST GENERATION AMERICANS}

\section{ItALIAN}

\section{America as a Place to Make Money ${ }^{1}$}

If I am to be frank, then I shall say that I left Italy and came to America for the sole purpose of making money. Neither the laws of Italy nor the laws of America, neither the government of the one nor the government of the other, influenced me in any way. I suffered no political oppression in Italy. I was not seeking political ideals: as a matter of fact, I was quite satisfied with those of my native land. If I could have worked my way up in my chosen profession in Italy, I would have stayed in Italy. But repeated efforts showed me that I could not. America was the land of opportunity, and so I came, intending to make money and then return to Italy. This is true of most Italian emigrants to America.

I was born and reared in Baiano, a village in the hills, about fifteen miles from Naples. My folks were of the middle class; and like most Italians above the peasant class, they were willing to spend money to educate their children. Each family is ambitious that its sons shall be professional men; each desires to have a lawyer, a doctor, and a priest. I was to be a lawyer. I was sent to school, and then to college.

I wanted to find a place of employment that would give me a means of support and an opportunity to study. There was no place of that kind in my village; I went to Naples and looked; I went to Rome. Nothing! So I made up my mind to go to America, the land of opportunity. I said to myself: "I will shovel coal, I will wash dishes, I will do anything to get up, to get my chance." A man who has ambitions cannot do those things in Italy. There society is different. A man who wants to become a lawyer cannot begin by washing dishes: the lines separating one class of society from another are too rigid for that.

1 By Stefana Miele, in World's Work, Vol. XLI, pp. 204-06. 
What made me decide to go to America was the "Americans." In Italy, they call in jest the returned immigrant from the United States "an American." The minute you see him you can tell him. He smokes an American pipe, he wears American shoes, a cap, American clothes. He has new ideas. But the great change in him is that he has money - more money than he ever had before, more money than his old neighbors have. He is an advertisement that there is prosperity for the stranger in America.

I was about twenty years old when I first thought of going to America. But it is not so easy to leave one's native land: it was not until three years later that I said good-by to my father and mother and our neighbors. I did not think for a moment that it was for the last time - I was only going to America to make money and then return to Baiano and the old folks.

My father gave me a little money so that I could buy a second-class ticket. But I was young; I was starting on my first big adventure; and - in Naples my money went, this way, that way - I came in the steerage. It was no great hardship. My fellow-passengers were Italians, most of them laborers, men used to hard work. They were very happy - laughing, singing, playing - full of dreams, ambitions.

Then came Ellis Island!

Everyone crowded - discomfort - lice - dirt - harshness - the officers shouting "come here," "go there," as though they were driving animals. And then the uncertain period of detention - sometimes a week, sometimes two, three, or even four weeks - it is as though a man were in prison. Ellis Island does not give the immigrant a good first lesson in Americanization.

America wants the immigrant as a worker; but does it make any effort to direct him, to distribute him to the places where workers are needed? No; it leaves the immigrant to go here, there, any place. If the immigrant were a horse instead of a human being, America would be more careful of him; if it loses a horse it feels it loses something, if it loses an immigrant it feels it loses nothing. At any rate, that is the way it seems to the immigrant; and it strengthens his natural disposition to settle among people of his own race.

A man needs to be a fighter to come to America without friends. I was more fortunate than many: I had a brother in America. He worked in a private bank. He met me when I landed and took me to his home in Brooklyn. I looked for a job for about a month. I tried to get work on the Italian newspapers; I tried to get work in a law 
office. Finally, a friend took me to a Jewish law office, and I was employed - I was to get 25 per cent of the fees from any clients that I brought in: I stayed there two months and got $\$ 5$. Three months after I arrived in New York, I was given the kind of a place that I had looked for in vain in my native land - one that would enable me to support myself and study my chosen profession. I was given a place on an Italian religious newspaper. I worked from eight in the morning to six in the evening, and attended the night course of the New York Law School.

It was about August when I landed in America, and already there was election talk. (It was the year McClellan ran for Mayor). I met some of the Italian-American politicians. It is said that I have a gift for oratory. The politicians asked what would be my price to talk in the Italian sections of the city. I said that I did not want anything. I made speeches for McClellan, and I have made speeches in every campaign since.

That was one of the first things that struck me in America - that everyone working in politics was working for his own pocket. Another thing that also amazed me was that most of the men elected to an office in which they are supposed to deliberate and legislate, were in reality only figureheads taking orders from some one else. They had no independence, no individuality. Another discovery was that the Italians with most political influence were men of low morality, or low type. Then I discovered the reason: the politicians needed repeaters and guerillas, and that was why "the boss had to be seen" through a saloon- or dive-keeper.

A thing that seemed very strange was the way the American newspapers magnified crime in Italian districts, how they made sensational stories out of what were really little happenings, how they gave the Italians as a people a character for criminality and violence. No less strange was the way the Italian newspapers answered the American press. They were both building up a barrier of prejudice. If I were to judge America through the American newspapers, I would not have become an American citizen; or if I could know America only through the Italian-American newspapers I would say that the Americans are our enemies.

It must be frankly admitted, however, that there is a change in the second generation, a change that is too frequently not for the better. As I have said, the majority of Italian immigrants come from the rural districts of Italy, and because there is no policy of distribu- 
tion, most of them settle in the big cities. They are not prepared to meet the situation presented in a big industrial centre. They think to apply the same principle in bringing up children that had been applied in the little village or on the farm in Italy. They let the children run loose. And in the streets of the crowded tenement districts the children see graft, pocketpicking, street-walking, easy money here, easy money there, they see the chance to make money without working. The remedy is to be found in distributing the newly arrived immigrants.

Most of what I have said has been of the faults of America. I have spoken of them because they are things that hold back Americanization.

America has been good to me. I have prospered here as I could not have prospered in Italy. I came to make money and return; I have made money and stayed. A little more than five years after I had landed at Ellis Island I was admitted to the New York bar. I have already had greater success than I dreamed, when I left Italy, that I should have. And I look forward to still greater success. For me, America has proved itself and promises to continue to prove itself the land of opportunity, but I have not forgotten Italy - it is foolish to tell any Italian to forget Italy. I say Italy; but for me, as for the others, Italy is the little village where I was raised - the little hills, the little church, the little garden, the little celebrations. I am forty years old, but Christmas and Easter never come around but what I want to return to Baiano. In my mind I become a little child again. But I know enough to realize that I see all those old scenes from a distance and with the eye of childhood.

But even if I wanted to return to Italy, my children would not let me. America is their country. My father is dead. I have brought my mother here. When an Italian brings his parents to America, he is here to stay.

America is a wonderful nation. But we make a mistake if we assume that the Anglo-Saxon is the perfect human being. He has splendid qualities but he also has faults. The same thing is true of the Latins. The Anglo-Saxon is preëminently a business man, an executive, an organizer, energetic, dogged. But in the Anglo-Saxon's civilization the Latin finds a lack of the things that go to make life worth living. I remember the returned Italians, the "Americans," that I used to see at Baiano: they had made money in America and were prosperous and independent, but they had also lost something 
- a certain light-heartedness, a joy in the little things - the old jests no longer made them laugh. The Latin has the artistic, the emotional temperament, a gift for making little things put sunshine into life, a gift for the social graces. If the Latin could get the qualities that the Anglo-Saxon has, and give to the Anglo-Saxon those that he lacks - if all the nationalities that make up America could participate in this give-and-take process - then we would have a real Americanization.

\section{ItALiAN}

\section{From a Deserter from the Italian Army to an American Merchant,} But Still Dissatisfied

I was born at Cassano, Italy, in 1885, fourth of a family of six children. My father was a fireman in a brick yard. We were very poor; I remember having meat but twice a year and white bread only when ill. At seven I started working for my uncle, a wealthy comb manufacturer, and at ten left school completely to work in a jewelry shop for fifty cents per week. I had two main interests. When fifteen I joined the gymnastic team, playing my first game at Manza when Humbert I, King of Italy, was shot by an anarchist on the campus. My other interest was reading. All of my allowance I didn't spend on games; I used to purchase books, one of which was the poliglotto moderno to teach the English language at home. I also secured newspapers and books through the jewelers union to which I belonged.

In June, 1905, I was called by the government to be examined for service in the army, but the physician, finding my stomach too weak, sent me home for a year. In 1906 I was called for eighteen months of service. Having no money to start a business for myself, realizing that my eyes were failing from the eleven years in the jewelry shop work, and facing service in the army, I saw only a dark future ahead. More than once I thought of going to America. I was left alone with my mother and two younger brothers to work to support the family, and pay the debts left by my brothers' expenses to America. After debating these problems, I made up my mind that my place was at home and I would serve in the army when the time came.

On October 20 I presented myself at the military headquarters in my district and went through the customary examinations. That night we went out to a restaurant and, while talking to some soldiers, we told them that we were going to the hospital the next day. They 
told us that all the men this doctor sent were sure to go home. We were so glad that we paid drinks to everybody. I wrote to my mother that I was sure of going home in a few days. At the hospital next day, out of 48 only two were able to serve; the other 46 were sent home and I was one of the two.

I began thinking of my mother waiting for me, how she would be running out to see if I was in every carriage that went by the house. I was worrying and could not stay with my friends; for they were very happy. The toilet was the only place where I could cry out my worry and plan what to do. I was tired of living, and only the thought of my mother prevented me from committing suicide. Finally I could stand it no longer, and planned to slip away and take the train home. I missed my train, but started to walk to the next city. I ran part of the way as the towers of the old castle seemed to be following me. On arriving at home, I found my mother and brother trying to get my things together. I had sent word by some new friends that I was leaving the army. My mother and brother came down the steps crying. Mother told me to return as I would be jailed for deserting the army. I told her I would return if she wanted me to; but the way I said it, she knew I was desperate. I wanted to go to Paris to a cousin, but she advised me to go to America, where my brothers would help me find work.

That same night I took the last train out for the border, walked up the mountain and down the other side into Switzerland. The next day my mother came with a town merchant and arranged for my ticket for America. Seven of the nine days were rough, and I had not been used to ocean traveling. I was very sick and ate very little. On landing I was directed to a steamboat that took me to New York. I cannot explain about the Customs House, and even now I don't know how it all happened. All immigrants were obliged to buy a box full of nuts, cakes, etc., and there I was on the boat half starved and nothing to eat while the rest of the immigrants were devouring sandwiches and cakes. I was all alone with no Italian to talk to. Well, I said to myself I can stand it until tonight; for by then I'll be with my brothers. I little dreamed how far it was from New York to New Hampshire. At the pier, where I landed from the little boat, there were two wagons, and I was crowded into one of these with a bunch of immigrants whose nationality I did not know. As nobody gave the driver any money when he asked for some, he dumped us down among the trunks. Near the sailors' quarters a can- 
vas stretched over some poles served as my bed. There I slept without pillows or blankets. I was seated on a trunk watching the sailors, mostly colored men, come down for supper. One noticed me and brought a large sandwich which I devoured in two bites. I thanked him in English and he spoke to me, but I told him I didn't speak English. In Boston I was sent to a taxi driver to be transferred to North Station. I had quite a lot of change, some Swiss, French, and ninety cents in American money, a half dollar being the largest piece of silver. I took out a handful of this mixture and extended it to the driver. He started for the half dollar, but thinking it too much, I closed and withdrew my hand. He got mad and called me all kinds of names. I then offered my mixture, not daring to say a word. At the station he bought my ticket and showed me to the train.

When I reached my destination, the conductor told me to get out. I could see no town, only two or three houses and a lot of bare trees. A taxi driver inquired if he could assist me, and I answered in the affirmative. He was not sure of the address because there is a great deal of difference when a person learns by a teacher and when he teaches himself. He stopped in front of my cousin's fruit store and waited for me to get out. I couldn't believe this was my cousin's store, because the year before he had come to Italy and described it as being like none in our native land. The driver waited a while and then started down street to speak to a man. I could see they were talking about me. I asked him for a pencil and with my hand showed him I was going to write the address. By this time my cousin, seeing my suit case with a rope around it (I believe that 95 per cent of the suit cases of immigrants from Italy get their handles broken off and have ropes fastened around them. Mine was like that), rushed out of his store. I went over to his house where his family began asking me a thousand questions. I told them first of all that I was starving and asked for food before answering these questions.

My oldest brother had a cobbler's shop and the other was working in a shoe shop. The day before Thanksgiving I started loading and unloading freight cars for a dollar a day. My brother and I were the only Italians there. I could not speak English and he knew very little. Many times when the old man for whom we were working told me to get something, either I didn't understand what he wanted or else didn't know where to get it. The poor old man used to swear at me and get what he wanted. 
Many times when thinking of my mother, my friends, and the good times of long ago, I cried, wishing I was there among them. Sunday was my worst day; for, as there was nothing to do, my worry increased. I felt miserably lonesome looking out of the window at the young fellows standing in the sun at the corner building telling stories. I thought they were awful. Sunday in Italy is the day to spend our money, the day for good times. But here the young fellows were standing in the sun like old people who were through enjoying themselves, and were saving money for their families. Nobody knows how much an immigrant suffers by this change of custom, work, and language.

Much suffering is the result of delusion. My own hands were nice, clean, and tender from working eleven years in a jewelry shop, but now they were full of blisters and my body was broken. America is not the same country our returned countrymen pictured it to us. Returning Italians come home bragging about how easy it is to make a good living with plenty of meat, eggs, beer, and wine. Everything, they say, is very low; a working man can save large sums every week. I have noticed that every time one of these fourflushers comes home, a bunch of young men leave for America. There is a saying that a man after landing in New York saw a five-dollar gold piece, while walking down street, but gave it a kick saying, "If I start to pick up money now, I'll be loaded before I am ready to go home." It is quite natural that a large number migrate to the United States where the dollar is worth more money. I don't remember any coming from South America with money or sending any home from there. What bitter disappointments await us here! The first two or three years it is hell, and some 50 per cent would return to their native country, even walk back were there no ocean, if they had the price and the courage to meet the town gossip.

My first real acquaintance with Americans began when I started working for my cousin in his fruit store. By this time I had gained some little working knowledge of the English language. I used to study my poliglotto after dinner while I was working in the shop, and whenever I had any spare time copy from newspapers so as to learn to write. It was easy to get in with Americans through my cousin, but not so easy in other localities. At one place my wife and I were there three or four months running a fruit store before the town people found that we were not as bad as they thought all Italians were. In some places where I have lived, I have found it difficult to find living 
quarters at first, but later have had many offers to rent. Even in this town I find it hard to rent a room; prospective tenants want to know how many children I have and then my name. When I tell them who I am, I know the outcome. Only last month a lady was sent to me by a matron for a room for her boy in my new $\$ 12,000$ house. When I told her my name, she said she would send the boy next Monday, but that was the last I ever saw of her, and the boy I never saw. My Italian name was enough for her. I don't dare use my name in advertising my business, knowing it would ruin my trade. On the whole, in every town I have lived, I have found it very hard at first to get acquainted and have been treated as an Italian, but I have always managed to make friends despite the prejudice against my national group.

In $1916 \mathrm{I}$ opened up a fruit store of my own in another town. I had very little money, and business was queer there. The policemen were against me, and every day there was something new to complain about. For more than two years I had to stand their abuses as I had no money to pay for a lawyer. Each time I complained to the police commissioners, I was nearly kicked out of their offices. One day in March a farmer, having some apples going to waste, made and sold me 25 gallons of sweet cider, the first I ever saw this time of the year. Two days later the chief came and asked if I had some sweet cider. I went home, drew out a bottle and took it to a lawyer, telling him of all the mistreatment that I had endured from the police. Two weeks later the chief of police was a plain citizen out of work. From then on my business prospered so that I had to give work to a girl and then to a man evenings and Saturdays. I overworked myself so that in $1923 \mathrm{I}$ took a pain in my back and spent a great deal of money going from one physician to another seeking relief. It was recommended that I take a vacation; consequently, I decided to leave my business in the hands of my brother and take my family back to Italy for a visit, our first during my seventeen years' residence in America.

Before I decided to go, I went to Boston to the Italian consul and told him about leaving the army (I was a deserter with a two years' jail sentence). He assured me that everything was all right - I was a free man like him. With my passport the government at Washington sent a paper saying that Italian citizens are subject to serve in the army until forty years of age and advising me that the American government could not help me over there. Again I went to the 
Italian consul and received assurance that I was pardoned with the rest. I then bought my tickets and invited relatives and friends to supper at my house. Just before train time that night, I received a cablegram from my younger brother in Italy saying not to go into Italy before seeing him in Paris. My wife began crying and did not want to go, but I said the consul knew more about it than my brother.

We made the trip. As the majority of travelers do, we criticized everything - the road, train, suits, houses, and children begging for money. My cousin, knowing the French language, took us to a hotel for dinner in Paris, and while eating advised me to stop near the boundary until I could get news from my brother. Accordingly my wife and children with my cousin went off for home in Italy. I was left alone in a strange town with strange people with no one to talk to. Time passed very slowly. Two days later my brother wrote me saying that a lawyer was going through the military tribunal to look up my case and he would advise me later what to do. Two more days, then my wife came and informed me that I must give myself up to the police and trust to being released; otherwise we would have to go back to America.

I could not bear to go back to America before going into Italy; all my friends had given me their addresses and wanted me to send them post cards; besides, I wanted to see my old town, relatives, and friends. We took the next train out and with our American passports got by the guards. Once in my native country, I thought I would stay and enjoy myself before surrendering. First I went to the American consul to see if he could help me get a duplicate of my identification card such as I received during the war, but he told me that I must procure that from my town. I told him I was willing to pay any price if he would send the telegram, but he left and I had to go out. For six weeks we traveled around while my brother went from one lawyer to another. At the end they all said for me to go back to America as soon as possible before I got caught. Taking their advice, we left Italy and reached Paris without any trouble. We had liked Italy so much that we promised to return for another vacation in four or five years.

I reached home feeling fine, thinking my pain cured, but after three or four months it returned more severe than ever. Finally, at the end of 1924, I decided to sell my business, believing I could never attend to it again. I wrote my sister explaining the circumstances and telling her how much income I had. She replied that 
everything was booming there and that I could live on my income and educate my children besides. I therefore sold my store and house with furniture and went back to Italy. This time we sailed on a national boat and landed at Genoa. The fact that I was a deserter did not worry me this time; for I was so bad off I did not care what happened to me.

My brother again busied himself hunting a good lawyer to fight my case. He found one well known at the military tribunal. I gave myself up as he demanded, and then he let me out on bond until my trial. After depositing 500 lire, I was released, tried, and cleared at my trial. I am an American citizen and now answer the call for the army from the American government. As a citizen my first American vote was cast for President Wilson, the best president we ever had. Now I am a free citizen of Italy because an Italian never loses his citizenship, no matter how long he stays out of Italy or how many countries he travels in or becomes a citizen of.

I bought a house and for a few months was very happy and contented, except when I received a letter or newspaper from my brother. I thought a little of my old life in America. At first I thought I never would be able to stand the filth and customs of Italian cities. I even dreaded to walk along the streets with my wife because the semipublic toilets were so embarrassing and the odor so nauseating. Even I told my cousins, wealthy manufacturers, that they ought to come to America and learn some decency.

Before the year was over, I went to the American consul and had my passport viséd another year. A few months later I began to think that I had only a few months before my passport expired and then it would be impossible for me to return to America. I found that my English was not so good; some words I was not sure whether they were right or not. Almost every day I went to meet the Paris train where quite a few American tourists stop for a drink or some fruit. By carrying these things to them, I could talk English. It seemed to me that I was becoming lost to America. For a few minutes I enjoyed the contact, and then it would all be over and I would return home. As the time came for my passport to expire, I began to worry; I didn't want to get shut out of the United States. I did like Italy, but I could not forget the years I spent in America, and more than all else I wanted to bring my children back to their native country. At length I wrote my brother asking him if he wanted me to care for his business while he made a visit to Italy. This would give me an 
opportunity to renew my passport. The necessary arrangements were made, and we sailed again for America.

It is hard for me to write my feelings on seeing New York, the skyscrapers and the busy boats and tugs. We were very happy and glad to be here on the land which we bade good-bye forever. Only the thoughts of our children in Italy saddened our happiness. On our arrival at my brother's, we were surprised to see so many people stop us to shake hands. This kept us busy for nearly an hour answering questions. Finally we got over to our friend's house and stayed there until night, and then returned to my brother's place. About eight months later we returned to Italy, thinking we would not worry for the next two years. On our way to New York I happened to look at the passport and found it good for only one year, after which it could not be renewed. That worried me a lot. As soon as I got home I went to Milan, to the American consul and told him that there had been some mistaks. He looked it over and asked how many times I had returned to Italy and I told him in 1923, 1925, and 1927. "Well," he said, "this visé is not a mistake; an American citizen stays in America and not in Italy. There is nothing I can do for you. You had better go back before that expires." I went home and wrote my brother in New Hampshire all about my difficulties and asked him to look out for a business location for me. I put a notice of sale on my Italian home, dug out my trunks, and got them ready for immediate use.

This was too much for me; I worried a great deal. I liked Italy very much, but at the same time I could not bear the idea of being shut out of the United States. More than that, my children would have to serve in the Italian army and would lose their American citizenship, doubtless damning me as long as I live. I found it exceedingly difficult getting a passport for the United States. This done, we again sailed for America. This trip was not as pleasant as the precading ones; on the others a job was waiting me. This time there was nothing waiting me - I didn't know where to go to find a job or buy a store. Many a night I could not sleep. For five months I was busy going from place to place looking for stores for sale. But nothing could I find that I liked. Most of them had been closed by the chain stores. At length, I decided to try my luck in this town. And here I am.

Note: Since writing this life history, the subject has sold his business and is again longing for Italy. In truth, he is almost persuaded to return to his 
native land, but the old question is ever present. Will he thereby be doing his children an injustice? Thus the conflict is beginning all over again.

\section{GREEK}

\section{A Greek Americanizes Mexicans}

I was born in the little town of Pikerni, province of Epirus, in the southwestern part of Greece - at present a disputed territory between Greece and Albania. My father, who was a merchant, died when I was about six years of age, and my only brother, younger than I, passed away a week later. Father's death laid on my mother the heavy burden and responsibility of caring and providing for little sister and me and for our grandparents who lived with us.

Mother sent me to school at an early age, but life was a burden, for she had to work hard to make ends meet and to make it possible for me to get an education. When I was about fourteen years old, I decided to leave home and chart out a channel for myself on the unknown sea of life, not realizing then that there were possibilities in store for me that I never dreamed of. I was determined to go out and try to make a living for myself and mother and sister. At first it seemed to be a perilous adventure fraught with dangers physical and moral which indeed were many and painful, but I started out to win. I went to Corfu, Greece, in 1896 . I was willing to work at anything, but I was quite dissatisfied with the people I worked for, and two years later I made up my mind to go elsewhere. I was thirsty for knowledge. I wanted an education, but where and how was a problem that I found impossible then to solve. I studied and read everything I could lay my hands on until the late hours of the night. I devoured current events, history, novels, and in fact any literature I could get hold of. I began to realize this world was larger than I had imagined heretofore. Reading such stories as the "Discovery of America" and Henry Stanley's adventures in Africa fired me with the spirit of adventure. I became very restless and dissatisfied. I thought I would go to Mount Athos in Macedonia, enter the monastery, and become a monk, but providence had decreed otherwise; instead of going to a monastery to live an ascetic life, I boarded a steamer and went to the city of Smyrna in Asia Minor, the city of the terrible and bloodthirsty Turks, the city of terrible ghosts of fears and nightmares.

I was a stranger among strange and hostile people, most of whom were Mohammedans. As they hated the Greeks and would massacre 
every one of them if they could, I knew my life was in danger. I had no friends I could rely on. There was no place I could find a shelter to spend the night. Doors were closed against me. I was often compelled to sleep outdoors. I was an outcast and a stranger on earth. I slept on a rough board bench on the sidewalk with no cover whatever to protect me from the cold. Often a heartless Turkish policeman would discover me and, thinking it was an unspeakable crime for a boy to try to catch a few hours sleep at night on the bench of a public sidewalk, in a rough tone of voice would order me to rise and move on.

$\mathrm{Oh}$, the heartaches, the sadness, and melancholy feeling that seized me in those days! I wished for daylight, but it was as dark as the darkest Egyptian night during my stay in Smyrna and in the interior of Asia Minor. I made up my mind to leave that country. I wanted to go back home to mother, for I was so homesick. I knew mother would be so glad to have me come home, but my heart would revolt against the thought of going back home empty-handed. I determined to go farther away from home, and one day I bade Smyrna adieu, and sailing along the coasts of Asia Minor, I landed in the city of Port Said, at the Mediterranean entrance of the Suez Canal, in Egypt. In this historic and strange land of the Pharaohs I tarried for a period of two years. I hardly think it is necessary for me to relate at this time my varied experiences of testings and trials during my exile in the land of bondage. Suffice to say that my cup of sorrows and heartaches did run over. I found that life in Egypt's sands had no charms for me. I left that country on board an English steamer bound for Scotland. From Scotland we went to South Wales. From South Wales we sailed to many parts of the world on English vessels. More than once we were shipwrecked.

In 1898 I read with great interest the incidents of the SpanishAmerican War, and I became an admirer of Americans. I admired their spirit of chivalry and gallantry. I never shall forget Captain Hobson's daring feat on the Merrimac, and the naval battles that crowned the American navy with laurels at Manila Bay and in Cuba. But it was in England that I met a young Greek who later came to the United States and settled in Pullman, Illinois, who induced me to come to this country. He described things quite favorably, and I decided to come. We left England on board the American transatlantic boat Westernland in March, 1903, landing at Philadelphia a few days later. 
I heard that America was a great and powerful nation, that this continent was inhabited by red men called Indians, and that there was wealth and plenty of it for everybody.

I spent four years in Chicago and Pullman before coming to California. As my ambition at first was to make money and then go back and live in my native country, I did not care what state I lived in so long as I realized the ambition of my life.

I came from Chicago to California in 1907 to enter a private school. I wanted an education and felt the need of preparation for a life's work of usefulness in the social and moral uplift of humanity. The hand of God moves in mysterious ways his wonders to perform. My original plans and ambitions came to an end right here. While attending school, I came in contact with the Mexican people and I became deeply interested in their social, moral, and spiritual uplift. I began to study the Spanish language, and during the last twelve or fourteen years, I have devoted most of my time and energy to the work of making better citizens out of the great number of the Latin American neighbors who come to the United States.

The work of Americanizing the immigrant appeals to me more than anything else, but I find it rather difficult to get in touch with the proper organization to collaborate in a work which is so interesting to me and which is so essential if the program of Americanizing the foreigner in California and other states in the Union is carried on to a complete success.

The first thing that interested me when I landed in the United States was the U.S. immigration officers in the immigration building in Philadelphia. The doctor examined me to see that I did not smuggle in any foot and mouth disease, or some other contagious disease. In no other country under the sun was I ever subjected to such scrutiny, and it was a sigh of great relief that I gave when I heard that I was admitted to this country as a persona grata.

The next thing that interested me was the passenger trains. The coaches seemed as if they were a mile long, and it looked as though you could put in them a regiment of immigrants. Think of it, they were lighted by electricity, heated with steam, equipped with upholstered and reclining chairs that gave real comfort by day and by night. And what a surprise to observe that the coaches were not divided into several compartments, marked I, II, III class, like those we had seen in Europe, Asia and north Africa. Of course, when I first saw the tall buildings in Chicago - they called them "sky- 
scrapers" - I had the surprise of my life. I marveled at the ingenuity of American architects. They certainly aim high in this country. The sight of so many factories impressed me with the thought that the Americans were very industrious. I also noticed that nearly everybody was reading newspapers, and all kinds of periodicals.

It was rather difficult for me at first to understand the cause of so much of prejudice and ill feeling on the part of Americans against foreigners. I could not see why they were so often made the recipients of so many insulting remarks. They would often call us "dagos," "greenhorns," etc. I didn't understand what it all meant. I tried to behave myself as well as I knew how and make as favorable impression on Americans as possible. Down deep in my heart I knew there must have been a reason for this hostile attitude toward the foreigner. After some observation, I discovered that this racial hostility was particularly strong against the foreigners from the south and east of Europe. The immigrants of the north of Europe seem to enjoy greater respect and social freedom than did the former. I tried to analyze this mental attitude of Americans toward these two particular classes of foreigners, and concluded that the Americans and Anglo-Saxon immigrants are closely bound by racial ties, that "this nation in all the essentials of its life and character was grafted upon a historically definite and distinguishable North European or Anglo-Saxon stock."

Also there must be another reason, perhaps more powerful than the first, i.e., the Americans in all probability feel that the North Europeans possess moral, ethical, and mental qualities superior to those possessed by the South Europeans., Was I mistaken in my belief? Judging human character by human action, I am bound to admit that the North European immigrants behaved much better than those of us who came from southeastern Europe. They had better moral standards. They were skilled laborers. They lived in better homes and they had their families with them. Moreover, they come to this country with a view of establishing here a permanent residence. They doubtless make better citizens.

In my opinion, the key that unlocked the gateway to success was a practical working knowledge of the English language. I knev very little of it when I came to this country. I realized the necessity of learning the language; for without it I could make but little progress. There was very little opportunity to get hold of the language 
in the Pullman car shops because the majority of the employees were a conglomeration of foreigners, a veritable tower of Babel crowd, a confusion of tongues. We addressed one another in what we believed to be the English language, conveniently using laconic phrases from our limited vocabulary. For emphasis' sake we supplemented our speech with the characteristic European gestures, an abundant supply of which we held in reserve against the day of emergency.

To overcome this difficulty I found my way into the public evening school. Later I changed my place of residence. I left the Greek colony and went to live with an American family. This was my turning point. I began to find my way. I was getting adjusted to the United States by establishing a point of contact with real Americans. I came to the parting of the ways, and here I followed the sign which said: "Keep to the right." I took out my first naturalization papers. I wanted to become an American citizen. The teaching and training at the public school are the links connecting the foreign element to the citizenship of this country.

It was very natural that I should feel at home with my own countrymen. Others were altogether strangers to me. I was glad to meet those of my own race in a strange land. They all tried to make it as pleasant as they could for me upon my arrival to this country. By dint of perseverance and thrift, many of my countrymen had made good in business.

I will take the liberty to mention three things that have given me a severe and painful shock since coming to this country. These are:

1. The wave of crime. One is appalled with the crime in the United States. In no other country can records be found to compare with ours. What is wrong? Is it not the slow process of justice, the legal technicalities, the inability of the prosecuting attorneys properly to present evidence conclusively, the criminal statutes which enable the criminals to protect themselves, light sentences and the use of minimum sentences, both of which breed contempt for the courts in the minds of people, and the allowing of crimes to go unpunished? If inflamed youth run amuck with no regard for others, well-paid alienists pronounce them innocent children, dreamers, "dementia Americana."

2. The divorce evil. The divorce mills are grinding fast in this country. Divorce spells the ruination of the American home. This nation is in danger of reverting to the immorality of paganism, unless it retuins to the morals of the New Testament. 
3. The freedom of young people. There is a freedom of young women in the modern stream of life that is indeed shocking. Parents either do not care or are powerless in exercising a restraining influence over their children. There is too much freedom in sex relations among young people. I believe that discussion of love matters is perfectly proper if they are discussed in the right spirit, but the billboards, the newspapers, and the movies are not the places for such matter. There are sentimental displays in many daily papers of such objectionable nature that they should be prohibited by law. Youth here is determined to chart out a channel for themselves. They refuse to be bound by tradition, by convention. I question sometimes whether parents raise their children or children raise their parents. In Greece we were taught to love, reverence, and obey parents, and to provide for them when they grow too old to care for themselves.

I attended a public school in Illinois when I first came to this country. Later I attended a private college in California, then a business college. I went to Texas and taught in that state. In all these associations, it has been my happy privilege to know and be associated with a great number of real, genuine Americans. I think the majority of them are the cream of the earth. My relations with them have been intimate, pleasant, and profitable. The more I associated with good Americans, the more I learned to love them. Nothing has ever occurred in my experience to cause a break of friendly relations. Of course, there are faults to find and weak points to observe, but that disease afflicts my own people as well as Americans. I think of this country as being the greatest benefactor of mankind; the defender of the rights and liberties of weaker nations and people. The government is on the shoulders of the people, and it shall not perish from the earth. The spirit of American democracy is permeating the heart and life of the nations of the world. Its people are always generous, always seeking an opportunity to express the spirit of benevolence and universal brotherhood when an emergency arises. Greece owes a debt to America for all the benefits she has received, especially since the World War, that money cannot repay.

I have no desire whatsoever to return to my native country. I married an American girl, and my two children were born in this country. My interests are here; it is my purpose to keep my children here. I came to make money and then return to live in the old country; but in later years I came to realize that money and wealth 
are not all there is in life. There are greater things than money and fame. The greatest value in life is the bringing of character to its highest efficiency. I find joy and contentment in the service of humanity; the joy that comes when other's griefs grow less. It is the man of wisdom, initiative, energy, and perseverance that can hope for success here and everywhere. But this is no place for idle dreamers, but for a definite program in life. Here everybody is given a fair chance, and it is up to him to make good or trail behind.

I believe in the universal brotherhood of man - that we are our brother's keeper and that human nature and human needs lay on us the responsibility to meet these needs. The strong should help the weak. These ideals can be worked out successfully only as they are based on the gospel of Christ. I want my children to grow up into useful manhood, men of sterling character, and good Christians, loyal to God and to the United States. I want to give them the best possible education which will fit them for life's work.

\section{MeXICAN ${ }^{1}$}

\section{Villa, the Rio Grande, and the United States}

"You like ver' much to know how I am come to America? Well, it no to make the tiresome story and I have not to be here so long that I forget. I think it is ver' funny, now, how I scramble round and round to get over here $-\mathrm{I}$ have one time too $-\mathrm{Si}, \mathrm{Si}$, pardon I begin at the first.

"I am Mexican, you can know that already. I am born in Hermosila, one long time ago. We live here till I am five and then we go to Vera Cruz. It is ver' nice there. I go to school, my sister too, and get pretty good educated. Mi padre have one good job and we like much to live here. Always I want to be a bank man; perhaps, they no work so ver' hard and yet have money, much! Mi padre, he say often to me, 'My son, be good and get good educated so you can be one big man some day. But my son, don't never be a soldier; all they do is get shot, for the government is for always getting them into the grand trouble.'

"Mi padre is very wise man, so I make always to mind what he say. The time it pass so ver' fast, like the birds when they go to south, and almost soon I am one big boy. Sometimes. I work and sometimes I am in the school and all the time I am ver' happy. On the street,

1 Life history obtained through the interview method. 
in the town, sometimes I see the Gringos that come from the big ships out in the harbor. Always they are clean and look so cool and nice and have much money. I think it be ver' nice to have much money and say when I am a man I will be ver' rich. I think I am now one man then - I am fifteen!

"There it is the trouble start. Men come riding through town on horses ver' swift. Mi padre say they mean no good, are one ver' bad sign, and keep Carmelita with me, close in the home. We not like thees much, so one day we think we go to walk on the street, when our padres not look so close. We have not to go far when a man come by and yell to us, 'Villa Vino! Villa Vino! Corre! Corre!' The horses we see coming down the street ver' close. I shove Carmelita under the vines that grow over the wall and lean against her so they no can see. Soon they go by. I see many boys and men with them that I know. They all are look scared and some are hurt. Then while I watch a soldier man stop in front of me. 'Here's one,' he say. I try to run away but he hold me. 'Not so fast,' he say, 'I think I like you to go maybe - when say comrade?' The other look at me, he feel my shoulder - my arm, and say, 'No, he is too little, he is cry for hees mama.' He laugh big at me and knock me down, but they do not make me go and they do not see Carmelita. For thees I am ver' glad and so soon as they are gone my little sister and I go fast to our home. Our padres are ver' angry with us and much frightened, and ver' soon we make to leave the city. Mi padre, he say he like to go somewhere to the place where the United States soldiers make everybody behave - maybe to U. S. A. So it is that we go on the train to Juarez.

"The town is all ver' excited about the war. They say Carranza soon kill Villa and war will be over! Mi padre shake hees head, an' say it is not so. Villa, he say, is one ver' bad man, and when he is mad, he be mad one long time. We not know how to go over to America. The soldier say no, and we can't speak English so that we can't know how. We try to speak the English, but it is ver' hard to learn. Se we must stay south of the big river. Mi padre, shake hees head ver' sad like and go out to find work.

"For many days it is quiet, like the quiet after lightning and we all wait for the thunder! At last it happen! Mi padre comes running home and we are to hide. The streets are full of horses and men, all shouting and making noises. Villa is come! My it is awful! He shoot up the whole town. Before we can go, the soldiers are come. 
Mi padre and I are put on one horse and made to ride with many other men.

"We ride for two - three hours, maybe, and then we come to a camp. It is in a deep canyon and is a muy grande camp. There is a man here with great moustaches, that talks to us. He tells us we will have great fun and make much money if we fight for him, but if we run away the soldiers shoot us. He is talk a long time and many cheer him when he is finish. But mi padre run up to thees man an he say if thees man just let me go he fight for him all he like.

"The big man roar to mi padre, 'You fight all the same! I make you fight!'

" "No! Then there to you!' He knock mi padre down hard to the ground. I would run to him, but the soldier, he say I only make it more worse.

"The big man say something loud and they catch mi padre up and drag him out in the open and leave him stand there alone. Still he is like dizzy from the knock in the head and he sway - so - while he stand there. Somebody shoot, he is straighten up quick like and then fall on hees face - like that - soon!

" "Padre mio," I call. He no answer me. I think I must die, but it is only the faint. I hear the big man roar about the 'example' and then all is dark. That night when I woke up the stars are over my head and I am ver' cold. All around the men are sleeping. I think of mi padre and am ver' lonesome, for I know he is dead. I am think of how he tell me I must never be soldier, so I make to leave. I slip by the man with the gun ver' soft like and go away across the desert.

"I go for the long way and after awhile I am ver' tired - I think I rest. I sit down by some bushes in the dark. There is one hand, that is look ver' big, reach out so strong like, and I am drag back. Oh! I am caught I think - but no - it is a boy like me. He say soft like and hiss through hees teeth, 'You crazy fool! You like to get caught. Don't you know they see you if you no hide?' I say I maybe can outrun them.

"'I guess you no know about guns and horses, eh?' and he laugh again at me - nasty - so.

"'I think they no shoot me,' I say, and he laugh again at me pitiful like.

"'You let them catch you and see if they no use the guns.'

"It is then I understand I am the deserter and they kill me if I 
am seen. For two days we are hide like we are much afraid to get shot. But when three days are come, I think I so soon get shot as to starve, so I crawl out to find something to eat. I do not go far and I see smoke and smell the food. Ah! My, but it is good! I climb up to the bank to look over and I nearly die. There is the camp!

"They have tell me in the night when people walk on the desert they walk round - you know - in the ring. I can understand that is what I have done. But now I think of nothing but to run. I jump up and am turn round - Oh! there in the front are two soldiers. I make just to sit back down.

"'So he have starve out, eh?", say one.

"WWell, well, I think the captain have to see you - maybe he like you - no es verdad?' and they both laugh to me - ver' bad.

"I am go to the captain; he look at me ver' fierce and say, 'Boy, learn your prayers, you will die en la mañana.'

"The next morning I am line up, with many other deserters, out in the desert. Behind us is one long line of guns.

"' Now,' say the Captain, 'I am ver' good, so I give you the chance to die like the soldiers - I say "Go!" - you run - maybe so you get away - Ha! Ha!'

"We all laugh, too, but it no is much fun - the guns are ver' grandes. Then we are on the line, some one say 'Go' - I hear the guns and then, like the red-hot knife, something hit my shoulders. The blow is ver' strong and I fall. I am bleed ver' much and I wrap my shirt over the cut, but the world go black and I am faint.

"When I wake up is like the great red ball in the west and I look round me. All over the ground are my friends. They do not stir, but are ver' quiet and still. I wrap my arm up, like I can, and crawl back in the bushes to rest. Soon some men come with horses and drag my friends away. It make me ver' sick and I slide away over the desert.

"All night I walk and in the morning I am come to Juarez. I go at once to my home but mi madre and Carmelita are gone away. Some kind friends take care of me till I am well. Then I try to go to U. S. again, but no, I find it cost me 50 pesos. I no can get the money, so I must go to work.

"The days are go past and all is quiet, but I know Villa will come again. I pray that I may go before he come. I know he kill me. Eighteen days are pass. I have nearly my money. Then come night, but Villa come too! The people are so scared, many shot in 
the streets. The houses take fire and all is like awful. While all is noise, I am slip away. I go to the American guard and beg to be let over only for once, but they say they no can do it for me! I look back, and the soldier are coming for me. I have only to die anyway and I think the river may not be so wide. So I jump from the grande bridge to the water.

"I seem to fall for one long time then the water is close over my head. I fight it away and begin to swim. I hear shouting from the shore but I go on. I do not even look back. The river is much swift and wide and I am go many miles down with the log I find, before I find America.

"I have one hard time to start. I no can speak the English only a little word some time. But I am always work ver' hard and soon I can go to Los Angeles. There I have one job ver' hard I am fix - no dig the ditches - grandes ditches. The work is ver' hard and the city is not so kind to strangers, so I think I try to find some better thing.

"One day a man say to me, 'Junito, you are ver' smart boy. Why you no go to school? You learn English and have one fine job if you want!'

"I say that is ver' fine - I like to go - but how am I to live? They no pay you to go to school!

"I have the friend, then, who say he is going to Santa Ana and if I go he let me help him work. I am still to be here. Soon I learn of the night school. Now, I have go there for two years. I have learn the English - is it not so?

"How old you say? I am twenty and two. You see thees shop? It is mine now. Here I have many fine bicycles. I have make much money that is in the bank on the street. Some day I am buy that bank maybe and the home here. Soon I see mi madre and Carmelita. They will come to live here too, but they no will have to swim the Rio Grande. I think they like America, mucho - like me.

"No, I am not yet the citizen. There is the little farm in Mexico that is mine and I lose it if I am the American. But soon I sell it when mi madre is here, then I be one fine American! It is good, here in America, I am know that I like to stay always.

"My is not one ver' good story, but you will be glad I am here mi amigo, no es verdad?" 


\section{Mexican}

Cannon Fodder in Mexico, Beast of Burden in the United States, But a Golden Opportunity at Last

It was in the Immigration Office at El Paso, Texas. "So you are looking for a better opportunity?" asked the official.

"What was your occupation in Mexico?" he inquired.

I had shame to say I was a school teacher and I said that I worked in a printshop. In fact this was my work before going to colegio.

"Show me your hands," he said. I extended my hands. "Poor boy," he continued, "your hands are very soft; don't you know that here you are going to work with pick and shovel?"

I replied: "Now I have left my country and I am ready for everything."

I had come from my native town, Parral in northern Mexico. The Revolution was then at its height; Villa was the terror of the North. As I could see no opportunity for my future, I resolved to come to the United States. In October of 1916 I left my home with sadness in my heart, abandoning everything to seek a better opportunity for my future. Arriving in El Paso, I began to dream as I glimpsed the city. I inquired of myself: "What will be my future in a foreign country, where I have neither friends nor acquaintances?"

The day after my brother, another friend, and I arrived at Jaurez, we crossed over into America. After making us answer many questions in the Immigration Office, the officials led us to the disinfecting plant. It did no good to tell them I had taken a bath a few minutes before; I had to take another, and meanwhile have my clothes disinfected. I made a bundle and tied it with my belt. It was placed in a very hot oven and came out ready to be put on again, but my belt, being of leather, was wrinkled with heat. They took the photograph of us, vaccinated us, and let us leave with the rest (about 100) through the back part of the building. There we were lined up and treated to pretty stories by labor agents. Some asked us if we wanted to go to California, while others begged us to go to Arizona, Colorado, or to other states of the Union. At last I resolved to go to Pennsylvania.

During the journey they gave us nothing to eat except crackers and sardines, heavy food for the digestion. Since that time I do not like even the odor of sardines. They prohibited us to open the 
windows of the car, having mistrust that we were going to escape. Every morning a man came in and counted us as if we were prisoners; every evening he did the same. And I asked myself: "Is this the land of liberty?"

After four days on the road, we arrived at Reading, Pennsylvania, about ten in the morning. I was very tired from such a long journey; on leaving the train, I felt a cold more icy than that of El Paso. They took us off to eat, and, after the meal, to work on the railroad track. They gave us big shovels to fill some coal cars. Everybody looked at us like curiosities, and some were afraid to come close to us. The only sympathy upon which we could count was that of the foreman, who never tired of telling us to work faster, and so we had to work ten hours daily.

Excessive work, little sympathy, and being in a foreign country filled with bitterness my heart and made me consider the Americans as my executioners and not as my brothers. I thought I should be better off in Mexico; but I remembered that my purpose had been to come in search of better opportunity and it gave me pain to return to my country in a worse condition than I had left it. Every evening I remembered my fatherland; I liked nothing in this country, since I found nothing except pick and shovel, as they had told me in the Immigration Office. There was a time when I longed that a train would run over me, such was the melancholy that I felt.

We lived in a house near the railroad tracks. It had no flowers. Every afternoon we used to come home from work, and to cook and prepare our supper and lunch for the next day. On Sundays while we were doing our washing, some American people from the town used to come and see us through the windows.

Every day the weather was getting more cold. One night it started to snow. We were making our lunches for the next day when somebody knocked at the door.

"Come in," we said.

"Hello, boys," the foreman said, "I have come to take you to go and clean snow from the switches."

We had to leave our cooking and went with him to the signal house. He gave us brooms and shovels. Large flakes of snow were falling down. We went out to clean switches, and after one hour, I did not know whether my hands were mine or somebody else's. With my hands half closed, I couldn't move my fingers, not even could I hold the broom. The tears came out of my eyes and of my 
nose. I knew that I was not crying, because I never cry with my nose. I was frozen to death.

The foreman took us back to the signal house and brought us to the stove which gave heat to the building. There, by the heat of the fire, we began to dry our clothes, and after warming ourselves a little, we took another time our lanterns, our brooms, and our shovels, and went out into the snow and cold. About one o'clock in the morning, the snow calmed itself and we went back to our house to sleep.

There arrived the Christmas of 1916 . We went to bed as was our custom. Perhaps Santa Claus came to all the homes except our house. The next day we did not work, because it was Christmas. We saw all very happy, but to us there was no one who should say "Merry Christmas." That night I dreamed that I was in Mexico and that it was my birthday. All my pupils had made me very pretty gifts. But this was a dream, nothing more. One week afterward was the day of the New Year, and I heard some say to others, "Happy New Year." I thought, "Maybe the year is happy, but not I."

A few days afterward I received a letter from my younger brother, who was in Indiana Harbor, near Chicago. He said: "Come; here the work is better than where you are." I took out my time, and joining all my capital, found I had collected in three months with many sacrifices forty dollars. When I arrived it was night and the snow was falling. I did not know how to speak English and I did not know the town. But I ventured to seek the address of my brother. I found him sick in bed with a strong cough and without any one to help him with anything. The owner was an Austrian, who came only to see my brother each time he wanted the rent. That same night I went to the drug store at the corner, and as best I could, I asked for a remedy for the cough and took it to my brother. After two days he could go to work in the steel company.

After working there two months, they told us that we had to become American citizens, or they would take the work from us. We were eight Mexicans who were working there, and no one of us wished to become a citizen. Instead we left the work. It was impossible for me to be a citizen of a country where there was no sympathy or consideration for me.

Three months we worked in a lead mine in Wisconsin, and then in the month of June we resolved to return to Mexico. Arriving at El Paso, we found that the Revolution had not yet ended. My brother took pneumonia, and when we had no money, I went to look 
for work in a cement factory. There I stayed, working nine hours a day and gaining a dollar and a half, with which I sustained my brother and myself. I did not feel very happy with this opportunity and looked for another, but without success until one day one of my friends told me that the best of the United States was California. Then I resolved to come to pick beets in California.

The 14th of September, 1917, forty-five of us, all Mexicans, left El Paso bound for California, and arrived at Zelzah, California, early on the 16th. The superintendent knew how to speak Spanish. As soon as we had breakfast, he took us to see the tents where we were to live, and what was my disgust to see that in place of bedding they had loose straw on the ground, without blankets or anything. This was an experience not very agreeable.

I had to say to the superintendent: "This is not just." And I asked him: "Would you like to sleep in a place like this?" His answer was "No." I told him then that if they treated us so, we would not work, and we were going to object. That same afternoon they brought us bedding and charged us nothing for it.

The second difficulty was the food; they gave us food about three days old, resulting that all of us got sick at the stomach. Then I had to object again to the superintendent. He discharged the cook, and on the day following he called me to his office to tell me not to go around stirring up the people, because he was going to send me to jail.

The beets were ended, and already they had us contracted for the cotton. They promised us a good place to sleep and to pay us three cents a pound. We arrived at Yuma, Arizona, at night, so that we should not know even where we had arrived; there in the station they divided us into different groups. I went with five others to a ranch not very far from Yuma.

The following morning it resulted that the rancher was going to pay us only two cents a pound, and he had no place where we could sleep. We did not like this and we said: "We will not work under those conditions."

"I will arrest you then," he said.

"Do it at any hour you like," we answered. But he did not do it.

We left the ranch and in Yuma they told us that the cotton was better in the Imperial Valley of California, where we directed ourselves immediately. We went to pick cotton on a ranch near Calexico. After a week of picking, I saw I could earn only enough to eat, be- 
cause I did not know how to pick fast and I left this beautiful opportunity to become a good cotton picker.

I left my companions and directed myself to Calipatria, where I found work cleaning ditches. Here they did not give me even straw to sleep upon, but I had to sleep out on the sand without bedding or anything. In the morning I would get up with my ears full of sand and as tired as the night before. My situation was getting worse day by day. Two weeks I could stand it, and I left the work, taking the train bound for Phœnix, Arizona, where I arrived the following day. At the time cotton picking was the only work, and I had to resign myself and go to picking. I stayed there until the cotton season was over.

One day in the month of April, 1918, when I was visiting the employment office in Phœnix looking for work, the owner of the office said to me: "Do you want a good job today?" "Yes," I said. Then he explained to me what he had to do.

"There have come to Phœnix agents for those who are shipping laborers to Alaska. Already they have five hundred Mexicans. We do not want them to go out from Phœnix. You tell all the Mexicans you can find not to go to Alaska, for they will make them work hard, and will not give them what they promise."

So all day I followed these Alaska agents around and when they stopped talking, I told the people not to go with them. I said: "They will make you work hard, and will not give you what they promise." With how much pleasure I did this, since I said to myself: "If they treat the Mexicans here so, what will they not do in Alaska?"

I went to work at a ranch to plant beets and there I stayed in that ranch until the month of July. When I could no longer stand the heat, I resolved to return to Mexico. It was the month of July, 1918, when I arrived at El Paso from Phœnix, Arizona, and determined to pass over into Mexico. But then I heard that the revolution had not yet terminated. I also began to think that I had not found the class of opportunity which I was seeking. I thought of my first experiences in the East, of those in El Paso, and of the last ones in California and Arizona. All of them were bitter. But on the other side of the frontier was the revolution. I did not know what to do.

Some days passed, and at last I chose the East and left for Pennsylvania a second time. So I wandered here and there until I arrived at San Francisco, the city of the Golden Gate. Here in truth I found the gate of opportunity. It happened in this way. 
One day I stood at the street corner, asking myself where to go next. Then an army sergeant touched me on the arm and said:

"Friend, do you not want to enter the American army?"

"How long?" I asked.

"One year or more," he said. I thought of all my sad experiences and then I said: "Yes, I will go for one year."

I was lying on my bunk one day in the Presidio barracks at San Francisco when suddenly I heard my mother's voice call me, "Jose, Jose." It was so plain, and I thought: "Can my mother have come from Mexico? Is she now below in the street?" I went to the window, but no one was there. Again I was in the bunk, and a second time I heard her voice, "Jose, Jose." I ran to the window, but again nothing. I remembered how she prayed always for me to be a minister. She was a beautiful Christian. I resolved to do it. After some time I found the Protestant Spanish Church in San Francisco and worked with them. That was four years ago. Now, thanks to God, I am their minister.

So I found my Opportunity. In the Christian Church I found friendship and sympathy. Now I want my countrymen to find the same. I want them to find it in the Christian Church. I want them to find it also in their working places. For there I did not find it and I know they need it there.

\section{Mexican-Indian}

\section{Running Away from Home, But Not to Marry. Why?}

An early dawn in a crisp January morning, a misty view of two cities divided by a wide but shallow river, the sounds of bells calling the faithful to early services, a moving train which slowly but surely was carrying me to lands unknown - these were my first impressions, my first picture, and my first introduction to the United States. I have had many introductions since, but none as vivid and lasting as this one.

My people left the place where their ancestors had first roamed the mighty Sierra Madre Mountains, and later, under the Spanish rule, suffered patiently the tyranny of the conqueror, until 1810, when they too joined the move for independence and freedom. How well they, lovers of freedom always, succeeded history tells. To those who groaned under the "iron fist" of Diaz, the man whom so many Americans seem to admire so much, expatriation seemed a heaven as 
compared with suffering under a system which deprived them of the very thing for which they bled and fought so faithfully. In the early '90s an uncle of mine left Mexico, disgusted with everything in general, and went to Texas. His letters were very encouraging regarding the prospects for Mexicans in that country. They brought us visions of wealth and freedom. Freedom appealed to father most. Conditions did not improve; men continued to "disappear" and nobody knew where. (This was one of Diaz's systems for ridding himself of any opposition in his new policies.) Nobody knew what would be next. None dared to speak or think. In such conditions father's decision to emigrate was born.

Lest he too might disappear, father with his family, including us six children, decided to move for freedom. We eame in the worst time of the year. Texas has two decided extremes. In our mountains the weather is ideal. One eannot tell the month by the clothes one must wear, or by the way the sun smiles. Mother and father found it hard to endure the snow. In our mountains the peaks miles away are eternally eovered with snow, but this is merely seen, not felt. I must admit a difference in these two terms. In the process of adjustment father died. His one regret was having to die in a foreign land. Mother, thoughtful of his last wish, took his remains to the mountains he loved so well, and there he lies today. Father's relatives wanted mother to return with all of us in order that they might help in our education and proper rearing. Fortunately mother had seen the advantages of being in the United States alone with a brood of six children to support, and the disadvantages of being in the same state in Mexico. She decided to face life alone in this new country; consequently the course of our life was completely changed.

On the hardships we underwent while in this transitory period I shall touch but briefly. Suffice it to say that we suffered. Mother was an excellent cook and housekeeper; she did not find it difficult to get work. Although she toiled every day, she found time to keep our clothes clean in order that we might look nice to our teachers. Social workers were then unknown, and no one, not even the kind Sisters who ministered to our intellects, ever bothered about us or seemed to worry about how or where we lived. It was thus in this huge Mexican eolony in Texas, where all of the Mexicans lived far removed from all American influences, that my education began.

Mother, like the rest of the Mexicans, believed that children were an asset. Elementary education might be all right, if the ehildren 
could be spared, but higher education was worse than foolish, especially for girls. With a million interruptions due mostly to the most unreliable of all crops, cotton, I finished my grammar school. Like our other countrymen, we graduated from roaming to city folks and moved to town. Being a girl, I was put to work, while my youngest brother was sent to school and given a chance to be somebody. I did not take kindly to this work, because I felt that I too could be somebody if I were permitted to continue my studies.

The idea of disobeying mother had never occurred to me, but I tried to reason with her, all to no avail. I must work, and to work I went. Laundry work seemed to be the only thing open for young Mexican girls, and there I went. We earned the paltry sum of $\$ 3.50$ a week, a great fortune it seemed to me. Soon I was earning $\$ 1.00$ per day after I learned to run the complicated machinery. The laundry, however, offered another special inducement to me. Books were a thing unknown in our house, unless the Lives of the Saints, written and sanctioned by the church, could be so classed. Prayer books of all sorts, and statues and pictures of saints in large numbers, were, as I remember, our sole source of knowledge. But all unknown to mother there was a public library on the very street leading to the laundry. I became a bookworm and spent all my spare time at this blessed place. The girls at the laundry would congregate around me at the noon hour to hear me read to them. I would recite poems, and a more interested audience no reader ever had. I became their official reader and writer. They looked up to me, and I yearned to know more. After all, the laundry became my opportunity. I felt with George Eliot when she once wrote: "You may try but you will never know what it is to feel the genius force of a man within you and suffer the slavery of being a girl!"

A change was going on within. Mother, sister, and my brothers could see and feel it. I literally burned with the desire to burst forth into action, where, how, or when was not very clear to me. I felt a tempest approaching, and somehow I knew that I would be directly in its path. No amount of talking from timid sister, who feared I would be lost in the maelstrom that would follow a complete break from the family wishes and customs, ever subsided my eagerness to do it and have it over with. Finally it came. I had a big book which once served the purpose of a ledger. It had many clean pages which I utilized to jot down quotations, and many original doggerels of my own. All my reading had been done in Spanish 
(I never shall cease to be grateful for the wise provision which has placed books in various languages in the public library); consequently my writing was in the same language. This scrap book of mine I always kept hidden, but somehow (and that is a mystery to me yet) mother found it, and I was doomed. It supplied mother with the reason for my seeming change. I had dared to disobey by thinking the unthinkable, and I must suffer the consequences. Either I must give up my unruly conduct or become an outcast. Days of bitterness followed. I was taken from the laundry and shut up to think it over. For days nobody spoke to me. I was to all purposes an outsider.

Lest any one thinks that this is an easy and pleasant thing to do, let me say right here that it is not. I still loved the Virgin Mary, and how I did pray to die! I did not die; a wise Providence provided an escape from this horrid situation. Somewhere I had heard that in California there were opportunities for every one. I confided in my sister my intentions to go to this state. At first she was horrified at the idea, and would not listen to my plan. Finally she consented to help me. We kept the whole thing a secret from everybody. Sister earned $\$ 9$ per week, and out of that she saved enough to assist me in my undertaking. One Sunday morning on our way to church, we went to the station, sister and I, and there we waited for the train. Dear sister, she wept. In my thoughts for adventure there was no room for tears. The train was once again bearing me from one known world to another unknown world. This time too, there was a mist as the train rolled out from the city, but not of early dawn, but of tears, which when I was alone could no longer be suppressed.

My hardest battles were fought with myself. I solved the conflict at home by turning my back upon it, but no amount of running away could save me from the conflict within. The thought of what people would say and think of me for leaving home was almost unbearable. No Mexican girl that I know of ever ran away for any purpose other than to marry. Of course, when the word went around that I had left home, wise heads would shake and the only question would be: "With whom?"

I had seen California on the map, but did not have the slightest idea of just how to get there. Fortunately the train settled this for me. I arrived, and my first thought was of a job. I sat in the Santa Fe station waiting-room and went over the "Help Wanted" advertisements. I landed a job, but not without difficulty. Hav- 
ing answered my "ad," I set out to find the place. A nice policeman gave me directions, but I must admit I understood them only in a deaf and dumb fashion. This job was doing everything except cooking, which I was to learn later and add to my list of duties, and netted me $\$ 10$ per month. "Nostalgia" is the Spanish word for homesickness. A real malady it is; I know.

When my housework was well under way, I began work at school. First let me say that although I had been in the United States for several years, I knew nothing about Americans or their country. I only knew that there were books in English and that in the Sister schools where I had been, an attempt had been made to teach me the language, but instead I had learned to pray in Bohemian. My English was, therefore, limited to books and nothing more. I felt greatly handicapped in not having a working or speaking English. I shall never forget the confusion at school. The rush, pushing, and loudness of all the students when the bells rang seemed to me like the confusion which must have existed at the Tower of Babel. I had never attended a public school before, and never dreamed that students could behave so, particularly to the teachers. To us the nuns who taught us were almost like the very saints themselves, and naturally occupied, so far as we were concerned, a place of their own. We never thought of being rude to them, or of being right down "sassy." The students' attitude toward their teachers was very apparent; I was shocked beyond words. I shall never get used to the attitude of the average American high school student toward his teacher. I thought the girls bold, and believed that the liberties the boys and girls took toward each other were almost beyond all words to tell. My courage almost gave way the first day. Always before, mother or brother had taken me to school; now here I was all by myself trying to get adjusted to this bedlam - a madhouse it seemed to me.

Each day I had something to overcome, and always from within. That ego, as every one knows, is an awfully important thing. I wonder if Americans working with foreign groups ever stop to think how deep this process of acculturation really goes, or how much of the objective changes are in reality subjective. I even heard a professor make the remark that a man from a certain group was assimilated because he dressed and played tennis just like an American. To my mind real and lasting assimilation should be a subjective process. I accept none other. 
Eight years elapsed before I returned home to clear the mystery of my sudden and unannounced departure. The Sunset Limited arrived at 3:00 A.M., and although our pullman had been sidetracked for the remainder of the night, certain people would have died had they been forced to wait till morning. At 3:30 I was aroused, and what seemed a triumphal procession was begun and terminated at sister's house. (She had married. The only sensible thing for a real Mexican girl to do.) It was the prodigal son's return, in more elaborate form.

What racial discriminations I have been able to find in but few Americans toward me, I have always overlooked. Even though they angered me for the time being, I have no enmity toward any group. While in Texas doing social work in the same town in which I first tasted of American life, I found many things being said that were not at all complimentary to the Mexican people as a whole. These I always attributed to ignorance on the part of Americans, and a malicious and well-organized system on the part of Mexican newspapers to keep the Mexican misinformed regarding the true spirit of the real people in this country. A year of such an environment was enough for me. I would try to explain to the Mexican his mistake in believing what the newspapers printed, and of judging all of this country by such backward sections as this part of Texas, but to no avail. I had become too Americanized for my opinion to carry much weight. A Mexican writer in describing me and my work for a Mexican newspaper in Mexico made this characteristic remark: "Señorita — comes from the land of Gaona. [I objected to this reference to the Mexican bullfighter too late. I felt that real and worthy men had come from my home state and that there was no necessity to mention a mere bullfighter. I hate the game anyway.] She was educated in California, and strange to say, her soul has remained true to Mexico. The 'savia pure' of her life was not poisoned by a Yankee education." I had to appear pleased, but I was not.

My experience in this city composed mostly of Mexicans, and all of my past experience with them, has convinced me that life in Mexico would be impossible for me. I could never be happy in a place where the most of us were considered less than the pet dog of the house. I know that now I could not stand by and see people, all of the same race, assigned to different compartments in the trains, or to different sections of the church, just because they wear a dif- 
ferent kind of dress or suit. I fear lest I should become violent and radical, perhaps a socialist of the worst kind. I have become in every sense a democrat. I want to remain thus, and in a newer light give a higher interpretation to the "Sueño Dorado" (Golden Dream) of my ancestors, who as they roamed through the mighty mountains and later bravely stormed the castle of Granaditas had as their only aim, worthy of life or death - Freedom.

\section{QUESTIONS}

1. What were the home conditions chiefly responsible for each immigrant's dissatisfaction? What advantage did each expect to gain?

2. Through what channels did these persons learn of America? Characterize the "American" in Italy.

3. By referring to the preceding chapter, compare the treatment of Latins at receiving points with that of Teutons.

4. What experiences led the Mexican youth (number 5) to "consider the Americans as my executioners and not as my brothers." Cite other examples of disillusionment. What factors are chiefly responsible for these disappointments?

5. Describe the personal disorganization of the Mexican-Indian girl (number 6).

6. What racial and cultural factors proved a handicap for the members of this group?

7. What is the Greek's (number 3) analysis of American prejudice toward foreigners, particularly South Europeans?

8. How do the Italian (number 1) and the Mexican-Indian (number 6) regard the press in relation to racial prejudice?

9. What does the Greek (number 3) consider as the gateway to success?

10. What occupational difficulties were encountered by these cases? To what extent did these apply to the Teutons whose histories appear in the preceding chapter?

11. From these documents, show how education helps and hinders assimilation.

12. In what respects could the returned immigrants not fit into the conditions in their native countries? What does this lack of adjustment show?

13. Make a composite list of immigrant reactions toward America and Americans as a whole, as revealed in this chapter.

14. Why cannot the taking out of citizenship papers be used as a criterion of assimilation in the case of the Mexican (number 4)?

15. What is Miele's (number 1) understanding of "real Americanization"?

16. How do you account for the fact that the Greek (number 3 ) is spending his time Americanizing Mexicans rather than Greeks? 


\section{CHAPTER XXXIV}

\section{LIFE HISTORIES OF SLAVIC FIRST GENERATION AMERICANS}

\section{Rumanian}

\section{Not a Girl, But an Army Deserter}

I was born in Breslau, Rumania, in the year 1891. My father was a merchant in our home town, and also owned three department stores in adjoining towns. There were seven children, four sisters and two brothers, of which I was next to the eldest, one brother being four years older. The conditions in Rumania for us were very good, as far as food, shelter, and education were concerned. I received schooling in common school, then was sent to a vocational school, where I graduated in the trade of a carpenter. The work was equivalent to our high school.

When my brother was eighteen he was drafted into the army, where he was required to train for three years, at practically no pay. All young men were required to spend three years in active military service; then they were placed on the reserve list. The common soldier was treated as of no standing. My brother came home at end of three years, very bitter, when I was seventeen years of age. He told my father and myself how the officers would strike them over the head with their swords, crack them on the back of the neck with the butt of a rifle for the slightest offense, would force them to blacken the officers' shoes, scrub their premises, and treat them brutally in many ways. One meal was composed only of weak soup and black bread. My father told me he had to go through the same torture in the army and to leave his work and home to join the army at call, whenever any slight agitation arose.

In the meantime, father had received letters from his brother, who had immigrated to Omaha, Nebraska, where he had become wealthy in taking up a homestead upon which a town was later built. So each time a letter came we started to plan to go to America, to the land of opportunities. To me it held the vision of a wild country full of game and Indians, where one could get lost or travel miles 
without seeing a human being. This was the land of adventure, freedom of religion, freedom from military service, all with the privilege of going and coming and living as you wanted to. Our plans crystallized into immediate action upon my receiving a summons from the government office to report within a short time for active duty for a three-year period in the army.

At this time I had full charge of one of our department stores, which would correspond favorably to the general store as found in smaller towns in this country. My father decided to leave Rumania at once with me, and come to America. He sold one store, and sent the bulk of the money he received down to a brother who was a doctor in Paris, France. The balance, in gold coin, we carried on us in leather belts. This trip was all kept a secret. Mother was left with my brother and sisters to dispose of the other stores, and as soon as possible to follow us to Omaha, Nebraska.

I left one day ahead of my father and traveled a day and a night by team, and stopped at the home of a friend. Here father joined me. I now changed to girls' clothing, and left that night with my father on the train for Hungary. The difficult task was to get past the government inspectors at the line. I worried a great deal, fearing they would examine me closely and discover my deception. I wore a bonnet that came well over my face. My face was very fair and round, but should I be required to remove my bonnet I feared the result.

We had no difficulty at the line, and next day we reached Bucharest. Here I changed to my regular clothing and reached Paris without difficulty. Here we visited a short time, until finally we left Le Havre for New York. The trip was a very stormy one and the boat was crowded. We were detained at Ellis Island several days. I could not understand what it was all about, as we had plenty of money with us. At last we arrived at Omaha. Here I went to work at once for my uncle, as repair man and carpenter, looking after his numerous houses. Later I took charge of a small truck farm he owned.

Here I was very restless. I had found nothing but work, had seen none of the wealth coming my way. So, I decided to learn the English language. This necessitated my coming back to the city. I spent several very hard years - working at various occupations. Work was scarce, as panic conditions after 1907-08 were still acutely felt. I worked with pick and shovel, and in packing houses, while at night I studied at night school. 
In the meantime I had sent to Rumania for a girl friend of the family, as I had met no girls in this country that I would want in my home; they were all so flighty and fresh. This took most of my money. We soon came to Los Angeles, where we had heard of the many advantages for the foreign-born. I now have worked in the movies as a stage carpenter since 1920. My father and mother, sisters and brothers, are all here. My sisters are also married, as well as my brothers. One brother has an orange-juice stand at Venice, California, where he is doing very well. My other brother is a successful actor on the stage. With the money from Rumania we bought property here, which has inereased in value.

We have very little social activity. It is a land of graft and polities, where the foreigner has a hard time, and is used only for what he can produce for the money kings. Even though I know my trade thoroughly, I am belittled as to my ability, given the worst end of the deal in the work, and not regarded as of equal status with the rest of Americans.

During the war I spent fourteen months as sergeant in the United States Army.

\section{Russian}

\section{From First to Final Papers. Excerpts from an Unfinished Diary}

The following pages represent merely a few excerpts from a diary which is still unfinished, because the author has to wait almost two years more to become an American citizen. They must, therefore, be accepted only as an unfinished attempt to illustrate the changes that are taking place in almost every immigrant, changes brought about through hard self-education in the ideas of Americanization.

July 5, 1923. At last I am in San Francisco. All preceding years from now on are the property of the past; new life has to be started. All I have been - my wealth sufficient for living in luxury, all traditions of the family which hardly will find application in this country, my dreams of serving for the benefit of my beloved country, my dear Russia - today become painful recollections. Today I, a son of wealth and noble blood, a student of political science, a senior eaptain in the Imperial Forces with all decorations allowed for the rank I held, the greatest of which are my four wounds, am a penniless immigrant. Today, after traveling through Europe and Asia seeking for rest and the right to be called a man, and finding myself insulted 
simply because I happened to be a Russian, though not guilty in Brest-Litovsk and in Bolshevism's crime, I become a stranger in a strange country, of which I knew and still know so little.

July $\%$. How strange it is to see the first dollars earned by physical work. Is this the reason the $\$$ has such high value everywhere? How sad that no English was required in our schools. My hopes that my French and German would help me are broken to pieces. "No sabe" is all the answer I hear to my "Parlez-vous français?" or "Sprechen Sie Deutsch?" How strange to feel after a number of years, during which death seemed near every minute, that nobody will ask me my past, or follow me to find out my activities.

July 9. I am started to school; it is easier to learn English than to teach Americans French or German. I must admit that a hard handicap confronts me; the first steps are so terribly hard. The only moral rest is that everybody in the foundry seems to be friendly, and that nobody is asking my past. There is no time for questions; the boss is too severe. And even so I could not explain anyway. Perhaps this is the better way. Very few real Americans appear to be common laborers; all are immigrants like myself. I wonder if Russians are also destined to live like these poor Italians, Greeks, and Mexicans? Let's hope not.

July 10. In a second-hand shop I met a Jew. He came over about ten years ago from Russia. Two facts surprised me: how he could leave Russia after the Great War was declared; and his statement that thousands of Jews were in "business." Strange conclusions come in my mind. Either all these Jews do not become Americans and remain Jews, or else the Americans become their followers and are cultivating the Jewish ideas of money making. Certainly and surely, the fact remains proved that no Americans in America are subject to common labor - that is the privilege of Italians, Greeks, Mexicans, and Russians.

July 12. Today I took out my first papers. Russia, will you forgive me? Why? How came that I so easily promised to become a good American citizen? Now that the fact is already a fact, it is difficult to express my feeling at the Immigration Office when I was signing my promise "So help me God." Was I renouncing my Russia that gave me my Russian name, that gave me the right of being a member of a human family that produced Tolstoy, Dostoevsky, Pavlov, Mendelyeev, and many others of whom every nation would be proud? No and no! I am ever ready at any moment to repeat 
again and again my renunciation of those who, under their inscribed flag of Liberty, Freedom, and Brotherhood, are exercising their power in a manner never before paralleled in history; but I do not renounce my love for the country which gave me all I had in these few years I can remember myself - I do not renounce mine Russian soul and the properties of mine Russian heart. Was I right to take out these first papers? I do not know.

But on the other hand, thanks to a special permission from this government, I was allowed to enter this country without any consular visé, or other necessary requirements. I had no documents to establish my identity. Therefore, the only solution was to take out papers to prove I came legally and had respect for those making this country their home. Strange, and at the same time unpleasant feelings, I have when I analyze what gave me this slip called "First." Thousands of my countrymen want to come, but are unable. Being here, I have the right to leave this soil and come back within the first year. To be sincere, I shall never have the moral right of leaving this country before I become a full citizen. But there is ever that impelling thought: Did I do right to take out the papers? Then I argue with myself that by renouncing Bolshevism, I am not giving up my Russian culture. Shall I like this country? Only time can tell. Now I know only the contradictory feelings of joy and somewhat of guilt feelings that are so hard to put into written words, feelings that constantly occupy me and cry out: "So help me God" and "Russia will you forgive me?"

July 14. Again I am without a job. I did not feel well yesterday, and when this morning I went to the foundry, my place was filled. Men seem to be machines; if one is not able to work, he is no good. Little wonder that in ten days I have seen so few horses! Americans must be great mathematicians - they can so effectively transform the real horses into the formula "H.P." Do these machine-made men have brains and real human properties? Still the old question occupies me: "What right do I have to my first papers?" Am I fit for the life here, where everything is so far from the ideas and ideals I have cultivated for all the years that composed my conscious life? Perhaps taking out my papers so soon was a crime. I will try to prove that I am not so bad.

July 28. My English is improving so much that many Russians, whom I meet at church, are jealous of me. I think that my French and German are helping a great deal in building my speech. These 
Russians are already acclimatized; they talk with a smile about their "jobs," about dollars, and difficulties. "Better be a free laborer than an insulted and imprisoned general," said my general, whom I knew in better days in Petrograd. Who knows, maybe he is right. August 8. I am still on the same job. I wish I could have a complete command of my English in order to offer myself to some more productive activities, and to show that the stock of immigrants from Russia after the Great War is different from those who came prior to 1914.

August 29. Today I am leaving for Los Angeles. It is strange to know that again tomorrow I shall once more be alone without my countrymen. I hope that being forced to hear only English, I shall profit.

September 30. After a picturesque switching from one job to another, I finally found a steady position, at least it now seems steady, though I should not be surprised to be without a job at any time. One must know how to do things here, a fact much to the disadvantage of nowday Russian immigrants. In fact, what knows a former officer, who was taught how to kill and how to die when his country is calling? What knows to do here in America a student of political science, who may be familiar with mental calculations of philosophy, sociology, and politics, but who does not know how to speak English, who does not know how to make himself understood? Being neither an artist, a musician, a blacksmith, a shoemaker, a tailor, or the like, what can I answer on every employer's first question: What do you know то ро? The only solution is to speed up and learn English as quickly as possible; that is our only way to success, and it is the basis of good citizenship.

October 11. Time is passing so slowly. Maybe my English is still far in the stage of very infancy.

October 15. Los Angeles looks the same as San Francisco - machines, machines, the same speed of life, the self-smiling faces of girls. How many good-looking faces, and at the same time, how few of them are good faces! I wonder what would my grandmother say if she could see these carmine lips, these half-dresses, and this visible independence of American girls. Seems that a girl can find a job much easier than a man. Is this the result of the Great War? At the same time it is hard to believe that all of them are "les des rues" - it is impossible to suppose that the American women in great numbers bear the stamp of low morality. The chance of work, the 
idea of self-support, and, in consequence, the right for independence seem to be the main characteristics and the main basis for the development of the American woman in the way she appears today.

October 22. As in San Francisco, the Americans seem to be not familiar with the European "Mon Dieu, Mon Roi, Ma Dame." Supposing that religion is becoming more and more individual every day, and supposing that gods like kings are disappearing every year, do they not realize "Ma Dame" is still present; and will always remain? Very few Americans give, or offer the ladies, seats in street cars. Is this the result of emancipation? Do the Americans realize that this motto does not enforce any obligations of a man toward a woman, but solely serves as a best proof of a gentle intellectuality of man? I wonder if I shall also become Americanized in this way.

January 3, 1924. A great day! I feel like a new and regenerated man. My overalls are thrown away; since today I am a bank clerk. I am not so brilliant, but this is better than anything I had before white collar, clean hands, and a chance to meet people. Go ahead, captain.

May 5. I received a letter from my mother and she wants to come over. I was sorry to have to answer her in the negative, because I must confess that I am not sure that I shall become an American citizen. Many changes have already taken place in my attitude toward politics, and toward obligations that I have for the United States. I still am in doubt whether or not I shall be able to become a good American citizen in the sense of giving something useful to this country as a proof of my appreciation for the hospitality she has shown me. All I feel, and all I can tell, at present, is that I am thankful.

May 12. Deposits. Checks. Every day it is the same routine. So many different faces, and at the same time how similar they are. The aged, women, young women, school children - all ask when depositing their savings: "How much is my balance now?" Everybody and everything is absorbed by the aromatics of the dollar. Is this the result of misinterpretation or "mania America"? Or is it the nervousness of my customers, while at my window, a chronical disease of the "dollar making idea?" It would be interesting to know how many Americans are trying to realize that, besides material wealth, there is a mental and intellectual development which presents wealth of greater value, as far as the progress of man in the name of humanity is concerncd. 
August 17. I have finished the book. It is so different from the history of my country, such different ideas, tendencies, and psychology. I wonder if Alexander II, born on February 19, 1861, knew that at the same time in America Lincoln was dreaming of the same idea of freedom for slaves? Would you who opposed and criticized this act prefer to feel and enjoy your freedom here in America, or would you like to know that tomorrow you will be executed by insane Bolsheviks, who are direct children of your psychology?

September 2. Americans are like children; they have movies on every corner, where admission is cheap. Here laughter is cheap; funny, senseless comedy prevails. Happy Americans are smiling without asking themselves how or why, or where is the sense. Yet these people gave to the world Edison, Longfellow, Poe, Washington, Lincoln, and Wilson. Strange! It is a crime to render Schubert's "Ave Maria" or Korsakov's "Song of India" into the cheap tempo of modern jazz. Are the Americans such poor students as to crucify the masterpieces of such well-recognized masters, or are they doing it to attract greater crowds and thereby make greater profits? If they are doing it for the latter reason, I am sorry for them.

April 5, 1925. A strange conversation was taking place today in the street car between two girls concerning a certain boy friend. Now I do not wonder, but I wonder what my feeling would have been two years ago. Perhaps it is better that I did not know any English when I first came. Now I know how to judge and how to find proper lighting for casualities. It is so comfortable to know a little of the language; it makes it so much easier to learn the psychology of my future countrymen.

September 11. Mother is still wanting to come over, and is asking how I could come to a decision to become an American. What can I tell her? It came gradually as a result of a certain evolution in psychology; the country seems to be so different from what it did two years ago. There were certain compromises that had to be made with self. I do not believe that I shall be able to give up my love for my mother country, but surely this country could not ask such a thing of me. To love his mother country is a natural right of every human being, and no one has the right of demanding the abdication of this love. It was thankfulness that impelled me to become a citizen. Will this country accept this appreciation as a sufficient factor for accepting me in the big family of Americans? Will the United States realize that this feeling of gratefulness is a sufficient guaranty 
of sincereness of the desire to become a loyal and good citizen? Sometimes painful doubts occupy the mind, and sometimes a reasonless joy replaces the moments of doubts.

January 21, 1926. Already a few months have passed since I changed my position and became translator in one of the patent offices in the city. The position offers much more interest, and is at the same time much more profitable because it keeps me continually in touch with foreign languages, and at the same time helps me polish my English. Laborer, clerk, translator - what next?

May 16. My friends are right; I must continue my work begun thirteen years ago in the University of Petrograd. Two reasons seem to be responsible: I shall never find a compromise with myself as an employee of a private firm; and second, I feel an obligation to become a servant of a nation that is rebuilding me.

September 26. Again I am a political science student, eight thousand miles away from my old Alma Mater. How strange to be again in classes, again with books, and again with the hopes of being a productive member of humanity! It would be an excellent thing for every graduate to return to college for repeating his courses; the analysis of the studies is so different after life has shown its practical side, and in consequence so much more complete.

March 21, 1927. What more can I say, now that I am expecting to be a citizen in about a year, a citizen of a country which was so strange to me four years ago, of a country which became my home, of a country in the name of which I am ready to undergo my final painful operation - the abdication of my mother country in full sense of sincerity and honor?

In these final pages I close the story of my life. Though unfinished this little diary brings me to the present. As I reflect, I find several things that stand out in my process of Americanization. America, being materialistic, offers a difficult background for the assimilation of the immigrant who does not place so great values on material wealth. It is my belief, however, that Americans with their financial genius and Russians with their great men like Tolstoy, Mendelyeev, Dostoevsky, Pavlov, Rubinstein, and many others will come together, and after reciprocal studies and reciprocal financial and moral support will start a new era in interpretation of international relations based on principles of good will for humanity as a whole. In coming to America I had no illusions, no ambitions, but only a hope to find a place where I could have a chance to do my duties as a man. I 
am still here, and will stay here, because the country showed me an example of gratitude which I had never had since my own exile from my Russia.

Finally, I want to ask you a question, Doctor, as an American: Do the United States, being a civilized country, feel that, besides legal provisions relating to the intercourse between the country and its citizens, they have a moral obligation toward the naturalized to guarantee that there will be never taking place on account of the United States a cause which would result in a painful conflict between the love for the mother country and the respect for the newly adopted country, which conflict for an honest and self-respecting man would have only one solution - the Death?

\section{Russian Jew}

\section{Out of Pogroms into Freedom}

Compared with other parts of Russia, the Ukraine is a very beautiful country with the tributaries of the beautiful Volga flowing through it. Its fine farming conditions, leading to a great deal of outdoor life, has developed the picturesque and typical folklore of these people. These good climatic conditions probably contributed a great deal to the good health and well-being of the 295 immediate descendants of the third generation Zvenogarodsky family. Great strength, an unusual physique, and the ripe old age of 107 was the great fortune of my great-grandfather, the father of the third generation. He was a great scholar and philosopher, these characteristics being handed down to his nine sons and still predominant in their families. It is with two of these sons that we are here most interested.

The younger of the two, my maternal grandfather, was an aristocrat in every sense of the word. His appearance was always of great concern to him, as was his home. It consisted of twelve mammoth rooms, including a dining room which seated 70 people. His library contained hundreds of volumes of the best literature and was considered the largest and most valuable private library in the Ukraine. Not only did he have a fine collection of books, but also paintings, tapestries, and rugs in excellent taste. It was in this home that all family reunions, gatherings, and weddings took place. He was also interested in civic affairs, and came in contact with such notables as Count Leo Tolstoy. Besides his many avocations, he had a very successful vocation - manufacturing. His wife, though not his equal 
in all respects, was a devoted mother to her son and three daughters. It was in this environment that my mother, their eldest child, began her life.

The other son, my paternal grandfather, quite different from his brother, was by far more interested in his books than anything else. By virtue of his profession, that of an attorney, he was interested in those who needed defense. His home was secondary to his scientific studies. It was in his library that he wrote his first books in Russian, Hebrew, German, and English. His desire for adventure, among other things, led him to take his family to America, leaving behind his eldest son, my father, who himself was married and busy with his own responsibilities.

The marriage of my father and mother was not at all romantic, since it was planned without the knowledge or consent of either person concerned. At the age of seventeen, my mother was called to her father's library and told that by mutual agreement of the parents she was to marry her cousin. Her own consent was not asked. At the same time, my paternal grandparents told my father, who was then twenty-five, that he was to marry his cousin and that they were going to her home to announce the engagement. Neither father nor mother had anything to say about their coming marriage, and saw each other for the first time since childhood at the announcement of their engagement. My father's physical beauty, his position, and family relationship apparently satisfied my mother, who was hardly old enough to have any choice at all. On the other hand, my father saw a very happy future life with his very beautiful and charming cousin.

They were shortly afterwards married and lived for a while with my maternal grandparents, where father owned a large shipping yard. Having a university education, he was able to maintain successfully his own business. It was here that the six oldest children were born, four of whom lived. Later they moved to another city, and in this place I, the tenth and youngest member of the family, was born. It was shortly after my birth that Russia was afflicted with the most terrible of massacres. These pogroms were an attempt to persecute and wipe out, if possible, the Jews of Russia.

The year of 1905 is known as Red Year in Russia, for it was then that without warning of any kind most pogroms occurred. In our city everything was apparently quiet. Father was out of town and mother alone with her six daughters. All of a sudden our neighbor 
rushed into our house with great alarm, shouting, "The Cossacks are coming! The Cossacks are coming!" Mother at once knew what this meant; and in her delirium hardly knew what to do. She finally accepted the kind offer of shelter in the attic of our non-Jewish friend. This was indeed a very noble deed, for protection of Jews was punishable by death. Here we stayed in this dark attic almost a week, hardly daring to breathe for fear of being heard by the enemy. The question of food was a very serious one, since the movements of every one were closely watched by the Cossacks. Everything was brought to us in the dead of night when the sentinels were asleep. From this meager description, you can perhaps imagine the fear and dread of the pogroms. Picture my mother with six tots, worried, half-starved, and almost choked to death from the smoke of the burning city.

Father returned as soon as he heard of the disaster, but by the time he arrived, the massacres were over and the Cossacks were leaving. He did not find his family for several days as the people, fearing the Cossacks, remained indoors. Seeing our home in ruins, he decided that we were among those dead. Mother, on the other hand, was positive that father had been killed upon entering the city. Imagine the family reunion when father finally found us. He was so overcome at seeing us all alive that he could not speak. He lost his voice and did not get it back until later. It was during this experience that father's hair turned grey practically overnight.

Deeming it best to come to America, we came directly to grandfather's farm in Connecticut. Not liking peasant life there, my parents moved to Cleveland, where my brothers were working. Our problems now began, chief of which was language. The younger members were at once sent to school, and in an effort to make us forget our native tongue our parents began discouraging the use of Russian. If we asked mother a question in our native tongue, she would answer in English, as best she could. As our brothers were working hard and had provided us a home in a fine neighborhood, we could enjoy the things that our new neighbors had. Our family accepted everything the community had to offer us - schools, evening classes, community centers, libraries, movies, etc. I must say that we made a great attempt to become Americans, and it is my conviction that we lost a great deal in so doing. I still believe that the culture we came from was superior to the culture that we accepted.

My oldest sister, having gone to a university in Russia where she studied medicine, was not satisfied with the crude factory job she 
at once obtained. She secured a position in the field of social work, and as she could speak German, French, and Russian, was able to carry on her work very well. She is now married to a young Russian dentist, whom she assisted through dental school. Two brothers are also dentists, the older having made quite a reputation through inventions along this line. $\mathrm{He}$ is a musician, although he has not accomplished anything in this field. His daughter, however, shows considerable promise. The other brother has three children, the two boys carrying on a profitable business in printing. Next in line comes my sister, whom I have always thought of as the "brains of the family." She is now making use of both her law and sociology, which she studied at Baldwin-Wallace, Chicago, and Columbia, as the director of a large philanthropic movement. Another sister became head bacteriologist in a leading hospital in Cleveland. Her little son at four reads, writes, spells, and is very brilliant in mathematics, to say nothing of his beautiful and extensive vocabulary in English. He has an intelligence quotient of 148. My twin sisters, like myself, attended teachers' college and are still teaching.

My parents, although their problems were many, seemed to have gotten around them. There is not in our family, as predominates in many foreign-born American homes, the difference of opinion on modern subjects between parents and their children. My father is a very understanding and broad-minded man, and my mother is equally understanding. They, like their children, did away in a large measure with the customs of their native country.

I almost forgot to tell how our name changed. Grandfather came to America about eighteen years before our family arrived. When he came, he found that it was very hard to get Americans to pronounce his name. At about this time his mother died. Her name was "Rivka" (In Hebrew). To perpetuate the memory of his mother's name he decided to change his to - When father came here, he immediately adopted the same name.

\section{Russian Jew}

\section{Through the World War and Russian Revolution to American Understanding}

I was born in that part of Russia which now belongs, unjustly in my opinion, to Poland, and spent the years of my childhood in the town of Brest-Litovsk where four cultures and influences curiously 
intermingled - Russian, Jewish, German, and Polish. It was a quiet provincial town, situated within the "Pale of Jewish settlement." But it was a great fortress, and thus when I think of my life in this city, I cannot help associating it with frequent impressive parades, the constant rattling and booming of rifle and artillery drills, and the general restless and colorful life of a great garrison.

At the age of nine, I prepared to enter the local gymnasium. Although I passed the entrance examinations, I was not admitted, for Jews were admitted to schools and universities only in certain quotas. I wept a little over the racial injustice which deprived me of the honor of wearing the gymnasiast's uniform. Still I hoped to be admitted at the next session. But in August (1914) the terrible catastrophe fell upon the world. Our city soon found itself near the fighting line. After the Carpathian disaster in the spring of 1915, the retreating Russian armies decided to make a desperate stand near the line of fortresses of which Brest-Litovsk was the center. All the civil inhabitants had to move out of the fortified zones. We became refugees and hastened into the depths of Russia, first to Minsk.

The Russian armies, betrayed by the high command (the Germanborn Czarina and her pro-German clique were chiefly to blame), deprived of shells and ammunitions, surrounded by spies, and armed only with valor and bayonets to oppose the stupendous technique of the German war machines, slowly retreated. As they approached Minsk, we moved to Voronezh, a beautiful and progressive Russian town where we remained through the war. It would occupy volumes to describe all I suffered in those days. Suffice to say I was ill with a most cruel typhus at the time our city was changing hands in a desperate struggle between Trotzky's Red armies and Denikin's White forces. My only medical assistance was that rendered by a physician, a friend of ours, who ignored bullets and shells to give medical aid. Parties of pillaging White Cossacks came into my room while I lay half-unconscious, and cut open my pillows with sabres and daggers, looking for money and valuables under pretense of searching for hidden arms. I drank my cup to the bottom in those days. Like many others, I suffered cold and hunger, for in the Russian cities one could not get bread for even diamonds. It was distributed sometimes at the rate of $\frac{1}{8}$ pound per day on special food cards, and sometimes it was not distributed at all. The poor city dwellers ate cabbage leaves, and what not.

It was my misfortune to have lived in Russia in those dreadful 
days; yet it was my good fortune and privilege too. Without being a theatrical poseur I may say that I played my little and modest rôle in the huge drama enacted in Russia. As a great modern Russian writer has said: "One hundred years from now people will think of the present time in Russia as the most beautiful manifestation of human spirit. But my shoes are torn and I would like to sit in a restaurant abroad and drink whiskey." Well, we looked toward America, where we had relatives. Father's brother, to whom he wrote, advised that there was nothing to lose in Russia and offered his assistance in getting us over.

At first I did not like the idea of migrating to America; to leave Russia, either forever or for a long time, did not appeal to me at all. At family councils I violently opposed the undertaking, but what could I, a seventeen-year-old boy, do? I did not have the nerve to remain behind; consequently father was able to sell the plan to me. He argued that there were advantages of living in a civilized country with a stable democratic government, no compulsory military service, an opportunity to secure an education and above all to live a secure and decent life. He persistently pictured to me the unstable situation in Russia, her enigmatic and uncomfortable future, and the horrors of approaching winter without sufficient fuel and food. My schoolmates were not so optimistic when I broke the news to them. While a few envied me, most of them declared: "There is no place like our Russia. You will realize this fully when you get into the capitalist's hell. America is a dreadful place. It is like a big spider, a big octopus that sucks blood out of you, and leaves you a bloodless, unthinking machine, an automat, a 'robot,' a 'la capec.'"

I must confess that most Russians have rather fantastic notions about life in America. Their ignorance, however, does not compare to the American ignorance of Russians. In Russia I have read many times that there is no middle class, that there are only two social strata - the numerous proletariat that has nothing to lose but its chains, and the small group of mighty and superhumanly opulent industrial magnates.

Our journey was a regular Odyssey; we had to cut through the impregnable wall of Russian and other bureaucracy. We journeyed through a world covered with yet unhealed wounds of the great conflict. Germany lay silent and prostrate at the feet of her pitiless victor and exploiter - France - and on the face of every German lay a grave consciousness of the great humiliation and tragedy 
of his country. I shall never forget that cold misty January morning in 1923 when I beheld for the first time the metropolis of the western hemisphere: These memories are not pleasant ones. To begin with, there was Ellis Island. Of course the American government has the undisputable right to regulate the influx of immigrants coming to her shores, but why should there be needless tortures, needless slaps on the self-respect of the immigrant, needless pushing and shoving of helpless and defenseless immigrants by smart Alecs in the uniforms of Immigration Officials? The treatment at Ellis Island is indescribable. There is here rich soil for early prejudices and misrepresentation. The immigrant cannot help thinking: "If I am treated like that right at the gate, what sufferings await me beyond?" In all I underwent no less than twenty examinations, all of which were unnecessarily offensive. I cursed the hour when our idea of going to America originated. Never was the human in me insulted so deeply. There comes an end to everything, even to Ellis Island proceedings. In the evening of the same cold January day which I have mentioned before, we were safely anchored in Connecticut at the house of my uncle.

I worked in many places and at many odd jobs - shoe-repairing, shining shoes, working in stores, and laboring in factories. I at length entered high school, finished, passed the entrance examination at Yale, and was admitted. But as it was exceedingly difficult for me to secure part-time employment in New Haven, I came to Los Angeles, where my mother has relatives in business. In the first months of my life in America, I felt myself uncomfortably lonesome and alone. I could not make acquaintances with Americans because I did not know their language. On the other hand, our relatives, who had left Russia some twenty-five years earlier, were people with ideas, habits, and ways of thinking diametrically opposite our own. Their conceptions of Russia struck me as false and erroneous. They came from the territory formerly known as the "Pale of Jewish Settlement," in which at that time the Russian influence was expressed only by administrative officers and policemen. They sneered at Russia. They did not believe that in Russia there were automobiles, street cars, and telephones; that Russia might be backward in quantity but never in quality. Their image of Russia was entirely different from the Russia I knew - the marvelously beautiful and majestic, great and beautiful even in suffering and humiliation. I could not listen indifferently to my relatives' abuse of Russia, and often 
indulged in arguments, trying to correct their conceptions of Russian life. But they treated me with condescending contempt as a pitiful "greenhorn," as so much more crude ore for the melting pot of America. It gradually dawned upon me that I had nothing in common with those self-satisfied Philistines, and I stopped associating with them. It was but little better in school. The students had no patience with my staggering English, and while they treated me courteously, they did not become friends of mine. It was in Los Angeles that $I$ began to acquire more or less intimate friends. Here, somehow, I felt at home. The Westerners were much more sympathetic and understanding than the Easterners. These exceedingly charming people reminded me of the dear old intelligentsia in the old country.

I have several very definite reactions to American life. The excessive attention paid to sports struck me most during my first months. They are all right per se, but the trouble is that all together too much attention is given to the spectacular. The greatness of Ancient Greece consisted in the harmonious combination of the culture of the body and spirit, but here, sad to say, the ape-like Dempseys and Babe Ruths are the only idols of the immense majority of the growing-up generation. Another thing that struck me is the constant discussion of the plight of modern youth. Americans seem to think that the problems of flaming youth are confined exclusively to them; they forget that all the world is going through a deep crisis, that all over the world there is going on a revaluation of all the old values, a severe inspection and examination of all old conventions and traditions. This crisis is in itself only a manifestation of the eternal law of change, accelerated by the colossal events of the later years. The great surprise in America is the untiring persistence with which it is being discussed in the press, from the pulpit, by educators, by statesmen, and by whom not. After all, the "jazzmania" of American youth does not reach so far and so deeply as do moods and spiritual struggle and crises of the Old World youth.

Most astonishing was the cult and worship of women. I was horrified at the unjust treatment of men in their relations with women. The whole institution of alimony, paying damages for breach of promise, etc., are revoltingly unjust. Of course a woman, divorced from her husband, should have a reasonable allowance for their children's support and her sustenance, but these provisions should not apply to gold-digging women and unsuspecting elderly bachelor hus- 
bands. I cannot understand the American worship of woman and everything feminine. Personally, I fail to be impressed by progress and advancement of modern women. The American theory is that she is superior in all save physical strength; my theory is that she is inferior to man both mentally and morally.

If we except the Ku Klux Klaners, the chauvinistic "hundred per centers," and the like, Americans are among the most lovable and finest people in the world. They have been cruelly abused as a nation money mad. All nations are that; ours is an age of beastly materialism and everywhere money is a god. Immigrants from Russia have a feeling of gratitude toward America. It was this country that first extended a generous brotherly hand in the great Volga famine in 1921. It was Woodrow Wilson who issued an appeal to the world to respect Russia's territorial integrity, and thus saved her from becoming the easy prey of British, French, and Japanese imperialists. It is the American who quickly and fully realizes the true appreciation of Russian art. No other two countries have so much in common, in spite of seeming contrasts. It will be of inestimable worth to the world, to mankind as a whole, if Russia and America will coöperate, because as some one has said, the ideal "super-man" will come from the blending of the Russian and American.

\section{Polish Jew \\ American Puzzles}

I was born in a small town in Poland. My grandfather was a fur dealer, but I cannot think of a name for my father's occupation. All I know about his work is that on Sunday morning he would set out with plenty of food and on Friday evening would return with a few sacks of dead rabbits, sheep, or wolves. I first heard of America when one of my uncles sent his picture from that country. When I asked where the photograph came from, I was told America. It aroused no interest in me at the time. The stories about America, as I heard them, were mostly fantastic. For instance, all a person had to do was to walk along the streets with a shovel and gather as much money as he pleased. The streets and pavements were covered with plush rugs - in other words America was a heaven. Accordingly I, an ignorant Polish boy, expected to find wagons with golden wheels, horses with golden horseshoes, but what I did find made me see how foolish I was in even thinking about such things. 
As disappointed as I was, however, I still noticed interesting things about me.

For the first time I saw a necktie. Naturally many questions came to my mind as to how it was made and how it stuck to the neck, and what its purpose was. Long pointed shoes, trolley cars, automobiles, and short trousers all raised a good deal of interest in me. I also found things that were difficult to comprehend. Why did children not go to school in summer? I had been accustomed to going every day in the year. I went to a playground every summer day, but could not understand why the other children were calling me "greenhorn, popcorn, five cents a glass." As I thought it was something great, I walked around the immediate neighborhood and sang the self-same words, "greenhorn, popcorn, five cents a glass." I could not understand why it was sufficient to push a button and not strike a match in order to make a light.

My greatest difficulty was the English language. I could not venture very far from home for fear of getting lost. I was thus kept at bay at all times; I could not play with other boys, and restless kid that I was, I had not patience to learn. When I watched the boys play, I just closed my eyes and played with the boys in the old country, in my own way, and in my own language. I was satisfied. My other great difficulty was the strangeness of my own countrymen; I was used to seeing them wear beards, close shop on Friday, and go to the synagogue. I could not understand why they did not do as they did in the old country.

I did not know that they were living in a new environment and that they had adjusted themselves to new conditions. In only a few respects did I find myself at home with them. They did not deviate, however, entirely from their innate culture; candles were still lit on Friday night and the same food as I ate was served. Now I marvel how they could make certain changes so quickly. A person who a few years ago would consider it a crime to walk along beardless now ridicules his friends who adhere to the old tradition. Of course the beardless man cannot be blamed; he did not do so willingly - he was forced by his new environment. People laughed at him and called "Ba" at every step. The more bold would not hesitate to throw bricks at him, bricks in the real sense of the word. On the other hand, his friends, being used to ridicule in the old country, would stick to the old tradition.

I could not help noticing that the children of immigrants were not 
respecting their parents; they were taking things in their own hands. Of course it hurt the old folks to see the freedom of the younger generation; for they had done as their parents, because both generations had grown up in the same environment. They could not see the unfairness of forcing children to follow the Old World traditions. And herein lies the cause for so many conflicts between parents and children of the first generation. On the whole, I adjusted to the new neighborhood and the people, but my parents never will try truly to adjust, no matter how long they live in a locality. I think they are a hindrance rather than a help when it comes to improvements; they are not doing a thing to improve conditions. Thus in our home circle is a conflict of cultures.

One is naturally struck with the number of divorces and family difficulties in this country. These occur mostly among the first generation. The reason is this: in the old country the girl is chosen for the boy by his parents in most cases. In nine cases out of ten, they live miserably, but the parents are satisfied. In this country the boy usually meets the girl at school, a party, or at work. When he brings her to his parents, they want to know all about her father, what he does, etc. Often she is not considered good enough for the son regardless of her own personal qualities. This meddling on the part of the parents causes many hardships for the boy who loves the girl. If a couple have any sense, they will move as far away as possible from their parents. Some parents are satisfied to see their children unhappy just so their pride (in most cases false) is not lowered. This is especially true among Jewish immigrants; they would sell their son or daughter as a husband or wife to the highest bidder just to satisfy their pride.

I am in favor of intermarriage because I want to see every race assimilated. I think it is impossible, and yet I sometimes think it is possible. Unless this takes place, the race problem will never be solved. Education tries to solve the problem, but only through spreading the tongue and enlightening the ignorant about other races. Since there will always be ignorant people, this phase of education will not go very far. Intermarriage is the surest way.

Sometimes I am in favor of laws discriminating against immigrants. When I notice the actions of my parents and other parents of the same type, I favor restriction; but when I see and meet parents, also immigrants, who behave as parents should, I oppose restriction. Such parents as these we need in America. 
Nothing has occurred to me to make me wish to avoid Americans, or to conceal my feelings in regard to them. Nevertheless, I would express my deepest feelings about the United States and some of its people by the one word prejudice. In the old country prejudice was expressed openly; here it is done in a nice way. I am not planning to return finally to my native country. Some day I and my children, if I ever have any, shall visit the native land.

\section{SERB}

\section{From Serb to American ${ }^{1}$}

Looking back across what is now almost half a century, it is difficult to say which was the greater influence in making me cut loose from my ancestral surroundings and come to America: a boyish desire for change and adventure, or a deep sense of political wrong. It was a runaway school-boy that passed through Castle Garden - the old immigrant gateway to America - but a school-boy who had a burning realization that his people had been wronged by their Emperor.

My ancestors were Serbs. They were of that branch of the old race, that in 1690, at the invitation of Leopold I, Emperor of the Holy Roman Empire, settled north of the Danube in the Province of Banat. Leopold granted these Serbs land, and guaranteed them political and spiritual freedom on condition that they would defend Austria against the Turks who, then at the height of their power, were threatening to sweep through central Europe. The Serbs of Banat kept their compact: they were the unyielding barrier against which the Moslem wave of invasion broke. More than this, they fought for the Austrian Crown against Frederick the Great, against Napoleon I, and other powers. In 1866, when Austria attempted to prevent the unification of Italy, my people, though their sympathy was with the Italian fight for liberty, continued loyal to their pledge given in 1690 to the Emperor and fought in his armies. I was only eight years old at the time, but I can remember that in our house, on one side of the picture of the patron saint, there was a picture of the Russian Czar, the head of the Orthodox church, and on the other side, a picture of Garibaldi in his red shirt and white trousers. We defeated the Italians but were sorry that Garibaldi lost.

Two years later, the Emperor broke the ancient compact: he

1 A talk with Michael Pupin, World's Work, Vol. XLI, pp. 270-73. 
turned the Province of Banat over to the Hungarian Crown, and the Serbs became vassals of the Magyar. I can remember the indignation in our village of Idvor; but what stands out in my memory, just as though it had happened yesterday, was my father saying to me: "The Emperor has betrayed us. I will see that you never serve in his army." I had a great respect for my father; to me he was an oracle, and his words, "the Emperor has betrayed us," made a vivid impression. I felt that there must be something rotten in Austria when even the Emperor would not keep his word.

When I was thirteen, I was sent to school at Prague. I, of course, had heard something of America. I read a little about the Civil War and formed a vague, boyish idealization of America. With the recent act of our Emperor for contrast, I thought Lincoln the greatest man that ever lived; he had pledged his word to save the Union and he kept it. But the only American thing of which I had a real knowlledge - a cover-to-cover knowledge, so to speak - was "Uncle Tom's Cabin." To me, America was the land of legend and romance, and I am afraid that was the real appeal that, one day early in March, 1874, made me run away from school, to America. I had just received my small monthly allowance from home. I sold my watch, my books, all my clothes except those I wore - and skipped, a fifteen-yearold adventurer. I reached Hamburg and sailed in the steerage for New York.

There was no Ellis Island in those days, no immigration authorities with troublesome questions. I had just five cents in my pocket when I stepped ashore at Castle Garden, and I promptly invested it in a piece of that great American institution - prune pie. That first impression of America was very good.

\section{CASTLE GARDEN}

People of the older generation will remember how housewives and farmers used to go to Castle Garden to get a "greenhorn." It was March when I increased by one the market supply of "greenhorns," and farmers were looking for help for the spring planting. A Swiss foreman from a farm in Delaware hired me. The Swiss could speak German and English; I could speak Serb, Bohemian, a very little German, and no English; so we did not have a great deal to say to each other during the journey to my new home.

When we reached the farm, I got my first big impression of the difference between America and Austria; as I looked at it, the farmer 
and his wife were my master and mistress. I was a menial, a servant, but they did not let me feel this - they took me in and treated me just like a boy. Another thing that surprised me was my bed: it was an iron bed with springs, and it had clean sheets and warm blankets on it.

The next day I was put to work hauling manure. I drove a pair of mules. It was the first time I had ever seen a mule and I suppose it was the first time those mules had ever seen a Serb. On the voyage across the Atlantic, my hat had blown off and I put on a fez that I had in my pocket. I had no money to buy another hat; so there I was wearing a Turkish fez, driving a team of mules over a Delaware farm.

The farmer had a daughter just about my age. She had beautiful yellow hair and pink cheeks. I had jet black hair and red cheeks. Perhaps it was the Turkish fez that interested her; she used to come in the evenings and sit beside the stove and teach me English. In a month I could talk quite lively.

Her father and mother treated me very kindly: Every one was kinder to the hired boy than people in the old country would have been. I soon realized that this was not because I was a boy and a stranger. I saw that the farmer and his wife treated the hired men with respect and kindliness; I saw that in this country there was no such things as master and servant in the European sense of the word. That realization made a big impression.

I was very comfortable and nice on that farm in Delaware, but before many months I said to myself: "I did not come to America to be a farmer." So I bade good-bye to the beautiful yellow hair and to my friends, and went to Philadelphia. I had a natural talent for drawing, and that got me a place with a photographer, retouching negatives. From there I went to New York; it was the metropolis, the great centre of American activity.

I got a job in a cracker factory in Cortlandt Street. My work was to feed a machine which stamped out crackers. I soon saw that the other workers, boys and girls, were quicker, more efficient. And it made me think: "They can beat me working with their hands; perhaps I can beat them working with my brain."

Meanwhile, I had learned English so that I could read it with comparative ease, though I still spoke it very brokenly. I bought the Sunday editions of New York newspapers, particularly that of the Sun. It was the day of the great Charles A. Dana, and the Sunday 
supplements were worthy of the Sun. They contained many articles on science that were both interesting and authoritative. I can remember articles by Professor Tyndall on light and radiant heat, articles on the work of Edison, who was then trying to develop the phonograph and the electrical motor. These articles turned my mind toward science, and I resolved to get an education that would qualify me to become a scientist.

I admired America and I wanted to understand it: just as I had become interested in knowing what made light and heat, so I wanted to know what made America. I read the speeches of Webster, Clay, Calhoun, and Lincoln. The Gettysburg speech I knew by heart; I was a Serb, but it stirred me to the roots. I read the American poets. Bryant was my favorite. His "Thanatopsis" I knew by heart.

This reading was correcting my English, but I had difficulty in pronunciation. My only associates were factory boys and girls; so I went to the theatre - always up in the top gallery, sometimes sitting on the floor - and listened to the English of Edwin Booth, Lawrence Barrett, John McCullough. Those were wonderful nights!

Bryant was connected with the Evening Post when I was working in the cracker factory. The newspaper office was only a few blocks from the factory; and occasionally, when I was taking a walk during the noon hour, I saw the great poet. I remember my amazement when I saw that he wore no decorations, no uniform, no plumes in his hat, as I used to see in Austria when a great official of state showed up. During these noon hour walks, I saw other great Americans President Hayes, William M. Evarts - men who were ruling the nation; and they were all dressed simply, just like myself. It made a tremendous impression on me. You people who were born here can not realize what that simplicity, that democracy in dress, means to a man who was born in one of the old countries of Europe - or rather, what it would mean to him if his mind were not poisoned by the vicious, lying propaganda of the soap-box agitator and the foreign language press.

At the end of that bitter contest of 1876, I stood all day in front of a newspaper office to learn if Hayes or Tilden was elected. It was raining pitchforks, but a big crowd stood there waiting. To me, it was a wonderful sensation, that watching for the "returns"; no king, no emperor, no czar, just a big crowd waiting peacefully, like all the rest of the nation, to see whom the majority had said should rule the country for the next four years. 
Hayes was declared elected, and the cry of fraud was raised; but the American people peacefully accepted the result of their election machinery. It was a wonderful object lesson in the practical working of American democracy!

In this same year I began going to night school at Cooper Institute, studying drawing, physics, and chemistry. It was also in this year that a crew from Columbia College won the Henley regatta. I thought that an American college that could send a crew to England that could beat the English universities at their own game on their own river I thought that this must be a pretty good college. So I decided that when I could enter a college, I would enter Columbia.

I worked in the cracker factory; I worked in other factories. By the time I was in my twenty-first year - nearly six years after I had landed at Castle Garden - I had saved $\$ 311$. However meagerly I lived, that would not take me very far in a college course. During the four years that I was at Columbia I worked at various jobs; during the summer vacation after the freshman year I mowed hay in the Hackensack meadows and earned $\$ 75$ besides my board. During the remainder of my college course I did considerable coaching of my fellow students.

Early in my freshman year there came a thing that marked an epoch in my life. Greek was a part of the required courses. Professor Merriam was then in charge of the Greek Department. He was a gentle, noble man. He took me up, helped and encouraged me. He invited me to his home. His wife was a gentle, noble lady. They made me not only a guest, a friend - they treated me like a son. It was my first intimate glimpse of American character, of home life that has been the backbone of the country. I learned what America was by coming to know real Americans and their life at home. More than this, it made me feel that I was no longer an utter outlander, a Serb among Americans; in one real American home I had been taken in, accepted. Only the man who has felt himself a stranger, an alien in a great country knows what a little social warmth does for his soul.

Among the students, however, I was still unaccepted; I was still the stranger, the foreigner, the fellow who talked with a queer accent. In my sophomore year, I took part in the "cane rush," the annual test of strength between the two lower classes. I was young and husky, and I won the "rush" for my class. Then I was raised up on the shoulders of my classmates. They cheered and hurrahed. For 
the first time they called me "Michael." At last I felt like one of the boys. For the first time I could say, "Now I am an American."

In the junior year, we were permitted a number of elective studies. I selected the constitutional history of the United States. I then learned those historical steps which were fundamental in the development of the nation: the Mayflower Compact, the Declaration of Rights, the Declaration of Independence, the Constitution. I then understood the Revolutionary War, Webster, Calhoun, Lincoln; all the impressions, the observations, the readings, that before had been detached, confused, now came together into a coördinated whole. I then understood the new theory of freedom, the democracy of America. It was one of the few great thrills which mortal men experience during their lifetime.

\section{Albanian}

\section{From Isolation to Confusion}

I was born April 24, 1906, in the small, isolated, mountain village of $\mathrm{P}$ Albania, a half-day's horseback ride from civilization. $\mathrm{P}$ was nothing more than a group of seven or eight rough farmhouses, a mountain hamlet at the base of a rugged, barren, and overtowering mountain range, the beginning of the Swiss Alps, to be exact: Life in this little mountain village was rough and simple. Agricultural pursuits formed the basis of living and were the modulators of all the coincident social institutions. Let me give you an outline of the life, occupations, struggles, ambitions, and natural surroundings of the people that inhabited my birthplace a quarter century ago.

Imagine, if you can, a few rough stone houses huddled together in the center of a green pasture land that lies at the foot of an ominously towering mountain range. Picture for yourself this same mountain range infested with bands of wolves and wild boars that were a continual source of worry to the cattle-raising inhabitants. Place yourself in the sunny fields of the Albanian agriculturist or around his fireside on the long winter evenings - and then you may be able to picture the background of my early life. My earliest remembrances are of the two-story, rock-walled farmhouse of my father; one which is quite typical of those commonly found in that location in Albania. These houses, inside, were finished off with plaster walls and wooden floors. The center of the house, and the center of the life in the house, was the huge fireplace in the living room. It was around this that the entire family gathered during meal times and the evenings at home. 
Around the fireplace of my father's home is where I first listened, with the avidity of the childish mind, to the anecdotes and legends of a simple-minded and superstitious people.

There was much to make the people of my birthplace a more or less rudimentary type. As stated before, the chief occupation was that of agriculture and the raising of cattle, sheep, and poultry. Men, women, and children worked in the fields together and participated in wood-cutting and milking the cows. The women were especially hardy. Very little distinction was made between the men and women as far as the work around the farm was concerned. Of course, the men took upon themselves the duty of hunting down the marauding wolves, and the women, similarly, tended to the home duties; but in the main, it was a case of share alike in the common duties of the day. No better example of the hardiness of the womenfolk can be given than of that shown in a story which my parents told me recently

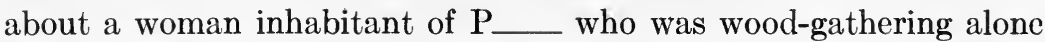
one day quite a way from town. She had expected childbirth for quite a few days and was suddenly overtaken by it while gathering this wood. She gave birth to the child, alone and unassisted, and then walked back to the town with the child wrapped in her apron. On her back was the load of wood that she had gone after in the first place.

Some of the earliest anecdotes that I remember are those regarding the attacks of wolves on the live stock. Every farm in P__ was surrounded by a nine-foot wall of stone. Inside of this wall was the farmhouse, a barn in which the live stock could be kept safely, and other buildings that might have to be used during the night. In this wall was made a gate large enough for a horse and team to be driven through. Outside the wall were located buildings containing such things as would be untouched by the wolves or wild boars. It was no uncommon sight to go out on the mountain slopes and find the remains of sheep that had been eaten by wolves during the day. To afford further protection against the wolves, it was a custom for every family to take turns in staying up throughout the night. All of the grown-up members of the family participated in this watch, because if a few wolves could be killed, the general welfare of the town would be so much increased.

School facilities in the town of my birth were rather crude, but nevertheless adequate. Two rooms in the corner of the church were set aside for this purpose. There are several very interesting experi- 
ences connected with the school and the church. It so happened that the church was set aside from the seven or eight houses that comprised the hamlet. Between these houses and the church was a mountain stream that was ordinarily quiet and peaceful. However, when a cloudburst hit the mountains above the town, or the winter snows on these-mountains melted under the rays of an unusually warm spring day, this peaceful little stream was turned into a roaring and raging torrent. The mountains, being practically devoid of any vegetation that might absorb the rain or melted snow, acted as a funnel which gathered in the water and sent it coursing down the river separating our church from the rest of the town. So powerful was this torrent of water that it swept before it an avalanche of boulders that ranged all the way to six feet in diameter. On more than one occasion I have been at church or at school and have heard the distant rumbling which meant the approach of a flood. The only thing to do was to drop everything and rush out across the bridge over the stream; for the minute this jerry-made structure of the farmers was hit by the flood, it was carried away like a newspaper before a hurricane. Sometimes the river flood would approach so fast that no one dared to risk his life on the bridge. In consequence, part of the entire population of the town would be marooned in the church and would have to wait until the water should subside and the stream could be safely waded. With every flood there was the necessity of building a new bridge. In this reconstruction just enough time was spent to build a structure that would hold a man on horseback, because no one could predict when it again would be swept away by a flood. Even though a school was provided for the children, they were not exempt from work around the farm. Their duties were light and consisted of such things as carrying meals to the men in the fields and assisting in the collection of fire wood.

The description of the floods that occurred in $\mathrm{P}$ _ might give one the impression that Albania is a cold, bleak, and unhospitable country.

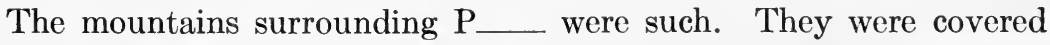
with snow for about ten months in the year and acted as nothing but a watershed for this same snow when it melted in the spring. The valleys, such as the one where $\mathrm{P}$ ___ was located (southern part of Albania) were, on the contrary, sheltered, fertile, and almost semitropical in aspect. The winters were very mild. Any snow that did fall remained but temporarily. The productive season was long and very favorable to the growing of grains, grapes, and olives. An 
average amount of labor would be sufficient to produce enough for any family to live on during the year. There was not much worrying about the future and very little trading with the outside world. In fact, $\mathrm{P} \_$was an almost entirely self-sufficing community. The looms in the farmhouses were worked by the inhabitants during the winter months and produced the cloth that was made into the clothes of the people. The skins of wild animals that were killed on the mountain-side could be made into the moccasins that the peasant wore while at work in the field. These skins could also be preserved in their natural state and exchanged as furs for the few things, such as sugar, spices, and metal implements, which the peasant did not produce. Money, as a means of trading, was almost entirely unknown; most all trading was accomplished by barter, and the only hired laborer of the community, the herdsman, was paid little above the recompense which he received by living as a member of the family. What little business there was in $\mathrm{P}$ _ was done almost entirely by verbal contract. The people trusted each other, not entirely because of an all-abiding faith in their fellow men, but because of a fear of starting a family feud if a contract or agreement were not executed as agreed upon. The fare of the peasant was very simple. Meat was used as a food but very little, and appeared on the table not more than twice a week. Predominating as food were the grains in a multitude of forms, butter fats, cheese, and olives. Wine was made by every family from home-grown grapes. It was used moderately, but continuously, as a natural part of the meal. Drunkenness was almost unknown by the people. It would seem hardly necessary to add that the people of Albania were very healthy. A people that lived in a moderate, sunny, and open climate and ate freely of protein-laden food could hardly fall victims to tuberculosis or other such diseases of modern civilization. A dentist would have gone out of business in that particular section of Albania.

The impressions and the influences that I have spoken of so far are those that occurred while $\mathrm{I}$ was living at $\mathrm{P}$ _. A person who is aware of the conditions that existed in Albania in the decade previous to the World War will recognize the truth of the statement when I say that my father was somewhat apprehensive as to the state of affairs that existed. Let me pause here to state why my father might have been in a better position to know of the political state of the country rather more than some of the other inhabitants of our native town. My father was a captain of the mountain police that patrolled 
the surrounding country and guarded against the numerous marauding bands of robbers. Being such, he had a broader view of affairs in general and undoubtedly was in a position to receive intelligence that might not be given to the ordinary farmer of Albania. In 1911 he decided that it was time to make a decisive move. He took me, with my two older brothers, my two younger sisters, and my mother, to the city of $\mathrm{K} \longrightarrow$, about 18 or 20 miles away. Here in $\mathrm{K}$, a city of about 25,000 people, we stayed at the home of my mother's father. Our father left us here and came to the United States, where he landed in Boston, was met by friends, and thence conducted to New Hampshire. Here he found a job in a shoe factory, a job which was to earn the money that brought us to America five years later. From my five-year stay in K I I gathered a multitude of new impressions, and will now relate an aspect of life in Albania which is at once more in keeping with the tempo of American life, but is still different enough to be interesting and of importance in my earlier background.

The first noticeable difference between the people in $\mathrm{K}$ and those which $\mathrm{I}$ had left behind me in $\mathrm{P} \_$__ was in that of dress. Instead of the rough home-woven woolens and the moccasins of untanned leather were found styles and materials that corresponded with those that might have been found in any European city at that time. As I became older, I was impressed with the extremely religious, or rather, superstitious fervor of the people. Around the fireside at night were heard tales that were mystifying to me then, as a youngster. One of these I remember in particular because it was supposed to have happened in $\mathrm{K}$. It seems that a band of robbers planned to enter the city and to plunder it at night. One by one the robbers came into the city and took rooms in separate lodging houses, having agreed beforehand to meet at a certain time and place. That night, as per the plan, about fifteen robbers descended upon the church and made away with a large sum of money that was deposited in the public communion box. The city was very upset next morning at the loss of the money, but felt that nothing could be done except to make a supplication to God. The matter drifted along for several days. Finally, one day during a church service, the leader of the band of robbers came in with the money that had been stolen, and much more besides. He explained by telling how more than half of his band had fallen prey to some inexplicable disease and that they, feeling this to be a visitation from a wrathful Deity, were returning the 
money with interest and were praying forgiveness from the community. The members of the church, rather than deliver the repentant robber to justice, did forgive him. Their reason for doing this was that they believed, as did the robbers, that the mysterious disease had been a visible manifestation of God's wrath and that not to forgive would be nothing less than a sacrilege.

Another significant impression that I obtained in $\mathrm{K}$ - was that of the street life. There were in the main three types of street venders; namely, the "Salep" man, the pastry man, and the vegetable man. Let me first explain that "Salep" is a beverage of Turkish origin that can best be compared to a spiced cocoa. The man selling this beverage walks around the streets with a portable charcoal fire to keep the drink hot and a tray suspended from his shoulders with straps. On this tray are cups into which he will pour a drink of "Salep" to those who want a warming drink. The "Salep" man was always at hand and was as common as the hot-dog man is at a college football game. Next in line comes the pastry man with an array of Turkish pastries. His big business comes after church and during holiday festivals. The next one to describe is the vegetable man who traveled around from house to house with his produce carried on the back of a donkey. He either sold his goods for money or was willing to barter for wheat husks, which he in turn could sell to cattle owners in the country for cattle feed. As far as I can remember, there was only one Jew in K . His occupation, quite typically, was that of rag collector. Somewhat related to this discussion would be one of the public markets. They are what one might expect them to be. The goods are brought in from the surrounding country districts by the mules of the farmers and are displayed at a fixed location on Thursday and Saturday of each week. The reason for having the market days so placed is that the Turkish day of rest, corresponding to the Christian Sabbath, is Friday. In this way the Turkish inhabitants of $\mathrm{K}$ - were enabled to make their purchases before the day of rest, as were the Christians on Saturday. Once the goods were taken home by the housewife, they were prepared in the usual manner, but were taken to a neighborhood bakery to be cooked. This practice was almost universal. The entire meal, from pastries to vegetables and meats, was cooked at this bakery. Payment for this service was either by actual money at regular time rates, or by an exchange of a bartered amount of finished pastries.

Now that I have discussed the external appearances of the life in 
$\mathrm{K} \quad$, let me give you an insight to the more intimate and underlying social organization. The chief motivation of these forces was that of political dissensions and religious suppressions. Until 1914 Albania was a Turkish protectorate; and Turkey was under the influence of the Russian Orthodox Church. At the same time Greece was ever endeavoring to attain a political ascendency in Albania. The social structure was a peculiar admixture of native Albanians and undesired Turks, who were interallied and subdivided by these factors of religious and political affiliation. These differences were most evident in the school which I attended while in $\mathrm{K}$. An Albanian child, such as myself, was not allowed to go to any school other than one under Turkish or Greek administration. This was to guard against the development of a feeling of nationalism among the Albanians, and the learning of a Christian language by their children. All Christian children went to Greek schools where they were compelled to read, write, and talk in Greek entirely. I remember that on one occasion soon after my arrival in $\mathrm{K}$ _ I was called upon in Greek by the teacher and answered him in the Albanian tongue. My supposed insurgency was quelled with a severe punishment. At the age of nine I could use the Greek tongue as fluently as I could the Albanian, although when outside of the school room I talked and wrote in the Albanian, as did the rest of our family, and associated with fellow countrymen. It is more than evident now that the teachers of the Greek schools did their utmost to influence their Albanian pupils in favor of Greece, for political reasons.

Family life in $\mathrm{K}$ _ was much the same as it had been in $\mathrm{P}$ the hearth was still the center of the family. Around my grandfather's fireplace I still continued to hear the anecdotes of past daily life and the stories of strange religious manifestations. The family loom was still in evidence, but was used more for the manufacture of rugs, tapestries, and blankets which could either be sold or used by the family as occasion presented itself.

One might be justified in asking whether life in Albania was entirely serious. Not so - people found amusement by things of their own doing. The boys of $\mathrm{K}$ ganged together in neighborhood groups and spent their time at such play as would correspond to that of similar gangs of boys in the United States. The older boys and men spent a part of their time in hunting trips. The furs of such animals as the mink and the raccoon brought very gratifying prices in other European markets. Weddings, however, were the occasions when 
everybody turned out for a good time. Friends and relatives up to the number of 150 were invited; five to twenty sheep and cattle were prepared for the feast; and numerous casks of wine were opened. There was quite a definite form to the preliminary celebration of the actual marriage ritual. On the night before the wedding the bridegroom was led through the streets of the city by a group of singing relatives and friends. He carried with him a water pitcher which was partially filled with water at the first public drinking fountain the procession came to. While at the fountain the bridegroom threw into the water at its base a fistful of coin which was fished out by small children who gathered around, knowing that this last was a usual part of the celebration. The same procedure was repeated at two more public fountains and then the procession found its way back to the home of the bridegroom. Here the general celebration continued throughout the night with a multitude of songs, toasts, and general good-natured pranks. Next morning preparation was made for the trip to the home of the bride. Messengers were sent ahead with casks of wine and bouquets of flowers. As soon as the bridegroom's party arrived at the home of the bride, the messengers were given gifts, the bridegroom showered the house with coin, the ladies in waiting sang several musical selections, and the best man placed slippers on the feet of the bride. If the actual marriage ceremony was to be held at a church, the ensemble then convened to that place, but if it was to be held at home, the priest came in and there was a ceremony which corresponded very much to the one practiced in the United States. After this the festivities continued for several days at the home of the new husband. In Albania there is no so-called honeymoon. Most all marriages are arranged on the dowry basis, and those among the higher classes are quite apt to be a matter of family alliance rather than of love. Divorce is not sanctioned by society in Albania, and is consequently very rare.

In a previous part of the discussion of my life in $\mathrm{K}$ I have spoken of the racial, political, and religious factions which were at constant odds with each other. My father's fear of serious trouble was well justified, for in $1914 \mathrm{~K}$ _ was the scene of a six-day siege, a part of the Balkan religious wars. In this war the Albanians were divided; those of Albania who professed the Mohammedan faith sided with the Turkish forces, while those of Christian faith allied themselves with the forces of Greece. Although the war was waged ostensibly for religious causes, it is much nearer the truth to say that 
both Greece and Turkey had their eyes fixed on the ultimate amount of Albanian territory which they might be able to annex. In the particular siege that I speak of, the city of $K$ _ was being held by the Turkish-Albanian forces against the invasion of the GreekAlbanian forces. K_ was situated in the foothills of the Swiss Alps and, surrounded as it was on three sides by these hills, was almost impossible to defend for any great length of time against the invading forces. The Greek-Albanian forces ranged along the tops of these hills with machine guns which they fired more or less continually for the six days of the siege. To move out of the house meant sure death; except for an occasional band of the besieged soldiers the streets were absolutely deserted. Even now, as I look back on some of the things that happened in those six days, I almost shudder to think of the horror that was divested upon the populace of that city by the invading forces. For six days and six nights, we children crouched along the walls of our home. It was impossible to tell when a fusillade of machine gun bullets would come crashing through a window or would spatter against the stone walls of the house to go ricocheting off into space. All would be quiet, and then suddenly several guns on the hills outside the city would open fire, probably upon some troop of the besieged forces which had ventured out. We would crouch more closely to the protecting walls as we heard the spray of bullets approaching down the street; we would quiver with fear as we heard them hit the floors and walls of our house or as they knocked bricks off the chimney down into the chimney; and then, as the deathspreading curtain of fire swept away to the next house, we would dare to breathe again. As the siege neared its end, people began to suffer from lack of food and water. The dead bodies of soldiers, straying children, and animals lay in the streets in the first stages of putrefaction. Fire had broken out in some parts of the town. It is a wonder that $\mathrm{K}$ _ withstood the siege for even six days. And when the invading Greek-Albanian forces did enter the town they had to fight down the armed resistance of the defenders. For days after the cessation of actual hostilities there were spasmodic outbreaks of armed conflicts. I can remember the relief with which we children finally ventured out of doors when the siege was finally lifted, but I can remember still more vividly the sights of death and disaster which met our eyes. There is one incident about the street fighting after the siege which I remember especially. We boys took the clothes from a fallen Greek soldier and stuffed them with straw to make 
quite a lifelike effigy, which was fastened to the end of a long pole. Then, hiding around the corner from where the Turks were stationed, we stuck the dummy soldier out in the open. The fire of the Turks was drawn to this supposedly Greek soldier. After the Turks had emptied their rifles of bullets a band of Greek soldiers would jump out from behind the corner where we were hiding and kill one or two Turks before they could scramble to cover. This trick worked on more than one occasion.

Prior to the revolution, conditions in Albania had constantly been growing worse. Letters from my father told of the seemingly fabulous wages which he was earning and of the living conditions in America which he was able to enjoy as a shoeworker. Finally, in 1916, we received a letter from our father telling us that he was ready to have us come to America. He went from New Hampshire to Naples and thence to Salonika, Greece, where he arranged to meet us. It took us eight days of travel on horseback to go from $\mathrm{K}$ to Salonika. We were under the care of guides all the way. At every turn of the road we were beset with dangers. The ground was covered with deep-crusted snow which the horses would break through ever so often. Most of the traveling had to be done at night for fear of robbers and the warring forces of the revolutionists. Even the roads themselves were treacherous, torn as they were by the shell explosions of the revolutionists. We finally arrived at Salonika, where we met our father after having been separated from him for five years. From here we went to $\mathrm{P}$ _ to stay at a hotel in waiting for the boat to take us to America.

While we were staying in this hotel I was the victim of a childish prank at the hands of one of my older brothers. It was nothing in itself, and at ordinary times would have been forgotten immediately, but at that particular time had consequences which might have proved far-reaching. One day as we were playing around in the hotel room, my brother got me down on the floor, sat on my chest, and clipped off my eyelashes with a pair of scissors. Due to this lack of protection my eyes became inflamed from the dust that was able to get into them, and they were indeed a sorry-looking sight when it was time for our family to be inspected by the emigrant authorities prior to our departure. The Greek officer in charge of inspection was convinced that I was infected with an eye disease which would prevent my entrance to the United States. For a while it looked as if I would have to stay back home alone or prevent the family from going to America 
if they did not want me to be separated from them. The doctor of the ship on which we were to travel took pity on me in my predicament. He assured the emigrant authorities that there was nothing the matter, and pledged himself personally to see that I would be in condition by the time we reached Ellis Island.

After this delay we finally boarded the ship and were off to the United States. On our way out through the Mediterranean we stopped at Algiers, Algeria, to take on coal. The sights of the white walls of the city and of the highly colored garb of the natives, as well as seeing salt water for the first time in my life, were all duly impressive. As we left the Mediterranean through the Straits of Gibraltar, we were stopped by British authorities and the ship searched for possible military spies. None being found, the ship was given final clearance papers and headed into the Atlantic for a voyage that was to take twenty-seven days. Every minute of the voyage was one of pleasure and of new sights to be marveled at. There were deck games, people from other parts of Albania, movies, and puppet shows to occupy the time. Fortunately for our family, we were able to travel first class and escape the squalid conditions of the regular third class immigrant passage. Although it was against the regulations of the ship, members of my family made it a point to do little favors for friends of theirs who were traveling third class and to bring them extra bits of food or ice water whenever possible.

After the long voyage across, we arrived in New York harbor on a foggy morning on the first of April, 1916. I had been told to watch for the Statue of Liberty, but was more impressed by the New York skyline. At the immigration offices at Ellis Island we had no trouble at all in being admitted, mainly because we had traveled first class. It was apparently the custom to assume that immigrants traveling first class were desirable, but that those in the third class should be rigidly inspected. The ship's doctor, true to his word, had cured me of the inflammation and even stood by me as I was inspected. My father was so pleased at the loyalty of the doctor that he gave me a twenty-dollar gold piece which I slipped into the doctor's hand. Naturally I had had my fears as to the possible outcome of the inspection, and after finding that I was accepted into the United States was more than relieved. This, I might add, was most certainly a favorable first impression of America.

From New York we went to New Hampshire, where my father had been established for five years. No one in my family except my 
father could speak a word of English. The new environment puzzled us with its complexities and its differences. We all wished most heartily, at first, that we were back in Albania. After a few days we were taken by hand and conducted to one of the grammar schools where there was a particular section for children speaking a foreign language. At first we carried with us almost continually an AlbanianEnglish dictionary. As children, we were not embarrassed at the mistakes in language and customs that we made. In a surprisingly short time we learned to converse amongst ourselves in English and to enjoy our new life. There were, after all, so many things that were better than in the old country: the living comforts, the amusements, and the freedom. In the section of the city where we lived there were four or five families of Albanians who had come from the same section of the old country as had we. They were glad to hear of their old friends through us. What seemed most strange to us at first was to hear them discuss with apparent familiarity the social affairs, politics, and labor conditions of the United States. One thing that was of a great help to us was that we did not have to worry over our finances. My father had been established in the city five years before our arrival, and my two older brothers were able to go to work soon after we came. The thing that shocked me most about America was the lack of respect shown by children for their parents and their older brothers or sisters. In Albania it was always the custom for the oldest son or daughter to be married first and for the others to wait their turn. This applied to all other things, as well as marriage.

At times it seems a bit difficult for me to realize that I was ever born outside of the United States and that up to the age of ten I could neither read nor write English. This realization is all the more difficult when I find that it is comparatively easy for me to carry on my work in the business fundamentals course at the university. I feel pleasure in reading such books and magazines as give me an insight to the conditions of Europe today, and of Albania especially. In fact, I feel as much an American as those who were native-born, and find that my interest in Europe is one such as any educated American might have. I will admit, though, that I am naturally somewhat prejudiced in this interest, but that $I$ still do regard the affairs from the American's viewpoint.

It has been interesting to compare the results of the Americanization process in its application to the generations of parents and children in families such as my own. The immigrant children try to copy 
the ways of the American children whom they meet in school, and are usually very successful in this; they want to be like their neighbors. The parents, who have not had the opportunities to make the numerous contacts presented to their children, tend to be reactionary and to cling to the deeply ingrained customs of their homeland. The thing that they miss the most of all is the friendships that they had before coming to the United States. A good example of the faith placed upon friendships in Albania might be that of the "brothers." These "brothers" are two boys, usually relatives, whose friendship is bonded and given religious significance by a ceremony of sanctification at the church. The effect of the American environment can be seen in a case that I know of where two "brothers" came to the United States. The friendship soon lapsed into a mere name, and then finally the idea of such a thing was laughed at.

I have now reached a point in my life where I think that I can pass judgment upon my new environment and upon my old. In the United States I find a highly organized social structure which will readily absorb immigrants such as I was - a society which will permit of internationality marriages; a society which gives a freedom to women that never existed in Albania; a society which has much to offer in the way of material advancement to the immigrant; and a society that does not definitely assign any one person to a fixed social level. Albania appears to me to be somewhat of the lazy man's country. There is no great worry over the future. There is no blind struggling against the lot that has been cast for any particular person. Conditions are taken as they are - and are met with such resources as are at hand.

Although I did feel at first that there was a hostility towards me, a foreigner in the United States, I have now overcome any such feeling and consider myself as much an American as any one else. If I ever return to Albania, it will be as a greatly interested tourist. I feel a bit of pity for my struggling countrymen in Albania and will, if I am ever in a position to do so, help them with any influence or finance that I might have at my command. 


\section{BULGaRIAN \\ Half an American ${ }^{1}$}

As I try to recall my earliest impressions of America, first come to mind the rotten tomatoes which native urchins hurled against us poor frightened immigrants as we trudged morning and evening from our quarters to the foundries and back. My impulse then was hatred for all Americans, whom I considered as omniscient giants before whose energy and ingenuity nature herself bowed. My first desire was to accumulate as much as possible of the proverbial American gold and beat it back to the old country.

Some, the more frugal and labor-loving ones, did precisely that. Through severe economy they saved a thousand dollars or so in the course of a few years and returned to the villages to resume their honored positions as masters of houses and families. There they augmented their properties by buying another vineyard, a couple more meadows; swept away the decayed thatch from the roofs of their houses and covered them with gleaming red tiles.

But the majority of us stayed. We soon got used to the tomatoes, even took for granted an occasional egg. We knew we were foreigners, and we were not slow in perceiving that while in our own country the word foreigner connoted guesthood, in America it carried an implication of contempt. We had come to stay and avail ourselves of the riches. No one likes a guest that has come to stay permanently.

We lived in clusters in the large cities and contemplated the American world through the windows of our coffee houses. Physically we were in America; mentally and spiritually in the old country. If ever an American ventured into our coffee houses we all stirred like the bees in a hive into which a slug has made its way. There was just as much excitement caused by the strange visitor as if he had visited our native village. We had created a world of our own within that greater world into which we only occasionally ventured.

This great world which encompassed ours was to me an immense confusion. Of its complicated pattern I could not discern a single stitch, much less begin to perceive the pattern itself. Filled with fright, I thought of the little native world with which I was intimate and whose mysterious life was not a mystery to me. Did I not help promote that life? I knew the grass grew in the meadows because

1 By Stoyan Christowe, in Outlook and Independent, Vol. CLIII, pp. 530-31, 555-57. 
we watered it; the grapevines sprouted and leaved profusely because we pruned them in the spring and weeded out the hampering growth from amidst their roots; the corn grew because we plowed the field and planted the seed there.

But here everything seemed purposeless and inexplicable. For ten hours every day I stood harnessed to a monstrous machine and bored holes into pieces of steel. I did not know whence those steel pieces came, how they were called, why I was punching the holes in them, where they were going from me, of what eventual use they would be. The whole city in which I lived was like that. People went about hurried in all directions. To what purpose, I could not divine. The whole of America was like that in those early immigrant days.

But gradually I began to perceive a faint rhythm in the cacophony and to discern a certain measure and line in the catastrophic disorder which surrounded me. The mist began to clear away and the mighty structure of America loomed before my vision like a lofty vague mountain at the earliest dawn.

As the American world took form before my eyes and slowly revealed itself to me, a dimness about the world I came from began to settle in my mind. The traditional names of the heroes of our land began to seem the names of heroes of a mythical world and to be crowded out of memory by names which would once have sounded strange to me. More and more America revealed itself, intriguing me farther and farther into amazing labyrinths, and captivating me with the crude sorcery of steel and iron, until I began to see beauty where I had once seen only frightful ugliness.

There started then to awake in me a fevered passion to become part of the magnificent, resplendent scheme which unfolded and grew before me. I studied the language with maniacal zest; read newspapers and magazines and books with the avidity of a fanatic. I read out loud bill-boards, posters, signs of all kinds, names of companies and corporations, names of streets and squares; and every word, every name opened new vistas to me. I was becoming saturated with Americanism.

More and more America captivated me. It alone was great; everything else was puppetry. The glare of this fantastic civilization blinded me to the achievements of any other nation. Europe was but a museum with its people the porters and guides in it. America was the living world, where men breathed, worked, created, built, sought the solutions of the mysteries of nature and harnessed the 
universe. I passed through a phase of blind provincialism; a sort of spell emanated from outward things coloring my vision and judgment.

In my passion to liken myself to the Americans, to rub out from my personality all foreign traits and characteristics, I suffered agonies. I would not content myself with straight and safe English. Americanisms, native idioms and localisms would give a certain authenticity to my own Americanism. And I was not cautious in their use; with the result that often I made myself ridiculous, saying things entirely different from what I intended to say. Once in my college days a fellow student and I passed on the campus two lovers. I noticed as they came by us that the young man was holding the girl so awkwardly that she walked with difficulty. My intention was merely to remark to my friend on the unnatural way in which the young man was holding his companion and I could well have said, "What a stupid way to hold a girl!" but precisely what I said was, "Say, that fellow's got that girl in a bad shape!" My friend laughed uproariously, but genially, and I with him. In those days I was not very self-conscious about my mistakes. I knew that my whole being was in process of change, that I was in a state of turmoil. My English was in ferment.

Years have passed since then. And I am now a different person. Still I often ask myself these questions: What has been the result of this long and blind gestation in the womb of America? Have I become an American? Has the storm in my being lulled now that I have spent two-thirds of my life in a struggle for readjustment and adaptation? The one answer that pounds in my mind most is this: Despite the readiness and zeal with which I tossed myself in the melting pot I still am not wholly an American, and never will be.

It is not my fault. I have done all I could. America will not accept me. I shall always be the adopted child, not the real son, of a mother that I love more than the one that gave me birth. It is hard for a man with ingrained native traits and characteristics to remake himself in the course of one generation. There is still something outlandish about me; mannerisms and gestures that must strike as odd one born and bred here; tints and nuances in my speech that must betray my foreign birth soon after I open my mouth to speak.

I once believed that America demanded complete surrender from those who adopted it as their mother. I surrendered completely. Then I discovered that America wanted more - it wanted complete 
transformation, inward and outward. That is impossible in one generation.

Then what is my fate, and the fates of the thousands who fall into my category, or, should I say; into whose category I fall? What are we? Are we still what we were before we came to America, or are we half Americans and half something else? To me, precisely there lies our tragedy. We are neither one nor the other; we are orphans. Having forsaken our own mothers to become the foster children of another, we find ourselves orphaned. Spiritually, physically, linguistically, we have not been wholly domesticated. And at the same time we have rendered ourselves incapable of resuming life in the old country.

While I am not a whole American, neither am I what I was when I first landed here; that is, a Bulgarian. Still retaining some inherited native traits, enough to bar me forever from complete assimilation, I have outwardly and inwardly deviated so much from a Bulgarian that when recently visiting in that country I felt like a foreigner and was so regarded. My Bulgarian speech is now cramped and rusty, clumsy and inadequate for my thoughts. I cannot now speak that language half so fluently as I speak English; nor can I write it with half the facility with which I string English words upon this page. In my audience with King Boris during my visit there I found myself compelled to ask permission from the King to speak to him in English. In Bulgarian I stammered and was hopelessly inarticulate.

I know hundreds who have been twenty and more years in America and who use English chiefly as their medium of communication, but speak it abominably, like foreigners, and speak their own tongues even less fluently. Some years ago I was interpreting in court for a Bulgarian who despite a continuous residence in this country of fifteen years still deemed himself unprepared to appear in court without an interpreter. We both found it more difficult to converse in Bulgarian than in English, and the court was greatly amused when we had to discard our mother tongue and wrestle in English for understanding.

Later, while I was traveling on a Bulgarian train the conductor came to tell me that in the adjoining compartment there was a Bulgarian who had been in America so long that his speech was no more comprehensible than that of a child of three. I asked to see my compatriot. I spoke to him in our native speech. He understood what I said, but when he attempted to reply his tongue was tied. Then I 
addressed him in English. His eyes lit up with joy and his face opened into a smile at the sound of English words in this land which was his birth soil. I was not surprised when I heard his English, which was only slightly more intelligible than his Bulgarian.

There are many such linguistic orphans in America. It is a difficult matter for one whose ancestors for centuries have twisted their lips in a certain manner, flung their tongues in this or that nook of the mouth, and otherwise adjusted and manipulated the speech organs to the articulation of peculiar native sounds to force these organs to the production of unnatural syllables.

Now I do not claim that America openly demands uniformity of the immigrant that has come to stay. The federal authorities when granting citizenship rights do not put one through a form of examination designed to ascertain whether he has attained to these qualities before they grant him his papers. But though the demand has not taken such concrete form it is nevertheless there palpably and none perceives it better than that immigrant who has been inoculated with the fever for Americanization. I have seen in the homes of foreigners certificates of American citizenship framed like college diplomas and hung on the walls. I have heard the owners of these diplomas of citizenship speak disparagingly of their own peoples and lands and exalt everything American, except prohibition. A kind of Americamania dominates their feelings and attitudes. Yet to the Americans themselves, I mean not the Americanized but the whole Americans, these proud citizens are Greeks or Bulgars or Polaks; not infrequently Dagos, Wops, Bohunks.

What then eventually happens to these people? Do they continue living in a shroud of deception, or do they sooner or later see through the illusion and tire of their fidelity to America? At length I believe every immigrant begins to think of the old country. Many return with the thought of looking things over and remaining there. But they immediately find that while they have not made of themselves whole Americans, they have become so different from their own people and their mode of living has undergone such a drastic change that the prospect of resuming habitation in their native lands depresses them. There by their own people they are regarded as Americans and are looked upon with a not too approving eye. In America they are foreigners. What are they? They speak well neither English nor their mother tongues.

I cannot forget the experience I had with a Greek-American whom I 
encountered in my travels in the Balkans. I was driving in a Ford through Chalcidia when, tired and thirsty, I asked my Greek chauffeur to stop in a little village for a drink of mastica and a cup of Turkish coffee. A gendarme walked to where we had stopped and asked whether we would be good enough to take along with us to Polygiros, a town some fifteen miles distant, an American who had been stranded in their village. I started at the word American and quickly informed the gendarme that I myself was one. It would be a pleasure indeed to accommodate a countryman of mine.

Seated alone at a table on the terrace of the village café was the American, a short, chubby fellow with a round face. He was dressed in a blue serge suit, a gray cap was pulled over his forehead. The native Greeks in their baggy Anatolian trousers stood or sat at a respectful distance from him and watched his every movement. His chest inflated, the man was surveying everything around him with a lordly air. Now he would sip his coffee, now finger the gold pendant on his watch chain, now pull up the legs of his trousers so that the crease might hang down straight. All these movements the villagers observed with profound and respectful interest. None dared to sit at his table or near him. Among them he was like an officer of an army of occupation. He was a sight! He seemed to be saying to everything and everybody around: "Look! I am an American! What are you? Nothing. Scum!"

The gendarme, the only person bold enough to speak to him, or probably the only person the man condescended to speak to, told him that I was an American. That he should meet an American in these isolated places was enough to fill him with joy. He rose quickly and gladly extended his hand to grasp mine. But the instant he heard me speak in Greek to my chauffeur, he drew back to himself, like a hedgehog at the point of a stick, and eyeing me suspiciously, said in a contemptuous tone, "You ain't no American! You're a Greek!"

He reclined back in his chair and assumed his pose of superiority. It was not until I had shown him my American passport and dazzled him with a flow of English, which he considered learned, and later told me was like "the English in the newspapers," that he warmed toward me and accepted my lift to his destination.

All the way to the next town he cursed the Greeks. He had been born in a Greek community in Asia Minor and had emigrated to America years ago. Now he had come to the new parts of Greece to 
buy a place and settle down. But he was like a fish out of water. Time and again he reassured me that he could not live among the Greeks in the homeland and that he counted the days until his return to America where he planned to buy a soda fountain in Lansing. For twelve years he had been in that business in Michigan.

As he spoke derisively of the Greeks, his own people, of how filthy and backward and uneducated they were, I kept looking at him and could not help thinking that in Lansing he was a Greek.

But how about myself? In Bulgaria I am not wholly a Bulgarian; in the United States not wholly an American, I have to go through life with a dual nationality. When in the United States I long for the sleepy villages and the intimate life of the Balkans. When I am in the Balkans I dream of America day and night. An American-made motor car seen on the street, an advertising poster announcing the showing of a motion picture made in the United States, anything closely or remotely connected with America is enough to send thrills through my spine. I was taking an afternoon nap in the house of a friend in Sofia and upon waking was told that I had been talking in my sleep. "What did I say?" I inquired, afraid of having revealed some secrets, with which one's head is always filled in the Balkans. "Nothing much," they comforted me, "You just kept blabbering about America!"

And shall I forget my joy upon my return to America! I was downright foolish. I felt like a child at the sight of his mother from whom it had been separated for months. Without unpacking my things, I left my room at the hotel and for nearly two hours walked up and down Broadway like a man possessed. Everything that my eyes beheld, I felt like embracing within my arms.

But here I am. A year has barely gone by and I am ready to embrace a Balkan donkey with fraternal affection. Yet I cannot leave America, though I am but half an American.

\section{QUESTIONS}

1. Taking the Old World conditions, show specifically what forced each person to migrate. In each instance what was the specific appeal? In what ways did the social and economic grouping of the individual heighten the appeal?

2. Pick out the Albanian (number 7) customs and compare them with customs of similar social groups in America. 
3. Which cases show most dissatisfaction in regard to religious conditions? Economic? Political?

4. How did the Serb's (number 6) experience upon entering differ from those of later immigrants?

5. Explain the circumstances of the Russian's (number 2) entrance.

6. What were some of the American puzzles to the Pole (number 5)? What other differences did these Slavs notice?

7. What conditions served to break the jar of culture conflicts in the case of the Russian girl (number 3)? Compare this document with that of the Russian (number 4), noting the influence of relatives on the early adjustment process.

8. What did these newly arrived immigrants think of their fellow countrymen in America?

9. What difficulties were experienced on account of language?

10. What does the Russian (number 2) mean by finding so "few real Americans"? Explain the Bulgarian's (number 8) meaning when he says: "Physically we were in America; mentally and spiritually in the old country" and "We had created a world of our own within that greater world into which we only occasionally ventured."

11. Analyze the personal disorganization and partial reorganization of the Russian (number 2).

12. Cite specific instances where the immigrant tried "to rule out from my personality all foreign traits and characteristics" in accommodating himself to American life.

13. What is the significance of sending home for a wife? (See number 1.)

14. Why did the Gettysburg address stir the Serb (number 6)? Why will the Bulgarian (number 8) never be wholly an American?

15. Analyze the Albanian's (number 7) comment: "At times it seems a bit difficult for me to realize that I was ever born outside of the United States and that up to the age of ten I could neither read nor write English."

16. What were the major steps in the Serb's (number 6) assimilation?

17. Discuss the loyalty of the Slavs to their native lands.

18. Should the United States force its citizens of foreign birth to fight against their native countries? 
CHAPTER XXXV

\section{LIFE HISTORIES OF OTHER RACIAL, NATIONAL, AND CULTURAL GROUPS OF FIRST GENERATION}

\section{AMERICANS}

\section{FINN}

\section{The Land Where a Man Is Free to Work ${ }^{1}$}

Though it is now eleven years since I left Finland, my native land, I have not as yet taken out my "first papers." During the first six years, I had no conscious desire to become a citizen; it was my intention to return to Finland and make my permanent home there. Then I made a two months' visit to my fatherland. The birth of my conscious desire to become an American dates from that visit. Even then, it was a thing of slow growth, for it is not easy to tear one's self loose from the old memories, the old associations. But I have at last made the decision. Perhaps in this very deliberateness, in this long weighing of the ties of blood and tradition against the opportunity and spirit of America, there is something that speaks eloquently, since the decision is for the latter.

It has taken me a long time to come to a decision; but except for the number of these years, my experience is typical of the Finnish immigrant. To speak more exactly; it was typical before Finland secured its independence; how it is now, I do not know. The Finn loves his native land. He comes to America to gather money to take home. Many who come, return; and of these, many again come to America - this time to stay. Dear as the fatherland is, America gives what the fatherland does not - an equality of opportunity, a freedom for effort, a chance to make money and progress. These are things that bring back the man who has once tasted them.

I was born and raised on a farm; and my father wanted me to be a farmer. But I had decided that I was going to become a professional man. To do that in Finland, a long and thorough education is necessary. When I was seventeen I left home with just thirty marks in

1 By Kalle Mäkinen in World's Work, Vol. XLI, pp. 273-76. 
my pocket and entered college. I made the eight years' course in seven, supporting myself as a copyist. Then I entered the university at Helsingfors. At that time I thought that I would become a civil engineer, and so I said to myself: "America is the place where they do the marvelous things in engineering - you will have to go there to finish your knowledge." But the thought was only to go, see, and learn. I never thought to expatriate myself. Finland was always to be my country.

Before long I gave up the idea of becoming an engineer, and decided on the ministry, and it was toward that profession that I worked during my four years in the university. I studied English, but it was only as a part of the modern language course that I was taking. In the same way, I studied American history. I was always greatly interested in Theodore Roosevelt. I thought him the greatest man in our generation. I said: "If there is a land that can produce such a man, there must be something more there than we have here." A college friend had gone to America, and he wrote me letters saying, "this is a great country" and telling me stories of what he was seeing. But in spite of all these things, my only feeling toward America was one of curiosity; I felt no temptation to make my home there.

When I graduated from the university, I was ordained a pastor in the Lutheran Church, the state church of Finland. In the next two years I held a number of pastorates in various parts of the country. Then my friend, who had left college to go to America, followed the way of so many other Finns, returning to his native land. He came to visit me. One day we saw in the newspaper an advertisement saying that there was a vacancy in the New York station of the Finnish Seamen's Mission Society, an organization that has stations in seaports all over the world. The appointment to the vacancy was to be for three years. Immediately my friend said: "This is the place for you; you are fit for America." With his urging and the idea in my head that it was an opportunity to visit America, I telephoned asking to be taken in consideration for the place, and mailed letters of recommendation, my diploma, etc. When the Board passed upon the applicants, I got all the votes.

Meanwhile, I had been appointed clerical secretary for the diocese. The bishop was the one who had ordained me: I was among friends. The salary was good. To a person of scholarly tastes, the surroundings were delightful. The temptation to stay was very big. But 
finally I said to my wife: "I shall take the appointment. We shall go to America. It is only for three years."

I shall never forget my first impressions of America. Our ship had stopped in the Upper Bay, and I saw that long strip of land covered with buildings, and some one said: "That's New York." It was not a good idea that I got of it; it looked so much like disorder. All around the shores of the harbor, wherever the eye turned, there seemed to be disorder. It made me feel very melancholy. Unless I remained for the three years, I would have to pay our passage back to Finland, which I could not afford to do. And I said to myself: "Oh, if those three years were only past and we could go home." When we landed, it seemed the same way - everywhere disorder. When I came to my mission, there, too, was disorder. I felt very homesick for Finland.

But soon I saw that here was a big field to help my people. I had been sent to New York to preach, to do spiritual work - nothing else. I preached and I might have half a dozen or even fewer listeners in my mission. I began to see that America was a different world from the one I had left, that it was more practical. Perhaps this was the first subtle influence of America upon me. In Finland I very likely would have willingly confined myself to preaching and have accepted philosophically whatever number came to listen to me, the Church being a state institution, I would get my salary whether people came or not. But in America, though my salary would continue just the same, I wanted to make my mission a success. I wanted to help the men that I had been sent to reach, and to accomplish this I was willing to subordinate the spiritual to the practical.

I fixed up a room where the men could come to read, to talk, write, or play games. I formed a club which we called the "Anchor Society." It met once a week. Always there were sailors from ships that were just in from remote corners of the globe. At every meeting I had a sailor give a talk. We called them lectures. After each "lecture" there was general discussion, many of the listeners having been to the same port, only not so recently. Occasionally the discussion was very lively, for some of the sailors may have had a little to drink, and the more lively the discussion the more the sailors enjoyed it. And they used to sing sailor songs and national songs. The old religious songs are very beautiful, but you cannot make young men sing only them. I said to myself: "Unless you let the sailors act like sailors, they will not come; and if they do not come, you cannot help them at all."

The Board in Finland heard how I was conducting the mission, 
and it wrote, finding fault, saying that $I$ had introduced too much of the earthly life, that there must be more of the spiritual, that there must be more preaching. But I continued as I had been doing, for the sailors came to the mission and they were supporting it. I believed that that was my justification. I had the right to draw money from the Board in Finland, but I have not had to ask for a single penny. Perhaps that is why the Board, though it never ceased reproving me for my methods, did not recall me.

As the sailors became my friends, I found that there were many practical sides to the help I could give. Many of the sailors knew no English, and so they called on me when they needed an interpreter. I often helped when they were trying to get places of employment. When they had legal papers sent to Finland, I would see that they got some one who could do it and give fair play. I visited them when they were sick in the hospitals - sometimes I visited them in prisons also.

\section{DEMOCRACY IN AMERICA}

It was while I was helping my sailor friends in these ways, that I got my first big impression of the spirit of America, of the thing that makes America different from the old world. When I visited the sailors in the hospitals, in the prisons, when I went to the police courts to help them, I was always treated with the courtesy that democracy says every human being is entitled to. If I wanted an audience with an official, I did not have to wait many hours as I would have had to do had I been in Finland; there was no delay or ceremony; I got an audience right away.

These practical demonstrations of the spirit of democracy made a very deep impression on me; but it was an impression that grew slowly because it grew out of experience that came at different times. The first thing that by itself aroused in me a very big feeling toward America happened during the first year that I was in New York. Finland was then a part of the Russian Empire, and so, of course, there was no Finnish consul here. Many Finns wrote letters to me asking questions that ordinarily would go to a consul. One day I got a letter from a Helsingfors merchant asking where he could buy American motor boats and the prices. I did not know anything about motor boats. I decided to ask the Government. So I wrote a letter of inquiry to "The Commercial Department, Washington, D. C.," enclosing a stamped and addressed envelope. I knew that 
in Finland you could not write to the Government in that way. I thought that my letter would go to the waste basket. But I said: "Any way, there is no harm to send it."

But in a few days the mail brought me one of those official envelopes that need no stamp. It enclosed my stamped envelope and a reply saying that my letter had been received and duly forwarded to the proper department. Then, a few days later, a letter from another department saying that my letter had been forwarded to it and that motor boat manufacturers had been notified of my desire for information. For weeks afterward, catalogues came from all over.

That made an astounding impression - a foreigner writes to a big department of the National Government and gets such prompt and courteous attention. In Finland, letters to the Government must be written on special forms, and they go through many bureaus. There would be much formality and delay. I said to myself: "It is true, here in America there really is democracy."

So far as I knew then, none of these things changed my feeling toward Finland. Many times I would be dreaming of the old places, of the old friends at home. When my work here was done, I was to go back, to live and die in Finland.

Then, suddenly, in 1911, two years after I had reached New York, my board asked: "Do you want to return to Finland? Answer yes or no by cable." Much of that night, I lay awake, thinking. I do not know why, but I had a feeling that I ought to stay here. The next morning I cabled that I would not return yet.

Two years later, another society asked me if I wanted to accept a place in Finland. Again America held me in the same strange way; I was always dreaming of Finland and yet I stayed.

It was in 1915 that the great day came - at last I was going home. But I left my furniture, my few little possessions, behind in America. If you ask me why, I could not tell you.

$\mathrm{Ah}$ ! it is a grand feeling when a man who has been many years away from his native land, at last returns. I can not describe what my feeling was when I crossed the border. Another passenger, on the way to Russia, exclaimed: "You are indeed happy; your face is really beaming."

\section{RETURN TO AMERICA}

It was summer, the time of the midnight sun. Finland was very beautiful, just as beautiful as I had been dreaming that it was - 
except that everything seemed a little smaller than when I left. I went to visit the old places, the old friends. It was very delightful. For two months I traveled about talking of the work of our mission society, trying to collect money for it. But all the time it felt like a big Sunday. Gradually the feeling came to me that I must go to some place and start to work again. At the end of the two months I sailed for America, to take up my work again in the mission.

I traveled by way of England, and sailed for New York on an American vessel. The night we left Liverpool it was dark and stormy, and there was danger of torpedoes and submarines. The sight of the American flag gave me a feeling that was a surprise. It made a very wonderful feeling to be under the flag that said: "Don't touch me it will be very dangerous."

When I landed in London I always had the feeling that everything was so old - like an old man, always decreasing, going down, down, down. When I reached America, everything seemed young and strong and growing. When I stepped ashore in New York, I said to myself: "This is the right place for you. This is the place to star' work."

For two more years I worked in the mission. Then America entered the war. Many of the Finns, sailors and others, did not know how to fill out the draft questionnaire. I helped hundreds of Finns with these and other papers. For two years I worked several hours every day at the Russian consulate. I was helping my countrymen in war times and I gladly did it without pay.

In 1919, when Finland was recognized as an independent state by the United States, the Finnish minister to Washington put me in charge of the passport office in New York City. I remained in charge of that office until September, 1920.

My experience in this passport work gave me a big view of the sentiment of the Finnish immigrant. Very, very many ask for passports to return to Finland. This is particularly so in the springtime when our native land is very beautiful. I would say: "What's the idea to go back to Finland now. In a short time you will want to return to America." And the reply would be: "Don't say that, pastor, I'm going to stay in Finland forever." But they came back - many, many of them.

Ever since I came to New York, I have handled money for Finns, for some who wanted to have it deposited here, for others who wanted to have it transported to relatives at home. For the first eight years 
it was mostly the sailors who asked me to do this for them, but requests also came from Finns in other occupations. The number of these latter has constantly grown, particularly since my work with the questionnaires and the passports. I have handled over a million dollars, transporting the money that was sent to relatives at home, through the biggest banking concern in Finland.

The manager of the foreign office of this banking concern visited the United States last summer. He made a long trip to the Pacific Coast and asked me to go with him. Then he asked me to take charge of advertisements for the beginning of a banking business here. My salary as pastor was small; the board was still complaining that my methods at the mission were too practical; I had found that I could be useful in other ways than as a pastor; and my family was growing. So I sent to Finland my resignation as pastor of the mission. I am now to become an American business man.

I like the freedom here. If I am a pastor and my private life is all right, I am honored; if I am a business man and my private life is all right, I am honored. In Finland, they would not understand a pastor becoming a business man; but in America, if a man is able to do a thing, he gets a chance to do it.

\section{Hungarian}

\section{From Hungarian Banker to American Pastry Merchant ${ }^{1}$}

In June, 1913, I was living in Budapest, a subject of the AustroHungarian monarchy. So far as the government was concerned, I was a contented subject: I had no quarrel with the laws; I was satisfied with a monarchical form of government. I was content to live and die a Magyar subject of the House of Hapsburg. In less than three months I was living in New York, I had taken out my "first papers," and was resolved to become and remain an American citizen.

It was economic and social conditions that wrought the change.

I held a good position in a bank in Budapest. Every morning I was driven to my work in a fiakker, and every afternoon I was driven to my home. I mention that fiakker because it can be taken as a symbol of the old life in Budapest, just as the 5 cent subway ride to business can be taken as a symbol of life in New York. In Budapest, it was easy, gay, frivolous; almost every one who made a pretense to what we called "living," spent more than he earned. I do not want

${ }^{1}$ By Bertalan Barna, in World's Work, Vol. LXI, pp. 206-08. 
to forget the good things in the old life - Magyar hospitality was open-handed, warm, fine; but financially, Magyar social life was built on straw - almost all were living beyond their incomes. If a family tried to reduce its expenses, to live truthfully, it lost caste.

It was in this June, 1913, that the bank in which I held a position changed its president. The old president had been a good friend to me, and I wanted to remain his friend; but the officers said to me: "He is now our business enemy; you no longer can go to see him." I answered: "I work faithfully for you; but who my friend is is my own business." The officers said: "No, that is not true." So I resigned my position.

And now it was that I first thought: "I shall go to America!"

I did not know much about America. What I had read made me, think that it was a very cold country where the people always wore fur coats. And because it was a new country, I thought it would be crude, undeveloped. But I had also heard that it was rich and big, that it had big railroads, big factories; I had seen pictures of its "skyscrapers." All these things made me think that America was the place to look for a business opportunity. But there was something else - the spirit of America: I had heard that in America a man could start as a boot-black, as a street-sweeper, could start in the lowest position, and, if he had the ability, could work his way up to the highest; that it is not where a man starts but his ability that counts. I had heard that it was a wonderful country for the man who wants to work, that every willing worker gets a chance to work, an opportunity to develop his ability; that the smallest man, if he has it in him, can grow to be among the biggest. I believed that this was really the spirit of America, because I had seen returned Magyars, laborers, men who had worked in the steel mills of America; and I had seen that a great change had taken place in them so that they stood out from among their old neighbors. It was that they had an independence in their bearing - no more taking off of their hats and servile bowing of the shoulders when they passed in the streets someone of higher social station, but the manner of one man to another.

I went home and said to my wife: "Listen, dear. I am going to America. I will try it for a year. If I succeed then I shall send for you and the child." (I have a boy who was then three years old.) "If I do not succeed, then I shall return."

After one night my wife said: "You speak no English; you have no friends in America: it will be very hard for you to make a living. 
If you leave me here, you will have to support this home and also pay for a home for yourself somewhere in America. It will be easier if I go with you and make a home for you."

To this I objected: "But we shall have to live very economically in America. You would have to cook and you do not know how." (We had three servants in our home in Budapest.)

"You will have to learn to do many things that you never had to do before. I too can do the same. It is better that we go together."

We sold our furniture. We did not want to let it go into the hands of dealers: that would be too hard. We wanted friends to have it; and even though they could not pay us until some months after we arrived in America, we sold it to them.

- In July, 1913, with my wife and three-year-old boy, I left Budapest, bound for New York. We had lots of clothing, and all of this we took with us; that was one thing that we would not have to spend any money for until many months after our arrival in America. After paying for second-class passage, I had just $\$ 260$ left.

We were not sorry to leave Budapest; our minds were occupied with new hopes, new responsibilities. On our journey to America, we had only one real worry: "How will we have a bath?" In Budapest only the well-to-do have baths in their homes. In New York we would be poor people living among poor people. We never dreamed that in the cities of America almost everyone has a bathroom in his home.

It was not necessary for us to land at Ellis Island. The immigration officials came on board and passed us. They were very courteous, and so too were the customs officials on the dock.

My first impression of Americans was that they were courteous, very ready to help the stranger. My first impression of America was surprise at its development: I had come to a young country, but in its development it was like an old country. I think it would amaze Americans if they knew what Europeans expect to find when they land in New York.

Through recommendations that I had got on the ship, I got a little apartment on the west side of Manhattan Island. The next day was Sunday, and I got a little chart and rode up and down on the elevated railways and in the subways, so that I would know something of our new city. Monday, I went to a furniture store that I had seen from the window of the train on the elevated railway, and spent $\$ 107$ for furniture and things for housekeeping. On the way home I 
bought a chicken. I remember how difficult it was for us to ascertain how to open the chicken; but I helped my wife, and we had our first dinner in our American home.

Besides Hungarian, I spoke Slavic, French, and German. In going around the city, the German helped me, but not always. Even when I could not make myself understood, I found the Americans more friendly, more open than are the people of my native land.

To some of the people in the house where I had my apartment, I said: "I want to get work to do." And they said: "What can you do?" "I am willing to do anything," I replied. "I will sweep the streets if it is necessary to begin so." "But you can not become a street sweeper unless you have made the declaration that you intend to become an American citizen," they told me. So the next day I went down and made the necessary declaration.

Then some one told me that because I spoke French and German he could get me a job as "omnibus" in a hotel at Long Beach. All day I carried off soiled dishes, set tables, put on ice-water, bread, and butter. That night I got $\$ 3$ as wages, and I had got $\$ 2$ tips from the waiters that I had helped $-\$ 5$ for the day. When I got home to my wife, I waved the money: "Voila! Money the first day."

Now see what it is to live in America: within three weeks after I land - an immigrant without friends, almost without money - I decide that I shall become my own boss. When I was in Budapest, I was interested in a company that manufactured an embrocation that was very popular throughout Hungary. I knew the formula. I decided to make this embrocation and market it among the Hungarians in America. I stopped being an "omnibus"; at night I manufactured the medicine in my apartment; and in the day I peddled it to Hungarian grocery and other Hungarian places.

We paid $\$ 26$ a month for rent; my wife spent $\$ 4.50$ a week for food; we had plenty of clothes that we had brought with us from Budapest; I worked on an average twenty hours a day.

Within three months I took a partner. He stayed in New York and manufactured the embrocation while I traveled as a salesman. I traveled for a year and went through sixteen states. It was an experience that brought me nearer and nearer to the American spirit and taught me to love America better and better. It is the place where there is the fair chance and the free spirit. Comparing the laborer in America with the laborer in Europe, the one in America 
lives a thousand per cent. better and gets a thousand per cent. better treatment. Here it is just one man to another.

I was never lonesome for Hungary - never for a minute. I had become like a man turned inside-out. In Budapest life is gay and light and frivolous; people live too much for the moment. In America you look with more serious eyes. Life is truer here. The biggest secret to this truer life is two little words - Mr. and Mrs. It is not count and prince and duchess, but just Mr. and Mrs. - those two simple titles cover everything, do for everything. It makes you feel much nearer, one man to another, than when there are a dozen different ranks and you have to bow and salute each rank just so.

Then I sold out to my partner for $\$ 1,500$. I said to my wife: "Now we are not worried for money: I will look for a better place."

I took the business telephone directory and I went through the list of brokers, looking for one with a French or a German name: I speak those languages and I knew that it was in such an office that I could be of use. I picked out a broker and went to see him. He asked: "What can you do?" I answered: "To speak quick; if I make you a dollar, will you let me have a few cents of it?" "All right," he replied, "start tomorrow." The first week I brought him business so that he said I should have a salary of $\$ 20$; the next week I brought still more so he said my salary should be raised to $\$ 35$; the third week it was raised to $\$ 50$; the fourth week, to $\$ 80$; and he kept me at $\$ 80$ a week for the nine and a half months that I was with him.

I solicited brokerage business among my friends, and all my friends were Americans. Since coming here, I never sought Hungarians in a social way. Ever since I landed I wanted to become a real American, and the only way for an immigrant to become a real American is to have as much contact as possible with Americans. There should be no "Little Hungary," no "Little Italy," nor other colonies of that kind in America.

In the course of the World War, business in Wall Street became bad. I gave up my place in the brokerage office. My wife and I thought of many things - of a mushroom farm - of a regular farm then, after many hesitations, we decided to embark in a French pastry shop. We opened our shop in January, 1916. In August, 1917, we opened a second shop, in an expensive residential quarter. In March, 1918, we opened a third shop, on Fifth Avenue, in the shopping district. We have tried to deal honestly, to give people their money's worth; and if you do that, America pays you well. 
I got my final naturalization papers as soon as the law permitted. I had been an officer in an artillery regiment in my native land, but I am proud that it was a Hungarian-American who fired the first American gun in the World War, that no Hungarian put a stain on his allegiance during the struggle.

After the war was over, I started a movement to feed the starving children of Hungary. We fed over a hundred thousand for nine months. We are now shipping thirty thousand cases amounting in value to about four million dollars, from individuals in America to individuals in Hungary. If my old compatriots are in need, I will give them all the aid I can but I am proud and happy to be an American citizen.

\section{Armenian}

\section{Out of Massacres into a "Most Wonderful" Country}

I was living in Bitlis with my husband and three children. We had a beautiful home with all the comforts possible in Armenia servants, caretaker, and gardener. It was in October, 1921, that we heard rumors of a Turkish invasion with reports of massacres in Kharpoot and other neighboring towns. One day, late in the month, my husband called me on the telephone, saying, "I am dying - flee at once and take the children!" I heard a gasp and the receiver dropped. I could hear nothing more - could get no response to my ringing the telephone. I gathered up my jewels - diamonds and pearls - my three children, and started out. Because I knew a few. words of Turkish I got across the Turkish lines - out into the open country. There were hundreds of others fleeing for their lives. We ran and walked to a railroad station where we were taken on board a train. For three days we traveled - slowly, all the time hearing the firing of the Turks on near-by towns. On the third night the train stopped suddenly and the conductor shouted, "Turks!" That was enough. We all scrambled over one another to get out of the train. We ran - ran - ran. All this time we had had only bread to eat. My children were hungry and crying. All night we ran - we did not know where; but in the morning we came upon a large estate, which was the summer home of some Turkish official of the government.

No one was there - only a caretaker and herder of the sheep. The sheep herder spoke the Armenian language and was very kind to us. We were six hundred in number and we were given the use of the immense cellar formerly used to store wines, etc. We all crowded 
into this hole in the ground as the Turkish army was advancing. Here we stayed for three months - not once daring to emerge to the light - as we were surrounded by Turks all the time. Our food consisted of grass that our friend the sheep herder brought us daily, and once he brought us milk and another time a bag of apples. After three months, we were told one morning that the Turks had been driven away by English soldiers, and that it was safe for us to emerge from our underground home. None of us wanted to stay longer in that cellar and four hundred of us had died and we were very uncomfortable sleeping on their bodies and inhaling the unpleasant odors arising from a veritable graveyard.

The light blinded many, and we were all taken to hospitals. Our stomachs were distended from our grass diet, and we were too weak to stand. Many of our number died in the hospitals from over-eating. My children and I ate only small pieces of dry toast for several days; then we were able to take milk, etc. After we had regained strength, immediately we set out for Bitlis to find some trace of my poor husband and his fate. In his office I saw his blood spattered on the walls. I knew what that meant. He had written me a short note which I found in his desk. What a sight to greet my eyes! My husband gone, my home wrecked, and nothing left me but life. Still a worse thing happened! I was forced to give my oldest child, a beautiful girl, to a Turkish soldier. Today she lives in Constantinople, and constantly writes me, begging for food and imploring me to get her away and to America. My two boys and I are very happy here in this America, but my heart breaks for my daughter who is a slave to a Turk.

\section{Armenian}

\section{Massacres At Their Worst}

I was born in Turkey of Armenian parents, both of whom were members of the local Protestant Congregational Church. Father was a clothing manufacturer, and grandfather was a lawyer, well known throughout Turkey. It was in my fifteenth year that the World War began, and then followed the persecutions and massacres of Armenians. Nearly all our properties were confiscated, and later my father was killed. By no means could I avoid my share of the troubles. The story itself is too long to be told in a few pages or volumes. "Fate" tried to claim me too. But I never lost my courage, never yielded, fought my fate, and overcame it. 
In the spring of 1919 , when only nineteen years old, I was elected to represent forty thousand Armenians in their case against the former governor, under whom the massacres in our district were organized. The case ended, and I had a part in bringing about a death sentence for the criminal gang leader. While in Constantinople, I took an active part in Armenian national affairs, not to avenge the blood of my people, but to satisfy justice. I also published several articles in local dailies, mostly on political subjects, and also a small collection of unpublished poems, as well as several speeches delivered at various times. In the meantime I discovered how greatly education in school could help me for the successful accomplishment of the task for which I was born - the uplifting of both material and spiritual conditions of humanity. I matriculated at Roberts College and completed with high grades the largest amount of work ever done in the history of that college by any student.

The defeat of the Greek army in 1922 turned the political outlook very dark, and it was no longer possible for me to remain in Constantinople. I proceeded to America, expecting to become naturalized and make it my permanent residence. I had heard of America since I was five, and thought it must be a supernatural country, a veritable fairy land. Had I been older, I would have known that Americans are like other people, and things that are being accomplished here might be done elsewhere. If a man is superstitious or ignorant, he gets preconceived ideas.

Personally, I admired more than one phase of American life, especially the political liberty and the freedom of individuals. Economically speaking, I was impressed with the immensity of the natural resources of America. There is an unusually large class of extremely open-minded men as well as an unusually large class of the opposite. Those who are well trained and can handle world politics are much keener than I had expected. Education has not done as much for the lower class as it should. The average American is no better educated than the average Turk. I am speaking from an intellectual point of view and not from that of civilization. Intellectual leaders have made America, not the average individual.

I had no difficulty in finding my way about or getting adjusted to America; social life was the most difficult. Most foreigners have absurd ideas about it, and lack the language of understanding, as well as friends. I felt more intimate with my fellow countrymen here than I expected. I found them better off, considering difficulties, hard- 
ships, and temptations. One can hardly expect any foreigner to do as well in America as he might in his own country. In the old country girls are much more modest than in America, but I am wondering if the average Armenian girl would be as good as the American girl if she had the same opportunities. The average American girl's behavior deserves the true respect of every man. I would not take away the opportunities. These conditions have changed my own ideas a great deal. There is a great conflict between parents and children in the process of Americanization. As an educated person, I expect to meet the problems that come my way.

I have been fortunate in making quite intimate acquaintances with several leading educators. I attend, generally, American churches and some political meetings. The schools are mostly responsible for my contacts with Americans. I live entirely among Americans, but I must confess I still cling to many ideals and practices peculiar to my Armenian culture. Family ideals are much higher in Armenia than here. Divorce is such a terrible thing that a man would rather suffer or commit suicide than to divorce his wife. I lived nineteen years in my own community in Armenia and never heard of one single divorce; here it is a daily affair. I do not believe in internationalism. I believe one's own family should stand against the community, the community against the nation, and the nation against the world. I do not care whether the race problem is solved or not. I do not believe in the intermarriage of races. As for my children, I have the same ambitions as any American father.

If I had one chance of a lifetime to express what I feel deepest about the United States and its people I should say "most wonderful," in spite of all I know. It really is not ideal, but is more nearly so than any other country, and my hope and faith is that it will become much nearer an ideal in the future.

\section{Maltese}

\section{Algiers, Montreal, and San Francisco}

I always consider myself Maltese, but I am really a native of Algiers. My father is Maltese, and my mother was French; so I have at my command the Maltese, French, Italian and English languages. When I was six years old, we left Algiers. My mother longed for her own country; possibly it was a premonition, for when we had been there only two years, she died. My father immediately took his 
motherless flock of nine to his own home in Malta, and there I remained for ten years. I learned my father's trade - carpentering and became quite expert, even at that early age. In the meantime my father had married a Maltese widow with five children. When I left for America, one of these was my promised bride, a girl of sixteen, two years my junior. Later, my sister married my sweetheart's brother; so the two families have intermarried three times.

My father had a brother in Montreal who was a Jesuit priest, and also a number of friends there, although the Maltese have not settled to any great extent in Canada. Many were the letters my father received telling about the advantages of the new country, its size, its resources, and particularly the good wages paid to laborers and artisans. In Malta one dollar a day was all a first-class carpenter could command; so at last my father, two brothers, and myself decided to come to the wonderful land so highly praised by my uncle. As I have said, there were few Maltese in Montreal, and I worked with French and English from the beginning. Because I could speak these languages I had no trouble in finding my way about. My work was different here, because in Malta we don't build wooden houses, but these are easier to construct, and it was a simple matter to learn how to use the new material. Our home life, if such it may be called when four men try to run a house for themselves, was, of course, Maltese; we continued to eat the Maltese style of cooking, for we knew no other, though when we patronized Canadian restaurants, we found ourselves growing to like the food served there. We didn't wait for our old-country clothes to wear out before we bought "American" ones and as I am a good "mixer," it was not long before I felt quite at home. Although my father found the climate severe, he was satisfied because he thought in time he would accustom himself to it; so in two years we sent for the most of the family. Within another year I claimed my bride; we were both young - I was only twentytwo, but I was earning good wages and had saved considerable since my coming. At the end of five years my father decided to come to San Francisco; the climate of Montreal was as great an objection as ever, and besides, my Jesuit uncle had gone home to Malta. We heard that in California there were even greater opportunities than in Canada, and San Francisco, with its large Maltese colony, attracted us; so ten years ago we came here.

American home life was to me the most shocking thing about the new country - the "looseness" of the girls, the lateness of marriage, 
the small size of the family, and divorce. We Maltese believe in looking after our girls - this in America as well as back home.

When I lock the door at ten o'clock at night, I want to know that all my family is in. When my girls grow up, they can visit friends with their mother and me, or have their friends at our house, but no running around American fashion.

The most interesting thing when I first came here was the size of everything, particularly the stores; also the railroads and highways so much movement, so much business on all sides. After life in our little village in Malta, and the "small French town I lived in as a little boy, American business was indeed gigantic.

I have never been ambitious to be rich. Many of the Maltese are very saving, but I believe in supporting my family well. I built our house myself, which is roomy and exceedingly comfortable, and we always have good food. My pleasure is in my young family growing up, and as long as I am well and strong, I don't ask for anything else. We have many American friends, though we don't do much visiting, for we have so many relatives, and then my wife and I both have plenty of work to do. Last summer an American neighbor of ours wanted my wife to go camping with her, but my wife doesn't care for the country. Of course, in my work I associate with Americans all the time. I suppose reading American books and papers would be good for me, but I never have time, except for the newspapers occasionally. We have a number of societies connected with our church, particularly for the children. Some of them are entirely religious and some are social. Our priest is a good organizer, and our cultural and social life is principally connected with the church and our homes. We do not seek it elsewhere. Our devotion to these two centers also accounts for the fact that divorce is practically unknown among us. In the ten years I have been here in San Francisco, I have known of no marital troubles among the Maltese until just now, when it is rumored that a woman I know, who has been deserted by her husband, is going to sue him for divorce.

I have never had any difficulties with my neighbors, or with Americans in general. My wife and I are both good-natured and adaptable, and all our relations with Americans have been pleasant ones. Sometimes I think Americans don't understand our ideals of home life, and consider us unreasonable and old-fashioned; where we do try to imitate them, in making as much money as we can, we are criticized again - but then, we criticize them; so it's fair play. 
If I had plenty of money, I would like to go back to Malta - it is so beautiful, and they have the best fish in the world. But how am I ever going to be rich with the big family I am raising? And for a poor man, America is the best. My ambitions have been realized here, and here I shall stay. I know my children would not be satisfied in Malta; when my wife cooks a Maltese dish, they do not care for it, and when we talk about the old days at home, they just look at us, as if Malta was too far away and too strange a place for them to be interested in. I want my boys to choose their own trade when they grow up, or study for a profession if they wish to; my girls will probably learn office work. They will be safer there than working in a factory, where all kinds of boys and girls are thrown together. And then, of course, they will marry and have their own homes. A few of our women have married Americans and are apparently happy. I don't see any objection whatever.

\section{Filipino}

\section{Born during American Bombardment, But Hopes to See Philippine Independence}

It was during that troublous period of Philippine-American hostilities following the Spanish-American War that I was brought into this world in the Philippine Islands. This was February 12, 1899, when the Americans were bombarding the island of Panay, my birthplace. Little did I dream of the significance of the events of those days when my people, after three centuries of Spanish domination, were to pass into the hands of a greater and nobler people. When Filipino resistance died out, peaceful American occupation began a new era in the pages of Philippine history.

My parents reared me in our humble dwelling on the banks of the Aklan River. At the age of three I lost my loving mother during a severe cholera epidemic. My father placed me in a small private school conducted by an old grey-haired man, the sacristan of the church. The school was very poor in more ways than one. Planks supported by empty petroleum barrels served as our desks. We read aloud in studying our lessons, and I thought then that the loudest reader was the most brilliant child. In spite of these unscientific methods, I am grateful to the old gentleman for teaching me to read and write. Later I was transferred to a private school. As it was very religious, I had to memorize the catechism and other religious 
materials in Spanish. I had to recite verbatim to the teacher without knowing what was flowing out of my mouth. Discipline was strict and corporal punishment swift. There were the long horsewhip and "palmadas" to make me study hard. Even in this atmosphere, I learned a few words in Spanish, as well as the simpler fundamental processes in arithmetic. Meanwhile an American public school had already been established in my town. Attendance was compulsory, and this created hatred for the Americans. Children playing on the streets were caught and put in school. As a result few children were enrolled, for they ran and hid at the approach of a white man on the streets. Little did the Filipinos dream that such a compulsory method would result in untold benefits. The people did not know what the Americans were doing for them. As they looked upon Americans as intruders, they, regarded them with an attitude of hatred. My father shared this idea, and did not send me to the public school. As years have gone by this attitude has changed; people now send their children, and hate the government because their children can no longer be accommodated in public schools. The great increase in desire for education has made schools overcrowded, so much so that thousands are turned away each year for lack of room.

At the age of eight I was sent to public school. Although I knew how to read and write in Spanish, I was totally ignorant about America and Americans. I was not even aware that the American flag was already waving on the flagpole in front of the schoolhouse. I had the idea that the Spaniards were still in the Philippines and that every white man I saw was a Spaniard. From my readers and geography, I learned a great deal about America. As time passed on, Americans came to our locality; consequently my ideas of this country took on more concrete form. My interest, however, was not aroused until after my graduation from high school. Perhaps my lack of interest may not be understood. During the early days of American occupation, the roughness of American soldiers made the natives look at Americans as if they were not as civilized as the Spaniards. During recent years, due chiefly to the coming of American teachers, the natives have learned that Americans are a refined people, vigorous, and progressive, and have gradually abandoned old Spanish customs for those of Americans. Today Filipinos look upon the people of this country as composing the greatest nation on earth.

I desired to continue my studies in Manila, but our poverty forced me to teach instead. After the death of my father and the marriage 
of my sisters who had been helping me, I thought I was free to launch out for myself. By changing positions, I was able to attend lectures at the University of Manila in the evenings. I was satisfied with my meager salary, just so long as it enabled me to continue my studies. When I was within one year of graduation, an unforeseen circumstance took place that brought me to this country.

My interest in America had been growing every year since the time I left my little native town, but it had not reached the point of causing me to take steps to cross the ocean. I had looked upon America as a very, very far country, one which would cost a great deal to reach. Then too, I wanted to finish my work for the bachelor's degree in the University of Manila. It was the close of the school year of 1926 that I made my decision to leave my native land. One night I found myself at the home of a distant relative, who had recently returned from America. In the course of the conversation, he told me I would be able to continue my studies if I had the will to do it, and even went so far as to offer me help. I reasoned the advantages and disadvantages of such a move. I considered the advantages graduates of American colleges have over Filipino graduates in the teaching profession, the value of travel, which in itself is a liberal education, and finally the desire for new experience. I said to myself, "I shall now realize my dreams to see that great and wonderful country." With a small sum sufficient for a steerage fare and two borrowed woolen suits I set out. After about a month of travel, I set foot on American soil on May 28, 1926.

When I landed in San Francisco, I had but two dollars in my pocket to start life in America. I located the place I had to stay in San Francisco, and after paying the baggage man for the transfer of my troublesome trunk I carried with me, I found myself penniless. Thanks to the Filipino club of that city, I obtained temporary board and lodging on credit, pending the arrival of help from a friend of the man who induced me to come to this country. In about two weeks the man came and took me to San Pedro, where I worked for six months. It gradually dawned upon me that I made a mistake in coming across; my job was anything but steady, and I could find no opportunity to study. I came to Los Angeles, where I found a university that $I$ could attend in the evenings and a number of friends, town mates of mine. They helped me in my efforts to become adjusted educationally and economically.

It is a little over a year since I landed in America, and the impres- 
sions I have gained will doubtless cling to my memory forever. The first most interesting thing was the long line of piers studding the waterfront of San Francisco harbor, and the many stone buildings overlooking the bay. Manila has seven good piers, and I thought them many; but when I saw hundreds of them in San Francisco, I could not help but be amazed. For the first time I recognized the great progress of America. The length of time I have been here has convinced me of the greatness of this republic. Another vivid impression was the bustle and activity I found everywhere. I thought Manila a busy city, but such activities as I find here make that city an insignificant equal. Even the hurry that seems to characterize pedestrians on the street finds no parallel in my country. Commercial and industrial activities reign supreme.

When in San Francisco, I watched endless lines of pedestrians. In these lines there seemed to be more women than men. The opposite prevailed in my country; more men were found on the streets. At first I thought there must be more women in this country; then I came to attribute this reverse of conditions to the difference in custom. In my country a lady seldom goes out of the house alone without a chaperone, while here the girls go to shows, dances, and parties unaccompanied by older persons. Girls here come and go as they please. I can't say I approve of this freedom. Some women are quite formidable in America. I do not mean to imply that all women here are immodest, but I find much that shocks my sensibilities. There is more candor with-which Americans express themselves in love matters here than anywhere else in the world. Personally, I cannot reconcile my views on divorce with those of Americans. Divorce news is one of the everyday items. I have always looked upon the United States as a model in everything for Filipinos, but when it comes to divorce, I believe she ceases to be a model. Sometimes it makes me think that there is legalized polygamy in this country, because people change wives as often as they wish to. The easiness with which they can obtain a decree makes this possible. To me a person divorced several times is nothing but a polygamist. In the Philippines one seldom hears of a divorce case in a lifetime. This is why my views will perhaps never be reconciled with those of this country.

Before closing this little history of mine, I should like to explain why Americans have misjudged and misunderstood Filipinos. American ignorance of Filipinos is appalling; many think that the group 
of islands across the Pacific is inhabited by a bunch of semi-civilized people incapable of advancement and progress. In America Filipinos do not have much chance on account of the low estimate given them as a people. As a result, they are made the victims of unfair discriminations. Race prejudice may be one reason for this. The acts of a few unworthy ones have been laid at the door of the whole race, as if these misdeeds were representative of the true Filipino!

I am now realizing my ambition in coming to America, although under very great difficulties. It is my desire to return to my native land as soon as I can finish my studies here; for I believe that my place of service is right there with my people. I am learning much in this country for which I am grateful. One of my ideals for my country is independence. The Filipinos, like other people, are a freeloving people, and it is our sincere desire that America in her altruistic spirit will soon grant us that greatest boon for which we have been aspiring, our independence.

\section{HINDU}

\section{Giving His Best to Us, But Denied Naturalization}

While I was attending high school in the Punjab in India, I received a letter from a Hindu in Canada which stirred up in me a desire to go to America. This letter stated that in Canada it would not be possible for me to secure clerical work such as an Indian high-school graduate would expect, but that there was ample opportunity to make one's way by means of manual labor. Since I was not particularly interested in clerical work, I decided to go to Canada after I graduated from high school. At first I worked at ordinary labor, but in a short time I went into the real estate business, in which I succeeded so well that I decided to go to school and return to India during each summer vacation. I spent three years in Canada, after which I returned to India for eleven months.

I then came back to America and entered an agricultural college, where I studied for three years. During the summers I worked to earn my school expenses. I had to leave the college before graduation because my brother was seriously injured in an automobile accident. This resulted in some big hospital and doctor's bills which I have been working to pay, and have only just now paid the last of them. My brother is staying with me, but he will be a cripple all his life. I have now been in the United States eighteen years, nine of which 
have been spent in the Imperial Valley in ranching and doing common labor. The alien land law has made the future somewhat uncertain, and so I am looking around for some other means of livelihood. I am now taking a commercial course by correspondence from the International Correspondence School. A friend of mine suggested that I take up the practice of law, but it would now be impossible for me to practice in the courts. I should like to be a citizen of the United States, and have made application, but have not been granted any naturalization papers.

We Hindus came to America to better our condition materially, it is true, but in the main a number of us came here to study American agriculture that we might take some new ideas back to India to help develop the methods of farming there. America has said a lot about helping India and has actually borne this out by sending missionaries, but on the other hand, has not accorded just treatment to the Hindus in America. They were admitted and then the prejudice began to develop. A few years ago the Farm Bureau at El Centro issued a report that the Hindus were overrunning the Valley, that there were thousands of them. I made a count of the Hindus and found only 268. With these figures in one hand and the Farm Bureau document in the other I went to the director and gave him a good sound lecture. I told him that he should have had more accurate information before giving out any figures. I told him that we had entered legally and that he had no business in stirring up such sentiment against us. At the same time I gave the Farm Bureau head some information about the history and culture of India. At another time a group of women became stirred up and passed a set of resolutions which were unfair to the Hindus. I also gave some of them some good sound information. I have, however, had the privilege of seeing a great change in the sentiment toward the Hindus in the Valley. A few years ago the lawyers in the courts would argue on the basis of race inferiority and would talk about the heathen Hindus and stuff of that sort. I called the attention of a number of lawyers to their woful lack of information and a great change has come over the courts. When a case involving a Hindu is tried now, it is argued purely on its own merits. Some years ago when I walked about the streets of El Centro a number of persons would call me bad names and even spit on me. That was hard to bear, but now I am glad to report that a decided change for the better has come about. A number of Americans are quite conceited and overbearing. At one time, in a conversation with ar 
American, I said to him, "You talk about sending Christ to India. Search the records of Calcutta University and you will find that Christ was an Indian. We gave you Christ at one time and we will give Him to you a second time."

During the time of the anti-Oriental agitation in 1918 the Hindustani Welfare Society was organized to be of assistance to the Hindu group. This society gave assistance in the matter of contracts and gave out useful information. As the occasion for this has now passed away to a considerable extent, the society does not function as it used to do. It now aids in case of sickness or other difficulties. In the event of any difficulty the association gives assistance in the matter of filing papers. There are no salaried officers - all the services are voluntarily given. The Hindus on the whole are temperate and belong to a temperance society. Before the passage of the Eighteenth Amendment, however, there were some arrests for drunkenness.

During my period of residence in America, I have been impressed by the progress which is generally shown. I was impressed by the school system when I first arrived and I am still a strong advocate of the system, except in one particular. I do not think the system of coeducation as it is carried on is good, because the two sexes are permitted to mingle too freely without proper supervision. I have always held liberal views relative to the education of women, but I do not think the system of coeducation is the best. Before I left India, I read a book in Hindustani on the education of women and this appealed to me. When I saw the educational opportunities given the women in America, I was heartily in accord with it.

The Hindus in America are exerting an influence on India. They have been responsible for increasing trade between India and America; they have influenced agricultural methods and are bringing about some changes in the ideas on caste. I am strongly in favor of doing away with untouchability and of breaking down the caste barriers to a certain extent. I would not, however, completely break down the caste barriers. I think that a certain amount of caste would be good for America because certain groups ought to have a place where they should be kept. I am of the opinion that it has been bad for India that she has for so long a time been under foreign domination; she would have been just as well off without England. We Hindus in America are trying to help India by making money contributions to the nationalist schools in India. I have several planks for the national platform of India among which are the doing away of untouchability 
and the establishment of general education. I am going to write out my platform and send it to the next Indian National Congress.

\section{Chinese}

\section{Though Denied Citizenship, a Chinese Aids American Institutions}

I was born in Kuong Tun Province. My father was a merchant and a farmer. He had other people who worked for him on his farm. We did not have much money; considered poor people. I came over here when I was fifteen years old. Like all Chinese, I came on account of the gold; lots of money in this country. I landed in San Francisco. I stayed first with my uncle and worked for him. It took me thirty-two days to come across in a wooden steamer with sidewheels. Before I came, I had gone to Chinese school for a few years. After working for my uncle for three or four months, I started dishwashing and housework for white people. I was at this for ten years. In $1880 \mathrm{I}$ came to Portland. I started business there for myself. I have little business in San Francisco before I come to Portland. My business in Portland called Japanese Bazaar. At that time, everybody cares to buy Japanese goods - Chinese goods not amount to much. You have to sell as Japanese goods instead of Chinese goods. I have much success and big reverses. I go bankrupt in 1916-17. I lose big fortune, between $\$ 300,000$ and $\$ 400,000$.

Then I come to Seattle. I start same kind of business that I am doing now. I have been able to make small fortune since I came to Seattle. I marry in San Francisco, 1893. I think my wife born here - I don't know. I have made only four trips back to China since I came, two trips eight years ago and two trips last year. I have four children who attend school in Portland. Boy go to university one year, but stop when I lose my money. My boy he go to Chinese school too. He should have learn a lot, but my old woman no good too much indulgence, not make them work hard enough.

In San Francisco had lots of trouble. When I first came, Chinese treated worse than dog. Oh, it was terrible, terrible! At that time all Chinese have queue and dress same as in China. The hoodlums, rough-necks, and young boys pull your queue, slap your face, throw all kind of old vegetables and rotten eggs at you. All you could do was to run and get out of the way. Nobody would ever try to stop them. Down on Third Avenue was big bridge. Chinese would walk under bridge, and white boys would stand on top of bridge and throw 
stones and spring on top of you. Oh, those days were very bad, very bad! Two or three times, I remember Chinese killed by mob in San Francisco. No English school was over here when I came. The only place I learn English was place I work once. The daughter of the lady I work for help me with few lessons. I study very hard myself, very hard. At the time I quit, I grasp things very quickly, not like now, too old. Portland not so bad as San Francisco. Few years after I came, they drive all Chinese out of Portland. When I in Portland, I stay very close to my store. My store outside of Chinese town, in white district; so when they drive Chinese out of Portland, they no touch me; they forget all about that I was in Portland, but they very cruel, very mean to Chinaman at that time in Portland, and they drive them out. I very glad that I was in American district.

When I came to this country, everything seem strange to me. No, I not notice divorce. At that time I came, I not notice American women, this due to effect of old Chinese customs. In China, you know, no freedom for women. Young Chinese boy not allowed to look at women on street. I very bashful; so I was very timid. I do not care to look at American women at all. You know in China when I come they used to bind women's feet. Stay in their house mostly, do needlework and things of that kind. They have little club together. The women associate with one another. Very seldom see women with men. They never allowed the opposite sexes to go into these clubs, and then another thing I notice when I come to this country, American people not work so hard as Chinese. They never stand for treatment like Chinese do. From the time I was a little fellow, I brought up in work from sunrise to sunset. I work all my life like that. You talk a lot about Chinese in this country, a great deal of Chinese have labor for children, make them work too hard. The people of China have no comfort compared to this country. The best time of my life was when I stole away from school and went up on the hill and played and picked berries. Then I forget everything. These very happy days for me. At this time I wear very few clothes, just pants and shirt, no shoes, no hat, that's all. China, you know, is very poor country. After I fourteen, I no afford to go to school no more. I have to help support the family. I have to work, as I say before, from sunrise to sunset. I have to live on very economical basis, little rice, little meat. Mosquitoes, they were terrible; bedbugs terrible, too. At that time, it was too much hard work, had to go to town every day and had to carry everything on my back, carry goods into 
town and bring things back every time. At that time, implements were very crude to work the soil. I was a mere child but had to work like man. When I do this, my body nothing but skin and bone. The religious part of Chinese life, oh, that terrible task, too much time at sacrifice and everybody scared, very scared, great fear.

My father considered very intelligent man, same as general secretary to public affairs, but he not very strong. He have rheumatism, very hard for him to work, but he like to be man of means more than work. Finally, my grandfather come, this take some of the work off my shoulders, but with my father in public work like this, it give me better insight into Chinese life and Chinese customs. You know Chinese compelled to buy incense and burn them to images, never neglect. They do this every fifteen days, go to temple, or what Americans call Joss House, where idols are. The ignorant Chinese people think these idols very powerful. These religious customs of China hold the Chinese down very much - too much fear.

The trouble with most Chinese of this country, they do not live among the better class of white people. They live among the low class of white people. These kind of people are no good, they have no morality, no Christian spirit. This not help Chinese, very bad for Chinese, and very bad for white people too. These low class white people say, "John, John, no good Chinaman" and things like that. This I think very bad for Chinese.

When I go to temple, oh, I very scared. I have to go there. My father make me go, but I go anyway, because I scared to stay away. Oh, I very much afraid. Everybody have to pay to burn incense, have to pay also the man who lights the incense. Nothing but fear, fear, all the time fear.

I thank the Lord that I am a Christian. I enjoy the hope of salvation of the Christian life. I say to all Chinese to give up their life to Jesus Christ for their sake and for His, and then really live the proper way. I am very glad that I am now in a very humble state and in a proper state of mind for my higher life. This is the result of good human dealings and association with Christian Chinese and white people.

I do a big wholesale business and meet competition with white people, make big fortune, but I lose my big fortune in Portland, due to family trouble. I lose everything, two or three hundred thousand dollars. Now I am in Seattle. When I first came here, I have very bad health and no money, but now I make another small fortune. I 
am very thankful for this, and I think I am able to do this because I am a good man and a Christian man. Now I am an old man, and I want to make a larger fortune next few years, so I can soon stop and help the people of China with the money that I make and the poor people of this country. When I come to Seattle, I work very hard. I nearly lose my life two or three times. My business that I in, and the health that I in, very, very hard for me. Now I am enjoying very good health same as, or maybe better than, twenty-five years ago when I younger.

You know when I in Portland, I think labor class cause all the trouble and cause Chinese rising. I no have dealings with labor class at all. I always deal with superior class, the best class, of white people, so I never in any trouble. I never have any trouble, I kept away from the labor element.

I turn Christian in 1877. When I turn Christian, I lose lots of friends on account of this. My relatives outcast me. They are afraid I bring disgrace and curse upon the family. My family feel very bitter at this time; try to tell me to come back to the Chinese faith. Now this very different. My family - lots now have turned Christian. They invite me to come to Chinese meetings, and they very proud of me because I have made money in this country and because I am a Christian and a good man. They like my support. But this has come gradual, not all at once. It started about twenty years ago, and now I think everybody in my family not care whether I Christian or not. In fact, great many of my family are now Christian. Practically all the leaders of China are Christian, so the people of China cannot look down upon Christianity any more.

No, I never ask to join tong. They know that I have very strong Christian leanings, that I work very hard in the Christian faith; so they would not ask any Christian to belong to their organization. I do not know whether Christians belong now or not, but this many years ago. Sure, I have trouble with tongs. Long time ago, I lease building in Portland, a big building. I could not use it all myself. I leased part of it to a man who belonged to tong; so I have to get a new lease. They raised my rent, so I only feel it fair that I raise the rent of tong man who rent from me; so I go and tell him he have to pay $\$ 95$ a month now. Before he pay $\$ 75$ a month. He say "No sir. I not pay $\$ 95$ a month. You not charge me $\$ 95$ a month. You not dare put me out. You do that, I tell my tong, but I tell him I have to have $\$ 95$ a month anyway, and then he send some men to see me 
and ask me to come to a meeting. Of course, I not raise his rent or cause trouble. I afraid they say that if I go to United States court they kill me. I don't know. Maybe they kill me. I not sure. Another time, they think I talk against tong to some Christian people. They come to me and tell me that I talk against tong, and if I not stop they coming to kill me, but they make me pay money just same. They say. I hurt tong. Sure, I think some people working for me belong to tong. If they good workmen, no difference to me. I don't care. Sometimes, you know, they force Chinese to belong to tong. - - they force him to join tong. He want to get men go work for cannery. The only way he can get men is to join tong. He no want to join. They want $\$ 300,000$ to let him out of tong. Another case, ——, he work Seattle National Bank. He member of tong. Then they have war. He scared. Bank have to take him, look after him, keep him from getting killed. Afterwards, he try to get out. "No," they say, "no let him out." Finally, the bank have to pay fifteen hundred dollars to get him out. He gets so scared he go back to China. He no like stay here any more. No, these tongs I don't think are any good, only cause trouble. All members bad fellows of Chinatown belong to tong, may be a few good ones, but they forced in. Chinese very afraid of tong, very afraid.

Chinese younger generation in this country go a little too fast, lots temptation. They go in lotteries and gambling. Very few go on in father's business, get very lazy. You know in China father get control of everything of children, but this country not like that; all they want to get out of father is support. They no want to work, no want to do anything useful, just gamble, all sorts bad things.

My wife a Christian at time I get married. You know at that time very few suitable women for me to marry. I get mission girl. Even in this country, many of the Chinese girls still bind feet, they heathen. Of course, I no want marry heathen. I want marry Christian. Girl in this country at that time worth three or four thousand dollars. I no want to pay three or four thousand dollars for wife - that just same as endorsing Chinese custom. I no want to endorse Chinese custom. I am not in sympathy with Chinese custom; so I have to get wife from mission. This old woman cause my downfall seven years ago; ah, she no good; she just no account. Much better I never marry at all than marry her.

After I been in business few years, my name very well known. I make lots money. I invest my money in all sorts of things; so when 
panic come, I very hard hit. I lose some real estate and things like that. This panic during Cleveland administration, but after this three more years then I make big business again. I build up big reputation all over country for myself again. Just before I came up here to Seattle three, four, five, or six years before, my relatives cause me lots of trouble. I don't know this until I go to bank. Bank refuse my credit. I no understand. First time bank ever.refuse. I have relative help me run store. He buy too much stock, too much gamble. At this time, I have hop business, took near Portland. I think I make lots money. I hold hops for long time. Hold too long, then English agent for big English hop company swindle me out of lots money. This cause me to go bankrupt. He make lots money out of me, but he come back from England on Titanic. You know what happen to Titanic. This God's way to show me that he no good. The idea that he go down on Titanic make me feel very happy.

It is a mystery how when I broke in health, I came to Seattle and take charge of a store here. I manager of Chinese department. I not here very long when I see that store in very bad condition. Then it go into hands of receiver. They appoint me receiver. I work very hard for six months. I pay back two-thirds of all money. Then I go to man who owns store. I tell him I buy this store and in six months I pay back the rest of money owing, so that's what I did. Then I call store Chinese Trading Company or Chinese Emporium.

Now I have lots of trouble now. My son cause me lots trouble. I want my son to come back and go into business with me. He is in Detroit with my old woman, but she have bad influence over him. He no want to come back. He say he come back about a year ago, and I order lots goods because I think he help me sell them, and when he no come back, this put me in financial embarrassment. I am glad now that he no come back. He is low-living man - has no consideration for others. I very glad he no come back; he no good. Not all his fault, mostly old woman's fault, but you think he would come back when I in poor health in Seattle and help me, but he no want to come back until I make money. I start him in business in Detroit to make money, but he no thank me, he very ungrateful, no good. In my business, I just same as American, I employ American stenographer, American bookkeeper. I never lose any law cases. I have two or three, but always win. I conduct my business just same way as American. Since I been here in this business in Seattle, I make maybe little over a hundred and forty-five thousand dollars. 
I have no trouble in Seattle with Immigration Officials. In Portland, some dishonest official make examination of my testimony. $\mathrm{He}$ try to make me believe that I cannot come back to this country because I lost my money and because I often talk against Immigration Official due to treatment they give my friends, so he have it in for me. He try to make it as disagreeable as possible for me, but I tell him that if he. not let me in, I take the matter to Government. I have some good friends in Portland. Mr. W- L-, banker, come and help me. They get scared and then they go. But in China, I have numerous experiences when I there, and hear of many experiences where American Consul and Chinese who work for American Consul in his office very crooked indeed - want lots money to let Chinese come to this country. One case, my nephew come to this country. The doctor told him his eyes not very good; so my nephew take a hundred dollars from his pocket, and say with a hundred dollars could his eyes be fixed? The doctor say, "Yes." He treat my nephew twice and then he come to this country. That just the same as bribe.

Yes, I think about ten or fifteen per cent Christians in this country, not any more. Lots of Chinese have no religion at all, no old country religion, no Christianity, just no good. Everybody look up to Christianity now, because they know what Christianity did for China in the last twenty-five years.

Yes, I very popular in Portland. Many of American people they very good friends of mine. Very often I asked to have dinner at their homes, and very often I take them to lunch with me. I enjoy American people in Portland very much. I think at this time, the people there very tidy to me because they know I have great interest in work at mission with Chinese people. Nighttime, I go to Presbyterian Church and help preach. Then in morning, I go to Episcopal Church. I help build and pay for the Methodist mission in Chinatown of Portland. I have man in my store work part time, rest of time he work at this mission. I pay him full salary. I do lots of organizing in this way, follow classes, Sunday schools and things like that. One time, I pay mortgage on Episcopal Church in Portland. At that time, money very tight. Nobody have money. Clergyman come to me with tears in his eye. He say, "You pay mortgage and then we pay you back -otherwise we lose church." I have to raise money, but I do this to pay off mortgage. Then my banker told me that very bad thing to do when I owe him money; that I should not have done this. Then 
some American people told me I should not do this. It cause me much hardship because I not much loose money in my business. It cause me much mental suffering, but now I very glad I could do it.

Now I think I going to make big fortune either in oil or in tobacco business. Oil business I have made little money, but I think we strike oil this year; then I be very rich man. With this money, as I say before, I going to help the people in China, and help the people in this country. I just want money for the good I can do with it. I have now money to live on myself.

No, never commit adultery in China. I never hear of but one case in all the time I in China. They kill him. There is no murder in China. There is no temptation. Chinese people really very good.

No, I would not have become an American citizen a long time ago. At that time we were too much in disfavor. It would not have been right for me to have become an American citizen, but later, I would have been delighted to have become American citizen. Now, since I have lived and made my money in this country, I should be able to become American citizen.

I like it in this country for its customs and its sanitation, also for the protection and climate of this country, but China is the other way in these things, no authority, no protection, climate poor, no sanitation; but on account of my age, I think I must go back to China to live among my family, just the same, say, you would want to go back to the people who know you who would be kind to you and would treat you properly.

I do not blame the Chinese for all their badness, because the white people encourage them in their wrong ways. The Chinese associate for the most part with the low-class Americans. The Chinese only get the bad customs, the bad habits, the bad influence of Americans. The Chinese people are ignorant for the most part that are in this country, and do not realize that they are privileged to associate with better people.

Yes, I have much trouble to get place to live in. For two years, after I come, I live in the back part of my store, but then I make a little money and want to get away from the store. I do not want to live in Chinatown, because I am not in sympathy with the habits and conditions in Chinatown, so I try to buy a house. They will not sell to me because I am alien, but I have to buy it in one of my children's name, because they are born in this country. This make it very bad for me, because I want to use this for part of my collaterals to 
get credit from the bank, but they will not allow me to do this because it is not in my name. This is very unfair, very unjust. I never have any trouble with my neighbors here, because I mind my own business, never bother my neighbors, never bother anyone; so they never bother us.

My wife, she example of Chinese spoiled by low-class Americans. She have all the vices, all the badness of the American people with none of the virtues. I wish she have never been born.

My boy marry a China girl in the country. I think she born in Portland. I think that all right for them to do that. They both born in this country, both not much account, but it not right for Chinese man born in China to marry Chinese woman born in America. They will not be happy. They do not have same training, the same feeling about the home the girls do in China. It will make him very sick to think that his life will be spoiled by no-account Chinese boys and girls.

This new law very unjust - cause a great deal of trouble. The old law exclusion of the laborer, that bad enough, but Chinese used to this law of 1880 . This law I think really made for Japanese, but they afraid to say only Japanese, because Japan very strong nation, might make great deal of trouble, so they have to include Chinese, too, but it is not necessary for Chinese, because they have exclusion law, and Chinese in this country are getting less each year. That is what the law is to accomplish, and that is why they should not have a new law. I don't think this is right. You say the Japanese bring their women to this country, have lots of children, big families, and all the women work. That is not so with Chinese. Very few Chinese women come to this country. Their children do not work. The women do not work. That is why the Chinese are not the same as the Japanese. For most part, all the Chinese go back to China. They do not want to come and populate this country, but most Japanese when they come to this country want to stay here and populate it. I fear if this law continues, it will hurt trade between China and this country. I think the Chinese may boycott America like they did some years ago in Japan, and also when the Ambassador's son (Chinese) went home to China and told about the treatment he received at the embarkation office. He was a very indignant young man and caused much excitement over this, so for six or eight months the Chinese people boycotted American goods, causing the loss of hundreds of thousands of dollars to this country. I think if the Chinese do this, this law will 
soon be changed. If the American people had this same law applied to them in China, they would make a big howl and big fuss, but because China is weak, they force China. This is not right.

Now Chinese man very hard in this country. No, they are not faithful to their wives - just the same as wild men. Have no regard for their wife at all. All they think the wife is good for is to bring children into the world to continue the family, the idea of ancestral worship, but women in China very different. They are very faithful to their husbands. I don't know of any case where a woman was not faithful to her husband.

The Chinese live about the same way in this country as they do in China. If they picked up two or three blocks of King Street and put them in Hong Kong, the customs and habits of life would be very little different from those in China. However they gamble very much less in this country than in China. The women also are given more freedom in this country, after they come here, by their husbands than they ever had in China, but outside of these two things, the customs and habits are the same here as in China, that is, amongst those living in Chinatown.

Christian movement and education in China are growing very, very fast. I think it will only be a matter of twenty or thirty years when China will nearly be able to equal the United States in this respect. I do so hope that this will happen.

No, the Chinese have no problems in this country. I think it would be better if they had some property to live in, but they have never considered enough really about it. They do not like hard problems. I do not think of any particular problem, except that the Chinese associate and are living with very low-class people. This thing should be remedied. Outside of that, I do not know of any other problem.

\section{JAPANESE}

\section{Grateful for American Opportunities, But Prefers to Live as a Social Human Being}

I was only about seven years old when my father came to America some twenty-five years ago. I have only very dim recollections of the day when I saw him leave for America, clad in a European suit of clothes and bidding farewell to his relatives and friends. But I was too young then to know where he was going and why he left us behind. I was simply happy to see the big crowd at the station and the loco- 
motives running to and fro in the big yard. It was not until I studied the American history and geography in the third year in high school that I found that my father was one of those who ventured to cross the Pacific to make a fortune, inspired by the boom that then prevailed throughout the island empire.

Years passed by, ten in all. We received frequent letters and remittances from our father in America. During this time we - my mother, my younger sister, and I - lived in a house next to my grandfather's house. In my last year in high school father wrote saying he intended calling us to America. Immediately afterwards he sent us several thousand dollars to wipe out the debt of our family and to prepare for the trip to America. According to his letter, he had started truck gardening in a suburb of a California city and wanted the family to be with him. My mother insisted on starting immediately, but I preferred to finish my last year in high school.

During this last year the study of the English language gave me special interest, because my coming to America within the year was certain, and I expected having a fine opportunity to attend school in this country. As our graduation drew near, most of my classmates were busy discussing the nature and standing of colleges and worrying over entrance examinations, which were given for the purpose of eliminating over half the applicants. But for my part I had no such worry at all; instead I amused myself with youthful dreams of America. I used to draw out the text of foreign history and a map of the United States to study about this country or the route I was to follow in my travel.

One day, shortly after graduation, I was invited by our principal to take lunch with him and several of the teachers. In course of the conversation he informed me that he could secure financial aid if I desired to continue my studies. Very much proudly, I thanked him cordially for his kindness and triumphantly stated that I was coming to America to study in the colleges here with the aid of my father. They were very glad to hear my program, and the English teacher at once gave me a card of introduction to an American missionary to our city. It was in this way I had my first opportunity to visit an American at his home. He was the second foreigner with whom I exchanged the words, the other being our English teacher from London. I was very kindly received and assured that I should have no difficulty in reaching America. My first impression of Americans was very good, and I was happy when I pictured myself in an Ameri- 
can school, studying with such kind people. Of course I had read and heard about unpleasant aspects of Japanese exclusion from public schools, but as the distance is so great, I did not feel the effect directly upon me.

In February my father sent me an important document issued by the Japanese consul at San Francisco, certifying that my father had so much of the personal property. With this attached to the application form which I filled in myself, I went to the central police station. It was my first experience to pass under the magnificent gate, and I could distinctly feel that the beat of my heart was a bit disturbed. Why should it not be? In Japan a boy of seventeen is considered simply as a kid, who is supposed to "keep the mouth shut up." I happened to be in the uniform of my high school; consequently, for this simple reason, I was rather cordially received by the police, of whom but few pass beyond the grammar grades. This was but an example of the common practice in Japan to treat the superiors with utmost respect and cordiality, and to receive the inferiors with a somewhat contemptuous attitude. This peculiar custom is, of course, due to the feudal system which was the political institution until only sixty years ago. Therefore, I received here in the police station a striking impression which, when I saw Americans talking and receiving each other so freely and friendly, brought out a vivid contrast of the two cultures. It seems to me that the English language spoken in America is tremendously simple in regard to the terms and usages of honorifics as compared with those complicated ones in Japanese.

In a few days after I filed my application, a policeman (according to the reports of the neighbors) was sent to investigate about me and my family. There being no dark phases, I received notice to report for the passport. The red stamp "non-immigrant" gave me the privilege of entering without any physical examination, even should I travel as a cabin passenger. All was now ready for me to begin my journey across the ocean to the land of my dreams, the land where gold coins were found on the streets, where people could get rich in a single day purchasing lottery. There were thousands of people in my city alone aspiring for the Golden Gate of fortune, but the strict immigration laws of America and the so-called "gentleman's agreement" existing between Japan and the United States barred these people from fulfilling their ambitions. The Japanese government was very faithful indeed in observing the treaty between her and America. It enforced the regulation with the aid of its efficient police system 
so well that it was sometimes regarded as being too strict and using too much of the red tape.

It was raining a little as I left to board the steamer, but nevertheless my relatives and friends gave me a great send-off. Due to lack of funds, I was obliged to purchase a steerage ticket. As a result of this economy, I had to spend a week in an isolation barrack before going aboard. This week was a long and dreary one. There were about 70 people, including wives and children of Japanese already in America and picture brides on their way to meet their unseen husbands. I played ball and chatted with a Russian boy, who with his mother was going to Hawaii. On the day our ship left, my aunt again came to see me. She seemed to be very sad to lose me, and could not talk at all except a few simple words, although I used to admire her silvery tongue in the ordinary days and sometimes was afraid of her everlasting vocabularies in scolding me. I too felt funny and could not speak. But a word or two on such an occasion was sufficient to convey fully our ideas to each other.

Late in the afternoon a long whistle blew, and our ship slowly moved down to the Pacific. As the last rays of the setting sun fell upon the white wall of the old castle of Wakayma, I could dimly see my native city far away. I bade farewell to it and prayed the health and good luck of those who were so good to me. Now I was on my way to America. I was sorry to leave my aunt so lonesome, but I did not feel lonesome myself, because of the gaiety on board, the anticipation of uniting with my family, and the many sights of interest. In the open sea of Totomi, famous for its long swells and raging seas, I witnessed the mighty power of the ocean which turned the coast into a cloud of white spray and dashed its waves to the rocks without intermission.

For eighteen days we saw only water, sky, the sun, the moon, and the stars. On ship we spent the day reading and chatting. Some played the phonograph, some sang popular songs, others played cards, and a few discussed politics. Those who had been in America before explained the nature of the work that the majority of Japanese were engaging in in America, and also about language and customs. I had no opportunity to speak English with foreigners in the second and first cabins, but I made the acquaintance of three Greeks bound for Canada. As I recalled some incidents among facts of the history of Greece, I was proud in showing them that even a poor Oriental lad in the steerage had something to tell them about one of the oldest 
countries in the world. I was a boy after all. They sang for me, played mandolin, and even spared me some of the good candy they had with them. In reward to their favor, I presented a can of famous Japanese cookies which they consumed with great appetite. But they never forgot to tease a boy as everybody does on some occasion. They taught me what the word "sweetheart" means. On crossing the international date line, I reminded a story I had read a long time ago, and securing an empty bottle, I enclosed a note with my signature, date, and a few lines of remarks, and threw it in the water. I like to know what has become of it. I spent some time explaining to fellow passengers the reason for the two same dates on crossing this line.

As we sailed into the harbor of Victoria in Vancouver, I beheld high mountains snow clad, and felt the cold morning breeze as it swept the surface of the blue sea. The sun shone brightly, and the houses painted with colors scattered among the green trees on the island reflected themselves on the calm water. The scene was picturesque, and I still feel that I see it in front of my eyes now. At Victoria I had to part with my Greek friends. At Vancouver Prince Tokugawa, chairman of the board of peers, left the ship. Canadian officials and the Japanese consul extended their cordial welcome to this Japanese nobleman, and a musical band played the Japanese national hymns in his honor.

On the following morning we found ourselves at Seattle. The view of this city in the night was the most beautiful one. Situated on a hill facing to the harbor, it is itself an amphitheatre full of illumination at night. I had never seen such a magnificent night view before, and there I saw the mighty power of America. Next day the American immigration inspectors came on board. After the physical examination, each was called for a series of questions. When my turn came, I entered the room and tried to take off my overcoat. But the officer through the interpreter told me to keep it on because the day was cold. Moreover, when he saw me standing beside the table, he asked me to take a seat in front of him across the table. It gave me another good impression, showing me a practical example of liberal custom in America. Had I been in Japan, it would have been necessary to take off the overcoat and remain standing before the officer. After a few questions, I was asked to show evidence.that my father was in America. I took out a letter and presented it. In it there was a paragraph calling attention to some possible mistreatment from bad boys. As the interpreter translated it, there came a big laugh from 
the officer, and tension of the atmosphere was dispelled. The English of this man sounded to me splendid, and I could not help but envy him for such a fluent English speaking. Questions over, attired in a new suit, new overcoat, new hat, new shoes, new shirt and tie - all new - I bade farewell to all my friends and cheerfully descended the gangboard to set my first step upon American soil.

My first words on American land were: "Is this the inspection room?" This sentence I framed after half an hour of hard study. To my astonishment the officer was clever enough to catch my sluggish pronunciation, and answered "Yes." But pity me, I was not prepared to proceed the conversation further. Without a word I opened my suit case before him. It was marked O. K. On examining my trunk, he found some school books. I replied to his comment, "Yes, I am going to school in America." This was my second belabored sentence pronounced in America. My first American pleasure was a bath and a meal of fresh fish and vegetables. I shall never forget the dish of fresh cucumber salad after the cold storage fish and the regular rice on board. I stayed in Seattle three days waiting for a ship to San Francisco. Entirely out of expectation, I encountered an old friend my second day. He showed me the city. Thus I could not but approve the old Japanese proverb, "The world is narrow, though it may seem very wide." In due time I arrived in San Francisco and took the train for Los Angeles. Although I was assured that the train goes straight to that city, I never failed to take out my map of California to check up the stations as we went along, being afraid that the train might go astray to some different part of the state.

As our train pulled into the station, my parents and sister ran up to me. I was happy indeed to meet my mother and sister, with whom I parted just one year ago in Japan, and my father, whom I had not seen for ten years, and whose face was familiar only through photographs. My father was so glad to see me that he introduced me to all his acquaintances on the street. When he left Japan, I was only a little child of seven years.

I came to America with the hope of attending school, but the financial condition of my father did not warrant this. I thought it better, therefore, to establish a solid financial foundation before I entered school life. Twelve years of farming! It is a long story and would occupy a whole book; let me print here just a few principal events. 
The truck farming in the vicinity of Los Angeles has kept pace with the development of the city. But there has been no systematic way of adjusting to market conditions, and as a result trucking has been highly speculative. Under adverse conditions like these, it was almost prohibitive for the majority of farmers to see profit even though they might work hard till dark from early in the morning, receiving in many instances the censure of Americans about their women's labor on the farm. Furthermore, in 1913 ownership of land was denied Japanese and their leases restricted to a period of three years. In 1920 the leasing power was deprived of us, and under the present status even the crop contract is prohibited. Today the only way open to Japanese on the farm is to serve as a common laborer. We suffered much from these alien farm laws, and even after twelve years of strenuous effort, I was not entitled to own a parcel of land. However, I was lucky enough to save some during the high prices in war times.

I had many bitter experiences, trying to stabilize our financial condition and care for my father, whose mind had grown a little weak on account of hard work and advancing age. After a few years my parents could visit the old country for a year's vacation. My sister married, and her husband became my partner. I had several nerveracking experiences, one of which $\mathrm{I}$ here relate. I used to leave the ranch at midnight with produce for the market, arriving there about three o'clock in the morning. Once two men drove up to my wagon in an automobile and commanded me to stop. I did as ordered. One held the revolver at my chest, although his hand was trembling. The other searched all over my body for money, but was so drunken he spent five minutes in locating my purse in a pocket of the pants. At the same spot I was held up again. This time there were three, the extra man remaining in the car. Finding nothing this time, they got in their car and hastily rode away. Before leaving me they took off and threw away my pair of glasses, which I later found with the aid of moonlight. I was lucky because I didn't get hurt in either case. In those days the holding up of market wagons was quite common, and many times drivers were beaten very badly with gas pipe, revolver, or other weapons. Few were apprehended by the police; consequently the farmers banded together in coming to town, each carrying a shot gun. I remember a case where the driver of the second wagon of a "caravan" sent a fatal shot to a hold-up man who attempted to attack the first wagon. These events gave me good experi- 
ence, because I could find out how I feel and behave myself in such a case. In both cases my purse contained only 40 or 50 cents in small change, which I had for a cup of coffee in the market. Those robbers must have been greatly disappointed to find such small amounts comparing to their daring deeds.

While my parents were in Japan, they met a young girl who is my wife now. She is a daughter of one of our relatives and was about twelve years old when I left Japan. I had been acquainted with her but speaking the truth, I didn't know much about her. My aunt recommended her as my wife. After a few months of investigation and negotiation our marriage was finally arranged through the hands of my father, my aunt, and the mother of my wife. My parents brought her on their return, and we were married in San Francisco. Since then we are living very happily in a harmonious mood, each trying to adjust to the other. We are already father and mother to three children, and are very proud of it. According to what I have heard and actually observed in this country, the basis of the marriage of the American people is the love of each other, and the marriage takes place after some period of courtship. It seems to me a very good plan which is more logical in the process than the method used in Japan. There the marriage is arranged by the so-called middleman in the majority of cases. The bride and groom do not know each other until a few days before the ceremony. The reports of this middleman are taken as the basis of judgment or determination to marry. Friends or relatives generally act as the middleman. I have heard that the divorce rate is increasing. The cause may be attributed to the lack of sincere concept of marriage, because the American way leaves no room for blame if it is intelligently observed. The divorce rate among Japanese in America is very low. Many Japanese writers in America attribute this to the women's traditional respect for their chastity, the great virtue of Japanese women cultivated during the course of two thousand years. The Japanese girls of the second generation are watched very closely on this point.

At the intervals of the lease, I tried to quit farming to enter the school life which was my first ambition in America, but the saving never reached this point. I kept on farming with my brother-in-law and we saved some. Then that hateful influenza attacked us, and my sister died, leaving a four-year-old boy. Finally, after more reverses, I was able to make a budget for college. Although I felt that I was a little too old then to resume my school life, being thirty 
years of age, I determined to carry out the plan in the sense of a vacation after twelve years of hard work on the farm.

I found three personal friends among Americans while farming. Of course there were hundreds of so-called friends on business relations. But these cannot be said to be true friends in strict sense, because they are gradually forgotten when the business relation ceases. These boys, then about ten or twelve years old, used to come to the market to secure odd jobs, like holding the team or nailing up crates, for 50 or 75 cents. I was very glad to give work to these boys; I loved their spirit of independence. In Japan boys know not how to work for their spending money, only to ask their mothers for it. They were clean, decent, good-natured, but poor. I am glad I was not wrong in judging them. One especially has made good. He is married to a girl friend of old grammar school age and has his happy home in the western part of the city. Whenever we meet we talk about the old times when he consumed a bowl of rice with chop-sticks at my house in the country. A second by dint of hard work graduated from Stanford last June. A third is an Irish policeman. In the spring of 1923, when my lease expired and I could not secure any lot in the new subdivision, he told me to come over to his place and live. I was glad to accept his kind offer and built a house on his place. I am willing to leave him that house as a present whenever I go away. We helped each other in every case; we spared each other something new and good to eat; we lived in absolute harmony. I do not belong to any American organizations, and do not have many friends among Americans. But I am quite content with the few true friends I have just mentioned.

Japanese in America, particularly the first generation, seek their amusements mostly among their own group. Picnics are numerous. New motion pictures are constantly shown. Lectures and debating are frequently given out. Banquet and tea parties are numerous. Baseball and tennis are played almost everywhere, although the golf is limited to a certain group. Sometimes big meetings for fencing, jujitsu and wrestling attract thousands of sport lovers among fellow countrymen, while dancing parties are most popular among the second generation. I frequently visit American theaters to train my hearing and also attend ball games, but I have had no experience of attending any American social meetings. It is the general tendency of the majority of Japanese in America to be too sensitive or nervous in guessing the mental attitude of Americans; thus they try to keep 
away from their circles. This is the principal reason why we have so few American friends.

In college after twelve years of farming life. During my country life I tried to learn English by reading, but it was hard because I had never been to school in this country. My original intention of early days was to study electrical engineering. But I feared that my head might not be too strong for that course after so many years of muscular work. Therefore, I chose the course of commerce in which I was much interested in connection with my business in the market. My great trouble was English. I worked hard on my lessons, but when I saw sometimes my papers came back with great big questions, I was discouraged. Yet I stuck to the lesson as I did the farming before. I was admitted as a special student in summer session, and was allowed to register as a freshman the fall session. Since then study and stick to it have been my motto. By attending three summer sessions, I have saved one semester. However, it was out of my expectation that the average grade for all courses turned out to be almost a "B." The most pleasant thing I have experienced in my school life here has been the goodness, kindness, and attentiveness of the professors, from whom I have had lectures. Some of them were so good as to point out and correct even grammatical mistakes. The students are all good to me, and whenever I ask anything of them, they have been very glad to explain it to me.

One thing that I did not feel good about was the fact that a salesman in the students' store used to keep me waiting a long time before serving me. His attitude was to pretend not to see me. It might have been that he did not see me, but I have heard the same story from other Japanese, Filipinos, Chinese, and colored students. This kind of thing might be quite common outside the school, but I did not expect that it would occur on the university campus. I do not know the temper and the characteristics of other foreign people, but I can say that for Japanese it is the courtesy that counts more than the saving of a few cents in such a case. But in general I am very glad that I was allowed to study in this institution and very grateful for special attention of professors and fair treatment by the school.

After graduating next February, I am going to visit my old country. Maybe I shall not come back to this country for the following reasons:

1. My parents are living now in Japan and I must take care of them, because I am their only son. 
2. Japanese communities in America have rather too many college graduates already, and there is no position waiting for them.

3. It is hopeless to get a position among American firms.

4. The future for the children is not promising.

5. The varieties of business we can undertake are limited by numerous circumstances.

6. No matter how easily we may earn our living, we always feel some kind of pressure on our heart.

I am a cosmopolitan, and I am not particular as to the place where I live. I am willing to go to any part of the world where there is a call. But I prefer to go where I can be treated as a man socially.

\section{Korean}

\section{Not an American Citizen by Law, But with the Head}

I was born in the beautiful peninsula in Korea. The climate is very good; we have many beautiful wild flowers and many fruits. My father was doctor of Confucian philosophy. I have three brothers and two sisters, and all was very good and happy in our house. Then my father began to drink too much wine. I no can have the education like my older brother. All the money is for wine. My mother eries and cries; my grandmother is shamed.

Then came to our town some very good Americans; they are Christians. They build very big beautiful hospital. Beside the hospital they build Christian school. In this country you call them Adventists. I go to listen to their teaching. My grandmother shake her head; she say, "Oh my boy, you get some dreadful new ideas."

At this time I work in factory, I cut off my pigtail like new-fashioned Chinese boy. My grandmother she ery much; she say, "Oh, you no more good Korean Confucian boy! For the year I comb your hair, I make you pigtail. I am so proud of your long black pigtail. What is the matter with you, you got no more respect for your ancestors?" I said, "Grandmother I love you and respect you; I like to obey you, but these days have to cut off pigtail, catch in machines, have to work too hard to wear pigtail."

My grandmother she say, "You pretty good boy anyway, I suppose it's all right." Well all right, I go to Christian Church, I like it. Confucian religion very beautiful, but Confucians are scholars; read all about religion, but don't do any. Christians read about Christian religion and then go do it. All right, these very good people; I want 
to learn from them. Next they say to me, "You want job in hospital and go to Christian college?"

Well, I go to school and work my way in Christian college and hospital two years; then I am secretary. My best friend go through Christian high school and Christian college. He very clever man. I promise help him; we love each other like husband and wife. Now I got pretty good money we go for trip to Hong Kong. We want see some American life. America friend invite us to club at night. Then first time I see American men and women dance together. I think now they dance tango and fox trot; at this time I do not know. That time I look and look and can't understand.

I say to my friend, "What is this American custom, husband and wife holding each other close and play together like that." Then I say, "Oh this very nice, when they have festival husband and wife play together like this." Then my friend say, "Oh you some young boy, don't you know they not married? If they married, then no interest." Then I say, "Oh! please take me home, my head all upset. I worried. These good people do this dreadful thing. My father not take my mother's hand before he married. You get some book to tell these strange American custom."

Next thing I made friends with many good nice young Korean men, but we do not like Japanese government. One time all Koreans ordered out in the streets; Emperor of Japan is dead. They carry his picture through the streets and we all have to bow the head and shut the eyes. But I and two other, good nice young men, do not shut the eyes; we stand straight. Then Japanese policeman take us to jail. He says, "What's this, you young men never obey the law:" He take us to the judge. "What's this, young men? What's the big idea, young men; you Bolshevik?"

"We are Christians; we didn't do any wrong. We cannot bow in front of picture; dead body is not emperor; we cannot bow before dead body."

They let us go, but after that spies all the time. In winter footsteps were on the snow outside my house. Japanese government is enemy of good nice young man. Good nice young man, he read and think, and can teach the people to be independent. Bad young men lazy and drink, never do anything to trouble the Japanese government. Pretty soon my friend with family and I myself come to America.

In America we come, and my friend say, "Now is the chance I want 
to get educated. I must learn many things. I must learn the doctor and then do some work." "Well all right," I say, "you go to best school." He find one good American school for doctor. It is called Johns Hopkins, and is far east. "Well, all right," I say, "you go school. I watch family and children while you gone." Well, he go, and I work in fruit stand in big store. I work many weeks and earn much money. I save the lot of money and buy fruit stands. Pretty soon I have many stands, one by every chain store in many towns. Well, my money it go and keep friend in the doctor school and I watch with his family. Then when two years they gone, my friend he send me and tell he doctor now; he win big honor in bacteriology, and he soon come home again to that family.

Well, I have one partner in my fruits business, many time I think I do not understand. He say it is all right. Then one day we not very good friends. I think my partner he not the honest man. I am sad, I want no partner no more. I say, "You better take business and give me some money." He give me not much money, but I think, well all right, I am glad to not be partner any more anyway. I say, "I take what you give me, all right." So - I come to Los Angeles where I take business with bookkeeper in Korean produce place. I bookkeeper in hospital in Japan with a Christian school. Now it is well, I work in day, I study my books in evening, and I go to school to learn more about this civilization.

I cannot be American citizen with the law, but I am with the head. I am happy in United States because forty-eight stars are over my head, and I always will do everything to serve this country.

\section{West Indian Negro}

Seeking for Happiness and Contentment in a Land of Race Prejudice

I was born in St. Vincent, British West Indies. Before coming to the United States, I worked as a gentleman's attendant and as a druggist's assistant. I was not satisfied with the positions, however, and left because I had ambitions to travel in order that I might further my education and later become a doctor of medicine.

As far back as I can remember in my youth, I heard of the United States, and I always thought of it as a place where one's ambitions could be easily realized. The stories I heard were generally those of America's achievement in commerce and education since she gained her independence from England. Because of the opportunities to 
help one's self in the way of working and studying at the same time, I decided to come to the United States. A friend of mine lived here in California, and because of its climate and its progress since its inception into the Union, he advised me to come here.

The tall buildings, the crowded streets, large stores, beautiful theatres, and the general hustle and bustle of the workers were the most interesting things I saw when I first came to the United States. The living of certain races in different parts of the city was difficult for me to comprehend, especially of those who were in better circumstances as to wealth and profession. My greatest difficulty was to know the directions north and south, east and west. Since I was born on a small island, I never used any such expressions as $x$ is in $y$ direction; therefore I had to adjust myself to them. My countrymen looked strange in their manner of dress. Yet I immediately felt at home with them as soon as we started a conversation. Color prejudice shocked me most, especially as white Americans abroad speak so favorably about advantages one gets when he is in America, irrespective of class, color, or creed. My reactions regarding the behavior of the children of immigrants are that these children are not so docile as they might have been if they were in the West Indies.

Since I was born in the West Indies and attended school there where English was constantly taught, the average conversation in America was nothing new to me. I read almost every magazine or book that the average intelligent American reads. I have the acquaintance of several Americans of nearly all walks of life, and have been socially prominent. Nothing prevented me from making any acquaintance which I may require except my anticipation of color hatred by the white Americans. I have been a member of the Episcopal Church from childhood, and a member of the Foresters and Odd Fellows lodges. All three, coupled with my calling as an insurance salesman, bring me in touch with Americans. My own people are fostering many civic organizations in this country. Family difficulties are not as prevalent among us as they are here; neither are divorces or desertions. The elasticity of the divorce laws and the desire of getting things which their earning powers cannot afford are my explanations about these subjects. People work much harder here than they do in the West Indies. Weather conditions here I think are the cause of it.

I was fortunate in judging some one here who recommended me to a 
good home as soon as I arrived; consequently, I have had no real difficulty in securing a suitable place to live. Derision of foreigners by some Americans is the one greatest thing that stands out in my mind; hence my desire to avoid some Americans. The West Indian Negro believes that the American Negro does not like him, and the American Negro believes that the West Indian Negro considers himself superior to him. As a result, there are endless friction and jealousy between the two groups. I am planning to return to my native country and to take my children there, but only for a visit. As an immigrant here I have a larger field for work. After being brought up here and educated here, children could never fit themselves to life in a small place like the West Indies. My present occupation would never have been thought of in my native land, since the masses have not been educated to the value of services rendered them by this work. The laws which discriminate against immigrants have prevented me from enjoying the privileges of native Americans; yet the effects were not great since I removed them by naturalization. Had I been an Asiatic, it would have been quite different.

My ambitions have not been realized here. I am still searching for that which may bring me happiness and contentment in old age. My illusions have been those of thinking of going at the things I want and getting them without finding any barriers - such as the colored man experiences here. I have adjusted myself to this fallacy of my thoughts. I am now rather cosmopolitan; such an ideal is likely to be realized if a better understanding between the different races and classes obtains. My ambition for my children is that they will grow up and not be taught about the things which cause us to have misunderstandings among ourselves, and thus be able to look at life in a broader light. As far as intermarriage, I am not in favor of it, but only for one reason, the unhappiness and dissatisfaction to the parties concerned because of ostracism.

\section{QUESTIONS}

1. Describe briefly the background conditions of each immigrant in this chapter. Into what social groups may this group of immigrants be divided?

2. Make an outline of the reasons for their emigrations. Show how the same general reasons differed in the various social groupings.

3. What were the dominant factors in shaping the individual desires to 
emigrate? What inducements did the Finn (number 1) have to remain in his native country? The Hungarian (number 2)?

4. Describe the Filipino's (number 6) contrast of Manila and San Francisco.

5. Why was the Korean's (number 10) "head all upset" at the night club? Explain why the Chinese (number 8) did not "care to look at American women at all." Cite other reactions to our culture.

6. What were the chief disappointments of this group? To what causes do you attribute these?

7. Account for the differences in attitudes regarding American home life (numbers 4 and 5 especially). Compare woman's position in America with that of other women in the countries from which these immigrants came.

8. Describe the adjustment of the Maltese (number 5) to Canadian conditions.

9. Why did the West Indian Negro (number 11) find accommodation so difficult? Why did the Maltese (number 5) not enter more into American life? What is the significance of the statement by the Japanese (number 9): "I . . . do not have many friends among Americans"? Why did the Finn (number 1) change from pastor to business man?

10. What groups must seek social relationships among their own kind?

11. Using the cases in this chapter, discuss the inconsistency in our immigration laws.

12. What are your reactions to the discrimination against these immigrants?

13. How would you attempt to measure the nature and depth of each person's assimilation?

14. Discuss the various opinions advanced regarding intermarriage and amalgamation.

15. State specifically why some plan to return to their native lands, while others evince no such desires. 


\section{PART VIII}

SECOND GENERATION AMERICANS 



\section{CHAPTER XXXVI}

\section{SECOND GENERATION AMERICANS IN PROCESS}

\section{Living in Two Culture Worlds}

If one may judge from the scarcity of literature on the subject, few writers have considered that American-born children of immigrant parentage present a problem for study. On the other hand, those who have studied the adjustment of these children realize that they live in two worlds. "The hardships endured by immigrants," writes Mr. John Valentine," "have often been pictured, but the mental agonies undergone by the children of immigrants, born in the United States but of old-world citizens, are ten times more poignant."

The immigrant may become disgusted with conditions and withdraw into his own colony and remain essentially unchanged. "But a deeper, more harrowing struggle awaits the child of alien parents born into an alien home in America." ${ }^{2}$ On the streets, in the schools, from the English papers, and in the movies, the children of immigrants acquire ideas foreign to their parents. They attempt to carry these into their homes, but it is often impossible for their parents to comprehend them. Likewise the outside world ridicules the language and ideas which these children bring from their homes. As they grow older the struggle becomes keener, and isolation increases until many find themselves amused or disgusted strangers within their own homes. Many succumb rapidly to Americanization, while a few withdraw into their own colony and remain strangers in the land of their birth. Many oscillate between the two worlds, concealing many things from their parents by using one set of behavior patterns in their home and another outside.

Thaddeus Sleszynski, ${ }^{3}$ on the basis of their reaction to the immigrant colonies, divides the second generation into five groups. The first group conforms to the standards of the colony. Members of this

1 "Of the Second Generation," Survey, Vol. XLVII, p. 956.

2 Lyons, Eugene: "Second-Generation Aliens," Nation, Vol. CXVI, p. 490.

3 "The Second Generation of Immigrants in the Assimilation Process," Annals of the American Academy of Political and Social Science, Vol. XCIII, pp. 156-61. 
group generally come from homes with large families, which are on a low economic level. Because of the poor economic conditions they leave school early and go to work. Most of them grow up as an integral part of the colony. They continue to reside there, to speak the language, to read the language newspapers, to marry within the group, and to satisfy their social life there. Most of them become unskilled laborers, but some keep small shops and stores, and a few become professional people. The few who receive professional training do so on a mimimum amount of money and begin the practice of their profession heavily in debt. Because of the economic handicap, they acquire only a superficial knowledge of American life and fail to gain an understanding of the higher culture of their own group.

Members of the second group make little or no use of the language of their parents. Some are born outside the colony and never learn the language; others are born within the colony, leave it, and forget the mother tongues. Through the influence of the schools, economic conditions, or association with American friends, they come to despise the language and customs of their parents. They leave the colony, change their names, and are lost in the larger American society.

The third group contains a small number of artists, musicians, and writers, whom the colony claims, but who have no interest in the colony. Although they do not deny their race or change their names, they feel no direct kinship with the immigrant community, and often regard it with contempt.

The fourth group includes those, who, through superior abilities and better opportunities, have won a place in both the immigrant colony and the American community. They often gain positions of leadership in both groups. They live outside the colony but keep in touch with it. Usually they are public-spirited citizens, physicians, lawyers, bankers, and business men. Being able to speak the foreign language and understanding the better elements in both the foreign and the American culture, they interpret America to the immigrants and the immigrants to America. Some of them, however, take advantage of their position to the detriment of both groups.

The fifth group is confined to a few social workers who speak the foreign language. Most of these were born in the foreign colony, and a few have had the advantage of a liberal education. Because of their ability to speak the foreign language, they have been selected as interpreters and remain as mediocre social workers. They are familiar with the traditions and social conditions in the colony, and many of 
them take an active part in its social and religious life. They stand between two forces - the American welfare agency which wishes to make its work efficient, and their own colony which they generally favor as much as possible. On the one hand, they conceal the evils in the colony, and on the other, they fear to condemn the forces in the larger American community which help produce the evils in the colony.

Whatever their group, the second generation are subject to forces for Americanization which they are powerless to stop. The immigrant colony is not self-sufficing; most of the older members must secure employment on the outside, and the children go to school, where they come in contact with Americans. The inevitable changes resulting from these outside contacts cannot be permanently resisted, and often the second generation children become promoters of rapid changes. They are in two culture worlds, and conflicts inevitably arise with both the home group and the outside group. Adjustment, however, must eventually take place. For pedagogical convenience we may say that the process involves conflicts, disorganization, reorganization, and assimilation. Not all children of immigrant parentage pass through all these stages or experience them in the same degree of intensity; but they are stages in the experiences of a large group.

\section{Cultural Conflicts}

If the children of immigrants did not come into contact with American influences, perhaps they would have no more conflicts with their parents than native children of native parentage - certainly no more or more intense than the educated children of illiterate or ignorant parents experience in their homes. But contacts with Americans bring into vivid contrast the two cultures, and generally result in parent-child conflicts. The intensity of these conflicts depends upon many factors, such as language, education, recreation, occupation, social and religious ideas. If the parents belong to an English-speaking group, the language difficulty is removed, but other conflicts may be acute. If the parents are Protestants, religious conflicts may not arise. If the parents belonged to the educated or wealthy group of their own country, the adjustment of the children is generally easier, but in some cases it is intensified.

On the other hand, in case the parents are poor and uneducated, come from non-English speaking countries, profess a different religion, 
or live in a foreign colony, the conflicts are usually more violent. Much, however, depends upon the nature, ambitions, ideas, ideals, customs, and traditions of the parents, as well as the type of American influences playing upon the children. If the parents belong to a different biological group, as the Orientals and Negroes, then the color conflict is introduced. This continues indefinitely and complicates the cultural conflicts.

1. Language Conflicts. Immigrants vary widely in their attitudes toward their mother tongue. A few hold to it tenaciously, refusing to attempt to learn English; many speak English along with their mother tongue; and some drop their mother tongue as soon as they learn English. For many years the majority of our immigrants have come from non-English speaking countries. Many of these speak two or more foreign tongues when they come, but owing to lack of opportunities to continue their use, to the reactions of Americans to a language which they do not understand, or to the desire of the immigrant to learn English, they drop the foreign languages. "When my parents came to this country," writes a Lithuanian Jew, "both could speak several languages. But due to the lack of people to converse with, and their ambition to learn the language of their adopted country, they have forgotten how to speak all these languages except a few words. They have made no attempt to maintain the language, customs, and traditions of Lithuania. I suppose the reason for this is that the Jews and Lithuanians were in constant battles, and they wished to forget as much as possible. I cannot even speak the language of the Jews, a thing I am really sorry of. If I knew it, however, I would have no opportunity to use it, as English is always the language of our home." An Italian writes: "There has been no effort on the part of my parents to maintain the language and customs of their native country. They were eager to learn the language of the United States; so we were always taught to speak to them in English."

Many immigrants continue to speak their mother tonguc for some years after they come to this country, and their older children learn it, but gradually English supersedes the mother tongue and the younger children speak only English. "In our home," writes an Italian, "there were no attempts to continue the language and customs of the old country after my parents learnt English. Of the three children, I am the only one who can speak or read Italian. My brother and sister do not understand it." A German lady says: "My father was a well-educated college man with a ready use of five 
languages, but we spoke English entirely at home. We could partly understand when father or mother sometimes said something in German, but we answered in English. The older children knew more German words and sentences than we did - it had died out in the home when we arrived. I never knew a full German sentence until I studied the language in college."

Some immigrants not only drop their mother tongue but refuse to teach it to their children. A Portuguese lady told the author that her father stopped speaking his mother tongue soon after he came to this country, and refused to associate with Portuguese and to permit his children to learn the language. Some immigrants think that the use of a foreign language in the home handicaps their children in learning English. An Italian father told the writer that he and his wife ceased speaking Italian to their children because it seemed to hinder them in learning English. The study by Dr. E. de S. Brunner of Immigrant Farmers and Their Children, confirms this contention.

On the other hand, many parents see the advantage of knowing two or more languages, and encourage their children to learn and retain the foreign language. Some groups, as the Japanese, Chinese, and Jews, often establish language schools, to which the children go each day after they come from the public schools. A large number of the French Canadians maintain parochial schools where English is largely disregarded and the instruction is in French. Other immigrants send their children to the foreign-language churches and Sunday-schools, hoping thereby that their children will learn and maintain the language of their ancestors. Some parents try to force their children to learn and speak their native language. "Tell me," said an Armenian business man, "what to do with my four-year-old daughter? She has gotten so that she will not speak a word of Armenian. I have tried to persuade her and I have punished her, but nothing does any good. She understands it I know, and spoke it until a few weeks ago. Now she will not speak a word under any condition, and even tells people she cannot speak it. Somewhere, somehow, she seems to have gotten the idea that it is degrading to speak Armenian." A second generation Syrian says: "Certain efforts have been made to have the language maintained, but I have always avoided attempting to speak or understand it to any great extent. It was not as difficult as it might have been since my parents spoke English most of the time when not talking between themselves or to others of the same nationality. There has been a tendency for me to avoid members of the racial 
group of my parents. I am ashamed to be seen among them; I do not like their folkways or customs, do not understand their language, and do not like to be considered one of them. This.may be selfishness or ignorance on my part, but nevertheless I have always chosen to remain away from this group. I have been embarrassed by members of this language group in America on occasions when it has been necessary for me to meet with American friends in their presence. It is obvious that the different views of the two groups is a source of embarrassment. I have also been embarrassed by being 'dragged' into their midst. I understand Americans far better than I do my own people; among them I feel as if I were a man without a country."

The reactions of the children of immigrants to the language of their parents are interesting indeed. Like the Armenian child, many four-, five-, and six-year-old children of immigrants refuse to use the language of their parents. Through the influence of other children they come to despise anything foreign, and refuse to speak the language because it identifies them with foreigners. On the other hand, many children of immigrants continue to speak the language of their parents, perhaps wholly, until they enter school, and then drop it. Many young men and women have told the writer that they understand the language of their parents, but cannot speak it.

Often the English-speaking children come to feel themselves superior to their non- or broken-English-speaking relatives. They feel humiliated when forced to accompany them on the streets and act as interpreters. An Italian who speaks English with an accent complains that his younger brother, a high school lad of fifteen years, refuses to accompany him on the streets because "I am not going down the street with a Dago."

Scores of young people have revealed their humiliation because of the poor English of their parents. Naturally the parents do not like to be corrected by their children, but the children, understanding English and American customs, while their parents do not, become the buffer for all the sneers hurled at the immigrant group. To the youngster this is humiliating, but later it becomes amusing. A young man writes: "It used to humiliate me, but now I am amused to hear my father and mother pronounce some English words; for instance, church and chair. The Swedish pronunciation of $c h$ is like sh in English, so that 'church' is to them 'shurch' and 'chair' is 'shair'. It seems impossible to change them from that pronunciation, because I 
have corrected them numerous times, but it is still 'shurch' and 'shair.'"'

Another source of friction between children and their immigrant parents is the habit of the parents' speaking to each other in the mother tongue before the American friends of their children. Many second generation people have spoken of their embarrassment when they invited some of their high school or college friends to their homes, only to have their parents begin talking to each other in a language their friends could not understand. Such experiences cause friction in the home and isolate the children from their parents. The children fail to appreciate the struggles of their parents with a foreign language, their humiliation because of "broken" English, and the comfortable and customary habit of speaking their mother tongue. And the parents fail to understand the position of their children and the reaction of the friends of their children because of the foreign language.

Many second generation Americans come to see the advantage of using two or more languages and regret that they are not able to do so. An Italian university student writes: "I cannot write, read, speak, or understand the language of my parents. I consider it a big shame for people to lose their language. I would give a lot to know the language of my parents." A young man confesses, "My father did not teach me to speak German, but if I ever have any children, I am going to teach them to speak German at home."

Those who have retained the language of their parents along with English are usually proud of the fact after they reach maturity. A Ukrainian writes: "I always use the language of my parents when I am at home, and I like to meet persons here in college who speak the same language. I like to go home after being away for a while, for there is nothing better than to hear the native tongue spoken." Although the foreign language caused them humiliation and the loss of prestige in their youth, in maturity it gives them a decided advantage with added prestige. In college they have the advantage over their classmates. A different culture world is open to them. They are often sought as interpreters, translators, and research workers, and thus feel superior to most of their classmates and fellow citizens. A Dane writes: "I am very glad indeed that my parents saw to it that I retained their language. Through my knowledge of Danish I have acquired a knowledge of Norwegian, Swedish, and German. Thus a great world is opened up to me which otherwise would have been closed." 
2. Educational Conflicts. Children of immigrants ordinarily experience three types of conflicts in school; conflicts with other students, conflicts with parents, and conflicts with teachers. In school the other students often make sport of the immigrant children, laugh at their English, call them nicknames, and otherwise humiliate them. A Dane writes: "The only time in all my life that I had any difficulty was during the war. I was young and many of the boys in school called me Kaiser, spy, etc., which hurt my feelings very much at that time. I would not feel hurt now, as only the ignorant French and Irish were the ones doing the personal damage."

Immigrants vary widely in their attitudes toward our public schools. Some groups, like the Chinese, Japanese, and Jews, make the fullest use possible, coöperating in every way. The Asiatic child seldom presents any problem from the point of view of compulsory attendance or discipline. Until the Asiatics met with so much prejudice on the Pacific Coast, many of the parents opposed the language schools. They wanted their children to grow up as good American citizens in every respect. But now they fear the future, and are insisting that their children learn their mother tongue, for economic conditions may force them to go to the Orient to seek a livelihood. Many of the children, however, manifest little interest in the language of their parents, and make no effort to learn it.

Other groups, like the French Canadians, Poles, and Irish, establish parochial schools and send their children to these in preference to the public schools. The prime purpose of these schools appears to be to teach the religion and language of the parents. Many parents today, however, are refusing to send their children to parochial schools and are giving whole-hearted support to our public schools.

Many immigrants see little advantage in education. They permit or even force their children to leave school just as soon as they reach the employment age, and put them to work to help support the family. If their children remain in school, they often do so without the encouragement or aid of their parents. A young Pole says: "I am here in the University of Illinois trying to complete a six-year medical course, and I am having a hard time of it. The Poles, you know, are not much for education. Their idea is to make money, and they only favor going to school when a lot of money is to be made out of a little education. They think that professional training is a waste of time. My father refuses to contribute a cent toward my education, but my mother helps me all she can." 
Because some teachers are prejudiced and hold erroneous ideas in regard to immigrants, the children of immigrants are made to suffer. An Italian girl writes: "The only important crisis in my life resulting from immigrant parentage was due to the narrowness of some people here in this university. My freshman year a professor flunked me in English because of my foreign parentage. He remarked afterwards that I was foreign and didn't know anything."

3. Occupational and Recreational Conflicts. Many immigrants have a hard struggle in this country to support their families, a fact which colors their attitudes toward work and play. A few go to one extreme and so completely relieve their children of responsibilities that they make failures of them, but most immigrants insist upon their children's working, and deny them the pleasures other American youths enjoy. The author remembers the frown upon the brow of a high school boy when his foreign-born mother kept telling him before some of his American companions to "quit foolin' 'round and geet besy," and again when his father told him that he could not go to a Four $\mathrm{H}$ Club meeting because he had to stay in the store. "While I was in high school," writes an Italian girl, "I had many desires to help the school as much as I could, but every time I did so, I received a severe scolding from my father. His theory was 'all work and no play.' Even against his wishes I stayed to baseball games and to any function to which I was needed. But when I graduated and the principal presented me with a big loving cup, things were different."

A large number of immigrant parents attempt to follow the Old World pattern, and try to induce their children to follow their occupation. But the children have imbibed the spirit of American independence and look for something better. As a result, large numbers rise several degrees above their parents in the industrial scale. Their struggles upward, however, are fraught with many difficulties. A number, partially or wholly, escape the characteristic American prejudice by changing their names. This is especially true of Jews, Greeks, Italians, Poles, and French Canadians. Others keep their names but avoid their use on signs and stationery, using instead "American" or the name of the town in which their business is located. Many of those who do not try to conceal their foreign connection meet with much prejudice and often become sadly discouraged. A young man writes: "After I graduated from college I had several chances to hold good positions had I been of another race. I made good in all that I was given an opportunity to do. In one job I was 
in complete control of a group of men in the building of an 18-hole golf course. Another man was sent on as a sort of straw boss who did odd jobs, but when the job was completed he was made assistant superintendent. I found out later that, although my work was absolutely satisfactory and that I got the men to do more and better work, the Big Chief disliked 'Wops,' and the other man got the job because he was a Yankee. After several more attempts at various lines, I found that the same attitude is widespread. I decided to come back to the university and prepare to be a teacher. It is my last effort - if I lose out, then?"

4. Social Conflicts. Although many immigrants quickly drop the customs, traditions, and social ideas of their native land and accept those of America, others try to retain the Old World culture in totality or in part, and train their children accordingly. The children, however, soon become accustomed to the customs, traditions, and social ideas of America, and consider those of their parents as old-fashioned and antiquated. "My parents," writes a Scotchman, "have always held to the customs which they think better than American, which seem to be in the majority; however, they've taken over many American customs which they consider better. On these we do not always agree." A French Canadian says: "My parents have always made a great effort to maintain their language, customs, and traditions. I was sent to a French parochial school and always read the French papers, but strange to say I have very few French-speaking friends. We keep a few customs and traditions such as drinking wine along with meals, and we celebrate certain holidays during the year. I have often been embarrassed by members of my racial group in America by being in a group of uneducated people. And I have made sport of the customs, ideas, and practices of my racial group. I always feel more closely drawn to my American acquaintances because I am American-born and have the customs, traditions, and ideas of other Americans."

5. Religious Conflicts. Religion is another source of conflict between children and their immigrant parents, and between the children and the outside world. Naturally the parents take their children to their church and wish them to grow up in the "faith of their fathers." But the children are exposed to broadening influences in schools and have companions of other faiths; consequently some change churches, but a large number become liberal and indifferent. Many second generation people confess that they rarely or never attend church, 
because the churches of their parents are too narrow. Some attend church with their parents when at home, but never go when away. They claim that they attend only to please their parents and get nothing out of the service. Others refuse to go in spite of the protests of their parents. Such indifference on the part of their children is trying indeed to parents who retain Old World ideas, and especially to the conservative Catholic and Jewish groups, whose churches have been compact and have served not only for religious purposes but for political and social as well. While many second generation Jews, Catholics, and Protestants never attend any church, others change to a church of their liking. A young man whose father is a Greek Catholic and whose mother is a Roman Catholic compromised by becoming a Unitarian. A young man writes: "I at first attended a church of my parental language, but when I got old enough to have a few ideas of my own, I changed to an American church. The American church was much more liberal. The Swedish church was run by people of the older generation who had been brought up under the strict discipline of the Lutheran Church and attempted to run their church in the same way. I think that children born of foreigners should attend American churches as they are a help in Americanization. The churches of foreign nationalities I think endeavor to keep the customs and languages of the old countries."

A brilliant student who was valedictorian of his class in high school became engaged to a Gentile girl, but the girl refused to marry him unless he graduated from the university, and his parents refused to send him to the university unless he broke his engagement. During his freshman year he would tell his parents that he was going to a pre-legal meeting on the campus, disconnect the speedometer, and drive down to see his girl. By his junior year he was a member of a Jewish fraternity, had left his Gentile girl, and was associating almost altogether with Jews. When asked for an explanation, he replied: "Well, when I entered the university I made no difference between Jews and Gentiles, but the Gentiles would not associate with me, and their fraternities would not bid me; so there was nothing else to do but associate with Jews."

A young man writes: "If I didn't love my parents too dearly to hurt them, I would marry a certain American girl with whom I kept company one summer. The danger is not passed, however. The more girls I know, the more I love the 'certain one' and I - well, I know we've talked it over many times - it would kill my parents, and I 
would much rather suffer myself. They are from the old country and have Old World ideas. I have often dreamed, wouldn't it be wonderful if all the religions, races, countries, nations, and parents (especially), should proclaim that races and religions are abolished, and that we are all one race and one religion. We should intermarry and live as one great family. I know that it will take centuries for such a thing to happen, but it will happen gradually. The great factor that makes a race is its religion, and religion is getting to be 'old-fashioned.' The Jewish religion is passing out fast, and I think that my children will be left to do as they please, but - who knows I might have just enough religion to remember my parents, and do as they did, and thus keep our world from progressing."

\section{Disorganization}

Torn between two cultural worlds, with language, religious, occupational, and many other conflicts, the children of immigrants sometimes become disorganized to such an extent that they readjust with difficulty. "At home," writes a Swedish young woman, "love affairs and freedom of women are hardly mentioned - my parents are very conservative. But when one goes away to college, how things do change! Many times the parents are wrong - for they should tell the children about sex and help them meet their problems. My parents have very set ideas and often it is a great relief to get away from home. At present I am torn between two forces - the conservatism of my parents and the liberalism of college - and I hardly know where I am." A Lithuanian writes: "I sometimes feel relieved when I can get away from home. I act as a kind of interpreter for my parents. They expect me to be able to explain to them the various American customs, ideas, and ideals that they do not understand. They wish to know these customs, ideas, and ideals, but have no one to turn to except their American-born children, who must act as interpreters for the parents in many ways, and act as a buffer between them and the Americans. Such a strain is wearing on one's nerves and leads to moroseness. Consequently, I often feel relieved to be away from home."

A German writes: "I suppose it is due to the fact that I had immigrant parentage and had to do without many things I wanted, that I have developed a great tendency to pull back, to feel inferior socially, to be too reticent, too quiet, too much the introvert type." A second generation Jew says: "I have on certain occasions felt that I 
have lost status among my American friends, especially when some one, not knowing my race and religion, has dropped a remark insulting the race as a whole or in part. The experience generally amuses me. At first I think of the person's narrow-mindedness, then I become angry, and finally cynical and morose."

\section{Reorganization}

Disorganization is an unhappy state and one from which most people seek to escape. Consequently the child of the immigrant begins early to consider things in their true relationship, and to reorganize himself so that he may fit into the social situation of which he is a part. He isolates disturbing factors, substitutes satisfactory elements, effects compromises, and begins to adjust himself to the forces about him. "I can remember," writes a Swede, "when in the grammar. school the question was always brought up among the children as to who was a full-blooded Yankee. At that age I wished very much that I was one, but I soon outgrew that and now I am perfectly happy at being Swedish." An Italian says: "At first, as a child, the ignorant called me 'Wop' and 'Dago,' and said that I would never amount to anything more than a ditch digger. Naturally, at first, I hated and avoided all Americans, but later I snapped out of this, and found that many of the Americans were all right, and those living near our neighborhood were friendly and one's race made little difference.". A Lithuanian writes: "I used to worry lots because my parents were born in a foreign country. Now, on the whole, I am glad of the fact. These parents are able to show me and teach me to be more broadminded and liberal than the average American child. I have found that the average child of foreign parentage is more willing to listen to the other fellow, to give the other fellow a chance to explain his ideas, than the average American child of native parents."

\section{Assimilation}

"Until I started this paper, I never gave a thought to the fact that I am the child of immigrants." Such is the statement of many second generation Americans. In fact, children, young men and women, and older men and women appear emotionally disturbed when it is suggested that they write a life history because their parents were born in a foreign country. The thought that they are in any way connected with an immigrant seems to disturb them when it is first suggested. A professor of sociology in a large Middle Western uni- 
versity relates that he went home from school crying when he first discovered that his parents were born in Denmark.

With most children of immigrants the process of assimilation is so natural that they never give it a thought. "Being American," writes an Irish lad, "I have always been treated as such, and the only time I have been interested in Ireland is when it has cropped up in my history assignments. Our home life has been thoroughly Americanized, and to us Ireland has been merely an element in the British Empire."

"In high school," says an English Canadian, "I was a member of the Hi Y Club, the DeMolay, and two church organizations. At the clubs and church I met the boys and girls of American-born parents and felt no distinction between them and myself. Why should I? We went to the same dances, did the same things, and went to the same school. I am an American with American ideas and customs. The United States is my country, and I shall always uphold her, even against the country of my parents." A Swede says: "I am proud of the fact that I am an American-born citizen, but I am not ashamed that my parents are not American-born eitizens. I think that they are just as good, if not better citizens than a good many native-born citizens." A Pole writes: "I have no interest in the native country of my parents, except in its relation to America. Europe seems to me to reek with bloodshed. My mind associated persecutions, massacres, intolerance, ignorance with it. America is in a direct opposite position - one of enlightenment."

Many second generation people express a desire to visit the native land of their parents, but do not wish to remain there. "I would like to go to Italy," says an Italian, "and see what it is like and that is all. I do not feel that I have lost anything there, and this is my country anyway." Another says: "Since I speak Italian, I would like to travel in Italy, but also in other European countries. Otherwise, Italy means no more to me than any other foreign country."

On the other hand, one finds some second generation Americans who are only partially assimilated. This appears to be due to the experiences which they have had with Americans of the old stock. "I would say," writes a Canadian, "that Americans are too narrowminded, too much in love with money, too cock-sure, and with them it is all AMERICA, and nothing else. 'America is the only country in the world,' seems to be the common feeling. I was born here, have always lived here; so I suppose I am an American; but if I could 
have gone to Canada and taken out my papers to become a Canadian citizen, I would have done so without any hesitation. But I have received my education and living in this country and guess I can't complain too much."

A second generation Dane says: "I dislike the old New England Yankees very much. They are ignorant and apt to think themselves better than any one else, when all they have to base it on is a little money. They are self-conceited and narrow, and think the whole world is in New England. They are intolerant and hypocritical in actions. They are also prone to bluff. The people I have met from the West and South are very likable. I think that American politics are the worst in the world, and I see no sense in voting at all while they remain so. I intend to visit the country of my parents and I may remain there; it all depends on what happens to me. I feel more closely drawn to my parents' people than to Americans."

\section{QUESTIONS, EXERCISES, AND PROBLEMS FOR INVESTIGATION}

1. Why do we speak of the children of immigrants as living in two culture worlds?

2. How do you account for the fact that so little attention has been given to the problems of the second generation? How do those who have studied the second generation regard these problems? Discuss the origin of such problems.

3. Characterize each of Sleszynski's groups of second generation Americans.

4. What forces for Americanization play upon the children of immigrants? To what extent may these be evaded?

5. What steps are generally involved in the process of adjustment?

6. What is meant by culture conflicts? Give examples. Should we assume that all conflicts between the first and second generations are due to the influence of two cultures? Upon what does the intensity of these conflicts depend?

7. What are the chief difficulties in language conflicts?

8. Refer to first generation documents and cite instances of parents who do not speak the English language. Account for the fact that some immigrant parents retain the native language while others drop it. What groups generally attempt to retain the native language?

9. Enumerate the advantages and disadvantages of maintaining separate language schools. Why do many children of immigrants refuse to use the language of their parents?

10. Cite instances in which parents have humiliated their children by not 
speaking English fluently. Analyze these cases from the point of view of the second generation.

11. Explain why many are proud of their ability to speak the language of their parents after they reach maturity.

12. Discuss the main types of conflicts which children of immigrants experience in school.

13. What immigrant groups take fullest advantage of our public schools? What groups least? Explain the change in attitude of Orientals toward the language schools. Give reasons why certain foreign groups, such as the French Canadians and Poles, desire to maintain their language.

14. Explain the attitude of many immigrants toward higher education. Be specific. To what extremes do immigrant parents go in regulating the work and recreation of their children? See documents of the preceding chapters.

15. How do some teachers react to immigrants or children of immigrants?

16. What are some of the occupational disadvantages that confront the second generation?

17. Explain the social and religious conflicts of the second generation.

18. Account for a greater prevalence of religious conflicts among Jews and Catholics than among Protestants.

19. Analyze the disorganization of the second generation. How does it differ from that of the first generation?

20. In what respects does the assimilation of the second generation differ from that of the first? Why do many appear quite emotionally disturbed when they really realize that they are the children of immigrants?

21. Compare second generation attitudes toward the parent's native land.

22. How do you account for the differences in assimilation?

23. Read and report on Stern, E. G., My Mother and I.

24. Read the following articles by Dr. W. C. Smith: "Second Generation Oriental Americans," Journal of Applied Sociology (Sociology and Social Research), Vol. X, pp. 160-68; "Born American, But-," Survey, Vol. LVI, pp. 167-68; "Changing Personality Traits of Second Generation Orientals in America," American Journal of Sociology, Vol. XXXIII, pp. 922-29, and report on the second generation Oriental-Americans. 


\section{CHAPTER XXXVII}

\section{LIFE HISTORIES OF TEUTONIC SECOND GENERATION AMERICANS}

\section{ENGLish-IRISH}

\section{Father Overbearing, Mother Ultra-Religious, Family Disorganized}

I seldom think of myself as other than American. Neither I nor any other member of my family, so far as I know, has ever had an un-American thought. My brothers volunteered for service in the World War, and I reported for Red Cross service. If, in my youth, I ever gave the seemingly spontaneous Americanization of my parents a thought, it probably seemed natural to me that, speaking the same language, my people adjusted themselves naturally and painlessly. It was, therefore, quite a shock to hear the statement that the English are the hardest people to Americanize. I was about to hotly refute the accusation by citing my father as the perfect example, but suddenly I recalled that his naturalization was forced. He, being a deserter from the English navy, was a man without a country, but nevertheless subject to arrest and court-martial by the English government.

As a child I took his change of allegiance as a matter of course, caring nothing for the details. As it is not feasible to consult him on this matter at present, I shall relate the circumstances as best I can, beginning with his enlistment. From all reports, my paternal grandfather was a very severe man, a hard disciplinarian and taskmaster for his family of five husky, high-spirited boys. One after another, as they grew to manhood, they found the home discipline unbearable. The eldest son left home at an early age to seek his fortune in America. After twenty years of fairly successful business life in America, he returned to his native land for a visit. He arrived in London about midnight. His eagerness to see his mother and father urged him to go straight home, though the hour was late. The household had long since retired, and was aroused only with great difficulty. Finally one of the upper windows was thrown open and a bluff voice demanded; "Who's there?" The son answered: "It is I, father. I just arrived and found it impossible to compose myself for 
rest at a hotel. I hurried out here." His father replied: "Well, you managed to stand it for twenty years; seems as though you could have stood it until morning."

It was from such a home as this, sadly lacking in love and sympathy, that my father ran away at an early age. He enlisted as a seaman and served many years in the English navy, visiting all parts of the world. $\mathrm{He}$ participated in petty warfare in India and Africa, all the while accumulating a dissatisfaction and disgust for the attitude of England toward her colonies. I know nothing of the nature of his contract, but I understand that he applied for a release and was denied his request. When his vessel sailed from an especially desirable port, he was not on board. In cold print the word "deserter" seems very dishonorable; certainly it does not fit the fine character of my father as I know him, silent, unemotional, and the most patriotic American I ever knew.

Mother came to this country from Ireland when she was eighteen years old. Four years later she and father were married. By dint of hard work and thrift, they saved enough to buy a farm in Ohio, and here not only hewed a home out of the primeval wilderness, but also raised a large and patriotic family. My mother, like the good Catholic she is, gave birth to eleven children. Although they spent their early lives in poverty, my parents never complained of their lot. They have often expressed themselves as grateful to have had the opportunity of establishing their home and raising their family in America. No one of the nine surviving children has achieved any outstanding merit; neither has any one of them been a delinquent, dependent, or pauper. Surely whatever induced the young Englishman to desert his ship has not proved him incapable of rearing a goodly crop of American citizens.

I believe my father considers England as truly the mother country of America, the latter a continuation and evolution of the same civilization. It was he who first pointed out to us that the Revolution was against the English administration rather than against the English people. He deplored England's oppression of Ireland. My mother, though proud of her home, realized that it would never have been possible to acquire fertile acres in the emerald isle. She had often seen her own father's small farm overrun by hunting parties and her father kept in a condition approximating serfdom by unjust taxation. She loved Ireland and still does, but she loves her American home more. 
All of us received a little more education than the community standard required. Many of our neighbors considered children primarily as an asset in the development of the farm, and criticized my parents accordingly. Nevertheless, they saw to it that we went to school. Our earliest schooling was obtained at the little log school hard by. My mother craved a church school with all the financial strain it entailed, or rather in spite of it. With the aid of a maiden aunt, sometimes we lived in town during the winter. For a short while father established a business there. But when the financial strain became too great, we went back to public school. If a child has a high intelligence quotient, he will probably receive an education at a church school, but if he is slow, as I was, it is little short of a crime to send him to a church school. I did not even have the ambition to play. I wish it were possible to abolish such schools. Possibly a few are worthy, but those I encountered were a positive menace to childhood. I should like to see the state in a position to supply all of the education its people can utilize. But why rave on?

Among our early neighbors were many Scandinavians and Germans. The children spoke the language of their parents. We, in contrast, felt ourselves to be outstanding Americans because we spoke the language of the United States. Our father was a citizen; theirs were not. Our parents could read and write; theirs could not. Overlooking the cultural background of two languages in the homes of our friends, we felt superior. Of course mother spoke a little Gaelic and possessed a few books in that language, but she reserved this language solely for the convenience of talking with her brother and sister, who frequently visited us. Father didn't enjoy the use of the second language, but complained very little. Taken as a whole, my attitude toward my home is not different from that of Americans, pure and undefiled. To be sure we were hampered with poverty, and I compared my home unfavorably with that of my wealthier friends. Yet, poverty is a comparative term, dependent upon one's background. I have always been proud of my parents. With the exception of a pleasing, almost indiscernible brogue, my mother speaks excellent English. My father's enunciation is free from any noticeably broad $a$; it is entirely devoid of any cockney expressions common to so many Londoners - his $h$ 's are in the correct place. The "King's English" has always been an object of veneration with him. He talks good "United States" without the slang.

The sad family break for me has come about through my inability 
to adhere to my mother's religion. My father belonged to the Church of England before his marriage, but mother insisted that he become a Catholic. This he did, but has maintained an indifference ever since. Knowing my mother, I consider this acquiescence more than justifiable. I am told that with advancing years she becomes more devout. Much of the peace and harmony in our home may be attributed to my father's negative attitude. It would be impossible to live with mother comfortably and not accept; at least outwardly, her religion. This mental twist is often labeled psychopathic, but let us remember she is a product of the dear old land of fairies. She came from Cork county, near Killarney, where there is a fairy in every bog and the witches and ghosts are real. How could she escape religion or superstition in such an atmosphere? My mother took to her religion with all the fervor of her impulsive, emotional Irish nature. When visiting her, I need all the tact I possess to keep off the subject, and more than I own when she brings up the matter. It is worthy of note that those of us whose work has taken us away from home a great deal have become "backsliders," while those who have remained near have adjusted their religion accordingly. The force of environmental factors looms large.

For my own religion, I am not at all sure I have any. It is said: "Once a Catholic, always a Catholic." Speaking for myself and other members of my family, I can truthfully say: "An overdose in childhood, disgust and mistrust for the remainder of a lifetime." I feel that there is nothing so destructive to intelligence as religion the way we present it to the child mind. I should like to see one generation reared with adequate ethical and moral training, free from hampering, outworn dogma. I should like to see them left to develop a religion for themselves. But even with my uncanonical ideas, I have not been brave enough to rear my two children outside the pale. I have never insisted on their attendance at church, merely consented. They seem to enjoy thoroughly the Episcopal services, and I derive a great deal of pleasure from the beautiful, flowing language of the Book of Common Prayer, the dignified order of service, and the freedom from emotionalism.

While some of us have never been able to adjust to mother's religion, other members of our family have not been able to adjust to father's dominance. He has been very little more successful in handling boys than was his father. An Ohio farm is a sentence for life; the soil is rich and will produce, but it is killing work to make it do so. 
Ever since I became old enough to think on the subject, I vowed I would die an old maid before I would marry a farmer. I did eventually marry a rancher, but that is another story. My brothers are all big, well-built, strong, muscular men, not averse to a reasonable amount of work, but not one of them has been able to work with father on the farm. All are doing well and do not seem to resent father's attitude now that they are engaged in less arduous and more profitable work. Often they take their vacations together and journey home to help in the harvest. Only one seems morose, but he has tried more than once to take the burden from the shoulders of my aging father, and has found it a waste of time and energy to follow father's directions.

My husband, now dead, came of a family so long Americanized that there is a difference of opinion as to when the break was made. I could not see that his ideas toward the United States differed essentially from my own. His son by a previous marriage early developed a love of music, and has become an exceptional musician. If I can give music to the world through this child, perhaps I shall be able to justify myself as an immigrant once removed. Desire for recognition? My daughter also, to the fond eyes of a mother, seems worth working for and with. Life is full, busy, and very much worth while.

\section{German}

\section{Patriotism on the Rampage}

I was born in a distinctly rurban community in Iowa. Up to the age of sixteen, I lived on a farm just outside the town limits, and, due to the nearness to town life, enjoyed many advantages socially and educationally. Having come to Iowa as a boy in 1849, father spent his youthful years clearing the wilderness to make a home for his parents, and later for himself. During the winter months, when Iowa climate allowed no outside activities, he continued his education in a log schoolhouse near his father's farm. When grown to manhood he taught some of the neighbors' children in this same schoolhouse. Mother, having arrived in America at the age of eighteen, was no longer of school age (that is, her practical nature as well as her purse demanded that she make a living instead). She felt happy to have attended the Volksschule in her native Germany. Often she expresses regrets at not being able to write the English language, though she speaks it reasonably well. 
Thanks to the progressive spirit of my father and to the self-sacrificing coöperation of my mother, no economic hindrances were allowed to interfere with the regularity of school attendance by each twelfth of our patriarchal family group. Well do I remember the admonitions of my mother: "Keep your marks high, and don't cause the teacher any trouble." As a result, I seriously questioned my right to speak in a personal manner to my teachers. During my fifth year of school life, I was destined to sit at the feet of a pedagogical tyrant, a woman who had little sympathy for children, an irascible disposition, and no patience. One morning the highways were so blocked with snow that it was necessary to shovel our way through to school. I implored my father to let me return home with him in the sleigh and be called absent, rather than go through the tardy door and have the finger of scorn pointed at me by the children, and the teacher's angry words and frowning looks directed toward me. The punishment on this particular occasion was twenty minutes after school every evening for two weeks to make up the minute of tardiness, and a demotion from the "A" division to the " $\mathrm{B}$ " in scholarship. After that my father was converted to my plan of truancy.

It was in my school career that I felt a gap between the social phase of my rural life and that of my town classmates. In fact, it became quite unusual to be invited to their social functions because I was a country girl of foreign parentage whose social ambitions did not coincide with those of town club mothers. How keen was my disappointment when I was refused a birthday party or a chance to go on an excursion up the river!

After finishing high school I had to stay at home a year as I was too young to teach and also too young to go to college as my sisters had done. How I loathed going out into a rural community for a whole year, and how I longed to assume the college airs of my sisters! Being a rural teacher was even worse than dreading the ordeal. I was fortunate enough to know the German language of the people, else I should have been extremely bored and unhappy. My chief ambition was to get back in town Friday night. During the long winter when it was impossible to commute, I had nothing to do but read yellow farm journals and play with the baby in the household. The next year saw me taking a two-year teacher's course, which was the most practicable thing to do. I had set my heart on a musical career, but this met the stern disapproval of my parents, although they had given me music lessons six years under a private instructor. 
I have made several moves since I became a teacher, each change being a step forward.

It is interesting to me in filling out application blanks to read: "Were you born in America?" In one case of a personal interview, the superintendent asked me whether or not I belonged to the German branch of the Reformed Church in the United States. Just after the war began, German was taken out of the curriculum in the small Dakota high school where I was teaching those classes, and I was forced to look elsewhere for a position. That was the incident which led to my specialization and eventually to my professional advancement. However, being of German descent, I, with those of like heritage, experienced many social as well as professional insults.

In times of great emotional strain such as accompanied the last war, even our institutions sometimes fail to function. It was so in the small town where I lived. German-speaking people were repeatedly driven from places of business or the post office where they happened to meet daily. A Red Cross worker was overheard to utter, "Damn the Dutch, they never did amount to much." The pastor of the German church was attacked in his study one Saturday evening while preparing a memorial sermon for one of his members who was killed in action; he was dragged down Main Street by four masked men and up to a temporary platform in the heart of town to deliver a patriotic address. However, "they who came to scoff, remained to pray," for his loyal spirit of patriotism was poured forth in fluent strains. One member of the Council of Defense attended every service in that church for more than a year, and various members of the congregation were summoned before the Council because they had not paid enough to the allotted amount for that church in voluntary collection for the Red Cross.

Following such actions, it is not surprising that I never felt inclined to admit that I was of German descent; in fact, in one case I failed to qualify for a position because of my German name. It is not for me to pass judgment upon the American people since I am American-born, but there is evidence of the fact that they are quite unmindful of the contribution these German people have made toward the settlement and economic stability of their realm and also that they forget the significance of German civilization and scientific investigation. Much as I admire German achievements, I should not care to settle permanently in that country. I should like to see the beauties of the Rhine and other things of interest. The German folk- 
tales lead me to believe that a trip through that part of the world would be much the same as Alice's experiences in Wonderland.

There are some German communities which are over-conservative in the matter of providing educational advantages for their children. One of these is near the little town of my birth. One is impressed while driving through the country by the fine farmhouses and large barns, by the waving fields of grain - a sure index of prosperity by the large herds of dairy cattle and swine, by the large orchards of ripening fruit, by the yards alive with chickens, and ponds dotted with ducks and geese; while perhaps just a half mile farther, a lonely little one-room schoolhouse surrounded by tall weeds and barbed wire fence stands as an undeniable". testimony of the educational consciousness of that community. Past this lonely corner hundreds of beautiful, expensive automobiles travel daily without taking note of the situation. It is no wonder that "Gustave" is ready to stay out of school for the slightest excuse.

In this same community the little country church presents a rather unusual situation. All the women line up on the walk before church and wait for the men to enter their pews in the church before taking their seats on the other side. When the annual church picnic is held, all of the women wait until the men have been served, before eating. Hymn books are furnished the men first; if any are left, the remainder go to the women.

A very interesting family came into this community from Germany a few years ago. They were well educated and refined, the wife being city bred. Nevertheless, she felt very keenly her duty to wait upon her husband at every turn. When he would return home from a visit among his parishioners (he was a clergyman), she immediately tended to the livery and also removed his storm rubbers and overcoat for him. Among her other duties were milking the cow, weeding the garden, mowing the lawn, cleaning the garage and outbuildings, and all the domestic services necessary. She is very superstitious; if people coming to church are caught in a shower, she predicts death and weeping in some parishioner's family during the week; if it rains into an open grave, some other death will soon follow; if a bride-elect allows the groom to see her wedding gown before the day of the wedding, unhappiness will be their lot; if a person stubs his toe on the entrance to the church, some sin will be committed before he leaves. Of course, these customs and ideas are quite as much a source of amusement to me as to the American-born of Americans, because 
my contacts have all been with that type, or those who are assimilated into that group.

During my early years I spoke the German language entirely, but when I became of school age, I preferred speaking the English language to my sisters and brothers as well as my playmates. To this day, largely because my mother speaks rather brokenly, I use the German in speaking to her. I also write her German letters, though it is difficult for me to express myself as clearly as in English. Only recently have I tried consciously to overcome such expressions as "yet," "already," "sit by me," "make my hair," "stood in the paper," etc. It has been of great value to me to know the language both in a cultural and in a practical way; it helps bridge the gap between the acquaintances of my parents and their Americanized offspring; it has helped me in continuing my education; it is a comfort to those of the older generation who have not thoroughly mastered the American language to be able to converse freely with one who can fully interpret their communicated ideas; it is an asset to one living in a German community from a business and a professional standpoint.

My first recollection of songs my mother taught me was "Die Lorelei" and it became so much more impressive when I learned the story in connection with it. My early religious training was in the German language: I had German-speaking Sunday School teachers; a German pastor preached; all organizations in the church were conducted in German, although socially the English language was spoken among the younger generation; church chorals were in German; the ritual and catechism were also in the same language. As a consequence, many of the children of immigrants ceased to attend church; they felt it gave them more prestige to attend American churches where the services were in English. But the older generation has gradually been supplanted by young people, and there is now no trace of the German language. Many of those who left are now returning to our church. In my case, I have been careful not to accept invitations to lead chorals, or to assume any prominent rôle. There has been a changed attitude toward me and my attainments, one of antagonism. On the gther hand, I have become more independent of their social influence. I am sorry, however, to find myself forgetting more and more the little idiomatic expressions once so helpful; I am quick to notice any German accent in the speech of that nationality. Thus, in one way or another, we of the second 
generation break away from the language of our parents and modify their institutions, once so Germanized.

It has been my policy to make my visits at home rather short, as I have gradually moved away from the sentiments of that home. Mother has been a typical German housewife; she kept herself in a decidedly inferior position, although my father never demanded absolute authority over his wife and children. To one who has lived in a family so organized, there is a tendency to rebel in the other direction. That may be the reason my four older sisters and I are so madly pursuing a professional career. The fact that my interests are in the direction of a career has alienated me from my original group of members of the family and neighbors, because we find little to talk about except families and domestic happenings. Our experiences are so different; we have almost nothing in common.' In my immediate family, it is a trial to convince them that $\mathrm{I}$ am as much interested in them now as when our lives ran parallel. There is certainly a tendency to become estranged from a family group after a long absence. The passage of time has solved many problems for my German-born parents, such as the amalgamation of social and economic interests, the wider scope of business and educational enterprises, and the wider dissemination of literature and information; and an understanding appreciation of their problems by their American-born children has eased their adjustments to changing conditions and the Americanization of their offspring.

\section{German}

\section{Fighting, Not for Germany or the United States, But to Keep Peace in the Family}

My parents both came from Germany. Father was a soldier in the War of 1870 and advanced rapidly on account of his great bravery and courage. His people had come earlier, but he was forced to serve in the German army. As soon as the war was over, he, being lonesome, followed them to America. Having a good education and very valuable experience in dealing with people, he was a match for the shrewd grafters who prey upon immigrants. My mother's people were less fortunate in this respect. Her father was Bürgermeister of the little town in which she was born. Being people of means and traditional importance, they were considered much the best people. The rumors of war forced them to leave 
Germany to escape war and to protect a son from service. Had they known what was before them, they would doubtless not have been so eager to leave. On arriving in the United States, they looked for a greeting in the faces of Americans. When addressed as "greenhorns" they thought they were being welcomed and were easily induced to go to a hotel, where the proprietor detained them as long as he could. At last, when their money was gone, they sensed the situation and moved on. Both father and mother were disappointed with America and moved to German communities in order to escape the isolation hovering over them. It was in one of these communities that they met, wooed, and married.

Northern Wisconsin was my birthplace. The particular town was a tough, rough place, a gathering place for lumberjacks and tramps. Its one main street was half a mile long, and was accredited at one time with having 65 saloons, to say nothing of houses of prostitution and gambling dens. Our house was on the outskirts, adjoining large fields and swamps. It was in these fields and swamps by the river, and in the woods, that I spent my early childhood, afraid of nothing but the vileness of the city itself. As a child I would walk at the outer edge of the sidewalk so as not to be near the doors of the saloons. But as I grew older and my father began drinking, I often went to bring him home. In fear and trembling I ventured in, often receiving a compliment or a pat on the head. From these attentions I shrank as if from a viper. My father, however, loving me above all the rest of the children, would never refuse to come home with me or give me the pay check. In later years, I could not help but deny my residence there. As a defense against the town, mother told us of her country and of the fine stock from which we came, thus kindling in us a family pride.

Before I entered school, I knew no language save German. I felt strange, isolated, and lonesome. No one but my teacher made me comfortable. Those first days were sentences and the school a prison. I dreaded them, hated them; they were nothing but pain to me. But once in speaking terms with the language, I soon advanced to the head of my class. Mother helped me a great deal, often explaining the meaning in German to me. She, as my father, was well educated and had a great deal of what is ordinarily termed culture. In like manner I passed through high school, and came out with flying colors. My reading, however, never came up to standard, due to a poor start and a foreign language in the home. I have a reading 
complex which I have never been able to overcome. At times I have been complimented very highly on my oral reading, and at others I have stammered and fidgeted. My feelings just won't change.

Books never interested me. Besides having an inferiority complex, I never had much opportunity for leisure. Father injured his knee. After many months of care under quack doctors, he was forced to have his leg amputated far above the knee. I had to become his helper. As a consequence, while other girls were reading or playing, I was helping father in his shop. From my experience, I can today contract for a house, use a hammer, shingle and side a house, and do a number of such things. Besides I became a good mathematician. This is one example of the loyalty of a second generation child for its parents.

I became restless after I graduated from high school. It had been necessary for me to return from college on account of financial difficulties. I became so unhappy that not even work could make me otherwise. At length I secured a local rural school position three miles away. Every other night I walked home, usually on a railroad track alive with bums. I was not afraid of them, for even among tramps there is a code of morals. Becoming sick, I had to give up my job. The same restlessness came back, but with more intensity. All the girls and boys I had known were away at school. I could not fit in with other crowds; I was isolated. Then, when the clouds seemed darkest, I met a very kind gentleman, an engraver by trade and a college graduate. I also had an opportunity to go on the stage - it was a large company. My parents objected; they thought that a girl lost her character on the stage. I did not think so; I thought a girl of character could be good no matter where she was, or went. All my friends were gone, there was no chance for more education, and of course my family thought marriage the only thing for a girl.

We were married and now have a son - a darling little fellow, much like myself in temperament, in likes and dislikes, and in mechanical inclinations. When I was first married, my house took all my time; I stayed at home doing this and that. My husband scolded because I did not return my calls, because I did not have Mr. and Mrs. X. over for dinner (Mrs. X. and I were not neighborly), because I did not go to church, because I spoke German with my mother, and because I did not go out more. I was simply following in my mother's footsteps. She had stayed at home and had not 
entered into society because her means would not allow her to go with whom she wanted and because she could not enter into American things and enjoy them. She had never been overly neighborly; what other pattern had I?

I did not long remain at home; I made a social name. But I was still not happy. I had to go with women much older than myself, and not at all like myself. Instead of becoming a part of them I became a spectator. I can go to a party or dance and enjoy myself quite well unless I look at it from the point of how silly it is, and then I want to go home. As a child I never had a park to play in; today I cannot enjoy going to a park. In fact, I am bored to death.

Strange to say, much as I am American, I have, nevertheless, an opinion of Americans as a whole as if I did not belong. America as a nation is egotistical, and Americans are overbearing. We must not forget that we are not the only nation on earth, or the best example of one. As a girl I would not think of doing many things other girls, whose parents were pure Americans, did. On the other hand, I find much to criticize in regard to my racial group. During the war there were many Germans who, unable to keep their opinions to themselves, often said and did things that embarrassed me beyond words. At one time we had a neighbor, a typical German (I do not think my people represent the average German coming over as an immigrant), who would get out on the sidewalk and talk loudly and furiously. Needless to say, I was often sorry to be of German ancestry when he raised such a commotion. The way the Germans wear their hats gives me occasion for mirth. With the men the hat is in perfect balance, just set on. With the women the hat rides on the back of the head. I have often laughed at the "Dutchie" dress and customs of Germans. Mother has a remedy for every ill, a tea for every ache. Often I have assisted newly arrived immigrants in finding addresses and the like, but I have done the same for strangers.

Once in my life I did not even want to speak German. That was when I began to speak English well. It was only in my last year at high school that I again took up my mother's language. Knowing I was going away from home to school and that she could not read or write English well, I learned to write the German script. This was a great joy to her, and also pleasant to me, as I could continue to confide in her. We were thus drawn closer together. In traveling, I have been glad to know the German language well. It has given me something in common with chance acquaintances. I have never 
felt any pride in Germany, but I have always greatly respected my German relatives, who hold excellent positions in the native country.

Our religious experiences were rather peculiar. Mother had been forced to learn the Bible from one end to the other. Her parents prayed before and after meals, and from the time a storm began till it ceased. My father was reared in the Catholic Church. He became altar boy, where he saw so many things he believed nothing. $\mathrm{He}$ observed such terrible things, he believed even less after the war. The people from the little German church in our town kept urging mother to send us to Sunday school and language school. Because she did not comply with their wishes, we were left outside the church circle, and also somewhat estranged from the German community. Instead of going with Germans, we went with whom we pleased. A book mother happened to buy gave us a much broader view of the . life of Christ. We learned that Christ was a genius, and not a divine character. Had my friends been aware of the ideas I entertained, I should straightway have been consigned to the ranks of infidelity. However, I will wager I have as good a code of morals as most of them.

I believe in the freedom of women; they should have a chance. However, my parents think a woman should not be taken away from home where she is most needed. For my part, I am disgusted with the way girls speak of love affairs and how unashamed they are girls for girls. Even with my sisters, I have a certain amount of modesty, but during the past year at a private girls' school, I have been shocked. Mother is astonished at the freedom girls take with men nowadays. Of course all old people think the world is getting worse.

Often I ask myself: "Is mother really an American?" How can she be? Once feeling a loyalty to a certain country, can she wholly destroy that sentiment? I am sure she is a good American; she has brought up her children to be. She respects our country's laws and lives in harmony in an American community. But when she comes in contact with Germans, she has something more in common with them - the language of her native country. She cannot help having sympathy for them and some loyalty left for the country of her birth. I would not have her different, but there have been occasions when I wished she would use English instead of German (she can speak English quite well). I have called her attention to this more than once. Her persistence caused me a great deal of trouble during the war. My husband's people are Yankees; consequently I carried a 
burden so heavy I did not have time to think of Europe. I had all I could do to keep peace in the family. My own stand was: If the war had been with England instead of Germany, the other side of the house could be counted pro-English, and my folks would have been loyal Americans. It is just how the shoe fits. My husband resents my speaking German with mother; this is America, he says, not Germany.

\section{Norwegian}

\section{Under the Wing of a Fussy Norwegian God}

I was born and reared in a village in North Dakota. This section might very properly be called "New Norway," because over an area of more than 600 square miles the settlers were almost exclusively Norwegian. Father received a fairly good education in Norway, about the equivalent of two years of college work. On arriving in this country, he became court reporter and then county auditor. Later he entered the ministry, becoming pastor of the Norwegian Baptist Church and editor of the "Afholdsbasunen" (Temperance Trumpet). Largely through his efforts, North Dakota entered the Union as a dry state. Mother came from a remote valley in Norway, where her educational advantages were limited. An itinerant pedagogue came for a few weeks each year and conducted the "omgangsskole" (perambulating school). On arriving in this country, she and her mother together went to public school until they could read English. I learned my letters from the same teacher fourteen years later. Mother never spoke English if she could avoid it, but she read avidly, in English and Norse alike, anything bearing on the Bible.

My whole schooling was acquired in this local institution of learning. Throughout my school life I was most interested in English, prisoner's base, and the personalities of my teachers. To me they were a race apart, Americans, keepers of the keys of wisdom, perfect in every way. My first disillusionment came when one of them married the town barber. I could not understand how a woman who knew everything and could teach school could do so plebeian a thing as to marry. Marriage then meant a cessation from wageearning.

I read everything I could lay my hands on from the Bible in Norse, including the Apocrypha, to Peruna Almanacs. I read a host of cheap women's magazines emanating from Augusta, Maine, and circulated in our town mainly because youngsters were always soliciting 6,8 , or 
10 subscriptions at $25 \phi$ per year in order to get a magic lantern or some other species of junk. I read father's theological books when nothing more exciting could be had. I perused such disharmonic crosses as "Harmonies of the Gospels," Smith's "Concordance," Mrs. E. D. E. N. Southworth's novels, and Mary Augusta Holmes's lurid novels. The big event occurred when an American neighbor moved away and willed me a three-foot shelf of what I thought to be dime novels. I carefully smuggled them into our attic and nearly put my eyes out reading them, feeling delightfully wicked all the while. Many of these self-same novels I later reread for a course in the modern novel. I was most interested in The Cloister and the Hearth by Charles Reade, for it was my first intimation that Catholics lived and loved as other human beings. Also it was the first window opened into the past except, of course, for my Bible study. Having no sisters, I enjoyed Little Women. One other book interested me because I couldn't figure out why it meant so much to mother - the Book of Job. She read and reread this to brother and me. He had the gift of easy slumber, but I didn't, and I would listen hard to see what there was about it that always plunged her into such deep thought.

My father died when I was about four years old, and my mother when I was thirteen. Father's particular brand of evangelism was not productive of material wealth, and as a result mother had to put up a brave struggle. I had not realized how very, very poor we were; for she filled our home to overflowing with love, joy, and fun. No joy in life can ever compare with the miracle that followed the opening of our missionary barrel, sent us each year. Clothing for all, some books for father, and a few toys for Johnnie and me were the usual contents. A brown velvet dress with a long train came in our final barrel, and it was the cause of the last truly hilarious mood in which I saw my mother. Our little village then did not even have sidewalks. For a number of years brother's Sunday suits were fashioned from brown velvet. Dresses in those days ran into yardage.

As far back as I can remember, I have wanted to be a missionary to India. That had been my father's ambition, and I felt incumbent to "carry on." I became restless and dissatisfied immediately following mother's death. She was affectionate toward us and would often sit and hold one or the other of us in her lap while she sang old Norse "viser" (ballads). Our neighbors disapproved, as it is against Norwegian ethics to make any public display of affection toward any 
person after babyhood. It is believed to be a sure way to spoil a child. All and sundry immediately set to work to "unspoil" us. Their methods were quick and sure. After this experience, I thought I should like to be a librarian, as I imagined that I could keep away from people and live among books. I, however, had to make use of available occupational possibilities. In the summer I worked on farms, doing housework, pulling wild oats and mustard, and always and always cooking and washing dishes. We ate five times each day on a regular and well-regulated North Dakota farm. I sewed for my neighbors in town and made a little money that way. In this way I secured money for my books and absolute necessities. My clothes I inherited. Under the circumstances, it seemed wise to teach until I could finish university and get into the missionary end of my career. I should have gone into the teaching game wholeheartedly had my mother not opposed it. Humility was a cardinal tenet of her faith; she thought teaching drew one away from God because it made women domineering and self-satisfied. For me there was no choice; in our town, a woman taught, or clerked, or cooked.

Because of mother's early death, I had to work too hard to have time to take part in and learn any kinds of organized games. Today I feel socially deficient in this line. My missionary aspirations were encouraged by all my family, and it is a cross to them that I am not in that work now. They sympathized with my desire for an education, all except the two uncles who happened to have money. Fortunately for them, their attitude deterred me from asking them for help in finishing school. Instead I struggled on, and gave my health a permanent dent in the battle. After teaching school twelve years, I again entered school. It was an escape from the many restrictions, galling to the spirit, imposed by my little church and neighborhood group. I have reveled in certain features of city life, such as libraries, lectures, theaters, and my neighbor's indifference. My daydreams have all been concerned with further education and travel, particularly a long and leisurely trip through Norway. Nothing has happened to change the course of my life so plainly marked. The death of my mother meant the death of the spontaneous joy that was mine in childhood. I had my invalid brother to plan and work for; my whole future was planned to include better care for him. I have never been able to laugh in sheer abandon since his death ten years ago, and the death two years later of the dear aunt who mothered us. As I look back over these years, I realize I have lost money through 
mistaken charity, and have injured my health by overwork. By my preoccupation with work, I have lost my desire and the capacity to enter into social life.

I have experienced few conflicts in accommodating myself to conditions in America. When I was a little girl, I kept away from one American girl who was the daughter of the ex-governor, the richest man in town. I wore a pair of brown stockings which mother had knit for me as a Christmas present. All the other girls wore black and this girl made fun of my non-conformist hosiery. Murder being out of the question, I just hated her - none too silently. I have always been glad I had the grace not to let my mother know I wasn't happy in those stockings. Mother did not fully appreciate conditions in America, and did not realize what it meant to the child of an immigrant to have an American child make fun of her clothes.

Since I had to do the cooking and dishwashing, I included the Norse idea of five meals a day in my ridicule. While I was doing chores, it was hard work and no joking matter. I have made sport of the Norwegian's theoretical hatred of the Swede and his naïve assumption that a Norseman is the salt of the earth and the savor thereof. As I grew older, I found that Norsemen did not have a monopoly on this. I have in the past derided the parochial view of my church group, but now I think I can make some allowances. At times I have felt embarrassed by the behavior and language of some of the older people of my racial group. One time I took a short trip with an older friend and was very much embarrassed by her broken English. I used to be very much interested in the immigrants from Norway, who drifted into our village. My interest was due to the fact that they came "bearing gifts," or brought news from our relatives in Norway. The time was when I felt more closely drawn to these immigrants than to the Americans, but that day is past; I have been away from real immigrants so long I think they would seem just a little alien.

I read, write, and speak Norwegian, and that gives me a reading acquaintance with Swedish. I used Norse interchangeably with English until I came West. In fact, most of us "bilinguals" spoke English supplemented by any good Norwegian word we thought would lend emphasis. It has been a real inhibition to have to confine myself within the purlieus of one language, particularly during periods of stress and strain. The knowledge of this language has been of inestimable value to me, for through it I have access to another 
literature and culture. Furthermore, I could never have gotten along in North Dakota without it, as it was the common language of the village of my childhood. Even now I worship in Norse. Being a pedestrian, I engage in frequent involuntary prayers as I roam around, and "instinctively" I think them in Norwegian.

Sometimes I am proud of Norway, and sometimes I despise her, as I did when, for economic reasons, she took a backward step and repealed the prohibition law. I hate national conscience ruled by the pocketbook. The success of Norwegians in the field of literature and exploration thrills me deeply.

The church dominated my life for the first twenty years. My church group was almost entirely Norse, with the exception of one Swedish and one Danish family. I was most interested in sermons on controversial subjects, but most in Sunday School, as I was a teacher from my eleventh year on. I was least interested in father's street evangelism and jail meetings; these embarrassed me beyond words. The Norwegian Baptist Church still meets most of my needs. Its intense moral earnestness, simplicity in service, and insistence upon the spiritual as the highest values always serve as a tonic. I sometimes detect a suspicion of intolerance toward new truth, and this troubles me. As regards the church and other institutions, there is no use in throwing away the old culture completely until another has been investigated. Traits of culture should be carefully selected and rejected.

I have experienced little conflict with my language group. Mother spoke Norse, we spoke English, but that was all right; so did most of the other families. At times I have felt hampered by the direct sermonizing I have had to endure when I failed to conform to the standards of my group. Although members of my language group appear narrow in a number of respects, they seem to think that every one is entitled to all the freedom one can use properly. They recognize the authority of the government and of God, but their God is a fussy one who bothers about very minute details. The only time that I really lost status and experienced a violent conflict was when I became engaged to an Italian Catholic. To my surprise, I found that my group was right - my fiancé's habit of thought and mine were poles apart and utterly irreconcilable. He accepted authority in religion, in politics, in economics, and in love; while I am from Missouri and must have demonstrable reasons for the faith that is in me. The Americanborn children of my language group seem to have little difficulty in 
making adjustments to American life. My solution to the problems that confront us of the second generation is a vital education, and an attempt to make fast the values we inherit from both sides of the Atlantic. Our great problem is to retain what is of worth in our Norse heritage and to fit this into our American environment.

\section{BELGIAN}

\section{Trying to Take His Place as a Real American}

I was born in Belgium in the city of Antwerp, and spent three years of my Belgian life in a small town near this city. My father was working in the coal mines near by at the time of my birth. He later shoveled coal into the fires on an oil ship, and still later learned the trade of making cigars. The only education my parents had was secured in grammar school. Both being members of large families, they were forced to go to work early.

Just before the World War a great deal was said in Belgium concerning the opportunities of making money in the United States. Borrowing money from a friend, father came to New Hampshire. He was met by friends and was soon at work in a cigar shop, where he made a sufficient amount of money to pay off his debt and to purchase furniture for a little home. One year later he sent for his family - a wife and three children. One boy was fifteen, another nine, and I, the youngest, three. I am in reality a second generation Belgian.

Our first home seemed good to us; it was a flat in a six-tenement house in the Belgian neighborhood. In many respects it was not so good. There was the disadvantage of hearing only Belgian, with no opportunity to learn English. Every bit of the furniture was really forced on father by a clerk who used this excellent opportunity to unload an old stock on an ignorant immigrant. As a result we had a conglomeration of odd pieces of antique furniture which no one else would have.

The time came for me to go to school, and mother, accepting the advice of some friends, sent me to kindergarten. After attending one class, I went home and told mother how the other children had made fun of me. That was the last of the kindergarten for me. A year later I entered the primary school, but I was slow in learning. That was not entirely my fault, as my parents could not speak a word of English. My knowledge of the language was very little better. The 
children did not know just how hard it was for me and laughed at every word I uttered. Needless to say, it was a weird combination of Belgian and English. Finally my parents decided to send me to a special-help class where I made more progress. My teacher seemed to realize my difficulty and, having a small class, could devote more attention to me. Many words troubled me, such as rough. One time I was sent to the store for vinegar. I knew the Belgian word for vinegar, but not the English; the clerk could not understand what I wanted. Then a brilliant idea struck me. Knowing that vinegar was sour, I told him onions in a bottle. Well, I never got what I was sent after.

Our contacts in school and at the homes of our new friends brought many changes into our Belgian home. Our customs were brought into contrast with those of our English-speaking acquaintances. Our meals were different; we had a little of everything at one time - a quarter pound of ham, a little tongue, a little sausage, etc. Dinner consisted of a large saucer of soup, followed by meat and potatoes served in the same saucer. We no longer follow this routine at the table. Dad finally decided to move away from the Belgian district in order to give us more opportunities. Life among Belgians is hard; they want to prosper, but they don't know how to go about it. Then too, the Belgian people tend to cling to the Belgian customs and habits. One is forced to talk Belgian from morning till night if one stays in the Belgian quarter. The factories are manned with Belgians for the most part. Seldom does a Belgian associate with any one except his own people. The children grow up embodying the culture of their parents. It was such conditions as these that my father wished to leave behind.

My brother wanted me sent away to school at the end of my first year in high school, but money was lacking, as father still had some debts to meet. I began working by selling and tailoring while in high school. In my last year at high school, I earned around sixteen dollars a week. My line of work brought me into contact with the "four hundred." They were surprised to see a fellow in his junior year selling tailor-made clothing. The necessity of working robbed me of real boyhood days; I was made a grown-up before my time. I had to jump from the place of a youngster to that of a sophisticated young man. Another factor helped to push the behavior pattern of maturity upon me; I was not given the opportunity to dance or have any pleasures as my parents had the remote idea that I must not stay 
out later than eleven o'clock. Changes are taking place, however, at home. My sister now attends school dances with one of the high school boys. Even my parents have attended some of the social functions, and have come in contact with the teachers. They are gradually learning to manage the English language. None of these social events can take the place of my father's beer. From youth on, the Belgian drinks beer; but prohibition has taken this one great pleasure from him. The laws are given constant consideration and we abide by them, but it is hard for the older Belgians to give up their beer.

Some young people of native American parentage feel that they are better than I am. This is shown in their attitude toward me, and is met by my inclination to associate with those who are more congenial. I am proud of my nationality as every one should be; but if I can avoid talking about nationality at a social function, I do so. I have been embarrassed time and again by people of my language group. They are very loud in their speech. One time I was at a dance with a girl who is on a higher social plane than I am as far as financial connections go. A certain person rushed over and said a few words in my native tongue. I don't know just what the girl thought of me, for he had neither manners nor intelligence. She never knew my nationality before that occasion. When I was a youngster I wanted my relatives from Belgium to come over, and could see no reason why my brothers should object. Now I realize it would cause the family to become disorganized again. Should they come, it would be necessary to pay some attention to them, but so far as I am personally concerned it would be precious little. I dislike to speak the language, and worse to have my parents speak it when I take them to a theater. Every one stares when the foreign language is not Greek, Italian, or Jewish. Although I am a member of a country club, a social fraternity, and other organizations, very few people know my nationality.

We have practically nothing to do with the church. Many people in my home city have asked father why we do not attend church and suggested that being born Catholics, we should take an interest in church (Belgians are born into the Catholic Church). My father replies by saying that he did not believe in the church in the old country and conformed only through compulsion. As mother shares a similar attitude, we have been brought up not to attend church. In the old country a person not a member of the church was looked down upon by the community. It would be impossible to secure ems 
ployment if a person did not belong. As the church never impressed us in Belgium nor in America, we were free to do as we wished in regard to our religion. And we wished not to attend.

Although broad in their views of religion, my parents retain many old ideas. I often feel relieved when I get away from home. If I knew that I could get them to see both sides of a question instead of only one, I could have more patience with them; but that seems impossible. When such crises arise, I wish they were native-born; for then they would not have to go through these conflicts and processes of adjustment, and I would be spared the pain of witnessing their disorganization. Even as it is, they are much better off here than they would be in Belgium. Life in the United States cannot be compared with that in Europe. The middle class can compare with the highest class on that continent, financially speaking. Nevertheless, my father talks continuously of going back to his native soil. When I see how hard it is for my grandparents to get along in Europe, I am more than ever thankful that father brought me over here.

As far as my nationality goes, I do not think it will hinder me much in the United States. The American people as a whole will help one get along if things go right. Although I can never be president of the United States, I can fill other positions open to me. I may visit Belgium in 1933, but I am sure that I could never remain permanently. Because United States money is worth so much in Belgium and living is so cheap, father thinks he could live the rest of his life on $\$ 12,000$. I simply could not live there because Belgian culture is so far behind ours, and I have been brought up under altogether different environmental conditions. Father, believing that a person who starts to work early will always keep it up, has insisted on a college education for us. Therefore, we are going to college and are trying to take our places as real Americans.

\section{Lithuanian}

\section{Embarrassed by the Lithuanian Customs of His Parents}

I do not know much about my grandfather except that he left a large family and an estate consisting of a farm, some animals, and $\$ 60$ in cash. Conditions were anything but desirable in that country at that period. Lithuanians were subject to the rule and teachings of the Czar. Children could be taught only in the Russian language, and houses and neighborhoods were spied upon to see that the order was obeyed. Those disobeying were flogged and otherwise mistreated. 
Father never attended school, but learned to speak Lithuanian as well as the required Russian. Later he added Polish and English. While he lacks a formal education, he learned a great deal from his early experiences in his native land. At the age of six he began herding cattle. At daybreak he would take the cattle to pasture, returning at sunset. His lunch consisted of half a loaf of rye bread with some vegetables, and of meat only on rare occasions. Like the other herd boys, he often climbed trees for birds and bird eggs, which he fried. At night he slept on a bed of straw in a corner of the house during warm weather, and on top of the huge fireplace in winter. Wooden bowls and wooden spoons were used for table service. The entire family sat around a large rough table and all ate from the same bowl. Pork and white bread were considered a great treat. On Sunday the family rose early in order to reach church for mass. Father, however, now has none too much confidence in the priests of his church. He believes that their chief aim is to deprive their parishioners of their last cent. His ideal priest is one who holds mass barefooted and shows signs of having undergone some forms of hardship. Doubtless he was more interested in bull fights than these long drives to early mass. It was the custom of my grandfather to let his bull go against one of some neighbor. The animal with the sharpest horns usually won, and the scene was one of horrid bloodshed. Homes were leagues apart, and the means of communication were all but nil. The family circle by the fireplace was very common; it was the general meeting place for family and visitors. There were no places to visit near at hand. It was such political, economic, and social conditions that my father sought to escape by coming to America. In his own words, he came "in search of peace and a better living."

Three years after my father came to this country, I was born. My father and mother were both mill operatives, earning about six dollars each per week. My mother was accustomed to hard labor; Lithuanian women have to work on practically the same footing as men. They work on the farm, about the house, or wherever they are needed. Mother's educational advantages were the same as those of my father - group talks and farm work. My parents have made several changes of residence in the New Hampshire town in which they located. Each change has been for economic and social reasons. Finally father bought a three-tenement house with a huge barn in the rear. This barn he remodeled into a nine-car garage, which he rented to the employees of a shoe shop near by. With this and the 
rent from the two tenements, he was able to meet most of his bills, and thus save some money each week to place in the bank.

At the age of six I was placed in school and there remained through high school, but without much interest in the pursuit of knowledge. In high school, however, I did become somewhat interested in Latin, chiefly because I made good marks, and thus gained a certain prestige. My parents were interested in my public performances in plays and choirs. I acted many short parts in Lithuanian plays. Father forced me to take piano lessons for four years, but I regret to say I cannot play the fundamental scales now. While in high school, I worked in a neighboring shoe shop in the afternoons for five dollars a week, and went to camp in the summer. I did not care to finish the fourth year, but father thought otherwise.

Meanwhile my parents saw to it that I was making some progress with the Lithuanian language. Whenever possible, they tried to teach me the language, customs, and traditions of my people. Often I have been embarrassed by my Lithuanian heritage. Being a "Lit" hindered me at high school. Often I burned with humiliation on occasions when my people were in the presence of a group of Englishspeaking people. My mother used her hands freely when she spoke. Often I went shopping with her and was always sorely chagrined when she pointed to an article she admired with awkward gestures, and expressed her opinion of it in a rising voice. Of course I suggested that she should not do so and so, but I have passed this stage now. But whatever cultural differences or failings my parents may have, they have ever held high ideals for me. It is their wish that I study medicine and become a surgeon. They have worked hard for me, and I only hope that I can repay them some day during their lifetime.

With such a big ambition for me, my parents have not been in sympathy with many of my diversions from the chosen path. During my early years I was interested in collecting pictures and copying them, but I had to do this on the sly, as they continually told me to pay more attention to my school books and to their language. Although they advised me to study English as well as Lithuanian, we spoke Lithuanian at home. I was very much interested in sports and left my studies to play; the results were many spankings. At the age of fourteen, they sent me to work in a shoe shop. I did not mind the work, but I did resent having only twenty-five cents a week for spending money. I totally disliked to be kept under such restriction. 
and as a proof of my independence I broke away as much as possible from their teachings.

My folks have worked hard to rear and educate their children and at the same time to accumulate some savings. They, however, are not too well pleased with America. They believe there is no country like Lithuania. They have often told me that the atmosphere, the soil, the water, and the food could in no way compare with these things in their native land. Father claims that the natives of this country are weaklings, whereas those in Lithuania are all brawny, strong individuals capable of enduring hardships. I have pointed out the fact that possibly parts of this country could compare to Lithuania. He has promised to take us for a short visit. I certainly would like to see the land I have heard so highly praised.

For my part I have been none too well pleased with Lithuanian families who live on farms near by. The women are shabby and dirty in appearance, some barefooted. I presume that there were too many bills on hand to spend money on shoes and clothes. Furthermore, there were about three or four youngsters running around to be cared for. There was a difference, however, where the family had children in high school. They were more prosperous and more at ease from the looks of the clothes and footwear. While I am of the opinion that women in America are allowed too much freedom and that women should not in any way approach the status of men, I do not admire many Lithuanian women in America. In Lithuania they are restricted to the kitchen and to obedience to their maintainers. I never heard of a Lithuanian woman mentioned for her achievements in public life.

While my parents are not typically Lithuanian, they have maintained much of their Lithuanian culture and come in contact with Lithuanian traits among their neighbors. At the table mother uses no knife or fork to pick out each piece of meat except in slicing enough for a handful. She changes these tactics slightly, however, whenever visitors are present. Having been accustomed to a single large bowl in Lithuania, she cannot seem to place enough plates on the table at the beginning of the meal. Dozens of times either she or some one else must get up to secure the missing articles. No "pardon" or "excuse me" is ever offered. To a small extent my sisters retain these characteristics. No one rises when a member leaves a group. Whistling is forbidden by my parents on the ground that it brings unhappiness in later life. Reading at meals is outlawed, as the per- 
son of such habits acquires a weak memory and finds difficulty in memorizing. Singing and whistling when in an automobile are also on the black-list. They say the present happiness is certain to bring bad luck before the trip is over.

My parents have never told me anything about sex relations. Their earliest story was that I came from a stork, but later it was modified to the extent that I was fished out of a pool. I used to wonder what kind of fish hooks they used. I did, however, learn much about sex relations from the older boys.

I have been to several funerals among my people, the Lithuanians, and have found them very interesting regardless of the sorrow that is brought to the family and relatives of the deceased person. In all cases, I have noted to some extent the customs employed. I believe that it is best for me to describe the funeral that I went to rather recently as a typical example.

A Lithuanian boy, age 17, had died, and I was asked to be one of the pall-bearers along with five other fellows. As customary, we carried our dead friend to church where services and final rites were said for him. We then laid him at rest in a little cemetery known as the St. C- Cemetery, a few miles from the city. After this solemn performance, the parents of the deceased invited us along with others that participated in the funeral to their home. On our arrival at the home, we found the table laden with food, plates, and drinks of all kinds. There was tonic, beer, beet-wine, and a bottle of whiskey (or booze) on the table. The food consisted mostly of cold meat, such as salami, pressed ham, boiled ham, along with both white and dark bread.

We sat down around the table - some of us forced to, others voluntarily - and started eating. Each of us drank about a bottle of beer and a couple of glasses of tonic, when the father of the dead boy came in and started to pass the booze around. He took the first drink and passed it along as far as it could go. It was emptied just beyond us and refilled again and again until I believe I had about four glasses of it in me and also a stomach full of food. All of us had a slight edge on at that time and we decided to go out. As we reached the door, the father enticed us to take another "hooker" before going, agreeing that it would be our last. So, naturally, we took our last swallow and bade farewell to the father and mother, and left our deepest regrets for the loss of their son.

I cannot say how long this post-funeral reception lasted or how 
much drinking went on after I left. Of course the housework was done by friends. Friends and relatives remain till late in the day on the occasion of funerals. The corpse is seldom ever left alone in a room of the house during the three days that the coffin is kept at the house. Father and mother spent one night at the home of this boy, I recall. Whenever a person dies, the room in which the coffin is kept is closely examined to make sure that the pictures and mirrors are covered with cloth or turned back side front. I do not know why this is done, but it is evidently the survival of some ancient superstition.

My parents often speak offensively of the Poles, who have taken as much territory from Lithuania as possible. They fear these Poles have intercepted letters to Lithuanians. In fact, they tell stories to the effect that Poles have inspected the contents of mail before it reached its destination. The Lithuanian hatred of this group is due to the suffering that they have undergone at the hands of the Poles. My people, and I as well, dislike to be called "Polacks." But to most people "Lit," "Jugo," and "Polack" are all one and the same. Whenever such a confusion is made, father immediately puts the person responsible as being very ignorant. I believe my parents feel, just as I do, that to be a Lithuanian is much better than to be a Pole. Here in America my people appear to have no prejudice toward members of this national group; this hatred is reserved for the Poles in Poland, and is due to Polish oppression of Lithuanians.

Newly arrived immigrants from the native land of my parents do not interest me unless they are relatives. I would regard them as "greenhorns." My American acquaintances are of more interest than those from the native land of my parents. Why shouldn't they be? Am I not a citizen of America, born and bred here? I do, however, like to talk in Lithuanian to a Lithuanian about Lithuania or daily occurrences. I never read any books about my parents' country, but expect to in the near future.

\section{QUESTIONS}

1. Describe the home conditions in the native country of the Belgian's (number 5) parents, showing how these probably influenced his American home. What Lithuanian culture traits were retained in the home (number 6$)^{\circ}$ ? In what respects could these young men be said to be living in two culture worlds?

2. Why does the Norwegian girl (number 4) say her section "might very properly be called "New Norway"'? Why did the German girl's 
(number 3) parents move to German communities? Discuss the disadvantages of such communities upon the second generation.

3. Show how American culture traits crept into the new homes on this side.

4. Pick out quotations showing conflicts resulting from two languages.

5. How does the English lady's (number 1) idea of schools differ from that of her mother? Why is the native language school not so important with Teutonic as with other immigrants?

6. In what respects do parents and second generation children differ in regard to occupations and professions (see numbers 2 and 4 )?

7. How did the Norwegian (number 4), the Germans (numbers 2 and 3), and the Belgian (number 5) find themselves handicapped socially?

8. Account for the strength of religious teaching in some of the homes and the indifference in the others.

9. In what respects is disorganization evident in the family life of these people? How much of this is due to foreign influences? To personality problems?

10. What examples of a feeling of lowered status do we find?

11. How has the English lady (number 1) reorganized her attitudes and behaviour to maintain harmony with her family? The German (number 2)?

12. Taking these six cases, pick out (1) the points upon which the second generation are not yet assimilated; (2) those upon which they are assimilated. How do the education, religion, and status of the parents retard and influence the assimilation of the second generation? 


\section{CHAPTER XXXVIII}

\section{LIFE HISTORIES OF LATIN SECOND GENERATION AMERICANS}

\section{Portuguese-Scotch}

\section{Little Influence by a Strange Racial Mixture}

I was born in California and have spent most of my life there. My father was a riding master, and was born in the Azores (Portugal). He attended a Catholic school, reaching the equivalent of our eighth grade. He, however, was able to speak several languages. Having broken away from this church, he felt very bitter toward his early educational experiences. Mother was born of Seotch parents in eastern Quebec. She reached the tenth grade. My parents sent my sister and me to private schools and gave us all kinds of indulgences. We were very well contented with our lot, due probably to a dash of Latin disposition. Father did not exactly approve of higher education for girls, but the "Scotch" in the family won out, and we became professional - sister a nurse and I a teacher.

My occupation has been the same since the beginning. Once I was forced to resign on account of my religion. The president of the board of trustees, being a Presbyterian minister, discovered that I was a Unitarian, "not fit to teach the young." Next year I was told I need not plan to come back. I have often been asked if I am a Catholic, due, I suppose, to my Latin name. No difficulties have oecurred on account of my race. I sometimes feel my attitude toward those of other races and my own treatment by full Americans were engendered in the nature of my native city. There being no foreigners there, we were treated quite well. In fact, the literary and artists' colonies are very anxious to take the foreigner "in."

My sister and I are going this summer to Europe for four months, but not to look up relatives. Only the older people are left, and they speak no English, only Gaelic. Besides, I doubt if these relatives know we exist - so complete was the break my parents made with the old country. I remember father used to strive to impress on immigrants how Americanized we had become. He was so eager to 
hasten the process that he refused to teach us his language. Mother fast forgot hers. Father did not speak English till he was twenty-two years old, and mother was ten. As neither knew the language of the other, it was an absolute necessity that English should be the language of our home. I have always felt a pride in the adventures of the Portuguese and the history of the Scotch Highlanders. My acquaintances, however, have always been Americans.

As my father was Catholic and my mother Protestant, my sister and I had our choice of going to any church we desired, but we had to go somewhere. I went to the Methodist two months, the Episcopal a year and a half (longer on account of the singing which I enjoyed greatly), Presbyterian one year, and finally wound up by being a Unitarian. So far the last named meets my needs in the religious realm.

My American-born relatives on my father's side have been very thrifty ranchers. All the first generation born here have gone through high school, and several through college, and all of the second generation born in this country upon attaining the right age have gone to college. One cousin, named Miller (de Mello in the old country), sent his four children partially through high school and he has been practically shunned by the rest for his non-progressive attitude toward education. Some of the relatives, I hear, blame it on his Italian wife.

The adjustment on my maternal side has not been necessarily very great. The Scotch think they are so great, anyway, that they don't need any adjusting to American ideas and ideals. I think the reason for my father's rapid Americanization was due to this isolation from any foreign colony.

\section{French}

\section{Born of French Parents; Otherwise a Full-Fledged American}

I was born and lived for eighteen years in a little town on the shores of Lake Superior, in northern Michigan. Finns, Swedes, English, French, Italians, Poles, Germans, and representatives from other races of Europe made up the inhabitants of this town. Most of them were either miners or woodsmen. Most of my early life was spent with people of this class, people working hard to get ahead. I chummed around with the children of many families, principally with Finnish lads.

My people are of French descent. Father married in Europe, and 
spent some time traveling in Africa and Europe before coming to this country. While in the "Dark continent" he followed many occupations, such as picking cocoanuts and working in the mines with the natives. Returning to Europe, he traveled as a tinsmith - a trade at which he is still very handy. His folks were very poor and were accustomed to getting along with very little. As a result, he never attended school for a single term. Wishing to get away from such conditions, he left my grandmother, my mother, and my brother and came to the United States. Mother too was accustomed to poverty, her father having died when she was rather young. Both came to America from similar backgrounds, and with similar determinations to succeed.

Father came ahead of mother. From New York he went to Illinois, where he had relatives. He worked in the coal mines for fifty cents per day. After a short time he came to Michigan. Even though his salary was very low, he saved enough to purchase transportation for my mother. As his mother had inherited a small estate, she did not wish to leave it. Often he sent her a few dollars so that she could buy a loaf of white bread or sugar for special occasions. This little estate she left to father at her death; he was her only relative.

During the first years father and mother suffered more in America than they ever had in Europe. All the mines in upper Michigan and Wisconsin were closed, and many of the people suffered from want of food and clothes, as the winters were very severe. These experiences were undergone during the Democratic administration of Cleveland, and were responsible for the political affiliations of my parents. They told us time and time again to avoid the Democratic party. This explains why, up to the present, upper Michigan has been a strong Republican fortress. Up to President Wilson's term, they feared a return of the evil days.

After coming to America mother opened a boarding and rooming house for some twenty miners, while father worked in the mines. It took work to feed, launder and mend clothing, for that many men, besides keeping several cows, many chickens and pigs, cultivating a garden, and on top of all this being responsible for an ever increasing family of children. It was during this period that I was born, and before me two brothers and one sister. After me came three more brothers and another sister. My parents continued to slave for some years to raise their family and provide for the future. After many years of hard labor, they gave up their hard work, and with combined 
resources opened a small store. The business is well known today, although father has retired and turned it over to his children. I am, however, an inactive partner. I could never get interested; somehow the charge-credit system did not appeal to my business sense.

Although our parents had little educational opportunities, they insisted that we attend public school every day that it was in session. I found, and still find, difficulty with my college work because of my poor foundation. I imagine most of the teachers who came to our little mining town were from the city and thought anything good enough for us children of miners. I doubt if they ever thought any of us would attend school elsewhere. All my expenses were borne by my parents; during my four years at college they never denied me anything.

Both my parents were brought up as Catholics and compelled us to attend church while we were young, but as we grew up, they allowed us to stay away if we chose. They themselves never broke faith with the Catholic Church, but I am sure that they do not approve of all that it does or stands for. We, consequently, have had religious freedom, and several of us have never affiliated with any religious denomination.

During my high school days, I became bored and dissatisfied with life in general. I entered the university without the least idea of what I would make of myself. This matter was never discussed at home, as my parents had no idea I cared to enter college. In college I found interests; in science I found something to work toward, and by association I gained much from the arguments on politics, religion, and the like. All through college and since, I cannot see where I have been handicapped because of race or foreign parentage. I have never been questioned about my ancestry, and have never talked about it. Being born an American and having been brought up to respect America, I have not the slightest inclination to be anything else. With the folks, their mind still lingers in the memories of the past, but they too have become loyal Americans, as is proved by the fact that father became a citizen shortly after his arrival. They have no desire or intention of leaving America. Again I say that I cannot see, in my case, that I have ever felt different from any other person born of full-blooded (as possible) Americans. I was brought up in an American community and taught to respect its laws, its schools, and other institutions. America is the same to me as if my whole family tree had originated here. 


\section{ITALIAN}

\section{An American in All Respects, Except in Blood}

A small town in the foothills of the White Mountains of New Hampshire acclaims me as a native son. My mud-throwing, windowbreaking, and shoe-wearing days were in this unfortunate town. To this place my father immigrated from Italy at the age of seventeen. He had attended grammar school in his native country and had worked himself through a cutting and designing school. At present he is head of a prospering business, a deacon of the town's Congregational Church, and treasurer of the local Rotary Club. Mother was also born in Italy, coming to America at the age of four. She is a high school graduate.

I, being more or less a prodigy, or so considered by my fond parents, was sent to school at four. Studies came easily and I finished in ordinary time and went to a couple of preparatory schools to be better prepared for college. Such a foolish idea! I was already developed mentally beyond my age, and, being not well developed physically, found myself left out of boys' games. This made me shy and out of place. Although I went in for sports and achieved success, my schoolmates' first impressions did not seem to change. Every once in a while some one of them would call me a "Wop." At first I fought them, only to receive the worst of the conflict nine times out of ten. Under the circumstances, I gradually reverted to silence. As I grew older I began to realize the heritage that was mine, and I pitied the poor fools who attempted to hurt my feelings. Even now though, it hurts when some one uses the expression. Sometimes I feel positive hatred for the poor class of Italians who are responsible for the general low estimation of the race.

Father wished me to speak the Italian tongue, but mother, being more thoroughly Americanized, did not share his desire. I learned to understand it fairly well, but not to speak it. To my knowledge I was denied nothing I desired. Intellectually, however, I desired something I could not get at home - the constant use of the English tongue in the most correct manner. I had to rely on school and outside contacts for that.

As my father was broad-minded, he, even in my earliest years, told me to pick the profession I desired. This attitude was really extraordinary in view of the fact that most of the boys that I knew who were sons of Italian immigrants were practically forced into their fathers' 
trades. Indirectly, I trace my yearning for a literary life to my Italian parentage. One summer I sold subscriptions; this was the most revealing occupation one can imagine. I saw life almost at its worst and learned considerable psychology of human beings besides. Another summer I was a bell-boy in a hotel, again learning to gauge people for their worth. I resented the superior attitude of many guests, who were no better than the bell-boys. Another summer I broke up with several jobs. I worked for a time in a factory, whose force was made up entirely of Poles and Lits. Although they were comparatively ignorant, I learned to admire their industriousness and cheerful outlook in America, the land of opportunity.

All close branches of my parents' families are here in America. I do not plan to visit the native land of my parents. Mussolini has passed an idiotic law which considers all foreign-born Italians, one generation removed, still under the jurisdiction of Italy. That means if I go to Italy before I am forty-five years old, I shall have to serve two years in the Italian army. Is that right? NO! What do I owe Italy that should compel me to waste two years of my life for her benefit, and even possibly die? Whatever affection I may have had for Italy as a country disappeared with that avaricious law.

My closest friends have always been Americans. In college I became a member of a social fraternity that excluded all but Protestants. The fact that I am not Catholic has gone a long way toward throwing me in with Americans only. I have never wished my parents were of another race, but they have hurt me beyond words. I have brought friends of mine to visit or have a meal with me. My parents are always genial enough, but they often address each other in Italian, which of course is not understandable to guests. They feel at sea, and I feel even more embarrassed. I have had a great deal of trouble with my parents, the basic reason being domestic inharmony between them. It has proved unhappy for every one. They are never settled. Arguments break out frequently. I prefer to be away when the storm breaks. I am relieved to be away. It isn't really a home as far as happiness goes. Nothing is lacking in the way of finances or comfort, but I hate the parental squabbles, the eternal fighting.

I have never been subjected to contact with newly arrived immigrants. I have nothing in common with them, I feel, however, a pride in the heritage that is mine. I am glad that I am what I am in intellect and soul. But as a person, I am American in customs and manners. I have often wished my parents had been born in America, 
for I would be more truly an American in that I would have a more Americanized background. But for my own part, I feel that I am an American in all respects, except blood. I account for my degree of Americanization as due to my environment. A group in the East Side of New York would be rather enmeshed in its own race; whereas, a person living in a small democratic town (as my birthplace) would be free to develop as and with the native Yankees.

\section{ITALIAN \\ Of the United States, But Identified with Italo-Americans}

I was born of Italian parents in Pennsylvania, about twenty years ago. Both my father and mother came from the middle class. Father had a fair Italian education, in addition to his American training. On the other hand, my mother had no education save experience in household duties, which were emphasized above all else in her station of life. Father started on his adventure in life by building houses and aiding the coming Italian immigrants, and, in a short time, became a builder, interpreter at court, a community counselor, getting the poor ignorant Italian immigrants out of various difficulties.

The nationality of my parents has doubtless played a prominent part in my life. I cannot say that I have been the victim of bitter difficulties on account of my Italian ancestry, but I have experienced slight annoyances and prejudices on account of it. I have thought too much of my nationality and myself to let discrimination hurt me, although I have been annoyed. Certainly, I can trace many desirable qualities to my parents. They taught me respect for my elders, even older sisters and brothers; they gave me their religion; and instilled in me high ethical ideals, or morals, concerning the company of men and the observance of certain social occasions such as spending my holidays, particularly Christmas and Easter, at home. These teachings, I may say, have been Italian, but they have helped me and my relation to society. No effort was made to retain the Italian language, but the utility of a foreign language was constantly stressed.

During my early years I always desired an education, due to the constant encouragement of my father. Having been, and still being, a student, I have spent my spare time in reading books, helping my mother with household duties, nursing sick members of the family, offering aid in interpreting for Italians, doing office work, swimming, playing tennis, attending parties, doing social work, and church work. 
My parents have not always sympathized with my early aspirations, but this lack of sympathy has made me work all the harder. At other times their sympathy has been a great incentive to buckle up and go onward.

Laws discriminating against immigrants have affected me in two ways. Whenever I could see, or can see, that discrimination is produced through prejudice, it makes me angry; but when I understand the utility of such a law, without the prejudice behind it, I accept if for our good - for the good of the people of the United States. Absolute and open discrimination against Italians has had great influence on my attitude and philosophy of life. Such crises have made me, more than ever before, want to show these prejudiced foreigners (for all of us are foreigners) what the Italian means to society. I feel that I should make every effort to uplift the Italian status through setting forth what real Americanism is, and what it demands. I am doing my utmost to demand more consideration for my people who are so entirely different from the Celts, and whose customs are not so easy to become effaced. A consideration of the problems that confront me has resulted in a strong determination to retain my identity as an Italo-American, and not remain isolated from Italian groups, but with them. I have found that as soon as an Italian becomes educated, he immediately claims to be a full American with not a particle of interest in his co-Italo-Americans. This affiliation tends to keep Italianism on the lowest level. How can these people arise from the bowels of the earth, for that is where they are placed in America, unless their educated people remain with them to uplift them?

Whenever I have met Americans of native parentage, who enjoyed and desired my company, I never avoided them. In fact, my best friend, in whom I place absolute confidence, is an American. She is, however, real in character. I have never concealed my feelings in regard to Americans, for I have never expressed them without due consideration and reason.

America, to me, is a land of superiority in comparison with other countries. I would never want to live in any other country. As for Americans, to me, they are entirely separate from America. They are foreigners also; but they have had the utmost advantage in having come from northern Europe to an America awaiting to be saturated with the customs and ideals. As a result people from northern Europe have little difficulty in adjusting themselves, while 
those from southern Europe meet with great difficulties. Generally speaking, Americans ignore and look down upon Latin Americans. They are never taken entirely into the melting pot, and consequently they accumulate in groups along the edge of the American pot. It is not always the fault of the Latin American that he doesn't mix; he is usually never allowed to mix.

Obviously the question arises: "How much of an American am I?" It is impossible to answer in a single sentence. I hope to go some day to Italy for cultural purposes, but I am too much of an American to want to live there permanently. I have read many books about the native land of my parents, but not from any sense of pride because it was their homeland. I am proud of Italy for what she is. I speak Italian whenever the occasion demands, just as I would Spanish or French. In fact, I feel a little proud in being able to use it a little more smoothly and coherently. Of course I realize the handicap of newly arrived immigrants from Italy, and sympathize with them, but my attitude toward them is that of an American, not an Italian. I am more American than Italian, although I am proud of my Italian heritage. I have never wished that my parents belonged to any other racial group, but I have, at times, wished that they were native-born Americans so that our offspring might sooner be called not ItaloAmericans, but Americans - our ultimate aim. My parents do not believe in the total independence of children, and neither do I. We believe that women should be equally free as men, an opinion not shared by other members of our group. The freedom with which Americans discuss love affairs and sentimental matters encourages me, for I am quite prone to speak openly, but intelligently, of these topics. In conclusion, I may sum up by saying that I have never felt I should devote myself wholly to money making, or to the language group of my parents.

American-born children of Italian parents are meeting their problems in different ways. For my part, I have never had more than the ordinary parent-child difficulties with my father and mother. These were usually settled by punishment of some kind. Some of the Italians are saving every penny towards educating their children, while others are doing nothing about the welfare of their offspring. I think that the problems of the second generation can only be solved through education. 


\section{Greek \\ Son of a Notorious Greek Bandit}

My mother and father were Greeks of the poorer class; they were the children of shepherds. My mother's education did not amount to much, and my father didn't have any whatsoever. They lived in Greece during dangerous times. Although Greece had declared her independence, the Turks still meddled in national affairs. They would often enter a village, massacre numerous Greeks, and throw small babies against the wall, killing them instantly. As my father could not stand this terror, he ascended the mountains and stayed there for twenty years, killing Turks right and left. He was considered one of the greatest bandits in Greece, and was sought by the government. Three times he was captured and as many times escaped. Requiring money and provisions, he robbed, but did not kill, his own people. Being such a notorious bandit, two governments tried to take him. Since he could not be captured, my mother, brother, and sister were placed in jail in order to make him surrender. He would sneak down from the mountains and bring money secretly. Finally my mother and her children were released, but too late to save my brother's life. He died soon after being set free, and my father remained as free as ever.

Nevertheless, he realized that conditions could not go on as they had. He assembled the members of his family and started for America. They went from Greece to Italy, crossed the Alps, journeyed to France, and from thence to New York. New Hampshire became their home. America means work in order to survive; consequently father, mother, and sister took advantage of this means of survival. But father did not work long; his environment in the mountains of Greece had made him lazy. He hasn't labored a single day in eighteen years - I think he must have the mountain fever. His anatomy is like that of a horse, but apparently human nature did not adapt him for manual labor. Instead of working for his family, he lives like a king, indeed better than a king or president, off the wages of my mother. He has nothing to worry about, but devotes his time to sleeping, drinking, and smoking cigarettes.

My mother saw to it that I attended school. First I went to a Greek grammar school. When this school building was destroyed, I went to the American school. I learned the English language and also adopted American customs. My brother (my sister had died, twins 
had been born, and one of these had died) and I spoke English at home, but as our parents objected to the foreign language in the home, we had to confine our conversations at home to Greek, and reserve our newly acquired language for the outside world. When I graduated from high school, I made preparations to go to work and help mother support the family, but to my astonishment she objected. She insisted that I go to college. I could not agree. I could not see how she could support a family of four, one of whom would be in college. Besides, I recognized myself as only an average student, and frankly speaking was afraid to attempt to do college work. Since she was so determined, I told her I would take the medical course. This she opposed on the grounds that it would require too much money and that a doctor did not amount to much. Instead she set her heart on making a teacher out of me. I tried to reason with her, pointing out that there was no money in teaching - certainly not enough to support myself plus the family. She didn't like my attitude, and to please her I tried a teachers' course at our state university for one term. At the end of this time I went home and told her that I did not like this course, and would not return unless she permitted me to change my course. We had a great argument. I again tried to show her that there would not be enough money, that I could not help her. She hotly declared that she could support herself and did not want me to consider her. I then tried another argument. I pointed out that being so distinctly foreign appearing, I could not secure a position; they would all be given to pure Americans. I showed her that in a profession I wouldn't have to worry about Americans as I would be my own boss. I never convinced her, but we compromised on dentistry. Now I am working toward that profession, hoping to be able sometime to support my parents.

During all these years she has never received more than $\$ 15$ per week in the mills. She is the most economical woman I ever saw. She has never sent her laundry out, never goes to the movies, always knits and makes all the clothes, underwear, and stockings, and sells to neighbors things she makes at home. As soon as she comes in from the mill, she goes right to work. She is not lazy like my father and brother. My father always liked my brother because of a fancied resemblance to himself. He gave him money, clothes, and everything he wanted, and treated him with overindulgence. My brother's ambition was killed, and after being expelled from school, 
he refused to work, knowing he could get anything he wanted out of his father. Today father sees his mistake, but too late - my brother is spoiled; in fact he is nothing but a bum. As a child he was never corrected; father prevented mother from even spanking him. I, on the other hand, was brought up by my mother to obey her explicitly. Thank God for this upbringing. All during my school days I worked at whatever I could find to do. She took my money and placed it in the bank for me, using her own to support her lazy and idle family. For all that she has done for me, I am eternally grateful. To me she is the most wonderful woman in the world. When I get through college I will do anything in the world for her; I am willing to sacrifice my life just for my beloved mother.

\section{Greek}

\section{Desire for Recreation Stronger Than the Walls of Any Church}

In 1909 I was born in a small village of Greece, situated in a mountainous and God-forsaken part of the country. I can barely remember the day I landed in the United States. My father was one of the earliest Greek immigrants to the United States, having come in 1903. Four years later he returned and married my mother, but knowing there was no opportunity in Greece, returned to America alone. Father had secured a grammar school education in his home town but mother had never attended school, as public schools at that time were closed to women. It was believed that women needed no education.

At first my father had worked in textile factories in Massachusetts, but finding life in factories unbearable, he settled on a farm where sunshine and fresh air prevailed in abundance. It was to a New Hampshire farm that mother and I came to make our home. There I remained outside English contacts until school opened in the fall. I shall never forget the first few weeks; I was unable to speak a word of English, and my teacher was unable to understand a word of Greek. I was given games to play until I automatically learned to make myself understood. In a few months I was rattling off the English language fluently. The boys, all native-born, kept making fun of me, because I could not answer back. About two years later, after having gained some experience in American fist fights, I made myself recognized as an equal. Then bye-gones became bye-gones. I was then a friend to all and was treated as such by all. All our 
neighbors were from the beginning Americans; therefore, I was acquainted only with American school boys and girls and grew up in total ignorance of life as it exists in Greek sections.

My first contacts with boys of my own race came when father conceived the idea of sending me to a Greek school to learn the language of our forefathers. Thus at the age of twelve my troubles began. I liked not the school nor the students, who were native-born Greeks, while I was foreign-born. I was forced to continue this ordeal of torture from four till six each school day until I finished grammar school. Although I was sure I had sufficient schooling, father insisted I enter high school. After lengthy arguments, he won, and four years later I found myself in possession of a high school diploma. I was now eighteen and a "big shot" in my own estimation. For the first time my father gave me the choice of going to work or to college. I chose the latter. As I commute from home, I have never been able to take much part in sports or other campus activities. My spare time I spend working on the farm. Father has never sent me off to work for wages in order to supplement the family income. I have always been my own boss as I work.

I, knowing so little of Greece or the life as it exists there, have no intention of returning to the country I left when a mere baby. In fact, I am prejudiced against Greeks in America because they fail to adopt American customs. I sincerely believe that every immigrant, whatever his nationality may be, should not settle in a district with his kinsmen, but should distribute himself separately. Immigrants would then adopt American culture easily and painlessly, and would relieve the necessity for slums and unbearable sights. On the other hand, I have nothing to be ashamed of, because my nationality has contributed to the world just as much as any Irish or English-born Americans. Although I was forced to learn Greek, I am now glad I can use it. The only time that my brothers and I employ this language is in speaking to our parents. It is impossible to hear it outside. I often think that the Greek language will pass out in a few generations. When I consider everything, I find my leaning strong toward America. No American-born, or cultured, person could settle down in a country like Greece where such a low plane of living exists.

When I was a child I attended ehurch regularly. Now that I have a clear understanding of the meaning of the word "religion," I seldom go to church more than once a year. There are many customs in the 
Greek Church which should be done away with by now. But the old generation is bound to observe these old customs, and so long as they are in power, no improvement can be made. I can see no reason why a person should attend an American church. After all, there is no distinct American church. The Episcopal is very similar to the Greek Orthodox. I have attended both Protestant and Catholic churches, and I fail to see any special merits of any church. It has been a custom to exclude seats in the Greek Church. It is generally believed that a person goes to church for the purpose of salvation and should stand up and keep his mind on the Lord his Savior, not sit down and fall asleep during mass. The church which I attend has been supplied with seats for several years. I was surprised to learn that there were only a few objections to the installation of seats. Those who objected are men between the ages of seventy and eighty. One of them is so prejudiced that every Sunday now he stands up alone during mass. The Greek Orthodox Church is full of ikons. These are painted pictures or images of the Lord and other saints. They are similar to the statues of saints found in Roman Catholic churches. I can see no reason why they should still be used. In the first place the Greek Church broke away from the Catholic Church because of idolism. If ikons are not idols, I should like to know what they really are. The mass in the Greek Church lasts from seven in the morning till eleven o'clock. There is no church on earth, no matter how holy it may be, that can enclose me within its walls for four hours every Sunday. I would prefer to go hunting or riding rather than shut myself up in a church. At Easter and Christmas my conscience tells me that I ought to go, and I generally obey it. Old-fashioned customs similar to those pointed out above will be done away with in the Greek Church by the younger generation.

It is a custom in Greece that the father should give his daughter a dowry. It often happens that a man loses most of his property in giving dowries to his daughters, especially if he has six or more. This custom may appear strange to Americans and perhaps cause them to believe that it is due to illiteracy or lack of intelligence. The dowries are given because of necessity. Greece is an agricultural country. Over ninety per cent of the people earn their living by agriculture. The country is closely settled and the price of land is high. The average person has very little money because he manufactures at home practically everything he uses, and has very little to sell in exchange for money. When a couple are married, the 
parents of each are obliged to give them whatever they have, so they can open their own household and earn their own living. Many times the father is obliged to give to his daughter some of his wheat fields which supply him with grain. Thus after several generations the land is subdivided so many times that some members of the family have to migrate to foreign countries or starve at home. In America the dowry is most always eliminated in marriage. Why? It is not the custom of this country because there is the opportunity to work and the dowry is not needed. Here, after their marriage, the couple usually go to work. In Greece there are no factories where the couple can work and earn their living. This places marriage under the control of the parents. Almost always the parents select the bride. The girl with the largest dowry is the best bride. The parents must select a groom who will be able to support their daughter. There are many cases where girls have married against the wishes of their parents and finally returned to their parents for aid and support.

Customs are generally regulated by environment and economic conditions that exist in the particular country. In America Greek girls marry whomever they wish, because they are able to secure employment and earn their own living without the aid of their parents. Divorces are also common among the Greeks in this country. In Greece a divorce is regarded as a disgrace. In America a woman may divorce her husband, enter a factory, and live independently. In Greece it is just the opposite. She has no place to go but to her parents. Realizing that she will be a burden to her parents, she continues to live with her husband no matter how he treats her.

I do not have much to say about love affairs in America. From what I have seen (I am now twenty-one) I am inclined to support the attitude of my race - that is, to allow little freedom to the fair sex. I am now speaking through what I have seen, not what I believe. The love affairs that exist between young people at the age of fourteen or fifteen are unnecessary and injurious to the nation. The sentimental matters that are brought out in the movies are not criticized by me, but they can never receive the approval of the adults of my race. Of birth control, I can see no reason why the average family should have more than three children. More children mean poverty to the average family, while less children are destructive to the nation. Boys of my race are given as much freedom as the American youth. The girls, on the other hand, are not given so much 
freedom, on account of love affairs. If such affairs are not settled peacefully, the daughter will have to leave the home of her parents and live independently. I know of several such cases.

\section{Greek-Serb}

\section{Marika: A Kindergarten Cast-Off ${ }^{1}$}

I met Marika (pronounced like paprika), dolefully emerging from the gate of the school yard used by the kindergarten children. The time was Monday morning and the occasion the first day of school. Marika's short, squat little figure, the length of her plaid cotton skirt, as well as the dark oval that was her face, set her apart indubitably as a foreign child. Marika was, however, far from foreign to me. I shifted my nurse's bag and held out my hand, and Marika moved to my side with as much dispatch as grief and wounded dignity would permit in a Grecian woman.

I have known Marika well for five years, ever since that bitter morning when I induced her, by means of smart slaps of my hand and repeated alternate immersions in hot and cold water, to draw her first breath in our sooty, slummy world. Had I not also presided over the whole period of her infancy, imparted to her old world mother the beguiling art of boiling bottles, and instructed her in the superior merits of milk, as an article of infant diet, over Turkish coffee? Had I not nursed her through pneumonia after measles, and irrigated her discharging ear after whooping cough? Had I not weighed and measured her monthly at the Settlement clinic, had I not rejoiced as her oval face grew ruddicr, and did I not love the grave seriousness of her small nature, so mature and matronly at the meager age of five?

"Marika, dear, what's the trouble?" I asked as we walked hand in hand down Main Street. "Didn't you start to school this morning?"

"The teacher," Marika replied, lifting a countenance of unutterable anguish, "she will not have me."

"Will not have you?" Mentally I dedicated to outer darkness the kindergartner who would not, at first glance, gather Marika to her bosom.

"She say," continued Marika, "she say I not know nothing. She say I not years enough old."

${ }^{1}$ By Maude McClave Brown, in Survey, Vol. LVII, pp. 360-61. 
“Aren't you five, dear? Can't you start to kindergarten when you are five?"

"It is not my birthday till Friday," wailed the child. "She say I not years enough. She say I not know nothing."

"Oh, Marika, dear," I said, holding the dark little hand close. "Your birthday isn't till Friday, and so the teacher will not let you begin kindergarten. Won't she let you start next Monday?"

"No, she say, 'too many children.' She say, 'not till next year.' She say I not years enough, she say I not know nothing."

With Marika a little runlet of quiet tears, I made my way down Main Street into the foreign quarter. I wondered how I could minister to mental anguish such as hers. Remembering that she could speak Greek, I sought to divert her mind by having her interpret for me at the home of an Athenian patient. Behind the Pan-Hellenic Pool Room, in a very briefly "furnished" room, lay old Mrs. Paleologos, babbling in her own tongue, perhaps of far-off purple mountains and violets crowning ruined heights.

"Ask her, Marika, how she is today."

"Pohs eesthey, Paraskeue?" said Marika, standing close to the bed, and peering, like Red Riding Hood, into the grandmotherly old Greek face. An ancient hand, brown as wrapping paper, reached out to touch the child's head, and the symptoms and advice flowed back and forth among us, Greek and English, English and Greek, in a steady triologue. Beyond us, in the Pool Room, the balls cracked ceaselessly together, separated, and rolled smoothly to the cushion. The players were Greeks who had exchanged their ancient birthright of manly games in the stadium for the cigarette-laden air, the cards, the punch-boards, and poker-sheets of the Pool Room.

When our errand with Mrs. Paraskeue Paleologos was ended and we were again on Main Street, I bethought me of Rubitza Reichovitch, my bedridden Serbian patient.

"If you will come in here with me, Marika, while I see Mrs. Reichovitch, I will go on down to the Settlement and take you home."

As Marika stolidly complied and we entered Rubitza's bare and spotless kitchen, I remembered that Savo and Dorinka, the children of the house, would be at school, and I would have no interpreter.

"We won't stop here after all, Marika," I said, turning. "I can't speak Mrs. Reichovitch's language. I will come again when school is out."

Marika eyed me gravely, and moved unperturbed toward the front 
room, where she knew the patient would be lying, on a bright and brassy bed.

"I speak for you, she speak our language, too."

"No, dear, she is not Greek, she is Serbian."

"I not speak Greek to her," Marika patiently explained. "I speak Serbian to her. My father, he Serbian. He teach it me. I speak for you."

When I had greeted my patient with the smiles and pillow-shakings which a nurse can administer in all languages, Marika assumed her best feather-bedside manner and asked at my bidding,

"Dalsi oosala medetzina? Have you taken your medicine?"

So the interpreting progressed, until we said "Sboggom, Goodbye," and emerged again upon Main Street.

Then I remembered that Marika's mother had originally come to America with the praiseworthy purpose of teaching Greek in the public schools. Finding the call for this language languishing, in both the lower and the higher grades, she had done "ye nexte best thinge" for herself and married the Serbian boarder in her sister's home.

"How splendid, Marika, that you can speak both Greek and Serbian. You speak them so prettily, too, and interpret beautifully."

But Marika's mind had reverted to her early morning miseries and she repeated to me, quite irrelevantly, the words of the teacher.

"She say I not know nothing. She say I not years enough old."

"Now, Marika, one more stop and we will be home. Victoria Sutria, here over the Rumanian grocery, has to be told about the application for her baby's side. Pete will be here and he can talk to her."

But when we had penetrated the doubtful regions above the grocery, we found Pete temporarily absent. Victoria, preparing eggplant for dinner, smiled and set a chair, but looked with vacancy and vacuity at my sign language about the compresses.

"They must be hot," said I, pointing in despair to the stove which was out. As I rose to light a fire, heat water, and demonstrate the mystery of the applications, Marika was suddenly at my side. Pointing to the water and the cloth she said quickly:

"Kalt!"

Comprehension awoke on the face of Victoria.

"Oh no," said I hurriedly, mistaking Marika's word for German, "they mustn't be cold, they must be hot." 
Marika stood her ground gravely.

"Kalt!" said Marika.

"Hot!" said I.

"Kalt," translated Marika, manfully.

"Hot," I replied in useless repetition.

At this sorry juncture the belated Pete appeared, tossed Marika aloft and asked me the difficulty.

"I am trying to tell Victoria to use hot cloths on the baby, and I cannot make her understand the word 'hot'."

"Kalt," repeated Pete, grinning toothily at his wife, and pointing to the water.

"But doesn't ' $k a l t$ ' mean cold?" I asked in desperation.

Pete laughed and explained.

"In German, yes, 'kalt' is cold, but in Rumanian, no, it is hot. In old country once a German fellow he drive sick Rumanian woman to doctor. It miles and miles, and it winter. She have fever. She lie in wagon, and she cry to him, 'Kalt, kalt!' He think she cold, so he take blanket and cover her. They drive 'long, she say 'Kalt, kalt!' He take horse blanket, he cover her. They drive 'long, she say 'Kalt, kalt!' again. He take off coat and put on her. She fight him and scream, 'Kalt, kalt!' He have no more, he drive fast to doctor. When he get there, she all - what you call it? - sweat. She better. But she so mad she knock that German fellow for a cuckoo. She say she was hot, and German fellow he think she say she cold."

Overwhelmed by this linguistic curiosity, I departed with Marika's hand in mine. At the foot of the dark stairs I suddenly turned to my small companion.

"Marika," I demanded, "How in the round world did you know the Rumanian word for 'hot'?"

Marika looked up gravely as ever.

"Our boarder, he Rumanian. He teach me talk like his little girl in old country. He like me have language like his little girl."

"Well," said I slowly, "Greek, and Serbian, and Rumanian. Rumanian, and Serbian, and Greek."

"She say," responded Marika reminiscently, "I not know nothing."

When I led Marika to the corner of her alley, I stopped and addressed her. I used the language and I assumed the mien which we retain for our high-born and high-brow friends.

"Marika," said I, "since the Child Labor Amendment seems 
irrevocably lost, and since ladies of youth and leisure can now lawfully earn their bread by their brawn or their brains, I shall not hesitate to recommend you for the post of Official Interpreter in the Hellenic, Slavonic, and Italic tongues, in the Probate, Juvenile and Domestic Relations Courts of this city."

"Weep not, oh Maiden, because the portals of the kindergarten are closed against you. Grieve not that you cannot sit in a circle and sew a wool seam. I, from the lowly foothills of a college education and hospital training, salute you upon your far linguistic height."

The little girl's eyes were puzzled.

"I mean, dear," I hesitated to interpret myself, "If you can't go to school you can go with me to the sick people and talk to them for me."

"She say I not know nothing," Marika insisted doubtfully. And then, as she grasped my suggestion, the comfort to her hurt pride made her tear-smeared little face glow. "Yes, yes, - I know something - I help you make the sick ones well - Greek ones, Serbian ones, Rumanish ones. There is something that I know Yes! yes! yes!"

\section{MeXICAN \\ One of the People of This Great United States}

I arrived in a little town of Arizona in 1870 with my father, mother, and several brothers and sisters. As I was a mere babe in arms, I count myself as a member of the second generation Mexicans. Certainly I had no choice in the matter of our immigration to this country. As I have heard since, my parents came to this country because they believed they could more easily support their family here than in the section from which they came in Mexico. As for settling in Arizona, I have been told that the funds gave out at this point, thereby determining their destination for them. In the parts of Mexico I have visited, I have observed a favorable reaction to America. People regard it as a country with plenty of work, and a fine opportunity for amusement. From personal contacts, I learned that visitors admire greatly our modern conveniences and up-to-date business methods. All these things must have been quite a contrast for my parents, who, in their little native Mexican town, were accustomed to farm life in an isolated rural district with no railroad facilities. And they, as others just mentioned, were impressed with their new surroundings. 
I did not have a very good opportunity to secure an education, as schools, even in the United States, were not very plentiful at that time. During my six years in school, I learned to speak the English language, but not so well as I would like. I read a great deal, English classics and English stories by the best authors.

When very young I worked at odd jobs. As the pay was better and work more certain, I went into the mines, and labored underground for a number of years. After my marriage, we went to a town near by and entered the grocery business. After twenty years, due to old age, I sold out. During all these years I was in contact with American people every day. I can truthfully say I have always been respected by them, and have in turn respected them. I might state that I took out my naturalization papers in 1892.

I am a member of several organizations, such as Woodmen of the World, Fraternal Home Insurance Society, and Alianza Hispana Americana Society. The last named was founded some thirty years ago and has for its motto: "Protection, Morality, and Instruction." We count many Americans among our members. From the very beginning, I have had faith in the society as a means of bringing the Spanish people of the United States and Mexico to an understanding of the better things of life. Through it we are improving social conditions, caring for widows and orphans, and just now planning to build an orphan asylum.

My family consists of five girls and two boys. Three have finished high school and normal, and the others are now finishing their grade school work. One daughter is at a university in California, preparing for social work among non-English-speaking children, another daughter is doing commercial work for the United States Department of Agriculture, and a son is at present railroad accountant for the Southern Pacific Railroad of Mexico, where his knowledge of Spanish has helped him considerably.

We have always owned our own home, and have accumulated much property in the past twenty years. Just recently I had a modern home erected in one of the most exclusive residential districts of the city, and I, together with my family, seem to be quite welcome in this neighborhood. Nothing has ever occurred to make me wish to avoid American people. Perhaps it is because our interests have been common and our everyday life has been much the same. I have found that only narrow and uneducated people are prejudiced against the Mexican people, and sometimes all foreigners. They 
close their eyes to the ambition and intelligence of the Mexican people, and snub them on every occasion. As a narrow-minded person is not a very agreeable person to deal with, and as I use a little discrimination in choosing my friends, I can say that troubles along this line have been negligible. I have many friends among the American people, am in daily contact with them, and can say that my life runs just as smoothly as if no foreign blood flowed through my veins. Were I to express what I feel deepest about the United States and its people, I should have to consider myself one of the people of this great United States. I can only say that if I moved to another country, I should be terribly homesick.

I believe that the reason foreigners are misjudged is because of the inability of most of the American people to understand them in their own language, and thereby get acquainted with their own peculiar customs and beliefs. Now, in case of the Mexican people, it appears to me that it is rather an injustice to class the Yaqui Indians and other Indians, who are partly civilized and who migrate into this country, many of them as laborers, as Mexicans. Of course, they are Mexicans, just as the Indians of America are Americans; but they are not the Mexican people who guide the affairs of Mexico or who constitute the nation or the republic. Regarding the laborers who come to this country, I do not want to commit myself as saying that all of these are Indians, as many Mexican people, because of unfortunate conditions in Mexico, have been forced to come here to seek work. Many Easterners have only seen Mexican Indian laborers; consequently they form an entirely wrong impression of the Mexican people. So long as there are people who cannot conceive the Mexican people as being any more than these Indians, I do not blame them for the estimation they place on the group as a whole.

I am not planning to return to Mexico. I have one son over there now, and believe he has a wonderful opportunity. Since Mexico is now a rich field for the person who can speak both English and Spanish, it may be that some of my other children will locate there, but that will be of their own accord.

\section{QUESTIONS}

1. Which of these persons seem to be more truly living in two culture worlds? Which in more nearly a purely American environment?

2. On what points have conflicts of culture occurred? 
3. In which of these homes have there been difficulties in regard to two languages? Account for the lack of interest in a second language in the Portuguese lady's (number 1) home. Account for the insistence of the foreign language in the home of the Greek (number 5). Of what particular advantage has Spanish been to the Mexican family (number 8$)$ ?

4. How did Marika (number 7) learn so many languages?

5. What conflicts are cited with respect to education in these life history documents?

6. Relate the early school experiences of the Greek lad (number 6); of Marika (number 7); of the French youth (number 2). In what respects were these due to the local environment?

7. To what extent has foreignness affected the social status of the person?

8. Account for the rather violent reaction of the Greek (number 6) against religion. Elaborate on the Italian's (number 3) statement that the fact that he was not a Catholic greatly aided him in associating with Americans.

9. To what is the disorganization in the Italian (number 3) family due? What factors are responsible for keeping the Greek family (number 5) together? How does the Greek family pattern differ from that of . Americans in general?

10. Why did the Mexican (number 8 ) have so little difficulty in assimilating into American life?

11. How is the Italian girl (number 4) trying to organize her life? Why has she determined to identify herself with Italo-Americans? Contrast the assimilative processes in the two Italian and the two Greek documents.

12. Why does the Italian girl (number 4) regard America and Americans in separate categories?

13. What are the various reactions of these people to the native countries of their parents? Why does the Italian youth (number 3) speak so bitterly of Italy?

14. In what respects may it be said that the assimilation of Latin second generation Americans is conditioned by the local environment? What is Marika's (number 7) special problem in becoming Americanized? 


\section{CHAPTER XXXIX}

\section{LIFE HISTORIES OF SLAVIC SECOND GENERATION AMERICANS}

\section{Rumanian}

\section{Firm for the United States}

I was an infant of fourteen months when my parents, peasants of Rumania, started for America with me and my three-year-old brother. Of course I have no memories of Rumania, and am culturally speaking an American. However, I learned from my parents that our life in Rumania was quite rustic, although our native town was considered quite important. Our home consisted of a little cottage, with a yard in which a few vegetables were grown. Father's last occupation was that of a baker. To the people of our native location, America is a place flowing with milk and honey. To be sure, the inhabitants are not as well off as the average townsfolk of the United States, but they greatly exaggerate the differences between the opportunities in the two countries.

Two of mother's brothers had already migrated to the United States to the City of Brotherly Love. They settled in Philadelphia merely because the ship happened to stop there. The reason for their emigration was the hope of finding better opportunities than native Rumania offered. Our family came actuated by the same motives. My parents arrived with a potentially low standard of living; at first we lived in a second-floor room of a house. The earliest jubilant incident I remember is the time we moved into a whole three-room house. For several days I admired it in ecstasy. And this large house was still on the same street, a cobblestone alley, dirty and dusty in pleasant weather, muddy on rainy days. Our next move took us out of the slums, but in attaining a better neighborhood we had to sacrifice comfort. We set up home in two rooms on the second floor of a meat market, where we had to use a rear exit through an alley. A couple of years later, there being now a third child, we rented a five-room house on another street. Since then we have lived in fairly good homes in comparison to what we have gone through. 
Father and mother are of a quiet, rather reticent nature; consequently their community activity is practically limited to voting. But as to coöperating in improving conditions in the community, they gladly do all they can. While not of the type that buys improvements lavishly and suffers the time-payment collector to worry, they are trying to improve our home as much as possible. In respect to segregating and desiring no better living conditions, the people of the United States misjudge immigrants. They must live among their kind in the foreign sections of the city for a few years, until their earning capacity increases, they learn something of American customs, and acquire a working knowledge of the English language. Soon they move out all over the city. Although Philadelphia has a Rumanian section, the majority of Rumanians whom my father knows live scattered over the city.

Thanks to my early arrival in America, I speak and write English as well as the average American. I have no first-hand knowledge of Rumania, and my short life there gave me no feeling for the country. If I ever go there, it will be only a visit, such as I would make to any other foreign country. My condition is by far different from what it would have been had I remained in Rumania; there I certainly would not have been in a university. Several years of my life would have been spent in military training. My sister is also enjoying better social opportunities. My parents, however, are often anxious about her social contacts because in their youth they never had such freedom. I think, on the whole, Rumanian children probably get much more social freedom than was given children of my parents' generation.

As long as national political distinctions exist, I am firm for the United States. However, if internationalism were to become popular, I should favor it. We of this enlightened age have no business engaging in the primitive inter-tribal wars. Edueational measures to promote toleration, and free expression are the only safe means to achieve this.

\section{Russian Molokan}

\section{A Tragic Life in Two Culture Worlds}

My family came to Los Angeles when I was a baby. A big man in Russia, a preacher or something like that, had a vision in which all Russians were warned to come to California where there is no snow at any time. My people thought it would be a wonderful country 
and a strange place, because in Russia there is much snow and cold weather. This man also predicted a terrible war in the near future. There was, you see. This was a strong appeal, as the Molokans will not fight any country, war being against their religion. From Los Angeles we went to Mexico, then back here again. Again we moved, this time to Utah, and again returned to Los Angeles. With all this moving, I had little chance to go to school.

Americans think because Russians wear beards that they have no sense. They do this because Christ wore a beard and never shaved. The women too get their style of dressing from the Bible. The Holy Mary wore something over her head and loose clothes. Of course, the Russians had to have bands on theirs to keep them up. That is the reason the Russian women dress the way they do, with loose clothes and shawls over their heads. I only dress that way when I go to church. I couldn't enter dressed in American style; I must wear the Russian shawl over my head. However, I don't go; I just hate to go to that place. I used to go and sit on the bench and not take part. The old folks don't like it because I don't go to church. They feel awful about it.

The old folks have queer ways; that makes it hard on the children. It is impossible to change their ideas. Sometimes I feel sorry for the old folks, but after a person has been around Americans, he just can't stand the Russian way of living. What an awful hole I live in! I just can't bring my American friends here. Once we lived for a short time in a better apartment house, but not for long. Once when I could not shake my friend at the corner, I lied to him. I told him I lived in the apartment house because I was ashamed to let him know where I lived. After he had gone, I went home. Well, one Sunday he and a young couple, friends of his, came out to see me. The people at the apartment house told him where I lived. Then it was known I lied. I never saw him again, but I heard later that he said I lived in an awful dump. And that place was much better than my present home. I always try to keep my friends away from my home and my folks; they have that crazy old religion.

I am working, making $\$ 23$ per week dipping chocolates. All of the girls are American; they surely are fine. I have never worked with Russian girls, and I never want to. At the factory we are well acquainted; we go to dances and other places together. I go to their homes and meet their boy friends, but I can never ask them here, to this disgraceful dump. They don't suspect I am Russian; 
I never tell that, believe me. Besides being ashamed of my folks and home, I would be afraid to invite my friends to visit me. I don't want to get killed. The Molokans are against any race that is not Russian; it is against their religion to mix races. They would rather I would marry just any Russian in preference to the best American that ever was. All the Molokans think the same. When some of the Russian girls go to American dances, their folks half kill them. The American boys are better than the Russian boys. I don't like the ways of Russian boys. If I can meet the right American man, one I think would make a good husband, I would marry him. I don't know what my folks would say; I know they raised an awful fuss when my older sister married a Russian Catholic. Being Holy Jumpers, they don't have anything to do with Catholics. My sister and her huśband have a pretty little bungalow outside the Russian district. My brother-in-law is so kind and good to my sister that the old folks don't feel quite so bad now. But as for me, I go with a boy until he begins to think something of me; then he finds out about how queer my parents are and drops me like a hot cake. I can't blame him, however, for not wanting to get mixed up in a family like this.

I know a great deal about American ways of living, enough to hate the Russian way. I want to go to night school when it opens next fall. Besides moving a lot, my folk, like other Molokans, don't want their children to go to school. They want their children to go to work and get married to some Russian when they are about sixteen years old.

\section{UKrainian ${ }^{1}$}

\section{Only Disgust and Hatred for the Land of His Parents}

I was born in one of the poorest sections of a city in New Hampshire. My first remembrance is a dungeon-like brick building, with apartments enough to suit a palace and filthy enough to suit any herd of swine.

It was also the time during which the Democratic party was offering its services cheap, and the poor people were helplessly grasping any prospect which came along. When the war came, my people and friends rose in violent denunciation of the Democrats. Helplessly I

1 This man does not know just where his parents were born in Austria-Hungary, or to what branch of the Slavs he belongs. He thinks he is of Ukrainian descent because of language similarities. 
formed a hatred for President Wilson which lasted until I entered high school and learnt to admire and respect him as I do no other man outside of Justice Holmes. As youngsters we were influenced by our folks in denouncing the party for our poor condition. What could we do?

My father had gone back to Europe and left my mother with me. We both moved about the city trying to find more suitable living quarters, and in this process I never had an opportunity of becoming established in one school. After eight years of this hectic life, we moved out into the country. It was here that I can truthfully say that I began to live. I had only existed before. Here in the country I found excellent companions, a wonderful environment, and an excellent school. Each immediately began to withdraw me from the person who had existed in filthy surroundings, with "tough gangs," and gone to no special school.

Although we lived and could live cheaply, I always think of that period of my life as one of "earthly paradise." Except for a gang of Irish boys, who were numerous here, and who made my life at school somewhat miserable because I was a Russian (my parents were born in Austria-Hungary, but that made no difference to these boys; I knew too much about Russia in my history class to suit them) and because my mother was illiterate (I had ventured this information to the teacher during a class discussion), I led a life which satisfied me thoroughly. I entered a Boy Scout club, met a group of very nice boys, and made friends with the scoutmaster, with whom I spent some pleasant evenings. Outside the club, I disliked any social groups and never went to any parties. I developed, through being alone more often than I had been, a great liking for reading books, papers, and magazines, the last two being my source for political knowledge.

I also began to teach my mother to speak English, but I am sorry to say she never learned enough to acquire a moderate knowledge. How could she when she never had any opportunity to learn any fundamentals of education? Fatherless and motherless as a child, she was taken by an aunt and put to work in the fields till she was nineteen years of age. Had she refused, she would have been "apprenticed" to a neighbor to work for her living or a meager pay till she was old enough to offer herself and her services. Girls of sixteen or more received their social education by offering to work at weddings or general housework. It was more a custom to do so than a willingness on the part of the girl. 
Alone, except for a few neighbors of our own nationality, my mother spoke of Europeans (her own) and their customs. She told me of the lack of schools in many of the towns (hers included), the feudal system of living, of the obsequious manners before the lords of large domains, and of the supreme faith and belief in religion as a panacea for everything. Her views of the priests often fill me with rage, and I wondered how long people could have endured such absolute control by these "holy(!)" fathers!!!

With the neighbors we observed many interesting customs, most of which, I noticed, died one by one year after year as the people became more Americanized. At present I scarcely remember any of the customs or traditions which the boys were supposed to uphold and remember.

From my first contact with government and law through my history course in public school, I have been interested in acquiring a knowledge of law. My ambition therefore centered toward becoming a politician. I read various articles and magazines dealing with political topics, thinking in this way I could get a good start.

Aside from numerous hunting trips, all of my spare time was put into reading frontier novels and non-fiction books on a variety of minor subjects. Reading served as my one and only recreation. I never felt free to go alone anywhere, unless it was to go to the library. But as I grew older I relied more and more upon myself to furnish my recreation, and thus formed a trait which prohibits me from associating with boys for any length of time. College has shown me that this is a damnable trait to have; yet my efforts to lose it are of no avail. I go alone.

In all my efforts the only sympathy I ever received was from my "country" friend. My mother and others stressed too often the "drag" and elevated station of life necessary in politics. Now, as I look back, I curse myself for being fool enough to believe those whose only prominent characteristic was the "gift of gab."

My mother realized the tremendous help a college education is to a boy in America, and from my early youth she had begun to save her money so that I could go to college. The various changes of residence she made served two purposes. First, the cheapness of the places helped her to economize; and secondly, they introduced me to a broader view of life in general. I learned to see the difference between wealth and poverty, to note the benefits and advantages easily reached through wealth, to lose faith in religion, and to think of the world and 
its people in terms of cold and fickle reality. I do not call myself an atheist, but I must confess that I cannot bear religion as I can other things. Probably it is due to the silly, childish contempt for my mother's priests and their religion that I say that. Some habits or beliefs are more concrete and lasting than others.

Probably my disgust with life run by religion can be attributed to the fact that from the time my father returned to Europe, I was alone in all my problems of daily life, for my mother had to work. Thus I never had a father's guidance, and I cannot say that I have any or the minutest liking for him. I still wonder why he returned to Europe. However, I know, though I am the only child, that my mother did not spoil me, and that she has sacrificed too much of her and my happiness and her health to have me where I am. Is it worth it?

Due to my almost hermitical existence, my hobbies and interests actually grew on me. I loved to go trapping and canoeing and still do. My mind often wandered into the governments of the various countries of the world, and I was easily susceptible to this sort of "daydreaming."

Though leading a double life (life of my mother, her language, and customs, and my life as an American with American people in an American school), I was able to judge my mother's people by the American and vice versa. I used to use my mother's people as a means of refuge from this drab and monotonous existence with Americans. Thus I was constantly varying, constantly judging the good and bad points of each. When I had gained an idea of America and her people, I was entering high school, and before I had graduated that idea or opinion had not changed so very much. I thought of America in terms of her government, and her people in terms of her politicians. America was a "lie" and her people "liars," to me a gregarious congregation of hypocritical parasites!

I dislike my mother's countrymen of their unconcerned let-comewhat-will nature, but I disliked Americans more because they ought to know and do know enough to improve their state but do not. Still I wouldn't go to my mother's native country were my passage and bills paid by others, or were I honored by the whole tribe as a hero. Why I wouldn't I do not know, but I know that I hate, despise, and scorn the country. It may be an inherent nature, or it may have been acquired gradually in my talks with my mother.

I can remember instances in which my mother stressed the necessity of my acquainting myself thoroughly with the traditions, cus- 
toms, habits, and practices of her people, although she did not usually appear enthusiastic about the matter, she seemed to feel she had done her duty in merely mentioning my obligations. I recall that I overdid myself in ridiculing her. I replied stubbornly that I lived in America, was born here and would die here, an American. At almost regular intervals an immigrant would arrive, and my mother and I would pay her or him a visit. I would listen to more hateful and disgusting conversation of European customs and traditions, which seemed to undergo very little change. For no reason, except it revived my mother's enthusiasm, I disliked these new immigrants, whose descriptions varied according to their ability to talk or "gab." A group of boys of my nationality and I got a great deal of fun out of discussing the peculiar and seemingly fantastic habits of our mothers' people. We always considered ourselves Americans and never made any effort to follow our parents' requests to uphold their traditions. We only spoke our language to our parents, who understood no other, and, unlike the French, spoke only English among ourselves. As a result it almost amounts to a lesson in a foreign language when I speak to my mother nowadays.

Although I often tried to analyze my nationality and its attributes to me, I have not found any qualities of which I can be proud. In disgust I have often wished I had American-born parents in order that I could judge myself better through the actions and habits of my countrymen. I felt like an outcast. I have only recently realized that I have suffered from an inferiority complex of class-consciousness, or should I say race-consciousness.

As I have said before, the only group of boys I ever associated with was the Boy Scout club of which I was a member for two or three years. And it was only because the scoutmaster retired that I left the group. I never tried or wanted to join with another group of boys. I formed one friendship with a boy that grew till we were as brothers, and we refused to let any other person enter our realm of friendship.

As with boys, I was the same in regard to going to church. I only went because my mother made me go. I used to regard Sundays with the hatred of a boy whose best holiday was spoiled. Custom forbade our having benches in the church, on which the people could sit during the sermon, and thus it was an ordeal to go to church. I often wished I had been born an Englishman so that since I had to go to church, I could, at least, sit down when I was tired. Because the 
American churches take into consideration the attending children and hold their interest by often speaking to them directly, I am sure that I never would have acquired the distaste for going to church that I have, had I attended an American church. It is for this reason I would advise children of immigrants to attend American churches. We were told to go to church because our parents spoke of the church as the "dwelling-place of God."

Had I had any brothers or sisters, I feel positive that I would have been regarded as the black sheep of the family. All of my views were pro-American and anti-European. Any bit of praise my mother attempted to attribute to her people or country, I laughed at it and showed her how backward the people were. Whenever my dear mother told me of the shocking relationships existing between American men and women, and their seeming unconcern for their children, I agreed with her. I know that European women make very good mothers and wives. It was a known fact that a woman was born as a helpmate for man, and that is how she was regarded. Even as an American-born child of immigrants, I wish I could wipe out, exterminate, the custom of posting almost nude women in the movie billboards, of selling trash which can be bought cheaply, and of discussing much too often sex and its one hundred and one substitutes. How much better it would be for children whose ages range from four to fourteen! In the heat of numerous arguments, I often suggested that we (mother and I) take a long, wide tour of the United States in order that my mother could see for herself that what I often said was true. But we never went, and I never had the courage or desire to leave my mother for any length of time.

As I look back upon the group of boys I used to go with sometimes, I find that I am the only one attending a higher institution than a high school. Why? My mother made herself parsimonious for my benefit. I see the others working in shoe factories or small offices. Their parents are still working in the cotton or woolen mills, satisfied if there is enough to eat and a place to sleep. Others, dreaming of their youth, have bought houses and farms and get a great deal of pleasure out of tilling the soil in the spring. Before there can be any successful man among those children of our parents, another generation will have to come and go, and the other generation is the one of which I am one person. Get an education, I command myself, and marry an intelligent woman. Have children, give them a thorough education, and there will arise among them a man capable to compete 
with the chaotic problems of the United States. Only in this way can a person satisfy his thirst for success.

\section{Pole}

\section{The Handicap of a Name}

I was born in a city in Massachusetts with a population of about 14,000. I am the son of what might be considered a typical Polish family. My parents came from Austrian Poland many years ago. They had no educational opportunities in the old country, but after coming here, they picked up the reading of Polish and the speaking and writing of English of their own accord. They had a very hard time after coming to the United States. Later my father learned to be a weaver; then he conducted a grocery store for about fifteen years. Just now he is unable to work. In the old country my parents were farmers.

I attended grammar school to the ninth grade, but did not graduate. Like most Polish boys, I went to work at the age of fourteen. I worked for five years, then entered school again. It was because of my athletic ability that I entered school again. I had a hard task before me when I entered the secondary school. Everything came hard to me and I had to put in hours of studying in order to get my work done. It is true with me today; I cannot grasp things very easily. It seems that I have to put in double the time others do to get my work completed. Yet, in spite of the fact that I had been out of school for five years and had to support myself in school, I completed the four years in the academy in three years and am completing the four-year college course in four years and one summer.

I always wanted an education, but my parents could not afford to send me. While working, I saved some money which gave me a start, then worked during school and vacations. When I went to work, I was satisfied with the work I was doing. I did not understand anything beyond my home town. I did not have an opportunity to mingle with the higher classes of people, therefore was satisfied with my surroundings. Some time after I began working, I began to attend classes at a gymnasium. This gave me a vision of better conditions and a desire to better my position. I also took a correspondence course which helped me some.

In grammar school I had some conflicts because of foreign and 
Polish parentage, but nothing serious. In the academy and college, I experienced no difficulty whatever. I was taken into one of the oldest social fraternities and into other groups without any difference whatever so far as I could tell. I did not consider that immigrant or Polish parentage would make any difference in a profession. I now realize that it makes a world of difference. I have tried desperately hard for three months to secure a teaching-coaching position, but so far I have secured no offer. The other day I went and interviewed the president of a teachers' agency. He suggested that I change my name. Many of the superintendents of schools think that because my name ends in "ski" that I am Jewish, and they don't want a Jew. One of my Polish friends was unable to secure a position for two years after his graduation from college. Then he changed his name, taking a familiar English name, and immediately secured a position. I hate to change my name. It will hurt my folks and make them mad. They would never be able to understand my plight. I am going to try it a little longer, but I may have to change it. I hate to do so, not only because of my folks and friends, but also because it is part of me and would affect my personality. Can a man be true to himself and change his name that way?

In another way I find that Polish fellows are handicapped in securing teaching positions. After the school authorities find that we are not Jewish, they reject us because of religion. The Protestants think all Poles Catholics, and they don't want Catholics. On the other hand, the Catholic school authorities don't want us, because we did not go to Catholic schools, and they are afraid that we are not good Catholics.

My parents were brought up as Roman Catholics, but some years ago a group of Poles, including my folks, organized a Polish National Catholic Church in the town. This church has the Roman Catholic ritual, but does not recognize the Pope. After some years this church which they had organized died. Since then, they do not go to any church. I seldom ever go to any church. Somehow the church doesn't mean anything to me any more. It seems to me that what the Roman Catholic Church does for the Poles is to get all of their money it can, and keep them in ignorance.

We always spoke the Polish language at home, and lived up to the customs our parents taught us. That is why I do not feel that I am satisfied when I go home for a vacation. Nothing there seems to interest me any more. I speak the Polish language very well, and 
often do so. This, however, is not because I have any more interest in Poland than any other foreign country. I am not planning to go to Poland, but retain the language because I feel that it gives one certain advantages to be able to understand two languages. I cannot see any reason why I should be interested in Poland. I am an American, and expect to remain here. It is the United States that has given me an opportunity, and not Poland.

I feel more closely related to the Americans than I do to the Polish people. In the academy and here in the university, practically all my friends are native-born Americans of American parentage. However, I realize what the immigrants go through to make themselves understood and get along. I also see from my parents and others where the immigrants are lacking in the necessary requirements to be on a level with the educated class of Americans. Polish immigrants retain the old ideas, and it seems that you cannot drive them out of their heads.

I have had many difficulties with my parents. Most of these were caused because I tried to tell them where they could change their ways so as to better themselves and their children. They have the old ideas, while I am an American. As I could never get a satisfactory response from them, I will never try again. It seems that I always feel relieved when I get away from home. This has all happened since I went away to school. Now, when I do go home for a short visit, I feel out of place, and wish to get out immediately. I have several brothers and sisters, but I am the only one that has taken an interest in education. Now I am isolated from my people and have little in common with them. My parents and sisters seem proud that I am graduating from a university, but I have nothing in common with my brothers, it seems, and cannot talk to either of them for fifteen minutes. I do not assume any superiority around my people, but my brothers assume an inferior attitude when I am around and do not appear comfortable. We never go down the street together, and seem to have nothing in common.

I associate very little with the Polish fellows I grew up with. There are five that are away in college. When we happen back at the same time we have a good time together. But the others - well, they speak and say a few words and pass on. I have not changed in my attitude toward them, but they do not seem to want to be with me any more. While I treat them as I always did, they assume an inferior attitude and seem restless and unhappy when around me. My 
brothers seem happy with them but not with me. I am almost completely isolated from them now.

The American-born children of Polish parentage are not doing much better than their parents. Most of them do not have much opportunity. Polish families are large and the children are forced to go to work at an early age. What time they have off from work they spend in cheap amusement, trying to get some kick out of life to counteract the monotonous daily labor. They do not get much opportunity to come in contact with Americans of the middle and upper classes, so retain many of the old ideas brought over by their parents. If they could be kept in school, most of these ideas would be overcome.

\section{Russian JeW \\ The Curse of Being Born a Jew}

My mother was born in a small town in southern Russia. Her father, a merchant, was given special privileges in carrying on his business. But a change in petty officers, one of whom disliked him intensely, made it so hard to earn a living that he decided to join a son in America. Mother stopped awhile in London with another son. While there she worked in a clothing shop, went to school at night, and became an active trade unionist. Father was likewise born in an unknown town in southern Russia. Being an extremely delicate child and unfit for manual labor, he was chosen to carry on the family tradition, teaching Hebrew. At thirteen years of age, he was hired out to teach boys twice as big and older than himself. His earnings were collected beforehand by his mother. He taught himself Greek and Latin preparatory to entering a Russian university. But he might have spared himself the trouble; he had the misfortune to be born a Jew. In Russia, as in many other countries of the world, this is an unpardonable sin. He was fast approaching the age when he would be old enough to be forced into compulsory military service. Deciding that he would not enlist to fight for a country which had imposed every imaginable punishment on his people, he escaped by way of Austria and Germany. After a year, he arrived in America. He met mother, and after their marriage opened a confectionery store and began attending school. Later he graduated in the school of pharmacy.

I was born in Philadelphia, and attended the public schools. The only time I came up against an objection to myself was when I ap- 
plied for admittance to college. Through some misunderstanding I was not considered fit to teach English as I did not have the proper background. Since I never had any intention of teaching English, the matter corrected itself. But just think what might have happened had I wished to teach the English language!

At six I began attending a Hebrew school. This was a folk school, not a religious school. In fact, it was erected to counteract the effect of the Talmud Torals (religious Hebrew schools). So many of the present immigrants had suffered so much under the restricted and narrow teachings at home that they swung to the other side entirely. They are nationalist and not religious. My brother has passed his thirteenth year unconfirmed. A Gentile cannot grasp the significance of this fact. It is one of the most terrible things that could happen from an orthodox point of view. He speaks Jewish at home, though not as much as English. But all of us are acquainted with the customs, habits, thoughts, and literature of Judea.

I always wanted to be a teacher and received the encouragement of my family, for they all see that independence is essential to a woman. One friend of my father attempted to dissuade me. $\mathrm{He}$ said that it was a waste to spend money educating me since I would probably get married. I thanked him for this interest, but assured him that marriage was not my goal. He was horrified at my very modern views upon the subject. Each time I meet him the occasion for another lecture on the subject is given. It is really too funny; I enjoy his arguments immensely.

After the World War, when my kinsfolk were being murdered right and left, without mercy or reason, I was very much disturbed. My father and mother still had relatives in their former country, who wrote us the most heart-rending letters, full of woe and lamentations. Vividly do I remember my grandmother, as she sat and read my aunt's letters, weeping meanwhile. Mother's cousin became insane she had been forced to view the execution of her entire family. Newborn babies were impaled on drunken soldiers' swords. All these people looked toward America as their salvation. And then the doors were closed. Its effect on me? I shall leave that to the reader's power of deduction.

In school I made various acquaintances and was admitted to an honorary society, having chapters all over the country. Practically all were Americans. Here, also, I met and formed a friendship with an ideal American girl. I see her often and hope that this friendship 
will exist forever. I haven't gone out of my way to avoid Americans of native parentage, but on more than one occasion they have made me feel badly. Often in class, when we were discussing one thing or another, I would bring up, as examples, quaint customs that my mother used to perform in her country. Immediately, their faces would light up with ridicule, and instead of appreciation for the variety of ways of doing things, they would only laugh at customs different from their own. Once when I was undergoing a physical examination, the doctor, after she found out that my parents came from Russia, with a smirk and air of condescension on her face, asked me, "Do you speak Russian?" I answered coldly, "We speak English."

Sometimes at home, among ourselves, we would ridicule certain things that my parents would tell us. With our spirit of independence, it was difficult to understand why they were so blindly obedient to their parents. Sometimes my father would read a joke from the Jewish paper, the point of which we couldn't see. Finally, we - and my father blames me for it - began to refer to this as "Jewish Humor." We don't any more. My father asserted his authority as the lord and master of the family and put a stop to it.

There is one thing that I can stand less than anything else - loud speaking. This is a feat that my race indulges in. They usually find it necessary to speak loudly, accompanied by both arms, in order to convey an idea. It does embarrass me horribly to be the unwilling listener to somebody else's troubles when I enter a car. I dread the moment it stops, for then the conversation is entirely audible. I sometimes blush with shame at myself, when I find that I am trying to convey the idea to other people that I am not connected with those people racially or otherwise. That is why I rarely attend the Jewish theater, for the place is in a hubbub most of the time. The audience never comes till the curtain rises, and the intermission is the signal for the exchange of opinions from one end to the other.

Immigrants from my parents' country have interested me always. Usually, they were relatives of some sort, and if you know the numbers making up my parents' family, you wouldn't wonder at my astonishment to see another one. Really the race will never die out. These people are of interest because they have new experiences to relate. I expected them to be astonished at our mode of living, but for the most part they are not, having lived in European capitals. It was very interesting to hear of their adventures with the Bolshe- 
vists, or Cossacks, but secretly I felt glad these people were elderly and would not depend on me to show them around. There was about them a difference that evokes remarks in public places, and I, being one hundred per cent human, do not care to be associated with these remarks.

I never particularly enjoy reading the books of Russians. They are usually so gruesome and pessimistic that for weeks after reading them I can hardly be lived with. They have the power of making me morbid and disgusted with life and things in general. I am deeply interested in Russia, not because it is Russia, but because my surprise is often aroused that Russia could exist in its medieval state until 1914. I could but wonder how one-sixth of the earth's surface could remain for so long in the hands of but a few. It usually fills me with revulsion even to think of the old Russia. Of course, the country is vastly improved, but it is that impression of the bleeding Russia that my parents knew that stays with me. If I ever fulfill my desire to travel, I shall see the sights and remain no longer.

I could count the times I have been to a synagogue. I have an advantage in that I can follow the ceremony, for I understand the language. When I feel especially blue around the day of atonement, I generally go to synagogue. We always make it a rule for some one to fetch my grandmother home, as she becomes weak from fasting. I do not know what struck me first, the stupidity of the people placing their trust in a being who maltreats them so, or whether they were particularly blessed in that they could believe in such a being. But the ceremony and the chanting of the choir, the rabbi, and the congregation are beautiful. I cannot stand a reformed temple. These are very attractive in structure and program, but they lack that spirit which the synagogue has. When one enters a synagogue, one feels that one is a Jew in the full meaning of that term.

I have never been particularly moved to devote my entire life to the service of my fellow Jews. I don't feel as if they need it. A part of the cultural heritage of the Jew is the ability to make himself at home in whatever country he happens to be. American Jews will work out their own problems. They are aware of the subtle prejudices against them. They accept them and work out their salvation on that basis. It is difficult, and one is often disgusted, but to some people competition is an incentive. We will not be put down. We often meet in associations of some kind like the Avukale (Torch) and discuss the problems of Jewish students on American college campuses. I 
may also add that nowhere, except college, is one faced with secularization because of race. There are different fraternities based on race, color, and religion. Of course, in these one is supposed to make life-long friendships and it would be impossible, wouldn't it, to make a friend of a Jew or Negro? In a country like America, with all its cant of freedom and equality, it is a sad state of affairs when fellow students go different ways when they join fraternities. We have some little pride, and when we are clearly shown that we are not wanted, we refrain from repeating the mistake.

Sometimes, when I have had a painful day for no reason at all, in seclusion I cry out: "Why did I have to be born a Jew? Why must I suffer all this agony for no fault of my own?" Gentiles, some of them, wonder why I don't feel complimented when they remark that I don't look Jewish. I remember once I was working on a Jewish holiday in a department store. I was eyed askance by the other workers, but because I was working on that day, they didn't take me for a Jew. Before the store opened, the floor lady called the workers together and said, "Let's make the best showing we can and let those God damn Jews know that we can do without them." She probably had no reason to hate her Jewish workers. That hatred is probably part of her social and cultural heritage. It is prejudiced attitudes like that which we must endure. We are condemned without a hearing. But we grit our teeth and carry on. It is our only alternative. I should like to be optimistic and hope that when people will become more tolerant (Will they ever?), they will give up their falsely formulated conception of the Jew. This, and only this, will remove our problem and make living fairly tolerable.

\section{Russian Jew}

\section{No Handicap in Being a Jew}

I was born in the city of New York, spent the early part of my life in Iowa, and now live in southern California. My parents were born and reared in Russia and received an elementary education in Russian and Hebrew schools. They learned English by means of tutors in their adopted country. At present father is a jewelry engraver and manufacturer. I am, therefore, a Jew by birth, but unlike others, find no handicap in being a Jew.

When I hear some one speak of a racial superiority I think, "What an ignoramus you are, or you must be an educated fool." There has 
always been the idea among some of the Jewish people and among many of the "enlightened Christian missionaries" that the Jewish people are the "Chosen People." Whenever I hear this I always think, "Chosen for what? Chosen to be the people of a God whom the Jewish people refuse to recognize, or chosen to be the object of hatred and race prejudice?" I refuse to grant the presumption of the superiority of one people over another, and discard the idea that the Jews are any better than any one else as a race. My attitude is based on a supposed saying of Napoleon Bonaparte, "What man has done, man can do." Although my path will be rugged, due to my racial ancestry, I propose to do what others have done. After all, a capable person is judged by the individual that he is, and not the race to which he belongs. I would not become a convert to Christianity; that would just put a different light on the same problem. The attitude would be: There goes a converted Jew (a meshumed). I should be neither Jew nor Gentile. A few drops of water cannot change the heritage of a thousand years. Although I am not religious, a Jew is a Jew under all circumstances, and he would lose respect of his own people without gaining any from the Gentiles by his renunciation. The solution is not based on religious or philosophical reasoning, but on practical concepts of the problem of a Jew. The greater the number of barriers, and the more difficult the problem to be solved, the greater the reward and more sweet the victory.

When I speak of Americans, I am looking from the inside out. Each race has its own good and bad points. I have found a great many Americans to be crude and unrefined, as well as a great many Jews. Those persons I avoid as much as possible. I would just as soon tell an American what I thought of him as I would a Jew. There is a certain type of American that I keep at a distance, the type that is always offering me "religious salvation." The "salvation" that he offers to me is so intermixed with racial persecutions and inquisitions that the very idea is obnoxious. There is a saying in the law: "He who seeks equity must do equity." When the missionary comes to me with his tale of salvation, he must come to me with clean hands and an open mind. He does not come to me with the idea of "saving my soul," but of making his place in Heaven more secure. If he lived the true life of a Christian, he would not have to make his place secure; it would be there waiting for him. He comes to the Jew with the spirit of condescension, trying to show that the faith he professes to believe in is better than the one upon which it is based. The Jew 
knows more of Christianity than the missionary does himself. His faith is built uponphilosophical reasoning, and not upon an hysterical emotional basis. His religion is not based on a fear and a reverence for a loving and at the same time a revengeful God, but on an understanding of the relationship between God and Man, and Man and Man. One cannot become a Jew by having a few drops of water sprinkled on his head, or by making an acceptance in a moment of hysteria or during an emotional stress, such as is carried on by evangelists. To become a Jew the individual must prove to the religious teachers that he has studied the faith and understands the faith that he is joining. Thus, when one of the "soul savers" comes to me, he must know more about the religion which he is trying to take away from me.

Americans, taken as a whole, are prone to believe anything that the newspapers or some agitator tells them. To know the history of one's country is to understand the present-day history in the light of past events. One should be able to see through the shams and hypocrisies that are so prevalent in every age. Americans, if they knew the actual facts, would know that the Pilgrims did not come to this land for the purpose of attaining religious liberty, but that they came to these shores to establish an order of religion which turned out to be a system of religious tryanny unequaled except in medieval history.

On the other hand, I find much to embarrass me in the behavior of my language group. I have lived the greater part of my life among Gentiles and have acquired the same outlook on certain social questions. When I see certain people belonging to my group, at some of the beach resorts, drive down in their small cars, built to carry four or five comfortably, unload two or three families with seven or eight or even nine children, all under the age of ten, with enough camping equipment to make a load without the persons in the car, sit down on the beach and allow the children, in bathing suits all too large for them and gathered from all four corners of the earth, to run shrieking and yelling like a bunch of wild animals just let out of their winter quarters, I am disgusted. But that is not all; while some of the distracted parents are trying to get the children together again, others are giving coins to begging children who will presently come back bringing dripping ice cream cones or bottles of colored soda water. I am now ready to leave, but there is yet more to follow. The children get ready to bathe, and the parents start to yell again. It is "Becky, don't go so far out in the "wadder"" or "Becky, come up 
higher." At length they unpack the food and indulge in more shrieking and yelling, while the youngsters are being assembled. There is enough food for twice the number of people present; but by a process of eating at intervals for the whole afternoon, they manage to get rid of it, watermelon and all, leaving the rinds buried in the sand for some unsuspecting individual to soil his clothes on. Some more yelling, arguments, and crying of babies follow, and then the day at the beach is done. It is a situation such as this that humiliates me. I do not blame the members of my language group, beyond censuring them for not getting out of the self-imposed Ghetto. If they did so, they would change.

I do not use the language of my parents at all, although I can understand the greater part of what is said to me. I write, speak, and think altogether in English. The same is true of my acquaintances. I have many more among Americans than among Jews. My most intimate friends do not belong to my own race. With these I am more free to discuss religion and other difficult problems. I, in turn, receive their confidences. I have one friend whose parents ask me what he intends to do at times; to them his business dealings and other events are a closed book. There is another man with whom I discuss intimate problems; I hope to help cure him of an inferiority complex. In these and other cases, the relationship has been that of man to man, and not that of one race to that of another.

In my younger days, I was always a member of a group in which no distinctions were made. The whole group met at my house or that of some other member. I did not, however, attend their church or Sunday School. A share of school honors came my way. In college I did not join a fraternity until my second year, but during this year I was always invited over to fraternity houses to attend their social functions. The next year I joined, but later withdrew. My fraternity brothers criticized me for not limiting my acquaintances to my fraternity brothers. Upon leaving, it seemed that a chain had been taken off; I again started to broaden my friendships.

My relations with the synagogue are very limited, but I do not feel any loss. The trend of modern thought is too far advanced for all the churches, barring none. They refuse to recognize new knowledge that has arisen, and thus fail to adjust to the present modern conditions. Instead they accept the old worn-out dogmas, or else give very silly excuses to make the new knowledge coincide with the old. The whole religious situation is like an individual trying to push back 
a locomotive, and saying all the while, "No, you shall not go forward; our fathers never rode in or saw a locomotive, and therefore you shall not exist." The child of the immigrant has enough of a handicap as it is without heaping upon him an antiquated system of theology. If the church limited itself to the teachings of morality as given by Jesus and the prophets, including Moses, there would not be any need for more than one church. When churches go out of this field, they are doomed to failure. Morality does not change; it is only the degree that changes. The church has for the most part discarded the teaching of morality and has gone into everything under the sun except what it is supposed to do. Why should the child of an immigrant go to church, as this institution teaches hatred or abhorrence of another religion different from its own? The place now for the teaching of morality is in the home or in the schools.

My parents always say that a Jew and a Gentile should never marry, because such marriages are usually failures. But personally speaking, I have never found a Jewish girl that I thought I could marry. As to the failure and the unhappiness, I shall have to find out for myself. Between the new and the old generation there is the inevitable conflict between the custom and tradition of the world. I have seen cases where the children become strangers to their parents because of the failure of the parents to keep up with their children. The children, on the other hand, refuse to keep the old customs; the children act and think like Americans, and the parents like those of the Old World. Fortunately for me, my parents discarded their Old World customs as rapidly as possible and kept as far away as possible from segregated settlements. There is one point in which my father insists on retaining his foreignness; with some words having a Latin or German root, he maintains the old pronunciation, giving as a reason that such a word in Russian is pronounced in this way and that this is the way he learned it.

The Jews, as do most foreign races, have the problem of breaking away from the segregated districts, wherein the old customs prevail. The Ghetto was forced on the Jews, and they still retain it. It was originally for the purpose of kecping them in, and now it keeps them from getting out. They feel that the Jewish race cannot be preserved without the preservation of the Yiddish language and customs. Thus, when the children reared in such groups get outside, they are supposed to have all the advantages of a generation of American life, but in fact they are at a disadvantage, for they are neither American nor 
Jew. They are not a mixture, but a combination - part American here and part Jewish there.

\section{Polish Jew}

\section{Jew or Christian?}

"Don't trust a 'Goi.",

I had a vague notion that these words of my father were based on an unwarranted prejudice; my own experiences with Gentiles had been entirely without mishap. I never thought of myself as different from my playmates. I continued to play with boys and girls of my age, without considering the possibilities of a difference between us. In later years, however, I came to wisdom; for, you see, I was only ten at that time. One day a playmate, the only Jewish boy of my acquaintance, was captured by an organized gang from the "Hollow," the dreaded tough guys from the lower end of the town, brought into the woods, and tied to a tree. I thought they were going to do something dreadful. What they actually did does not matter. It was disgusting as well as cruel and cowardly. Their actions were accompanied with cries of "Christ Killer" and other derogatory names belonging to that class. My blood boiled as I witnessed my first expression of anti-Semitism.

I don't think this experience affected me for very long. I am fairly certain, however, that a vague consciousness of my Jewishness began with the two episodes I have mentioned. Although I continued to play with boys and girls as an equal, I had a dim notion in the recesses of my memory that all was not "Peace on earth, good-will toward men." Nevertheless, I cannot remember any other occurrences during my elementary school life that made me think of my racial position. Again father reminded me of the prejudice against our group when I entered high school and began to consider the choice of a profession. I still did not believe him, and continued through high school with a firm and growing conviction that a decent Jew is as welcome and desirable among Gentiles as he is among his own. It is quite evident that $I$ had begun to think, as my conviction implies a certain amount of reasoning involving a realization of a split between Jews and Gentiles. I also became curious about my ancestry.

I learned that my father was born in Warsaw, Poland, and that his parents, rabbinical people, died when he was a mere boy. At thirteen he came to this country, and peddled trinkets, in Boston. Finally 
he came to Maine and established a route which he maintains today. We, however, were never permitted to speak of his occupation at school as peddling; we were taught to say our father was a dry goods merchant. This is practically all I could ever learn of my father's story, for he is quite reticent about his past and dislikes to retrospect. Mother, on the contrary, is quite voluble when she speaks of the old country. She was born in Russia, the daughter of a lumberman. Being a younger child, she was forced to carry the burden of the housework and was denied the opportunities of an education. Judging from her picture, it must have been a pretty little foreigner who followed her older brothers and sisters to America. As far as I can learn, all she did was to sit and wait for some one to come to marry her. Father chanced along, and the match was quickly made. Neither had much education. In a country where a Jew's life is in constant danger, educational opportunities were few. Father reads and writes well, and mother reads not only well, but voraciously and omnivorously. Father's special forte is current politics and world affairs. He also understands the financial organization of the country and government. In fact, he is much better informed than I am along these lines. I have always been proud of his knowledge and mother's interest in reading.

At no time in my school life was I concerned to any extent with my racial position. In our town of about six thousand, two-thirds are French, one-third Irish, and the rest of us don't count much. There are a dozen Jewish families. The hill, where we live, is the stronghold of a Protestant minority. Most of my early playmates were either Methodists or Baptists. My best friends were Greeks, Frenchmen, and Irishmen, as well as a few Protestants. I had a heterogeneous coterie. There were no Jewish boys in my class, and the Jewish boys in town lived in the "Hollow"; consequently circumstances threw me in with all kinds but my own. In such a mixed group, race distinction did not play a very large part in our lives. I heard the usual cheap jokes, including those about the Jew, but these I came to regard as cheap humor. No direct affront toward the Jew ever hurt me. I had not yet been conditioned to a sensitiveness in that respect. I also had no animosity or contempt for any other race or creed. My father hated Catholicism because he had witnessed pogroms instituted by the Eastern Catholic Church in Poland. But his prejudice never tainted me; I was accustomed to take things as I found them, not as they were reported to me. 
In high school I began to think, especially along the lines of religion. The three Protestant, three Catholic, and the little one-room Jewish church gave me opportunity for observation. Being neutral, I heard the Catholic and Protestant points of view, and concluded that there was much bigotry and unchristian feeling on both sides. My own religious education was not strict; my only reaction was a feeling of insufferable boredom. Each member of the congregation tried to outsing each other member, and the confusion and discord were perfect. There was nothing beautiful or inspiring about it, and I learned nothing but to hate the annual periods of torture, when I must sit for hours and listen to the racket. I received the usual training in Hebrew for my confirmation at thirteen. Here again I learned to dislike something related to my religion. I was taught to repeat Hebrew without understanding it. My resentment showed itself in an incident that ended my training. One sultry July day when my brother and I were painfully parroting the Hebrew, we began to show signs of rebellion. The instructor anticipated it by taking off his belt and using it as a strap. My brother retaliated by a push, and we both escaped through the window to freedom. Thus was our Hebrew education terminated.

I now regret exceedingly that we were not better taught, since I now realize the scholarly value of a knowledge of Hebrew. Father's long career in America, coupled with his sensibleness, weaned him away from a great many Old World ideas. The restrictions on our foods were our sole adherence, and mother followed these more from sense of habit than from conviction. My parents' language is flexible; both use Jewish and English, although mother is prone to use more Jewish than father. In only one respect has father ever been strict: we must attend church day, and if we do not, he considers any variation as a lack of personal respect.

Ever since I can remember, I have been drilled on two ideals - an education and a worthy profession. Ambition is a habit just as anything else, and I was especially well drilled in that particular habit. When I was ten years old, I took a paper route, and I have worked from that time to this at all kinds of work, for the purpose of earning money for an education. That is what is called ambition. If analyzed, it is the inevitable consequence of much early training in the two ideals mentioned. Jewish parents, and foreigners generally, are what is called ambitious. The reason is that they are appreciative - of our system of free education. Besides, they have worked hard, 
and with them struggling is synonymous with existence. This feeling is carried over to the children, who also work hard, display ambition, and incur the enmity and enviousness of their weaker predecessors in the land.

Indirectly, then, I missed much that I would have enjoyed had I been of native parentage. My whole school life was one of work, self-denial, and study. I really did not know for what I worked until I came to college. I only knew that I must work, and that it was not good to be, like some of my friends, lazy and dependent. Later I came to realize that I must work three times as hard to go one-third as far as my native-born friends. I had many examples in the years that followed of the lack of self-reliance of the native-born, and I saw that their connections and not their merit gave them desirable positions.

My parents started me on the road to an education and kept me there. Failure knew no sympathy. Success was not praised. It was expected. This loveless treatment has resulted in a lack of affection for my parents. In other words, I have not been emotionally trained to reciprocate love at home. Nevertheless, I am conscious of the sacrifice, denial, and assistance of my parents and shall sometime make a full return. At the end of high school I said that my principal objectives in life were to remain honest, provide for my folks, and pursue a field of thought for which I was materially best fitted, and which I thought college would reveal to me.

To summarize this part of my life from the point of view of this autobiography, I should say that I grew up almost wholly unconscious of any difference made by race, and that I did some objective thinking on race distinctions in later high school days. I have used the past tense largely in the foreground because it refers to feelings and thoughts now altered or gone. College has made a big difference in my thoughts concerning race position. Generally, I have turned toward subjective thinking and have developed a consciousness of my race and somewhat of an inferiority complex as far as social intercourse goes. The reason for this change is well worth considering.

There are, roughly, two types of Jews: the country-bred and the city-bred. I belong to the former. The country-bred, I have observed, are thoroughly assimilated. They are usually indistinguishable from native children, except in facial appearance and other physical features. The city-bred are what I call Jewish Jews. That 
is, they have all the idioms, mannerisms, and character of the Old Country Jew. They talk loud, gesticulate, lisp, speak gutturally sometimes, are eager, arrogant, and in a petty way conversationally intolerant and impatient. All these characteristics, or most of them, are not in themselves unpleasant or bad, but they are different from native characteristics, and are, therefore, objectionable to the natives.

In college I first met the city Jew. I did not like him for the same reason that my native playmates did not. His manners were different. They irritated me, especially because they seemed to reflect upon me, for I too was a Jew. I could not help disliking those characteristics; yet I realized that they were not intrinsically bad. And I realized, too, that they were inevitable because of the segregation and clannishness of the city Jew. Still I was not proud to associate myself with that brand of Jewishness. But I was forced to. The Jews had their own fraternity, and I came to the realization that the days of free mingling were over, that adults stuck to their kind, and that it would be looked upon as a presumption for one kind to attempt to mix with another.

That was my first real racial conflict and an adjustment was necessary. I became bitter at the unfairness of it all. I was not ashamed of being Jewish, and I was really proud of the achievements of my race. But $I$ was ashamed of this foreign-acting set and did not want to attach myself to it. I have not yet made an adjustment. By early environment, by inclination, and by immediate preference, I belong and desire to form one with the children of native-born. But I cannot do so for reasons of social convention. It's unfair.

I have spoken to my father of this conflict, and he suggests that I affiliate myself with my own. He argues that there are many refined, intelligent Jews among them. I agree with him, but I am conditioned by this time against the name of Jew, and though I realize that it is a fault, I cannot make up my mind to identify myself with a group whom I have come to learn are generally despised or disliked.

The conflict has made me very introspective. I keep asking myself if I am very Jewish looking. I wonder if I could change my name and pass as an "American." I feel very conscious of my race in company with Gentiles. I am altogether unhappy. I know the solution, but I haven't the courage to adopt it. I could affiliate myself definitely with the Jews, and select a career which would allow of no discouragements or disappointments due to contact with those who dislike Jews. That is, I could go into Jewish Social Service work 
or something similar. I have an older brother who achieved something remarkable in comparison with the "American" boys' achievements. He worked his way through college and did well in his studies. But when he graduated, he found that he had to change his name to secure a teaching position, and he still experiences that implied affront to his race, which hurts more than direct insult, when he interviews men for a position.

As I say, I have become introspective. I feel at times that I should be ashamed of myself, and that I am cowardly. At other times I think that eowardice is acting contrary to one's convictions, and then I attempt to rationalize for the purpose of justification. And I reason it out in this way. I am not being cowardly to avoid something which I don't like - the Old Country mannerisms. And that doesn't necessarily eonstitute being a Jew, anyway. What is a Jew, then? A Jew, I figure, is one who believes in the Law, the God of his fathers. In that respect I cannot be a Jew. I have studied both Testaments a bit, and I have come to have certain ideas regarding them. It seems to me that Christianity, with its doctrine of a merciful, forgiving God and its doctrine of personal kindness or charity, is an improvement upon the first great principles of monotheism which the Jews established, and I consider the Jews at fault for neglecting Christianity. I also believe Catholicism and Protestantism to be perversions of Christianity. I had pretty well fixed these ideas in my mind when I was going through high school, and when I came to college, they did not help me to become a Jew.

I have often wished that my parents were native-born Americans, but I would not give up my heritage for anything. I am proud that I am a descendant of the people of Moses, Jacob, David, Solomon, and Christ. I am essentially selfish. I want to be the proud possessor of ancient and honorable blood; yet I wish my present problem to be solved in order that I may have an easier immediate life. After all, I am not much of an idealist, and I fail to get a compensating satisfaction from my descent. I take an interest in literature about my people which is due to ordinary intellectual curiosity, the same as I would have toward any other subject for thought. I am afraid that my interest, however, is slight and is not due to a mental participation. The same is true about my parents' native land. I would like to visit their birthplaces, and to know more about them. I suppose that their coming from those places enhances a natural curiosity, but I cannot say that I am fervently interested. 
In my present state of mind I am considering my brother's attempt, and think that I shall follow him. That is, I believe I shall try to make myself an "American." It will be necessary for me to attach myself to some church, since every one these days wants to know your religion. Every employment office and company asks the question. Then will come my real conflict. It will be cowardly i.e., against my convictions - to become anything, Protestant or Catholic. Why should I join either church when I neglected my own, since I believe no more in either of them? I am afraid that I am going to consult my personal interests, be a coward, and live a lie.

Sometime I shall marry. It may be an American girl. Then my parents would be displeased, but not greatly. I have met many Jewish girls and can say from wholly unbiased, scientific observation, as well as unscientific emotional reaction, that I like the non-Jewish girls better. I don't believe much in dividing into types in that way, but observation and feeling force me to do so.

My parents are thoroughly American, except in one respect, ambition for their children. That seems to be their whole life; nothing else matters. Americans, all parents for that matter, are ambitious for their children, but none so actively and sincerely as the Jewish parent. My parents want me to study hard; they allow a modicum of pleasure and time for recreation, but being young and full of spirit, I often exceed the limit. There is no sympathy at home for such slips; I am liked as long as I work and study hard. I have often resented this attitude because it seems too materialistic. I desired and expected love, not for achievement but for the sake of family feeling only. I haven't found it, but I have learned to adjust my ways to theirs.

I must say frankly that I don't care much about the future of the Jew in America. I am too selfish; I consider too much my personal social status. I have often tried to puzzle out the probable fate of Jews here in America, but I am not of prophetic vision. The problem balks me, and I turn back into my selfish self again. Superficially speaking, it seems to me that in spite of clubs, schools, hospitals, and social workers, the freedom and increasing heterogeneity of the country has doomed Judaism here. If a Jew can act like an American and get away with it, he will. Each year the opportunities seem to grow greater. If I can't get away with it myself, I'll turn Jew and aid the cause. But I'll probably succeed the other way. Six million 
people allowed to mingle freely among over one hundred million people are bound to lose their identity. But then I look at the problem from another angle. Religion and social structure are in a state of flux now, and it may be that a stronger and better Judaism will prevail. As to what should be, I am also uncertain. Is it better for a country to have many conflicting races and creeds, or is it better to have them melted into a common pot? Being unfit to preach or teach on the question, how can I advise the multitude when I have not yet made satisfactory personal adjustment?

\section{QUESTIONS}

1. Read Young, Pauline V.: "The Russian Molokan Community in Los Angeles," American Journal of Sociology, Vol. XXXV, pp. 393-402, and show how this Russian girl (number 2) lived in two culture worlds. In which of the other documents is there evidence of a "divided" culture pattern?

2. Account for the differences in the attitudes of the second generation Slavs toward their parents' native lands. Analyze the Ukrainian's (number 3) hatred of his parents' native land.

3. What is the general attitude of these second generation Slavs toward the language of their parents? What language problems are revealed by the Jewish documents?

4. Which of these persons suffer most from conflicts relating to their education? Analyze each.

5. What occupational problems are the Pole (number 4) and Polish Jew (number 7) facing? What seem to be the underlying causes?

6. What were the social handicaps of the Molokan (number 2) girl? How has the Pole (number 4) lost intimate contact with his brothers? What is the gulf between the Russian Jew (number 6) and his parents?

7. Account for the differences in opinion regarding the handicap of being a Jew (numbers 5 and 6). What characteristics of the Jewish race are especially objectionable? Describe the beach scene mentioned by the Jew (number 6).

8. Which of these persons have forsaken their religion? In what respects do the Poles, Molokans, and Jews find their parents' religion obstacles? How does the Jew (number 6) analyze the status of the Jew and religion in general?

9. Discuss briefly the most outstanding examples of personal disorganization.

10. How does the reorganization of the Rumanian (number 1) differ from that of the Molokan (number 2)? Why did the rural community 
seem like an earthly paradise to the Ukrainian (number 3)? Note the influence of environment on the various processes of assimilation. 11. Describe the Ukrainian's (number 3) efforts to Americanize his mother. Compare other examples of parent-child assimilation.

12. What are the various opinions toward intermarriage?

13. How do the second generation Americans regard their problems and what ultimate solutions do they hope for? 


\title{
LIFE HISTORIES OF OTHER RACIAL, NATIONAL, AND CULTURAL GROUPS OF SECOND GENERATION AMERICANS
}

\author{
I. FinN \\ A Finn, But an Outsider in Finnish Circles
}

I was born and reared in a section of a Massachusetts town which is separated from the main part of the town by a wood approximately one-half a mile in width. This separation created a definite community and set the dozen Finnish families off by themselves. The men worked together in the farming plots and quarries, while the children banded together against uptown gangs. On Sunday the whole community turned out and walked to church together. Perhaps I should state that in earlier times two Finnish factions arose churchers and the socialists - and neither would have anything to do with the other. We children took up the battle, and participated in many verbal arguments and fist fights. True to my group, I honestly hated the socialist Finns. This conflict, however, died out when we began to attend high school and think of courting.

I can't remember learning to speak English. As a first-grade child, I assumed the rôle of interpreter for Finnish children and became the official.interpreter for my mother, who has never uttered a word of the English language. Often I had my difficulties with the vocabularies. A classmate was shouting, "Men can't have any more liquor!" after the enactment of prohibition. I was mystified, for I had no idea what liquor meant. Shopping with mother was a sore trial and required a great deal of candy and movie money as a compensation. When she would object to the price of goods, I would cry, since I dreaded to convey her objection to the clerk. Often the business transaction reached a magnitude too great for me, but there was nothing to do but do my best. The Finnish paper also gave me some trouble. On the occasion of its arrival at the post office, I would wrap it in an English paper, or else hide it under my coat while taking it home. 
Unlike my mother, father spoke beautiful English. Although a laborer, father took an active part in the educational and religious work of the community. At church, he was "lukkari"; that is, he played the organ and later the piano, and led the congregation in singing. Each year he conducted a musical festival. The office of "lukkari" and the musical festivals are of Finnish origin and are fast dying out in this country. Father was a lecturer, particularly in the temperance societies. During the summer, he conducted language schools in the native language, but unfortunately my lack of interest kept me from caring for Finnish until I was grown. When father died, these cultural influences passed out of my life. Father's relatives had held municipal offices in Finland, while mother's had been peasants of the distinctly feudal kind.

My change in attitudes at this period may be traced to the changes that came about in our lives. Mother began taking in washing and moved the family to a cheaper location in Finn Alley. I straightway joined a gang, broke windows, fought other gangs, and more than once fell into the hands of the police. We were especially antagonistic to the Boy Scouts and their leader, a local minister, all of whom we regarded as "sissies." Mother suddenly made a visit to an adjoining state, which then seemed as far away as Europe. In another month, I saw my stepfather for the first time. Soon we were living in New Hampshire and with eight additional brothers and sisters in addition to the four boys of our family.

My twelfth year was my last in grammar school and came very nearly being my last in school. At first I enjoyed the freedom of farming in summer and chopping wood in winter, but after four years of this life, I concluded I did not care to chop wood all my life. The stories of the Finn lumberjacks concerning their adventures in Canada interested me immcnsely. They were a motley crowd; some of them had served terms, others had attended schools, while still others belonged to the type "try to find what has been, if you can." When I proudly assured them I was not cutting school, but a workman, they looked at me with a peculiar glance. The old lumberjacks always recommended an education. But an education to me always seemed like a big proper noun to which I would never have any relation.

When I did return to school, I found it difficult to speak even approximately correct English. In a play in which I was taking part, I had a hard time to keep simple words like them and that straight, 
and a still worse time at the dance that followed. I could not dance, and I felt that no girl would want to take a chance with a hick who couldn't speak English intelligently and who looked the rural part to perfection. I did learn to dance, but not from the kind of people I wanted to. Being overly ambitious, I antagonized the other students. My athletics, however, served as a kind of compensation. At first I was enthusiastic and thought all the fellows I knew should also take advantage of such educational opportunities as I was grasping. But I don't believe a single Finn was a bit interested in what I had to say. To them and their group, success meant a good job; book learning was regarded as useless. They called me scholar and continually reminded me that big jobs came by pull, not by education. They constantly said to me, "You are a Finn and will always be." I never told any one that I was trying to go to school in order to get a good job. These attitudes are prevalent among rural Finns.

My own situation is especially difficult. Mother, being uneducated and very religious, found my ideas heart-rending. I assumed the attitude that she knew nothing, and preferred a dance with Englishspeaking people in preference to going to church. Although completely broken from the church, I now go sometimes in order to see the Finnish people. I feel an outsider. I know it would break her heart if she knew the real situation. Nevertheless, I do derive much pleasure from my ancestry. Once when working I learned from the boss where to find a bunch of Finns. Many pleasant evenings I spent listening to old Finnish folk songs, mythology, and superstitions. I became so interested that I have since spent many happy hours reading Finnish literature. There is something that makes my flesh reach out into their very existence. I now have the background for the Finnish culture.

I have a very personal problem. For my personal advancement, I believe it necessary to keep away as much as possible from my national group, where I am pointed out merely as one of the Finns. Away from this group, I feel alone, as myself, not as myself and a group of which I am a part. Still, even if I am identified as a Finn, I lack the foreign tinge that really makes me one of them. I want to be careful that the difference may never become too great, the gap too broad. Then I should irretrievably lose an essential part of my life - human relationships that should exist between parents and children of like culture and blood. To despise or neglect my likeness would be despising and neglecting myself. And as for the country of 
my parents, I am very proud of its progress and am pained when it takes the wrong side of a question.

\section{FinN \\ Proud of Being a Finn}

I was born of Finnish parentage in a small mining town in the southwestern part of Wyoming, to which my parents had emigrated for economic reasons. Father came over at the age of fifteen and started work at once in the coal mines. When I was almost five years of age, we moved to Cuba, where father had some years before bought twenty acres of uncleared land for farming purposes. Here on the sugar cane farm, I spent the best part of my childhood with American, French, and Swedish children for my playmates. Unable longer to endure the hot Cuban climate, my parents sold the farm and returned to the United States, this time to southwestern Pennsylvania. My next six years were spent in a small mining town composed of the greatest conglomeration of immigrants I have ever seen. Hardly an European nationality was unrepresented. In 1925 a coal miner's strike was called, the mines were closed, and the union was broken. Deciding to return to the land, father bought a run-down farm in New Hampshire and again became a farmer.

In my school experiences I found no difficulties because of my foreign ancestry, as in these communities the majority of the children had foreign-born parents, just as I did. My parents have made no attempt to retain Finnish customs or traditions other than to live in communities with others of the same race. They cannot speak English sufficiently well to feel at home among English-speaking people. For my part, I use both languages fluently. As a child I was ashamed to speak Finnish before native-born Americans, but now I am glad to be able to speak more than one language. I only speak English with Finns because I feel more at home with it, not because I am ashamed of speaking Finnish.

After trying several hobbies, among them electricity, I finally hit upon agriculture, and took up several projects. I have had to discontinue my rabbit business since entering college, but I still have my two registered calves, which I hope to make the foundation of a registered Guernsey herd. I am now in my second year in college, a special student in the Department of Agriculture. Why have I decided on this career? Had my father remained a coal miner, I do 
not think I should have accepted mining as my life work. Had I remained in Cuba, I might have made a struggling sugar cane farmer. I do not know; however, I believe my ambition would have pulled me to accomplish something more than my immediate environment had to offer.

I am now interested in government and politics. It is my ambition to become a farmer and as such to take a part in the government of the state. I realize that a man with a foreign-sounding name will have difficulty in appealing to an American electorate. With the help of the Finnish electorate, I hope to reach at least the state legislature. It is not my intention to live among Finns, just because they are Finns, but because they are progressive and maintain an excellent community spirit. I believe I could be just as happy among Americans, equally progressive. I am proud to point to the fact that most of the Finns, with perhaps fifty cents in their pockets and half their belongings in mortgage, came to New England to farms deserted by the Yankees, and have gone forward since, instead of backward.

Perhaps I should point out the distinction between the progressive and reactionary Finns. The latter maintain Finnish patriotic societies, such as the Knights of Kalevala (Kalevalan Ritarit). Such organizations are regarded with contempt by my group, as these tend to retard assimilation by putting the welfare of Finland before that of America. I have grown up among the progressives, the element that has given so many freethinkers and has discarded the last vestige of religion. As regards my home, I never saw either of my parents in a church, although both were brought up as staunch Lutherans. It is needless to say that I belong to no Finnish clubs or other organizations, except agricultural clubs and other community organizations of which Finns compose part of the membership. I am especially proud of the bull club I helped to organize among Finnish farmers with the purpose of securing and owning coöperatively a high-grade animal.

We consider ourselves as Americans. Father became a citizen at the earliest possible moment. He is still interested in happenings in the old country, but only as a college alumnus remembers his alma mater. I remember no occasion when I wished my parents were native-born Americans. Having lived among so many groups of foreigners, I have never been forced to consider my nationality very seriously. Had I lived in an atmosphere of racial hatred, I should probably have a different story to tell. For my part, I made out as 
well being a Finn once removed as if I had been born 100 per cent American. I am just as proud of being a Finn as some other fellows are of being Americans.

I like to read about Finland and have perused most of the books in English. I find it a wonderfully interesting land in its geographical, ethnical, and historical aspects, where in the face of innumerable natural handicaps, the Finns have made a living and developed a country and a nation. Finland, as we know, was the first state in the world to grant the right of suffrage to women and had the world's first socialist prime minister. Having assumed this objective attitude toward Finland, identified ourselves with the progressive element, and having discarded all religious customs, I find myself handicapped in attempting to describe any customs of the old country now retained among the Finns in America. Certainly a people who would be radical enough to eliminate entirely such an universal custom as religion would not hesitate to discard other conservative traits of culture.

I can refer to no other custom so characteristic of the Finns in America as their indispensable "sauna" or steam bath house. No matter where the Finns have gone, they have built a bath house. I have found such houses even in the smallest Finnish communities in Cuba, where it is eternally hot. Nearly every farmer has his own, which he warms up once each week. In larger towns, where private ownership is impossible, some ingenious Finn usually sets up a large community bath house and operates it for profit. Many Finns prefer brown to white bread. The American wants his of bolted wheat, the Finn of coarse rye. Although hardtack is more expensive, it is generally served in Finnish households. Clabbered milk is another peculiar article of the Finnish diet. It is usually eaten with bread. Salt fish, uncooked, is likewise quite popular. Finnish people drink large quantities of milk; it is served instead of tea or coffee. Coffee is served to every visitor, much as tea is served in England. It is the established custom to serve coffee to all callers, and the custom for each Finn to average four or five cups a day.

\section{Hungarian}

\section{Upholding the Hungarian Spirit}

I was born of Hungarian parents in New York. Both parents were natives of Hungary, the town being now a part of Czechoslovakia. 
Father came to this country when eleven, but returned with his parents and served his three years in the Hungarian army. After the period of service was over, he rejoined his parents, who had again come to the United States. Mother came at the age of sixteen years and has been here ever since. She came alone and lived with friends. After their marriage my parents settled in New York. Father was the first person to help organize a Hungarian Reformed Church in his town. I spent my early childhood here and received my education at the public schools. My parents, being very strict, saw to it that I not only attended the Hungarian services, but those of the English church as well. In this way religion became a great factor in my life, and early I joined several religious organizations. My work with the Hungarian youth certainly brought out the Hungarian spirit that I had stored away but never used. I began to love Hungarian music, history, and literature. Never did I dream that Hungary was so interesting. Her literature, art, and above all her music inspired me immensely. I sincerely hope that some day I may visit this wonderful country. My interest became so deep that I wanted to train for missionary work among the Hungarian people here in America, but father opposed this idea and caused me to give up my ambitions along this line. Because I am interested in Hungarians, I have by no means given up my American friends or withdrawn from their society. I am a member of the Eastern Star and thoroughly enjoy the meetings.

Due to mother's health, we came to California. I had to leave all my relatives, childhood pals, and above all the church in which I grew up. I knew there would be no Hungarian church in our new location, and I was afraid I should forget how to speak the language. It seemed to me as though I were going to some wilderness instead of a civilized and prosperous city.

Shortly after our arrival, a young minister whom I had known for five years came to organize a church. I assisted him; today we have a splendid congregation. Much of my time I devote to this work. As our services are held in the English Reformed Church building we are brought more closely in contact with English people. I also belong to the Young People's Society of this church, and in this way bring about a closer relationship with our Hungarian young people. Often we serve on the programs of the English organizations. My friend talks on Hungarian customs and I render Hungarian music. By these means we hope to bring out the best in both native heritages. 
Such a policy will certainly be of benefit to the Hungarian people as it will make them feel more free and help them learn American ideas sooner. Outside my church work, I am attending the university and working as secretary to the principal of a public school. The time I have left, I devote to the young people. My friend and I, with the help of our congregation, are trying to uphold the Hungarian spirit, but at the same time we are trying to make splendid citizens.

\section{Armenian}

\section{The Ups and Downs of an Armenian}

I was born in Harpoot, Armenia, a few miles from Mount Ararat. My father and mother were both teachers, graduates from the Congregational Missionary College of Harpoot, and members of the better social class. Father came to America, and mother followed shortly with us children, who were mere infants. They took up their abode in Connecticut, and it was there, in Hartford, I spent my boyhood days. At school the kids shunned us because we were Armenians, and refused to play with my brother and me. Being denied social intercourse with boys of my age, I felt more or less bored and unhappy. This state of affairs changed, however, when I mastered the English language without a pronounced accent, and began to associate with some German and Swedish boys in our community.

After I finished grammar school, my father wanted me to become a mechanic. In fact, he actually got me a job at the machine shop where he was employed. My hands were always in grease, my shirts always dirty, and I could not wear a collar and necktie; therefore I determined to quit and make a man out of myself. A job in a drug store gave me the idea of becoming a pharmacist, and the bent of Armenians toward business caused me to turn toward drugs as a profession. I worked at night and went to school in the day time, and in this way took my training. The little time $\mathrm{I}$ had for recreation I spent at a movie or at my fraternity. I worked at the drug business in Boston, till offered the position of assistant chemist to a firm in New York. Having married a girl from California, I became obsessed with the "get rich" idea at that time so powerful in her native state. Accordingly we migrated to California, bought a ranch, farmed for six years, and then went broke. I immediately took up my profession, and I hope to stay in it the rest of my life. In all this 
shifting, I learned a great lesson - a person should stay in the work he knows something about. The minute I gave up pharmacy I went broke; the minute I went back to it I prospered.

The crisis in my life came with my financial break. And with it was associated a most unpleasant social aspect. I had never anticipated difficulties on account of my race, but a sad awakening awaited me at Fresno. In that town, in which Armenians predominate everywhere in business, I found that my race was excluded from any possible social or religious intercourse with Americans. Singularly enough, the Americans there are not of a high class. All foreigners are absolutely separate and distinct from the Americans. This is the only place in the United States where prejudice exists against the Armenian race, and is due, I judge, to the fact that Armenians own about 98 per cent of the ranches and farms. The effect of the discrimination was very depressing on me, and would have made a bad citizen out of me, had I not been educated enough to know it was due to local business jealousy.

I enjoy reading about the customs and habits of Armenians, Turks, Kurds, Arabs, and allied nationals. I am not proud of my native country, for as a nation it is null and void. The one outstanding feature is that she was the first nation on earth to accept the Christian religion. The low state of civilization there would make it impossible for my family ever to be happy in such an environment. Most of the language and customs we have discarded. My wife and I speak to each other in English, but I use Armenian in conversing with my parents. Once in a while my wife cooks an Armenian dish, when we feel that deep-rooted blood relationship to our parents. My parents, on the other hand, will eat nothing but Armenian dishes cooked in the old-fashioned Armenian way. Although I have lost most of my Armenian culture, I am still not in accord with many practices in America.

I would allow freedom to the average boys and girls, but require a strict observance of the rules of society. I most certainly would abolish the present-day custom of boys and girls riding alone in an automobile at any time of day or night, who are not man and wife. I would also put a ban on petting parties. On the other hand, I would modify prohibition so as to allow wines and beers; otherwise the young people of America will surely go to ruin through secret drinking and petting parties. Children should mind their parents more and more by severe punishment. Teachers should reproach 
the students for every small and minute mistake; fear breeds obedience among children. A great many Armenians are now intermarrying, although the tendency has been for this group to insist on marriage within the group. In my own case, I was dissuaded from marrying a girl to whom I was engaged and to marry a descendant of my own group. I believe, however, that in another decade or so, the race barrier will be entirely broken down.

\section{Syrian}

\section{America is My Country, and Americans Are My Countrymen}

I was born in Massachusetts of parents born in Syria. They came to the United States in order to earn a better living. Syria is a poor country, and a majority of the people live on the bare necessities of life. Some of them even have to eat wild fruits and grass in order to keep alive. One of my friends was forced to exist on such a diet. Almost every one deals in agriculture, and the young men who do not follow this occupation enter the army. If a person in Syria cannot support himself, he must seek aid from relatives or else starve; there are no overseers of the poor. Physical strength dominates, and strength, not intelligence, rules the country. It was from such an environment that my parents came to America, hoping to find life easy, as had been pictured to them by Syrians. Father, who was a stone cutter, became a weaver in the new country, and mother took her place beside him at the looms. In our home they maintained the Syrian manner of living.

Most of these customs they transplanted to American soil, in thought if not in actual behavior. Most Syrians eling to the Old World manner of conducting funerals and marriage festivals. When a Syrian dies, all his acquaintances and friends spend three nights in mourning, and on the day of his funeral sing a song relating all his life work, which is very lamentable. All the Syrians in the community give the bridegroom and bride a reception, at which there is much drinking, feasting, singing of Syrian songs, and finally a speech by the bridegroom. Before the marriage ceremony, the man finds whether or not the bride-to-be is pure (a virgin); and if not, he calls the marriage off. On the whole, men have little to do with women in Syria, women being considered very much inferior. Men congregate in coffee houses, drink, play cards, and talk, but the women remain at home. In these houses much of the Syrian culture 
is maintained. All Syrians of this country greet each other as brothers. One custom, however, was not brought over. In Syria a stranger is given room and board for three days and nights without being questioned as to his mission, but at the expiration of this period, he is questioned as to his business. As I associated with natives to a great extent, I-was subjected to non-Syrian influences.

My parents left me in care of a hired woman, who permitted me to run the streets as I pleased. I loafed and gambled, and otherwise ran wild. But I do not blame my uneducated parents, who were working ten long hours every day in the mills. Being poor and knowing the value of a dollar, they urged me to seek a profession. After some experience on a construction gang, in the mills, and in a store, I decided to learn business for myself. Although I am of immigrant parentage, I do not think this will affect me in America. I feel that America is my country and that Americans are my countrymen. I shall surely never return to Syria. I know practically nothing of the language; the country is under the protection of another country, and is in a very backward state; and should I go, it would be necessary to readjust my whole life over again. This attitude, however, does not spoil the joy of visiting a newly arrived immigrant to hear news of that country. I am afraid that this interest is more a desire to obtain information than to learn about my parents' native land. Every time I think of my poor start in life and of the bitter struggle they have had in America, I wish they had been born native Americans. Taken as a whole, I have no pronounced feeling either way toward the land of my parents.

I happened to have been reared as a Catholic. In Syria each town has its own peculiar brand of religion, Catholic, Protestant, or Mohammedan. It so happened that the prevailing sect in the region from which my parents came was Catholic; consequently I was brought up in that faith. In early life the relation was close, but as years went by the breach became wider. Right now I am skeptical. I do not believe that a person should take as his religion the one in which he was reared, just because he was forced into this channel. I believe attending American churches will be of great benefit to immigrant children, as it will draw them closer to Americans.

I have had a few conflicts with my parents, due mostly to the question of substituting American for Syrian customs. These are inevitable conflicts that arise as the Old and New World cultures 
meet. Even though Syrian parents associate in a business way with Americans, they largely remain Syrian in their living. And in the manner of living grow the seeds of discord.

\section{Hawaitan-born Chinese}

A Chinese But Not an American; An American But Not a Chinese. What Am I?

It is my privilege to be a native of the city of - , which is in Hawaii, the "Paradise of the Pacific" and the "Melting Pot of the Nations." It is also my privilege to be born of Chinese parentage. My mother also is a native Hawaiian of Chinese parentage; my father was born in China, I believe. But he spent the greater part of his life in Hawaii; ever since he was a child, and before the islands were annexed to the United States, he had lived in Hawaii. Both of my parents are American citizens; and so I may be said to be a second generation "Chinese-American." Neither my mother nor I have seen China yet, though we hope to make it our home some day. (I suppose that in China we would be called "American-Chinese.")

My mother reads English, speaks it with fair accuracy, and writes it with very little understanding of the rules of punctuation. She also reads and writes quite a great deal of Chinese. She had very little schooling in Chinese and English. Thanks be to the compulsory school law which compelled my grandmother to send her children to school, my mother was able to attend school as far as the third grade and to learn the fundamentals of reading, writing, and arithmetic. With the aid of her children and through her own industriousness, she has acquired a fairly good command of both the Chinese and the English language. She reads the American newspapers with the aid of a dictionary. I am proud to say that I have a very capable and talented woman as my mother - a woman who is very mild and gentle in her manners and who has a very calm and sweet disposition, and a woman who is loved by all who know her. My father, of whom I am also proud, was greatly interested in education; and he himself was an intellectual man with plenty of initiative and action. He was rather well versed in Chinese and he had a fairly good command of the English language, although his schooling was very meager. He was very active in promoting the welfare of the Chinese language school in - He was a man of great will power and of force; he was very sincere, frank, and open; and he was well loved by his friends. 
There are ten of us children - two boys and eight girls. I am the eldest; and my baby sister was only five days old when my father was killed in an automobile accident more than a year ago. One of my sisters will graduate as a teacher in June from normal school; one is a junior in high school; another is a freshman in high school; and still another is in the sixth grade of the "select" grammar school. My brother, who is seventeen years of age, is a freshman in the University of Hawaii; and my younger brother, who is eight years old, is in the fourth grade of the "select" grammar school. All of my sisters and brothers, excepting my older brother, the three youngest sisters, and the sister who is in the normal school, are also attending the Chinese language school. My older brother and sister have graduated from the Chinese school; and they are quite well versed in Chinese. I attended the Chinese language school irregularly for three years; but that has been so long ago that I have forgotten nearly all that I did learn. Now I speak but very little Chinese and with great inaccuracy.

English was spoken mostly in our home; my father was perhaps the only one who spoke Chinese all the time. Of course, he was anxious that we should have a good command of our native language and speak Chinese fluently; but we found it more convenient to converse in English - at least, I did. My mother was anxious to learn the English language; and so she too spoke English frequently. When she spoke in Chinese, we would reply in English. Through disuse I have forgotten how to speak my own tongue; whenever I hear myself speaking a few words of Chinese, I am amused because my accent is foreign, not Chinese, and the sounds I make are very imperfect and incongruous to my ears. What sentences I can construct in Chinese are not Chinese, but translations of English sentences; and hence they usually are not intelligible to the Chinese people, but they are more or less intelligible to the Chinese who speaks English and can think in English. I am sorry, and feel ashamed that I have neglected my own tongue in learning the English language. In my negligence, I failed to realize the value and significance of knowing my own tongue; I thought that since I was to live in Hawaii, where the English language is the medium, I need learn no other but the English language. But I have changed my ambitions and have set service in China as my goal; and with much sorrow, regret, and grief - so to speak - I realize that I must learn to master my own tongue, which has become more foreign 
to me than French. Furthermore, certain experiences which I have had since coming to America, and which I will relate later, have made me feel the shame, chagrin, and humiliation of a Chinese not knowing his own tongue and the tragedy of the "man without a country."

Here, I must say a few words about Hawaii and the part it has played in my life. Hawaii is truly very cosmopolitan, and democratic in spirit. All nationalities and races are placed on as equal a footing as can be expected of mere human individuals, all of whom, I believe, are biased by nature and have prejudices of one sort or another. These different nationalities and races mingle together rather freely - as freely as the differences in customs, ideals, culture, etc., will permit. The younger generation mingle more freely since they are brought up under the same environment and trained in the same public schools. In the public schools, every one is given an equal chance; the Chinese, Japanese, or Portuguese is given the same recognition as the American in scholastic attainments, etc. There are two "select" schools into which those capable of advancing more rapidly than the average may seek admission through examinations given by the school. No one, because of color, race, or creed, is barred from entering these select schools if he has proven himself qualified for the work given. During my senior year in high school, a Portuguese boy was elected president of the student body, a Japanese boy was secretary, and I was vice president. Among those chosen to speak at graduation was an American, a Japanese, and myself - a Chinese. For years the Orientals have ranked the highest in scholastic achievement in this high school. In my class of one hundred and ninety-seven members, another Chinese girl and I took first and second places, respectively, on the scholastic honor roll. In the honor society - a scholastic and social honor society - called the "McKinley Citizenship Club," there were members of all nationalities. Of course, the Americans usually led in the social activities; but if the student of another nationality had any initiative, any capacity, and any desire, he too could lead, for the opportunity would not be denied him. There is little or no distinction in the social activities of the school.

I never felt prejudiced against any race or nationality; I had as warm friends among the Japanese, Koreans, Americans, and Portuguese as I had among people of my own race. Perhaps this lack of race prejudice was due mostly to the fact that we all thought 
as Americans. I considered myself an American and all others as Americans - all of us being American citizens by birth on American soil. I did not stop to think of myself as being distinctly a Chinese, and of my friends as being distinctly Americans, or Japanese, or some other nationality. I was proud of my citizenship; I was proud of America; there was no other land for me - not even China. I felt like a true American in blood and in spirit; it never occurred to me that I am only a Chinese made American in spirit only. I presume there were many, the majority of America's foreign citizens in Hawaii, that felt as I did. We felt intensely loyal and patriotic to America - particularly during the period of the World War when American patriotism was at its height. This feeling for America is largely fostered by the public schools - by its teaching through the subject of American history and civics and by its democracy.

The public schools in Hawaii are taught by teachers of all races, all nationalities. They are open to all and free to all. The children of the different nationalities mingle freely together in the schoolroom and on the school grounds; there is no segregation on a racial basis. These schools maintain as high a standard as the public schools here do, and in some cases higher standards. We are taught as Americans - taught loyalty, patriotism, civic virtue, good citizenship, etc. America is set before us as the most wonderful, the most glorious, the most beautiful country; there is none other like her. The wonderful and glorious history of America is taught in the grammar grades - all through the grades - and in high school. Before I was through high school, I had acquired the "American ego." I was apt to scorn things, ideas, customs, etc., that were not American; I thought of America as being on a much higher plane of civilization than other countries in Europe and in Asia. America was first and last for me.

I adopted the so-called "American or white man's religion" Christianity - when I was twelve years of age and while my people still worshiped their various and numerous idols and bowed themselves down before the ancestral tablet. There was not much objection on my parents' part to my religion; they considered it my personal matter and did not interfere. I was not compelled to worship as they did, but was free to worship as I pleased. My father believed in Jesus Christ as a great teacher, but he denied the deity of Christ. My mother, on the other hand, did not have much faith in the power of Christian religion, for she was constantly confronted 
by the irreconcilable, hypocritic Christian who gave her many doubts about Christianity. We had many long arguments over my religion.

Having adopted a different religion and thus having a different point of view of life from that of my family, it was natural that I should be more or less estranged from my family. Furthermore, my father was rather conservative, and so he could not quite concede to all of my American habits. There were some habits and ideas which were not particularly good for me to adopt but which I adopted just the same; I did not realize this at the time but I can see it now. For example, the American idea of equality; I was so possessed by this idea that I insisted on carrying it out at home; I tried to put myself on an equal footing with my parents. I discarded the Chinese custom of respect and reverence for elders, and for old age, and for parents. ' Of course, I later found my idea impracticable and erroneous. I was also more Americanized than my people; and so gradually, I sort of grew out of the family circle. The American ego and the American air of independence had too strong a foothold in me. However, this American ego and pride of mine, and my spirit and ideals of America, were to be cruelly shattered when I came to this country.

I was most thrilled when I left Hawaii for the United States; I was bound for the "promised land" as Mary Antin was when she set sail from Europe for America. I was more than thrilled when we sailed into Golden Gate harbor and landed in San Francisco. No words could describe my feeling as I landed in San Francsico and saw the tall buildings so closely packed together, heard the noise of the big city, watched the people hurry along as fast as they could, and gazed at the many wonderful things in the stores - in the department stores particularly, for I had never seen a department store before. I was fascinated, entranced, thrilled once, twice, thrice. I spent three weeks in San Francisco and had the most wonderful time; everything was new, so fascinating, and so interesting - the shops, the theaters and vaudeville shows, the parks, the amusement parks, the circus, the people and all. I enjoyed my sojourn in San Francisco so much that even now I feel thrilled whenever I am there - the memories of my first visit come back to me and thrill me over and over again.

Leaving San Francisco sorrowfully, I came to Los Angeles. I might say that I had not planned to come here to school; I had planned to enter the University of Washington at Seattle, Washington, but 
somehow my plans got changed and I came to Los Angeles. As soon as I arrived here, I went immediately to the University to register. My misery began as soon as I saw the University and its campus. Oh, what a disappointing place, what a horrid-looking place it was as compared to the campus of Stanford University and to the one of California, both of which I had visited while in San Francisco! I felt the tears filling my eyes.

I found a home and work with an American family living near Inglewood. The location of the home was to me at the end of the earth - in one of its corners. I had much trouble with the street cars for the first week. I had no idea that the streets were so long; one day I took a wrong car and had to walk many, many blocks before I found another street car which took me home safely. My work was new, but I enjoyed it. It was cooking and house cleaning plus washing on Saturdays. The house was very well equipped with modern conveniences and I was much fascinated by them. The family was nice to me, though not much interested or very congenial. I was very, very lonesome; I had no friends; I found Americans staring at me as though I were a strange being.

I realized very soon that I was not an American in spite of the fact that I had citizenship privileges. At the University, I was referred to as a foreign student; I objected to being called such at first; I insisted that I was an American - born on American soil and coming from an American country or state. But soon I learned that I was laughed at, mocked for my contention that I was an American and should be treated as such. The Americans were not friendly to me; I was more accustomed to the friendly, democratic, cosmopolitan spirit and atmosphere in Hawaii, and so I was very lonesome and homesick. There were many Chinese students on the campus, but I could not identify myself with them. Those from China were too much of a Chinese for me to have congenial relationships with; I could not understand them, nor sympathize with them; in fact, I was disappointed in them. As for the native California Chinese students, I could not understand them either; they were more Americanized than I; their Americanism was different from that which I had been accustomed to in Hawaii. They were not quite so democratic; in fact, they were more or less snobbish. I was very miserable for weeks; my work was getting heavier, the hours became longer; I had no opportunities to make friends, for I was kept very busy between school work and house work. In the evening, I was 
often not through with my work until nine o'clock; then I was tired, lonesome, and homesick, with lessons staring me in the face. I did not get much studying done, and as a consequence I was behind in my school work. Finally, when I could stand it no longer, I found a new home and moved there. I was near the University and my work was less heavy. I had more opportunities to make friends and more time for study. But I was still unhappy. The folks I lived with were not congenial; I was greatly disappointed, for I had always regarded the Americans as being very democratic, kind, congenial, hospitable, and gracious. I had heard also of the many Americans who had opened their homes to the foreign students. However, I was determined that I should overcome all these disappointments and obstacles. On learning of my unhappiness, my parents sent for me and asked me to return home; but this only made me more determined to fight my own battles and to come out victorious.

I gradually learned that I am a foreigner - a Chinese; that I would be wiser to admit it and to disclaim my American citizenship, particularly when I am in a Chinese group. I accepted my title as a foreign student more graciously. I became more accustomed to the stares of the American people, to their remarks, and to their sneers; I did not feel any less inferior to them; I did not feel antagonistic toward them, but I was disappointed and deeply hurt. But I was more deeply hurt by the Chinese students. They regarded me as an American-Chinese - an inferior product; they scorned me for not knowing my own tongue - rightly so, I believe. I felt humiliated and chagrined to think that I had prided my American citizenship above my own nationality when my American citizenship really means nothing - nothing in the United States - except the privilege of voting. A Chinese student even said this to me: "Why, you are not a Chinese; you think you are one. You are an American." And the Americans say: "You come from China (Japan frequently), don't you? When are you going back to your country?" Verily, I am a "man without a country."

I love America and would be her citizen, but she will not have me; there is no place in American society for the foreigner to do anything to contribute to American life. His poor contribution may only be made in the factory, in the sweat shops, in the mines, in the lowest and darkest slums of society. What chance is there for the capable, learned foreigner? No chance; but I do not blame the Americans entirely, for I am acquiring more of a sense of nationalism and can 
readily sympathize with the Americans. While I am being more and more Americanized, adopting more and more American customs, habits, and ways of thinking, I am also feeling more sympathetic for China - a great deal more sympathetic than I have ever been before. I am acquiring a love for her as I never had before. I am beginning to feel a sense of nationalism. "China for the Chinese!" "America for the Americans!" While I love America, I love China also now. I see no place in American life for me; and I see very little place for me in China, but there is more hope there than there is here. The Chinese will not accept me very readily and gladly, perhaps; but when I go to live in China, I shall expect to live as a Chinese and to think as a Chinese. I don't know how I should give up the American habits that I have so long been accustomed to; I don't suppose I'll ever give up some of them. When I become "Chinafied," I suppose I will still be American to a certain extent. But the process of "Chinafying" me has already begun; and so, I believe I could be "Chinafied." I have almost lost the American ego; I am beginning to see the superiority of some Chinese customs and habits to some American customs and habits. I am feeling for the Chinese and as a Chinese more than I have ever. I look forward with great joy and fascination to living in China and working there; at the same time, I cannot help but dread it also - dread the time when I shall have to make the change from American to Chinese ways and standards of living, habits of thinking, etc. Often, I feel afraid and want to decide not to go there; but I realize that the doors of opportunity are opened wider in China for me than they are here. Nevertheless, I love America just the same; nothing could change my love for her. How can one having lived in America not love her, not feel her wonder and glory? It will be a sorrowful day when I shall turn my back upon America's shores and bid adieu to American life.

I suppose some will ask, "Why don't you take your American habits, etc., back to China and Americanize your people?" But that is just the thing I don't want to do. I do not wish China to be materialized as America is today. I hope industrialism and the god of gold will never enter into China; China should give up ancestorworship in its extreme form, but she should not give it up entirely. She should adopt Christianity - not in American form, but in the "Chinafied" form. She should acquire some of America's more progressive methods in industry; but she must not acquire America's industrialism where men are mere cogs in the wheel, where men are 
divided into capital and labor, where the "Almighty Dollar" reigns supreme, leaving the workers, the servants, to huddle together in the filthy, unspeakable, miserable slums. China must educate her illiterate millions, but that education must make for service, not exploitation. China's real revolution and strife today is not political; it is social and particularly religious. China has gotten along remarkably well without a national government - this does not mean that she does not need a national government; she does - every country does. But China's political revolution is only the minor phase of her real revolution. China is in a transition period; she is turning her back upon the past and she sees nothing in the present to help her out in the future. I am sure that she cares not for the Occidental civilization; I hope she will build a civilization of her own - one superior to the one of today; one where the spiritual forces of life reign supreme. In this great struggle of China's I have faith that America will always stand as her faithful friend and helper. How can I love America enough for all that she has given and meant to me, and how can I love China without wanting to serve her when she needs me! My love for both is mingled with joy, sorrow, regrets, disappointments, and heartaches; but how my soul and heart are lifted up to the heavens away from the cruel remarks and acts of both Americans and Chinese to me, when I think of how I do love both America and China!

Note. In the fall of 1923 interviewee's father died, and interviewee left for Honolulu. Before leaving she bade good-bye to her friends, with tears in her eyes, for she evidently believed that her life in the United States was at an end. She was going home, as the eldest of a large family of fatherless children, to do her duty in whatever way she was most needed.

Three weeks later she appeared unexpectedly at the University and applied for readmission to her classes, without explanation. She was readmitted; to her intimate friends she explained what had happened. Upon her arrival in Honolulu, conditions at home had been made very uncomfortable for her. Because she had previously become a Christian, she was accused of bringing the wrath of her father's gods upon him, causing his sudden death by accident. To be blamed in what seemed to her to be a wholly unjust way was more than she could stand. Life at home, with her father gone and the finger of criminal but unjust blame ever upon her, was unbearable. She could not return to China; she could not stay in Honolulu; so she turned to her Christian friends in Los Angeles. They understood, and could give her a social response in the hour of her bereavement and trial better than she could get at home; consequently she returned to the University.

Now, evidently, she finds herself being referred to in Los Angeles as a foreigner so of ten that she dreads the time when college is completed and she "makes her 
way" among those who treat her as a "foreigner," even though she is a native American. Hawaii is unthinkable. China itself is the brightest ray of hope, and yet she feels her inadequacy for living in the homeland of her parents, whose language she has not mastered, and from whose traditions she has moved away. If China should fail in her needs for response and recognition, what then?

\section{Chinese}

\section{Never an American, Always a Chinaman}

I born in Portland forty-nine year ago. My father was merchant in Portland; he had large store there. I went to Chinese school little time in Portland, not very long. I go to American school also. My mother tell me when I eight year old that I have to go to China. I go to China and stay there until eighteen year old. I learn all Chinese custom and go to Chinese high school. I got wife before come back first time when I eighteen year old. I leave wife in China. When I first come back this time I go to my father's business. I stay with him about ten year. My brother in this business too. After this I go to San Francisco. Go into importing and exporting business there. Have very good business there. When quake come, it raise hell with everything. After this trouble no more business. Then I go to Denver. Stay there two years in same kind of business. I go back to Portland and go into business with father, uncle, and brother again. I come to Seattle first time December, 1915. I open up same kind of business Seattle as Portland. My father born in China, Canton Province. All my brothers and sisters born in this country. Two my brothers dead now. My father dead too. When he die he leave good business for long time. My uncle look after it for us. Every place they treat me just the same. I don't care which place just so long business good; that all right with me. I do business with many; black, brown, white, any color just the same. I do not want to bring my wife to this country. Very hard get her in. I know how immigration inspector treat me first time when I come back eighteen year old. I come back first time lots of trouble. They think me not citizen. My father have to go to court. They keep me on boat for two or three days. Finally he got witness and affidavit prove me to be citizen. They let me go; so I think if they make trouble for me they make trouble for my wife. I no like trouble; so I think best my wife stay in China. Maybe my wife try to come to this country they find hookworm something matter with her. I get news my wife dead in 
China. Three boys I have by this wife. This new law no good. Won't let me bring boy into country. I asked immigration inspector about this, but he say no, I can't bring him. Sure I go back to China two times. Stay ten or fifteen months each time.

I have dealings with immigration officer once, first time in 1906 after business in Vancouver. No let me into Canada unless I American citizen. I have to get paper showing this so that let me in Canada. Then in 1922 I have business Canada again. A friend of mine steal lots of money. I go Canada to get him. They let me in all right, but they take my paper. When I come back they no give my paper to me. Inspector tell me new law. I believe him. I asked my attorney about this when I come to Seattle. He say everybody know I eitizen. I no need paper. But about two month ago I want to go to Tia Juana. Cousin of mine want me to buy into business, and I have to have paper to go out of country. I tell inspector at Sumas keep my paper. I say it going to be hell a lot of trouble to get paper back, so I no go Tia Juana. I tell immigration inspector to damn new law this country.

In China I hear that it very hard to see American Consul. All American Consul have Chinese work for them. These Chinese very poor class of men. You go in to see Consul, this Chinaman he say, "Slip me little money, I fix it up for you." I no think Consul get money. Just Chinese work for him get it. This kind of job for Chinese considered very good. I only hear this. Every time treat me fine.

Lots of time people insult me. Once I remember I go barber shop. I sit one hour no ask me what I want. Pretty soon barber say, "What you want?" I tell him I want hair cut, how much? He say $\$ 3$. That make me mad, but I make him cut my hair just same. I say, "All right, I have my hair cut." He give me good hair cut. When he through I pay him $\$ 3.50$. He very surprised. He tell me come again. I never go to white bastard again. Once I go into restaurant; they refused to serve me. I no want to cause trouble; so I just walk out. Whole lots of things like this happen, but I forget. Now when I want to eat I go to chop house. No trouble there. My second wife take my little girl born in this country to have her hair cut at beauty shop. They say they very sorry, no cut Chinese hair. Oh, my wife get mad. She go see my lawyer and tell him about it. He write letter. They write letter back and apologize. All the time I tell my wife to keep away from those swell places, only make trouble. Sure I marry second wife Portland; she not like most girls born in this country. 
She pretty good. I live in store in residential district. When I in Portland I want to live in residential district, but they make lots of trouble if you try to live outside Chinatown. One friend, he born in this country, he buy $\$ 6000$ house in select city district. White people make hell lot trouble for him. They take it to court. He fight it. Just the same they kick him out. He can own house but no live here. I think that very unjust. Those people very uncivilized, have no regard for humanity. So when my friend had so much trouble I decided to stay in Chinatown. Nobody care there.

Yes, I belong to Sun Ning what some white people call tong. Sure, help in business way. All the same Mason just like white people join club. Bigger business, know more people. These societies or tongs are courts of Chinese justice. Chinese people no like to go American court. I think 99 per cent like this. Like settle trouble out of court. Sometimes one man one society get very mad man other society, maybe kill him. Then the society tell the man who kill that he better pay and look after other man's family. This right, you think? But society no like to have anybody get killed. These society grow up long time ago. Lots of little family squeezed by big family. Two or three little family join together against big family. Make big family play fair. My society make everybody in it play fair. Sure we associate with people of other society too. Something the same idea labor union, only labor union no stick together. Most labor union men no good. Chinese society men much better. Me being citizen, I vote in all election. Sure I vote every time I get chance. When I young fellow I felt that I American; I no Chinaman. Now I get more sense. I know I never be American, always Chinaman. I no care now any more.

I am not in favor of intermarriage. All right at first maybe, but Chinese custom different American custom. One case I know of. Friend of mine marry preacher daughter. She live with him five years; then she take everything and go away. Make lots of trouble for this man. Chinese people no like this. You Chinese, you marry Chinese, that's better. I think most Chinese in this country like have their son go China get married. Under this new law, ean't do this. No allowed marry white girl. Not enough American-born Chinese to go around. China only place to get wife. Not allowed to bring them back. For Chinaman, very unjust, not human, very uncivilized. Chinese girl I think very much better than American-born Chinese - no spend so much money, no like go shows. All they think about 
stay home help husband, save money. American-born Chinese girl, my God, spend lots of money, buy all the time, pretty clothes, fancy shoes. American girl no know Chinese custom, no like big family, little family. Yes, I think China boy much better marry girl in China.

My people be in this country long time. My grandfather come to this country. When I in China he tell me about work on railroad and work in laundry. Before when he go back they have the check system. Make Chinese carry paper tell who they are. Some inspector today make Chinaman show card. All same dog license. After a while Christian people of this country make them stop that kind of business. I pretty near forget all about,this. But last year I in San Francisco; started this same kind of thing again. I sitting in store with some other men. Big fellow walk in; he say, "Let's see your paper." I say "Who the hell are you?" He show me United States Secret man. I tell him I born in this country. No have paper; they keep them at Sumas 1922. I show him I business man from Seattle. He look my card. He say all right, but he take some other men, lock them up for day or two. I don't think this business last very long. Chinese Consul San Francisco make big holler. Very hard to tell whether people treat better now than before. Sometime I think so, sometime I don't think so. If you hard working man, you can make living this country. Most Chinese this country merchants and those who help merchants. Eastern people treat Chinese very much better than on Pacific coast. I guess cause not so many there. I think most people this country raise hell - Chinese, Greeks, Dagoes, newcomers to America, most of them no good bastards.

Most of the Chinese not very religious this country. Doesn't make much difference whether you Christian or not. One time Christian looked down upon. Not that way any more. Yes, some day I think I go back to China. Maybe I stay, maybe not. Not sure about going back because I own lots of property here, have lot of building to look after. Maybe I cannot find anybody to buy or take care of it for me. City grows. Property be more valuable all the time. Some day I think worth lots of money.

I hope this survey do lot of good for Chinese people. Make American people realize that Chinese people are human. I think very few American people really know anything about Chinese. Maybe this survey help them to know more. I hope so. 
VIII. JAPANESE

\section{Three Roads, and None Easy ${ }^{1}$}

I was riding in a Pullman car last winter, returning home to Los Angeles from a visit in the East, when I struck up an acquaintance with the Negro porter. Seeing that I was not a white man, but a Japanese, he beckoned me to come into his inner sanctuary by the wash-room several times during the course of the long, monotonous journey; and there, as we sat secluded, the Negro whispered to me stories of his people.

This porter was an intelligent fellow, a college student who was staying out of school that one year to make some money with which to continue his studies; and he seemed to know what he was talking about. Among the many things he told me, he dwelt at some length upon the difficulty which his people were experiencing in entering into suitable vocations. "I really don't know why I'm going to college," he confessed. "Outside of a few professions such as that of a physician or a teacher among our own people, there is no place in society for a college-educated Negro. The Negro is looked upon as a servant, and the white man will not recognize him as anything else. Why, I have several friends right on this railroad who are college graduates and now are working as Pullman porters; and in the eyes of the white man they are no different from any other Negro porter." That statement surprised me then, and I thought proudly to myself: "Thank goodness, we Japanese in America are not like the Negroes. We are not a scrvile people." I listened to the porter's story with a detached, condescending sympathy. But since then I have been thinking and observing, and recently, in my own experience, I have come across incidents which are forcing me reluctantly to wonder very seriously if the new generation of American-born Japanese on the Pacific coast is not facing the same problem as the Negroes in finding suitable vocations.

A few months ago I met an American-born Japanese fellow who had just been graduated with high honors in electrical engineering from a university of the Middle West. Every other member of his class had been offered a position before graduation, by electrical concerns near the university, and upon graduation they had stepped right into their professional field. But this one Japanese, simply because of his race, could not get a position. He had drifted to Los

1 By Kazuo Kawai, in Survey, LVI, pp. 164-166. 
Angeles, still seeking work, and the last I heard of him that he had finally secured a minor position in a little third-rate electrical shop in Honolulu, which offered practically no chance for advancement.

I know of another American-born Japanese who was graduated after specializing in foreign trade in the college of commerce of the foremost university on the Pacific coast. But no American firm would employ him as long as white applicants were available, although they might not be quite so capable as he, and no Japanese firm in America was doing enough business to need a specialist in foreign trade, so for months this man was without work. Finally, the manager of the San Francisco branch offices of the T. K. K. Steamship Lines took pity on him and gave him a position as a clerk in his office, at seventy dollars a month. Cases like these could be multiplied indefinitely.

The minor positions which these college graduates finally secured would not be so bad if there were some chance for advancement, for young graduates must all start at the bottom of the ladder. But there is very little chance to rise, for the Americans make no distinction between the second generation Japanese and the older Japanese, and we are all treated equally badly. It is impossible, at least on the Pacific coast, to imagine a Japanese in any high position which would require Americans to work under him. If, in order to avoid troublesome contact with American workers, we man a whole industry from top to bottom with Japanese, as we have tried to do in some fields, such as farming, fishing, and in some cases the hotel and restaurant business, the cries of "yellow peril" and "peaceful penetration" are immediately raised, and august state legislators feel it their duty to safeguard the commonwealth by taking drastic steps to oust us from our business by legislative measures. Or if we limit ourselves to businesses which cater to only the Japanese community, we are accused of being unassimilable and clannish, an undesirable element in American society. But however that may be, the Japanese community here in America is too small to support many businesses or professions by itself.

Our community is not self-sufficient. We can't stand off and live our own lives. We've got to find a place in American society in order to survive. And yet, no matter what our qualifications may be, evidently the only place where we are wanted is in positions that no American would care to fill - menial positions as house-servants, gardeners, vegetable peddlers, continually "yes, ma'am"-ing.

So, many of my friends are giving up the fight. "Why get an 
education?" they say. "Why try to do anything at all? Probably we were meant to be just a servile class. We can't help it, so let's make the best of a bad bargain." These constitute the new shiftless, pleasure-seeking second-generation element in the heretofore industrious, thrifty Japanese community. The nicer individuals who accept this defeatist philosophy are a little more subtle. Instead of trying to drown out their unhappiness with mere pleasure-seeking, they turn to the church and religion to afford them comfort and relief from their economic and social misery, and they hold a cheaply optimistic, goody-goody idea that if they stay in their place, work hard and please the Americans and remain happy in the position where God has placed them, surely the Christian Americans, out of the generosity of their hearts, will throw out to them a few more crumbs to ease their condition. Personally, I see no use in the cheap optimism of that type of religion which could deaden the ambitions and aspirations of those who suffer from social injustice, so as to make them contented with their lot.

I was urging a very close friend of mine the other day to go on to college. We were in high school together, and he made a name for himself by his outstanding abilities. But now he sees no use in continuing his studies. His attitude is - "What's the use of going to college? I have a little fruit-stand, and I give the American customers the kind of service they want. I have a comfortable income. I am happy. But you go on to college and get a lot of theories that make you dissatisfied with the condition of the Japanese here. You want to change things. But just the same, after graduation, you fellows all come around to my fruit store begging for a job." And what he said is apparently true. But if we are merely going to be a generation of fruit-stand keepers we are not going to be of much value to ourselves as a people, nor to the American community.

If it is so hard for us to get into suitable vocations here, why don't we go back to Japan? we are frequently asked. Only a few days ago I was walking across the Quad on our campus with an American classmate, and he turned around to me and said: "Gee! you fellows are lucky! Look at the great advantage you American-educated fellows have over the rest of your people when you go back to the old country." I suppose his attitude reflects that of most Americans. "Well," I should like to ask, "what do you mean by going back to our old country? We've never been there in the first place." Most of us were born here, and we know no other country. This is "our old 
country" right here. As to having advantage over the people in Japan, we have the wonderful advantage of being quite unable to speak their language or read their papers, of being totally ignorant of their customs, history, or traditions, of holding different ideals, of thinking in different ways. Yes, we have as much advantage over the people in Japan as a deaf mute has over a man in possession of all his faculties. An American would have an infinitely easier time in Japan than we would, for they would excuse a foreigner if he made mistakes, but we, with our Japanese names and faces, would have to conform to their rigid standards or else be "queer." As for advantage in education, with some of the universities over there like Imperial, Waseda, and others ranking with the leading universities of the world, what chance have we products of the American rah-rah system against their mature scholars? The trouble with us is that we have been too thoroughly Americanized. We have attended American schools, we speak English exclusively, we know practically nothing of Japan except what an average American knows; our ideals, customs, mode of thinking, our whole psychology is American. Although physically we are Japanese, culturally we are Americans. We simply are not capable of fitting into Japanese society, so we are destined to remain here.

Yet, placed as we are between the devil and the deep sea, some of us are willing even to take the chance of going to Japan to seek our fortunes there. One of my friends, a chemist by training, unable to find a position here as such, is soon to leave to try his luck in adapting himself to Japan. Another, a girl about to be graduated from the university after specializing in secretarial training, said to me: "After I graduate, what can I do here? No American firm will employ me. All I can hope to become here is a bookkeeper in one of the little Japanese dry goods stores in the Little Tokyo section of Los Angeles, or else be a stenographer to the Japanese lawyer here." So now she is planning to go to Japan, where she has already been promised a position in a large shipping concern.

"If I should get married over there," she confided to me jokingly, "there is nothing to prevent me from getting a prime minister for my husband; but if I remain here, I can marry only a gardener, or a cook, or at best a small merchant; or, if very fortunate, a dentist or a doctor." Among my friends, I know two other American-born Japanese girls who are soon going to Japan, both as teachers of English in the schools there. Some of the most valuable of the American-born 
Japanese are going to Japan and are being lost to America. No doubt they can do their work properly over there, but I am wondering what satisfaction they will get, living alone among strangers in a land that is entirely foreign to them, fighting against a whole social system into which they do not fit.

But others of our group intend to stay here and see the thing through. We don't intend to suceumb to our environment. We believe that our duty is to stay here and make a distinetive contribution to American life just as other national groups have contributed to American life in the past. But in order to make this contribution we must be given the opportunity to develop ourselves normally. Our immediate outlook is of course very dark. But our policy is to get the best education we can, to hold to the highest ideals we know, and to keep ever before us the vision of what we might aceomplish, even though for a while we cannot find vocations befitting our abilities. Then we shall be so dissatisfied with existing conditions that we shall be working continuously to change them. Only by such continuous hammering away will any change come about. Of course it is going to be hard on the individual who will have to plug away at an inferior position when he is really capable of something better. But this seems to be the only course which will bring any ultimate improvement. And to the eredit of the American-born Japanese, many of them are following this policy, and a few of them are beginning to find their proper places in society.

For myself, I am frankly puzzled. I see some of my friends practically admitting defeat and settling down to a life of docile servitude. I see others of my friends so impatient that they are willing to take the desperate gamble of trying to adapt themselves to life in Japan. And I see still others buckling down to the long and difficult task of trying to change conditions. None of the three ways seems very inviting to me, but I suppose that my sympathy lies with the last group.

My desire is to choose as my life work some profession which will allow me to utilize my peculiar characteristics as a member of the second-generation Japanese in America to the best advantage in making a distinctive contribution to American life. In a general sort of way, I believe that I have found such a life work. I think of the fact of race conflict, of the white and the colored races clashing all over the world, but particularly over the Pacific Basin, of the occidental culture which has spread and expanded ever westward, and the oriental culture which has spread eastward until both have half en- 
circled the globe and are now meeting across the Pacific Basin, of the challenge which that situation offers for interpreters who can bridge the gap. Then I think of myself, culturally a child of the Occident, understanding the Occident as my very own; but still racially a child of the Orient, very ignorant of the Orient, to be sure, but so constituted that with proper effort I could learn more of the Orient than could full Occidentals. Then here is my mission in life, to interpret the East to the West, and to contribute to America the knowledge accruing from a proper interpretation.

To prepare myself best, I am studying the history of the Orient, and especially the history of the relations between the Occident and the Orient. If I can learn oriental history and can teach it to Americans, I believe I will be rendering some service to America. In view of my preparation, I suppose that the most likely thing for me to do is to become an instructor in oriental history in some American university. But in view of the vocational situation of the Japanese in America, I cannot tell how I shall finally come out. In the end, I may have to seek out my college-despising friend and beg for a job at his fruit-stand. But in the meantime, there is nothing like at least trying for the biggest thing I can think of doing.

\section{British West Indian Negro}

\section{Battling against Prejudice and Segregation}

Although born in British West Indies, I was brought to this country so early that in reality I am a second generation. I attended elementary school in the West Indies for two years and completed grammar school and high school in Massachusetts. Fortunately race and nationality did not cause any difficulties for me from my instructors, but several times I was snubbed and ridiculed by my colored American classmates because I was of West Indian origin and a foreigner. Many Afro-Americans evidently cannot tolerate West Indians.

I was denied nothing merely because of my foreign nationality, but suffered the deep humiliation common to all dark-skinned people in the United States; inferior considerations, and oftimes ridicule from white young associates for being what I am, a Negro. I, as well as my parents, had not acquired the inferiority complex which the accepted American educational system seems to stamp upon all the non-white students, and consequently was encouraged to pursue that 
field of service which would enable me to accomplish the most good medicine. I am studying yet and work during my spare time to meet current expenses. I play the piano for the most of my recreation. $\mathrm{My}$ only difficulty along these lines is caused by insufficient time adequately to improve this side of my education. I generally feel free to use the playgrounds and parks, but have refrained a few times through apprehension that I would probably be denied the use of the swimming pool along with the white youngsters, a condition which actually exists in many places. I do not feel entirely free now; I know better. Every Negro, even though he be cultured and refined, has the same feeling. I would not and can not kid myself in the face of facts that are undeniable, though shameful. I have always aspired to be a physician and have been given consistent sympathetic consideration and encouragement by all the members of my home and all my friends. The only aspiration of mine that was discouraged was my wish to be President of the United States. Lack of sympathy in this at an early date helped me to realize that in this country there are certain unwritten limitations placed before the Negro irrespective of his ability.

My experience has been wide and varied. I have worked as a laborer, scullion, book salesman, and anything honorable to help finance myself. It was for the purpose of better educational opportunities that we left the West Indies. I am acquiring as much of my education as I can through my church and its system of schools. The Seventh Day Adventists have in operation a wonderful system of schools and colleges. The thing I have learned in these schools has been a love for mankind and a resolution to devote my life in the alleviation of human suffering, leaving monetary rewards secondary. I have also studied at the universities of Michigan and Southern California. In all these relationships I have encountered difficulties. While to some of us the obstacles of race, nationality, and language act as spurs toward success, to others of us, these difficulties furnish an excuse for failure. Personally, the more acute these are, the more I am determined to possess something which cannot be taken away and stands on its merits. That is knowledge.

It is impossible to avoid conflicts; Americans seem to be obsessed with racial prejudice. There is little sympathetic understanding of the newcomer. Those who do not completely master the language are regarded as foreigners, and Afro-Americans are accorded less consideration than unnaturalized foreigners. I conceal my feelings be- 
cause I believe that in this circumstance "silence is wisdom." America is a land of opportunity; but its philosophy, based solely on materialism with little regard for idealism, has ruined its fair name. Its discrimination and prejudice toward the man of dark complexion, and especially toward the Negro, bear mute testimony. Nevertheless, I must remain here and contend for economic emancipation, which is basic to social education and emancipation.

I have often been embarrassed because my fellow countrymen would not contend for their rights. Why should the Negro not employ the same methods used by the whites? Why should the Negro allow lynching to continue when this group comprises the majority in many Southern states? I feel more closely drawn to newly arrived immigrants from my native land than to white Americans or AfroAmericans. Since English is the language of the country of my birth, I have had no difficulties in that way. Although I do not know any African language, I am proud of the country of my forefathers, and of the West Indies for that matter.

Since entering college, I have associated more with white Americans than with any other group, and am learning their psychology. I have also come in contact with them in church work. It is my belief that American children of immigrant parentage should attend whatever church suits them, or not attend at all - just as they wish. Religion is a personal privilege, and no person should dictate religious doctrines to another. As to love affairs, I think they should be discussed freely and ennobled, but not belittled or made disgusting by billboards, newspapers, and movies.

The second generation of West Indian Negroes desire to be free as any other people. This feeling is perhaps stronger among West Indian Negroes than among native Negroes of the United States. The West Indian Negroes here are studying and are vitally interested in solving the economic problems of the Negro in America. They cannot continue to submit to discrimination and will fight prejudice and segregation forever.

\section{QUESTIONS}

1. In what respects are the Chinese, Japanese, and West Indian Negroes forced to live mostly in native culture worlds? To what extent is the "American Chinese" (number 6) living in both, but not really participating in either? In each of the documents, point out culture traits that have been transplanted to America. 
2. How did the Finnish young man (number 1) regard his parents' language? Why is the Hawaiian girl (number 6) deeply chagrined at not being able to speak the foreign language?

3. What is the Finn's (number 1) attitude toward education? Why has the Armenian (number 4) felt almost no handicap in school? What educational problem confronts the Japanese (number 8)?

4. Discuss the-occupational limitations placed upon dark-skinned persons of American birth. In what manner will the "American Chinese" (number 6) and the Japanese (number 8) never find complete vocational adjustment? How did the Armenian (number 4) overcome his obstacles?

5. How is the West Indian (number 9) doubly handicapped socially? Explain the nature of the ostracism of the Hawaiian girl (number 6). Why does the Finn (number 1) feel an outsider in his home circle? Compare the social standing of the two Finns in their respective communities (numbers 1 and 2).

6. Discuss the place of the church in the Hungarian (number 3 ) girl's life. What has been the rôle of religion in the Hawaiian girl's (number 6) tragedy? Account for the complete break of the Finn (number 2) from the church. What is the attitude of the other cases toward religion? How do these attitudes differ from those of the parents?

7. Which documents show the greatest amount of personal disorganization? In which are reorganization most difficult?

8. Account for the differences in the processes of assimilation of the two Finns (numbers 1 and 2). Why is the Hawaiian girl (number 6) an American in spirit only? Why does the Chinaman (number 7) know he can never be an American? In what ways is he already an American? To what extent has the Syrian (number 5) family become Americanized?

9. From the second generation documents prepare a report on the problems of assimilation among the children of immigrant parents. 



\section{PART IX}

THIRD GENERATION AMERICANS 



\section{CHAPTER XLI}

\section{THIRD GENERATION AMERICANS IN PROCESS}

The third generation of Americans reveals the extent to which the grandchildren of immigrants have become, or are becoming, culturally absorbed in American life. Literature on this subject is practically non-existent, and information is exceedingly difficult to secure. Here we are forced to rely wholly upon life history documents and interviews. Intermarriage has taken place to such an extent that few claim to be of pure racial or national stock, and assimilation has been so rapid and complete that few cultural residues remain.

1. Interest in Race and Nationality. A surprisingly large number of third generation Americans are not sure where their grandparents were born or to what groups they belonged. Most of these who do know confess little or no interest in the racial or national groups of their grandparents. A young lady writes: "I have never been interested, yet very well satisfied with my ancestry. I think the three groups I belong to make a very good mixture. I think there are certain objectionable characteristics in each, but I do believe when an Englishman can have some of the sense of humor of the Scotch or Irish, and can get off of his exaggerated dignity by the infusion of Scotch or Irish blood, he can enjoy living more and make more friends." Another young lady says: "I have heard very little about race in my home, except that father thinks the Scotch are superior to all other races. I feel no particular interest for the Scotch." A young man writes: "I am just as proud of being of German descent as I should imagine any one else would be of theirs. If I were not of German stock, I don't know what I would rather be. All that I care is that I am an American." Another German says: "My nationality has never been in any way obnoxious or a hindrance to me, for no one knows that I am anything but American for generations, and my pride of race all lies in America. The Stars and Stripes forever!"

Some of the third generation Americans who have been proud of their racial group are disappointed when members of that group do not readily adjust themselves to conditions here. It is a contest between Americanism and ancestral loyalty in which nationalism gen- 
erally wins. A young man says: "The only time I have ever felt ashamed of it [his racial group] was when a party of Germans refused to take out citizenship papers and adapt themselves to the American way of living. I think when an immigrant comes to this country he should take out citizenship papers if he is eligible."

Sometimes members of the third generation group are taught to be proud of one parental group and ashamed of another. A young lady writes: "We have been taught to be rather proud of our English blood, and rather ashamed of the Irish. I do not know why." Another says: "I have always been proud of my nationality - more so of being Norwegian than Irish. I think the reason for this is because my mother's people were so much better educated than my father's people, who were Irish." A young lady, reared in the section of a city where the French had an inferior social standing, writes: "My name may be French, but I claim that I am not. I suppose that my descent is $\frac{1}{2}$ French, $\frac{1}{4}$ English, and $\frac{1}{4}$ Dutch - I prefer the English and Dutch."

Occasionally a third generation dislikes his racial stock and wishes to belong to another. A young man of French Canadian and Irish stock says: "I have often wished to belong to some other nationality or racial group. My preference would be toward the English because I think they are the ruling type in the United States, but I think that I get this feeling because I am among a class who think that way too. If I had been born and reared in Canada, I doubt if my thoughts would so run."

2. Interest in Language. In general, the attitude of the third generation Americans toward the language or languages of their grandparents is more sympathetic than that of the preceding generation. The second generation child often refuses to speak the language of his parents because to do so connects him with foreigners. The third generation child, on the other hand, does not appear to have this feeling, and frequently manifests a considerable interest in the language of his grandparents. "I have been interested," writes a young lady, "so far as to make it [French] one of my major subjects. I have been very interested in learning it. When I was very small, however, I used to feel ashamed to have my mother talk to us in French when there were any Americans around who could not speak it."

Many of the third generation wish that their parents had maintained the foreign languages and taught them to speak these. "Ger- 
man was never spoken in my home," writes a young woman, "and no one there understood it. I would enjoy learning it because I now live with an uncle who speaks German fluently. I never think of him as being a foreigner because he is definitely Americanized, although his parents speak with a marked accent, and employ German culture and customs." A teacher says: "I have often wished that my parents spoke their mother tongues so that I could have learned them as a child. That is the only interest $I$ have in learning anything about Germany, Sweden, or Denmark, except that I would like to travel through these countries just to see what they are like."

On the other hand, some of the third generation appear to be very prejudiced toward a foreign language. "My father," writes a young man, "never used the Scotch dialect and does not know it any better than I do. I am very little interested in it except to despise it as I do the use of improper English." Another young man says: "I am not interested in speaking German. I have never understood it. I have never attempted to learn it. During the World War the intense feeling of pro-Germanism in our town made us somewhat ashamed to hear our relatives speaking German."

3. Interest in Customs, Tradition, and History. Very few third generation Americans appear to be interested in the customs and traditions of the racial or national groups of their grandparents or in their national histories. They are so far removed that they have lost touch with these things. The process of Americanization is so rapid, and the attitudes of the groups with whom they associate are so antiforeign, that they are indifferent if not antagonistic. The few who develop an interest usually do so in connection with school work. Even then they are rarely more interested in the history and customs of their grandparents' group or groups than in those of any other foreign group or nation. A young woman of German descent says: "I cannot think of any more specific instance in which I adhere to the opinions, customs, and traditions of my grandparents, than that I am particularly fond of beer." A third generation of Irish descent says: "I do not think there are any opinions, customs, or traditions of my grandparents that I would substitute for my own customs, opinions, or traditions, being as I am an American citizen." Another young man says: "I do not enjoy reading books about the native land of my ancestors. I have never felt a sense of pride in knowing about this land, but, rather, a feeling of repugnance toward the autocracy of these people, particularly the German men." 
A few are interested in the romantic history of the country of their grandparents, but it is doubtful if they are any more interested in it than they would be in like history of any other foreign country. "I have never read," says a third generation Scotch, "any books on Scotland nor desire to do so. The only thing I like about that country is the romantic history." A Norwegian writes: "I have never been interested in the traditions or history of the Norwegian people, although I have felt a sense of pride when listening to my mother telling stories of the early Vikings or Norsemen."

Some third generation Americans grow up and take over so completely the attitudes of their companions that they feel no relationship with the group or groups of their grandparents. A teacher writes: "Never has the question of ancestry been involved in speaking of these people [Germans] except during the World War when a German woman was teased by the children of the town for having a picture of the Kaiser hanging on the wall in her living room. I took part in this so-called sport, but I never realized I could have been criticized for being of German descent. Never have I thought of myself except as an American. I have no interest in German history, literature, art, or any of the other factors of their culture. I have studied some of their customs, social life, and political history, but only as a student of history and not because of my particular interest in the country." A French Canadian says: "Instances in which I adhere to the opinions, customs, and traditions of my grandparents are rare, in fact I do not recall any. I was sent to the 'Irish convent' as we called it, a parochial school in the Irish district. Consequently my chums were of that nationality, and I always wore my green on St. Patrick's Day. After having been away from that city and those chums, I find I have no inclination to go back. I know I have changed, for I detest the ways of the group I formerly associated with. They are just not my kind and now we have nothing in common. In so far as the history, traditions, and customs of my nationality group are concerned, I am not interested to any extent. The literature has not interested me any more than the works of any other race."

On the other hand, some have grown up in foreign colonies where the customs, traditions, and histories of their grandparents' groups have been reverenced and taught to them. They have imbibed this and continue their interest. A young French lady writes: "I believe I know as much about the history, traditions, and customs of the nation of my grandparents as I do of any other country, probably 
more. I have heard about the traditions and customs at home, and I have learned of its history in studying French in school. I have enjoyed reading about their native land, and have felt a sense of pride in knowing of this land."

4. Interest in America. Whatever may be the attitude of the first and second generations of Americans toward American institutions and national problems, the third generation are as completely assimilated into American life as conditions permit. Even those who are discriminated against because of color or religious differences have their interests centered in the United States. All are so far removed from the lands of their grandparents that they feel no connection with these nations or their problems, and see no reason why the fact that their grandparents came from a foreign country should cause them to be considered in the process of assimilation. A young woman of German descent says: "I become extremely impatient with all immigrants when they hold to their mother country tenaciously after taking up their abode in this country." A young man of Irish-English ancestry writes: "I am primarily an American. I have always lived in the United States, have always followed American traditions, customs, and habits. I do not see how any one could be any more American than I am." Another young man writes: "I have never felt (and I know of no one who has done so) that I was anything but an American, so I have been spared the trials that immigrant children usually have to pass through. My grandfather entered legal work in Denver and soon had a very good position in the Federal Court there. His many years of work in the courts gave him every opportunity to become acquainted with all the American customs, and it was not long before he was thoroughly Americanized. My parents also chose all their friends from Americans; so as far as being Americanized goes, I could really be classed as being in the fourth generation as I am the third generation of accepted Americans."

In conclusion it might be said that the first generation starts the process of assimilation in America which is completed by the third generation of Americans. Sometimes the first generation not only begins but completes the process; more often the second generation finishes it; certainly the third does. The process is rapid and often ruthless. Indeed, the rapidity of this process is advantageous in that it helps to prevent discrimination and aids social adjustment, but it is disadvantageous in that many cultural elements are lost before Americans have time to select the better elements and adopt them. 


\section{QUESTIONS, EXERCISES, AND PROBLEMS}

1. Why is it worth while to consider the third generation of Americans?

2. Why do most of the third generation manifest no special interest in the races and nations of their grandparents?

3. What are the effects when there is a mixed ancestry?

4. Why do some dislike their racial group and wish to belong to another?

5. Compare the general interest of the third, second, and first generation of immigrants in race and nationality.

6. How does the attitude of the third generation toward the language of their grandparents differ from that of their parents?

7. Compare the attitudes of the first and third generations toward ancestral language.

8. Account for the lack of interest of the third generation in the customs, traditions, and history of the racial or national groups of their ancestors.

9. How do they react if they grow up in a foreign colony?

10. Analyze the interest of the third generation people in the United States. How does this differ from the second generation? The first? 


\section{CHAPTER XLII}

\section{LIFE HISTORIES OF TEUTONIC THIRD GENERATION AMERICANS}

I. English-German

\section{Thoroughly American in Thought and Deed}

I was born in Massachusetts, and attended school in that state. My father was born in New Hampshire and lived there until he was sixteen years old, at which age he moved to Boston. My mother was born in Maine, but was brought to Massachusetts while a baby and sent to school in that state. From my father's side I trace my ancestry to the Germans; from my mother's to the English. Her parents were born in Canterbury, lived there until they were twenty, married, and sailed for Canada, where grandmother had relatives. Shortly they moved to Maine. It is quite evident that I am a Nordic. I have never lived in a distinct community of either Germans or English. In the town in which I spent most of my early years the population consisted of Germans, English, Irish, Bohemians, Poles, Italians, and a scattering of other nationalities. Being newer arrivals, the Poles, Italians, and Bohemians were regarded as the foreigners.

I have no great interest in my nationality groups, although I have always held a sort of foolish pride in the Nordics, whom some authors claim are superior in vigor and mentality. I also have a certain personal pride in being able to trace my mother's ancestors to Governor Winthrop, who came over in the Mayflower. Nevertheless, I always ridiculed some of my great-uncles, who came over bringing a chart of the family tree. This they thought and talked about more than anything else. Otherwise, I am impartial about my national groups. My indifference is probably due to the fact that neither of my parents ever mentions our ancestry. I enjoy and feel some sense of pride in reading books dealing with these countries. However, I do not select these books on purpose - I merely get a little added enjoyment from reading about England and Germany. Neither my parents nor I speak a foreign language. While not interested in the language of my German grandparents, I am not ashamed of it. 
I have never been kept out of any clubs or called names on account of my nationality. Never for a minute have I wished to belong to another group. I have never known anything about the customs of my grandparents. Often I have felt somewhat sorry when ill feeling occurred between America and my grandparents' native countries. This attitude is due to my belief in friendliness among nations rather than to any loyalty toward my nationality groups. I am thoroughly American in thought and deed.

\section{English-Irish-German}

\section{Militaristic Prussians and Peace-Loving Quakers Combined}

My grandparents on my mother's side were born in the Province of Prussia near Berlin, Germany. My grandfather's name was Heinrich von $\mathrm{G}-$ - of the Prussian nobility, but without wealth, for he spent what he could accumulate in high living. My grandmother came from a line of merchants and musicians, all of considerable wealth. Her parents died when she was a child, and she was raised by her eldest brother, who was proprietor of a large mill.

My grandfather upon attaining his maturity dropped the title of "von," significant of his descent from the nobility, and allied himself with the common people, because of his democratic beliefs. $\mathrm{He}$ thoroughly despised the reverence which had to be continually given to the nobility on pain of a heavy fine or imprisonment, for as slight an offense as failing to take off one's hat and standing at attention when one of the upper class passed by. Then, too, he did not want his boys under the grinding heel of militarism; for three years of their early manhood had to be spent in rigorous military service, and then they were subject to the call of the government at a moment's notice.

In about the year 1867 he became imbued with the idea of coming to the United States in order to get from under the yoke of German militarism and live where democracy was supreme. Very soon after he reached America, he took out naturalization papers and became a citizen. He never seemed to regret this step, and was always intensely loyal to the land of his adoption. This country was passing through the severe effects of the Civil War, and all business was at a low ebb. The cost of living was very high. Nevertheless love of freedom from the oppressions of his mother country carried him through all the obstacles and hardships which beset his path. 
My grandmother reacted in a very different way. In the fatherland she had had a beautiful home with servants, fine clothes, and all that was needed to make her comfortable. From her childhood she had an affliction in one of her knees, which made her lame, and she was used to every care and attention. Grandfather was a good provider but no saver, and consequently lived up to his income year by year. Upon coming to America, he had nothing to fall back upon but his salary earned in taking charge of a mill. He located in a little country town in Iowa, which is now extinct. He rented a two-room house and furnished it very meagerly, the bedsteads being sawed timber nailed together, with ticks filled with straw for mattresses. The other furnishings were such as were necessary for the very simplest kind of housekeeping. Into this place he put my grandmother with her six well-kept children. One can imagine her reaction when she reached her destination. Despair and gloom settled upon her spirit; her only satisfaction in it all was being reunited with her husband. She had been compelled to come steerage as a result of grandfather's lack of cash. There were trying times with sickness and other hard circumstances, but also much of the humorous. They had music and dancing with much merrymaking on the boat.

A group of young fellows who had evaded the vigilance of the German emigration laws were also leaving the fatherland. Young men of military age could not leave the country. These boys took grandmother and her little family, the youngest a baby in arms, under their care. When transits were made, each carried one child in safety to the next point in their travels. There was no difficulty in passing the immigration officers at Ellis Island and they were at last in America.

They landed in New York in a drenching rain. The eldest girl of ten years was given charge of the tinware used to eat from on shipboard. She carried this paraphernalia in her apron. This was almost too much for her pride, and she tells yet how the tears streamed down her cheeks about as rapidly as the rain was falling from the clouds. In the midst of the tumult a strange woman, attracted by my mother, who was then a rosy-cheeked child of about three years, snatched her and was rapidly making away with her, when one of the young men of the company saw it, and rescuing her presented her again to my frantic grandmother.

My grandmother had brought her wardrobe of beautiful things silk dresses, lovely hats, and silk parasols to match. There was fine linen underwear and household linens of all descriptions, but for all 
of these there would be no use in this little country village of Pennsylvania Dutch settlers. For one year she wept almost constantly, thinking of the lovely life and friends she had left behind. It took many years before my grandmother became in any degree reconciled to her new mode of life and the hardships which she had never known in her fatherland. At times she would dress herself in some of her beautiful clothes and go to visit a friend who also was depressed and weeping for her home across the sea. My mother remembers one beautiful blue silk dress with ruffles from the top to the bottom of the skirt held out by hoops, with a small basque and full upper sleeves and close-fitting wristbands with fine lace collar and cuffs. Her hat was of blue chiffon trimmed with forget-me-nots and lace. With this she carried a parasol of blue silk to match, with a white bone handle and all covered with small ruffles. As she walked along the street all the women turned out and watched her until out of sight, for they had never seen anything like that in their lifetime. When these lovely clothes were beyond further repair, she was never able to replace them. But the time did come when grandmother was glad to be a citizen of the United States of America and happy that her children had the privilege of growing up "in the land of the free and the home of the brave."

Grandfather insisted on the children's speaking German in the home, but had them attend the English school and become American in their ways. Grandmother really wanted to talk English and seemed to like it better than the German. About thirteen years after coming to America, my grandfather died and left grandmother to wring a living from a little farm which she cultivated with the aid of her children, of which there were eleven by this time.

My father is of English-Irish descent on his mother's side - a Quaker family for generations back. His father was an Eastern Yankee and he really doesn't know just the line of descent. My grandfather's name was Johnston, which showed him to be of English descent - the name Johnson is ordinarily considered Swedish. For some reason or other the " $t$ " was dropped in my grandfather's time and was never taken again by any of his children. Grandfather Johnson fought on the side of the North in the Civil War and died in camp of typhoid fever. He left his wife with five small children living in a log cabin in the woods of Ohio. Relatives helped them some, but my father knew nothing but privation as a child. He tells of the days upon days when they had nothing to eat but parched corn, 
baked on the open grate. When my father was only ten years old, he came in one day to find his mother sitting dead in her chair, the victim of heart failure. The children were put out with relatives some were treated well, and others, like my father, suffered from the cruelty of uncles who saw a chance to get hard farm work done for nothing. My father finally ran away from this place where he was so unhappy and got into a better family. He managed to get a high school education, taught school for a time, and then gathered the family together again.

I was born in Iowa, where my father was engaged in the wholesale produce business - the third of five children. Except for a few years in a small town of Iowa, which I scarcely remember, we have lived in cities - Des Moines, Denver, and Pasadena; so I have never been in a group of any particular nationality. We have always belonged to the Quaker Church as a result of father's faith. As a child, mother told us something of German customs and recited little German verses that she remembered, but we never felt an intense interest in the land of her birth. During the war it was difficult for me to work up any great hatred against German people, though I never thought once of sympathizing with them. But I knew that my little grandmother was not a blood-thirsty Hun as pictured in the papers, even though she was a Prussian, and loved her fatherland. Mother and my aunts and uncles are all thoroughly American without the slightest trace of German accent, although they are able to converse in German. No one would point to them and say, "There goes a German." They look American. The only thing that ever reminds us of German customs is mother's habit of making pfeffernüsse at Christmas time. I have never been ashamed of my German blood, although I didn't mention it during the war, because even some of my best friends would have given me a black look of hate, in spite of my intense loyalty and my work for my country.

We have always laughed at mother's German name - Fräulein

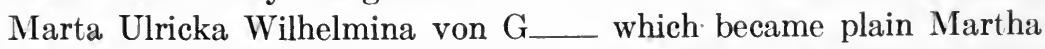
here in the United States of America. And when I see the real German settlers, who still dress in a peculiar way and have an accent, I always feel that they have no place with the type of Germans my mother belongs to - they seem to be of another nationality.

I never studied German in schools, but my mother's birth probably influenced my oldest sister when she took up German in high school and college and prepared for a German teacher, which plan 
never materialized on account of the war. Instead of burning her German books, as most of her compatriots in school did, she just put them away until now they are in good standing again.

We have never been considered foreign in any way, except that many people have taken us for Swedish because of the name Johnson and the fair hair and blue eyes. Even my mother is never taken for German. She is a very handsome woman. As a child she lived in a community of "foreigners" and never seemed to have any unpleasant experiences resulting from her nationality. She always considers herself American.

In fact I feel proud of my nationality because I feel that the sturdy qualities of the German settlers in this country have helped to make it what it is today. I am proud of the ideals which brought my grandfather to America. I am proud too of the Yankee-Quaker ancestry of my father's side of the family. When one thinks of it, it is rather a funny combination - a line of peace-loving Quakers on the one side, and militaristic Prussians on the other.

\section{Scotch-Irish-German}

\section{Not of America's Bluebloods}

Not being of Mayflower extraction, I suppose I must satisfy myself with that rather overworn squib and say that my ancestors came here when the immigration laws were a bit more strict. At all events, I am the granddaughter of immigrants (three of the four) rather than of America's bluebloods.

I was, as were my parents, born in Philadelphia, in which city we have continued to live. My father's parents were born and raised in Ireland, one in Tyrone and the other in Donegal; and both came to America in their youth, met here, were married, and settled in Philadelphia. My mother's father was brought to America from Germany when he was only two years old. Her mother was of German extraction, but was born in Philadelphia, and lived there.

One of my father's relatives in a fit of rashness had the family history traced and was told that she was a descendant of Mary Queen of Scots. (I suppose, however, for a few dollars more it could have been traced to Elizabeth.) Nevertheless I may safely say that the nationality on my father's side would be Scotch-Irish. My mother's would be German. Thus, putting them all together my descent would be from Scotch-Irish-German. The language would therefore 
be Indo-European - on the one hand Celtic and on the other Germanic. Taking race in the popularly accepted sense, mine would be Caucasian. If, however, you take it according to the location of the groups, it would be of that far-famed paragon of all virtues the Nordic Group.

I have never had the experience or pleasure of living in a community where either Gaelic or German has been spoken. In fact, as far as language goes, I cannot decide whose knowledge of German is more limited, my mother's or mine. I can boast of about ten phrases while she, with some imagination, might be able to hold a conversation. Since the Irish spoken today is not very different from English, there has been no special influence from that language on the home. I do remember, though, that I used to enjoy listening to some of the quaint phrases of my grandmother, but I still cannot decide whether that was because they were from the language of my ancestors or merely because of the curious, almost lilting note in the sound of them.

I have had no real personal interest in the history, traditions, or customs of my "nationality group" as you term it. However, I have in an impersonal way been interested in them merely as one would be in those sides of any people. I must admit that I have been quite fond of German history and the development toward an empire, and I suppose with a bit of romancing one might attribute that to my ancestry, but I have never done so. Then, during the last war, I do not know whether it was my ancestry or mere common sense that made me argue (as one of eight can) that no people could be quite so bad and terrible as the Germans were supposed to have been, and the apparent fallacy of that made me wonder at times whether we had entered the war merely to protect Belgium's rights - but I still continued to sell Liberty bonds and sing war songs.

In my home we do not keep to the traditions of either side of the family. This seems sad, in a way. I suppose that in general, in the third generation, when the father and mother in the second generation have not been of the same nationality, many of the traditions are lost. I do know of several customs or traditions we keep. For instance, we celebrate Christmas and New Year's rather after the fashion of the German idea. This was more noticeable in my grandmother's home, however. A rather unimportant custom which we keep at least in a modified form at home is one concerning Good Friday. Mother said that in her family this had been considered the only holy day in the year. Now she allows us no meat on that day. 
Some traditions in my mother's home (before she was married) are rather interesting and were quite surprising to me. For instance, there was the unquestionable adage that anything untidy was Irish. They realized the absurdity of this to a certain degree, but held to it as a sort of sacred motto. There was a very noticeable desire on the part of the parents to have the children marry Germans or people of that extraction - so much so that any friends who were of another nationality were not given quite the cordial welcome as one of their own. Though they were Protestants, they would have preferred their children to have married a German Catholic in preference to a Protestant of some other nationality. I mention this feeling to show the contrast in my father's home. Here religion rather than nationality predominated. In fact, I believe my grandmother would have accepted any horrible torture rather than have the knowledge that her children would marry Catholics. This is an indelible Scotch-Irish tradition which they carried from their old country. The feeling of almost hate and bigotry has not been carried into our immediate family. In fact, though it interests me, I can hardly conceive of its really existing in the minds and hearts of any one to the extent it did in theirs. I often wonder if it would have been had both my parents been of that stock.

At home we are interested, as I said before, merely impersonally to a great extent in the various customs, etc., of our ancestors. Now, I would attribute this to the fact that after one lives in America, or any country, for all one's life - and this has also been the case of the parents - one does not think of himself as being of Russian, German, Scotch, Irish or what-not descent, but just that one is an American, unless at some time the topic of nationality is brought up specifically and directly. Then it is the love of talking and discussion as well as any national feeling that makes one tell of the nationalities of ancestry. I may be wrong in this surmise, but I rather believe it true, judged in the light of my very limited experience.

Often I have wished that I could belong to not just one other nationality but many (each time a different one), but only with the very definite idea that I could change back to my own. This may sound a bit absurd. But what I mean is that I would like to know and really understand the reactions of various nationalities to the same stimulus, not gaining this knowledge from the point of view of the bystander or the textbook, but from the point of view of the par- 
ticipant. Of course, I realize that this is impossible, but it does make a rather interesting thought to play with.

The more I think of what I have written, the less it seems to me that it will be of any value or aid in showing the place of the third generation - grandchildren of immigrants - unless it be in the fact that those descended from people such as mine are either very easily assimilated and therefore there is no feeling, marked or otherwise, between them and the people who have lived here a greater number of generations; or perhaps it may be in the fact that this country embodies so many elements of both German and Irish that there is no special feeling of distinction; or, on the other hand, it might mean that both Americans and these other two groups have the same fundamentals, and many of the same superficialities. Whatever it is, I do not pretend to say; at all events, neither my parents nor I have felt that we are anything but Americans.

\section{IRISH \\ Only a Photograph}

I was born in New Hampshire. I do not know a great deal about my ancestors, except the place where my parents were born. My father was born in Massachusetts, and my mother in New York, in a small village on the Canadian border. I don't know anything about my father's parents, and all I know about my mother's is that my grandfather ran the linehouse nearest the border village. I have always considered myself of Irish descent, although the only proof of this is an old photograph of a castle with the following wording on it: "Site of McSwiney ancestral eastle, Sheephaven, Ire." This picture is the only thing whatsoever that I have ever known that shows anything about my ancestors. Neither my father nor my mother seemed to know anything about this picture and treated it as a joke. There has never been any nationality discussions in the home, and I haven't had any experience with racial or any other kind of prejudice as far as I can remember.

\section{German}

\section{German to the Third Generation}

I was born in Ohio and spent eighteen years of my life in a homeloving, German-speaking community. Both of my parents were born and reared in this same location. My grandparents, maternal and 
paternal, however, were born in Germany, just where I do not know. Mother's father followed the medical profession, having at one time been Court Physician to the royal family in Berlin. Later he and his wife came to America, where he spent the remainder of his life following his chosen profession. My father's parents came over in their younger years and were married in this country. At one time this grandfather was honored with the titles of Postmaster and Justice of Peace in his community, my birthplace. Having been reared in such a community, where one hundred per cent of the population spoke either High German or a Low German dialect, my father's family of seven children grew up more or less with the customs and ways of living of these people.

I knew practically nothing of the English language until I entered the public schools at the age of six. At home we used German, and after I went to college, father always wrote his letters in German script. These I prize very highly, and simply marvel at the beautiful construction. During my younger years, I enjoyed hearing my grandparents describe customs in the old country, but I must confess that their struggles in the new country interested me more.

Until the World War, I always felt proud of being able to speak German when an opportunity arose. Because I was labeled "Dutch" and "German" several times, and because of the high feeling of sentiment against the German people, I suffered a lowered pride. Although these mere titles themselves had no direct effect on me, they made me aware of a lower rating on the part of some of my fellow countrymen. But now I enjoy speaking the language, just for the sake of talking it. The real high-grade German is a beautiful-sounding language when spoken well, and I always enjoy hearing my parents speak it. Toward German immigrants I have a fellow feeling of sympathy, and want to help them if I can.

I have never been kept out of any group or club on account of my parentage, and have never had a strong desire to be a member of any other nationality group. I don't say this through a sense of pride in my own ancestry, but because I know that my ancestry cannot be changed and that I am here to make the best of it with my fellow men under the existing conditions and circumstances, regardless of nationality or ancestry. I once read a magazine article entitled "Considering Who Grandpa Was, We Aren't So Bad After All," which made quite an impression on me. And now, after associating the ideas derived from reading this article with the teachings and ideas 
derived from my recently completed course in Sociology, I am able to form many new ideas regarding my belief in human nature, and the probable outcome of reciprocal, psychical interactions between persons.

\section{German}

\section{Never Correlated German Grandparents with Self}

It is very seldom that I am aware of the fact that I am a third generation immigrant, or that my grandparents were actually born in another country. It is only when I go to visit my grandmother, and that happens only on rare occasions, that I realize how. German they are; but I never correlate their being German with myself at all. Both my paternal and maternal grandparents came as brides and grooms to Philadelphia and settled in the German portion of the city. As they became more used to the new country, they mingled more with Americans, and finally moved out of the German section. They apparently did not find it difficult to make this gradual transition to American ways, for they never mention the process. I have often heard them speak of the trip over and its impressiveness, but their acclimation to our ways must have been so gradual through the German groups in which they first lived that they were unaware of the change. The process of reacculturation is a very difficult and tedious adjustment and is rarely totally accomplished when one moves into a new culture when he is fully mature. For this reason my grandmothers, although they are American in many ways, retain some German traits, even after almost fifty years. On the other hand, a relative who was but a year old when he came, grew up and received all his impressions in the new country.

I have never lived in direct contact with people of my own nationality other than my grandparents, and my associations with them were very close in my early years. During vacations my grandmothers began the practice of speaking to me in German. I soon became accustomed to that tongue and believe I could understand anything they might say to me in that language. Although both speak English fluently, they like to use their native tongue with one whom they trained themselves. I am looking forward to studying German next year, but of course it will not be easy, as I understand merely spoken German, and probably a local dialect at that. Nevertheless, I feel a natural eagerness for the course and expect to enjoy it far more than the Latin and French I have had to take. 
I have always taken a certain pride in German accomplishments and traditions. It was only during the World War that I felt pained to reveal my German ancestry, but those days rapidly passed. I always feel a little swell of pride when my professors mention the work of some outstanding German scholar. Other than in this superficial sense, my interest in German things is practically nil. I do not find its history so fascinating as that of other countries, and I am disgusted with its literature. My father, who probably feels more closely bound to Germany than I, once, in a moment of ancestral pride, bought a complete set of German masterpieces. Sadly enough, he has read only one or two volumes. I have removed the paper wrappers from several others, but neither of us can appreciate the heavy German style.

My mother speaks German with such difficulty that one cannot understand her, but my father can use it fluently. He finds it very beneficial in his practice, since many of his clients are German-speaking friends of my grandparents. I never feel ashamed of the language, but I am embarrassed when my grandmothers use it in public places. In such localities, anything foreign attracts much attention and makes me uncomfortable. And yet I realize it would hurt my grandmothers to mention this fact. German to them seems far more usual than English.

I have never known any recent immigrants from Germany, but I have seen a friend of my aunt several times. She wears such outlandish Dutchy costumes that I find it difficult to keep a straight face in her presence. I am sure I should be ashamed were I forced to travel with her in a crowded street car. But I would feel this way about any foreign person; the average American does not like to have notoriety thrust upon him by an odd-looking companion.

My brothers and sisters, from our own views, are not German in appearance. The fact that a friend has discovered that I can translate her first-year German sentences has forced me to recognize my nationality. I take no offense at all; it is a mere coincidence. Doubtless I would retaliate, should a similar occasion arise. On the whole, I am usually unaware that I am a third generation German immigrant, but when I actually become cognizant of this fact it does not embarrass me in any way, except in the instances of going to the theater with my grandmothers; then I certainly wish I were English. On all other occasions, I greatly admire the German race and its works. Even during the World War I placed all the blame upon the 
Kaiser and thus felt at ease to praise (inwardly of course) the courage and pluck of the Germans. I suppose I shall always be slightly prejudiced in this respect, but it is only human to value one's own ancestors and consider them to be the best type.

There are still a few German characteristics in our home. First of all, our style of cooking is predominantly German, because mother learned this art from my grandmother and we are perfectly satisfied with the results. The unused classics represent fine intentions, if nothing else. Our understanding of German and our feeling of pride toward things German are outcomes of our ancestry. Finally, I think that our family all possess some of the German physical and mental traits. We are tall, healthy, good eaters, and active. We are also rather perseverant and conscientious, and possess the German ability to "plug away" at things. Sometimes I become disgusted with myself for being conscientious, but then I attribute it to my inherited nature and forget about it. In these ways we are really German, but we are unaware of the facts unless we pay particularly close attention to them. One may conclude, therefore, that by the time a person is removed from his ancestral home by two or three generations, he has little in common with it and is only slightly affected by its customs.

\section{German-Dane}

\section{The Trip to Germany}

I was born and educated in Salt Lake City, Utah, as were my father and mother, also. My mother's parents came originally from Denmark. My father's father was born in Canada and his mother in a little village near New York City. My parents belong to the Nordics, my father being of German descent and my mother of Danish. About seventy years ago my grandfather on my mother's side, together with the rest of his brothers and his parents, left their homes to come to America. Grandfather's mother and father did not leave the land of their birth with the sole purpose of avoiding political oppression or religious persecution. They came to America as did many others who came at that time, with the objective of happier and more contented home life, better business, and education for their children. Grandfather's father was a merchant and owned several sailing vessels. These, together with all real estate, were sold, and preparations made to emigrate to America.

My great-great-grandparents became ill and did not survive the 
journey to the New World. They were buried at sea. My grandfather with his brothers landed in New York only to be swindled of all that had been left to them. After a hard struggle, my grandfather then decided to pioneer to Utah, where he established himself in business, and has remained ever since.

The Teutonic blood of my father's lineage has always been of more intrinsic interest to me for the reason that a family genealogy has been compiled and it dates back to the sixteenth century. The old family members came originally from Potsdam near Berlin. In 1922, in company with several other boys, I took a trip to Germany, and had the pleasure of living among them in Hanover, Dresden, Chemnitz, and Essen (which lies in the Ruhr district). Up until this time I had been rather prejudiced against the Germans; for in spite of all the family pride as to the German origin, I had been influenced by the propaganda which was so freely circulated during the War. But after living among them, I have only sincere respect and highest regard for this group. I learned to love them as I do my own people. Their hospitable spirit is beyond comparison. And as empire builders and colonists they are untiringly persistent and thorough.

At the outbreak of the Civil War, the Germans living here and detesting slavery as they did played no small rôle and supported the North whole-heartedly. This same spirit of freedom always evident with the Germans has made them resent the present attitude of France and the world powers in regard to the occupation of the Ruhr district. In spite of the oppression and revolutions which resulted from the World War, this love of freedom, together with the ability to "stick" to a purpose, has enabled them to outlive that period of financial and political distress which threatened to destroy them as a nation. The mark has been stabilized and pre-war conditions are now being bettered.

The Germans are thrifty and they have taught America much in regard to farming, etc. They have subdued the wilderness, and by crop rotation they have conserved the strength and the value of soil where they have farmed. The un-American practice of working women in the fields has enabled them to out-buy the native Americans.

Germans love good music, good drama, and good literature. Their social diversions have helped to change and to soften the tone of Puritan intolerance. I like the German language, and enjoy reading and speaking it very much. Its possibilities are unlimited, especially in music and drama and good literature. 
Upon returning to this country after having lived in dem Vaterland, I have met Germans whom I had known in Germany and with whom I had been rather well acquainted. A false pride at first made me hesitate at accepting them here on the same grounds of friendship as we there enjoyed. Perhaps it was their appearance, their accent, or some such thing which stimulated a temporary feeling of shame. However, I have helped several families in getting established here. It is because of the very much evident German culture and great attainments of the Germans in general that such things as the oldfashioned appearance of the newly arrived are forgotten and his intrinsic value as Burger and builder is realized.

When a youngster I was addressed several times as the "Swede." I remember that such names made me angry, and as a result I complained about the matter to my parents. My mother, being of Danish parentage, defended the race by telling me of such Scandinavians as Lief Ericson who discovered America in 1000 A.D., and of others who boldly swept down on England as conquerors. This soothed my anger and I proudly admitted my descent at being so addressed, after that incident.

The Danish are good losers in politics, and while they do not provide qualities for political leadership, they do make cool-blooded, self-controlled citizens. The Germans with their background of culture and ability as observers and investigators have distinguished themselves.

\section{German-Dutch-Swiss-Dane}

They were Just German, and I Wasn't

I am of the so-called Nordic group, but from a mixture of nationality groups. My maternal grandmother was born in Germany and my grandfather in Holland. My paternal grandfather was born in Switzerland and my grandmother in Denmark. My parents were born in Minnesota and Iowa. I was born in St. Paul, Minnesota, and spent the first fourteen years of my life there. At that age all of us moved to California. I claim to be wholly of Teutonic blood.

I know very little about the traditions, customs, and histories of the native lands of my grandparents. Apparently, my grandparents followed these rather closely, but their children did away with them. Their traditions, customs, folklore, etc., would be interesting, but they are difficult for a third generation person to find out. The second generation usually rebels against them, and as a result they 
are forgotten or left untold, and the grandchildren never have any way of knowing.

I have never lived in a community made up of my racial group, but my maternal grandparents did, and I visited them. I looked upon the community as interesting but the people as being different from myself.

My parents do not speak the language of their parents, and they never seem to desire to speak it. When my mother was young, some of her school companions made fun of her for speaking German. This made her, her sister, and her brother angry; consequently they learned English and never spoke German again. I have never had any special interest in the German language. I was reared in a nonGerman community, although six miles north of us was a very strong German town. There they had their parochial schools, and practically every one spoke German in the streets and stores. I never thought of placing myself in their class at all, not that I considered them lower than I; they were just German, and I wasn't. However, when I started to high school, in preparation for a scientific course, I wished to study German, but at that time, due to the War, German had been removed from the high school curriculum.

While I cannot say that I am ashamed of being of German descent, I have often thought that it would be good to be descended from the English. Not that I regret my own, but it seems that we of German descent have a background and certain difficulties to overcome which the English do not have when they arrive here. Again, I feel that when there are considerable differences in culture, that people lose something in the process of Americanization. Often the transition is so rapid that essential elements of the old culture are lost, the person becomes disorganized, and as a result a lopsided personality develops.

So far as I know, I am just as much American as any one else. My attitudes toward the native lands of my grandparents are the same as those toward any other foreign country. My attitude toward any newly arrived immigrants is that if they don't like it here, they should return to their own country. A favorite expression of Dad's, which I learned as a youngster is, "The trains and boats run both ways, and there are no chains on the dissatisfied residents." 


\section{Norwegian-Scotch-English}

\section{An American with France and Italy as Homelands}

As I was born in the United States, of American parents who spoke the English language exclusively when in my presence, it did not seem at all necessary to consider my descendency until of late. Though I lived in foreign countries most of my life, I always considered myself an American. If people inquired regarding my descent, I replied that I was an American; for it was sufficient for me that both of my parents had been born and raised in the United States, and that all of my grandparents were at least naturalized citizens.

When I was barely two years old, business connections required that my father reside in France; consequently my mother and I went over to Europe with him and established our home in Paris. During the five years we made our home there, America became rather an indistinct memory, merely something with which I might proudly connect my nationality, even though it was a rather vague worship of idealism. At the time France seemed home to me, for I had learned to speak the French language almost immediately. We had French servants, our neighbors were mostly French, and the few little English children with whom I associated always spoke to me in the language of the country in which we lived. We took frequent trips to Germany, England, Italy, and Belgium, and I always looked forward to returning "home" to Paris. For it was home to me; and I never dreamed, when we left Paris for a visit to America in 1914, that I should never return except on a short trip. War to me seemed not a cruel battle but an interesting event. Our departure when the Germans came within twelve kilometers of Paris, even though it meant the loss of my home, was but another of the delightful trips my father planned. The bustle and confusion of the thousands leaving the city added interest to the occasion, made me hate the "Boches" a little more, but that was all; the whole affair we children considered a gay fairy tale, with Germany the hated dragon, and France, to whom we were ever loyal, the lovely princess.

Upon arriving in Chicago in the fall of 1914, I began to hear more of my ancestors, but my main interest in nationalities remained in the countries I had visited. Though both of my mother's parents were Norwegians who had been naturalized and often spoke Norwegian in the house, I never attempted or tried to learn it. I naturally picked up enough of it so that I could understand the trend of 
conversation, but never spoke it, preferring to use French or English; I was far too patriotic to France to ever utter a word of German, so I gradually began to forget it. I disliked the Teutons with all my heart, though it was of course mere prejudice and the influence of environment; and I strengthened my liking for the countries of my paternal ancestry - that is, Scotland and England - for they were among the staunch Allies. The fact that most of my characteristics had been inherited from these branches of the family had really nothing to do with my exceedingly biased opinions; which opinions I believed were correct, but at the time I had nothing whatsoever to substantiate them.

A year later we moved to Italy to make our permanent home. Previously this country meant little to me, but it did not take me more than four months to be entirely fired with Italian patriotism. I instinctively liked the people. I went to an Italian public school. No one ever took me for a foreigner; so I felt perfectly at home among them and became practically one of them. Had I been a person of fair complexion who spoke the language with an accent, I would probably never have conceived such a permanent liking for, and understanding of, these people. It pleased me to be mistaken for a native, though I still retained my pride in the United States. Yet at the end of five years I hated to return to America; it seemed all right as a distant ideal, but as a place in which to live I did not like it. France and Italy were my home, not America, nor Norway, nor Scotland, nor England. But we returned, and came to live in the West.

It is only since this time that I have been at all interested in our family history. I found that both of my maternal grandparents had spent their youth in Norway. As they were born there, I am really half Scandinavian. I was never, however, at all proud of the fact. I don't care for the average Scandinavian immigrant; he both bores and amuses me. The only reason I am at all anxious to go to Norway is because the scenery and geology of the country interest me. It is not so with Scotland, the birthplace of my paternal grandparent; I like Scotchmen whole-heartedly, am proud of my Scotch blood, and would like to live in the country for a few years in order to learn the true Scottish language. Previously I have only toured the country on short trips. For England I cherish the same feelings, and would like to know more of the people from whom my paternal grandmother descended a generation ago. They were people of influence in Eng- 
land and in the early days of America, having been the founders of a noted Pennsylvania city.

This is the only extent to which other countries interest me. California and Italy are the only places I should care to consider as a home, and of the two I prefer California; after six years Italy is probably so changed that it would never seem the same. After all is considered, I believe I am quite happy to be an American.

\section{DANE}

\section{Foreign Born, But a Third Generation}

I was born on an island off the west coast of Denmark. My parents, both American citizens, had been traveling on the continent, but because of the impending event, went to visit my great-uncle in Denmark, where I arrived. I am, therefore, a third generation American. On my mother's side I had relatives in the United States in 1638. Two of her ancestors signed the Declaration of Independence. Another was a major in the Continental Army, later a general in the War of 1812, and still later a general in the Mexican War. My mother's father was with Sheridan, in an official capacity in the Civil War. A brother was in the Spanish American War, and the same brother was a commander of a submarine chaser in the World War. My mother's family was a militant family indeed! On the other side, my paternal grandfather ran away from Denmark on account of having participated in a duel, which was illegal, and joined the navy during the Civil War. After his marriage, he came to New York. It became necessary for my father, who was next to the youngest of twelve children, to help support the family, composed mostly of girls. $\mathrm{He}$ had a divine voice. Although he was offered numerous chances to train his voice in Europe, and even made good in a try-out at the Metropolitan Opera House, he declined. His ambitions were not along those lines, for that would take too much time and money for the pecuniary returns, and money was needed immediately, not for himself, but for others.

Finally he became apprenticed to a steam fitter, but he didn't care for the work. Still, the family had to eat. He stuck to it and in time became a heating contractor, with his own men and some leisure time. Can you imagine anything more ludicrous than a steam fitter writing poetry? Yet he had two books published before he married. With that driving force - money - ever at his heels, he at last managed 
to get together enough to marry and travel in Europe for three years and at last to do the things he had always longed to do, without financial worries. Then, after the return to America, the War came along, only to take away the savings gleaned from hard work. And he had to begin plugging again, this time to support his own children.

After residing in the home of my uncle for about four months, my parents took me to Italy, Spain, Portugal, and France with them until a year was up. They then went back to Denmark and left me with an uncle, who, by the way, is a Lutheran minister, and a very indulgent aunt, for eight years. I was taught all the things Danish girls are supposed to know. I learned to speak English, German, Danish, and French. I could embroider and knit, write and read. I knew nothing of mathematics and still don't. During the World War I was safe, way up north, living in a manse in the hills and mountains. Our winters we spent in Copenhagen.

I came to the United States in 1919, traveling in care of the steward. I was promptly turned over to my parents, whom I did not remember and did not care for. They showed me a little blond, curly-haired boy whom they said was my brother. I had never heard of him. My father had sent me toys; consequently I knew who he was, but my relatives seemed strange to me. Now I could play with children and immediately began to turn into a tomboy. Boys were always good companions, and I still think of them in that way. They initiated me into all the rough games. I got a slightly fractured skull from a baseball bat, and an arm broken in football. I soon became their ringleader. I was sent to the Children's Court for malicious mischief the gang and I had pulled tar paper off a shanty roof in order to find a still inside. The only thing in there was antique furniture, and the rain ruined that before many days. I soon dropped my foreign accent, learned the slang of the day, and forgot the languages I once knew. I became completely Americanized, according to the modern version of the word.

I graduated with highest honors from grammar school. As I needed both tanning and training, I was sent to a private school. Although I graduated with honors, taking prizes in languages and science, and winning a scholarship to Cornell University, I hated the environment. I despised the girls; they were so simpering and affected. I liked the blunt honesty of the boys. I could rely on them, and they were always ready for some new escapades. Next I was placed in college in New York. I had wanted to study medicine, 
but as this was not approved by my family, I had to go to college with no end in view, and no ambition toward finding one. I went to art galleries and to all the current plays and operas. I saw life in Greenwich Village and I had a glorious year. I did not worry about failing; I did not care. Mother wanted me to become a school teacher, and I had rather die than become one. She says that I am going to college until I graduate if it takes me twenty years. She will surely make a failure in both demands. In the meantime she has ruined my whole life.

The summer of 1928 I went back to Europe. We traveled all the continent, spending most of our time in Italy. On my return, I came to New England to college. How I hate it here! It is so narrowing and narrow - typically New England. Father became ill, and I returned to care for him. After his death, I returned and made a sufficiently high grade to become a sorority pledge. I doubt if I ever graduate. If I had been able to have had my way about it, I should never have begun it. I am growing domestically inclined and do believe that a woman's place is in the home unless she has something great to offer the world. I highly approve of the double standard and doubt if there will ever be a single standard. I don't believe in woman's suffrage; neither do I approve of woman's drinking and smoking. I have tried both. I feel that I am maturing in my ideas. If I cannot be a physician, I will be a nurse sometime. I am dissatisfied and bored; I won't become a school teacher.

Although I was born in a foreign country and spent eight years there, I do not feel like an immigrant, even a third generation. I don't believe any one ever regarded me as such. Although I do respect my family tradition, I think genealogy and ancestry are all rot. Immigrants at Ellis Island seem like animals, surely not as people having any bonds or ties in common with me. I have never been made to feel inferior to anyone. Although I am prejudiced toward Negroes and Catholics, I try not to think of religion in connection with my friends. Nevertheless, I regard all religion as bunk.

\section{QUESTIONS}

1. In which of these documents is there evidence (1) of a determined effort to keep alive patriotism for the countries of the grandparents; (2) of indifference? What effect did living in a German community have upon the German girl (number 5)? Why should a person born abroad be considered as a third generation American (number 10)? 
2. Using numbers 7 and 9 as a basis, show how pride in nationality shifts.

3. Account for a greater pride in certain of their ancestral groups among third generation Americans of mixed ancestry.

4. What is the general attitude toward foreign languages? Give some of the reactions expressed. Why did the German-Dutch-Swiss-Dane (number 8) girl probably have no more interest in German?

5. How do these third generation Americans regard family trees? What definite traits of ancestral culture seem to make the greatest impression on this group?

6. What are some of the reasons given for knowing so little of the customs of the grandparents?

7. To what extent may interest in the history of the country from which the grandparents came be taken as an index of national pride? Why does the English-German (number 1) hold "a sort of foolish pride in the Nordics"? What was the attitude of the Germans or part Germans toward Germany and native Germans during the World War? Which ones would like to belong to different national groups?

8. Why is a document like number 4 significant in studying the assimilation of the third generation Americans?

9. Contrast documents 5 and 6 , and account for the difference of attitudes toward Germany.

10. Taken as a whole, how Americanized is this group? 


\section{CHAPTER XLIII}

\section{LIFE HISTORIES OF OTHER RACIAL, NATIONAL, AND CULTURAL GROUPS OF THIRD GENERATION AMERICANS}

\section{French}

\section{A French Background Overlaid with Americanization}

A tiny, brisk little lady with a big, merry dimple in her chin, and huge, dark eyes, who crooned jolly little jingles in French - the language I learned along with my baby English - that was my first recollection of my maternal grandmother. She had come over from France as a young girl of nineteen when her father was sent to Philadelphia on business. Two years later she married a young American architect and later gave birth to four children. The youngest, a girl, was named Anna.

She was brought up on the old lore and traditions of the France so dear to the heart of her mother. She was sent to a school near by, and as a charming French "jeune fille" studied art in Paris to complete her education. There she met a young American chemist, fell in love with him, and their nuptials were solemnized on their return to the United States. They joined Anna's parents, and it was there, in February, 1911, that I was born. My first years were spent there, and I remember little of them except that from my earliest days I spoke French as well as English. In fact, my family used French altogether at home, and I recall my embarrassment more than once when, at a party, in the midst of pinning the tail on the donkey, I was literally hauled out by my little hostess's mother and pled with: "Oh, Bobsy, talk French for Mrs. Drake, won't you, dear?" Whereupon Bobsy did it and was exclaimed over like a curiosity.

It was my little French grandmother, with whom I was frequently left alone, who made an indelible mark upon me in my early childhood. I listened by the hour to her tales of French heroes and heroines. She taught me to love and understand French literature. Now I revel in the works of the great French authors. There are no more charming writers than the French. They are philosophical and 
spirited. De Maupassant, Balzac, Daudet - all names to conjure with!

When I reached school age I was sent to a French school run by a jovial Frenchman. I had more difficulty with my English grammar than with my French. When I was nine years old, I started in public school and continued there till I ended my high school career. At first, in school, I hated French and France, for it was continually thrown before me. I wanted to be like other girls, and not this curiosity to be pulled out and exclaimed over when a visitor entered the school. The children continually taunted and teased me about my "Frenchiness." "Ye ole frog," the boys would call me, insisting that I could not talk without using my hands. Well, I still use them, and doubt if I could do without them. At first I was hurt by these taunts and the numberless questions put to me, and many a night I stole into bed and cried myself to sleep. As schooldays progressed, I learned to like France, but now, when I wish to be different, my French is scarcely noticeable.

At home we still speak French when we are alone, and we still cling to many of the old French customs, partly in memory of that gay little French grandmother and partly because we love the old customs. On Christmas Eve, lighted candles peer out from our windows to ward off evil spirits hovering around, and we retire precisely at eleven-thirty to be in bed at the mystic hour of twelve when Noël is rung in and his blessings descend on those folk at peace with the world.

I have felt the great difference between the code of morals of my grandmother and that of young America. From the time I was able to walk until I was ten years old, I was not allowed out of the house unless accompanied by my parents or Félicité, an old French servant of my grandmother. From the age of ten on, I was permitted to go to school alone, but I was allowed no contact with the opposite sex unless I was properly chaperoned. Indeed, this liberty was not permitted me until I was a high school junior, and then it included only the homely pleasures around town. Till the day of her death, my grandmother sincerely believed that I was speedily "going to the dogs."

When the Eighteenth Amendment was passed, we, at home, could not understand or agree with it; for ever since I can remember, wine was placed on our table. Even I, as a child, was permitted to drink wine. We often had company for dinner, for they said our meals 
were "different" and our bouillabaisse and salades au safran were particularly famous. Often our whole meal would consist of a single huge tureen of bouillabaisse or of a stew. We do not crowd our tables with food, and only on a rare occasion do we serve course dinners.

The French immigrants of today are principally men and women of the better class. They seem natural to me, for I am used to their ways and customs. They are energetic folk and good, hard workers men who come to seek a livelihood for their families, and women who join their husbands. Of course, there are a few adventurers, but they are in the minority. For the most part, the French people, the supposedly chic and unconventional, are much more conservative than the Americans.

I am thoroughly American in every way now, but often I long to visit that country across the sea and see the shrines to the men and women I have learned to admire, and browse in the country I have dreamed of. But then, am I truly American with this old lore and these customs clinging to me? I doubt if I can ever get away from my French background, and I don't want to.

\section{French Canadian}

\section{Shall I Change My Name and My Religion?}

On an uneventful day, I was born in a small town in New Hampshire, where I have spent all my life, except the years I have been away at school. Although I claim to be a third generation French Canadian, I have a little other blood in my veins. My mother's grandmother was the daughter of a Frenchman and an Irish woman, who met on the boat coming over and were married as soon as they reached Canada. My mother's mother spoke English and ridiculed her husband, who was typically French and spoke little English. My other ancestors were French Canadians, farmers of average wealth and social positions.

Besides French my parents speak English without a noticeable accent. About three-fourths of the time they use English, and the remainder French. It seems easier for them at times to express certain things in French. I understand French perfectly, but can hardly speak it at all. As youngsters, we children came to consider French inferior and the speaking of it as degrading. Now I regret not being able to use more than one language. Mother, striving to be like her American neighbors, sent us to public school, and reared us according 
to the tastes and habits she had acquired by living among typical Yankees. Thus we were not thrown into close contact with French Canadian culture, although we consider ourselves French, strange to say. Mother's religious beliefs, however, were always unchanged.

The part of the town in which I lived was composed chiefly of natives and those who spoke English, but two streets below us was the stronghold of the French Canadians, who, being recent immigrants, or un-Americanized residents, spoke French and attended the parochial schools. Quite naturally our family did not associate with this group. Once a crowd of very poorly dressed immigrants came to our house seeking a family whose name resembled ours. After a number of questions, we directed them to the lower end of town, thereby indicating to our neighbors that these "Canucks" (typical French Canadian farmers) were neither relatives nor friends of ours. My parents once made a trip to French Canada, but were displeased with conditions there. Later they made other visits, each time speaking disparagingly of the life there, especially the crude methods of tilling the soil. Father's sister sent us a photograph of her family recently. This picture from the Paribanks region gave us quite a bit of entertainment, as our relatives were dressed in the oddest cut of clothes, and looked the parts of "Canucks." I suppose it is because the French Canadians here and in Canada are so different in culture from us that we look down upon them. I cannot honestly say that I ever felt a sense of pride in the people or land of my forefathers. I have really tried to convince myself that $I$ am wrong in considering French Canadian culture as inferior, but I find it very difficult to put aside all the emotions of my early experiences. As a graduate student, I work up a little interest in their history, traditions, and customs, but I must confess that my major, history, rather than a sense of racial pride or kinship has been the cause.

How vividly I remember the times we children were called "frog" or "dirty French" at school! These humiliating experiences threw us on the defense, but I never felt our replies ever cut so deeply or hurt so long as the insults hurled at us. My parents likewise recall many persecutions at the hands of Americans, and the destruction of property by "American" stones. They remember how they dreaded to see a French Canadian family move into the community, as the French Canadians had lower standards of living, never improved their property, and, by cluttering up the yards, caused property to decrease in value. My parents feel that the Americans were justified 
in their attitude. I had a teacher in the grades who detested French Canadians, and always increased her punishment for offenses committed by our national group. Her favoritism toward American children was very marked. No doubt our religion has played an important part in these discriminations.

Unjust as our treatment has been, I must, in all honesty, admit that we have brought much of it upon ourselves. And this unusual behavior is an offense to the Americanized French Canadian, just as it is to the Yankee. On New Year's Eve and Day, French Canadians celebrate to the "nth" degree. The old Yankees call it the French Fourth of July, and this figure of speech could be taken quite literally. Most of the men get uproariously drunk, and proceed to go around shaking hands with all their relatives and friends, with much kissing, etc. The women follow along sober, as a rule, but participate in hand shaking and kissing. Singing and dancing are also indulged in to the extreme. The noise and disturbance are not kindly accepted by the Yankees. Although the French Canadians have modified their celebrations to some extent in this country, they still make this the day of days.

I have often wished that my parents belonged to a more "American" group. Americans seem to fit everywhere, and have more confidence than I have. It is the boy with an American name, like Smith, or Grant, that is wanted. Often I suspect that parents have advised their children to avoid French Canadians. I cannot say definitely that my nationality has kept me out of clubs and fraternities; I know something has. No doubt religion has played its rôle. It certainly did in one instance; for I was left out of a club composed of my playmates, and organized by a Y. M. C. A. leader. I felt quite lonesome and was almost totally isolated; nevertheless I soon overlooked the incident and again resumed my relationships with these Protestant playmates. As a senior last year, I made a desperate effort to secure a teaching position, but somehow the other fellow always beat me to it. Not to be outdone, I came back this year and took the Master's degree, doing janitor work to support myself. By superb effort, I have secured a mediocre position for next year. It seems that I shall have to change my name and church, as several of my friends have done, if I am to compete on an equal basis with the old American stock. I have been told, however, that this prejudice is confined chiefly to New England, and that I would not experience discrimination on this score elsewhere. 
I have no patriotism for Canada; I feel that I am an American, and very much the same as a typical one. So far as I am able to judge, I have broken completely with all the French customs and attitudes, all save membership in the Catholic Church. But I am not in harmony with the doctrines of this church. I see no difference in the fundamental principles of religions and cannot accept the dogmatic teachings of my church. I soon discovered I would have no friends if I continued to express my real views on religion. Now I keep such thoughts to myself, and go to church when I think it will be to my material advantage to do so.

\section{French Canadian No "Le Beau Canada" for Me}

I was brought up in New Hampshire, as were my father and mother before me. When a girl, mother attended an Ursuline convent in Canada, later completing a course in nursing in Massachusetts. Of my grandparents I know almost nothing, except that they were French Canadians from near Quebec and spoke French. The section of the city in which I was reared consisted chiefly of French Canadians, many of whom, even boys, were recent immigrants. Upon reaching working age, many of these boys went to work at the compulsion of their fathers. Even the few who continued in school showed little intelligence, and seemed to care nothing for an education. I now understand that I was never a part of this community; these people simply were not my kind.

So far as I am concerned, my racial history is of no interest to me. The traditions and customs of my ancestral group are odd - that is all. Their celebrations of New Year, Easter, and many of their patron-saint holidays are strange. On the other hand, my parents display quite a bit of interest in the doings of French Canada; mother is particularly concerned with everything that takes place in Quebec or Montreal. She thinks so much of that country that she does not seem to realize that she is no longer living in the Province of Quebec. My grandparents could not live another day if they could not receive a daily Canadian paper. My maternal grandmother can talk of nothing but what a wonderful country Canada is, how much superior everything is, and how much better everything is done in Canada. I have heard so much talk that I am no longer interested in "Le Beau Canada." Besides, these wonderful places are in reality of little im- 
portance. Living with people who forever prate of the past gets me where nothing else does. I would not care ever to live or have anything to do with these people or places. I cannot see family trees for love or money. And the country - well, that is a place to keep out of.

All the family speak French, but we do not use it to a great extent. It comes natural to use it around the neighborhood, as most every one speaks French. Really, I am quite interested, since I realize the value of being able to speak two languages. However, I sometimes feel ashamed to be in the presence of a person who can speak French only. I hardly know whether I am ashamed of the language or the person. At any rate, I know I feel cheap when I have to be the go-between.

I feel sorry for newly arrived immigrants; they will soon be saying that this country is not like the old country, and that they should not have left home to come here and be out of a job. Always wanting something beyond them! It is just such a class of people that causes trouble everywhere. They are never satisfied - go on strikes and kick because things are not what they want them to be. If you ask me, Canadians are excellent when it comes to finding fault with anything and everything.

I have been called a "Canuck" because of my ancestry, and every time I hear the name it gets under my skin. Father had similar experiences. Boys used to call him "frog" or other names in the same class, and, as was the custom, the guilty party had to fight until he won or lost and had to admit that he was what the name implied. I, so far as I know, have not been kept out of organizations on account of being French Canadian; but I have kept out of certain groups rather than mix with people whom I did not like any too well. In fact, I am rather proud to be able to avoid groups whose rating is not so high in the public mind. I can't say that I should like to belong to another racial group, but I cannot condone all this group sees fit to do. I don't admire the red flannel that immigrants think they must wear. French Canadian boys on New Year's can make an American breakdown look like a kid's cider party. The death of a child means little to the fond parents. The older people believe that taking a bath on a certain day before sunrise will free the person from sickness and disease throughout the year. A French Canadian thinks nothing of wrapping himself in a blanket and sleeping on a pile of snow. It seems to me that a person with any brains would not follow some of these customs. 
Not being interested in French Canadians, I have never given any consideration to problems that might arise between Canada and the United States. Such situations would no doubt be taken care of by the few men of English descent there, and we could take care of our side here.

\section{Spanish-French-English-Irish-Dutch I am Here. What Am I?}

I was born in Brooklyn, New York, as were my father and mother. My grandparents were immigrants; consequently I am a third generation American, but I hardly know what kind. My mother's father was a Frenchman, born somewhere in France. Her mother was Spanish, having been born in Madrid, Spain. She was distantly related to De Soto, the great Spanish explorer. On my father's side my grandmother was of English-Irish extraction, and her husband a Duteh-English combination. Thus I must be a combination of Spanish, French, English, Irish, and Dutch. Regardless of what I am, I am here, a weird combination, and must make the best of it. Rightly or wrongly, I claim to be of the Latin group. This is probably largely due to the fact that my name has come down from the Romans of old. But to be more specific, I elaim that I belong to the Spanish group. This is perhaps due to the fact that my grandmother was Spanish and had a Cuban as her second husband, and my mother spoke Spanish.

I know very little about the eustoms, history, or traditions of the Spanish or French. What I do know I have learned through reading, as my folks never told me a thing about the aforesaid. However, I have read some books, in connection with my school work, on the Spanish, and have felt some sense of pride in their accomplishments. My parents taught me neither their mother tongues nor any other foreign language. The only language I am interested in, and that only in a eommercial way, is Spanish. I am studying this language because I have an uncle who is in South Ameriea working for an oil company. I am studying petroleum engineering in this university.

I have always tried to help any newly arrived immigrants, because I know how hard it must be for those who eome to a new country, where they have very few things in common with the other people around them. I have never been ashamed of any foreigner whom I knew to be trying to do his best but I have no patience with any one 
who tries to live off the people surrounding him. I think anybody shows his ill breeding by laughing at a foreigner, for he would be just as much a stranger in their country as they are in ours.

Although I am a combination of different racial and national groups, I have never wished to belong to any particular racial group. I am as much American as anybody, and I try to conduct myself so as to be as good a one as possible. The United States, to me, is the best nation in the world, and is superior to all other nations.

\section{Spanish}

\section{Call Us Spanish Americans, Please}

I was born in San Jacinto, California, and spent my early life in San Jacinto and Los Angeles. My parents were born in San Diego, California, and have spent their life in Southern California. My grandparents were born in San Sebastian, Spain. Later they came to California, where they spent the remainder of their lives. I, therefore, trace my descent to the Spanish national or racial group, and am a third generation Spanish American.

I have studied a great deal about the history, traditions, and customs of the Spanish. I have always been interested in Spanish things. I have heard some of this at home. However, at home we were always taught to be good Americans and to take an active part in the community in which we lived. I enjoy reading books about Spain. I am teaching Spanish; naturally I want to get all the information possible. At times $I$ have felt a sense of pride in knowing about Spain. I am very much interested in this mother tongue, and I have never felt ashamed of it or ashamed to use it. My parents received their education in this country, but they could speak Spanish fluently. They always spoke it to us at home; consequently we learned the Spanish just as well as the English, from childhood.

I have never wished to belong to any other nationality or racial group. The Spanish constitute one of the great historical divisions of the Latin group, and I think being of Spanish descent is just as good as being of any other. It is my opinion that I would have felt differently about being of Spanish descent and speaking the language had I grown up in some other part of the United States. Since this area once belonged to Spain and was settled by the Spanish, the influence of the Spanish culture is very strong. This makes it very easy for people of Spanish descent to adjust themselves. Again, many of 
the old, historic, aristocratic families are of Spanish descent. This adds prestige to the Spanish in this part of the country.

On the other hand, the situation is complicated by Mexico. Most of the immigrants from Mexico are peons, the lowest class in Mexico. They are mostly Indian with a thin veneer of Spanish. To be mistaken for a Mexican, and to be discriminated against as they are, is a very unhappy experience. Naturally, the people of Spanish descent feel superior to the Mexicans and do not wish to be mistaken for them. This is the chief reason that the people of Spanish descent in the Southwest wish to be known as Spanish Americans.

In regard to my attitude toward the United States, I am just as much American as any one else. I am just as ready to support the policies of the United States against Spain as I would be against Germany, Japan, or any other foreign country.

\section{ITALIAN}

\section{Prejudiced Toward the United States}

Well near midnight, on February 20, 1907, I was brought into the world in a house in Connecticut, which was to be my home for eighteen years. Mother was born in New York, father in Connecticut, and my four grandparents in the mountains near Genoa, Italy. At sixteen my grandfathers came to this country and later sent for two young Italian women, who became their wives. My paternal grandfather was the first Italian to settle in the little Connecticut town, now my native town. There are, however, only about 200 Italians of Genoese lineage out of a present Italian population of 25,000. My maternal grandfather likewise was the first Italian to settle in another near-by town. In addition to the Italian ancestry, I trace a distant strain of Teutonic blood. This goes back to the days of Charlemagne when a German soldier settled in the mountains of northern Italy.

Since I have never lived in a community composed of Italians, I have never been identified with my racial group. I have noted, however, that there is a marked difference in those from the north and those from the south. The northern Italians have a higher standard of living, are more energetic, and are more honored in America. My parents do not associate with those from the south, confining their dealings strictly to business. I have never wished to belong to another national group, because I am of a stock that has left an im- 
pressionable record behind. I enjoy reading of their achievements. I have never experienced the sensation of being called a "Wop," but I have resented the term when applied to others of our group. When I showed resentment, I received a lame apology in the form that I was not included in the term. Really, my features and name do not identify me with Italians. This heritage has not hindered me in any way. Should differences arise concerning the United States and Italy, I would be apt to be prejudiced toward this country.

I am interested in the Italian language, and am sorry it is not used in my home. My father uses it in business. I think it very beautiful. Our only custom is serving wine in the home. It is not universal, however, as some of our relatives live in New England and are abstainers. This Italian custom has been modified by the standards of the local communities in which our relatives have lived. Although many third generation Americans are ashamed of immigrants from their native land, I am not. I realize that my own grandparents had many obstacles to overcome in finding their way about the country. I am, then, not ashamed of my Italian ancestry, but am, nevertheless, a full American.

\section{Italian-French Canadian Ancestry Doesn't Count}

I was born and reared in a small New Hampshire town. My father was born in Boston and lived there until his father put him on the state. After four years in another city, he was brought back to work for his father in a small town. Mother, though born in Vermont, moved to the same town, married, and with my father established our home. Her parents were French Canadians, who moved to the United States after some thirty years. My paternal grandfather was born somewhere in Italy, lived there about twenty-five years, married, and then came to this country. Father, the youngest of four children, was deprived of $\dot{a}$ mother's care at his birth. Grandfather returned to Italy, remarried, and again came to the United States. Father, due to his unjust treatment at the hands of his father, has never been interested in his ancestry. For my part, I am immensely interested in the history and traditions of the Italian people, and think them the best people in the world. Although my parents speak French and Italian on rare occasions, I cannot speak either. Still, I am not ashamed of these languages; a language doesn't make a person. Why should one be ashamed of the language of one's grandparents? 
On several occasions, I have been classified as a foreigner, but I was not bothered. Some people would have been hurt, but I knew it was done in fun. These people, after all, were just as foreign as I am. Many of our greatest men have been foreigners; consequently I have nothing to embarrass me. Lazy people do not wish to succeed, while many foreigners are eager to make a name for themselves. I have never been ashamed of my racial groups. One's ancestry doesn't make any difference; it all depends on one's own character as to whether or not one amounts to anything in life. I want to see Italian immigrants make good. I admire their ways and habits, and believe they will take their places later on, even if many seem to be slow in getting started.

All the traditions my parents observe at present are certain feast days. We go to Boston to visit relatives for some of these. Otherwise we have departed from the customs of our ancestors.

\section{POLE}

\section{Three Handicaps - Race, Religion, and Name}

I, a third generation Polish American, was born and reared in Connecticut. Due to the illiteracy of my parents and the tendency in our family to regard Germans in a more favorable light than Poles, I have never been able to learn much about our relatives from the old country. My paternal grandparents were born in Poland, as was my maternal grandmother. My maternal grandfather, though of Polish extraction, was born in Prussia and called himself a German. All four came to the United States and settled in Pennsylvania, in what cities I do not know.

I have never lived in a community made up of my own racial group. My closest contacts have been at church, and I must confess that the closer these contacts become, the less I like Poles. I have been told that this dislike is due to my having met only the uneducated class. It is true that most Poles of my acquaintance have been ignorant foreigners, shop hands, whose ideas and customs differ markedly from those of Americans. This group is laughed at and avoided. On the other hand, I have known a few young Poles who, after attending college, became quite conceited. Again I have been advised that I could learn to like this group. Maybe so. All I know now is that I have never found a Polish group that I like.

Nationality seldom enters our conversation at home, and I seldom 
give it a thought, unless provoked to do so. Mother always taught us that we were Americans, and we grew up centering our interests in America. My parents were born American citizens, speak the English language fluently, and sent us to public school, where we imbibed attitudes of loyalty toward the United States. The tales of my grandparents and their experiences in Europe seemed too much like fairy-story fabrications to be associated with facts. The continual confusion and irregularities of the government of Poland have drawn my interest away from the history and traditions of my national group. I notice the Polish national leaders never work in unison, and each displays a jealousy. It seems to me that a Pole seldom lasts long. Among my national group in America, there has never been an outstanding one. From them I expect no great achievement. If difficulties and war were to arise between the United States and Poland, I would naturally fight for the United States against Poland, just the same as against any other foreign country.

My parents and I can speak Polish, although we seldom use it. On the few occasions in which I have served as interpreter, I have felt a wave of pride, an increased prestige and status. In the Polish language itself, I have no interest. Nor have I ever been proud of knowing about Poland. As for Polish immigrants, I am somewhat hostile toward them, just as toward any immigrants. I am both ashamed and amused at them - ashamed of their ignorance and amused at their peculiarities, especially their accent when trying to speak English. Somehow I feel that Polish immigrants do not belong here.

When called a Polack, or some other similar name, I did nothing, but wanted to show what I was made of, and that I could stand up and take a beating. Of course such nicknames hurt, although I tried to compensate by considering the persons who called me them as quite ignorant. I do not recall hearing that my parents had such difficulties. This was no doubt due to the fact that they did not live outside Polish communities.

So far as I know, I have never been excluded from groupss on account of my Polish ancestry. I belong to a national fraternity and other organizations. I have been told that this democratic campus is not typical of other campuses, and that even my rather important athletic honors would not cancel my foreign tinge at other schools. Many times I have wished that I belonged to another racial group, one not looked upon with so much disfavor. Yet I feel that it is only a matter of luck that I was born white instead of black. So far my 
religion has not been a handicap, but I fear it may some day, as Protestants have the dominant hand in American affairs. Although not strong in my beliefs, I attend the church of my grandparents and parents - the Polish Roman Catholic. I may change later, as I consider religion, as race, an accident. My Polish name gives me greatest concern; my professors can't pronounce it, nobody can spell it, and people stare at me peculiarly when introduced. Educated people recognize my name as Polish, but the masses are liable to call me a Jew, Pole, Russian, or German. I realize three Polish generals played an important part in the Revolutionary War, and had several towns named after them. I am not exactly ashamed of a Polish name, but it is hard to pronounce and spell, and serves to identify me with a group with whom I desire no connection.

\section{Russian Jew}

\section{Three Generations of Conflict in One Family}

Having been reared from early childhood in the presence of parents born and educated in New York and Philadelphia, and grandparents who came from Russia, I have often been amused to see how the two generations differ in their reactions to some of my expressed opinions and actions. For eight years I was practically brought up by my grandmother in a manner similar to the one used for mother, except English was used on me instead of Jewish. As I grew older, I learned to understand the speech of the older members of the household, by picking up a word here and there. At the age of five years, I was sent to kindergarten, and here, for the first time, I came in contact with children of my own age, whom I regarded as queer. Many could not understand English and many of those who pretended to speak it used such a peculiar pronunciation that I could not resist the temptation to imitate their blunders for the benefit of the family. At such performances my parents would smile and sometimes laugh, reminding me half-heartedly that I should not do this; but my grandparents would be furious and declare that I was not receiving the proper training. To them it was a disgrace for a child to make fun of its own group and language.

As we still live in the same Jewish neighborhood where mother, as a girl in short dresses, paraded the streets, we quite naturally have lost the old associates, and do not care to mingle with the newer comers. Our neighbors consider us as American Yankees, too stuck 
up to mingle with them. Really, we do not care to gossip and listen over and over again to the tales brought from across the water. Their pleasure lies in crowding together into one room during the winter or around the doorstep during the summer, relating to each other their family troubles, the happenings of the day, or else bemoaning the fact that present-day situations do not resemble those of their youth, and that children of today are now wild and less obedient to their parents. They cannot see the use of spending an entire evening reading a book or listening to a radio. As for young girls going to shows and coming home with strange young men in their cars, such conduct is outrageous, unbelievable! Sometimes it is impossible for them to comprehend that $I$ am still a respectable person of society. They cannot see the reason for attending college, and call mother foolish for wasting money on my education, as I shall surely marry and not give her the benefit of my earnings. According to their line of reasoning, the proper thing is to send their sons and daughters to work and live on their earnings. They are perfectly content for their daughters to struggle on in some gloomy factory until so exhausted and disgusted with the monotonous life that they marry men ignorant, vulgar, and often as savage as their forefathers - men who desire a wife only for the sake of satisfying their animal instincts.

Although one may overlook the shocked attitude of neighbors, one cannot, however, lightly ignore the opinion of one's own family upon certain subjects. Since mother and dad have succeeded in keeping up with the modern trend of progress, they are seldom surprised by anything that I should desire to do or wear, and feel that they can fully trust me. My grandparents, on the other hand, often feel that a reprimand is necessary. If I should wear a dress an inch above my knees or suggest cutting my hair in an extreme boyish bob, they always remark on the lack of modesty among modern youth. Although they think midnight is too late for me to come home, they refrain from scolding me, as they think it the mother's duty to set the home-coming hour of her daughter. Often I find grandmother sitting up on some pretext, but in reality worrying for fear something has occurred to detain or wrong me. I must, nevertheless, give my grandparents credit for changing some of their attitudes and being silent on others. In some instances they have changed, and in others, they have met situations so new that they have no basis for deciding whether or not they are right or wrong. Since rearing their own 
family, they have realized the necessity for an education, and are just as anxious, if not more so, than my own parents to see me do well in my studies.

I have never been able to correct my fault of taking a superior attitude toward foreigners. I disparage immigrants who attempt to imitate us in our behavior. Their ridiculous way of combining colors and fashions in their attempt to modernize their appearance and dress has always appeared to me absurd, and instead of aiding them and offering them advice, I ridicule them to others because of their lack of taste and peculiar ways. Still obtaining pleasure from their manner of speech, I imitate them before my friends, who, like myself, take their grammatical errors and wrong pronunciation as a huge joke, and often, instead of encouraging them we make fun of them. Although they may be of our race, religion, and language, we regard them as aliens who must have lived, because of their different dress and actions, as barbarians, and who we feel should be humble and thankful that they have been fortunate enough to enter our country and take advantage of our education and progress in furthering their own ends and becoming a little more civilized.

\section{FinN}

\section{A Finn by Race, an American by Culture}

In early youth my parents came to the United States; therefore, they received their only Finnish cultural influences from their parents and Finnish playmates. I am for this reason culturally American, but Finnish by race. My mother had a number of Finnish contacts during her girlhood, while my father had practically none. The extent of mine has been through visits with my mother. My parents can speak Finnish, but do so only when visiting those who know no English. I understand a little of it, but cannot speak it.

My parents are interested in the advancement of Finland, and my father takes great pride in the showing Finland has made in athletics. I enjoy reading books of travel about Finland, especially those describing life in the taverns; but I do not care for their poetry - to me it seems very mournful and full of sadness. Their music is similar to Russian music and has a deep meaning. The work of the greatest Finnish composer, Sibelius, has won world-wide recognition, and represents a very good interpretation of the life of the land.

I have never been called a foreigner, nor has the fact that my 
parents were born in a foreign country prevented me from joining any clubs or gatherings. I have never felt sensitive in regard to my race or ashamed of it. My father as a boy, upon coming here to live, had difficulty in understanding his playmates. He was a curiosity, I suppose, until he could speak English. He was the first foreigner they had seen.

I don't believe that I adhere to any customs or opinions of my grandparents, but my parents, to a limited extent, do. For example, they follow the custom of drinking coffee every afternoon and with meals, much as the English people drink tea. My mother and father try to go to a sauna (the steam bath common among the Finns and Swedes) whenever possible. They have not told me very much about Finnish people, and I have had few contacts with our racial group. I have, however, never wished to belong to another racial group. I am glad that I belong to a northern European group rather than a southern European one.

\section{QUESTIONS}

1. Show the influence of the first generation Americans (numbers 1 and 9) on the grandchildren.

2. In what respects do the French Canadians (numbers 2 and 3) feel ashamed of their nativity group?

3. What circumstances give the Spanish lady (number 5) pride in her nativity group? What is her reaction to Mexicans? Why do the people of Spanish descent in the Southwest wish to be known as Spanish Americans? What evidence is there among these persons of a pride in north European ancestry?

4. Why did the Pole's (number 8) relatives wish to identify themselves with Germans? Account for his dislike of Poles and Poland.

5. In which documents is there indifference toward the nationality of the grandparents? Why?

6. Why did the French girl (number 1) learn to hate French? Explain what the French Canadian (number 3) means by saying: "I hardly know whether I am ashamed of the language or the person." Why did the other French Canadian (number 2) regard the speaking of French as degrading?

7. Why is the Spanish-French-English-Irish-Dutch man (number 4) interested in Spanish only? What is the Spanish girl's (number 5) attitude toward Spanish? Analyze: "I am not ashamed of these languages; a language doesn't make a person" (number 7).

8. In which of these homes have customs of the grandparents' countries 
been preserved? Why is there so little evidence of Finnish culture in the Finnish girl's (number 10) home?

9. Why does the Pole (number 8 ) hold on to his religion? What was the French family's (number 1) reaction to prohibition? How does the grandmother's code of morals differ from that of the granddaughter? Mention some of the most outstanding customs that have survived to the third generation.

10. Why has the Pole (number 8 ) lost companionship with his group?

11. Make a list of the expressed reactions to the United States and Americans. Can the French girl (number 1) be truly an American without getting away from her French background which she wishes to maintain?

12. Compare and contrast the three processes of assimilation in documents 1. and 9.

13. Prepare a paper comparing the processes of assimilation in the first, second, and third generations of Americans. 


\section{INDEX}

Abyssinia, 182, 334, 426, 455. See Ethiopia.

Accommodation, 517-18.

Achæan, 18, 193, 197.

Achinese, 435.

Act: of Toleration, 297; of Union, 33; of Union and Safety, 340.

Adalia, 372.

Aden, 421, 425.

Adrar, 465.

Afghan, 333, 413, 414, 441. See Pathan.

Afghanistan, 25, 255; general description, 441; political development, 441-42; economic development, 442-43; social conditions, 443.

Africa, Chap. XXIX: general description, 454-55; political and economic development, 455-65; general social conditions, 465-69; immigration and emigration, 469-70.

Africa: independent countries - Ethiopia, 455-56, Liberia, 456; possessions in - France, 457-59, Great Britain, 459-62, Portugal, 462-63, Belgium, 465, Italy, 464, Spain, 465.

African, 171, 177, 427, 455, 456; slaves, 450.

Aino, 399.

Alan, 165.

Alaska, 244.

Albania, 182, 192, 303, 307, 324; and Yugoslavia, Chap. XX: general description, 313-14; political development, 314-15; economic development, 315-17; social conditions, 317; immigration and emigration, 317-18.

Albanian, 5, 15, 178, 193, 240, 242, 322, 371 ; first generation life history, 621-33.

Albigenses, 140.

Alemanni, 20, 94.
Algeria, 99, 334, 454, 457.

Alpine, 5, 18, 25, 29, 32, 49, 79, 93, 179, 239, 242, 256, 292, 313.

Alsace-Lorraine, 51, 52, 54, 133, 137, 138, 139.

Amalgamation, 490.

American: colonization society, 456; colonies, 51; freedmen, 456; Negroes, 335, 456; Polish Society, 290.

Americanization, 519, 520, 521.

Anatolia, 182, 367, 368, 372, 432. See Turkey.

Andalusian, 219, 233.

Angle, 29.

Anglo-Egyptian Sudan, 459, 460, 462. Anglo-Russian agreement, 442, 445.

Anglo-Saxon, 30, 142, 198.

Angola (Portuguese West Africa), 165, 169, 462, 463.

Animist, 12, 417, 436.

Annam, 384, 429, 430.

Antin, Mary: ¿24.

Aquitanian, 135.

Arab, 5, 16, 153, 166, 169, 171, 172, $333,334,369,371,375,377,378,379$, $385,413,414,423,424,425,426,429$, $431,432,433,444,448,449,454,457$. 458, 462, 464, 466, 469. See Moor.

Arabia, 12, 18, 367, 368, 369, 375; general description, 449-50; political and economic development, 450-51; religious and social conditions, 451-52.

Araucanian, 217.

Argentina, 22, 49, 63, 91, 99, 145, 163, $174,189,250,275,289,313,379,484$, 503, Chap. XV.

Arian, 285.

Armenia, 255, 372.

Armenian, 5, 14, 18, 145, 248, 256, 260, $266,267,269,276,277,281,327,334$, $368,371,372,374,444,448,449$, 
479, 508, 509; first generation life histories, 653-54, 654-56; massacres, 277.

Aryan, 5, 14, 18, 25, 192, 333, 334, 413, $414,441,444,448$.

Aryo-Dravidian, 413, 419.

Asiatic, 5-18, 120, 121, 123, 125, 128, 240, 439, 467, 468, 486; barred zone, 429; Mongrels, 49, 279; Russia, 252, 262, 412; Turkey, 379, 497.

Assam, 413, 416, 418, 420.

Assimilation, 519-22, 705-07.

Assyrian, 16, 18, 153, 334, 433.

Australia, 6, 7, 11, 17, 21, 25, 112, 127, $189,313,335,396,410,428,434,485$, 497, 503; and New Zealand: general description, 120-21; political development, 121-22; economic development, 122-23; social conditions, 123-24; immigration and emigration, 124-25.

Austria, 25, 69, 81, 95, 96, 135, 154, 177, $180,181,200,244,253,279,281$, $282,283,289,292,294,296,297,298$, $300,305,311,350,354,355,370,445$, 509. See Germany and Austria, Chap. III.

Austria-Hungary, 22, 137, 178, 182, $203,245,249,250,275,288,297,303$, $307,308,310,312,313,315,323,324$, 374, 508; Dual Monarchy, 52, 53, 54, 357.

Austrian, 12, 235, 253, 288, 299, 301, $308,312,356,364,375,486$.

Avar, 243, 295, 306, 320, 321.

Azerbaijan, 255, 256, 260, 267, 372.

Azores, 165, 166, 167, 175, 469, 470.

Aztec, 202, 203, 206, 209, 219.

Babylon (Chaldea), 16, 334, 367, 376, $444,450$.

Bagdad railway, 54, 374, 375, 451.

Balch, E. G.: 493.

Balkan, 192, 259, 313, 315, 325, 327, 329, 378; Peninsula, 192, 199; States, 49, 52, 324, 327.

Balt, 104, 107, 109, 337, 339, 340, 341, $343,345,347$.
Baltic, 15; states, 23, 54 .

Banat, 48, 241, 244.

Bantu, 16, 17, 125, 335, 454, 458, 463, 465.

Barbary States, 455.

Barna, B.: 648.

Barred zone, 333, 436, 437, 497, 500. See Asiatic barred zone.

Basque, 5, 29, 134, 142, 152, 165, 219, 221, 256.

Basutoland, 460, 468, 469.

Batavian, 79, 80.

Bavaria, 49, 51, 57, 194, 306.

Bechuanaland, 460.

Bedouin, 334, 433, 450, 451, 466.

Belgian: Africa, 463; Congo, 79, 82, 84, 463; first generation life history, 557-59; second generation life history, 728-31.

Belgium, 11, 25, 48, 49, 51, 133, 134, 135, 144, 145, 154, 169, 387, 405, 463. See Holland and Belgium, Chap. V.

Bengal, 413, 416, 418.

Berber, 17, 134, 152, 153, 166, 176, 334, 454, 457, 458, 466, 469.

Bessarabia, 241, 245, 252, 259, 284, $286,323$.

Bhutan, 412.

Bismarck: 51, 53, 56, 59, 75.

Blumenbach: 334, 434.

Bodart, G.: 138.

Boer, 126, 127, 435.

Bogardus, E. S.: $379,500,501,502$, 503, 504.

Bogomil, 309, 310, 326.

Bohemia, 50, 51, 52, 280, 281, 285, 292, 293, 294, 295, 296, 297, 329.

Bohemian, 5, 22, 300, 354, 509. Sec Moravian.

Bokhara, 263, 267, 269, 274.

Bolivia, Chap. XV.

Boody, B. M.: 490.

Borneo, 428, 434, 435.

Bo-Russian, 101.

Bosnia, 48, 304, 305, 308, 309, 311, 313, 323, 369; -Herzegovina, 303, 309, 310.

Bosnian, 5, 307, 311, 312. 
Bourdon, Jean: 144.

Bowman, Isaiah: 8, 35, 49, 54, 133, 175, 251, 262, 291, 318, 366, 397, 437.

Brahman, 414, 418, 419.

Brandenburg, 281.

Brandenburg, B.: 513.

Branson, E. C.: 144.

Brazil, 8, 22, 49, 63, 91, 99, 145, 163, $167,168,169,170,174,189,200$, $212,216,250,275,289,313,379,395$, $410,470,485,503$, Chap. XV.

Britain, 20, 69, 123, 203, 417, 425, 432, 457.

British, 120, 125, 126, 127, 128, 134, $146,148,228,229,234,373,375$, $381,401,402,414,415,419,420,421$, $423,425,427,428,431,450,456,461$, 462, 470; Empire, 8, 148, 252, 386; expansion, map of, 28; Isles, 22, 23, 124, 212. See The United Kingdom, Chap. II.

British possessions: Africa, 459-62; Arabia, 421-26; Asia, 412-29; Borneo, 427, 439; China, 428; East Africa, 461-62; Guiana, 216, 219, 420; Honduras, 216; India, 412-21; North America, 22, 212; Oceania, 412, 428-29; other Asiatic possessions, 426-29; South Africa, 460; West Africa, 460-61. See British Teutonic Colonies, Chap. VIII.

British West Indian Negro, second generation life history, 820-22.

Briton, 30, 134, 142.

Brown, Maude M.: 753.

Brunner, E. de S.: 486, 490.

Buddhism, 12, 391, 405, 406, 426, 436, 440.

Bukovina, 52, 241, 244, 253.

Bulgaria, 98, 192, 199, 200, 241, 242, 243, 245, 303, 304, 307, 308, 312, 369, 370; Chap. XXI: general description, 320-21; political development, 321-25; economic development, 325-26; religious development, 32627 ; educational development, 327 28; social development, 328-29; immigration and emigration, 329-30.
Bulgarian, 5, 21, 197, 240, 305, 311, 333 , 338, 356, 484, 509; church, 327; exarchy, 328; first generation life history, 634-40.

Bureau of Immigration, 110, 179, 236, 242, 274, 311, 339, 455.

Burgundian, 81, 94, 134.

Burma, 384, 415, 420.

Bushmen, 17, 454, 465.

Byzantine, 157, 160, 239, 247, 266, 268, 367, 368, 370, 376; Empire, 193, 375; patriarchate, 258.

Cahan, A.: 524.

Cambodia, 429, 430.

Cameroon, 461.

Canada, 17, 21, 23, 25, 49, 63, 91, 99, $123,127,134,135,145,189,200,237$, $250,275,289,313,365,395,410,421$; and Newfoundland: general description, 112-13; political development, 113-14; economic development, 11416; general social conditions, 116-17, physiographic and cultural areas, 117; immigration and emigration, 117-20.

Canary Islands, 152, 465.

Caninefate, 79.

Cape Verde Islands, 165, 166, 167, 175, $462-63,469,470$.

Carinthia, 51, 311.

Carniola, 51, 52, 303, 311.

Caroline Islands, 155, 399, 402, 405.

Carpathian Russia, 292.

Carr-Saunders, A. M.: 490.

Carthaginian, 16, 152, 165, 179.

Causes for immigration, 477, 507-12.

Celebes, 435.

Celt, 5, 15, 18, 29, 30, 134, 142, 236, 490. See Alpine.

Celtiberian, 134.

Central America, 17, 99, 202, 212. See South and Central America, Chap. XV.

Ceylon, 169, 420, 426, 427.

Chaldean, 5, 153, 333, 334, 444. See Babylonian.

Characteristics of immigrants, 42-44: 
Albanians, 313-14; Bulgarians, 333; Chinese, 381-82; Finns and Esthonians, 338-39; French, 143-44; Germans and Austrians, 63, 64; Greeks, 198-99; Japanese, 399; Jews, 425; Negroes, 335; Poles, 290; Portuguese, 166; Russians, 252-57; Scandinavians, 74-76; Spaniards, 152-53; Yugoslavians, 304.

Cherkasi (Ukrainians), 253.

Chile, 10, 12, 99, Chap. XV.

China, 8, 12, 54, 165, 170, 212, 234, 352, $369,375,399,400,403,404,407,409$, $425,428,429,436,440$, Chap. XXV: general description, 381-83; political development, 383-88; economic development, 388-90; religious development, 390-92; educational development, 392-93; social conditions, 393-95; immigration and emigration, 395-96.

Chinese, 5, 15, 17, 21, 119, 121, 125, $178,406,408,427,431,434,437,439$, 441, 484, 495, 497, 502; exclusion, 481; first generation life history, 666-75; second generation life history, 811-14.

Christian, 12, 14, 36, 158, 159, 184, 194, $244,245,249,285,297,322,326,353$, $360,369,375,376,405,406,417,422$, $424,425,432,433,436,447,448,456$, 458.

Christowe, S.: 634 .

Cimmerian-Thracian, 257.

Circassian, 274, 320, 426.

Cochin China, 429, 430.

Cohen, Israel: 438.

Cohen, Rose: 524.

Colombia, Chap. XV.

Comenius: 297, 298.

Commons, J. R.: 38, 479.

Confucianism, 12, 391, 392, 393, 394, 405.

Congresses and conferences: Berlin, 248, 323; London, 435; Mannheim, 96; Paris, 248; Stanz, 95; Vienna, $81,95,180,431,435$.

Copt, 153, 334 .
Cossack, 5, 263, 283, 333.

Costa Rica, Chap. XV.

Courland, 103, 104, 105, 108, 110, 259.

Creole, 232, 233, 236.

Crete, 17, 194, 195.

Croat, 5, 52, 178, 307, 309, 311, 312, $350,356$.

Croatia, 51, 52, 303, 304, 307, 308, 353; -Slavonia, 294, 309, 310.

Crusades, 140, 142, 143, 167, 171, 339, $343,355,360,422$.

Cuba, 155, 163, 211, 203, 212, 213, 250, 395, 403, 470, Chap. XV.

Culture, 16, 17, 29, 193, 194, 197, 230$31,257-58,328,392,407,493$; areas, 16-17, 465-66; comparisons, 513-14; conflicts, 693-704.

Curry, J. C.: 17.

Cypress, 192, 444, 457.

Cyrillic alphabet, 239, 242, 248, 300, $307,311,326$.

Czech, 5, 52, 61, 255, 281, 292, 301, 354, 356, 509, Chap. XIX; in Chicago, 485.

Czechoslovakia, 10, 48, 49, 54, 55, 134, $138,144,241,279,306,350,352,424$, Chap. XIX: general description, 292-93; map, 293; political development, 293-96; economic development, 296-97; religious development, 297-98; educational development, 298-99; social conditions, 299-300; immigration and emigration, 300301.

Dalmatia, 5, 353, Chap. XX.

Damão, 165, 436.

Dane, 30, 339, 486; first generation life history, 551-54; third generation life histories, 845-47, 847-48, 851-53.

Danish, 5, 339; invasions, 37.

Danzig, 47, 48, 54, 283.

Davis, Jerome: 35, 271, 278.

Deniker, J.: 5, 240, 304, 382.

Denmark, 10, 25, 30, 48, 52, 54, 88, 280, 285. See The Scandinavian Countries, Chap. IV. 
Departure of immigrants, 484-85.

Difficulties in coming to America, 478-79.

Disappointments of immigrants, 514-16.

Disorganization: of immigrants, 51617 ; of second generation, 704-05.

Dissatisfaction in native land, as cause for emigration, 507-10.

Distribution of immigrants, 485-86.

Diu, 165, 436.

Dixon, R. B.: 4, 49, 493.

Dobruja, 241, 245, 323.

Dodecanese, 177, 178, 182, 192, 372 .

Dorian, 18, 193.

Dravidian, 16, 335, 413, 414, 433.

Duncan, H. G.: '4, 7, 23, 504, 523.

Dutch, 5, 50, 68, 121, 126, 129, 167, 169, $236,385,401,414,426,435,436,459$, 478 , 479, 485; Asia - general description, 434; political development, 434-35; economic development, 435; social conditions, 436; Borneo, 434; East India company, 126, 434; East Indies, 78, 434, 451; Guinea, 78, 216; third generation life history, 847-48; West Indies, 78.

Early: attitudes toward immigration, 493-94; wanderings, 17-20.

East: Africa, 334, 465, 466; India company, 414, 416; Indies, 395, 436.

Economic development. See economic development under separate countries.

Economic: divisions of the world, 8-12; effects of immigration, 488-89.

Ecuador, Chap. XV.

Edict: of Nantes, 141; of Toleration, 107.

Educational conflicts of second generation, 700-01.

Educational development. See educational development under separate countries.

Egypt, 16, 17, 18, 193, 370, 402, 444, $445,459,460,466,468$.

Egyptian, 131, 334, 376, 431, 469; Sudan, 375.
Emigration: reasons for, 22-23; prohibitions of, 274, 409.

Empire Settlement Acts, 42, 123.

England, 51, 53, 69, 86, 98, 135, 136, $137,139,141,147,157,168,169,171$, $180,194,200,205,220,222,223,228$, $232,245,272,285,323,325,371$, 416, 420, 445, 480, 494, 509.

English, 5, 15, 16, 30, 90, 126, 149, 167, $172,186,198,203,207,213,234,235$, $249,330,374,399,406-07,415,418$, $425,467,479$; in the United States, 478; first generation life histories, 535-39, 539-41; second generation life history, 709-13; third generation life histories, 833-34, 834-38, 849-51.

Eritrea, 177, 178, 426, 464.

Eskesen, E. V.: 551.

Eskimo, 108, 252, 259, 338, 339, 340, $341,342,344,347$.

Esth (Esthonian), 255, 333, 334, 337, $338,339,34$;, 345, 346, 347, 352.

Esthonia. See Finland and Esthonia, Chap. XXII.

Ethiopia (Abyssinia), 455-56, 467.

Ethiopian, 5, 333, 334.

Euskarian, 5, 134.

Evans-Gordon, W.: 272.

Fairchild, H. P.: 40, 43, 63, 64, 151, $191,201,238,291,300,302,313,319$, $366,477$.

Federated Malay States, 427.

Ferenczi, Imre: 21, 41, 46, 62, 100, 212, 236, 251, 278, 302, 398, 478.

Fiji Islands, 420, 428.

Filipino, 515; first generation life history, 659-63.

Finland, 22, 52, 66, 252, 259; and Esthonia, Chap. XXII: general description, 337-39; political development, 339-43; economic development, 34344; religious development, 344-45; educational development, 345-46; social conditions, 346-47; immigration and emigration, 347-48.

Finn, 5, 68, 253, 255, 256, 274, 320, 333, 
$334,352,360,368,371,382,486$; first generation life history, 642-48; second generation life histories, 79194, 794-96; third generation life history, 870-71.

First Generation Americans in Process, Chap. XXI: causes for immigration, 507-12; first impressions and discoveries, 512-17; accommodation, 517-18; naturalization, 518-19; assimilation, 519-22.

First generation life histories. See life histories, first generation.

Fisher, S. G.: 489.

Flanders, 81, 84, 135.

Flemish, 5, 22, 78, 79, 80, 81, 84, 85, 87, $88,89,90,91,134,142$.

Foreign: commerce, 11-12; investments, 11-12, 29, 208; problems, 485.

Formosa, 387, 390, 395, 399, 400, 402, $404,407$.

France, 8, 11, 22, 25, 29, 32, 35, 48, 49, $51,52,53,55,81,86,90,91,97,98$, $113,114,119,122,131,152,155,164$, $177,180,181,189,194,220,222,228$, $232,245,248,259,260,273,283,284$, $289,325,372,375,386,387,401,412$, 428, 429, 430, 432, 459, Chap. IX: general description, 133-35; political development, 135-39; economic development, 139; religious development, 139-42; educational development, 142-43; social development, 143-44; immigration and emigration, 144-49.

Frank, 20, 94, 134, 143, 180.

Franklin, B.: 493.

Free-thinking societies, 298, 301.

French, 5, 15, 16, 51, 87, 88, 94, 117, $121,154,167,168,179,183,186,193$, 203, 207, 210, 211, 216, 224, 231, 234, $235,236,242,249,270,315,370,374$, $377,414,430,432,441,448,456,457$, $459,468,470,479,482,485,491$; second generation life history, 73941 ; third generation life history, 855-57.
French Canadians, 114, 116, 118, 491, 501; third generation life histories, 857-60, 860-62, 865-66.

French possessions: Africa, 456-59Equatorial Africa, 458, West Africa, 458, Somaliland, 456, 458-59; Asia, 429-34 - Indo-China, 429-31, 439, Syria, 431-34; Canada, 133, 14649.

Frisian, 79.

Galicia, 48, 52, 119, 166, 247, 253, 280, 284.

Gambia, 461.

Gamio, M.: 214, 215.

Gandhi: 415, 416.

Garibaldi: 179, 181, 185.

Garis, R. L.: 398, 503.

Gaul, 18, 20, 30, 32, 134, 135, 140, 143, 314.

General description of countries. See general description under separate countries.

Georgia, 255, 267, 269, 372.

Gepidae (Goths), 243.

German, 14, 16, 18, 20, 68, 84, 88, 89, $93,94,96,103,104,105,107,108$, $110,113,125,134,136,142,178,179$, $185,186,193,194,203,207,210,213$, $231,234,235,241,249,255,270$, $280,281,282,285,286,288,292$, 293, 294, 295, 298, 303, 306, 308, 311, $312,315,337,339,341,343,352,355$, $357,360,361,362,364,374,375,402$, $461,464,479,483,491,492,509,510$, 513; first generation life history, 545-51; second generation life histories, 713-18, 718-23; third generation life histories, 833-34, 834-38, 838-41, 841-43, 843-45, 845-47, $847-48$.

German possessions: Cameroon, 458; colonies, 53-54; East Africa, 79, 126, 461-462, 463; Samoa, 120; Southwest Africa, 126; Togoland, 458.

Germany, 11, 22, 25, 35, 67, 69, 75, 80, $82,85,86,90,91,118,133,135,137$, $138,139,141,155,169,181,182$, 
$188,189,212,225,245,259,260,279$, $284,292,296,324,342,353,354,365$, $373,375,382,387,435,440,445,458$, 477, 480; and Austria, Chap. III: general description, 47-49; political development, 49-53; economic development, 53-56; religious development, 57; educational development, 57-58; social development, 58-60; immigration and emigration, 60-64.

Gheg, 314, 316, 317.

Gibbons, H. A.: 278, 437, 452.

Gôa, 165, 170, 436.

Golden Age: Bulgaria, 321, 328; Czechoslovakia, 293; Greece, 193; Italy, 179; Persia, 444; Poland, 281, 290; Serbia, 304; Spain, 160.

Gordon, L. J.: 507.

Goth, 20, 179, 193, 243, 314, 321.

Great Britain, 11, 21, 35, 53, 54, 55, 61, $81,112,118,121,168,169,170,222$, $223,260,372,374,386,387,390,391$, $401,402,412,416,418,428,435,440$, $441,442,446,447,456,459,460$. See The United Kingdom, Chap. II. Great Russian, 253.

Greece, 17, 18, 29, 131, 241, 303, 308, $313,315,316,317,318,320,324$, $325,326,330,373$, Chap. XIII: general description, 192-93; political development, 193-95; economic development, 195-96; religious development, 196-97; educational development, 197-98; social development, 198-99; immigration and emigration, 199-200.

Greek, 5, 14, 101, 125, 132, 153, 156, $157,160,165,178,179,180,184,185$, $192,239,244,245,246,249,254,255$, $257,267,311,314,316,317,321,322$, $326,327,329,353,367,368,369,370$, $371,372,374,376,377,431,444,491$, 508,509 ; first generation life history, $573-78$; second generation life histories, 747-49, 749-53, 753-57.

Greek: Catholic (Uniate), 197, 239, 248, 286, 298, 299; Church (Orthodox), 196, 197, 199, 248, 266, 267,
$307,309,312,313,316,326,327,345$, $375,468$.

Greenland, 67, 68.

Gruening, E.: 212, 215.

Guam, 155, 224, 228.

Guatemala, 203, Chap. XV.

Guinea, 152, 165, 465.

Gypsy, 5, 153, 256, 320, 364.

Haiti, 403, 470, Chap. XV.

Hale, E. E.: 494.

Hall, P. F.: 478, 489.

Hamite, 16, 134, 179, 334, 454, 455.

Hanseatic League, 53, 104.

Hart, H. G.: 448, 453.

Hasanovitz, E.: 524.

Hawaii, 175, 224, 396, 409.

Hawaiian second generation life history, 802-11.

Hejaz, 450, 451.

Helvetian, 94, 95, 311.

Herskovits, M. J.: 465, 471.

Herzegovina, 5, 48, 323, Chap. XX.

Herzl, T.: 423.

Hindi, 256, 418, 444.

Hindu, 5, 12, 333, 441, Chap. XXVII; first generation life history, 663-66.

Hindustan, 414.

Hitti, P. K.: 519.

Hittite, 18, 131, 256, 519.

Hohenzollern, 50, 51, 52, 245.

Holland, 25, 126, 135, 136, 141, 154, $374,401,412,434,435,478$; and Belgium, Chap. V: general description, 78-80; political development, 80-83; dispute between Holland and Belgium, 82; economic development, 82-85; religious development, 85-87; birth control, 88; educational development, 87-88; social conditions, 88-90; immigration and emigration, 90-92.

Hollander, first generation life history, 554-57.

Honduras, Chap. XV.

Hopper, Bruce: 264.

Hottentot, 17, 335, 454, 465.

Huguenot, 126, 140, 141, 145, 485. 
Hun, 49, 50, 134, 139, 243, 320, 321, 352.

Hungarian (Magyar), 50, 180, 243, 247, 279, 281, 294, 299, 312, 485; first generation life history, 648-53; second generation life history, 796-98.

Hungary, 48, 49, 51, 52, 118, 135, 145, $241,242,243,275,280,281,295,301$, 303, 307, 370, 384, 425, 508, Chap. XXIII: general description, 350-53; map, 351; political development, 353-58; economic development, 35860 ; religious development, $360-62$; educational development, 362-63; social development, 363-65; immigration and emigration, 365 .

Hunter, R.: 489.

Huntington, E.: 3, 17.

Iberian, 5, 131, 132, 142, 152, 165, 232.

Iceland, 67.

Illyria, 5, 131, 240, 321, Chap. XX.

Imamate of Yeman, 451.

Immigrants: classification, 5; destination, 22; number and distribution, 482-86; crime among, 491-92; age, 488; pauperism among, 492; illiteracy among, 492; prejudice among, 492-93; early attitudes toward, 493-94; quotas for different countries, 499; first impressions of, 512-17; culture comparisons, 51314; disappointments of, 514-15; disorganization among, 516-17; accommodation among, 517-18; assimilation, 519-22.

Immigration: periods of, 477-79; old versus new, 481-82; effects of, 48893; causes of, $21,477,507-12$. See Immigration to the United States, Chap. XXX and First Generation Americans in Process, Chap. XXXI.

Immigration and emigration. See immigration and emigration under separate countries.

Immigration laws: first federal, 479; first comprehensive federal, 481 ; re- strictive, 493-500; quota, 497-98; national origins, 498-99.

India, $7,16,18,20,54,136,165,167$, $169,170,256,335,375,381,382,402$, $426,429,431,435,442-43,445,448$, 451; general description, 412-14; political development, 414-16; economic development, 416-17; religious development, 417; educational conditions, 418-20; immigration and emigration, 420-21.

Indian, 17, 69, 113, 147, 202-04, 209, $212,213,217,218,219,226,232,236$, 419; East. 5, 12, 19, 128, 333, 385, 421, 427, 428, 437, 468, 469.

Indo-Aryan, 413, 418; -Chinese, 5, 333, 334, 430, 431, 439; -European, 14, 18, $239,256$.

Indonesian, 428.

Inquisition, 154, 158, 159, 160.

Interest of third generation Americans: in race and nativity, 827-28; in language, 828-29; in customs, traditions and history, 829-31; in America, 831.

International migrations, 20-23.

Iranian, 5, 14, 266, 441, 444, 447.

Iraq (Mesopotamia), general description, 421; political development, 421; economic development, 421-22; social conditions, 422 .

Ireland, 27, 33, 34, 52, 90, 203, 362.

Irish, 5, 12, 22, 113, 266, 477, 479-80, $482,485,491,492,493,494,502,509$; third generation life history, 841 .

Islam, 171, 378, 443, 466.

Italian, 21, 50, 52, 94, 98, 125, 133, 134, $142,146,172,198,234,235,236,242$, $244,294,307,311,315,317,374,457$, 484, 486, 491, 492, 503; first generation life histories, 561-65, 565-73; possessions in Africa, 464; second generation life histories, 742-44, 74446 ; third generation life histories, 864-65, 865-66.

Italy, 5, 11, 18, 22, 48, 55, 131, 135, 137, $142,144-45,154,192,212,245,248$, $260,303,308,313,318,324,334,353$, 
372, 374, 387, Chap. XXII: general description, 177-79; political development, 179-83; economic development, 183-84; religious development, 184; educational development, 18486; immigration and emigration, 188-90; effects of returned emigrants, 487 .

Janissaries, 305, 368, 369.

Japan, 12, 21, 170, 212, 234, 235, 259, $381,384,386,387,392,393,509,514$, 521, Chap. XXVI: general description, 399-400; political development, 400; economic development, 404-05; religious development, 405-06; educational development, 406-07; social development, 407-09; immigration and emigration, 409-10.

Japanese, 5, 16, 17, 119, 125, 235, 276, $333,338,368,381,382,388,395,420$, $426,427,501,512,513,514,515,520$; first generation life history, 67585 ; second generation life history, 815-20.

Jat, 413, 418.

Java, 395, 434, 435, 436.

Jefferson, Thomas: 494.

Jesuit, 56, 141, 158, 159, 298, 400, 405. Jew (Hebrew), 5, 12, 16, 108, 140, 141, $145,153,157,158,159,160,166,167$, $171,172,173,184,241,247,248,266$, $274,275,279,281,283,285,286,287$, $289,290,292,298,309,327,333,347$, $358-59,363,364,367,374,375,421$, $422,423,424,425,429,447,448,450$, $457,464,468,477,479,485,491,509$.

Jmoud, 101.

Jugoslavia. See Yugoslavia.

Jutes, 29, 30.

Jutland, 67, 68.

Kalmuk, 5, 333, 338, 382.

Kapp, F.: 478.

Kara Kalpak, 257.

Karelia, 338, 339.

Kashmir, 413.

Kawai, Kazuo: 815.
Kellor, F.: 488.

Ketter, 85.

Keyserling, Count Hermann: 329.

Khazar, 352.

Kiaochow, 387, 402.

Kionga Triangle, 169.

Kirghiz, 257.

Klepht, 194.

Koraichite, 451.

Korea, 384, 387, 392, 399, 400, 402, 404, $405,407,409$.

Korean, 5, 16, 276, 333, 338, 339, 368, $406,484,509,515,520$; first generation life history, 685-87.

Kroeber, A. L.: 14, 15.

Kumani, 243, 247, 322.

Kun (Cuman), 354.

Kurd, 368, 373, 421, 444.

Kurdistan, 373, 375, 422.

Kurile Islands, 399, 400, 402.

Kutzo-Vlach, 241. See Vlach.

Lamaism, 391.

Land: utilization, 10; distribution in United States, 34 .

Languages, 14-16; and nationalism, 22-23; conflicts among second generation, 696-99; number of persons speaking each, 16; spoken in different countries, 30, 68, 69, 93-94, $147,337,341,342$.

Laos, 429, 430.

Lapp, 5, 68, 225, 333, 337, 338, 368.

Latin, 12, 14, 17, 29, 30, 49, 57, 101, $107,132,143,160,193,198,242$, $248,249,280,307,309,311,312,314$, $316,317,321,333,362,370,375$, 376, 378, 481; America, 131, 163, 174, 189, 209, Chap. XV; group, Part III; life histories, Chaps. XXXIII, XXXVIII, XLIII.

Latvia, 25, 252, 279, 337; and Lithuania, Chap. VII.

Lewisohn, L.: 516.

Liberia, 456-57.

Libya, 177, 178, 182, 334, 372, 375.

Liechtenstein. See Switzerland and Liechtenstein, Chap. VI. 
Life histories: (1) Teutonic first generation, Chap. XXXII: English, 53539, 539-41; Scotch, 541-45; German-Russian, 545-51; Dane, 551-54; Hollander, 554-57; Belgian, 557-59. (2) Latin first generation, Chap. XXXIII: Italian, 561-65, 565-73; Greek, 573-78; Mexican, 579-83, 584-89; Mexican-Indian, 589-95. (3) Slavic first generation, Chap. XXXIV: Rumanian, 596-98; Russian, 598-605; Russian Jew, 605-08, 608-13; Polish Jew, 613-16; Serb, 616-21; Albanian, 621-33; Bulgarian, 634-40. (4) Other first generation, Chap. XXXV: Finn, 642-48; Hungarian, 648-53; Armenian, 653-54, 654-56; Maltese, 656-59; Filipino, 659-63; Hindu, 663-66; Chinese, 666-75; Japanese, 675-85; Korean, 685-87; West Indian Negro, 687-89.

Life histories: (1) Teutonic second generation, Chap. XXXVII: English-Irish, 709-13; German, 713-18, 718-723; Norwegian, 723-28; Belgian, 728-31; Lithuanian, 731-36. (2) Latin second generation, Chap. XXXVII: Portuguese-Scotch, 73839; French, 739-41; Italian, 742-44, 744-46; Greek, 747-49, 749-53; Greek-Serb, 753-57; Mexican, 75759. (3) Slavic second generation, Chap. XXXIX: Rumanian, 761-62; Russian Molokan, 762-64; Ukrainian, 764-70; Pole, 770-73; Russian Jew, 773-77, 777-82; Polish Jew, 782-89. (4) Other second generation, Chap. XL: Finn, 791-94, 794-96; Hungarian, 796-98; Armenian, 798-800; Syrian, 800-02; Hawaiian-Chinese, 802-11; Chinese, 811-14; Japanese, 815-20; British West Indian Negro, 820-22.

Life histories: (1) Teutonic third generation, Chap. XLII: English-German, 833-34; English-Irish-German, 83438; Scotch-Irish-German, 838-41;
Irish, 841; German, 841-43, 84345; German-Dane, 845-47; German-Dutch-Swiss-Dane, 847-48; Norwegian-Scotch-English, 849-51; Dane, 851-53. (2) Other group third generation, Chap. XLII: French, 855-57; French Canadian, 857-60, 860-62; Spanish-FrenchEnglish-Irish-Dutch, 862-63; Spanish, 863-64; Italian, 864-65; ItalianFrench Canadian, 865-66; Pole, 866-68; Russian Jew, 868-70; Finn, 870-71.

Ligurian, 5, 131, 179.

Lithuania, 5, 15, 22, 25, 252, 254, 259, 274, 279, 281, 289; and Latvia, Chap. VII: general description, 101-03; political development, 103-05; Polish dispute, 104-05; economic development, 105-06; religious development, 107-08; social conditions, 108-09; immigration and emigration, 10911.

Little Russian (Ukrainian), 253.

Littoral race, 131.

Livonia, 103, 104, 105, 259.

Lollard priests, 31 .

Lombard, 135, 179, 180, 243.

Luxemburg, 47, 85, 133, 145, 294.

Lyons, Eugene: 693.

Macao, 165, 385, 436.

Macedonia, 241, 314, 321, 323, 324, $329,509$.

Madagascar, 334, 456, 458, 459.

Magyar, 5, 20, 52, 241, 242, 246, 250, $255,256,292,293,295,299,303$, $307,308,311,312,333,334,338$, $370,371,382,484$. See Hungary, Chap. XXIII.

Mäkinen, K.: 642 .

Malabar, 431, 436.

Malay, 5, 333, 334, 382, 399, 420, 427, 429, 434, 437, 467; Archipelago, 334 434; Peninsula, 427.

Malaysia, 165, 334, 335, 428, 434.

Malo-Russian (Ukrainian), 253.

Malta, 370. 
Manchuria, 276, 381-83, 388, 390, 391, $395,399,403,410$.

Maori, 121.

Marathas, 413-14.

Marshall Islands, 399, 402.

Mayo-Smith, R.: 479.

Mede, 18, 367, 444.

Mediterranean race, $5,18,25,29,32$, $49,79,93,131,132,179,192$, 242, 257, 292, 304, 313.

Mesopotamia, 18, 372, 375, 420, 444.

Mestizo, 202, 210, 212, 217-18, 232, 233, 236.

Mexican, 5, 118, 163, 485, 501, 502, 508,518 ; first generation life histories, 579-83, 584-89, 589-95; second generation life history, 757-59.

Mexico, 11, 63, 149, 216, 219, 224, 230, 232, 233, 236, 312, 395, 518, Chap. XIV: general description, 202-03; political development, 203-05; economic development, 205-08; religious development, 208-09; educational development, 209-10; social development, 210-12; immigration and emigration, 212-14.

Miele, S.: 561.

Migrations: periods of, 17-20; map of, 19; restrictions upon, 21.

Miller, H. A.: 301, 316, 493.

Millspaugh, A. C.: 447.

Mirza, Y. B.: 524.

Missionaries, 14, 234, 511.

Mithraism, 447-48.

Mogul, 414.

Mohammedan (Moslem), 12, 16, 23, $134,135,140,153,158,160,166$, $170,180,194,196,229,244,248$, $249,266,267,269,274,307,309,312$, $314,316,318,322,327,334,361$, 367-70, 375-77, 379, 392, 414, 417, $419,421-22,425,427,432,433,436$, 446, 447, 450, 451, 458, 467, 509.

Moldavia, 241, 243, 244, 245, 281, 354.

Molly Maguires, 480-81.

Mongol, 20, 243, 255, 258, 354, 384, $413,414$.
Mongolia, 12, 381, 382, 383, 385, 389, $391,410$.

Mongolian, 5, 15, 68, 134, 202, 256, $320,333,334,335,338,352,368,376$, 381, 399, 429, 434, 439, 441, 444.

Mongolo-Dravidian, 413.

Monroe Doctrine, 122, 205, 222, 223, 225, 403, 467.

Montenegro, 5, 197, 303, 305, 306, 308, $309,312,315,323,324,329,484$.

Moor, 153, 154, 156, 157, 159, 160, 161, $166,167,171,172,173,179,219,229$, 233.

Moravia, 5, 51, 52, 280, 281, 292, 293, 294, 296, 297, 300.

Morocco, 146, 152, 156, 375, 454, 457, 458.

Mozambique (Portuguese East Africa), $165,169,462,463$.

Muscovite, 253.

Mussulman (Pomak), 327.

Naples, 135, 154, 180.

Napoleon, 51, 70, 81, 95, 137, 142, 154, $168,180,220,222,307$; III, 181, 205.

Natural resources, $10-11,115,122-23$, $170-71, \quad 195-96,226-29,246-47$, 253-54, 262-65, 284, 296-97, 308, $315,325-26,344,359-60,374-75,390$, $405,417,421-22,424,427,430,435$, $440,443,447,456,457,458,461,463$, 464.

Naturalization, 518-19.

Negrillo, 335, 455.

Negrito, 335, 434.

Negro, 5, 153, 166, 167, 173, 175, 202, 204, 213, 217, 218, 232, 233, 234, $236,333,334,335,354,434,455,458$, 464, 466, 469, 470, 488, 491.

Netherlands, 51, 90. See Holland and Belgium, Chap. V.

Newfoundland, 112, 136. See British Teutonic Colonies, Chap. VIII.

New Guinea, 434, 435.

New Zealand, 8, 17, 21, 25, 189, 428, 497. See British Teutonic Colonies, Chap. VIII. 
Nicaragua, 216, 218, 221, 224, 228, 403.

Nigeria, 461, 467.

Nitti, F.: 284, 292, 358.

Nordic, 5, 49, 79, 93, 101, 239, 255, $292,334,348,490$; superiority, 489 , 495.

Norman, 20, 29, 30, 134, 179, 314.

North: Africa, 134, 233, 334; America, $6,7,10,11,12,14,134,189,288$, 365; Borneo, 427; Rhodesia, 460.

Norway, 22, 25, 52, 66, 337. See The Scandinavian Countries, Chap. IV.

Norwegian, 5, 22, 485; second generation life history, 723-28; third generation life history, 849-51.

Nova Scotia, 113, 136.

Nyassaland, 461.

Oceania, 6, 10, 12, 22, 133, 335, 412, 429.

Oman, 426, 429, 452.

Oriental, 119, 120, 180, 184, 268, 270, $274,352,353,400,407,409,413,434$, $445,510,514,518,520$.

Origin of race attitudes, 500-01.

Orth, S. P.: 478-79.

Oskison, J. M.: 525.

Ostrogoth, 180.

Other racial, national, and cultural groups, Part V; Chaps. XXXV, XL, XLIII.

Ottoman, 193, 306, 307, 314, 323, 368, 369.

Pagani, 311. See Dalmatians.

Palatinate (Germany), 50, 61, 478, 493.

Palestine (Flstin), 18, 193, 250, 289, $368,369,372,421,424,425,429,432$; general description, 422; economic development, 424 ; social conditions, 424-25.

Panama, 216, 218, 219, 220, 227, 234, 403; Canal, 224, 229.

Pan:-Americanism, 23; -Europeanism, 23; -Islamism, 23; -Latinism, 22; -Slavism, 22, 239, 259; -Teutonism, 22.

Panunzio, C. M.: 516, 518, 524.
Papacy, 140, 197, 247, 327, 360.

Papal States, 142, 180, 181.

Paraguay, Chap. XV.

Parsîs, 447-48.

Peace: of Adrianople, 245; of Augsburg, 56; Conference, 316, 352, 355, 358, 445; of Nystad, 340; of Stolbova, 340 ; of Teusina, 339 .

Pelasgian, 131, 192.

Pelew Islands, 155.

Persia, 18, 169, 193, 250, 255, 260, 429, 497; general description, 443-44; political development, 444-46; economic development, 446-47; religious development, 447-48; educational development, 448; social conditions, 448-49.

Persian (Tajik), 14, 153, 256, 333, 367, $378,385,413,414,421,441,444,446$, 447, 449.

Peru, 395, 410, Chap. XV.

Pescadores (Hokoto), 387, 399, 402.

Philippine Islands, 155, 164, 224, 396, 399, 428, 434.

Phœnician, 16, 132, 152, 153, 156, 157, 160, 193, 195, 197, 279, 431, 450.

Pittard, E.: 77, 99, 131, 164, 175, 190 , $201,214,251,277,291,319,330$, 348, 366, 380, 396, 411, 437, 470.

Poland, 22, 48, 49, 51, 54, 70, 80, 81, $101,103,104,110,118,138,144,145$, $241,247,252,254,258,259,274,275$, 281, 292, 294, 354, 362, 384, 424, 425, Chap. XVIII: general description, 279-80; political development, 28084; partitions, 281-82; economic development, 248-85; religious development, 285-86; educational development, 286; social development, 286-88; immigration and emigration, 288-90.

Pole, 12, 61, 63, 105, 107, 134, 185, 243, $255,258,266,275,289,292,356,485$, $491,493,508,509$; second generation life history, 770-73; third generation life history, 866-68.

Polish, 5, 21, 107, 108, 246; Jew, 119; Jew, first generation life history, 
613-16; Jew, second generation life history, 782-89; rebellion, 258, 283.

Political: causes of immigration, 508; effects of immigration, 491.

Political development. See political development under separate countries.

Polynesian, 333, 334, 428.

Pomerania, 69, 70, 280, 281.

Population: world, 3-8; increase, 4, 6; distribution, 6-7, 9; density, 7; movements, 3, 17-23; races, 6 , 334; future areas, 7-8.

Population, separate countries: Aden, 426; Afghanistan, 441; Africa, 125; Albania, 313; Algeria, 457; AngloEgyptian Sudan, 462; Angola, 462; Arabia, 450-51; Australia (and New Zealand), 120-21; Belgian Africa, 463; British Africa, 459; British Arabia, 421; British Asia, 412; British Borneo, 428; British China, 428; British Oceania, 428; British West Africa, 460, 461; Bulgaria, 420; Canada (and Newfoundland), 11213; Ceylon, 426; China, 381, 384; Czechoslovakia, 292; Egypt, 459; Ethiopia, 455; Federated Malay States, 427; Finland (and Esthonia), 337; France, 133; French Africa, 456; French Asia, 429; French Canada, 146; French India, 431; French Indo-China, 429; French Syria, 431; French West Africa, 458; Germany (and Austria), 47-49; Great Britain, 40-41; Greece, 192; Holland (and Belgium), 78; Hungary, 350-51; India, 7, 412-14; Italian Africa, 464; Italy, 177-79, 188; Iraq, 421; Java, 434; Japan, 399, 403, 404, 410; Jews in Palestine, 425; Jews in the world, 425; Lithuania (and Latvia), 102-03; Liberia, 456; Madagascar, 459; Malay, 334; Mexico, 202-03; Morocco, 457; Negro, 335; Persia, 443; Poland, 279; Portugal, 165, 174; Portuguese Africa, 412; Portuguese Asia, 436; Rhodesia, 460; Rumania, 241-
42, 246; Russia, 252-57; Scandinavian countries, 67; Siam, 439; Somaliland, 458; South (and Central) America, 216-17; Spain, 152; Spanish Africa, 464; Straits Settlement, 427; Switzerland, 93-94; Transjordan, 426; Tunis, 457; Turkey, 367; Union of South Africa, 128-29; United States, 478-79; Yugoslavia, 303.

Porto Rico, 155, 216, 224, 469, 510.

Portugal, 53, 86, 99, 131, 152, 154, 401, $412,436,458$, Chap. XI: general description, 165-66; political development, 166-69; economic development, 169-71; religious development, 171-72; educational development, 172-73; social development, 173-74; immigration and emigration, 174-75. Portuguese, 5, 121, 161, 216, 217, 219, $226,231,235,236,385,400,405,414$, 463, 470, 492; Africa, 462-63; Asia, 436-37; Negroes, 469; second generation life history, 738-39.

Principe Islands, 165, 462.

Protestant, 12, 14, 38, 116-17, 135, 140-41, 154, 159, 172, 184, 230, 234, $248,266,285,286,294,297,298,300$, $301,309,327,361,362,392,468$, 477, 480, 495, 502.

Prussia, 51, 69, 81, 101, 103, 110, 279, 280, 281, 282, 284, 285, 300.

Psychosis, 39, 138.

Pupin, M.: 616.

Pygmy, 17.

Quebec Act, 147.

Quota laws, 497-98.

Quotas for different countries, 499.

Races, classification and number of, 4-8.

Racial attitudes: origin of, 500-03; variations in, 501-02; changes in, 502-03; in South Africa, 127-28.

Racial mixtures in Central and South America, 216-18.

Rajput, 413-14, 418. 
Ravage, M. E.: 511, 517, 521, 524.

Razovsky, C.: 518.

Red Russian (Ukrainian), 253.

Religion: as cause for conflicts, 184, 702-04; as cause for emigration, 509; condition of world, 12-14; map of, 13.

Religious development. See religious development under separate countries.

Religious groups in Africa, 418.

Religious struggles and persecutions, $50,81,140-41,154,158-59,194$, 247-48, 266-68, 273, 285-86, 297-98, $323-24,372$.

Restrictive legislation, 125, 493, 500 .

Riff, 334, 454.

Rihbany, A. M.: 524.

Riis, J. A.: 522, 524.

Ripley, W. Z.: 4, 25, 76, 77, 92, 99, 131, $132,164,175,190,201,240,251,277$, $291,302,319-20,330,348,366$, 380.

Roman, 16, 80, 94, 131-32, 134, 143, $147,153,156,158,160,165,166,185$, 193, 242, 247, 306, 314, 376, 431; Catholic (and Church), 12, 36, 37, 39, $57,116,117,123,124,135,136,149$, $154,155,159,170,182,183,197,204$, $208,229,230,239,248,266,282$, 285-86, 290, 297, 298, 300, 307, 309, $311,312,316,321,326,345,361,392$, 468, 477, 482, 502, 509; Empire, 20, 139, 321, 405, 431; See, 179.

Rome, 17, 29, 30, 160, 161, 167, 179, 180, 184, 186, 193, 316.

Ross, E. A.: 4, 62, 64, 76-77, 233, 478, 492.

Roumelia, 323.

Ruanda, 78, 79, 463.

Rumania, 5, 49, 51, 52, 55, 98, 138, 145 , $192,194,197,200,240,241,255,274$, $279,292,293,303,320,321,323,324$, $330,350,356,357,359,365,370, .484$, 508, 513, Chap. XVI: general description, 241-42; political development, 245-46; economic development, 24647; religious development, 247-48; educational development, 248-49; social development, 249 ; immigration and emigration, 249-50.

Rumanian: first generation life history, 596-98; second generation life history, 761-62.

Russia, 6, 8, 11, 21, 23, 49, 51, 54, 61, $69,70,80,81,103,106,108,109,110$, $145,179,181,194,200,205,241,244$, $245,247,249,279,281,285,289,299$, $300,305,320,321,323,325,329,337$, $338,339,341,345,346,371,372,381$, $382,386,387,401,404,424,425,433$, 441, 442, 508; Chap. XVII: general description, 252-57; political development, 257-62; map, 261; economic development, 262-65, religious development, $258,266-68,282,298$; educational development, 268-69; social conditions, 269-74; immigration and emigration, 274-77; movement to Siberia, 275-76.

Russian, 5, 15, 56, 101, 105, 107, 134, $228,235,249,282,283,288,289,293$, $294,298,322,337,339,340,342,345$, $353,354,355,356,381,444,445,446$, $485,493,512$; first generation life histories, 598-605, 605-08, 608-13; second generation life histories, 76264, 773-77, 777-82; third generation life history, 868-70.

Russification, 242, 259, 282, 338, 346.

Russive (Ukrainian), 253.

Ruthenian, 5, 52, 61, 63, 118, 119, 241, $253,272,273,275,281,289,292,298$, $352,356,492,493,508,509$.

Sakhalin (Karafuto), 399, 400, 402, 405.

Salvador, Chap. XV.

Samoa (Tutuila), 224.

San Marino, 8, 179.

Santo Domingo, 403, 470, Chap. XV.

Saracen, 179, 431.

Sarawak, 427, 428.

Sardinia, 131, 135, 154, 177.

Sart, 257.

Saxon, 20, 29, 30, 51, 135, 140, 293. 
Scandinavia, Chap. IV: geographic conditions, 66-67; general description, 66-68; political development, 68-71; economic development, 71; religious development, 72-73; social conditions, 73-74; immigration and emigration, 74-76.

Scandinavian, 5, 30, 134, 180, 480, 485, 492; languages, 68 ; in the United States, 74-76.

Scotch, 5, 29, 479, 511; first generation life history, 541-45; second generation life history, 738-39; third generation life history, 849-51.

Scotch-Irish, 38, 62, 478; third generation life history, 838-41.

Scotland, 27, 32.

Scythian, 18, 257.

Second Generation Americans in Process, Chap. XXXVI: five groups, 693-94; life in two culture worlds, 693-95; culture conflicts, 695-704; language conflicts, 696-99; educational conflicts, 700-01; occupational and recreational conflicts, 701-02; social conflicts, 702 ; religious conflicts, 702-04; disorganization, 70405 ; reorganization, 705; assimilation, 705-07.

Second generation life histories. See life histories, second generation.

Seljuk (Turk), 367, 368.

Semigall, 101.

Semite, 5, 15, 16, 225, 333, 334, 431, $444,450,454$.

Serb, 5, 21, 52, 197, 243, 325, 356, 484, Chap. XX: first generation life history, 616-21; second generation life history, 753-57.

Serbia, 137, 199, 322, 323, 324, 329, $330,354,369$, Chap. XX.

Sergi, G.: $25,131,179,334$.

Shan-Siamese, 15.

Shantung, 387, 402.

Shintoist, 12, 405.

Siam, 395, 427, 429, Chap. XXVIII: general description, 439; political development, 439; economic devel- opment, 439-40; social conditions, 440-41.

Siberia, 8, 12, 21, 342, 399, Chap. XVII.

Siberic, 5, 333, 334, 338, 368.

Sicily, 51, 131, 135, 154, 177, 179, 180, 192.

Silesia, 51, 54, 279, 281, 284, 292, 296.

Sinhalese, 426.

Sinitic, 5, 333, 334, 381, 429, 439.

Sinkiang (Eastern Turkestan), 381, $382,383,390$.

Slav, $12,49,52,53,101,179,180,193$, $194,197,203,239,240,321,328,352$, $363,364,368,370,505$, Part IV.

Slavic, $14,16,17,50 ; 52,131,322,326$, $329,333,338,345,354,481$; life histories, Chaps. XXXIV, XXXIX, XLIII; groups, Part IV.

Slavonia, 48, 51, 52, 303, 308, 311.

Slavonic, 5, 101, 226, 240, 257, 303, 310, 326,328 .

Slesvig, 52, 54, 67; -Holstein, 30, 64, $75,76$.

Sleszynski, T.: 693.

Slovak, 5, 52, 255, 312, 350, 356, 484, Chap. XIX.

Slovakia, 280, 292, 298, 299. See Czechoslovakia, Chap. XIX.

Slovene (Wend), 48, 52, 178, 306, 311.

Slovenia, 303, 308, 309, 310.

Slovenian, 5, 309, 312.

Smith, W. C.: 708.

Smyrna, 372, 373.

Social conditions. See social conditions under separate countries.

Social effects of immigration, 491-93.

Social problems, caused by immigration, 480 .

Sokol, 294301.

Somaliland, 177, 178, 426, 461, 464.

South Africa, 21, 25, 169, 335, 396, 418, $420,435,465,467$, Chap. VIII.

South America, 6, 7, 8, 10, 11, 12, 14, $63,99,134,174,188,189,420$, and Central America, Chap. XV: general description, 216-19; political development, 219-25; economic development, 225-29; religious development, 
229-30; educational development, 230-32; social development, 23234 ; immigration and emigration, 234-37.

Southern Rhodesia, 460, $46 \overline{8}$.

South Slav, 303, 364, Chap. XX.

Spain, 20, 22, 29, 53, 86, 98, 131, 133, $135,136,137,145,167,169,171,179$, $204,205,210,212,213,220,229,423$, $429,458$.

Spanish, 5, 15, 50, 81, 177, 186, 202, $204,208,213,216,217,219,220$, 230, 231, 236, 242, 470, 485; Africa, 464-65; America, 5, 135, 236, 237; Jews, 309; Morocco, 458, 464; Netherlands, 81, 154; third generation life histories, 862-63, 86364 .

Stella, A.: 492.

Styria, 50, 51, 52, 303, 311.

Sudan, 454, 459, 462, 466.

Sudanese, 335, 454 .

Suevi (Swabians), 153, 165, 166.

Suff rage, 70, 83, 105, 155, 182-83, 222, $260,343,347,402$.

Sugimoto, E. I.: 518, 524.

Sumatra, 434, 435.

Swede, 105, 339, 478, 485.

Sweden, 22, 25, 51, 104, 136, 258, 285, 337, 338, 339, 340, 341, 345. See The Scandinavian Countries, Chap. IV.

Swedish, 5, 49, 50, 84, 94, 134, 235, 315, $337,346,378,486$.

Switzerland, 22, 25, 54, 61, 133, 134, $135,177,189,220,373$, and Liechtenstein, Chap. VI: general description, 93-94; political development, 94-96; economic development, $96-97$; religious development, 97; educational development, 97; social development, 98; immigration and emigration, 98-99.

Syria, 5, 18, 153, 213, 235, 333, 367, $368,370,372,376,379,421,429,431$, $432,433,434,492,508$

Syrian, second generation life history, 800-02.

Szekler (Magyar), 241, 355, 364.
Tajik (Persian), 257, 441.

Tamil, 426.

Tanganyika (German East Africa), 461. Tangier, 457-58.

Tartar, 5, 18, 20, 49, 103, 243, 253, 254, $257,260,263,267,268,269,274$, $279,281,295,320,333,338,352$, $364,369,382,384,385,444$.

Teutonic, $5,12,17,25,120,131,134$, $140,143,153,161,166,239,280,292$, 293, 304, 317, 333, 339, 345, 479, 481; group, Part II; life histories, Chaps. XXXII, XXXVII, XLII.

Third Generation Americans, Part IX: Third Generation Americans in Process, Chap. XLI: interest in race and nationality, 827-28; interest in language, 828-29; interest in customs, traditions, and history, 829-31; interest in America, 831.

Third generation life histories. See life histories, third generation.

Thompson, W. S.: 20, 60.

Tibet, $15,333,381,382,383,389$, 391, 395.

Tonkin, 382, 429-30.

Toshk, 314, 316-17.

Transcaucasia, 252, 255, 256, 260, 266, $269,274,276$.

Transjordan, 421, 425, 426, 429.

Trans-Siberian railroad, 276.

Transylvania, $48,51,52,250,341,342$, $343,355,356,361,364$.

Treaties and agreements: Berlin, 323; Brest-Litovsk, 260; Bucharest, 245; Karlowitz, 307; Lansing-Ishii, 403; Lausanne, 192, 372, 373; Mersen, 180; Paris, 32; Portsmouth, 402; Sèvres, 372-73; Shimonoseki, 387, 402; Tordesillas, 169; Trianon, 358; Utrecht, 81, 113; Verdun, 135; Westphalia, 136.

Tripoli, 182, 454, 464.

Tunis, 10, 454, 457 .

Turanian, 18, 334, 367, 368.

Turk, 5, 15, 17, 49, 50, 56, 194, 198, $199,243,246,247,249,256,258,277$, $304,306,307,310,311,312,314,316$, 
$317,318,320,322,323,324,327,329$, $333,338,352,354,355,356,359,361$, $364,382,421,422,423,433,444$, 460, 484, 500, 501, 502.

Turkestan, 252, 263, 265, 274, 441.

Turkey, 12, 135, 182, 192, 195, 200, $233,244,245,260,267,276,305$, $318,320,322,323,324,325,328$, 330, 432-33, 442, 445, 451, 507, 508, Chap. XXIV: general description, 367-69; political development, 36973; economic development, 373-75; religious development, 375-76; educational development, 376-77; social conditions, 377-78; immigration and emigration, 378-79.

Turkoman, 257, 263.

Uganda, 423, 461.

Ukraine, 241, 252, 255, 260, 262.

Ukrainian, 241, 253, 254, 272, 279, 299; second generation life history, 764-70.

Unfederated Malay States, 427.

Uniate, 197, 239, 266, 298, 309, 311.

Union: of Kalmar, 69; of Lublin, 103; of Utrecht, 81.

Union of South Africa, 459, 463, 468; general description, 125-26; political development, 126-27; economic development, 127; social conditions, 127-28; immigration and emigration, 128-29.

United Kingdom, 11, 25, 478, 480, 483, 485, Chap. II: general description 27-29; political development, 29-33; economic development, 33-36; religious development, 36-37; educational development, 37-38; social development, 38-40; immigration and emigration, 40-44.

Ural-Altaic, 15, 320, 334, 338, 368.

Uruguay, Chap. XV.

Urundi, 78, 79, 463.

Valentine, J.: 693.

Vandal, 20, 153, 165, 180.

Vámbéry, A.: 364.

Venetian, 179, 193, 307, 314.
Venezuela, Chap. XV.

Vilborg, 341.

Villari, L.: 279, 487, 503-04.

Virgin Islands, 224, 469.

Visigoth, 134, 140, 153, 166-67, 180.

Vlach, 193.

Voivodina, 307, 309, 310.

Vorarlberg, 95.

Wales, 27, 32.

Wallach (Vlach), 242, 356, 451, 452.

Wallachia, 241, 243, 244, 354.

Walloon, 79, 85, 87, 88, 89, 90, 91.

Wars: American Revolution, 147, 148, 282, 288; Austrian Succession, 136; Balkan, 192, 195, 305, 324, 328; Civil, 114, 480; Crimean, 194, 245; Franco-Prussian, 52, 55, 62, 136, 137, 181, 493; French and Indian, 136; French Revolution, 85, 114, 220, 447; Hundred Years, 135, 143; Hussite, 295, 297; $\mathrm{Na-}$ poleonic, 20, 59, 61, 108, 146, 357, 426, 435; Polish Succession, 136; Russo-Japanese, 242，259， 387; Russo-Turkish, 248, 305; Spanish Succession, 81, 478; Thirty Days, 194; Turko-German, 244; TurkoIranian, 413; Turko-Tartar, 255, 256, 382, 441; World War, 8, 53, 54, 78-79, 88, 96-97, 126, 139, 177, $178,239,241,246,252,273,283$, $288,294,306,307,329,330,337$, 350-53, 372, 374-75, 387, 445, 464. Wend, 69, 311, 350. See Slovene.

West Indian, life history, 687-89.

West Indies, 17, 134, 420, 421, 469, Chap. XV.

White Russian, 252, 253, 254, 255, 262. See Ruthenian.

"Why Am I an American?" 525-35.

Wilkinson, H. L.: 59, 122, 235, 288.

Wissler, C.: 14.

World: A Glimpse of, Chap. I: commerce, 11; culture areas, 16-17; economic divisions, 8-11; language, 1416; political divisions, 8 ; population, 3-8; religious conditions, 12-14. 
Yaqui, 202, 204, 213.

Yen, J. Y. C.: 393.

Yezo Islands, 399, 400.

Young Turks, 323, 324, 371.

Yugo-Russian (Ukrainian), 253.

Yugoslavia, 48, 49, 55, 138, 177, 182, $192,240,241,294,320,350$, and Albania, Chap. XX: general description, 303-04; political development, 304-08; economic development, 30809; religious development, 309; educational development, 309-10; social development, 310-11; immigration and emigration, 311-13.

Zadruga, 310, 311, 329.

Zambo, 202, 217-18, 232, 233.

Zionism, 423-25.

Zoroaster, 447-48.

Zouave, 334.

Zulu, 335, 454, 465. 









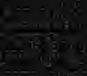

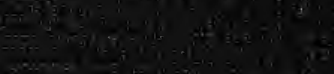

20

and 0

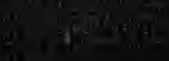

